Historic, Archive Document

Do not assume content reflects current scientific knowledge, policies, or practices. 

a SDII

, R23

\section{USDA}

United States

Department of

Agriculture

Forest Service

Tongass National Forest

R10-MB-425

July 2002

Uis
Shoreline

Outfitter/Guide

\section{Draft Environmental Impact} Statement

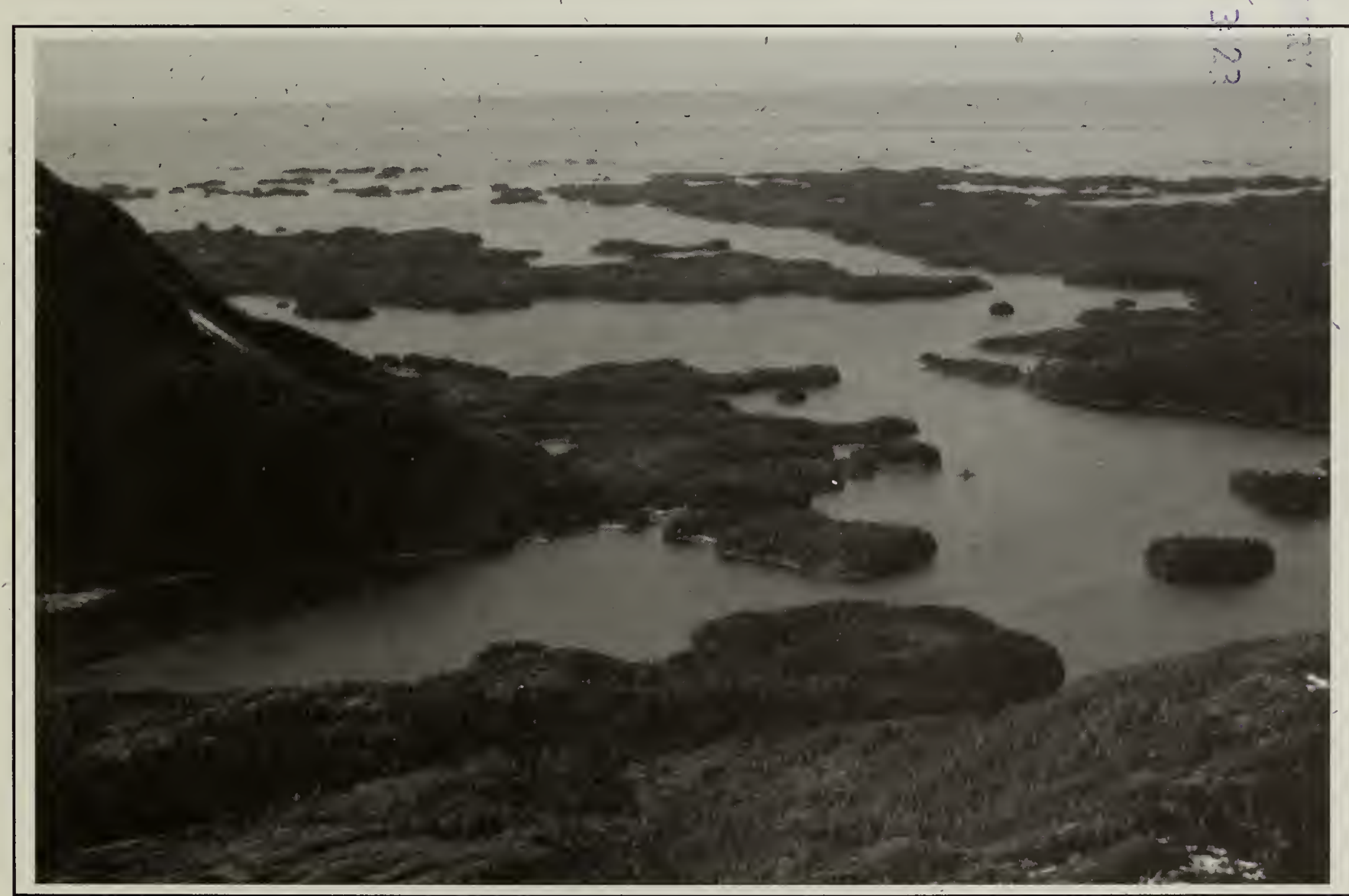





\begin{tabular}{lll}
$\begin{array}{l}\text { United States } \\
\text { Department of } \\
\text { Agriculture }\end{array}$ & $\begin{array}{l}\text { Forest } \\
\text { Service }\end{array}$ & $\begin{array}{l}\text { Alaska Region } \\
\text { Tongass National Forest }\end{array}$ \\
\hline
\end{tabular}

204 Siginaka Way

Sitka, AK 99835

Phone: (907) 747-6671

Fax: (907) 747-4331

$\begin{aligned} \text { File Code: } & 1950 \\ \text { Date: } & \text { June } 21,2002\end{aligned}$

\section{Dear Reviewer:}

Here is your copy of the Draft Shoreline Outfitter/Guide Environmental Impact Statement. This document describes the no-action alternative and four action alternatives. At this point, Alternative 5 is the preferred alternative. However, please review all of the alternatives since all alternative have equal standing at this time. Any alternative, combination of alternatives, or a new alternative within the range of these alternatives may be selected in the final decision.

I am the Responsible Official for this project and will make the decision on whether or not to allow the permitting for outfitter/guide use, the amount of the recreation carrying capacity to be allocated to guided use, and the conditions under which guided use will be permitted.

Your comments are important and will help me make my decision. Comments that are substantive and specific to the Shoreline Outfitter/Guide project are the most valuable. It is important for those interested to respond to this DEIS within the comment period with comments and objections that can be meaningfully considered during the development of the Final Environmental Impact Statement. Comments or objections made at a later date or during the appeal period may not be considered, if no comments were made on the DEIS.

Because this is type of recreation analysis is relatively new for the Tongass National Forest and involves complex issues, and because the comment period is overlapping with the comment period for the Draft Supplemental EIS Roadless Area Evaluation for Wilderness Recommendations, I have extended the comment period on the Draft EIS to 90 days from the normal 45 day period in order to obtain full public comment. The comment period will start from the date the Notice of Availability of the Draft EIS is published in the Federal Register, expected to be in July. A public notice will also be placed in the Juneau Empire, the newspaper of record. The deadline for comments is predicted to be in October.

Please send written comments to Shoreline Outfitter/Guide Project, Attn: Mary Beth Nelson, USDA Forest Service, Tongass National Forest, 204 Siginaka Way, Sitka, Alaska 99835-7316. If you need additional information or if you would like additional copies of this Draft EIS, please call Mary Beth Nelson at (907)-747-6671.

Sincerely,

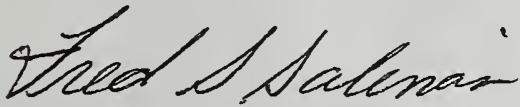

FRED S. SALINAS

Deputy Forest Supervisor 



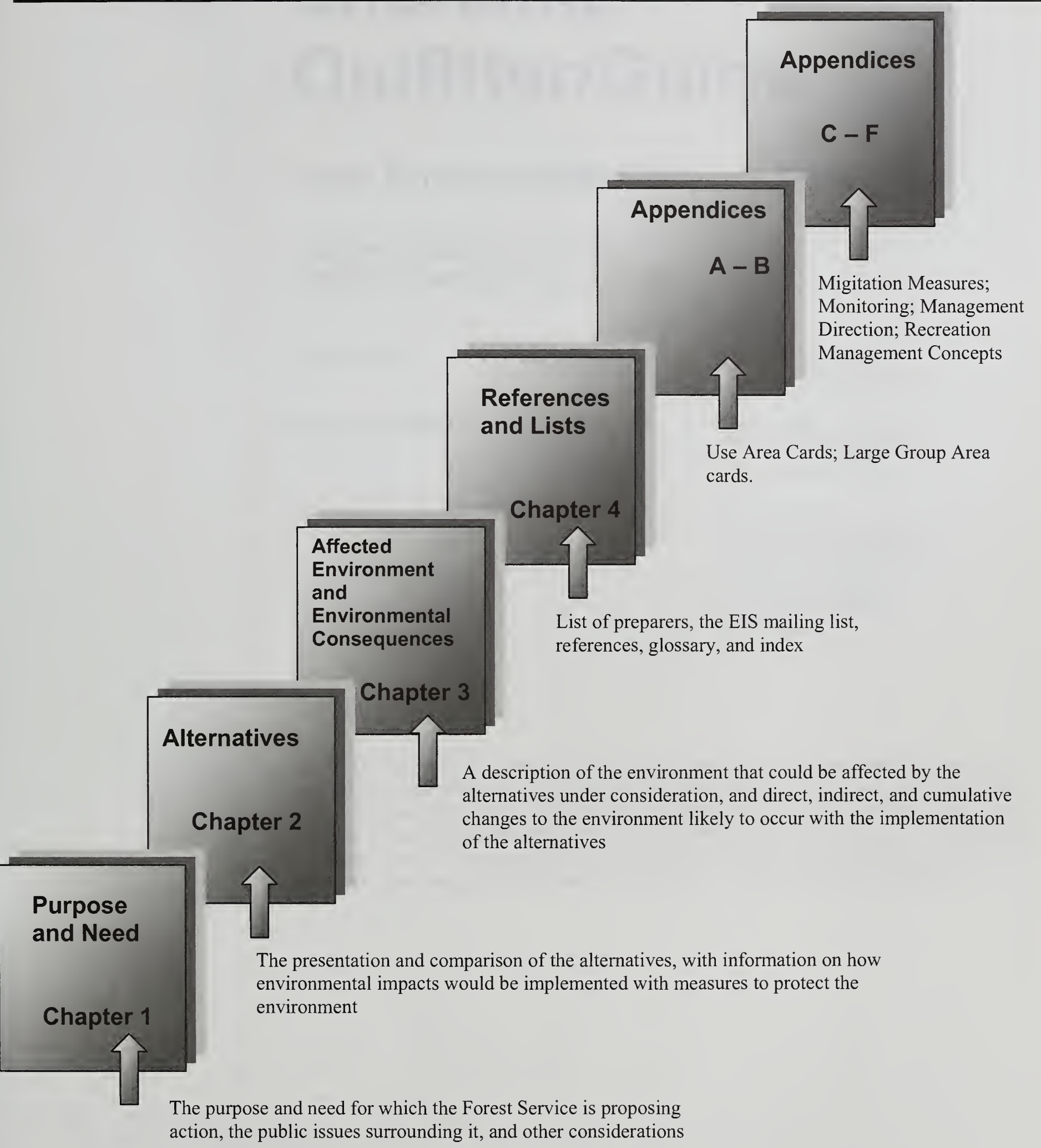





\section{Shoreline Outfitter/Guide}

\section{Draft Environmental Impact Statement}

\section{Tongass National Forest USDA Forest Service, Alaska}

Lead Agency

Responsible Official

For Further Information Contact

\author{
USDA Forest Service \\ Tongass National Forest \\ Deputy Forest Supervisor \\ Tongass National Forest \\ Sitka, Alaska 99835 \\ Bob Dalrymple \\ Sitka Supervisors Office \\ Tongass National Forest \\ 204 Siginaka Way \\ Sitka, Alaska 99835 \\ 907-747-6671
}

\section{Abstract}

The USDA Forest Service proposes to allocate commercial recreation carrying capacity for outfitter/guide use on the analysis area that includes: Admiralty Island National Monument, Juneau, Hoonah, and Sitka Ranger Districts. Allocations vary among alternatives. The actions analyzed in this Draft EIS are designed to implement direction contained in the 1997 Tongass Land and Resource Management Plan. This draft environmental impact statement describes five alternatives that provide different combinations of resource outputs and effects. 


\section{Table of Contents}

\section{Executive Summary}

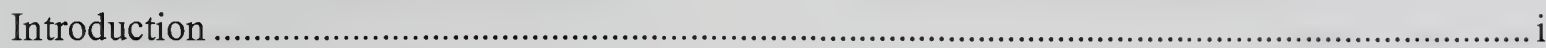

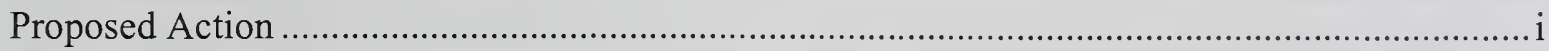

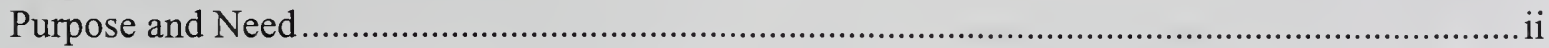

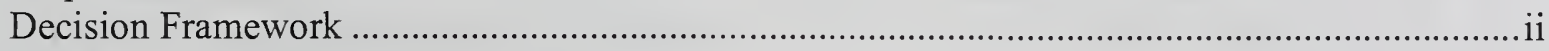

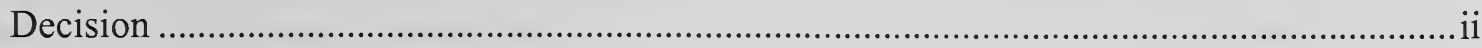

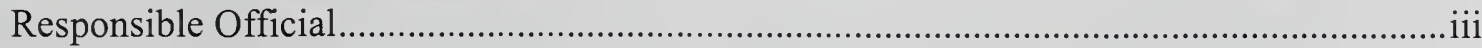

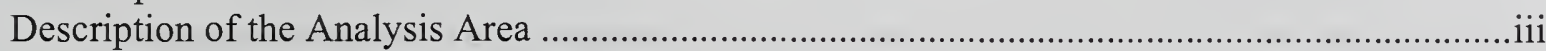

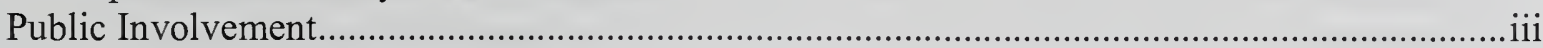

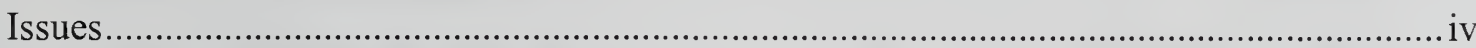

Issue 1. Availability of Recreation Opportunities for the Guided and Unguided

Recreationist ........................................................................................................ iv

Issue 2. Economic Opportunities and Potential Effects on Outfitter/Guide

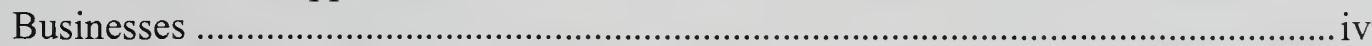

Issue 3. Conflicts Within the Commercial Recreation Industry ................................... iv

Other Environmental Considerations......................................................................iv

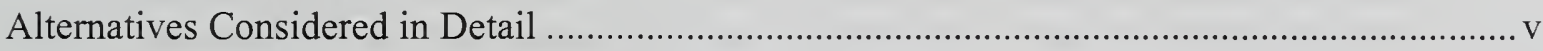

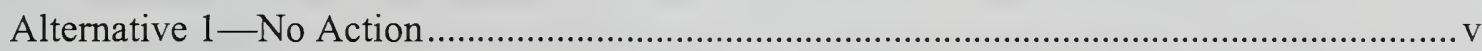

Alternative 2 - Proposed Action...................................................................................

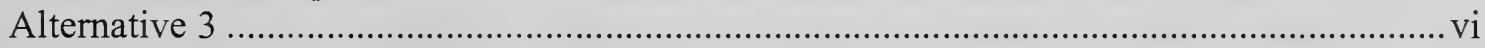

Alternative 4 ...................................................................................................

Alternative 5 ................................................................................................... vii

Identification of the Preferred Alternative .........................................................................ix

Comparison of the Alternatives............................................................................................

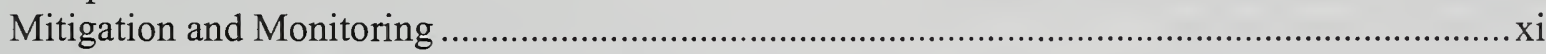

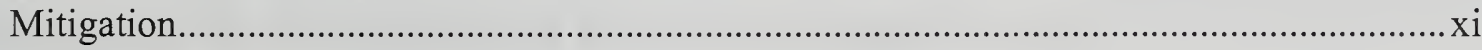

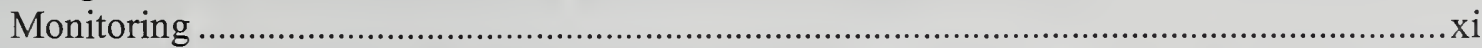

\section{Chapter 1-Purpose and Need}

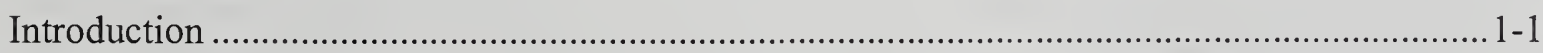

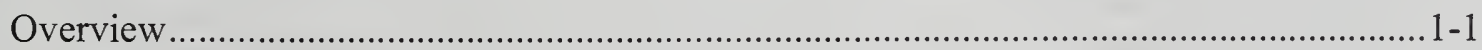

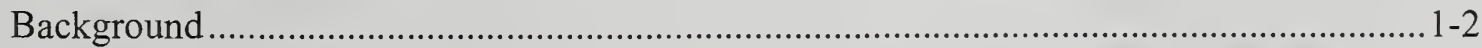

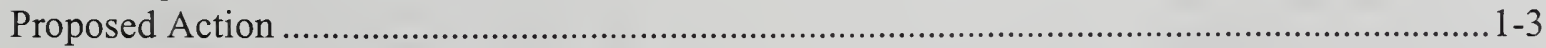

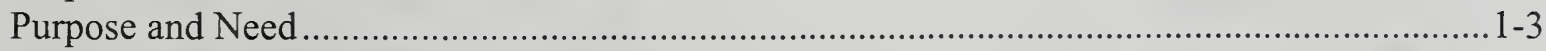

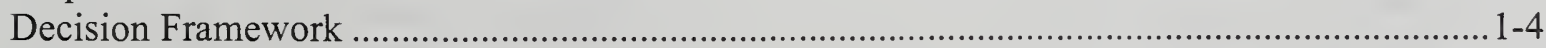

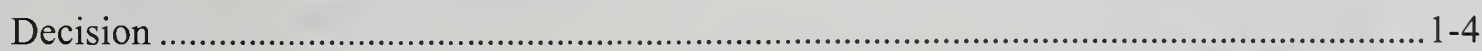

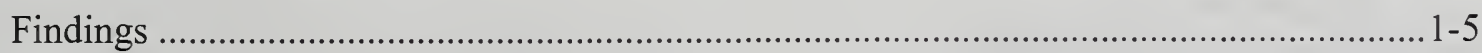

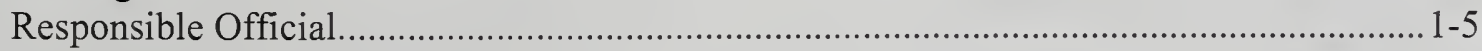

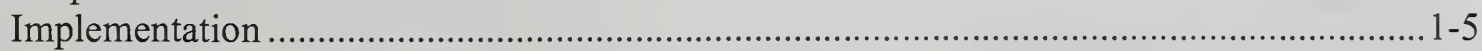

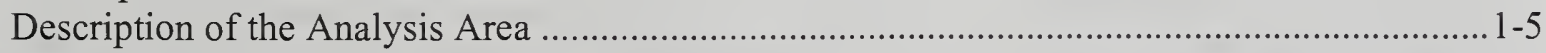

Geographic Location and Boundaries....................................................................... 1-5 


\section{Table of Contents}

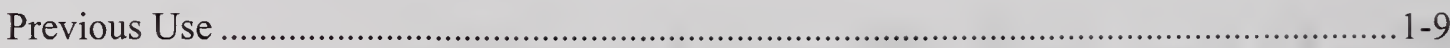

Current and Future Projects ....................................................................................

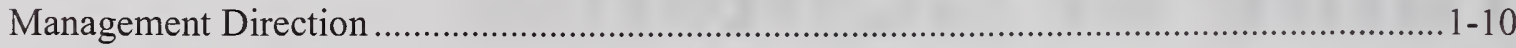

Forest Service Levels of Direction ...........................................................................1-10

Relationship to Forest Plan ................................................................................1-11

Goals and Objectives................................................................................1-12

Land Use Designations...................................................................................1-12

Forest Plan Standards and Guidelines .................................................................1-13

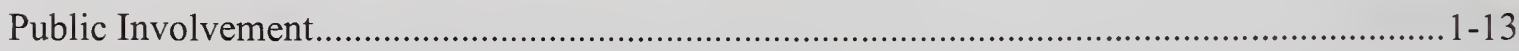

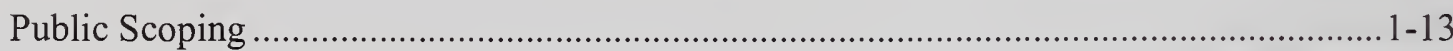

Schedule of Proposed Actions..................................................................................1-13

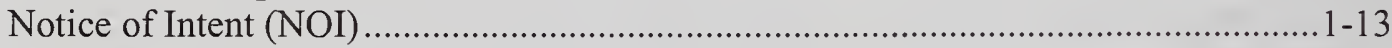

Mailing List ........................................................................................... 1-14

Scoping Milestones ……............................................................................1-14

Consultation with Federally Recognized Tribal Governments and Other Government

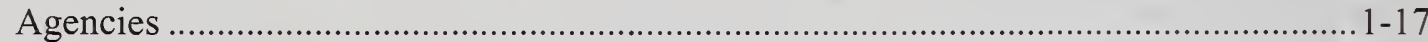

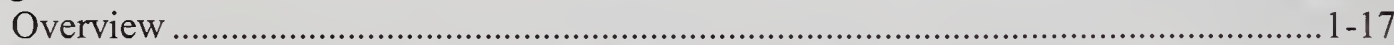

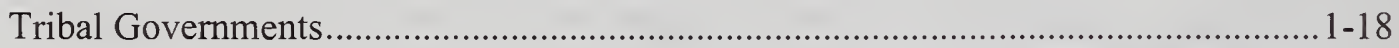

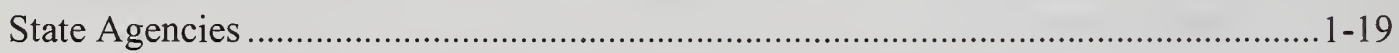

Other Federal Agencies ................................................................................ 1-20

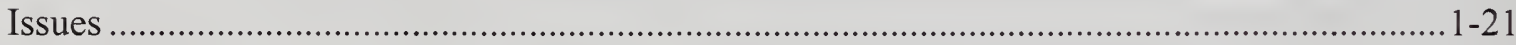

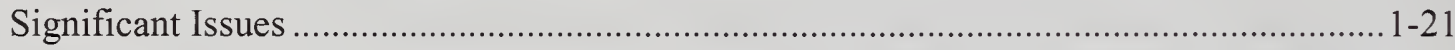

Issue 1. Availability of Recreation Opportunities for the Guided and Unguided Recreationists ...............................................................................................

Issue 2. Economic Opportunities and Potential Effects on Outfitter/Guide

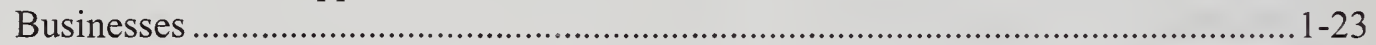

Issue 3. Conflicts Within the Commercial Recreation Industry .................................1-24

Other Environmental Considerations.........................................................................1-25

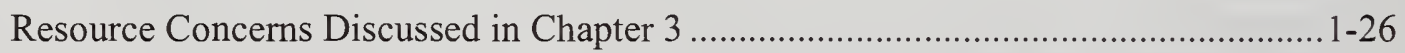

Issues Beyond the Scope of this EIS ...............................................................1-26

Applicable Laws and Executive Orders ......................................................................

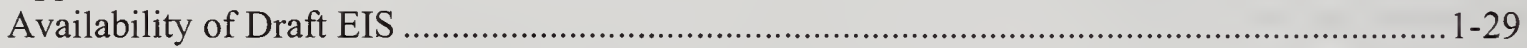

\section{Chapter 2-Alternatives}

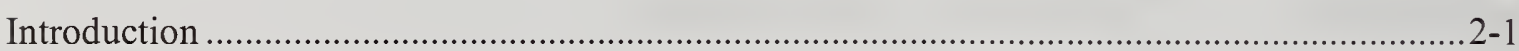

Alternative Development Process .................................................................................

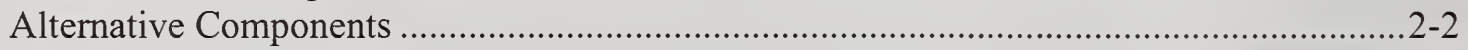

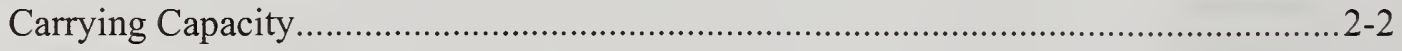

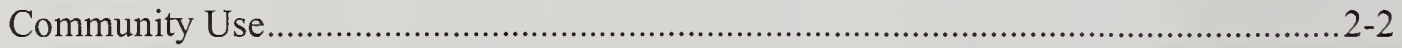

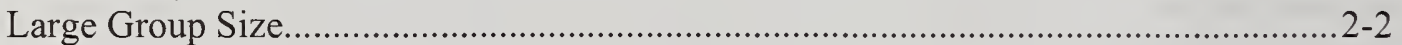

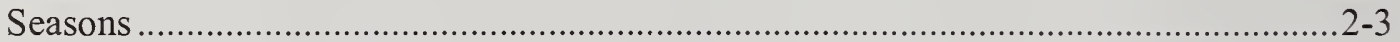

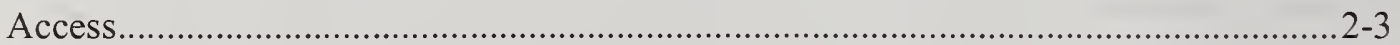

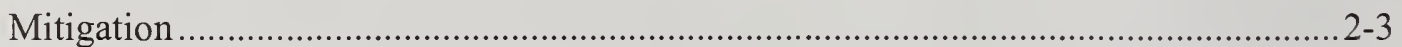

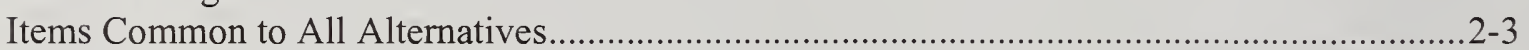

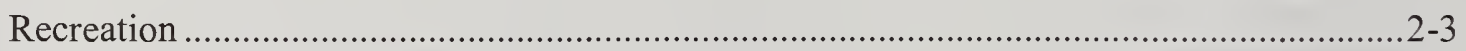

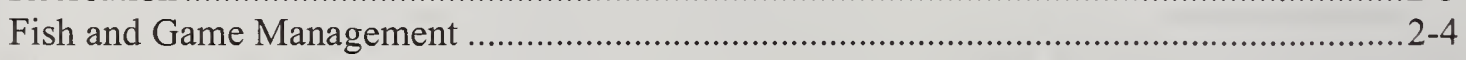

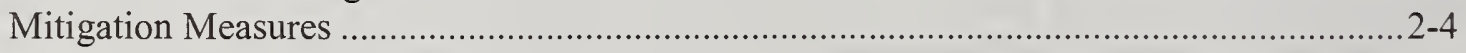

Riparian Management Areas................................................................................. 


\section{Table of Contents}

Fish Habitat and Water Quality .............................................................................2-4

Eagle and Raptor Nests ........................................................................................... 2-4

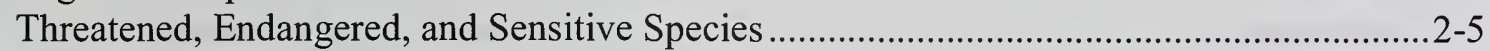

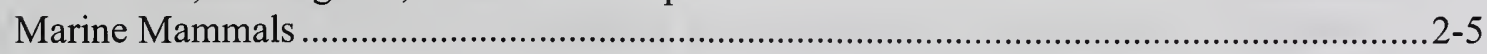

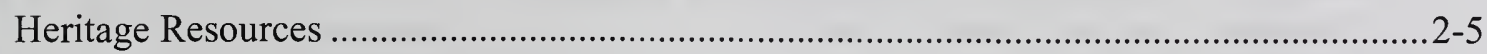

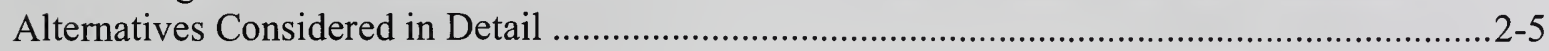

Alternative 1 - No Action...............................................................................................

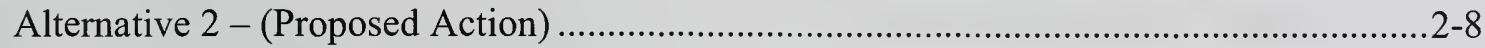

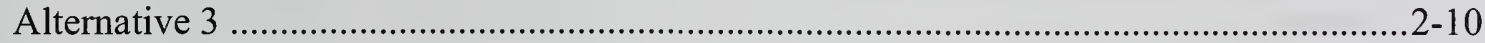

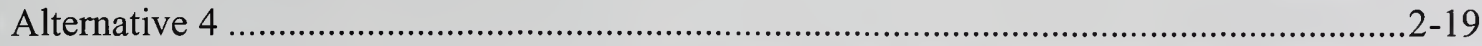

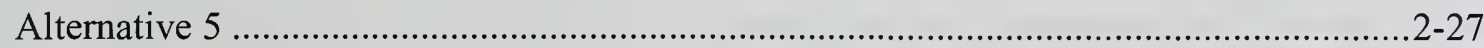

Identification of the Preferred Alternative ………………................................................2-2-35

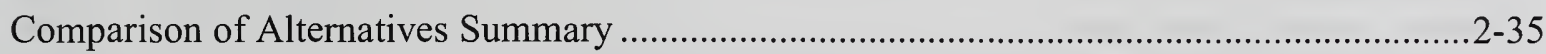

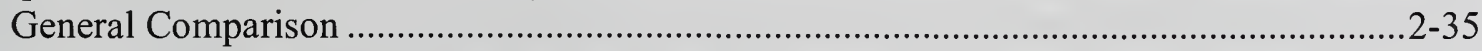

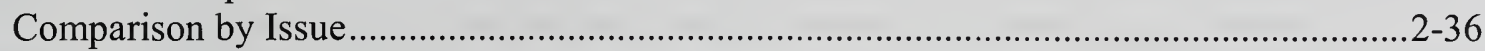

Issue 1: Recreation Opportunities Available for Guided and Unguided

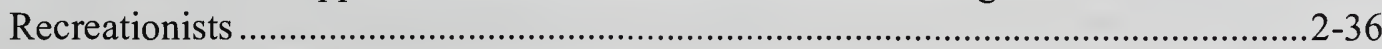

Issue 2: Economic Opportunities and Potential Effects on Commercial Outfitter/Guide

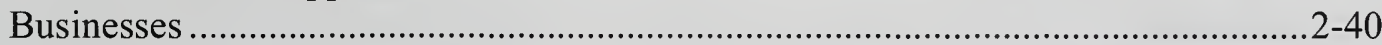

Issue 3: Conflicts within the Commercial Recreation Industry ....................................2-43

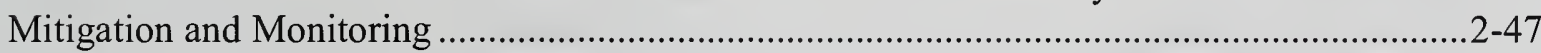

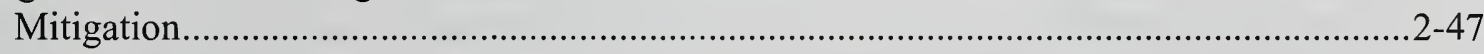

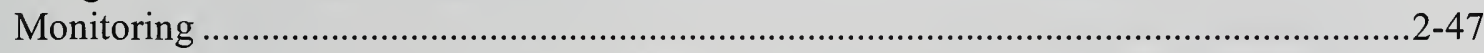

Alternatives and Proposals Considered but Eliminated from Detailed Study ...........................2-247

No Commercial Use on the National Forest ................................................................2-48

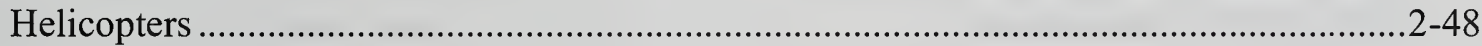

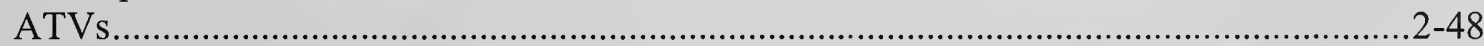

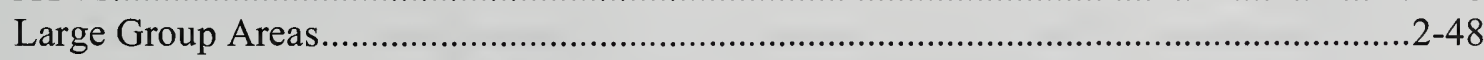

Big Game Guided Hunting Allocations ...........................................................................2-48

\section{Chapter 3-Affected Environment and Environmental Consequences}

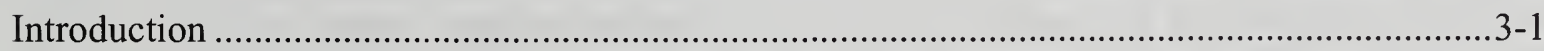

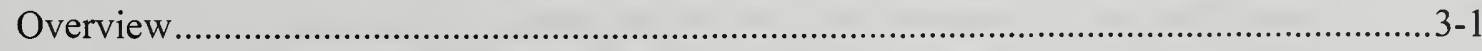

Administrative Land Divisions .................................................................................

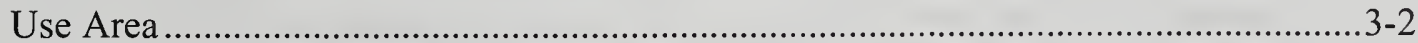

Land Use Designation (LUD) …………………….............................................

Value Comparison Unit (VCU) ...........................................................................

Wildlife Analysis Area (WAA) ............................................................................

Game Management Unit (GMU) .........................................................................

Guide Use Area (GUA) ..................................................................................

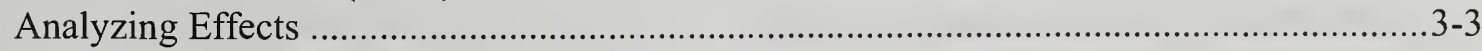

Direct, Indirect, and Cumulative Effects ..................................................................3-3

Unavoidable Adverse Effects ................................................................................

Short-term use and Long-term Productivity ..................................................................... $3-3$

Irreversible and Irretrievable Commitments .............................................................3-3

Available Resource Information .......................................................................... 3-4 


\section{Table of Contents}

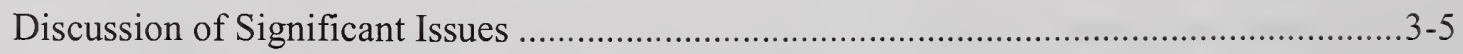

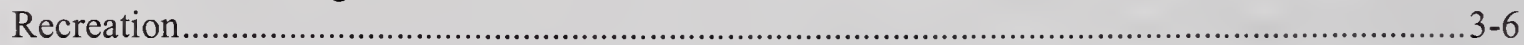

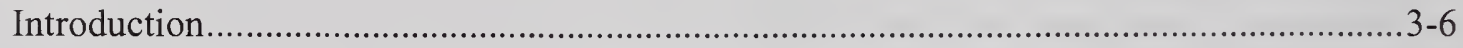

Forest Plan and the Recreation Opportunity Spectrum ...............................................3-6

Recreation Carrying Capacity Analysis ..................................................................3-7

Affected Environment.....................................................................................

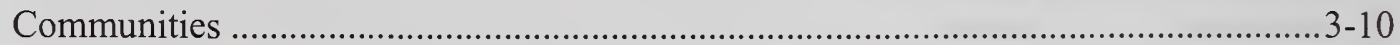

Recreation in the Analysis Area .........................................................................

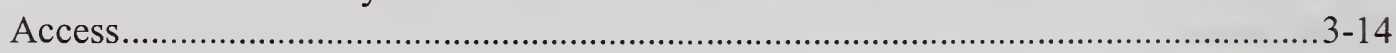

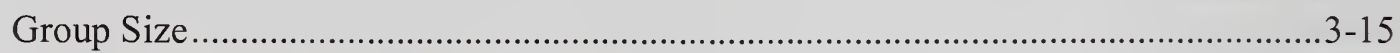

Role of the Commercial Outfitter/Guide ....................................................................

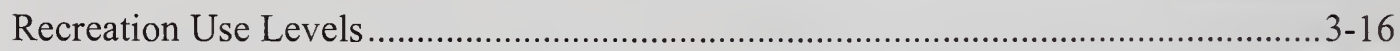

Environmental Consequences ............................................................................... $3-24$

Effects on Guided and Unguided Recreationists (Issue 1) .......................................3-24

Economic Opportunities and Potential Effects on Outfitter/Guide Businesses

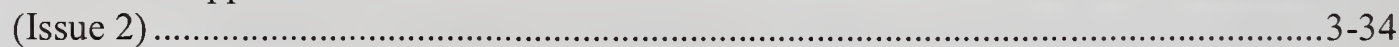

Conflicts within the Commercial Recreation Industry (Issue 3) ..................................3-53

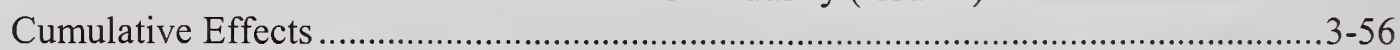

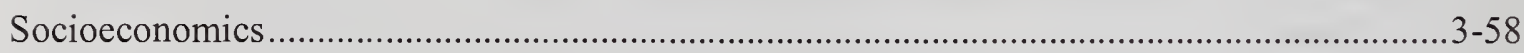

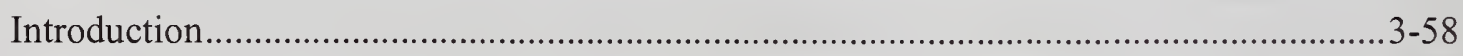

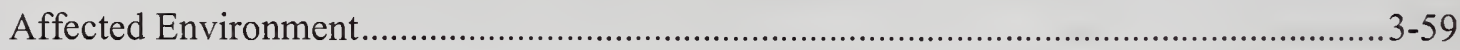

Community Profiles ……………………………………................................

Regional Economic Trends ..............................................................................

Recreation, Tourism, and Outfitter/Guides ………………………………………....3-63

Implications of Expanding Activity ....................................................................

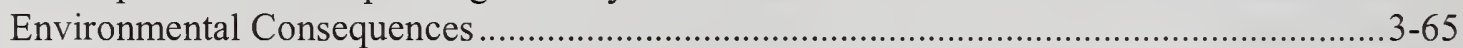

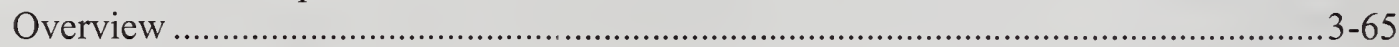

Socioeconomic Effects on Non-commercial Users (Issue 1) .......................................3-66

Socioeconomic Effects on the Recreation Industry (Issue 2).......................................3-66

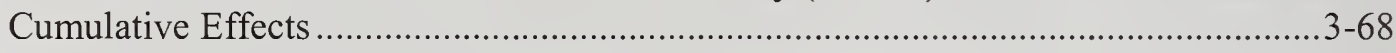

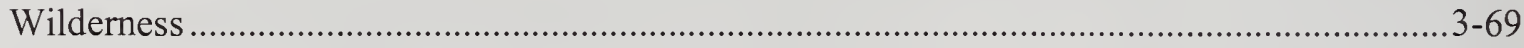

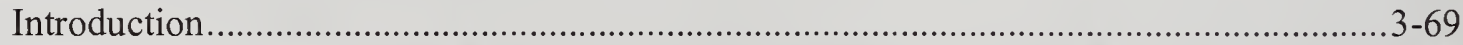

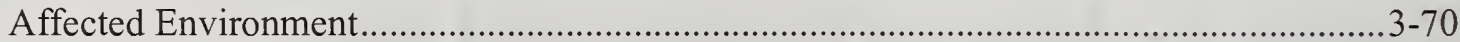

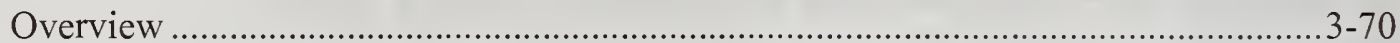

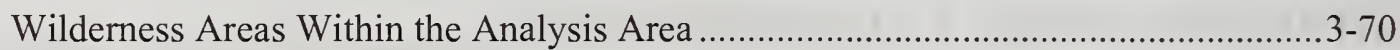

Environmental Consequences .......................................................................................

Direct Effects on Recreation Users and the Recreation Industry (Issues 1 \& 2)...........3-73

Indirect Effects on Recreation Users and the Recreation Industry (Issues $1 \&$ 2) ........3-79

Cumulative Effects on Recreation Users and the Recreation Industry (Issues 1 \& 2).3-80

Summary of Wilderness Effects ........................................................................ $3-81$

Roadless Area Evaluations for Wilderness Recommendations......................................3-82

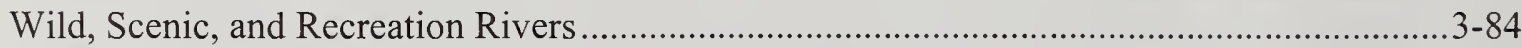

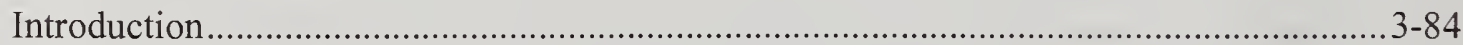

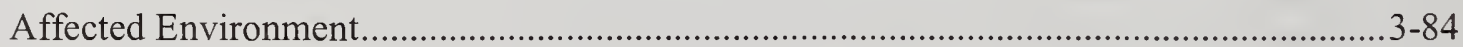

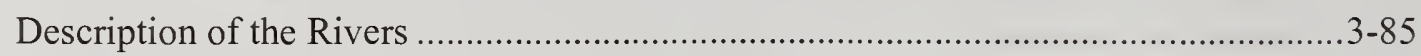

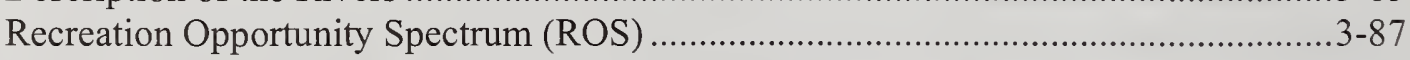

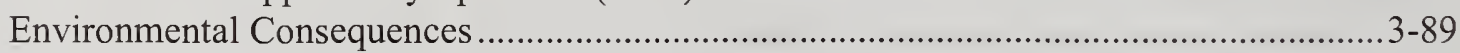

Direct and Indirect Effects ................................................................................

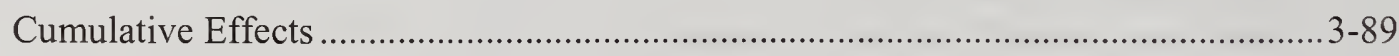

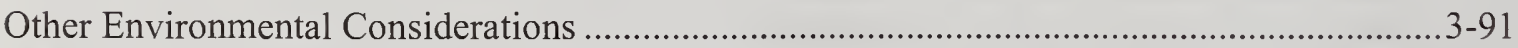

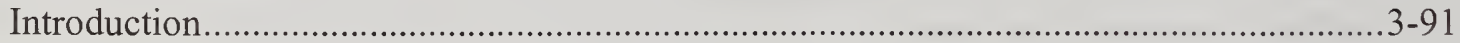




\section{Table of Contents}

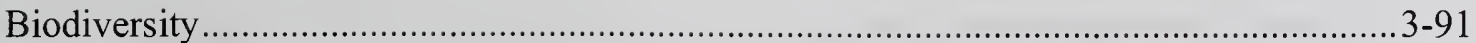

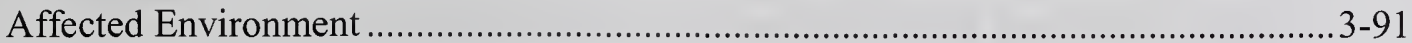

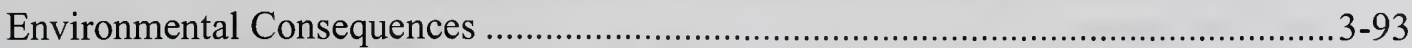

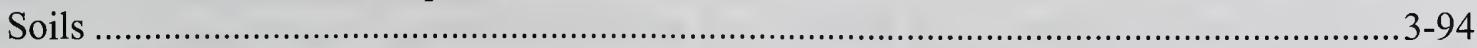

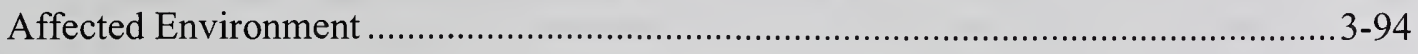

Environmental Consequences ............................................................................

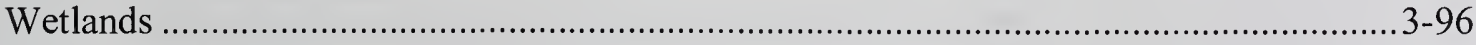

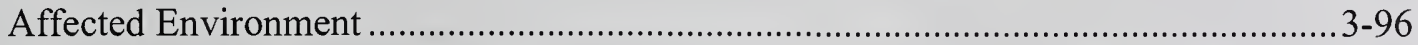

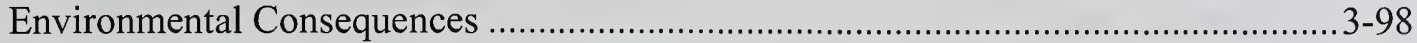

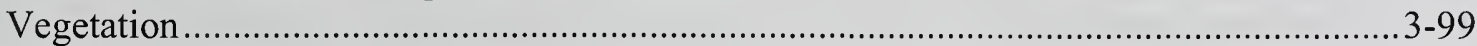

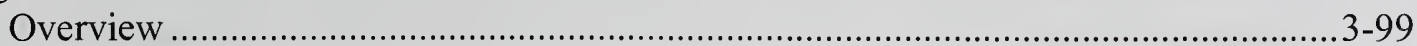

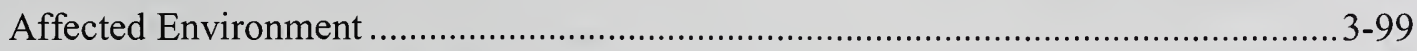

Environmental Consequences ..........................................................................

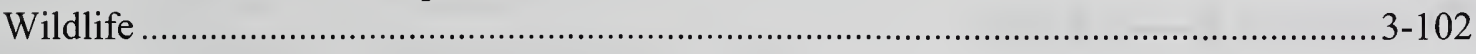

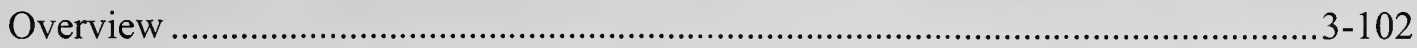

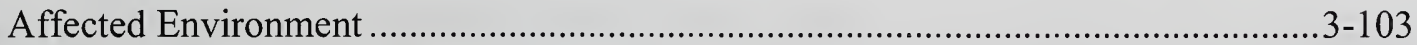

Environmental Consequences ............................................................................

Fish Habitat and Water Quality .........................................................................

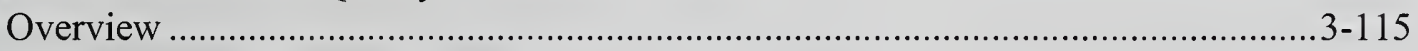

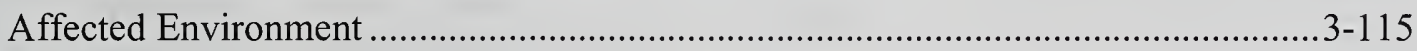

Environmental Consequences .........................................................................

Threatened, Endangered, and Sensitive Species …………………................................3-126

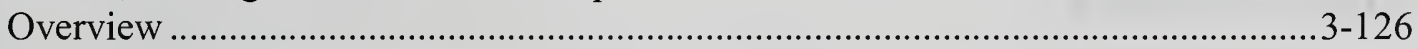

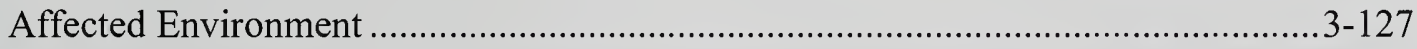

Environmental Consequences …………………………………………….... $3-130$

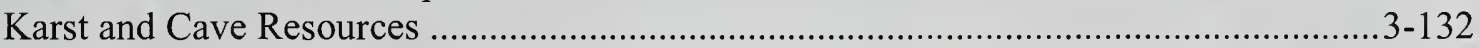

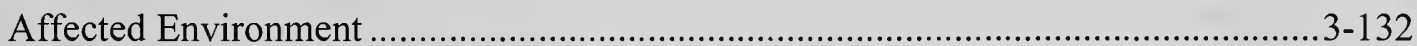

Environmental Consequences ........................................................................

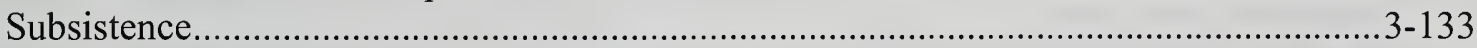

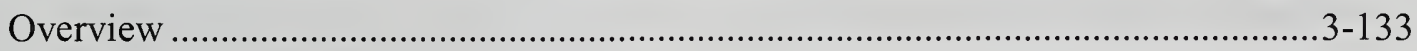

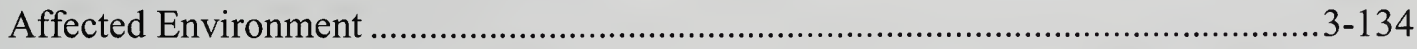

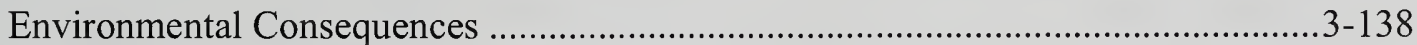

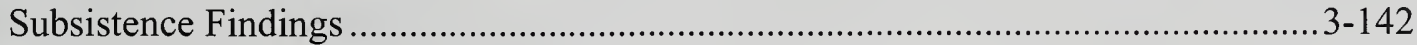

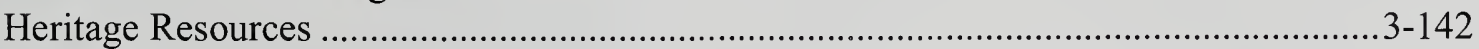

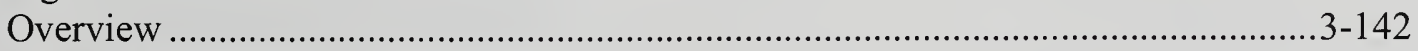

Affected Environment .................................................................................

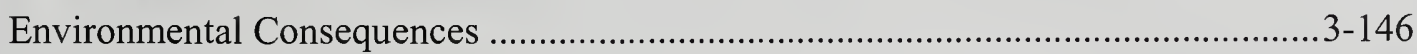

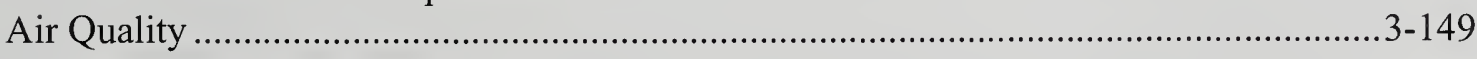

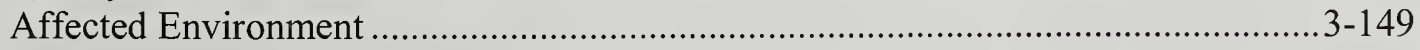

Environmental Consequences ............................................................................

Specifically Required Disclosures ............................................................................

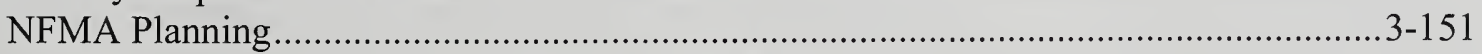

Tongass Land and Resource Management Plan and Alaska Regional Guide .............3-151 Laws

Endangered Species Act......................................................................................

Bald Eagle Protection Act....................................................................................

National Historic Preservation Act...........................................................................3-151

Federal Cave Resource Protection Act of 1988 ......................................................

ANILCA Evaluations and Findings …………………….................................

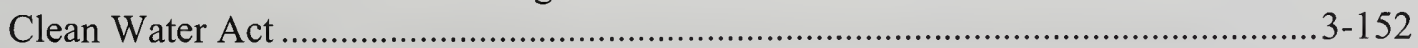

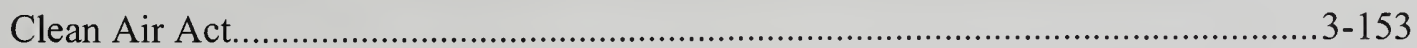




\section{Table of Contents}

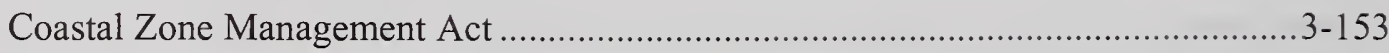

Magnuson-Stevens Fishery Conservation and Management Act ............................. 3-154

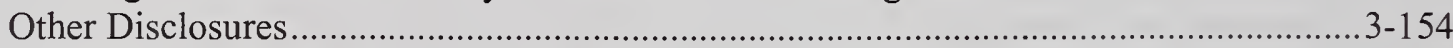

Effects on Prime Farm Land, Range Land, and Forest Land ................................3-154

Effects on Civil Rights, Women, and Minorities ....................................................3-154

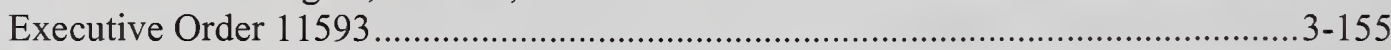

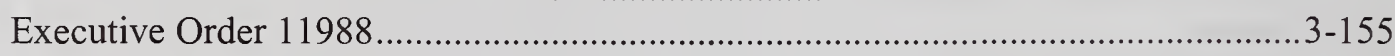

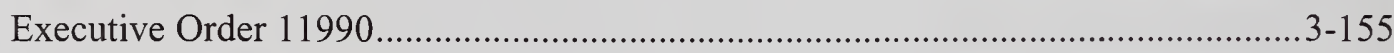

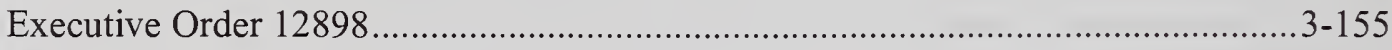

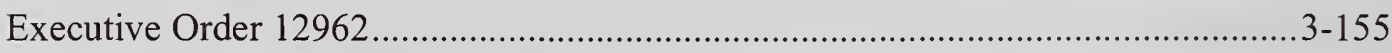

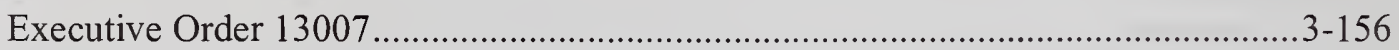

\section{Chapter 4-Lists}

Glossary.

Glossary-1

References References- 1

Preparers Preparers-1

Recipients of the Draft EIS Recipients-1 Index Index-1

\section{Appendices}

A-Use Area Cards

B-Large Group Area Cards

$\mathrm{C}$-Mitigation

D-Monitoring

E-Management Direction

F-Recreation Management Concepts 


\section{Table of Contents}

\section{List of Tables}

\section{Chapter 1-Purpose and Need}

Table 1-1. Acres of Each Use Area

$1-6$

\section{Chapter 2-Alternatives}

Table 2-1. Alternative 1 (No Action), Commercial Allocation by Use Area and Season..........2-7

Table 2-2. Alternative 2, Commercial Allocation by Use Area and Season .............................2-9

Table 2-3. Alternative 3, Commercial Allocation by Use Area and Season ...........................2-11

Table 2-4. Alternative 3, Enclave Large Group Areas ........................................................2-12

Table 2-5. Alternative 3, Fifteen-Percent Large Group Areas ..........................................2-13

Table 2-6. Alternative 4, Commercial Allocation by Use Area and Season ............................2-20

Table 2-7. Alternative 4, Enclave Large Group Areas ......................................................2-21

Table 2-8. Alternative 4, Fifteen-Percent Large Group Areas .............................................2-21

Table 2-9. Alternative 5, Commercial Allocation by Use Area and Season ...........................2-28

Table 2-10. Alternative 5, Enclave Large Group Areas ........................................................2-29

Table 2-11. Alternative 5, Fifteen-Percent Large Group Areas .............................................2-30

Table 2-12. Comparison of Alternatives, General..................................................................

Table 2-13. Comparison of Alternatives, by Issue .............................................................2-46

\section{Chapter 3-Affected Environment and Environmental Consequences}

Table 3-1. Forest Plan Guidelines for Numbers of Social Group Encounters Per Day, by ROS Class

Table 3-2. Dates and Number of Days of Seasonal Use

Table 3-3. Amount (Acres) and Type of Recreation Opportunity (ROS) Available Within the Shoreline Zone, by Use Area

Table 3-4. Amount (Miles) and Type of Recreation Opportunity (ROS) Available Within the Shoreline Zone, by Use Area

Table 3-5. Current Commercial Use (Group Days) and Percentage of Total Carrying Capacity, by Season and Use Area (1999 Levels)

Table 3-6. Commercial Use (Group Days), by Activity, Season, and Percent of Total Use, 1999

Table 3-7. Percent of the Shoreline Zone (Area) Available in Each Recreation Setting to

Provide the Expected Recreation Experience (ROS), for All Alternatives.

Table 3-8. Percent of Shoreline Miles Available in Each Recreation Setting to Provide the

Expected Recreation Experience (ROS), for All Alternatives...........................................3-26

Table 3-9. Recreation Carrying Capacity and Commercial Allocation, by Alternative...........3-28

Table 3-10. Proposed Enclave Areas in Each Alternative.................................................... 3-30

Table 3-11. Proposed Fifteen-Percent Areas in Each Alternative.............................................3-31

Table 3-12. Total Numbers and Acres of Large Group Areas .............................................3-31

Table 3-13. Total Commercial Allocation Compared to Current (1999) Commercial Use Levels, by Alternative ...............................................................................................3-36

Table 3-14. Current (1999) Commercial Use Beyond Total Seasonal Allocation Levels, by Alternative, in Group Days 


\section{Table of Contents}

Table 3-15. Projected Future Use Levels (Assuming a Doubling of Current Commercial Use)

Beyond Total Seasonal Allocation Levels, by Alternative, in Group Days

Table 3-16. Alternative 2 Use Areas with Current Use Approaching (within 20\%), At, or Over the Allocation, by Season

Table 3-17. Alternative 4 Use Areas with Current Use Approaching (within 20\%), At, or Over the Allocation, by Season

Table 3-18. Alternative 5 Use Areas with Current Use Approaching (within 20\%), At, or Over the Allocation, by Season

Table 3-19. Structure and Growth of Personal Income in the Analysis Area, 1970-1998 ......3-62

Table 3-20. Wilderness Areas Within the Analysis Area.....

Table 3-21. Estimated Potential Commercial Use in Wilderness, by Alternative, Based on 1999 Use Levels

Table 3-22. Roadless Areas within the Shoreline Analysis Area

Table 3-23. Total Length (Miles) of Wild and Scenic Rivers Recommended in the

Forest Plan and That Flow Through the Analysis Area.....

Table 3-24. Forest Plan Guidelines and Recommended Wild and Scenic River Corridor Area

Within the Analysis Area, for All Alternatives.

Table 3-25. 1999 Commercial Use in Recommended Wild and Scenic River Corridors Compared to Commercial Use in the Use Area...

Table 3-26. Ecological Subsections of the Shoreline Outfitter/Guide Analysis Area.............3-92

Table 3-27. Wetlands in the Shoreline Zone

Table 3-28. GMU 1, Percentage of Successful Brown Bear Hunters, by Their Residency, 1986-1998

Table 3-29. GMU 4, Percentage of Successful Brown Bear Hunters, by Their Residency, 1992-1998.

Table 3-30. Potential Bear-viewing Sites

Table 3-31. Streams and Fish Stocks Recently Affected by Protective Management Actions3-118

Table 3-32. Potential Guided Freshwater Sport Fishing Effort, by Alternative.....

Table 3-33. Number of Sites with Use Estimated to Exceed 300 Visitors Per Year.

Table 3-34. Number of Fifteen-Percent Areas and Enclaves with One-half Mile of

Anadromous Stream

Table 3-35. Sensitive Plant Species, Alaska Region

Table 3-36. Guide Use Areas with Carbonate Rock Within One-half Mile of Shore $3-133$

Table 3-37. Community Use for Deer, by WAA

Table 3-38. Number and Percent of Deer Harvest, by Community and by WAA

Table 3-39. VCU Sensitivity to Disturbance, ADF\&G Ranking

Table 3-40. Average Subsistence/Personal Use Salmon Harvest, and Permits Returned to ADF\&G, by Stream, 19951999

Table 3-41. Heritage Resource Surveys Completed Since 1986, and Sites Identified Since 1975 Within the Analysis Area. 


\section{Table of Contents}

\section{List of Figures}

\section{Chapter 1-Purpose and Need}

Figure 1-1. Map of the Analysis Area

Figure 1-2. Forest Plan LUD Color Map.....

\section{Chapter 2-Alternatives}

Figure 2-1. Map of Alternative 3 Large Group Areas, Part 1 ...........................................2-15

Figure 2-2. Map of Alternative 3 Large Group Areas, Part 2 ..........................................2-17

Figure 2-3. Map of Alternative 4 Large Group Areas, Part 1.............................................2-23

Figure 2-4. Map of Alternative 4 Large Group Areas, Part 2............................................2-25

Figure 2-5. Map of Alternative 5 Large Group Areas, Part 1............................................2-31

Figure 2-6. Map of Alternative 5 Large Group Areas, Part 2............................................2-33

\section{Chapter 3-Affected Environment and Environmental Consequences}

Figure 3-1. Commercially Guided Individuals, by Activity, 1999 .................................. 3-22

Figure 3-2. Commercially Guided Groups, by Activity, 1999 …...................................... 3-22

Figure 3-3a. Alternative 2, Comparison of the Proposed Commercial Allocation and Current

(1999) Use Levels, by Use Area During the Spring Season.

Figure 3-3b. Alternative 2, Comparison of the Proposed Commercial Allocation and Current

(1999) Use Levels, by Use Area During the Summer Season .....

Figure 3-3c. Alternative 2, Comparison of the Proposed Commercial Allocation and Current

(1999) Use Levels, by Use Area During the Fall Season

Figure 3-3d. Alternative 3, Comparison of the Proposed Commercial Allocation and Current

(1999) Use Levels, by Use Area During the Spring Season

Figure 3-3e. Alternative 3, Comparison of the Proposed Commercial Allocation and Current

(1999) Use Levels, by Use Area During the Summer Season ......

Figure 3-3f. Alternative 3, Comparison of the Proposed Commercial Allocation and Current

(1999) Use Levels, by Use Area During the Fall Season

Figure 3-3g. Alternative 4, Comparison of the Proposed Commercial Allocation and Current (1999) Use Levels, by Use Area During the Spring Season... 3-46

Figure 3-3h. Alternative 4, Comparison of the Proposed Commercial Allocation and Current

(1999) Use Levels, by Use Area During the Summer Season

Figure 3-3i. Alternative 4, Comparison of the Proposed Commercial Allocation and Current

(1999) Use Levels, by Use Area During the Fall Season

Figure 3-3j. Alternative 5, Comparison of the Proposed Commercial Allocation and Current

(1999) Use Levels, by Use Area During the Spring Season.

Figure 3-3k. Alternative 5, Comparison of the Proposed Commercial Allocation and Current

(1999) Use Levels, by Use Area During the Summer Season..... 3-50

Figure 3-31. Alternative 5, Comparison of the Proposed Commercial Allocation and Current

(1999) Use Levels, by Use Area During the Fall Season

Figure 3-4. Total Use Above Allocation as a Percent of Total Use, Assuming 1999

Commercial Use Levels and Twice-1999 Levels .....

Figure 3-5. GMU 1C, Brown Bear Harvest, 1986-1998. .3-106 


\section{Table of Contents}

Figure 3-6. GMU 1D, Brown Bear Harvest, 1986-1998

3-106

Figure 3-7. GMU 1, Percentage of Successful Brown Bear Hunters, by Their Residency, 1986-1998

Figure 3-8 GMU 4, Brown Bear Harvest 1992-1999, Compared to Four Percent Harvest Rate

Figure 3-9 GMU 4, Percentage of Successful Brown Bear Hunters, by Their Residency, 1992-1998

Figure 3-10. Guided Freshwater Sport Fishing Use on the National Forest, 19962000

Figure 3-11. Distribution of Sport Fishing Use on Streams in the Analysis Area During 1999

Figure 3-12. Freshwater and Saltwater Fishing Effort in the Analysis Area and Surrounding Saltwater, 19971998 $3-125$ 


\section{Executive Summary}

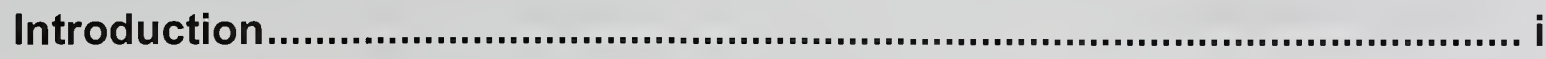

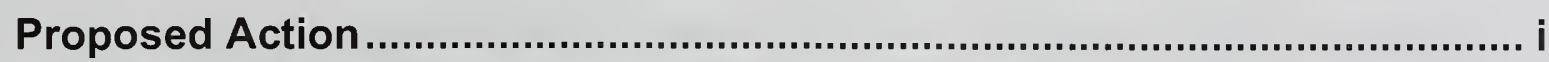

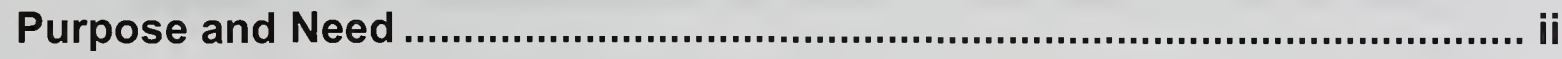

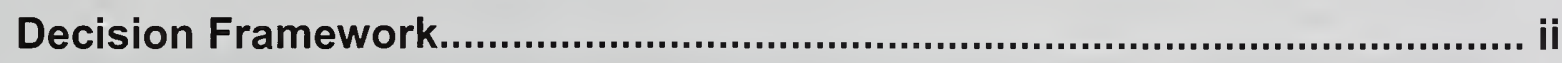

Description of the Analysis Area ................................................................ ii

Public Involvement and Issues ................................................................... iii

Alternatives Considered in Detail ................................................................. v

Comparison of the Alternatives ..................................................................... ix

Mitigation and Monitoring .............................................................................. 


\section{Executive Summary Key Terms}

Carrying capacity (recreation) - The estimated maximum number of groups of people who could recreate in an area and still have a specified type of recreation experience.

Commercial use - Any use of the national forest for which a fee is charged by an outfitter/guide.

Enclave - Area where large groups can occur on a regular basis throughout the season.

Fifteen-Percent area - Places where large groups can occur only on an occasional basis, for less than 15 percent of the primary use season.

Group - A group consists of one or more individuals recreating together as a social unit. Groups are used as the basic unit in this analysis

Group days - A measurement of recreation use by groups using the national forest on a daily basis.

Large group - Group made up of a number of people that exceeds the general maximum group size for a specified type of recreation experience in the ROS. Large group size varies by LUD and ROS.

Recreation Opportunity Spectrum (ROS) - Used to plan and manage recreation by types of recreation experience.

Shoreline zone - The analysis area extending inland approximately one-half mile from mean high tide.

Use Area - Distinct geographic areas used in this analysis as the basis for defining and managing recreation use. 


\section{Executive Summary}

\section{Introduction}

The U. S. Department of Agriculture (USDA), Forest Service, has prepared this draft environmental impact statement (Draft EIS) on the potential effects of authorizing commercial outfitting and guiding activities on the shoreline of the Admiralty Island National Monument, and Hoonah, Sitka, and Juneau Ranger Districts on the Tongass National Forest, Alaska Region (Region 10). Five alternatives are analyzed and presented. This EIS was prepared according to the regulations implementing the National Environmental Policy Act (NEPA, 40 CFR 1500-1508).

This analysis was initiated due to the expiration of the decision made from the Chatham Area Outfitter/Guide Limited Use Environmental Analysis (USDA Forest Service 1993). Following that expiration and in response to concerns over increases in recreation and tourism on the Tongass National Forest, the Forest Service placed moratoriums on permitting additional commercial outfitter/guide use in many locations and on commercial brown bear guiding in one Game Management Unit. The moratorium will continue until a recreation carrying capacity and allocation analysis are completed. The total recreation carrying capacity of the analysis area was determined and documented in the Shoreline Recreation Carrying Capacity Analysis for the Admiralty Island National Monument, Hoonah, Juneau, and Sitka Ranger Districts on the Tongass National Forest (USDA Forest Service 2001). This EIS further analyzes potential effects of authorizing different levels of commercial outfitting and guiding activities within the shoreline zone of the analysis area.

\section{Proposed Action}

The proposed action (Alternative 2) authorizes issuing commercial permits for shoreline-based activities (above mean high tide) on National Forest System lands located on the Admiralty Island National Monument, and the Hoonah, Sitka, and Juneau Ranger Districts. Activities include but are not limited to: sightseeing, hiking, camping, photography, boating, hunting, freshwater fishing, and nature viewing. These activities generally occur within one-half mile inland from the mean high-tide line, or along streams and trails accessed from the shoreline.

The proposed action allocates a specific amount of the recreation carrying capacity to commercial use for each Use Area and each season. The allocation ranges from 5 to 40 percent of the total recreation capacity depending on the Use Area. Each allocation is based on factors such as the proximity of the Use Area to communities, the amount of subsistence use, and potential resource impacts. Commercial outfitter/guide use would be limited to 10 percent or less of the total recreation capacity during the spring and fall seasons to keep the number of social encounters low and to provide more opportunities for solitude. For more details on the proposed action, see Alternative 2 in Chapter 2. 


\section{Executive Summary}

Commercial activities that involve taking fish or game will be authorized under the regulations and harvest limits established by the Alaska Board of Game, Alaska Board of Fisheries, and the Federal Subsistence Board. If fish or game harvest levels were to approach harvest limits, Special Use permits could be restricted and use allocated among outfitter/guides through the Special Uses administrative process.

\section{Purpose and Need}

The purpose of this action is to manage outfitter/guide use of the Tongass National Forest shoreline zone within the analysis area in a manner consistent with the Forest Plan. This management would balance commercial and non-commercial recreational opportunities and reduce the potential for user conflicts. Guided visitor use levels would be managed to maintain quality recreation experiences without degrading forest resources or the recreation experiences sought by both guided and unguided recreationists.

This action is needed to meet Forest Plan goals and objectives relating to recreation, tourism, and economic support to communities; and to meet the increased demand for guided recreation while protecting the ecosystem. Former management direction for outfitters and guides has expired; current direction is provided on a case-by-case basis. Comprehensive, consistent direction is needed for managing commercial recreation use across the analysis area.

Forest Plan goals and objectives applicable to the Shoreline Outfitter/Guide analysis area include those that:

- offer a range of recreation opportunities consistent with public demand,

- contribute to the local and regional economies of Southeast Alaska,

- provide national forest visitors with visually appealing scenery, and

- allocate recreation use consistent with the ecosystem goals and objectives in the Forest Plan while protecting forest resources.

\section{Decision Framework}

\section{Decision}

The decision based on this EIS will authorize the issuing of commercial use permits on the national forest within the shoreline zone of the analysis area. The decision, which will be documented in a Record of Decision (ROD), will:

- Specify the amount of the carrying capacity allocated to commercial recreation use for each Use Area in each season,

- Specify the types of commercial recreation activities permitted,

- Specify the methods of access approved for commercial use,

- Specify the type and location of areas where large commercial groups can occur and under what conditions, 


\section{Executive Summary}

- Specify the mitigation measures for commercial recreation activities to reduce user conflicts and resource impacts, and

- Establish monitoring requirements.

The decision will not:

- Regulate or allocate the amount of recreation carrying capacity for noncommercial or unguided use,

- Address or authorize ground-disturbing activities, assign sites, or other forms of development, or

- Make allocations to specific commercial businesses.

This decision will also establish findings including the following:

- Whether there may be a significant restriction on subsistence uses,

- Whether the activities are consistent with the Alaska Coastal Zone Management Plan, and

- Effects on Essential Fish Habitat.

\section{Responsible Official}

The Deputy Forest Supervisor of the Tongass National Forest is the responsible official who will sign the ROD. The responsible official may select any one of the alternatives in the Final EIS (including the no-action alternative) or a modified alternative (for example, combining parts of different alternatives), as long as the effects of the modified alternative have been fully analyzed and disclosed in the Final EIS.

\section{Description of the Analysis Area}

The entire Shoreline Outfitter/Guide analysis area includes approximately 7,018,700 acres of the Admiralty Island National Monument, and the Hoonah, Sitka, and Juneau Ranger Districts on the northern half of the Tongass National Forest. The shoreline zone of the analysis area extends one-half mile inland from mean high tide. Approximately 995,400 acres of the shoreline zone is within the national forest. This includes approximately 5,300 miles of shoreline.

Two areas on Admiralty Island were excluded from the analysis: Mitchell Bay and environs, which is the area surrounding the Village of Angoon, and the Pack Creek Zoological Area. The national forest shorelines associated with the Juneau and Sitka road systems also are not included in this analysis.

The analysis area is divided into Use Areas. These areas are shown in Chapter 1 of the EIS (Figure 1-1).

\section{Public Involvement}

Public scoping was the key process used to identify issues in this analysis. Scoping began in October 1998 and continued through the summer of 2001. Many methods were used to notify the public and request input for the analysis, including: public meetings, presentations to organizations, personal communications, scoping documents, newsletters, and radio news stories. Specific key features included the 


\section{Executive Summary}

Schedule of Proposed Actions, the project Notice of Intent, the project mailing list, and other scoping milestones. The original Notice of Intent (NOI) was published in the Federal Register on January 18,2000. A Revised NOI was published in the Federal Register on April 5, 2001 to inform the public of changes in the scope of the analysis and schedule

The Forest Service fostered collaborative stewardship by working closely with other government agencies and federally recognized tribal governments and entities. Collaboration took various forms: formal and informal consultations with tribes and agencies, as well as reviews by agencies with regulatory authority over activities considered in the Shoreline Outfitter/Guide EIS. Some commercial outfitter/guide activities authorized by this decision may require permits from other federal and state agencies.

Issues

Significant issues for the Shoreline Outfitter/Guide Draft EIS were identified by: the public during scoping, current agency issues, and comments from other government agencies.

The following three significant issues emerged from the scoping efforts. Each issue is displayed to stand alone. However, there is some overlap between the issues due to the different perspectives of individual recreationists and the recreation industry.

Each alternative was evaluated against the issues. Measures included both qualitative and quantitative values. Many of the measurements generated are directly proportional to the amount and season of recreation carrying capacity allocated to commercial use.

\section{Issue 1. Availability of Recreation Opportunities for the Guided and Unguided Recreationist}

Issue 1 focuses on the people who recreate on the national forest. Both guided and unguided recreationists often pursue the same type of recreation experience. The issue reflects the need for a variety of quality recreation opportunities for both guided and unguided recreationists on the national forest. It revolves around social interactions and recreation experience expectations and the effects on those interactions and expectations from the management of commercial uses as described in the alternatives.

\section{Issue 2. Economic Opportunities and Potential Effects on Outfitter/Guide Businesses}

Issue 2 focuses on the recreation industry rather than on individual recreationists. It responds to recreation industry concerns about economic opportunities and the influence of outfitter/guide management on their businesses.

\section{Issue 3. Conflicts Within the Commercial Recreation Industry}

There is a broad diversity in the types and size of businesses involved in commercial recreation. Some of these differences can lead to conflicts among the different commercial recreation businesses. These conflicts are the focus of Issue 3, which also deals with social interactions and expectations for recreation experiences.

\section{Other Environmental Considerations}

In addition to the significant issues described above, the public raised many other concerns during the scoping period. Although these concerns may be addressed to varying degrees in the analysis, they were not considered significant issues. as 


\section{Executive Summary}

defined by the National Environmental Policy Act (NEPA), and they did not drive the development of alternatives to the proposed action. Other concerns are not related to the decision or their resolution is outside the scope of this analysis. Many potential resource effects would have the same mitigation in all alternatives or are controlled through adherence to Forest Plan standards and guidelines.

Concerns were expressed about the following resources, which are addressed in Chapter 3 under Other Environmental Considerations: biodiversity, soils, wetlands, vegetation, wildlife, fish habitat and water quality, threatened and endangered species, karst and cave resources, subsistence, heritage resources, and air quality.

\section{Alternatives Considered in Detail}

Alternative 1 No Action
Alternative 1 (no action), and Alternatives 2 (proposed action), 3, 4, and 5 were considered in detail. The proposed action is the initial proposal that was developed to meet the purpose and need. The other action alternatives apply different strategies, based on the significant issues, to satisfy the purpose and need. Specific commercial allocations by Use Area and season for each alternative are presented in detail in Chapter 2 of the EIS.

The no-action alternative for this EIS, Alternative 1, represents the existing condition of recreation management in the analysis area. Alternative 1 would continue the present management practices of the outfitter/guide Special Uses program. It would not provide a specific allocation of the recreation carrying capacity to commercial use and it would not preclude commercial use.

- Individual Special Use permits would continue to undergo separate analysis annually.

- No specific allocation for commercial recreation carrying capacity currently exists and none would be made. Commercial use would be equal to the actual use authorized annually on a case-by-case basis, which could be up to 50 percent of the recreation carrying capacity (USDA Forest Service 1997b; pp 4-41).

- Outfitters and guides would apply for permit renewal, but no new or additional priority use permits would be issued. The existing moratoriums limiting commercial use would continue. These include the brown bear guide moratorium and site-specific commercial use moratoriums on the Admiralty Island National Monument and Hoonah, Sitka, and Juneau Ranger Districts.

- No specific large group areas would be designated for active management. Group size and occurrence would continue to be determined under Forest Plan direction.

- Commercial use would not be managed on a seasonal basis.

Alternative 2 is the proposed action. It provides a specific commercial use allocation for each Use Area and season, with a moderate level of commercial use.

- Up to 16,894 commercial groups would be able to use the analysis area through the spring, summer, and fall seasons. 
- Approximately 21 percent of the total recreation carrying capacity would be allocated to commercial use for the analysis area as a whole through all seasons. Individual Use Area allocations range between approximately 10 and 40 percent of the total recreation carrying capacity.

- Emphasis is on limited commercial use during the spring and fall seasons to reduce encounters and provide more opportunities for solitude. Spring and fall allocations would be about 10 percent of the total carrying capacity.

- Allocations in Use Areas with communities are generally reduced and range between 10 and 30 percent of the carrying capacity.

- This alternative would not designate large group areas for active management. Group size and occurrence would continue to be determined under Forest Plan direction.

- This alternative would not authorize wheeled airplane access.

- No commercial use on the Mud Bay River would be authorized.

- Guided sport fishing on Redoubt Lake and Stream, Salmon Lake, Nakwasina River, St. John the Baptist River, and Fish Bay River would be seasonally restricted to no more than two guided groups at a time.

- Site-specific descriptions, resource considerations, and mitigation measures for each Use Area are provided in Appendix A.

\section{Alternative 3}

Enclave-Area where large groups can occur on a regular basis

throughout the season.

\section{Fifteen-Percent}

Area- Place where

large groups can occur only on an occasional basis, for less than 15 percent of the primary use season.

\begin{abstract}
Alternative 3 provides a specific commercial use allocation for each Use Area and season. It was developed to evaluate the highest allocation level allowed in the Forest Plan. Specific Use Area allocations would allow for the most growth in the recreation industry. In general, there is less emphasis on providing opportunities for solitude and more on increasing visitor access to the national forest. There are fewer restrictions on commercial use; restrictions are primarily for essential resource protection.
\end{abstract}

- Up to 40,658 commercial groups would be able to use the analysis area through the spring, summer, and fall seasons.

- Approximately 50 percent of the total recreation carrying capacity would be allocated to commercial use through all seasons.

- Spring and fall season allocations would be 50 percent of carrying capacity.

- Allocations in use areas containing communities would be 50 percent of the carrying capacity.

- Forty Enclaves would be designated for large group use.

- Large group use in Enclave areas would be allowed in all seasons. Group size in these areas would be limited to 75 people and only one large group would be able to use an area at a time.

- Twenty-three Fifteen-Percent areas would be designated for large group use.

- Large group use could occur in Fifteen-Percent areas in spring, summer, and fall seasons. Group size in these areas would be limited to 75 people and only one large group would be able to use an area at a time. 


\section{Executive Summary}

- Limited wheeled airplane landings would be allowed in Neka Bay and Mud Bay with weekly and daily restrictions.

- Limited commercial use would be allowed on the Mud Bay River.

- Site-specific descriptions, resource considerations, and mitigation measures for each Use Area are provided in Appendix A.

- Site-specific descriptions, resource considerations, and mitigation measures for each large group area are provided in Appendix B.

\section{Alternative 4}

Alternative 4 provides specific commercial use allocations for each Use Area and season. It provides the lowest commercial allocation. Overall, there is an emphasis on providing more opportunities for recreation experiences with solitude. This alternative is the most restrictive on commercial uses to reduce social conflicts.

- Up to 6,192 commercial groups would be able to use the analysis area through the spring, summer, and fall seasons.

- Approximately eight percent of the total recreation carrying capacity would be allocated to commercial use for the analysis area as a whole through all seasons. Allocations to each Use Area range between 5 and 25 percent of the total carrying capacity.

- This alternative emphasizes greater limits on commercial use levels to reduce encounters and provide more opportunities for solitude during both the spring and fall seasons. The spring allocation would be up to 15 percent of the carrying capacity and the fall allocation would be up to 25 percent in some areas.

- Allocations in Use Areas containing communities would be less than 15 percent of the carrying capacity.

- Fifteen Enclaves would be designated for large group use. Large group use in Enclave areas would be allowed in all seasons. Group size in these areas would be limited to 75 people, and only one large group would be able to use an area at a time.

- Five Fifteen-Percent areas would be designated for large group use.

- Large group use could occur in Fifteen-Percent areas in only the summer season. Group size in these areas would be limited to 75 people, and only one large group would be able to use an area at a time.

- Limited wheeled airplane landings with daily and weekly restrictions varying by season would be authorized in Mud Bay.

- Guided sport fishing on Redoubt Lake and Stream, Salmon Lake, Nakwasina River, St. John the Baptist River, and Fish Bay River is seasonally restricted to no more than two guided groups at a time.

- Limited commercial use varying by season would be allowed on the Mud Bay River.

- Site-specific descriptions, resource considerations, and mitigation measures for each Use Area are provided in Appendix A.

- Site-specific descriptions, resource considerations, and mitigation measures for each large group area are provided in Appendix B. 


\section{Executive Summary}

Alternative 5

Alternative 5 provides a specific commercial use allocation for each Use Area and season. It provides a moderate level of commercial use. There are some restrictions to commercial use to reduce social conflicts.

- Up to 18,495 commercial groups would be able to use the analysis area through the spring, summer, and fall seasons.

- Approximately 23 percent of the total recreation carrying capacity would be allocated to commercial use for the analysis area as a whole through all seasons. Allocations in each use area range between about 10 and 40 percent of the carrying capacity. The allocation varies to achieve sitespecific management objectives.

- Alternative 5 emphasizes a limited commercial use to reduce encounters and provide more opportunities for solitude during only the spring season. Spring allocation would be about 10 percent of the total carrying capacity.

- Allocations in Use Areas with communities are generally reduced and range from 10 to 40 percent of the total carrying capacity.

- This alternative would designate 33 Enclaves for large group use.

- Large group use in Enclave areas would be allowed in all seasons. Group size in these areas would be limited to 75 people, and only one large group would be able to use an area at a time.

- This alternative would designate 14 Fifteen-Percent areas for large group use.

- Large group use could occur in Fifteen-Percent areas in only the summer season. Group size in these areas would be limited to 75 people, and only one large group would be able to use an area at a time.

- Limited wheeled airplane landings would be allowed in Neka and Mud Bays under daily and/or weekly restrictions. Neka Bay landings would only be authorized for differently-abled access with seasonal restrictions.

- Limited commercial use varying by season would be allowed on Mud Bay River.

- Guided sport fishing on Redoubt Lake and Stream, Salmon Lake, Nakwasina River, St. John the Baptist River, and Fish Bay River is seasonally restricted to no more than two guided groups at a time.

- Site-specific descriptions, resource considerations, and mitigation measures for each Use Area are provided in Appendix A.

- Site-specific descriptions, resource considerations, and mitigation measures for each large group area are provided in Appendix B. 


\section{Executive Summary}

Identification of the Preferred Alternative
Alternative 5 is identified as the preferred alternative at this time to assist the public in their review of this document. However, all of the alternatives have equal standing with the responsible official. Alternatives may be modified or a new alternative developed in response to public comments on the Draft EIS.

\section{Comparison of the Alternatives}

Tables Sum-1 and Sum-2 provide summary comparisons of the five alternatives. See Chapter 2 of this EIS for details.

Table Sum-1. Comparison of Alternatives, General

\begin{tabular}{|c|c|c|}
\hline Alternative & General Description & $\begin{array}{l}\text { Amount of Total Recreation } \\
\text { Capacity Allocated to } \\
\text { Commercial Use }\end{array}$ \\
\hline $\begin{array}{c}1 \\
\text { no action }\end{array}$ & $\begin{array}{l}\text { Existing conditions, continues } \\
\text { present management practices of the } \\
\text { outfitter/guide Special Uses program. }\end{array}$ & $\begin{array}{l}\text { No specific allocation, } \\
\text { commercial use allowed on a } \\
\text { case-by-case basis. } \\
\text { Up to } 50 \%\end{array}$ \\
\hline $\begin{array}{c}2 \\
\text { proposed action }\end{array}$ & $\begin{array}{l}\text { Emphasis on limited commercial use } \\
\text { during spring and fall, no large group } \\
\text { areas, no wheeled airplane access }\end{array}$ & $\begin{array}{c}\text { Moderate } \\
\text { Approximately } 21 \%\end{array}$ \\
\hline 3 & $\begin{array}{l}\text { Less emphasis on providing } \\
\text { opportunities for solitude, more } \\
\text { emphasis on increasing visitor access } \\
\text { and commercial opportunity }\end{array}$ & $\begin{array}{c}\text { Highest } \\
\text { Approximately } 50 \%\end{array}$ \\
\hline 4 & $\begin{array}{l}\text { Emphasis on providing more } \\
\text { opportunities for solitude }\end{array}$ & $\begin{array}{c}\text { Lowest } \\
\text { Approximately } 8 \%\end{array}$ \\
\hline $\begin{array}{l}5 \\
\text { preferred alternative }\end{array}$ & $\begin{array}{l}\text { Emphasis on limited commercial use } \\
\text { during spring, some large group } \\
\text { areas, limited wheeled airplane } \\
\text { landings in some places }\end{array}$ & $\begin{array}{c}\text { Moderate } \\
\text { Approximately } 23 \%\end{array}$ \\
\hline
\end{tabular}


Table Sum-2. Comparison of Alternatives, by Issue

\begin{tabular}{cc|c|c|c|c}
\hline Issue / & \multicolumn{5}{c}{ Alternative } \\
\cline { 3 - 7 } Unit of Measure & 1 & 2 & 3 & 4 & 5 \\
\hline
\end{tabular}

\section{Issue 1 - Recreation Opportunities for Guided and Unguided Recreationists}

Recreation experience opportunities available as anticipated by the Forest Plan and ROS

Acres that could potentially change from Semi-primitive to a more developed ROS setting in the Enclave areas

Total recreation carrying capacity (group days) available to guided recreationists

Estimated number of people who could use commercial services to access the national forest (assumes commercial group size of six)

Number of Enclaves allowing large group use

Total area (acres) of Enclaves

Number of Fifteen-Percent areas allowing large group use

Total area (acres) of Fifteen-Percent areas

Limits on commercial use in Use Areas with communities

\begin{tabular}{r|r|r|r|r} 
Yes & Yes & Yes & Yes & Yes \\
0 & 0 & 8,865 & 3,065 & 6,790 \\
$* *$ & 16,894 & 40,658 & 6,192 & 18,495 \\
243,948 & 101,364 & 243,948 & 37,152 & 110,970 \\
0 & 0 & 40 & 15 & 33 \\
0 & 0 & 7,949 & 2,888 & 6,092 \\
0 & 0 & 23 & 5 & 14 \\
0 & 0 & 5,210 & 765 & 3,066 \\
No & Yes & No & Yes & Yes \\
\hline
\end{tabular}

\section{Issue 2 - Economic Opportunities and Potential Impacts on Commercial Outfitter/Guide Businesses}

Recreation experience opportunities available for commercial use as anticipated by the Forest Plan and ROS

Commercial allocation available in group days

Percent of recreation capacity allocated to commercial use

Current (1999) commercial use levels in group days

Group days available for industry growth above current (1999) use levels

Number of Use Area seasons approaching, at, or near allocated capacity

Number of areas designated for large groups

Quality of recreation experience available for commercial use as anticipated by the Forest Plan

Contributes to business stability and certainty by establishing predictable use levels and allowing for multi-year Special Use permits

\begin{tabular}{r|r|r|r|r} 
Yes & Yes & Yes & Yes & Yes \\
NA & 16,894 & 40,658 & 6,192 & 18,495 \\
$3-50^{* *}$ & 21 & 50 & 8 & 23 \\
2,410 & 2,410 & 2,410 & 2,410 & 2,410 \\
NA & 14,484 & 38,248 & 3,782 & 16,085 \\
NA & 10 & 0 & 4 & 8 \\
0 & 0 & 63 & 20 & 47 \\
NA & Yes & Yes & Yes & Yes \\
No & Yes & Yes & Yes & Yes \\
\hline
\end{tabular}

Issue 3 - Conflicts Within the Commercial Recreation Industry

Establishes recreation management seasons.

Limits commercial allocations in the spring season

Limits commercial allocations in the fall season

Use of specific mitigation measures to reduce conflict

Designates Enclaves and Fifteen-Percent Areas for large group use

Specifies maximum size of large groups

\begin{tabular}{r|r|r|r|r} 
No & Yes & Yes & Yes & Yes \\
No & Yes & No & Yes & Yes \\
No & Yes & No & Yes & No \\
NA & Yes & Yes & Yes & Yes \\
No & No & Yes & Yes & Yes \\
No & No & Yes & Yes & Yes \\
\hline
\end{tabular}

** No specific allocation is made. Commercial use is allowed on a case-by-case basis up to 50 percent of the recreation carrying capacity. 


\section{Executive Summary}

\section{Mitigation and Monitoring}

Mitigation

Monitoring
The analysis documented in this EIS discloses the possible adverse impacts that may occur from implementing the actions proposed under each alternative. Measures have been formulated to mitigate or reduce these impacts. A comprehensive list of mitigation measures apply to the commercial recreation activities for all of the action alternatives. These are listed in Appendix C, Mitigation Measures. In addition, site-specific resource concerns and mitigation measures are listed on the Use Area cards in Appendix A and on the Large Group Area Cards in Appendix B.

Monitoring is a critical component of this project. Commercial recreation management at the scale proposed in this analysis is relatively new to the Forest Service in Southeast Alaska. Many of the social facets of recreation are not well understood. Recreation use levels are dynamic and fluctuate from year to year. Reliable site-specific unguided recreation use information is not currently available. The environmental effects of recreation use are also not well known. Through monitoring, the Forest Service can achieve a better understanding of these effects and adapt its management as necessary. A monitoring plan is provided in Appendix D. 


\section{Executive Summary}

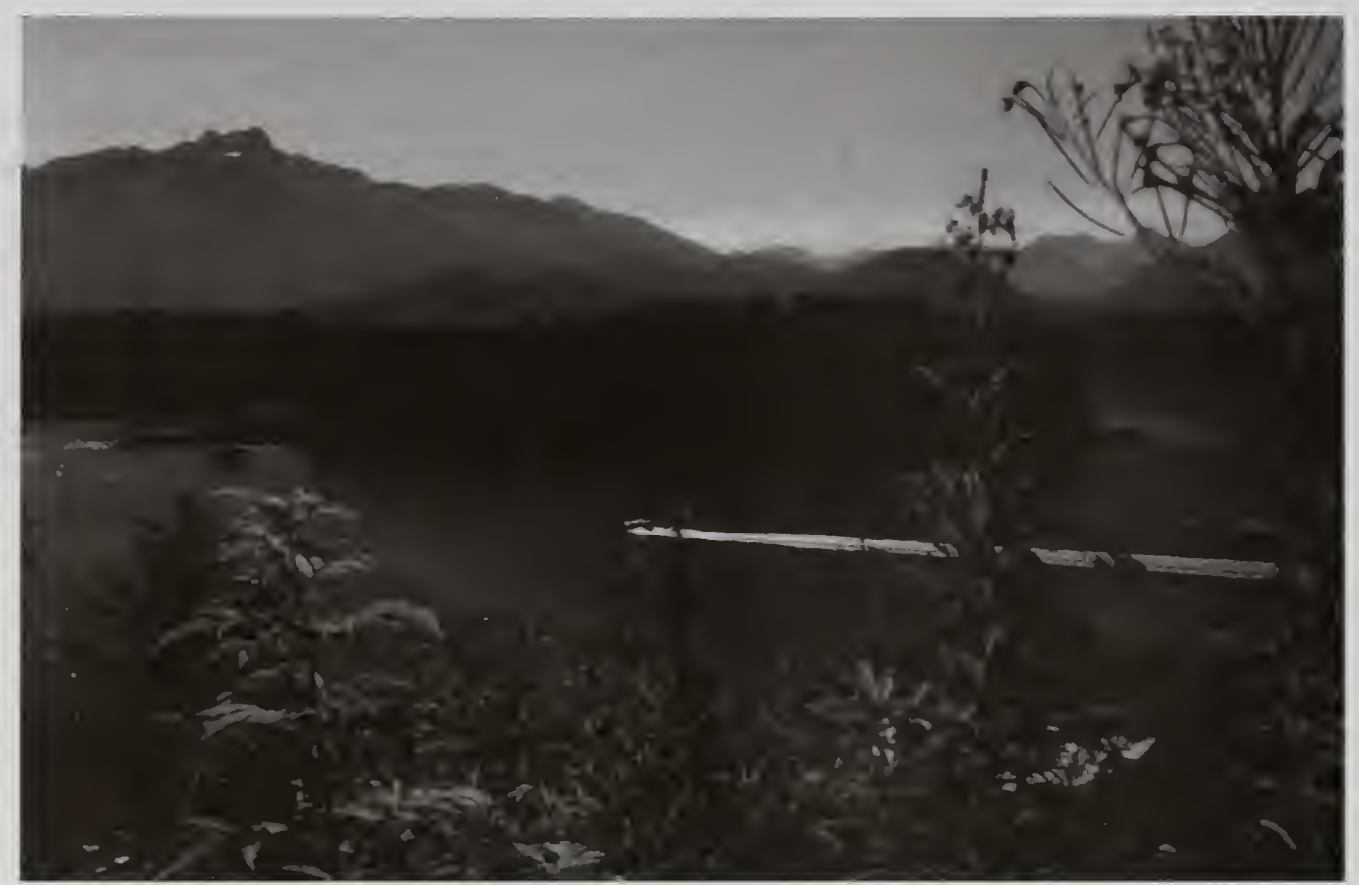




\section{Chapter 1 \\ Purpose and Need}

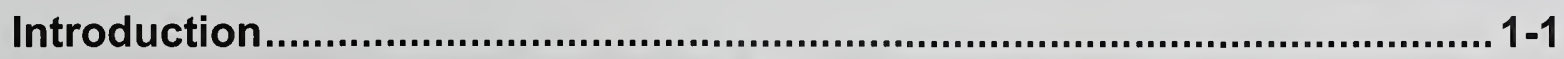

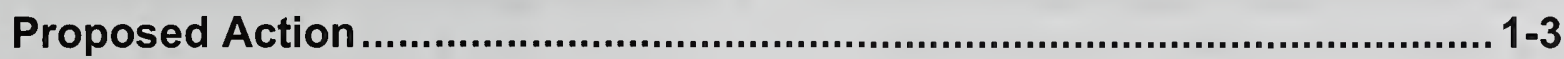

Purpose and Need ......................................................................... 1-3

Decision Framework.............................................................................. 1-4

Description of the Analysis Area ........................................................ 1-5

Management Direction ................................................................ 1-10

Public Involvement ................................................................... 1-13

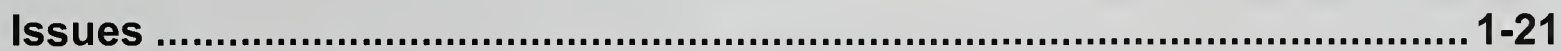

Applicable Laws and Executive Orders ................................................1-28

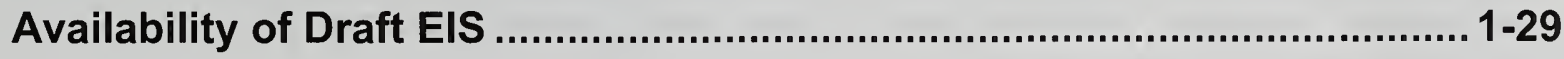




\section{Chapter 1 Key Terms}

Carrying capacity (recreation) - The estimated maximum number of groups of people who could recreate in an area and still have a specified type of recreation experience.

Commercial use - Any use of the national forest for which a fee is charged by an outfitter/guide.

Environmental Impact Statement (EIS) - A statement of environmental effects of a proposed action and alternatives to it.

Proposed action - An initial proposal by a federal agency to authorize, recommend, or implement an action.

Recreation Opportunity Spectrum (ROS) - A system for planning and managing recreation that categorizes recreation opportunities into seven classes (see Appendix F).

Use Area - Distinct geographic areas used in this analysis as the basis for defining and managing recreation use.

Scoping - Early and open communication with the public used to determine the scope and significance of a proposed action, what level of analysis is required, what information is needed, and what level of public participation is appropriate.

Significant issue - Under NEPA, refers to issues that are used to formulate alternatives, prescribe mitigation measures, or analyze environmental effects. 


\section{Chapter 1 \\ Purpose and Need}

\section{Introduction}

\section{Overview}

This EIS tiers to the Forest Plan and its Final EIS (USDA Forest Service 1997) and incorporates other documents by summarization and reference where appropriate. Additional documentation, including resource analyses with more detailed information of the analysis area, may be found in the project planning record located at the Forest Supervisor's Office in Sitka, Alaska. Other reference documents such commercial outfitting and guiding activities on the shoreline of the Admiralty Island National Monument, and Hoonah, Sitka, and Juneau Ranger Districts on the Tongass National Forest, Alaska Region (Region 10). Direct, indirect, and cumulative environmental impacts and any irreversible or irretrievable commitment of resources that would result from the proposed action and alternatives are disclosed in this document. Five alternatives are analyzed and presented.

The Forest Service manages its lands to provide the public with a variety of recreation opportunities. We can influence the recreation experience by providing different settings for recreation, ranging from wilderness to fully accessible trails and campgrounds, and by providing different facilities, such as cabins, boat moorings or roads, that make an area more accessible. Through this analysis, we are working to manage the recreation setting by regulating the number of commercially guided groups using specific areas.

This EIS was prepared according to the Council of Environmental Quality (CEQ) regulations implementing the National Environmental Policy Act (NEPA; 40 CFR 1500-1508). The document structure is illustrated on the inside front cover.

- Chapter 1 explains the purpose and need for the proposed action. It discusses how the Shoreline Outfitter/Guide EIS relates to the 1997 Tongass Land and Resource Management Plan (USDA Forest Service 1997b) and identifies the significant issues driving alternative development. The Tongass Land and Resource Management Plan, as amended, is referred to as the Forest Plan in this document.

- Chapter 2 describes and compares the proposed action, alternatives to the proposed action, and the no-action alternative.

- Chapter 3 describes the natural and human environments potentially affected by the proposed action and alternatives; the chapter also discloses the potential effects of the alternatives.

- Chapter 4 contains the list of the analysis team members, the Draft EIS distribution list, references, glossary, and index.

- Appendices provide additional information and background on specific aspects of the proposed project. 


\section{Background}

Carrying capacity is the number of groups of people in an area who would be able to enjoy a specified recreation experience. as the Forest Plan are available at public libraries throughout Southeast Alaska as well as at the Forest Supervisor's Office in Sitka. The Forest Plan is available on the Internet ( $w w w . f s . f e d . u s / r 10 / t \operatorname{lmp}$ ) and on CD-ROM upon request.

The Tongass National Forest provides unparalleled outdoor adventure opportunities. Most recreation opportunities are dispersed in isolated, wild settings, although most of the actual recreation use on the national forest occurs at visitor centers and other developed sites.

Recreation and tourism are increasing on the Tongass National Forest. Commercial recreation has grown substantially in the past decade. Tourism is of growing economic importance to Southeast Alaska, creating employment and income opportunities throughout the region. Nature-based travel and tourism provide a window through which an increasingly urban society can enjoy and appreciate the natural world.

Outfitters and guides are important partners with the Forest Service because they provide equipment, services, and local knowledge and experience to national forest visitors who prefer or need to be guided. Because of the remote and rugged nature of Southeast Alaska, commercial outfitter/guide services provide one of the few ways some forest visitors can access the national forest.

The current Shoreline Outfitter/Guide analysis began with the expiration of the decision made from the Chatham Area Outfitter/Guide Limited Use Environmental Analysis in 1998 (USDA Forest Service 1993). Some people who responded during scoping were concerned that recreation growth would compromise values they feel are important, including: solitude; opportunities for primitive or semi-primitive experiences; and access to fish and wildlife for viewing, hunting, or fishing. Increasing numbers of recreationists may lead to crowding and displacement of residents and negatively affect fish and wildlife resources.

Specifically, concern is growing about increasing commercial recreation use on the Tongass National Forest. In response to this concern, the Forest Service placed moratoriums on permitting additional commercial outfitter/guide use in many locations within the analysis area and on commercial brown bear guiding in Game Management Unit 4 until a recreation carrying capacity and allocation analysis were completed.

The Forest Service first determined the total recreation carrying capacity of the analysis area, which is documented in the Shoreline-Based Recreation Carrying Capacity Analysis for the Admiralty Island National Monument, Hoonah, Juneau, and Sitka Ranger Districts on the Tongass National Forest 2001 (Carrying Capacity Analysis). (USDA Forest Service 2001) The carrying capacity is the number of groups of people, both guided and unguided, in an area that would be able to enjoy a specified recreation experience.

The carrying capacity was based primarily on Land Use Designations (LUD) and associated Recreation Opportunity Spectrum (ROS) classes identified in the Forest Plan. This EIS further analyzes potential effects of authorizing commercial outfitting and guiding activities on the shoreline of the analysis area. 
The proposed action

(Alternative 2)

authorizes issuing

commercial permits

to shoreline-based

activities (above

mean high tide) on

National Forest

System lands.
A 'proposed action' was identified early in the process to briefly describe the actions and their magnitude. This proposed action authorizes the issuance of commercial outfitter/guide permits in the shoreline zone of the analysis area. It allocates a portion of the recreation carrying capacity to commercial outfitter/guide use and provides management direction to reduce the potential for user conflicts and protect forest resources. The proposed action provided the starting point for the interdisciplinary team (IDT) and helped focus public and other government agency comments. Comments were used to identify significant issues and develop alternatives to the proposed action.

The proposed action (Alternative 2) authorizes issuing commercial permits to shoreline-based activities (above mean high tide) on National Forest System lands located on the Admiralty Island National Monument, and the Hoonah, Sitka, and Juneau Ranger Districts.

Activities include but are not limited to: sightseeing, hiking, camping, photography, boating, hunting, freshwater fishing and nature viewing. These activities generally occur within one-half mile of the saltwater shoreline, or along streams and trails accessed from the shoreline. Commercial recreation activities are generally oriented to wild land experiences and are primarily boat-based, though some groups use floatplanes, helicopters or wheeled planes to access specific areas. Boats are also generally used as base facilities and for sleeping when activities are longer than day trips. If boats are not used for lodging, guided groups generally use tents and 'leaveno-trace' practices when camping. Group size is usually less than 12, although larger groups (both guided and unguided) may be present.

The proposed action allocates a specific amount of the recreation carrying capacity to commercial use for each Use Area (Table 1-1) and each season. The allocation ranges from 5 to 40 percent of the total recreation capacity depending on the Use Area. Each allocation is based on factors such as the proximity of the Use Area to communities, the amount of subsistence use, and potential resource impacts.

Commercial outfitter/guide use would be limited to 10 percent or less of the total recreation capacity during the spring and fall seasons to keep the number of social encounters low and to provide more opportunities for solitude. For more details on the proposed action, see Alternative 2 in Chapter 2.

Commercial activities that involve taking fish or game will be authorized under the regulations and harvest limits established by the Alaska Board of Game, Alaska Board of Fisheries, and the Federal Subsistence Board. If fish or game harvest levels were to approach harvest limits, Special Use permits would be restricted and use allocated among outfitter/guides through the Special Uses administrative process.

\section{Purpose and Need}

The purpose of this action is to manage outfitter/guide use of the Tongass National Forest shoreline zone within the analysis area consistent with the Forest Plan. This management would balance commercial and non-commercial recreational oppor- 
tunities and reduce the potential for user conflicts. Guided visitor use levels would be managed to maintain quality recreation experiences without degrading forest resources or the recreation experiences sought by both guided and unguided recreationists.

This action is needed to meet Forest Plan goals and objectives relating to recreation, tourism, and economic support to communities (see below); and to meet the increased demand for guided recreation while protecting the ecosystem. Former overall management for outfitters and guides has expired; current direction is provided on a case-by-case basis. Comprehensive, consistent direction is needed for managing commercial recreation use across the analysis area.

This action provides a comprehensive assessment of commercial use in the analysis area and a framework for reviewing and processing outfitter/guide requests. It supports the administration of the Forest Service Special Uses program through improved efficiency in issuing multi-year permits. The decision would define commercial opportunities and allow the issuance of priority use permits that would provide a more stable business environment to the recreation industry. Priority use permits can be issued for up to five years and are subject to re-issuance on a preferential basis at the end of their term.

Forest Plan goals and objectives applicable to the Shoreline Outfitter/Guide analysis area include those that provide for a range of recreation opportunities consistent with public demand, provide a diversity of opportunities for resource uses that contribute to the local and regional economies of Southeast Alaska, provide national forest visitors with visually appealing scenery, and allocate recreation use consistent with the ecosystem goals and objectives in the Forest Plan. Recreation-related goals and objectives are described in more detail in the Management Direction section of this chapter.

\section{Decision Framework}

\section{Decision}

The decision based on this EIS will authorize the issuing of commercial use permits on the national forest within the shoreline zone of the analysis area. The decision, which will be documented in a Record of Decision (ROD), will:

- Specify the amount of the carrying capacity allocated to commercial recreation use for each Use Area in each season,

- Specify the types of commercial recreation activities permitted,

- Specify the methods of access approved for commercial use,

- Specify the type and location of areas where large commercial groups can occur and under what conditions,

- Specify the mitigation measures for commercial recreation activities to reduce user conflicts and resource impacts, and

- Establish monitoring requirements, 


\section{Purpose and Need}

The decision will not:

- Regulate or allocate the amount of recreation carrying capacity for noncommercial or unguided use,

- Address or authorize ground-disturbing activities, assigned sites, or other forms of development, or

- Make allocations to specific commercial businesses.

\section{Findings}

\section{Responsible Official}

\section{Implementation}

This decision will also establish findings including the following:

- Whether there may be a significant restriction on subsistence uses,

- Whether the activities are consistent with the Alaska Coastal Zone Management Plan, and

- Effects on Essential Fish Habitat

The Deputy Forest Supervisor of the Tongass National Forest is the responsible official who will sign the ROD. The responsible official may select any one of the alternatives in the Final EIS (including the no-action alternative) or a modified alternative (for example, combining parts of different alternatives), as long as the effects of the modified alternative have been fully analyzed and disclosed in the Final EIS.

The decision will be implemented through the Special Uses administrative process. Commercial use permits will be authorized under the direction of the Special Uses Management Manual (FSM 2700) and Handbook (FSH 2709.11). Mitigation measures will be implemented through permit requirements and provisions, and administration and program monitoring. Monitoring will occur during and after the administration of Special Use permits and as part of program monitoring.

Outfitter/guide activities involving the taking of fish or game will be implemented under Alaska Board of Game, Alaska Board of Fisheries, and Federal Subsistence Board regulations.

Commercial use will be limited as it approaches the allocated use level in specific Use Areas. When commercial use becomes limited and there is competitive interest, permits will be allocated among qualified outfitter/guides through a competitive Special Uses process.

\section{Description of the Analysis Area}

The Shoreline Outfitter/Guide analysis area includes approximately 7,018,700 acres (Table 1-1) of the Admiralty Island National Monument, and the Hoonah, Sitka, and Juneau Ranger Districts on the northern half of the Tongass National Forest (Figure 1-1). This includes approximately 5,300 miles of shoreline. The shoreline zone of 
the analysis area extends one-half mile inland from mean high tide. Nearly 995,400 acres of the shoreline zone is national forest.

Two areas on Admiralty Island were excluded from the analysis: Mitchell Bay and environs, which is the area surrounding the village of Angoon; and the Pack Creek Zoological Area. The Mitchell Bay and environs area has unique Alaska National Interest Lands Conservation Act (ANILCA) requirements, which require a separate analysis. Pack Creek Zoological Area has specific Forest Plan direction and is managed under a separate management plan. In addition, the national forest shorelines associated with the Juneau and Sitka road systems are not included in this analysis because they are managed within the developed recreation program.

The analysis area is divided into 38 geographical Use Areas (Figure 1-1). Thirtyseven of these use areas contain a shoreline zone and are described in detail in Appendix A. The remaining Use Area covers the Juneau Icefields, which do not have a shoreline zone.

Table 1-1. Total Acres of Each Use Area

\begin{tabular}{|c|c|c|c|c|c|}
\hline Use & General Location & Acres & Use & General Location & Acres \\
\hline $01-01$ & Skagway Area & 300,931 & 04-04B & Kelp Bay & 134,900 \\
\hline 01-02 & Haines Area & 20,065 & $04-04 \mathrm{C}$ & Baranof Warm & 30,289 \\
\hline $01-03$ & East Chilkats & 376,318 & $04-05$ & $\bar{S} W$ Admiralty & 115,125 \\
\hline 01-04A & Berners Bay & 271,903 & 04-06A & Pybus Bay & 55,137 \\
\hline 01-04B & N. Juneau coast & 93,260 & 04-06B & Eliza Harbor & 84,684 \\
\hline 01-04C & Taku Inlet & 344,594 & 04-07 & Gambier Bay & 205,726 \\
\hline 01-04D & Slocum Inlet & 17,210 & 04-08 & NE Admiralty & 130,459 \\
\hline 01-04E & Juneau Icefields & 724,218 & 04-09 & Seymour Canal & 87,778 \\
\hline $01-05 \mathrm{~A}$ & Taku Harbor & 20,642 & $04-10 \mathrm{~A}$ & Greens Creek & 2,698 \\
\hline 01-05B & Port Snettisham & 372,752 & 04-10B & NW Admiralty & 269,848 \\
\hline $01-05 \mathrm{C}$ & Windham Bay & 268,300 & $04-11$ & Hoonah Area & 336,986 \\
\hline 01-05D & Tracy Arm & 625,105 & $04-12$ & Tenakee Inlet & 345,711 \\
\hline 01-05E & Fords Terror & 24,374 & $04-13$ & Peril Strait & 250,314 \\
\hline 04-01A & Gut Bay, Baranof & 138,639 & $04-14$ & Slocum Arm & 79,339 \\
\hline 04-01B & Port Armstrong & 75,704 & $04-15$ & West Chichagof & 253,656 \\
\hline $04-02 \mathrm{~A}$ & Redoubt Lake & 55,990 & $04-16 \mathrm{~A}$ & Point Adolphus & 8,900 \\
\hline 04-02B & Whale Bay & 272,576 & $04-16 \mathrm{~B}$ & North Chichagof & 64,621 \\
\hline 04-03 & Sitka Area & 388,739 & $04-16 \mathrm{C}$ & Idaho Inlet & 52,521 \\
\hline 04-04A & Lake Eva, Rodman & 87,891 & $04-16 \mathrm{D}$ & Port Althorp & 30,807 \\
\hline
\end{tabular}

Total Acres for All Use Areas $=\mathbf{7 , 0 1 8 , 7 1 0}$ 


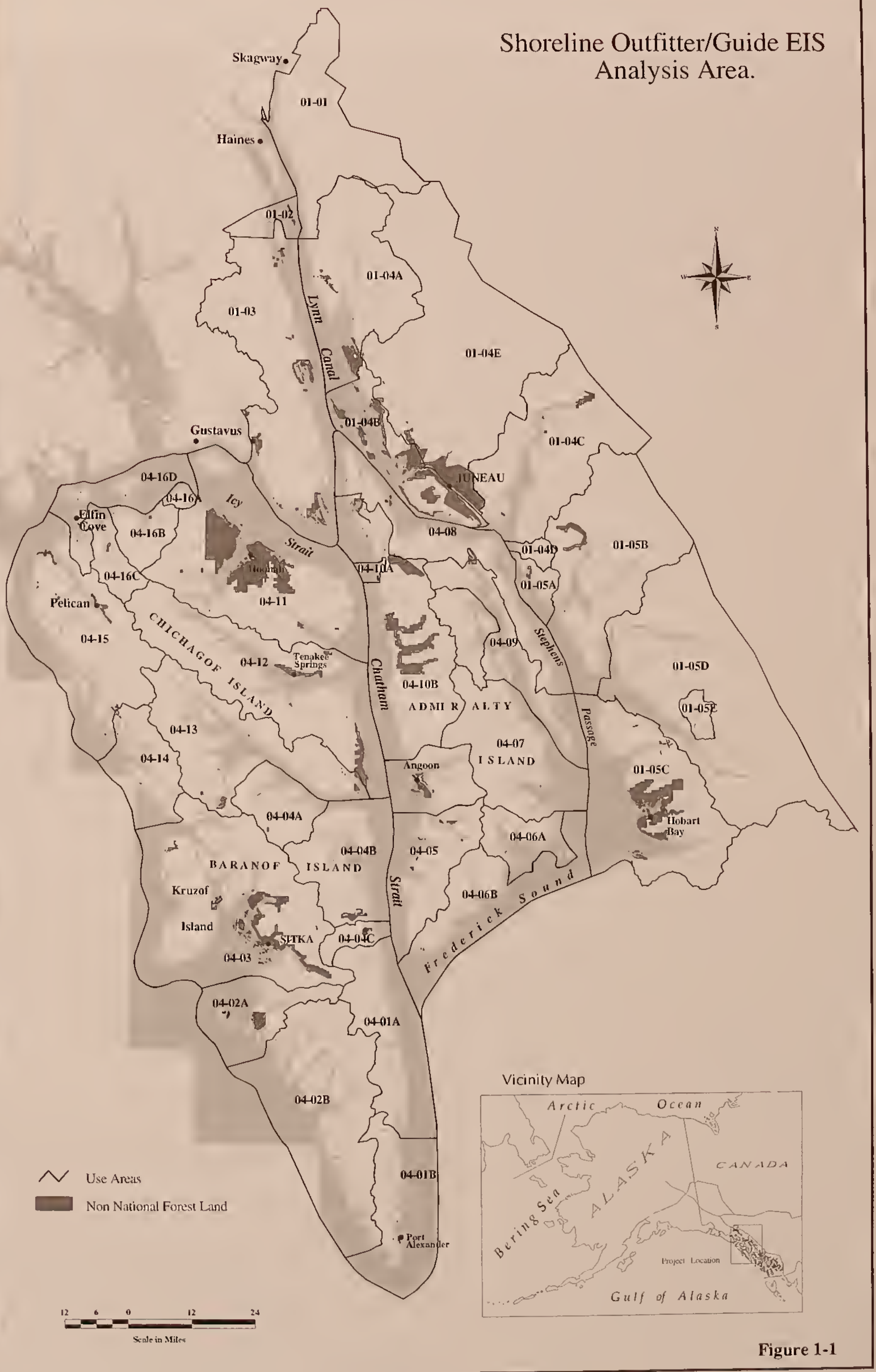


1 


\section{Previous Use}

Visitors have been attracted to the Tongass National Forest to experience the wild scenery and bountiful fish and wildlife for more than a century. Excursion boats were plying the waters of Southeast Alaska as early as the 1890s. Although the area is considered wild and pristine, it has been influenced by human use, especially along the shoreline where access from saltwater is easy. Portions of the shoreline have been modified by the development of villages, canneries, salteries, mines, and timber harvest. Recreation development on the Tongass National Forest consists primarily of remote recreation cabins and shelters with primitive trails leading into the forest. Eleven communities lie within the analysis area, most of which have ferry service. Private, tribal, and state land is distributed throughout the analysis area in relatively small tracts and is often associated with some form of development.

Commercial recreation has occurred historically throughout the analysis area, although use has increased greatly in the past decade.

This analysis considers current activities in or adjacent to the analysis area and activities that are likely to occur in the 'reasonably foreseeable future'. The timeframes of reasonably foreseeable future projects vary but tend to be ten years or less. Listed below are some past, present, and future analyses that may influence recreation management in the Shoreline Outfitter/Guide analysis area. They are incorporated into this analysis by reference.

- The Shoreline Recreation Carrying Capacity Analysis for the Admiralty Island National Monument, Hoonah, Juneau and Sitka Ranger Districts on the Tongass National Forest 2001 This analysis developed the recreation carrying capacity used in the Shoreline Outfitter/Guide analysis.

- The Stikine Area Outfitter/Guide Environmental Assessment and Finding Of No Significant Impact (1996) This decision allocated a portion of the carrying capacity to commercial outfitters and guides on the Petersburg and Wrangell Ranger Districts to the south of the analysis area.

- Limited Use Outfitter/Guide EA (1993) This environmental analysis authorized outfitter/guide use on the former Chatham Area administrative unit.

- Supplement to the 1997 Tongass Land and Resource Management Plan-Roadless Area Evaluation for Wilderness Recommendations This supplement evaluates and considers roadless areas within the Tongass for recommendation as potential Wilderness areas. The preferred alternative identified in the draft supplement does not recommend any additional Wilderness areas, and the analysis in this Draft EIS is based on that preferred alternative. A final decision on the recommendation of additional Wilderness Areas is expected in the fall of 2002. If that final decision differs from the preferred alternative, the Final Shoreline EIS will consider those changes in its analysis.

- The Tongass National Forest Schedule of Proposed Actions (SOPA) This Schedule of Proposed Actions lists the numerous near-term projects in or adjacent to the analysis area on the Tongass. The SOPA is 
published quarterly to notify the public of current and upcoming activities for which public input is requested (see Public Involvement section later in this chapter). The projects listed on the SOPA have been reviewed and considered in this analysis.

- Alaska Department of Natural Resources Draft Northern Southeast Area Plan (NSEAP) The Draft Northern Southeast Area Plan provides management direction for state lands in and adjacent to the analysis area.

- Alaska Department of Natural Resources Juneau State Land Plan December 1993 The Juneau Plan provides management direction for state lands surrounding the Juneau area.

- State of Alaska Coastal Management Program (ACMP) This program plan identifies management programs and processes for management of the Alaska Coastal Zone.

- Sitka District Coastal Management Program (as amended) This management plan identifies coastal resources, management objectives, and recreational opportunities for the City and Borough of Sitka.

- Sitka Parks and Recreation Plan, City and Borough of Sitka, Alaska, 1991 This plan identifies the recreation resources and objectives of Sitka City and Borough lands.

- Hoonah Coastal Management Plan This coastal management plan identifies coastal resources, management objectives, and recreational opportunities for the City of Hoonah.

- Angoon District Coastal Management Program This coastal management plan identifies coastal resources, management objectives, and recreational opportunities for the City of Angoon.

- Juneau District Coastal Management Program This coastal management plan identifies coastal resources, management objectives, and recreational opportunities for the City and Borough of Juneau.

- Haines Coastal Management Program This coastal management plan identifies coastal resources, management objectives, and recreational opportunities for the City and Borough of Haines.

- Skagway Coastal Management Program This coastal management plan identifies coastal resources, management objectives, and recreational opportunities for the City and Borough of Skagway.

- Revised Pelican Coastal Management Program This coastal management plan identifies coastal resources, management objectives, and recreational opportunities for the City of Pelican.

\section{Management Direction}

Forest Service Levels of Direction
Management direction governing this project comes from the national, regional, and forest levels. Direction becomes increasingly more specific from the national to the project level. 


\section{Purpose and Need}

The Forest Service Strategic Plan incorporates the priorities of the Forest Service Natural Resource Agenda. These priorities include watershed health and restoration, sustainable forest management, the national forest road system, and recreation. The Strategic Plan (2000 Revision) outlines long-term goals and objectives that set the course and provide guidance for agency actions.

The Forest Service Recreation Agenda guides programs and activities to meet the recreation goals and objectives of the Strategic Plan. Recreation management on national forests is designed to meet the nation's present and future needs for outdoor recreation in a manner that protects the health, diversity, and productivity of the land.

The Alaska Region Strategic Priorities provide emphasis and guidance in the key program areas of recreation and tourism, communities, Alaska Natives, and organization and employee effectiveness. The Regional Forester's strategic objective for recreation and tourism is for ecologically sustainable recreation and tourism to become a steady, reliable component of the economies of national-forestdependent communities and other communities in Alaska.

From these priorities, the Regional Forester developed the Alaska Region Recreation and Tourism Strategic Plan. The Shoreline Outfitter/Guide analysis is a key task to implement the Recreation and Tourism Strategic Plan. Healthy, vibrant economies and good land stewardship are Alaska Region objectives.

Several regulations, manuals, and handbooks guided this analysis. Regulations governing commercial recreation fall under the Special Uses Program regulated under 36 CFR Part 251 - Land Uses. The following manuals and handbooks were also referred to during the analysis:

- Recreation, Wilderness, and Related Resource Management Manual (FSM 2300)

- Publicly Managed Recreation Handbook (FSH 2309.23)

- Recreation Facilities Handbook (FSH 2309.24)

- Trails Management Handbook (FSH 2309.18)

- Special Uses Management Manual (FSM 2700)

- Special Uses Handbook (FSH 2709.11)

- The ROS Users Guide Handbook

See Appendix E for more details.

Relationship to Forest Plan
National forest planning takes place at several levels: national, regional, forest, and project. The Shoreline Outfitter/Guide EIS is a project-level analysis; its scope is confined to addressing the significant issues and possible environmental consequences of the actions. It does not attempt to address decisions made at higher levels. However, it does implement direction provided at those higher levels. Where appropriate, the Shoreline Outfitter/Guide Analysis tiers to the Forest Plan.

The National Forest Management Act (NFMA) addresses the management requirements for all national forest resources and provides guidance in the preparation of the regional guide and forest plans. It also includes specific direction for the management of resources from a national perspective using the RPA 


\section{Purpose and Need}

The Shoreline

Outfitter/Guide

analysis is designed

to achieve Forest

Plan goals and

objectives and move

the analysis area

toward the desired

conditions.
Assessment and Program to determine demand, supply, and the relative costs and benefits of both market and non-market outputs.

The Forest Plan sets forth direction for managing the land and resources of the Tongass National Forest. It is the result of extensive analysis documented in the Tongass Land and Resource Management Plan Final Environmental Impact Statement (FEIS) and 1997 Record of Decision.

Many of the Forest Plan standards and guidelines applicable to the Shoreline Outfitter/Guide analysis are listed under the Items Common to all Action Alternatives section in Chapter 2. Standards and guidelines are also discussed in Chapter 3 and Appendix E.

\section{Goals and Objectives}

The Shoreline Outfitter/Guide analysis is designed to achieve Forest Plan goals and objectives and move the analysis area toward the desired conditions. The Forest Plan includes forest-wide goals and objectives, as well as area-specific Land Use Designation (LUD) goals, objectives, and desired future conditions. Applicable forest-wide goals and objectives (see Forest Plan, pp. 2-3 through 2-5) include:

- Provide diverse opportunities for resource uses that contribute to the local and regional economies of Southeast Alaska.

- Support a wide range of natural resource employment opportunities within Southeast Alaska's communities.

- Provide a range of recreation opportunities consistent with public demand, emphasizing locally popular recreation places and those important to the tourism industry.

- Manage the Forest's recreation settings in accordance with the Recreation Opportunity Spectrum (ROS) standards and guidelines for each Land Use Designation (LUD).

- Provide for the continuation of subsistence uses by all rural Alaskan residents.

- Evaluate and consider the needs of subsistence users in making project land management decisions.

- Manage designated Wilderness to maintain an enduring wilderness resource while providing for public access and uses consistent with the Wilderness Act of 1964 and the Alaska National Interest Lands Conservation Act of 1980 (ANILCA).

\section{Land Use Designations (LUDs)}

The Forest Plan uses Land Use Designations (LUDs) to guide management of the Tongass National Forest. Each LUD provides for a unique combination of activities, practices, and uses. The Shoreline Outfitter/Guide analysis area includes 16 LUDs (Figure 1-2). Goals, objectives, and desired future conditions of each LUD that apply to recreation and tourism are summarized in Appendix E and are described in detail in the Forest Plan. The amount of the analysis area in each LUD and in other ownership is also displayed in Appendix E. 


\section{Forest Plan Standards and Guidelines}

Standards and guidelines for the management of the recreation resource are specified to achieve the objectives and goals of the LUD (Forest Plan, Chapter 3). There are also standards and guidelines that apply across the national forest and all LUDs (Forest Plan, Chapter 4). The standards and guidelines that apply to the Shoreline Outfitter/Guide Analysis are summarized in Chapter 2 of this document under Items Common To All Action Alternatives.

\section{Public Involvement}

Public involvement is a key component of the planning process. The Council on Environmental Quality (CEQ) defines scoping as:

...an early and open process for determining the scope of issues to be addressed and for identifying the significant issues related to a proposed action. The scoping process is used to invite public participation, identify public issues, and obtain public comment at various stages of the environmental analysis process. Although scoping is to begin early, the process continues until a decision is made.

The following paragraphs describe the public involvement process for the Shoreline Outfitter/Guide Analysis.

\section{Public Scoping}

Public scoping was the key process used to identify issues in this analysis. We used an extensive public scoping process because of the importance of the analysis to both guided and unguided recreationists. Carrying capacity use allocations had not previously been determined at this scale on the Tongass National Forest and we wanted full public participation. Scoping began in October 1998 and continued through the summer of 2001. The analysis has been open to public input throughout the planning process.

Many methods were used to notify the public and request input for the analysis, including: public meetings, presentations to organizations, personal communications, scoping documents, newsletters, and radio news stories. Key features of this process are described below.

\section{Schedule of Proposed Actions}

The Tongass Schedule of Proposed Actions is published on a quarterly basis to inform the public of activities being considered across the Tongass National Forest. People are invited to request more information and be on the mailing list for each project. This schedule is mailed to anyone who requests it and is available at Forest Service offices. It can also be found on the Tongass National Forest Internet site www. fs.fed.us/r10/tongass. The Shoreline Outfitter/Guide analysis has been listed on the Schedule of Proposed Actions since the fall of 1996.

\section{Notice of Intent (NOI)}

A Notice of Intent (NOI) to prepare an environmental impact statement informs the public of the analysis at the national level. Publication of an NOI in the Federal 
Register is required under the National Environmental Policy Act. The original NOI was published in the Federal Register on January 18, 2000. A Revised NOI was published in the Federal Register on April 5, 2001 to inform the public of changes in the scope of the analysis and schedule.

\section{Mailing List}

A Shoreline Outfitter/Guide Analysis mailing list was established and maintained to provide interested citizens, groups, and agencies with information and documents. The list consists of approximately 485 individuals, groups, and government agencies that have expressed interest in this project. As people responded to various scoping documents or meetings, their names were added to the list. The mailing list for the Draft EIS is provided in Chapter 4 of this document.

\section{Scoping Milestones}

The Shoreline Outfitter/Guide Analysis started with an extensive series of public meetings, which generated interest in the communities and with special interest groups in the analysis area. The initial concerns expressed by big game guides included their perception of crowding while guiding bear hunting clients, and the potential to over-harvest bears. During 1998 and 1999, public meetings were held in Sitka, Juneau, Angoon, Tenakee Springs, Hoonah, Port Alexander, and Pelican (via teleconference). Meetings also were held with the Alaska Wilderness Recreation and Tourism Association (AWRTA) and the Sitka Conservation Society at their invitations. Additionally, the analysis was discussed in presentations to the Alaska Board of Game, Regional Federal Subsistence Board, and at the Common Ground workshop in Hoonah.

A scoping package was mailed to the public in October 1998 that provided background information, the purpose of and need for the project, the proposed action, and the draft 1998 Recreation Carrying Capacity analysis. The focus of the early scoping package was on providing a direct allocation to brown bear guided hunting activities.

After review of the letters received in response to the scoping package, the responsible official decided that the proposed action being considered in the Shoreline Outfitter/Guide Analysis might have significant effects on the human environment, calling for an EIS to be prepared rather than an environmental assessment (EA). As a result, the first Notice of Intent (NOI) to prepare an environmental impact statement was published on January 18, 2000 in the Federal Register (Vol. 5, No. 11 p. 2575). 


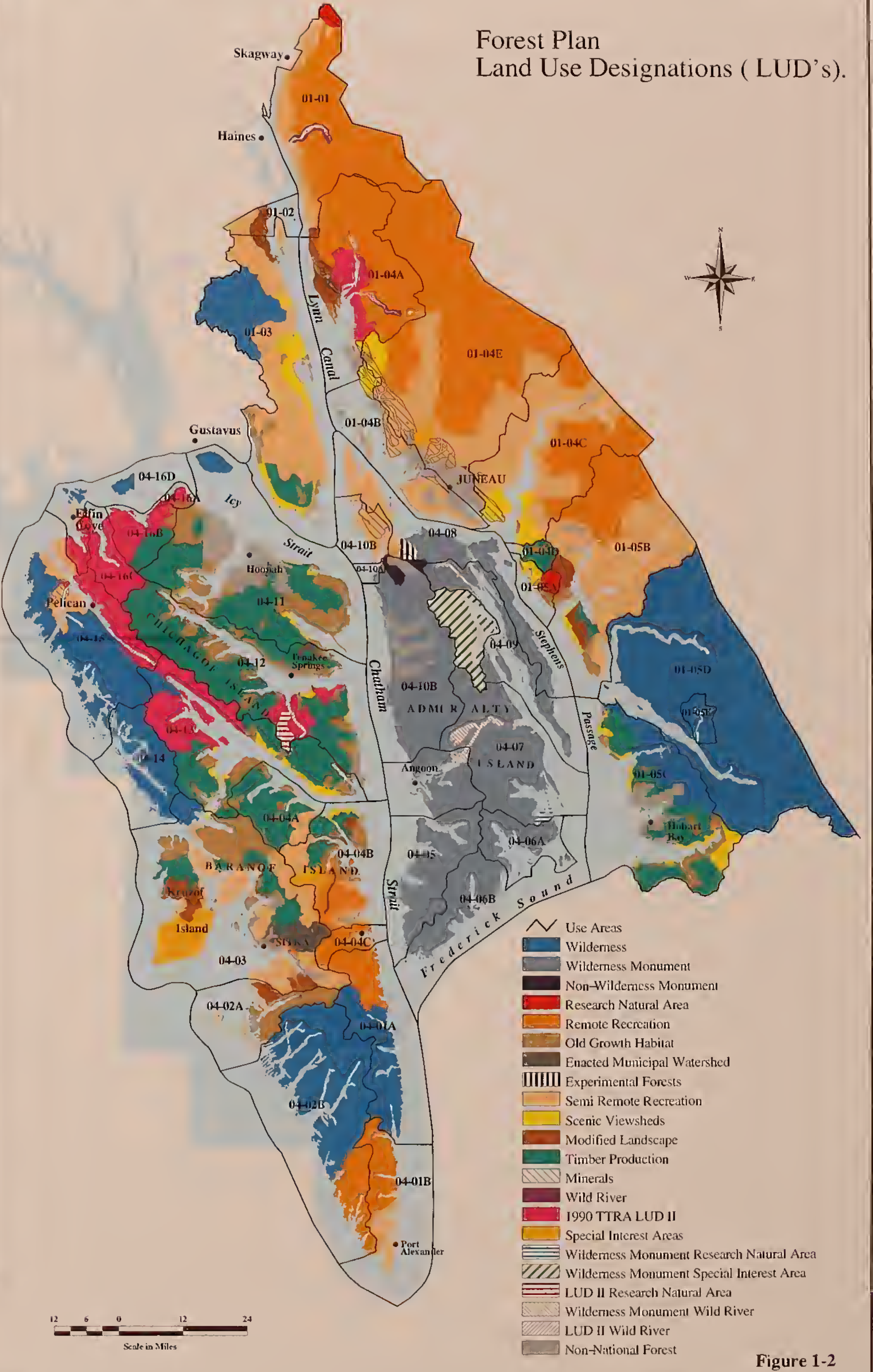



A notice announcing the preparation of an EIS was mailed in February 2000 to people who had expressed interest in the project. An update on the project was sent out in June 2000.

Alaska Public Radio stations ran a series during 2000 and 2001 on the "Crowding of the Tongass" which included information on the Shoreline Outfitter/Guide Analysis.

Response letters from the public led the Forest Service to broaden the focus of the project early in 2001. The analysis area was expanded and the proposed action was revised to no longer provide a direct allocation to brown bear guided hunting activities. Brown bear guided hunting is now included within the overall commercial allocation. A Revised Notice of Intent reflecting the changes was published on April 5, 2001 in the Federal Register (Vol. 66, No. 66, pg 18072). The response letters were also used to develop issues.

Another analysis update was mailed to interested parties in April 2001 and explained the changes made in the analysis. It also identified the issues developed from the comments and provided preliminary alternative themes.

Additional meetings were held in communities within the analysis area throughout the spring and early summer of 2001, including Angoon, Kake, Hoonah, Port Alexander, Tenakee Springs, Sitka, Pelican, Elfin Cove, Gustavus, Haines, Klukwan, and Juneau. These meetings were announced through local newspapers, cable TV scanners, radio stations, and public bulletin boards. Issues and alternative themes were displayed and discussed at these meetings, as were maps showing Forest Plan direction, Use Areas, and 1999 commercial use.

Consultation with Federally Recognized Tribal Governments and Other Government Agencies

\footnotetext{
The Forest Service

works at a government-

to-government level

with federally

recognized tribes. The

consultation process will

continue throughout the stages of the analysis.
}

The Forest Service fosters collaborative stewardship by working closely with other government agencies and federally recognized tribal governments and entities. Collaboration may take the form of formal and informal consultations with tribes and agencies, as well as reviews by agencies with regulatory authority over activities considered in the Shoreline Outfitter/Guide EIS. Some commercial outfitter/guide activities authorized by this decision may require permits from other federal and state agencies.

\section{Overview}

The Forest Service coordinates the review of the analysis with several other agencies. The purpose of these reviews is to coordinate overlapping authorities and jurisdictions among agencies and to share information and expertise. In some cases, the reviews are required because another agency has authority to issue permits for specific proposed activities. In other cases, the reviews allow interaction with other agencies responsible for certain environmental conditions, such as clean water or healthy wildlife populations. This interagency cooperation helped identify ways to avoid or mitigate possible harmful environmental effects. In most cases, discussions continue with these agencies throughout the EIS process.

Many of the scoping responses we received were related to recreation use on the saltwater and tidelands. We have worked closely with the Alaska Department of Natural Resources (DNR), which manages these areas. DNR is also currently preparing a management plan, the Northern Southeast Area Plan (NSEAP), for state lands within and adjacent to the Shoreline Outfitter/Guide analysis area. The 
NSEAP shares similar analysis area boundaries and timelines with the Shoreline Outfitter/ Guide analysis. We are coordinating the Shoreline Outfitter/Guide analysis with the DNR to enhance the compatibility of commercial use allocation and management, to the extent possible, with adjoining lands, tidelands, and waterways under state jurisdiction. The Forest Service and NSEAP team held joint public meetings in five communities so the public could comment on both projects at the same time.

We have also worked closely with the Interagency Recreation and Tourism Working Group, which includes agency representatives from the U.S. Fish and Wildlife Service, Alaska Department of Fish and Game, Alaska Department of Commerce and Economic Development, Alaska Department of Natural Resources, and the Forest Service.

\section{Tribal Governments}

The Forest Service works at a government-to-government level with federally recognized tribes. Tribal governments include those groups recognized under the National Historic Preservation Act, the Native American Graves Protection Repatriation Act, and the Archaeological Resources Protection Act. In Alaska, for the purposes of heritage program consultation, Indian tribes as defined in the National Historic Preservation Act's implementing regulations (36 CFR 800.16(m) include tribal governments recognized under the Wheeler-Howard Act of 1934 (Indian Reorganization Act [IRA]) as well as village and regional corporations created by the Alaska Native Claims Settlement Act. The initial contact for this analysis occurred with a letter sent to each tribal government with a brief project summary. The consultation process will continue throughout the stages of the analysis.

Follow-up consultations were made with the following tribal governments and Native Corporations:

Angoon Community Association

Chilkat Indian Village

Chilkoot Indian Association

Douglas Indian Association

Hoonah Indian Association

Organized Village of Kake

Petersburg Indian Association

Sitka Tribe of Alaska

Skagway Village
Central Council of Tlingit \& Haida Indian Tribes

Goldbelt, Incorporated

Huna Totem, Incorporated

Kake Tribal Corporation, Incorporated

Klukwan, Incorporated

Kootznoowoo, Incorporated

Shee Atika, Incorporated

Sealaska Corporation

During the consultations, we received valuable information on subsistence uses, important cultural areas and issues, and traditional lifestyles and values. Both guided recreation opportunities and concerns were provided. These were included in the analysis. Generally, the Tribal governments recognize the need for an outfitter/guide management plan. They wish to participate in the commercial recreation industry while ensuring that is occurs in an ecologically sustainable manner, which protects 


\section{Purpose and Need}

their cultural heritage and lifestyle. The consultations will continue into the future as part of the project monitoring.

\section{State Agencies}

\section{Alaska Division of Governmental Coordination}

The Alaska Division of Governmental Coordination coordinates state responses relative to the Coastal Zone Management Act (CZMA). Federal lands are not included in the definition of the coastal zone as prescribed in the CZMA. However, when federal agencies conduct activities or development affecting the coastal zone, CZMA requires that they be consistent to the maximum extent practicable with the approved State Coastal Management Program. The Forest Service makes the determination of consistency with the Alaska Coastal Management Program (ACMP)(see Chapter 3). The Forest Service's consistency determination is reviewed in a process coordinated through the Alaska Division of Governmental Coordination (ADGC).

The current Memorandum of Understanding between the State of Alaska and the Forest Service Regional Forester outlines standards against which the consistency evaluation will be made. The following standards are included in the agreement:

- Alaska Statute Title 46, Water, Air, Energy, and Environmental Conservation;

- Alaska Forest Practices Act of 1993;

- District Coastal Management Program.

Forest Plan standards and guidelines and the mitigation measures described in Chapters 2, 3, and Appendix $\mathrm{C}$ of this document are comparable to or exceed state standards.

The Alaska Coastal Management Program also contains standards and criteria for a determination of consistency for activities within the coastal zone. It provides for the development of local District Coastal Management Plans. The standards and criteria are primarily for activities that involve construction or water use. The Shoreline Outfitter/Guide analysis relates to section 6 AAC 80.060 RECREATION. "(B) Districts and state agencies shall give high priority to maintaining and when appropriate, increasing public access to coastal water." Some commercial recreation activities may require outfitters and guides to apply for permits from the applicable state agencies through the ACMP process.

\section{Alaska Department of Natural Resources}

The Department of Natural Resources (DNR) is the land management agency for state uplands, tidelands, and submerged lands. DNR is also responsible for authorization for occupancy and use of state tidelands and submerged lands.

The Northern Southeast Area Plan (NSEAP) is currently being prepared by the DNR. The NSEAP will serve as the land management plan for state lands adjacent to the national forest in the Shoreline Outfitter/Guide analysis area. Certain activities involving occupancy and use of tidelands and submerged lands may require outfitter/guides to be authorized by the Alaska DNR. 
Alaska Department of Environmental Conservation (DEC)

The Department of Environmental Conservation regulates water and air quality.

Alaska Department of Fish and Game (ADF\&G)

The Department of Fish and Game manages fish and game resources and provides input on habitat management and the management of federal subsistence fish and game populations.

\section{Alaska Board of Game}

The Board of Game develops game management regulations and policy.

\section{Alaska Board of Fish}

The Board of Fish develops fish management regulations and policy.

Alaska Department of Commerce and Economic Development (DCED) The Department of Commerce and Economic Development is involved in economic, community development issues, and state commerce.

Alaska Division of Community Development - Alaska Office of Tourism The Office of Tourism provides information and planning on state tourism.

Alaska Division of Occupational Licensing

The Division of Occupational Licensing provides state business licenses. It also regulates big game guides and provides state guide permits.

Alaska State Historic Preservation Officer

Manages state inventory of cultural properties.

\section{Other Federal Agencies}

\section{U.S. Environmental Protection Agency}

The Environmental Protection Agency provides review and comment.

\section{U.S. Army Corps of Engineers}

The Army Corps of Engineers has oversight of navigable waters and wetlands.

\section{U.S. Coast Guard}

The Coast Guard provides law enforcement and safety on the saltwater. It manages marine licensing and certifications.

\section{National Marine Fisheries Service}

The National Marine Fisheries Service (NMFS) has oversight and jurisdiction over marine mammals and marine threatened and endangered species.

\section{U.S. Fish and Wildlife Service}

The Fish and Wildlife Service (USFWS) has oversight and jurisdiction over eagles and other threatened and endangered species.

Federal and State Permits, Licenses, and Certifications

Some commercial outfitter/guide activities authorized by this decision may require permits from other federal and state agencies. 
Significant issues are used to develop and compare alternatives, prescribe mitigation measures, and analyze the environmental effects.
Issues

An issue is defined as a point of discussion, debate or dispute about the environmental effects of the proposed action. Some issues are considered 'significant' because of the extent of their geographic distribution, the duration of their effects, or the intensity of interest or resource conflict. Significant issues are used to develop and compare alternatives, prescribe mitigation measures, and analyze the environmental effects. For an issue to be considered significant at the project level, it must be relevant to the specific project and appropriately addressed at that level. Significant issues for the Shoreline Outfitter/Guide analysis were identified by: the public during scoping, current agency issues, and comments from other government agencies. Similar issues were combined where appropriate.

The IDT used an issue-sorting process to analyze comments received during scoping The process is intended to ensure that all significant issues are identified and that all relevant issues are appropriately addressed in the analysis. Each comment received during scoping was considered a potential issue and was evaluated to determine whether the related issue was addressed through alternative design, addressed through implementation of project-specific mitigation measures, or beyond the scope of the project.

Factors that are quantifiable, linked to cause-and-effect relationships, and responsive to the issue are the ones that are used to compare the environmental effects among alternatives. Some other concerns can be mitigated the same way in all alternatives and are described in Chapter 2 under Items Common to all Action Alternatives. These concerns are also discussed under Other Environmental Considerations in Chapter 3.

The following three significant issues emerged from the scoping efforts. Each issue is displayed to stand alone. However, there is some overlap in components and measures between the issues, to encompass the different perspectives of individual recreationists and the recreation industry.

\section{Issue 1. Availability of Recreation Opportunities for the Guided and Unguided Recreationist}

Issue 1 focuses on

the people who

recreate on the

national forest.
Issue 1 focuses on the people who recreate on the national forest. Both guided and unguided recreationists often pursue the same type of recreation experience. The issue reflects the need for a variety of quality recreation opportunities for both guided and unguided recreationists on the national forest. It revolves around social interactions and recreation experience expectations and the effects on those interactions and expectations from the management of commercial uses as described in the alternatives.

Many people commented that the existing or increasing level of commercial use is causing crowding or displacement of local residents and independent travelers who recreate on the national forest. As commercial recreation has grown, many local residents are feeling displaced or crowded in their local areas and in remote areas where they expect primitive experiences. Some commented that they are being 
'over-run' in their own backyards, traditional subsistence areas, and favorite places. Many people, especially in the smaller communities, expressed concern that they would not be able to maintain their lifestyle and access to forest resources in the future with continued tourism growth.

Some comments pointed out that many people, especially non-residents, do not have the skills, knowledge, or equipment to access the Tongass National Forest yet still desire to visit and recreate on the national forest. Commercial outfitters and guides were said to provide an essential service by assisting these people.

Some comments specifically identified local resource impacts by guided recreationists. Others felt that commercial use has fewer resource impacts on a perperson basis than unguided use because commercial use occurs under administrative oversight that encourages minimum impact on the land.

Subsistence users expressed concern that commercial outfitter/guide activities are displacing them and decreasing access to traditional hunting, fishing, and gathering areas. Subsistence users were interested in maintaining their access to resources and to protect the quality of their experience.

Some expressed a desire for 'commercial free zones.' Other people requested 'local commercial zones' to allow local control in decisions affecting tourism's role in the community use area and local economy. Several comments listed specific areas and locations they would like to see set aside, including traditional subsistence use areas and Coastal Zone Management Plan special places.

Most respondents felt that the quality of the recreation experience needs to be maintained and that commercial use needs to be controlled.

There are concerns that some types of recreation activities are displacing other activities, both guided and unguided.

\section{Units of Measure for Issue 1}

Each alternative will be evaluated on the variety and quality of recreation opportunities for guided and unguided recreationists. Measures for this issue include both qualitative and quantitative values. Many of the measurements generated are directly proportional to the amount and season of recreation carrying capacity allocated to commercial use. To respond to this issue each alternative will be compared against:

- The allocation of recreation carrying capacity to guided recreationists, by specific Use Area, by season, and by Use Areas containing communities;

- The amount and type of available recreation opportunities for guided and unguided recreationists;

- An estimate of the number of people able to access the forest with commercial outfitters/guides;

- The type, number and acres of designated large group areas;

- The opportunities for solitude; and

- The effects on unguided recreation use. 


\section{Purpose and Need}

Issue 2 focuses on the recreation industry rather than on individual recreationists.

\section{Issue 2. Economic Opportunities and Potential Effects on Outfitter/Guide Businesses}

Issue 2 focuses on the recreation industry rather than on individual recreationists. It responds to recreation industry concerns about economic opportunities and the influence of outfitter/guide management on their businesses.

The recreation industry expressed concerns about the opportunity for their businesses to continue to grow and diversify. Recreation businesses understand that their economic viability is contingent upon their being able to provide a quality recreation experience.

Commercial recreation and tourism are increasing in importance in the economy of Southeast Alaska. While most comments support some limits on commercial use, many respondents were concerned about the economic impacts of restrictions and limits on commercial use. Comments reflected the great diversity of the commercial recreation industry; competition exists among different segments of the commercial outfitter/guide industry, and decisions about the allocation of commercial uses will affect these segments differently.

Concerns about the economic future of the recreation industry revolve around business stability and sustainability, and around reducing uncertainty. The ability to obtain long-term permits (up to 5 years) was said to enhance certainty and stability of commercial recreation businesses.

The number of registered big game guides has increased substantially over the past decade in the analysis area, which has raised concerns that the level of guided hunting may not be sustainable because of declining experiences and game population concerns. Existing big game guides expressed concern that their businesses remain large enough to be economically viable; they want to maintain their current or historical use levels and limit new entrants into the business. Other existing commercial providers also expressed interest in limiting commercial use.

Still others are concerned that there will be no opportunity to start a new business in recreation and that only existing operators will have permits.

Some newer tour operators expressed concern that the proposed action would limit opportunities for growth. There are concerns that smaller companies would be unable to compete for business in the analysis area.

Some tour boat operators providing services to large groups felt they have been progressively excluded from areas of the national forest over the past two decades. They expressed the need for more areas on the national forest where larger groups can recreate. 


\section{Units of Measure for Issue 2}

The effects on outfitter/guide economic opportunities will be evaluated for each alternative. Measures for this issue include both qualitative and quantitative values. Many of the measurements generated are directly proportional to the amount and season of recreation carrying capacity allocated to commercial use. The units of measure include:

- The allocation of the recreation carrying capacity to commercial use;

- The amount of currently unused commercial recreation carrying capacity available to the industry for growth;

- The number of use areas approaching, at, or over the allocated commercial use capacity;

- The number, type, and location of large group areas available for commercial use;

- The amount and type of available commercial recreation opportunities; and

- Business benefits.

\section{Issue 3. Conflicts Within the Commercial Recreation Industry}

There is a broad diversity in the types and size of businesses involved in commercial recreation. Some of these differences can lead to conflicts among the different commercial recreation businesses. These conflicts are the focus of Issue 3, which also deals with social interactions and expectations for recreation experiences.

different commercial recreation businesses are the focus of Issue 3.

Different commercial recreation businesses often want to provide a certain type of recreation experience. Conflicts can arise when incompatible activities occur in close proximity. Comments highlighted conflicts between commercial outfitter/guide operations due to the types of activities, number of clients, group size, and boat sizes. Some operators also expressed interest in limiting the total number of commercial outfitter/guides who would be using the shoreline in order to maintain the existing recreation experience.

Some businesses disagreed over various methods of access that were perceived to adversely affect the recreation experience. Helicopter and wheeled airplane access was seen as incompatible with some boat or foot travel access. Large commercial outfitter/guide operations that are increasing in number and size were said to displace smaller commercial operations. Several comments mentioned that often the activities of smaller operations tend to be similar and compatible, minimizing conflicts, while larger operations are often engaged in activities that detract from the setting and expectations of smaller groups. Some smaller commercial businesses believe they are being displaced from their traditional use areas by larger commercial operations. Some comments requested that areas be specifically designated as small group or large group use areas. Concerns were expressed that because of their size, larger groups more directly degrade forest resources and social settings than smaller groups.

Some commercial operators said that they want to expand their business into the spring and fall 'shoulder seasons'. Others pointed out that such expansion would encroach on big game hunting guides who can operate only during limited hunting seasons, generally spring and fall. Big game guides also noted that they need 


\section{Purpose and Need}

solitude to have successful hunts, and they felt that allowing other types of commercial outfitter/guide uses during hunting seasons could decrease hunting opportunities, cause loss of historical use, and decrease customer satisfaction. The concern seemed to focus on crowding as the key element in allowing additional commercial operators on the shoreline during hunting seasons; some big game outfitter/guides noted a decline in client satisfaction of their hunting experience due to crowding and encounters.

On the other hand, rough rocky coastlines, with relatively few safe anchorages, limit the number of locations from which larger tour boats can provide their clients with access to the national forest. Some tour boat operators said they are feeling crowded out of areas that were once available for their larger group use.

Some commercial outfitter/guides involved in non-hunting activities, such as flyfishing, hiking, nature study, or wildlife viewing, also expressed concerns about crowding and the need to provide their clients with a pristine setting and experience. Some expressed the opinion that hunting is not compatible with wildlife viewing.

Units of Measure for Issue 3

Each alternative will be assessed as to its potential to reduce conflicts among the different commercial recreation operators. Measures include both qualitative and quantitative values. Many of the measurements generated are directly proportional to the amount and season of recreation carrying capacity allocated to commercial use. The measures include:

- The allocation of recreation carrying capacity to commercial use, by amount;

- The allocation of recreation carrying capacity to commercial use, by season;

- The management of access, activity, group size, and seasonal and day-of-theweek use to prevent inter-commercial use conflicts; and

- The number, type, and location of large group areas available for commercial use.

\section{Other}

Environmental Considerations
In addition to the significant issues described above, the public raised many other concerns during the scoping period. Although these concerns may be addressed to varying degrees in the analysis, they were not considered significant issues, as defined by the National Environmental Policy Act (NEPA), and they did not drive the development of alternatives to the proposed action. Others are not related to the decision, or their resolution is outside the scope of this analysis. Many potential resource effects would have the same mitigation in all alternatives or are controlled through adherence to Forest Plan standards and guidelines. 


\section{Resource Concerns Discussed in Chapter 3}

Concerns were expressed about the following resources, which are addressed in Chapter 3 under Other Environmental Considerations:

- Biodiversity,

- Soils,

- Wetlands,

- Vegetation,

- Wildlife,

- Fish habitat and water quality,

- Threatened and endangered species,

- Karst and cave resources,

- Subsistence,

- Heritage resources, and

- Air quality.

\section{Issues Beyond The Scope Of This EIS}

The following comments received during scoping are not specific to this analysis or relate to decisions at a higher level of planning.

Many comments reflected issues of jurisdiction. The Forest Service has jurisdiction over permitting commercial activities on National Forest System lands. The Alaska Department of Fish and Game (ADFG) and the Federal Subsistence Board (FSB) have jurisdiction over managing, controlling, and regulating wildlife and fish populations on National Forest System lands. The Alaska Department of Commerce and Economic Development, Division of Occupational Licensing, and Big-Game Commercial Services Board have jurisdiction over registering big game guides.

Combine the State of Alaska DNR Northern Southeast Area Plan and the Shoreline Outfitter/Guide Analysis into one EIS

The National Environmental Policy Act encourages combining federal projects under one environmental analysis and document when it would eliminate duplication of effort. However, the State of Alaska and the USDA Forest Service manage their lands and conduct their planning processes under different jurisdictional authorities and methods. The Forest Service is working closely with the State of Alaska Department of Natural Resources to ensure that the management of the national forest and the adjacent state lands and waters are compatible to the maximum extent practicable.

The Forest Service should manage saltwater use whether it is under state or federal jurisdiction.

Many public comments were about recreation and other uses on the saltwater rather than on the national forest. Perceptions of crowding are occurring primarily on the saltwater, which provides most of the access to the national forest in the analysis area. The national forest generally extends from mean high tide landward and has open access to the public in all but a very few areas. The Forest Service is currently not exercising jurisdiction over saltwater or submerged tidelands. The State of 
Alaska has filed quiet title to submerged lands underlying marine waters within the boundaries of the Tongass National Forest. The United States continues to claim ownership of the submerged lands. This matter is in litigation. Pending the outcome of this litigation, the Forest Service has assented in general to state management of lands below mean-high tide.

Address commercial use of the waterways and all upland use

Several comments stated the analysis should include all commercial use activities on all lands and waterways rather than limiting the scope of the analysis to shorelinebased activities on the national forest. The Forest Service does not have authority to manage other land ownerships or state waterways, although the Forest Service does confer with these owners. National forest beyond the shoreline zone was not included in the analysis because very little commercial use occurs in that area.

There should be no corporate commercial use of the national forest Some people requested that no preference be given to large corporations for outfitter/guide permits on the national forest. No Forest Service policy currently exists that provides a preference toward an outfitter/guide business based on the incorporation or size of the business. Whether such a preference should exist is a matter of national policy and is outside the scope of this analysis.

Permit only local residents as outfitters and guides

A number of residents wanted to sustain their communities and support local employment by restricting outfitter/guide permits to local residents. Section 1307 of the Alaska National Interest Lands Conservation Act (ANILCA) provides for a local preference for operators providing visitor services, except for sport fishing and hunting guiding activities. The Forest Service has proposed regulations to implement Section 1307 on conservation system units within the national forests in Alaska. The preferences provided by Section 1307 are applicable when there is a need to limit use through the number of permits issued and there is competition in awarding permits. Pack Creek is an example of such a site. Under the proposed regulations, (a) the location of the commercial outfitter/guide activity must be within a conservation system unit, and (b) a 'local resident' is defined as an individual, who is an Alaska resident living within the local area for 12 consecutive months prior to the issuance of the solicitation for application for a permit and who maintains his or her primary permanent residence and business within the local area. The 'local area' means that area within 100 miles of the location within the conservation system unit where the visitor services will be authorized.

The Forest Service will not apply Section 1307 local preferences in areas where use must be limited until the final regulations are in place. Except where already authorized for a longer term, permits in these areas will be provided on an annual basis until the regulations are finalized.

Ensure monitoring and enforcement

Several people commented that without effective monitoring of use and enforcement of laws related to commercial activities, the entire capacity analysis and allocation is meaningless. A monitoring plan is included in Appendix D. A monitoring and implementation plan will be included in the Record of Decision. 


\section{Applicable Laws and Executive Orders}

Below is a partial list of federal laws and executive orders pertaining to the analysis. While most pertain to all federal lands, some of the laws are specific to Alaska. Disclosures and discussions of findings required by these laws and orders are contained in Chapter 3 of this EIS.

- Organic Act of 1897-instructs the Secretary of Agriculture to preserve and regulate occupancy and use of the national forest.

- Bald and Golden Eagle Protection Act, 1940 (as amended)

- Multiple-Use Sustained-Yield Act of 1960 — clarifies the purposes for which national forests were established, which include outdoor recreation, range, timber, watershed, wildlife, and fish.

- Wilderness Act of 1964 - established the National Wilderness Preservation System, consisting of federal lands designated among other purposes, to preserve their "primeval character and influence."

- Land and Water Conservation Fund Act of 1964 - "assists in preserving, developing, and assuring accessibility to all citizens of the United States of America...such quality and quantity of outdoor recreation resources as may be available and are necessary and desirable... by providing funds for federal acquisition of certain lands and other areas." This act also provides for collection of recreation use fees for recreation sites, facilities, equipment, or services.

- National Historic Preservation Act of 1966 (as amended)

- National Trails System Act of 1968-established a national system of recreation, scenic and historic trails "in order to provide for the everincreasing outdoor recreation needs of an expanding population."

- Wild and Scenic Rivers Act of 1968, amended 1986 — established a system to preserve rivers with "outstandingly remarkable" scenic, recreational, geological, fish and wildlife, historical, cultural, or other similar values.

- National Environmental Policy Act (NEPA) of 1969 (as amended)

- Clean Air Act of 1970 (as amended)

- Alaska Native Claims Settlement Act (ANCSA) of 1971

- The Alaska Coastal Management Act of 1977

- Marine Mammal Protection Act of 1972

- Endangered Species Act (ESA) of 1973 (as amended)

- Forest and Rangeland Renewable Resources Planning Act (RPA) of 1974 (as amended) - directs the Secretary of Agriculture to periodically assess the forest and rangeland resources of the nation, and to submit to Congress, at regular intervals, recommendations for long-range Forest Service programs essential to meet future resource needs. 
- National Forest Management Act (NFMA) of 1976 (as amended)established a forest planning process, with regulations stating that forest plans will provide "for the safe use and enjoyment of the forest resources by the public."

- Clean Water Act of 1977 (as amended)

- Coastal Zone Management Act (CZMA) of 1972 (as amended)

- American Indian Religious Freedom Act of 1978

- Archeological Resources Protection Act of 1979

- Alaska National Interest Lands Conservation Act (ANILCA) of 1980includes a variety of provisions with direct or indirect implications for recreation management on national forests such as access, traditional activities in wilderness, and taking of fish and wildlife.

- Cave Resource Protection Act of 1988

- Tongass Timber Reform Act (TTRA) of 1990

- Native American Graves Protection and Repatriation Act of 1990

- Magnuson-Stevens Fishery Conservation and Management Act of 1996

- Executive Order 11593 (cultural resources)

- Executive Order 11988 (floodplains)

- Executive Order 11990 (wetlands)

- Executive Order 12898 (environmental justice)

- Executive Order 12962 (aquatic systems and recreational fisheries)

- Executive Order 13007 (American Indian sacred sites)

- Executive Order 13084 (consultation and coordination with tribal governments)

- Executive Order 13175 (consultation and coordination with tribal governments)

- Executive Order 13186 (migratory bird protection)

\section{Availability of Draft EIS}

The Notice of Availability of this Draft EIS will be published in the Federal Register and as a legal notice in The Juneau Empire, the newspaper of record for decisions to be signed by the Tongass Forest Supervisor or Deputy Forest Supervisor.

Publication in the Federal Register initiates the public comment period, which usually is 45 days. However, because this is a new type of analysis for the Tongass National Forest, involving complex issues, and because the review period is likely to overlap with the comment period for the Draft Supplement to the 1997 Tongass Land and Resource Management Plan-Wilderness Evaluation, the deciding official is extending the comment period to 90 days in order to obtain full public comment.

EIS documents will also be mailed to federal and state agencies, federally recognized tribal governments, municipal governments, Southeast Alaska libraries, and anyone 
else who requested them. Recipients of the Draft EIS are listed in Chapter 4. The Draft EIS is also available at the Admiralty National Monument; Hoonah, Sitka, and Juneau Ranger District offices; and the Forest Supervisor's Offices in Sitka,

Petersburg, and Ketchikan. Comments received during the Draft EIS review period will be evaluated and included in the analysis. The EIS may be modified to respond to these comments. Responses to the comments will be included in the final environmental impact statement. Publication of the final environmental impact statement is expected in 2002. 


\section{Chapter 2 Alternatives}

Introduction. 2-1

Items Common to All Action Alternatives .......................................................

Alternatives Considered in Detail .................................................................

Comparison of Alternatives Summary ........................................................35

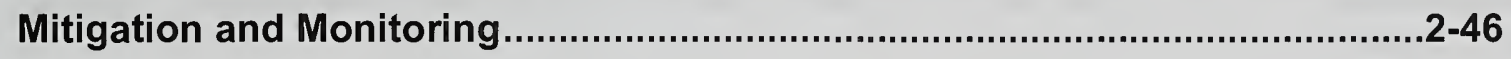

Alternatives and Proposals Considered but Eliminated................................2-46 


\section{Chapter 2 \\ Key Terms}

Carrying capacity - The estimated maximum number of groups of people who could recreate in an area and still have a specified type of recreation experience.

Commercial use - Any use of the national forest for which a fee is charged by an outfitter/guide.

Enclave - Area where large groups can occur on a regular basis throughout the season.

Fifteen-Percent area - Places where large groups can occur only on an occasional basis, for less than 15 percent of the primary use season.

Group - A group consists of one or more individuals recreating together as a social unit. Groups are used as the basic unit in this analysis

Group days - A measurement of recreation use by groups using the national forest on a daily basis.

Large group - Group made up of a number of people that exceeds the general maximum group size for a specified type of recreation experience in the ROS. Large group size varies by LUD and ROS. For large group areas in this EIS, large groups are defined as 21-75 people.

Mitigation - Measures designed to counteract or reduce environmental impacts.

Recreation Opportunity Spectrum (ROS) - A system for planning and managing resources that categorizes recreation opportunities into seven classes.

Shoreline zone - The analysis area extending inland approximately one-half mile from mean high tide.

Use Area - Distinct geographic areas used in this analysis as the basis for defining and managing recreation use. 


\section{Chapter 2 Alternatives}

\section{Introduction}

Chapter 2 summarizes the development of alternatives that meet the Purpose and Need and respond to the significant issues described in Chapter 1. The proposed action, alternatives to the proposed action, and the no-action alternative are described. A comparison of the alternatives is presented at the end of the chapter using information summarized from Chapter 3, Affected Environment and Environmental Consequences.

\section{Alternative Development Process}

The original proposed action was based on the draft 1998 Chatham Area Salt-water Shoreline-Based Recreation Carrying Capacity Analysis (USDA Forest Service 1998a) and developed after a series of public and interagency meetings beginning in 1995. The proposed action and the draft recreation carrying capacity analysis were sent to interested parties for public comment in October 1998 (see Chapter 1).

The 1998 proposed action and scope of the analysis were both modified in response to the public comments and additional analysis. The following items were changed.

- Expanding the analysis area to include the Tracy Arm-Fords Terror Wilderness.

- Subdividing some Use Areas to facilitate a more site-specific analysis of management concerns.

- Developing uniform recreation seasons for all Use Areas to facilitate the analysis of the various recreation uses.

- Changing the title of the analysis to "Shoreline Outfitter/Guide Environmental Impact Statement" to better reflect the scope of the analysis (The word "saltwater" in the original title was removed because it led to confusion and misconceptions that the analysis would determine use on saltwater. This analysis covers only commercial recreation uses occurring on the national forest uplands within the shoreline zone.)

- Identifying locations and conditions where large size commercial groups may occur.

- Broadening the proposed action to include all commercial recreation providers in the overall commercial recreation allocation; (Big-game guided hunting allocations are now included within the overall commercial recreation allocation. If commercial uses should become limited, allocations to specific outfitter/guide uses would be accomplished through the Special Uses administrative processes).

- Amending the Forest Plan was no longer needed (All activities in the analysis would fully comply with Forest Plan direction.) 
Revising the proposed action to limit commercial allocations in the spring and fall seasons and allow more opportunities for solitude and a primitive recreation experience.

- Considering the use of helicopters and wheeled planes in site-specific locations.

The draft 1998 recreation carrying capacity analysis was updated to respond to public comment and reflect the current situation. It is documented in the ShorelineBased Recreation Carrying Capacity for the Admiralty Island National Monument, Hoonah, Juneau, and Sitka Ranger Districts, 2001 (USDA Forest Service 2001), which is referred to as the recreation carrying capacity analysis or the Shoreline $R C C$ in this document.

\section{Alternative Components}

Issues developed from the scoping process, Forest Plan direction, the Recreational Opportunity Spectrum (ROS), the recreation carrying capacity analysis, and resource information were used to develop the alternatives. The proposed action and each alternative to the proposed action provide different responses to the significant issues. Each action alternative is designed to meet the purpose and need and the desired future conditions for the analysis area. The action alternatives emphasize a different mix of allocations, settings, and seasons of use to reduce potential recreation conflicts. The range of alternatives addresses the diversity of recreation and tourism concerns.

Each action alternative represents a specific proposal developed through interdisciplinary evaluation to allocate the number of group days by season and describe mitigation measures and conditions for commercial use in each Use Area.

\section{Carrying Capacity}

Recreation carrying capacity is defined as the number of groups of people in an area who would be able to enjoy a specified recreation experience. The total amount of recreation carrying capacity available in the analysis area was determined in the recreation carrying capacity analysis (USDA Forest Service 2001). That analysis defined Use Areas and determined the recreation carrying capacity for each Use Area in group-days based on the Recreational Opportunity Spectrum (ROS) and Forest Plan. A more detailed discussion of the recreation carrying capacity analysis is presented in Appendix F.

\section{Community Use}

The amount of commercial use allocation varies by alternative and Use Area. In Use Areas with communities, commercial allocations were reduced in some alternatives.

\section{Large Group Size}

Concerns about commercial group size led to the development of a pool of areas where large group use would be considered. (The specific size of a 'large group' varies depending on the Land Use Designation and ROS.) Two types of large group areas were developed:

'Enclaves' are areas where large groups can occur on a regular basis throughout the season; and 


\section{Alternatives 2}

'Fifteen-Percent Areas' are places where large groups can occur only on an occasional basis (for less than 15 percent of the primary use season).

Through additional analysis and public comment, the large group area pool was reduced. Each alternative proposes different numbers of Enclaves and FifteenPercent areas.

\section{Seasons}

Three distinct recreation seasons were identified to provide a management tool to address the different types of recreation that occur in the different seasons. (See Chapter 3, Recreation section, for season dates.) The seasons also provide more flexibility in making allocations across the year. Allocations were not developed for the winter season because outfitter/guide use is very low during this period. Commercial use allocations vary between the seasons in the alternatives.

\section{Access}

Different methods of mechanized transportation used to access the national forest were evaluated. Boats, floatplanes, wheeled-planes, helicopters, and ATVs were considered for each Use Area.

\section{Mitigation}

Many concerns identified during scoping can be eliminated or reduced through mitigation. Mitigation measures to reduce resource effects apply to all the action alternatives, while those that reduce social effects or conflicts vary by alternative.

\section{Items Common to All Action Alternatives}

The Forest Plan provides many measures to mitigate or prevent negative impacts to the environment in the planning and implementation of land management activities. All applicable Forest Plan LUD standards and guidelines have been incorporated along with applicable Forest Service manual and handbook direction. The analysis also developed several recreation management strategies that apply to all the action alternatives. The following are some of the key items that apply to all the action alternatives.

\section{Recreation}

The following items apply to all the action alternatives.

- The national Recreational Opportunity Spectrum (ROS) and the Forest Plan are used to define recreation expectations for a quality experience.

- Commercial recreation allocations are based on the capacity developed in the recreation carrying capacity analysis.

- Recreation activities will meet all applicable laws, regulations, and management direction.

- Use Areas provide specific geographic recreation management areas. 
- The types of commercial recreation activities proposed in all the alternatives are primarily dispersed and remote wildland activities that include, but are not limited to: sightseeing, hiking, biking, back-country camping, nature viewing, photography, kayaking, hunting, fishing, and similar activities that do not necessitate any ground disturbance.

- Methods of access included in all the alternatives are boats, kayaks, and floatplanes. Motorized boat restrictions apply to all action alternatives to protect resources and public safety.

Fish and Game Management

\section{Mitigation Measures}

The State of Alaska and the Federal Subsistence Board manage fish and game populations to ensure healthy viable populations. Outfitter/guide activities involving the taking of fish or game would be authorized under the regulations and harvest limits established by the Alaska Board of Game and the Federal Subsistence Board. Alaska Board of Game harvest recommendations for guided big game hunting, including brown bear, apply to all alternatives. If fish or game harvest levels should approach or reach the harvest limits, Special Use permits would be restricted and, if necessary, use would be allocated among the outfitter/guides through the Special Uses administrative process.

Mitigation measures applied to all alternatives to limit resource impacts are listed in Appendix C. Site-specific mitigation measures for each Use Area are also displayed in Appendix A and for each large group area in Appendix B.

Riparian Management Areas are of special concern for fish, water quality, and wildlife values. These areas are delineated and protected under the Forest Plan riparian standards and guidelines.

Forest Plan standards and guidelines for riparian areas are applied to all streams within the Shoreline Outfitter/Guide analysis area to protect fish habitat and water quality. Best Management Practices (BMPs) would be applied to minimize the risk of land management activities impairing water quality. Use Area narratives describe streams that require specific protection measures during implementation (Appendix A). Protection measures are specified to protect soil and water quality.

The Forest Service and the U.S. Fish and Wildlife Service have a Memorandum of Understanding that establishes a habitat management zone with a 330 -foot radius around each bald eagle nest tree. Guided groups are prohibited from camping in this zone. Outfitter/guide activities will avoid disturbing known eagle, goshawk, and other raptor nesting sites during active nesting and rearing seasons.

\section{Eagle and Raptor Nests}


Threatened, Endangered, and Sensitive Species
Biological assessments have been completed for threatened or endangered species potentially inhabiting the analysis area. Applicable Forest Plan standards and guidelines for each sensitive species are incorporated to ensure that any listed species or its habitat would not be adversely affected. The responsible agencies have been consulted.

The National Marine Fisheries Service (NMFS) requires all boats to stay at least 100 yards away from humpback whales. NMFS has also established air, sea, and land critical habitat zones around several Steller sea lion haul-outs in Southeast Alaska. The recommended viewing distance for all other marine mammals is 100 yards. Additional standards and guidelines for marine mammals are found in the Forest Plan.

All heritage sites will be avoided by excluding them from guided use, except for two historical sites. These two sites offer opportunities for site interpretation and stewardship and are discussed in Chapter 3. Heritage sites will be protected through avoidance, mitigation, regulatory enforcement, and monitoring. A cultural resource Determination of Effect will be submitted to the Alaska State Historic Preservation Officer.

\section{Alternatives Considered in Detail}

Alternative 1 (no action), and Alternatives 2 (proposed action), 3, 4, and 5 are considered in detail. The proposed action represents the initial proposal to meet the purpose and need. The other action alternatives represent different ways of satisfying the purpose and need by applying different strategies based on the significant issues discussed in Chapter 1. Tables 2-1, 2-2, 2-3, 2-6, and 2-9 display commercial allocations by Use Area and season for each alternative.

\section{Alternative 1 - No Action}

The Council on Environmental Quality (CEQ) regulations require a 'no-action' alternative be analyzed in every EIS. The no-action alternative for this EIS, Alternative 1, represents the existing condition of recreation management in the analysis area. Alternative 1 would continue the present management practices of the outfitter/guide Special Uses program. It would not provide a specific allocation of the recreation carrying capacity to commercial use and it would not preclude commercial use. The details of this alternative are listed below and displayed in Table 2-1. Figure 1-1 in Chapter 1 shows the location of each Use Area.

- Individual Special Use permits would continue to undergo separate analysis annually.

- No specific allocation for commercial recreation carrying capacity currently exists and none would be made under Alternative 1. Commercial use would be equal to the actual use authorized annually on a case-by-case basis, which could be up to 50 percent of the recreation carrying capacity (Forest Plan, 1997; pages 4-41).

- Outfitters and guides would apply for permit renewal, but no new or 
additional priority use permits would be issued. The existing moratoriums limiting commercial use would continue. These include the brown bear guide moratorium and site-specific commercial use moratoriums on the Admiralty Island National Monument and Hoonah, Sitka, and Juneau Ranger Districts.

- No specific large group areas would be designated for active management. Group size and occurrence would continue to be determined under Forest Plan direction.

- Commercial use would not be managed on a seasonal basis. 


\begin{tabular}{|c|c|c|c|c|c|}
\hline \multirow[b]{2}{*}{ Use Area } & \multirow[b]{2}{*}{ General Location } & \multicolumn{4}{|c|}{ Commercial Allocation (Group-Days) } \\
\hline & & Spring & Summer & Fall & Total \\
\hline $01-01$ & Skagway Area & $* *$ & $* *$ & $* *$ & $* *$ \\
\hline $01-02$ & Haines Area & $* *$ & $* *$ & $* *$ & $* *$ \\
\hline 01-03 & East Chilkats & $* *$ & $* *$ & $* *$ & $* *$ \\
\hline $01-04 \mathrm{~A}$ & Berners Bay & $* *$ & ** & $* *$ & $* *$ \\
\hline $01-04 \mathrm{~B}$ & N. Juneau Coast & $* *$ & ** & $* *$ & $* *$ \\
\hline $01-04 \mathrm{C}$ & Taku Inlet & $* *$ & ** & $* *$ & $* *$ \\
\hline $01-04 \mathrm{D}$ & Slocum Inlet & $* *$ & $* *$ & $* *$ & $* *$ \\
\hline $01-05 \mathrm{~A}$ & Taku Harbor & ** & ** & ** & $* *$ \\
\hline 01-05B & Port Snettisham & $* *$ & $* *$ & $* *$ & $* *$ \\
\hline $01-05 C$ & Windham Bay & $* *$ & $* *$ & $* *$ & $* *$ \\
\hline 01-05D & Tracy Arm & $* *$ & $* *$ & $* *$ & $* *$ \\
\hline $01-05 E$ & Fords Terror & ** & $* *$ & $* *$ & $* *$ \\
\hline $04-01 \mathrm{~A}$ & Gut Bay, Baranof & $* *$ & $* *$ & $* *$ & $* *$ \\
\hline 04-01B & Port Armstrong & $* *$ & $* *$ & $* *$ & $* *$ \\
\hline $04-02 \mathrm{~A}$ & Redoubt Lake & $* *$ & $* *$ & $* *$ & $* *$ \\
\hline 04-02B & Whale Bay & $* *$ & $* *$ & $* *$ & $* *$ \\
\hline $04-03$ & Sitka Area & $* *$ & $* *$ & $* *$ & $* *$ \\
\hline 04-04A & Lake Eva, Rodman Bay & $* *$ & $* *$ & $* *$ & $* *$ \\
\hline 04-04B & Kelp Bay & $* *$ & $* *$ & $* *$ & $* *$ \\
\hline 04-04C & Baranof Warm Springs & $* *$ & $* *$ & $* *$ & $* *$ \\
\hline $04-05$ & SW Admiralty & $* *$ & $* *$ & $* *$ & $* *$ \\
\hline $04-06 \mathrm{~A}$ & Pybus Bay & $* *$ & $* *$ & $* *$ & $* *$ \\
\hline 04-06B & Eliza Harbor & $* *$ & $* *$ & $* *$ & $* *$ \\
\hline 04-07 & Gambier Bay & $* *$ & $* *$ & $* *$ & ** \\
\hline 04-08 & NE Admiralty & $* *$ & $* *$ & $* *$ & $* *$ \\
\hline 04-09 & Seymour Canal & $* *$ & $* *$ & $* *$ & $* *$ \\
\hline $04-10 \mathrm{~A}$ & Greens Creek & $* *$ & $* *$ & $* *$ & $* *$ \\
\hline 04-10B & NW Admiralty & $* *$ & $* *$ & $* *$ & $* *$ \\
\hline $04-11$ & Hoonah Area & $* *$ & $* *$ & $* *$ & $* *$ \\
\hline 04-12 & Tenakee Inlet & $* *$ & $* *$ & $* *$ & $* *$ \\
\hline $04-13$ & Peril Strait & $* *$ & $* *$ & $* *$ & $* *$ \\
\hline 04-14 & Slocum Arm & $* *$ & $* *$ & $* *$ & $* *$ \\
\hline $04-15$ & West Chichagof & $* *$ & $* *$ & $* *$ & $* *$ \\
\hline $04-16 \mathrm{~A}$ & Point Adolphus & $* *$ & $* *$ & $* *$ & $* *$ \\
\hline $04-16 B$ & North Chichagof & $* *$ & $* *$ & $* *$ & $* *$ \\
\hline $04-16 C$ & Idaho Inlet & $* *$ & $* *$ & $* *$ & $* *$ \\
\hline $04-16 \mathrm{D}$ & Port Althorp. & $* *$ & $* *$ & $* *$ & $* *$ \\
\hline & Total & $* *$ & $* *$ & $* *$ & $* *$ \\
\hline
\end{tabular}

** No specific allocation is made. Commercial use is allowed on a case-by-case basis from current levels of 2,410 up to 40,638 ( 50 percent of the recreation carrying capacity). 


\section{Alternatives}

\section{Alternative 2 - (Proposed Action)}

Alternative 2 is the proposed action. It provides a specific commercial use allocation for each Use Area and season, with a moderate level of commercial use. The details of this alternative are listed below and displayed in Table 2-2. Figure 11 in Chapter 1 shows the location of each Use Area.

- Up to 16,894 commercial groups would be able to use the analysis area through the spring, summer, and fall seasons.

- Approximately 21 percent of the total recreation carrying capacity would be allocated to commercial use for the analysis area as a whole through all seasons. Individual Use Area allocations range between approximately 10 and 40 percent of the total recreation carrying capacity.

- Emphasis is on limited commercial use during the spring and fall seasons to reduce encounters and provide more opportunities for solitude. Spring and fall allocations would be about 10 percent of the total carrying capacity.

- Allocations in Use Areas with communities are generally reduced and range between 10 and 30 percent of the carrying capacity.

- This alternative would not designate large group areas for active management. Group size and occurrence would continue to be determined under Forest Plan direction.

- This alternative would not authorize wheeled airplane access.

- No commercial use on the Mud Bay River would be authorized.

- Guided sport fishing on Redoubt Lake and Stream, Salmon Lake, Nakwasina River, St. John the Baptist River, and Fish Bay River would be seasonally restricted to no more than two guided groups at a time.

- Site-specific descriptions, resource considerations, and mitigation measures for each Use Area are provided in Appendix A. 
Table 2-2. Alternative 2, Commercial Allocation by Use Area and Season

\begin{tabular}{|c|c|c|c|c|c|}
\hline \multirow[b]{2}{*}{ Use Area } & \multirow[b]{2}{*}{ General Location } & \multicolumn{4}{|c|}{ Commercial Allocation (Group-Days) } \\
\hline & & Spring & Summer & Fall & Total \\
\hline $01-01$ & Skagway Area & 42 & 424 & 47 & 513 \\
\hline 01-02 & Haines Area & 21 & 212 & 24 & 257 \\
\hline 01-03 & East Chilkats & 84 & 848 & 94 & 1,026 \\
\hline $01-04 \mathrm{~A}$ & Berners Bay & 42 & 106 & 47 & 195 \\
\hline 01-04B & N. Juneau Coast & 25 & 64 & 28 & 117 \\
\hline $01-04 C$ & Taku Inlet & 50 & 127 & 56 & 233 \\
\hline 01-04D & Slocum Inlet & 42 & 106 & 47 & 195 \\
\hline $01-05 \mathrm{~A}$ & Taku Harbor & 25 & 254 & 28 & 307 \\
\hline 01-05B & Port Snettisham & 84 & 848 & 94 & 1,026 \\
\hline $01-05 C$ & Windham Bay & 109 & 1,102 & 122 & 1,333 \\
\hline 01-05D & Tracy Arm & 50 & 509 & 56 & 615 \\
\hline $01-05 E$ & Fords Terror & 13 & 127 & 14 & 154 \\
\hline 04-01A & Gut Bay, Baranof & 34 & 339 & 38 & 411 \\
\hline 04-01B & Port Armstrong & 29 & 297 & 33 & 359 \\
\hline $04-02 \mathrm{~A}$ & Redoubt Lake & 84 & 848 & 94 & 1,026 \\
\hline 04-02B & Whale Bay & 76 & 763 & 85 & 924 \\
\hline 04-03 & Sitka Area & 168 & 424 & 188 & 780 \\
\hline $04-04 \mathrm{~A}$ & Lake Eva, Rodman Bay & 34 & 339 & 38 & 411 \\
\hline 04-04B & Kelp Bay & 38 & 382 & 42 & 462 \\
\hline $04-04 \mathrm{C}$ & Baranof Warm Springs & 13 & 127 & 14 & 154 \\
\hline $04-05$ & SW Admiralty & 25 & 191 & 28 & 244 \\
\hline 04-06A & Pybus Bay & 13 & 127 & 14 & 154 \\
\hline 04-06B & Eliza Harbor & 13 & 127 & 14 & 154 \\
\hline 04-07 & Gambier Bay & 25 & 254 & 28 & 307 \\
\hline 04-08 & NE Admiralty & 118 & 594 & 132 & 844 \\
\hline 04-09 & Seymour Canal & 42 & 318 & 47 & 407 \\
\hline $04-10 \mathrm{~A}$ & Greens Creek & 17 & 170 & 19 & 206 \\
\hline 04-10B & NW Admiralty & 29 & 297 & 33 & 359 \\
\hline $04-11$ & Hoonah Area & 59 & 223 & 66 & 348 \\
\hline 04-12 & Tenakee Inlet & 63 & 557 & 71 & 691 \\
\hline $04-13$ & Peril Strait & 67 & 509 & 75 & 651 \\
\hline $04-14$ & Slocum Arm & 34 & 297 & 38 & 369 \\
\hline $04-15$ & West Chichagof & 84 & 636 & 94 & 814 \\
\hline $04-16 \mathrm{~A}$ & Point Adolphus & 25 & 159 & 28 & 212 \\
\hline $04-16 B$ & North Chichagof & 25 & 159 & 28 & 212 \\
\hline $04-16 \mathrm{C}$ & Idaho Inlet & 25 & 159 & 28 & 212 \\
\hline $04-16 \mathrm{D}$ & Port Althorp & 25 & 159 & 28 & 212 \\
\hline & Total & 1,752 & 13,182 & 1,960 & 16,894 \\
\hline
\end{tabular}


Alternative 3 provides a specific commercial use allocation for each Use Area and season. It was developed to evaluate the highest allocation level allowed in the Forest Plan. Specific use area allocations would allow for the most growth in the recreation industry. In general, there is less emphasis on providing opportunities for solitude and more on increasing visitor access to the national forest. There are fewer restrictions to commercial use; restrictions are primarily for essential resource protection. The details of this alternative are listed below and displayed in Table 23. Figure 1-1 in Chapter 1 shows the location of each Use Area.

- Up to 40,658 commercial groups would be able to use the analysis area through the spring, summer, and fall seasons.

- Approximately 50 percent of the total recreation carrying capacity would be allocated to commercial use through all seasons.

- Spring and fall season allocations would be 50 percent of the carrying capacity.

- Allocations in Use Areas containing communities would be 50 percent of the carrying capacity.

- Forty Enclaves would be designated for large group use (Figure 2-1 and Figure 2-2 and Table 2-4).

- Large group use in Enclave areas would be allowed in all seasons. Group size in these areas would be limited to 75 people and only one large group would be able to use an area at a time.

- Twenty-three Fifteen-Percent areas would be designated for large group use (Figure 2-1 and Figure 2-2 and Table 2-5).

- Large group use could occur in Fifteen-Percent areas in spring, summer, and fall seasons. Group size in these areas would be limited to 75 people, and only one large group would be able to use an area at a time.

- Limited wheeled airplane landings would be allowed in Neka Bay and Mud Bay with weekly and daily restrictions.

- Limited commercial use would be allowed on the Mud Bay River.

- Site-specific descriptions, resource considerations, and mitigation measures for each Use Area are provided in Appendix A.

- Site-specific descriptions, resource considerations, and mitigation measures for each large group area are provided in Appendix B. 
Alternatives

Table 2-3. Alternative 3, Commercial Allocation by Use Area and Season

\begin{tabular}{|c|c|c|c|c|c|}
\hline \multirow[b]{2}{*}{ Use Area } & \multirow[b]{2}{*}{ General Location } & \multicolumn{4}{|c|}{ Commercial Allocation (Group Days) } \\
\hline & & Spring & Summer & Fall & Total \\
\hline $01-01$ & Skagway Area & 210 & 530 & 235 & 975 \\
\hline $01-02$ & Haines Area & 105 & 265 & 118 & 488 \\
\hline 01-03 & East Chilkats & 420 & 1,060 & 470 & 1,950 \\
\hline $01-04 \mathrm{~A}$ & Berners Bay & 210 & 530 & 235 & 975 \\
\hline 01-04B & N. Juneau Coast & 126 & 318 & 141 & 585 \\
\hline $01-04 \mathrm{C}$ & Taku Inlet & 252 & 636 & 282 & 1,170 \\
\hline 01-04D & Slocum Inlet & 210 & 530 & 235 & 975 \\
\hline $01-05 \mathrm{~A}$ & Taku Harbor & 126 & 318 & 141 & 585 \\
\hline 01-05B & Port Snettisham & 420 & 1,060 & 470 & 1,950 \\
\hline 01-05C & Windham Bay & 546 & 1,378 & 611 & 2,535 \\
\hline 01-05D & Tracy Arm & 252 & 636 & 282 & 1,170 \\
\hline 01-05E & Fords Terror & 63 & 159 & 71 & 293 \\
\hline 04-01A & Gut Bay, Baranof & 168 & 424 & 188 & 780 \\
\hline 04-01B & Port Armstrong & 147 & 371 & 165 & 683 \\
\hline 04-02A & Redoubt Lake & 420 & 1,060 & 470 & 1,950 \\
\hline 04-02B & Whale Bay & 378 & 954 & 423 & 1,755 \\
\hline $04-03$ & Sitka Area & 840 & 2,120 & 940 & 3,900 \\
\hline $04-04 \mathrm{~A}$ & Lake Eva, Rodman Bay & 168 & 424 & 188 & 780 \\
\hline 04-04B & Kelp Bay & 189 & 477 & 212 & 878 \\
\hline $04-04 \mathrm{C}$ & Baranof Warm Springs & 63 & 159 & 71 & 293 \\
\hline 04-05 & SW Admiralty & 126 & 318 & 141 & 585 \\
\hline 04-06A & Pybus Bay & 63 & 159 & 71 & 293 \\
\hline 04-06B & Eliza Harbor & 63 & 159 & 71 & 293 \\
\hline 04-07 & Gambier Bay & 126 & 318 & 141 & 585 \\
\hline 04-08 & NE Admiralty & 588 & 1,484 & 658 & 2,730 \\
\hline 04-09 & Seymour Canal & 210 & 530 & 235 & 975 \\
\hline $04-10 \mathrm{~A}$ & Greens Creek & 84 & 212 & 94 & 390 \\
\hline 04-10B & NW Admiralty & 147 & 371 & 165 & 683 \\
\hline 04-11 & Hoonah Area & 294 & 742 & 329 & 1,365 \\
\hline $04-12$ & Tenakee Inlet & 315 & 795 & 353 & 1,463 \\
\hline $04-13$ & Peril Strait & 336 & 848 & 376 & 1,560 \\
\hline $04-14$ & Slocum Arm & 168 & 424 & 188 & 780 \\
\hline $04-15$ & West Chichagof & 420 & 1,060 & 470 & 1,950 \\
\hline $04-16$ A & Point Adolphus & 126 & 318 & 141 & 585 \\
\hline $04-16 \mathrm{~B}$ & North Chichagof & 126 & 318 & 141 & 585 \\
\hline $04-16 \mathrm{C}$ & Idaho Inlet & 126 & 318 & 141 & 585 \\
\hline $04-16 \mathrm{D}$ & Port Althorp & 126 & 318 & 141 & $\begin{array}{r}585 \\
\ldots\end{array}$ \\
\hline & Total & 8,757 & 22,101 & 9,800 & 40,658 \\
\hline
\end{tabular}


Table 2-4. Alternative 3, Enclave Large Group Areas

\begin{tabular}{|c|c|}
\hline Use Area & Enclave Area \\
\hline $01-01$ & Katzehin Falls \\
\hline 01-02 & Sullivan Mountain \\
\hline $01-03$ & Cant Cove \\
\hline $01-03$ & Homeshore \\
\hline $01-03$ & Howard Bay \\
\hline 01-04B & Shelter Island \\
\hline $01-04 \mathrm{C}$ & Sunny Cove \\
\hline 01-05B & Mallard Cove \\
\hline 01-05B & No Name Cove \\
\hline 01-05B & Point Anmer \\
\hline $01-05 \mathrm{~B}$ & West Gilbert Bay \\
\hline $01-05 C$ & Fanshaw \\
\hline $01-05 \mathrm{C}$ & North Windham Bay \\
\hline $01-05 C$ & Port Houghton \\
\hline $01-05 \mathrm{C}$ & Sand Bay \\
\hline 04-03 & Dry Pass \\
\hline $04-03$ & Eagle River Road \\
\hline 04-03 & Noxon \\
\hline 04-04A & Lake Eva Trail \\
\hline 04-04A & Point Elizabeth \\
\hline $04-04 \mathrm{~A}$ & Rodman Bay \\
\hline 04-04A & Saook \\
\hline 04-04B & Hanus Bay \\
\hline 04-04B & Kelp Bay - Middle Arm \\
\hline 04-04B & Portage Arm \\
\hline 04-08 & Cordwood Creek \\
\hline 04-08 & Fowler Creek \\
\hline 04-11 & 8-Fathom Dock \\
\hline 04-11 & Kennel Creek \\
\hline $04-11$ & Red Cliff Islands \\
\hline $04-11$ & Salt Lake Bay Dock \\
\hline 04-12 & Corner Bay Road \\
\hline $04-12$ & Crab Bay \\
\hline 04-12 & West Tenakee - Goose Flats \\
\hline $04-13$ & Poison Cove \\
\hline $04-13$ & Sitkoh Bay Road \\
\hline $04-13$ & Ushk Bay \\
\hline $04-15$ & Bohemia Basin \\
\hline $04-15$ & Three Hill Island \\
\hline $04-16 \mathrm{D}$ & George Island \\
\hline
\end{tabular}


Table 2-5. Alternative 3, Fifteen-Percent Large Group Areas

\begin{tabular}{ll} 
Use Area & Fifteen-Percent Area \\
\hline $01-04 B$ & Douglas Island \\
$01-05 B$ & Point Coke \\
$04-03$ & Fish Bay \\
$04-03$ & Nadezhida Islands \\
$04-04 A$ & Duffield \\
$04-04 B$ & Bourbon Creek Road \\
$04-04 B$ & Cosmos Cove \\
$04-11$ & Iyoukeen Peninsula \\
$04-11$ & Neka Bay - South Bight \\
$04-11$ & Neka Bay - North Bight \\
$04-12$ & Saltery Bay \\
$04-12$ & Seal Bay \\
$04-12$ & Trap Bay \\
$04-13$ & Moser \\
$04-13$ & Nelson Falls \\
$04-13$ & Nismeni Point \\
$04-13$ & Patterson Bay \\
$04-13$ & Patterson Bay -North Point \\
$04-13$ & Todd Road/Lindenburg Head \\
$04-16 A$ & Damp Marker \\
$04-16 A$ & Pinta Cove \\
$04-16 C$ & Big Shaw Island \\
$04-16 C$ & Fox Creek \\
\hline &
\end{tabular}


2 Alternatives

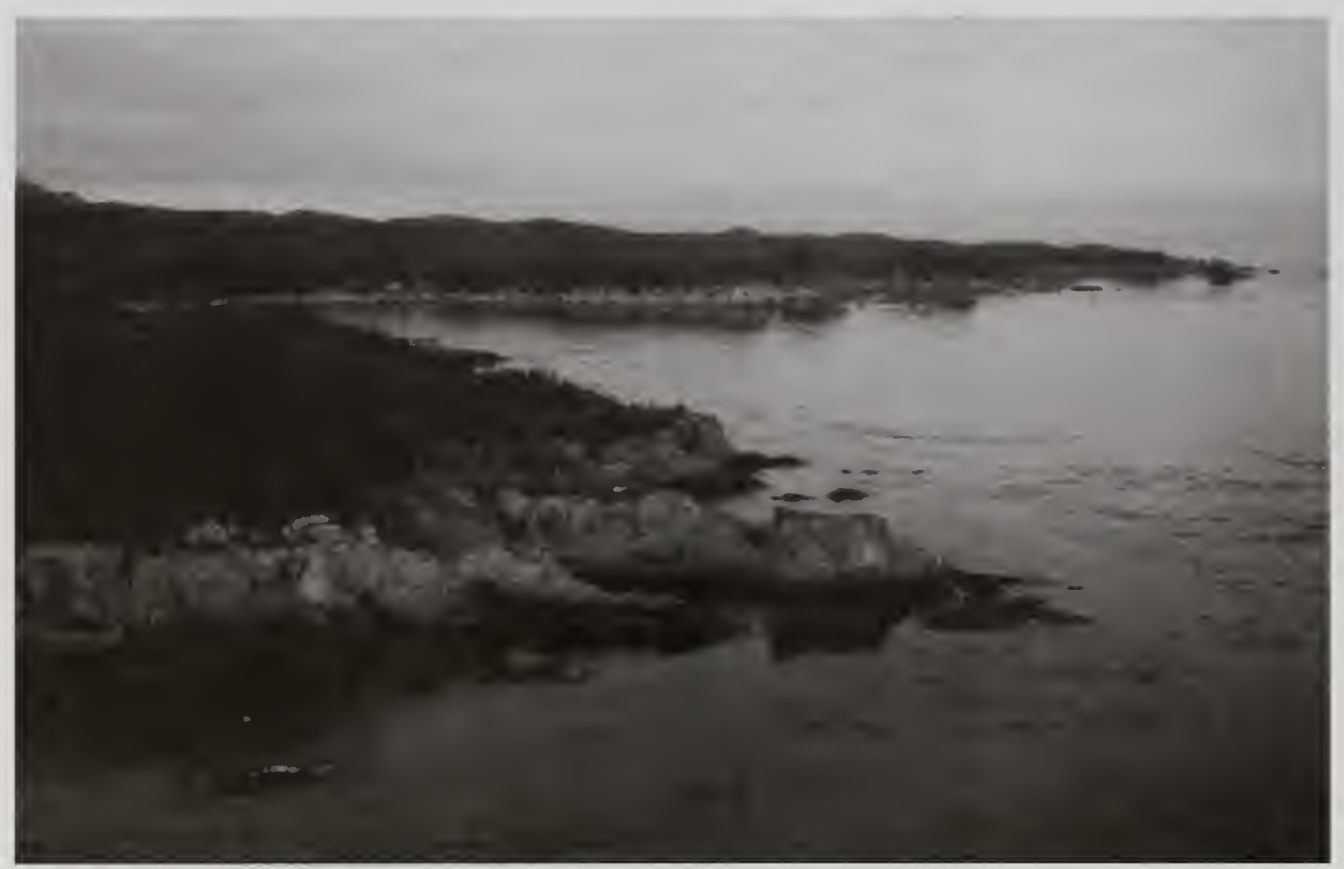




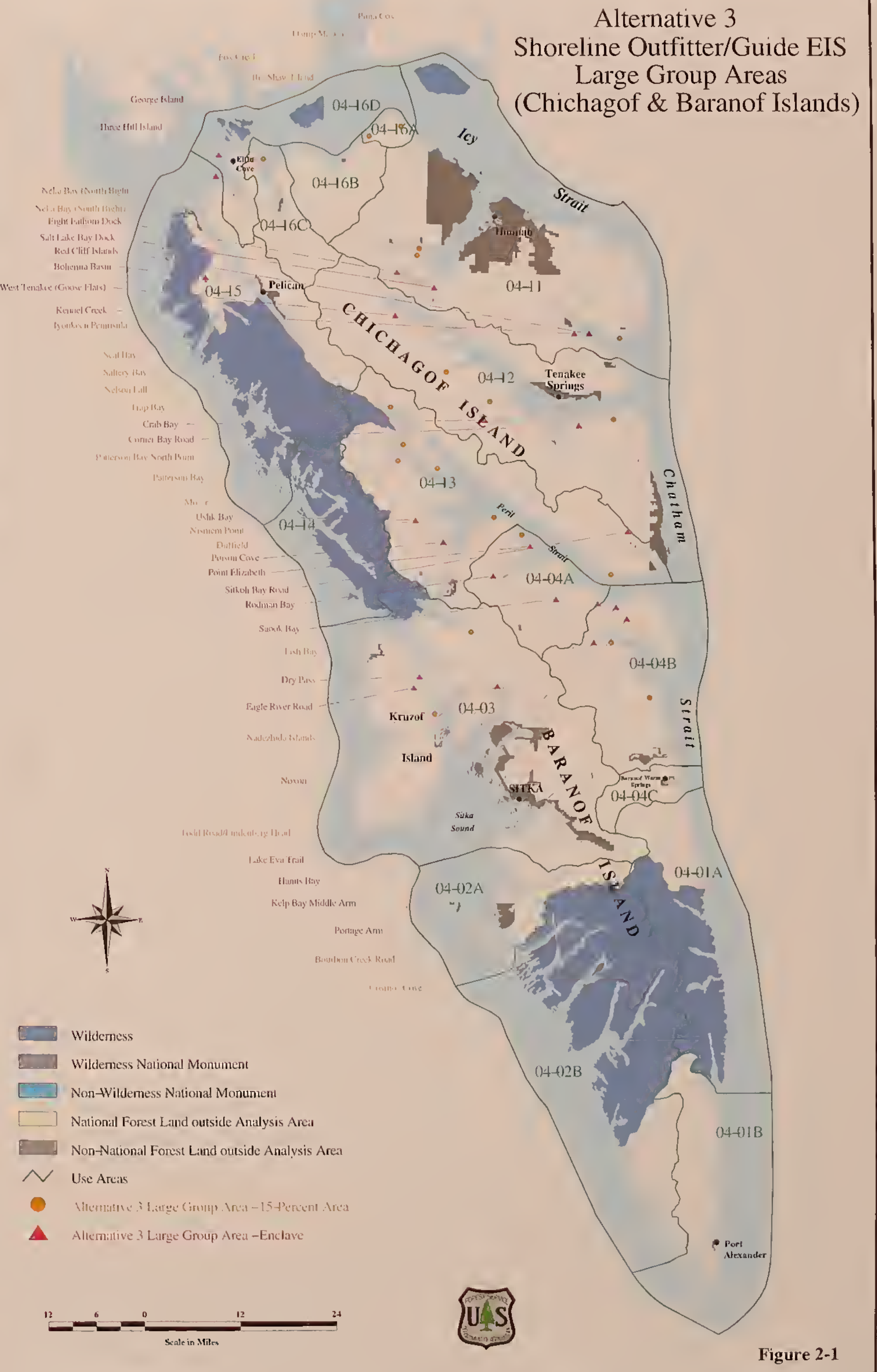





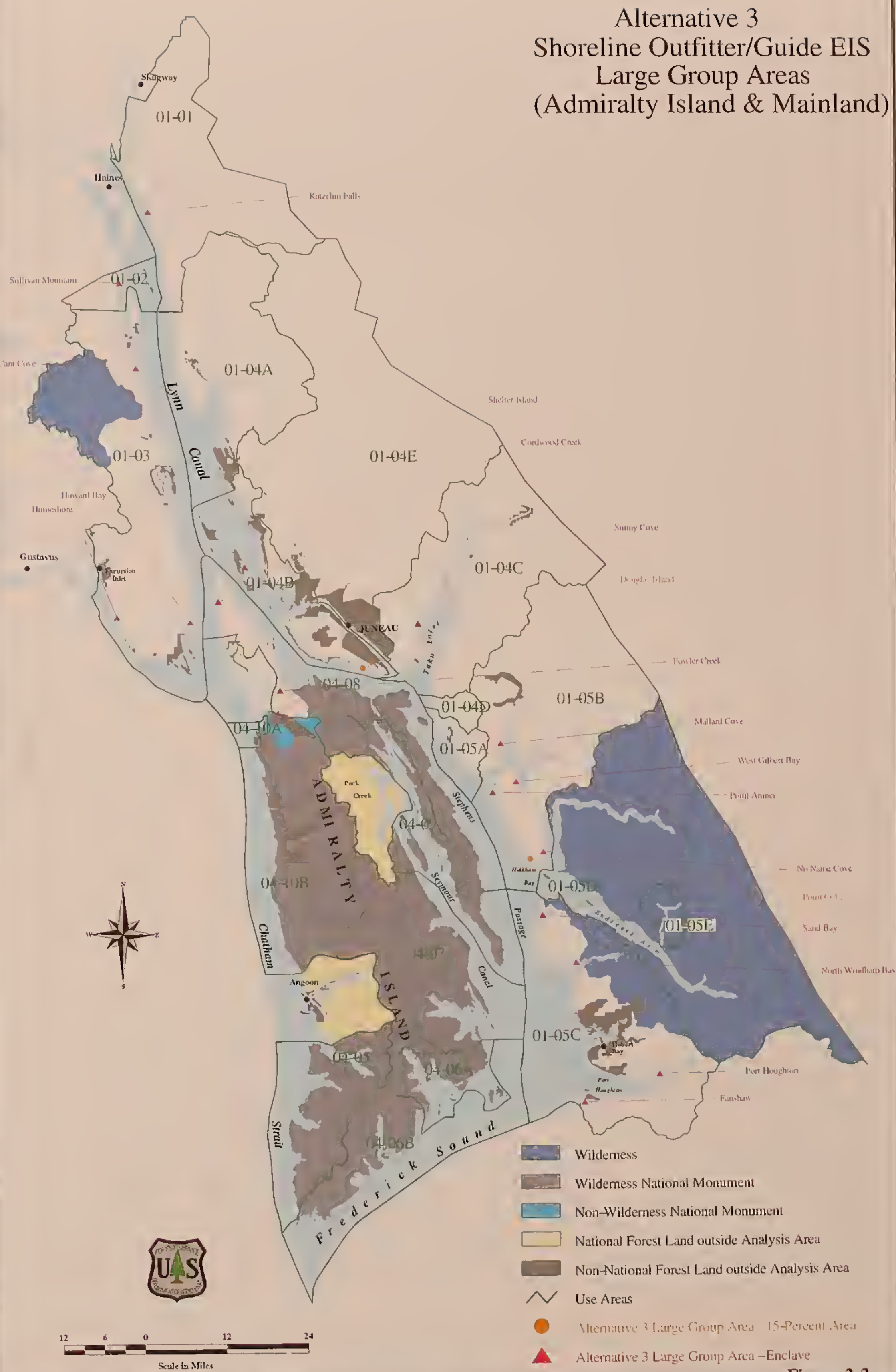

Figure 2-2 



\section{Alternatives 2}

\section{Iternative 4}

Alternative 4 provides specific commercial use allocations for each Use Area and season. It provides the lowest commercial allocation. Overall, there is an emphasis on providing more opportunities for recreation experiences with solitude. This alternative is the most restrictive on commercial uses to reduce social conflicts. Details of this alternative are listed below and displayed in Table 2-6. Figure 1-1 in Chapter 1 shows the location of each Use Area.

- Up to 6,192 commercial groups would be able to use the analysis area through the spring, summer, and fall seasons.

- Approximately 8 percent of the total recreation carrying capacity would be allocated to commercial use for the analysis area as a whole through all seasons. Allocations to each Use Area range between 5 and 25 percent of the total carrying capacity.

- This alternative emphasizes greater limits on commercial use levels to reduce encounters and provide more opportunities for solitude during both the spring and fall seasons. The spring allocation would be up to 15 percent of the carrying capacity and the fall allocation would be up to 25 percent in some areas.

- Allocations in Use Areas containing communities would be less than 15 percent of the carrying capacity.

- Fifteen Enclaves would be designated for large group use (Figures 2-3 and 2-4 and Table 2-7).

- Large group use in Enclave areas would be allowed in all seasons. Group size in these areas would be limited to 75 people, and only one large group would be able to use an area at a time.

- Five Fifteen-Percent areas would be designated for large group use (Figures 2-3 and 2-4 and Table 2-8).

- Large group use could occur in Fifteen-Percent areas in only the summer season. Group size in these areas would be limited to 75 people, and only one large group would be able to use an area at a time.

- Limited wheeled airplane landings with daily and weekly restrictions varying by season would be authorized in Mud Bay.

- Guided sport fishing on Redoubt Lake and Stream, Salmon Lake, Nakwasina River, St. John the Baptist River, and Fish Bay River would be seasonally restricted to no more than two guided groups at a time.

- Limited commercial use varying by season would be allowed on the Mud Bay River.

- $\quad$ Site-specific descriptions, resource considerations, and mitigation measures for each Use Area are provided in Appendix A.

- $\quad$ Site-specific descriptions, resource considerations, and mitigation measures for each large group area are provided in Appendix B. 
Table 2-6. Alternative 4, Commercial Allocation by Use Area and Season

Commercial Allocation (Group Days)

\begin{tabular}{|c|c|c|c|c|c|}
\hline \multirow[b]{2}{*}{ Use Area } & \multirow[b]{2}{*}{ General Location } & & & & \\
\hline & & Spring & Summer & Fall & Total \\
\hline $01-01$ & Skagway Area & 21 & 53 & 24 & 98 \\
\hline $01-02$ & Haines Area & 15 & 30 & 15 & 60 \\
\hline $01-03$ & East Chilkats & 42 & 106 & 47 & 195 \\
\hline $01-04 \mathrm{~A}$ & Berners Bay & 21 & 53 & 24 & 98 \\
\hline 01-04B & N. Juneau Coast & 15 & 32 & 15 & 62 \\
\hline $01-04 \mathrm{C}$ & Taku Inlet & 25 & 64 & 28 & 117 \\
\hline 01-04D & Slocum Inlet & 21 & 70 & 24 & 115 \\
\hline $01-05 \mathrm{~A}$ & Taku Harbor & 15 & 32 & 15 & 62 \\
\hline 01-05B & Port Snettisham & 42 & 156 & 47 & 245 \\
\hline $01-05 \mathrm{C}$ & Windham Bay & 55 & 138 & 61 & 254 \\
\hline 01-05D & Tracy Arm & 25 & 64 & 33 & 122 \\
\hline 01-05E & Fords Terror & 15 & 33 & 15 & 63 \\
\hline $04-01 \mathrm{~A}$ & Gut Bay, Baranof & 19 & 80 & 37 & 136 \\
\hline 04-01B & Port Armstrong & 27 & 68 & 16 & 111 \\
\hline $04-02 \mathrm{~A}$ & Redoubt Lake & 42 & 106 & 47 & 195 \\
\hline 04-02B & Whale Bay & 38 & 193 & 42 & 273 \\
\hline $04-03$ & Sitka Area & 84 & 212 & 94 & 390 \\
\hline 04-04A & Lake Eva, Rodman Bay & 33 & 175 & 19 & 227 \\
\hline 04-04B & Kelp Bay & 29 & 191 & 25 & 245 \\
\hline $04-04 \mathrm{C}$ & Baranof Warm Springs & 15 & 30 & 15 & 60 \\
\hline 04-05 & SW Admiralty & 38 & 111 & 71 & 220 \\
\hline $04-06 \mathrm{~A}$ & Pybus Bay & 19 & 111 & 15 & 145 \\
\hline $04-06 \mathrm{~B}$ & Eliza Harbor & 19 & 30 & 15 & 64 \\
\hline 04-07 & Gambier Bay & 38 & 76 & 15 & 129 \\
\hline $04-08$ & NE Admiralty & 59 & 148 & 66 & 273 \\
\hline 04-09 & Seymour Canal & 31 & 53 & 24 & 108 \\
\hline $04-10 \mathrm{~A}$ & Greens Creek & 15 & 140 & 15 & 170 \\
\hline 04-10B & NW Admiralty & 44 & 37 & 29 & 110 \\
\hline 04-11 & Hoonah Area & 70 & 158 & 33 & 261 \\
\hline $04-12$ & Tenakee Inlet & 37 & 80 & 35 & 152 \\
\hline $04-13$ & Peril Strait & 101 & 92 & 74 & 267 \\
\hline $04-14$ & Slocum Arm & 50 & 42 & 19 & 111 \\
\hline $04-15$ & West Chichagof & 42 & 199 & 47 & 288 \\
\hline $04-16 A$ & Point Adolphus & 15 & 159 & 15 & 189 \\
\hline 04-16B & North Chichagof & 21 & 159 & 15 & 195 \\
\hline $04-16 \mathrm{C}$ & Idaho Inlet & 16 & 159 & 21 & 196 \\
\hline \multirow[t]{2}{*}{ 04-16D } & Port Althorp & 15 & 156 & 15 & 186 \\
\hline & Total & 1,229 & 3,796 & 1,167 & 6,192 \\
\hline
\end{tabular}




\section{Alternatives 2}

Table 2-7. Alternative 4, Enclave Large Group Areas

\begin{tabular}{ll} 
Use Area & Enclave Area \\
\hline $01-03$ & Homeshore \\
$01-04 C$ & Sunny Cove \\
01-05B & Mallard Cove \\
$01-05 B$ & No Name Cove \\
$01-05 B$ & West Gilbert Bay \\
01-05C & Port Houghton \\
01-05C & Sand Bay \\
04-04A & Lake Eva Trail \\
$04-04 A$ & Rodman Bay \\
$04-04 B$ & Kelp Bay - Middle Arm \\
$04-12$ & Corner Bay Road \\
$04-12$ & West Tenakee - Goose Flats \\
$04-13$ & Sitkoh Bay Road \\
$04-15$ & Three Hill Island \\
$04-16 D$ & George Island \\
\hline
\end{tabular}

Table 2-8. Alternative 4, Fifteen-Percent Large Group Areas

\begin{tabular}{ll} 
Use Area & Fifteen-Percent Area \\
\hline $04-13$ & Nelson Falls \\
$04-13$ & Patterson Bay \\
$04-16 \mathrm{~A}$ & Damp Marker \\
$04-16 \mathrm{~A}$ & Pinta Cove \\
$04-16 \mathrm{C}$ & Fox Creek \\
\hline
\end{tabular}


2 Alternatives

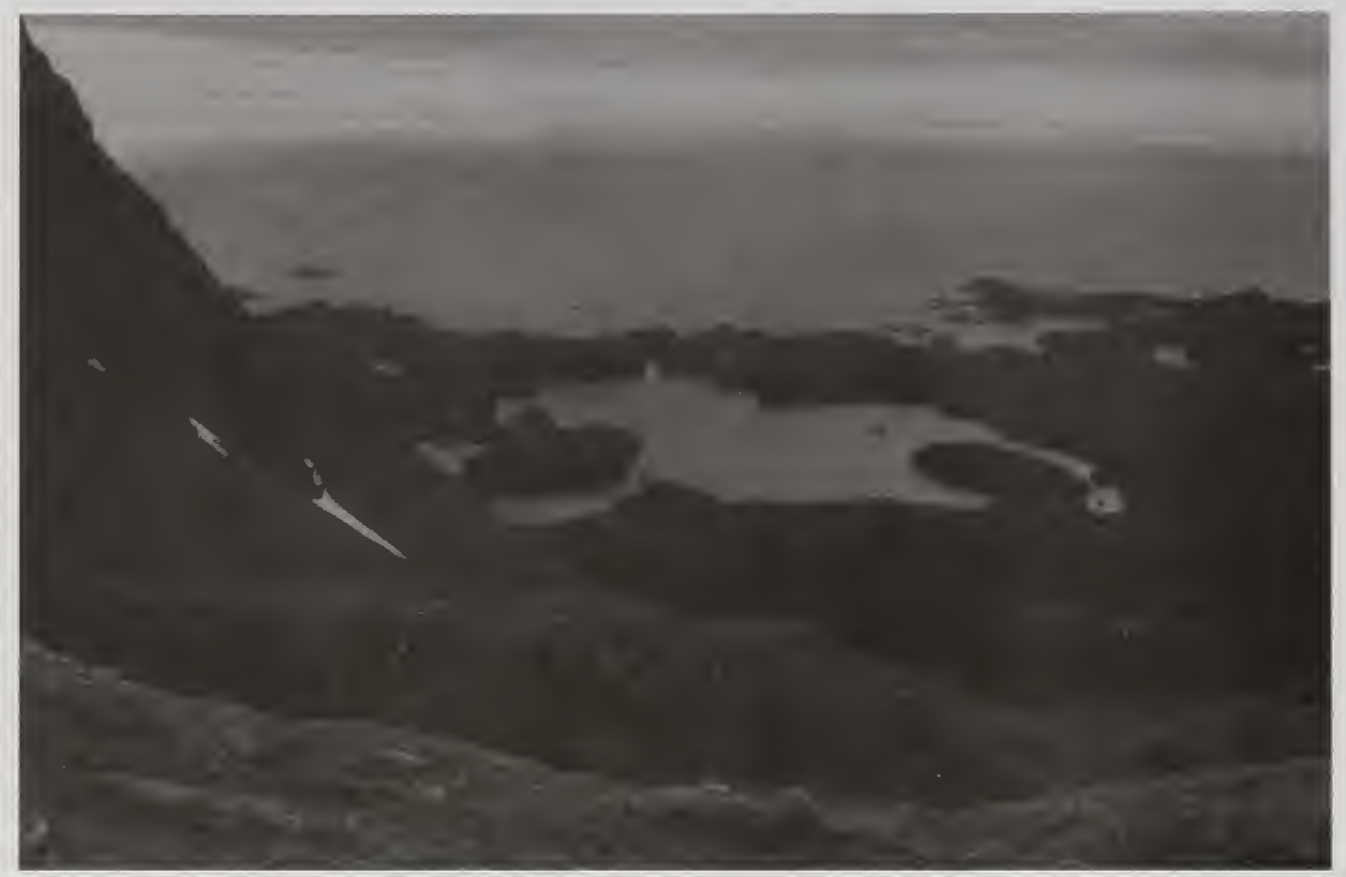




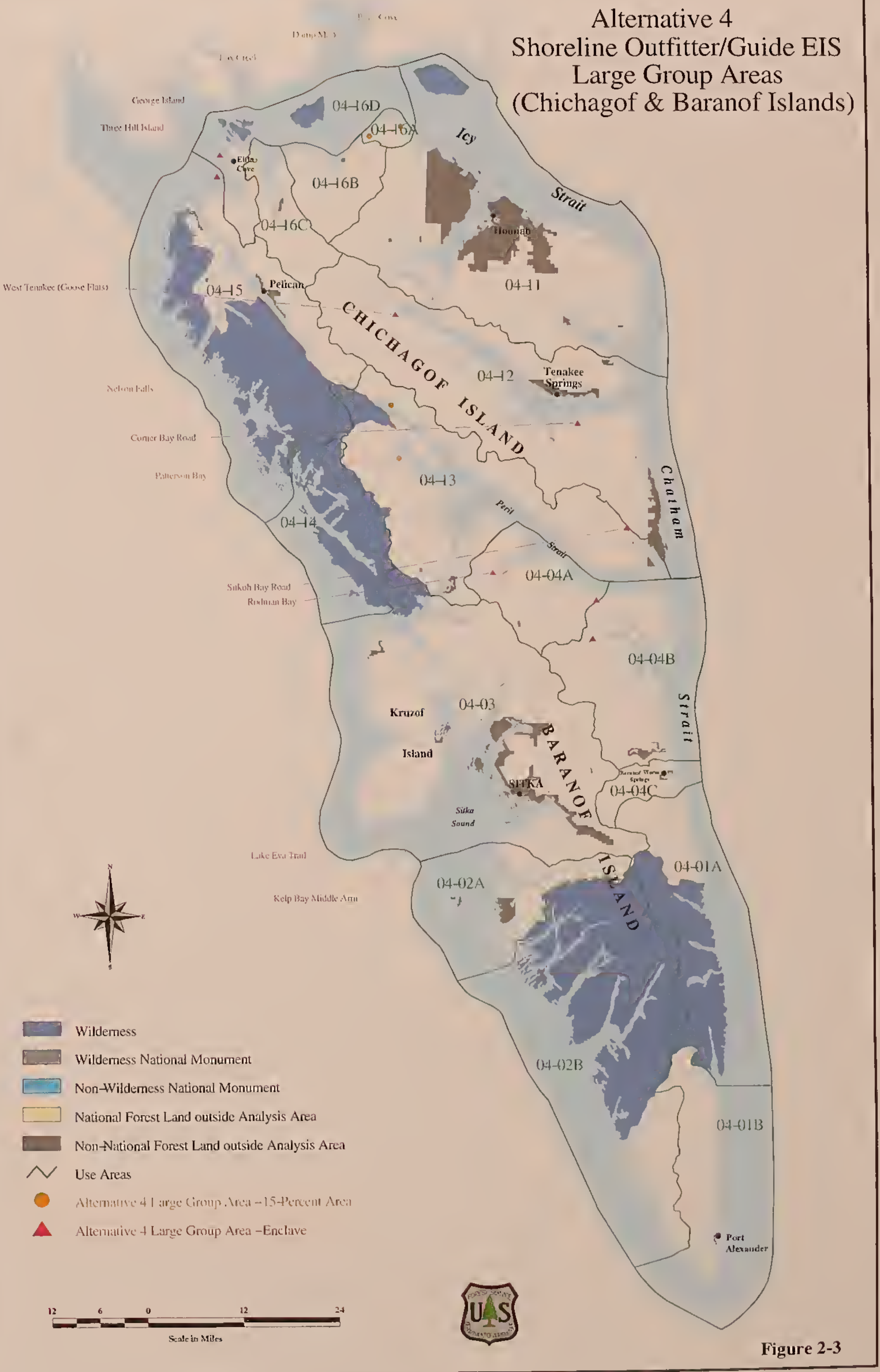





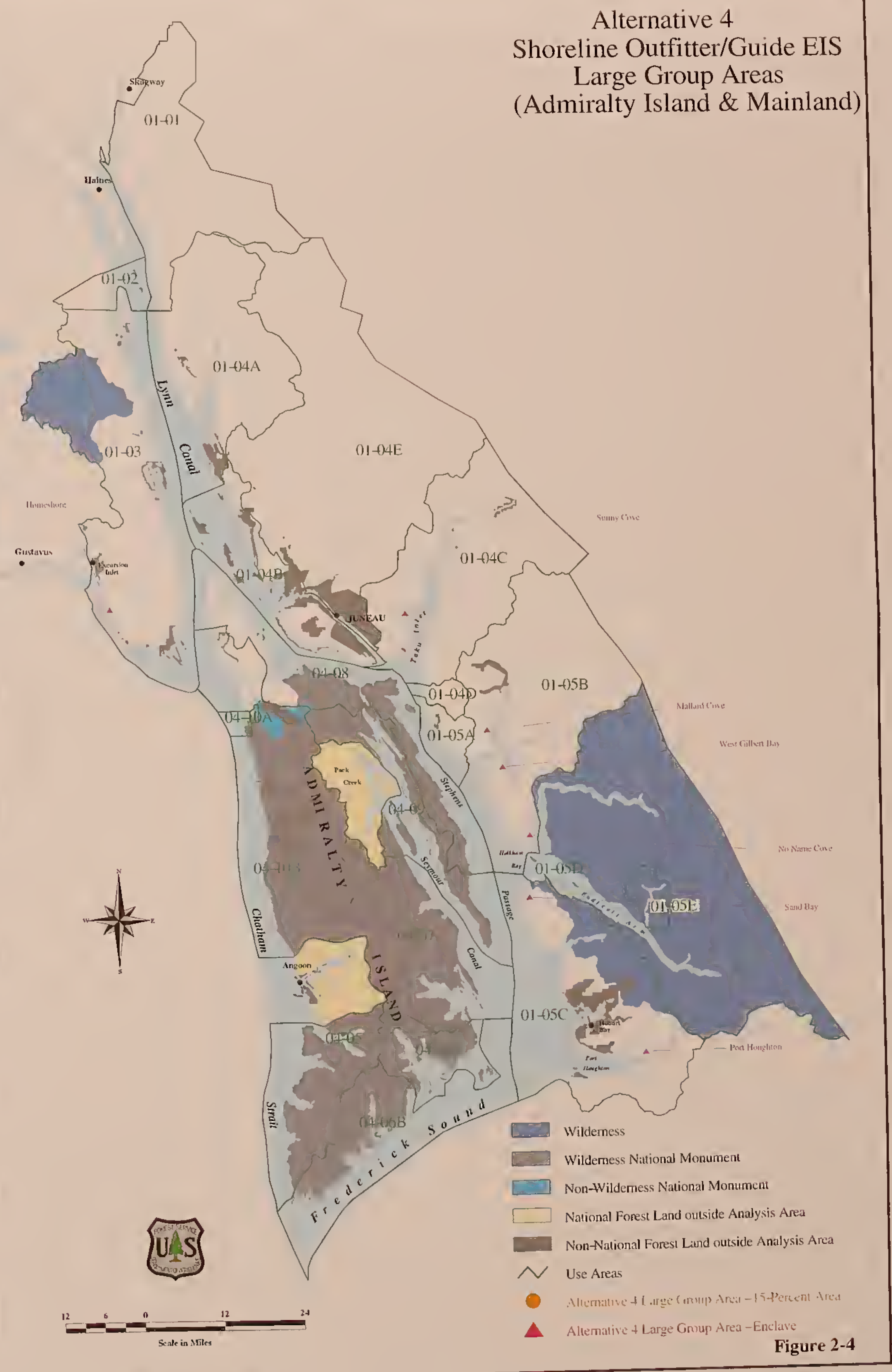




\section{Alternative 5}

Alternative 5 provides a specific commercial use allocation for each Use Area and season. It provides a moderate level of commercial use. There are some restrictions to commercial use to reduce social conflicts. The details of this alternative are listed below and displayed in Table 2-9. Figure 1-1 in Chapter 1 shows the location of each Use Area.

- Up to 18,495 commercial groups would be able to use the analysis area through the spring, summer, and fall seasons.

- Approximately 23 percent of the total recreation carrying capacity would be allocated to commercial use for the analysis area as a whole through all seasons. Allocations in each use area range between about 10 and 40 percent of the carrying capacity. The allocation varies to achieve site-specific management objectives.

- Alternative 5 emphasizes limited commercial use to reduce encounters and provide more opportunities for solitude during only the spring season. Spring allocation would be about 10 percent of the total carrying capacity.

- Allocations in Use Areas with communities are generally reduced and range from 10 to 40 percent of the total carrying capacity.

- This alternative would designate 33 Enclaves for large group use (Figures 25 and 2-6 and Table 2-10).

- Large group use in Enclave areas would be allowed in all seasons. Group size in these areas would be limited to 75 people, and only one large group would be able to use an area at a time.

- This alternative would designate 14 Fifteen-Percent areas for large group use (Figure 2-5 and Figure 2-6 and Table 2-11).

- Large group use could occur in Fifteen-Percent areas in only the summer season. Group size in these areas would be limited to 75 people, and only one large group would be able to use an area at a time.

- Limited wheeled airplane landings would be allowed in Neka and Mud Bay under daily and/or weekly restrictions. Neka Bay landings would only be authorized for differently-abled access with seasonal restrictions.

- Limited commercial use varying by season would be allowed on Mud Bay River.

- Guided sport fishing on Redoubt Lake and Stream, Salmon Lake, Nakwasina River, St. John the Baptist River, and Fish Bay River would be seasonally restricted to no more than two guided groups at a time.

- Site-specific descriptions, resource considerations, and mitigation measures for each Use Area are provided in Appendix A.

- Site-specific descriptions, resource considerations, and mitigation measures for each large group area are provided in Appendix B. 
Table 2-9. Alternative 5, Commercial Allocation by Use Area and Season

Commercial Allocation (Group-Days)

\begin{tabular}{|c|c|c|c|c|c|}
\hline \multirow[b]{2}{*}{ Use Area } & \multirow[b]{2}{*}{ General Location } & & & & \\
\hline & & Spring & Summer & Fall & Total \\
\hline 01-01 & Skagway Area & 42 & 212 & 118 & 372 \\
\hline $01-02$ & Haines Area & 21 & 106 & 59 & 186 \\
\hline 01-03 & East Chilkats & 84 & 424 & 235 & 743 \\
\hline $01-04 \mathrm{~A}$ & Berners Bay & 42 & 106 & 118 & 266 \\
\hline 01-04B & N. Juneau Coast & 25 & 64 & 71 & 160 \\
\hline $01-04 \mathrm{C}$ & Taku Inlet & 50 & 127 & 141 & 318 \\
\hline 01-04D & Slocum Inlet & 42 & 106 & 118 & 266 \\
\hline $01-05 \mathrm{~A}$ & Taku Harbor & 25 & 106 & 71 & 202 \\
\hline 01-05B & Port Snettisham & 84 & 424 & 235 & 743 \\
\hline $01-05 C$ & Windham Bay & 109 & 551 & 306 & 966 \\
\hline 01-05D & Tracy Arm & 50 & 254 & 141 & 445 \\
\hline 01-05E & Fords Terror & 13 & 60 & 35 & 108 \\
\hline 04-01A & Gut Bay, Baranof & 34 & 339 & 94 & 467 \\
\hline 04-01B & Port Armstrong & 29 & 297 & 82 & 408 \\
\hline $04-02 \mathrm{~A}$ & Redoubt Lake & 84 & 848 & 235 & 1,167 \\
\hline 04-02B & Whale Bay & 76 & 763 & 212 & 1,051 \\
\hline 04-03 & Sitka Area & 470 & 1187 & 526 & 2,183 \\
\hline 04-04A & Lake Eva, Rodman Bay & 34 & 339 & 94 & 467 \\
\hline 04-04B & Kelp Bay & 38 & 382 & 106 & 526 \\
\hline 04-04C & Baranof Warm Springs & 13 & 127 & 35 & 175 \\
\hline $04-05$ & SW Admiralty & 25 & 127 & 71 & 223 \\
\hline 04-06A & Pybus Bay & 13 & 127 & 35 & 175 \\
\hline 04-06B & Eliza Harbor & 13 & 127 & 35 & 175 \\
\hline 04-07 & Gambier Bay & 25 & 127 & 71 & 223 \\
\hline 04-08 & NE Admiralty & 118 & 296 & 329 & 743 \\
\hline 04-09 & Seymour Canal & 42 & 212 & 118 & 372 \\
\hline $04-10 \mathrm{~A}$ & Greens Creek & 17 & 127 & 47 & 191 \\
\hline $04-10 \mathrm{~B}$ & NW Admiralty & 29 & 149 & 82 & 260 \\
\hline 04-11 & Hoonah Area & 59 & 371 & 165 & 595 \\
\hline $04-12$ & Tenakee Inlet & 63 & 557 & 176 & 796 \\
\hline $04-13$ & Peril Strait & 67 & 678 & 188 & 933 \\
\hline $04-14$ & Slocum Arm & 34 & 297 & 94 & 425 \\
\hline $04-15$ & West Chichagof & 84 & 636 & 235 & 955 \\
\hline $04-16 \mathrm{~A}$ & Point Adolphus & 25 & 254 & 71 & 350 \\
\hline $04-16 B$ & North Chichagof & 25 & 254 & 71 & 350 \\
\hline $04-16 C$ & Idaho Inlet & 25 & 159 & 71 & 255 \\
\hline \multirow[t]{2}{*}{$04-16 \mathrm{D}$} & Port Althorp & 25 & 159 & 71 & 255 \\
\hline & Total & 2,054 & 11,479 & 4962 & 18,495 \\
\hline
\end{tabular}


Table 2-10. Alternative 5, Enclave Large Group Areas

\begin{tabular}{ll} 
Use Area & Enclave Area \\
\hline $01-01$ & Katzehin Falls \\
$01-02$ & Sullivan Mountain \\
$01-03$ & Homeshore \\
$01-04 B$ & Shelter Island \\
$01-04 C$ & Sunny Cove \\
$01-05 B$ & Mallard Cove \\
$01-05 B$ & No Name Cove \\
$01-05 B$ & Point Anmer \\
$01-05 B$ & West Gilbert Way \\
$01-05 C$ & Fanshaw \\
$01-05 C$ & North Windham Bay \\
$01-05 C$ & Port Houghton \\
$01-05 C$ & Sand Bay \\
$04-03$ & Eagle River Road \\
$04-04 A$ & Lake Eva Trail \\
$04-04 A$ & Point Elizabeth \\
$04-04 A$ & Rodman Bay \\
$04-04 A$ & Saook \\
$04-04 B$ & Hanus Bay \\
$04-04 B$ & Kelp Bay - Middle Arm \\
$04-08$ & Cordwood Creek \\
$04-08$ & Fowler Creek \\
$04-11$ & 8-Fathom Dock \\
$04-11$ & Kennel Creek \\
$04-11$ & Red Cliff Islands \\
$04-11$ & Salt Lake Bay Dock \\
$04-12$ & Corner Bay Road \\
$04-12$ & West Tenakee - Goose Flats \\
$04-13$ & Poison Cove \\
$04-13$ & Sitkoh Bay Road \\
$04-15$ & Bohemia Basin \\
$04-15$ & Three Hill Island \\
$04-16 D$ & George Island \\
\hline & \\
\hline
\end{tabular}




\section{Atternatives}

Table 2-11. Alternative 5, Fifteen-Percent Large Group Areas

\begin{tabular}{ll} 
Use Area & Fifteen-Percent Area \\
\hline $01-04 B$ & Douglas Island \\
$01-05 B$ & Point Coke \\
$04-04 B$ & Cosmos Cove \\
$04-11$ & Iyoukeen Peninsula \\
$04-11$ & Neka Bay - South Bight \\
$04-11$ & Neka Bay - North Bight \\
$04-12$ & Seal Bay \\
$04-13$ & Nelson Falls \\
$04-13$ & Nismeni Point \\
$04-13$ & Patterson Bay \\
$04-13$ & Todd Road/Lindenburg Head \\
$04-16 A$ & Damp Marker \\
$04-16 A$ & Pinta Cove \\
$04-16 C$ & Fox Creek \\
\hline
\end{tabular}




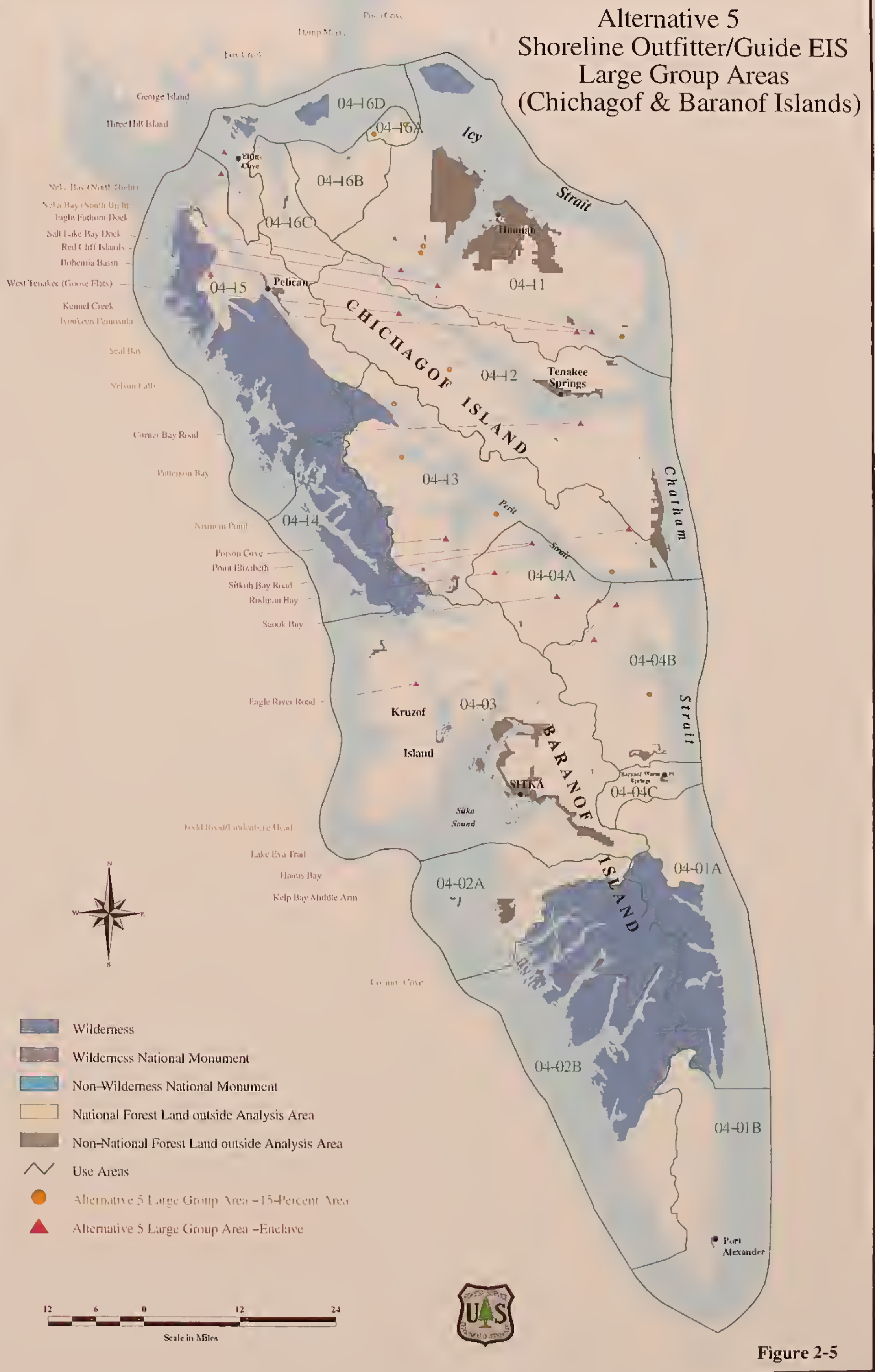





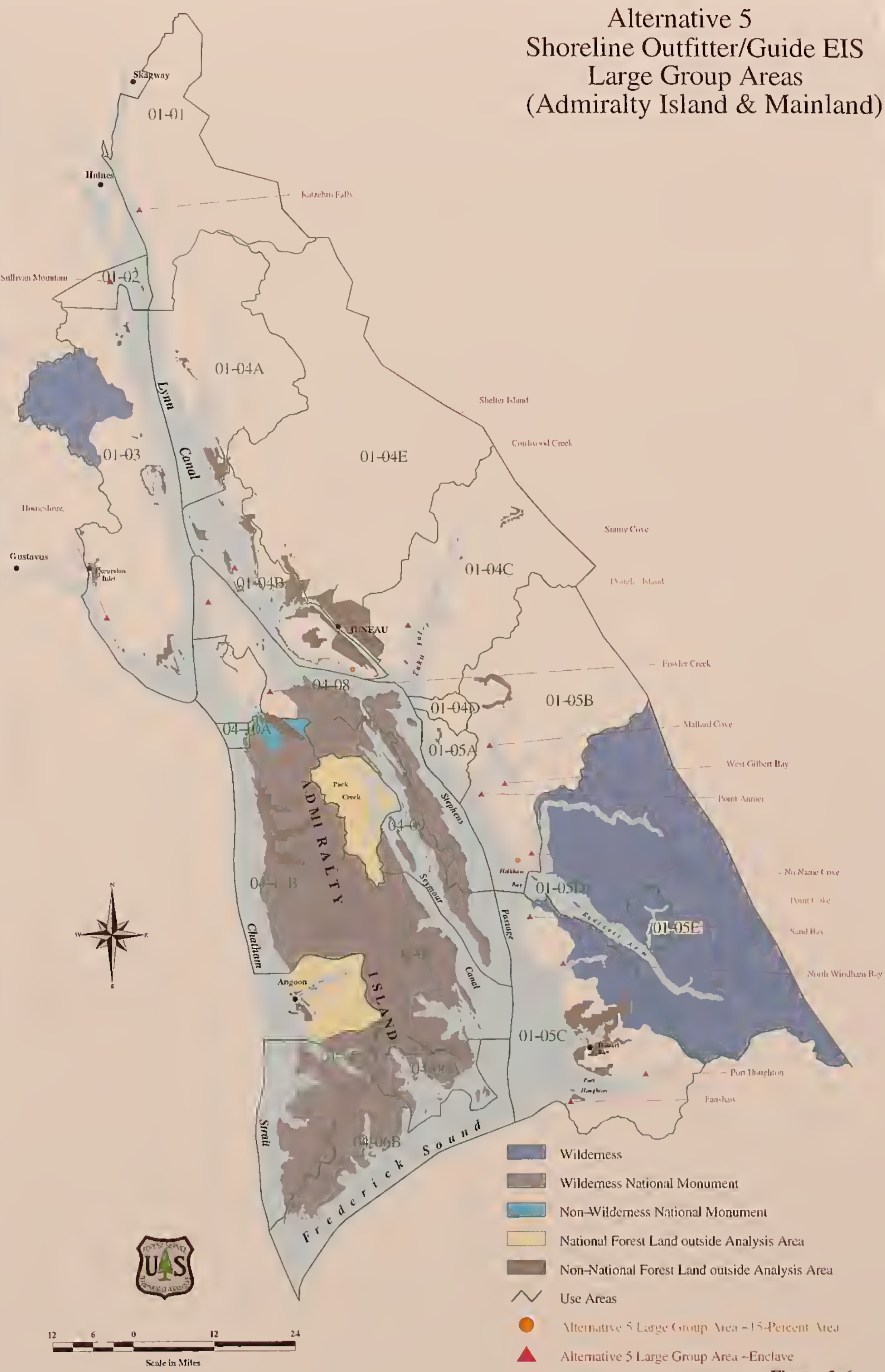

Figure 2-6 

Identification of the Preferred Alternative

\section{General Comparison}

Alternative 5 is identified as the preferred alternative at this time to assist the public in their review of this document. However, all of the alternatives have equal standing with the responsible official. Alternatives may be modified or a new alternative developed in response to public comments on the draft EIS.

\section{Comparison of Alternatives Summary}

This section provides a summary of the differences among the alternatives and how they respond to the significant issues (see Chapter 1). The differences are summarized in Tables 2-12 and 2-13. More detailed comparison of the effects of the alternatives is presented in Chapter 3.

General differences among the alternatives are shown in Table 2-12.

Table 2-12. Comparison of Alternatives, General

Amount of Total Recreation Carrying Capacity Allocated to Commercial Use

No specific allocation. Commercial use allowed on a case-by-case basis. Up to $50 \%$

2 proposed action 3 4 5 preferred alternative
Emphasis on limited commercial use during spring, some large group areas, limited wheeled airplane landings in some places.
Moderate

Approximately $21 \%$

Highest

Approximately $50 \%$

Lowest

Approximately $8 \%$

Moderate

Approximately $23 \%$ 


\section{Comparison by Issue}

All of the alternatives would provide the variety and types of recreation experience anticipated in the Forest Plan.

\section{Issue 1: Recreation Opportunities Available for Guided and Unguided Recreationists}

This issue focuses on the individual guided and unguided recreation user. It incorporates both qualitative and quantitative measures including the types of recreation opportunities available, the recreation carrying capacity allocation to commercial use, the number of people able to access the national forest using guides, areas where larger groups can recreate, the concentration/dispersion of recreation use, opportunities for solitude, and the effects of commercial use on unguided recreationists.

\section{Recreation Opportunities Available}

The Forest Plan and Recreational Opportunity Spectrum (ROS) are used to define the types of recreation experience available (Appendix F). Current recreation experiences range from Primitive to Rural ROS class, with the majority of the area providing Primitive or Semi-Primitive recreation opportunities. The Use Area allocations were made within the carrying capacities and criteria of each ROS class; therefore, none of the ROS classifications would be changed under the alternatives. Although no specific allocations would be made under Alternative 1, the commercial allocation is equal to the use authorized on a case-by-case basis from current levels up to 50 percent of the carrying capacity.

All of the alternatives would provide the variety and types of recreation experience anticipated in the Forest Plan. Commercial activities and allocations would not exceed Forest Plan standards and guidelines under any alternative. These include commercial recreation use occurring within Wilderness and eligible wild, scenic, and recreation river corridors.

Some alternatives identify specific areas for large group use as allowed in the Forest Plan. While group size is one of several criteria in determining the ROS class, large group size specified in this analysis is not considered to be a significant enough factor to change the ROS by itself in either the Fifteen-Percent or Enclave areas. However, if the regularly occurring large group use in the Enclave areas should result in the need for more development and site hardening in the future, these changes combined with the large group size and increased use levels could result in change in the ROS to a more developed classification. The Forest Plan allows ROS changes in development level up to the Rural ROS class in these Enclaves. Alternative 3 identifies 7,949 acres in Enclave areas having the potential to change to a more developed ROS class; Alternative 5 identifies 6,092 such acres; and Alternative 4 identifies 2,888 such acres. Alternatives 1 and 2 do not designate any Enclave areas for large group use and do not permit any commercial activities with group sizes larger than generally allowed by the Forest Plan LUD.

\section{Commercial Allocation Levels}

The total commercial allocation levels provide a measure of the amount of recreation use available to guided recreationists. The allocation levels also provide a measure of the potential for crowding. The action alternatives provide a range of total allocations and allocations by Use Area and season.

In general, the perception of crowding could correlate to the amount of carrying capacity used. The more use an area receives, by both guided and unguided recreationists, the greater the potential perception of crowding. 


\section{Alternatives 2}

The highest total commercial allocation would be made under Alternative 3, which would provide 40,658 group days. Alternative 5 would provide 18,495 group days, followed closely by Alternative 2 with 16,894 group days. The lowest total allocation would be Alternative 4 with 6,192 group-days. Alternative 1 makes no specific commercial allocation; commercial use is allowed on a case-by-case basis from current levels up to 50 percent of the carrying capacity. Current commercial use (1999) is approximately 2,410 group-days. The total allocations in all the action alternatives would exceed the current (1999) levels of guided recreation use.

The large amount of available recreation carrying capacity in the analysis area will meet the demand for unguided recreation in all alternatives, considering projected increases in local resident populations and the anticipated number of independent travelers visiting the analysis area.

Number of People Using Commercial Services to Access the National Forest All of the action alternatives allow for increased use over current (1999) levels. Approximately 14,000 people used outfitter/guides to visit the forest in 1999 . Assuming an average guided group size of six people, Alternative 3 would allow these numbers to increase up to 243,948 annually. Alternative 5 would allow 110,970 people, followed closely by Alternative 2 with 101,364 people per year. Alternative 4 would allow the fewest people, 37,152, to hire commercial services. These alternatives show a maximum allocation and may not represent actual future use.

\section{Large Group Areas}

Group size was an important component in potential conflicts between guided and unguided recreationists, with guided use generally occurring in larger group sizes. Alternatives 3, 4, and 5 propose varying numbers of Enclaves and Fifteen-Percent areas to accommodate people recreating in large guided groups (Tables 2-4, 2-5, 2-7, 2-8, 2-10, and 2-11). These areas would have a defined recreation experience which may include the presence of large groups. Other recreationists could anticipate the presence of large groups in these areas and avoid them if they desired a different recreation setting. However, both guided and unguided recreationists could use these large group areas.

Alternative 3 designates the most large group areas, 63 (40 Enclaves and 23 FifteenPercent areas); followed by Alternative 5, designating 47 large group areas (33 Enclaves and 14 Fifteen-Percent areas); and Alternative 4, with 20 large group areas (15 Enclaves and 5 Fifteen-Percent areas). Alternatives 1 and 2 do not designate any areas for large group use and do not permit any commercial activities with group sizes larger than generally allowed by the Forest Plan.

\section{Opportunity for Solitude}

The desire for solitude and the 'Alaska' experience is an important consideration for both guided and unguided recreation use. Solitude is a social experience measured in terms of the expected number of other groups encountered and the size of those groups. The opportunities for solitude are defined by the expected number of social encounters in the ROS and Forest Plan.

The opportunities for solitude are related to the commercial use allocations for each Use Area, measured by the overall commercial allocations and each seasonal 
allocation. Higher commercial allocations would increase the potential for high levels of use and a corresponding higher number of encounters and fewer opportunities for solitude. Conversely, lower allocations result in fewer commercial groups using an area, thereby providing more opportunities for solitude.

Opportunities for solitude as defined by ROS and the Forest Plan would be available over most of the analysis area in all alternatives at levels anticipated by the Forest Plan. However, some Use Areas would have fewer opportunities for solitude during the summer season.

Alternative 4 would provide the most opportunity for solitude because it has the lowest commercial allocation and it limits commercial use to about an average of less than 10 percent of the carrying capacity in both the spring and fall seasons. Alternative 2 would follow because it has the next lowest allocation and also limits commercial use to ten percent of the carrying capacity during the spring and fall seasons. Alternative 5 provides the third most opportunity for solitude because, while it has an allocation similar to Alternative 2, it limits commercial use to ten percent in only the spring season. Alternative 3 would provide the least opportunity for solitude because it has the highest allocation through all seasons.

\section{Effects on Unguided Recreationists}

No use levels or regulations would be established for unguided recreationists in this action. If total recreation use should approach the total carrying capacity of a Use Area in the future, both guided and unguided use would need to be managed and would be evaluated in a separate analysis.

Although individuals may not have the recreation experience they desire in all areas at all times, none of the alternatives would have significant adverse effects on unguided recreationists over the analysis area as a whole. Effects from commercial use on the recreation experience for unguided recreationists would come primarily from the potential for the perceptions of crowding and group size. Higher allocations allow a greater number of people, which increases the potential for crowding. The effects from all of the alternatives would be within the range of those anticipated in the Forest Plan. The more primitive recreation experiences anticipated by the Forest Plan would be available in all alternatives. No significant effects on recreation sites are expected in any alternative since all use levels and activities would comply with Forest Plan standards and guidelines and mitigation measures.

The alternatives provide different ways to reduce the potential effects of commercial use on unguided recreationists. These include:

- reducing allocations in Use Areas containing communities,

- closing or restricting specific areas to commercial use,

- restricting large group use to specific areas,

- limiting commercial use in certain seasons, and

- imposing limitations and restrictions on commercial use to reduce social conflicts. 


\section{Alternatives 2}

Large group areas were not located in Use Areas containing communities or in areas receiving heavy local use in any alternative.

Alternative 4 would have the least potential to have effects on unguided recreationists for several reasons. It has the lowest potential for crowding because it has the lowest commercial allocations. Allocations in all Use Areas containing communities are less than 15 percent, and spring and fall allocations are limited to 10 and 25 percent respectively (but averaging less than 10 percent). Alternative 4 proposes a limited number of large group areas and has the most potential to restrict commercial use.

Alternative 2 would have the second lowest potential to have effects on unguided recreationists. It has the second lowest potential for crowding because it has the second lowest commercial allocations. It has reduced allocations (from 10 to 30 percent of the carrying capacity) in Use Areas containing communities. Commercial allocations are limited to ten percent in spring and fall. Large group use areas would not be designated. Alternative 2 has some restrictions on commercial use.

Alternative 5 would have potential effects on unguided recreationists similar to Alternative 2. Alternative 5 would have a slightly higher potential for crowding non-commercial use, although the total allocation and allocations in Use Areas containing communities are similar between the two alternatives. Alternative 5 proposes large group areas, which would reduce potential effects of large groups on unguided recreationists. Commercial use allocations would be limited to ten percent only during the spring season. Alternative 5 has some restrictions on commercial use.

Alternative 3 has the most potential to have effects on unguided use. It has the highest allocation and the highest potential for crowding. It designates the most areas for large group use. It does not reduce commercial allocations in Use Areas that contain communities and it does not limit commercial use in the spring and fall seasons. Alternative 3 has fewer restrictions to commercial use to reduce social conflicts than the other alternatives.

\section{Wilderness and Recommended Wild and Scenic Rivers}

Commercial recreation use in Wilderness areas could affect values such as solitude, sense of isolation, sense of remoteness, self-reliance, challenge and risk, and the 'untrammeled' natural character. As allocations increase, there is an increased potential for higher levels of use in Wilderness, but it is difficult to accurately predict where increased use will occur or how much impact will take place. To provide a comparative basis for describing the different alternative allocation effects on Wilderness, an estimated level of potential use was developed based on the 1999 commercial use level of 859 total groups (Table 3-21). Alternative 3 is projected to have the most commercial use in Wilderness (14,637 total groups), followed by Alternatives 5 (6,704 groups), 2 (6,082 groups), and 4 (2,229 groups). Alternative 1 makes no specific allocation. All alternatives would provide commercial use levels that are consistent with Forest Plan Wilderness goals, objectives, standards, and guidelines. Effects on wilderness values in specific locations would be mitigated by increased regulation at these sites.

Commercial recreation use levels within Recommended Wild and Scenic River corridors are included in the alternative commercial capacity allocation for the Use 


\section{Alternatives}

Higher allocations may mean that more people use commercial services to access the national forest, resulting in more income to businesses.

However, higher allocations may not be beneficial to types of outfitter/guide businesses that rely on opportunities for solitude.
Areas containing the rivers. Use levels will comply with the Recreation Opportunity Spectrum (ROS) guidelines for group size and number of encounters. ROS guidelines will apply equally in all the alternatives; therefore, there will not be a difference in use levels or effects among the alternatives. No large group areas are proposed within or near a Recommended Wild and Scenic River corridor in the analysis area in any alternative. The closest large group area to a Recommended Wild or Scenic River is the Katzehin Falls Enclave proposed in Alternatives 3 and 5.

\section{Issue 2: Economic Opportunities and Potential Effects on Commercial Outfitter/Guide Businesses}

Issue 2 focuses on the recreation industry and involves both qualitative and quantitative measures. Measures include:

- recreation capacity allocated for commercial use,

- allocations compared to the 1999 commercial use levels,

- allocations limiting current use,

- opportunities for industry to serve large groups,

- the types of available recreation experience to provide to the public, and

- the general impacts of the alternatives on outfitter/guide businesses.

\section{Recreation Capacity Available for Commercial Use}

The commercial use allocation is the primary way the alternatives affect the commercial recreation industry. Total allocation can be related to the general economic benefits of commercial recreation. Higher allocations may mean that more people use commercial services to access the national forest, resulting in more income to businesses. The related economic benefits would provide the highest potential for commercial recreation growth. However, higher allocations may not be beneficial to types of outfitter/guide businesses that rely on opportunities for solitude. The alternatives display maximum allocations and may not represent actual future use.

Total commercial allocation and the allocation by individual Use Area and season vary by Alternative (see Tables 2-1, 2-2, 2-3, 2-6, and 2-9). Alternative 3 makes the highest total allocation of 40,658 group days, followed by Alternative 5 with 18,495 group days, Alternative 2 with 16,894 group days, and Alternative 4 with 6,192 group days (Table 3-9). Alternative 1, the no-action alternative, makes no commercial allocation but does allow commercial use on a case-by-case basis. The current moratoriums limit the potential for growth.

Quantity of Recreation Capacity Available Above Current (1999) Use Levels Commercial allocations are compared to current (1999) commercial use levels to determine the opportunities for or restraints on growth. Commercial allocations in the action alternatives are above current commercial use levels over the analysis area as a whole. However, current use is at or above the allocations in specific Use Areas during the spring and fall and will be limited. 


\section{Alternatives 2}

There is substantial room for overall commercial use to grow beyond the 1999 levels in all alternatives. Alternative 3 would have the most currently unused total allocation with 38,248 group days, followed by Alternative 5 with 16,085 unused group days, Alternative 2 with 14,484 unused group days, and Alternative 4 with 3,782 group days.

All action alternative allocations would provide currently unused capacity during the summer season. Alternative 3 would have currently unused capacity available in all Use Areas in all seasons. Alternative 2 would have no additional capacity in five Use Areas during the spring and one use area in the fall. Alternative 5 would have no additional capacity in five Use Areas during the spring. Alternative 4 would have no additional capacity in one Use Area during the spring.

If growth in recreation/tourism industry use were to double from current levels over the next 10 years, all of the action alternatives would still be able to accommodate that overall growth. Alternative 1 could expect restrictions in growth due to the moratoriums. Alternative 3 would allow a doubling of current use levels in all Use Areas in all seasons. Allocations for Alternatives 2 and 5 would not allow a doubling of current use levels in some Use Areas in the spring and fall seasons. Alternative 4 would allow a doubling of current use in all Use Areas in all seasons, but use levels would closely approach the allocation. Any additional growth under this alternative would result in limits in all seasons.

\section{Use Area Seasons at or Near Seasonal Capacity Allocation}

Current (1999) seasonal commercial use is approaching (within 20 percent), at, or beyond the seasonal allocation for some Use Areas in some alternatives. Commercial allocations may limit current use levels, future entry, or growth of outfitter/guide operations in Alternatives 2, 4, and 5 in some Use Areas in some seasons. Outfitter/guides would have to move to other areas with available capacity or compete for the commercial use allowed in these Use Areas.

Even if commercial use levels were to reach the allocation, commercial use would be limited to the allocation level. None of the alternatives would limit commercial use across the entire analysis area, but site-specific restrictions could be expected in most alternatives should use continue to grow at these sites. The spring season has the greatest potential for limits followed by the fall season.

Current use levels would be approaching, at, or near the seasonal allocation in ten Use Area seasons under Alternative 2, eight Use Area seasons under Alternative 5, and four Use Area seasons under Alternative 4. Alternative 3 has no Use Areas at or near the allocation. Alternative 1 does not allocate capacity, but use could potentially be allowed to grow up to 50 percent of the carrying capacity.

\section{Number and Type of Areas Designated for Large Group Use}

Large groups are primarily associated with tour boats offering nature viewing recreation experiences. Demand for this type of recreation is increasing. Most large group use occurs during summer. Large group use occurs in relatively few areas of the forest because the businesses providing services are constrained by the need to maintain schedules and the need for access points that can accommodate large boats.

Alternatives 3 and 5 would allow for growth in the industry by providing more large-group areas and scheduling flexibility. Alternative 4 would provide 


\section{Atteratives}

approximately the same number of areas currently being used by large groups. Large group areas would not be designated under Alternatives 1 and 2; under these alternatives, businesses that currently provide these types of services would have to limit their group size to Forest Plan standards.

Alternative 3 identifies 63 large group areas (40 Enclaves, 23 Fifteen-Percent areas), followed by Alternative 5 with 47 large group areas (33 Enclaves, 14 FifteenPercent areas). Alternative 4 identifies 20 large group areas, with 15 Enclaves and 5 Fifteen-Percent areas.

\section{Recreation Opportunities Available for Commercial Use}

Outfitter/guides rely on a predictable quality of recreation settings to provide to their clients. Most forest visitors using commercial services expect a certain recreation experience. Recreation activities and use levels in all of the action alternatives would comply with Forest Plan standards and guidelines and would result in the type of recreation experience defined by the Forest Plan and Recreational Opportunity Spectrum. A variety of recreation settings would be provided for commercial use in all alternatives, including use in Wilderness and suitable Wild, Scenic, and Recreation rivers.

Alternative 4 would provide the most opportunities for more primitive recreation experiences, because it has the lowest commercial allocation, followed by Alternatives 2 and 5 with similar allocations; Alternative 3 would have the least opportunity for more primitive experiences because it has the highest allocation. Alternative 1 does not make an allocation and would not ensure a predictable quality of recreation experience.

\section{Outfitter/Guide Business Benefits}

The action alternatives would provide a degree of business stability and sustainability and would reduce uncertainty in the future for outfitter/guide businesses. The commercial use allocation in each action alternative would provide enough capacity to sustain current businesses and offer potential growth for the recreation industry. The action alternatives would also provide longer term permits and an opportunity to obtain priority use permits. The action alternatives would provide a predictable quality of recreation setting to enhance business stability and sustainability.

Alternative 1 would not make a commercial allocation and would not provide any degree of certainty for future business. Permits would be temporary with no additional priority use permits being issued. The current moratoriums would remain in effect, potentially limiting future growth.

\section{Issue 3: Conflicts Within the Commercial Recreation Industry}

There is a broad diversity in the types and sizes of businesses involved in commercial recreation and the recreation activities they promote. Some of these differences can lead to conflicts among the different commercial recreation businesses. The alternatives provide different commercial and seasonal allocations, strategies, and measures to reduce potential conflicts within the recreation industry. 


\section{Alternatives 2}

\section{Commercial Allocation}

The seasonal allocations in each Use Area would provide different levels of use that reflect perceptions of crowding. In general, higher use levels would provide more opportunities for groups who are not seeking solitude. The lower allocations would provide the potential of fewer group encounters and fewer conflicts between guided groups.

Alternative 3 would have the highest total allocation resulting in the most potential for group encounters and conflicts, followed by Alternatives 5 and 2 with similar allocations, and Alternative 4 with the lowest allocation and the least potential for group encounters and conflict. Alternative 1 makes no commercial allocation, and industry conflicts are expected to continue.

\section{Seasonal Commercial Allocations}

One of the primary strategies used to reduce conflicts within the commercial recreation industry is to establish and manage recreation use by seasons. Many types of outfitter/guide businesses have specific needs and requirements in order to serve their clients. Some outfitter/guide activities are more sensitive to crowding, need large areas for their activities, or are more constrained by regulations than other outfitter/guides. Managing commercial recreation use by season can help alleviate some of the potential for conflicts. Allocating less commercial use during spring and fall would provide more opportunities for those types of activities that require or seek more space and solitude. Limiting allocations would reduce the number of groups that could interact and the potential for conflicts.

All of the action alternatives establish and allocate use by season. Alternative 1 does not establish recreation management seasons.

All the action alternatives provide higher allocations in the primary use season, summer, which serves to concentrate commercial use in this season.

Alternatives 2 and 4 would have the greatest restrictions on seasonal use by limiting the commercial allocation to approximately ten percent of the carrying capacity in both the spring and fall. Alternative 5 would limit the commercial allocation to approximately ten percent of the carrying capacity only in the spring. Alternative 3 would not limit seasonal allocations during spring or fall. Alternative 1 does not make commercial allocations.

\section{Measures to Reduce Industry Conflict}

The alternatives address conflict potential among outfitter/guide businesses through their design and mitigation measures. Management strategies were developed to reduce potential conflicts among outfitter/guides. Many of these also serve to reduce potential conflicts between commercial and non-commercial users. These include limits on group size, the number of groups in an area at one time, seasons of use, length of stay limits, methods, and restrictions on access, and mitigation measures to reduce social conflicts. Most measures apply to all of the action alternatives.

Access methods are specified to reduce conflicts in the action alternatives. Helicopter and commercial all-terrain-vehicle (ATV) use is not proposed in any alternative. Motorized boat restrictions apply equally to all the action alternatives. Wheeled plane access is allowed at varying levels among the alternatives. 


\section{Alternatives}

Generally, the higher levels of use would result in greater potential for conflict. Alternative 3 would provide the highest amount of use during all seasons and thus would have the highest potential for conflict. Alternatives 2, 4, and 5 would provide lower allocations, especially during the spring and fall hunting seasons. Alternative 4 would have the lowest potential for conflicts since it has the lowest seasonal and overall allocations.

Alternatives 2 and 5 would have the same potential for conflicts during the spring since use area allocations would be the same (Tables 2-2 and 2-9). However, the potential for conflicts would be higher during the fall season under Alternative 5 .

Alternatives 4 and 5 would further reduce the potential for conflict between large groups and hunters because large group use of the Fifteen Percent areas would be authorized only in the summer and not during the spring and fall. Alternative 3 would allow use in Fifteen-Percent areas in all seasons. Alternatives 3, 4, and 5 limit group size in the large group areas to 75 people, and only one large group can be in an area at a time to limit social impacts on other large groups and other users.

Alternative 1 does not provide specific measures to reduce conflict between outfitter/guides. Measures could be developed on a case-by-case basis.

\section{Designation of Large Group Areas}

Designation of large group areas would reduce the potential for conflicts by accommodating recreationists in large groups at appropriate sites.

Large group areas provide places where businesses can provide services to people who prefer to recreate in large groups. Large group areas also identify places where other outfitter/guides can expect to see large groups and can avoid these areas if they desire a different recreation setting. The areas also serve to concentrate large groups and their associated resource impacts into specific portions of the forest. Seasonal limits on large group use would reduce potential conflicts between big game guides and tour boat groups. Other areas of the forest would be available for outfitter/guides who serve small groups.

Large group areas vary by number and location in the alternatives. Alternatives 3, 4, and 5 would designate large group areas. Groups in these areas would be limited to 75 people, and only one large group would be able to use an area at a time. The most large group areas, 63 , would be designated under Alternative 3; use of these areas would be allowed through all three seasons. Alternative 5 would designate the second most large group areas with 47; the Fifteen Percent areas would only be available for use in the summer season. Alternative 4 would designate the fewest large group areas with 20; the Fifteen Percent areas would be available for use only in the summer season. Alternatives 1 and 2 do not identify any areas for large group use. 
Table 2-13. Comparison of Alternatives, by Issue

Issue /
Unit of Measure

\begin{tabular}{l|l|l|l|l}
\multicolumn{5}{|c}{ Alternative } \\
\hline 1 & 2 & 3 & 4 & 5 \\
\hline
\end{tabular}

Issue 1 - Recreation Opportunities for Guided and Unguided Recreationists

Recreation experience opportunities available as anticipated by the Forest Plan and ROS

Acres that could potentially change from Semi-primitive to a more developed ROS setting in the Enclave areas

Total recreation carrying capacity (group days) available to guided recreationists

Estimated number of people who could use commercial services to access the national forest (assumes commercial group size of six)

Number of Enclaves allowing large group use

Total area (acres) of Enclaves

Number of Fifteen-Percent areas allowing large group use

Total area (acres) of Fifteen-Percent areas

Limits on commercial use in Use Areas with communities

\begin{tabular}{r|r|r|r|r} 
Yes & Yes & Yes & Yes & Yes \\
& & & & \\
$* *$ & 0 & 8,865 & 3,065 & 6,790 \\
243,948 & 16,894 & 40,658 & 6,192 & 18,495 \\
0 & 101,364 & 243,948 & 37,152 & 110,970 \\
0 & 0 & 40 & 15 & 33 \\
0 & 0 & 7,949 & 2,888 & 6,092 \\
0 & 0 & 23 & 5 & 14 \\
No & 0 & 5,210 & 765 & 3,066 \\
Yes & No & Yes & Yes \\
\hline
\end{tabular}

\section{Issue 2 - Economic Opportunities and Potential Impacts on Commercial Outfitter/Guide Businesses}

Recreation experience opportunities available for commercial use as anticipated by the Forest Plan and ROS

Commercial allocation available in number of group days

Percent of recreation capacity allocated to commercial use

Current (1999) commercial use levels in number of group days

Number of group days available for industry growth above current

(1999) use levels

Number of Use Areas seasons approaching, at, or near allocated

capacity

Number of areas designated for large groups

Quality of recreation experience available for commercial use as anticipated by the Forest Plan

Contributes to business stability and certainty by establishing

predictable use levels and allowing for multi-year Special Use permits

\begin{tabular}{r|r|r|r|r} 
Yes & Yes & Yes & Yes & Yes \\
NA & 16,894 & 40,658 & 6,192 & 18,495 \\
$3-50^{* *}$ & 21 & 50 & 8 & 23 \\
2,410 & 2,410 & 2,410 & 2,410 & 2,410 \\
NA & 14,484 & 38,248 & 3,782 & 16,085 \\
NA & 10 & 0 & 4 & 8 \\
0 & 0 & 63 & 20 & 47 \\
NA & Yes & Yes & Yes & Yes \\
No & Yes & Yes & Yes & Yes \\
\hline
\end{tabular}

\section{Issue 3 - Conflicts Within the Commercial Recreation Industry}

Establishes recreation management seasons.

Limits commercial allocations in the spring season

Limits commercial allocations in the fall season

Use of specific mitigation measures to reduce conflict

Designates Enclaves and Fifteen-Percent Areas for large group use

Specifies maximum size of large groups

\begin{tabular}{r|r|r|r|r} 
No & Yes & Yes & Yes & Yes \\
No & Yes & No & Yes & Yes \\
No & Yes & No & Yes & No \\
NA & Yes & Yes & Yes & Yes \\
No & No & Yes & Yes & Yes \\
No & No & Yes & Yes & Yes \\
\hline
\end{tabular}

** No specific allocation is made. Commercial use is allowed on a case-by-case basis up to 50 percent of the recreation carrying capacity. 


\section{Mitigation and Monitoring}

\section{Mitigation}

Monitoring

The analysis documented in this EIS discloses the possible adverse impacts that may occur from implementing the actions proposed under each alternative. Measures have been formulated to mitigate or reduce these impacts. These measures were guided by the direction from applicable laws and regulations, manual direction, the Forest Plan, and other sources such as the Southeast Alaska Unit 4 Brown Bear Management Strategy (Alaska Board of Game 2000).

A comprehensive list of mitigation measures apply to the commercial recreation activities for all of the action alternatives. These are listed in Appendix C, Mitigation Measures. In addition, site-specific resource concerns and mitigation measures are listed on the Use Area cards in Appendix A and on the Large Group Area Cards in Appendix B.

Mitigation measures would be incorporated at the implementation stages during the Special Use permit preparation and administration. Resource concerns and mitigation measures may be further refined during the monitoring and administration of commercial use if additional information becomes available.

Monitoring is gathering data and information and observing the results of management activities to provide a basis for evaluation. It serves as a quality control process for implementing the project. The evaluation of monitoring results for this project will provide a feedback loop to make corrective actions as needed to provide resource protection and the desired recreation opportunities.

Monitoring is a critical component of this project. Commercial recreation management at the scale proposed in this analysis is relatively new to the Forest Service in Southeast Alaska. Many of the social facets of recreation are not well understood. Recreation use levels are dynamic and fluctuate from year to year. Reliable site-specific unguided recreation use information is not currently available. The environmental effects of recreation use are also not well known. Through monitoring, the Forest Service can achieve a better understanding of these effects and adapt its management as necessary.

A monitoring plan is provided in Appendix D. It defines monitoring steps during Special Use permit administration and for specific resources. Annual interagency reviews will be an important part of the monitoring plan.

\section{Alternatives and Proposals Considered but Eliminated from Detailed Study}

The following alternative and alternative components were considered during the analysis for the Shoreline Outfitter/Guide analysis area but were eliminated from detailed study in this EIS. This does not eliminate the alternatives or components from future analyses and does not prevent them from being reconsidered following the review of comments to this draft EIS. 


\section{No Commercial Use on the National Forest}

\section{Helicopters}

We considered an alternative that would allow no commercial use of the national forest within the analysis area. This alternative was dropped from further consideration because it would not meet the stated purpose and need of the project. Commercial use of the national forest is allowed and encouraged by legislation, specifically the Mineral Leasing Act of 1920; the Granger-Thye Act of April 24, 1950; the Wilderness Act of September 3,1964; and Title V, Federal Land Policy and Management Act of October 21, 1976. This congressional direction is the basis of Forest Service national policy, which encourages commercial recreation to provide for the recreational enjoyment of national forests by people who otherwise may not have the ability or opportunity to do so. As a matter of national policy, banning commercial uses of the national forests is an issue outside the scope of this analysis. Such a ban would go against national policy and Forest Plan direction and would deny access to most of the Tongass for a significant proportion of the population of the United States who do not have the necessary knowledge, skills, and equipment to access and enjoy this national forest. In addition, banning commercial use from the national forest would have a detrimental impact on the regional economy, which relies heavily on recreation and tourism. The Tongass National Forest is the main land manager in Southeast Alaska, and other land ownerships could not meet the needs for recreation.

We considered many methods of recreation access, including helicopters. Historically there have been few outfitter/guide helicopter landings within the analysis area. No helicopter use is currently permitted and no helicopter landings have been proposed by outfitter/guides within the shoreline zone of the analysis area. Therefore helicopter access was considered but eliminated from this analysis.

All-terrain vehicles (ATVs) are a popular access method in some parts of the national forest. The IDT considered ATV access, but there has been no historical commercial use from ATVs so it was eliminated from this analysis.

\section{Large Group Areas}

Numerous large group areas were considered but then eliminated from consideration. See Appendix B (Table B-2) for a list of the eliminated large group areas and the reason they were dropped.

\section{Big Game Guided Hunting Allocations}

The original 1998 proposed action made specific recreation carrying capacity allocations for big game guided hunting, primarily for brown bear hunting. Based upon public comment and additional analysis, this focus was determined to be too narrow. The proposed action was expanded to include all commercial recreation providers in the overall commercial recreation allocation. Big game guided hunting allocations are now included within the overall commercial recreation allocations in the alternatives. Specific allocations to individual guiding businesses will occur through the Special Uses administration process. 
Alternatives

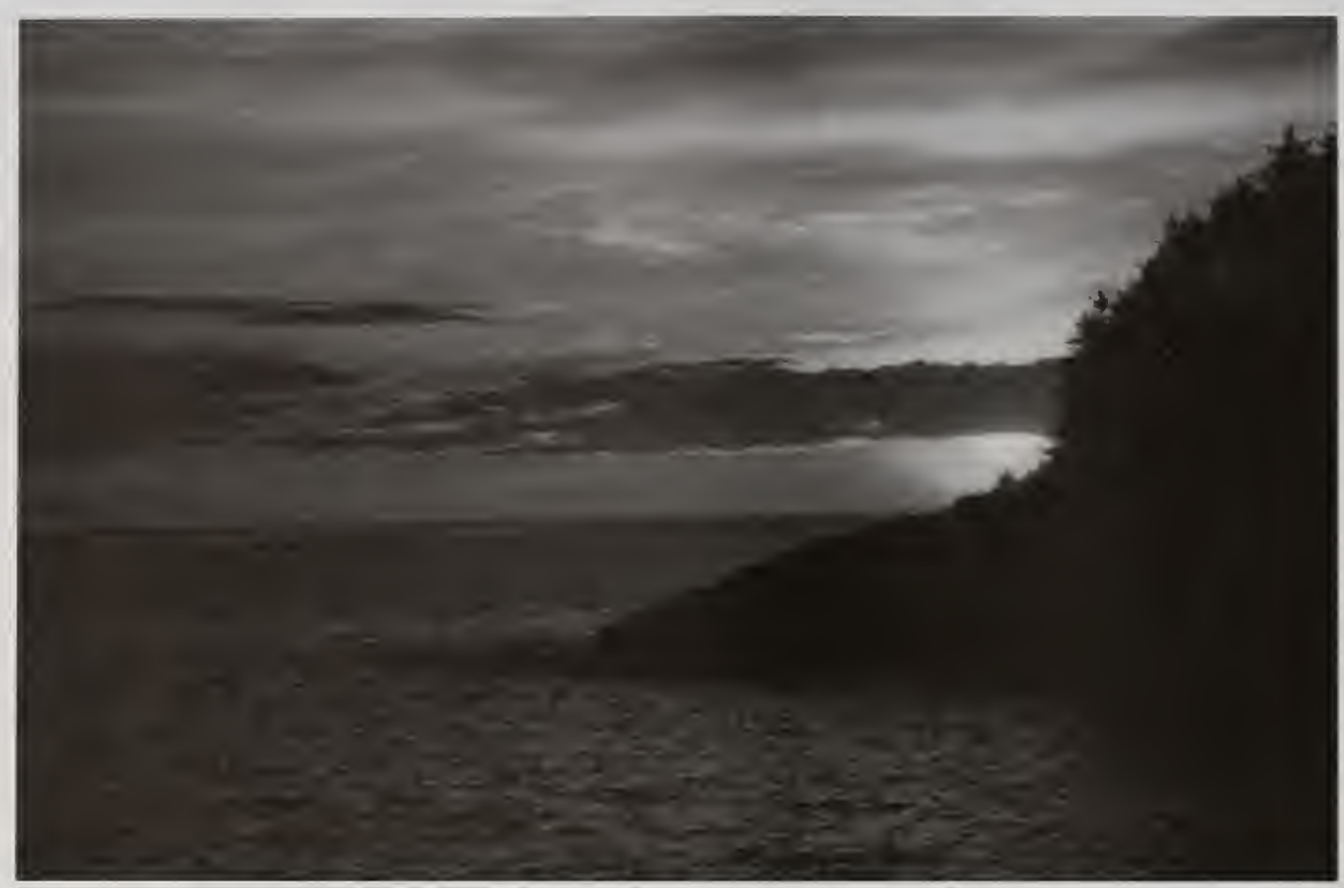




\section{Chapter 3 Affected Environment and Environmental Consequences}

Introduction.

3-1

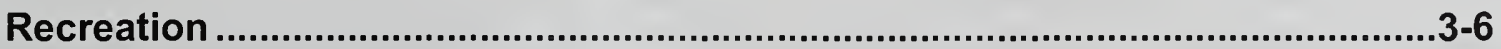

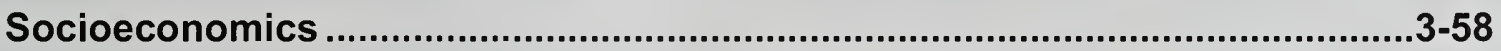

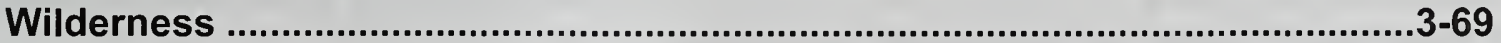

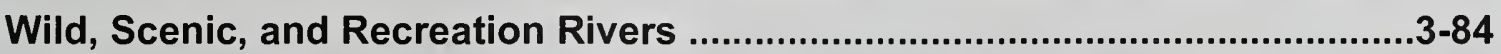

Other Environmental Considerations ..............................................................

Specifically Required Disclosures ................................................................3-151 


\section{Chapter 3 \\ Key Terms}

Carrying capacity - The estimated maximum number of groups of people who could recreate in an area and still have a specified type of recreation experience.

Commercial use - Any use of the national forest for which a fee is charged by an outfitter/guide.

Cumulative effects - The impacts on the environment resulting from the addition of the incremental impacts of past, present, and reasonably foreseeable future actions regardless of what agency (federal or non-federal) or person undertakes such actions.

Direct effects - Environmental effects that occur at the same time and place as the initial cause or action.

Enclave - Area where large groups can occur on a regular basis throughout the season.

Fifteen-Percent Area - Places where large groups can occur only on an occasional basis, for less than 15 percent of the primary use season.

Indirect effects - Effects that occur later in time or are spatially removed from the activity but would be significant in the foreseeable future.

Group - A group consists of one or more individuals recreating together as a social unit. Groups are used as the basic unit in this analysis.

Group days - A measurement of recreation use by groups using the national forest on a daily basis.

Large group - Group made up of a number of people that exceeds the general maximum group size for a specified type of recreation experience in the ROS. Large group size varies by LUD and ROS.

Management Indicator Species (MIS ) - Vertebrate or invertebrate wildlife species whose response to land management activities can be used to predict the likely response of other species with similar habitat requirements.

Mitigation - Measures designed to counteract or reduce environmental impacts.

Recreation Opportunity Spectrum (ROS) - A system for planning and managing recreation resources that categorizes recreation opportunities into seven classes.

Shoreline zone - The analysis area extending inland approximately one-half mile from mean high tide.

Use Area - Distinct geographic area used in this analysis as the basis for defining and managing recreation use. 


\section{Chapter 3}

\section{Affected Environment and Environmental Consequences}

\section{Introduction}

\section{Overview}

\section{Administrative Land Divisions}

This chapter provides information concerning the existing environment of the Shoreline Outfitter/Guide analysis area, and potential consequences for that environment as a result of this project. Also presented is the scientific and analytical basis for the comparison of alternatives presented in Chapter 2. Each resource potentially affected by the proposed action or other alternatives is described by its current condition and uses. Other findings required by policy and law are included at the end of the chapter.

The chapter begins with a description of the affected environment and environmental effects on the recreation resource associated with the three significant issues in the Shoreline Outfitter/Guide analysis area (see Chapter 1). Following the recreation section are discussions of socioeconomic considerations, Wilderness, and Wild and Scenic Rivers. The Other Environmental Considerations section discusses other resource concerns raised during scoping that the IDT found not to be significant issues as defined by NEPA. These other concerns include: (1) potential effects (environmental consequences) that are mitigated in the same way in all alternatives or (2) resources that are not significantly affected by any alternative.

For all resource areas under discussion, direct, indirect, and cumulative effects are disclosed. Effects are quantified where possible, and qualitative discussions are also included. Means by which potential adverse effects will be reduced or mitigated are described (see also Chapter 2, and Appendices A, B, and C).

Discussions of resources and potential effects are based on existing information included in the Forest Plan, other project environmental analyses, project-specific resource reports, agency and scientific studies, and related information. Where applicable, such information is briefly summarized and referenced to minimize duplication. The planning record for the Shoreline Outfitter/Guide EIS includes all project-specific information, including resource reports, documentation of field investigations, and information gathered from public meetings. The planning record is located at the Sitka Supervisor's Office, Sitka, Alaska, and is available for review during regular business hours. Information from the record is available upon request.

The land within the Tongass National Forest has been divided in several different ways in order to better describe the different resources and facilitate systematic and consistent analysis. These divisions vary depending on the resource because the relationship of each resource to geographic conditions and zones varies. 


\section{Environment and Effects}

Use Areas are distinct
geographic areas used
in the analysis to
define and manage
recreation use.

\section{Use Area}

The Shoreline analysis area was divided into Use Areas because it is too large and complex to manage as one area. Use Areas are the key land divisions used in the Shoreline Outfitter/Guide EIS to define and manage recreation use. They are designed to provide distinct geographical areas at a size that allows meaningful recreation management. Recreation carrying capacity allocations were determined for each Use Area, providing a consistent basis for permit administration and monitoring. Figure 1-1 in Chapter 1 shows the location of these Use Areas. These Use Areas are also subdivisions of Guide Use Areas used by the Alaska Department of Fish and Game to manage commercial big game guiding.

\section{Land Use Designation (LUD)}

The Forest Plan established Land Use Designations (LUD). Each LUD provides for a combination of activities, goals and objectives, and uses. There are 16 LUDs within the Shoreline Outfitter/Guide analysis area. Standards and guidelines for these LUDs were used to determine recreation carrying capacity, group size, and resource protection measures. LUDs within the analysis area are discussed and displayed in Chapter 1 and Appendix E.

\section{Value Comparison Unit (VCU)}

Value Comparison Units are distinct geographic areas, each encompassing a drainage basin containing one or more large stream systems. Boundaries usually follow major watershed divides. The Shoreline Outfitter/Guide analysis area includes all or portions of more than 300 of the 926 VCUs on the Tongass National Forest. VCUs are used in wildlife and subsistence analysis.

\section{Wildlife Analysis Area (WAA)}

Wildlife Analysis Areas are land divisions used by the Alaska Department of Fish and Game for wildlife population analyses. Subsistence use is compiled by WAA. The Shoreline Outfitter/Guide analysis area includes all or portions of approximately 75 WAAs.

\section{Game Management Unit (GMU)}

Game Management Units (GMUs) are land divisions delineated and used by the Alaska Department of Fish and Game to implement Alaska Board of Game hunting and trapping regulations such as seasons and bag limits. The Shoreline Outfitter/Guide analysis area includes all or portions of GMUs 1C, 1D, and 4.

\section{Guide Use Area (GUA)}

Guide Use Areas are land divisions originally delineated by the Alaska Board of Guides. Currently, the Alaska Department of Community and Economic Development, Division of Occupational Licensing, limits big game guides to using no more than three GUAs at one time. The Forest Service also considers GUAs in managing outfitter/guide activities on the national forest. 


\section{Analyzing Effects}

Environmental consequences are the effects of implementing an alternative on the physical, biological, social, and economic environment. The Council on Environmental Quality (CEQ) regulations implementing the National Environmental Policy Act (NEPA) include a number of specific categories to use for the analysis of environmental consequences. Several categories are applicable to the analysis of the proposed project and alternatives and form the basis of much of the analysis.

\section{Direct, Indirect, and Cumulative Effects}

Direct environmental effects are those occurring at the same time and place as the initial cause or action. Indirect effects are those that occur later in time or are spatially removed from the activity but would be significant in the foreseeable future. Cumulative effects result from incremental effects of actions, when added to other past, present, and reasonably foreseeable future actions, regardless of which agency or person undertakes actions. Cumulative effects can result from individually minor but collectively significant actions taking place over a period of time.

Effects may be beneficial or adverse. Many adverse effects can be reduced through the design of the project or through remedial actions during project activities. Forest Plan standards and guidelines, Best Management Practices and mitigation measures are incorporated into this analysis. They would be implemented and enforced through administration of outfitter/guide permits and monitoring resource conditions to limit the extent, severity, and duration of resource effects.

\section{Unavoidable Adverse Effects}

Implementation of any action alternative may cause some adverse environmental effects that cannot be effectively mitigated or avoided. Unavoidable adverse effects often result from managing the land for one resource at the expense of the use or condition of other resources.

\section{Short-term Use and Long-term Productivity}

Under the Multiple-Use Sustained Yield Act, and the National Forest Management Act, all renewable resources are to be managed so that they are available for future generations. The allocation and permitting of a commercial outfitter/guide use is a short-term use of the forest resources. It is a low impact and short duration use that is compatible with sustainable ecosystem management. Long-term productivity is the capability of the land and resources to continue producing goods and services long after the project has been implemented. Consumptive recreation uses such as fishing, hunting, and berry picking can continue over time if the populations and long-term productivity of the land are maintained. Long-term productivity is maintained through the design of the alternatives and application of resource protection measures described in Chapters 2 and 3 and Appendix C.

\section{Irreversible and Irretrievable Commitments}

Irreversible commitments are decisions affecting non-renewable resources such as soils, wetlands, unroaded areas, and heritage resources. Such commitments are considered irreversible when the resource has deteriorated to the point that renewal can occur only over a great period of time, at great expense, or not at all. The 


\section{Environment and Effects}

\author{
Available \\ Resource \\ Information
}

destruction of an archaeological site is an example of an irreversible commitment. No irreversible effects are expected to occur as a result of this project.

Irretrievable commitments represent opportunities foregone for the period during which resource use or production cannot be realized. Such decisions are reversible, but the production opportunities foregone are irretrievable. Recreation use from the Shoreline project will result in no irretrievable commitment of forest resources.

There is incomplete knowledge about many of the conditions and relationships of forest rcsources and social needs. Recreation management is a complex and developing science. Wildlife population dynamics and habitat relationships are not completely understood. Interactions of recreation opportunities, economic and social conditions, and the affected communities are the subject matter of a complex and cvolving science. However, the basic data and central relationships are sufficiently well established for this analysis to adequately assess and disclose the possible advcrse environmental consequences, and for the responsible official to make a reasoned choice among the altcrnatives.

Although there is not a lot of scientific research specifically related to commercial recreation and its social and environmental effects in southeast Alaska, there has bcen a good collection of environmental analysis in the past for commercial recreation use, recreation development, and similar actions. The Shoreline Outfitter/Guide analysis relied on the past 25 years of environmental analysis and outfitter/guide permit administration and the professional judgment of the IDT to build and support the assumptions used in this analysis.

During the past 25 ycars, the Forest Service has conducted approximately 270 cnvironmental analyses through the NEPA process, including 151 CE's, 109 EAs, and 3 EISs relating to recreation or similar activities on the Tongass National Forest. These analyses werc reviewed and are included in the Shoreline Outfitter/Guide analysis here by reference. They can be found in the Tongass NEPA Library at www. fsweb.sitka.chatham.r10.fs.fed.us/nepa_index_spreadsheet. These previous analyscs included public comment, Biological Evaluations, heritage resource detcrminations and other resource findings and effects. A review of this collection of analyses has not shown any significant adverse effects from recreation use on forest resources.

In addition, the Forest Service has issucd over 440 permits per year on the Tongass, of which approximately 288 arc within the study area. Outfitter/guide use is regulated and monitored through the administration of these permits. The permit files are located at the authorizing office for each permit. These files were reviewed as part of this analysis and are incorporated here by reference. No significant adverse effects to forest resources from guided use have been identified during permit administrative monitoring.

This analysis used recreation and resource information from the Forest Plan, GIS inventory data, GIS models, field inventories and observations, Alaska Department of Fish and Game (ADF\&G) population and harvest data, actual commercial use data, and related recreation tourism and sociocconomic data from other state and 


\section{Environment and Effects 3}

federal agencies. Professional judgment was used where reliable data and information were not available.

\section{Discussion Of Significant Issues}

Some measures are
repeated for each issue to
display the different
perspectives unique to
each issue.

A significant issue provides the focus for one or more alternatives, can be used to compare alternatives, and is used to track environmental effects throughout the analysis. Significant issues were identified through public and internal scoping. Chapter 1 describes the issues and the process used to identify them.

After identifying significant issues and developing alternatives to respond to them, methods were determined to evaluate how each alterative would respond to the issues. Methods chosen were quantitative (where possible), predictable, responsive to the issue, and linked to cause-and-effect relationships. Significant issues within the scope of the project decision are:

- Availability of recreation opportunities for guided and unguided recreationists.

- Economic opportunities and potential impacts on commercial outfitter/guide businesses.

- Conflicts within the commercial recreation industry.

- The issues are addressed in detail in the following sections: Recreation, Socioeconomics, Wilderness, and Wild and Scenic Rivers. Effects discussions focus on how each alternative responds to each significant issue. Some measures are repeated to display the different perspectives unique to each issue. The alternatives are rated against each other and the existing condition. 


\section{Environment and Effects}

\section{Introduction}

This analysis focuses on management of the recreation setting, by regulating the number of commercially guided groups using specific shoreline-based areas.

\section{Recreation}

This section describes recreation use and corresponding environmental and social conditions, and the potential environmental effects of the alternatives relative to the significant issues and resources of concern. This introduction provides a brief discussion of the analytical basis for comparing the different alternatives proposed in Chapter 2. Further details on recreation management concepts are found in Appendix F.

The analysis area is managed for multiple uses including recreation and wilderness resources. The Forest Service plays an important role in the changing and diverse economic environment of Southeast Alaska.

Some forest management activities result in a product that is relatively easy to measure. For example, a timber sale will produce a specific amount of timber; the construction of a fish pass will allow fish to access a measurable area of new habitat. It is more difficult to quantify the products of this project, which seeks to manage or enhance a wildland recreation experience. People have a wide range of expectations and values, and they have many different definitions of a satisfying recreational experience.

The challenge for the Forest Service is to respond to the public's desires for various kinds of settings and access. The Forest Service manages its lands to provide the public with a variety of recreation opportunities. We can influence the recreation experience by (a) providing different settings for recreation, ranging from wilderness to fully accessible trails and campgrounds; and (b) providing different facilities, such as cabins, boat moorings or roads, that make an area more accessible. This analysis focuses on management of the recreation setting, by regulating the number of commercially guided groups using specific shoreline-based areas.

Our goal is to provide opportunities for quality recreation experiences sought by both guided and unguided users that will not adversely affect forest resources. This will be accomplished by managing the analysis area so that each Use Area conforms to the Recreation Opportunity Spectrum (ROS) class setting indicators stated in the Forest Plan.

\section{The Forest Plan and the Recreation Opportunity Spectrum}

The Forest Plan provides the management framework for the recreation resource. Recreation and tourism management goals for the Tongass National Forest were developed through scientific review and in response to public comment.

The Forest Plan divides land into a series of areas, each of which is described by a land use designation (LUD). Each LUD has a management prescription that includes goals, objectives, and a desired future condition. LUDs also include standards and guidelines for managing recreation and the other forest resources. See Chapter 1 of this EIS for a discussion of the Land Use Designations.

The Forest Plan assesses recreation and tourism resources by assigning a range of appropriate recreation settings for each LUD using the ROS. These classes cover the full range, or spectrum, of recreation opportunities. Each LUD may include more 


\section{Environment and Effects 3}

than one ROS class. The ROS classes, from least developed to most developed, are listed below.

- Primitive

- Semi-Primitive Non-motorized

- Semi-Primitive Motorized

- Roaded Natural

- Roaded Modified

- Rural

- Urban

The ROS is an inventory tool used to describe the existing condition of recreation opportunities on the national forest. Guidelines for each ROS class describe the physical, social, and managerial setting components that affect the kind of experience forest visitors may expect. ROS guidelines in the Forest Plan are used to guide management activities in order to maintain or attain a defined range of recreation opportunities. ROS classifications used in the Forest Plan by LUD are displayed in Appendix F, Table F-1.

For each ROS class, the Forest Plan identifies setting indicators that describe the class. The indicators are:

- visual quality,

- access,

- remoteness,

- visitor management,

- on-site recreation development,

- social encounters, and

- visitor impacts.

The standards and guidelines for ROS classes are found in Appendix F, Table F-2.

\section{Recreation Carrying Capacity Analysis}

Recreation carrying capacity is the number of recreation users that can be accommodated in a given area without loss to the quality of the natural environment and/or the visitor experience. The Shoreline Based Recreation Carrying Capacity Analysis for the Admiralty Island National Monument, Hoonah, Juneau, and Sitka Ranger Districts 2001 (or Shoreline RCC) (USDA Forest Service 2001) documents an analysis that determined the recreation carrying capacity of the shoreline zone on the four districts. It is used as the basis for determining effects in this EIS. The shoreline zone extends from mean high tide to approximately one-half mile inland. Carrying capacity numbers were derived by determining the existing recreation experience, the number of groups at one time within each specific Use Area, considering the ROS class standards for social encounters indicated in the Forest Plan, local anchorages and topographic features. 


\section{Environment and Effects}

'Group'-may be one person recreating alone, or more than one person recreating together.

\section{'Groups-at-one- \\ time'-the number of groups that could recreate in a specific area without exceeding the number of group encounters specified by the ROS class.}

\section{Types of Recreation Carrying Capacity}

The following four types of recreation carrying capacity were considered in the Shoreline RCC. The social carrying capacity was found to be most limiting and was used to develop the recreation carrying capacity. For further details on the types of carrying capacity in the analysis area, see Appendix F.

- Physical - The amount of recreational use that can physically occur in a defined space without regard to the quality of the experience.

- Facility - The amount of recreational use that can occur within the constraints of existing facilities and improvements intended for visitor needs, such as parking lots, trails, docks, restrooms, and developed campgrounds.

- Ecological - The amount of recreational use that can occur without creating unacceptable impacts on the ecosystem.

- Social - The amount of recreational use that can occur without impairing social experiences. Social carrying capacity is the level of use beyond which social impacts exceed acceptable levels specified by evaluative standards (Shelby and Heberlein 1986). These standards are developed by: 1) establishing a known relationship between use level or other management parameters and social impacts. 2) Agreement among relevant groups about the type of recreation experience to be provided. 3) Agreement among relevant groups about appropriate levels of social impact. These numbers are not absolutes, but are the product of value judgments and science (Hendee et al 1970). The social capacity numbers can change over time as values and expectations change.

LUD and ROS standards and guidelines developed in the Forest Plan establish a relationship between management parameters and social impacts. Public scoping for the Forest Plan was used to determine the recreation wants and needs of different users. This public input was the basis for the range of ROS opportunities provided by different Land Use Designations. The appropriate level of social impacts was addressed in the Forest Plan by assigning a specific range for the number of encounters and size of group to the ROS classification guidelines and outfitter/guide special use permit administration.

Social carrying capacity was determined in terms of the daily number of groups in an area limited by the specified number of group encounters. Group encounters are an important part of the ROS classification used to define the expected recreation experience. The goal is to manage the area so that the number of group encounters per day is within Forest Plan ROS guidelines Table 3-1. These guidelines identify the number of encounters one may expect to experience in a day, maximum party size, and number of parties within sight or sound of dispersed campsites.

Three components are used in this analysis to manage social recreation carrying capacity for the analysis area: Use Areas, groups-at-one-time, and seasons of use.

Use Areas -The analysis area was subdivided into 38 Use Areas, 37 of which contain a shoreline zone and are included in this analysis. The other area contains the Juneau 


\section{Environment and Effects 3}

Icefields. See Figure 1-1 and Appendix A for the location and description of each Use Area.

Groups-at-one-time - The number of social encounters a group has while recreating is the basic social recreation component for the carrying capacity assessment. The Shoreline $R C C$ defines the recreation carrying capacity in terms of group days. These are determined by establishing the number of groups that can be in an area at one time. Recreation in the analysis area occurs primarily with groups of people rather than as individuals.

Table 3-1. Forest Plan Guidelines for Numbers of Social Group Encounters Per Day, by ROS Class

\begin{tabular}{lcc}
\hline & \multicolumn{2}{c}{ Number of Encounters } \\
\cline { 2 - 3 } ROS Class & Non-Wilderness & Wilderness \\
\hline Primitive & Less than 3 & Less than 3 \\
Semi-primitive & Less than $10^{*}$ & Less than 6 \\
Roaded Natural & Less than $20^{*}$ & Not applicable \\
Roaded Modified & Less than $20^{*}$ & Not applicable \\
Rural & No guideline & Not applicable \\
Urban & No guideline & Not applicable \\
\hline
\end{tabular}

*During at least $80 \%$ of the primary use season.

Encounters between individuals within a group are not counted because the people within the group typically choose to be with each other. Groups of people on boats traveling, sightseeing, fishing, or anchored on the saltwater were not considered to be national forest users for the purposes of this EIS and are not factored into the groups-at-one-time figure in the carrying capacity. Groups on the salt water at access points to the national forest were considered only in conjunction with their upland use. See Appendix F and the Shoreline $R C C$ for more information on methodology and data sources.

\section{Seasons}

In order to better manage for the different activities and use levels occurring at different times of the year, we identified recreation seasons to provide a temporal measure for recreation management and use. The seasons are displayed in Table 3-2.

The summer season is the busiest season of the year for both commercial and noncommercial recreation activities except hunting, which occurs primarily in spring and fall. The end of the spring season and the beginning of the fall season are known as 'shoulders' to the peak summer season; shoulder seasons are becoming increasingly busy for some activities, especially sightseeing. Because little or no commercial recreation use occurs during the winter season, no specific management allocations are proposed in this analysis for the winter season. 


\section{Environment and Effects}

Table 3-2. Dates and Number of Days of Seasonal Use

\begin{tabular}{lllc}
\hline Season & Starting Date & Ending Date & Length in Days \\
\hline Spring & April 20 & May 31 & 42 \\
Summer & June 1 & September 14 & 106 \\
Fall & September 15 & October 31 & 47 \\
Annual & April 20 & October 31 & 195 \\
\hline
\end{tabular}

\section{Affected Environment}

$\overline{\text { Recreation activities within }}$ and adjacent to the analysis area are strongly marine oriented.

\section{Communities}

The Shoreline analysis area lies within a land of spectacular scenery and abundant wildlife. The 17-million-acre Tongass National Forest encompasses about 80 percent of the land in Southeast Alaska, including most of the coastal rainforest.

Eleven communities are found within the project area: Juneau, Sitka, Port Alexander, Tenakee Springs, Pelican, Elfin Cove, Gustavus, Angoon, Hoonah, Haines, and Skagway. The highest levels of recreation use are centered near these communities. Types of recreation include tourism (including cruise ships and historical and cultural tourism), guided fishing and hunting, wildlife viewing (including whale watching), and many others. For community profiles related to recreation, see the Socioeconomics section later in this document.

\section{Recreation in the Analysis Area}

A thick, temperate rainforest dominates much of the analysis area. Rainfall ranges from 24 inches per year in Skagway to 72 inches in Juneau and more than 192 inches annually in Little Port Walter. Forested mountains rising from the saltwater provide unique and remote coastal recreation opportunities found in few areas in the world. Recreation enthusiasts are able to view a variety of natural landforms and wildlife such as glaciers, old-growth forests, humpback whales, spawning salmon, and bald eagles.

The large amount of land area in the Tongass National Forest provides a great diversity of recreation attractions and opportunities. Most of these recreation activities take place in, and depend on, settings that are primarily undeveloped and widely dispersed. Most of the area is wild and remote, with limited road access only locally available around the communities in the analysis area. Recreation facilities, primarily cabins and shelters, are limited. The analysis area is a place where people generally expect a remote and wildland experience. However, the surrounding saltwater, which is not currently managed by the Forest Service, allows for easy motorized boat and floatplane access for most of the analysis area, including Wilderness areas.

For a display of the types and amount of different recreation opportunity settings available within the analysis area, see Tables 3-3 and 3-4 for the acres and miles of shoreline in each ROS classification; see Appendix A for further discussion on and descriptions of individual Use Areas. 


\section{Environment and Effects 3}

Recreation activities in the analysis area cover a broad spectrum of uses, from hunting and fishing to wildlife watching, photography, and kayaking. The recreation activities within and adjacent to the analysis area are strongly marine oriented, with the national forest providing the background for both land and marine-based recreation. Almost all recreation activities occurring on the national forest are within $1 / 4$ to $1 / 2$ mile of the saltwater shoreline, or up streams accessed from the shoreline. People use kayaks, small motorboats, sailboats, charter boats, floatplanes, state ferries, and cruise ships to sightsee and recreate.

Recreationists take advantage of mostly remote, dispersed, wild-land-oriented activities such as sightseeing, hiking, backcountry camping, nature viewing, and photography. Wildlife is abundant in the analysis area, and people often see wildlife such as bald eagles, brown and black bears, and humpback whales, in a natural setting. Forest visitors also come to view and photograph tidewater glaciers and other dramatic coastal landscapes

Hunting (both guided and unguided) is the predominant recreation activity occurring along shorelines in the spring and fall during brown bear and deer hunting seasons. Brown bear hunting occurs predominantly along the shoreline and for distances up streams, while deer hunting may occur anywhere inland. Because the spring and fall hunts are in the 'shoulder' seasons (rather than the peak summer season), the number of other non-hunting recreationists in spring and fall is less than during the summer season. Many people also hunt and fish, both for sport and for subsistence. Nonresidents may visit the analysis area for the challenge of hunting bear, moose, and mountain goat, while many local residents count on the yearly hunting season to fill their freezers with deer or moose meat for the winter.

World-class sport fishing opportunities abound in both fresh and saltwater. Some people visit the Tongass specifically to experience salmon runs. Many local residents are also avid anglers, and they may rely on the annual fish runs to provide food as well.

People often participate in several different activities in one or more settings on any given trip, or they may find their desired experience in a single setting. Different activities lead to different numbers of people in a group, and to different amounts of time spent on the forest throughout the year. The following are four examples of how people recreate on the Tongass.

- The average unguided group includes three people in a skiff or small boat. They tend to recreate on a day use basis and usually are within the home range of a community.

- The average guided group is six people in a larger boat. They tend to recreate in the project area on a day use basis and may or may not be in the home range of a community.

(Continued after tables) 


\section{Environment and Effects}

Table 3-3: Amount (Acres) and Type of Recreation Opportunity (ROS) Available Within the Shoreline Zone, by Use Area

\begin{tabular}{|c|c|c|c|c|c|c|c|c|c|}
\hline Use Area & Primitive & $\begin{array}{c}\text { Semi- } \\
\text { Primitive } \\
\text { Non- } \\
\text { motorized }\end{array}$ & $\begin{array}{c}\text { Semi- } \\
\text { Primitive } \\
\text { Motorized }\end{array}$ & $\begin{array}{l}\text { Roaded } \\
\text { Natural }\end{array}$ & $\begin{array}{c}\text { Roaded } \\
\text { Modified }\end{array}$ & Rural & Urban & $\begin{array}{c}\text { Non- } \\
\text { National } \\
\text { Forest }\end{array}$ & $\begin{array}{c}\text { Total } \\
\text { Shoreline } \\
\text { Zone } \\
\text { in Acres }\end{array}$ \\
\hline 01-01 & 6,384 & 7,819 & 2,372 & 3,008 & 0 & 0 & 0 & 0 & 19,583 \\
\hline 01-02 & 0 & 838 & 1,534 & 0 & 0 & 0 & 0 & 515 & 2,887 \\
\hline 01-03 & 0 & 13,811 & 13,539 & 534 & 1,440 & 0 & 0 & 10,521 & 39,845 \\
\hline $01-04 \mathrm{~A}$ & 19,163 & 10,253 & 5,710 & 162 & 0 & 0 & 0 & 4,681 & 39,969 \\
\hline 01-04B & 0 & 3,483 & 1,440 & 6,133 & 0 & 119 & 10 & 21,390 & 32,575 \\
\hline $01-04 \mathrm{C}$ & 1,069 & 16,836 & 12,249 & 5,223 & 0 & 0 & 0 & 2,505 & 37,882 \\
\hline 01-04D & 0 & 406 & 520 & 523 & 10 & 0 & 0 & 0 & 1,459 \\
\hline $01-05 \mathrm{~A}$ & 0 & 1,998 & 1,734 & 1,608 & 0 & 0 & 0 & 741 & 6,081 \\
\hline 01-05B & 20,284 & 12,720 & 9,135 & 5,587 & 0 & 26 & 0 & 710 & 48,462 \\
\hline $01-05 \mathrm{C}$ & 3,626 & 17,796 & 13,513 & 32 & 224 & 0 & 0 & 12,425 & 47,616 \\
\hline 01-05D & 17,702 & 10,437 & 12,307 & 0 & 0 & 0 & 0 & 0 & 40,446 \\
\hline $01-05 E$ & 6,016 & 636 & 0 & 0 & 0 & 0 & 0 & 0 & 6,652 \\
\hline 04-01A & 29,410 & 0 & 408 & 0 & 0 & 0 & 0 & 0 & 29,818 \\
\hline 04-01B & 18,455 & 3,694 & 3,598 & 0 & 0 & 0 & 0 & 512 & 26,259 \\
\hline $04-02 \mathrm{~A}$ & 860 & 5,141 & 5,591 & 7,286 & 203 & 0 & 0 & 3,360 & 22,441 \\
\hline 04-02B & 79,284 & 2,100 & 1,525 & 0 & 0 & 0 & 0 & 0 & 82,909 \\
\hline 04-03 & 5,266 & 32,099 & 17,499 & 12,367 & 9,182 & 0 & 0 & 15,154 & 91,567 \\
\hline 04-04A & 0 & 5,431 & 2,043 & 0 & 5,983 & 0 & 0 & 52 & 13,509 \\
\hline 04-04B & 8,154 & 12,023 & 3,345 & 0 & 6,319 & 26 & 0 & 559 & 30,426 \\
\hline $04-04 \mathrm{C}$ & 895 & 973 & 811 & 0 & 0 & 0 & 0 & 554 & 3,233 \\
\hline 04-05 & 18,141 & 269 & 6,145 & 0 & 0 & 0 & 0 & 1,040 & 25,595 \\
\hline 04-06A & 18,219 & 0 & 0 & 0 & 0 & 0 & 0 & 29 & 18,248 \\
\hline 04-06B & 16,357 & 1,561 & 1,775 & 0 & 0 & 0 & 0 & 37 & 19,730 \\
\hline 04-07 & 21,142 & 0 & 3,716 & 0 & 0 & 0 & 0 & 24 & 24,882 \\
\hline 04-08 & 10,990 & 6,196 & 10,810 & 6,501 & 0 & 0 & 0 & 1,693 & 36,190 \\
\hline 04-09 & 16,856 & 11,307 & 5,433 & 0 & 0 & 0 & 0 & 447 & 34,044 \\
\hline $04-10 \mathrm{~A}$ & 68 & 239 & 1,693 & 0 & 0 & 0 & 0 & 48 & 2,048 \\
\hline $04-10 \mathrm{~B}$ & 7,835 & 4,316 & 4,196 & 4,708 & 0 & 0 & 0 & 1,851 & 22,906 \\
\hline $04-11$ & 33 & 11,391 & 20,545 & 0 & 8,408 & 0 & 0 & 16,013 & 56,390 \\
\hline $04-12$ & 4,183 & 10,190 & 20,673 & 59 & 10,012 & 0 & 0 & 8,065 & 53,182 \\
\hline $04-13$ & 20,892 & 10,406 & 8,414 & 353 & 10,258 & 0 & 0 & 2,178 & 52,501 \\
\hline $04-14$ & 27,802 & 887 & 1,082 & 0 & 0 & 102 & 0 & 302 & 30,175 \\
\hline $04-15$ & 36,069 & 12,508 & 17,312 & 0 & 0 & 133 & 0 & 2,932 & 68,954 \\
\hline $04-16$ A & 0 & 1,332 & 1,746 & 0 & 0 & 0 & 0 & 0 & 3,078 \\
\hline $04-16 \mathrm{~B}$ & 0 & 3,449 & 3,130 & 0 & 0 & 0 & 0 & 167 & 6,746 \\
\hline $04-16 \mathrm{C}$ & 4,843 & 2,664 & 2,144 & 118 & 0 & 0 & 0 & 476 & 10,245 \\
\hline 04-16D & 0 & 5,882 & 9,765 & 191 & 0 & 16 & 0 & 214 & 16,067 \\
\hline Total & 419,998 & 241,091 & 227,452 & 54,393 & 52,039 & 422 & 10 & 109,195 & $1,104,600$ \\
\hline
\end{tabular}


Table 3-4: Amount (Miles) and Type of Recreation Opportunity (ROS) Available Within the Shoreline Zone, by Use Area

\begin{tabular}{|c|c|c|c|c|c|c|c|c|c|}
\hline Use Area & Primitive & $\begin{array}{c}\text { Semi- } \\
\text { Primitive } \\
\text { Non- } \\
\text { motorized }\end{array}$ & $\begin{array}{c}\text { Semi- } \\
\text { Primitive } \\
\text { Motorized }\end{array}$ & $\begin{array}{l}\text { Roaded } \\
\text { Natural } \\
\end{array}$ & $\begin{array}{l}\text { Roaded } \\
\text { Modified }\end{array}$ & Rural & Urban & $\begin{array}{c}\text { Non- } \\
\text { National } \\
\text { Forest }\end{array}$ & Total Miles \\
\hline 01-01 & 34 & 10 & 16 & 23 & 0 & 0 & 0 & 0 & 83 \\
\hline 01-02 & 0 & 0 & 10 & 0 & 0 & 0 & 0 & 10 & 20 \\
\hline $01-03$ & 0 & 0 & 95 & 2 & 5 & 0 & 0 & 93 & 195 \\
\hline 01-04A & 176 & 37 & 47 & 0 & 0 & 0 & 0 & 24 & 284 \\
\hline 01-04B & 0 & 0 & 0 & 29 & 0 & 0 & 0 & 132 & 161 \\
\hline $01-04 \mathrm{C}$ & 2 & 23 & 108 & 30 & 0 & 0 & 0 & 18 & 181 \\
\hline 01-04D & 0 & 0 & 2 & 3 & 0 & 0 & 0 & 0 & 5 \\
\hline 01-05A & 0 & 1 & 9 & 10 & 0 & 0 & 0 & 4 & 24 \\
\hline 01-05B & 122 & 13 & 62 & 28 & 0 & 1 & 0 & 2 & 228 \\
\hline 01-05C & 16 & 16 & 108 & 1 & 0 & 0 & 0 & 74 & 215 \\
\hline 01-05D & 4 & 64 & 89 & 0 & 0 & 0 & 0 & 0 & 157 \\
\hline 01-05E & 17 & 5 & 0 & 0 & 0 & 0 & 0 & 0 & 22 \\
\hline 04-01A & 122 & 0 & 1 & 0 & 0 & 0 & 0 & 0 & 123 \\
\hline 04-01B & 87 & 0 & 48 & 0 & 0 & 0 & 0 & 6 & 141 \\
\hline $04-02 \mathrm{~A}$ & 2 & 0 & 78 & 171 & 2 & 0 & 0 & 26 & 279 \\
\hline 04-02B & 493 & 15 & 17 & 0 & 0 & 0 & 0 & 0 & 525 \\
\hline 04-03 & 25 & 56 & 154 & 141 & 41 & 0 & 0 & 170 & 587 \\
\hline 04-04A & 0 & 10 & 16 & 0 & 27 & 0 & 0 & 1 & 54 \\
\hline 04-04B & 41 & 48 & 30 & 0 & 38 & 0 & 0 & 5 & 162 \\
\hline $04-04 \mathrm{C}$ & 3 & 0 & 7 & 0 & 0 & 0 & 0 & 4 & 14 \\
\hline $04-05$ & 71 & 0 & 30 & 0 & 0 & 0 & 0 & 10 & 111 \\
\hline 04-06A & 124 & 0 & 0 & 0 & 0 & 0 & 0 & 1 & 125 \\
\hline 04-06B & 77 & 4 & 19 & 0 & 0 & 0 & 0 & 1 & 101 \\
\hline 04-07 & 117 & 0 & 16 & 0 & 0 & 0 & 0 & 1 & 134 \\
\hline 04-08 & 42 & 0 & 47 & 46 & 0 & 0 & 0 & 14 & 149 \\
\hline 04-09 & 79 & 59 & 36 & 0 & 0 & 0 & 0 & 2 & 176 \\
\hline $04-10 \mathrm{~A}$ & 0 & 0 & 9 & 0 & 0 & 0 & 0 & 0 & 9 \\
\hline $04-10 \mathrm{~B}$ & 27 & 0 & 31 & 15 & 0 & 0 & 0 & 11 & 84 \\
\hline $04-11$ & 0 & 3 & 150 & 0 & 32 & 0 & 0 & 82 & 267 \\
\hline 04-12 & 5 & 0 & 141 & 0 & 32 & 0 & 0 & 35 & 213 \\
\hline $04-13$ & 79 & 16 & 58 & 3 & 44 & 0 & 0 & 17 & 217 \\
\hline $04-14$ & 221 & 0 & 23 & 0 & 0 & 1 & 0 & 2 & 247 \\
\hline $04-15$ & 359 & 10 & 235 & 0 & 0 & 0 & 0 & 28 & 632 \\
\hline $04-16 \mathrm{~A}$ & 0 & 0 & 11 & 0 & 0 & 0 & 0 & 0 & 11 \\
\hline $04-16 B$ & 0 & 4 & 30 & 0 & 0 & 0 & 0 & 1 & 35 \\
\hline $04-16 \mathrm{C}$ & 17 & 0 & 18 & 1 & 0 & 0 & 0 & 3 & 39 \\
\hline $04-16 \mathrm{D}$ & 0 & 0 & 90 & 0 & 0 & 0 & 0 & 4 & 94 \\
\hline Total & 2,362 & 394 & 1,841 & 503 & 221 & 2 & 0 & 781 & 6,104 \\
\hline
\end{tabular}




\section{Environment and Effects}

- At one end of the activity spectrum, guided bear hunting consists of many groups at any given time, in small group sizes of one or two people. Hunters are dispersed across a large area of the shoreline, and they are near or within the shoreline zone for a relatively long period (from 5 to 10 days) during the spring and fall seasons. Their use is consumptive and is heavily influenced by regulations from state agencies.

- At the other end of the use spectrum, nature viewing tour boats consist of relatively few groups at any given time, with large group sizes (from 12 to 70 people) concentrated in the summer season. These tour groups are concentrated in relatively few areas of the forest shoreline; their use is short-term (usually two or three hours) and non-consumptive. Tour groups are primarily influenced by physical conditions allowing for large boat access and their route schedules.

Most outfitter/guides using the national forest access it by boats from saltwater. Some clients are dropped off on beaches, while others are also guided on land. Some operations focus on both fresh and saltwater fishing. Other outfitter/guides offer 'eco-tourism' packages that include sightseeing, short hikes, and wildlife viewing. The majority of charter boats in Southeast Alaska operate exclusively on saltwater for fishing or sightseeing without ever using the national forest.

Most recreation in the analysis area occurs as day trips originating from a nearby community (see Socioeconomics section). When people use the national forest for overnight trips, they generally use boats as base facilities and for sleeping, regardless of the type of activity. If boats are not used, remote tent camping is the norm.

There also are 17 Forest Service public recreation cabins accessible by saltwater within the analysis area. These cabins, except those receiving very low use, are only for non-commercial use.

\section{Access}

The Tongass National Forest is a forested archipelago. The marine waters flowing between islands serve as the 'road' to this national forest. Recreation access to the analysis area is primarily by motorized boats and floatplanes. Helicopters and wheeled planes are used to a lesser extent. A unique and challenging aspect of recreation management in the analysis area is that almost the entire shoreline, including designated Wilderness areas, is immediately adjacent to saltwater, which allows motorized boat traffic and floatplane access.

People can access the national forest and recreate on the saltwater in a number of ways including: canoe or kayak, personal motor or sailboat, charterboat, floatplane, state ferry, tour boat, or cruise ship. Most of the non-motorized access is in the form of kayaks, although kayaks are often transported to remote locations by motorized boats.

Because of the nature of the marine water access, recreation users tend to be highly mobile. Opportunities to encounter other parties are much greater for these highly mobile users than they would be if each party stayed in one location for the duration of its outing. Conversely, this mobility also allows people to avoid each other. Guided and unguided groups tend to disperse themselves geographically, with many 


\section{Environment and Effects 3}

In this analysis, we use an average commercial group size of six people. Average group size for noncommercial users is estimated at three people.

Commercial use is defined as any use of the national forest for which a fee is charged by the outfitter/guide. groups moving around to seek areas without other people. If a bay or anchorage appears crowded, a group may avoid entering that bay to access the uplands.

\section{Group Size}

Group size refers to the number of people recreating together and is an important factor in social interactions involved in recreation. Group size is an attribute of the recreation setting and is an important component in the expectations for a recreation experience. Numbers and types of social interactions with people other than one's own group significantly affect the quality of one's recreation experience.

Different groups respond differently to group size. For example, a group of kayakers camping on a beach may have a negative response to a large group of people from a tour boat on a sightseeing walk, but the large group from the tour boat may respond favorably to the kayakers.

There are a variety of group sizes of groups recreating in the analysis area. While groups generally have fewer than 12 people, larger groups, both guided and unguided, may also be present. In this analysis, we use an average commercial group size of six people. This figure is based upon the commercial use data reported from 1997 through 1999. For unguided users, average group size is estimated at three people, based on observations and professional judgment. Larger groups are often associated with commercially guided groups from tour boats. The largest guided group on the national forest reported in 1999 was 70 people from a tour boat. Most guided groups from tour boats range from 12 to 20 people in size.

The Forest Plan LUD and ROS provide guidelines for group size. (See Table F-2 in Appendix F). The Primitive ROS class generally has a maximum party size of 12 people. Semi-Primitive and Semi-Primitive Motorized ROS classes outside of Wilderness generally have a maximum party size of 20 people. The more developed ROS classes do not specify a maximum group size.

\section{Role of the Commercial Outfitter/Guide}

The Forest Service authorizes commercial use to make it easier for the public to visit national forests. Because of its remote and rugged nature, much of the Tongass requires good outdoor skills and/or specialized equipment for recreation. Many people do not have the skills or equipment but still want to try a particular activity or visit a remote area. Commercial outfitter/guides are important recreation partners with the Forest Service because they provide these services and opportunities to access the Tongass National Forest, where appropriate, for those people who cannot or do not desire to experience this area on their own. Commercial outfitters and guides also often provide outdoor education and promote an appreciation and understanding of the natural environment. Commercial outfitter/guides also can help maintain different classes of recreation settings by distributing people into underused areas.

Additionally, the Forest Service recognizes that the tourism industry is an important part of the economy of Southeast Alaska. Commercial operators provide services that add economic value to a recreation activity. 
Expectations often vary: what is remote to one may seem intolerably crowded to another.
Outfitter/guides operating in national forests are required to have a special use permit authorizing them to provide commercial services to the public. Commercial use is defined as any use of the national forest for which a fee is charged by the outfitter/guide. Types of activities provided by outfitter/guides on the project area include big game hunting, freshwater fishing, remote setting nature tours and wildlife viewing, and camping. They also provide gear, boats, and access to the National Forest. A variety of businesses have commercial use permits for the analysis area, ranging from small family-run operations, to larger corporations, to non-profit organizations. Local non-profit organizations focusing on education and social services, such as the Sitka Community Schools, Sheldon Jackson College, the University of Alaska Southeast, and Raven's Way Southeast Alaska Regional Health Center (SEARHC), constitute a large amount of the commercial use in some areas, especially around Sitka.

\section{Recreation Use Levels}

Precise information on recreation and tourism use on the national forest is generally not available. Except for locations where fees are collected or where people can be easily counted, most of the use data are based on long-term observations, anecdotal information, and professional estimates adjusted with quantitative indicators where available. Commercial special-uses permits and recreation cabins reservations are the primary sources of quantifiable data. Most data on non-commercial use is available from peripheral sources that are often not directly related to use on the analysis area.

The Shoreline Outfitter/Guide Analysis used the most current information available. Many of the recent use patterns for Alaska and the United States have been documented in the Draft Revised Chugach Land Management Plan (USDA Forest Service 2000) and are incorporated in this analysis. We considered preliminary information from the 2000 Southeast Alaska Commercial Recreation Survey Preliminary Report (Alaska Division of Community and Business Development 2001). We also noted observations from field personnel, the public, and the recreation industry.

\section{Resident and Non-resident Use}

In general, residents and non-residents are seeking the same recreation experience and types of activities. Because Alaska has a reputation for vastness, rugged beauty, and solitude, both residents and non-residents expect to find these qualities in the recreation settings. However, residents and non-residents may view the 'Alaskan experience' differently. Expectations often vary depending on a person's background; what is remote to someone from an urban area may seem intolerably crowded to a person who has grown up in rural Alaska.

The Forest Plan sets aside many areas for primitive or semi-primitive recreation. However, some people may have a higher expectation of wildness and solitude in certain areas than is provided for in the Plan. This may cause a perception of crowding, and result in a recreation experience that did not meet the visitor's expectations.

Alaskan residents place a high value on the quality and availability of outdoor recreation opportunities, and ready access to these plentiful recreation opportunities 


\section{Environment and Effects 3}

is a strong quality-of-life component. The estimated proportion of Alaskan adults who participate in outdoor activities is generally much higher than for the rest of the United States (Bowker in press). Resident recreation often involves the gathering of fish, game, berries, mushrooms, and other plant products.

Both residents and non-residents may use the services of outfitter/guides. However, non-residents use outfitter/guides more often, because they lack the local knowledge or necessary equipment. Non-resident brown bear hunters are required to use big game guides. Most guided sport fishing clients are non-residents (Southeast Marketing Council 1988).

Residents of the communities in the analysis area usually use their own boats and equipment to access the national forest. Personal boats are often smaller than charter boats used by non-residents. Consequently, resident group size is smaller than nonresident group size.

Both guided and unguided users who have selected areas closer to towns or popular areas should expect to see more people during their outings. These expectations correlate with ROS classifications and standards for number of encounters from the Forest Plan. Season and weather, along with location, may affect the number of encounters experienced or expected. For example, a person generally expects to run into fewer people in April than in July. Expectations for a recreation experience change during the more crowded summer season or during deer hunting season within the home range of a town or community.

Residents express more concerns than non-residents that some areas are too crowded or will be too crowded in the near future. There is often a strong local interest in maintaining the status quo. Residents of the smaller communities in the analysis area reported feeling crowding from residents of larger nearby communities. Residents also often view non-residents negatively when encountering them on the forest. On the other hand, non-residents are less likely to object to encounters with residents during their outing; seeing the lifestyles and activities of residents may be a positive and desirable part of non-residents recreation experience.

\section{Non-commercial Use}

Non-commercial use in this analysis is defined as unguided use. It is use for which no special use permit is necessary and for which no one receives financial remuneration or other gain for services provided on the national forest.

The amount of unguided use occurring in the analysis area is difficult to quantify because reliable data is largely unavailable. Some recreation demand information is available on national and state levels, but Southeast Alaska is less studied. The remote and extensive nature of the analysis area makes monitoring of unguided use very difficult and costly. There is easy motorized access over saltwater from a multitude of communities; access is usually by boat or floatplane, and access can occur along almost the entire coastline. There are only a few points, such as Tracy Arm, where access is restricted enough that monitoring of unguided use can be done effectively. Since good information is not available, surrogate information from several sources was used to estimate unguided use levels and trends.

Recreation use information for this analysis was taken from the Forest Plan. We considered general information available in the Forest Service's national 
Infrastructure (INFRA) database. The most recent INFRA data available are from 1998 and are used to project future recreation trends at a large scale. We analyzed the Recreational Information Management (RIM) national database for historical information. We also reviewed comments from the public and observations from the Southeast Alaska Wilderness Exploration Analysis and Discovery (SEAWEAD) organization. The Tongass National Forest began using a new information system this year called the National Visitor Use Monitoring System, which uses a sampling approach to generate forest-level use information with a statistically defined level of accuracy. Data are not yet available but this system should provide more accurate non-commercial recreation use information in the future.

We also considered state and regional population growth, state visitation information, Forest Service recreation cabin rentals, and national and state recreation use information displayed in the Draft Chugach Land and Resource Management Plan.

Alaska's population has continued to increase over the past several decades. U.S. Census Bureau information collected in 2000 shows that there has been a 14 percent increase in population statewide since 1990 , compared to a 13.1 percent increase for the nation as a whole. However, this growth is not spread evenly across Alaska and may not apply to Southeast Alaska or to communities in or adjacent to the analysis area.

Although state and regional population changes do not necessarily have a direct translation to non-commercial use, this information in conjunction with the other indicators can provide a reasonable approximation of increasing recreation activity levels. Some aspects of population change would create different effects. For example, it could be presumed that an increasing segment of middle to high income individuals would translate into more use of the national forest, as more disposable income is likely to provide the opportunity to access the national forest more frequently. Alaska's median household income is almost 80 percent above the median U.S. household income (although family size in Alaska is also slightly higher than that for the U.S. as a whole). In general, recreation locations that require boat or plane access can be considered as being frequented more often by those from higher income brackets because of the cost of getting to a destination. Areas around communities are more likely to be used by middle and lower income groups for all activities, but particularly those activities that include recreational food gathering, hiking, fishing, and hunting. Comments heard during community public scoping meetings suggest that this is likely to be true.

In general, visits to Alaska by all modes of access have increased by more than twofold over the period from 1985 to 1997 (Alaska Division of Community and Business Development 1998). Although visitation figures are for non-residents, and most of these are from large cruise ships, a general upward trend for resident use may also be inferred from this information. Additionally, following September 11, 2001, the Forest Service Washington Office predicted the likelihood of an increase in recreation use of national forests, as people may be inclined to cancel longdistance trips and trips requiring air travel.

Rentals of Forest Service cabins, generally restricted to non-commercial use only, are another indicator of general non-commercial recreation trends. There have been 


\section{Environment and Effects 3}

changes in the numbers of cabins on some districts, affecting overall cabin use numbers for the northern Tongass. Another complicating factor has been the inception of an off-site cabin rental system, which may cause a higher number of users to avoid registration, although it appears they may still use cabins without obtaining a permit. Therefore, the use of some cabins may appear to be declining, but in actuality a decline in the number of individuals paying for cabin use may be more correct. From 1994 to 2000, there were no large changes in the numbers of people or nights of cabin use. Use at cabins administered by the Hoonah Ranger District has remained steady over that time; Admiralty National Monument cabins and Juneau Ranger district cabins have increased, however. Two new cabins were added to the rental system during this time.

The Forest Plan indicates that Southeast Alaska residents account for the majority of recreation activity on the national forest (Forest Plan, Part 2, p. 3-433). Despite what appears to be an increasing trend for both commercial and non-commercial use, there are few locations where potential capacity seems to have been reached, due in part to the relatively sparse population of Alaska as a whole. During scoping, residents identified relatively few specific locations as being crowded. Ranger boat monitoring trips and field observations made by Forest Service personnel throughout the primary use season usually encounter few if any individuals or groups ashore. This indicates that unguided use has not approached capacity limits at most locations across the national forest. Exceptions include places such as Port Althorp near Hoonah and Fords Terror in Tracy Arm-Fords Terror Wilderness.

There are reports of some commercial use occurring illegally (without permits),

Total commercial use

in 1999 was 2,410

group days, which is

approximately 3

percent of the total

recreation capacity. which does not show up in the actual commercial use data; however, this illegal use is thought to be minor in relation to the overall amount of commercial use. There are also transporters, primarily floatplane businesses and some water taxi services, who only transport people to the national forest without filling the role of outfitter/guides. This type of use is classified as non-commercial in this analysis since it is in support of unguided recreationists.

Unguided recreation use is estimated to be far below the available recreation carrying capacity levels based on many indirect measures including Forest Plan projections, census information, recreational cabin use, Alaska Department of Fish and Game (ADF\&G) license and survey information, field observations, anecdotal information, and professional judgment. Only recreation use occurring on the national forest is included in these estimates, and they do not include use on the saltwater where most of the use and the reports of crowding are occurring. Unguided recreation use is not expected to increase at rates higher than the general population growth.

\section{Current Commercial Use Levels (1999 Data)}

Data on commercial use are much more complete and accurate than the data for noncommercial use. Outfitter/guides are required to report annual use as part of their permit terms. Historical use data were not collected or stored uniformly and are of limited use although some summary information exists. Use information from 1994 to 1999 shows a dramatic increase in the role of businesses supporting and promoting recreation use in the analysis area. The number of outfitter/guide clients has increased from approximately 1,550 in 1994 to 14,000 in 1999. 
The best information available for commercial recreation use in the analysis area is the 1999 commercial use data, which are based on use reports submitted by permitted outfitter/guides. The 1999 data are the most current complete data available and are used as a benchmark in this analysis. A summary of the 1999 commercial data showing use by season for each Use Area is displayed in Table 3-5. The total commercial use in 1999 was 2,410 group days, which is approximately 3 percent of the total recreation capacity.

Commercial recreation activities occurring in 1999 are displayed in Table 3-6, and in Figures 3-1, and Figure 3-2. Several observations can be made from the 1999 use information.

- Recreation use is not evenly distributed among the Use Areas. Some Use Areas experience much higher levels of use than other areas. However, this is not necessarily an indicator of crowding because of the differences in Use Area size.

- Most commercial recreation activity takes place in summer and corresponds with cruise ship activity, increased private boating by both residents and non-residents, and a general increase in resident recreation activity. Consequently, the summer months are likely the time in which perceptions of crowding and conflicts between different users will be most pronounced.

- The primary guided activities occurring on the national forest include big game hunting, fishing, hiking, camping, and sightseeing.

- Much of the guided activity in 1999 was related to either hunting or fishing. This implies a strong link between commercial recreation and healthy wildlife populations, especially when considering the role of wildlife viewing has in attracting visitors who engage in other activities such as camping and sightseeing.

- Hunting is the major guided activity in the spring and fall. While the summer months are the most crowded in terms of number of groups on the national forest, spring and fall bear guides and hunters may run into perceptions of crowding sooner than other users because this activity requires more space and solitude.

Several differences can also be observed when the number of groups and number of individuals participating in particular activities are examined (Figures 3-1 and 3-2). Guided fishing accounted for about one-quarter of the commercial use groups, and anglers made up almost one-fifth of the commercially guided individuals. Big game guides accounted for just over one-quarter of the groups, but these groups were small and only made up 8 percent of the individuals. Hikers involved in remote based nature tours included just about one-quarter of the guided groups but, because of their often large group sizes, made up 46 percent of the guided individuals. 
Table 3-5. Current (1999) Commercial Use in Group Days and Percentage of Total Carrying Capacity, By Season and Use Area

\begin{tabular}{|c|c|c|c|c|c|c|}
\hline Use Area & General Location & $\begin{array}{l}\text { Spring } \\
\text { Group Days }\end{array}$ & $\begin{array}{c}\text { Summer } \\
\text { Group Days }\end{array}$ & $\begin{array}{c}\text { Fall } \\
\text { Group Days }\end{array}$ & $\begin{array}{c}\text { Total Group } \\
\text { Days }\end{array}$ & $\begin{array}{c}\text { Total Recreation } \\
\text { Capacity Used } \\
\text { Commercially } \\
(\%)^{*} \\
\end{array}$ \\
\hline 01-01 & Skagway Area & 4 & 0 & 0 & 4 & 0.2 \\
\hline 01-02 & Haines Area & 0 & 0 & 0 & 0 & 0.0 \\
\hline $01-03$ & East Chilkats & 0 & 18 & 0 & 18 & 0.5 \\
\hline $01-04 \mathrm{~A}$ & Berners Bay & 4 & 25 & 0 & 29 & 1.5 \\
\hline 01-04B & N. Juneau Coast & 0 & 0 & 0 & 0 & 0.0 \\
\hline $01-04 C$ & Taku Inlet & 0 & 0 & 0 & 0 & 0.0 \\
\hline 01-04D & Slocum Inlet & 2 & 36 & 3 & 41 & 2.1 \\
\hline $01-05 \mathrm{~A}$ & Taku Harbor & 5 & 13 & 1 & 19 & 1.6 \\
\hline 01-05B & Port Snettisham & 0 & 80 & 0 & 80 & 2.1 \\
\hline 01-05C & Windham Bay & 11 & 52 & 2 & 65 & 1.3 \\
\hline 01-05D & Tracy Arm & 0 & 28 & 17 & 45 & 1.2 \\
\hline 01-05E & Ford's Terror & 2 & 17 & 0 & 19 & 3.2 \\
\hline 04-01A & Gut Bay, Baranof & 10 & 41 & 19 & 70 & 4.5 \\
\hline 04-01B & Port Armstrong & 14 & 35 & 7 & 56 & 4.1 \\
\hline $04-02 \mathrm{~A}$ & Redoubt Lake & 1 & 16 & 2 & 19 & 0.5 \\
\hline 04-02B & Whale Bay & 14 & 99 & 15 & 128 & 3.6 \\
\hline $04-03$ & Sitka Area & 35 & 35 & 26 & 96 & 1.2 \\
\hline $04-04 \mathrm{~A}$ & Lake Eva, Rodman B. & 17 & 90 & 9 & 116 & 7.4 \\
\hline 04-04B & Kelp Bay & 15 & 98 & 13 & 126 & 7.2 \\
\hline $04-04 \mathrm{C}$ & Baranof Warm Sp & 1 & 11 & 1 & 13 & 2.2 \\
\hline 04-05 & SW Admiralty & 20 & 57 & 40 & 117 & 10.0 \\
\hline 04-06A & Pybus Bay & 23 & 57 & 3 & 83 & 14.2 \\
\hline 04-06B & Eliza Harbor & 17 & 1 & 3 & 21 & 3.6 \\
\hline $04-07$ & Gambier Bay & 29 & 39 & 0 & 68 & 5.8 \\
\hline $04-08$ & NE Admiralty & 0 & 7 & 0 & 7 & 0.1 \\
\hline 04-09 & Seymour Canal & 16 & 3 & 0 & 19 & 1.0 \\
\hline $04-10 \mathrm{~A}$ & Greens Creek & 5 & 72 & 3 & 80 & 10.3 \\
\hline $04-10 \mathrm{~B}$ & NW Admiralty & 29 & 17 & 15 & 61 & 4.5 \\
\hline $04-11$ & Hoonah Area & 36 & 81 & 2 & 119 & 4.4 \\
\hline $04-12$ & Tenakee Inlet & 19 & 37 & 18 & 74 & 2.5 \\
\hline $04-13$ & Peril Straight & 78 & 47 & 38 & 163 & 5.2 \\
\hline $04-14$ & Slocum Arm & 29 & 3 & 1 & 33 & 2.1 \\
\hline $04-15$ & West Chichagof & 16 & 102 & 10 & 128 & 3.3 \\
\hline $04-16 \mathrm{~A}$ & Point Adolphus & 2 & 155 & 0 & 157 & 13.4 \\
\hline $04-16 B$ & North Chichagof & 11 & 97 & 2 & 110 & 9.4 \\
\hline $04-16 C$ & Idaho Inlet & 8 & 126 & 11 & 145 & 12.4 \\
\hline \multirow[t]{2}{*}{ 04-16D } & Port Althorp & 1 & 80 & 0 & 81 & 6.9 \\
\hline & Total & 474 & 1,675 & 261 & 2,410 & 2.9 \\
\hline
\end{tabular}

* Total recreation capacity in group days for analysis area is 81,315 . 


\section{Environment and Effects}

Table 3-6. Commercial Use (Group Days) by Activity, Season, and Percent of Total Use, 1999

\begin{tabular}{lccccc}
\hline \multicolumn{1}{c}{ Activity } & Spring & Summer & Fall & Total & Percentage \\
\hline Hunting & 392 & 14 & 212 & 618 & 26 \\
Camping & 19 & 285 & 1 & 305 & 13 \\
Fishing & 41 & 555 & 40 & 636 & 26 \\
Hiking & 14 & 547 & 4 & 565 & 23 \\
Sightseeing & 8 & 253 & 4 & 265 & 11 \\
Other & 0 & 21 & 0 & 21 & 1 \\
\hline Total & 474 & $\mathbf{1 , 6 7 5}$ & $\mathbf{2 6 1}$ & $\mathbf{2 , 4 1 0}$ & $\mathbf{1 0 0 \%}$ \\
\hline
\end{tabular}

Figure 3-1. Commercially Guided Individuals by Activity, 1999

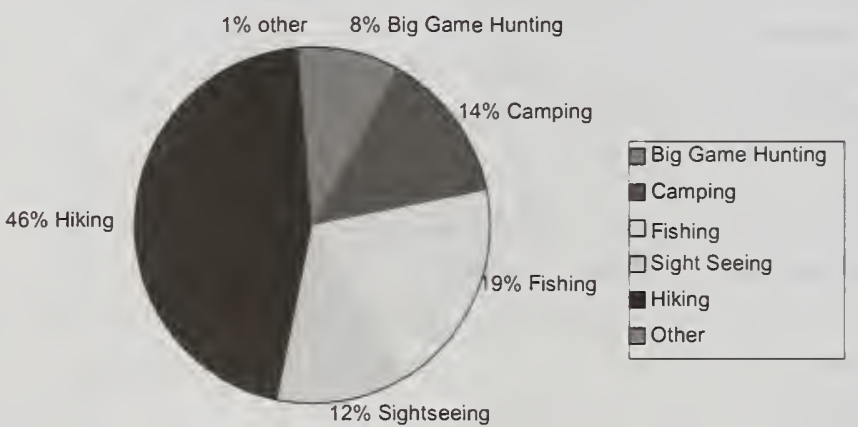

Other includes: picnicking, biking, and non-motorized freshwater boating

Figure 3-2. Commercially Guided Groups by Activity, 1999

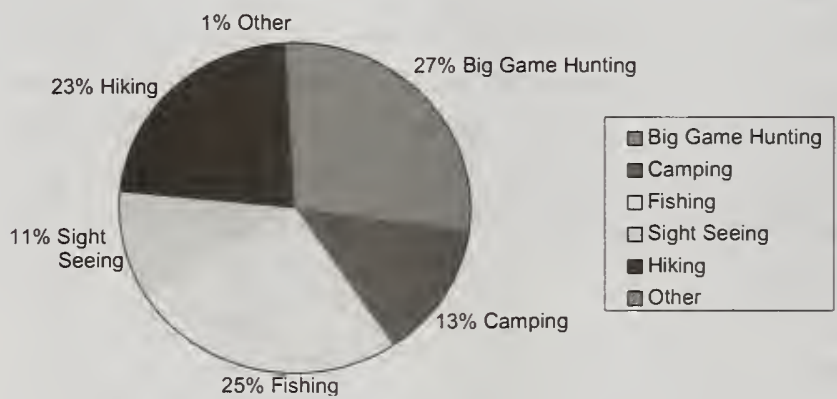

Other includes: picnicking, biking, and non-motorized freshwater boating 


\section{Environment and Effects}

\section{Heavy Use Areas}

Although the shoreline zone encompasses a large area of land, recreation opportunities are not available evenly along the shoreline. Several areas of the national forest have high use levels and/or limited capacity resulting in reports of a sense of crowding or the concern that it will soon occur. These areas are often referred to as 'hotspots' and have received special attention in this analysis. These hotspots are often in popular saltwater bays adjacent to the national forest. Although the Forest Service doesn't manage use on saltwater, commercial use on the national forest uplands may contribute to this sense of crowding in these areas.

There are approximately fifteen hotspots in the analysis area where there is an existing perception of crowding, although the amount of use, season of use, and the recreation activities vary between these sites. Some of these popular areas may seem crowded due to the relatively high levels of use while other areas seem crowded due to the presence of large groups, or due to large numbers of overnight campers.

The following are hotspots considered in the analysis: Eliza Harbor, Gambier Bay, Greens Creek, Brothers Islands, George Island, Idaho Inlet, Mud Bay, Pinta Cove, Point Adolphus, Mallard Bay, Williams Cove, Slocum Inlet, Kelp Bay, Lake Eva Trail, and Patterson Bay (See Appendix A).

\section{General Recreation Trends}

Projecting future recreation behavior assumes that future recreation preferences and levels of activity will remain much the same as they are now. Most visitors to the analysis area are from the United States, and national trends suggest increasing use levels in almost every form of recreation. The estimated proportion of Alaskan adults participating in various outdoor recreation activities is generally much higher than for the rest of the U.S. population. With a few exceptions, most recreation activities are predicted to increase at the same rate as the overall population growth in Alaska. However, as the population increases and its demographics change, recreation patterns are also subject to change. For example, national demographics point to the aging of the American population. As people age, they are less likely to participate in physically strenuous activities such as hunting or kayaking, and more likely to participate in activities such as walking, sightseeing, fish and wildlife viewing, bird watching, and fishing. Studies used in the Draft Chugach Land Management Plan Revision (USDA Forest Service 2000) estimate that visitors to Alaska will outnumber Alaskans participating in wildlife viewing by almost three to one by 2020.

Future use patterns are difficult to predict. However, sightseeing from saltwater currently is the largest recreation use in Southeast Alaska and it is likely that the analysis area will continue to be heavily used as a scenic resource by waterborne passengers, especially on cruise ships, in the future.

The Alaska Department of Labor has projected increases in cruise ship passengers of five to ten percent in 2002. The number of independent travelers is also increasing. Air passenger traffic into Juneau during the peak tourism months of June, July and August, has risen at an average rate of seven percent per year since 1991, although there is evidence that the rate is slowing in recent years (Colt et al. 2000). With the growth in the number of tourists has come a change in the characteristics of the typical Juneau tourist. Many of the new travelers are younger, more independent, 


\section{Environmental Consequences}

ROS Classes

* Primitive

* Semi-Primitive

Non-motorized

* Semi-Primitive

Motorized

* Roaded Natural

* Roaded Modified

* Rural

* Urban and interested in family activities, including those related to adventure and the environment (Alaska Dept. of Labor TRENDS website).

Changes in the economy that reduce disposable income may also reduce the number of non-residents who can afford to travel to the analysis area. However, effects of the economy and changing national demographics are not appropriately extrapolated down to the project level.

Future changes in technology may also affect use in the project area by making travel faster and easier. For example, jet boats and helicopters allow people to access areas once considered remote. In addition, increased fuel efficiency and speed of new boat engines allow smaller boat users to go farther from their communities in a single day.

The steady growth in the sale of non-resident fishing licenses, contrasted with steady numbers of resident licenses sold, indicates that non-residents' use of the national forest may be increasing faster than local use. This trend is consistent with the observations expressed in public meetings. Activities such as guided kayaking, hiking, and wildlife viewing and nature tours are also increasing on the analysis area.

Each alternative emphasizes a different mix of commercial allocations, settings, and measures to reduce user conflicts. Different interests and facets of recreation and tourism management are addressed across the range of alternatives. The following section describes the effects of alternatives on the different components of the recreation resource and issues. It includes a discussion of the effects on commercial and non-commercial recreation users and outfitter/guide businesses. Many of the same measures are repeated between issues to display the different perspectives unique to the issue.

\section{Effects on Guided and Unguided Recreationists (Issue 1)}

This issue focuses on the individual guided and unguided recreation user. Effects on both guided and unguided recreationists involve both qualitative and quantitative measures. Alternatives are compared for effects on recreation opportunities, commercial allocations, large group areas, provisions for solitude, and effects on unguided recreation use.

\section{Recreation Opportunities Available}

All the alternatives would provide the variety and type of recreation experience anticipated in the Forest Plan. Although no specific allocations would be made under Alternative 1, the commercial allocation is equal to the use authorized on a case-by-case basis up to 50 percent of the carrying capacity. The amount and type of recreation opportunities currently available on the national forest would be maintained. Commercial activities and allocations would not exceed Forest Plan standards and guidelines under any alternative. These include the commercial recreation use occurring within Wilderness and suitable Wild, Scenic, and Recreation River corridors.

The Forest Plan and Recreational Opportunity Spectrum (ROS) are used to define the types of settings that provide the recreation experience available on the national 
forest. The Use Area allocations were made within the carrying capacities and criteria of each ROS class for all action alternatives; therefore, none of the ROS classifications would change. The recreation settings available for each Use Area for all alternatives are displayed in Tables 3-3 and 3-4, earlier in this section. The amount and type of recreation setting available in each Use Area are presented in acres and miles of shoreline for each ROS class.

A variety of recreation experiences will be available in the analysis area: approximately 38 percent of the shoreline zone will provide primitive recreation experiences, while another 42 percent will provide semi-primitive recreation experiences at the levels of commercial use proposed by the alternatives.

A summary of the percent of the shoreline zone area available in each ROS class for all the alternatives is shown in Table 3-7. A summary of the percent of the miles of shoreline available in each ROS class for all the alternatives is shown in Table 3-8.

None of the alternatives would change the existing ROS class; however, some alternatives would increase the potential for a change in the ROS in the future. The alternatives vary in the maximum group size component of the social encounters setting indicator for the Semi-Primitive and Semi-Primitive Motorized ROS classes in the Old-Growth Habitat, LUD II, and Semi-Remote Recreation LUDs. These ROS classes generally limit the group size to 20 people. Three alternatives identify large group areas where group sizes larger than 20 people may occur. These areas can be quantified in terms of the number, size, and type of large group use. (See the Large Group Areas discussion, later in this section.)

\section{Table 3-7. Percent of the Shoreline Zone (Area) Available in Each Recreation Setting to Provide the Expected Recreation Experience (ROS), for All Alternatives}

\begin{tabular}{lc}
\hline ROS Class & Percent of Area \\
\hline Primitive & 38 \\
Semi-Primitive Non-Motorized & 22 \\
Semi-Primitive Motorized & 20 \\
Roaded Natural & 5 \\
Roaded Modified & 5 \\
Rural & $<1$ \\
Urban & $<1$ \\
Non National Forest & 10 \\
Total & $\mathbf{1 0 0 \%}$ \\
\hline
\end{tabular}




\section{Environment and Effects}

\section{Enclaves areas \\ where large groups \\ can occur on a \\ regular basis \\ throughout the \\ season.}

\section{Fifteen-percent}

areas-places

where large groups

can occur only on an occasional basis, for less than 15\% of the primary use season.
Table 3-8. Percent of Shoreline Miles Available in Each Recreation Setting to Provide the Expected Recreation Experience (ROS) for All Alternatives

\begin{tabular}{|c|c|}
\hline ROS Class & Percent of Miles \\
\hline Primitive & 39 \\
\hline Scmi-Primitive Non-Motorized & 6 \\
\hline Semi-Primitive Motorized & 30 \\
\hline Roaded Natural & 8 \\
\hline Roaded Modified & 4 \\
\hline Rural & $<1$ \\
\hline Urban & 0 \\
\hline Non National Forest & 13 \\
\hline Total & $100 \%$ \\
\hline
\end{tabular}

While group size is one of the several eriteria in determining ROS class, the group size specified in these large group areas is not considered a significant enough factor to change the ROS by itself in either the Fifteen-Perent or Enclave areas for this project. Large groups are limited in size to 75 people and only one large group can use an area at a time. In addition, large group use in Fifteen-Pereent areas is allowed only oecasionally and will not lead to a change in ROS. However in the Enclaves, if regularly oecurring large group use results in the need for more development and site hardening in the future, these changes combined with the large group size and increased use levels could result in change in the ROS to a more developed classification. The Forest Plan allows ROS changes in development up to the Rural ROS class in these Enclaves. These potential changes in ROS class can be quantified in acres.

Alternative 3 provides the most potential for changes to ROS elass. It identifies 7,949 acres in 40 Enclave areas that could change to a more developed ROS elass in the future. Alternative 5 has the second highest potential because it identifies 6,092 aeres in 33 Enclave areas. Alternative 4 has the third highest potential because it identifies 2,888 aeres in 15 Enclave areas. Alternatives 1 and 2 do not designate any areas for large group use and do not permit any commereial activities with group sizes larger than generally allowed by the Forest Plan, so they have the lowest potential for changes in ROS. See Tables 3-10, 3-11, and 3-12 for the areas and acreage designated for large group use by alternative.

\section{Commercial Allocation}

The total commereial allocation levels provide a measure of the amount of recreation use available to guided recreationists. They also provide a measure of the potential for crowding. The alternatives provide a range of total allocations and allocations by Use Area and scason. 


\section{Environment and Effects 3}

In gencral, perceptions of crowding may correlate to the amount of carrying capacity used. The more recreation use an area receives, by both guided and unguided recreationists, the greatcr the potential perception of crowding.

One measure of the potential impacts of commercial usc on unguided users is the proportion of a given Use Arca's total recreational capacity that is used by commercial operators. In general, ncgative impacts associated with crowding, such as encounters and noise, will vary directly with the proportion of recreational capacity that is actually uscd. Commercial use will add to the total usc of an area and therefore add to crowding and related ncgative effects.

Conversely, unguided use may also result in ncgative impacts to outfitter/guide clients and other unguided users, but these impacts are beyond the scope of this analysis.

The total allocations in all the action alternatives (Table 3-9) would excced the current (1999) level of guided recrcation usc of 2,410 group days. The highest total commercial allocation would be made under Alternative 3 , which would provide 40,658 group days. Alternative 5 would provide 18,495 group days, followed closely by Alternative 2 with 16,894 group days. The lowest total allocation would be Alternative 4 with 6,192 group-days. Altcrnative 1 makes no specific commercial allocation; commcrcial use is allowed on a case-by-casc basis and would range from the current use (1999) levels of 2,410 group days up to 50 percent of the carrying capacity $(40,658$ group days).

This analysis does not regulate or allocate recreation carrying capacity for unguideduse. Any unused commercial allocation would be available for unguided recreationists. Unguided recreation use levels are not precisely known. However, the large amount of available recreation carrying capacity in the analysis arca is expected to meet the demand for unguided recreation in all altcrnatives, considering projected limited increases in local resident populations and number of independent travelers visiting the analysis area.

If unguided use should increase to a point wherc, when combined with the commercial usc, it would rcach or excced the total carrying capacity of 81,316 group days, the recreation carrying capacity will be reviewed and either the ROS would be reclassified to less primitive classifications (allowing more encounters), or the unguided recreation use could also bc limited. This would be addressed in a separate analysis in the future.

Current commercial use levcls account for about 3 pcrcent of the total recrcation carrying capacity in the analysis area. See Table 3-5 for commcrcial usc and its relation to total capacity by Usc Area. However, certain Use Areas cxpcrience higher levels of commercial usc in some seasons. Point Adolphus (Use Arca 04-16), for example, had commercial usc levels of about 24 percent of summer capacity, and the nearby Idaho Inlet (04-16C) had commercial usc levels equivalent at about 20 percent of summer capacity. In addition to these areas, 12 other Usc Arcas experienced commercial usc levels between 10 and 20 percent of total capacity during at least one of the seasons in 1999. 


\section{Environment and Effects}

Table 3-9. Recreation Carrying Capacity and Commercial Allocation by Alternative

\begin{tabular}{|c|c|c|c|c|c|}
\hline & Alt. 1 & Alt. 2 & Alt. 3 & Alt. 4 & Alt. 5 \\
\hline $\begin{array}{l}\text { Total recreation carrying capacity in } \\
\text { group days }\end{array}$ & 81,315 & 81,315 & 81,315 & 81,315 & 81,315 \\
\hline $\begin{array}{l}\text { Total commercial allocation of } \\
\text { recreation carrying capacity in group } \\
\text { days }\end{array}$ & $\begin{array}{l}2,410 \text { to } \\
40,658^{*}\end{array}$ & 16,894 & 40,658 & 6,192 & 18,495 \\
\hline $\begin{array}{l}\text { Percent of total recreation capacity } \\
\text { allocated to commercial use }\end{array}$ & 3 to $50 \% *$ & $21 \%$ & $50 \%$ & $8 \%$ & $23 \%$ \\
\hline $\begin{array}{l}\text { Remaining total recreation carrying } \\
\text { capacity available after allocation in } \\
\text { group days. }\end{array}$ & NA & 64,421 & 40,657 & 75,123 & 62,820 \\
\hline $\begin{array}{l}\text { Percent of total recreation capacity } \\
\text { available after allocation. }\end{array}$ & NA & $79 \%$ & $50 \%$ & $92 \%$ & $77 \%$ \\
\hline
\end{tabular}

*Alternative 1 does not make a specific allocation; commercial use is authorized on a case-by-case basis and could range from current use levels $(2,410$ group days) to the maximum of $50 \%(40,658)$ allowed by the Forest Plan.

None of the alternatives provide total use levels below existing total use. However, some alternatives do limit commercial use in several Use Areas to levels lower than the current (1999) use during the spring and fall seasons. This could ease the sense of crowding in these areas. In Alternative 2, five seasonal Use Areas would reduce commercial use levels. Alternative 4 has one seasonal Use Area where existing commercial use would be reduced and Alternative 5 has four seasonal Use Areas where existing commercial use would be reduced. Alternative 3 would not reduce current commercial use.

\section{Number of People Using Commercial Services to Access the National Forest}

Not all people have the skills or equipment to participate in a particular activity or visit remote areas in the Tongass National Forest. Commercial outfitters and guides provide services that offer access, knowledge, and equipment to assist people who might otherwise be unable to recreate in their national forest. This analysis makes an estimate of the number of people who could use outfitter/guides to access the national forest if the full commercial allocation in each alternative were used. Assuming an average commercial group size of six people, Alternative 3 would allow up to 243,948 people to visit the national forest, followed by Alternative 5 with 110,970 people, Alternative 2 with 101,364 people, and Alternative 4 with 37,152 people over the three seasons. In comparison, approximately 14,000 visitors used commercial services in 1999.

\section{Large Group Areas}

The size of groups interacting in the national forest is an important part of the ROS social encounters setting indicator and has an effect on the perceptions of crowding and quality of the recreation experience.

The Forest Plan LUD and ROS provide guidelines for group size (See Table F-2 in Appendix F). Primitive ROS generally has a maximum party size of 12 people. Semi-Primitive and Semi-Primitive Motorized ROS generally have a maximum party 
size of 12 people in Wilderness areas and 20 people outside of Wilderness LUDs. This size can be occasionally exceeded in limited locations outside of Wilderness LUDs. For large group areas in this EIS, large groups are defined as groups that exceed the usual group size of 20 people in a Semi-Primitive ROS setting. The large group size ranges from 21 to 75 people in these large group areas.

Group size was an important component in potential conflicts between guided and unguided recreationists. Guided use generally occurs in larger group sizes. To address the concerns over large group size and the need for areas where these large groups can recreate, the IDT developed two types of large group areas with guidance from the Forest Plan. The first is an area where large groups can occur on a regular basis, referred to as Enclaves in this analysis. The second type is an area where large groups can occur only on an occasional basis, called Fifteen-Percent areas because their use is limited to 15 percent or less of the season. This equates to roughly one day per week. No large group areas were identified in Wilderness or areas with Primitive ROS.

Designating these large group areas not only identifies areas suitable for large group use but also notifies other recreationists that there is a high probability of encountering large groups in these areas. People can then avoid these areas if they are expecting a different recreation experience.

Large group areas are proposed in Alternatives 3, 4, and 5 (Tables 3-10, 3-11, and 312). Alternative 3 has 63 large group areas, with 40 Enclaves and 23 Fifteen-Percent areas. Alternative 5 has 47 large group areas, with 33 Enclaves and 14 FifteenPercent areas. Alternative 4 has 20 large group areas, with 15 Enclaves and 5 Fifteen-Percent areas. Alternatives 1 and 2 do not identify any areas for large group use. Site-specific information and mitigation measures for each area are provided in Appendix B. 
Table 3-10. Proposed Enclave Areas in Each Alternative *

\begin{tabular}{|c|c|c|c|c|c|c|}
\hline Type & Use Area & Name & Acres & Alt. 3 & Alt. 4 & Alt. 5 \\
\hline Enclave & 01-01 & Katzehin Falls & 7 & $\mathrm{X}$ & & $\mathrm{X}$ \\
\hline Enclave & 01-02 & Sullivan Mountain & 235 & $\mathrm{X}$ & & $X$ \\
\hline Enclave & 01-03 & Cant Cove & 38 & $\mathrm{X}$ & & \\
\hline Enclave & 01-03 & Homeshore & 39 & $\mathrm{X}$ & $\mathrm{X}$ & $\mathrm{X}$ \\
\hline Enclave & 01-03 & Howard Bay & 45 & $\mathrm{X}$ & & \\
\hline Enclave & $01-04 B$ & Shelter Island & 62 & $\mathrm{X}$ & & $\mathrm{X}$ \\
\hline Enclave & $01-04 \mathrm{C}$ & Sunny Cove & 66 & $\mathrm{X}$ & $X$ & $\mathrm{X}$ \\
\hline Enclave & $01-05 B$ & Mallard Cove & 96 & $\mathrm{X}$ & $\mathrm{X}$ & $\mathrm{X}$ \\
\hline Enclave & 01-05B & No Name Cove & 52 & $\mathrm{X}$ & $\mathrm{X}$ & $\mathrm{X}$ \\
\hline Enclave & $01-05 B$ & Point Anmer & 37 & $\mathrm{X}$ & & $\mathrm{X}$ \\
\hline Enclave & 01-05B & West Gilbert Bay & 12 & $\mathrm{X}$ & $\mathrm{X}$ & $\mathrm{X}$ \\
\hline Enclave & $01-05 C$ & Fanshaw & 48 & $\mathrm{X}$ & & $\mathrm{X}$ \\
\hline Enclave & $01-05 \mathrm{C}$ & North Windham Bay & 12 & $\mathrm{X}$ & & $\mathrm{X}$ \\
\hline Enclave & $01-05 \mathrm{C}$ & Port Houghton & 10 & $\mathrm{X}$ & $\mathrm{X}$ & $\mathrm{X}$ \\
\hline Enclave & $01-05 \mathrm{C}$ & Sand Bay & 59 & $\mathrm{X}$ & $\mathrm{X}$ & $\mathrm{X}$ \\
\hline Enclave & $04-03$ & Dry Pass & 476 & $\mathrm{X}$ & & \\
\hline Enclave & $04-03$ & Eagle River Road & 251 & $\mathrm{X}$ & & $\mathrm{X}$ \\
\hline Enclave & $04-03$ & Noxon & 203 & $\mathrm{X}$ & & \\
\hline Enclave & $04-04 \mathrm{~A}$ & Lake Eva Trail & 132 & $\mathrm{X}$ & $X$ & $X$ \\
\hline Enclave & 04-04A & Point Elizabeth & 72 & $\mathrm{X}$ & & $\mathrm{X}$ \\
\hline Enclave & $04-04 \mathrm{~A}$ & Rodman Bay & 252 & $\mathrm{x}$ & $\mathrm{X}$ & $\mathrm{X}$ \\
\hline Enclave & 04-04A & Saook Bay & 300 & $\mathrm{X}$ & & $\mathrm{X}$ \\
\hline Enclave & 04-04B & Hanus Bay & 278 & $\mathrm{X}$ & & $\mathrm{X}$ \\
\hline Enclave & 04-04B & Kelp Bay Middle Arm & 468 & $\mathrm{X}$ & $\mathrm{X}$ & $\mathrm{X}$ \\
\hline Enclave & 04-04B & Portage Arm & 424 & $\mathrm{X}$ & & \\
\hline Enclave & $04-08$ & Cordwood Creek & 48 & $\mathrm{X}$ & & $\mathrm{X}$ \\
\hline Enclave & $04-08$ & Fowler Creek & 42 & $\mathrm{X}$ & & $\mathrm{X}$ \\
\hline Enclave & $04-11$ & Eight Fathom Dock & 110 & $\mathrm{X}$ & & $\mathrm{X}$ \\
\hline Enclave & $04-11$ & Kennel Creek & 73 & $\mathrm{X}$ & & $\mathrm{X}$ \\
\hline Enclave & $04-11$ & Red Cliff Islands & 119 & $\mathrm{X}$ & & $\mathrm{X}$ \\
\hline Enclave & $04-11$ & Salt Lake Bay Dock & 91 & $\mathrm{X}$ & & $\mathrm{X}$ \\
\hline Enclave & $04-12$ & Corner Bay Road & 398 & $\mathrm{X}$ & $\mathrm{X}$ & $\mathrm{X}$ \\
\hline Enclave & $04-12$ & Crab Bay & 769 & $\mathrm{X}$ & & \\
\hline Enclave & $04-12$ & $\begin{array}{l}\text { West Tenakee (Goose } \\
\text { Flats) }\end{array}$ & 300 & $\mathrm{X}$ & $\mathrm{X}$ & $\mathrm{X}$ \\
\hline Enclave & $04-13$ & Poison Cove & 172 & $\mathrm{X}$ & & $\mathrm{X}$ \\
\hline Enclave & $04-13$ & Sitkoh Bay Road & 454 & $\mathrm{X}$ & $\mathrm{X}$ & $\mathrm{X}$ \\
\hline Enclave & $04-13$ & Ushk Bay & 106 & $\mathrm{X}$ & & \\
\hline Enclave & $04-15$ & Bohemia Basin & 1,043 & $\mathrm{X}$ & & $\mathrm{X}$ \\
\hline Enclave & $04-15$ & Three Hill Island & 362 & $\mathrm{X}$ & $\mathrm{X}$ & $\mathrm{X}$ \\
\hline \multirow[t]{2}{*}{ Enclave } & $04-16 \mathrm{D}$ & George Island & 188 & $\mathrm{X}$ & $\mathrm{X}$ & $\mathrm{X}$ \\
\hline & & Total Area in Enclaves & & $7,949 * *$ & 2888 & 6,092 \\
\hline
\end{tabular}

*Alternatives 1 and 2 do not designate Enclaves.

** Alternative 3 includes all of the Enclaves. 
Table 3-11. Proposed Fifteen-Percent Areas in Each Alternative *

\begin{tabular}{|c|c|c|c|c|c|c|}
\hline Type & Use Area & Name & Acres & Alt. 3 & Alt. 4 & Alt. 5 \\
\hline $15 \%$ & 01-04B & Douglas Island & 8 & $\mathrm{X}$ & & $\mathrm{X}$ \\
\hline $15 \%$ & 01-05B & Point Coke & 22 & $\mathrm{X}$ & & $\mathrm{X}$ \\
\hline $15 \%$ & $04-03$ & Fish Bay & 701 & $\mathrm{X}$ & & \\
\hline $15 \%$ & $04-03$ & Nadezhida Islands & 222 & $\mathrm{X}$ & & \\
\hline $15 \%$ & $04-04 \mathrm{~A}$ & Duffield & 223 & $\mathrm{X}$ & & \\
\hline $15 \%$ & 04-04B & Bourbon Creek Road & 346 & $\mathrm{X}$ & & \\
\hline $15 \%$ & 04-04B & Cosmos Cove & 426 & $\mathrm{X}$ & & $\mathrm{X}$ \\
\hline $15 \%$ & $04-11$ & Iyoukeen Peninsula & 314 & $\mathrm{X}$ & & $\mathrm{X}$ \\
\hline $15 \%$ & $04-11$ & Neka Bay North Bight & 347 & $\mathrm{X}$ & & $\mathrm{X}$ \\
\hline $15 \%$ & $04-11$ & Neka Bay South Bight & 457 & $\mathrm{X}$ & & $\mathrm{X}$ \\
\hline $15 \%$ & $04-12$ & Saltery Bay & 183 & $\mathrm{X}$ & & \\
\hline $15 \%$ & $04-12$ & Seal Bay & 351 & $X$ & & $\mathrm{X}$ \\
\hline $15 \%$ & $04-12$ & Trap Bay & 197 & $\mathrm{X}$ & & \\
\hline $15 \%$ & $04-13$ & Moser & 134 & $X$ & & \\
\hline $15 \%$ & $04-13$ & Nelson Falls & 113 & $\mathrm{X}$ & $\mathrm{X}$ & $\mathrm{X}$ \\
\hline $15 \%$ & $04-13$ & Nismeni Point & 144 & $\mathrm{X}$ & & $\mathrm{X}$ \\
\hline $15 \%$ & $04-13$ & Patterson Bay & 83 & $\mathrm{X}$ & $\mathrm{X}$ & $\mathrm{X}$ \\
\hline $15 \%$ & $04-13$ & Patterson Bay North Point & 81 & $\mathrm{X}$ & & \\
\hline $15 \%$ & $04-13$ & $\begin{array}{l}\text { Todd Road/Lindenburg } \\
\text { Head }\end{array}$ & 232 & $X$ & & $X$ \\
\hline $15 \%$ & $04-16 \mathrm{~A}$ & Damp Marker & 95 & $\mathrm{X}$ & $\mathrm{X}$ & $\mathrm{X}$ \\
\hline $15 \%$ & $04-16 \mathrm{~A}$ & Pinta Cove & 57 & $\mathrm{X}$ & $\mathrm{X}$ & $X$ \\
\hline $15 \%$ & $04-16 \mathrm{C}$ & Big Shaw Island & 57 & $\mathrm{X}$ & & \\
\hline $15 \%$ & $04-16 C$ & Fox Creek & 417 & $\mathrm{X}$ & $\mathrm{X}$ & $X$ \\
\hline & & \multicolumn{2}{|l|}{ Total Fifteen-Percent Acres } & $5,210 * *$ & 765 & 3,066 \\
\hline
\end{tabular}

*Alternatives 1 and 2 do not designate any Fifteen-Percent Areas.

** Alternative 3 includes all of the Fifteen -Percent Areas.

Table 3-12. Total Numbers and Acres of Large Group Areas

\begin{tabular}{|c|c|c|c|c|c|c|}
\hline \multirow[b]{2}{*}{ Alternative* } & \multicolumn{2}{|c|}{ Fifteen-percent areas } & \multicolumn{2}{|c|}{ Enclaves } & \multicolumn{2}{|c|}{$\begin{array}{c}\text { Total Large Group } \\
\text { Areas }\end{array}$} \\
\hline & Number & Acres & Number & Acres & Number & Acres \\
\hline 3 & 23 & 5,210 & 40 & 7,949 & 63 & 13,159 \\
\hline 4 & 5 & 765 & 15 & 2,888 & 20 & 3,653 \\
\hline 5 & 14 & 3,066 & 33 & 6,092 & 47 & 9,158 \\
\hline
\end{tabular}

* Alternatives 1 and 2 do not designate large group areas.

\section{Solitude}

Solitude and the 'Alaska' wildland experience are important components of the recreation experience for both guided and unguided recreationists. Solitude is a social experience measured in terms of the expected number of groups encountered 
None of the alternatives would have significant adverse effects on unguided recreationists over the analysis area as a whole, although individuals may not have the recreation experience they desire in all areas at all times. and the size of those groups. Opportunities for solitude are defined by the ROS and Forest Plan. Some people may have expectations of a recreation experience with fewer social encounters than provided by the Forest Plan and ROS.

The opportunity for solitude provided by each alternative is measured by the total commercial allocation and seasonal allocations for each Use Area. Higher commercial use allocations increase the potential for encounters and reduce the opportunities for solitude. Conversely, lower allocations result in fewer commercial groups using an area, thereby providing more opportunities for solitude.

Opportunities for solitude as defined by ROS and the Forest Plan would be available over most of the analysis area in all alternatives at levels anticipated by the Forest Plan (See Tables 3-3 and 3-4). However, some Use Areas would have fewer opportunities for solitude during the summer season.

Allocations are also made by season. To address concerns about the various recreation activities in the different seasons and the need for more solitude for certain activities, three distinct seasons for recreation use were defined: spring, summer, and fall (see Introduction to this section for season dates). The allocations of commercial use for each Use Area vary among these seasons for the project alternatives. In some alternatives, the allocations are limited to about 10 percent of the carrying capacity in the spring and/or fall seasons to reduce the number of group encounters and allow for more opportunities for solitude for both guided and unguided users.

Alternative 4 would provide the most opportunities for solitude because it provides the lowest commercial allocation and limits commercial use to about 10 percent of the carrying capacity in both the spring and fall seasons. Alternative 2 would provide the second most opportunities for solitude because it provides the second lowest allocation and limits commercial use to about 10 percent of the carrying capacity in both the spring and fall seasons. Alternative 5 would provide the third most opportunities for solitude because it provides the third lowest allocation and limits commercial use to about 10 percent of the carrying capacity in only the spring season. Alternative 3 provides the fewest opportunities for solitude because it provides the highest allocation and has no reductions in both the spring and fall seasons.

\section{Effects on Unguided Recreationists}

Unguided recreation use is not being regulated or allocated in this project. No use levels or restrictions are established for unguided recreationists. If total recreation use were to approach the total recreation carrying capacity in an Use Area in the future, both guided and unguided use would need to be managed and would be evaluated in a separate future analysis.

None of the alternatives would have significant adverse effects on unguided recreationists over the analysis area as a whole, although individuals may not have the recreation experience they desire in all areas at all times. Effects on the recreation experience for unguided recreationists from commercial use would come primarily from the commercial allocation levels which most influence the potential for perceptions of crowding and group size. Higher allocations allow a greater number of people, which increases the potential for crowding. The effects from all 


\section{Environment and Effects 3}

Large group areas were

identified in some

alternatives to reduce

potential social conflicts. of the alternatives would be within the range of those anticipated in the Forest Plan. The more primitive recreation experiences anticipated by the Forest Plan would be available in all alternatives. No significant effects on recreation sites are expected in any alternative since all use levels and activities comply with Forest Plan standards and guidelines and mitigation measures, which will reduce the effects.

The alternatives provide different ways to reduce the potential effects of commercial use on unguided recreationists. These include reduced allocations in Use Areas containing communities, closing or restricting specific areas to commercial use, restricting large group use to specific areas, limiting commercial use in certain seasons, and limitations and restrictions to commercial use to reduce social conflicts. The restrictions include the measures listed in Appendix C (Mitigation Measures) and measures found on the Use Area and Large Group Area cards (Appendices A and B).

To reduce potential conflicts between guided and unguided users, some alternatives have lower commercial allocations in Use Areas containing communities compared to Use Areas without communities. Alternatives 2 and 4 limit commercial use in all Use Areas containing communities. Alternative 5 has fewer limits on commercial use in some Use Areas containing communities. Alternative 3 would not limit commercial use in Use Areas containing communities.

Large group areas were identified in some alternatives to reduce potential social conflicts. Large group areas were not located in Use Areas containing communities or in areas with high local resident use in any alternative.

Other areas were closed or restricted to commercial use across all action alternatives.

Unguided use of streams has been highest during the fall when coho salmon are returning to natal streams. Mitigation measures are proposed for Alternatives 2, 4, and 5 to reduce conflicts between residents and non-residents on streams where high use has been observed. No more than two guided groups (participating in guided sport fishing activities) may be present at one time at Redoubt Lake and outlet stream, Salmon Lake, Nakwasina River, St. John the Baptist River and Fish Bay River from August 21 through the end of September.

Restrictions or mitigation measures to reduce potential conflicts between commercial and non-commercial recreation users vary by alternative. See Appendices A, B, and $\mathrm{C}$ for site-specific measures. In a relative ranking of the restrictions placed on commercial uses, Alternatives 4 and 5 would be the most restrictive, followed by Alternative 2 and then Alternative 3.

Forest Service administrative oversight over outfitter/guides and self-regulation within the commercial recreation industry tend to reduce potential impacts on noncommercial use. In general, there is higher degree of regulation on commercial recreation than on unguided use, resulting in potentially fewer resource and social impacts based on a given amount of use. There is also the incentive for commercial outfitter/guides to strive to provide a safe, high quality experience for the clients in order to continue in business.

In summary, Alternative 4 would have the least potential to affect unguided recreationists. It has the lowest commercial allocation and would provide the most opportunity for solitude. It limits commercial use to about 10 percent of capacity in 


\section{Environment and Effects}

Commercial use

allocation is the

primary way the

alternatives affect

the commercial

recreation industry. both the spring and fall season. Allocations in all Use Areas containing communities would be limited to less than 15 percent of capacity. It has the fewest large group areas of the alternatives that provide large group areas, and it has the most restrictions to commercial use to reduce social conflicts.

Alternative 2 would have the second lowest potential to have effects on unguided use because it has the second lowest commercial allocation and potential for crowding. It has reduced allocations (from 10 to 30 percent of the carrying capacity) in all Use Areas containing communities. It has restrictions on commercial use to reduce social conflicts. It would limit commercial use to 10 percent of capacity in both the spring and fall seasons. However, Alternative 2 does not designate any areas for large group use to reduce potential conflicts.

Alternative 5 would be similar to Alternative 2 in terms of effects on unguided recreationists. Alternative 5 would have a slightly higher potential of crowding unguided use, although the total allocation and allocations in Use Areas containing communities are similar between the two alternatives. Alternative 5 designates areas for large group use, which would reduce potential effects of large groups on unguided recreationists. It has reduced allocations (from 10 to 40 percent of the carrying capacity) for most Use Areas containing communities, and it has restrictions to commercial use to reduce social conflicts similar to Alternative 2. Commercial use allocations would be limited to ten percent during only the spring season under Alternative 5.

Alternative 3 has the most potential to have effects on unguided use. It has the highest allocations with the highest potential for a sense of crowding. It designates the most areas for large group use. It does not reduce commercial allocations in Use Areas that contain communities and does not limit commercial use in the spring and fall seasons. It has fewer restrictions on commercial use to reduce social conflicts than the other alternatives.

\section{Economic Opportunities and Potential Effects on Outfitter/Guide Businesses (Issue 2)}

Effects on the recreation industry involve both qualitative and quantitative measures. The following section begins with comparison of alternatives for the recreation capacity allocated for commercial use. The allocations are then compared to the 1999 commercial use levels. This section includes the allocations limiting current use; opportunities for industry to serve large groups; the types of recreation experience available to provide to the public; and the general effects of the alternatives on commercial operators.

\section{Recreation Capacity Available for Commercial Use}

The commercial use allocation is the primary way the alternatives affect the commercial recreation industry. Each action alternative makes an allocation of the recreation carrying capacity for commercial use. Alternative 1, the no-action alternative, does not make a specific commercial allocation, although commercial use could continue on a case-by-case basis up to 50 percent of the total recreation carrying capacity. Total commercial allocation, allocation by individual Use Area, and allocation by season vary among alternatives (Tables 2-1 through 2-3, Table 2-6, and Table 2-9, in Chapter 2). Alternative 3 would provide the highest total 


\section{Environment and Effects 3}

Estimates depict the relative differences among alternatives.

They are not meant to provide precise current or future market conditions. allocation with 40,658 group days, followed by Alternative 5 with 18,495 group days, Alternative 2 with 16,894 group days, and Alternative 4 with 6,192 group days (Table 3-9).

\section{Allocated Commercial Recreation Capacity Relative to Current (1999) Commercial Use}

To provide a comparison to the existing condition and a reference for the opportunities or impacts on commercial growth, the alternative commercial allocations are compared to current (1999) use levels for each Use Area and for the analysis area as a whole. The 1999 commercial use data are the most current and complete data available. The potential economic effects and future levels of recreation use are estimates, not absolute values. These estimates depict the relative differences among alternatives. They are not meant to provide precise current or future market conditions.

Recreation use in the analysis area is dynamic and fluctuates in the amount, time, and location of use. Current (1999) use may not be representative of future use levels.

If future use levels should reach the seasonal allocation in a Use Area, commercial use would be limited to the allocated level. Outfitter/guides may choose to go to other areas or if demand continues for an area, commercial use would be allocated to qualified individual outfitter/guides through a competitive special uses administrative process.

The action alternative allocations have the potential to create effects of crowding for guided use, or the use at these levels may limit the desirability of these areas, so commercial use could decline. The commercial allocations for each alternative are compared to 1999 use levels in Table 3-13 and in a bar chart format in Figures 3-3a through 3-31. 
Table 3-13. Total Commercial Allocation Compared to Current (1999) Commercial Use Levels, by Alternative

\begin{tabular}{|c|c|c|c|c|c|}
\hline & Alt. 1 & Alt. 2 & Alt. 3 & Alt. 4 & Alt. 5 \\
\hline $\begin{array}{l}\text { Total commercial allocation } \\
\text { available (Group Days) }\end{array}$ & $\begin{array}{r}2410 \text { to } \\
40,658\end{array}$ & 16,894 & 40,658 & 6,192 & 18,495 \\
\hline 1999 Commercial Use (group days) & 2,410 & 2,410 & 2,410 & 2,410 & 2,410 \\
\hline Currently unused allocation & $\begin{array}{r}\text { Up to } \\
38,248\end{array}$ & 14.484 & 38,248 & 3,782 & 16,085 \\
\hline $\begin{array}{l}\text { Percent of the alternative's total } \\
\text { commercial allocation used in } 1999\end{array}$ & NA & $14 \%$ & $6 \%$ & $39 \%$ & $13 \%$ \\
\hline
\end{tabular}

There is substantial room for industry growth beyond current (1999) use levels in all alternatives. Alternative 3 has the most currently unused total allocation available for growth, followed by Alternatives 5, 2, and 4 .

We evaluated the amount of current commercial use that would exceed allocated use in certain seasons to estimate the number of group-days that would be limited seasonally under each alternative (Table 3-14). We also analyzed this under a scenario projecting that commercial use would double over the next ten years (Table 3-15). Although current use levels are below the total allocation in all alternatives, current use levels in some Use Areas and seasons would exceed the allocation in some alternatives. The amount of use above the allocation would need to be dispersed to other areas with unused capacity. Use among qualified individual outfitter/guides in areas at capacity will be allocated through a competitive special use process. Unsuccessful outfitter/guides who were unwilling or unable to move operations to another area could lose business opportunities.

Table 3-14. Current (1999) Commercial Use Beyond Total Seasonal Allocation Levels in Some Use Areas, by Alternative, in Group Days

\begin{tabular}{cccc}
\hline Alternative & $\begin{array}{c}\text { Spring Use } \\
\text { Beyond Allocation }\end{array}$ & $\begin{array}{c}\text { Summer Use } \\
\text { Beyond Allocation }\end{array}$ & $\begin{array}{c}\text { Fall Use } \\
\text { Beyond Allocation }\end{array}$ \\
\hline 1 & 0 & 0 & 0 \\
2 & 29 & 0 & 12 \\
3 & 0 & 0 & 0 \\
4 & 4 & 0 & 0 \\
5 & 29 & 0 & 0 \\
\hline
\end{tabular}


Table 3-15. Projected Future Use Levels (Assuming a Doubling of Current Commercial Use) Beyond Total Seasonal Allocation Levels in Some Use Areas, by Alternative, In Group Days

\begin{tabular}{cccc}
\hline Alternative & $\begin{array}{c}\text { Spring Use } \\
\text { Beyond Allocation }\end{array}$ & $\begin{array}{c}\text { Summer Use } \\
\text { Beyond Allocation }\end{array}$ & $\begin{array}{c}\text { Fall Use } \\
\text { Beyond Allocation }\end{array}$ \\
\hline 1 & 0 & 0 & 0 \\
2 & 257 & 280 & 53 \\
3 & 0 & 0 & 0 \\
4 & 150 & 332 & 17 \\
5 & 257 & 167 & 9 \\
\hline
\end{tabular}

Most commercial use occurs in summer, and the allocations are higher in the summer to accommodate that use. Less use is allocated during the spring and/or fall seasons in some alternatives to provide more opportunities for solitude. The allocation in some of the Use Areas would be less than current use, and some outfitter/guides would need to move their operations to Use Areas with unused capacity. In Alternatives 2 and 5, 29 group-days of use would be displaced to other areas in the spring assuming current use levels. In Alternative 4,4 group-days would be displaced in the spring. Alternative 2 would displace 4 group-days in the fall. No current use would be displaced under Alternatives 1 and 3 .

Commercial recreation use is expected to continue to grow. Table 3-15 displays a projected future commercial use level that is double the current use. Doubling current use levels approximates a seven percent growth rate over the next ten years. Tourism growth rates have matched or exceeded this rate throughout the past decade (Schroeder et al. in press), although preliminary data indicate that growth may have slowed in the past few years (Colt et al. 2000).

Projected commercial use would be below the total allocation levels in all alternatives for the analysis area as a whole. However, projected use levels would exceed allocations in some Use Areas in all seasons in some alternatives.
This projected commercial use would also be below the total allocation levels in all alternatives for the analysis area as a whole. However, projected use levels would exceed allocations in some Use Areas in all seasons in some alternatives. In these areas, commercial use would become limited or displaced to other areas. In Alternatives 2 and 5, some 257 group-days would be displaced to other Use Areas in the spring season under the double-current-use scenario. In Alternative 4, there would be 150 group-days displaced during the spring. During the summer, Alternative 2 would have 280 group-days beyond the allocation in some Use Areas, Alternative 4 would have 332 group-days, and Alternative 5 would have 167 group days. In the fall, Alternative 2 would have 53 days over the allocation in some Use Areas, Alternative 4 would have 17, and Alternative 5 would have 9 group days over the allocation. No projected future use would be above the allocations in Alternatives 1 or 3 .

The amount of commercial use that is limited in individual Use Areas would be small relative to the total commercial use, even under the projected future growth assumption for all alternatives. Where commercial use reaches the allocation in specific Use Areas, there would be unused capacity available elsewhere in the analysis area. However, these alternate locations may not be as desirable. Alternate 
locations may not be as accessible or provide the same activities or quality of recreation experience. Consequently, the degree to which the displaced use affects individual outfitter/guides would depend on how well Use Areas can be substituted and the flexibility of outfitter/guide operations.

Economic activities and incomes can vary considerably between outfitter/guide operations. Certain locations are best suited for certain activities, such as wildlife viewing in areas where wildlife is abundant. Crowding even if an area is not used to full capacity may compromise the value of recreation activities. It is difficult to measure these effects numerically because of a lack of necessary data and accepted valuation techniques.

\section{Use Areas Currently At, Near, or Over Seasonal Allocation}

Commercial allocations may limit current use, future entry, and future growth of outfitter/guide operations in Alternatives 2, 4, and 5 in some seasons. Current (1999) seasonal commercial use is approaching (within 20 percent), at, or exceeding the seasonal allocation for some Use Areas (see Tables 3-16 through 3-18).

Alternative 2 has ten seasonal Use Areas where current use is at or near the seasonal allocation, followed by Alternative 5 with eight and Alternative 4 with four Use Areas where current use is at or near the seasonal allocation. Alternative 3 has no seasonal Use Areas at or near the allocation, and Alternative 1 does not make a specific capacity allocation.

Table 3-16. Alternative 2 Use Areas with Current Use Approaching (within $\mathbf{2 0 \%}$ ), At, or Over the Allocation, by Season

\begin{tabular}{|c|c|c|c|c|}
\hline Use Area & General Location & Spring & Summer & Fall \\
\hline 04-05 & SW Admiralty & Approaching & & Over \\
\hline 04-06a & Pybus Bay & Over & & \\
\hline 04-06B & Eliza Harbor & Over & & \\
\hline 04-07 & Gambier Bay & Over & & \\
\hline $04-10 \mathrm{~B}$ & NW Admiralty & At & & \\
\hline $04-13$ & Peril Strait & Over & & \\
\hline 04-14 & Slocum Arm & Approaching & & \\
\hline $04-16 A$ & Point Adolphus & & Approaching & \\
\hline \multirow[t]{3}{*}{$04-16 C$} & Idaho Inlet & & Approaching & \\
\hline & Seasonal Total & 7 & 2 & 1 \\
\hline & Grand Total $=10 \mathrm{Se}$ & al Use Areas & & \\
\hline
\end{tabular}


Table 3-17. Alternative 4 Use Areas with Current Use Approaching (within $20 \%$ ), At, or Over the Allocation, by Season

\begin{tabular}{clccc}
\hline Use Area & General Location & Spring & Summer & Fall \\
\hline $04-06 \mathrm{a}$ & Pybus Bay & Over & & \\
$04-06 \mathrm{~B}$ & Eliza Harbor & Approaching & & \\
$04-16 \mathrm{~A}$ & Point Adolphus & & Approaching & \\
$04-16 \mathrm{C}$ & Idaho Inlet & Approaching & 0 \\
& Seasonal Total & 2 & 2 & \\
\hline \multicolumn{5}{l}{ Grand Total $=$ 4 Seasonal Use Areas } \\
\hline
\end{tabular}

Table 3-18. Alternative 5 Use Areas with Current Use Approaching (within $\mathbf{2 0 \%}$ ), At, or Over the Allocation, by Season

\begin{tabular}{llccc}
\hline Use Area & General Location & Spring & Summer & Fall \\
\hline $04-05$ & SW Admiralty & Approaching & & \\
$04-06 a$ & Pybus Bay & Over & & \\
$04-06 \mathrm{~B}$ & Eliza Harbor & Over & & \\
$04-07$ & Gambier Bay & Over & & \\
$04-10 \mathrm{~B}$ & NW Admiralty & At & & \\
$04-13$ & Peril Strait & Over & & \\
$04-14$ & Slocum Arm & Approaching & Approaching \\
$04-16 \mathrm{C}$ & Idaho Inlet & 7 & 1 & 0 \\
\hline & Seasonal Total & 7 & \\
\hline
\end{tabular}

None of the

alternatives would

limit current use in

the analysis area as a

whole. Use would

be limited in some

Use Areas under

some alternatives

where seasonal

allocations would be

less than current use.
The effects of the alternative allocations on commercial operations are most easily distinguished by Use Area and season. Figures 3-3a through 3-31 display these effects visually in bar-chart format.

In summary, none of the alternatives would limit current use in the analysis area as whole. Use would be limited in some Use Areas where current use is over the seasonal allocation. The number of Use Areas with seasonal limits would increase in the future as tourism grows. Alternative 3 would provide the highest use levels and would not limit current use in any season in any Use Area. Alternatives 2 and 5 would have the next highest allocations and would limit current use in some Use Areas in some seasons. Alternative 2 would limit current use in four Use Areas during the spring, none in the summer, and one in the fall. Alternative 5 would be limit use in four Use Areas during the spring, but none in the summer or the fall. Alternative 4 would have the lowest allocation; it would limit use in one Use Area in the spring, but none in the summer or fall. If commercial use should continue to grow at historical rates, all the action alternatives except Alternative 3 would have seasonal limits in some Use Areas. 


\section{Environment and Effects}

Figure 3-3a. Alternative 2, Comparison of the Proposed Commercial Allocation and Current (1999) Use Levels by Use Area During the Spring Season

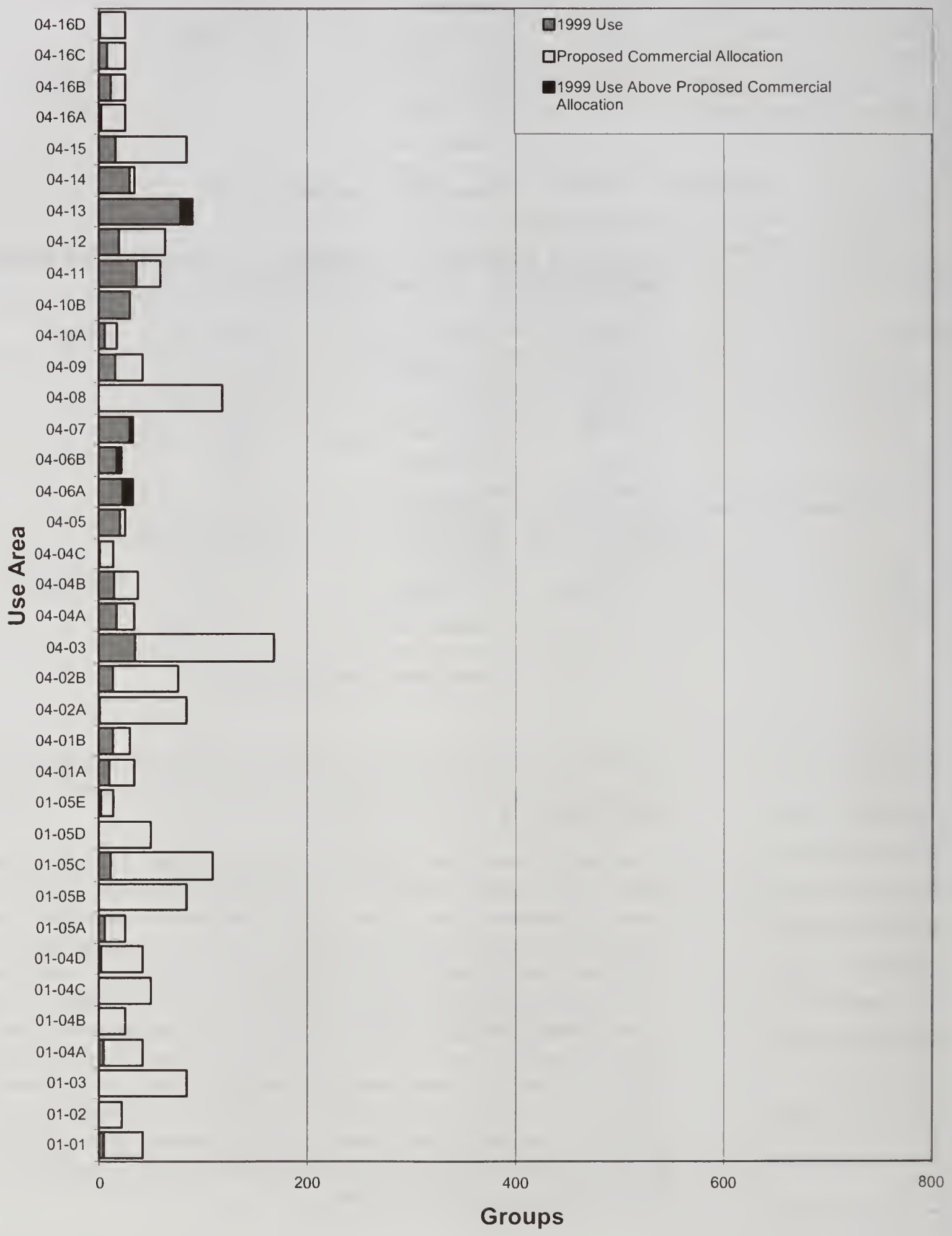




\section{Environment and Effects}

Figure 3-3b. Alternative 2, Comparison of the Proposed Commercial Allocation and Current (1999) Use Levels by Use Area During the Summer Season

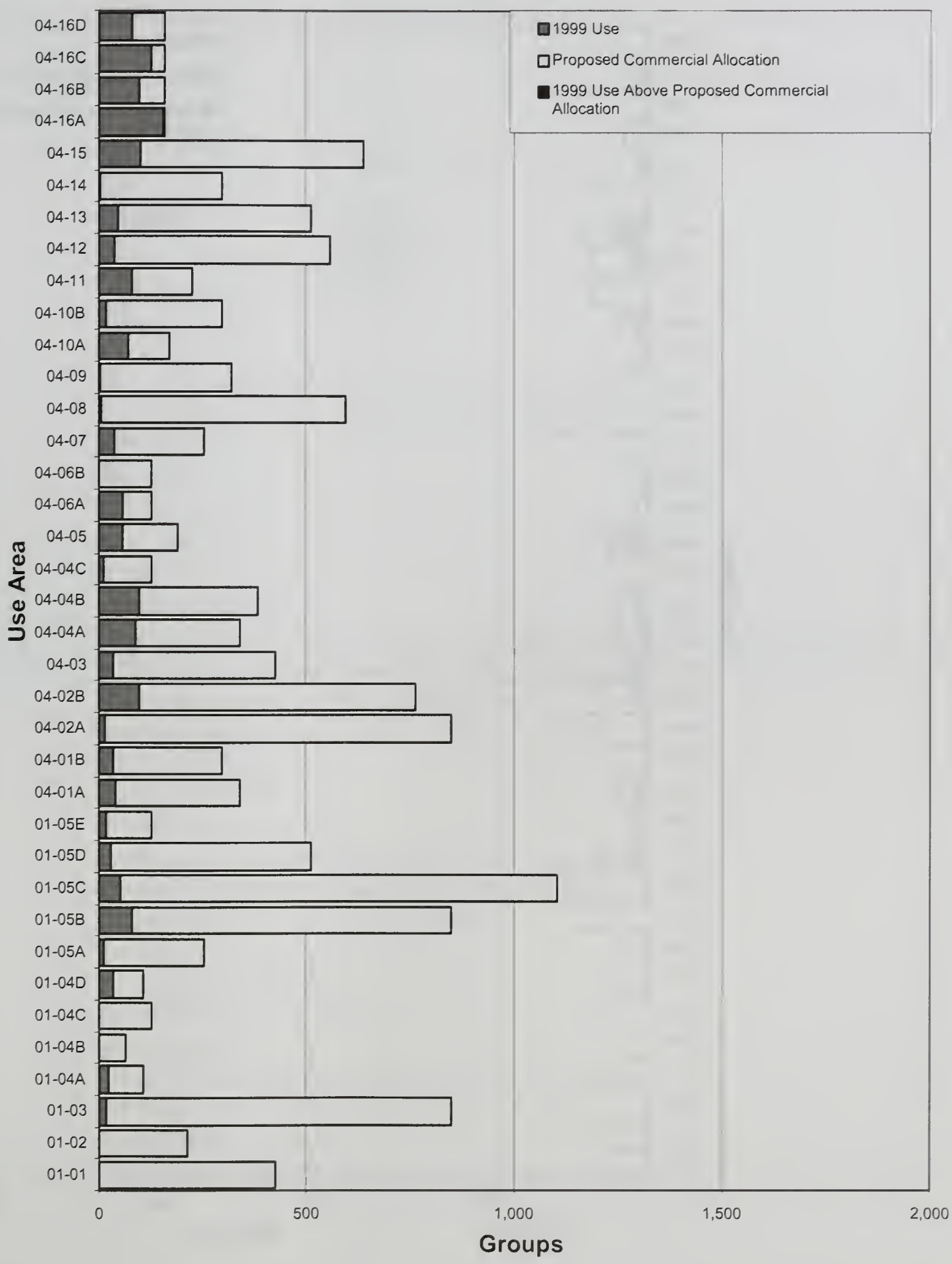


Figure 3-3c. Alternative 2, Comparison of the Proposed Commercial Allocation and Current (1999) Use Level by Use Area During the Fall Season

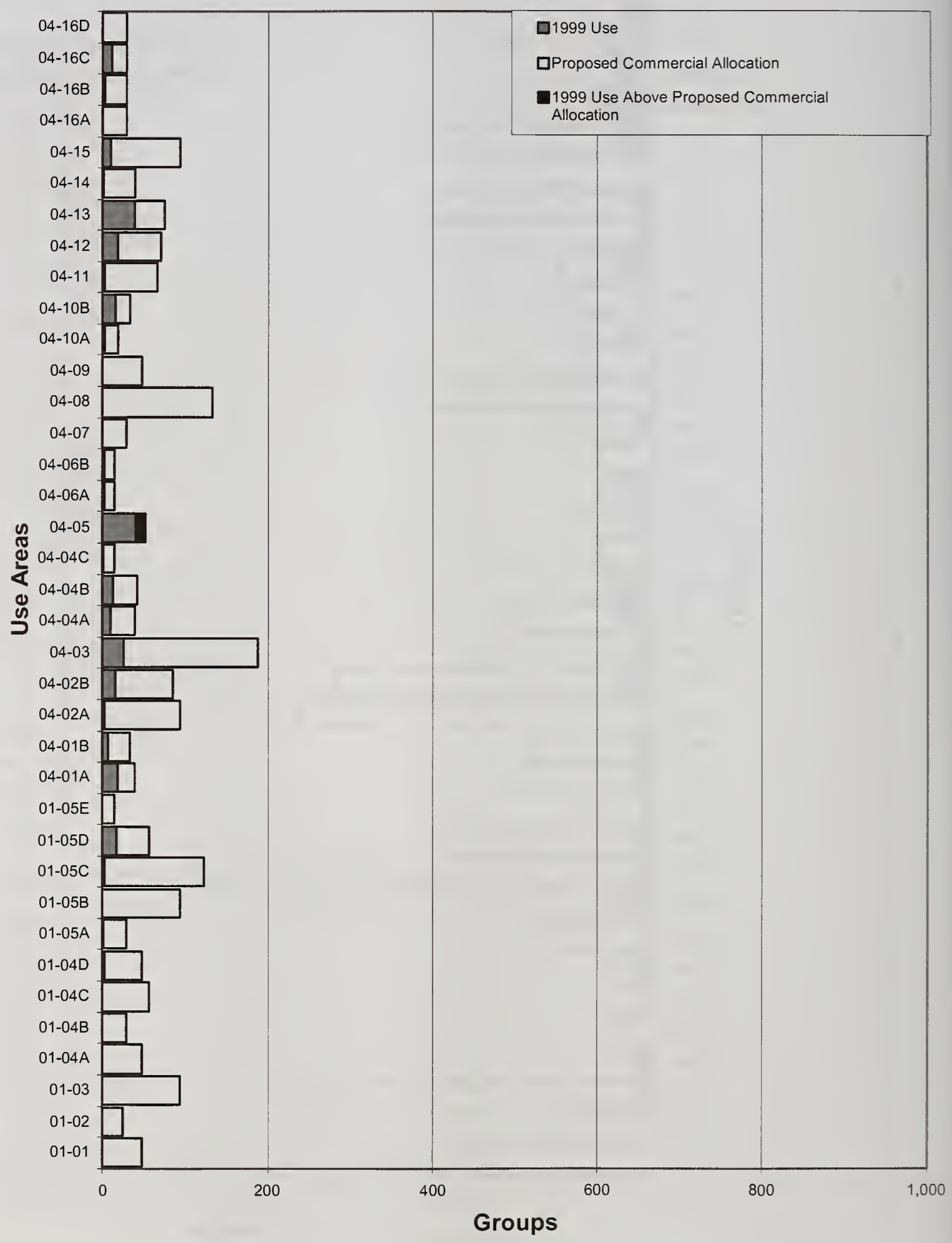




\section{Environment and Effects}

Figure 3-3d. Alternative 3, Comparison of the Proposed Commercial Allocation and Current (1999) Use Levels by Use Area During the Spring Season

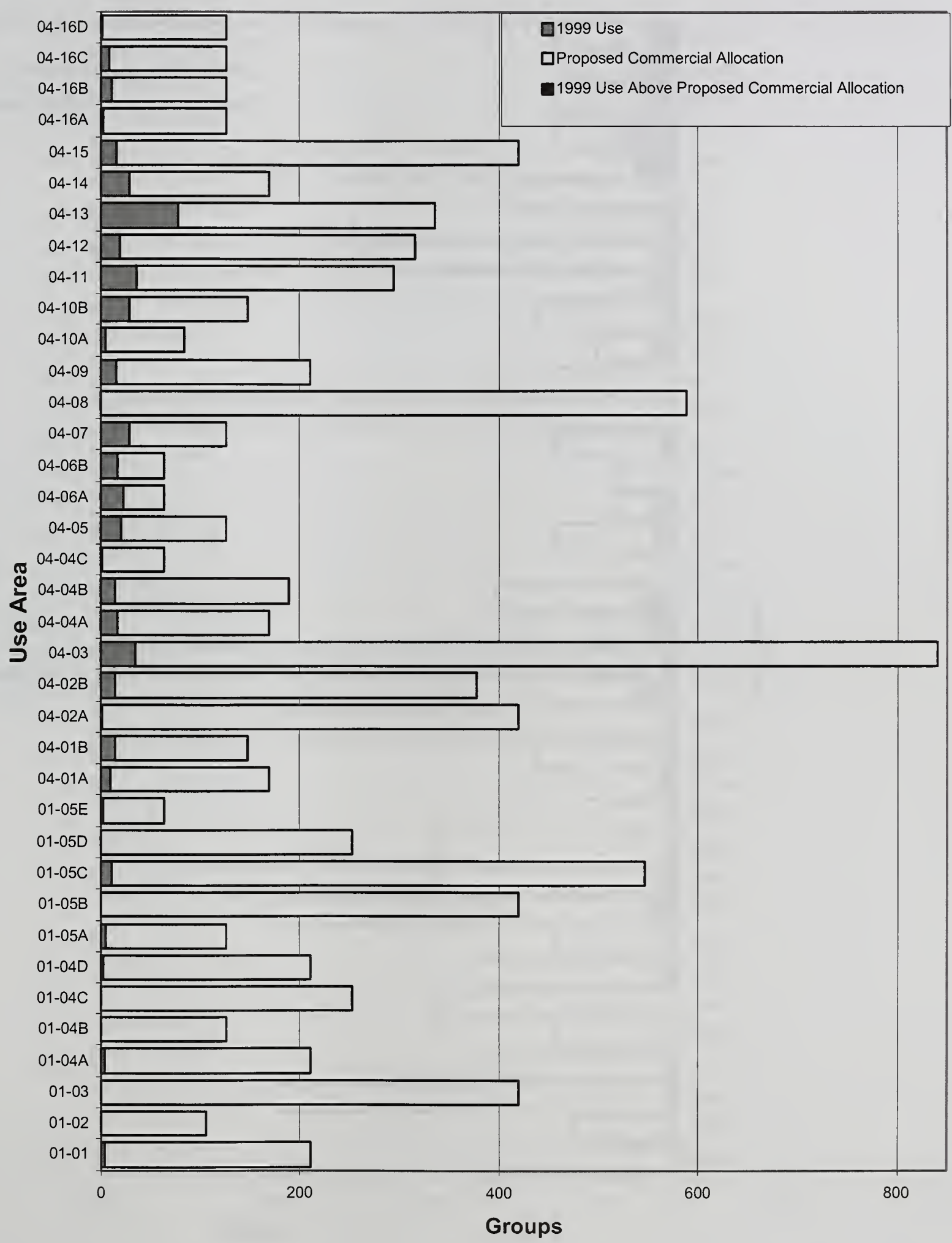




\section{Environment and Effects}

Figure 3-3e. Alternative 3, Comparison of the Proposed Commercial Allocation and Current (1999) Use Levels by Use Area During the Summer Season

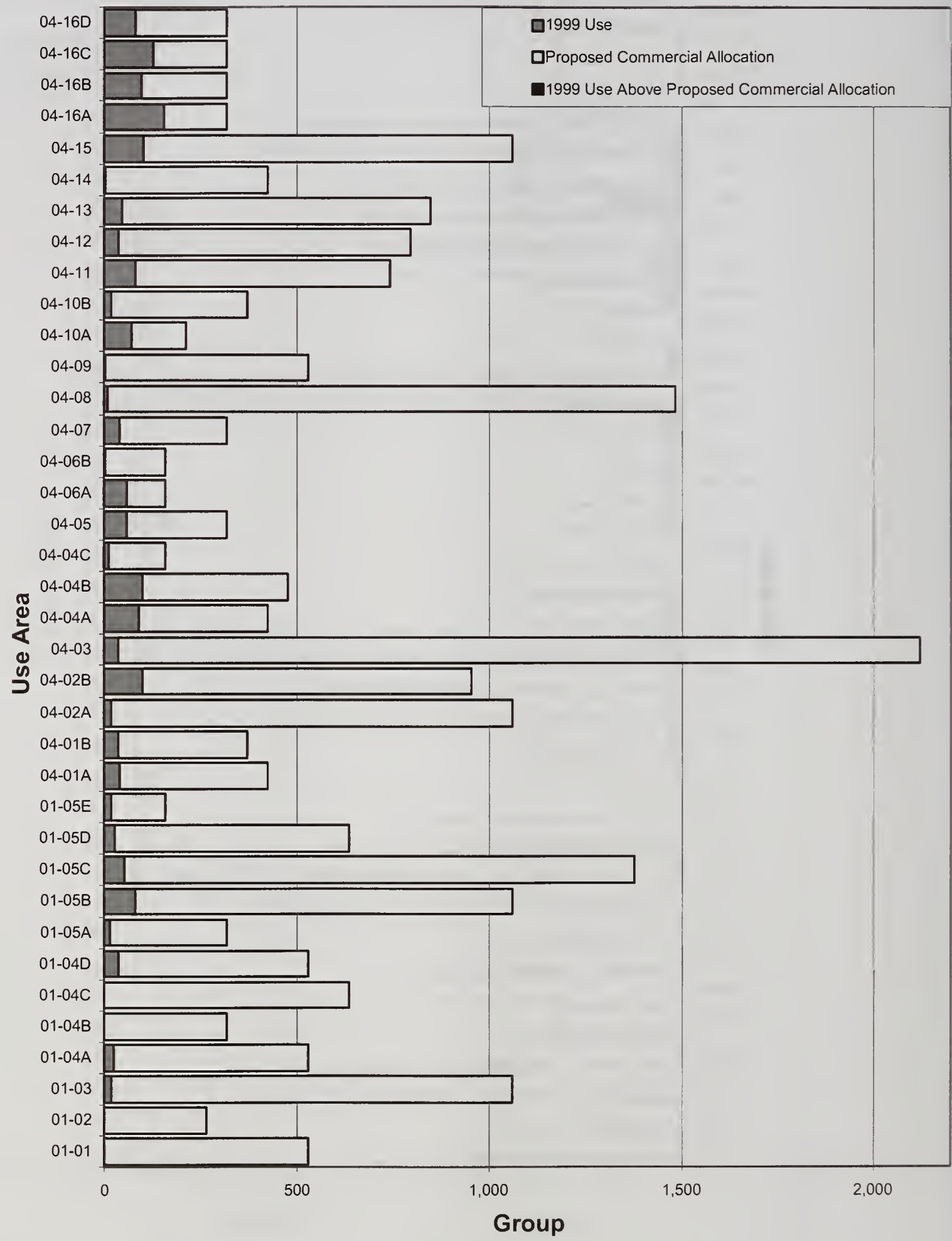




\section{Environment and Effects 3}

Figure 3-3f. Alternative 3, Comparison of the Proposed Commercial Allocation and Current (1999) Use Levels by Use Area During the Fall Season

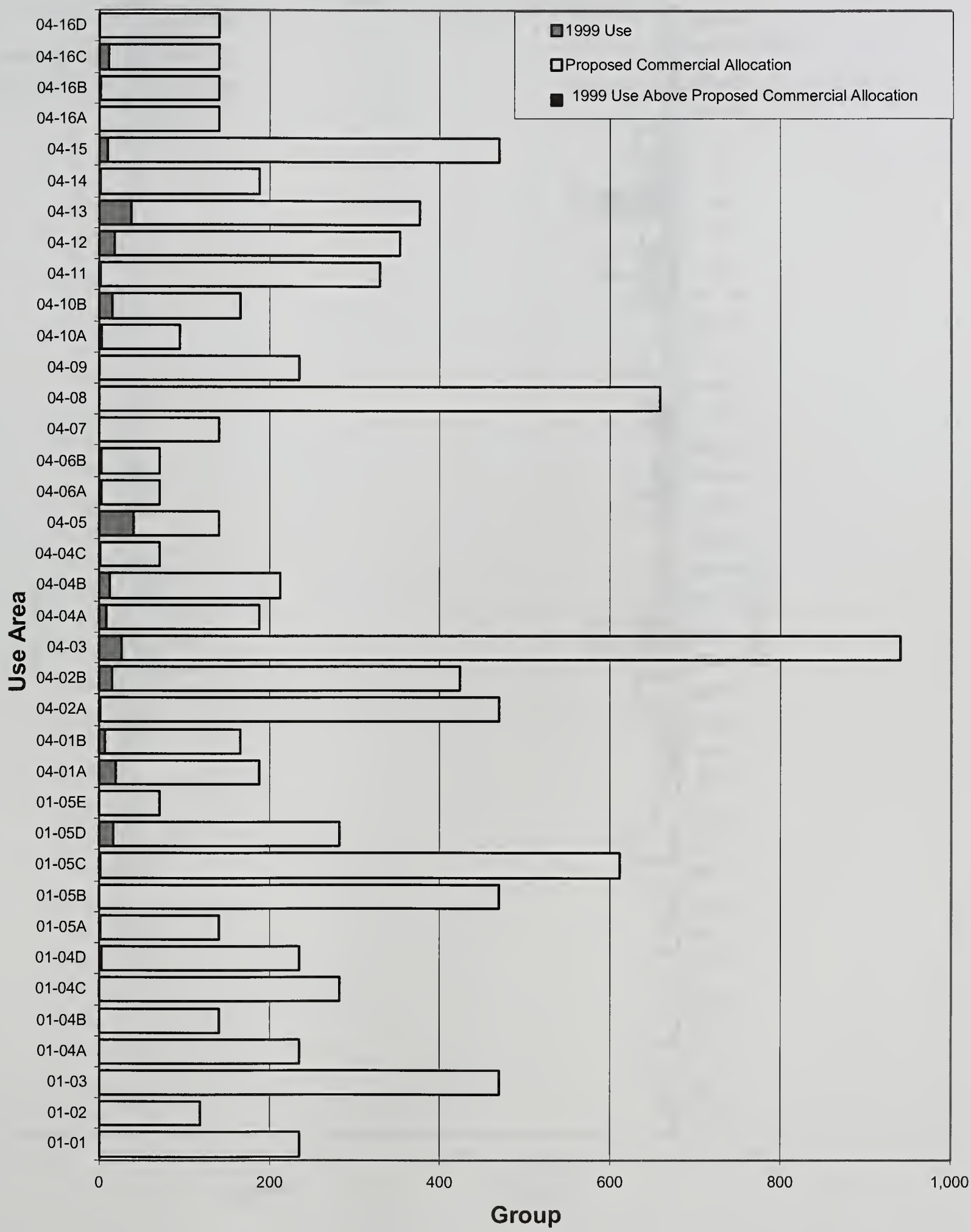


Figure 3-3g. Alternative 4, Comparison of the Proposed Commercial Allocation and Current (1999) Use Levels by Use Area During the Spring Season

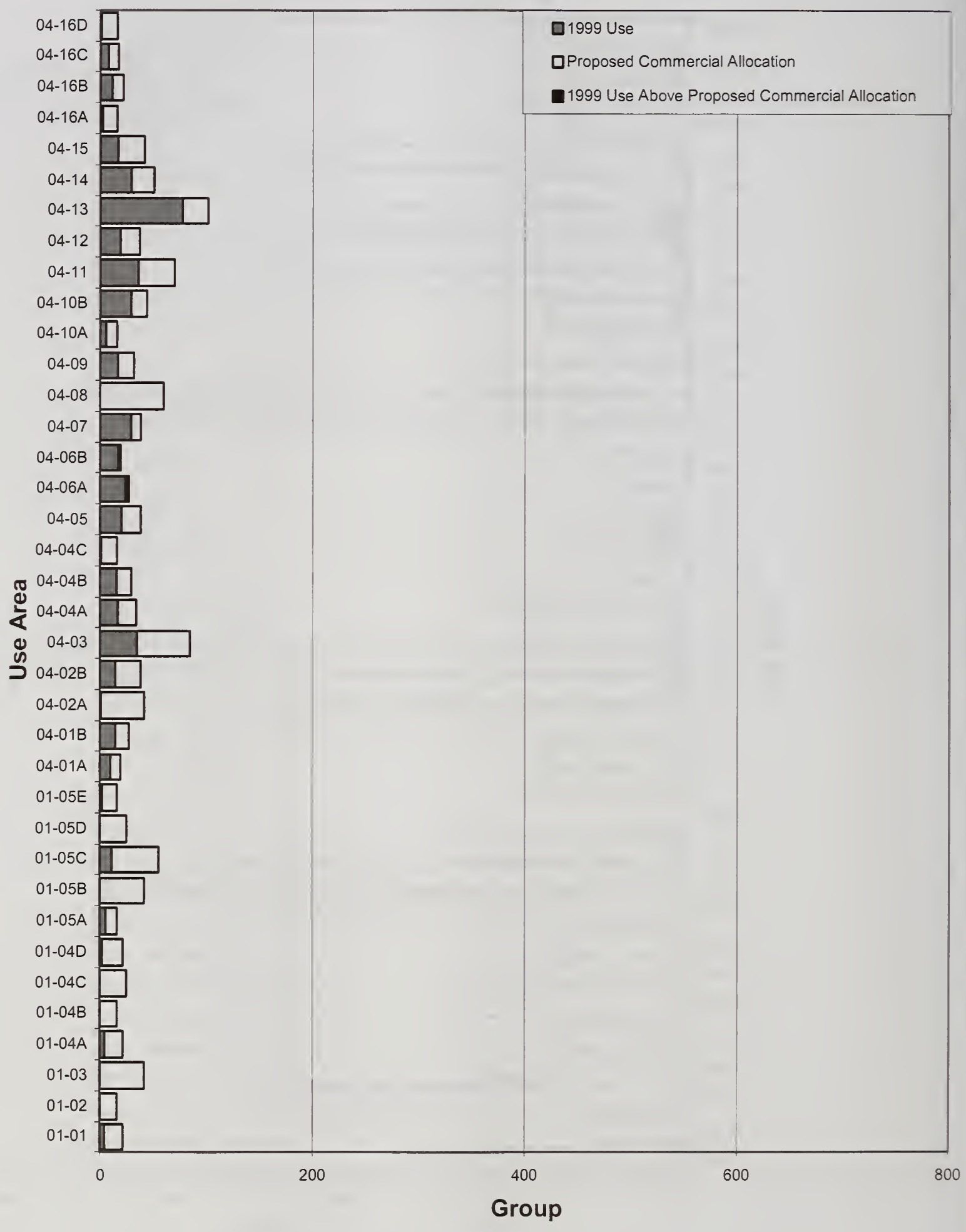




\section{Environment and Effects 3}

Figure 3-3h. Alternative 4, Comparison of the Proposed Commercial Allocation and Current (1999) Use Levels by Use Area During the Summer Season

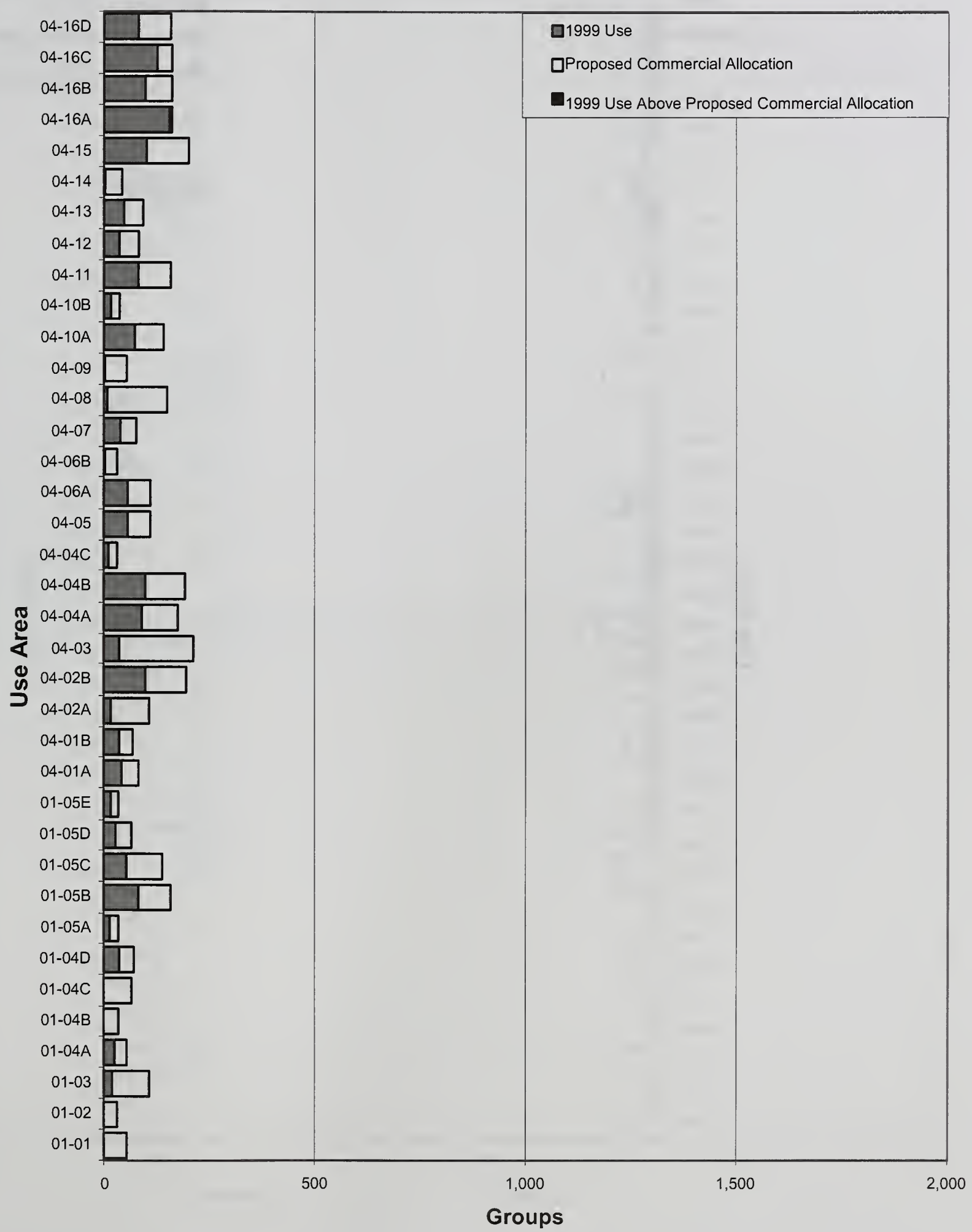


Figure 3-3i. Alternative 4, Comparison of the Proposed Commercial Allocation and Current (1999) Use Levels by Use Area During the Fall Season

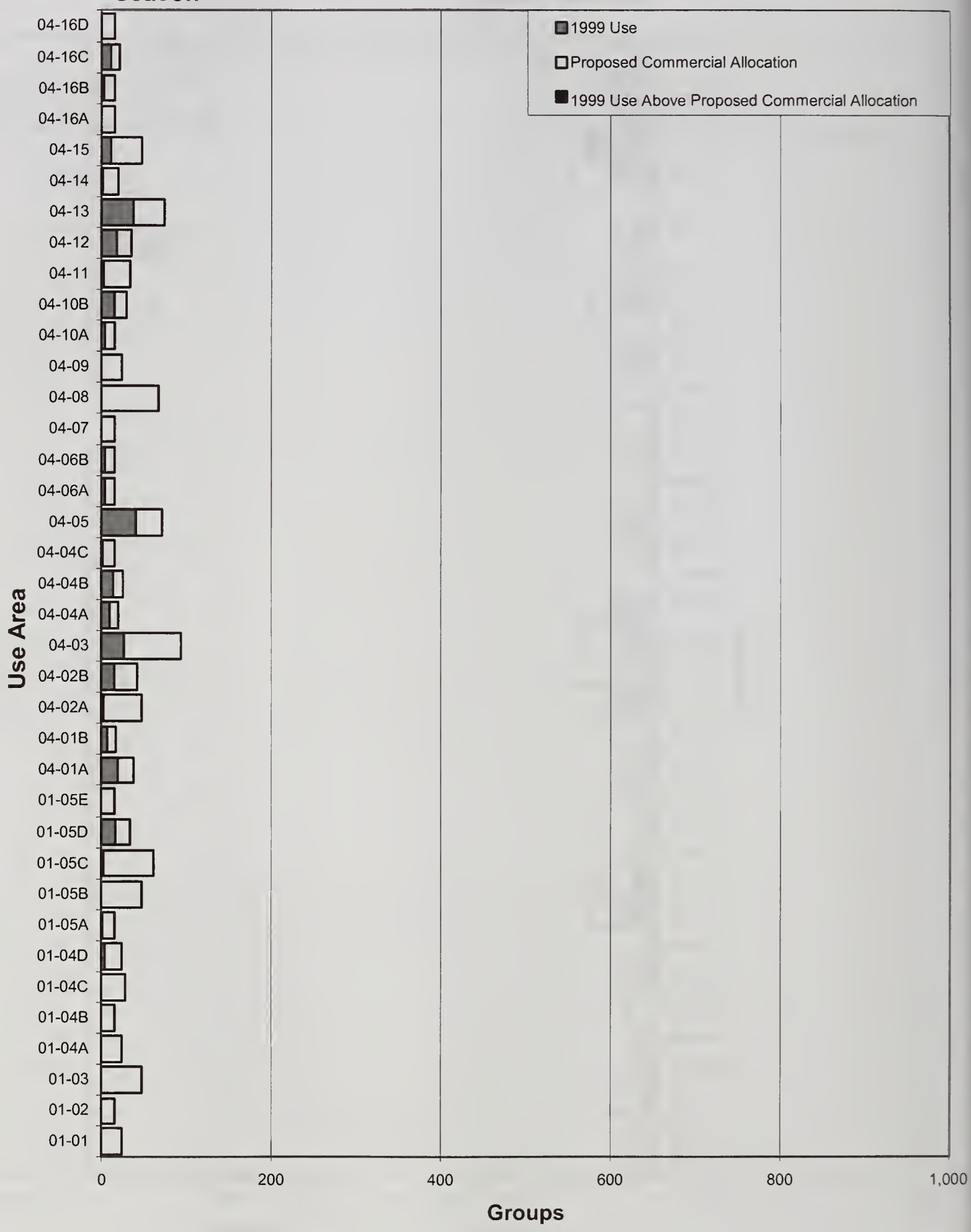




\section{Environment and Effects}

Figure 3-3j. Alternative 5, Comparison of the Proposed Commercial Allocation and Current (1999) Use Levels by Use Area During the Spring Season

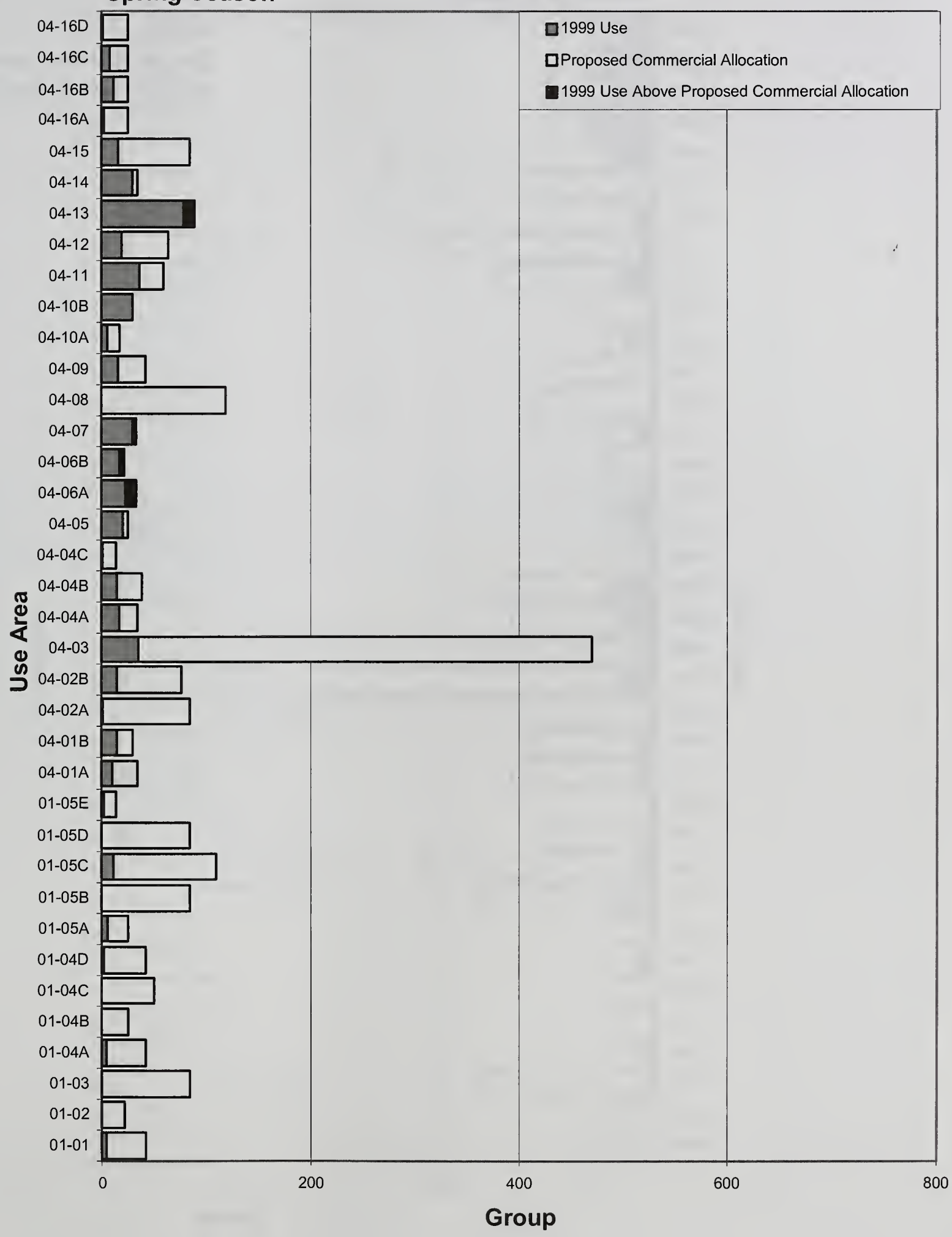




\section{Environment and Effects}

Figure 3-3k. Alternative 5, Comparison of the Proposed Commercial Allocation and Current (1999) Use Levels by Use Area During the Summer Season

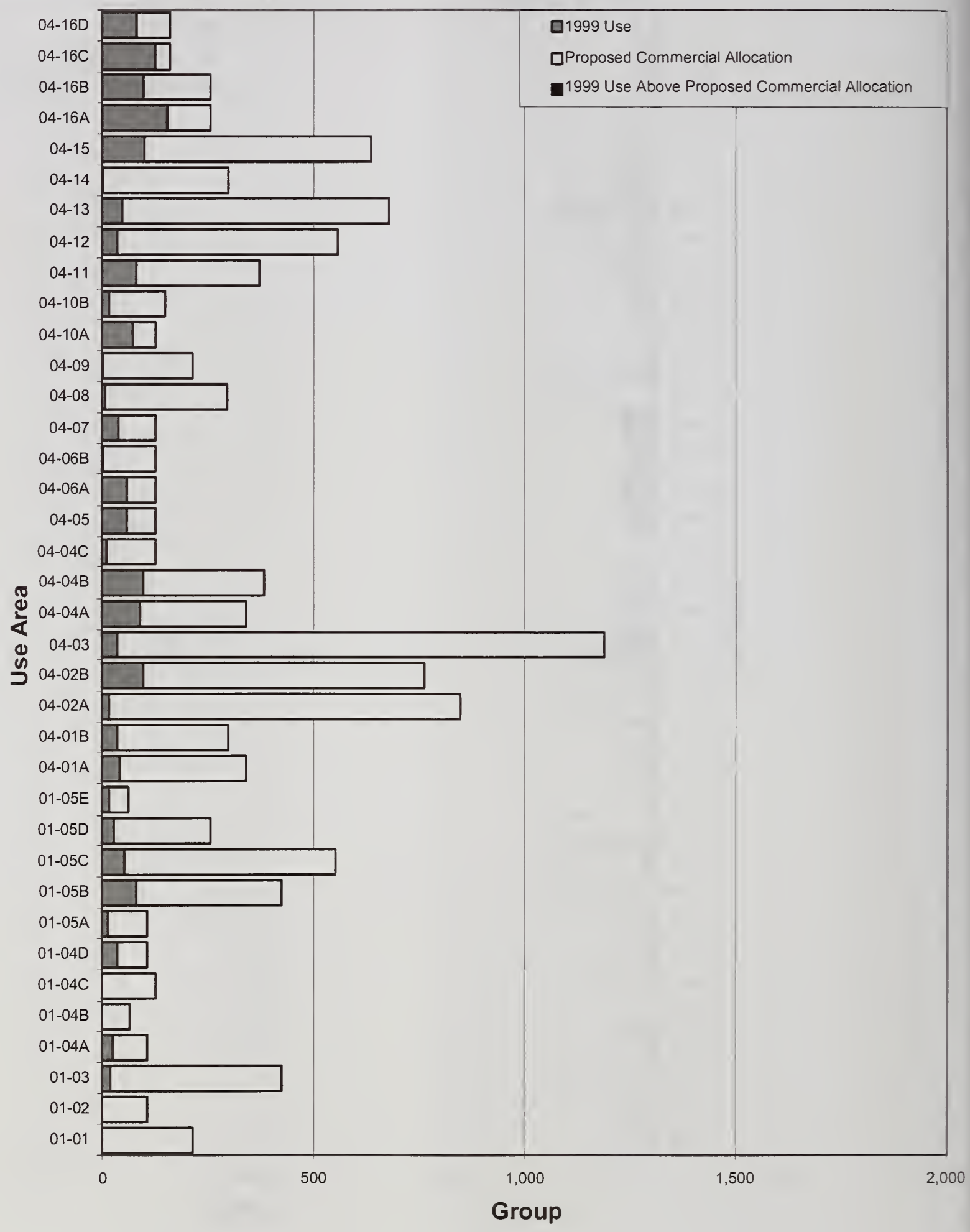




\section{Environment and Effects 3}

Figure 3-3I. Alternative 5, Comparison of the Proposed Commercial Allocation and Current (1999) Use Levels by Use Area During the Fall Season

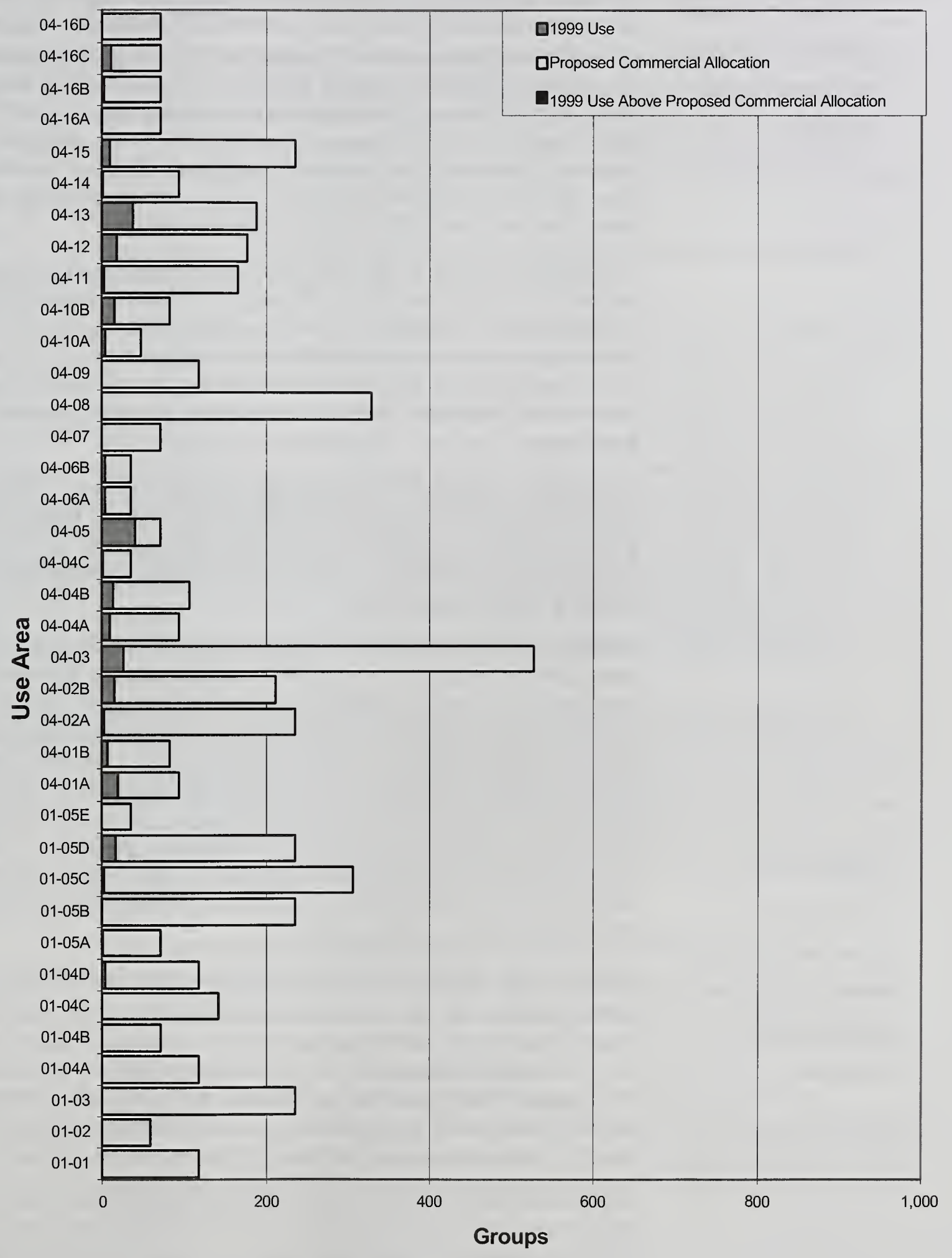




\section{Environment and Effects}

For large group areas

in this EIS, large group

size ranges from 21 to

75 people.

All the alternatives

would provide the variety and type of recreation experience anticipated in the Forest Plan.

\section{Number and Type of Areas Designated for Large Group Use}

Large groups are primarily associated with tour boats offering nature viewing recreation experiences. Many people use these tour boats to access the national forest, and demand for this type of recreation is increasing. Tour boats vary in size and passenger capacities; outfitter/guides offer recreation experiences for people in larger groups, generally ranging from 12 to 70 people. Most large group use occurs in the summer season. Time spent on the national forest is short (usually two or three hours) and activities are non-consumptive. Large group use occurs in relatively few areas of the national forest because the tour boat businesses providing these services are constrained by the need to maintain schedules and by safe access points that can accommodate larger boats.

For large group areas in this EIS, large groups are defined as groups that exceed the generally allowed group size of 20 people in a Semi-Primitive ROS setting. The large group size ranges from 21 to 75 people. The upper limit of 75 people is used because it is a national threshold for unguided groups requiring special permitting. The largest guided group ever reported on the national forest in the analysis area consisted of 70 people. Other commercial use would be permitted in these large group areas.

Alternative 3 identifies 63 large group areas (40 Enclaves, 23 Fifteen-Percent areas), followed by Alternative 5 with 47 large group areas (33 Enclaves, 14 Fifteen-Percent areas). Alternative 4 identifies 20 large group areas with 15 Enclaves and 5 FifteenPercent areas. Alternatives 1 and 2 do not identify areas for large group use (See Tables 3-10, 3-11, and 3-12).

Alternative 3 provides the most large group areas, allowing the most opportunity for growth and scheduling flexibility to businesses offering this type of recreation experience. Alternative 5 identifies the second most large group areas, which would provide somewhat less opportunity for growth and scheduling flexibility. Alternative 4 provides approximately the same number of areas currently being used by large groups although the locations are different; this alternative would offer less opportunity for growth on the national forest in LUDs allowing larger groups. Alternatives 1 and 2 do not identify areas for large group use. In these alternatives, businesses that currently guide large groups would have to limit their group size to the group size guidelines in the Forest Plan. Larger group use could only occur in those LUDS allowing large groups.

\section{Quality of Recreation Experience Available for Commercial Use}

Outfitter/guides rely on a predictable quality of recreation settings to provide to their clients. Most forest visitors using commercial services expect a certain experience. All of the alternatives would provide the variety and type of recreation experience anticipated in the Forest Plan. All recreation opportunities currently available on national forest would be maintained. A variety of recreation experiences will be available for commercial use in the analysis area for all alternatives.

The recreation opportunity settings available for each Use Area for all alternatives are displayed in Table 3-3 and Table 3-4. A summary of the percent of the shoreline zone acres available in each ROS class for all the alternatives is shown in Table 3-7. A summary of the percent of the miles of shoreline available in each ROS class for all the alternatives is shown in Table 3-8. Approximately 38 percent of the shoreline 


\section{Environment and Effects}

zone will provide primitive recreation experiences while another 42 percent will provide semi-primitive recreation experiences at the levels of commercial use proposed by the alternatives, which will benefit the businesses with clients desiring those experiences.

Alternative 4 would provide the most opportunities for more primitive recreation experiences because it has the lowest allocation, followed by Alternatives 2 and 5 with similar allocations, and Alternative 3 with the least opportunity for primitive experiences because it has the highest allocation. Alternative 1 does not make a specific allocation and does not ensure a predictable quality of recreation experience.

\section{Outfitter/Guide Business Benefits}

The outfitter/guide industry generally desires business stability and sustainability and would prefer to reduce uncertainty in the future.

All the action alternatives would make commercial allocations that provide some benefit of certainty to business by providing a predictable supply of group days in the future. They also would provide a predictable type of recreation setting (as defined by the Forest Plan and ROS classes) to enhance business stability and sustainability. This could lead to higher levels of client satisfaction when the recreation experience meets expectations. Each action alternative would provide a commercial use allocation that would sustain current business levels and provide potential for growth for the industry. However, levels of commercial capacity allocated by these alternatives may limit future entry or growth of outfitter/guide operations in the future in some Use Areas and some seasons. The action alternatives would allow the Forest Service to issue long-term permits up to five years in length subject to renewal and provide businesses with an opportunity to obtain priority use permits.

Alternative 1, the no-action alternative, does not make a specific commercial allocation but considers permit authorizations on a case-by-case basis; therefore it does not provide a degree of certainty for business opportunities in the future. The Forest Service would issue temporary (annual) outfitter/guide permits rather than long-term permits. Businesses would not have an opportunity to obtain priority use permits. The current commercial use moratoriums would remain in effect, which would mean uncertain opportunities for future growth.

\section{Conflicts within the Commercial Recreation Industry (Issue 3)}

There is a broad diversity in the types, sizes, and recreation activities of businesses involved in commercial recreation. Some of the differences can lead to conflicts among the different commercial recreation businesses. Conflict within the recreation industry often revolves around social interactions and expectations for recreation experiences. Outfitter/guides often desire to offer the same or over-lapping recreation experiences, and some recreation activities may not be compatible when they occur within close proximity to each other. The alternatives provide different allocations, strategies, and measures to reduce potential conflicts within the recreation industry. 
All the action

alternatives manage

recreation use by

season, which helps

to reduce the

potential for

conflicts.

\section{Commercial Allocation}

Each action alternative makes an allocation in group-days for each Use Area for commercial use. The allocations are a method to reduce conflicts by managing the recreation use levels for the experiences expected in the Forest Plan. The allocations provide different levels of use, which may result in different perceptions of crowding. In general, higher allocations will result in higher use levels, which will provide more opportunities for groups who are not seeking high degrees of solitude. The lower allocations will allow less commercial use resulting in fewer group encounters and less chance for conflicts between groups. Total commercial allocation and the allocation by individual Use Area and season vary by alternative (See Tables 2-1 through 2-3, Table 2-6, and Table 2-9 in Chapter 2). Alternative 3 makes the highest total allocation of 40,658 group days, followed by Alternative 5 with 18,495 group days, Alternative 2 with 16,894 group days, and Alternative 4 with 6,192 group days (Table 3-9). Alternative 1, the no-action alternative, makes no commercial allocation, and industry conflicts are expected to continue.

\section{Seasonal Commercial Allocations}

Many types of outfitter/guides have specific needs and requirements to serve their clients. Some outfitter/guide activities are more scnsitive to crowding. Big game outfitter/guides have a limited timeframe in which to operate (spring and fall hunting seasons) due to state game regulations, and thcy require solitude and large areas in which to operate for successful hunts. Other types of outfitter/guide activities not constrained by regulatory seasons are expanding their use into the spring and fall 'shoulder seasons', encroaching on the current big game hunting operations. This may decrease hunting opportunities, causing a loss of historical use and a decrease in customer satisfaction.

All the action alternatives manage recreation use by season, which helps to reduce the potential for conflicts among diffcrent types of commercial recreation activities. Seasons were established for all the action alternatives to bracket the hunting seasons and the primary summer use season (see Table 3-2). Alternative 1 does not establish recreation management seasons and does not have the ability to manage recreation by scason. Limits on commercial allocations in specific seasons can reduce conflicts betwcen different commercial recreation activities by reducing the overall commercial activity and thus reducing the number of commercial groups that might interact with each other. This decreases commercial use and provides more opportunities for solitude for those types of activities such as big game hunting and other businesses that seek more space and solitude (although competition for limited commercial use in these seasons may increase). It also serves to reduce the sense of crowding.

Alternatives vary in their commercial allocations in the different seasons. Some alternatives limit commercial allocations in the spring and/or fall season. Opportunities for growth into 'shoulder seasons' will be limited. All action alternatives would provide higher allocations in the summer, the primary recreation use season, which concentrates commercial use in this season.

Alternatives 2 and 4 have the greatest limits to seasonal use by limiting the commercial allocation to approximately 10 percent of the carrying capacity in both the spring and fall seasons. Alternative 5 would limit the commercial allocation to 


\section{Environment and Effects}

The alternatives also

address conflict

potential through

their design and

mitigation measures. approximately 10 percent of the carrying capacity in only the spring season. Alternative 3 does not provide limited seasonal allocations in the spring or fall. Alternative 1 does not make seasonal commercial allocations.

\section{Measures to Reduce Industry Conflict}

The alternatives also address conflict potential between outfitter/guide businesses through their design and mitigation measures. Management measures were developed to reduce potential conflicts between outfitter/guides. Many of these measures also serve to reduce potential conflicts between commercial and noncommercial users. These include limits on group size, the number of groups in an area at one time, seasons of use, length of stay limits, methods, and restrictions on access, and mitigation measures to reduce social conflicts. Most measures apply to all action alternatives.

Alternative 1 does not provide measures to reduce conflict between outfitter/guides. Alternatives 2, 4, and 5 would provide similar measures. Alternative 3 has some less restrictive measures.

Access methods are specified to reduce conflicts in the action alternatives. Helicopter and commercial ATV use would not be authorized in any alternative. Motorized boat restrictions apply equally to all action alternatives. Wheeled plane access is allowed at varying levels in some alternatives.

Generally, higher levels of use results in a greater potential for conflict. Alternative 3 would provide the highest amount of use during all seasons and therefore would have the highest potential for conflict. Alternatives 2, 4, and 5 would provide lesser allocations especially during the spring and fall hunting seasons. Alternative 4 would have the lowest potential for conflicts since it has the lowest total and seasonal allocations.

Alternatives 2 and 5 would have the same potential for conflicts during the spring since Use Area allocations would be the same (Tables 2-2 and 2-9). However, the potential for conflicts would be higher during the fall season under Alternative 5.

Alternatives 4 and 5 would reduce the potential for conflict between large groups and hunters because large group use of the Fifteen-Percent areas would be authorized only in the summer and not during the spring and fall. Alternative 3 would allow use in Fifteen-Percent areas in all seasons.

Alternatives 3, 4, and 5 would limit group size in the large group areas to 75 people, and only one large group would be allowed in an area at a time to limit the social impacts on other large groups and other users.

Alternative 1 does not provide specific measures to reduce conflict between outfitter/guides. Measures could be developed on a case-by-case basis.

Also see Appendix C (Mitigation) for specific information on measures to reduce conflict between outfitter/guides.

\section{Designation of Large Group Areas}

Group size is an important component in assessing potential conflicts between outfitter/guides. Large groups are primarily associated with the tour boats in the project area. Businesses serving large groups, such as the tour boats, are often seen 
to detract from the recreation experience provided by outfitter/guides who serve smaller groups.

However, outfitter/guides serving larger groups are also limited to where they can go by group size restrictions in many LUDs with primitive ROS settings. They are also physically limited by the requirements of their larger boats. Rough rocky coastlines with relatively few safe anchorages limit the number of locations from which larger tour boats can provide their clients with access to national forest.

To address the concerns over (a) the need for areas where tour boats can go with large groups and (b) potential conflicts between small and large group sizes, two types of large group areas are proposed: Enclaves and Fifteen-Percent areas. These large group areas accomplish several objectives. They provide areas where businesses can provide services to people who prefer to recreate in large groups, and they also identify areas where other outfitter/guides can expect to see large groups and then can avoid these areas if they desire a different recreation setting. They also serve to concentrate large groups and their associated resource impacts into specific areas of the forest; other areas of the forest will be available for outfitter/guides who serve small groups. Designating large group areas thus would reduce the potential for conflicts by accommodating recreationists in large groups at appropriate sites.

Three alternatives identify specific areas where outfitter/guides may guide large groups (see Tables 3-10 and 3-11). These large group areas also have restrictions to reduce conflicts between outfitter/guides. Groups in these areas are limited to 75 people. Only one large group can be in an area at a time to limit the social impacts on other large groups and other users. In addition, in some alternatives, large groups can use the Fifteen-Percent areas only during the summer season. Site-specific information and mitigation measures for each area are provided in Appendix B.

Alternative 3 provides the most large group areas: 63, with 40 Enclaves and 23 Fifteen-Percent areas, followed by Alternative 5 with 47 large group areas (33 Enclaves and 14 Fifteen-Percent areas), and Alternative 4, with 20 large group areas (15 Enclaves and 5 Fifteen-Percent areas). Alternatives 1 and 2 do not identify areas for large group use.

\section{Cumulative Effects}

One source of future recreation trends for Alaska and the nation is presented in the Draft Revision Chugach Land Management Plan (USDA Forest Service 2000). The studies cited in this plan predict an increase in recreation participation for all recreation activities, due both to an increase in the population and to an increase in the rates of per capita participation. Alaskan recreation participation is expected to increase at least at the rate of population growth. Activities may change as the population changes with age and other demographics. The rate of recreation growth is declining for visitors to Alaska when compared to the growth over the past decade. Past trends may not be indicative of the future as recreation is influenced by many factors including technological changes, fuel prices, and general economic trends.

Many of the cumulative effects were analyzed at the Forest Plan level when recreation levels and effects were determined. Forest development is progressing at lower rates than predicted in the Forest Plan, so changes from the Semi-Primitive 


\section{Environment and Effects 3}

ROS to the more developed ROS classes are not occurring at the levels anticipated in the Forest Plan.

Recreation use levels on the Petersburg and Wrangell Districts to the south of the analysis area are occurring within the limits established in the Stikine Area Outfitter/Guide EA. The effects of this analysis are not expected to change recreation use on the national forest adjacent to the analysis area.

Non-national forest land is scattered throughout the analysis area. Many of the cumulative effects would involve the current and future use of these lands and their influence on the shoreline zone. Some of these public lands, such as national and state parks, are specifically managed for recreation while others are managed for multiple uses including recreation.

Glacier Bay National Park and Preserve has a large influence on recreation use patterns, especially along the national forest shoreline along Icy Straits. Glacier Bay National Park and Preserve serves as a primary attraction to the area, and much of the use on the national forest is peripheral to use in the national park. Recreation management strategies within the national park have a direct effect on the surrounding areas. For example, commercial fishing bans within the national park have displaced those boats into the surrounding waters, increasing boat traffic and fishing activities in other areas adjacent to the shoreline. Visitor limits into the national park displace visitors to areas surrounding the park. Boat entry limits often involve boats gathering up at the entrance waiting to obtain a permit to enter the national park; these boats will often visit the national forest as they wait. Future Park Service plans are to keep visitor levels at the current level or decrease them. If use levels are not permitted to meet the expected increase in recreation demand, it is expected that some of that demand will be supplied by visits to the national forest shoreline zone. Two other small national parks, the Sitka Totem Park and the Klondike Park, lie within the analysis area. These are also major visitor attractions but they have little influence on the adjacent national forest.

State parks, including Sullivan Island, St. James Bay, Shelter Bay and Funter Bay, within the analysis area are specifically managed for recreation. Most of the other adjacent state land is managed for multiple-use, including recreation. No restrictions or development affecting recreation are anticipated on these state lands in the near future based on the Alaska DNR draft Northern Southeast Area Plan (NSEAP).

Much of the private land scattered throughout the analysis area, including Alaska Native corporation lands, could be developed for recreation. There are at least six existing remote lodges and several areas have been proposed as possible lodge sites, including Hobart Bay and Excursion Inlet. Any additional recreation development on private lands in the future would likely increase recreation use on the adjacent national forest. Additional development and a proposed ferry terminal at Berners Bay would change recreation use patterns in Lynn Canal. 


\section{Socioeconomics}

Introduction
The central characteristic of all the alternatives is that they manage commercial recreation activity or tourism (the terms are used interchangeably in this section) to a greater or lesser degree. This recreation activity, in turn, can affect local communities and economies in various ways. The ability of tourism to directly affect local employment by supporting outfitter/guides and related jobs is a major impact that is considered in this section. The impact of tourism activity on recreation opportunities for local residents (an essential amenity for many Alaskans) is also important. However, unlike the case of timber harvest, this impact would occur not so much through the physical alteration of the landscape as through the perceived quality of recreational experiences, particularly those changes resulting from crowding. Finally, growth in tourism in communities whose economies have historically been tied to traditional resource extraction activities may result in considerable changes in social structure and the local distribution of wealth (Cerveney, in press).

Several challenges are associated with measuring these impacts. The first challenge is a result of the overall difficulty of measuring and analyzing recreation and tourism activity. We often lack the data and methodologies needed to fully analyze recreation-related effects. Some aspects can be identified and addressed only in the course of public debate and future planning efforts. A second challenge lies in determining the breadth and depth of socioeconomic information needed to describe the affected environment and the expected consequences of the proposed alternatives. Recreation and tourism management will affect social and economic systems in ways that differ from more traditional resource-related activities; therefore, traditional approaches to impact assessment are not wholly adequate.

The Shoreline Outfitter/Guide EIS is limited to the management and allocation of commercial guiding activities in the northern portion of the Tongass National Forest. The following discussion concentrates mainly on the socioeconomic aspects of recreation and tourism within this analysis area. However, the issues dealt with here occur within a broader context of the entire region, and their importance extends beyond recreation and tourism concerns. Where necessary this broader context will be considered, but in a limited way. For more information on the overall socioeconomic conditions in Southeast Alaska, see the analysis completed for the Forest Plan. While somewhat dated, most of the general conclusions about longterm trends and the overall socioeconomic evolution of the region found in the Forest Plan analysis are still relevant and are incorporated here by reference (See also, Allen et al. 1998).

The following affected environment segment begins by introducing the communities within the analysis area, followed by a description of important regional economic trends. The role of outfitter/guides in the recreation and tourism industries follows. The affected environment concludes with a discussion of the social effects of increasing commercial recreation use levels. These discussions help provide a foundation for the socioeconomic effects analysis that concludes this section. 


\section{Environment and Effects 3}

\section{Affected Environment}

\section{Community Profiles}

The following community profiles display information related to recreation (Alaska Division of Community and Business Development 2001).

Juneau, the state capital, is the largest community in the analysis area (population 30,711 ) and a center for recreation use by both local residents and out-of-state tourists. Tourism is a significant contributor to the local economy during the summer months, providing nearly 2,000 jobs and $\$ 130$ million income. More than 683,000 passengers visited Juneau during 2001 from 539 cruise ship dockings, bringing over $\$ 80$ million into the local economy. Mendenhall Glacier, Juneau Icefield air tours, Tracy Arm, and the new Mount Roberts Tram are local attractions. Juneau is accessible only by air and sea. Scheduled jet flights and air taxis are available at the Juneau International Airport. Marine facilities include a seaplane landing area in Juneau Harbor, two deep draft docks, five small boat harbors, and a state ferry terminal. The Alaska Marine Highway System and cargo barges provide year-round services.

Sitka is the second largest community (population 8,835) and is a common stop for out-of-state visitors. Sitka is a port of call for many cruise ships each summer whose passengers bring over $\$ 11$ million into the local economy. Daily jet service is provided, and several scheduled air taxis and air charters are available. The City and Borough of Sitka operate five small boat harbors with 1,350 stalls, and a seaplane base. There is a breakwater at Thompson Harbor, but no deep draft dock. Cruise ships anchor in the harbor and lighter boats bring visitors to shore. The Alaska Marine Highway system operates a ferry terminal.

Port Alexander (population 81) is one of the smallest communities in the analysis area. Commercial fishing and subsistence uses of marine and forest resources constitute the economic base. Transportation is by float plane and boat, with a stateowned seaplane base available. Passengers can fly on the mail float plane from Sitka or can charter flights from Sitka, Petersburg, Wrangell, and Juneau. Other facilities include a breakwater, dock, and small boat harbor for moorage. There are no roads; skiffs are used for local transportation.

Gustavus (population 429) is located near the entrance to Glacier Bay National Park and Reserve and attracts a number of tourists and recreation enthusiasts during the summer months. Gustavus offers a state-owned airport with jet capability. Float planes land at nearby Bartlett Cove. Air traffic is relatively high during peak summer months, and several cruise ships include the Glacier Bay in their itinerary. There is a 10-mile local road connecting Bartlett Cove with the airport. Regulations limit the number of boats entering Glacier Bay. Permits are required from the National Park Service between June 1 and August 31. Glacier Bay tours are available from Bartlett Cove, Gustavus, and Juneau.

Hoonah (population 860) is the largest Tlingit village in Alaska. Many residents maintain a subsistence lifestyle that includes hunting, fishing, and gathering edible plants and berries. The state owns and operates an airport and a seaplane base that are served by scheduled small aircraft from Juneau. A state ferry terminal and harbor/dock area is available. There is an extensive road system on northwest Chichagof Island. 
Angoon (population 572) is the only permanent settlement on Admiralty Island. Angoon is a Tlingit village with a commercial fishing and subsistence lifestyle. It is accessible only by float plane or boat. Scheduled and charter float plane services are available from the state-owned seaplane base on Kootznahoo Inlet. Angoon's facilities also include a deep draft dock, small boat harbor, and state ferry terminal.

Pelican (population 163) is a fishing community, and most residents are commercial fisherman or fish processing workers. Pelican is dependent on boats, float planes, and the state ferry for access. Daily scheduled air taxi services are available from Juneau and Sitka. Facilities include a state-owned seaplane base, a small boat harbor, dock, and state ferry terminal. There is limited ferry service.

Elfin Cove (population 32) is a fish-buying and supply center for fishermen. Residents participate in commercial fishing, sport fishing, and charter services, so the economy is highly seasonal. Summer lodges and local retail businesses also provide employment. A state-owned seaplane base is available, with skiffs acting as the primary means of local transportation.

Tenakee Springs (population 104) has long been considered a retirement community and summer retreat for Juneau and Sitka residents, with few opportunities for local employment. While fish processing had historically been a mainstay of its economy, tourism is increasing in importance. Tenakee Springs is dependent on seaplanes and the Alaska Marine Highway for transport. The city owns a seaplane base and heliport, and scheduled or chartered float planes are available from Juneau. The state ferry provides passenger transportation only, since there are no vehicle landing facilities or local roads in Tenakee. The marine facilities include a small boat harbor and ferry terminal. There is a three-mile-long main street. Local transportation is primarily by bicycle or ATV.

Haines (population 1,811) is a northern terminus of the Alaska Marine Highway System, a cruise ship port-of-call, and a hub for transportation to and from Southeast Alaska. Many jobs are seasonal, with tourism businesses and access to the interior Alaska highway system becoming increasingly important. Haines is a major transshipment point because of its ice-free, deep-water port and dock, and year-round road access to Canada and interior Alaska. Air service is provided daily via the Haines airport and seaplane base.

Skagway (population 862) is a port of call for cruise ships and a transfer site for interior bus tours. In $1999,430,000$ cruise ship passengers brought $\$ 60$ million into the local economy; more than 150,000 independent travelers visited Skagway. The Klondike Gold Rush National Historic Park is a major attraction. The White Pass and Yukon Railroad is open seasonally, providing tours. The Klondike Highway and Alaska Highway provide a connection to British Columbia, the Yukon Territory, and the lower 48 states, or north to interior Alaska. Skagway is accessed by air, road, water, and rail services. The state owns the airstrip and seaplane base at the boat harbor, with scheduled air taxis. Skagway receives regular state ferry and barge services. A protected small boat harbor, boat launch, and boat haul-out are also available. 


\section{Environment and Effects 3}

\section{Regional Economic Trends}

Unless otherwise noted, the area considered throughout this economic analysis is the northern portion of Southeast Alaska excluding Juneau. This area includes the Haines and Sitka Boroughs, and the Skagway-Hoonah-Angoon Census Area. Boundaries and definitions for the Yakutat Borough and the Skagway-HoonahAngoon Census Area have changed repeatedly over the past 30 years, and allowances for this have been made in the construction of historical data. As a result, Yakutat Borough was included even though it is not part of the analysis area. However, Yakutat's reported 1998 population is 790, or less than 5 percent of the total population of the analysis area; the inclusion of Yakutat should have only a very small impact on the aggregate statistics considered.

Juneau was not included in the affected regional economic environment, although a substantial proportion of the economic activity that could potentially be affected by the project is based in that town. Because of Juneau's relative size, however, the potential effect of the outfitter/guide sectors covered in this analysis on the broader Juneau economy would be insignificant. Additionally, the inclusion of Juneau in aggregate statistics describing the analysis area would overwhelm the information about other smaller communities. In terms of the relative importance of the industry, these communities are far more dependent than Juneau is on the commercial recreation activity that would be managed under the proposed alternatives.

The regional economy of Southeast Alaska has undergone considerable change in the past few decades, which is reflected in income statistics for the analysis area. Table 3-19 displays key economic statistics for the analysis area along with national comparisons. Real per capita income in the analysis area increased at an annual rate of 1.2 percent over the 1970-1998 period, a rate considerably less than the 1.8 percent experienced nationally. This difference can be attributed to slower growth in total income in the region ( 2.5 percent versus 2.8 percent), but also to faster growth in population (1.3 percent versus 1.0 percent). Per capita incomes in the analysis area have historically been considerably higher than the national average, and as of 1998 they were still slightly higher. While the lagging performance of per-capita incomes in the region is a cause for concern, it is not indicative of significant poverty or economic distress at the regional level (although concentrated pockets of poverty are a distinct possibility, particularly in the smaller rural communities).

The main cause of lagging income growth in the study region is the sharp decline in manufacturing income in the past decade. In 1989, income in manufacturing (primarily wood products and seafood processing) attained a peak level of approximately $\$ 95$ million (adjusted for inflation to 1995 dollars). In 1998, the figure had fallen to just $\$ 27$ million. In spite of this virtual elimination of a sector that was once seen as the region's economic mainstay, both total and per capita income in the analysis area fell only 5 percent over the same period and population remained stable. The reason for the region's ability to adapt to the loss of most of its manufacturing activity is commonly assumed to be the expansion of tourism and commercial recreation activity. These sectors could potentially be affected by this project. 


\section{Environment and Effects}

Table 3-19. Structure and Growth of Personal Income in the Analysis Area, 1970-1998

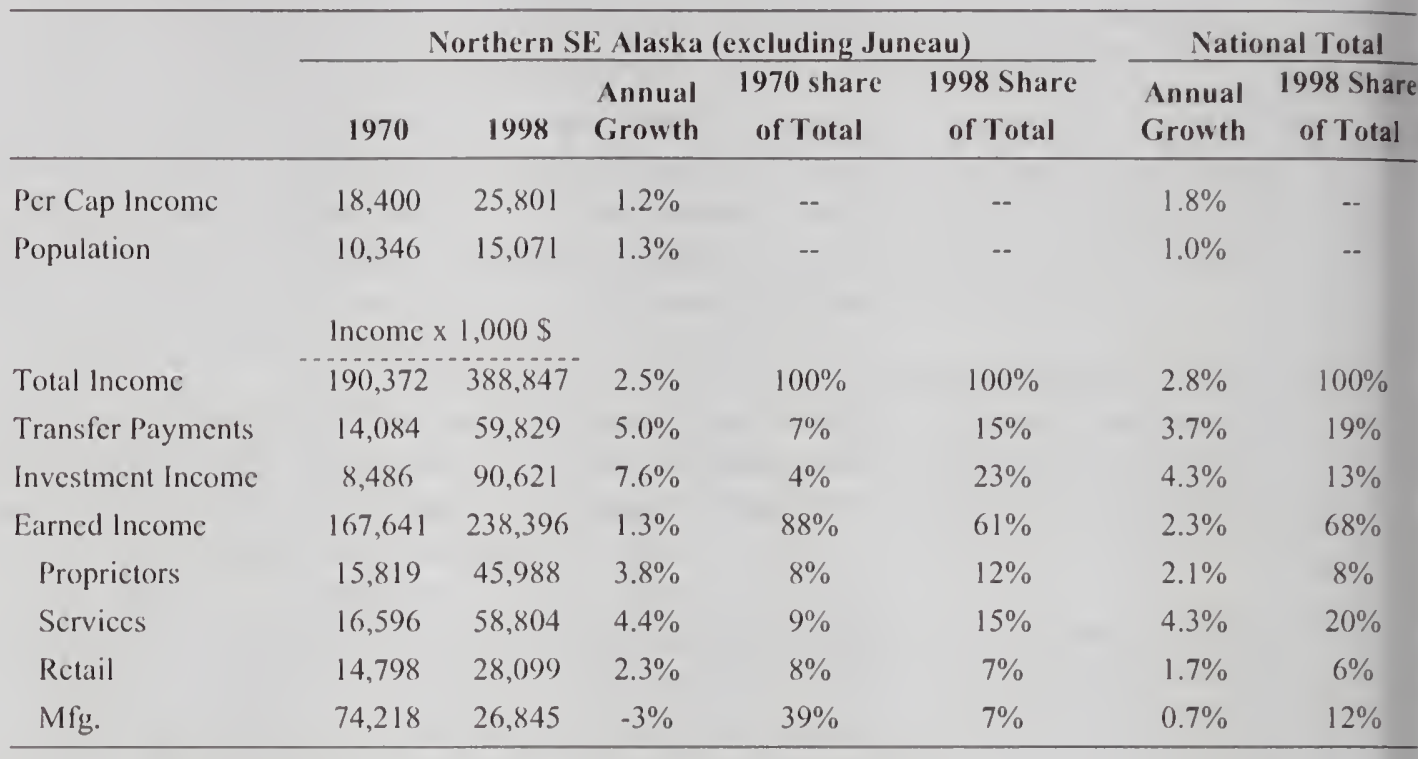

Source: Burcau of Economic Analysis Rcgional Economic Information System.

'Northern SE Alaska' is composed of Haines, Sitka and Yakutat Boroughs, and the Skagway-Hoonah-Angoon Census Area. Transfer payments include Social Security, Medicare, income maintenance programs, and payments from the Alaska State Permanent Fund. Investment ineome includes dividends, interest, and rent but not capital gains. Earned income is all incom derived from work activities. Proprictors" income refers to earnings by self-employed individuals including commercial fishers and owners of retail and service establishments. Totals may not match due to rounding error.

Table 3-19 provides some indication that tourism has effectively replaced manufacturing as the region's economic mainstay. The rapid growth in services, a sector that includes many tourism related activitics, is the main indicator of this replacement. Growth in proprietors' income, which includes commercial fishers but also self-employed owners of retail and serviec establishments, is additional evidence; commereial fishing employment has been relatively stable throughout much of the past few decades (USDA Forest Service 1997).

Tourism, however, may not be the most important souree of income growth in the region. Growth in unearned income (government transfer payments and investment ineome) has far outstripped growth of the earned income seetors (including serviees) and now accounts for about a third of total personal income in the analysis area. Investment ineome, in particular, has experienced rapid growth, and this category does not take into account capital gains from the reent stock market rise. Transfer payments, the bulk of which are composed of Social Security and related retirement benefits, Alaska Permanent Fund payments and 'other' payments to individuals, and Medicare and related medical benefits, have grown at a slower rate but still have outpaced any of the earned ineome eategories. A substantial proportion of unearned ineome is not tied to any given place; retirees, investors (including recipients of Native corporation distributions), and others can live anywhere in the United States and still receive their income; permanent fund recipients ean ehoose to live anywhere in Alaska. 


\section{Environment and Effects 3}

The largest and

fastest growing

element of

recreation and

tourism in Southeast

Alaska is the cruise

ship industry.
Therefore, a significant proportion of the region's economic base is tied not to the local production of goods and services but to the choice of individuals to continue to live in the small communities that are found in the analysis area. In Southeast Alaska, access to the natural environment and the range of subsistence and recreation activities this access entails, is a central element in the choice of individuals to remain in the region. Consequently, the breadth and quality of recreation opportunities for local residents may be as important in generating incomes in the analysis area as are commercial tourism and recreation operations catering to visitors. This needs to be considered when balancing commercial and noncommercial recreation access on the national forest.

\section{Recreation, Tourism, and Outfitter/Guides}

Providing an adequate description of the tourism industry in general, and the outfitter/guide sector in particular, is complicated by a number of factors. First is that the standard employment and income statistics do not identify a tourism sector per se, because much of the money spent by tourists goes to establishments (such as restaurants and hotels) that also serve other visitors or local residents. It is not possible to directly measure on a regular basis the amount of activity attributable to tourism in these sectors. Other establishments, such as outfitter/guides, primarily serve visitors, but they are commonly combined with other types of businesses (sports instruction for example) that serve local demand. These problems are further compounded by the fact that at the local level, and especially in sparsely populated areas, statistics for many sub-sectors are routinely blocked out to protect the privacy of individual establishments. Consequently, the standard set of employment and income statistics used in economic analysis are inadequate in measuring and tracking overall activity in the commercial recreation sector. However, other less direct information sources are available.

The largest and fastest growing element of recreation and tourism in Southeast Alaska is the cruise ship industry. One estimate places the total number of visitors coming to Southeast Alaska by cruise ship in 2000 at 632,000 , or slightly more than 8 visitors for every Southeast Alaska resident and well over twice the 235,000 cruise ship passengers reported to have visited Southeast Alaska in 1990 (Schroeder et al. in press, McDowell Group 2000). This number accounts for over three-fourths of the estimated total of 832,000 tourists visiting the region in 2000 , and its growth is equivalent to an 11 percent annual growth rate (resulting in a doubling every six to seven years). Whether this expansion can continue, however, is open to question, and anecdotal evidence suggests that total tourism growth in Alaska may be slowing (Colt et al. 2000).

\section{Implications of Expanding Activity}

The magnitude and rapid growth of the cruise ship industry has important implications for recreation planning. Shore excursions have become an integral part of the cruise ship experience, providing increased revenues for ship operators and opportunities for local entrepreneurs. This activity has been concentrated at major ports of call (such as Ketchikan, Juneau, or Skagway) and does not occur in the shoreline zone. Alongside the international cruise lines, however, several tour boat operators are active in the region, often taking their customers to places bypassed by the larger ships. To the extent that it occurs on the national forest, this activity could 
be affected by alternatives and the potential for crowding. Likewise, if growth in large cruise ship activity continues at its current rate, then limited capacity and crowding may force certain cruise lines to diversify their activities and locations, making greater use of the forest-based recreational use capacity in the analysis area. Growth in the tour boat industry may provide some indication of growth trends for independent visitors to Southeast Alaska.

The number of cruise ship passengers visiting the region, however, is a poor indicator of activity in the outfitter/guide sector. A recent survey of commercial recreation providers in Southeast Alaska, conducted by the Alaska State Division of Community and Business Development, provides a better indicator of the industry, although it is limited to a single point in time (Alaska Division of Community and Business Development 2001). The survey identified 736 commercial providers working in the region during the summer of 2000 , but the actual number of firms engaged in providing commercial recreation services is probably somewhat higher, since it is not likely that the survey was able to identify all providers. Of the 736 operators, slightly over half ( 58 percent) were identified as providers of saltwater fishing charters and related services. The remainder was more or less evenly divided among tour operators, hunting guides, and air and sea charters. Some 433 operators were based in towns within the analysis area (including Juneau).

Of the 736 surveys that were distributed, 193 were returned, a 26 percent response rate. The responses indicate growth in the industry, with 68 percent of responding firms having opened business within the past ten years; 73 percent reported increased business since 1995 . With 86 percent of respondents earning gross revenues of less than $\$ 100,000$, most of the firms were relatively small, but 6 percent reported revenues above $\$ 1$ million, including one firm with revenues exceeding \$10 million. A similar distribution is noticeable in terms of clients served, with the majority of firms serving fewer than 100 clients, a smaller number of firms serving considerably larger numbers, and one firm serving clients in excess of 100,000 a year. The survey also asked questions regarding the sensitivity of businesses to competing forms of land use. High concentrations of other recreationists, particularly group sizes larger than 50 , were identified by respondents as one of two factors having the largest potential negative impact on their business (the presence of jet skis was the other). The indication here is that concentrated use in large group areas may exclude other users from the immediate vicinity.

On average, each survey respondent employed 40 person-months of labor, or 3.25 full-time equivalents in the 2000 season. This number includes both full-time and part-time workers. By multiplying the total sample ( 736 firms) by the average employment per firm (3.25 full-time equivalents) we obtain an estimated 2,392 fulltime equivalents directly attributable to the outfitter/guide industry in Southeast Alaska. The estimate for firms based within the analysis area is 1,407 (433 x 3.25). These estimates are based on the assumption that: (1) the survey responses are representative of the true average for firms in the region; and (2) the sample of 736 includes all firms working in the region. Both of these assumptions are questionable, the first because no non-response-bias analysis could be conducted for the survey in spite of its relatively low response rate, and the second because it is highly unlikely that all the commercial recreation providers active in the region were identified. Consequently, these employment estimates need to be viewed with caution. They 
nonetheless do provide some indication of the general size of the industry. The survey did not specifically identify use on the national forest.

A more direct, but less comprehensive, source of information on outfitter/guides who depend on the national forest for recreation settings and opportunities is the actual commercial use permits data reported to the Forest Service. The data indicate that 90 firms received permits in the analysis area in 1999, serving a total of 14,096 clients. Of these, the 5 largest firms accounted for over half of the client base, and their activity was largely focused on providing hiking and sightseeing experiences for relatively large groups (freshwater fishing excursions with relatively small groups were important for one firm). This use was directly associated with the cruise ship industry either through linkages with cruise lines or because the firms in question ran their own tour boat services. These firms are most likely to take advantage of large group areas and other concentrated use areas provided under some alternatives. Under continued growth, they are most likely to face increasing constraints under the more restrictive alternatives, or more crowding under the less restrictive alternatives, especially in the more popular areas during the summer season.

In addition to popular summer group destinations, spring hunting activity on Admiralty Island has also been identified as an area where certain planning alternatives could potentially constrain commercial activity (see the Recreation section). In terms of number of clients, hunting's share of total commercial activity in the analysis area (as measured by the 1999 use permits) is relatively small, coming to just seven percent. This may be somewhat misleading, however, since guided hunting is more involved and expensive than day-hiking or general sightseeing, and it will thus have a proportionately larger economic impact on a per-hunt basis. This is particularly so for brown bear hunting, which accounts for over three quarters of total commercial hunting activity. As with large group hiking and sightseeing activities in the summer season, spring, and, to a lesser extent, fall hunting may be constrained in certain locations under several of the proposed alternatives. In this case, however, large group areas cannot accommodate increased demand. Moreover, bear hunting is also managed by limiting the number of bears harvested; since that limit is more restrictive than the commercial allocations provided by the alternatives, the bear harvest limits will likely determine the total bear hunting activity in the future.

\section{Environmental Consequences}

\section{Overview}

The potential effects of alternatives on recreation use are discussed earlier in the Recreation section of this document. In order to estimate economic effects, the recreation impacts must be translated into meaningful economic measures such as employment or income. Social impacts on communities in the region can then be at least partially inferred from the economic impacts, although important aspects of the social impacts will necessarily be overlooked.

As explained in the recreation section, the total capacity allocated to commercial use across the forest far exceeds expected overall use, even under a doubling of 1999 commercial use levels. However, while the total capacity exceeds total demand, commercial recreation use in specific Use Areas may be limited in some alternatives and seasons. Accurately predicting the effects of this on commercial use is difficult, mainly because we cannot predict the ability of commercial operators to replace one 


\section{Environment and Effects}

None of the

alternatives would

have an economic

effect beyond marginal

impacts on the

activities of a few

individual outfitters

and guides, assuming

that 1999 use levels

adequately

characterize the future. location with another. Additionally, for certain uses and certain locations it is possible that displacement or dispersal will occur well before allocated limits are reached because operators and their clients want to avoid crowding.

Given the uncertainties and lack of data, an accurate numerical estimation of job and income impacts is not possible. The following section provides a qualitative discussion of the possible effects of each alternative.

\section{Socioeconomic Effects on Non-commercial Users (Issue 1)}

As indicated in the description of the current socioeconomic environment, the natural amenities and recreation opportunities in Southeast Alaska are an important factor in attracting residents and keeping them in the region, and this is an important source of economic activity. To actually quantify these relationships and the expected impact of the proposed alternatives on them is currently impossible.

It is reasonable to assume that the more restrictive alternatives, to the extent that they actually do restrict future commercial activity, may also preserve recreational opportunities for local residents. At the same time, non-commercial use can also lead to crowding and to noise and site degradation. Therefore, restricting commercial use only is no guarantee that the quality and quantity of recreational opportunities for non-commercial users will be maintained.

\section{Socioeconomic effects on the Recreation Industry (Issue 2)}

The recreation section analyzed effects on outfitter/guides in terms of the amount of current use above the allocation that could potentially be limited. A projected future doubling of current use levels was also considered as a scenario. The doubling scenario is not meant as a prediction of expected future events so much as a general indication of the impact of planning alternatives under continued strong growth in the commercial recreation sector. See the Recreation section for more information.

Figure $3-4$ shows the estimated use that would be above allocation by alternative as a share of total use. These estimates are the summation of results from specific Use Areas. The first panel of the figure displays estimates based on 1999 use levels. The largest impacts would be found in Alternative 2, where around five percent of spring and fall activity (presumably hunting) would either be eliminated or displaced to less crowded areas. Alternative 5 likewise would limit some spring activity but none in the fall, and Alternative 4 would minimally limit spring activity. No limits would occur under Alternative 3. These estimates are upper bounds, and it is likely, particularly given the small numbers involved, that alternative locations could accommodate the use above allocation in these areas. Therefore, none of the alternatives would have an economic effect beyond marginal impacts on the activities of a few individual outfitter/guides, if 1999 use levels adequately characterize the future.

If past trends continue, however, commercial recreation use in the analysis area will continue to grow, although perhaps not at the same pace as seen throughout much of the 1990s. If this is the case, the impacts of the alternatives and the differences among them will be more important. The second panel of Figure 3-4 shows the same percent depiction of existing use above the allocation levels but this time under the projected future assumption of a doubling of 1999 use levels. Now the 


\section{Environment and Effects 3}

restrictions imposed by Alternatives 2, 4, and 5 on spring hunting activity are far more pronounced, ranging from around 15 percent to 27 percent. This means that guides working the spring season may find their options for growth more limited in the future, if there is a significant expansion of current business activities. Once again the ability of outfitters and guides to use alternative locations could mitigate these impacts. In addition, big game population harvest restrictions may limit the ability of hunting guides to increase their business activity more than recreation capacity allocations.

See Tables 3-14 and 3-15 for specific numbers of current and projected use levels that would be above total seasonal allocation levels.

Figure 3-4. Total Use Above Allocation as a Percent of Total Use, Assuming 1999 Commercial Use Levels and Twice-1999 Use Levels

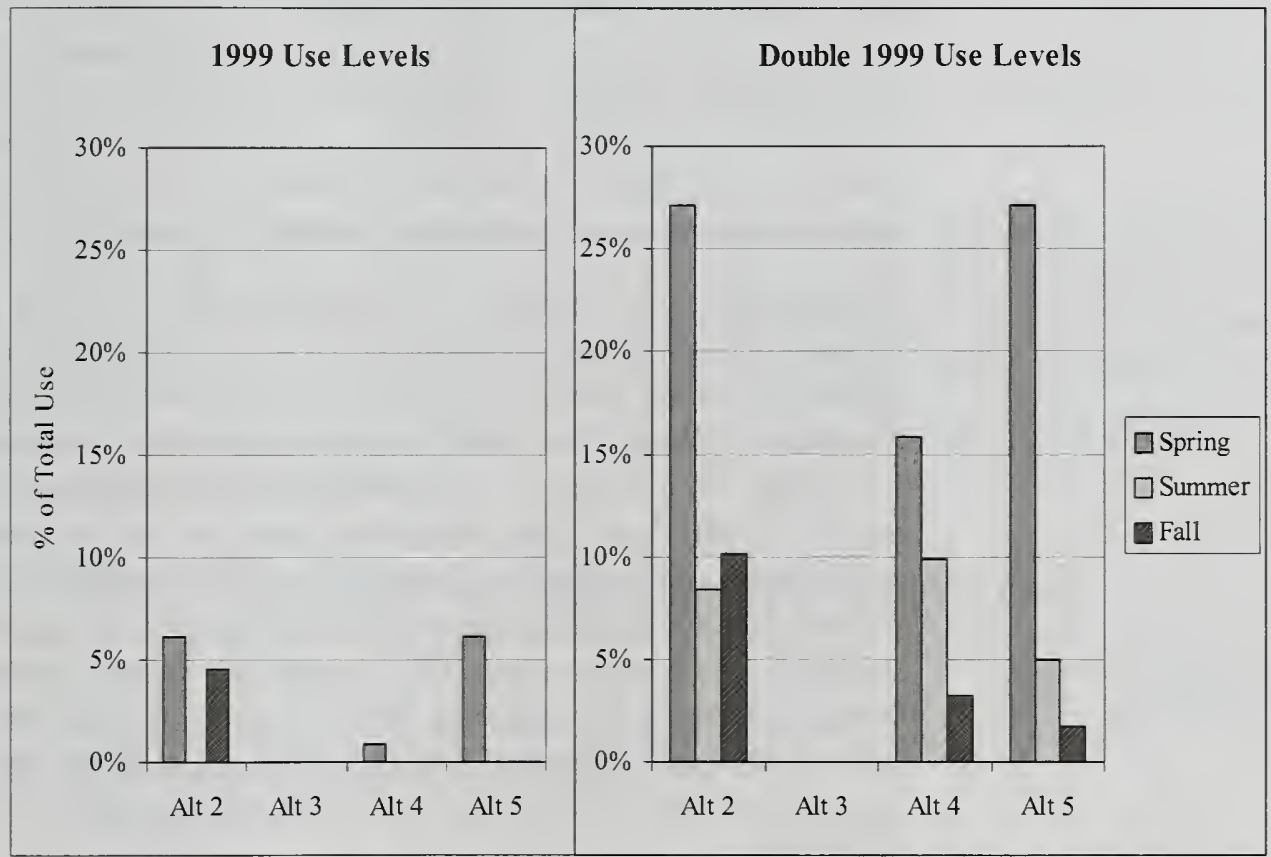

Source: USDA Forest Service. See Recreation Section, Tables 3-13 and 3-14, for corresponding numbers in group days. Alternative 1 is not shown because no specific allocations are made under the no-action alternative.

Under the projected doubling-of-use scenario, the summer season displays smaller potential impacts, with limited use levels ranging from five percent in Alternative 5 to eight percent in Alternative 2 and ten percent in Alternative 4. No limits would occur under Alternative 3. In terms of absolute numbers, summer season impacts could be equivalent or somewhat larger than those for the spring season. This is especially true where activity is based on a specific location, due, for example, to its scenic beauty, abundant wildlife, or other considerations such as access or convenient location relative to tour boat itineraries. The ability to take advantage of unused capacity elsewhere on the forest may be more constrained in these cases. On the other hand, the Enclaves and other concentrated use areas could significantly alleviate the limits on commercial use for firms catering to large groups. Consequently, even under the doubling-of-use scenario, there are likely to be 


\section{Environment and Effects}

marginal impacts to some operators (or the exclusion of new firms), but significant impacts on the industry as a whole appear to be unlikely.

\section{Cumulative Effects}

As described earlier, tourism is a major factor enabling many communities in the analysis area to adapt to recent sharp declines in the wood products and seafood processing industries. Since tourism has become a major element in the regional economy, any effects, positive or negative, become increasingly important.

Alternatives 2, 4, and 5 would result in a few minor local limits on current commercial recreation use levels, but these are likely not large enough to have a significant effect on the regional economy. No limits would occur under Alternative 3. All the action alternatives allow for growth in commercial use across the analysis area as a whole. Alternative 1 would not provide any amount of certainty regarding the allowed level of future commercial use. The outfitter/guide component of the overall tourism sector is relatively minor for the larger towns and the region as a whole, although in some of the smaller communities this is likely to become increasingly important. Cumulative effects of the action alternatives in terms of increased employment and revenue on the regional economy would likely be positive. The higher the alternative allocation to commercial, the more potential each alternative would have for cumulative growth in this sector.

Another less tangible but no less important factor are the amenity values and recreational opportunities provided by the national forest. These values and opportunities are a major ingredient in the quality of life enjoyed by the residents of Southeast Alaska. This analysis centers around how commercially guided recreation fits within the context of non-commercial recreation and the region's natural character, which is highly valued by residents and non-residents alike. Growth in regional population (when Juneau is included) and in non-commercial use from visitors has increasingly reduced the opportunity of experiencing solitude and wilderness in certain areas. The alternatives propose commercial recreation use that would contribute cumulatively to a reduction in those opportunities in proportion to the commercial allocation. Opportunities for solitude and wilderness experiences would still exist in the analysis area but at reduced levels from those currently available. 


\section{Environment and Effects 3}

\section{Introduction}

\section{Wilderness}

The National Wilderness Preservation Act of 1964 mandates that designated "wilderness areas ...shall be administered for the use and enjoyment of the American people in such a manner as will leave them unimpaired for future use and enjoyment as wilderness, and so as to provide for the protection of these areas, the preservation of their wilderness character, and for the gathering and dissemination of information regarding their use and enjoyment as Wilderness."

Congress designated Wilderness in the analysis area in two pieces of legislation. The Alaska National Interest Lands Conservation Act (ANILCA) of 1980 established four Wilderness areas within the analysis area totaling 2,174,634 acres. One area, Admiralty Island, was also designated as National Monument. Prior to ANILCA there were no designated Wilderness areas in the analysis area. In 1990, the Tongass Timber Reform Act (TTRA) amended ANILCA and designated two new Wilderness areas and one Wilderness addition, within the analysis area totaling 115,856 acres. This brings the total to 2,290,490 acres in six Wilderness areas within the analysis area (Table 3-20).

In ANILCA, Congress reaffirmed and expanded upon the purposes of wilderness as stated in the 1964 Wilderness Act, specifically for wilderness established in Alaska. In recognition of unique situations and established uses in Alaska, ANILCA also provided a number of specific exceptions to prohibitions of the Wilderness Act.

The Forest Plan manages Wilderness through specific Wilderness LUDs and standards and guidelines.

Table 3-20. Wilderness Areas Within the Analysis Area

\begin{tabular}{lcc}
\multicolumn{1}{c}{ Name } & $\begin{array}{c}\text { National } \\
\text { Forest Acres }\end{array}$ & $\begin{array}{c}\text { National Forest Acres } \\
\text { Within Shoreline Zone }\end{array}$ \\
\hline Wilderness Areas Established by ANILCA & & \\
Kootznoowoo* & 937,396 & 156,003 \\
South Baranof & 319,568 & 88,566 \\
Tracy Arm - Fords Terror & 653,179 & 47,091 \\
West Chichagof - Yacobi & 264,491 & 78,240 \\
Wilderness Areas Established by TTRA & & 9,754 \\
Young Lake Addition to Kootznoowoo & 18,462 & 13,489 \\
Chuck River & 74,298 & 393,143 \\
Pleasant-Lemesurier-Inian Islands & 23,096 & \\
\hline
\end{tabular}

* Kootznoowoo Wilderness includes the Young Lake Addition acres in analysis area.

Source: Total acreages are as reported to Congress with official boundary maps. These wildernesses include only the public lands above mean high tide. 


\section{Environment and Effects}

\author{
Affected \\ Environment
}

\section{Overview}

Many of the various wildland ecosystems of Southeast Alaska are represented within the Wilderness included in the analysis area. These areas include glaciers, offshore islands, seacoasts facing the open Pacific Ocean and inland passages, major river systems, and old-growth temperate rain forests. One of the largest areas, Kootznoowoo (Admiralty Island) Wilderness, contains vast, virtually intact ecosystems. The Wilderness areas are mostly in a pristine condition with the imprint of humans generally not noticeable. They offer outstanding opportunities for solitude and primitive recreation away from the shoreline.

Management intensity varies among Wilderness areas. The areas with the highest use tend to have the most need for management, which is geared toward helping resolve user conflicts and preserve the wilderness resource. Some areas, such as Kootznoowoo (Admiralty Island) and Tracy Arm-Fords Terror Wilderness Areas, have more intensive management programs such as campsite monitoring, use of permit systems (Pack Creek), wilderness ranger patrols, visitor contacts, and visitor education programs. West Chichagof and South Baranof have had campsite monitoring and inventory. Other Wilderness areas are managed less intensively.

Of the approximately 14,000 guided recreationists using the analysis area in 1999, there were some 3,500 commercially guided visitors recreating in 859 groups in Wilderness areas within the analysis area. Commercial recreation activities occurring in the Wilderness areas are similar to other areas in the analysis area with nature walks, fishing, hunting, camping, and sightseeing. Approximately 21 percent of these visitors and 15 percent of the groups camped in the Wilderness. Camping activities generally create the most impact of all recreation activities because of the length of stay and the site impacts of tents, social trails, and fire rings. The length of stay increases the potential for negative social and wildlife effects; wildlife may be affected by the longer presence of people, particularly during early morning and evening hours when animals are active.

While current (1999) commercial use levels are relatively light, the use is not evenly distributed and tends to concentrate in a few areas, including: Rakovoi Bay, Red Bluff Bay, Whale Bay, Pleasant Island, Fords Terror, Pybus Bay, and Brothers Islands.

\section{Wilderness Areas Within the Analysis Area}

The following section presents descriptions including information on access, facilities, use, and recreation opportunities for each of the Wilderness areas included in this analysis. The shoreline zone is only a small part of each Wilderness area.

\section{Kootznoowoo Wilderness (Admiralty Island)}

The 955,858-acre Kootznoowoo Wilderness within the Admiralty Island National Monument (including the Young Lake addition) is a largely intact coastal island ecosystem. The area was originally designated a national monument in 1978 by presidential proclamation, which recognized the island for its superlative combination of scientific and historical objects. There are 156,003 acres within the shoreline section of the Wilderness (16 percent of the total acres). The island is internationally known for its population of brown bears and bald eagles, and renowned for its old-growth spruce and hemlock forest. The area has also been 


\section{Environment and Effects 3}

designated a Man in the Biosphere Reserve, which includes fostering relationships between people and the biosphere by integrating social, physical, and biological sciences to address issues. Monitoring, research, and education are also important components of these reserves. Protection and study of Tlingit cultural resources, other historical resources, ecology, geology, brown bears, and bald eagle populations are specifically directed in the Forest Plan (USDA Forest Service 1997b). The Forest Plan goal for the island is to preserve the ecosystem so there are opportunities to study the various resources. Management objectives focus on inventory, research, protection, and interpretation of the resources, and on making that information available to the public and other agencies.

Recreation facilities include 14 public recreation cabins, 9 shelters, and 27 miles of trails. The Cross Admiralty Canoe Route and Pack Creek Bear Viewing Area are prime recreation attractions that receive concentrated visitor use. Except for Pack Creek and the Mitchell Bay area, visitors experience a moderately low frequency of encounters with other parties in most locations within the Wilderness. A great deal of use takes place on the shoreline and in adjacent saltwater where fishing, sightseeing, wildlife viewing and, photography occur. Despite the presence of boats and airplanes, Kootznoowoo remains a high quality wilderness experience. Opportunities for risk, challenge, remoteness, and solitude are generally good. Access is easier than some more remote Wilderness areas. The northeastern portion is easily accessible from Juneau by small boat or floatplane and affords consistently good opportunities for fall hunting. The Alaska Marine Highway provides transportation to Angoon on the west side of Admiralty Island, which serves as a portal for points south and east. Many of the interior lakes are accessible by short floatplane trips.

\section{South Baranof Wilderness}

The 319,568-acre South Baranof Wilderness is on the south end of Baranof Island. There are 88,566 acres within the shoreline section of the Wilderness ( 28 percent of the total acres). South Baranof is composed of high mountains rising from sea level to approximately 4,000 feet elevation within two or three miles of the beach. Much of the higher elevation is covered with permanent snowfields, cirques, and lakes, with waterfalls near the coast.

Generally, this Wilderness offers visitors outstanding opportunities for risk, challenge, remoteness, and solitude due to its inaccessibility and wild character, particularly on the Gulf of Alaska side. Visitors may have more frequent encounters with the sights and sounds of human activities adjacent to the shorelines of this Wilderness because commercial fishermen often seek refuge from storms in the many sheltered bays. There are three public recreation cabins and two trails totaling one and a half miles. Much of the recreation use is associated with these developed facilities but the bulk of the Wilderness offers a high degree of remoteness and solitude. Common recreation activities include freshwater lake fishing, big game hunting, camping, hiking, and boating. South Baranof Wilderness receives moderate deer and goat hunting pressure from Sitka, Kake, and Angoon residents. Beach combing, photography and fishing are also popular activities. 
Tracy Arm-Fords Terror Wilderness

The 653,179-acre Tracy Arm-Fords Terror Wilderness is about 50 miles southeast of Juneau. The only water access to the majority of this Wilderness is through Holkham Bay, adjacent to Stephens Passage. There are 47,091 acres within the shoreline section of the Wilderness (seven percent of the total acres). Tracy ArmFords Terror lies adjacent to the Chuck River Wilderness on the west. Long narrow fiords starting at salt water and reaching to 5,000 - to 7,000 -foot glacial covered peaks characterize the Wilderness. Dramatic water features in the area include cascades, waterfalls, and icebergs floating in salt water.

There are no public trails or facilities in this Wilderness. The major recreational use occurs in Tracy and Endicott Arms by large cruise ships and by smaller tour boats and permitted outfitter/guides, mainly from Juneau. The area also receives kayaking use by the general public. The highest use is attributed to cruise ships in Tracy Arm, resulting in the opportunity for solitude and remoteness often being interrupted by tours. Endicott Arm receives less use by tour boats, and opportunities for solitude and remoteness increase closer to the Dawes Glacier. Tracy Arm-Fords Terror Wilderness is very large, and the majority of this Wilderness offers outstanding opportunities for risk, challenge, remoteness, and solitude away from the shoreline.

\section{West Chichagof-Yakobi Wilderness}

This 264,491-acre Wilderness encompasses the western side of Chichagof and Yakobi Islands from Kakul Narrows to Soapstone Point. There are 78,240 acres within the shoreline section of the Wilderness (30 percent of the total acres). The distance of this Wilderness from population centers and its relative inaccessibility have allowed most of the area to retain its primitive wilderness character. Visitors can expect a high probability of experiencing isolation from the sights and sounds of humans, closeness to nature, tranquility, and self-reliance in an environment that offers a high degree of challenge and risk.

Facilities include four recreation cabins and five hiking trails totaling 6.8 miles. The opportunity for solitude is reduced around these facilities. Use is especially concentrated around the public recreation cabin at White Sulphur Hot Springs, a favorite stop for boaters, commercial fishers, kayakers, guided groups, and others who enjoy the hot springs. Some areas along the shoreline have a long history of human habitation especially related to mining. Visitation has been steadily increasing. Recreational fishing, sightseeing, camping, picnicking, hiking, hunting and gathering forest products have increased in popularity during recent years. Kayaking, in particular, has become a major recreational pursuit and means of transportation for visitors. Long-term increases in recreation will probably focus on the outer coast of Chichagof and Yakobi islands.

\section{Chuck River}

This 74,298-acre Wilderness area stretches from the Chuck River drainage and upper Windham Bay north to Point Astley on Holkham Bay (also known as Sumdum Bay) with the use of private lands within the Chuck River area. Subsistence use is moderate and includes a portion of the south side of Endicott Arm. There are 9.754 acres within the shoreline section of the Wilderness (13 percent of the total acres). The area is about 10 miles northeast of Hobart Bay and about 70 miles south of Juneau. It is adjacent to the Tracy Arm-Fords Terror Wilderness and abuts areas of current and planned logging activity. There are known mineral deposits, including 


\section{Environment and Effects 3}

old mines and numerous un-patented mining claims within the Wilderness. Recreation use has increased slightly and may increase if further development at Hobart Bay occurs. Fish habitat values are high and the area is a large producer of pink, chum, and coho salmon.

This Wilderness may offer a sense of solitude and remoteness once away from the shorelines of Windham Bay. The bay receives moderate boat traffic from pleasure vessels, small tour boats, commercial fishing vessels, and local cabin owners with inholdings. The Narrows and water depth at the head of the bay limit large boat access. A small, rustic lodge is present near the head of the bay. Recreation opportunities are primitive and there are no Forest Service public recreation facilities except for 0.8 miles of primitive trail. This area has a rich cultural history related to mining, fox farms, and homesteading.

Fishing and bear hunting are major recreational activities. The fiords and tidewater glaciers that draw cruise ships to neighboring Tracy Arm-Fords Terror are not present in this Wilderness. Because of this, the area still offers visitors an outstanding opportunity for risk, challenge, remoteness and solitude.

Pleasant-Lemesurier-Inian Islands

This 23,151-acre Wilderness consists of Pleasant Island, Lemesurier Island, and Inian Islands in Icy Strait between Chichagof Island and Glacier Bay National Park. There are 13,489 acres within the shoreline zone of the Wilderness (58 percent of the total acres).

Although no major fish streams are located on the islands, there is some deer and grouse habitat, and subsistence use does occur. The nearest communities are Gustavus, Elfin Cove, and Hoonah. Uses in and around this Wilderness include heavy cruise ship traffic accessing Glacier Bay, subsistence deer hunting on the islands, subsistence fishing in the surrounding waters by nearby residents, and extensive boat traffic from local residents. Most of the use affecting this Wilderness occurs in the surrounding waters. Because of the heavy use surrounding the islands, opportunities for risk, challenge, remoteness, and solitude are limited.

\section{Environmental Consequences}

\section{Direct Effects on Recreation Users and the Recreation Industry (Issues 1 and 2)}

Commercial recreation use in Wilderness could affect values such as solitude, sense of isolation, sense of remoteness, self-reliance, challenge and risk, and the untrammeled natural character. People are also concerned about the possible cumulative impacts to these wilderness values.

Wilderness resources and values are difficult to describe and quantify because of the complexity of the resource and the range and variety of personal feelings about Wilderness. This analysis uses the Wilderness Act of 1964, ANILCA (1980), and the Tongass Timber Reform Act (1990) to identify the primary values inherent in Wilderness. 


\section{Environment and Effects}

Each alternative is analyzed with regard to the effects on the following values:

- Opportunity for solitude, sense of isolation,

- Opportunity for a sense of remoteness - that is, remoteness from the sights and sounds of human activities,

- Opportunity and setting for primitive recreation, including the elements of challenge and risk, and

- Protection of the natural state of wilderness - undeveloped, untrammeled, unaltered, undisturbed ecosystems.

Effects on ecosystems such as soils, vegetation, fish, and wildlife are covered in other sections of this chapter.

Generally, factors associated with use are:

- Number of encounters,

- Impact on solitude,

- Dispersal of visitors,

- Displacement of visitors, and

- Resource degradation.

Not all of the factors listed above are independent of each other. For example, as encounters increase it could affect a visitor's sense of solitude or cause displacement of other visitors.

The actual effects of guided use for most factors are primarily proportional to the amount of overall use level provided in the alternative allocations. Higher allocations could result in higher levels of use with the associated diminished sense of solitude, isolation, and remoteness. Some people may sense a decrease in the feeling of risk and challenge knowing that other parties are in the area that could provide assistance in the event of emergency. High use levels could affect the physical characteristics of campsites and trails (bare soil and roots, soil compaction, vegetation loss, lack of firewood) as well as other characteristics (fire rings, litter, human waste). These characteristics are often measured through a process known as the Limits of Acceptable Change (LAC).

To provide a comparative basis for describing the different alternative allocation effects on Wilderness, an estimated level of potential use was developed based on 1999 commercial use levels. This use was split into two categories, day use and overnight use. Day use is typically boat-based and the duration is usually no more than several hours for the purpose of hikes, brown bear hunting, wildlife viewing, or general sightseeing. Overnight use lasts at least 14 hours in one location. Camping generally creates the most impact of all the activities. This is because of the length of stay and the establishment of tent sites, social trails, and fire rings. In addition, litter and human waste also tend to be of greater concern.

Table 3-21 compares estimated potential commercial use in Wilderness in different alternatives. These estimates assume that Wilderness use and camping levels will continue at the same proportions to the total allocation as they did in 1999. Thirtysix percent of the total commercial use in 1999 in the analysis area occurred in Wilderness. Fifteen percent of that Wilderness use involved camping. These 
percentages from the 1999 actual use data were extrapolated against the total allocations in each alternative to provide an estimate of potential Wilderness use in the future.

Table 3-21. Estimated Potential Commercial Use in Wilderness, by Alternative, Based on 1999 Use Levels

\begin{tabular}{|c|c|c|c|c|c|}
\hline \multirow[b]{2}{*}{ Commercial Use } & \multirow{2}{*}{$\begin{array}{l}\text { 1999Actual } \\
\text { Use }\end{array}$} & \multicolumn{4}{|c|}{ Alternative* } \\
\hline & & 2 & 3 & 4 & 5 \\
\hline Day Use (Groups) & 730 & 5,170 & 12,441 & 1,895 & 5,698 \\
\hline Overnight Use (Groups) & 129 & 912 & 2,196 & 334 & 1,006 \\
\hline Total Groups & 859 & 6,082 & 14,637 & 2,229 & 6,704 \\
\hline
\end{tabular}

*Alternative 1 is not shown because the no-action alternative makes no specific allocation. Commercial use is allowed on a case-by-case basis from current levels up to 50 percent of the recreation carrying capacity

Impacts from increased use would most likely be more acute at areas that have natural attractions or at sites that have physical characteristics that concentrate use such as Fords Terror and Tracy Arm. Protected anchorages and areas allowing easy boat access may also focus use on the adjacent sites such as the Brothers Islands. Impacts may also occur at specific locations where groups are dropped off or picked up (Harbor Island, Oliver Inlet). Most of these locations are along the shoreline where visibility and noise carry farther than if similar activities took place in a

\section{Dispersal-when}

people spread out and travel farther to find desirable and available campsites or places.

Displacement-when people avoid an area on a long-term basis because of regulation or crowding.

\section{forested area.}

Increasing levels of use may have other effects on Wilderness such as dispersal and displacement. These effects can be difficult to measure but are often due to the type and amount of use within a Wilderness. Dispersal is when recreationists spread out and travel farther to find desirable and available campsites or places to go ashore. In this analysis, dispersal is viewed as a short-term effect. As an example, a visitor may move farther down the shoreline of a bay because another group is using the preferred area. Displacement is more of a long-term effect resulting in a decision by visitors to avoid an area within a Wilderness based on previous experiences such as regulation or crowding. Displacement could mean relocating to another Wilderness or to a LUD that is capable of providing the desired recreation experience.

Dispersal within these Alaska Wilderness areas may not occur as easily as in other Wilderness areas. The lack of trails, very steep terrain, and thick vegetation in many locations make local dispersal physically more difficult. The relatively unique nature of coastal Wilderness ties the use of the land with the travel routes and attractiveness of marine waters. On the other hand, dispersal may also occur more easily because access is easily available along marine waters often accessed by motorized and other watercraft. Displacement most likely occurs more with local visitors who have a greater ability to make repeat visits to an area and can sense the degree of change. This type of displacement has been evident at Pack Creek. The proportion of residents visiting the site has declined from 50 percent to about 20 percent of the use.

As use increases beyond current levels, it is difficult to accurately predict where increased use will occur or how much impact will take place. In this analysis, it is assumed that use levels will continue to increase in areas currently receiving high levels of use up to the point where site-specific capacities are required. Additional 
areas that are currently only slightly used will also see an increase in use levels. It is also probable that similar areas nearby to these popular sites will act as a substitute and grow in popularity as well. For example, if one bay or an arm of a bay reaches capacity, than it is likely that the nearest bay offering similar attributes (protected anchorage, trail, open timber for hiking, good beaches) will experience increased use. Areas currently receiving very low or no use will also see increased growth depending on the commercial allocation as more popular areas reach capacity.

Specific potential direct effects of each alternative are discussed below.

Among the action alternatives, Alternative 3 would allow for the highest amount of commercial use and the highest amount of use in Wilderness. Estimated day use could increase from 730 groups to 12,441 groups, while overnight use would increase from 129 groups to 2,196 groups. However, this level of use is not likely to occur in the near future based on current growth rates. This use level is consistent with the Forest Plan standards and guidelines for Wilderness.

Alternative 3 would have the greatest potential to disperse and displace both guided and non-guided visitors compared to the other alternatives if visitors choose to avoid other users or the requirements of a permit system. There is a greater potential for some outfitter/guides to be displaced because the restrictions may make it difficult to conduct business or their client satisfaction could be decreased.

At this level of use, impacts on some heavily used campsites could exceed the limits of acceptable change that would trigger management actions. The most fragile and/or popular sites would be most susceptible, depending on the individual site conditions. More campsites would likely be affected under Alternative 3 than under the other alternatives. Site-specific monitoring will identify sites exceeding limits of acceptable change. Rest/rotation of campsites could be more difficult because of higher demand for sites. Specific sites could also be hardened but this is generally not encouraged over large areas of the Wilderness.

Alternative 3 would have the highest potential for regulation and strategies to limit use such as Wilderness use permits, use limits, zoning use by time and space, and limiting camping. These strategies would need to be implemented in broader segments of the shoreline area of a Wilderness rather than limited only at areas of concentrated use. The sense of solitude and remoteness could decrease for all visitors. The non-commercial and guided groups could both experience a greater loss of a sense of challenge and risk because of the potential increase in the number of encounters compared to the current situation. If Wilderness permits should become necessary, some visitors in the more crowded areas could have their sense of wilderness reduced because of the regulatory restraints such as campsite selection, visitor numbers, or date availability placed upon them.

Alternative 5 would allow for the second highest amount of total commercial use and use in Wilderness. Compared to 1999 commercial use levels, day use could increase from 730 groups to 5,698 groups while overnight use could increase from 129 groups to 1,006 groups. However, this level of use is not likely to occur in the near future based on current growth rates. This use level is consistent with the Forest Plan standards and guidelines for Wilderness. 


\section{Environment and Effects 3}

Alternative 5 has the second highest potential for crowding or other impacts that could occur in specific areas where there are attractions.

This alternative provides the second highest potential to cause dispersal or displacement of Wilderness users from concentrated areas of use. Displaced users may also elect to go to a less crowded Wilderness or to a non-Wilderness LUD that provides the recreation experiences they are seeking.

Impacts on campsites at specific locations could exceed the limits of acceptable change with this level of use, which would trigger management actions such as campsite hardening or rest/rotation. The most fragile and/or popular sites would be most susceptible, depending on individual site conditions. Site-specific monitoring will identify sites exceeding limits of acceptable change

Alternative 5 would have the second highest potential for regulation and strategies to limit use at specific locations where use might concentrate at levels causing effects beyond the acceptable level of change. These strategies could include Wilderness use permits, use limits, zoning use by time and space, and limiting camping. This could be done to prevent overcrowding at specific locations that have historically had the most use (best campsites, protection from the weather, natural attractions). Because of higher use levels, the sense of solitude and remoteness could decrease for some guided and unguided visitors. Unguided users would most likely experience a greater loss of a sense of challenge and risk at some of these specific locations. This might occur at some locations if visitors were required to register for the use of those locations when they obtain a permit. Guided visitors would probably not be adversely affected by the permitting process since their activities are already regulated through Special Use permits. Overall, however, the use of management strategies would be limited to concentrated use areas and not necessary for large portions of the Wilderness areas.

Alternative 2 has the third highest commercial use allocation and would allow for the third most potential for use in Wilderness areas. This alternative would allow for an increase in Wilderness use over 1999 use levels: estimated day use could increase from 730 groups to 5,170 groups, while overnight use could increase from 129 groups to 912 groups. However, this level of use is not likely to occur in the near future based on current growth rates. This use level is consistent with the Forest Plan Standards and Guidelines for Wilderness.

Alternative 2 could result in the dispersal of some users and the displacement of others. This may occur if visitors wish to avoid other users or as a result of requirements of a possible Wilderness permit system. Displaced users may also elect to go to a less crowded Wilderness or to a non-Wilderness LUD that provides the recreation experiences they are seeking.

Impacts on campsites at specific locations could exceed the limits of acceptable change with this level of use, which would trigger actions such as campsite hardening or rest/rotation. The most fragile and/or popular sites would be most susceptible, depending on the individual site conditions. Sites in Tracy Arm, Endicott Arm, Fords Terror, northern Seymour Canal, Brothers Islands, and Pleasant Island are areas that could be unacceptably affected. Site-specific monitoring will identify sites exceeding limits of acceptable change. 
Alternative 2 has more potential for regulation than Alternatives 1 and 4 but less than Alternatives 3 and 5 . At specific locations where use might concentrate at levels causing effects beyond the acceptable level of change, management strategies to restrict use such as Wilderness use permits, use limits, zoning use by time and space, and limiting camping would likely need to be implemented. This would be done to prevent overcrowding at specific locations that have historically had the most use (best campsites, protection from the weather, natural attractions). Because of higher use levels, the sense of solitude and remoteness could decrease for some guided and unguided visitors. The unguided user would most likely experience a greater loss of a sense of challenge and risk at some of these specific locations. This might occur at some locations if visitors were required to register for the use of those locations when they obtain a permit. Guided visitors would probably not be adversely affected by the permitting process since their activities are already regulated through Special Use permits.

Alternative 4 has the lowest commercial use allocation and allows for the least use in Wilderness. Estimated day use would increase from 730 groups to 1,895 groups while overnight use would increase from 129 groups to 334 groups. This level of use is consistent with the Forest Plan standards and guidelines for Wilderness.

At specific locations where use might concentrate at levels causing effects beyond the acceptable level of change, management strategies to restrict use such as Wilderness use permits, use limits, zoning use by time and space, and limiting camping may need to be implemented under Alternative 4. This would be done to prevent overcrowding at specific locations that have historically had the most use (best campsites, protection from the weather, natural attractions).

At these potential use levels, the sense of solitude and remoteness could decrease for some guided and unguided visitors. The unguided users would most likely experience a greater loss of a sense of challenge and risk at some of these specific locations. This might occur at locations if visitors were required to register for the use of those locations when they obtain a permit. Guided visitors would probably not be adversely affected by the permitting process since their activities are already regulated through Special Use permits.

Alternative 4 would have the least affect on dispersal and displacement of visitors, who could more easily avoid other users or the requirements of a permit system at a specific site. Some displaced users could also elect to go to a less crowded Wilderness or another LUD providing the recreation experiences they are seeking.

Impacts on campsites and other use areas would be low in Alternative 4 but could exceed the limits of acceptable change on a site-by-site basis with this level of use. These impacts would have management strategies such as campsite hardening or rest/ rotation that would reduce or minimize the impacts. The most fragile and/or popular sites would be most susceptible, depending on the individual site conditions. Site specific monitoring will identify sites exceeding limits of acceptable change.

Even at this relatively low level of use, there is the potential for crowding or other impacts that could occur at areas where there are specific site attractions. Overall however, it is not likely that the need to use of strategies to manage use throughout large shoreline portions of the Wildernesses would be necessary under Alternative 4. The probability for a remote experience away from the sights and sounds of human 


\section{Environment and Effects 3}

activities, with isolation and a sense of privacy while on national forest lands would be the greatest in this alternative.

The following places may become more popular as substitute sites for the currently most popular areas under Alternatives 2 and 5:

$\begin{array}{lll}\text { Eliza Harbor } & \text { Gambier Bay } & \text { Hood Bay } \\ \text { Chaik Bay } & \text { Patterson Bay } & \text { Gut Bay } \\ \text { Red Bluff Bay } & \text { Whale Bay } & \text { Kritoi Basin } \\ \text { Still Harbor } & \text { Port Banks } & \text { Cedar Pass } \\ \text { Crawfish Inlets } & \text { Leo's Anchorage } & \text { Cobol } \\ \text { Ford Arm } & \text { Klag Bay } & \text { Lake Anna } \\ \text { Black Bay } & \text { Goulding Harbor } & \end{array}$

The northeastern portion of Admiralty Island, and the White Sulphur Springs Area, including Sea Level Slough, Mirror Harbor, Inian Island, and Hoktaheen River are other possible sites.

Alternative 1 does not establish a specific allocation of commercial use. It provides a commercial allocation equal to actual use authorized on a case-by-case basis, which could be up to 50 percent of the carrying capacity. The existing moratorium on brown bear guiding and site-specific limits on commercial use in areas such as Fords Terror would continue. In addition, the existing commercial use stipulations at other Wilderness locations, such as prohibitions on outfitter/guide use above the grass flats at King Salmon River and Wheeler Creek, would remain in effect. Allocations would not be set for commercial use so use levels, and their effects are difficult to predict. The current level of use by the unguided recreationists could continue or increase. The Wilderness experience with remoteness from the sights and sounds of human activities, isolation, and a sense of privacy would be maintained.

\section{Indirect Effects on Recreation Users and the Recreation Industry (Issues 1 and 2)}

Indirect effects of these alternatives such as the spiritual and inherent intrinsic values of wilderness are difficult to measure. People who may not visit a Wilderness area may still appreciate wilderness vicariously and support the concept and need for wilderness. The sense that knowing there are still wild places on earth and the realization of the spiritually sustaining and cleansing powers these areas provide are important to many people, most of whom never visit wilderness. As visitor numbers increase within Wilderness, concerns regarding preservation of an enduring resource of Wilderness may increase. 
Specific potential indirect effects of each alternative include the following.

Among the action alternatives, the potential for indirect effects due to increased use would be greatest under Alternative 3 . Those people who benefit spiritually or vicariously from Wilderness may feel that some of the key characteristics inherent in Wilderness have been eroded.

Alternative 5 has the second highest potential to affect those users who benefit spiritually or vicariously from Wilderness. However, it is not likely they would be able to detect changes to key Wilderness characteristics.

Alternative 2 would probably not affect those users who benefit spiritually or vicariously from Wilderness. They would not be able to detect the kinds of changes that may be affecting actual visitors at the proposed level of use in this alternative.

Alternative 4 has the least potential to affect those users who benefit indirectly from Wilderness. It is not likely that such users would be able to detect the kinds of changes that may be affecting actual visitors.

The current low level of use and minimal impacts at most locations in Alternative 1 would not affect those people who derive spiritual or vicarious benefits from Wilderness.

\section{Cumulative Effects on Recreation Users and the Recreation Industry (Issues 1 and 2)}

Activity adjacent to Wilderness areas may also add to the cumulative effects of this project. Increased boat traffic on adjacent marine waters could have an effect on those areas where boats pass close to Wilderness. The type of boats passing by could also affect Wilderness users. Larger boats may have an effect because of their larger scale; smaller boats may have an effect because they can operate closer to shore where people are camping or hiking. Near-shore commercial fisheries may also contribute to the cumulative effects. Over-flights by aircraft for scenic tours and commercial purposes could also create a similar type of effect. All of these activities could contribute to noise, visual impacts, and a lesser feeling of solitude.

Another potential cumulative effect is development on private property adjacent to or on in-holdings within Wilderness areas, primarily in the form of lodges. These lodges would likely create increased activity in the adjacent Wilderness and waters and affect other Wilderness visitors. It is difficult to accurately predict future development on private lands but for this analysis, existing and currently proposed lodges are considered. It is assumed that they could have some effect, based primarily on their proximity to the Wilderness.

Specific potential cumulative effects of the alternatives could include the following.

Alternative 3 has the most potential for increased use in the form of additional plane and boat traffic accessing Wilderness or areas adjacent to Wilderness. The commercial allocation in this alternative could result in the development of more lodges and tourism-related businesses. Small communities adjacent to Wilderness such as Gustavus, Elfin Cove, Excursion Inlet, Hoonah, Tenakee, Pelican, and 


\title{
Environment and Effects
}

Angoon may be proportionately affected more than larger communities. Because of the level of increase, larger communities such as Juneau and Sitka could also be affected.
Alternative 5 would likely add to the potential for increased use in the form of additional plane and boat traffic accessing the Wilderness or areas adjacent to Wilderness, but it would be less than in Alternatives 3. The commercial allocation in this alternative could result in the development of more lodges and tourism-related businesses. Small communities adjacent to Wilderness such as Gustavus, Elfin Cove, Excursion Inlet, Pelican, Hoonah, and Angoon may be proportionately affected more than larger communities.

\begin{abstract}
Alternative 4 would likely add to the potential for increased use in the form of additional plane and boat traffic accessing the Wilderness or areas adjacent to Wilderness, but it will be less than in Alternatives 3 and 5. The commercial allocation in this alternative could result in the development of more lodges and tourism-related businesses. Small communities adjacent to Wilderness such as Gustavus, Elfin Cove, Excursion Inlet, Hoonah, Tenakee, and Angoon may be proportionately affected more than larger communities.
\end{abstract}

\begin{abstract}
Alternative 2 would likely add to the potential for increased Wilderness use in the form of additional plane and boat traffic accessing the Wilderness or areas adjacent to Wilderness. The commercial allocation in this alternative could potentially result in the development of more lodges and tourism-related businesses. Small communities adjacent to Wilderness such as Gustavus, Elfin Cove, Excursion Inlet, and Angoon may be proportionately affected more than larger communities.
\end{abstract}

Cumulative effects under Alternative 1 would be similar to those under the action alternatives. Currently four lodges on or directly adjacent to Admiralty Island are within the analysis area, and a fifth is under construction. A lodge exists on private land adjacent to the Chuck River Wilderness. In addition, management activities by other agencies may contribute to the use in or adjacent to Wilderness. For example, Glacier Bay National Park's 2001 vessel restriction displaced boats that normally visited the park. As a result, there was an increase in boat traffic in Tracy Arm that coincided with the vessel restriction.

\section{Summary of Wilderness Effects}

In summary, all of the alternatives provide commercial use levels that are consistent with the Forest Plan Wilderness goals, objectives, standards, and guidelines. As allocations increase, there is an increased potential for higher levels of use in Wilderness. The higher allocations would allow more people to visit the Wilderness, where they might not be able to go without the services of an outfitter/guide. These increased use levels could result in more effects on wilderness values in specific locations. The effects could be mitigated by increased regulation at these sites if necessary. However, this increased regulation could affect the untrammeled or unhindered aspect of the wilderness experience. 


\section{Roadless Area Evaluations for Wilderness Recommendations}

The Tongass National Forest is more than 90 percent roadless, including Wilderness. Only small areas where communities are developing, or where road construction and timber harvest have occurred, are developed to any noticeable degree. At various times in the past, "boom and bust" development resulted in the temporary development and occupation of small areas that have since been largely reclaimed by nature. Developed areas total 1.3 million acres, or about 8 percent of the Tongass. Southeast Alaska residents, who number approximately 73,000 , are virtually surrounded by land they consider wilderness. Routine travel and ordinary outdoor recreation activities may require a higher degree of skill, risk-taking, and selfreliance than are typically required of adventurous backcountry visitors on other National Forests. This wilderness and the lifestyles associated with it are highly prized by residents and visitors alike.

A total of 110 inventoried roadless areas were identified and examined for potential wilderness recommendations in the 1997 Tongass Forest Plan Revision Final EIS process that resulted in the 1997 Tongass National Forest Land and Resource Management Plan. The 110 roadless areas identified covered approximately 9.4 million acres of National Forest System land. An update of this inventory appears in the Draft Supplement to the 1997 Tongass Land and Resource Management PlanRoadless Area Evaluation for Wilderness Recommendations, which addresses 115 roadless areas totaling approximately 9.7 million acres. Thirty of these roadless areas fall within the Shoreline Outfitter/Guide analysis area. These are shown in Table 3-22.

Table 3-22. Roadless Areas within the Shoreline Analysis Area

\begin{tabular}{cl|cl}
\hline $\begin{array}{c}\text { Roadless } \\
\text { Area } \\
\text { Number }\end{array}$ & Roadless Area Name & $\begin{array}{c}\text { Roadless } \\
\text { Area } \\
\text { Number }\end{array}$ & Roadless Area Name \\
\hline 201 & Fanshaw & 317 & Point Augusta \\
301 & Juneau-Skagway Icefield & 318 & Whitestone \\
302 & Taku-Snettisham & 319 & Pavlof-East Point \\
303 & Sullivan & 321 & Tenakee Ridge \\
304 & Chilkat-West Lynn Canal & 323 & Game Creek \\
305 & Juneau Urban & 325 & Freshwater Bay \\
306 & Mansfield Peninsula & 327 & North Kruzof \\
307 & Greens Creek & 328 & Middle Kruzof \\
308 & Windham-Port Houghton & 329 & South Kruzof \\
309 & Juneau Islands & 330 & North Baranof \\
310 & Douglas Island & 331 & Sitka Urban \\
311 & Chichagof & 332 & Sitka Sound \\
312 & Trap Bay & 333 & Redoubt \\
313 & Rhine & 334 & Port Alexander \\
314 & Point Craven &
\end{tabular}

See Table 3.3-45 of the DEIS Roadless Area Evaluation for Wilderness Recommendations. pp. 3-152-153.

The DEIS Roadless Area Evaluation for Wilderness Recommendations provides a description of these roadless areas, an evaluation of their wilderness characteristics. 


\section{Environment and Effects 3}

as well as the effects of the alternatives from that analysis on wilderness values, recreation, tourism, outfitter/guides, and other forest resources. That analysis is incorporated here by reference.

The preferred alternative identified in the Draft Supplement does not recommend any additional Wilderness areas and the analysis in this Draft Shoreline EIS regarding the effects of outfitter/guide use on Wilderness areas is based on that Preferred Alternative. A final decision on the recommendation of additional Wilderness is expected in the fall of 2002. If that final decision differs from the preferred alternative, the Final Shoreline EIS will consider those changes in its analysis.

Recreation activities proposed in the Shoreline Outfitter/Guide EIS involve temporary short-term use and will not affect potential Wilderness or roadless characteristics. If a roadless area was recommended for Wilderness designation, group sizes and access methods could be affected. 


\section{Environment and Effects}

\section{Wild, Scenic, and Recreation Rivers}

\section{Introduction}

\section{Affected Environment}

The Wild and Scenic Rivers Act of 1968, as amended, provides a means for recognizing and protecting the outstandingly remarkable scenic, recreation, geologic, fish and wildlife, historical, cultural, ecological, and other values of selected rivers. The intent of including a river in the National Wild and Scenic Rivers System is to preserve the free-flowing condition of the river itself, as well as the characteristics of the river's immediate environment, for the enjoyment and benefit of present and future generations.

If a river is considered eligible and suitable, it is recommended by the land management agency for designation as a 'wild', 'scenic', or 'recreation' river. This is a preliminary administrative recommendation developed as part of the Forest Plan. Congress has the authority to act on administrative recommendations and make a wild, scenic, or recreation river designation.

The Forest Plan recommended six rivers (five wild rivers and one scenic river) flowing within the analysis area shoreline zone to be considered for inclusion in the National Wild and Scenic Rivers System (see Table 3-23). No Recreation Rivers within the analysis area were recommended. The Hasselborg River and Lakes was recommended as a wild river in the Forest Plan but it has been excluded from the analysis area.

The Forest Plan desired condition for a wild river is a natural, free flowing and undisturbed condition. Ecological processes and changes predominate. The outstandingly remarkable values of which the river was designated remain outstanding and remarkable. Recreation users have the opportunity for primitive and semi-primitive experience, solitude, and remoteness in a natural setting. Interactions among users are infrequent, and evidence of human activities is minimal. Facilities and structures are rustic in appearance and promote primitive recreation and tourism experiences.

The desired condition for a scenic river is generally unmodified, free-flowing condition. Ecological processes and changes may be somewhat affected by human uses. The outstanding remarkable values for which the river was designated remain outstanding and remarkable. Recreation users have the opportunity for experiences ranging from Primitive to Roaded Natural (ROS categories) in a natural-appearing setting. Resource activities within the river corridor are not visually evident to the casual observer. Interactions among users are moderate. Facilities and structures are rustic in appearance and promote semi-primitive recreation experiences and/or public safety. A yield of timber may be produced that contributes to the forest-wide sustained yield.

To date these rivers have not been Congressionally designated as Wild, Scenic, or Recreation rivers. However, recommended rivers will be managed to retain their free-flowing character and outstandingly remarkable values to maintain their eligibility for inclusion in the National Wild and Scenic Rivers System. Additional information can be found in the Forest Plan and project planning record. The miles and classification of the rivers are provided in Table 3-23. 


\section{Environment and Effects}

\section{Table 3-23. Total Length (Miles) of Recommended Wild and Scenic Rivers in the Forest Plan That Flow Through the Analysis Area}

\begin{tabular}{lccc}
\hline River Name & Use Area & Classification & Miles \\
\hline Katzehin River & $01-01$ & Wild & 10 \\
Gilkey River & $01-04 \mathrm{~A}$ & Wild & 9 \\
King Salmon River & $04-09$ & Wild & 8 \\
Lisianksi River & $04-15$ & Wild & 5 \\
Glacial River & $04-04 \mathrm{~B}$ & Wild & 10 \\
Kadashan River & $04-12$ & Scenic & 8 \\
\hline
\end{tabular}

\section{Description of the Rivers}

\section{Katzehin River}

The mouth of the Katzehin River is six miles southeast of Haines on the east side of Lynn Canal. The river originates directly from the Meade Glacier at 500 feet in elevation and flows 12 miles to the west before terminating in Chilkoot Inlet. There are about 9,960 acres within the river corridor. The Katzehin is of geologic interest because of the sedimentation from meltwater at the terminus of Meade Glacier, which is causing the river to aggrade (or build up its bed). This leads to the active development of a braided stream channel. The river contains a productive run of chum salmon, which contributes significantly to the commercial fishery in Chilkoot Inlet. The river is exceptionally scenic. From the origin at the Meade Glacier, it flows through a very broad and highly braided stream channel surrounded by high mountains. A significantly large stand of coniferous forest exists on the south-facing slopes, which is unusual for a site so far north on the Tongass National Forest. Except for a cabin located near the mouth of the river, the entire drainage is unroaded, undeveloped, and is considered inaccessible and wild for this region. The mouth of the river has been identified as a crossing for a potential transportation corridor linking Juneau with Skagway.

The river is outstandingly remarkable for its exceptional scenery, active geology, and the productive chum salmon run.

The Katzehin River corridor is being used for guided big game hunting and fishing. One guide recorded taking four groups into this area in 1999. The river corridor is accessed by airboats from Lynn Canal and wheeled planes landing on the river's banks.

\section{Gilkey River}

The Gilkey River is located 31 miles north of the Juneau Airport. The river originates from the receding Gilkey Glacier at 100 feet in elevation and flows west, then north, for nine miles before terminating at its confluence with the Antler River The river corridor contains 7,720 acres. Numerous glaciers feed the river through several tributaries, and the Gilkey is of geologic interest because of current glacial activities. This river is a highly braided stream channel and a classic example of a glacial outwash system. The river corridor is primitive and undeveloped with no impoundments on the river. The area receives some recreational use from Juneau 
residents. Wildlife characteristic of the area are similar to major coastal mountain range rivers and include moose, brown and black bear, wolf, and mountain goat. Fishery values in the drainage are considered moderate.

The river is remarkable for its geologic and scenic values.

The Gilkey River corridor is being accessed by airboats from Berners Bay for personal use. Commercial flightseeing, wildlife viewing, and kayak tours are operating in this area especially at the mouth of the Antler River, which is part of the corridor. A privately built cabin is at the mouth of Antler River; the owner has applied for authorization to continue occupying it. Non-commercial use of the Gilkey River corridor is estimated to be higher then other Wild and Scenic river corridors in the analysis area due to its proximity to Berners Bay, which receives a lot of recreation use by the residents of Juneau.

\section{King Salmon River}

The King Salmon River is 20 miles south of Juneau. The river originates at 800 feet in elevation and flows eight miles into a large tidal estuary in King Salmon Bay, Seymour Canal. There are 2,660 acres in the river corridor. Wildlife characteristic of the area includes brown bear and deer as well as high numbers of nesting bald eagles nearby. The estuary supports Canada geese and other waterfowl. The river has the only substantial island run of king salmon in Alaska and has pink, chum and coho salmon, and Dolly Varden char. The drainage is unroaded and undeveloped and is entirely within the Kootznoowoo Wilderness. Recreational use of the river corridor is largely for deer and brown bear hunting.

This river is outstandingly remarkable for its wildlife and fish values. It has the only substantial run of king salmon on an island in Alaska. The outstanding habitat in the drainage supports an abundant population of brown bear and deer.

The King Salmon River corridor also has more non-commercial users then some of the other river corridors because a number of Special Uses permit cabins are located on the shores of King Salmon Bay, which is adjacent to the river corridor.

\section{Lisianski River}

The Lisianski River originates in a small lake at 800 feet in elevation on the divide between Lisianski Strait and the Northern Arm of Hoonah Sound. It flows five miles to the west before terminating in Lisianski Strait ten miles from the community of Pelican. An old trail along the river connects Hoonah Sound to Lisianski Strait. The drainage is unroaded and undeveloped and is within the Lisianski River Upper Hoonah Sound legislated LUD II area. The drainage provides habitat for brown bear and Sitka black-tailed deer among other species. The river corridor contains 2,040 total acres.

This river is outstandingly remarkable for its wildlife and ecological values. The narrow band of forest along the river offers important deer habitat and is a likely travel corridor for brown bears.

The current commercial use in the corridor consists of big game hunting, freshwater fishing, and nature tours. Commercial fishing and charter sportfishing also occur at the mouth of this river. Most of the non-commercial use on the Lisianski River corridor initiates from the community of Pelican eight miles northwest of the 


\section{Environment and Effects 3}

corridor and from private land along the coast of Lisianski Inlet. Pelican has a population of 163 people.

\section{Glacial River}

The Glacial River contains 3,400 acres. The river originates at a glacier high on the east side of Baranof Island at 1,800 feet in elevation and flows another ten miles into the South Arm of Kelp Bay. The river passes through a steeply walled, glacial valley with impressive views of various ecotypes as the river drops 1,800 feet in elevation. The area's characteristic wildlife include brown bear, deer, and mountain goat. The ADF \&G Forest Habitat Integrity plan rated fishery values as low to moderate. The drainage is currently unroaded and undeveloped.

The river has outstanding scenic value because of the diverse terrain it crosses and the active glaciation occurring there. The geology and ecology of the drainage are remarkable because of the variety of landforms represented.

Current use of the Glacial River corridor comes primarily from non-commercial users who anchor their boats in the South Arm of Kelp Bay.

\section{Kadashan River}

The Kadashan River originates at 400 feet in elevation and flows nine miles to the north to terminate in Kadashan Bay in Tenakee Inlet. The community of Tenakee Springs is located four miles to the north across Tenakee Inlet. The river corridor contains a total of 2,600 acres. The entire Kadashan drainage is a legislated LUD II area. The drainage is roadless and undeveloped except for a low standard gravel road and several rustic cabins. The road parallels the river (about $1 / 4$ to $1 / 2$ mile from the river) for three miles upstream from the bay. The road is opened to vehicle traffic and is lightly used for recreation and subsistence access. It connects to the marine access point and Forest Service administrative site at Corner Bay and provides access into the drainage. The Kadashan drainage contains large stands of old-growth trees dominated by Sitka spruce and western hemlock. Wildlife includes large populations of brown bear and deer. The river contains important pink salmon runs, as well as Dolly Varden char, chum salmon, and steelhead. The estuary is also extremely productive. Portions of the estuarine zone and mouth of the river are private land. Alaska Department of Fish and Game (ADF\&G) fisheries cabins and a Forest Service research cabin are located within the river corridor.

The fish and wildlife values of this river are outstanding and the ecological value of the large riparian old-growth spruce/hemlock stand is remarkable. Scenic values of this drainage are of importance to the community of Tenakee Springs.

The primary use of this river corridor is non-commercial use from the residents of Tenakee Springs. Tenakee has a population of 104 people.

\section{Recreation Opportunity Spectrum (ROS)}

The Recreation Opportunity Spectrum (ROS) is used to define and manage recreation use in recommended Wild and Scenic Rivers in this analysis. (See the Recreation section of this chapter and Appendix F for more details on the ROS.) The Forest Plan defines the recreation standards and guidelines in terms of the ROS for encounters and group size. Commercial use will be managed under these guidelines. 


\section{Environment and Effects}

The recommended Wild and Scenic Rivers and their land corridor acreage within the shoreline zone, ROS classifications with commercial groups, and group size allocations within the analysis area are listed in Table 3-24.

Table 3-24. Forest Plan Guidelines and Recommended Wild and Scenic River Corridor Area Within the Analysis Area, for All Alternatives

\begin{tabular}{lllllc}
\hline River Name & $\begin{array}{c}\text { Use } \\
\text { Area }\end{array}$ & $\begin{array}{c}\text { River } \\
\text { Type }\end{array}$ & $\begin{array}{c}\text { ROS Class* } \\
\text { (Acres) }\end{array}$ & $\begin{array}{c}\text { Maximum } \\
\text { Group Encounters }\end{array}$ & $\begin{array}{c}\text { Group } \\
\text { Size }\end{array}$ \\
\hline Katzehin & $01-01$ & Wild & $\begin{array}{l}\text { P }(4,416) \\
\text { SPNM (768) }\end{array}$ & $\begin{array}{l}\text { Less than } 3 \text { groups/day } \\
\text { Less than } 10 \text { groups/day }\end{array}$ & 12 \\
Gilkey & 01-04A & Wild & P (4,131) & Less than 3 groups/day & 12 \\
King Salmon & 04-09 & Wild & SPM (192) & Less than 10 groups/day & 12 \\
Lisianski & $04-15$ & Wild & $\begin{array}{l}\text { SPNM (153) } \\
\text { SPM (80) }\end{array}$ & $\begin{array}{l}\text { Less than } 10 \text { groups/day } \\
\text { Less than } 10 \text { groups/day }\end{array}$ & 12 \\
Glacial & 04-04B & Wild & P (239) & Less than 3 groups/day & 12 \\
Kadashan & $04-12$ & Scenic & SPM (165) & Less than 5 groups/day & 20 \\
\hline
\end{tabular}

*P= Primitive, SPNM=Semi-Primitive Non-Motorized, SPM=Semi-Primitive Motorized

Current use within the river corridors falls well within the ROS guidelines for group encounters. However, the river corridors have a relatively limited recreational carrying capacity, and recreation use cannot easily disperse. The analysis has shown that, if the maximum total allocated use in the Use Area in each alternative occurred at the same proportional rate that commercial use occurred in the river corridors in 1999, the daily use ROS guidelines could be exceeded. Therefore, the guidelines for number of encounters per day are the limiting factor for recreation use in the river corridors rather than the overall allocations for the Use Area. These guidelines apply equally to all alternatives. The river corridors will be managed for number of commercial groups at one time, and that use will contribute to the overall Use Areas allocation provided by each action alternative.

Table 3-25 displays the 1999 Commercial Use occurring within the recommended wild and scenic river corridors. The 1999 use levels are relatively low and fall well within the ROS guidelines. 


\section{Environment and Effects}

Table 3-25. 1999 Commercial Use in Recommended Wild and Scenic River Corridors Compared to Commercial Use in the Use Area

\begin{tabular}{lllccc}
\hline River Name & $\begin{array}{c}\text { Use } \\
\text { Area }\end{array}$ & $\begin{array}{c}\text { River } \\
\text { Class }\end{array}$ & $\begin{array}{c}\text { 1999 Use in } \\
\text { Use Area } \\
\text { (Group Days) }\end{array}$ & $\begin{array}{c}\text { 1999 Use in River } \\
\text { Corridor (Group } \\
\text { Days) }\end{array}$ & $\begin{array}{c}\text { Use Occurring in } \\
\text { River Corridor } \\
\text { (\%) }\end{array}$ \\
\hline Katzehin & $01-01$ & Wild & 4 & 4 & 100 \\
Gilkey & $01-04 \mathrm{~A}$ & Wild & 29 & 0 & 0 \\
King Salmon & $04-09$ & Wild & 19 & 8 & 42 \\
Lisianski & $04-15$ & Wild & 128 & 120 & 94 \\
Glacial & $04-04 \mathrm{~B}$ & Wild & 126 & 26 & 21 \\
Kadashan & $04-12$ & Scenic & 74 & 74 & 100 \\
\hline
\end{tabular}

\section{Environmental Consequences}

\section{Direct and Indirect Effects}

Effects on Recreation Users and the Recreation Industry (Issues 1 and 2) Commercial recreation use levels within the recommended Wild and Scenic River corridors are included in the alternative commercial capacity allocation for the Use Areas containing the rivers. The applicable guidelines for number of encounters and group size will apply to commercial use in the river corridors within that allocation. All action alternatives will allow additional commercial use beyond the 1999 levels up to the point where guidelines for group encounters restrict additional use.

Use levels will comply with the ROS guidelines for group size and number of encounters; therefore, there will be no adverse effect on the recreation experience within the river corridors. ROS guidelines will apply equally in all the alternatives; therefore, there will not be a difference in use levels or effects among the alternatives.

Because the alternatives do not propose any construction or permanent use, there will be no effects on the free-flowing character and outstandingly remarkable values of these river corridors. They will continue to maintain their eligibility for inclusion in the national Wild and Scenic Rivers System. Guided recreation use permitted within the river corridors would occur at low levels, be limited in nature and of short duration, and would have no adverse effects on the river values.

\section{Large Group Areas}

No large group areas are proposed within or near a Wild and Scenic River corridor in the analysis area in any alternative. The closest large group area to a recommended Wild or Scenic River is the Katzehin River Enclave proposed in Alternatives 3 and 5. It was located approximately one mile south of the Katzehin River corridor to limit the effects of large groups on that wild river corridor.

\section{Cumulative Effects}

The cumulative effects on the recommended Wild and Scenic Rivers corridors are considered primarily from the potential for other activities and development occurring on lands adjacent to the river corridors. The Forest Plan LUD direction and standards and guidelines will define these activities. 


\section{Environment and Effects}

All of these recommended Wild and Scenic Rivers are surrounded by nondevelopment LUDs, which should have very little adverse effect on the outstandingly remarkable features of these rivers. Semi-Remote Recreation and Remote Recreation LUDs surround the Katzehin River corridor. A Remote Recreation LUD encompasses the Gilkey River corridor. A Wilderness National Monument LUD surrounds the King Salmon River corridor. The Lisianski River corridor is located in a Congressionally designated LUD II. A Semi-Remote Recreation LUD encompasses the Glacial River corridor. A LUD II and a LUD II Research Natural Area surround the Kadashan River corridor. There is private land at the mouth of the Kadashan River corridor, which could have a minor influence on the river corridor if it became more developed. 


\section{Other Environmental Considerations}

\section{Introduction}

\section{Biodiversity}

This section describes resources and other considerations that would remain largely unaffected by the proposed action or alternatives. Concerns about many of these resources were raised during scoping. The Forest Plan has addressed the management implications of most of these resources through the establishment of forest-wide standards and guidelines, which are designed to prevent, reduce, or mitigate adverse impacts at the project level.

\section{Affected Environment}

\section{Overview}

Biological diversity is the variety of all the plant and animal communities and species within an area, along with associated ecological processes. Biodiversity encompasses the variety of genetic stocks, plant and animal species and subspecies, ecosystems, and the ecological processes through which individual organisms interact with one another and their environments. Changes in biodiversity occur through natural processes and human activities. Effects of management activities on biodiversity are also described in other sections of this document, such as Soil, Vegetation, and Wildlife. This discussion describes biodiversity by ecological subsections, vegetation types, and the Old-growth Reserve Network.

\section{Ecological Subsections}

There are three terrain classes in the analysis area: active glacial terrains, inactive glacial terrains, and post-glacial terrains. Active glacial terrains are those land areas that are currently affected by glacial processes of ice accumulation and movement, meltwater streams with heavy bedloads, and deglaciated areas of primary succession. Inactive glacial terrains developed after the retreat of the continental ice sheet some 14,000 years ago. Post-glacial terrains developed under geologic processes other than glaciers, such as volcanic eruptions. Within these three terrain classes, are physiographic and geologic classes, which further refine the building blocks of biological diversity. The analysis area has a diversity of ecological subsections ranging from limestone to volcanics, which support a variety of vegetation types (Table 3-26).

\section{Vegetation Types}

Approximately 89 percent of the shoreline zone in the analysis area is forested. The remainder of the area is muskeg, natural grasslands, rock, brush fields, and avalanche chutes. Avalanche tracks, brush fields, and bare rock areas are common in the ecological subsections along the mainland and the steeper sections of Baranof Island. Muskegs are well represented throughout the analysis area in the ecological subsections that are flat and have extensive glacial marine sediments or volcanics. Natural grasslands are one of the more rare vegetation types. Alpine and ice snowfields are uncommon adjacent to the shoreline.

Natural grasslands are more accurately described as estuarine meadows and uplifted beach meadows. Estuarine meadows and uplifted beach meadows have a high diversity of vascular plant species. They are important not only because of their plant diversity but also because they are relatively rare in the analysis area and on the 


\section{Environment and Effects}

Tongass National Forest. Most of the sensitive species occurring in the analysis area occur in these habitats. In addition, estuarine meadows support berries that are of high value to both brown bears and humans.

\section{Table 3-26. Ecological Subsections of the Shoreline Outfitter/Guide} Analysis Area

\begin{tabular}{|c|c|c|}
\hline Ecological Subsection Names & $\begin{array}{l}\text { Forested Shore Zone } \\
\text { (acres) }\end{array}$ & $\begin{array}{l}\text { Harvested Shore Zone } \\
\text { (acres) }\end{array}$ \\
\hline Berg Bay Complex & 3,976 & 0 \\
\hline Boundary Ranges Icefields & 70.287 & 0 \\
\hline Cape Fanshaw Complex & 2,621 & 16 \\
\hline Central Baranof Metasediments & 35.326 & 1,113 \\
\hline Chilkat Peninsula Carbonates & 32.536 & 1.399 \\
\hline Freshwater Bay Carbonates & 36,781 & 2.252 \\
\hline Holkham Bay Complex & 97.269 & 225 \\
\hline Hood-Gambier Bay Carbonates & 47,609 & 0 \\
\hline Kook Lake Carbonates & 18.056 & 2.965 \\
\hline Mitchell-Hasselborg Till Lowlands & 20,439 & 0 \\
\hline Mount Edgecumbe Volcanics & 14,092 & 727 \\
\hline Necker Bay Granitics & 39.199 & 119 \\
\hline North Admiralty Complex & 15,366 & 0 \\
\hline North Baranof Complex & 32.668 & 4.774 \\
\hline North Chichagof Granitics & 61,351 & 1.082 \\
\hline Outer Coast Wave-cut Terraces & 79.113 & 2 \\
\hline Peril Strait Granitics & 39,449 & 4,053 \\
\hline Point Adolphus Carbonates & 18.182 & 516 \\
\hline Sitka Sound Complex & 58.976 & 3.191 \\
\hline South Admiralty Volcanics & 41.641 & 0 \\
\hline South Baranof Sediments & 36.399 & 0 \\
\hline St. Elias-Fairweather Icefields & 3,004 & 532 \\
\hline Stephens Passage Glaciomarine Terraces & 107.966 & 32 \\
\hline Stephens Passage Volcanics & 26.541 & 0 \\
\hline Stikine-Taku River Valleys & 11.858 & 0 \\
\hline Thayer Lake Granitics & 3,306 & 0 \\
\hline Ushk-Patterson Bay Granitics & 26.242 & 1.053 \\
\hline West Chichagof Complex & 30,504 & 0 \\
\hline
\end{tabular}

Few areas in the shoreline zone haven "t been influenced by some type of natural or human-caused disturbance. About 24,000 acres (2.4 percent) of the analysis area has been harvested since 1954 and exists as even-aged stands. Timber harvest occurred before 1954, either by selective or clearcut methods. throughout much of the analysis area. Under the current Forest Plan, logging is not allowed within 1,000 feet of beach or estuary fringe or within riparian buffers. See Appendix E for the Forest Plan land use designations governing future management activities within the shoreline zone. 
Old-Growth Habitat Reserve Network

Old-Growth Habitat Reserves were developed through the forest planning process as part of the comprehensive conservation strategy to assure long-term species viability. A network of small, medium, and large old-growth habitat reserves were distributed across the national forest to maintain connections between quality habitat areas. Non-development LUDs, beach fringe, and riparian buffers contribute to the conservation strategy by maintaining overall landscape connectivity. Nondevelopment LUDs in the analysis area include extensive areas of Wilderness, OldGrowth Habitat, Remote Recreation, Semi-Remote Recreation, Wild and Scenic River, LUD II, and Special Interest Areas. Habitat connectivity eases travel for wildlife species between areas of quality habitat.

\section{Environmental Consequences}

Direct and Indirect Effects

Effects on biodiversity are best measured at the landscape or forest level. None of the alternative guided recreation activities or use levels are expected to have any measurable effect on biodiversity at these levels. At a site-specific level, guided recreation activities could have potential effects by trampling or crushing native vegetation and by introducing non-native plant species.

Direct effects are expected to be slight and localized. The most vulnerable vegetation types are the upper estuarine meadows and uplifted beach meadows. People walking through the meadows could trample the herbaceous vegetation. Herbaceous vegetation could also be trampled in the understory of forested areas; however people would be more likely to stay on the trails. Trampling vegetation would have little effect within the forest canopy.

Bare ground resulting from the trampling of vegetation and the introduction of nonnative plant species by wind or carried by humans could create areas where these introduced species can out-compete the native plants and become noxious weeds. Noxious weeds would have a greater negative effect on the meadows than on the forests, because noxious weeds would not survive well under the limited light of the forest canopy. Hemp nettle, Galeopsis tetrahit, is a noxious weed that is currently established in meadows in Idaho Inlet and the south end of Admiralty Island.

Noxious weeds would have a higher potential of developing in and around areas containing estuarine and uplifted beach meadows with high levels of recreation use. These areas would potentially have more recreation use, which increases the potential of exposed or disturbed soil and the introduction of weed seeds.

The creation of multiple footpaths could also lead to small-scale habitat fragmentation and lead to a minor reduction of species richness. On a larger scale, the disturbances created by an influx of guided visitors could cause some daily or seasonal reductions of habitat connectivity by disturbing some animal species.

Higher numbers of people visiting sites would create a greater chance of vegetation trampling and non-native plant introductions during the growing season. Alternative 3 would have the greatest potential to have such effects on biodiversity. Alternative 4 would have the least potential to negatively affect biodiversity. Alternatives 2 and 5 would have similar potential effects on biodiversity since similar levels of commercial use would be allocated. 


\section{Environment and Effects}

\section{Cumulative Effects}

Previous timber harvest changed stand structure. Depending on the size of the created opening, plants that had previously occupied the sites were re-established or plants currently occupying the sites were able to regenerate. Many areas of past timber harvest have regrown and are often mistaken as pristine forest. A small portion of the analysis area is available for timber harvest in the future. The allocation of recreation use would have no cumulative effect on the reforestation of timber harvest areas.

Past recreational use has had little adverse effect except in small, localized areas where use has been concentrated and not managed. The mitigation measures proposed by the action alternatives would reduce even these minor impacts. If adverse effects should occur, guided recreation use will be limited or restricted, or the site will be hardened to reduce the impacts. Thus, there would be no measurable cumulative effects from recreation uses. On the coarse scale over the analysis area, the guided recreation use proposed by the alternatives would have no effects on biodiversity. Effects on the local-scale components of biodiversity are disclosed in the following sections.

\section{Soils}

Soils are the foundation of terrestrial ecosystems. Soil absorbs nutrient-rich water and releases it to microorganisms and plants, which become food and habitat for larger animals and people. Soils are a non-renewable resource because of the time it takes for them to form. There are many types of soils, and their specific properties determine the type of ecosystem they support and their resiliency to land management.

\section{Affected Environment}

\section{Soil types}

Soils in the analysis area have developed from a variety of unconsolidated and weathered mineral or organic parent materials. Mineral soils develop from weathered rock, and organic soils develop from decomposed plant materials. Topography, climate, and vegetation play important roles in the development of soil.

Mineral soil originates from bedrock that either weathered in place or was transported and deposited away from its place of origin. Mineral soils typically are covered with an organic layer ranging from a few inches to several feet thick. Several classes of mineral soils exist in the analysis area, including glacial till and alluvial, colluvial, and residual soils.

Because of the high amount of precipitation and low temperatures in the analysis area, organic materials accumulate faster than they decompose, resulting in the creation of thick organic layers. Organic deposits range from about an inch to more than 40 feet in depth. Organic soil development is greatest on level terrain but is also found on rolling hills and moderately steep to steep slopes. Organic soils are often found covering glacial deposits on relatively flat valley bottoms. Most organic soils in the project area are classified as wetlands.

\section{Soil Productivity}


Tree growth, wildlife

and fish habitat, and

recreation

opportunities are all

influenced by soil

quality.
Soil productivity is the inherent capacity of a soil to support the growth of specific plants or plant communities. It is critical to the forest because it affects the productivity of most other forest resources. Soil productivity is a product of soil quality and can be affected by on-site disturbances ranging from natural erosion and landslides to human-related disturbances, such as roads, boat ramps, recreation trails and picnic areas. Tree growth, wildlife and fish habitat, and recreation opportunities are all influenced by soil quality.

Soil productivity varies between soil types. In mineral soils most nutrients are produced and stored in the upper organic layers. Soil drainage, texture, depth, and site characteristics (including elevation, slope, and aspect) all determine the soil's productivity. The most productive soils, which generally support coniferous forest stands, are well drained to moderately well drained and moderately deep. They are found on floodplain terraces, moderately stable alluvial fans, hillslopes, mountain slopes, and uplifted beaches.

Most organic soils are found in non-forested and forested wetlands that support lowvolume forest, scrub-shrub, peatlands and alpine meadow plant communities. Organic soils are not considered highly productive, in terms of timber stand volume, but they are productive in terms of species richness and biomass. Poorly to very poorly drained organic soils support a wide variety of plant communities with high biomass and species diversity, and they are home to many species of fish and wildlife.

\section{Environmental Consequences}

Direct and Indirect Effects

Recreation management practices that tend to reduce soil productivity include the construction of roads, trails, and campgrounds. The loss of productivity is caused by removal of the surface organic layers and disturbance of surface and subsurface layers. The recreation activities proposed in the alternatives do not involve any construction or ground-disturbing activities and will not have an effect on soil productivity.

Some amount of soil disturbance is an unavoidable consequence of recreation use on the land due primarily to trampling. The level of disturbance varies with management practices and site characteristics. Soil Quality Standards (FSM 2554) address the potential of affecting soils from compaction, puddling, displacement, surface erosion, altered wetness, and damage by severe burning. Soil Quality Standards are national standards that set the limits on the amount of an activity area that can be in a disturbed soil condition. The Soil Quality Standards in the shoreline zone limit soil disturbance to 15 percent of the activity area. Any greater soil disturbance, exceeding the standards, constitutes significant impairment to the productivity of the land. The effects of soil disturbance are minimized through the implementation of Best Management Practices (FSM 2509.22) and mitigation measures provided in Appendix C.

The effects of recreation use on soils are not well documented. However, the guided recreation uses proposed in the alternatives are not expected to have any significant direct or indirect effects on soils because of the relatively low impacts of the activities and the low levels of use spread across the analysis area. 


\section{Environment and Effects}

\author{
Guided recreation \\ activities are not \\ expected to have any \\ significant effects on \\ soils because of the \\ relatively low impacts \\ of the activities and the \\ low levels of use \\ across the analysis \\ area.
}

\section{Wetlands}

Approximately 30

percent of the analysis area is wetlands.
All alternatives would meet or exceed Forest Plan standards and guidelines. Recreation activities proposed in the alternatives might have minor effects depending on the amount and type of guided activity that actually occur and the soil type on which it would occur. These effects would be mitigated with Best Management Practices and protection measures listed in Appendix C. Monitoring would indicate when recreation use approaches Soil Quality Standards. If adverse effects on the soil resource should be noticed, recreation use will be limited or restricted or the site will be hardened to prevent or mitigate adverse soil effects.

\section{Cumulative Effects}

Cumulative effects of the proposed actions on long-term soil productivity are directly related to the amount of soil disturbance that occurs through time and the amount of recovery that takes place in the soil system in that time. Since the alternatives do not propose any activities that cause soil disturbance, no cumulative effects are expected.

Minor soil disturbance, erosion, and the associated loss of productivity resulting from the proposed activities could occur from recreation use. Most effects of recreation would be relatively short term; they would last until disturbed sites recover with indigenous species sufficient to protect the soil surface and maintain soil productivity. Any necessary re-vegetation of disturbed sites, either through natural regeneration or by planting, would depend on the level of disturbance at each site.

Cumulatively, the level of soil disturbances from guided recreation use within each Use Area or large group area is estimated to be far less than 1 percent of these areas. It would not exceed or approach the Soil Quality Standard of 15 percent of the area.

For additional information related to soils, see the water quality, biodiversity, vegetation, and wetlands sections of this chapter.

\section{Affected Environment}

\section{Overview}

Wetlands are "those areas that are inundated or saturated by surface or groundwater with a frequency and duration sufficient to support, and that under normal circumstances do support, a prevalence of vegetation typically adapted for life in saturated soil conditions" (40 CFR 230.41(a)(1)). Wetlands are sites that generally have both saturated soils for at least a portion of the year and vegetation that is adapted to saturated conditions. Wetlands are valued for their physical, chemical, and biological functions. Wetlands moderate flooding, reduce runoff and sedimentation, provide wildlife and plant habitat, and sustain stream flow during dry periods. Physical functions include flood conveyance, surface and ground water regulation, sediment retention, and temperature moderation. Chemical functions include nutrient storage, $\mathrm{pH}$ moderation, and carbon storage. Biological functions include habitat for terrestrial, aquatic, and marine plants and animals. 


\section{Environment and Effects 3}

Distribution and Types of Wetlands

Approximately 30 percent $(302,416$ acres) of the analysis area is wetlands, which include deepwater habitats (lakes and ponds) (USF\&WS National Wetland Inventory). Deepwater habitats are more fully described in the fisheries and water quality section. Wetlands may be underestimated by 15-20 percent because wetlands less than one acre were not mapped and forested wetlands are not often detected in the mapping process. Different wetland types are found from sea level to mountaintop. Resource values associated with these wetlands vary, depending on biological qualities, proximity to water bodies, and the position on the landscape.

Wetlands are classified into five major systems: marine, estuarine, riverine, lacustrine, and palustrine (Cowardin et. al. 1979). This analysis focuses on four systems because the Forest Service does not administer activities in marine or subtidal estuaries. The intertidal estuarine system is where freshwater systems meet marine ecosystems, creating a brackish environment. Estuarine wetlands support complex and productive ecosystems critical to fish and wildlife. Riverine wetlands are fresh water habitats within river and stream channels. Lacustrine wetlands include the deepwater habitats of lakes deeper than six feet and larger than 20 acres. Palustrine wetlands are characterized by saturated soils and are typically referred to as marshes, bogs, muskegs, fens, and forested wetlands. Palustrine emergent wetlands support rooted, herbaceous plants adapted to saturated soils. They function as areas for recharge of groundwater and streams, deposition and storage of sediment and nutrients, and support a diversity of plants and resident and migratory wildlife. The two most valuable wetlands in the analysis area are palustrine emergent and estuarine wetlands. Table 3-27 displays the wetlands in the analysis area.

Table 3-27. Wetlands in the Shoreline Zone

\begin{tabular}{lcc}
\hline \multicolumn{1}{c}{ Wetland Systems and Subsystems } & Wetland Acres & \% of Project Area \\
\hline Intertidal Estuarine & 14,954 & 1.5 \\
Riverine & & \\
$\quad$ Tidal & 844 & 0.09 \\
Perennial & 6,324 & 0.6 \\
$\quad$ Total Riverine & 7,168 & 0.7 \\
Lacustrine & & \\
$\quad$ Lakes, ponds, aquatic beds and shores & 4935 & 1.0 \\
Palustrine & & \\
$\quad$ Moss-lichen & 980 & 0.1 \\
$\quad$ Emergent & 48,714 & 5.0 \\
$\quad$ Scrub-shrub & 34,160 & 3.4 \\
$\quad$ Forested & 186,933 & 19.0 \\
$\quad$ Total Palustrine & 270,787 & 27.3 \\
Total & $\mathbf{2 9 7 , 8 4 4}$ & $\mathbf{3 0 . 5}$ \\
\hline
\end{tabular}




\section{Environment and Effects}

No dredging or filling

of wetlands is

proposed; therefore,

effects on wetlands

due to guided

recreation activities

would be very limited.

\section{Management Activities on Wetlands}

Executive Order 11990, as amended, requires federal agencies to avoid to the extent possible the long- and short-term adverse impacts associated with the destruction or modification of wetlands. The Forest Plan includes standards and guidelines intended to avoid or minimize the loss of wetland area and to maintain and/or enhance the values and functions of existing wetlands (USDA Forest Service1997b; p. 4-111). No dredging or filling of wetlands is proposed in any alternative.

\section{Environmental Consequences}

Direct and Indirect Effects

No dredging or filling of wetlands is proposed in any alternative; therefore, effects on wetlands due to the proposed recreation activities would be very limited. Guided recreation users generally avoid activities in wetlands because the ground conditions are not conducive to easy or comfortable travel or camping. If guided recreationists cross wetlands, the primary effect on wetlands would be linked to soil disturbance. The wetland area affected by recreation activity would be low across the analysis area but would vary at specific sites. The amount of disturbance and degree of effect would be relative to the number of visitors and frequency of visits to the site. Effects on wetlands would be mitigated (Appendix C). If adverse effects should occur, guided recreation use will be limited or restricted, or the sites will be hardened to prevent the effects.

The following sections discuss potential minor effects.

Wetland Vegetation Loss of wetland vegetation would be a temporary effect on any type of wetland located in areas of intensive foot travel. This effect would be more prevalent at the large group areas where visitors would concentrate. Alternative 3 allocates the highest use and the most large group areas and would therefore have the highest potential of short-term vegetation loss, followed by Alternatives 5, 2, 4, and 1 .

Erosion and sediment loads Erosion and higher sediment loads in runoff would be expected where vegetation is trampled and mineral soils are exposed. Increased erosion rates and higher sediment loads would not result from the implementation of this analysis since wetland soils are organic and not mineral.

Puddling of organic soils Trampling of vegetation and disturbance of the organic mat overlying organic soils would cause the soils to puddle. Puddling is the loss of soil structure, which decreases water movement through the soil. It causes water to remain at the surface and reduces plant growth. Puddling effects are expected to be minor and very limited in extent. The potential for soil puddling is highest in large group areas and in alternatives with the highest allocation of use. Alternative 3 has the highest potential to cause soil puddling followed by Alternatives 5, 2, 4, and 1 .

Altered wetness Draining or ponding of the wetland can alter the water regime of a wetland. Altered wetness due to drying would not be an effect of any action resulting from this analysis. Ponding may result from heavy foot traffic, which would restrict water movement through the soil. This would be limited to a very small area with a minor, short-term effect. As with the other types of disturbance, the potential to alter wetness is related to the level of commercial use. Large group areas have the highest potential to alter wetness, as do alternatives that allocate the 


\section{Environment and Effects}

highest use. Alternative 3 would have the highest potential to alter wetness followed by Alternatives $5,2,4$, and 1 .

Loss of flood control None of the alternatives would affect wetland flood flow or the potential of wetlands to moderate floods.

Loss of wetland wildlife habitat Loss of wildlife habitat in wetlands would be temporary and seasonal because of the regeneration of vegetation and disturbance or displacement during commercial use seasons. Those alternatives that allocate large group areas or have high group allocations have the highest potential to adversely affect wetland wildlife habitat. Alternative 3 has the highest potential followed by Alternatives 5, 2, 4, and 1 .

\section{Cumulative Effects}

Because of the vast expanse of wetlands within Southeast Alaska, the cumulative effects of the proposed alternatives and other projects on wetlands would be minor. Many of the prime wetland habitats on the Tongass National Forest have been protected either by land use designations or by standards and guidelines specifically addressing wetlands. Few long-term cumulative effects would occur because vegetation would regenerate, and the implementation of Best Management Practices and mitigation measures would be required on project proposals. There would be no anticipated effects on the form or function of wetlands within the shoreline zone.

\section{Vegetation}

\section{Overview}

The shoreline zone is a mosaic of estuary plant communities, beach meadows, muskeg, shrubland, and coniferous forests. The type and amount of vegetation that grows in the analysis area is influenced by the parent material and drainage of the soil. Poorly drained soils result in the development of non-forested muskeg or scrub forests, and well-drained soils result in heavily timbered forests. For additional information, see the biodiversity, soils, wetlands, sensitive species, and water quality sections of this chapter.

\section{Affected Environment}

\section{Plant Communities and Cover Types}

Non-forested Plant communities in estuaries vary depending on soil drainage, duration of flooding, and water salinity. Tides flood the upper reaches of the estuaries only one to three times in a month. Plant communities are represented by red fescue/mixed forb, hairgrass/mixed forb, and bluejoint/fireweed/mixed forb types. Palustrine wetlands with sedges, mixed forbs, and sphagnum are often found in areas that have recently been uplifted and are poorly drained.

Uplifted beach meadows are very common around Icy Straight and Lynn Canal in the northern portion of the analysis area. Mixed forb community types dominate these well-drained surfaces. Some of the dominants include cow parsnip, fireweed, wild strawberries, and yarrow. The upper estuarine meadows and the uplifted beach meadows have some of the highest vascular plant diversity of any community types on the Tongass. 
Muskegs are found bchind the forestcd fringe in many parts of the analysis area, espccially on the Gastineau Formation (glaciomarine clays and silt) around Juneau. This parent material is poorly drained and flat, which develops into muskeg and poorly growing forests.

Shrublands occur in areas that are very steep such as where avalanches are common, as along Lynn Canal. Sitka alder and salmonberry generally dominate these slopes. Small patches of willows and alders also occur within some of the estuaries.

Forested The forests on Admiralty, Baranof, and Chichagof Islands have been described in the Forest Plant Association Management Guide (Martin et al. 1995). Soil drainage and amount of salt spray are the main determinants of the type of forest that dcvclops. In gencral, Sitka-spruce-dominated forests are adjacent to the shoreline and other trees dominate the forests further inland. Sitka spruce has a compctitive advantage in these areas because the seed is able to establish on mineral soil and it is more salt tolerant that other Southeast Alaska conifers. There tends to be exposcd mineral soil in these areas because frequent windstorms blow trees down and landforms continuously uplift because of plate tectonics and glacial retreat.

In many places along the shore, there are uplifted wave-cut terraces behind the modern beach fronted forest that rises $1 \frac{1}{2}$ to 3 feet ( 5 to 15 meters). On top of this terrace, the forest is often dominated by western hemlock and has a blueberry and skunk cabbage understory. Further back from the beach, the productivity often declines into a mixed conifer stand if the parent material is poorly drained and the slope is gentle.

The shoreline around Lynn Canal supports plant species adapted to well-drained soils. Paper birch forests occupy the thinner rocky shorelines in the Haines and Skagway areas. Other species such as Scouler's willow and cottonwood are also in the overstory of many forests.

Vegetation types will gradually change through natural succession. Disturbances created by floods, high winds, landslides, and avalanches impede the natural succession process and maintain current vegetation types on some sites. Other plant communities gradually become forests through the natural succession process. The highest uplifted beach meadows and estuary meadows are becoming forests as spruce encroaches in these areas. Conifers dominate cottonwood/spruce forests as the cottonwood die.

\section{Environmental Consequences}

\section{Direct and Indirect Effects}

Recreation use can affect the vegetative characteristics of an area. Repetitive use by people can result in an increased rate of plant mortality through soil compaction; physical injuries to trees; and trampling of shrubs, grass and forbs. In riparian zones. loss of cover can destabilizc stream banks. Plants are most susceptible to disturbance in the summer season when they are actively growing.

Effects on plant communities vary with the species, soil type, and vegetation type. Generally, graminoids (grass-like plants such as sedges, rushes, and grasses) are more resistant to trampling than are broad-leaf herbs. For example, as few as 25 one-way passes reduced relative vegetation cover by more than 50 percent in a 


\section{Environment and Effects 3}

Effects on plant communities vary with the species, soil type, and vegetation type. These effects are not well studied in Southeast Alaska. trampling study in a broad-leaved, herb-dominated subalpine meadow in Washington state; in a nearby alpine sedge meadow, 75 passes caused no cover change (Cole and Trull 1992). Vegetation type and species also influence recovery from trampling, with some types recovering completely after one year, and others still exhibiting reduced vegetative growth (Cole and Trull 1992). The effects of recreation on vegetation have not been well studied in Southeast Alaska.

Beach meadows and upper estuary meadows generally are the most susceptible to trampling because they are broadleaf and graminoid plant communities. Because of their relatively flat topography and open vistas, they are desirable places to recreate and often receive more use than other areas of the forest. These meadows tend to be in early successional stages due to the disturbance of the glaciers and tidal flooding, and they are some of the most limited plant community types on the Tongass. Forests are a much more common feature along the shore, have less species diversity, and are more resilient to trampling.

Vegetation in Southeast Alaska has generally evolved to withstand trampling and grazing. Vegetation grows rapidly and lushly during the growing season due to the large amount of rainfall and relatively mild temperatures. Plants generally recover quickly from disturbance. Effects on plant communities from guided recreation use are likely to be minimal since the recreation activities are generally of low impact, of short duration, and do not involve ground-disturbing activities. Guided recreationists tend to disperse throughout the analysis area and avoid concentrating unless there is a specific attraction. Some areas may receive more concentrated use and would require site hardening or limits to use once use levels begin to show adverse effects on the vegetation. Large group areas could also have more people at one time in a limited area, resulting in more potential for impacts on vegetation. Enclaves could have regularly occurring large group use, while Fifteen-Percent areas would have only occasional large group use.

The following paragraphs discuss possible effects from guided recreation activities.

- Frequent use of a site may lead to creation of informal footpaths and trails and changes in plant community composition or loss of soil integrity, thereby decreasing the size and vigor of the affected plant communities.

- There is a potential for recreationists to introduce exotic plants by carrying seeds or viable fragments on clothing or camping gear. Some of these exotic species could compete with native plants for available habitat. Species that are spreading on the forest are dandelions, widespread in Lynn Canal, but uncommon on the islands, and Hemp nettle, which is established at one popular site on the Hoonah District and is also common at the southern tip of Admiralty Island.

Most effects on vegetation from guided recreation use proposed in the alternatives can be mitigated. Forest Plan set standards and guidelines for the beach and estuary fringe (USDA Forest Service 1997b, p.4-4) will be applied to guided use. Best management practices (BMPs) will apply to recreation activities. Mitigation measures include restrictions on camping and plant collecting, guidelines for hiking, and the use of Leave No Trace practices. No plant collecting would be allowed in large group areas. See Appendix C for more information on mitigation measures. Sites will be monitored for adverse effects on vegetation (see Appendix D). 


\section{Environment and Effects}

Recreation use on sites showing excessive trampling or baring of soil or a reduction in species richness would be limited or restricted or the sites would be hardened to

prevent effects. Sites with evidence of a noxious weed problem would be included in the forest weed control program.

It is difficult to accurately predict effects of guided recreation use on vegetation. Both guided and unguided recreation uses are expected to increase. In general, the total commercial capacity allocation during the summer season is the best measure for the potential risk of negative effects. Higher allocations could result in higher use levels resulting in higher potential effects to vegetation. Alternative 3 has the greatest potential to affect vegetation because it has the highest allocation during the summer and proposes the most large group areas. Alternative 5 has the second highest potential because it has the second highest allocation and number of large group areas. Alternative 2 has the third highest potential but does not propose large group areas. Alternative 4 has the lowest potential because it has the lowest allocation and has few large group areas. Alternative 1 does not provide a specific allocation, although it could be similar to Alternative 3; however, Alternative 1 does not identify large group areas.

\section{Cumulative Effects}

Along with the effects of guided and unguided recreation use, natural plant succession and disturbance will continue in the shoreline zone. Vegetation will be trampled or grazed by wildlife. Exotic plant species may be introduced by other human activity. There is limited future development activity expected within or adjacent to the national forest that would have a significant effect on the vegetation resource. These cumulative effects on vegetation are not expected to be significant.

\section{Overview}

The Tongass National Forest provides habitat for 54 species of mammals, 231 species of birds, and 5 species of amphibians and reptiles. There are an additional 18 species of marine mammals found in Southeast Alaska which depend entirely on the ocean environment. There are also 45 bird species, and 3 amphibian or reptile species considered casual or accidental visitors to Southeast Alaska (USDA Forest Service 1997a). Many of these species inhabit the project area.

Wildlife is found in a diverse range of land types and plant communities and is adapted to climatic extremes, changes in habitat, predation, and hunting pressure. This results in a project area rich in both species and habitats. This richness is appreciated and valued by people. Wildlife may be viewed and photographed; harvested for sport or subsistence purposes; and valued for spiritual or ecological reasons. 


\section{Environment and Effects 3}

Important habitat

types that occur in

the analysis area

include beach fringe,

estuary fringe, old-

growth, second-

growth, and riparian

areas.

\section{Affected Environment}

\section{Wildlife Habitat}

Habitat is the environment in which a wildlife species occurs. It is described in physical and biological terms, which include elevation, topography, forest structure, and vegetation type. A wildlife species may occupy a range of habitat types at various times of the year. Important habitat types that occur in the analysis area include beach fringe, estuary fringe, old-growth, second-growth, and riparian areas.

Beach Fringe Habitat Beach fringe is the strip of land within a 1,000-foot horizontal distance inland from the saltwater shoreline, not including estuaries. It is a transitional zone between land and water, salt water and fresh water, and vegetated and non-vegetated conditions (USDA Forest Service 1997a). Forested areas in this transition zone receive heavy use by species that have high economic, recreational, subsistence, or aesthetic values. Brown bear, river otter, bald eagle, marten, and Sitka black-tailed deer are typical species that concentrate their activities in these forest stands during some or all seasons of the year.

Estuary Fringe Habitat Estuary fringe is the land within 1,000-foot horizontal distance around river mouths or estuaries. It is similar to beach fringe but because of its species diversity it has greater value to wildlife, especially brown bears, river otters, mink, bald eagles, and waterfowl.

Old-growth Habitat For this EIS, old-growth habitat refers to inventoried forest stands with a timber volume greater than 8,000 board feet per acre and having trees which are at least 150 years old, with an average diameter at breast height larger than nine inches. Old-growth forests typically posses the following characteristics:

- Large trees, with wide variation in tree sizes and spacing;

- Accumulations of large, dead, standing and fallen trees;

- A high incidence of trees with broken or deformed tops, disease, and decay; and

- Multiple canopy layers, with canopy gaps and understory patchiness.

These characteristics and the spatial arrangement of old-growth habitat influence the function of the ecosystem. Old-growth forests are important habitat for many species of wildlife, including brown bears and bald eagles.

Second-growth Habitat Second-growth habitats are even-aged stands less than 150 years old that have been commercially harvested. Second-growth habitat is of lower value to most wildlife species because conifer seedlings aggressively invade and eventually shade out desirable herbaceous vegetation (food plants).

Riparian Habitat Riparian areas occur along rivers and streams or around inland lakes, and contain elements of both aquatic and terrestrial ecosystems. These areas are important migration routes for some wildlife species, such as brown bears, because of the presence of food, water, and cover.

\section{Management Indicator Species}

Wildlife management indicator species (MIS) are species whose responses to land management activities can be used to predict the likely response of other species with similar habitat requirements. By using the MIS concept, the total number of species to be analyzed within a project area is reduced to a manageable set that 


\section{Environment and Effects}

Wildlife management

indicator species

(MIS) are species

whose responses to

land management

activities can be used

to predict the likely

response of other

species with similar

habitat requirements. collectively represents the complex of habitats, species, and associated management concerns. MIS are also used to help establish management goals for species in public demand, such as brown bear for sport hunting and subsistence uses. The Forest Plan standards and guidelines include the use of management indicator species to evaluate the potential effects of proposed actions affecting wildlife habitat (USDA Forest Service 1997).

The MIS chosen for this project are brown bear and bald eagle. Outfitter and guiding activities may affect these two species, as recognized in comments from the public. Brown bears and bald eagles are also associated, at least to some degree, with the habitats found along the shoreline.

Brown Bear, Ursus arctos Brown bears are common in Game Management Unit (GMU) 4 and less common in mainland GMUs 1C and 1D. Game Management Units are delineated by the Alaska Department of Fish and Game to facilitate their wildlife management activities. (See the annual Alaska Hunting Regulations booklet for additional information.) Brown bears commonly use habitats from sea level to the alpine zone. The habitat capability model currently in use identifies the late summer season as the most critical or limiting period for brown bears. During this season, many brown bears concentrate along low-elevation valley bottoms and streams, feeding on salmon and other edibles to put on enough weight for the winter. These are often the same areas of high human use, including deer hunting and brown bear viewing. During this season, brown bears use all of the habitats available to them, with estuaries and riparian areas having the highest habitat value.

The analysis area has about 1.6 million acres (in all land ownerships within the shoreline zone) within brown bear habitat. The ADF\&G estimates that there are approximately 4,155 brown bears in GMU 4 alone (Chichagof and adjacent islands, 1,550 bears; Baranof and adjacent islands 1,045 bears; and Admiralty Island, 1,560 bears) (ADF\&G 1999). ADF\&G has conducted extensive brown bear studies in GMU 4 for many years; however, no such research has been undertaken on Southeast Alaska's mainland. Based on "anecdotal hunter reports, department staff observations, and sealing records," ADF\&G reports that mainland brown bear populations are considered to be stable over the past several reporting periods (ADF\&G 1999).

In 1998, the Forest Service and ADF\&G signed a Master Memorandum of Understanding (MMOU) "to define a wildlife and fish conservation program on National Forest System lands which recognizes agency responsibilities and areas of cooperation and coordination." The Forest Service "Recognize(s) the Department as the agency with the authority, jurisdiction, and responsibility to manage, control, and regulate fish and wildlife populations on National Forest System lands unless such authority is superceded by federal law." ADF\&G, "Recognize(s) the Forest Service as the agency responsible for the management of National Forest System lands in Alaska and the fish and wildlife habitats on these lands" (USDA Forest Service 1998).

Hunting regulations for brown bears, which includes seasons and bag limits, are determined by the Alaska Board of Game (ABOG) and implemented and enforced by the ADF\&G and Fish and Wildlife Protection Troopers. The intent of these regulations is to ensure that sustainable populations of wildlife species are available 
for human consumption and enjoyment into perpetuity. (See Alaska Hunting Regulations for current hunting regulations, including seasons and bag limits.) Commercially guided hunting on the national forest must comply with all state hunting regulations and harvest limits.

Brown bears are also considered a subsistence resource and are subject to regulations determined by the Federal Subsistence Board (FSB) in a process similar to the Alaska Board of Game process. (See Subsistence Management Regulations for the Harvest of Wildlife on Federal Public Lands in Alaska for current regulations.) Commercially guided hunting on the national forest must comply with all federal hunting regulations and harvest limits.

ADF\&G also sets management objectives by GMU; this direction is displayed in the Federal Aid in Wildlife Restoration Annual Performance Reports and Management Reports (ADF\&G 1999, 2000a). Management objectives for GMU 1 include:

- Maintain an average age of annually harvested males no less than 6.5 years, with a male-to-female harvest ratio of at least 3:2, and

- Reduce the number of bears killed because of garbage habituation.

Management objectives for GMU 4 include:

- Maintain an average age of harvested males of at least 6.5 years with a male-tofemale harvest ratio of at least $3: 2$,

- Reduce the number of bears killed because of garbage habituation (as modified in the 2000 annual report),

- Monitor the harvest, seal harvested bears, and analyze harvest data (as modified in the 2000 annual report), and

- Monitor use of the Pack Creek viewing area on the Stan Price Wildlife Sanctuary (as modified in the 2000 annual report). This area is outside the project area for this EIS.

In general, the $\mathrm{ADF} \& \mathrm{G}$ reports conclude that brown bear populations in GMUs 1 and 4 are stable and the objective to harvest males of at least 6.5 years is usually met. It has been more difficult to meet the male-to-female harvest ratio of $3: 2$ and to reduce the number of bears killed due to garbage habituation.

Concerns have been raised that as the number of guided brown bear hunts increases, brown bear harvest levels will not be sustainable.

Tables 3-28 and 3-29 and Figures 3-5 through 3-9 display brown bear harvest, hunter success, and residency by Game Management Unit (GMU) in the project area. Available ADF\&G data, which varied in format, was used to generate the tables and figures. 


\section{Environment and Effects}

Figure 3-5. GMU 1C, Brown Bear Harvest 1986-1998

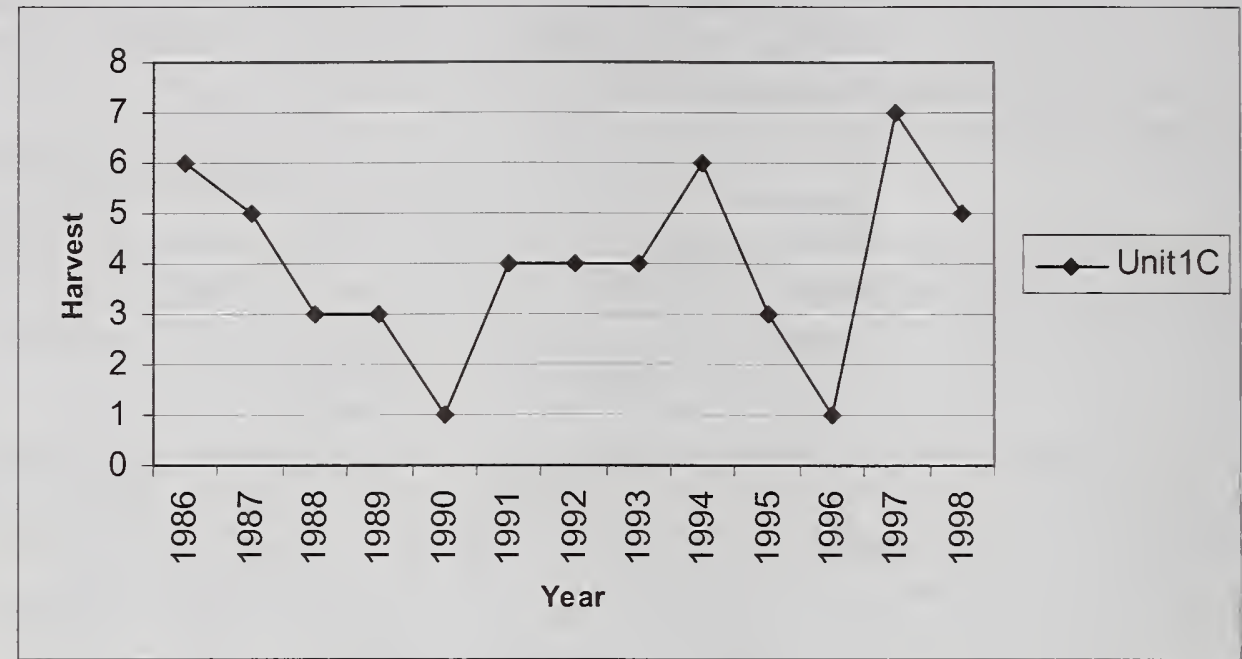

Source: ADF\&G 1998, 1999

Figure 3-6. GMU 1D, Brown Bear Harvest 1986-1998

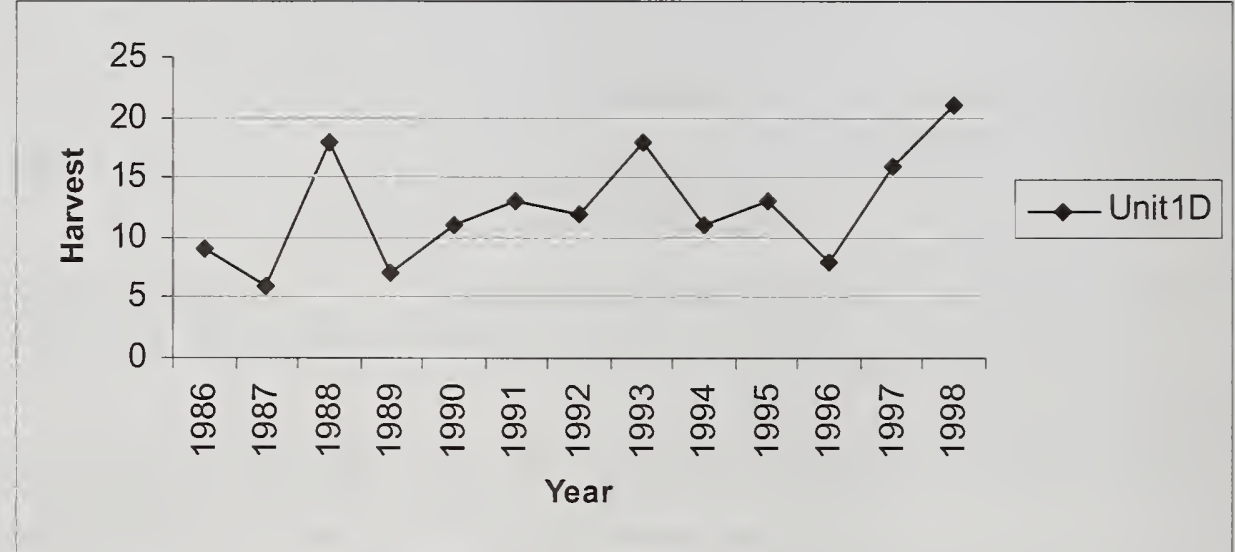

Source: ADF\&G 1998, 1999 


\section{Environment and Effects 3}

Figure 3-7. GMU 1, Percentage of Successful Brown Bear Hunters, by Their Residency, 1986-1998

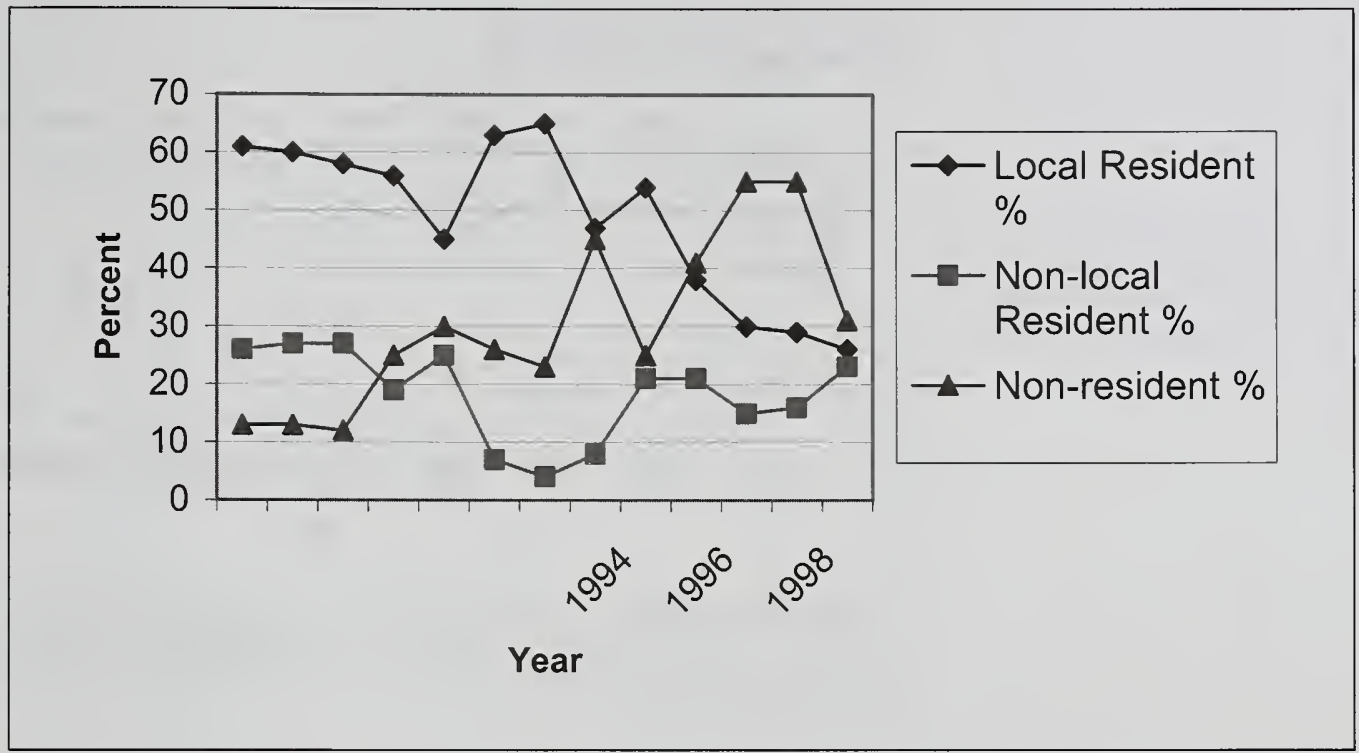

Table 3-28. GMU 1, Percentage of Successful Brown Bear Hunters, by Their Residency, 1986-1998

\begin{tabular}{lccc}
\hline & Local Resident & Non-local Resident & Non-resident \\
Year & $\%$ & $\%$ & $\%$ \\
\hline 1986 & 61 & 26 & 13 \\
1987 & 60 & 27 & 13 \\
1988 & 58 & 27 & 12 \\
1989 & 56 & 19 & 25 \\
1990 & 45 & 25 & 30 \\
1991 & 63 & 7 & 26 \\
1992 & 65 & 4 & 23 \\
1993 & 47 & 8 & 45 \\
1994 & 54 & 21 & 25 \\
1995 & 38 & 21 & 41 \\
1996 & 30 & 15 & 55 \\
1997 & 29 & 16 & 55 \\
1998 & 26 & 23 & 31 \\
\hline
\end{tabular}

Source: ADF\&G 1998, 1999 
Figure 3-8. GMU 4, Brown Bear Harvest 1992-1999, Compared to Four Percent Harvest Rate

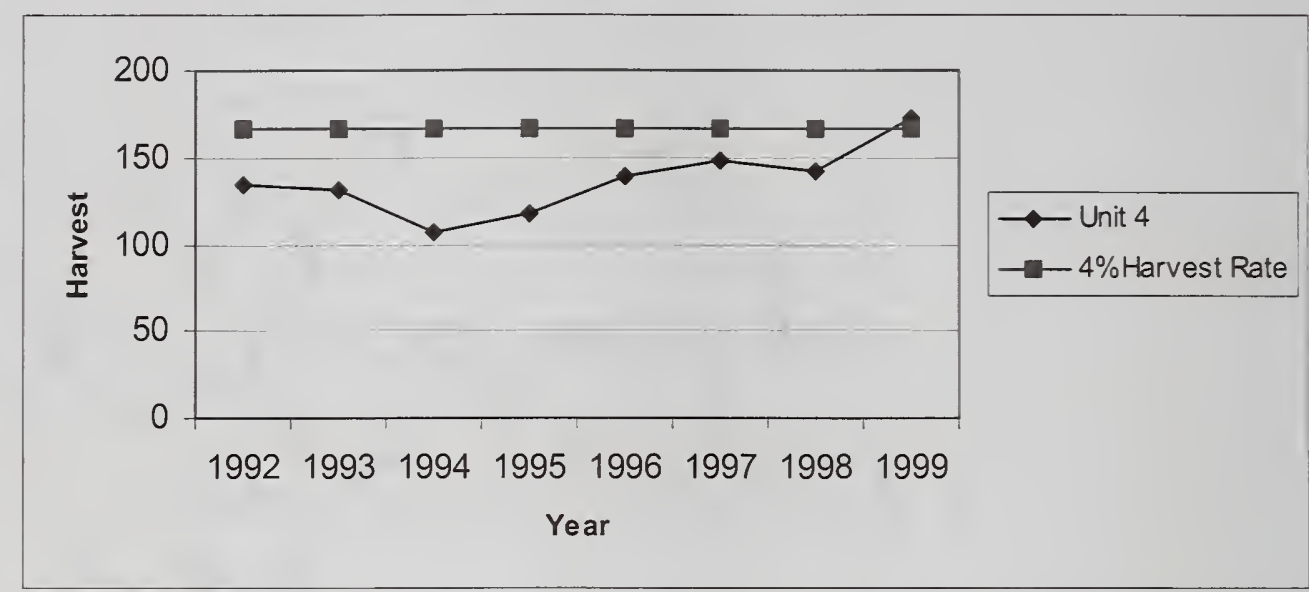

Figure shows ADF\&G recommended harvest rate of 4 percent or less ( 166 bears) in relationship to the actual harvest, as follows: $1992=135 ; 1993=131 ; 1994=107 ; 1995=118 ; 1996=139 ; 1997=148 ; 1998=142 ; 1999=173$.

Source: ADF\&G 1998, 1999

Table 3-29. GMU 4, Percentage of Successful Brown Bear Hunters, by Their Residency, 1992-1998

\begin{tabular}{cccc}
\hline Year & $\begin{array}{c}\text { Local Resident } \\
\%\end{array}$ & $\begin{array}{c}\text { Non-local Resident } \\
\%\end{array}$ & $\begin{array}{c}\text { Non-resident } \\
\%\end{array}$ \\
\hline 1992 & 18 & 25 & 57 \\
1993 & 7 & 33 & 60 \\
1994 & 15 & 18 & 67 \\
1995 & 12 & 22 & 66 \\
1996 & 14 & 19 & 67 \\
1997 & 12 & 13 & 75 \\
1998 & 10 & 22 & 68 \\
\hline
\end{tabular}

Source: ADF\&G 1998-1999 
Figure 3-9. GMU 4, Percentage of Successful Brown Bear Hunters, by Their Residency, 1992-1998

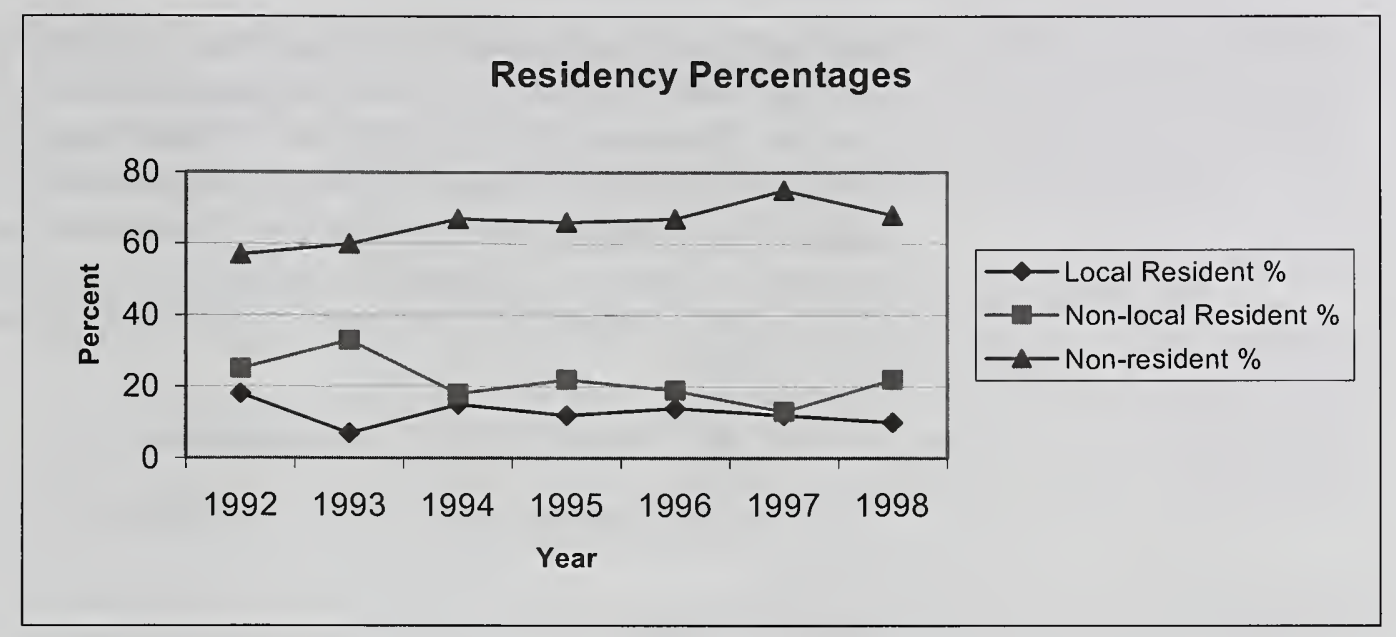

Source: ADF\&G 1998-1999

Bald Eagle, Haliaeetus leucocephalus The highest densities of bald eagles in North America are in Southeast Alaska. The most recent adult population estimate was more than 13,000 adult birds (1992 estimate); more than 8,000 nest sites were identified in a 1996 survey throughout Southeast Alaska. Almost 4,000 identified nest sites are located in the analysis area. Large portions of the analysis area shoreline zone have not been specifically surveyed for additional bald eagle nest sites because commercial recreation use is not expected to disturb eagle nesting habitat. Nesting habitat is primarily old-growth trees in riparian areas in close proximity to the coast. Over 90 percent of the known nests on the Tongass National Forest are within 500-feet of salt water (USDA Forest Service 1997).

There is a concern that guided recreation use may disturb and otherwise harm individual bald eagles, especially during the nesting season. Humans or machines, with the degree of response dependent on the proximity of disturbance, may disturb nesting bald eagles. Energy used in response to disturbance would be better spent caring for eaglets.

The Bald and Golden Eagle Protection Act of 1940 is the primary law that protects bald eagles in Alaska. In order to ensure that forest management activities do not result in a violation of the law, the U. S. Fish and Wildlife Service (USFWS) and the Forest Service maintain an interagency agreement for bald eagle habitat management in the Alaska Region. The agreement includes standards and guidelines for regulating human disturbance within identified bald eagle use areas. All identified eagle nest trees are surrounded by minimum 330 -foot radius protective habitat management zone (USFWS and USDA Forest Service 1990). See Appendix C Mitigation Measures for additional information.

Other Wildlife Concerns and Opportunities.

Marine Mammals The presence of people, especially recreating in large groups, can disturb marine mammals on land. The National Marine Fisheries Service (NMFS) 


\section{Environment and Effects}

provided known locations of harbor seal (Phoca vitulina) haul-outs within the project area (NMFS 2001).

Bear-viewing Opportunities There have been requests for additional areas for viewing bears. This analysis identified potential bear viewing sites (Table 3-30). However, the actual development of any of these bear-viewing sites will require additional planning in a separate environmental analysis. The Brown Bear Management Strategy (see Environmental Consequences, below) also provided recommendations and management guidelines for developing new bear viewing areas. These recommendations and management guidelines will be considered in a future analysis.

Table 3-30. Potential Bear-viewing Sites

\begin{tabular}{lcc}
\hline \multicolumn{1}{c}{ Bear Viewing Opportunity } & Sitka R.D. & Hoonah R.D. \\
\hline Lake Eva & $\mathrm{X}$ & \\
Saook River Estuary & $\mathrm{X}$ & \\
Saook River Mouth & $\mathrm{X}$ & \\
Saook River Trail & $\mathrm{X}$ & \\
North Hoonah Sound & $\mathrm{X}$ & \\
Kadashan River Estuary & $\mathrm{X}$ & \\
Camp Coogan & $\mathrm{X}$ & \\
Nakwasina & $\mathrm{X}$ & \\
Sick Cove & $\mathrm{X}$ & \\
Sitkoh Bay & $\mathrm{X}$ & $\mathrm{X}$ \\
Wukuklook Creek & & $\mathrm{X}$ \\
Kennel Creek & & \\
\hline
\end{tabular}

\section{Environmental Consequences}

Wildlife Habitat

All the wildlife habitats described earlier are represented at least to some degree within the analysis area shoreline zone. All of the alternatives include recreation management activities within these habitats. There is currently no standard methodology to measure direct impacts on habitat quantity or quality as a result of recreation management activities over the short or long term. Based on current knowledge and a review of data, historical outfitter/guide use in the analysis area has not shown measurable effects on wildlife. Biological Evaluations (BE) and Biological Assessments (BA) from past recreation management projects have shown no effect to wildlife populations or habitat.

Some very minor effects on vegetation due to trampling could influence wildlife habitat. Potential indirect effects on wildlife species from guided recreation activities include short-term displacement or avoidance of habitats by those wildlife species that tend to avoid people and their machinery. Avoidance will continue until the people and their machines leave the area. Generally, this would be a short-term impact, amounting to a few hours per day or week and widely scattered throughout the analysis area. While individual animals may avoid an area with humans, these 
dispersed short-term activities are not expected to result in any substantial increase in the risk that viable populations will not be maintained over time.

Maximum commercial recreation use levels range from the current 2,410 group days to 40,658 group days per year (Table $3-9$ ). If the total recreation carrying capacity is used (USDA Forest Service 2001) as an estimate for total recreation use levels for both guided and unguided recreationists, 81,316 group days per year could potentially occur within the analysis area.

These recreation use levels are within levels anticipated by the Forest Plan. Recreation use is unlikely to approach these levels in the near term. The recreation use that does occur will be of low impact, short duration and will not adversely affect wildlife habitat. This use will be dispersed across the shoreline zone of the analysis area of over one million acres and over 5,000 miles of shoreline habitat. Mitigation measures (Appendix C) have been identified to reduce or eliminate impacts.

If the total commercial use allocation were used as a measure for the potential risk of negative effects to wildlife habitat, higher allocations would provide potentially higher use levels. These higher use levels could result in higher potential risks for negative effects on wildlife habitat. Alternative 3, with the highest allocation (40,658 group days, or 50 percent of the total), would have the highest potential risk. Alternative 5 (18,495 group days, 23 percent of the total) would have the second highest, closely followed by Alternative 2 (16,894 group days, 21 percent of total). Alternative 4, with 6,192 group days ( 8 percent of the total) would have the lowest risk. Alternative 1 does not make a specific allocation, but could potentially be up to 50 percent of the carrying capacity, providing a risk equal to Alternative 3.

There are specific areas that could have higher or more concentrated levels of use or people recreating in larger group sizes at certain times of the year, which could have more potential to affect wildlife. Alternatives 3, 4, and 5 propose large group areas that vary in number, size, and type and that differ in times of use permitted during the year. These large group areas are dispersed throughout the analysis area to avoid concentrations of high recreation use, and they are located to minimize impacts to wildlife habitat.

Alternative 3 has the most sites allowing large group use (63) followed by Alternative 5 (47) and 4 (20). Alternative 1 and 2 do not propose large group areas. As more groups use these areas, the risk that individual animals may be disturbed and leave these areas will increase. See Tables 3-10 through 3-12, for acres, Use Areas, and summaries of large group area types and amounts.

The alternatives vary by timing of commercial use. Enclave areas allow daily large group use while Fifteen-Percent Areas allow large group use only periodically up to 15 percent of the season (approximately one day per week). Alternative 3 would allow large group use in Enclaves and Fifteen-Percent areas in all seasons.

Alternatives 4 and 5 would allow large group use in Enclaves in all seasons but would only allow large group use in Fifteen-Percent Areas during the summer season. 


\section{Brown Bear}

The effects of non-consumptive recreational activities on brown bears, such as viewing from boats (ranging from cruise ships to one-person kayaks), airplanes, and helicopters, or established bear-viewing areas are not well understood. Other recreational activities such as bike riding, sightseeing, camping, hiking, picnicking, and fishing that occur in brown bear habitats may also have an effect. It is difficult to predict the degree to which the presence of people recreating within brown bear habitats will disturb individual bears or cause long-term population viability problems.

The Forest Plan Record of Decision (ROD) concluded "that the old-growth strategy and specific species management prescriptions represent a balance of wildlife habitat conservation measures which consider the best available scientific information and, within an acceptable level of risk inherent in projecting management effects, will provide fish and wildlife habitat to maintain well-distributed viable populations of vertebrate species in the planning area, and maintain the diversity of plants and animals." (ROD, pp. 35-36). Specific to brown bears, the Forest Plan EIS states, "Alternative 11 (the selected alternative) likely presents the highest likelihood of maintaining viable long-term brown bear populations due to the extensive reserve system..."(p. 3-418). Specific to recreation and tourism, the ROD states “...the resource standards and guidelines and the changes in LUD allocations reflected in Alternative 11 (the selected alternative) are sufficient to maintain recreational and tourism opportunities throughout the Forest"(p. 22).

As human populations increase and more people go to their national forests for recreation opportunities, research has begun to focus on the impacts of these activities on wildlife. The Montana Chapter of the Wildlife Society prepared the comprehensive Effects of Recreation on Rocky Mountain Wildlife, A Review for Montana that included all of the vertebrate land species found in Montana (Joslin and Youmans 1999).

The chapter on Carnivores includes a section on grizzly bears that concluded that, "Grizzly bears are sensitive to human disturbance. However, they will readily habituate to ongoing and predictable human activity" (p. 7.26). It further states, "bears in multiple-use forest and wilderness environments are generally not subjected to ongoing and predictable patterns of human activity, thus they will avoid areas with heavy motorized or foot traffic and high road or trail densities" (p. 7.27). Interactions with brown bears can lead to habituation, which usually results in a dead bear or, occasionally, an injured or dead human. In general, the effect of motorized or foot traffic on bears was considered negative. This review noted that there are few studies quantifying the negative effects of foot traffic on bears (p. 7.27).

There has been little research in this area in Southeast Alaska. Currently, Southeast Alaska Wilderness Education and Discovery (SEAWEAD), a private organization interested in the management of the Tongass National Forest, has proposed a brown bear disturbance project on northwest Chichagof Island. The proposal is under review to determine if it will meet peer review standards and will provide useful scientific data. The ADF\&G has also expressed interest in developing studies to determine if human effects on bears are a concern. 


\section{Environment and Effects 3}

The short-term recreational use proposed in this analysis is not expected to have any impacts on brown bear habitat, which is protected by Forest Plan standards and guidelines. However, guided recreation use could result in human-bear interactions that could have impacts on bear populations and individuals. The adoption of recommendations from the Brown Bear Management Strategy (BBMS) will mitigate such impacts. A discussion of the BBMS follows.

Brown Bear Management Strategy In 1998, the Alaska Board of Game (ABOG) and ADF\&G Division of Wildlife Conservation sponsored a broad group of citizens and agency representatives to develop a Unit 4 Brown Bear Management Strategy (BBMS) (ABOG 2000). In November 2000, the ABOG voted to support the recommendations in the BBMS and encouraged the USDA Forest Service to incorporate the team's recommendations in this EIS. Many of the applicable recommendations have been incorporated into the mitigation measures designed to reduce or eliminate negative impacts to brown bears and their habitat (Appendix $\mathrm{C}$ ).

The BBMS recommended that the Forest Service "Maintain the current moratorium on new hunting guides in Unit 4 until the outfitter/guide analysis for the northern Tongass National Forest is completed." The Forest Supervisor has maintained the moratorium in Unit 4 and extended it to Unit 1. He also directed that no new applications for brown bear guide permits be authorized until this EIS is completed.

The BBMS also recommended that the Forest Service "Cap the number of guides at the current number (approximately 38); allow the number to decrease by attrition to 20 hunting guides maximum in Unit 4 over the long term." The Forest Supervisor has capped the number of bear hunting guides until this analysis is complete.

Another BBMS recommendation was to "Allocate outfitter/guide use on a client/hunt, rather than a service-days, basis." The Forest Supervisor has directed that brown bear hunting guide permits be authorized by number of clients by species hunted, or "hunts authorized" (one client equals one hunt). However, as noted earlier in this section (Tables 3-28 and 3-29), a 'hunt' does not necessarily equal a harvested brown bear.

Regarding the number of hunts authorized, the BBMS recommended, "Maintain essentially the same number of nonresident hunters (guided and next-of-kin) as the current annual average (148 compared to a current level of 147) with some redistribution of effort among the Guide Use Areas and an adjustment to allow for next-of-kin hunting effort in some areas." The BBMS recommended 144 nonresident guided hunts and 4 non-residents hunting with next-of-kin 'guides' for a total of 148 hunts. The Forest Supervisor is currently authorizing a maximum of 148 guided hunts on the national forest based on past use with no additional hunts. These 148 hunts plus 4 non-residents hunting with next-of-kin provides a total of 152 hunts.

The BBMS recommended to "Allocate guided hunts to the spring and fall seasons based approximately on ADF\&G's data of the historical percentage of use during the seasons." The Forest Service is currently developing an administrative process to allocate guided hunts between individual guides by location, season, and number of hunts. This is occurring in a separate analysis expected to be finished in 2002. 
Historically, Unit 1 non-resident (guided) brown bear hunters have had success rates ranging from a low of 13 percent to a high of 55 percent from 1986 through 1998. Unit 4 non-resident (guided) brown bear hunter success rates ranged from a low of 57 percent to a high of 75 percent from 1992 through 1998. Adopting these BBMS recommendations is not expected to result in higher hunter (guided and non-guided) success rates or other human-caused mortality rates above the sustainable population level because of the mitigation measures built into the management strategy for brown bears. ADF\&G must consider all forms of human-caused brown bear mortality, including hunting (guided and non-guided), poaching, and defense of life and property kills (DLP) in managing this resource. The BBMS made several recommendations to the Forest Service and ADF\&G that have been adopted to ensure that human-caused brown bear mortality does not exceed sustainable levels. If human-caused brown bear mortality exceeds recommended levels, adjustments in the number of hunters, adjustments in season or bag limits, or instituting drawing permits may be used to reduce mortality to sustainable levels. Restricting or capping the number of guides and the number of guided hunts may result in some additional brown bears available for harvest by resident and subsistence hunters if they choose to take advantage of them and the recommended mortality levels are not exceeded.

Managing guided brown bear hunts within the harvest limits and regulations established by the ABOG and the Federal Subsistence Board will ensure viable huntable populations. These hunts will be monitored annually with these agencies and adjustments or limits on guided hunting will be made if necessary.

\section{Management Indicator Species}

Bald eagle The bald eagle and riparian forest-wide standards and guidelines are specifically designed to protect nesting habitat for bald eagles. Bald eagle standards and guidelines and mitigation measures have proven effective as demonstrated by the high numbers of birds and stable population size. Therefore, no significant impacts that could lead to federal listing of bald eagles are expected from any of the alternatives.

Marine mammals Several potential large group areas were dropped during the planning process because of their proximity to mapped seal haul-outs. To avoid disturbing seals, there are no developments planned in the alternatives within one mile of any of the mapped seal haul-outs.

The Forest Plan provides standards and guidelines for marine mammal habitats, including harbor seals (p. 4-114). See the Mitigation section for additional information. These standards and guidelines have been effective in reducing or eliminating impacts to marine mammals and harbor seals specifically. Therefore, no significant impacts that could lead to federal listing of harbor seals are expected from any of the alternatives. 


\section{Environment and Effects 3}

\section{Cumulative Effects}

Cumulative effects include natural fluctuations in wildlife populations and harvest from unguided hunters. There are no immediate concerns regarding any wildlife species within the analysis area. The Alaska Department of Fish and Game and the Federal Subsistence Board manage wildlife to ensure sustained huntable populations through the use of hunting regulations. The effects of guided hunting on these populations are monitored. If it becomes necessary to protect any wildlife populations, sport or general hunting harvest, including guided hunting, will be restricted. The regulations and harvest limits imposed on guided hunting will ensure sustainable populations.

Because of the low impacts on wildlife habitat and populations from guided recreation activities and the mitigation measures in Appendix $C$ to reduce or eliminate impacts, the effects on wildlife from guided recreation use over the analysis area as a whole are expected to be minimal for all alternatives. Effects may occur in specific sites receiving concentrated or high levels of use, but these make up a small proportion of the analysis area. These effects would be mitigated.

Monitoring will also determine if impacts are higher than expected. If impacts become unacceptable, commercial use will be restricted or use levels will be limited.

\section{Fish Habitat and Water Quality}

Fish for This Analysis Management Indicators

- pink salmon

- coho salmon

- Dolly Varden char

- cutthroat trout

Others

- sockeye salmon

- steelhead trout

\section{Overview}

Fish are a component of the biodiversity in the analysis area. The annual spawning migrations of anadromous fish (such as salmon) are important to the function of many plant and animal communities. Many species of birds, mammals, and fish feed on the salmon and their eggs. Black and brown bears and bald eagles depend on spawning salmon and their carcasses for over-winter survival.

Fish and the other aquatic resources on the national forest support subsistence, commercial and sport fisheries, and traditional and cultural values. Abundant rainfall, streams with glacial origins, and watersheds with high stream densities provide a large number and diversity of freshwater fish habitats. Maintenance of this habitat, and associated high water quality, is the focus of state and federal natural resource agencies, user groups, Alaska Native organizations, and individuals.

\section{Legal and Administrative Framework}

The Federal Water Pollution Control Act (Clean Water Act) was enacted with the purpose of restoring and maintaining the chemical, physical, and biological integrity of the nation's waters. This Act, along with other land-use laws, enables state and federal governments to protect the "waters of the United States." In addition to laws and regulations, the Forest Service has adopted policies to assure that national forest management meets the intent of these laws. The Alaska Region's Soil and Water Conservation Handbook (FSH 2509.22, R10 Amendment 2509.22-96-1) applies laws and regulations and provides direction using Best Management Practices (BMPs) to ensure that the chemical, physical, and biological integrity of watersheds are maintained.

The Forest Plan standards and guidelines (pp. 4-5 to 4-74) define protection measures for stream and riparian management areas. In 1994, Congress requested the national forests of the Alaska Region to report on the effectiveness of habitat 


\section{Environment and Effects}

protections for anadromous fish. The report was titled, Anadromous Fish Habitat Assessment (AFHA). Forest Plan standards and guidelines will be implemented on all stream courses within the analysis area; these standards and guidelines meet or exceed all of the recommendations of the AFHA Team.

\section{Management Indicator Species}

The National Forest Management Act directs the use of Management Indicator Species (MIS) in forest planning to display the effects of forest management (36 CFR 219(9)(1)). MIS are species whose population changes indicate the effects of land management activities. They collectively represent the total number of species that occur within a planning area, the complex of habitats, and associated management concerns. As directed by the Forest Plan, pink salmon, coho salmon, Dolly Varden char, and cutthroat trout are MIS in this analysis. Pink salmon represent anadromous fish whose freshwater life period is limited by spawning gravel quantity and quality; coho salmon represent anadromous fish whose freshwater life period is limited by the area of stream and lake rearing habitat; Dolly Varden represent those species who occupy a wide range of freshwater habitats; and cutthroat trout represent fish species dependent on small freshwater stream systems. In addition, sockeye salmon and steelhead trout are included in the analysis. Sockeye salmon represent a critical subsistence resource and steelhead trout represent a valuable recreational sport fishing resource.

\section{Affected Environment}

Fisheries

Within the analysis area, lakes and streams with outlets to saltwater contain all five species of western Pacific salmon, Dolly Varden char, cutthroat trout, steelhead trout, and eulachon. Outfitter/guides target all the above fish species, except king salmon and eulachon, for freshwater fishing. State regulations prohibit harvesting of king salmon in freshwater in most streams in Southeast Alaska. Two sensitive populations of king salmon exist in the analysis area and are addressed under Sensitive Species. The fish considered in this assessment are:

- sockeye salmon (Oncorhynchus nerka)

- pink salmon (Oncorhynchus gorbuscha)

- coho salmon (Oncorhynchus kisutch)

- steelhead trout (Oncorhynchus gairdneri)

- cutthroat trout - anadromous and resident (Oncorhynchus clarki), and

- Dolly Varden char - anadromous (Salvelinus malma)

Anadromous fish spend part of their life in freshwater and part of life in saltwater. Salmon lay their eggs in redds (nests) dug in the gravel of streams and beaches. Newly hatched salmon (alevins) live in the spawning gravel attached to their yoke sac. Juvenile salmon emerge from the gravel and are free swimming. The amount of time juvenile fish spend in freshwater depends on the species, genetics, and growth. Pink and chum salmon start their downstream migration soon after emergence, while coho, sockeye, and king salmon spend zero to three additional winters in freshwater before migrating to the ocean. Salmon reach maturity in the ocean, returning to their natal streams to spawn and die and start the cycle again. 


\section{Environment and Effects 3}

Pink and coho salmon Since the mid-1970s, generally favorable climate and ocean conditions have resulted in high productivity and high marine survival of salmon (AFHA 1995). Harvests and escapements of wild coho and pink salmon are at historical high levels. Although no immediate concerns about over-fishing of pink or coho populations exist, protective management measures have been applied to one coho population (Table 3-31).

Steelhead trout Steelhead harvests peaked in 1986 and then started a dramatic decline. The ADF\&G closed several streams to the harvest of steelhead and placed restrictions on the use of bait starting in the early 1990s. By 1993, ADF\&G had closed 48 streams in Southeast Alaska and started monitoring steelhead abundance. In 1994 the Alaska Board of Fish adopted conservative steelhead management regulations of a one fish bag limit, two fish annual limit, and 36-inch minimum size limit for all Southeast Alaska.

Steelhead stocks have stabilized and appear to be recovering in some systems. The reduced harvests in the 1994 regulations and higher marine survival may be the reason for the recent population stability (Jones 2000). Interest in steelhead fishing remains strong, as indicated by an increase in fishing effort, although sport-fish steelhead regulations have reduced harvest.

Cutthroat trout In 1979, cutthroat trout harvests began to decline from over-fishing. ADF\&G initiated a stock monitoring program in the 1980s and proposed a cutthroat regulatory package that was adopted by the Board of Fisheries in 1994. The function of these regulations was to allow cutthroat to spawn at least once, decrease hooking mortality, and increase fish catch and size. Monitoring of these cutthroat trout regulations since 1994 has indicated that populations are recovering, although it is too soon to reach a definitive conclusion. Harvest of cutthroat trout was reduced from more than 10,000, during the 1980s to an average of 5,000 over the past five years. However, total sport catch, which includes both harvested fish and those caught and released, has increased over the past 5 years while fishing effort has remained the same.

Dolly Varden char Like cutthroat trout, Dolly Varden char are found throughout Southeast Alaska and exhibit both sea-run and lake or stream resident life cycles. Little stock assessment information is available regarding Dolly Varden. Because of the lack of information, an emphasis should be placed on monitoring Dolly Varden catch and harvest data.

Sockeye salmon In recent years, ADF\&G and the Federal Subsistence Board initiated emergency closures or additional restrictions on nine sockeye runs in the analysis area to ensure a sustainable subsistence fishery (ADF\&G Emergency Orders 01-20-01, 01-21-01, 01-10-00, 01,23,00, 01-32-00, 01-28-99, 01-23-98; ADF\&G Sport Fish regulations, 2001; and Federal Subsistence Regulations, 2001). These populations are important subsistence fisheries and have been the focus of recent or long-term stock assessments (Table 3-31). 


\section{Environment and Effects}

Table 3-31. Streams and Fish Stocks Recently Affected by Protective
Management Actions

\begin{tabular}{|c|c|c|c|}
\hline Location & $\begin{array}{l}\text { Use } \\
\text { Area }\end{array}$ & Species & Management Action \\
\hline Gut Bay drainages & 04-01A & sockeye & closed sport fishery \\
\hline Hoktaheen Lake & $04-15$ & sockeye & increased restrictions" \\
\hline Falls Lake drainages & $04-01 \mathrm{~A}$ & sockeye & closed sport fishery \\
\hline Klag Bay & $04-14$ & sockeye & $\begin{array}{l}\text { closed sport fishery and increased } \\
\text { restrictions }\end{array}$ \\
\hline Redoubt Bay and drainages & $04-02 \mathrm{~A}$ & sockeye & $\begin{array}{l}\text { closed sport and subsistence } \\
\text { fisheries }\end{array}$ \\
\hline $\begin{array}{l}\text { Silver Bay and Salmon Lake } \\
\text { drainage }\end{array}$ & $04-03$ & sockeye & $\begin{array}{l}\text { closed sport and subsistence } \\
\text { fisheries }\end{array}$ \\
\hline $\begin{array}{l}\text { Silver Bay and Salmon Lake } \\
\text { drainage }\end{array}$ & $04-03$ & coho & closed sport fisheries \\
\hline Sitkoh Lake drainages & $04-13$ & sockeye & closed sport fishery \\
\hline Surge Bay & $04-15$ & sockeye & increased restrictions \\
\hline Takanis Bay & $04-15$ & sockeye & increased restrictions \\
\hline
\end{tabular}

"Increased restrictions refer to both sport and subsistence fisheries.

\section{Riparian Habitat}

Riparian habitat is the interface between aquatic and terrestrial ecosystems. Riparian habitat includes the water, land, and plants adjacent to perennial streams, lakes, and other water bodies. The components of riparian habitat determine its form and function. The landform and geology determine the basic stream type; riparian vegetation maintains stream bank stability and floodplain integrity; and the water supports the vegetation and animal species dependent on the habitat. Riparian vegetation reduces water velocity on the floodplain, and the roots inhibit stream bank erosion. Riparian vegetation also provides shade and leaf and needle litter, which fuels aquatic food chains. Large woody debris (from fallen trees) provides fish cover, creates pools, and provides stream bank protection.

\section{Resource Use}

High value fishing streams are used to evaluate the effects of commercial recreation used in this analysis. Approximately 2,950 streams flow through the analysis area. Of these, about 1,444 streams (900 miles) are potentially habitat for anadromous fish (Class I). Most of these streams are less than 10 feet wide and support small populations of pink and coho salmon. The preferred fishing streams are typically the lower reaches of clear water streams that are 30 to 100 feet wide and flow through several miles of productive salmon habitat. These high value fishing streams are generally found on low gradient (less than two percent) streams in wide valleys that provide good pedestrian access. In the analysis area, 180 high value fishing streams were identified. This analysis does not attempt to define streams of greatest value to marine and commercial fisheries. Given the highly mixed stock nature of marine harvest, it would be difficult to categorize the value of individual streams to these user groups. 
There are an additional 1,340 miles of non-anadromous streams and streams unlikely to support any fish populations (Class II and III streams) within the analysis area. Outfitter/guide use has been concentrated on high value fishing streams; outfitter/guides spend minimal time on Class II and III streams.

Although guided freshwater sport fishing represents a small percentage (approximately one percent) of the total sport fishing effort in the analysis area and surrounding saltwater, use has steadily increased in recent years. Use records from 1996 to 2000 show guided freshwater sport fishing use has doubled (Figure 3-10). Guided freshwater sport fishing accounted for 25 percent of guided activities in the analysis area during 1999. Where possible, guides appear to be taking their clients to more remote streams. In 1999, approximately 80 percent of guided sport fishing use occurred more than 15 miles from the communities of Juneau, Sitka, Hoonah, Angoon, Tenakee Springs, and Kake. Although a few streams are obviously popular fishing destinations, data from 1999 indicate that most streams were visited by fewer than 15 groups throughout the year (Figure 3-11).

Figure 3-10. Guided Freshwater Sport Fishing Use on the National Forest, 1996-2000

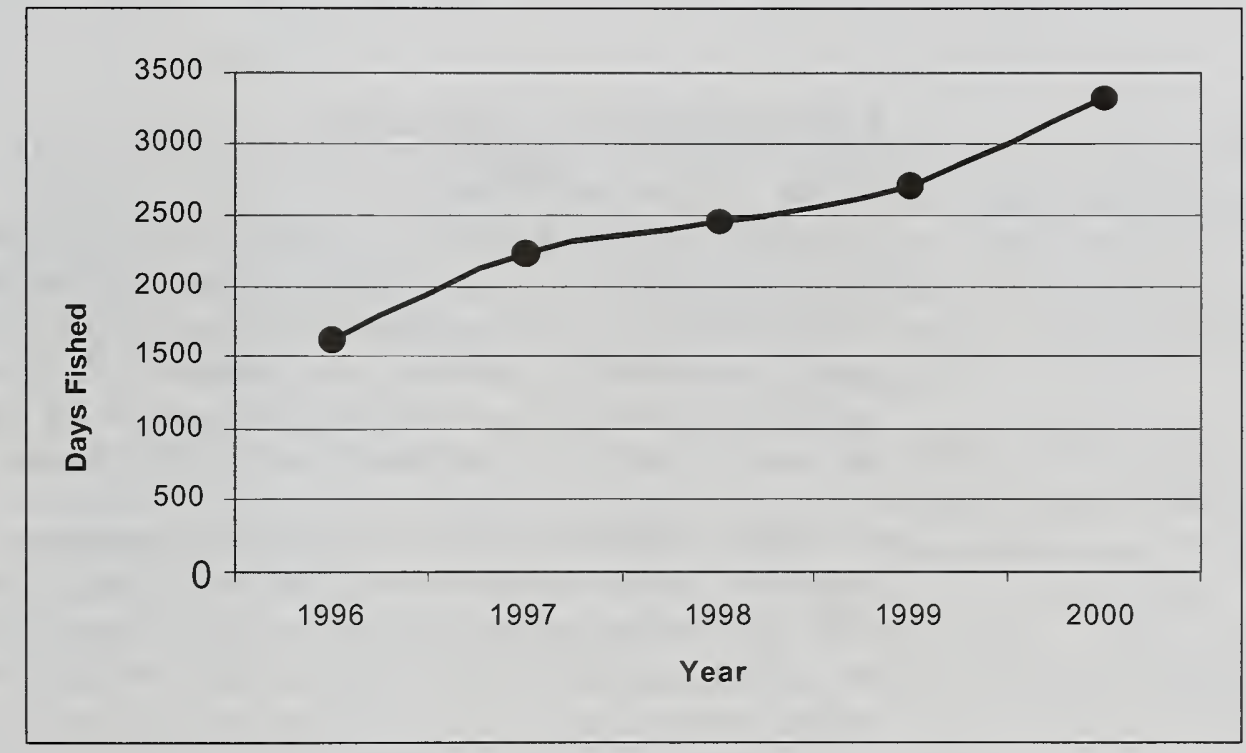




\section{Environment and Effects}

Figure 3-11. Distribution of Sport Fishing Use on Streams in the Analysis Area During 1999

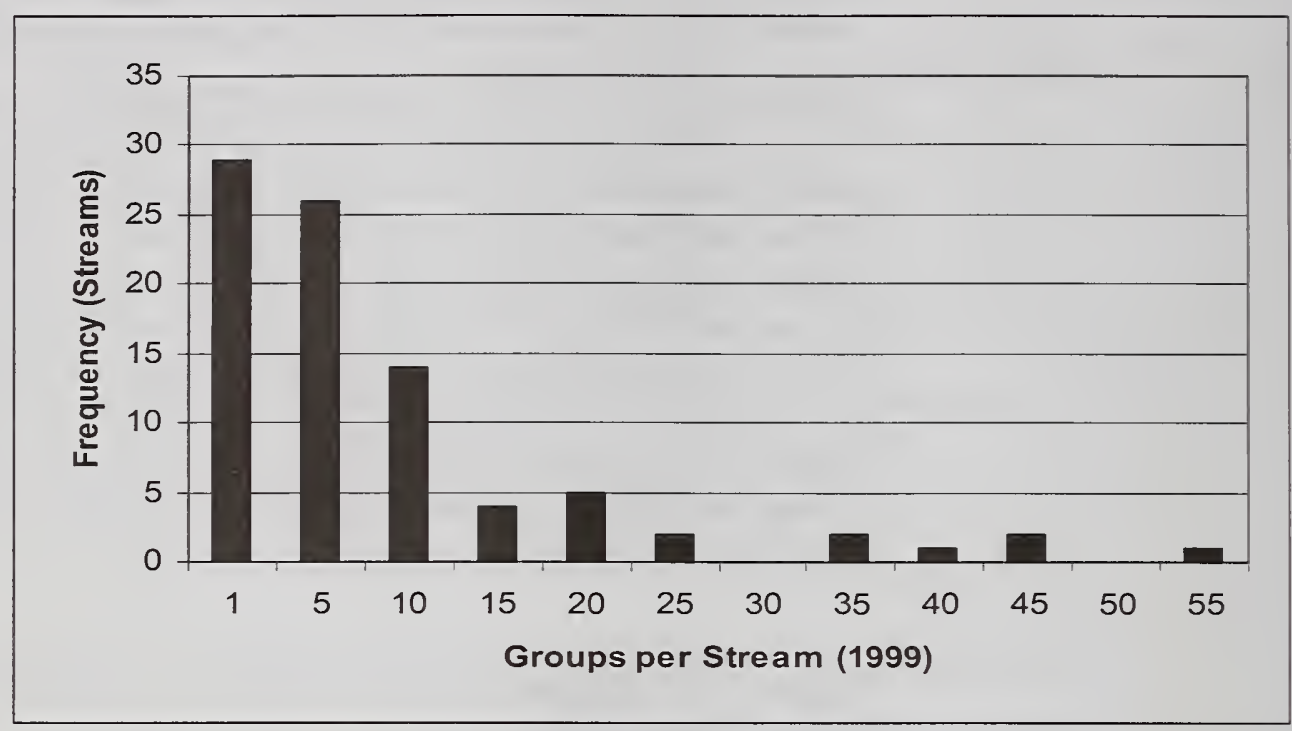

\section{Environmental Consequences}

\section{Direct and Indirect Effects}

Overview Recreation use of the national forest, including guided recreation, is expected to increase as the population of northern Southeast Alaska grows.

Concentrations of people along and in streams can lead to loss of overhanging banks, loss of stream bank vegetation and acceleration of stream bank erosion, and reduced egg viability and fry survival by disturbing spawning gravels. Increased fishing pressure can affect the sustainability of fish populations.

As outfitter/guide use increases, activity in riparian areas will make up a significant proportion of this increase and will not be uniformly dispersed across forest streams. Although current use levels of outfitter/guides have limited effects on fish habitat and production, approximately 50 percent of outfitter/guide use occurs near anadromous streams. In 1999, outfitter/guides identified 287 sites visited within the analysis area, of which 152 sites were located within one-half mile of an anadromous stream. Freshwater sport fish guides currently use approximately 90 of the 180 high value fishing streams. Some streams are more attractive to outfitter/guide clients; these streams will receive higher use and increase the potential for adverse resource effects. There would be no negative effects from commercial recreation on Class II and III streams because outfitter/guides spend minimal time on them. However, watershed and fisheries resource protection would be applied to both high value and other streams.

Fish Productivity The potential freshwater fishing effort and harvest varies by alternative. Assuming current use patterns continue ( 25 percent of guided use is freshwater fishing), Alternative 3 , which allows the highest number of groups, would potentially provide the most fishing days (approximately 61,000 ), followed by 
Alternatives 5, 2, and 4 (Table 3-32). As a comparison, this represents approximately 25 percent of the total 1999 sport fishing effort (guided and unguided) in the analysis area and surrounding saltwater. Although 61,000 fishing days represents a relatively large amount of effort, if current fishing practices persist it may not represent a large harvest. Analysis of 2001 catch and harvest records from freshwater guides estimated two percent of fish caught were harvested; guided sport fishermen typically practice catch-and-release fishing, which has an estimated mortality of 5 percent. Pink salmon and Dolly Varden composed 95 percent of the catch; these returns correspond with the cruise ship season, which provides the primary client base for guided fishing. Because of the low harvest rates projected for all alternatives in relation to the fish populations as a whole, it is not anticipated that implementation of any alternative will negatively affect fish production.

Table 3-32. Potential Guided Freshwater Sport Fishing Effort, by Alternative

\begin{tabular}{cc}
\hline Alternative & Estimated Days Fished \\
\hline 1 & 60,987 \\
2 & 25,341 \\
3 & 60,987 \\
4 & 9,288 \\
5 & 27,935 \\
\hline
\end{tabular}

Riparian Habitat and Water Quality Direct and indirect effects on riparian habitat and water quality associated with guided recreation use could potentially include: altering or damaging vegetation, discharge of human waste, gray/soapy water discharge, litter, walking in the stream, stream bank erosion, sedimentation, and fuel/oil spills. However, these effects can be mitigated. Many of these effects are associated with camping or concentrated use at campsites.

Outfitter/guide use permits will require compliance with BMPs and mitigation measures. These include BMPs 12.6 (Riparian Area Designation and Protection) and 12.8 (Oil Pollution Prevention and Servicing/Refueling Operations). Mitigation measures (Appendix C) will include camping restrictions, 'Leave No Trace' practices, wading restrictions, and potential watercraft restrictions. These measures restrict camping within 100 feet of perennial stream banks, lake shores, and other bodies of water, and require prevention and clean-up of fuel and oil spills. 'Leave No Trace' practices are also a requirement of the outfitter/guide permit and assure the proper disposal of human waste, gray/soapy water discharge, and litter.

Wading (walking in a stream) may kill salmon eggs or fry by direct crushing or disturbing the surrounding gravel. Roberts (1992) found that a single incidence of wading directly prior to hatch killed between 5 and 43 percent of the affected salmon eggs. Wading disrupts gravel, compacts it, and slows water flow around eggs. Roberts (1992) recommended wading restrictions be considered where fish populations are limited by insufficient or degraded spawning habitat and where intensive angler wading in spawning areas occurs during egg and pre-emergent fry development. None of the high value fishing streams identified or other streams used by outfitter guides currently meet these criteria. To mitigate potential effects 


\section{Environment and Effects}

from wading, permits will require outfitter/guides and their clients to travel between the high and low water marks (the area periodically de-watered) when practical.

The wake created by motorized watercraft can erode stream banks and the turbulence created by the power head can crush or excavate fish eggs. Studies on the effects of jet boats on salmonids have focused on the physical destruction of eggs and preemergent fry, effects of powerhead turbulence, and changes in spawning behavior. Horton (1994) demonstrated that the excavation of the stream bottom, eggs, and aelvins by jet boat traffic in shallow water was the most significant form of mortality. At water depths less than 9 inches, eggs, and pre-emergent fry mortality approached 100 percent in the $1-2$ foot zone directly below the boat. Jet boat impacts increase with boat size, amount of traffic, and spawning area traversed; impacts decrease with water depth. Although not commonly used in shallow streams, propeller-driven boats have been noted to create more disturbance than jetdriven boats in water depths of 7-10 inches.

Current motorized watercraft use levels are not considered to have measurable adverse effects on riparian and fish resources. However, increased motorized boat access may cause adverse effects that will need to be monitored. If these effects become measurable by visual observation during permit administration, motorized watercraft will be restricted on a site-specific basis. Restrictions may include permitting motorized watercraft use only in May and June (the period between emergence and spawning); restrictions on boat size and power; limiting use to water depths of three feet or more; limiting speeds to no wake; or excluding motorized use on specific sensitive portions of streams.

No restrictions on the main stems of large glacial streams within the analysis area would be necessary because salmon are unlikely to spawn in these systems. However, some tributary streams may provide spawning habitat. The unrestricted main river systems include:

- Taku River,

- Lace and Gilkey Rivers,

- Whiting River,

- Speel River,

- Endicott River, and

- Katzehin River.

Salmon eggs incubate in stream gravels for days or months until the fry emerge. Developing eggs require an adequate supply of dissolved oxygen for development. Excess sediment fills spaces between the gravel and obstructs the circulation of water and oxygen. Inadequate water circulation and dissolved oxygen extend the incubation period and reduce the size of the fry (Shumway 1964).

Bank erosion and bank building are continual processes in the function of streams; sediment is temporarily stored in pools and point bars until transported downstream during high flows. Wading releases small amounts of sediment, which temporarily clouds the water. Sediment is also released from the erosion of trails and roads. While salmon fry can tolerate short-term turbidity, it is not feasible to predict the impacts of specific erosion events on individual fish or fish populations. Recreation 


\section{Environment and Effects 3}

activities that may increase stream sedimentation can be evaluated, monitored, and mitigated.

Footpaths and stream bank erosion are some of the more noticeable signs of recreation use impacts on streams. Properly built and maintained trails within the riparian zone provide access while protecting the stream. However, un-maintained footpaths can promote bank erosion and damage to fish habitat and water quality. Foot traffic can remove the organic layer exposing the soil. Once the organic layer has been removed, rainfall encourages erosion, which is directly influenced by slope and soil texture. Riparian soils are typically mineral in nature and relatively resilient to erosion from foot traffic. The Alaska Region Trails Construction and Maintenance Guide (USDA 1991) estimated mineral soils can withstand approximately 600 one-way trips without affecting the soil's ability to repair itself from one year to the next. The riparian zone will likely contain pockets of organic soils or low wet spots that will become 'muck' holes at lower use levels. These areas are typically small and isolated and their erosion does not adversely affect fish habitat or water quality. See the Soils and Vegetation sections for additional information regarding affected resources.

Monitoring of some riparian sites outside the analysis area has shown that areas receiving 2,500 or more visitors annually have identifiable adverse effects on fish habitat and water quality due to recreation use. In riparian areas where foot traffic exceeds 600 one-way trips, the potential for adverse effects on fish habitat and water quality is more likely. If travel along a trail or at a site should exceed 600 people (one-way), the site will be evaluated for adverse effects on riparian resources. If riparian resources are being adversely affected, the impacts will be mitigated with BMPs 12.6 (Riparian Area Designation and Protection) and 16.4 (Trail Construction and Maintenance) or recreation use will be restricted.

To evaluate the effects of commercial recreation use on riparian resources (including fish habitat and water quality), sites where use would likely exceed 300 visitors were identified for each alternative. (Because most hikes involve a round trip along the same trail, 300 visitors will approximate 600 one-way trips.) The number of sites with potential adverse effects on riparian resources ranged from 3 to 26 (Table 3-33) among the alternatives. Adverse effects on riparian resources may occur at additional locations if use increases at other sites in the future.

The following assumptions are included in this analysis.

- Sites were identified where use occurred within one-half mile of an anadromous stream (although use may not have actually occurred in the riparian area).

- Sites were identified using 1999 use data (152 out of 287 sites identified).

- Increases in site use by alternative were estimated based on the allocation and historical use patterns.

- While Alternative 1 does not establish a specific allocation, commercial use could increase to up to 50 percent of the recreational carrying capacity. 
Large group areas are also expected to receive higher levels of recreation use in the future. Large group areas containing or adjacent to riparian areas are expected to have more potential to have an adverse effect on riparian resources (Table 3-34).

Table 3-33. Number of Sites Within One-half Mile of a Riparian Zone with Use Estimated to Exceed 300 Visitors Per Year

\begin{tabular}{cc}
\hline Alternative & Number of Sites \\
\hline 1 & 26 \\
2 & 12 \\
3 & 26 \\
4 & 3 \\
5 & 13 \\
\hline
\end{tabular}

Table 3-34. Number of Fifteen-Percent Areas and Enclaves Within One-half Mile of an Anadromous Stream

\begin{tabular}{cccc}
\hline Alternative* & $\begin{array}{c}\text { Fifteen-Percent } \\
\text { Areas }\end{array}$ & Enclaves & Total \\
\hline 3 & 12 & 28 & 40 \\
4 & 3 & 10 & 13 \\
5 & 6 & 22 & 28 \\
\hline
\end{tabular}

* Alternatives 1 and 2 do not designate Fifteen-Percent areas or Enelaves.

Effects on riparian

habitat and water

quality from guided

recreation use over the

analysis area as a

whole are expected to

be minor for all

alternatives.
Summary Of Direct And Indirect Effects If the total commercial use allocation is used as a measure for the potential risk of negative effects on riparian habitat, higher allocations would mean higher risk. Alternative 3 with the highest allocation would have the highest potential risk. Alternative 5 would have the second highest risk, closely followed by Alternative 2. Alternative 4 would have the lowest risk. Alternative 1 does not make a specific allocation but could potentially be up to 50 percent of the carrying capacity, providing a risk equal to Alternative 3 . See Table 3-9 for numbers of recreation group days allocated by alternative.

Effects on riparian resources will be mitigated through application of BMPs 12.6 (Riparian Area Designation and Protection) and 16.4 (Trail Construction and Maintenance). Because of the low impacts from guided recreation activities and the mitigation measures and BMPs, effects on riparian habitat and water quality from guided recreation use over the analysis area as a whole are expected to be minor for all alternatives.

\section{Cumulative Effects}

Cumulative effects include natural fluctuations in fish populations and harvest from other users. There are no immediate concerns regarding any fish species within the 
analysis area. Commercial fish harvest in the waters of Southeast Alaska has fluctuated widely from year to year as the fisheries are managed to meet escapement needs in the face of large natural variations in survivals and returns (Van Alen 2000). Harvest levels and escapements of wild coho and pink salmon are at historically high levels. Wild sockeye and chum stocks are below historical levels but efforts to rebuild escapements and returns are working and these stocks are generally healthy. Fluctuations in run sizes are partly attributable to changes in ocean productivity. The productivity of marine waters in the Gulf of Alaska, and the survival of salmon and steelhead trout, are both highly variable and cyclic. Since the mid-1970s, generally favorable climate and ocean conditions have resulted in good marine survival of salmon (AFHA 1995). Guided freshwater sport fishing represents a small part of the fish harvest. In the analysis area and surrounding waters, guided sport-fishing accounts for approximately 1 percent of the total sport fishing effort (Figure 3-12). In addition, approximately 90 percent of guided freshwater anglers practice catch and release.

Figure 3-12. Freshwater and Saltwater Fishing Effort in the Analysis Area and Surrounding Saltwater, 1997-1998

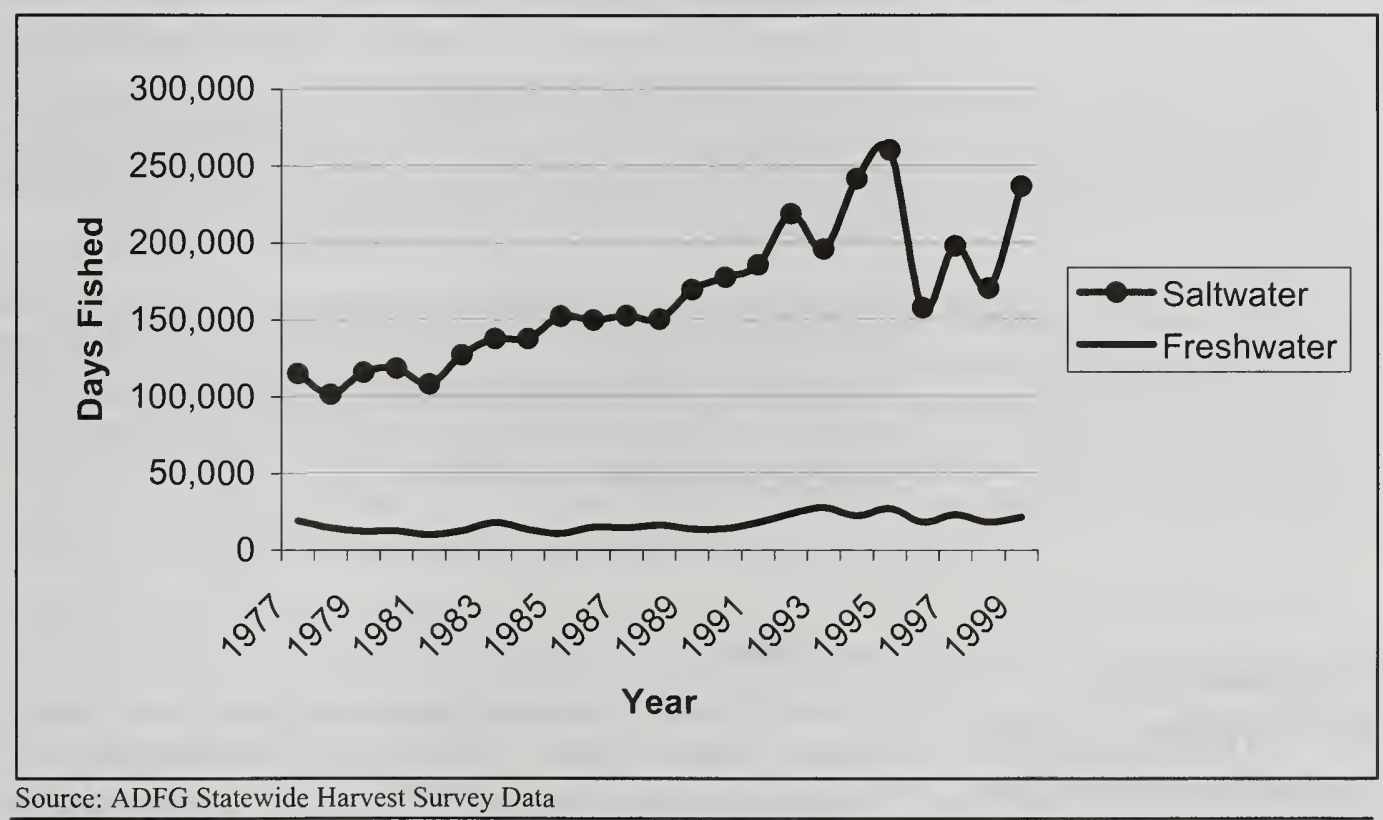

Summary of Cumulative Effects Some fish populations within the analysis area are currently near or at maximum sustained harvest levels. Regardless of the alternative implemented, these populations would continue to be managed by the Alaska Department of Fish and Game and Federal Subsistence Board through the use of fishing restrictions to ensure sustainable populations. Current and future fishing effort by guided freshwater sport fishing represents a minimal fraction of the total harvest in the analysis area and surrounding salt waters. The effects of guided freshwater fishing on these populations would be monitored using a catch and harvest logbook. 


\section{Environment and Effects}

\section{Essential Fish Habitat}

The National Marine Fisheries Service (NMFS) was consulted on this analysis using the formal and informal procedures of Section 305(b)(2) of the Magnuson-Stevens Fisheries Conservation Management Act (1996). Region and forest-wide standards and guidelines that protect and conserve essential fish habitat would be implemented under this analysis to maintain sustainable fisheries. Essential Fish Habitat (EFH) includes all freshwater streams accessible to anadromous fish, marine waters, and intertidal habitats. This includes all Class I streams, marine waters, and intertidal habitats of the Shoreline Outfitter/Guide analysis area.

The potential for adverse effects on riparian habitat by outfitter/guide activities leads to the finding that the project may adversely affect Essential Fish Habitat. See the riparian habitat and water quality analysis of this chapter for individual and cumulative effects on EFH.

No effects on associated salmon prey species are anticipated by the proposed action. Juvenile salmon are known to feed on aquatic insects, terrestrial insects, salmon eggs, and decaying salmon carcasses.

EFH species that may be affected by Forest Service actions include pink, chum, and coho salmon. Effects on EFH differ by alternative based primarily on the level of commercial recreation use available. As the potential for increased foot traffic in riparian areas rises with available commercial use, the likelihood of soil erosion increases (Table 3-33). Sediments originating from soil erosion may adversely affect EFH. Sediments may affect incubating eggs and larvae by reducing water quality and intergravel flow for developing eggs and larvae.

The level of adverse effects will need to be determined through site evaluation and monitoring. Mitigation of these effects will involve compliance with BMPs 12.6 (Riparian Area Designation and Protection) and 16.4 (Trail Construction and Maintenance) and mitigation measures. Application of BMPs will eliminate nearly all effects on EFH.

\section{Threatened, \\ Endangered, and Sensitive Species}

\section{Overview}

Federally listed threatened and endangered species are those plant and animal species formally listed by the U.S. Fish and Wildlife Service or the National Marine Fisheries Service under authority of the Endangered Species Act of 1973. as amended. Under the Endangered Species Act, an endangered species is defined as one that is in danger of extinction throughout all or a significant portion of its range. A threatened species is defined as one that is likely to become an endangered species within the foreseeable future throughout all or a significant portion of its range.

The Regional Forester of the USDA Forest Service has the authority to designate species as 'sensitive.' Sensitive species are those plant and animal species for which population viability is a concern, based on significant current or predicted downward trends in population or habitat capability. 
No plant or animal species listed as threatened or endangered are known to occur within the analysis area.

\section{Affected Environment}

\section{Endangered and Threatened Wildlife}

The Forest Service consulted with the U.S. Fish and Wildlife Service (USFWS) and the National Marine Fisheries Service (NMFS) as part of this analysis. No plant or animal species listed as threatened or endangered by the USFWS are known to occur within the analysis area.

Several species that are listed as threatened or endangered by the NMFS potentially occur in the general vicinity. One other species in the area has been recently petitioned but denied for listing. Most of these species (blue whale, fin whale, right whale, sei whale, sperm whale and leatherneck sea turtle) live in the open ocean and are not found in the analysis area.

Humpback whales are listed as endangered; they live in the marine environment and do not occur in the analysis area. However, they feed in the shallow, inside waters of the Southeast Alaska panhandle and are more likely than the other marine species to be exposed to human activity.

The Snake River sockeye salmon (Onchorhynchus nerka) is listed as endangered. This species does not occur within the analysis area and is not available to sport or subsistence fishing.

The upper Columbia River spring chinook salmon (Onchorhynchus tshawytshca) is listed as endangered and some stocks are threatened. These species may feed in the marine waters along the coast of the Tongass National Forest but they do not use local streams to spawn.

The Steller (northern) sea lion is also listed as threatened. Steller sea lions feed in the waters around the analysis area and use specific locations as rookeries or haulouts. The NMFS identified White Sisters as a critical rookery and Benjamin Island, Biali Rock, Biorka Rock, Cape Cross, Cape Ommaney, Gran (Ledge) Point, Lull Point, and Sunset Island as critical haul-outs. Twenty-seven of the 33 known Steller sea lion haul-outs in the analysis area are on the national forest.

The Kittlitz's murrelet (Brachyramphus brevirostris) was petitioned for listing as endangered. The USFWS declined to list the Kittlitz's murrelet at this time. These birds forage near tidewater glaciers and the outflow of glacial streams. They nest on talus slopes of high mountains. Known breeding areas within the analysis area include Port Houghton, Endicott Arm, and Tracy Arm. They may also breed near the tidewater glaciers in Taku Inlet and the small glaciers of Baranof Island.

\section{Sensitive Wildlife}

The northern goshawk (Accipiter gentiles laingi), osprey (Pandion haliaetus), Peale's peregrine falcon (Falco peregrinus pealei), trumpeter swan (Cygnus buccinator), and king salmon (Onchorhynchus tshawytscha) of the King Salmon River and Wheeler Creek runs are identified as sensitive species in Region 10 and the analysis area.

The Northern goshawk is a wide-ranging forest raptor that nests in old-growth forest habitats in Southeast Alaska. Goshawks generally select forest stands with large trees on gentle slopes at lower elevations for nesting and foraging (Reynolds 1989; USDA Forest Service 1990). Although goshawk nests are present in the analysis 


\section{Environment and Effects}

area, no nests or goshawk territories have been located in or near any of the proposed large group areas or Enclaves.

Osprey usually nest in broken-top spruce trees, either live or dead, and in western hemlock snags. They are found near water since their diet consists mainly of fish. There are no known osprey nests in the analysis area, but osprey may stop at some lakes in the analysis area to rest and feed during migration.

Peale's peregrine falcon is a subspecies of the peregrine falcon. It nests on the outer coast along the Gulf of Alaska and is closely associated with large seabird colonies (USDA Forest Service 1997a). Peale's peregrine falcon is not known to nest in the analysis area.

The breeding range of the trumpeter swan is concentrated along the Alaska Gulf coast and wetland areas in central and south-central Alaska (Bellrose 1980). Trumpeter swans that breed in Alaska, winter along the Pacific Coast from the Alaska Peninsula to the mouth of the Columbia River (Bellrose 1980). Each year, swans pass through southern Southeast Alaska in the spring and fall during migration to and from their breeding grounds. Swans that winter in Southeast Alaska usually move to large lakes and estuaries when the weather turns cold. They arrive in mid-October and generally leave for their breeding grounds by mid-April. During the winter of 2000-2001, the Forest Service and USFWS cooperatively conducted surveys for swans in Southeast Alaska (excluding Yakutat Ranger District). Many lakes and ponds in the analysis area have the potential to support nesting swans; however no nesting pairs are known to exist.

King Salmon River and Wheeler Creek populations of king salmon are island run stocks. No other naturally occurring runs of island king salmon stocks are known to exist in Southeast Alaska. All other natural king salmon runs occur on mainland rivers and streams. Both populations are located within the Kootznoowoo Wilderness on Admiralty National Monument.

\section{Sensitive Plants}

Eighteen plant species have been designated as sensitive by the Regional Forester for the Alaska Region, 16 of these species occur on the Tongass National Forest. Table 3-35 lists the Alaska Region Sensitive plant species and their status in this analysis. Six of these sensitive plant species are either not found in the shoreline zone of the analysis area or are not affected by recreation use because they occur in aquatic habitats or in tree crevices where they are not likely be trampled or disturbed. Two sensitive plant species are known to occur in the shoreline zone. Nine species are suspected of occurring in the shoreline zone, and nine could potentially be affected by guided recreation use, including those that are most likely to occur in beach, estuary, and riparian meadows. (They are unlikely along rocky or abrupt forest shoreline habitats, or in muskegs, or under forest canopy.) 


\section{Environment and Effects 3}

Table 3-35. Sensitive Plant Species, Alaska Region

\begin{tabular}{|c|c|c|c|c|c|}
\hline Scientific Name & Common Name & $\begin{array}{l}\text { Known } \\
\text { to occur } \\
\text { in the } \\
\text { shoreline } \\
\text { zone }\end{array}$ & $\begin{array}{l}\text { Suspected } \\
\text { to occur in } \\
\text { shoreline } \\
\text { zone }\end{array}$ & $\begin{array}{l}\text { Potentially } \\
\text { affected by } \\
\text { guided } \\
\text { recreation } \\
\text { in shoreline } \\
\text { zone }\end{array}$ & Habitat/Range \\
\hline $\begin{array}{l}\text { Aphragmus } \\
\text { eschscholtzianus }\end{array}$ & $\begin{array}{l}\text { Eschscholtz's } \\
\text { little nightmare }\end{array}$ & & & & alpine \\
\hline $\begin{array}{l}\text { Arnica lessingii } \\
\text { Greene ssp. } \\
\text { Norbergii }\end{array}$ & norberg arnica & & $\mathrm{X}$ & $\mathrm{X}$ & meadows \\
\hline $\begin{array}{l}\text { Carex } \\
\text { lenticularis var. } \\
\text { dolia }\end{array}$ & $\begin{array}{l}\text { Goose-grass } \\
\text { sedge }\end{array}$ & & & & alpine/subalpine \\
\hline Cirsium edule & Edible thistle & & & & south Tongass \\
\hline $\begin{array}{l}\text { Dodecatheon } \\
\text { pulchellum ssp. } \\
\text { Alaskanum }\end{array}$ & $\begin{array}{l}\text { Pretty shooting } \\
\text { star }\end{array}$ & & $\mathrm{X}$ & $\mathrm{X}$ & $\begin{array}{l}\text { rocky shorelines, } \\
\text { beaches }\end{array}$ \\
\hline Draba kananskis & $\begin{array}{l}\text { Tundra whitlow- } \\
\text { grass }\end{array}$ & & & & Chugach N.F. \\
\hline $\begin{array}{l}\text { Glyceria } \\
\text { leptostachya }\end{array}$ & $\begin{array}{l}\text { Davy } \\
\text { mannagrass }\end{array}$ & & $\mathrm{X}$ & & shallow water \\
\hline $\begin{array}{l}\text { Hymenophyllum } \\
\text { wrightii }\end{array}$ & $\begin{array}{l}\text { Wright filmy } \\
\text { fern }\end{array}$ & & $\mathrm{X}$ & & $\begin{array}{l}\text { tree and cliff } \\
\text { crevices }\end{array}$ \\
\hline Isoetes truncata & $\begin{array}{l}\text { Truncate } \\
\text { quillwort }\end{array}$ & & $\mathrm{X}$ & & aquatic plant \\
\hline $\begin{array}{l}\text { Ligusticum } \\
\text { salderi }\end{array}$ & Calder's lovage & & $\mathrm{X}$ & $X$ & meadows \\
\hline $\begin{array}{l}\text { Papaver } \\
\text { alboroseum }\end{array}$ & Pale poppy & & & $\mathrm{X}$ & $\begin{array}{l}\text { gravels, possible } \\
\text { in Lynn Canal }\end{array}$ \\
\hline $\begin{array}{l}\text { Platanthera } \\
\text { gracilis }\end{array}$ & Bog orchid & & $\mathrm{X}$ & $\mathrm{X}$ & $\begin{array}{l}\text { wet meadows, } \\
\text { muskeg }\end{array}$ \\
\hline Poa laxiflora & $\begin{array}{l}\text { Loose-flowered } \\
\text { bluegrass }\end{array}$ & $\mathrm{X}$ & & $\mathrm{X}$ & $\begin{array}{l}\text { wet meadows, } \\
\text { open forest }\end{array}$ \\
\hline Pucinellia glabra & $\begin{array}{l}\text { Smooth alkali } \\
\text { grass }\end{array}$ & & & & Chugach N.F. \\
\hline $\begin{array}{l}\text { Puccinellia } \\
\text { kamtschatica }\end{array}$ & $\begin{array}{l}\text { Kamchatka } \\
\text { alkali grass }\end{array}$ & & $\mathrm{X}$ & $\mathrm{X}$ & $\begin{array}{l}\text { upper beach } \\
\text { meadows }\end{array}$ \\
\hline $\begin{array}{l}\text { Romanzoffiea } \\
\text { unalaschensis }\end{array}$ & $\begin{array}{l}\text { Unalaska mist- } \\
\text { maid }\end{array}$ & $\mathrm{X}$ & & $\mathrm{X}$ & $\begin{array}{l}\text { rocky outcrops, } \\
\text { streamsides, } \\
\text { forest edges }\end{array}$ \\
\hline $\begin{array}{l}\text { Senecio } \\
\text { moresbiensis }\end{array}$ & $\begin{array}{l}\text { Queen Charlotte } \\
\text { butterweed }\end{array}$ & & $\mathrm{X}$ & $\mathrm{X}$ & $\begin{array}{l}\text { heath, wet } \\
\text { meadows }\end{array}$ \\
\hline $\begin{array}{l}\text { Stellaria } \\
\text { ruscifolia ssp. } \\
\text { aleutica }\end{array}$ & $\begin{array}{l}\text { Cicumpolar } \\
\text { starwort }\end{array}$ & & & & alpine/subalpine \\
\hline
\end{tabular}




\section{Environmental Consequences}

\section{Endangered and Threatened Wildlife}

No federally listed threatened or endangered species will be adversely affected by the proposed actions.

Management activities on the uplands that have effects on humpback whale prey species would have indirect effects on the whale populations. No ground disturbance would result from this analysis that would have a negative effect on humpback whale prey. Therefore, the proposed action and alternatives to it would not adversely affect humpback whale populations.

Snake River sockeye salmon does not occur within the analysis area and is not available to sport or subsistence fishing. The proposed action and alternatives would not affect the Snake River sockeye population.

Upper Columbia River spring chinook salmon do not use local streams to spawn. Therefore, this project would have no direct effect on the population. This analysis does not include any large-scale, ground-disturbing activities and would not have any direct effect on chinook salmon prey and would not indirectly cause a reduction in the salmon population.

Many factors are responsible for the threatened status of Steller sea lion populations, most of which are outside the jurisdiction of the Forest Service. One factor within the scope of this analysis is the amount of human disturbance at haul-outs and rookeries on the national forest. No camps would be allowed within one mile of a critical sea lion haul-out or rookery. Therefore, the proposed action and alternatives would not have a direct or indirect adverse effect on the Steller sea lion population.

The Kittlitz's murrelet has been petitioned for listing, however the USFWS has declined to list this species at this time. The Forest Service will work with the USFWS to protect this species. Several factors are listed as potential causes for Kittlitz's murrelet population declines, one of which is human disturbance on breeding and feeding grounds. These alternatives are not expected to adversely affect the Kittlitz murrelet population, because little or no guided use is occurring in areas on the national forest where Kittlitz's murrelets occur. If the Kittlitz murrelet is listed, then the activities in these areas will be reconsidered but the Forest Service does not have jurisdiction over the marine environment used by the murrelet.

Sensitive wildlife

Although goshawk nests are present in the analysis area, no nests or goshawk territories have been located in or near any of the proposed large group areas or Enclaves. If active nests are discovered in or near these areas, mitigation measures would be applied to prevent disturbance to the nesting pair and their fledglings (USDA Forest Service 1997b, p. 4-116).

There are no known osprey nests in the analysis area. If active nests were discovered in the Analysis Area, Forest Plan standards and guidelines would be followed (USDA Forest Service 1997; p. 4-92).

Peale's peregrine falcon is not known to nest in the analysis area. If a nest were discovered in the analysis area, Forest Plan standards and guidelines would be implemented. 
No nesting pairs of trumpeter swans are known to exist. If nests were discovered in the analysis area, Forest Plan standards and guidelines (USDA Forest Service 1997; p. 4-92) would be implemented.

Both populations of island run king salmon (King Salmon River and Wheeler Creek) are located within the Kootznoowoo Wilderness on Admiralty National Monument. Outfitter/guide permits that would increase harvest pressure on these runs would not be issued (USDA Forest Service 1997; p. 4-92). State fishing regulations prohibit the taking of king salmon in all freshwaters in the analysis area. Anglers target other fish species and use fishing gear that is not attractive to king salmon, and they tend to fish streams that do not support king salmon runs. No harvest or catch of king salmon have been reported from guided activities on these streams. Thus, guided sport fishing would not negatively affect the viability of king salmon in King Salmon River or Wheeler Creek.

\section{Sensitive Plants}

No Sensitive plants are known to have been adversely affected by recreation activities on the Tongass National Forest. Previous biological evaluations and monitoring have not shown adverse effects. Any potential effects would depend on the species and its ability to withstand and recover from disturbance; the time of year, type, location, and duration of use of the recreation activity; and the number of people using a specific site. Potential effects on sensitive plants from guided recreation use come primarily from trampling. Repeated trampling may damage the plant for the current growing season or permanently destroy the plant. Long-term use such as over-night camping will have a greater potential effect than short-term day use. There is a lesser possibility of impacts due to plant collecting. High levels of recreation use during the growing season in areas of potential habitat for sensitive plants increase the potential for impacts to these plants.

Effects on sensitive plants can be minimized by avoiding sites where these plants are known to exist and by using mitigation measures to reduce the potential impacts. Guided recreation will not be permitted at site-specific locations where sensitive plants are known to exist.

Sites with likely habitats that receive high levels of recreation use (including large group areas) will be surveyed and monitored during permit administration. If additional sensitive plant locations are found, they will be excluded from commercial recreation use.

There is a potential risk of guided recreation activities affecting unknown sensitive plants, but the risk is expected to be minor because of the low impact and short duration of these activities, the relatively low levels of commercial recreation dispersed across a large area, and the application of mitigation measures. Potential impacts would be limited to individual plants and are not likely to cause a trend to federal listing or loss of viability for any alternative.

Higher allocations could result in higher use levels resulting in higher risk for potential impacts on sensitive plants. Alternative 3 has the greatest potential to affect sensitive plants because it has the highest allocation during the summer and proposes the most large group areas. Alternative 5 has the second highest potential because it has the second highest allocation and number of large group areas. Alternative 2 has the third highest potential but does not propose large group areas. 
Karst and Cave

Resources
Alternative 4 has the lowest potential because it has the lowest allocation and has few large group areas. Alternative 1 does not provide a specific allocation, although it could be similar to Alternative 3; however, Alternative 1 does not identify large group areas. For more information, see the Vegetation section in this chapter and the mitigation measures listed in Appendix C.

Cave resources are protected under the Federal Cave Resources Protection Act of 1988. The intent of the Act is to protect cave resources; however, most caves and associated features are integral to karst landscape. The Tongass National Forest manages karst as an ecological unit to ensure protection of the cave resources.

\section{Affected Environment}

Karst is a geologic landform underlain by carbonate (limestone and marble) rocks within which a subsurface drainage system has developed (USDA Forest Service 1997; p. 3-82). The carbonate rocks are dissolved by the acidic groundwater to form caves. Most caves in Southeast Alaska are found in karst landscapes. Caves can also be found in other types of bedrock but are generally not as common. Lava tubes and sea caves formed by mechanical abrasion, erosion, and weathering are examples of other types of caves.

The Kennel Creek, lyoukeen, and the limestone member of the Pt. Augusta formations exhibit karst and epikarst features in the analysis area. These features are more common at higher elevations in the subalpine and alpine habitats. At low elevations, the karst features are often covered by glacial till or uplifted marine sediments. There are only a few areas in the analysis area where carbonate formations in alpine and subalpine habitats are within one-half mile of the shore (Table 3-36).

\section{Environmental Consequences}

This analysis does not authorize commercial activities within caves. A separate analysis would be needed if a commercial operator should propose use of the caves. Therefore, none of the alternatives in this analysis would affect karst or cave resources. Increased recreational use may lead to the discovery of caves, at which time management plans would be developed if recreation use is determined to be appropriate. 


\section{Environment and Effects 3}

Table 3-36. Guide Use Ares with Carbonate Rock Within One-half Mile of Shore

\begin{tabular}{ccc}
\hline Guide Use Area & Low elevation (acres) & Alpine/ Sub-alpine (acres) \\
\hline $01-02$ & 49.2 & 0 \\
$01-03$ & 4989.5 & 0 \\
$01-05 \mathrm{D}$ & 234.1 & 138.6 \\
$04-05$ & 1644.5 & 56.6 \\
$04-06 \mathrm{~A}$ & 1844.1 & 0 \\
$04-07$ & 667.1 & 0 \\
$04-10 \mathrm{~B}$ & 929.5 & 0 \\
$04-11$ & 8839.5 & 501.6 \\
$04-12$ & 8228.5 & 320.7 \\
$04-13$ & 621.4 & 0 \\
$04-15$ & 586.8 & 0 \\
$04-16 \mathrm{~A}$ & 240.8 & 0 \\
$04-16 \mathrm{~B}$ & 145.8 & 0 \\
$04-16 \mathrm{D}$ & 2245.2 & 67.8 \\
\hline
\end{tabular}

\section{Overview}

The Alaska National Interest Lands Conservation Act (ANILCA) defines subsistence, in part, as: "the customary and traditional uses by rural Alaska residents of wild, renewable resources for direct personal or family consumption as food, shelter, fuel, clothing, tools, or transportation" (ANILCA, Sec. 803). ANILCA provides for the continuation of these uses "consistent with sound management principles, and the conservation of healthy populations of fish and wildlife" (ANILCA, Sec. 802). For many rural Alaskans, subsistence is a way of life and also carries cultural and religious meaning.

The analysis of subsistence uses and resources on the national forest, and of potential effects resulting from management activities, is also required by ANILCA (Sec. 810). This analysis typically focuses on food-related resources, which are the resources more likely to be affected through loss or alteration of habitats from landaltering activities. The identification, protection, and interpretation of cultural and historical resources on federal lands are covered under other legislation, including the National Historic Preservation Act (See the Heritage section of this chapter).

The ANILCA 810 analysis focuses on three factors of the subsistence resource: abundance and distribution, access to the resources, and human competition for the resources. If it is found that a significant restriction on subsistence resources may occur from a specific project or if the project would add cumulatively to a significant restriction for a geographic area, additional analysis and findings are required.

The following discussion and analysis are based on the detailed subsistence information and analysis contained in the Forest Plan FEIS, Chapter 3, Subsistence. See also the Fisheries and Wildlife sections of this chapter for additional information. 


\section{Environment and Effects}

The Tongass Forest Plan Revision FEIS provides a comprehensive analysis of subsistence resources and potential effects, both Tongass-wide and for each rural community of Southeast Alaska. That analysis concluded that forest-wide, under full implementation of the Forest Plan, the only subsistence resource that may, in the future, be significantly restricted is subsistence use of deer (Forest Plan FEIS, pp. 3224 to 3-229; Forest Plan 1999 Record of Decision pp. 58-59).

Guided recreation activities involving the taking of fish and game are considered general or sport uses that are regulated by the Alaska Board of Fisheries, Alaska Board of Game, Alaska Department of Fish and Game, and the Federal Subsistence Board to ensure healthy viable fish and game populations. ANILCA provides a priority for rural subsistence users if any fishing or hunting restrictions become necessary to protect the resource. General or sport uses are the first to be restricted. Federal management of subsistence resources other than fish began on July 1, 1990. Federal management of fish resources in navigable streams began on October 1, 1999.

\section{Affected Environment}

\section{Subsistence Resources and Uses}

The principal subsistence resources in and adjacent to the analysis area are salmon, trout, shellfish, deer, brown bear, marine mammals, upland birds, waterfowl, furbearers, timber, firewood, and plants. Populations and subsistence use of shellfish, marine mammals, furbearers, upland birds, waterfowl, timber, firewood, and plants are not affected by commercial recreation use. Commercial recreation has the most potential to affect subsistence resources when permitted activities involve guided sport fishing and hunting. Historically, guiding hunting in the analysis area primarily involves brown bear hunting with a very minor amount of deer hunting.

Except for deer, use of these wildlife species for subsistence purposes is relatively minor. (Forest-wide, measured by weight, deer account for 21 percent of subsistence food resources, and all other land mammals 4 percent [Forest Plan FEIS, p. 3-224]). Salmon and trout are the principal subsistence fish resources of the area; they are harvested in both fresh and saltwater. Potential effects on these fish and wildlife species as subsistence resources are discussed below. Analyses of the fish and wildlife resources of the project area are found under those headings in this chapter.

Sitka Black-tailed Deer Community use of deer for subsistence purposes is well documented and studied for the rural communities of Southeast Alaska (see Forest Plan FEIS, pp. 3-210 to 3-223 and 3-523 to 3-528, Appendix H, and the Deer Harvest Map in the map packet). Community use of specific geographic areas for obtaining deer is estimated by the Wildlife Analysis Areas (WAAs) used by the State of Alaska. Historically, there has been only one outfitter/guide who brings in clients to hunt Sitka black-tailed deer. These hunts are in Guide Use Area (GUA) 04-13 (northwestern shoreline of Peril Strait). In 1999, eight clients in two groups hunted during the fall season. GUA 04-13 includes all or portions of WAAs 3308, 3309 . 3310,3311 , and 3312 .

Community use of each WAA for deer is displayed on the Community Deer Harvest map included with the Forest Plan FEIS. Table 3-37 displays the communities that use these WAAs. 


\section{Environment and Effects 3}

Table 3-37. Community Use for Deer, by WAA

\begin{tabular}{l:l:l:l:l}
\hline WAA 3308 & WAA 3309 & WAA 3310 & WAA 3311 & WAA 3312 \\
\hline Angoon & Juneau & Haines & Elfin Cove & Haines \\
Juneau & Ketchikan & Skagway & Pelican & Skagway \\
Ketchikan & Petersburg & Juneau & Juneau & Juneau \\
Petersburg & Sitka & Petersburg & Kake & Kake \\
Tenakee Springs & Tenakee Springs & Sitka & Ketchikan & Petersburg \\
Wrangell & & Yakutat & Sitka & Sitka \\
Yakutat & & & Wrangell & Wrangell \\
\hline
\end{tabular}

Community use is further discussed and displayed in the Forest Plan FEIS in the Communities portion of Chapter 3 (pp. 3-523 to 3-685) and in Appendix H. For each community, Appendix H identifies those WAAs (ordered by highest use to lowest) accounting for 75 percent of that community's deer harvest. WAAs 3309 and 3312 are not used by any community to obtain 75 percent of their community deer harvest. WAA 3308 is an important area for Angoon (page H-64). WAA 3310 is an important deer hunting area for Sitka (page H-89), Skagway (H-90), and Yakutat (H-95). WAA 3311 is another important area for Sitka residents (page H89). Table 3-38 displays the average number of deer and percent harvested annually in each WAA by community residents.

Table 3-38. Number and Percent of Deer Harvest, by Community and by WAA

\begin{tabular}{llrr}
\hline WAA & Community & Number of Deer (\%) \\
\hline 3308 & Angoon & 20 & $(4.1 \%)$ \\
3310 & Sitka & 186 & $(10.3 \%)$ \\
& Skagway & 2 & $(10.3 \%)$ \\
& Yakutat & 1 & $(10.3 \%)$ \\
3311 & Sitka & 227 & $(12.2 \%)$ \\
\hline
\end{tabular}

Alaska Department of Fish and Game (ADF\&G) has ranked Value Comparison Units (VCUs) and communities according to sensitivity to disturbance. Disturbance in this context means any land use activity that could adversely affect subsistence uses and was generally meant to apply to timber management activities. Table 3-39 displays rankings applicable to the analysis area, except for Skagway and Yakutat. Skagway did not have any VCUs ranked in GUA 04-13. Yakutat was not ranked because the ADF\&G felt that there were few activities, such as timber harvest, that would adversely impact subsistence uses there. 


\section{Environment and Effects}

Table 3-39. VCU Sensitivity to Disturbance, ADF\&G Ranking

\begin{tabular}{|c|c|c|c|c|}
\hline Community & Lowest & Low & Middle & High \\
\hline Angoon & $\begin{array}{l}\text { VCU } 2900 \\
\text { VCU } 2990 \\
\text { VCU } 2880\end{array}$ & & & VCU 2450 \\
\hline Sitka & $\begin{array}{l}\text { VCU } 2490 \\
\text { VCU } 2620\end{array}$ & VCU 2840 & VCU 2430 & $\begin{array}{l}\text { VCU } 2450 \\
\text { VCU } 2460 \\
\text { VCU } 2470 \\
\text { VCU } 2480 \\
\text { VCU } 2850 \\
\text { VCU } 2860 \\
\text { VCU } 2830 \\
\text { VCU } 2820 \\
\text { VCU } 2810 \\
\text { VCU } 2790 \\
\text { VCU } 2660 \\
\text { VCU } 2890 \\
\text { VCU } 2900\end{array}$ \\
\hline
\end{tabular}

Brown Bear Brown bear are considered a subsistence resource (USDA Forest Service 1997, page 3-219); however, the number of brown bears that are harvested for subsistence purposes is so small that data are not collected (USDA Forest Service 1997, page 3-218, footnote 2).

There is a concern that brown bears will not be available in the future for elders to pass on traditional environmental knowledge to young people or to engage in spiritual association with the brown bear. As a result of this concern, in 2000 the Federal Subsistence Board allowed registration permits for up to five brown bears to be harvested for educational purposes associated with teaching customary and traditional subsistence harvest and use practices. To date, no brown bear education permits have been issued.

Fish Table 3-40 identifies 30 locations within the analysis area or adjacent saltwater where subsistence or personal fisheries activities have occurred historically. These sites included those with reported subsistence or personal use salmon harvests from 1995 to 1999. Information regarding historical subsistence trout, steelhead trout, and Dolly Varden char harvest is not available.

Most subsistence salmon harvest occurs on saltwater, typically with a gill net. Sockeye salmon are the primary subsistence and personal use fish species harvested. Although the amount of actual use of the national forest for subsistence fish harvest is not accurately known, it is assumed that only a small fraction of subsistence harvest occurs on the national forest. Most of the personal use harvest on the national forest occurred at Sweetheart Creek, where fish were caught from shore primarily by dip and cast nets. 
Table 3-40. Average Subsistence/Personal Use Salmon Harvest and Permits Returned to ADF\&G by Stream, 1995-1999

\begin{tabular}{|c|c|c|c|c|c|c|c|}
\hline \multirow[b]{2}{*}{ Use Area } & \multirow[b]{2}{*}{ Site Name } & \multicolumn{5}{|c|}{ Number of Fish Harvested } & \multirow{2}{*}{$\begin{array}{l}\text { \# Permits } \\
\text { Returned }\end{array}$} \\
\hline & & Sockeye & Chinook & Coho & Pink & Chum & \\
\hline 04-01A & Falls Lake & 970 & 1 & 3 & 26 & 22 & 61 \\
\hline $04-06 \mathrm{~A}$ & False Point Pybus & 77 & 0 & 1 & 5 & 0 & 4 \\
\hline 04-01A & Gut Bay & 453 & 0 & 0 & 2 & 1 & 36 \\
\hline 04-04B & Hanus Bay & 76 & 0 & 0 & 0 & 0 & 7 \\
\hline $04-15$ & Hoktaheen Cove & 1,122 & 0 & 6 & 33 & 42 & 45 \\
\hline $04-15$ & Klag Bay - fish camp & 1,477 & 0 & 5 & 13 & 4 & 48 \\
\hline $04-12$ & Kook Lake & 288 & 0 & 16 & 13 & 10 & 19 \\
\hline $04-14$ & Lake Anna & 10 & 0 & 0 & 2 & 2 & 1 \\
\hline $04-14$ & Ford Arm & 360 & 0 & 0 & 2 & 2 & 14 \\
\hline $04-14$ & Fortuna Straits & 109 & 0 & 0 & 6 & 3 & 10 \\
\hline $04-12$ & Little Basket Bay & 22 & 0 & 0 & 0 & 0 & 0 \\
\hline $04-2 B$ & Necker Bay Lake & 5,677 & 0 & 0 & 41 & 6 & 103 \\
\hline $04-03$ & Neva Creek & 132 & 0 & 1 & 122 & 436 & 8 \\
\hline $04-02 B$ & Politofski Lake & 32 & 0 & 0 & 2 & 0 & 2 \\
\hline 04-02B & Redfish Bay & 728 & 0 & 2 & 1 & 0 & 20 \\
\hline 04-02 & Redoubt Lake & 3,760 & 0 & 6 & 14 & 12 & 267 \\
\hline $04-03$ & Salmon Lake Stream & 188 & 5 & 0 & 52 & 26 & 16 \\
\hline $04-12$ & Sitkoh Lake and Bay & 31 & 0 & 0 & 38 & 12 & 3 \\
\hline $04-15$ & Surge Bay & 30 & 0 & 0 & 0 & 0 & 3 \\
\hline $01-05 B$ & Sweetheart Creek & 3,105 & 1 & 29 & 2 & 180 & 180 \\
\hline $04-15$ & Takanis Bay & 48 & 0 & 1 & 1 & 0 & 2 \\
\hline $01-04 \mathrm{C}$ & Taku River & 1,090 & 20 & 62 & 110 & 3 & 121 \\
\hline 04-11 & Neka River & 0 & 0 & 26 & 7 & 8 & 2 \\
\hline $04-12$ & Pavlof River & 0 & 0 & 0 & 16 & 11 & 1 \\
\hline $04-03$ & Aluetkina Bay & 24 & 0 & 0 & 0 & 1 & 1 \\
\hline $04-11$ & Seagull Creek & 0 & 0 & 0 & 0 & 6 & 0 \\
\hline 04-08 & Admiralty Creek & 0 & 0 & 0 & 20 & 15 & 0 \\
\hline 04-08 & Bear Creek & 0 & 0 & 0 & 0 & 3 & 0 \\
\hline $04-15$ & Lisianski River & 0 & 0 & 0 & 4 & 0 & 0 \\
\hline \multirow[t]{2}{*}{$04-16 B$} & Mud Bay River & 0 & 0 & 1 & 0 & 0 & 0 \\
\hline & Total & 19,809 & 27 & 159 & 532 & 805 & 976 \\
\hline
\end{tabular}

Source: ADF\&G subsistence/personal use reports and surveys

In recent years, $A D F \& G$ and the Federal Subsistence Board have imposed harvest restrictions on one coho and five sockeye subsistence fisheries on the Sitka Ranger District (see Table 3-31). Increases in the human populations and subsistence harvest levels combined with fluctuations in fish population abundance have led to harvests near or at the maximum sustainable level on these stream systems. Under ANILCA, a priority for use for these fish will be granted to rural users if restrictions on harvest are necessary to protect the resource. If further restrictions on use 


\section{Environment and Effects}

become necessary, then that is the point at which a significant restriction on subsistence uses may occur. Such a restriction could occur from either reduced abundance or increased competition.

\section{Environmental Consequences}

\section{Overview}

This analysis of effects is based on the ANILCA categories previously mentioned: access, abundance/distribution, and competition.

Populations, habitats, and subsistence use of shellfish, marine mammals, furbearers, upland birds, waterfowl, and plants for timber, firewood, food, and fiber would not be affected by commercial recreation use proposed in this analysis.

Commercial recreation has the most potential to affect subsistence resources when permitted activities involve guided sport fishing and hunting. Historically within the shoreline zone, these primarily involve guided brown bear hunting and guided fishing with a very minor amount of guided deer hunting. No other wildlife hunting is commercially guided in the analysis area. Use of other wildlife species for subsistence purposes is relatively minor and would not be affected by commercial recreation activities. Salmon and trout are the principal subsistence fish resources of the area. The only guided fishing within the scope of this analysis is guided fishing in freshwater occurring on the national forest. Saltwater fishing and fishing on other land ownerships is outside the scope of this analysis.

\section{Access}

The activities proposed in this analysis are short duration recreational use. These activities should not change or restrict access to the project area for subsistence uses. The area is accessible by boat, floatplane, and, to a lesser extent, roads. Roads currently access the uplands from marine access points scattered throughout the development VCUs within the project area.

\section{Abundance and Distribution}

With application of the Forest Plan riparian standards and guidelines, BMPs, mitigation measures, and state and federal fishing regulations on commercial recreation use on the national forest, no significant adverse effects on salmon or trout

There is a possibility of a restriction on subsistence uses on some stream systems regardless of any alternative in this analysis. populations or habitats are anticipated as a result of implementation of any alternative and no alternative is expected to add cumulatively to significant adverse effects.

Some drainages on the Sitka Ranger District have populations of coho salmon and/or sockeye salmon at or near maximum sustainable harvest levels. The abundance of fish in these systems will continue to fluctuate from year to year, providing enough fish for all user groups to use in some years and limited or no use for any user group, including subsistence users, in other years. There is a possibility of a restriction on subsistence uses on these stream systems regardless of any alternative, including the no-action alternative. The state and the Federal Subsistence Board regulate guided fishing and subsistence use on these systems to prevent adverse impacts on the resource or subsistence use. None of the alternatives would contribute any additional effects to this situation. 


\section{Environment and Effects 3}

With the application of the Forest Plan habitat conservation strategy (including oldgrowth habitat reserves) and species-specific standards and guidelines, mitigation measures, and state and federal regulations protecting wildlife populations and subsistence use, no significant adverse effects on wildlife populations or habitats are anticipated as a result of implementation of any alternative and no alternative is expected to add cumulatively to significant adverse effects.

There are declines in deer habitat capability within the analysis area, which are measurable and will occur regardless of any alternative in this analysis. These declines represent an anticipated cumulative trend resulting from the harvest of oldgrowth timber containing deer habitat. The Forest Plan provides measures to minimize declines in deer habitat capability by protecting key deer winter habitat, the most important habitat component in the project area, including: 1,000-foot beach and estuary fringe no-timber harvest zones along all saltwater beaches and estuaries; the application of riparian buffers along all streams; and the location of a small old-growth habitat reserve in each VCU (major watershed). All of these measures result in at least some protection of important deer winter habitat, as well as other subsistence resources.

\section{Competition}

In addition to these measures to minimize loss of subsistence resources in the project areas, deer habitat decline must also be put in the perspective of subsistence use of deer in the area. As discussed above, four Southeast Alaska communities Angoon, Sitka, Skagway and Yakutat, rely on subsistence deer harvest in the analysis area for a portion of their subsistence food needs.

Historical deer harvest levels, and potential direct and cumulative effects of full implementation of the Forest Plan (Alternative 11) in conjunction with the anticipated future demands for deer, are displayed and discussed for each Southeast Alaska community in Appendix $\mathrm{H}$ of the Forest Plan FEIS. Three levels of deer use are evaluated for each community for those areas (WAAs) the community most relies on:

- Use by community residents only;

- Use by all rural (subsistence) hunters; and

- Use by all hunters (including those from non-rural communities and hunters from out of state, neither of whom are considered subsistence users under ANILCA).

Under ANILCA, a priority for use will be granted to rural users if restrictions on use of a resource are necessary. If there are not enough deer available for hunting, guided sport hunting will be the first user group to be restricted to little or no use. Guided deer hunting and subsistence use are regulated by the state and the Federal Subsistence Board, whose regulations governing guided hunting will prevent adverse impacts on the deer resource or subsistence use.

In order for a WAA to produce on average enough deer for species viability and for human uses (subsistence and other hunting), deer harvest by humans must not exceed a certain average percentage of the habitat capability for that area. The Forest Plan FEIS (p. 3-537) analysis makes two assumptions in this regard: 
- Hunters in areas where harvest or demand is within 10-20 percent of habitat capability may experience reduced hunter efficiency and moderate difficulty in obtaining deer, and

- In areas where demand (or current/historical use) exceeds 20 percent of habitat capability, deer harvest may be restricted either directly or indirectly.

The analysis for Angoon (1997 Forest Plan FEIS pp. 3-529 to 3-532, and H-64) displays current (historical) use of WAAs 4055, 4054, 4042, 4041, and 3308, where residents of Angoon obtain approximately 75 percent of their average annual deer harvest. WAAs 4055 and 4054 are adjacent to the community of Angoon; WAA 4042 includes the community of Angoon; WAA 4041 is south of WAA 4055; and WAA 3308 lies west of Angoon across Chatham Strait. Current average deer harvest (1987-1995) in all of these WAAs is 455 deer for all hunters, or 2.5 percent of the 1995 habitat capability. By the year 2005 (assuming full Forest Plan timber harvest levels), with habitat capability down slightly and demand up slightly, use by all hunters in these WAAs is projected to be 3.0 percent of habitat capability.

No significant adverse effects on deer populations or habitats are anticipated in these WAAs as a result of implementation of any alternative, and no alternative is expected to add cumulatively to significant adverse effects. Based on short-term cumulative effects of past and predicted future projects, no restrictions on use by subsistence hunters would occur.

After 100 years of full implementation of the Forest Plan (long-term cumulative effects), demand by all hunters in these WAAs is projected to reach 5.5 percent of habitat capability. Thus for long-term cumulative effects of past and predicted future projects, no restrictions on use by subsistence hunters would occur.

The analysis for Sitka (1997 Forest Plan FEIS pp. 3-644 to 3-649, and H-89) displays current (historical) use of WAAs 3002, 3001, 3003, 3311, 3310, 3314, $3416,3104,3105$, and 3207, where residents of Sitka obtain approximately 75 percent of their average annual deer harvest. WAA 3002 includes Sitka; WAAs 3001 and 3003 are adjacent to Sitka; WAAs 3311,3310, and 3314 are north of Sitka in the Peril Strait area; WAA 3416 is on the outer coast of Chichagof Island; WAAs 3104 and 3105 include Kruzof Island; and WAA 3207 is located south of Sitka. Current average deer harvest (1987-1995) in all of these WAAs is 2,711 deer for all hunters, or 13.4 percent of the 1995 habitat capability. By the year 2005 (assuming full Forest Plan timber harvest levels), with habitat capability down slightly and demand up slightly, use by all hunters in these WAAs is projected to be 16.2 percent of habitat capability.

No significant adverse effects on deer populations or habitats are anticipated in these WAAs as a result of implementation of any alternative, and no alternative is expected to add cumulatively to significant adverse effects. Based on short-term cumulative effects of past and predicted future projects, no restrictions on use by subsistence hunters would occur. This is due in large part because the Forest Plan timber harvest activities have not been fully implemented.

After 100 years of full implementation of the Forest Plan (long-term cumulative effects), demand by all hunters in these WAAs is projected to reach 29.6 percent of habitat capability. Regardless of the implementation of any alternative from this 
There are declines in deer habitat capability within the analysis area, which are measurable and will occur regardless of any alternative in this analysis. project, a significant possibility of significant restrictions on use by subsistence deer hunters could occur in these WAAs in the future, based on long-term cumulative effects of past projects and predicted future projects.

The analysis for Skagway (1997 Forest Plan FEIS pp. 3-650 to 3-654, and H-90) displays current (historical) use of WAAs 3836, 3629, 3310, 3002, 4146, 4044, and 4222, where residents of Skagway obtain approximately 75 percent of their average annual deer harvest. WAA 3836 is located on the north end of Admiralty Island; WAA 3629 is located in Tenakee Inlet across from Tenakee Springs; WAA 3310 is located in upper Peril Strait; WAA 3002 includes Sitka; WAA 4146 is located on the east side of Admiralty Island inside Seymour Canal; WAA 4044 is located on the west side of Admiralty Island opposite Freshwater Bay; and WAA 4222 is located on the north end of Chichagof Island. Current average deer harvest (1987-1995) in all of these WAAs is 1,718 deer for all hunters, or 12.7 percent of the 1995 habitat capability. By the year 2005 (assuming full Forest Plan timber harvest levels), with habitat capability down slightly and demand up slightly, use by all hunters in these WAAs is projected to be 15.2 percent of habitat capability.

No significant adverse effects on deer populations or habitats are anticipated in these WAAs as a result of implementation of any alternative, and no alternative is expected to add cumulatively to significant adverse effects. For short-term cumulative effects of past and predicted future projects, no restrictions on use by subsistence hunters would occur. This is due in large part because the Forest Plan timber harvest activities have not been fully implemented.

After 100 years of full implementation of the Forest Plan (long-term cumulative effects), demand by all hunters in these WAAs is projected to reach 28.1 percent of habitat capability. Regardless of the implementation of any alternative from this project, a significant possibility of significant restrictions on use by subsistence deer hunters could occur in these WAAs in the future, based on long-term cumulative effects of past projects and predicted future projects.

The analysis for Yakutat (1997 Forest Plan FEIS pp. 3-676 to 3-680, and H-95) displays current (historical) use of WAAs 3315, 3416, 4055, 3629, 3310, 4256, and 3417, where residents of Yakutat obtain approximately 75 percent of their average annual deer harvest. WAA 3315 is located at the mouth of Peril Strait on the south side; WAA 3416 is located on the west side of Chichagof Island; WAA 4055 is located on Admiralty Island south of Angoon; WAA 3629 is located in Tenakee Inlet across from Tenakee Springs; WAA 3310 is located on the north end of Peril Strait; WAA 4256 includes the Pleasant/Lemesurier/Inian Islands; and WAA 3417 is on the north part of Chichagof Island south of Yakobi Island. Current average deer harvest (1987-1995) in all of these WAAs is 1,004 deer for all hunters, or 6.0 percent of the 1995 habitat capability. By the year 2005 (assuming full Forest Plan timber harvest), with habitat capability down slightly and demand up slightly, use by all hunters in these WAAs is projected to be 7.2 percent of habitat capability.

No significant adverse effects on deer populations or habitats are anticipated in these WAAs as a result of implementation of any alternative, and no alternative is expected to add cumulatively to significant adverse effects. Based on short-term cumulative effects of past and predicted future projects, no restrictions on use by subsistence hunters would occur. 


\section{Environment and Effects}

None of the

alternatives will

restrict

subsistence uses.
After 100 years of full implementation of the Forest Plan (long-term cumulative effects), demand by all hunters in these WAAs is projected to reach 13.2 percent of habitat capability. Thus for long-term cumulative effects of past and predicted future projects, no restrictions on use by subsistence hunters would occur.

\section{Subsistence Findings}

None of the alternatives by themselves present a significant possibility of a significant restriction on subsistence use of deer, brown bear, furbearers, marine mammals, waterfowl, salmon, other finfish, shellfish, timber, and plants in the analysis area. No alternative will add cumulatively to significant adverse effects on use of the subsistence resources. This finding is based on the potential alternative effects on subsistence resource abundance and distribution, competition, access, and considering historical use of the project area, public comment and tribal consultations.

There is a possibility of restrictions to subsistence use within some areas of the analysis area, regardless of this project. When the cumulative effects of past and reasonably foreseeable future projects within the analysis area are considered, there is a possibility of a restriction of subsistence uses of deer for residents of Sitka and Skagway in the long-term future. There is a present and future possibility of restrictions of subsistence use of coho and sockeye salmon fisheries in the Redoubt, Hoktaheen Lake, Surge Bay, Takanis Bay, Silver Bay, and Salmon Lake stream systems for residents of Sitka. The alternatives proposed in this project will not contribute to those restrictions.

Abundance and Distribution

Guided recreation will not adversely affect abundance or distribution. The Forest Plan, BMPs and mitigation measures protect habitats. Populations are protected by state and federal regulations.

\section{Competition}

Subsistence use will not be restricted by competition from guided recreationists. Guided fishing or hunting are considered sport or general uses and will be regulated to provide a priority for subsistence users if any restrictions become necessary to protect the resource.

\section{Access}

Guided recreation use will not change or restrict access to the analysis area for subsistence users.

\section{Overview}

Heritage resources on the Tongass National Forest include a diverse array of prehistoric and historical sites and are evidence of at least 10,000 years of human occupation and use. Although the exact date of Tlingit occupation is not known, oral histories and ethnographic accounts indicate that the Tlingit have occupied Southeast Alaska for centuries and were expanding their occupation northward at the time of European contact. The Shoreline Outfitter/Guide analysis area encompasses the north half of the Tongass National Forest, excluding Yakutat, and crosses the 


\section{Environment and Effects 3}

traditional boundaries of several Tlingit Kwans. The analysis area falls into the traditional territory of the following Tlingit groups (listed geographically from south to north): Kake, Sitka, Angoon, Taku, Auk, Hoonah, Chilkoot, and Chilkat. These groups have left their mark on the land evidenced by a variety of sites: villages, seasonal campsites, rock art, sacred and religious areas, and resource utilization areas.

The historical period in Southeast Alaska began in 1741 with Vitus Bering's second Kamchatka Expedition. That winter Bering's ship ran aground on the Commander Islands; the survivors discovered and used the highly valuable sea otter fur. Upon their return home that spring, the Russian survivors established a fur trade with the Orient. The trade boomed and the British and American traders soon joined in the sea otter trade. The Russian-American Company rapidly built up its presence in Southeast Alaska based upon their success in the trading industry. As Russia lost control of the sea otter trade, the company became financially strapped and maintaining a presence in Southeast Alaska became less important to the company. Eventually the Russian government sold Alaska to the United States. Since then, human activities including fishing, whaling, mining, fur farming, tourism, and timber harvest for both wood and pulp industries have developed in the analysis area and have left evidence on the land.

Tribal consultations are an important part of heritage resource management. The tribal governments and corporations were consulted during the analysis process (Chapter 2). The input received during these tribal consultations was invaluable in identifying culturally important or sensitive areas and avoiding them or regulating guided recreation management to protect these areas. Tribal government consultation will continue through the annual consultation process with other agencies (Appendix D Monitoring).

Authorization to manage heritage resources comes principally from the National Historic Preservation Act (NHPA) of 1966 (U.S.C. 470). In this Act, Congress declared "the historical and cultural foundations of the Nation should be preserved as a living part of our community life and development in order to give a sense of orientation to the American people." Other legislation, implementing regulations, and direction in Forest Service Manual 2360 (Special Interest Areas), and the Forest Plan guide the Heritage Resource program to identify, evaluate, preserve and protect significant heritage resources on a forest-wide and project-specific basis.

Section 106 of the NHPA is the driving force behind the Heritage Program. The Alaska Region of the USDA Forest Service, the Alaska State Historic Preservation Officer, and the Advisory Council on Historic Preservation have established guidelines and stipulations set forth in a Programmatic Agreement, which is currently being revised. As part of the required Section 106 review, all identified sites are evaluated against standard criteria for inclusion on the National Register of Historic Places established in 36 CFR 60.4. If a site is determined to be 'eligible', a formal determination of effect is completed per 36 CFR 800 . Requiring guided recreationists to avoid cultural sites is the primary management tool used to protect cultural resources in this analysis. Two cultural sites discussed later in this section allow for guided use with monitoring. Cultural sites will be protected and adverse effects mitigated if the sites are threatened. 


\section{Environment and Effects}

Outfitter/guide use is not expected to result in the discovery or disturbance of human remains. However, if human remains are discovered, they will fall under the conditions of the Native American Graves Protection and Repatriation Act (NAGPRA).

Outfitter/guide use is also not expected to restrict Native American access to traditional religious or spiritual sites that are protected under the American Indian Religious Freedom Act (AIRFA).

\section{Affected Environment}

\section{Heritage Surveys}

Site-specific heritage resource surveys to locate and identify cultural sites have occurred in the analysis area over time. Table 3-41 identifies the miles and number of surveys completed since 1986 in each Use Area and the number of cultural sites identified since 1975.

A total of 415 cultural sites have been identified in the shoreline zone of the analysis area. These cultural sites represent the majority of the known cultural sites on the north half of the Tongass National Forest; however, additional cultural sites lie beyond the shoreline zone. A variety of both prehistoric and historic cultural sites have been identified and are represented by cultural sites such as villages, canneries, fish weirs, homesteads, middens, and fur farms. 


\section{Environment and Effects 3}

Table 3-41. Heritage Resource Surveys Completed Since 1986 and Sites Identified Since 1975 Within the Analysis Area

\begin{tabular}{|c|c|c|c|c|}
\hline Use Area & General Location & No. of Sites & No. of Surveys & Miles of Survey \\
\hline 01-01 & Skagway Area & 5 & 5 & 2.25 \\
\hline 01-02 & Haines Area & 0 & 2 & 2.00 \\
\hline 01-03 & East Chilkats & 13 & 9 & 14.50 \\
\hline $01-04 \mathrm{~A}$ & Berners Bay & 6 & 11 & 28.50 \\
\hline 01-04B & N. Juneau Coast & 13 & 3 & 4.25 \\
\hline $01-04 \mathrm{C}$ & Taku Inlet & 4 & 5 & 1.25 \\
\hline 01-04D & Slocum Inlet & 0 & 1 & 4.75 \\
\hline $01-05 \mathrm{~A}$ & Taku Harbor & 1 & 2 & 0.50 \\
\hline $01-05 B$ & Port Snettisham & 2 & 1 & 0.25 \\
\hline $01-05 C$ & Windham Bay & 14 & 30 & 51.50 \\
\hline 01-05D & Tracy Arm & 4 & 16 & 4.50 \\
\hline $04-01 \mathrm{~A}$ & Fords Terror & 0 & 0 & 0 \\
\hline 04-01B & Gut Bay, Baranof & 3 & 8 & 3.50 \\
\hline 04-01E & Port Armstrong & 6 & 78 & 28.00 \\
\hline $04-02 \mathrm{~A}$ & Redoubt Lake & 8 & 9 & 2.50 \\
\hline 04-02B & Whale Bay & 15 & 22 & 3.75 \\
\hline $04-03$ & Sitka Area & 53 & 76 & 76.50 \\
\hline $04-04 \mathrm{~A}$ & Lake Eva, Rodman Bay & 8 & 17 & 41.50 \\
\hline 04-04B & Kelp Bay & 16 & 28 & 73.50 \\
\hline $04-04 \mathrm{C}$ & Baranof Warm Springs & 1 & 1 & 0.50 \\
\hline $04-05$ & SW Admiralty Island & 23 & 35 & 14.00 \\
\hline $04-06 \mathrm{~A}$ & Pybus Bay & 8 & 14 & 8.50 \\
\hline $04-06 \mathrm{~B}$ & Eliza Harbor & 8 & 17 & 5.75 \\
\hline $04-07$ & Gambier Bay & 18 & 38 & 16.00 \\
\hline 04-08 & NE Admiralty Island & 5 & 13 & 10.50 \\
\hline $04-09$ & Seymour Canal & 6 & 16 & 10.50 \\
\hline $04-10 \mathrm{~A}$ & Greens Creek & 4 & 2 & 3.25 \\
\hline $04-10 \mathrm{~B}$ & NW Admiralty Island & 3 & 4 & 2.50 \\
\hline $04-11$ & Hoonah Area & 36 & 41 & 63.50 \\
\hline $04-12$ & Tenakee Inlet & 55 & 49 & 128.75 \\
\hline $04-13$ & Peril Strait & 36 & 80 & 72.50 \\
\hline $04-14$ & Slocum Arm & 10 & 26 & 5.50 \\
\hline $04-15$ & West Chichagof & 22 & 61 & 19.25 \\
\hline $04-16 \mathrm{~A}$ & Point Adolphus & 0 & 8 & 5.00 \\
\hline $04-16 B$ & North Chichagof & 4 & 6 & 2.50 \\
\hline $04-16 \mathrm{C}$ & Idaho Inlet & 3 & 8 & 2.25 \\
\hline \multirow[t]{2}{*}{$04-16 \mathrm{D}$} & Port Althorp & 2 & 8 & 3.00 \\
\hline & Total & 415 & 750 & 717.25 \\
\hline
\end{tabular}




\section{Environment and Effects}

Potential effects on

the cultural resource

due to recreation use

come primarily from

increased vandalism.

\section{Environmental Consequences}

\section{Direct and Indirect Effects}

Potential effects on the heritage resource due to human use come primarily from increased looting and vandalism. Cultural sites can be dug up, looted, or destroyed. However, outfitter/guide permits require the protection of cultural resources, therefore permitted guided use has little, if any, direct effect. Concentrated recreation use at a site can also cause indirect effects such as site trampling, increased erosion, and disturbance and displacement of cultural artifacts. For example, trampling the surrounding area can result in site erosion or plant cover loss, thereby exposing the site to weathering. Effects on cultural sites from guided recreation can be eliminated or reduced by avoiding the site or by using mitigation measures to reduce the potential impacts.

Much of the shoreline zone within the analysis area falls within the cultural high probability area. Because of the large scale of the project area, the analysis focused primarily on areas of potential effect (APE). An APE is the geographic area(s) within which an undertaking may directly or indirectly cause alterations in the character or use of cultural properties, if any exist. The areas of potential effect in this analysis are the locations receiving high or concentrated levels of use, including the Enclave and Fifteen-Percent large group areas. These large group areas are more likely to have an impact on heritage sites. Cultural sites in large group areas will be protected primarily by not allowing guided recreation use at the cultural sites, except as noted.

Initially, more than 130 large group areas were considered throughout the analysis area. Approximately 75 of these were eliminated for a variety of reasons, including 27 that had cultural sites associated with them, thus avoiding potential impacts. From 20 to 63 of these remaining large group areas are considered in the different alternatives. (Tables 3-9 and 3-12) Thirty-five of these large group areas have been surveyed with no cultural sites found. The remaining large group areas will be surveyed before the Final EIS is prepared. If cultural sites are found in these areas, they will be avoided by excluding the cultural site to guided use. Avoidance and mitigation measures will minimize any adverse impacts to cultural sites.

Other areas outside of the APE are much less likely to be affected due to the low levels of use and low impacts of guided recreation activities. Excluding the cultural sites from guided use will also protect cultural sites in these areas. Guided recreation use occurring throughout the shoreline zone at the relatively low levels proposed in the alternatives are not expected to have impacts on cultural resources with application of mitigation measures and enforcement of cultural resource regulations.

Based on past monitoring of known cultural sites in areas receiving commercial recreation use, no direct effects on heritage resources from the guided recreation proposed in the alternatives are anticipated. The types of non-ground disturbing recreation activities and the relatively low levels of use over the analysis area as a whole, combined with mitigation measures, administrative oversight, and enforcement of regulations, are expected to result in minimal effects. Specific areas receiving high levels of use will be surveyed and monitored to prevent impacts. 


\section{Environment and Effects 3}

Commercial recreation use is unlikely to increase to allocation levels in the near term. Large group areas and other areas receiving high levels of guided use will be monitored through permit administration to ensure protection of cultural resources. A formal determination of effect will be submitted to the Alaska State Historic Preservation Officer.

There are four large group areas listed below which contain cultural sites. Two of these sites are proposed to allow guided use because there is an opportunity for cultural interpretation to inform visitors of the local history as well as convey a cultural awareness and stewardship message about heritage resources. A variety of mitigation and monitoring measures are recommended to protect these sites from impact.

- Two cultural sites exist at the Sand Bay Enclave (Use Area 01-05C) proposed in Alternatives 3, 4, and 5. One midden site was extensively surveyed and tested in 1983. A second cultural site has discrete features that are not likely to be affected by people walking over the site. These cultural sites will be avoided by excluding them from guided use. Avoidance and annual monitoring and evaluation of these cultural sites during permit administration are expected to keep disturbance to a minimum. Should the discrete features become affected by guided recreation use, additional restrictions will be applied to ensure that the site is not damaged. Eligibility of both these cultural sites for inclusion in the National Register of Historic Places has not been determined.

- Three cultural sites exist in the North Windham Bay Enclave (Use Area 0105C) proposed in Alternatives 3 and 5. A small midden site located within this enclave is well removed from the focus of recreation activity. Evidence of mining activity has also been found, but it also is well away from the center of recreation activity, and will likely not attract attention. People walking around the Enclave would not negatively affect the mine adit feature. Eligibility of these two cultural sites for inclusion in the National Register of Historic Places has not been determined. These cultural sites will be avoided by excluding them from guided use. Avoidance and annual monitoring and evaluation of these cultural sites during permit administration are expected to keep disturbance to a minimum. The Alaska SHPO determined an additional site, a fox farm, Not Eligible for listing on the National Register in 1983. This site provides an opportunity for interpretation. The historical fur farm industry has generally not been well interpreted in Southeast Alaska. This site has the potential to reach a large number of visitors and be educational as well as convey a message of cultural awareness and site stewardship.

- Three cultural sites were identified at the Todd Road \& Lindenberg Head (Use Area 04-13) Fifteen-Percent Area proposed in Alternatives 3 and 5. One of these cultural sites was determined Eligible for listing on the National Register Eligibility in 2000 by Alaska SHPO. The eligibility of the other two cultural sites for inclusion in the National Register of Historic Places has not been determined. All of these cultural sites will be avoided by excluding them from guided use. Avoidance, mitigation, annual monitoring, and evaluation of these cultural sites during permit 


\section{Environment and Effects}

administration are expected to keep disturbance to a minimum. The guided recreation activity will be allowed along the road system and away from the heritage site locations. Access to the road from the beach will be limited to a corridor at the marine access point. The Todd Cannery site also has good potential for interpretation and education for the historical fish cannery industry in the future. This site could reach a large number of visitors and be educational as well as convey a message of site stewardship.

- The World War II cannon emplacement at George Island Enclave (Use Area 04-16D) is proposed in Alternatives 3, 4, and 5. It currently receives relatively high levels of guided recreation use because of its historical interest and spectacular views of Icy Strait and Cross Sound. Eligibility of this cultural site for inclusion in the National Register of Historic Places has not been determined. The cannon emplacement is very durable. Current monitoring of this site has not yet identified any negative effects resulting from public use. Monitoring will continue during permit administration and additional interpretation is recommended for this site.

Outfitter/guide use will not occur uniformly across the analysis area. Potential effects on cultural sites are more likely in high use areas. Effects on heritage resources will be mitigated through avoidance of cultural sites, application of mitigation measures, oversight and enforcement of laws and regulations, interpretation, site hardening, and use restrictions where necessary.

Alternative 3 has the most sites with potential high concentrated use, followed by Alternatives 5, 2, 4, and 1 .

If the total commercial use allocation were used as a measure for the potential risk of negative effects on cultural sites, higher allocations would provide potentially higher use levels. These higher use levels could result in higher potential risks for negative effects on the heritage resource. Alternative 3 with the highest allocation would have the highest potential risk. Alternative 5 would have the second highest, closely followed by Alternative 2. Alternative 4 would have the lowest risk. Alternative 1 does not make a specific allocation but could potentially be up to 50 percent of the carrying capacity, providing a risk equal to Alternative 3.

\section{Cumulative Effects}

Cumulative effects on cultural sites occur through natural erosion, weathering, and decay, as well as from land development and increased visitation. The increased recreation use may expedite erosion and could lead to vandalism. Monitoring known sites would identify site changes and enable early mitigation to reduce cumulative effects. Site interpretation that includes a strong stewardship message could help to prevent future negative site impacts. If large group areas show signs of unacceptable impacts from recreation use, these locations could be excluded from use or the site could be hardened to prevent impacts. Site hardening could include boardivalk or gravel trail construction, fencing, restroom facilities, or other structural features. This would be covered in a future analysis.

Based on past monitoring of known cultural sites and recreation use, no cumulative effects on heritage resources from the commercial recreation proposed in the alternatives are anticipated beyond the natural decaying process. The types of nonground-disturbing recreation activities and the relatively low levels of use over the 


\section{Environment and Effects 3}

\section{Air Quality}

\section{Class 1 airsheds}

(Clean Air Act) - areas

subject to the most

limiting air pollution

restrictions, generally

large Wilderness areas

and national parks, and

some tribal areas. analysis area as a whole combined with mitigation measures, administrative oversight, and enforcement of regulations are expected to result in minimal effects. Specific areas receiving high levels of use will be surveyed and monitored to prevent impacts. The cumulative effects of the alternatives are not likely to result in adverse impacts on the heritage resources because of avoidance measures, mitigation measures, increased administrative oversight, and enforcement of cultural protection regulations.

\section{Affected Environment}

Baseline air quality information collected between 1989 and 1992 on the Tongass National Forest, including the Shoreline Outfitter/Guide analysis area, indicates the air quality is generally good (USDA 1994). Exchange of air typically comes from relatively pollution-free air off the Gulf of Alaska. The cool temperature and frequent rains typical of Southeast Alaska cleanse the atmosphere and contribute to the general high air quality. Air pollution in the analysis area arises from area sources, such as the larger communities of Juneau and Sitka. Air pollutants are concentrated by temperature inversion and by places where terrain, particularly mountains, limits atmospheric dispersal. These conditions exist in the Mendenhall Valley in Juneau and formerly in the Silver Bay area in Sitka when the pulp mill was in operation (USDA Forest Service 1994).

The analysis area is governed by the Alaska Ambient Air Quality Standards (Alaska Administrative Code, Title 18, Chapter 50) set forth by the Alaska Department of Environmental Quality (ADEC). The entire Shoreline Outfitter/Guide analysis area is a Class II airshed and does not have specific attainment criteria under the Clean Air Act. The Outfitter/Guide analysis area is exempt from needing an air quality impact analysis because the nearest Class I airshed, Denali National Park, is more than 200 miles away.

Sources of airborne pollutants in the analysis area include homes and businesses in Juneau, Sitka, and the other smaller communities, which expel exhausts from heating, cooking, cleaning, and business operations. Residential and commercial open-air burning occurs in backyards and business lots. Some communities operate incinerators and others have open air burning for trash disposal. Road transportation includes cars, buses, shuttles, and large trucks from neighboring communities. Ferries, barges, and small boats operate year-round. Air traffic consists of small planes and helicopters. All of these sources increase during the summer tourist season. In addition, cruise ships dock at Juneau and Sitka between May and September and travel in many of the inlets, bays, and channels in the analysis area. Cruise ship operations produce exhaust that is usually visible as stack emission.

Small inlets in the Juneau area were measured for particulates before and after the cruise ship tourism season for one year in 2000. Preliminary results indicate that ambient air quality remained good to moderate during the tourism season, where many cruise ships entered the Juneau area. Particulates increased 35 percent from pre-tourist season, but remained at healthy Prevention of Significant Deterioration (PSD) levels (PSD less than 100). No air quality alerts are necessary at PSD levels 


\section{Environment and Effects}

less than 100, which indicates good to moderate air quality (ADEC 2001). These preliminary findings are for one area in Southeast Alaska.

\section{Environmental Consequences}

Direct and Indirect Effects

All of the alternatives could have limited, short-term effects on ambient air quality. Such effects, primarily in the form of boat motor emissions, are likely to be indistinguishable from other local sources of airborne particulates, including other boat and motor vehicle emissions, dust, motor vehicle traffic, residential and commercial heating sources, other marine traffic, and emissions from burning garbage. The largest source of emissions from the project is likely to be from the larger tour boats. Four stroke outboard motors, which produce less noise and air pollution than the two stroke motors, are becoming more common on small motorboats. To mitigate the effects on air quality, outfitter/guide vessel operators must comply with all state and federal air quality regulations and ensure that exhaust emissions are within regulatory limits. Campfires used by commercial operations will have a negligible effect on air quality because only a few outfitter/guides would be building campfires and these would be widely dispersed throughout the analysis area.

Assuming that most of the effects on air quality would come from combustion engines used for commercial access to the shoreline area and that the amount of emissions is directly related to the number of people being guided, the higher the commercial use allocation, the more the potential for effects on air quality. Therefore, Alternative 3 would have the higher potential of having short-term effects on ambient air quality, followed by Alternatives 5, 2, 4, and 1 .

\section{Cumulative Effects}

Depending on the number and frequency of cruise ships and other motor vessels entering the bays and inlets of the area, pollutants may accumulate in any one or a number of sites. Because of the overall air circulation and high amount of precipitation of Southeast Alaska, it unlikely that cumulatively, these pollutants will reach quantities that exceed ambient air quality in the analysis area. 


\section{Specifically Required Disclosures}

All alternatives in the Shoreline Outfitter/Guide EIS are consistent with other federal and state environmental laws and executive orders. These laws and orders have been met to the extent practicable and the effects have been analyzed and documented. Several of the laws and executive orders listed in Chapter 1 require project-specific findings or other disclosures. These are included here and in the Record of Decision. They apply to all alternatives considered in detail in this EIS.

\section{NFMA Planning}

Laws

\section{Tongass Land and Resource Management Plan}

All project alternatives fully comply with the Tongass Land and Resource Management Plan (1997). This project incorporates all applicable Forest Plan forestwide standards and guidelines and management area prescriptions as they apply to the analysis area, and complies with Forest Plan goals and objectives. All required interagency review and coordination has been accomplished.

The Forest Plan complies with all resource integration and management requirements of 36 CFR 219 (219.14 through 219.27). Application of Forest Plan direction for the analysis area ensures compliance at the project level.

\section{Endangered Species Act}

None of the action alternatives is anticipated to have a direct, indirect, or cumulative effect on any threatened or endangered species in the Shoreline Outfitter/Guide analysis area or elsewhere. The National Marine Fisheries Service was consulted regarding the actions described and the effects on threatened and endangered marine species within the proposed analysis area. Formal consultation with the U.S. Fish and Wildlife Service was not necessary for this project since no terrestrial threatened or endangered species are known to occur within the analysis area. A Biological Assessment has been completed and is included in the planning record.

\section{Bald Eagle Protection Act}

To comply with the Bald Eagle Protection Act, management activities are restricted within 330 feet of an eagle nest site by a Memorandum of Understanding (MOU) between the Forest Service and the U.S. Fish and Wildlife Service. None of the action alternatives is anticipated to have a significant direct, indirect, or cumulative effect on any bald eagle habitat. If any nests are found that may be affected, the MOU and Forest Plan standards and guidelines will be followed.

\section{National Historic Preservation Act}

Heritage resource surveys of various intensities have been conducted in the Shoreline Outfitter/Guide analysis area, following inventory standards approved by the Alaska State Historic Preservation Officer and the Advisory Council on Historic Preservation. These surveys include background and existing literature searches and fieldwork complete with subsurface testing. Native communities have been contacted, and public comment encouraged. The opportunity to discuss known or suspected heritage resources in or near the analysis area was encouraged at public 


\section{Environment and Effects}

meetings held in Sitka, Petersburg, Angoon, Hoonah, Klukwan, and Kake. The following federally recognized tribes were consulted during the analysis:

Petersburg Indian Association

Sitka Tribe of Alaska

Shaqua Indian Village

Shilkat Indian Village

Hoonah Indian Association
Organized Village of Kake

Angoon Community Association

Chilkoot Indian Association

Douglas Indian Association

The State Historic Preservation Officer will be consulted with our findings that no known historical properties will be affected because of our documentation and monitoring efforts.

\section{Federal Cave Resource Protection Act of 1988}

Forest Plan karst and caves standards and guidelines are applied to areas known or suspected to contain karst resources. No guided use of caves will be permitted under this analysis. A separate analysis would be needed if a commercial operator should propose use of a cave. Therefore the action alternatives will not have a direct, indirect, or cumulative effect on any significant cave in the analysis area.

\section{Alaska National Interest Lands Conservation Act (ANILCA) Evaluations and Findings}

A subsistence evaluation was conducted for the five alternatives considered in detail, in accordance with ANILCA Section 810. The evaluations in the Subsistence Report on abundance and/or distribution, access, and competition for harvested resources in the Shoreline Outfitter/Guide analysis area indicate that there will not be a significant possibility of a significant restriction to the customary and traditional subsistence uses of wildlife, fish and shellfish, marine mammals, other foods, or timber resources as a result of this analysis.

However, past habitat change due to timber harvest and an expanding human population make it possible that there could be a restriction to the customary and traditional subsistence uses of salmon and deer in the distant future in portions of the analysis area. This possibility exists regardless of the implementation of any of the alternatives in this analysis.

\section{Clean Water Act}

Congress intended the Clean Water Act of 1972 (Public Law 92-500) as amended in 1977 (Public Law 95-217) and 1987 (Public Law 100-4) to protect and improve the quality of water resources and maintain their beneficial uses. Section 313 of the Clean Water Act and Executive Order 12580 of January 23, 1987 address Federal agency compliance and consistency with water pollution control mandates. Agencies must be consistent with requirements that apply to "any governmental entity" or private person. Compliance is to be in line with "all Federal, State, interstate, and local requirements, administrative authority, and process and sanctions respecting the control and abatement of water pollution." 


\section{Environment and Effects 3}

The Clean Water Act (Sections 208 and 319) recognized the need for control strategies for nonpoint source pollution. The National Nonpoint Source Policy (December 12, 1984), the Forest Service Nonpoint Strategy (January 29, 1985), and the USDA Nonpoint Source Water Quality Policy (December 5, 1986) provide a protection and improvement emphasis for soil and water resources and water-related beneficial uses. Soil and water conservation practices (BMPs) were recognized as the primary control mechanisms for nonpoint source pollution on National Forest System lands. The Environmental Protection Agency supports this perspective in their guidance, "Nonpoint Source Controls and Water Quality Standards" (August 19, 1987).

The site-specific application of BMPs, with a monitoring and feedback mechanism, is the approved strategy for controlling nonpoint source pollution as defined by Alaska's Nonpoint Source Pollution Control Strategy (October 2000). In 1997, the State approved the BMPs in the Forest Service's Soil and Water Conservation Handbook (FSH Handbook 2509.22, October 1996) as consistent with the Alaska Forest Resources and Practices Regulations. This Handbook is incorporated into the Tongass Land Management Plan.

Recreation activities and uses in this project will occur in accordance with standards, guidelines and direction contained in the Forest Plan, Best Management Practices and applicable Forest Service manual and handbook direction. Appendix C (Mitigation Measures) contains specific practices prescribed to prevent or reduce non-point sediment sources. Monitoring and evaluation of the implementation and effectiveness of Forest Plan standards and guidelines and Best Management Practices will occur. Project activities are expected to meet all applicable State Water Quality Standards Regulations.

State regulations provide for variances from anti-degradation requirements and water quality criteria. The commercial recreation operators are responsible for compliance, including obtaining any variance required by the state. The Forest Service will monitor for compliance through permit administration. The Forest Service expects the Shoreline Outfitter/Guide analysis area activities to fully qualify for any variance if required by the state, according to the criteria in $18 \mathrm{AAC} 70.015$.

All recreation activities and uses in this project will occur in accordance with Best Management Practices listed in 33 CFR 323.4(a). No permits under Section 404 of the Clean Water Act are expected.

\section{Clean Air Act}

Emissions expected from implementation of any of the action alternatives would be of short duration and are not expected to exceed state of Alaska Ambient Air Quality Standards (Alaska Administrative Code, Title 18, Chapter 50).

\section{Coastal Zone Management Act}

The Coastal Zone Management Act of 1972 (CZMA), while specifically excluding federal lands from the coastal zone, requires that a federal agency's activities be consistent with the enforceable standards of a state's coastal management program to the maximum extent feasible when the agency's activities affect the coastal zone. 
The State of Alaska developed the Alaska Coastal Management Program in 1977 to evaluate any projects within the coastal zone.

A Memorandum of Understanding specifies procedures between the U.S. Forest Service and the state of Alaska. The state agencies involved are the Division of Governmental Coordination, Department of Fish and Game, Department of Natural Resources, and the Department of Environmental Conservation. This memorandum serves to describe the process and expedite the review of whether a proposed project is consistent with the Alaska Coastal Management Program.

The Forest Service developed the proposed action and alternatives to be consistent, to the maximum extent feasible, with the enforceable policies of approved state management programs. The Forest Service has determined that all the alternatives for the Shoreline Outfitter/Guide analysis area are consistent. to the maximum extent feasible, with the Alaska Coastal Management Program, as outlined in the Memorandum of Understanding. The state will review and comment on this determination.

\section{Magnuson-Stevens Fishery Conservation and Management Act}

Based upon the analysis the Forest Service has determined that the proposed activities are unlikely to adversely affect essential fish habitat within the Shoreline Outfitter/Guide analysis area.

According to the agreement between the National Marine Fisheries Service and the USDA Forest Service dated August 25, 2000, an assessment was done in this EIS that included:

- A description of the proposed action;

- An analysis of individual and cumulative effects of the proposed action on the essential fish habitat, the managed species, and associated species such as major prey species, including affected life histories;

- The Forest Service's views regarding effects on essential fish habitat; and

- A discussion of proposed mitigation, if applicable.

The Draft Environmental Impact Statement with this determination was sent to the National Marine Fisheries Service for review.

\section{Other Disclosures}

\section{Effects on Prime Farm Land, Range Land, and Forest Land}

No prime farm land or range land will be adversely affected by the action alternatives. Forest land will maintain its long-term productivity

\section{Effects on Civil Rights, Women, and Minorities}

This analysis will not cause adverse impacts to civil rights, women, or minorities. 


\section{Executive Order 11593}

Executive Order 11593 directs federal agencies to provide leadership in preserving, restoring, and maintaining the historical and cultural environment of the nation. The work accomplished for the Shoreline Outfitter/Guide analysis area in accordance with Section 106 of the National Historic Preservation Act meets the intent of this Executive Order.

\section{Executive Order 11988}

Executive Order 11988 directs federal agencies to take action to avoid, to the extent possible, the long and short-term adverse impacts associated with the occupancy and modification of floodplains. A floodplain is defined as the lowland and relatively flat areas adjoining inland and coastal waters including flood prone areas of off shore islands, including at a minimum that area subject to a one percent or greater of flooding in any given year."

Recreation activities and uses will have minimal to no effect on floodplains. Forest Plan standards and guidelines and Best Management Practices for riparian areas are followed. Effects on floodplains from project activities have been avoided or minimized as much as possible.

\section{Executive Order 11990}

Executive Order 11990 requires federal agencies to avoid, to the extent possible, the long-term and short-term adverse impacts associated with the destruction or modification of wetlands.

This project avoids affecting wetlands whenever practicable, but because wetlands are so extensive in the analysis area, it is not feasible to avoid all wetland areas. Impacts due to recreational use of wetlands are expected to be minimal.

\section{Executive Order 12898}

Executive Order 12898 directs federal agencies to identify and address the issue of environmental justice, which concerns adverse human health and environmental effects of agency programs that disproportionately affect minority and low-income populations.

Public meetings were available to all people in and near the project area and advertised through the local media, newspaper, TV scanner, local radio stations, and posted flyers at grocery stores and other businesses. See Chapter 1, Public Participation.

Implementation of the action alternatives will not cause adverse health, social, or environmental effects that disproportionately affect minority and low-income populations. See also the ANILCA Section 810 findings.

\section{Executive Order 12962}

Executive Order 12962 directs federal agencies to conserve, restore, and enhance aquatic systems to provide for increased recreational fishing opportunities nationwide. Section 1 of the Executive Order is most pertinent to the Shoreline 


\section{Environment and Effects}

Outfitter/Guide analysis area. Section 1 directs federal agencies to evaluate effects on aquatic ecosystems and recreational fisheries, develop and encourage partnerships, promote restoration, provide access, and promote awareness of opportunities for recreational fishery resources.

The effects of this project on freshwater and marine resources were evaluated during the analysis. With the application of Forest Plan standards and guidelines, including those for riparian areas, no significant adverse effects on freshwater or marine resources will occur.

Partnerships continue to be used to leverage federal project funds to address water quality concerns in areas of the Tongass National Forest, although none have been proposed for recreational fisheries in conjunction with this analysis.

\section{Executive Order 13007}

Executive Order 13007 directs federal agencies to accommodate access to and ceremonial use of American Indian sacred sites by Indian religious practitioners and to avoid adversely affecting the physical integrity of such sacred sites. There are no known sacred Indian sites in the Shoreline Outfitter/Guide analysis area. Consultation with local federally recognized tribes (See NHPA listing of tribes consulted) occurred during this analysis. 


\section{Chapter 4 Lists}

Glossary .

4- 1

References 4-11

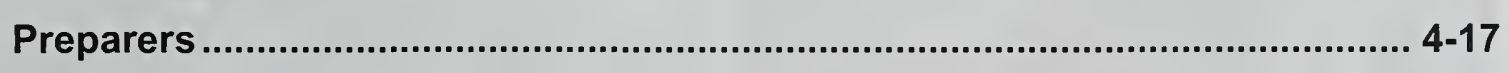

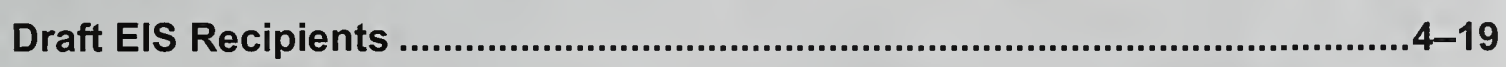

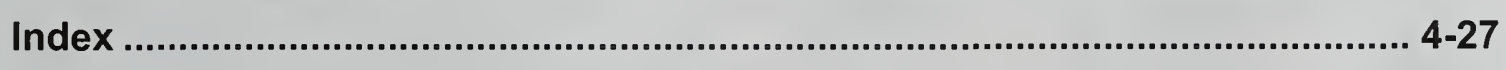




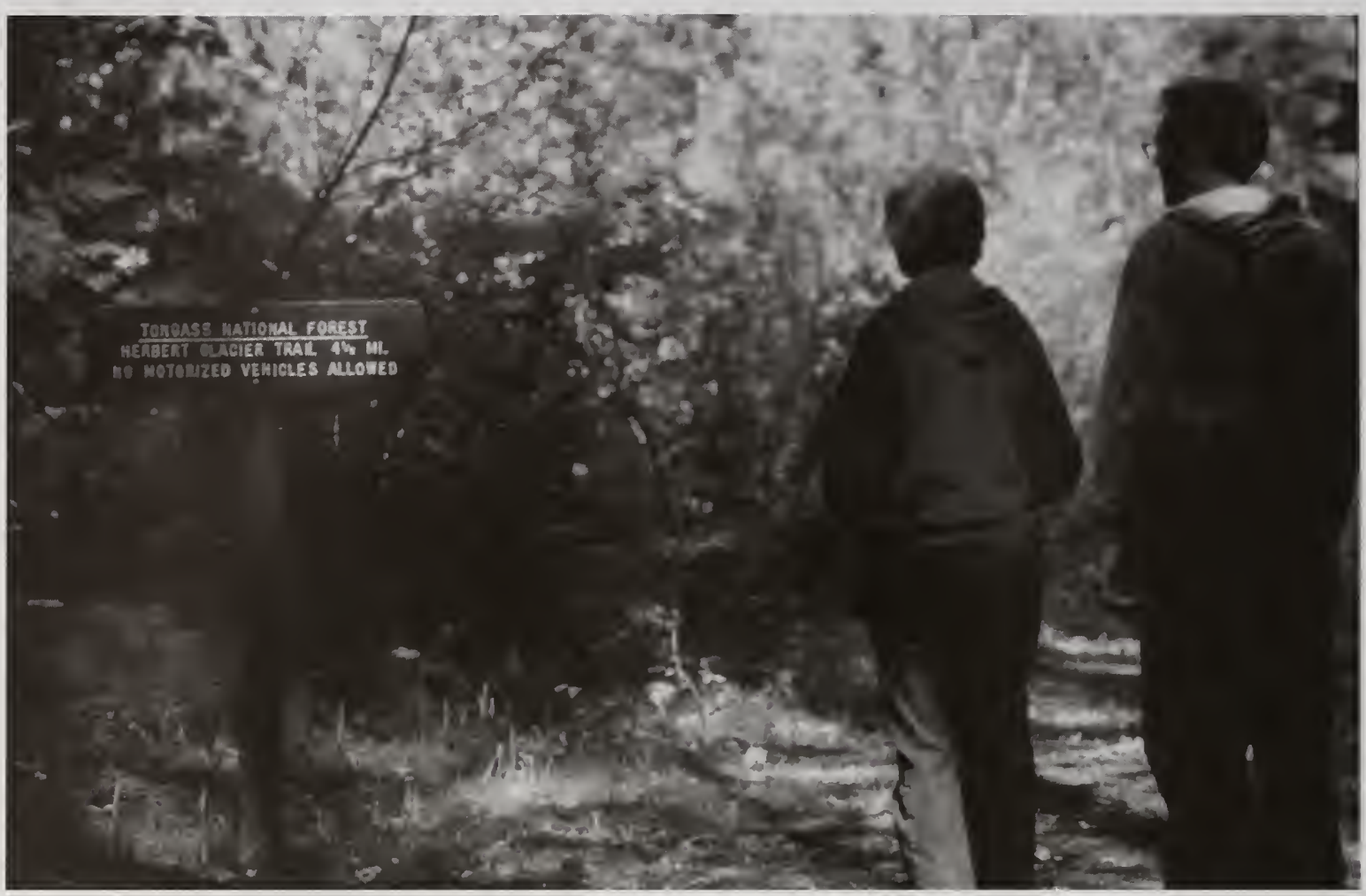




\section{Glossary}

Adfluvial fish

Alaska Heritage

Resource Survey (AHRS)

Alaska National Interest Lands Conservation Act (ANILCA)

All-terrain Vehicle (ATV)

Alpine/subalpine habitat

Anadromous Fish

Aquatic Habitat

Management Unit (AHMU)

Beach Fringe

Biological Assessment

Biological Evaluation

Biological Opinion

Carrying Capacity

Climax Plant

Community

Commercial use
Species or populations of fish that do not go to sea but live in lakes and enter streams to spawn.

The official list of cultural resources in the State of Alaska, maintained by the Office of History and Archaeology, Alaska Division of Parks and Outdoor Recreation.

The Alaska National Interest Lands Conservation Act of December 2, 1980, Public Law 96-487, $96^{\text {th }}$ Congress, 94 Stat. 2371-2551. Passed by Congress in 1980, this legislation designated 14 national forest wilderness areas in Southeast Alaska. Section 810 requires evaluations of subsistence impacts before changing the use of these lands.

A motorized four-wheeled vehicle less than 40 inches wide that is restricted by law from operating on public roads for general motor vehicle traffic.

The region found on a mountain peak above tree growth, generally above 1,500 feet in elevation.

Fish (such as salmon and steelhead) that spend part of their lives in fresh water and part of their lives in salt water. Anadromous fish ascend from the sea to spawn in freshwater streams.

A mapping unit that displays an identified value for aquatic resources. It is a mechanism for carrying out aquatic resource management policy (See Stream Class).

The area, typically forested, that is inland from saltwater shorelines.

A type of biological evaluation conducted for major federal actions requiring an environmental impact statement, in accordance with legal requirements under Section 7 of the Endangered Species Act (16 U.S.C. 1536(c)). The purpose of the assessment and resulting document is to determine whether the proposed action is likely to affect a species that has been listed or proposed as an endangered or threatened species.

A documented Forest Service review of Forest Service programs or activities in sufficient detail to determine how an action or proposed action may affect any species that has been listed or proposed as threatened, endangered, or sensitive.

An official report by the U.S. Fish and Wildlife Service (USFWS) or the National Marine Fisheries Service (NMFS) issued in response to a formal Forest Service request for consultation or conference. It states whether an action is likely to result in jeopardy to a species or adverse modification of its critical habitat.

The estimated maximum number of groups of people who could recreate in an area while achieving management objectives.

A community of plants and animals that is relatively stable over time and which represents the late stages of succession under the current climate and soil conditions.

Any use of the national forest for which a fee is charged by an outfitter/guide. 


\section{Glossary}

\author{
Connectivity
}

Cumulative Effects

\section{Deer Winter Range}

\section{Desired Future Condition}

Developed Recreation

Direct Effects

Direct Employment

Discount Rate

Dispersal (recreation)

\section{Dispersed Recreation}

\section{Displacement (recreation)}

Distance Zone

Enclave

Endangered Species

Endemic
A measure of the extent that forest areas between or outside reserves provide habitat for breeding, feeding, dispersal, and movement.

The impacts on the environment resulting from the addition of the incremental impacts of past, present, and reasonably foreseeable future actions regardless of what agency (federal or non-federal) or person undertakes such actions. Cumulative impacts can result from individually minor but collectively significant actions occurring over time.

Locations that provide food and shelter for Sitka black-tailed deer under moderately severe to severe winter conditions. Usually associated with high volume old growth stands at low elevation and with south aspects.

A statement of the ultimate goal for resources and uses of an area.

Recreation that requires facilities that, in turn, result in concentrated use of an area, such as campgrounds and picnic areas. Facilities in these areas might include roads, parking lots, picnic tables, toilets, drinking water, and buildings (See Dispersed Recreation).

Environmental effects that occur at the same time and place as the initial cause or action.

The jobs that are immediately associated with a given activity.

The rate used to adjust future benefits or costs to their present value.

Refers to when recreationists spread out and travel farther to find desirable and available campsites or places to go ashore. In this analysis, dispersal is viewed as a short-term effect. As an example, a visitor may move farther down the shoreline of a bay because another group is using the preferred area.

Recreational activities that are not confined to a specific place and are generally outside developed recreation sites. This includes activities such as scenic driving, hiking, backpacking, hunting, fishing, snowmobiling, cross-country skiing, and recreation in primitive environments (See Developed Recreation).

More of a long-term effect than dispersal, resulting in a decision by visitors to avoid an area within a Wilderness based on previous experiences such as regulation or crowding. Displacement could mean relocating to another Wilderness or to a LUD that is capable of providing the desired recreation experience.

Areas of landscapes visible from priority travel routes and use areas categorized by distance criteria (Foreground: 0 to $1 / 4$ mile, Middleground: $1 / 4-1 / 2$ to $3-5$ miles, or Background: greater than 3-5 miles). Used as a frame of reference in which to discuss landscape characteristics and management activities.

Area where large groups can occur on a regular basis throughout the season.

Any species of animal or plant that is in danger of extinction throughout all or a significant portion of its range. Plant or animal species are identified by the Secretary of the Interior as endangered in accordance with the 1973 Endangered Species Act.

Found in a particular locality; indigenous. 
Environmental Impact Statement (EIS)

Essential Fish Habitat
(EFH)

Estuary

Fall Season

Fifteen-Percent area

Forbs

Forest Plan

Forest Land

Forest-wide Standards and Guidelines

Geographic Information System (GIS)

Group

Group-days

Groups-at-one-time

Habitat

Heritage Resources
A statement of environmental effects of a proposed action and alternatives to it. A Draft EIS is released to the public and other agencies for review and comment. A Final EIS is issued after consideration of public comments. A Record of Decision (ROD) is based on the information and analysis in the Final EIS.

Includes all freshwater streams accessible to anadromous fish, marine waters, and intertidal habitats. This includes all Class I streams, marine waters, and intertidal habitats of the Shoreline Outfitter/Guide analysis area.

An ecological system at the mouth of a stream where fresh water and salt water mix and where salt marshes and intertidal mudflats are present. The landward extent of an estuary is the limit of salt-intolerant vegetation, and the seaward extent is a stream's delta at mean low water.

September 15 - October 31

Places where large groups can occur only on an occasional basis, for less than 15 percent of the primary use season.

A category of herbaceous plants that are not included in the grass, shrub, or tree categories; generally smaller flowering plants.

The Tongass Land and Resource Management Plan is the source of management direction for the Tongass National Forest. It specifies activity and output levels for a 10 15 year period.

Land at least 10 percent occupied by forest trees of any size or formerly having had such tree cover and not currently developed for non-forest use.

A set of rules and guidance that directs management activities and establishes the environmental quality, natural renewable and depletable resource requirements, conservation potential, and mitigation measures that apply to several land use designations.

A computerized map database that is used to store and evaluate site-specific information.

A group consists of one or more individuals recreating together as a social unit. Groups are used as the basic unit in this analysis (see Large Groups).

A measurement of recreation use by groups using the national forest on a daily basis.

The number of groups that could recreate in a specific area without exceeding the number of group encounters specified by the ROS class to achieve a specific type of recreation experience.

The sum total of environmental conditions of a specific place that is occupied by an organism, population, or community of plants or animals.

The prehistoric or historical district, site, building, structure, or object included in, or eligible for inclusion in, the National Register of Historic Places. The term includes artifacts, records, and remains that are related to and located within such properties. 


\author{
Home Range \\ (Community)
}

Indirect Effects

\section{Indirect Employment}

Interdisciplinary Team (IDT)

\section{Irretrievable \\ Commitments \\ Irreversible \\ Commitments}

Karst

Land Use Designation
(LUD)

Large Group

Large Group Area

Large Woody Debris

(LWD)

Log Transfer Facility

(LTF)

Management Indicator Species (MIS)

\section{Marine Access Points (MAPs)}

\section{Middleground}

The recreation places lying within 15-30 miles of communities. This is the typical distance one could travel in a day by small boat or on a limited community road system.

Effects that occur later in time or are spatially removed from the activity but would be significant in the foreseeable future.

The jobs in service industries that are associated with or support a given activity.

A group of individuals with different scientific and resource expertise. The team is assembled out of recognition that no one scientific discipline is sufficiently broad to adequately address natural resource management. Through interaction, participants bring different points of view and a broader range of expertise.

Loss of production or use of renewable natural resources for a period of time. The production or use lost is irretrievable, but not irreversible.

Decisions causing changes that cannot be reversed. Often applies to nonrenewable resources such as minerals and cultural resources.

A type of topography that develops in areas underlain by soluble rocks, primarily limestone. Dissolution of the subsurface layer results in areas of well-developed, surface drainage that are sinkholes, collapsed channels, or caves.

A defined area of land, identified by the Forest Plan, to which specific management direction is applied.

Group made up of a number of people that exceeds the general maximum group size for a specified type of recreation experience in the ROS. Large group size varies by LUD and ROS. In this EIS, large groups are defined as $21-75$ people.

For this EIS, specific areas where groups of 21-75 people may be allowed. The two types of large group areas are Enclaves and Fifteen-Percent areas.

Any large piece of relatively stable woody material having a least diameter of greater than 3.9 inches ( 10 centimeters) and length greater than 39 inches (one meter) that intrudes into the stream channel.

Formerly referred to as Terminal Transfer Facilities, Log Transfer Facilities include the site and structures used for moving logs and timber products between land-based and water-based transportation.

Vertebrate or invertebrate wildlife species whose response to land management activities can be used to predict the likely response of other species with similar habitat requirements. The National Forest Management Act regulations prescribe the use of management indicator species.

The site and structures used for moving people, vehicles, logs, and timber products from land-based transportation forms to marine water-based transportation forms. These include log transfer facilities (LTFs).

The visible terrain beyond the foreground where individual trees are still visible but do not stand out distinctly from the landscape. The area is located from $1 / 4$ to $3-5$ miles from the viewer. 


\section{Glossary 4}

Mitigation

Monitoring

Multiple Use

Muskeg

National Environmental Policy Act of 1969

(NEPA)

\section{National Forest \\ Management Act \\ (NFMA)}

National Register of
Historic Places

Non-commercial use

Numen

Old-growth Forest

Old-growth Habitat Reserve
Measures designed to counteract or reduce environmental impacts. These measures may include: avoiding an impact by not taking a certain action or part of an action; minimizing an impact by limiting the degree or magnitude of an action and its implementation; rectifying the impact by repairing, rehabilitating, or restoring the affected environment; reducing or eliminating the impact over time by preservation and maintenance operations during the life of the action; or compensating for the impact by replacing or providing substitute resources or environments.

A process of collecting information to evaluate whether or not objectives of a project and its mitigation plan are being realized. Monitoring can occur at different levels: to confirm whether mitigation measures were carried out in the matter called for (Implementation Monitoring); to confirm whether mitigation measures were effective (Effectiveness Monitoring); or, to validate whether overall goals and objectives were appropriate (Validation Monitoring).

The management of all the various renewable surface resources of the National Forest System so that they are used in the combination that will best meet the needs of the American people; harmonious and coordinated management of the various resources, each with the other, without impairment of the productivity of the land, with consideration being given to the relative values of the various resources.

A bog, often dominated by sphagnum moss, frequently with deep accumulations of organic material, occurring in wet, poorly drained northern regions. Peatland.

An act declaring a national policy to encourage productive harmony between humans and their environment, to promote efforts that will prevent or eliminate damage to the environment and the biosphere and stimulate the health and welfare of humans; to enrich the understanding of the ecological systems and natural resources important to the nation and to a Council on Environmental Quality.

A law passed in 1976 that amends the Forest and Rangeland Renewable Resources Planning Act, requires the preparation of Forest plans, requires the identification of management indicator species, and defines parameters for timber suitability.

A register of cultural resources of national, state, or local significance, maintained by the Department of the Interior.

In this analysis, refers to unguided use; use for which no special uses permit is necessary and for which no one receives financial remuneration or other gain for services provided on the national forest.

The spirit of a place.

Ecosystems distinguished by old trees and related structural attributes. Old growth encompasses the later stages of stand development that typically differ from earlier stages in a variety of characteristics that may include larger tree size, higher accumulations of large dead woody material, multiple canopy layers, different species composition, and different ecosystem function. The structure and function of an old-growth ecosystem will be influenced by its stand size and landscape position and context.

A contiguous unit of old-growth forest habitat to be managed to maintain the integrity of the old-growth forest ecosystem. 


\section{Outfitter/guide}

\section{Particulates}

Plant Association

Priority Travel Routes

Productive Old Growth

\section{Proposed Action}

Recreation Carrying

Capacity

Recreation Opportunity Spectrum

(ROS)

\section{Recreation Places}

\section{Recreation Sites}

\section{Resident Fish}

Riparian Management Area

Roadless Area

\section{Scoping Process}

Those who, generally for compensation, facilitate the use, enjoyment, understanding, and appreciation of national forest recreation settings where the need for service has been identified and is compatible with objectives and management direction.

Solid particles or liquid droplets suspended or carried in the air.

Climax forest plant community type representing the endpoint of succession.

Land adjacent to the Alaska Marine Highway, cruiseship routes, flightseeing routes, high use recreation areas, and other marine and land-based travel routes, that are seen by more people, more frequently and for a greater duration of time than other areas of the national forest.

Old-growth stands capable of producing 20 cubic feet per acre per year with 8,000 or more board feet of timber per acre.

An initial proposal by a federal agency to authorize, recommend, or implement an action.

A social recreation carrying capacity is the estimated maximum number of groups of people who could recreate in an area and still have a specified type of recreation experience.

A system for planning and managing resources that categorizes recreation opportunities into seven classes. Each class is defined in terms of the degree to which it satisfies certain recreation experience needs based on the extent to which the natural environment has been modified, the type of facilities provided, the degree of outdoor skills needed to enjoy the area, and the relative density of recreation use.

Identified geographical areas having one or more physical characteristics that are particularly attractive to people in recreation activities. Recreation places may be beaches, streamsides or roadside areas, trail corridors, hunting areas, or the immediate area surrounding a lake, cabin site, or campground.

A specific site and/or facility occurring within a recreation place. Some examples of recreation sites are: recreation cabins, trailheads, picnic areas, and wildlife viewing blinds.

Fish that are not anadromous and that reside in fresh water on a permanent basis. Resident fish include cutthroat trout and arctic grayling.

The area including water, land, and plants adjacent to perennial streams, lakes, and other bodies of water that is managed for the inherent qualities of the riparian ecosystem.

An area of undeveloped public land identified in the roadless area inventory of the Forest Plan within which there are no improved roads maintained for travel by means of motorized vehicles intended for highway use.

Early and open communication with the public used to determine the scope and significance of a proposed action, what level of analysis is required, what information is needed, and what level of public participation is appropriate. Scoping focuses on the issues surrounding the proposed action and the range of actions, alternatives, and impacts to be considered in an EA or EIS. 


\section{Sensitive Species}

\section{Shoreline Zone}

Significant Issue

Special Interest Area

Spring Season

Stand

Stream Class

Structural Diversity

Subspecies
Animal and plant species identified by the Forest Service Regional Forester as potentially susceptible or vulnerable to activity impacts or habitat alterations and, therefore, in need of special considerations during land management activity planning.

The area approximately one-half mile inland from mean high tide line.

Under NEPA, refers to issues that are used to formulate alternatives, prescribe mitigation measures, or analyze environmental effects. Issues are 'significant' because of the extent of their geographic distributions, the duration of their effects, or the intensity of interest or resource conflict. 'Significantly' requires considerations of both context and intensity, as developed in the CEQ regulations, sec. 1508.27.

A designation for an area possessing unique or unusual scenic, historical, prehistoric, scientific, or other characteristics.

April 20 - May 31

A group of trees occupying a specific area and sufficiently uniform in composition, age arrangement, and condition as to be distinguishable from the forest in adjoining areas.

A way to categorize stream channels based on their fish production values. Also known as Aquatic Habitat Management Unit (AHMU) Class. There are four stream classes defined by the Forest Plan. They are:

Class I Streams and lakes with anadromous or adfluvial fish habitat; or high quality resident fish waters listed in Appendix 68.1, Region 10 Aquatic Habitat Management Handbook (FSH 2609.24), June 1986; or habitat above fish migration barriers known to be reasonable enhancement opportunities for anadromous fish.

Class II Streams and lakes with resident fish populations and generally steep (6-15 percent) gradient (can also include streams from $0-5$ percent gradient) where no anadromous fish occur, and otherwise not meeting Class I criteria. The fish populations have limited fisheries values and generally occur upstream of migration barriers, or the streams have other habitat features that preclude anadromous fish use.

Class III Perennial and intermittent streams with no fish populations but which have sufficient flow or transport sediment and debris to have an immediate influence on downstream water quality or fish habitat capability. These streams generally have bankfull widths greater than five feet and are highly incised into the surrounding hillslope.

Class $I V$ Intermittent, ephemeral, and small perennial channels with insufficient flow or sediment transport capabilities to have an immediate influence on downstream water quality or fish habitat capability. These streams generally are shallowly incised into the surrounding hillslope.

The diversity of forest structure, both vertically and horizontally, which provides for variety of forest habitats such as logs and multi-layered forest canopy for plants and animals.

An aggregate of similar populations of a species generally inhabiting a geographic subdivision of the range of the species and differing taxonomically (for example, different size or color) from other populations of the species. 


\section{Glossary}

Summer Season

Sustained Yield

Threatened Species

Tiering

Tongass Resource Use Cooperative Survey (TRUCS)

Transporter

Use Area

Value Comparison Unit (VCU)

Viable Population

Viewshed

Visual Quality

Objective (VQO)
June 1 - September 14

The amount of renewable resources that can be produced continuously at a given intensity of management.

Any species that is likely to become an endangered species within the foreseeable future throughout all or a significant portion of its range and that has been designated in the Federal Register by the Secretary of the Interior as a threatened species under the Endangered Species Act.

Elimination of repetitive discussions of the same issue by incorporating by reference the general discussion in an environmental impact statement of broader scope; for example, this EIS is tiered to the Forest Plan EIS.

A study done to gather information on subsistence uses of the Tongass National Forest.

A business that only provides point-to-point transportation for clients. Transporters do not usually require a permit to transport unguided visitors to the national forest.

Distinct geographic area used in this analysis as the basis for defining and managing recreation use. Use Areas are subdivisions of Guide Use Areas used by the Alaska Department of Fish and Game to manage commercial big game guiding. Use Areas provide distinct geographical areas at a size that allows meaningful recreation management for specific areas of the national forest.

A distinct geographic area that generally encompasses a drainage basin containing one or more large stream systems. Boundaries usually follow easily recognizable watershed divides. These units were established in the Forest Plan to provide a common set of areas for which resource inventories could be conducted and resource value interpretations made.

Fish or wildlife populations that have the estimated number and distribution of reproductive individuals to ensure their continued existence and that are well distributed in the national forest.

A distinct area of land visible from identified travelways (boat route, recreation road, or trail) or recreation places (recreation cabin or anchorage).

A desired level of scenic quality and diversity of natural features based on physical and sociological characteristics of an area. Refers to the degree of acceptable alterations of the characteristic landscape.

Adopted VQO - The VQO to be achieved as a result of management direction identified in the approved Forest Plan. Adopted VQOs represent the visual resource objective for the Forest Land Management Plan period, normally 10 years (FSH 2309.22, R-10 Landscape Management Handbook).

That area that contributes water to a drainage or stream; portion of a forest in which all surface water drains to a common point. Can range from a few tens of acres that drain a single small intermittent stream to many thousands of acres for a stream that drains hundreds of connected intermittent and perennial streams. 


\section{Glossary 4}

Wetlands

Wild and Scenic River

Wilderness

Wildlife Analysis Area (WAA)

Winter Range
Areas that are inundated by surface or ground water with a frequency sufficient, under normal circumstances, to support a prevalence of vegetative or aquatic life that requires saturated or seasonally saturated soil conditions for growth and reproduction. Wetlands generally include muskegs, marshes, bogs, sloughs, potholes, river overflows, mud flats, wet meadows, seeps, and springs.

River or section of a river so recommended or designated under the 1968 Wild and Scenic Rivers Act or by an act of the Legislature of the state or states through which the river flows.

Area designated under the 1964 Wilderness Act. Wilderness is defined as undeveloped federal land retaining its primeval character and influence without permanent improvements or human habitation. Wilderness areas are protected and managed to preserve their natural conditions. In Alaska, the Tongass Timber Reform Act of 1990 and ANILCA also have designated Wilderness Areas.

A division of land used by the Alaska Department of Fish and Game for wildlife analysis.

An area, usually at lower elevations, used by big game during the winter months; usually smaller and better defined than summer ranges. 
4 Glossary

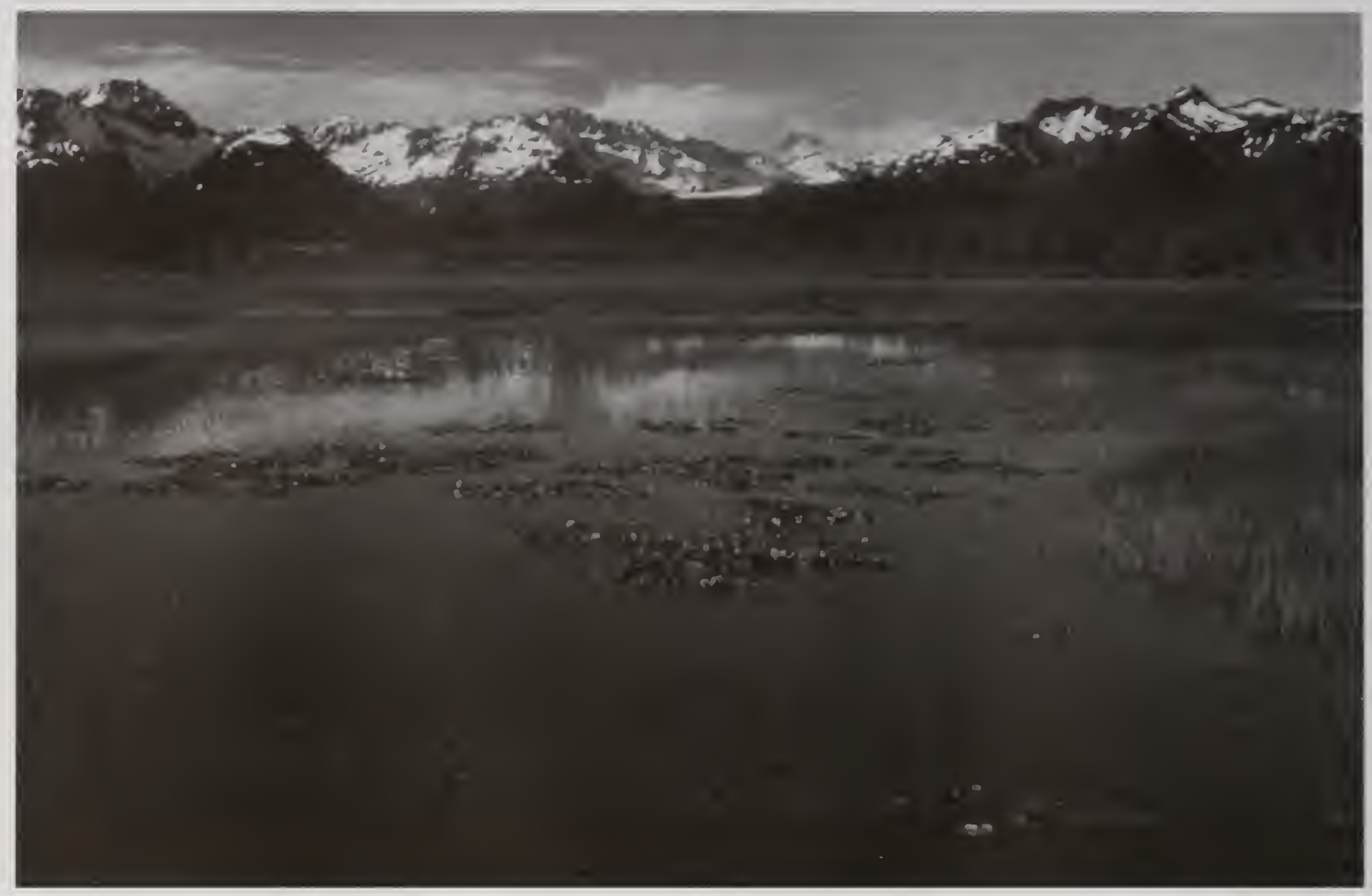




\section{References}

The following list of references includes both literature cited in this EIS and other sources of information used in the Shoreline Outfitter/Guide analysis. Complete reference lists are included in individual resource reports that are on file in the Shoreline Outfitter/Guide planning record.

Alaska Board of Game [ABOG]. 2000. Southeast Alaska unit 4 brown bear management strategy - recommendations of a citizens and agency brown bear management advisory team. Douglas, AK. 90 pp.

Alaska Department of Fish and Game [ADF\&G]. 2001. Run forecasts and harvest projections for 2001 Alaska salmon fisheries and review of the 2000 season: The short version. Regional Information Report No. 5J01-02. Juneau, AK: Alaska Department of Fish and Game.

Alaska Department of Fish and Game [ADF\&G]. 2001a. Sport fishing emergency order No. 120-01. Sitka, AK: Alaska Department of Fish and Game.

Alaska Department of Fish and Game [ADF\&G]. 2001b. Sport fishing emergency order No. 121-01. Sitka, AK: Alaska Department of Fish and Game.

Alaska Department of Fish and Game [ADF\&G]. 2001c. Sport fishing news release No. 01-0601. Sitka, AK: Alaska Department of Fish and Game.

Alaska Department of Fish and Game [ADF\&G]. 2001d. Southeast Alaska sport fishing regulations summary. Juneau, AK: Alaska Department of Fish and Game.

Alaska Department of Fish and Game [ADF\&G]. 2000. Alaska hunting regulations, No. 41. Effective 1 July 2000-30 June 2001. Juneau, AK: Alaska Board of Game. 120 pp.

Alaska Department of Fish and Game [ADF\&G]. 2000a. Brown bear. Hicks, M.V., editor. Federal aid in wildlife restoration; annual performance report, survey-inventory activities 1 July 1999-30 June 2000. Douglas, AK: Division of Wildlife Conservation.

Alaska Department of Fish and Game [ADF\&G]. 2000b. Sport fishing emergency order No. 123-00. Sitka, AK: Alaska Department of Fish and Game.

Alaska Department of Fish and Game [ADF\&G]. 2000c. Sport fishing emergency order No. 132-00. Sitka, AK: Alaska Department of Fish and Game.

Alaska Department of Fish and Game [ADF\&G]. 2000d. Sport fishing emergency order No. 110-00. Sitka, AK: Alaska Department of Fish and Game.

Alaska Department of Fish and Game [ADF\&G]. 2000e. Sport fishing news release No. 1-23-00. Sitka, AK: Alaska Department of Fish and Game.

Alaska Department of Fish and Game [ADF\&G]. 2000f. Sport fishing news release No. 1-32-00. Sitka, AK: Alaska Department of Fish and Game. 


\section{References}

Alaska Department of Fish and Game [ADF\&G]. 1999. Brown bear. Hicks, M.V. editor. Federal aid in wildlife restoration, management report, survey-inventory activities 1 July 1996-30 June 1998. Douglas, AK: Division of Wildlife Conservation.

Alaska Department of Fish and Game [ADF\&G]. 1999a. Sport fishing emergency order No. 108-99. Sitka, AK: Alaska Department of Fish and Game.

Alaska Department of Fish and Game [ADF\&G]. 1998. Brown bear. Hicks, M.V., editor. Federal aid in wildlife restoration, management report, survey-inventory activities 1 July 1994-30 June 1996. Douglas, AK: Division of Wildlife Conservation.

Alaska Department of Fish and Game [ADF\&G]. 1998a. Sport fishing emergency order No. 123-98. Sitka, AK: Alaska Department of Fish and Game.

Alaska Department of Fish and Game [ADF\&G]. Unpublished data. Southeast Alaska subsistence/personal use data from 1989 - 1999. Juneau, AK: Alaska Department of Fish and Game, Southeast Region.

Alaska Department of Fish and Game [ADF\&G]. Unpublished data. Southeast Alaska statewide sport fish harvest survey estimates data from 1997 - 1999. Juneau, AK: Alaska Department of Fish and Game, Southeast Region.

Alaska Department of Fish and Game [ADF\&G]. Unpublished data. Sport fish license sales data for communities within the analysis area during 1993 - 2000. Juneau, AK: Alaska Department of Fish and Game, Southeast Region.

Alaska Department of Fish and Game [ADF\&G]. Unpublished data. Commercial salmon harvest data for waters surrounding the project area during 1990 - 2000. Juneau, AK: Alaska Department of Fish and Game, Southeast Region.

Alaska Division of Community and Business Development. 2001 (unpublished). 2000 Southeast Alaska Commercial Recreation Survey Preliminary Report. Alaska Division of Community and Business Development, Alaska State Government, Juneau, AK. Report and data on file with Guy Robertson, USDA Forest Service, Alaska Region (grobertson02@fs.fed.us).

Allen, S.D.; Robertson, G.; Schaefers, J. 1998. Economies in transition: An assessment of trends relevant to management of the Tongass National Forest. General Technical Report PNWGTR-417. Portland, OR: USDA Forest Service, Pacific Northwest Research Station.

Bald and Golden Eagle Protection Act. June 8, 1940. Public Law 76-567, Ch. 278, 54 Stat. 250. as amended; 16 U.S.C. 668(note), 668, 668a-d.

Bowker, J.M. 2001. Outdoor Recreation by Alaskans: Projections for 2000-2020. General Technical Report PNW-GTR-527. Portland, OR: USDA Forest Service, Pacific Northwest Research Station.

Brookover, T. 2001. Letter regarding steelhead conservation concerns by USDA Forest Service. Douglas, AK: Alaska Department of Fish and Game, Sport Fish Division. 
Brooks, D.; Haynes, R. In press. Recreation and tourism in south central Alaska: Synthesis of recent trends and prospects. General Technical Report PNW-GTR-511 Portland, OR: USDA Forest Service, Pacific Northwest Research Station.

Cole, D.N. 1995. Disturbance of natural vegetation by camping: Experimental applications of low-level stress. Environmental Management. 19(3):405-416.

Cole, D.N.; Trull, S.J.; 1992. Quantifying vegetation response to recreational disturbance in the North Cascades, Washington. Northwest Science. 66(4):229-236.

Colt, S.; Martin, S.; Tomeo, M.; Twardock, P. In press. Recreation and tourism in south central Alaska: Patterns and prospects. Anchorage, AK: University of Alaska, Alaska Pacific University, Institute for Social and Economic Research.

Ellis, R.J.; Calvin, N.I. 1995. Status of anchorage suitability for use by ecotourism charter boat operators and guides in Southeast Alaska. Prepared for Alaska Institute for Sustainable Recreation and Tourism, November 1995.

Farrar, D.R. 1999. Genetic and morphological analyses of Botrychium plants collected in the vicinity of Yakutat, Alaska, in Summer 1998. Ames, IA: Iowa State University.

Farrar, D.R. 2000. A genetic assessment of the systematic relationships of western moonwort species (Botrychium subgenus Botrychium). Ames, IA: Iowa State University.

Halupka, K.C.; Bryant, M.D.; Wilson, M.F.; Everest, F.H. 2000. Biological characteristics and population status of anadromous salmon in Southeast Alaska. General Technical Report PNW-GTR-468. Portland, OR: USDA Forest Service, Pacific Northwest Research Station.

Hendee, J.; Stankey, G.; Lucas, R. 1990. Wilderness Management. Second edition. North American Press. 546pp.

Horton, G.E. 1994. Effects of jet boats on salmonid reproduction in Alaskan streams. Masters thesis. Fairbanks, AK: University of Alaska. 79 pp.

Howe, A.L.; Walker, R.J.; Olnes, C.; Heineman, G.; Bingham, A.E. 1999. Harvest and catch in Alaska sport fisheries during 1998. Fishery Data Series No. 99-41. Juneau, AK: Alaska Department of Fish and Game. 210 pp.

Jones, D.; Brookover, T. 2000. Southeast Alaska trout and steelhead management. Report to the Alaska Board of Fisheries. Douglas, AK: Alaska Department of Fish and Game, Division of Sport Fish.

Joslin, G.; Youmans, H.; coordinators. 1999. Effects of recreation on Rocky Mountain wildlife: A review for Montana. Committee on Effects of Recreation on Wildlife, Montana Chapter of The Wildlife Society. 307 pp.

Knudsen, E.E.; Steward, C.R.; MacDonald, D.D.; Williams, J.E.; Rieser, D.W., editors. 2000. Sustainable fisheries management: Pacific salmon. Boca Raton, FL: D.W. Lewis Publishers. 


\section{References}

Lipkin, R.; Murray, D. 1997. Alaska rare plant field guide. Washington, DC: U.S. Department of the Interior.

Martin et al. 1995. Plant Association Management Guide. Juneau, AK: Tongass National Forest.

McDowell Group. 2000. The economic impacts of the cruise ship industry in Southeast Alaska. Prepared for Southeast Conference, October 2000. Juneau, AK: McDowell Group.

Paustian, S.; et al. 1992. Channel type users guide, Tongass National Forest, Southeast Alaska. R10-TP-26. Juneau, AK: USDA Forest Service, Region 10.

Roberts, C.B.; White, R.G. 1992. Effects of angler wading on survival of trout eggs and preemergent fry. North American Journal of Fisheries Management 12:450459.

Schroeder, R.; Cerveny, L.; Robertson, G. In press. Tourism growth in Southeast Alaska: Trends, projections, and issues. General Technical Report PNW-GTR-XXX. Portland, OR: USDA Forest Service, Pacific Northwest Research Station.

Shelby, B.; Heberlein, T.A. 1986. Carrying capacity in recreation settings. [CITY]: Oregon State University Press.

Shumway, D.L.; Warren, C.E.; Doudoroff, P. 1964. Influence of oxygen concentration and water movement on the growth of steelhead trout and coho salmon embryos. Transactions of the American Fisheries Society 93:342356.

Southeast Alaska Marketing Council. 1988. Southeast Alaska Pleasure Visitor Research Program. Summer 1988.183pp.

Stensvold, M.C. 1994. A working guide to the sensitive plants of the Alaska Region. Sitka, AK: USDA Forest Service.

U.S. Department of Agriculture [USDA], Forest Service. Undated. The ROS users guide.

U.S. Department of Agriculture [USDA], Forest Service. 1986. ROS book. [CITY]: USDA Forest Service.

U.S. Department of Agriculture [USDA], Forest Service. 1991. Alaska Region trails construction and maintenance guide. RT10-MB-158. Juneau, AK: USDA Forest Service.

U.S. Department of Agriculture [USDA], Forest Service. 1994. Lichens of Southeast Alaska, an inventory. R10-TB-45. Juneau, AK: USDA Forest Service. 143 pp.

U.S. Department of Agriculture [USDA], Forest Service. 1995. Anadromous fish habitat assessment report to Congress. R10-MB-279. Juneau, AK: USDA Forest Service, Pacific Northwest Research Station and Region 10.

U.S. Department of Agriculture [USDA], Forest Service. 1997. Tongass Land Management Plan Revision Final Environmental Impact Statement. January 1997. Doc. No.R10-MB-338b. Juneau, AK: USDA Forest Service. 


\section{References 4}

U.S. Department of Agriculture [USDA], Forest Service. 1997a. Tongass Land Management Plan Revision Record of Decision. May 1997. Doc. No. R10-MB-338a. Juneau, AK: USDA Forest Service.

U.S. Department of Agriculture [USDA], Forest Service. 1997b. Land and Resource Management Plan, Tongass National Forest. Doc. No. R10-MB-338dd. Juneau, AK: USDA Forest Service.

U.S. Department of Agriculture [USDA], Forest Service. 1998. Master Memorandum of Understanding between United States Department of Agriculture Forest Service, Alaska Region and Alaska Department of Fish and Game. Doc. No. 98RMU-10-010. Juneau, AK: USDA Forest Service, Regional Office.

U.S. Department of Agriculture [USDA], Forest Service. 1998a. Unpublished. Draft Tongass National Forest, Chatham Area, Salt Water Shoreline-Based Recreation Carrying Capacity Analysis (Excluding Yakutat Ranger District), Marshal, M. and Humphrey, L. Sitka, AK: USDA Forest Service. $57 \mathrm{pp}$.

U.S. Department of Agriculture [USDA], Forest Service. 2000. Chugach Land Management Plan Revision Draft Environmental Impact Statement. Juneau, AK: USDA Forest Service.

U.S. Department of Agriculture [USDA], Forest Service. 2001. Unpublished. Shoreline-based recreation carrying capacity analysis for the Juneau, Sitka, Hoonah, and Admiralty Island National Monument Ranger Districts, Tongass National Forest, 2001, Dalrymple, R., editor. Unpublished report available at the Tongass National Forest Supervisors Office, Sitka, AK.

U.S. Department of Commerce [DOC], National Marine Fisheries Service [NMFS]. 2001. Northern Southeast Alaska 1997 harbor seal haul-out locations. Withrow, D., Leader, Alaska Harbor Seal Task Force. Excel spreadsheet. Seattle, WA: DOC National Marine Fisheries Service. $7 \mathrm{pp}$.

U.S. Department of Commerce [DOC], National Marine Fisheries Service [NMFS]. Not dated. Alaska marine mammal viewing guidelines-protected resources. Brochure. Juneau, AK: DOC, National Marine Fisheries Service.

U.S. Department of the Interior [USDI], Fish and Wildlife Service. 2001. Subsistence management regulations for the harvest of wildlife on federal public lands in Alaska. Anchorage, AK: USDI, Fish and Wildlife Service, Office of Subsistence Management.

U.S. Department of the Interior [USDI], Fish and Wildlife Service. 1990. Interagency agreement between the USDI Fish and Wildlife Service, Alaska Region, and the USDA Forest Service, Alaska Region. Doc. No. 89-010. [CITY]: USDI, Fish and Wildlife Service.

Van Alen, B. 2000. Status and stewardship of salmon stock in Southeast Alaska. In: Sustainable fisheries management: Pacific salmon, Knudsen, E. E. et al., editors. Boca Raton, Florida: Lewis Publishers. 


\section{References}

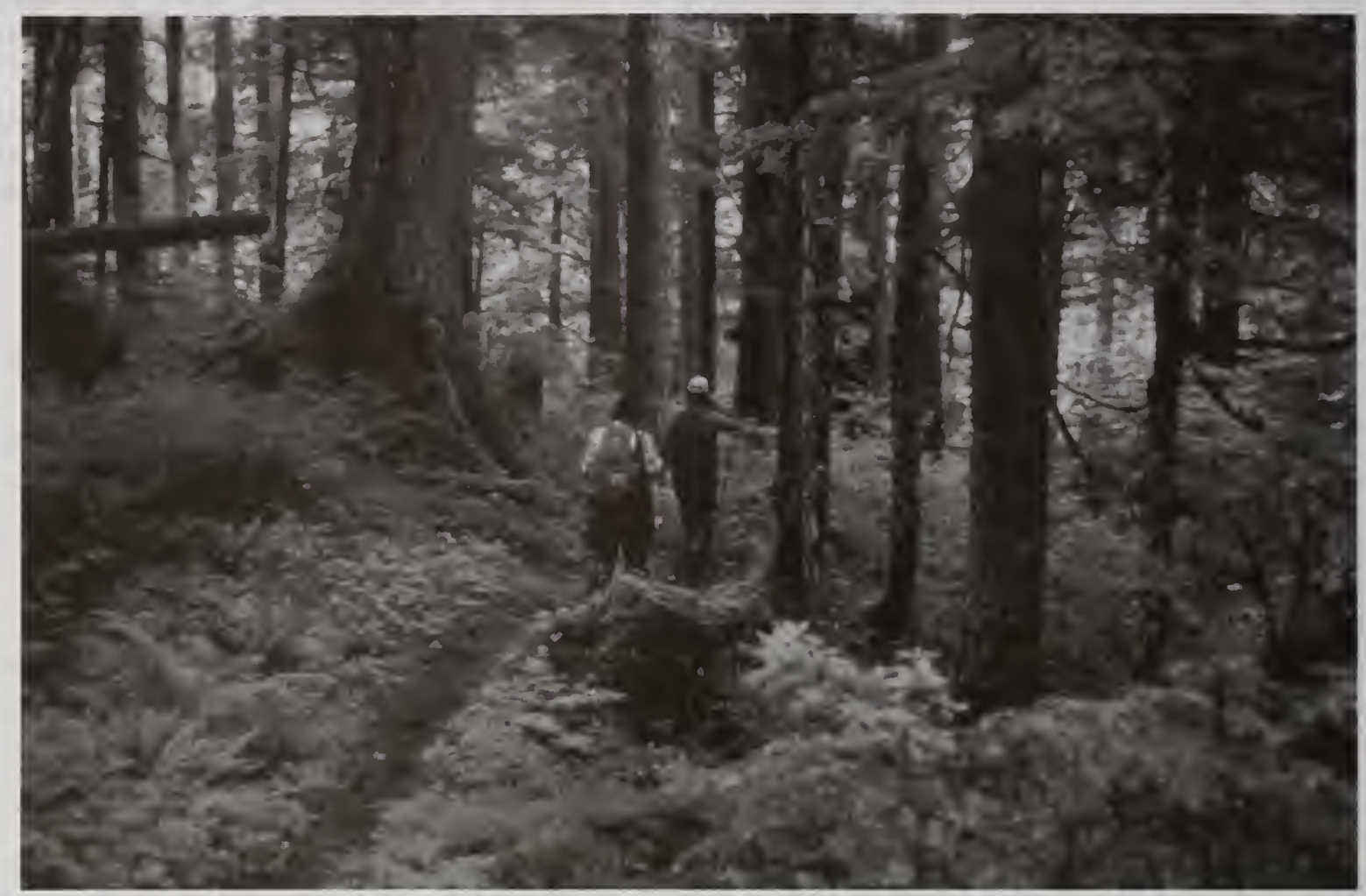




\section{Preparers}

Bob Dalrymple

MaryBeth Nelson

Mary Carr

Geno Cisneros

Ken Coffin

Sara Grove

Karen Iwamoto

Mike Johnson

Cindi Lagoudakis

Mark Laker
Position: IDT Leader

Experience: Forest Service - 27 years

Education: B.S. Forest Management

Position: Assistant IDT Leader

Experience: Forest Service - 19 years

Education: B.S. Recreation Area Management

Position: Writer/Editor

Experience: Forest Service - 10 years

Education: M.S. Biology, B.A. English

Position: $\quad$ Forestry Technician

Experience: Forest Service - 14 years

Education: B.S. Natural Resources Management

Position: Writer/Editor

Experience: Forest Service - 1 year

Other relevant experience - 12 years

Education: $\quad$ M.S. Fish and Wildlife Management, B.S. Biology

Position: Land Management Planner

Experience: Forest Service - 14 years.

Education: M.S. Forest Resources, B.A. Biological Sciences

Position: Sitka Zone Archaeologist

Experience: Forest Service - 21 years

Education: B.A. Anthropology and History

Position: $\quad$ Lands, Minerals and Wilderness Specialist

Experience: Forest Service - 13 years

Education: B.S. Forest Management

Position: Special Uses and Recreation Planning Specialist

Experience: Forest Service - 16 years

Education: B.S. Forest Management

Position: Ecologist/Fisheries Biologist

Experience: Forest Service - 9 years

Education: M.S. Fisheries, B.S. Marine Biology 


\section{Preparers}

\begin{tabular}{|c|c|c|}
\hline Ginny Lutz & $\begin{array}{l}\text { Position: } \\
\text { Experience: } \\
\text { Education: }\end{array}$ & $\begin{array}{l}\text { Computer Specialist } \\
\text { Forest Service - } 13 \text { years } \\
\text { B.A. Biology }\end{array}$ \\
\hline Barry McDonald & $\begin{array}{l}\text { Position: } \\
\text { Experience: } \\
\text { Education: }\end{array}$ & $\begin{array}{l}\text { Special Uses Administrator } \\
\text { Forest Service - } 23 \text { years } \\
\text { Natural Resources Management }\end{array}$ \\
\hline Ken Post & $\begin{array}{l}\text { Position: } \\
\text { Experience: } \\
\text { Education: }\end{array}$ & $\begin{array}{l}\text { Wilderness Program Manager } \\
\text { Forest Service }-24 \text { years } \\
\text { M.S. Wildland Recreations Management } \\
\text { B.S. Natural Resource Management }\end{array}$ \\
\hline Guy Robertson & $\begin{array}{l}\text { Position: } \\
\text { Experience: } \\
\text { Education: }\end{array}$ & $\begin{array}{l}\text { Regional Economist } \\
\text { Forest Service }-8 \text { years } \\
\text { Ph.D. Forest Economics, M.A. International Studies, } \\
\text { B.A. Philosophy }\end{array}$ \\
\hline Julie Schaefers & $\begin{array}{l}\text { Position: } \\
\text { Experience: } \\
\text { Education: }\end{array}$ & $\begin{array}{l}\text { Region } 2 \text { Social Scientist } \\
\text { Forest Service - } 12 \text { years } \\
\text { M.S. Natural Resource Economics, B.S. Forest } \\
\text { Recreation Resources }\end{array}$ \\
\hline Michael Shephard & $\begin{array}{l}\text { Position: } \\
\text { Experience: } \\
\text { Education: }\end{array}$ & $\begin{array}{l}\text { Ecologist } \\
\text { Forest Service - } 6 \text { years } \\
\text { M.S. Botany, B.A. Geology/History }\end{array}$ \\
\hline Linn Shipley & $\begin{array}{l}\text { Position: } \\
\text { Experience: } \\
\text { Education: }\end{array}$ & $\begin{array}{l}\text { Wildlife Program Manager } \\
\text { Forest Service - } 24 \text { years } \\
\text { National Marine Fisheries Service - } 2 \text { years } \\
\text { B.A. Biology and English Literature }\end{array}$ \\
\hline
\end{tabular}




\section{List of Draft EIS Recipients}

The following is a list of agencies, organizations, and persons to whom the Shoreline Outfitter/Guide Draft Environmental Impact Statement was sent.

Agencies
Advisory Council on Historic Preservation

Alaska Board of Game, Unit 4 Brown Bear Management Team

Alaska Department of Environmental Conservation

Alaska Department of Fish and Game, Wildlife Division

Alaska Department of Fish and Game, Division of Habitat \& Restoration

Alaska Department of Fish and Game, Division of Sportfish

Alaska Department of Fish and Game, Division of Subsistence

Alaska Department of Fish and Game, Division of Wildlife Conservation

Alaska Department of Fish and Game, Division of Wildlife Protection

Alaska Department of Natural Resources

Alaska Division of Governmental Coordination

Alaska State Historical Preservation Office

Alaska State Office of Housing \& Urban Development

Bureau of Land Management, Alaska State Office

Federal Aviation Administration, Alaska Region Headquarters

Federal Highway Administration, Western Region

Federal Railroad Administration

Housing and Urban Development, Environmental Review Division

Interstate Commerce Commission

National Marine Fisheries Service, Habitat Conservation

National Marine Fisheries Service, Protected Resources Mgt. Division

National Park Service, Alaska Region

U.S. Air Force, Deputy Assistant Secretary

U.S. Army Corps of Engineers, Northwest Division

U.S. Coast Guard

U.S. Department of Agriculture, APHIS

U.S. Department of Agriculture, Forest Service

U.S. Department of Agriculture, Forest Service, PNW Research

U.S. Department of Agriculture, National Agricultural Library

U.S. Department of Agriculture, Natural Resources Conservation Service

U.S. Department of Agriculture, Office of Civil Rights

U.S. Department of Agriculture, OPA Publications Stockroom

U.S. Department of Defense

U.S. Department of Energy, Office of Environmental Compliance

U.S. Department of Interior, Office of Environmental Policy \& Compliance

U.S. Department of Transportation

U.S. Environmental Protection Agency, Region X

U.S. Environmental Protection Agency, Office of Federal Activities

U.S. Fish and Wildlife Service 


\section{Recipients}

U.S. Naval Observatory

U.S. Navy, Chief of Naval Operations

Libraries

Alaska State Library, Government Publications

Craig Public Library

Douglas Public Library

Elfin Cove Public Library

Haines Public Library

Hyder Public Library

Kake Community Library

Kasaan Community Library

Ketchikan Public Library

Kettleson Memorial Library

Mendenhall Valley Public Library

Pelican Public Library

Petersburg Public Library

Skagway Public Library

Tenakee Springs Public Library

Thorne Bay Community Library

Wrangell Public Library

Media

Juneau Empire

Raven Radio

KFSK

KTOO

Organizations and Businesses
Adams Alaska Safari

Admiralty Island Bear Association

Admiralty Island Sightseeing

Admiralty Tours

Admiralty Wilderness Adventures

Adventure Sports, Inc.

Alaska Angling

Alaska Charter Service

Alaska Coastal Adventure Charters

Alaska Coastal Outfitters

Alaska Cross Country Guiding

Alaska Discovery, Inc.

Alaska Fish Tales

Alaska Fly'N'Fish Charters

Alaska Guide Service

Alaska Native Brotherhood, Hoonah

Alaska Native Tours

Alaska on the Home Shore

Alaska Outdoor Adventures

Alaska Outdoor Recreation Services
Alaska Travel Adventures

Alaska Travel Industry Association

Alaska Tugboat Charters

Alaska Tugboat Tours

Alaska Up Close

Alaska Visitors Association

Alaska Vistas

Alaska Water Charters

Alaska Waters, Inc.

Alaska Yacht Charters

Alaskan Outback Adventures

All Aboard Yacht Charters

Alpine Guide Service

Anahootz Alaskan Adventure

Anahootz Guiding Co.

Angling Unlimited

Angoon T\&H Community Council Aqua Sports Enterprises Archipelago Kayaking Adventures Arrowhead Transfer Inc. 


\section{Recipients 4}

Alaska Paddle Sports

Alaska Passages

Alaska Peak and Seas

Alaska Pacific University

Alaska Professional Hunters Assoc.

Alaska Research Voyages

Alaska Seair Adventures

Alaska Sightseeing

Bluewater Adventures

Brabazon Expedition

Breakaway Adventures

Bud's Guiding Service

C.A.R.E.

Cascadia Wildlands Project

Charter Company

Chatham Cannery Ltd.

Chichagof Charters

Citizens Advisory Committee on

Federal Areas

Cloudberry Adventures LTD

Coastal Helicopters, Inc.

Coastal Island Charters

Coastal Wilderness Charters

Cove Lodge

Crew International Tours

Cross Sound Lodge

Cruise West

Cycle Alaska

Dave Duncan \& Sons Inc.

Defenders and Friends of Admiralty

Island and Tongass Wildlands

Watch

Deishu Expeditions

Destination Wilderness

Discovery Foundation

Discovery Shipping, Inc.

Dolphin Charters

Dolphin Jet Boat Tours

Duen Sailing Adventures

Eagle's Nest Charters

Earthjustice Legal Defense Fund

Echo Ranch Bible Camp

Economic Development Committee,

Wrangell

Elfin Cove Lodge
Aukquan Traditional Council

Auk Ta Shaa Discovery

AWRTA

Boat Company

Baranof Expeditions

Baranof Wilderness Lodge and

Beyond Boundaries Expeditions

Bay View

Bear Creek Outfitters

Glacier Bay Adventures

Glacier Bay Country Inn

Glacier Bay Park Concessions

Glacier Bay Tours

Glacier Bay Tours/LO

Glacier Bear Lodge

Glacier Guides, Inc.

Goldbelt Corp.

Goldbelt Tours

Great Chase Charters

Greatland Guides

H.I.C. Tours

Haines T\&H Community Council

Harbor Mountain Tours

Harlequin Lodge

Hawkeye Stages \& Tours

Hook \& Eye Charters

Hoonah T\&H Community Council

Hoonah Traditional Tribal Council of Elders

Howard Charters

Huna Totem Corporation

Icy Strait Adventures

Inner Harbor Lodge

Inside Passage Charters, Inc.

Inside Passages

Island Waterways

J.\&L. Gifts \& Antiques

Janaggen Touring \& Guiding

Juneau T\&H Community Council

Jungles, Deserts \& Mountains

Kake Tribal Corporation

Kay C Charters

Killisnoo Wood and Lumber

Kings Run Charters

Klukwan Incorporated

Klukwan T\&H Community Council 
Elfin Cove Non-Profit Corp.

Ellis Inc.

Equinox Wilderness Expeditions

ERA Helicopters, Inc.

Experience Alaska's Southeast

Eyak Adventures

Fish Doctors LLC

Fish Like Me Lodge and Charters

Fishing Bear Charters

Flywater Adventures

Forbes Marine Service

Forest Conservation Council

Fossman Guiding \& Outfitting

Friends of Admiralty Island

Friends of Berners Bay

Gastineau Guides, Inc.

Leonard's Landing Lodge

Lindblad Special Expeditions

Lisianski Inlet Lodge/Charters

Lisianski Inlet Resource Council

Longacre Expeditions

Lynn Canal Conservation, Inc.

Maple Leaf Charters

McIntosh Foundation

Midnight Sun Charters

Nahanni River Adventures, Ltd.

National Outdoor Leadership School

Nat'l Audubon Society

Nine Lives Charters

Norris Charters

North Alaska Expeditions

North Gulf Charters

Northern Outdoor Adventures

Northern Star Charters

Northstar Trekking

Northwestern University

Norton Outfitters

Nunatak Kennels, Inc.

Otter Cove Bed and Breakfast

Out of Bounds, Inc.

Pacific Catalyst

Packer Expeditions

Palco Charters

Parker Guide Service

Pelican Paddling

Peterson's Guide and Charter
Kootznoowoo Corporation

L\&M Charters

Landmark Tree Project

Last Frontier Tours

Laughing Raven Charters

Seahook Charters

Sealaska Corporation

Sealaska Cruises Inc.

Sealaska Heritage Foundation

SEAWEAD

Seawind Cruises

SeaWolf Adventures

See Alaska Tour \& Charters

Seminars Afloat

Shearwater Charters

Shee Atika Inc.

Sheinberg Associates

Shelter Cove Publishing

Sitka Conservation Society

Sitka Sportsman

Sound Sailing

South Passage Outfitters

Southeast AK Conservation Council

Southeast Alaska Flyfishing

Southeast Alaska Guides

Association

Southeast Alaska Guiding

Southeast Alaska Tourism Council

Southeast Conference

Southeast Guide Service

SouthEast Hunts

Spirit Walker Expeditions

Stickeen Wilderness Adventures

Stikine Jet Boat Association

Stikine River Song

Stories \& Legends

Taku Conservation Society

Tanaku Lodge

Temsco Helicopters, Inc.

Tenacious Charters

Tenakee Hot Springs Lodge

Tenakee Springs Indian Community

Territorial Sportsman

Thayer Lake Lodge

Timber Wolf Charters

Tok River Outfitters 
Pettijohn \& Sons

Port Conclusion

PTS Tours

Pybus Point Lodge

Quyana Marine

Rain Country Transport

Rain Walker Expeditions

Raven Charters

Raven's Fire, Inc.

Raven's Way/S.E.A.R.H.C.

Real Alaska Adventures, Ltd.

Rocky Pass Resort

Ron's Alaska Charters

Ryman's Italio Sport Camp

SE AK Ocean Adventures

SE Alaska Conservation Council

SE Alaska Cruises, Inc

Sea Mist Charters

Sierra Club, Alaska Chapter

Silver Wind Charters

Sitka Tribal Tours

Skaflestad Guiding

Skaqua Traditional Council

Snoozin Moose Guide Service
Tongass Kayak Adventures

Tongass Outdoor Adventure Center

Tourism Advisory Committee

Tourism Working Group

TRI Bed \& Breakfast of Glacier Bay

Tyme Air, Inc.

Whaler's Cove Lodge

Wild and Scenic Rivers Program

Wild Rockies Field Institute

Wilderness Enterprises

Wilderness Swift Charters

Wilderness Ventures

Wind Over Mountain

Windham Bay Lodge

Wolf Track Expeditions

Women's Flyfishing

Wrangell Chamber of Commerce

Wrangell Cooperative Association

Wright Tours

Yakutat Bay \& River Charters

Young's Fishing Service

Yukon Jack's Glacier Tours

\section{Public Officials, Angoon Community Association}

Cities, and

Federally

Recognized Tribes
Angoon Fish and Game Advisory Committee

Central Council of Tlingit and Haida Indian Tribes of Alaska

Chilkat Indian Village

Chilkoot Indian Association

City and Borough of Sitka

City of Angoon

City of Hoonah

City of Kake

City of Pelican

City of Wrangell

Douglas Indian Association

Elfin Cove Fish and Game Advisory Committee

Gustavus Community Assoc.

Hoonah Indian Association

Icy Strait Fish and Game Advisory Committee

Juneau/Douglas Fish and Game Advisory Committee

Kake Fish and Game Advisory Committee

Organized Village of Kake

Pelican T\&H Community Council 


\section{Recipients}

Petersburg Indian Association

Port Alexander Fish and Game Advisory Committee

Sitka Fish and Game Advisory Committee

Sitka Tribe of Alaska

Skagway Village

Tenakee Springs Fish and Game Advisory Committee

Tlingit-Haida Central Council

United States Representative, Don Young

United States Senator, Frank Murkowski

United States Senator, Ted Stevens

Individuals

\author{
Sandi Anderson \\ Peter Andruss \\ Bruce Baker \\ Jerry Barber \\ Kent Barkhau \\ Chris Beck \\ Lavern Beier \\ David Benitz \\ Joel Bennett \\ Nancy Berland \\ Brian Bits \\ Jack Blackwell \\ Nathan Borson \\ Judy Brakel \\ William Brent \\ Susan Brook \\ Ralph Burnett \\ Peter Butz \\ Norm Carson \\ Jason Carter \\ Charles L. Chandler \\ Darrell Chandler \\ Judith Chandler-Hood \\ Larry Chuderewicz \\ Bob and Lucas Clark \\ Lawrence Cobb \\ Greg Cook \\ Mary Coulter \\ Eric Decker \\ Mary Demmert \\ Ron Dick \\ Ronald M. Dippold \\ Janet Doherty \\ Larry Dunn \\ Larry Edwards
}

Linda Fabrello Johanna Fagen

Jim Faro

Bob Fraker

Clay Frick

Anissa Frick

Richard W. George

Debra Rose Gifford

Randy Gluth

Rich Gordon

Kezia Graham

Gary Gray

Dennis Hams

Dave Hanna

Dave Hardy

Dennis Harms

Tuck Harry

Karla Hart

Shannon Haugland

Mary Hervin

John Hill, Sr.

Royal T. Hill

Bob Hinman

R. Hoagland

Guy Hoppen

Chris Howard

Neil Huddleston

Walter Jack

Hank Jack

Frank \& Pauline Jim

Floyd \& Jennie Jim

Moses Johnson

Jean and Marty Remund

Frank Rogers

Helen Clough/ Rollin Young 
Ward Eldridge

Bob Ellis

Karen Johnson

Loyal Johnson

Moses Johnson

Paul Johnson

Eric W. Jordan

Jim Keeling

Gretchen Keiser

Kerry Kirkpatrick

Betsy Knutson

Nikki Koehler

Nellie Kookesh

Floyd M. Kookesh

Harvey and Ann Kortman

Joe Kulanik

Aurah Landau

John Latham

John and Linda Lawson

Stephen Lee

Bud Lehnhausen

Hank Lentfer

Bob Lesher

Hank Leutfer

Steve Lewis

John Littlefield

Cindy Longstretch

Jodi Lozori

Eli Lucas

Richard Lundahl

Debbie Manion

Ken Marchbanks

Joanna Markell

Wade P. Martin

Mim McConnell

Kenny Meserve

Ben Mitchell

Dan Muller

The Mulligan Family

John Murray

Michael Murray

Luke Nelson

Melanie Nelson

Richard Nelson

Scott Newman

Jack Ozment
William H. Paddock

Arlen Pearsall

Beth Pendleton

John Peterson

Patty Phillips

Marvin Proctor

Rick Purves

Marty Raymond

Kenneth Rear

Mark Rorick

Jimmie C. Rosenbruch

S. Rutter

Dan Sailor

Julie Schaefer

Lynn Schooler

Kenneth E. Schoonover

Sue Schrader

Susan Schrader

Mark Schwan

Florian Sever

Greg Seymour

Gene Shanks

Elizabeth Shaw

Jeff Sloss

T. Smith

Ron Smith

Deb Spencer

Brent Stedman

Karen Stepaneako

David Steward

Gary Timothy

Floyd Tomkins

Mike Vanning

Pat Veesart

Victor Voit

Michael Ward

Ted Whited

Dan Williams

Tabby Williams

R. Wilson

Rita Wilson

Diane Wirth

Vicki Wisenbaugh

Peter Wright

Jacob Yearty

Gayle Young 


\section{Recipients}

J. Young

S. Youngberg

Deborah Younger

Lance Youngquist

John Zabielski 


\section{Index}

\section{A}

Access

$2-3,2-37,2-43,3-14,3-29,3-5$

3-71, 3-138, 3-142, 3-148

Admiralty Island

$1-1,1-2,1-3,1-5,1-6,1-9$,

3-7, 3-61, 3-66, 3-69, 3- 70,

3-71, 3-79, 3-81, 3-93, 3-101,

$3-104,3-141,3-145$

Air Quality $3-149,3-153$

Alaska Board of Fish

$1-3,1-5,1-20,3-117,3-134$

Alaska Board of Game

$1-3,1-5,1-14,1-20,2-4,2-46$,

$3-2,3-104,3-105,3-113,3-134$

Alaska Dept. of Commerce and Economic Development

$1-18,1-20,1-26$

Alaska Department of Fish and Game

$1-18,1-20,1-26,3-2,3-5,3-13$

$3-87,3-104,3-105$ to $3-109$,

3-113, 3-114, 3-115, 3-117,

$3-125,3-134$ to 137

Alaska Department of Labor

3-24

Alaska Department of Natural Resources

$1-10,1-17,1-18,1-19,1-26$

Alaska Marine Highway

$3-60,3-61,3-71$

Alaska National Interest Lands Conservation Act

$1-6,1-12,1-27,1-29,3-69$,

(ANILCA)

3-73, 3-133, 3-134, 3-137, 3-138,

3-139, 3-152, 3-155

Alaska State Historic Preservation Officer

$1-20,2-5,3-143,3-147,3-151$,

Alternative Components

$2-2$

Alternative Development

$2-1$

Analysis Area

$1-5,3-10,3-63,3-69,3-70,3-82$

$3-85,3-88,3-92,3-120,3-125$

$3-130,3-145$

Angoon

$1-6,1-10,1-14,1-17,1-18,3-10$,

Army Corps of Engineers (ACOE)

3- $61,3-62,3-63$

Availability of Draft EIS

$1-20$

$1-29$

\section{B}

Bald and Golden Eagle Protection Act. $1-28$

Best Management Practices (BMP) 2-4, 3-33, 3-95, 3-96, 3-99, 3-101, 3-151, 3-121, 3-123, $3-124,3-126,3-138,3-142$, 3-153, 3-155

Biological diversity $1-26$

Brown bear $1-2,1-14,1-17,2-4,2-6,2-4$, 3-11, 3- 17, 3- 66, 3-70, 3-74, 3-79, 3-86, 3-87, 3-92, 3-103, $3-104,3-105,3-112$ to $3-115$, 3-134, 3-136, 3-138, 3-142 


\section{Index}

C

Carrying capacity

$1-13,3-7$

Clean Air Act

$1-28,3-149,3-153$

Clean Water Act

$1-29,3-115,3-152,3-153$

Coastal Zone Management Act (CZMA).

$1-19,1-29,3-153$

Commercial allocations

2-39, 2- 40, 2- 41, 3-39

Commercial recreation

$1-2$ to $1-4,1-9,1-11,1-18,1-19$, $1-21,1-23$ to $1-25,3-4,3-5,3-9$,

$3-18$ to $3-20,3-25,3-26,3-34$,

3-35, 3-54, 3-55, 3-59, 3- 62,

3- 64 to 3-69, 3-109, 3-111,

3-118, 3-120, 3-123, 3-126,

3-131, 3-134 3-138, 3-146,

3-148, 3-153

Competition

$1-23,1-27$

Council on Environmental Quality (CEQ).

$1-1,1-13,2-5$

Cruise ships

$3-10,3-11,3-18,3-24,3-60$,

$3-61,3-72,3-73,3-112,3-149$,

$3-150$

Cultural resources

1-29, 3-71, 3-144, 3-146, 3-147

Cumulative effects 2-1, 2- 3, 2- 4, 2- 5, 2- 36, 2-39, $2-40,2-42,2-43,2-46,2-47$, $3-1,3-3,3-58,3-69,3-80,3-81$ 3-89, 3- 94, 3-96, 3- 99, 3-102, 3-115, 3-124, 3-126, 3-139, 3-140, 3-141, 3-142, 3-148, 3-154

D

Desired condition $1-12$

Desired future condition

$1-12,2-2,3-6$

Dispersal $3-67,3-75,3-77,3-78,3-149$

Displacement $1-2,1-21,3-67,3-74,3-75,3-77$, 3-78, 3-95, 3-99,3-110, 3-146

Diversity $1-4,1-11,1-23,1-24$

E

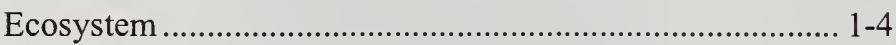

Employment .............................................................. 1-2, 1-12, 1-27

Enclaves

$2-2,2-3,2-10,2-19,2-27,2-36$, $2-37,2-42,2-45,3-27,3-30$,

$3-31,3-32,3-53,3-57,3-69$,

3-101, 3-111, 3-124, 3-128,

$3-130$

Endangered species

$1-20,1-26,2-5,3-126,3-130$,

3-151

Environmental Protection Agency (EPA).

$1-1,1-20,1-25,1-28,3-3,3-153$ 
Federal Cave Resource Protection Act. 3-152

Federal Subsistence Board

1-3, 1-5, 1-14, 1-26, 2-4, 3-105,

3-114, 3-115, 3-117, 3-125,

$3-134,3-136$ to $3-139$

Findings.

$1-5,3-142,3-152$

Fish habitat $1-26,2-4,3-73$

Fishing $1-2,1-3,1-22,1-25,1-27,2-4$, 2-8, 2-19, 2- 27, 3-3, 3-9, 3-10, $3-11,3-14,3-16,3-17,3-18$, 3-20, 3-23, 3-24, 3-25, 3- 34, 3-58, 3-60, 3-61, 3-63, 3-65, 3- $66,3-70$ to $3-73,3-85,3-86$, $3-112,3-116$ to $3-121,3-125$, 3-127, 3-130, 3-131, 3-134, 3-138, 3-142, 3-143, 3-155

Forest Plan .1-1 to $1-4,1-6,1-11$ to $1-13$, $1-17,1-19,1-25,2-1$ to $2-6$, 2- 8, 2-10, 2-36 to $2-39,2-42$, 2-45, 2-46, 2-47, 3-1 to 3-9, 3-15 $3-16$ to $3-19,3-25$ to $3-30$, 3-33, 3-53, 3-54,3-55, 3-58, 3-59, 3-69, 3-71, 3-76, 3-77, 3-78, 3-81, 3-82, 3-84, 3- 85, 3-87 to 3-92, 3-96, 3-98, 3-100, 3-101, 3-104, 3-111 to 3-116, 3-130, 3-131, 3-133, 3-134, $3-135,3-138$ to $3-143,3-151$, 3-152, 3-153, 3-155, 3-156

\section{G}

Game Management Unit (GMU). 1-2, 3-2, 3-104 to 3-109

Geology $3-71,3-85,3-87,3-118$

Gilkey River............... $3-85,3-86,3-90,3-122$

Glacial River $3-85,3-87,3-90$

Glacier Bay National Park. $3-58,3-60,3-73,3-81$

Group size $1-24,1-25,2-2,2-36,2-37,2-38$

$2-40,2-42,2-43,2-44,2-45$ 3-2, 3-14, 3-15, 3-17, 3-21, $3-26,3-27,3-29,3-30,3-33,3-53$, $3-56,3-57,3-65,3-83,3-88$, $3-89,3-111$

Groups-at-one-time 3-8, 3-9

Guide Use Area $3-2,3-113,3-133,3-134$

Gustavus $1-17,3-10,3-60,3-73,3-80,3-81$ 


\section{Index}

H

Haines

$1-6,1-10,1-17,2-7,2-9,2-11$,

2- 20, 2-28, 3-10, 3-22, 3-61,

$3-62,3-63,3-85,3-100,3-135$, 3-145

Helicopter $1-24,2-43,2-47$

Heritage resource

$1-26,3-4,3-142$ to $3-148,3-151$

Hoonah $1-1,1-2,1-3,1-5,1-6,1-9$, $1-10,1-14,1-17,1-18,1-30$, 2-2, 2- 6, 2-7, 2- 9, 2- 11, 2-20, $2-28,3-7,3-10,3-19,3-22$, 3- 81, 3-82, 3-86, 3-101, 3-110, 3-119, 3-143, 3-145, 3-152

$J$

Juneau

1-1,1-6, 1-9, 1-10, 1-14, 1- 17 $1-29,1-30,2-2,2-6,2-7$, 2-9, 2-11, 2- 20, 2-28, 3-7, $3-9,3-10,3-19,3-22,3-24$, $3-60$ to $3-65,3-69,3-71,3-72$, 3-81, 3-82, 3-85, 3-86, 3-100, 3-119, 3-135, 3-145, 3-149

K

Kadashan River 3-85, 3- 87, 3-90, 3-110

Karst $1-26$

Katzehin River $3-85,3-89,3-90,3-122$

King Salmon River 3-79, 3-85, 3-86, 3-90, 3-127, 3-128, 3-131

L

Land Use Designation (LUD)...... 1-2, 1-12, 1-13, 2-2, 2-3, 2-36, $3-2,3-6,3-7,3-8,3-15,3-26$, 3- 29

Large groups/Large Group Areas 2-2, 2- 3, 2-12, 2-13, 2- 21, 2-29 2-30, 2- 37, 2- 39, 2-40, 2-42, $2-44,2-45,2-47$

Large groups/Large Group Areas $1-23,3-24,3-26,3-29,3-30$, $3-32,3-35,3-53,3-56,3-57,3-66$, 3-69

LUD II 3-26 
M

Management Indicator Species (MIS)

3-103, 3-104, 3- 114, 3-116

Marine Mammal Protection Act. $1-28$

Mitigation measures

$1-4,1-5,1-19,1-21,2-2,2-3,2-4$

2- 8, 2-10, 2-19, 2- 27, 2-38,

2-43, 2-45, 2- 46, 3-3, 3-30,

3-34, 3-56, 3-57, 3-94, 3-95, 3-99

$3-101,3-111,3-113$ to $3-115$,

$3-121,3-124,3-126,3-130$ to 132

3-138, 3-139, 3-142, 3-146, 3-148,

3-149

Monitoring.

2-5, 2-46, 3-2, 3-3, 4, 3-17,

3-18, 3-193-70, 3-71, 3-76,

3-77, 3-78, 3-96, 3-115, 3-117,

3-123, 3-126, 3-131, 3-143, 3-144,

$3-146$ to $3-148,3-152,3-153$

$N$

National Environmental Policy Act (NEPA).

$1-1,1-14,1-25,1-26,1-28$

3-1, 3-3, 3- 4

National Forest Management Act (NFMA)

$1-11,1-29,3-3,3-116,3-151$

National Historic Preservation Act (NHPA) 1-18, 1-28, 3-133, 3-143, 3-151,

3-155, 3-156

National Register of Historic Places (NRHP) 3-143, 3-147, 3-148

Native American Graves Protection and Repatriation Act of 1990 $1-29$

Northern Southeast Area Plan (NSEAP) $1-10,1-17,1-19,3-58$

Notice of Intent (NOI) $1-13,1-14,1-17$

o

Outfitters and guides $1-2,1-4,1-9,1-19,1-22,1-27$ $2-5,3-15,3-29,3-68$

$\boldsymbol{P}$

Pelican $1-10,1-14,1-17,3-10,3-61$ $3-80,3-81,3-86,3-135$

Planning record $1-1,3-1,3-84,3-151$

Preferred alternative $1-9,2-35,3-83$

Proposed action $1-1,1-3,1-13,1-14,1-17,1-21$, $1-23,1-252-1,2-2,2-5,2-8$, 2-35, 2-47, 3-1, 3-91, 3-96, 3-104

Public involvement $3-126,3-130,3-154$

Purpose and need. $1-13$

$1-1,2-2,2-5,2-47$ 


\section{Index}

$\boldsymbol{R}$

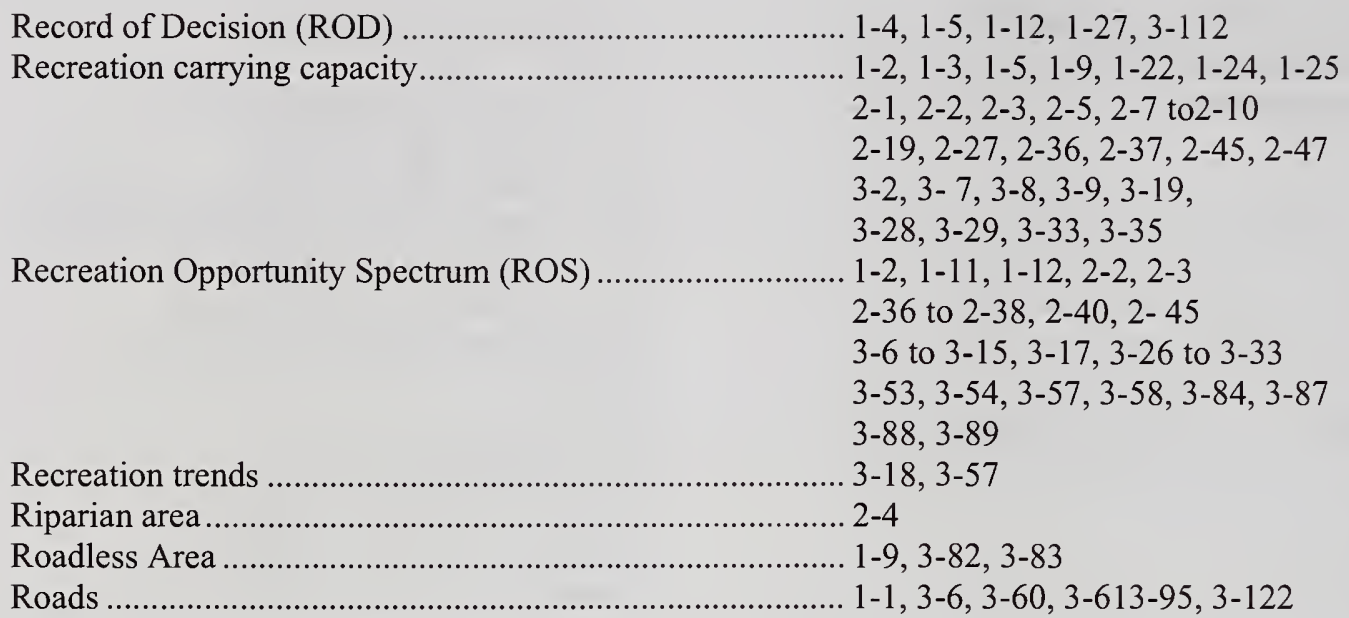

$S$

Schedule of proposed actions (SOPA) .................................. 1-9

Scoping

$1-2,1-13,1-14,1-17,1-21,1-25$

$1-26,2-2,2-3,3-1,3-5,3-8$,

$3-18,3-19,3-91$

Seasons

$1-3,1-24,2-2$ to $2-4,2-8$,

$2-10,2-19,2-27,2-38,2-39$

$2-41,2-43,2-44,2-45$

$3-2,3-8,3-9,3-11,3-14,3-28$

$3-29,3-33$ to $3-40,3-54,3-55$,

$3-56,3-67,3-99,3-103,3-104$,

$3-111,3-113$

Sensitive species

2-5, 3-92, 3-99, 3-126, 3-127

Shoreline zone.

$1-3$ to $1-6,1-27,2-1,2-47$

3-7, 3-8, 3-14, 3-24, 3- 26, 3-53,

3- 58, 3-64, 3-70, 3-73, 3-84,

3- 88, 3-91, 3-92, 3-95, 3-99,

$3-102,3-104,3-109$ to $3-111$,

3-128, 3-129, 3-138, 3-144, 3-146

Sitka

$1-1,1-6,1-9,1-10,1-14$,

$1-17,1-18,1-30,2-2,2-6$,

$2-7,2-9,2-11,2-20,2-28$,

3-1, 3-7, 3-10, 3-16, 3-22,

3-58, 3-60 to 3-63, 3-71, 3-81

3-82, 3-86, 3-87, 3-92, 3-100,

3-103, 3-110, 3-119,

$3-134$ to $3-143,3-145,3-149$

3-152

Soil.

2-4, 3-74, 3-91, 3-93, 3- 94, 3-95

3-96, 3-98, 3-99, 3-100, 3-101,

$3-102,3-115,3-123,3-126,3-153$

South Baranof Wilderness 3-71

Special Uses

$1-3,1-4,1-5,1-11,2-1,2-4$

$2-5,2-35,2-47,3-36,3-86$ 


\section{Index 4}

Standards and guidelines

$1-12,1-13,1-19,1-25,2-3,2-4$ $2-5,2-36,2-38,2-42,3-2,3-3$

$3-6,3-7,3-8,3-25,3-34,3-69$, $3-76$ to $3-78,3-87,3-89,3-91$, 3-96, 3-98, 3-99, 3-101, 3-104, $3-109,3-112$ to $3-115,3-126$,

3-130, 3-131, 3-138, 3-139, 3-151

$3-152,3-153,3-155,3-156$

State Historic Preservation Officer (SHPO) .1-20, 2-5, 3-147, 3-152

Subsistence 1-3, 1-5, 1-12, 1-14, 1-18, 1-20, 1-22, 1-26, 2-4, 3-2, 3-11, 3-60, 3-61, 3-64, 3-72, 3-73, 3-87, $3-102$ to $3-105,3-114$ to $3-118$, $3-127,3-130,3-133$ to $3-142$, $3-152$

\section{$T$}

Tenakee Springs 3-10, 3-61, 3-87, 3-119, 3-135 $3-141$

Tongass Land and Resource Management Plan (TLRMP) .. 1-1, 1-9, 1-12, 1-29 (see Forest Plan) 3-82, 3-151, 3-153

Tourism $1-2,1-4,1-11,1-12,1-14$, $1-18,1-20,1-22,1-23,2-2$, 2-41, 2- 47,3-5, 3-6, 3-10, 3-14, 3-16, 3-24, 3- 25, 3- 38, 3-40, $3-59,3-60,3-61,3-62,3-63$, 3-64, 3-69 3-80, 3-81, 3-83, 3-84, 3-112, 3-143, 3-149

Trails $1-1,1-3,1-9,1-11,1-28$ 3-6, 3- 8, 3-70, 3-71, 3-72, 3-74, 3-75, 3-93, 3-95, 3-101, 3-122, 3-123

Transportation .2-3, 3-60, 3- 61, 3-71, 3-72, 3-85, 3-133, 3-149

Tribal government 1-17, 1-18, 1- 29, 3-143

\section{$U$}

U.S. Fish and Wildlife Service (USFWS) 1-18, 1- 20, 2-4, 3-109, $3-126$ to $3-128,3-130,3-151$

Unguided recreationists $1-4,1-13,1-21,1-22$ $2-36$ to $2-39,3-5,3-19,3-25,3-28$, 3-30, 3-32, 3-33, 3-34, 3-35

$3-79,3-111$ 
V

Value Comparison Unit (VCU) 3-2, 3-135

Vegetation $1-26,3-74,3-75,3-91,3-93,3-94$ 3-96, 3-98, 3-99, 3-100, 3-101, 3-102, 3-103, 3-110, 3-118, $3-120,3-121,3-123$

W

Water quality 1-26, 2-4, 3-96, 3-97, 3-99, 3-115, $3-121,3-123,3-124,3-126$, 3-153, 3-156

Wetlands $1-20,1-26,1-29,3-4,3-95,3-96$ $3-97,3-98,3-99,3-155$

Wild and Scenic Rivers. $1-28,2-39,3-1,3-5$, $2-39,3-84,3-85,3-87,3-88$, $3-89,3-90$

Wilderness $1-1,1-9,1-11,1-12,1-14$, $1-28,1-29,2-1,2-36,2-39,2-42$, $2-47,3-1,3-5,3-6,3-9,3-10$, $3-14,3-15,3-18,3-19,3-26$, $3-30,3-69$ to $3-83,3-90,3-93$,

Wildlife Analysis Area (WAA) 3- 112 3-2 


\section{Appendices}

A- Use Area Cards.

B- Large Group Area Cards.

C-Monitoring

D-Mitigation Measures

E-Management Direction

F- Recreation Management Concepts 


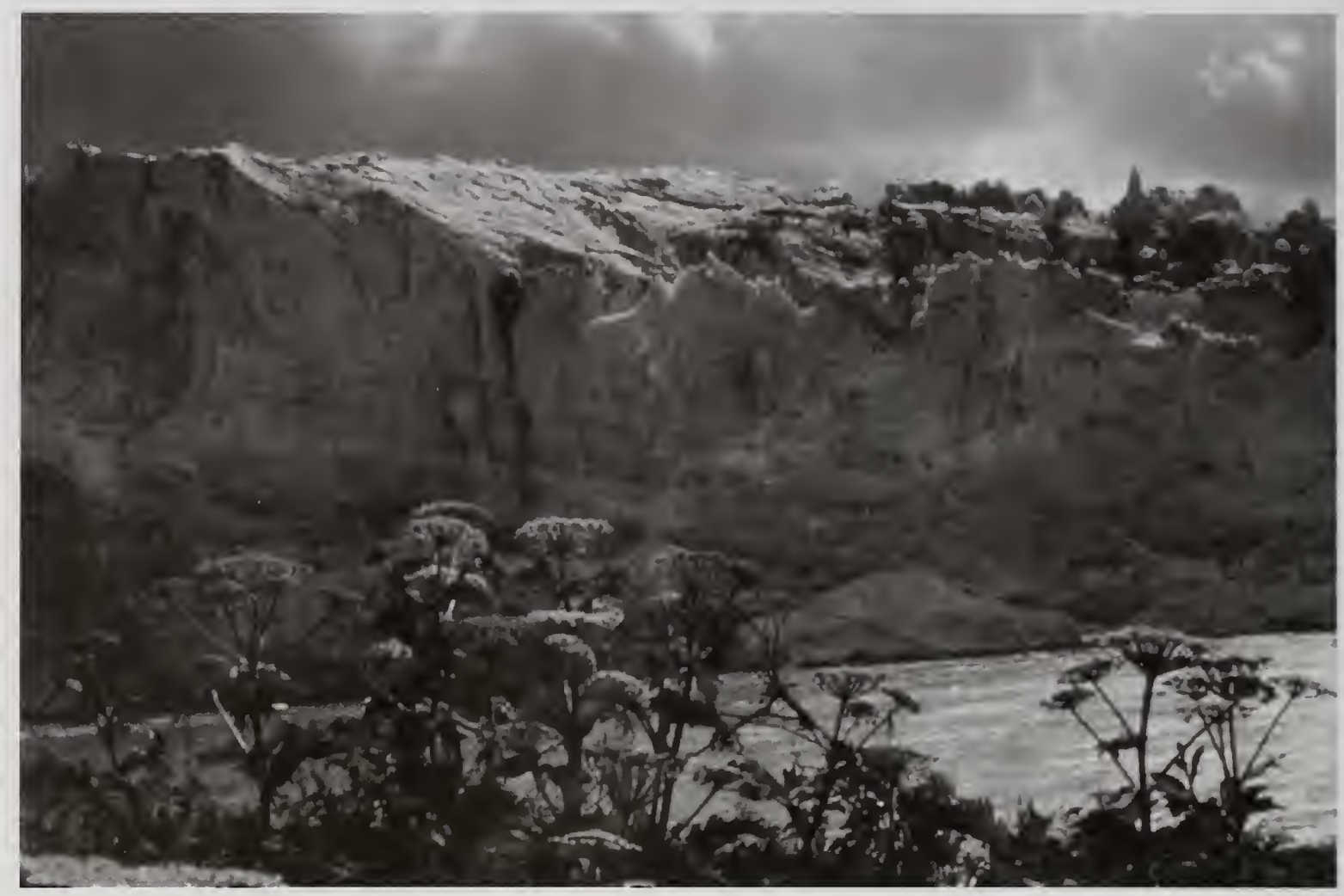




\section{Appendix A Use Area Cards}




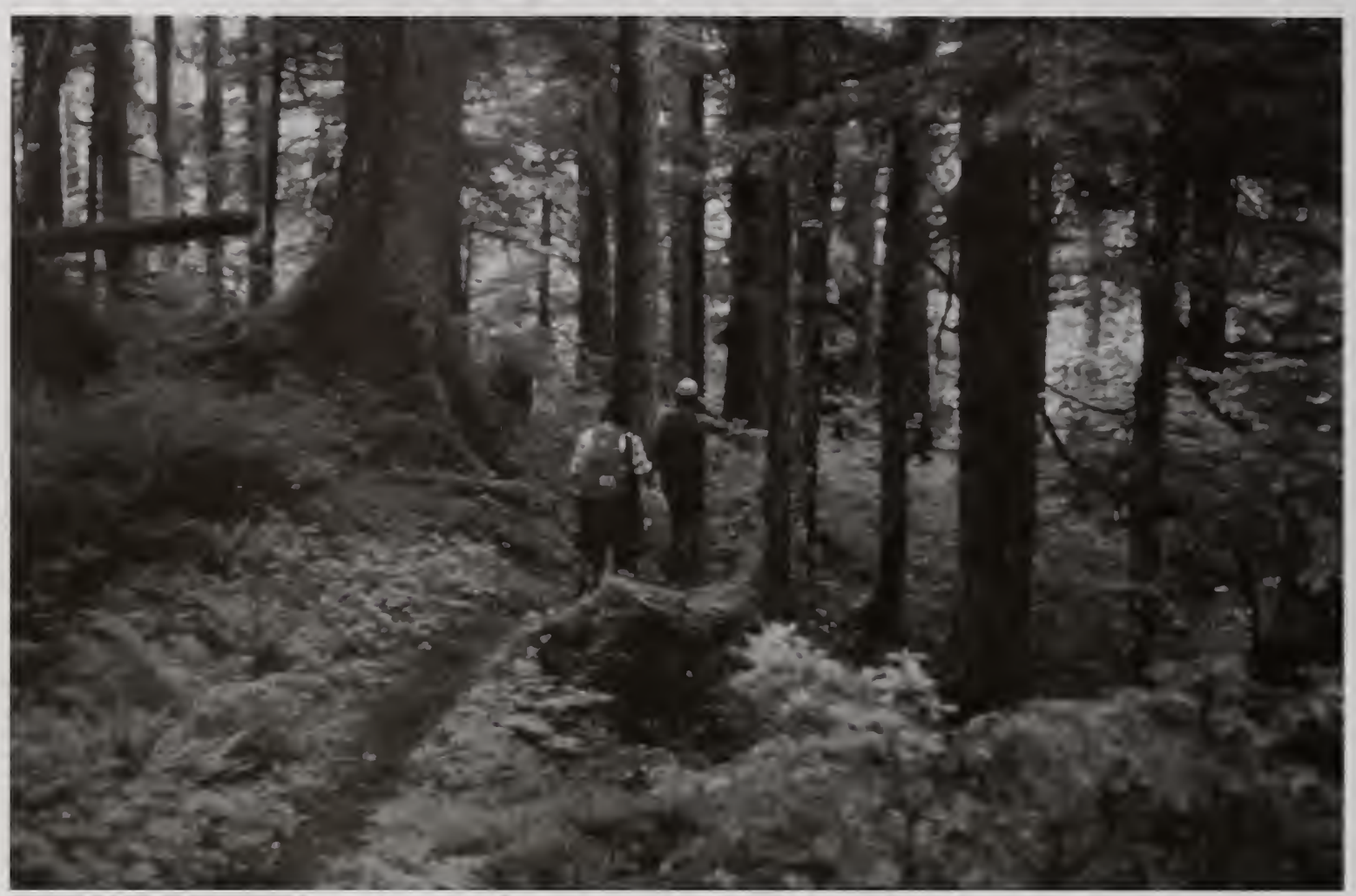




\section{Appendix A Use Area Cards}

Use Areas are geographic areas used in this analysis as the basis for defining and managing recreation use. Use Areas provide distinct geographical areas at a size that allows meaningful recreation management for specific areas of the national forest.

The following Use Area cards are used to provide site-specific information and resource considerations relating to commercial recreation management for each Use Area. They support the information provided in Chapters 2 and 3. The seasonal allocations and specific measures are displayed for each alternative. Most resource concerns are mitigated through mitigation measures listed in Appendix C, which apply to guided recreation use across the entire analysis area and are not repeated for each Use Area. Resource concerns specific to the Use Area are listed on the card and in Appendix C. Figure A-1 displays the general location of the Use Areas.

The information on these cards will be used to prepare and administer outfitter/guide permits. The mitigation measures will be incorporated into the document as permit stipulations where applicable. The permit conditions will be enforced through permit administration.

Table A-1. List of Use Areas

\begin{tabular}{ll|ll}
\hline Use Area & \multicolumn{1}{c|}{ General Location } & Use Area & \multicolumn{1}{c}{ General Location } \\
\hline $01-01$ & Skagway Area & $04-04 \mathrm{C}$ & Baranof Warm Springs \\
$01-02$ & Haines Area & $04-05$ & SW Admiralty \\
01-03 & East Chilkats & $04-06 \mathrm{~A}$ & Pybus Bay \\
01-04A & Berners Bay & $04-06 \mathrm{~B}$ & Eliza Harbor \\
01-04B & N. Juneau Coast & $04-07$ & Gambier Bay \\
01-04C & Taku Inlet & $04-08$ & NE Admiralty \\
01-04D & Slocum Inlet & $04-09$ & Seymour Canal \\
01-05A & Taku Harbor & $04-10 \mathrm{~A}$ & Greens Creek \\
01-05B & Port Snettisham & $04-10 \mathrm{~B}$ & NW Admiralty \\
01-05C & Windham Bay & $04-11$ & Hoonah Area \\
01-05D & Tracy Arm & $04-12$ & Tenakee Inlet \\
01-05E & Fords Terror & $04-13$ & Peril Strait \\
04-01A & Gut Bay, Baranof & $04-14$ & Slocum Arm \\
04-01B & Port Armstrong & $04-15$ & West Chichagof \\
04-02A & Redoubt Lake & $04-16 \mathrm{~A}$ & Point Adolphus \\
04-02B & Whale Bay & $04-16 \mathrm{~B}$ & North Chichagof \\
04-03 & Sitka Area & $04-16 \mathrm{C}$ & Idaho Inlet \\
04-04A & Lake Eva, Rodman Bay & $04-16 \mathrm{D}$ & Port Althorp \\
04-04B & Kelp Bay & & \\
\hline
\end{tabular}




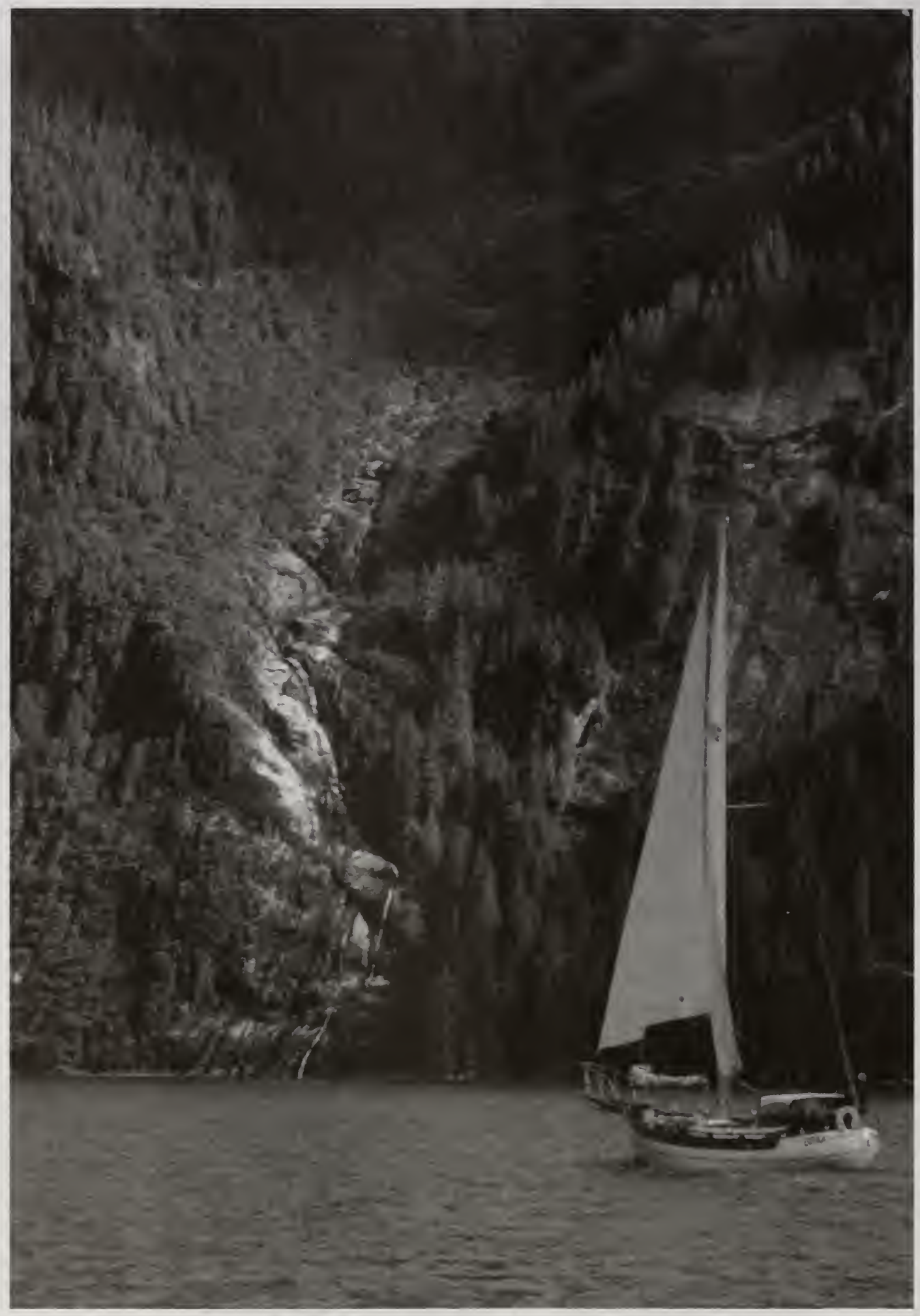




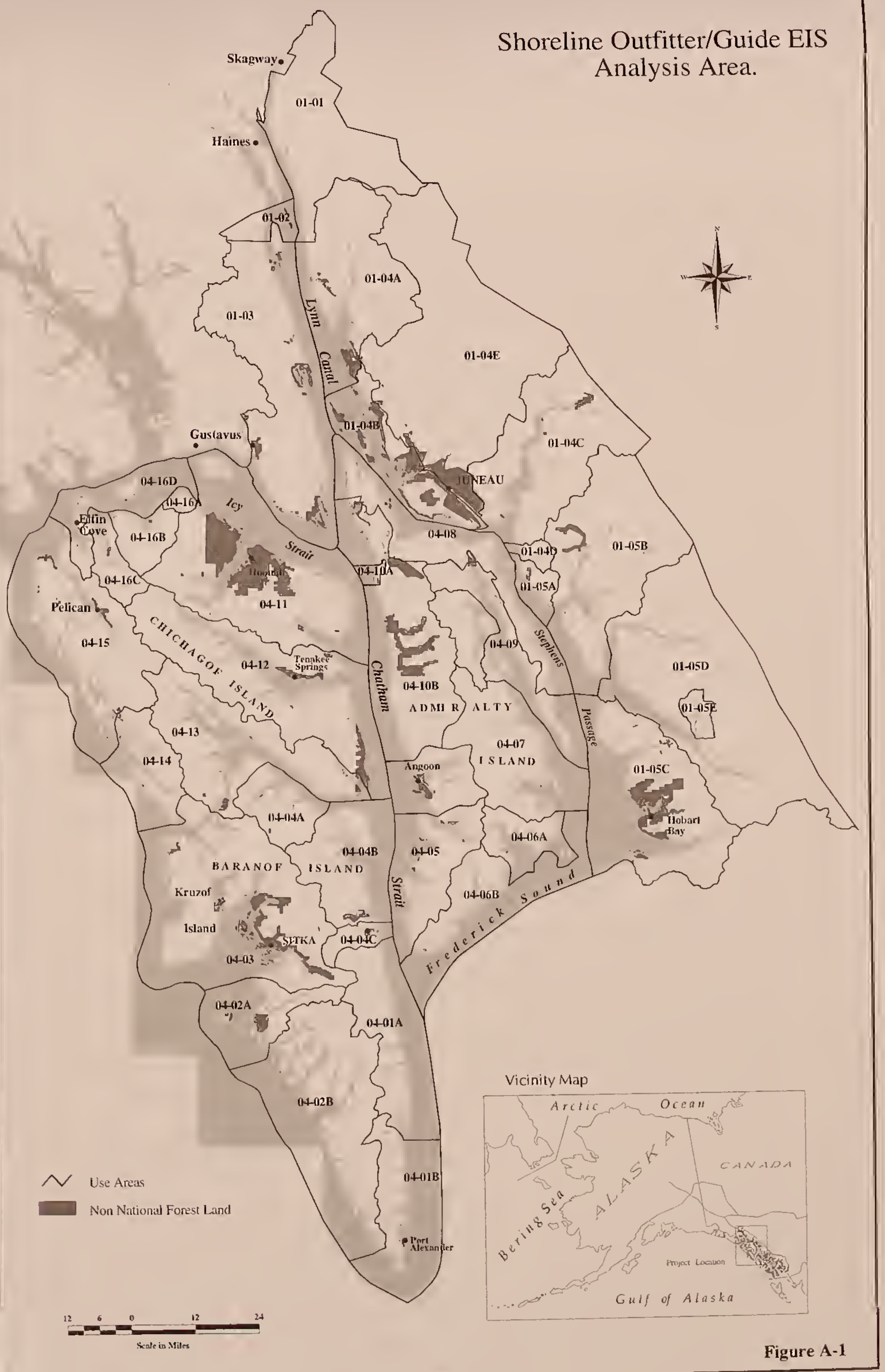





\section{Use Area 01-01}

Skagway Area - Juneau Ranger District

\begin{tabular}{|c|c|c|c|}
\hline \multicolumn{2}{|l|}{ Recreation Carrying Capacity (total capacity for all users) } \\
\hline Groups at one time & Spring & Summer & Fall \\
\hline 10 & 420 & 1,060 & 470 \\
\hline
\end{tabular}

\section{Description}

This use area extends from the Skagway area south to, but does not include, Sullivan Island within eastern Lynn Canal. The area is characterized by steep, rocky and often inaccessible shoreline. A notable exception is the Katzehin River area, which is the focus of both commercial and non-commercial activity.

LUDs $\quad$ Modified Landscape, Remote Recreation, Semi-Remote Recreation, Wild River, and Transportation and Utility System

ROS

Primitive, Roaded Natural, Semi-Primitive Motorized, and Semi-Primitive NonMotorized

National Forest Shoreline 83 miles

Miles

National Forest Shoreline $\quad 19,583$ acres

Acres

Communities Skagway, pop. 825; Haines, pop. 1,811

Alaska Coastal Skagway Coastal Management Program

Management Act Haines Coastal Management Program

Forest Service Facilities

Public Recreation Cabins Katzehin (limited access and not within the rental system)

\section{Non-National Forest System Lands}

Otter Creek Hydroelectric

Recreation Use

Area Attractions

Commercial Use

Scenic views and hunting, and fishing

By far, the highest use in the area is as a pass-through for over 700,000 cruise ship passengers arriving in Skagway. Other uses include guided big game hunting and fishing. This area is a primary flight path for flightseeing and local commuter aircraft. Airboats are used in the Katzehin River area to travel inland from Lynn Canal.

Non-commercial Use

Fly in visits to Katzehin cabin, hunting, fishing, sightseeing, and Alaska Marine Highway

Use Patterns

Commercial fishing, Alaska Marine Highway route, boat-based outfitter guide activity and recreational boaters

Primary Use Areas

Taiya Inlet, Lynn Canal, Katzehin River, wheeled aircraft land on an unmaintained airstrip near Katzehin River and there is airboat use within the Katzehin River drainage.

Areas of Concern The Katzehin River is a recommended Wild River. 


\section{Use Area 01-01}

\section{Skagway Area - Juneau Ranger District}

\begin{tabular}{|c|c|c|c|c|c|c|c|c|c|c|c|c|c|}
\hline \multicolumn{14}{|c|}{ Management/Resource Considerations } \\
\hline \multicolumn{2}{|l|}{ Subsistence } & \multicolumn{12}{|c|}{ There are no anticipated restrictions on subsistence resource users. } \\
\hline \multicolumn{2}{|l|}{ Wildlife } & \multicolumn{12}{|c|}{$\begin{array}{l}\text { NMFS has identified two Steller sea lion haul outs in this use area. Twenty-nine } \\
\text { mapped bald eagle nests also occur in this use area. }\end{array}$} \\
\hline \multicolumn{2}{|l|}{ Fisheries } & \multicolumn{12}{|c|}{$\begin{array}{l}\text { The terrain in this area drops steeply into Lynn Canal offering little habitat for fish } \\
\text { spawning or rearing. Five Class I streams have been mapped in the area. No streams } \\
\text { were identified with high fishing values. }\end{array}$} \\
\hline \multicolumn{2}{|l|}{ Botany } & \multicolumn{12}{|c|}{$\begin{array}{l}\text { Four surveys were completed along the shoreline covering } 0.25 \text { miles. One survey in } \\
\text { saline meadow near the mouth of the Katzehin River identified Eleocharis } \\
\text { kamtschatica. }\end{array}$} \\
\hline \multicolumn{2}{|l|}{ Cultural/Heritage } & \multicolumn{12}{|c|}{$\begin{array}{l}\text { Five surveys have been completed covering } 2.25 \text { miles. Five historic sites were } \\
\text { identified. }\end{array}$} \\
\hline \multicolumn{14}{|c|}{ Alternative Comparisons } \\
\hline & Alt. 1 & \multicolumn{3}{|c|}{ Alt. 2} & \multicolumn{3}{|c|}{ Alt. 3} & \multicolumn{3}{|c|}{ Alt. 4} & \multicolumn{3}{|c|}{ Alt. 5} \\
\hline \multirow{2}{*}{$\begin{array}{l}\text { Commercial } \\
\text { Allocation } \\
\text { (groups by } \\
\text { season) }\end{array}$} & \multirow[b]{2}{*}{ N/A } & Spr & Sum & Fall & Spr & Sum & Fall & Spr & Sum & Fall & Spr & Sum & Fall \\
\hline & & 42 & 424 & 47 & 210 & 530 & 235 & 21 & 53 & 24 & 42 & 212 & 118 \\
\hline Enclaves & N/A & \multicolumn{3}{|c|}{ None } & \multicolumn{3}{|c|}{ Katzehin Falls } & \multicolumn{3}{|c|}{ None } & \multicolumn{3}{|c|}{ Katzehin Falls } \\
\hline $15 \%$ Areas & N/A & \multicolumn{3}{|c|}{ None } & \multicolumn{3}{|c|}{ None } & \multicolumn{3}{|c|}{ None } & \multicolumn{3}{|c|}{ None } \\
\hline
\end{tabular}

\section{Mitigation}

See Appendix C for mitigation measures.

Guided use on the Katzehin River, a recommended Wild River, is limited to one group per day. 
Use Area - 01-01

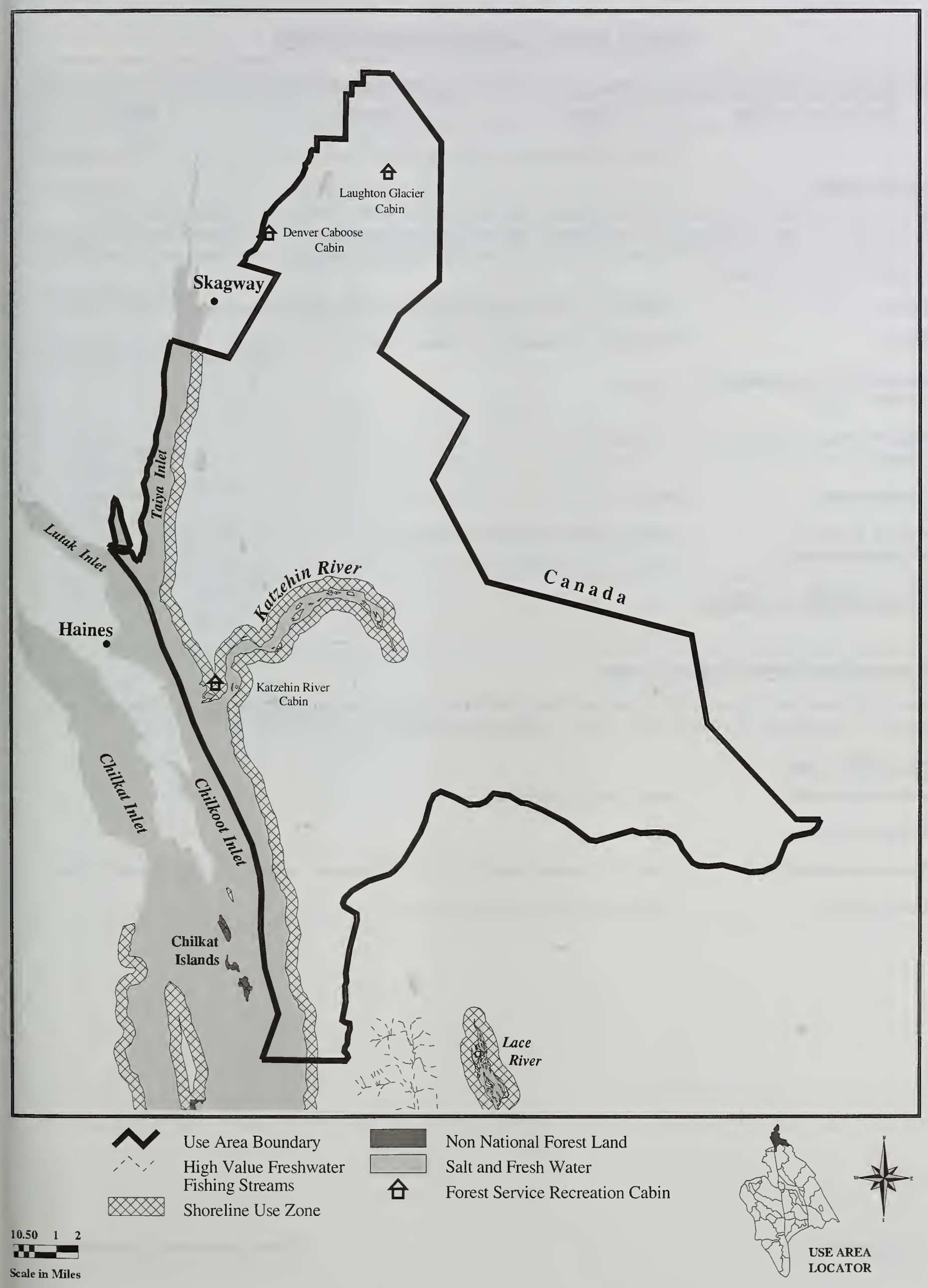




\section{Use Area 01-02}

\section{Haines Area - Juneau Ranger District}

\begin{tabular}{|c|c|c|c|}
\hline \multicolumn{2}{|l|}{ Recreation Carrying Capacity (total capacity for all users) } \\
\hline Groups at one time & Spring & Summer & Fall \\
\hline 5 & 210 & 530 & 235 \\
\hline
\end{tabular}

\section{Description}

This use area includes the western shoreline of Lynn Canal from Taiya Point near Skagway, to Haines, and south to Sullivan Island. Only a small portion of the mainland near Sullivan Island is within the Juneau Ranger District. There are few sheltered anchorages along this stretch of shoreline and weather conditions frequently cause rough seas in this portion of Lynn Canal, which limits use.
LUDs
Modified Landscape, Semi-Remote Recreation, and Transportation and Utility System.
ROS Semi-Primitive Motorized and Semi-Primitive Non-Motorized.
National Forest Shoreline 10 miles
Miles
National Forest Shoreline $\quad 2,372$ acres
Acres
Communities None
Alaska Coastal Haines Coastal Management Program
Management Act

\section{Forest Service Facilities}

None

\section{Non-National Forest System Lands}

Most of the shoreline in this area falls within the Haines State Forest and Resource Management Area, Chilkat State Park, and the Sullivan Island State Marine Park. There are also private inholdings within this use area.

\section{Recreation Use}

Area Attractions

Commercial Use

Non-commercial Use

Use Patterns
Scenic, hunting and fishing

Very low

This area is primarily used by Haines and Skagway residents and some Juneau residents Some localized use on Sullivan Island 


\section{Use Area 01-02}

\section{Haines Area - Juneau Ranger District}

\section{Management/Resource Considerations}

Subsistence

Wildlife

Fisheries

Botany

Cultural/Heritage
There are no anticipated restrictions on subsistence resource users.

In this use area, there are 13 mapped bald eagle nests

Three Class I streams have been mapped in this area. No streams were identified with high fishing values.

There are no known sensitive plants within this use area. This area has not received intensive surveys.

There are no known cultural sites within this use area. Two surveys have been completed covering two miles.

\section{Alternative Comparisons}

\begin{tabular}{|c|c|c|c|c|c|c|c|c|c|c|c|c|c|}
\hline & Alt. 1 & & Alt. 2 & & & Alt. 3 & & & Alt. 4 & & & Alt. 5 & \\
\hline \multirow{2}{*}{$\begin{array}{l}\text { Commercial } \\
\text { Allocation } \\
\text { (groups by } \\
\text { season) }\end{array}$} & \multirow[b]{2}{*}{ N/A } & Spr & Sum & Fall & Spr & Sum & Fall & Spr & Sum & Fall & Spr & Sum & Fall \\
\hline & & 21 & 212 & 24 & 105 & 265 & 118 & 15 & 30 & 15 & 21 & 106 & 59 \\
\hline Enclaves & N/A & & None & & Sull & $\operatorname{ran} \mathrm{Mo}$ & ntain & & None & & Sull & an $\mathrm{Mo}$ & atain \\
\hline $15 \%$ Areas & N/A & & None & & & None & & & None & & & None & \\
\hline
\end{tabular}

\section{Mitigation}

See Appendix $C$ for mitigation measures. 
Use Area - 01-02

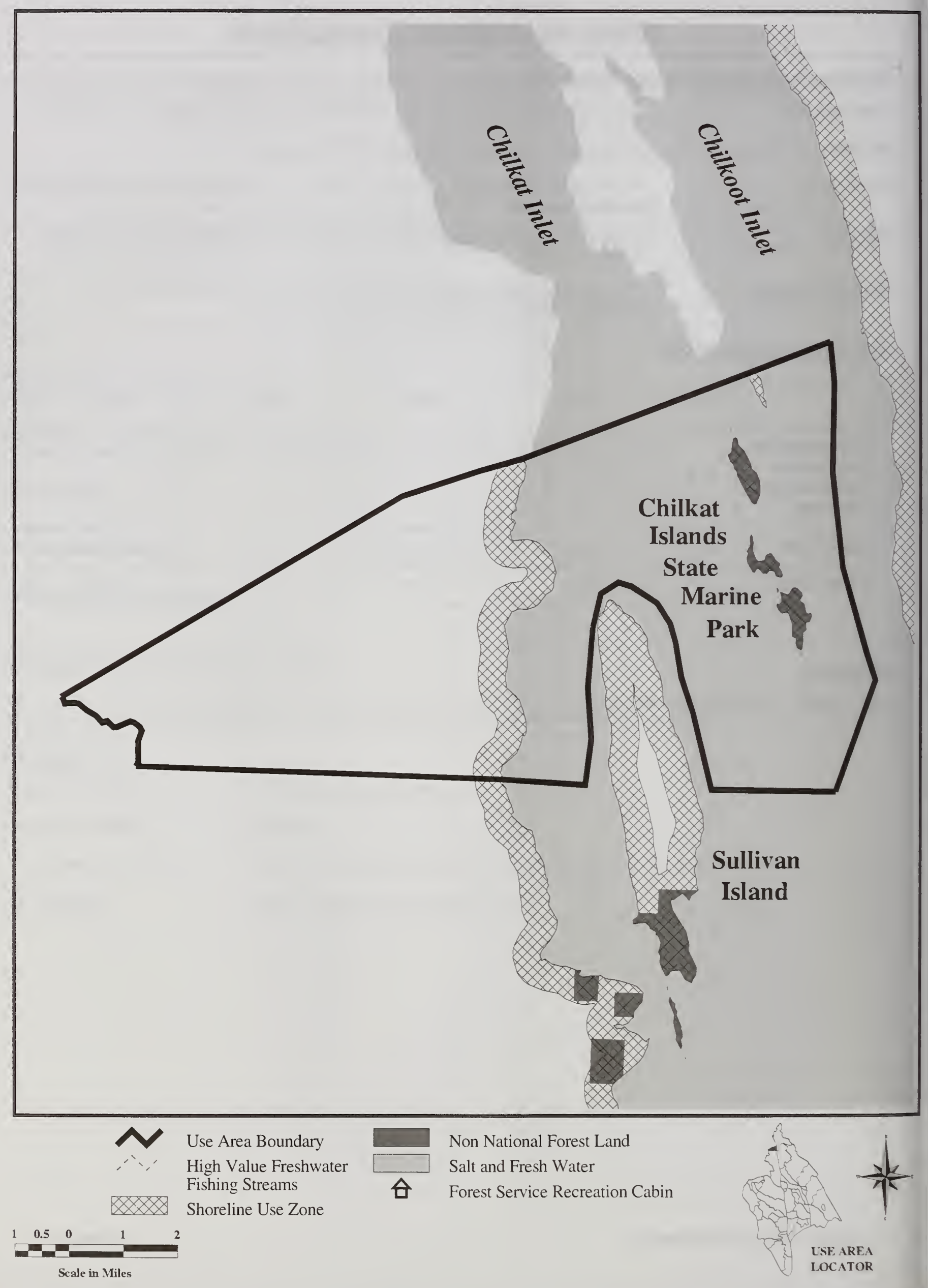




\section{Use Area 01-03}

East Chilkats - Juneau Ranger District

\begin{tabular}{|c|c|c|c|}
\hline Recreation Carrying Capacity (total capacity for all users) \\
\hline Groups at one time & Spring & Summer & Fall \\
\hline 20 & 840 & 2120 & 940 \\
\hline
\end{tabular}

\section{Description}

This use area is adjacent to Glacier Bay National Park to the west and includes the western shoreline of Lynn Canal from Sullivan Island Marine Park to Point Couverden and the shoreline on the east side of Excursion Inlet. The Homeshore area has had previous logging, and a road system exists in this area.
LUDs
ROS
Modified Landscape, Old-Growth, Semi-Remote Recreation, Scenic Viewshed, and Transportation and Utility System
Roaded Modified, Roaded Natural, Semi-Primitive Motorized, and Semi-Primitive Non- Motorized

National Forest Shoreline 102 miles

Miles

National Forest Shoreline $\quad 29,324$ acres

Acres

Communities

Alaska Coastal

Management Act

\section{Forest Service Facilities}

A logging road system on Point Couverden, storage units, and trailer pads associated with timber sale planning are located within this use area. There is an existing log transfer facility site at Homeshore.

\section{Non-National Forest System Lands}

Private and state lands are located at Sullivan Island, William Henry Bay, St. James Bay, and in Excursion Inlet. The State of Alaska administers St. James Bay State Park, a marine park at Pt. Couverden, and maintains a floating dock offshore at Pt. Couverden.

\section{Recreation Use}

Area Attractions

Commercial Use

Scenic views, wildlife viewing, some hunting and fishing

Non-commercial Use

Use Patterns
Brown and black bear hunting, moose hunting, freshwater fishing, sightseeing, and bicycle tours

Non-commercial use is generally offshore sport fishing, deer, moose and black bear hunting.

Shoreline use in this area is primarily by residents of Haines, Juneau, Skagway, Hoonah, Gustavus, and Excursion Inlet. 


\section{Use Area 01-03}

\section{East Chilkats - Juneau Ranger District}

Primary Use Areas

Excursion Inlet, Howard Bay, the log transfer site at Homeshore, William Henry Bay,

Square Bay, and Boat Harbor. Fixed wing aircraft land at the mouth of the Endicott River to access the area. The area inside the tree line has many trails and old logging roads.

There is an unmaintained airstrip, which gets moderate use just inside the tree line at

Endicott River.

\section{Management/Resource Considerations}

Subsistence

Wildife

Fisheries

Botany

Cultural/Heritage

\section{Alternative Comparisons}

\begin{tabular}{|c|c|c|c|c|c|c|c|c|c|c|c|c|c|}
\hline \multirow{3}{*}{$\begin{array}{l}\text { Commercial } \\
\text { Allocation } \\
\text { (groups by } \\
\text { season) }\end{array}$} & \multirow{3}{*}{$\begin{array}{l}\text { Alt. } 1 \\
\text { N/A }\end{array}$} & \multicolumn{3}{|c|}{ Alt. 2} & \multicolumn{3}{|c|}{ Alt. 3} & \multicolumn{3}{|c|}{ Alt. 4} & \multicolumn{3}{|c|}{ Alt. 5} \\
\hline & & Spr & Sum & Fall & Spr & Sum & Fall & Spr & Sum & Fall & Spr & Sum & Fall \\
\hline & & 84 & 848 & 94 & 420 & 1,060 & 470 & 42 & 106 & 47 & 84 & 424 & 235 \\
\hline \multirow[t]{3}{*}{ Enclaves } & N/A & \multicolumn{3}{|c|}{ None } & \multicolumn{3}{|c|}{ Homeshore } & \multicolumn{3}{|c|}{ Homeshore } & \multicolumn{3}{|c|}{ Homeshore } \\
\hline & & & & & \multicolumn{3}{|c|}{ Howard Bay } & & & & & & \\
\hline & & & & & \multicolumn{3}{|c|}{ Cant Cove } & & & & & & \\
\hline $15 \%$ Areas & N/A & \multicolumn{3}{|c|}{ None } & \multicolumn{3}{|c|}{ None } & \multicolumn{3}{|c|}{ None } & \multicolumn{3}{|c|}{ None } \\
\hline
\end{tabular}

\section{Mitigation}

See Appendix C for mitigation measures.
There are no anticipated restrictions on subsistence resource users.

In this use area, 345 bald eagle nests have been mapped.

This area contains productive fish streams important to the commercial fishing industry, non-guided sport fish users, and the guided sport fishing industry. Guided sport fishing use is focused on early season Dolly Varden char and mid-season pink salmon fishing opportunities. Twenty-six Class I streams have been mapped in this area, of which seven streams in this area have been identified with high fishing values. Most of these streams support populations of chum, pink, and coho salmon, as well as Dolly Varden char and cutthroat trout. A small stream in the area supports a small run of sockeye salmon that are an important subsistence resource for residents of Hoonah. Small runs of steelhead are found in some systems. A stream on the west side of Excursion Inlet is productive for its size and contains both summer and fall runs of chum salmon.

Two different Botrychium species in addition to Zigadenus elegans and Platanthera obtusata were recorded during nine surveys. These species all occurred within the beach meadow or upper estuary meadow vegetation community types. Beach meadows, especially at Howard Bay and Endicott River. are an attraction.

Two historic and 11 prehistoric sites were identified in 9 surveys covering 14.5 miles. 


\section{Use Area 01-04A}

\section{Berners Bay - Juneau Ranger District}

\begin{tabular}{|c|c|c|c|}
\hline \multicolumn{2}{|l|}{ Recreation Carrying Capacity (total capacity for all users) } \\
\hline Groups at one time & Spring & Summer & Fall \\
\hline 10 & 420 & 1,060 & 470 \\
\hline
\end{tabular}

\section{Description}

This use area includes the shoreline from approximately 16 miles north of Berners Bay east of Sullivan Island, to Echo Cove. Berners Bay itself is rich in wildlife, including sea lions, porpoises, sea birds and whales. The Juneau road system ends at Echo Cove, where a small harbor is located. This area has been proposed for a transportation corridor between Juneau and Skagway.

$\begin{array}{ll}\text { LUDs } & \text { LUD II, Modified Landscape, Old Growth, Remote Recreation, Semi-Remote } \\ & \text { Recreation, Scenic Viewshed, Wild River, and Transportation and Utility System } \\ \text { ROS } & \text { Primitive, Roaded Natural, Semi-Primitive Motorized, and Semi-Primitive Non- } \\ \text { Motorized }\end{array}$

National Forest Shoreline 260 miles

Miles

National Forest Shoreline $\quad 35.288$ acres

Acres

Communities A portion of the City and Borough of Juneau is within this use area. A small community exists at Kensington mine, and at Echo Cove on private land.

\section{Forest Service Facilities}

\section{Public Recreation Cabins Berners Bay}

\section{Non-National Forest System Lands}

The Kensington mine, a major silver producer, is located just above Pt. Sherman. A smaller private mine, the Jualin, is on the north side of Berners Bay, and a private church camp exists on an old homestead located at Echo Cove. The state maintains a small harbor at Echo Cove, which is the end of the Juneau road system. Goldbelt, a Native corporation that uwns timberland, has considered developing a ferry terminal and other facilities in this location. There is a state park at Point Bridget, and private residences along the shoreline.

\section{Recreation Use}

Area Attractions

Commercial Use

Non-commercial Use

Use Patterns
Scenic views, kayaking, fishing, hunting, sightseeing and nature watching

Commercial kayak tours and floatplane tours operate in the area. especially in the vicinity of the mouth of the Antler River in addition to wildlife watching tours.

Berners Bay receives substantial boat-based use from Juneau residents, and the area is a popular kayak destination. Shoreline areas north of Berners Bay do not attract the activity found within the bay.

Use in this area is varied and high including, commercial gillnetting, commercial sport fishing, flightseeing tours, land-based tours, and subsistence use. Berners Bay has cultural significance for Native groups in the area. Cruise ships and the Alaska Marine Highway system travel close to shore outside the bay. Airboats are used to access inner bay areas. 


\section{Use Area 01-04A}

\section{Berners Bay - Juneau Ranger District}

Primary Use Areas

Areas of Concern
Berners Bay is the primary focus of activity.

Potential development on private land at Cascade Point. The Gilkey River is a recommended Wild River.

\section{Management/Resource Considerations}

Subsistence

Wildlife

Fisheries

Botany

Cultural/Heritage
There are no anticipated restrictions on subsistence resource users.

NMFS has identified one Stellar sea lion haul-out; 129 bald eagle nests have been mapped in this use area.

Watersheds in this use area are large producers of coho, pink and chum salmon. Sixteen Class I streams have been mapped in the area, two with high fishing values. The Berners River, a tributary to Berners Bay, is used by ADF\&G Commercial Fisheries Division as a coho salmon index stream. Local sport fishers use the tributaries of Berners Bay, primarily Berners River. Because of the shallow nature of the inner bay, most of this use takes place via airboats and jet boats, which keeps fishing use low.

No rare or sensitive plants have been detected from three surveys.

Six prehistoric and three historic sites have been identified from 11 surveys covering 28.5 miles.

\section{Alternative Comparisons}

\begin{tabular}{|c|c|c|c|c|c|c|c|c|c|c|c|c|c|}
\hline & Alt. 1 & \multicolumn{3}{|c|}{ Alt. 2} & \multicolumn{3}{|c|}{ Alt. 3} & \multicolumn{3}{|c|}{ Alt. 4} & \multicolumn{3}{|c|}{ Alt. 5} \\
\hline \multirow{2}{*}{$\begin{array}{l}\text { Commercial } \\
\text { Allocation } \\
\text { (groups by } \\
\text { season) }\end{array}$} & \multirow{2}{*}{ N/A } & Spr & Sum & Fall & Spr & Sum & Fall & Spr & Sum & Fall & Spr & Sum & Fall \\
\hline & & 42 & 106 & 47 & 210 & 530 & 235 & 21 & 53 & 24 & 42 & 106 & 118 \\
\hline Enclaves & N/A & \multicolumn{3}{|c|}{ None } & \multicolumn{3}{|c|}{ None } & \multicolumn{3}{|c|}{ None } & \multicolumn{3}{|c|}{ None } \\
\hline $15 \%$ Areas & N/A & \multicolumn{3}{|c|}{ None } & \multicolumn{3}{|c|}{ None } & \multicolumn{3}{|c|}{ None } & \multicolumn{3}{|c|}{ None } \\
\hline
\end{tabular}

\section{Mitigation}

See Appendix C for mitigation measures.

Guided use on the Gilkey River, a recommended Wild River, is limited to one group per day. 


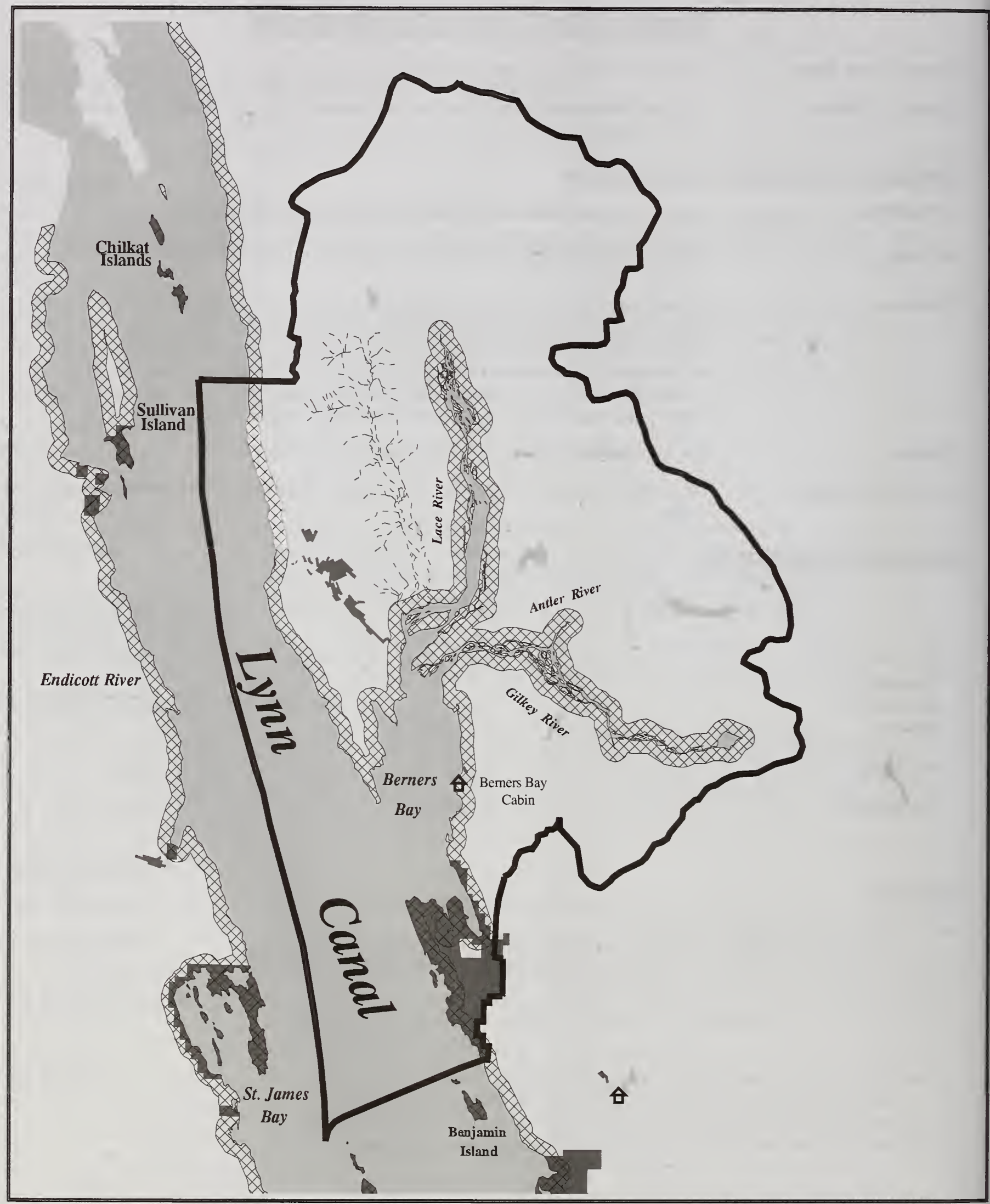
Use Area Boundary High Value Freshwater Fishing Streams Shoreline Use Zone

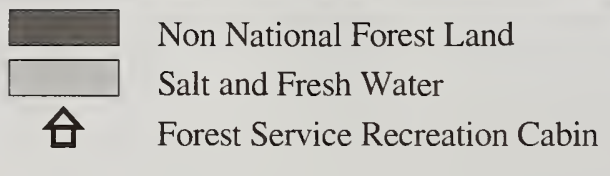

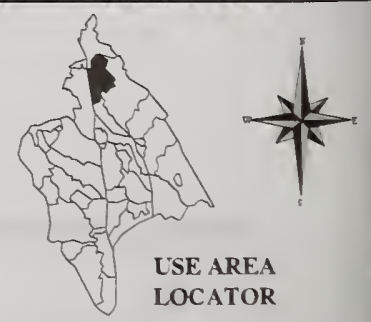




\section{Use Area 01-04B}

North Juneau Coast - Juneau Ranger District

\section{Recreation Carrying Capacity (total capacity for all users)}

\begin{tabular}{|c|c|c|c|}
\hline Groups at one time & Spring & Summer & Fall \\
\hline 6 & 252 & 636 & 282 \\
\hline
\end{tabular}

\section{Description}

This use area extends from Point Bridget State Park along the Juneau Road System and the shoreline from south of Pt. Bridget State Park to Point Salisbury, including Douglas, Shelter, Lincoln, and Benjamin Islands. Continuing south from Point Bridget State Park along the Juneau road system, the use area extends to just south of Thane to Point Salisbury.

\section{LUDs}

ROS

National Forest Shoreline 30 miles

Miles

\section{National Forest Shoreline 11,185 acres \\ Acres}

Communities

Alaska Coastal

Management Act System
Old Growth, Semi-Remote Recreation, Scenic Viewshed, and Transportation and Utility

Rural, Roaded Natural, Semi-Primitive Motorized, and Semi-Primitive Non-Motorized

Population of the combined Juneau-Douglas community is more than 30,000 people.

Juneau District Coastal Management Program

\section{Forest Service Facilities}

Numerous trails and developed recreation associated with the road system are excluded from this analysis.

\section{Non-National Forest System Lands}

Land ownership along much of the shoreline, mainland, and on the islands is other than national forest. Shelter Island has private residences, and a state marine park. Lincoln Island is in private ownership. Benjamin Island is not in the National Forest System. Recreation residences occur on the west side of Douglas Island near Pt. Hilda.

\section{Recreation Use}

Area Attractions

Commercial Use

Non-commercial Use

Use Patterns

Primary Use Areas

\section{Proximity to Juneau}

This area has low commercial use in terms of special use authorizations, though the marine areas adjacent to land receive heavy commercial use.

Private vessels actively utilize Stephens Passage on the west side of Douglas Island. Other non-commercial activities in this area include beachcombing, wildlife watching, fishing, picnicking, camping, hiking, kayaking, and other water and shore-based activities.

Activity is concentrated primarily along the Juneau road system; harbors at Auke Bay, Harris, Aurora, and Douglas Harbors; and North Douglas Boat Launch. The area is on a primary flight path for the Juneau International Airport and for flightseeing tours.

Concentrated use occurs on most beach access points along the Juneau road system and east to the north Douglas shoreline. Areas of primary concentration on national forest would be Eagle Beach, Auk Recreation site, the Dupont Trail, and the west side of Douglas Island. 


\section{North Juneau Coast - Juneau Ranger District}

\section{Management/Resource Considerations}

Subsistence

Wildlife

Fisheries

Botany

Cultural/Heritage

\section{Alternative Comparisons}

\begin{tabular}{|c|c|c|c|c|c|c|c|c|c|c|c|c|c|}
\hline & Alt. 1 & \multicolumn{3}{|c|}{ Alt. 2} & \multicolumn{3}{|c|}{ Alt. 3} & \multicolumn{3}{|c|}{ Alt. 4} & \multicolumn{3}{|c|}{ Alt. 5} \\
\hline \multirow{2}{*}{$\begin{array}{l}\text { Commercial } \\
\text { Allocation } \\
\text { (groups by } \\
\text { season) }\end{array}$} & \multirow{2}{*}{ N/A } & Spr & Sum & Fall & Spr & Sum & Fall & Spr & Sum & Fall & Spr & Sum & Fall \\
\hline & & 25 & 64 & 28 & 126 & 318 & 141 & 15 & 32 & 15 & 25 & 64 & 71 \\
\hline Enclaves & N/A & \multicolumn{3}{|c|}{ None } & \multicolumn{3}{|c|}{ Shelter Island } & & & & \multicolumn{3}{|c|}{ Shelter Island } \\
\hline $15 \%$ Areas & N/A & \multicolumn{3}{|c|}{ None } & \multicolumn{3}{|c|}{ Douglas Island } & \multicolumn{3}{|c|}{ Douglas Island } & \multicolumn{3}{|c|}{ Douglas Island } \\
\hline
\end{tabular}

\section{Mitigation}

See Appendix C for mitigation measures.
There are no anticipated restrictions on subsistence resource users.

NMFS has identified one Stellar sea lion haul-out. In this use area, 319 bald eagle nests have been mapped.

Two Class I streams have been mapped in this area and are not associated with high fishing values. The majority of streams within the use area occur on land owned by the City of Juneau. These streams are important to local residents and contain stocks of chum, pink, and coho salmon, Dolly Varden char and cutthroat trout. Small populations of steelhead are produced in a few of these systems. Some of the streams in the Gastineau Channel area receive hatchery-enhanced runs of coho, chum, and king salmon. Because of their easy access by Juneau sport fishers, most receive some degree of sport fishing use. Salt-water surrounding this area receives heavy guided fishing use.

Individuals of the genus Botrychium were documented within an upper estuarine meadow. Six surveys were conducted in the area.

Eight historic and five prehistoric sites have been identified within this use area from three surveys covering 4.25 miles. 


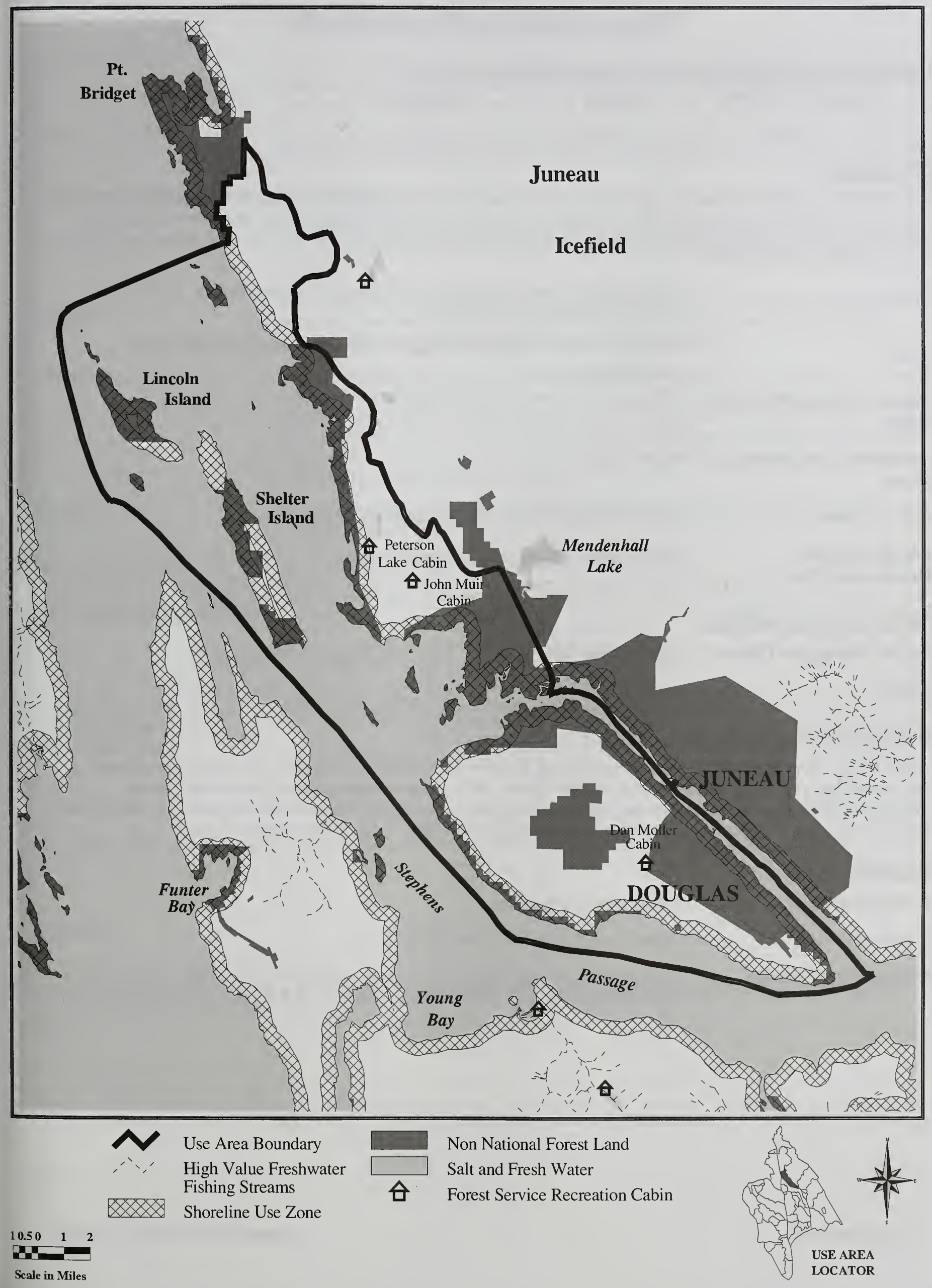


Taku Inlet - Juneau Ranger District

\begin{tabular}{|c|c|c|c|}
\hline Recreation Carrying Capacity (total capacity for all users) \\
\hline Groups at one time & Spring & Summer & Fall \\
\hline 12 & 504 & 1,272 & 564 \\
\hline
\end{tabular}

\section{Description}

This use area includes Pt. Bishop, the Taku River to the Canadian border and south of Taku Inlet to north of Slocum Inlet on the east side of Stephens Passage. The Taku River is a heavily used flight-seeing corridor, and receives significant fishing and pleasure craft use as well. The Taku River is of cultural significance. The river has tidal influences for miles upriver, which limit navigation.
LUDs
Old Growth, Remote Recreation, Semi-Remote Recreation, Scenic Viewshed, and Transportation and Utility System
ROS
Primitive, Roaded Natural, Semi-Primitive Motorized, and Semi-Primitive
Non-Motorized

National Forest Shoreline 163 miles

Miles

National Forest Shoreline

35,377 acres

Acres

Communities

A small enclave of homes near the Canadian border

Alaska Coastal

Management Act

Juneau District Coastal Management Program

\section{Forest Service Facilities}

Public Recreation Cabins

Taku Glacier Cabin

Trails

Pt. Bishop

\section{Non-National Forest System Lands}

Annex Creek power plant and penstock are situated on the north Taku Inlet shoreline about $31 \frac{1}{2}$ miles upriver from Stephens Passage. On the south shore about 6 miles upriver, Taku Lodge operates primarily during the summer.

Additionally, there is an area of homes and property near the Canadian border. Private recreation cabins are located near Twin Glacier Lake, Yehring Creek, and other locations within Taku inlet. Lake Dorothy Hydro Project.

\section{Recreation Use}

Area Attractions

Scenic views and glaciers

Commercial Use

Guided sport fishing and commercial fishing

Non-commercial Use

These activities include fishing, day boating, hiking, and hunting for goat, moose and bear. Most activities on Forest Service lands outside of flightseeing, are water-based. 


\section{Use Area 01-04C}

\section{Taku Inlet - Juneau Ranger District}

Use Patterns

Primary Use Areas
This area includes a heavily used flightseeing route (up to 30,000 passengers during the summer season) to the Taku and Norris Glaciers. There is also a high volume of floatplane traffic to sightsee and to access the Taku Lodge.

Though the waterway receives considerable use, few shoreline activities occur downriver due to inaccessible shoreline and the vagaries of river bars.

\section{Management/Resource Considerations}

\section{Subsistence}

Wildlife

Fisheries

Botany

Cultural/Heritage
An annual average of 121 personal use-fishing permits have been returned for use on the Taku River. There are no anticipated restrictions on subsistence resource users due to this project.

NMFS has identified one Steller sea lion haul-out in this area. Thirty-three bald eagle nests have been mapped in this area but it is assumed that nests are located along the shoreline in numbers at least equal to surveyed areas to the west.

Thirty-four Class I streams have been mapped in this area and 5 were identified with high fishing values. Though outside the analysis area, the Taku River system is a large transboundary river that supports stocks of all five pacific salmon species, Dolly Varden char, and cutthroat trout. The system is important to Alaskan and Canadian commercial, sport, and subsistence fisheries. Juneau residents use the lower Taku River and its tributaries for recreational sport fishing.

No rare or sensitive plants were identified from seven surveys that covered approximately one mile of shoreline.

Five surveys covering 1.25 miles revealed four historic sites.

\section{Alternative Comparisons}

\begin{tabular}{|l|c|c|c|c|c|c|c|c|c|c|c|c|c|}
\cline { 2 - 12 } \multicolumn{1}{c|}{} & Alt. 1 & \multicolumn{3}{c|}{ Alt. 2 } & \multicolumn{3}{c|}{ Alt. 3 } & \multicolumn{3}{c|}{ Alt. 4 } & \multicolumn{3}{c|}{ Alt. 5 } \\
\hline $\begin{array}{l}\text { Commercial } \\
\begin{array}{l}\text { Allocation } \\
\text { (groups by } \\
\text { season) }\end{array}\end{array}$ & N/A & Spr & Sum & Fall & Spr & Sum & Fall & Spr & Sum & Fall & Spr & Sum & Fall \\
\cline { 2 - 13 }$y$ & 50 & 127 & 56 & 252 & 636 & 282 & 25 & 64 & 28 & 50 & 127 & 141 \\
\hline Enclaves & N/A & \multicolumn{3}{|c|}{ None } & \multicolumn{3}{c|}{ Sunny Cove } & \multicolumn{2}{c|}{ Sunny Cove } & \multicolumn{2}{c|}{ Sunny Cove } \\
\hline 15\% Areas & N/A & \multicolumn{3}{c|}{ None } & \multicolumn{3}{c|}{ None } & \multicolumn{3}{c|}{ None } & \multicolumn{3}{c|}{ None } \\
\hline
\end{tabular}

\section{Mitigation}

See Appendix C for mitigation measures.

Outfitter/guide use will not be allowed on Turner Creek on weekends or during state and federal holidays to reduce the potential conflicts with unguided users. 


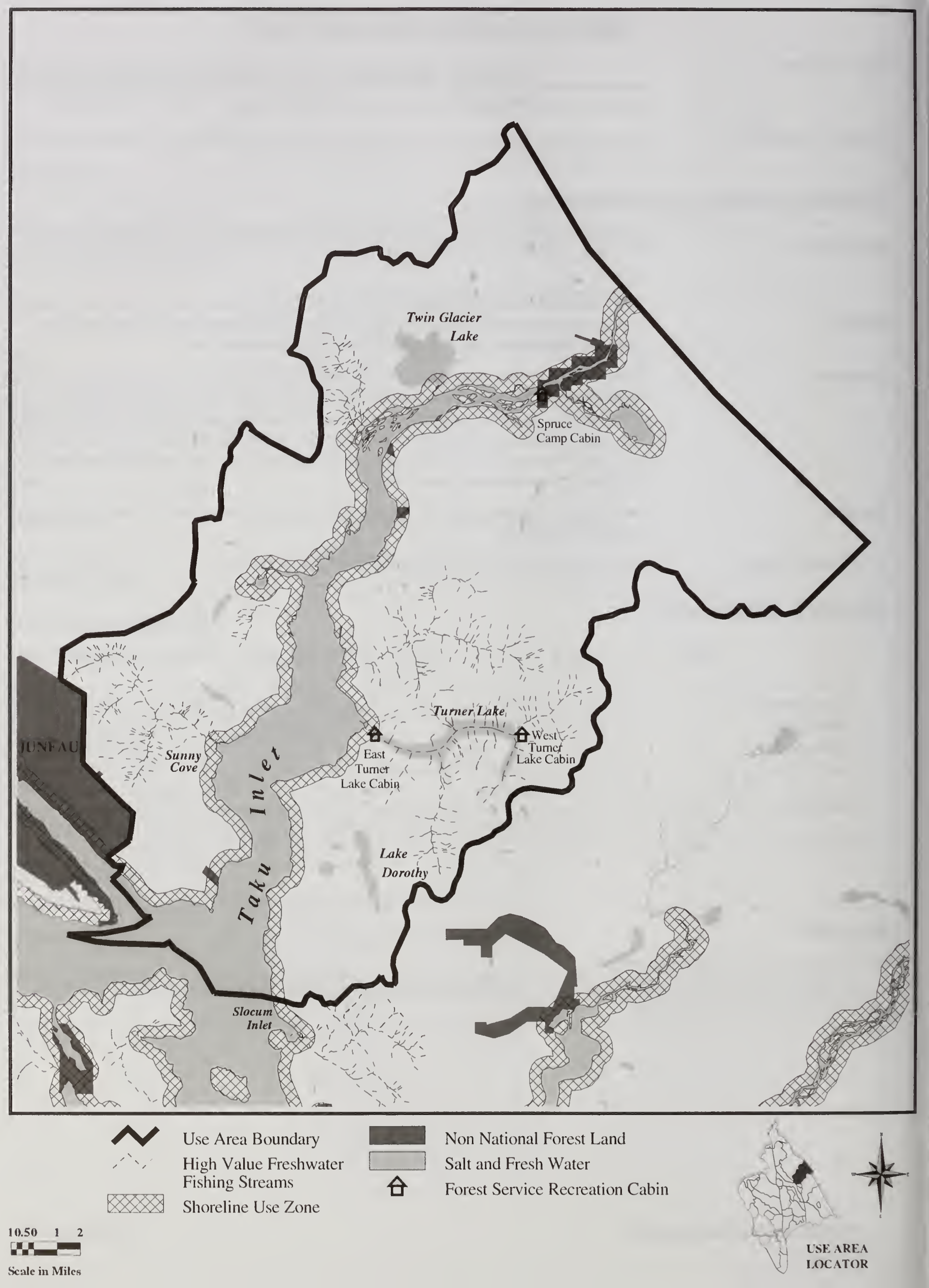




\section{Use Area 01-04D}

\section{Slocum Inlet - Juneau Ranger District}

\section{Recreation Carrying Capacity (total capacity for all users)}

\begin{tabular}{|c|c|c|c|}
\hline Groups at one time & Spring & Summer & Fall \\
\hline 10 & 420 & 1,060 & 470 \\
\hline
\end{tabular}

\section{Description}

Includes Slocum Inlet and the surrounding area. Its proximity to Juneau and shelter it provides from Taku winds make it an easily accessible and a popular destination.

LUDs

ROS

National Forest Shoreline 5 miles

Miles

National Forest Shoreline $\quad 1,459$ acres

Acres

Communities

Alaska Coastal

Management Act

Forest Service Facilities

None

\section{Non-National Forest System Lands}

None

\section{Recreation Use}

Area Attractions

Commercial Use

Non-commercial Use

Use Patterns

Primary Use Areas
Old Growth, Scenic Viewshed, Timber Production, and Transportation and Utility System

Roaded Modified, Roaded Natural, Semi-Primitive Motorized, and Semi-Primitive Non-Motorized

None

Juneau District Coastal Management Program
Hunting, fishing, and crabbing

Although Slocum Inlet is somewhat shallow, it does receive commercial fishing use. Crabpot storage is authorized inside the inlet in support of the commercial Dungeness crab harvest. Commercial outfitter guided freshwater fishing occurs at the head of the inlet.

This area is attractive for saltwater personal fishery and sport fishing, clamming, Dungeness and king crabbing. It is also a popular hunting area. In the past, it has been proposed as a possible area for transplanting Juneau's 'garbage bears'.

Although small, Slocum Inlet receives intense local use from commercial fishing and crabbing as well as from recreational users. There is a power transmission line that transects this area.

Head of Slocum Inlet 


\section{Use Area 01-04D}

\section{Slocum Inlet - Juneau Ranger District}

\section{Management/Resource Considerations}

\section{Subsistence}

Wildlife

Fisheries

Botany

Cultural/Heritage
There are no anticipated restrictions on subsistence resource users as a result of this project.

NMFS has identified one Steller sea lion haul-out in the use area. There are 3 mapped bald eagle nests in this use area.

Three Class I streams have been mapped in this area, one of which is identified as a high value fishing stream. It is located at the head of the bay, with a large inter-tidal grass flat, and supports abundant runs of pink and chum salmon. This stream receives little nonguided sport fishing pressure. Because of its relatively close proximity to Juneau, few potential conflicts with non-guided fishers, and consistent runs of pink and chum salmon, this stream receives relatively high use from guided sport fishers.

There are no known sensitive plants in this use area. This area has not received intensive surveys.

\section{Alternative Comparisons}

\begin{tabular}{|l|c|c|c|c|c|c|c|c|c|c|c|c|c|}
\cline { 2 - 13 } \multicolumn{1}{c|}{} & Alt. 1 & \multicolumn{3}{c|}{ Alt. 2 } & \multicolumn{3}{c|}{ Alt. 3 } & \multicolumn{3}{c|}{ Alt. 4 } & \multicolumn{3}{c|}{ Alt. 5 } \\
\hline $\begin{array}{l}\text { Commercial } \\
\begin{array}{l}\text { Allocation } \\
\text { (groups by } \\
\text { season) }\end{array}\end{array}$ & N/A & Spr & Sum & Fall & Spr & Sum & Fall & Spr & Sum & Fall & Spr & Sum & Fall \\
\cline { 2 - 14 } & 42 & 106 & 47 & 210 & 530 & 235 & 21 & 70 & 24 & 42 & 106 & 118 \\
\hline Enclaves & N/A & \multicolumn{3}{c|}{ None } & \multicolumn{3}{c|}{ None } & \multicolumn{3}{c|}{ None } & \multicolumn{3}{c|}{ None } \\
\hline $\mathbf{1 5 \%}$ Areas & N/A & \multicolumn{3}{c|}{ None } & \multicolumn{3}{c|}{ None } & \multicolumn{3}{c|}{ None } & \multicolumn{3}{c|}{ None } \\
\hline
\end{tabular}

\section{Mitigation}

See Appendix C for mitigation measures. 
Shoreline Outfitter/Guide EIS

Use Area - 01-04D

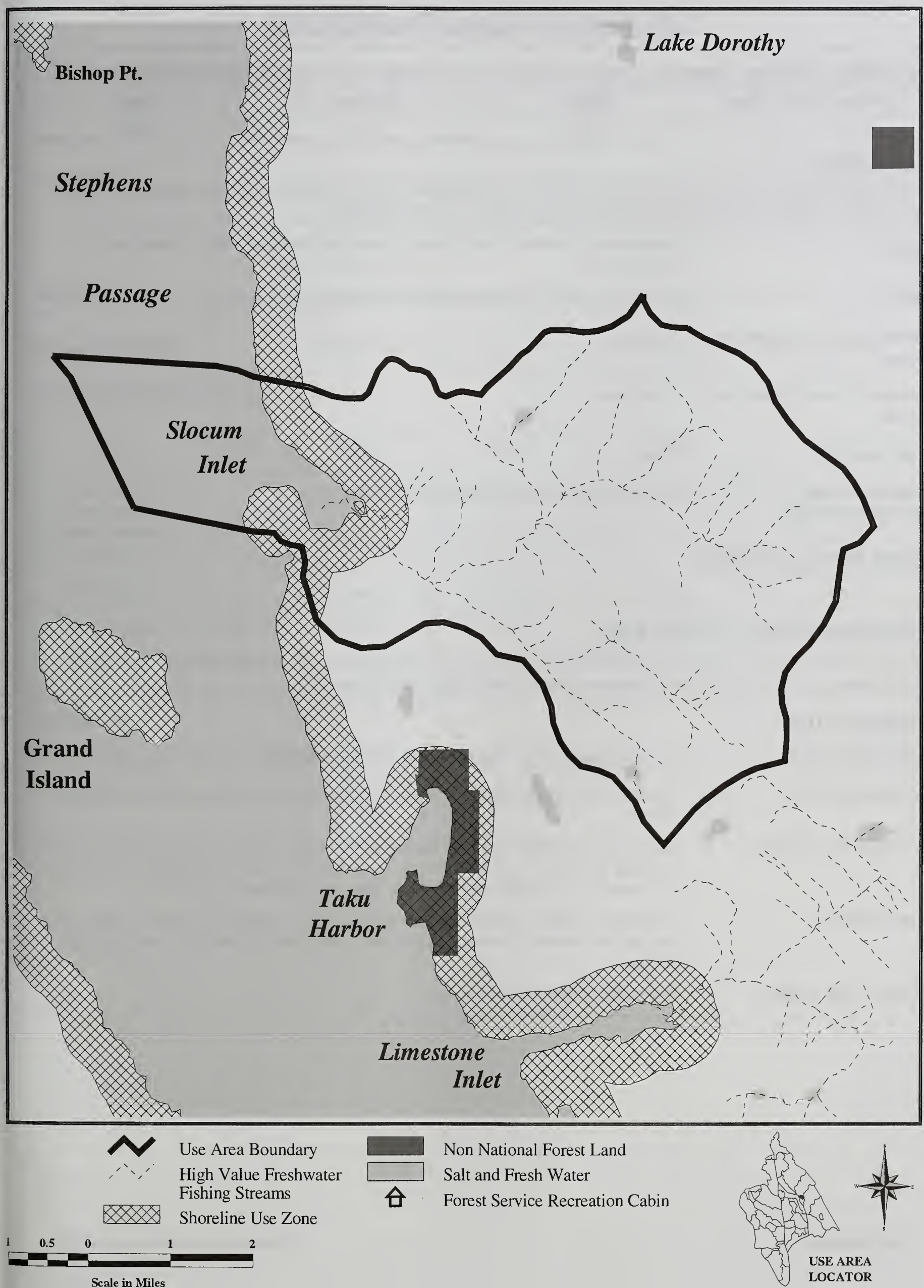




\section{Use Area 01-05A}

\section{Taku Harbor - Juneau Ranger District}

\begin{tabular}{|c|c|c|c|}
\hline \multicolumn{2}{|l|}{ Recreation Carrying Capacity (total capacity for all users) } \\
\hline Groups at one time & Spring & Summer & Fall \\
\hline 6 & 252 & 636 & 282 \\
\hline
\end{tabular}

\section{Description}

This use area extends from Circle Point to the mouth of Port Snettisham along the eastern shoreline of Stephens Passage.

Taku Harbor is the largest protected anchorage between Juneau and Port Snettisham.

\begin{tabular}{|c|c|}
\hline LUDs & $\begin{array}{l}\text { Old Growth, Research Natural Area, Scenic Viewshed, and Transportation and } \\
\text { Utility System }\end{array}$ \\
\hline ROS & Primitive and Semi-Primitive Non-Motorized, and Roaded Natural \\
\hline $\begin{array}{l}\text { National Forest Shoreline } \\
\text { Miles }\end{array}$ & 20 miles \\
\hline $\begin{array}{l}\text { National Forest Shoreline } \\
\text { Acres }\end{array}$ & 5,340 acres \\
\hline Communities & None \\
\hline $\begin{array}{l}\text { Alaska Coastal } \\
\text { Management Act }\end{array}$ & Juneau District Coastal Management Program \\
\hline
\end{tabular}

\section{Forest Service Facilities}

None

\section{Non-National Forest System Lands}

Uplands in Taku Harbor were state-selected for community recreation. A state marine park and two private parcels are located along the shoreline. The state maintains a public dock within Taku Harbor.

\section{Recreation Use}

Area Attractions

Commercial Use

Non-commercial Use

Use Patterns

Primary Use Areas
Community anchorage, kayaking, and wildlife viewing

Guided freshwater fishing at the head of the bay, commercial gill netting, and crab pot storage

Uses include saltwater sport fishing, nature watching, hiking, personal clam harvest, and crabbing. Suicide Cove is used as a destination and haul out for kayakers. Slocum Inlet is also used by kayakers as a rest stop on the way north across Taku Inlet.

Proximity to Juneau makes Limestone Inlet and Taku Harbor both easily accessible and popular destinations. The area receives heavy boat traffic, including cruise ships and barges.

Limestone Inlet and Taku Harbor 


\section{Use Area 01-05A}

\section{Taku Harbor - Juneau Ranger District}

\section{Management/Resource Considerations}

Subsistence

Wildlife

Fisheries

Botany

Cultural/Heritage
There are no anticipated restrictions on subsistence resource users.

There are 20 mapped bald eagle nests in the use area.

Two Class I streams have been mapped in this area. There is a very small stream that enters Taku Harbor, which likely does not support significant runs of anadromous fish. Limestone Inlet has a high value fishing stream flowing through an inter-tidal grass flat that supports large runs of pink and chum salmon and likely receives little non-guided sport fishing pressure.

There are no known sensitive plants in this use area. This area has not received intensive surveys.

Two surveys covering 0.5 miles were conducted with one prehistoric site identified.

\section{Alternative Comparisons}

\begin{tabular}{|c|c|c|c|c|c|c|c|c|c|c|c|c|c|}
\hline & Alt. 1 & \multicolumn{3}{|c|}{ Alt. 2} & \multicolumn{3}{|c|}{ Alt. 3} & \multicolumn{3}{|c|}{ Alt. 4} & \multicolumn{3}{|c|}{ Alt. 5} \\
\hline \multirow{2}{*}{$\begin{array}{l}\text { Commercial } \\
\text { Allocation } \\
\text { (groups by } \\
\text { season) }\end{array}$} & \multirow[b]{2}{*}{ N/A } & Spr & Sum & Fall & Spr & Sum & Fall & Spr & Sum & Fall & Spr & Sum & Fall \\
\hline & & 25 & 254 & 28 & 126 & 318 & 141 & 15 & 32 & 15 & 25 & 106 & 71 \\
\hline Enclaves & N/A & \multicolumn{3}{|c|}{ None } & \multicolumn{3}{|c|}{ None } & \multicolumn{3}{|c|}{ None } & \multicolumn{3}{|c|}{ None } \\
\hline $15 \%$ Areas & N/A & \multicolumn{3}{|c|}{ None } & \multicolumn{3}{|c|}{ None } & \multicolumn{3}{|c|}{ None } & \multicolumn{3}{|c|}{ None } \\
\hline
\end{tabular}

\section{Mitigation}

See Appendix C for mitigation measures. 
Shoreline Outfitter/Guide EIS

Use Area - 01-05A

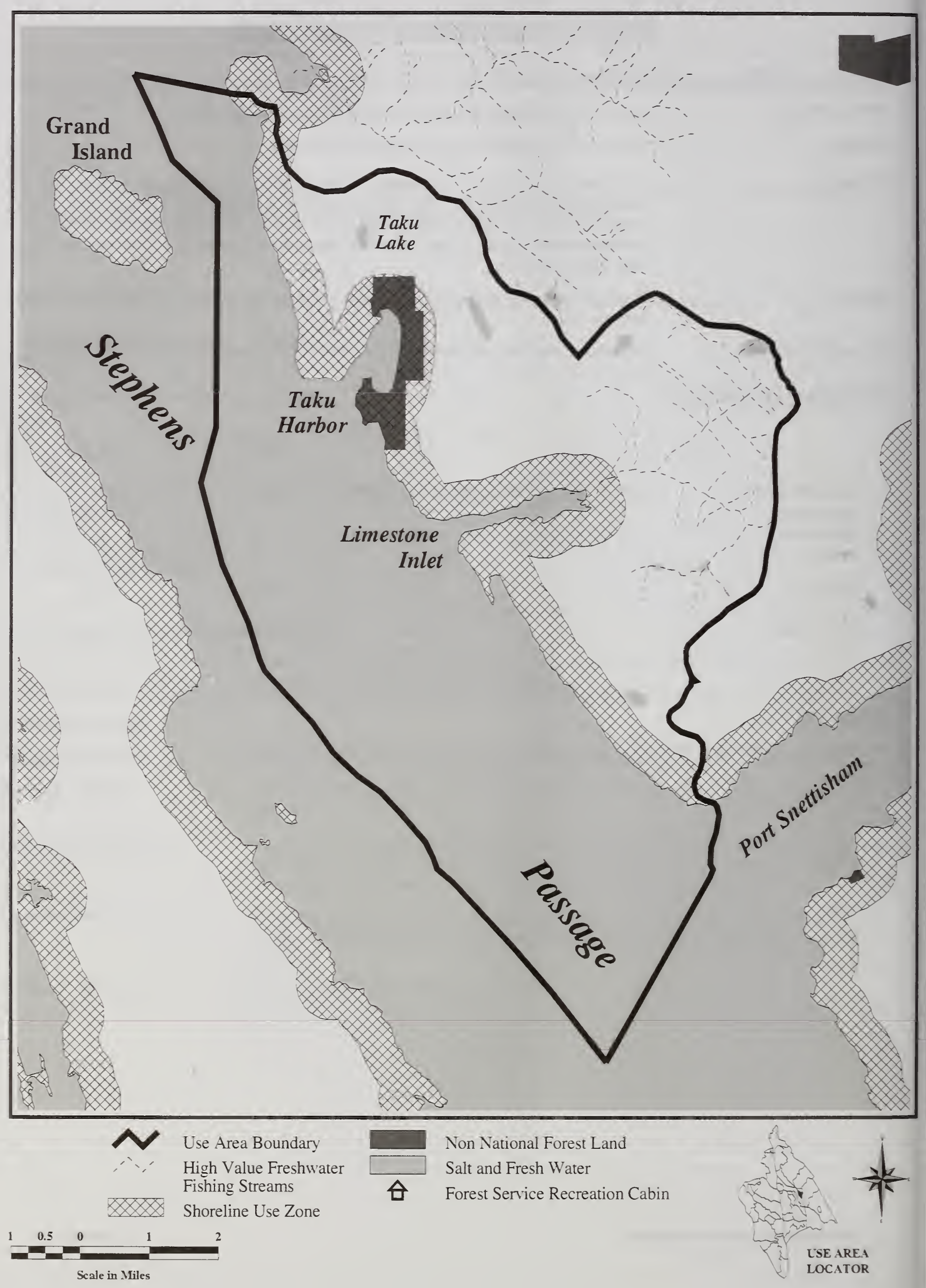




\section{Use Area 01-05B}

Port Snettisham - Juneau Ranger District

Recreation Carrying Capacity (total capacity for all users)

\begin{tabular}{|c|c|c|c|}
\hline Groups at one time & Spring & Summer & Fall \\
\hline 20 & 840 & 2,120 & 940 \\
\hline
\end{tabular}

\section{Description}

From Point Coke at the entrance of Port Snettisham and south to the entrance of Holkham Bay

\begin{tabular}{|c|c|}
\hline LUDs & $\begin{array}{l}\text { Modified Landscape, Old Growth, Remote Recreation, Semi-Remote Recreation, Scenic } \\
\text { Viewshed, Timber Production, and Transportation and Utility System }\end{array}$ \\
\hline ROS & $\begin{array}{l}\text { Primitive, Roaded Natural, Semi-Primitive Motorized, Semi-Primitive Non-Motorized, } \\
\text { and Rural }\end{array}$ \\
\hline $\begin{array}{l}\text { National Forest Shoreline } \\
\text { Miles }\end{array}$ & 226 miles \\
\hline $\begin{array}{l}\text { National Forest Shoreline } \\
\text { Acres }\end{array}$ & 47,752 acres \\
\hline Communities & None \\
\hline $\begin{array}{l}\text { Alaska Coastal } \\
\text { Management Act }\end{array}$ & Juneau District Coastal Management Program \\
\hline
\end{tabular}

\section{Forest Service Facilities}

None

\section{Non-National Forest System Lands}

The largest private inholding includes the Port Snettisham Power Plant situated on 2,666 acres of state-selected lands. It provides power to the City and Borough of Juneau. There is also a large fish hatchery on private land.

\section{Recreation Use}

Area Attractions

Commercial Use

Non-commercial Use

Use Patterns

Primary Use Areas

Close to Tracy Arm Wilderness, which allows for both a visit to Tracy Arm and shore excursion on same day, unaltered forest, shoreline conducive to walking, salmon viewing. Fishing and hunting occur within Port Snettisham and Gilbert Bay, in particular.

Mountain goat and brown bear hunting and sightseeing

Activities include wildlife viewing, bear hunting, and freshwater fishing; this unit is easily accessible from Juneau and has a number of anchorages.

This area receives a high number of commercial gillnetting, shrimping, and crabbing vessels. Williams Cove receives concentrated use from commercial sightseeing and nature watch tours.

Mallard Cove, Whiting River, Sweetheart Creek, and the head of Gilbert Bay, and Williams Cove 


\section{Use Area 01-05B}

\section{Port Snettisham - Juneau Ranger District}

\section{Management/Resource Considerations}

\section{Subsistence}

Wildlife

Fisheries

Botany

Cultural/Heritage
There are no anticipated restrictions to the use of subsistence resources due to this project

NMFS has identified one Steller sea lion haul-out in this use area. There are 89 mapped bald eagle nests.

Thirty-four Class I streams have been mapped in this area. There are several tributary streams and lakes in the Whiting River drainage that provide sport-fishing opportunities. All of these streams and lakes are outside of the shoreline zone. A stream in Speel Arm will likely have large numbers of hatchery-enhanced sockeye salmon in the future making it attractive to both guided and non-guided sport fishers. Gilbert Bay contains three streams with high fishing values. The outlet stream of Sweetheart Lake supports a hatchery enhanced run of sockeye salmon, is a popular personal use fishery for residents of Juneau, and provides some sport fishing opportunities.

No rare or sensitive plants were found after the completion of two surveys that covered 0.5 miles of shoreline.

Two prehistoric sites were identified in this use area from one survey covering 0.25 miles.

\section{Alternative Comparisons}

\begin{tabular}{|c|c|c|c|c|c|c|c|c|c|c|c|c|c|}
\hline & Alt. 1 & \multicolumn{3}{|c|}{ Alt. 2} & \multicolumn{3}{|c|}{ Alt. 3} & \multicolumn{3}{|c|}{ Alt. 4} & \multicolumn{3}{|c|}{ Alt. 5} \\
\hline \multirow{2}{*}{$\begin{array}{l}\text { Commercial } \\
\text { Allocation } \\
\text { (groups by } \\
\text { season) }\end{array}$} & \multirow{2}{*}{ N/A } & Spr & Sum & Fall & Spr & Sum & Fall & Spr & Sum & Fall & Spr & Sum & Fall \\
\hline & & 84 & 848 & 94 & 420 & 1,060 & 470 & 42 & 156 & 47 & 84 & 424 & 235 \\
\hline \multirow[t]{5}{*}{ Enclaves } & N/A & \multicolumn{3}{|c|}{ None } & \multicolumn{3}{|c|}{ Mallard Cove } & \multicolumn{3}{|c|}{ Mallard Cove } & \multicolumn{3}{|c|}{ Mallard Cove } \\
\hline & & & & & \multicolumn{3}{|c|}{ West Gilbert Bay } & \multicolumn{3}{|c|}{ West Gilbert Bay } & \multicolumn{3}{|c|}{ West Gilbert Bay } \\
\hline & & & & & \multicolumn{3}{|c|}{ Point Coke } & & & & \multicolumn{3}{|c|}{ Point Coke } \\
\hline & & & & & \multicolumn{3}{|c|}{ No Name Cove } & \multicolumn{3}{|c|}{ No Name Cove } & \multicolumn{3}{|c|}{ No Name Cove } \\
\hline & & & & & \multicolumn{3}{|c|}{ Point Anmer } & & & & \multicolumn{3}{|c|}{ Point Anmer } \\
\hline $15 \%$ Areas & N/A & \multicolumn{3}{|c|}{ None } & \multicolumn{3}{|c|}{ None } & \multicolumn{3}{|c|}{ None } & \multicolumn{3}{|c|}{ None } \\
\hline
\end{tabular}

\section{Mitigation}

See Appendix C for mitigation measures.

Guided fishing use is prohibited during the personal use sockeye fishery in Sweetheart Creek (Gilbert Bay). No more than two guided groups may be present at one time during other times of the year to avoid potential conflicts with unguided users.

State sport fishing regulations are in place to regulate fishing near fish structures on Crescent and Speel Lakes, as well as streams draining into Gilbert Bay. 


\section{Use Area - 01-05B}

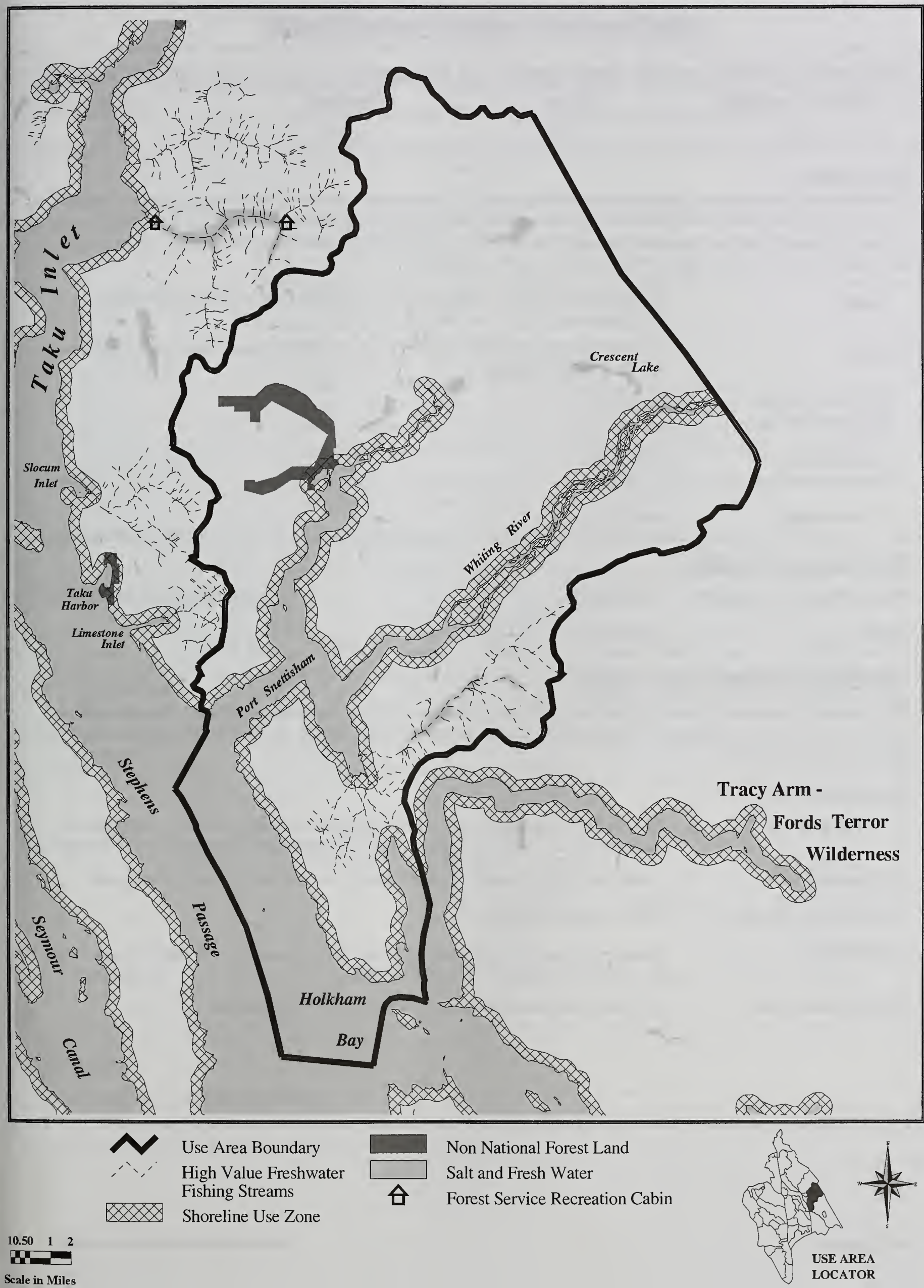




\section{Use Area 01-05C}

\section{Windham Bay - Juneau Ranger District}

\begin{tabular}{|c|c|c|c|}
\hline Groups at one time & Spring & Summer & Fall \\
\hline 26 & 1,092 & 2,756 & 1,222 \\
\hline
\end{tabular}

\section{Description}

This use area extends from Pt. Astley to west of Endicott Arm, southward to Windham Bay continuing to the Juneau Ranger District Boundary south of Port Houghton. Windham Bay is a popular area for hunting, and for private, as well as commercial vessels, despite its narrow channel. It serves as an entry point to Chuck River Wilderness. Hobart Bay is an area that has had extensive logging, and is under private ownership.

LUDS

ROS

National Forest

Shoreline Miles

National Forest

Shoreline Acres

Communities
Old Growth, Semi-Remote Recreation, Scenic Viewshed, Timber Production.

Wilderness, and Wilderness Monument

Roaded Modified, Roaded Natural, Primitive, Semi-Primitive Motorized, and SemiPrimitive Non-Motorized

141 miles

\section{5,191 acres}

Hobart Bay

\section{Forest Service Facilities}

Public Recreation Cabins Port Houghton

Trails

Taylor Lake

\section{Non-National Forest System Lands}

Private property occurs in Hobart Bay. Extensive timber harvesting. The state maintains an offshore float for boats at Entrance Island where a recreation residence is also permitted. Irivate lands are also found in Port Iloughton, Windham Bay, and the Chuck River.

\section{Recreation Use}

Area Attractions

Commercial Use

Non-commercial Use

Use Patterns

Primary Use Areas
Close to Tracy Arm allowing for same day visit with shore excursion. Scenic views, unaltered forest, wildlife viewing, kayaking, good beach access, diversity of landforms.

Freshwater fishing, wildlife viewing, nature tours, black and brown bear hunting

Fishing, camping, hunting

Though some activity in this area originates from Juneau there is also influence from Petersburg, approximately 45 miles south.

Sandborn Canal, the head of Port Houghton and Windham Bay 


\section{Use Area 01-05C}

\section{Windham Bay - Juneau Ranger District}

\section{Management/Resource Considerations}

Subsistence

Wildlife

Fisheries

Botany

Cultural/Heritage
There are no anticipated restrictions on subsistence resource users.

NMFS identified two Stellar sea lion haul-outs in this use area. In this use area, 258 bald eagle nests have been mapped.

Forty-one Class I streams have been mapped in this area, with five of these identified as having high fishing values. This area is far from both Juneau and Petersburg, and therefore receives light sport fishing pressure. Chuck River supports runs of pink, chum, coho, and king salmon, Dolly Varden char, cutthroat trout, and possibly steelhead. Hobart Bay has one stream that was identified as having high fishing values. In addition to this system there is a salt-chuck located within Hobart Bay. These systems contain pink, chum, and coho salmon, as well as Dolly Varden char and cutthroat trout. Port Houghton contains very productive freshwater systems with four streams identified as having high fishing values. The largest of these is the Rusty River, which flows into the salt-chuck at the head of Port Houghton. This stream contains runs of pink, chum, sockeye, and coho salmon as well as Dolly Varden char, cutthroat trout, and possibly steelhead. Another important stream in Port Houghton is at the head of Sandborn Canal. This stream has runs of pink, chum, and coho salmon, Dolly Varden char, cutthroat trout, and steelhead.

Poa laxiflora was found at two sites associated with tufted hairgrass. Ten surveys were completed on 0.75 miles of shoreline.

Thirty surveys covering 51.5 miles revealed 8 historic and 6 prehistoric sites in this use area.

\section{Alternative Comparisons}

\begin{tabular}{|c|c|c|c|c|c|c|c|c|c|c|c|c|c|}
\hline & Alt. 1 & & Alt. 2 & & & Alt. 3 & & & Alt. 4 & & & Alt. 5 & \\
\hline \multirow{2}{*}{$\begin{array}{l}\text { Commercial } \\
\text { Allocation } \\
\text { (groups by } \\
\text { season) }\end{array}$} & \multirow{2}{*}{ N/A } & Spr & Sum & Fall & Spr & Sum & Fall & Spr & Sum & Fall & Spr & Sum & Fall \\
\hline & & 106 & 1,102 & 122 & 546 & 1,378 & 611 & 55 & 138 & 61 & 109 & 551 & 306 \\
\hline \multirow[t]{4}{*}{ Enclaves } & N/A & \multicolumn{3}{|c|}{ None } & \multicolumn{3}{|c|}{ Sand Bay } & \multicolumn{3}{|c|}{ Sand Bay } & \multicolumn{3}{|c|}{ Sand Bay } \\
\hline & & & & & \multicolumn{3}{|c|}{ N. Windham Bay } & & & & \multicolumn{3}{|c|}{ N. Windham Bay } \\
\hline & & & & & \multicolumn{3}{|c|}{ Port Houghton } & \multicolumn{3}{|c|}{ Port Houghton } & \multicolumn{3}{|c|}{ Port Houghton } \\
\hline & & & & & \multicolumn{3}{|c|}{ Fanshaw } & & & & \multicolumn{3}{|c|}{ Fanshaw } \\
\hline $15 \%$ Areas & N/A & \multicolumn{3}{|c|}{ None } & \multicolumn{3}{|c|}{ None } & \multicolumn{3}{|c|}{ None } & \multicolumn{3}{|c|}{ None } \\
\hline
\end{tabular}

\section{Mitigation}

See Appendix C for mitigation measures.

A cultural site management plan covering protection, interpretation, and monitoring will be in place before guided use will be permitted at the North Windham site for interpretive purposes. 


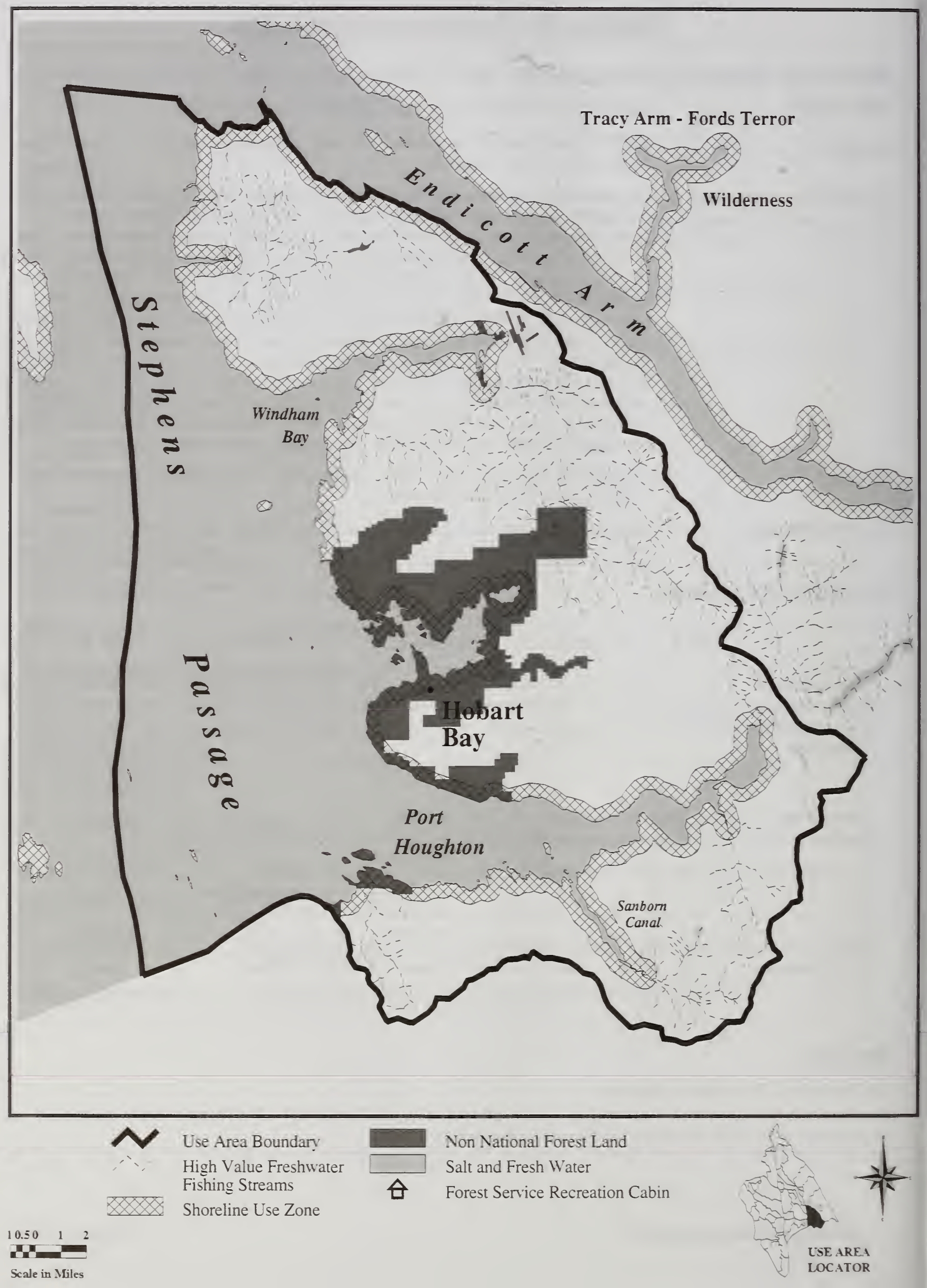




\section{Use Area 01-05D}

\section{Tracy Arm - Juneau Ranger District}

\begin{tabular}{|c|c|c|c|}
\hline Recreation Carrying Capacity (total capacity for all users) \\
\hline Groups at one time & Spring & Summer & Fall \\
\hline 12 & 504 & 1,272 & 564 \\
\hline
\end{tabular}

\section{Description}

This large use area includes the Tracy Arm and Endicott Arm Wilderness areas.

LUDs Semi-Remote Recreation, Wilderness

ROS

Primitive, Semi-Primitive Motorized, Semi-Primitive Non-Motorized

National Forest Shoreline 157 miles

Miles

National Forest Shoreline $\quad 40,446$ acres

Acres

Communities None

Alaska Coastal Portions fall within the Juneau District Coastal Management Program.

Management Act

Forest Service Facilities

None

\section{Non-National Forest System Lands}

None

\section{Recreation Use}

Area Attractions

Commercial Use

Non-commercial Use

Use Patterns

Primary Use Areas
Scenic view and glaciers

Kayak camping, goat and bear hunting, nature tours, and sightseeing

Sightseeing, camping, kayaking, hiking, fishing, hunting, wildlife viewing, and photography

There is a high amount of cruise ship traffic that enters Tracy Arm to view the North and South Sawyer Glaciers. This area is also popular for kayakers. Endicott Arm receives higher levels of commercial fishing use than Tracy Arm, and has been a less-frequented destination for recreationists, although use is increasing. Commercial crab pots are stored in numerous places in Endicott Arm.

Various sites along Tracy Arm 


\section{Use Area 01-05D}

\section{Tracy Arm - Juneau Ranger District}

\section{Management/Resource Considerations}

Subsistence

\section{Wildlife}

Fisheries

Botany

Cultural/Heritage
There are no anticipated restrictions on subsistence resource users.

While only 20 bald eagle nests have been mapped in this area, it is assumed that nests are located along the shoreline in numbers at least equal to surveyed areas to the north. Goat hunting within Tracy Arm.

These fiords contain extremely steep terrain providing for few streams with good fish habitat and fishing opportunities. Eight Class I streams have been mapped in this area. No streams have been identified with high fishing values.

Botrychium ferns were found at one beach meadow site. Five surveys were completed on one mile of shoreline.

Three prehistoric sites and one historic site were discovered during 16 surveys of the area that covered 4.5 miles.

\section{Alternative Comparisons}

\begin{tabular}{|l|c|c|c|c|c|c|c|c|c|c|c|c|c|}
\hline & Alt. 1 & \multicolumn{3}{|c|}{ Alt. 2 } & \multicolumn{3}{c|}{ Alt. 3 } & \multicolumn{3}{c|}{ Alt. 4 } & \multicolumn{3}{c|}{ Alt. 5 } \\
\hline $\begin{array}{l}\text { Commercial } \\
\begin{array}{l}\text { Allocation } \\
\text { (groups by } \\
\text { season) }\end{array}\end{array}$ & N/A & Spr & Sum & Fall & Spr & Sum & Fall & Spr & Sum & Fall & Spr & Sum & Fall \\
\cline { 2 - 13 }$y$ & 50 & 509 & 56 & 252 & 636 & 282 & 25 & 64 & 33 & 50 & 254 & 141 \\
\hline Enclaves & N/A & \multicolumn{3}{|c|}{ None } & \multicolumn{3}{c|}{ None } & \multicolumn{3}{c|}{ None } & \multicolumn{2}{c|}{ None } \\
\hline 15\% Areas & N/A & \multicolumn{3}{|c|}{ None } & \multicolumn{3}{c|}{ None } & \multicolumn{3}{c|}{ None } & \multicolumn{3}{c|}{ None } \\
\hline
\end{tabular}

\section{Mitigation}

See Appendix C for mitigation measures.

Goat and other big game issues will be addressed at the annual meeting with ADF\&G. If necessary, harvest restrictions will be placed on guided hunting. 
Shoreline Outfitter/Guide EIS

Use Area - 01-05D

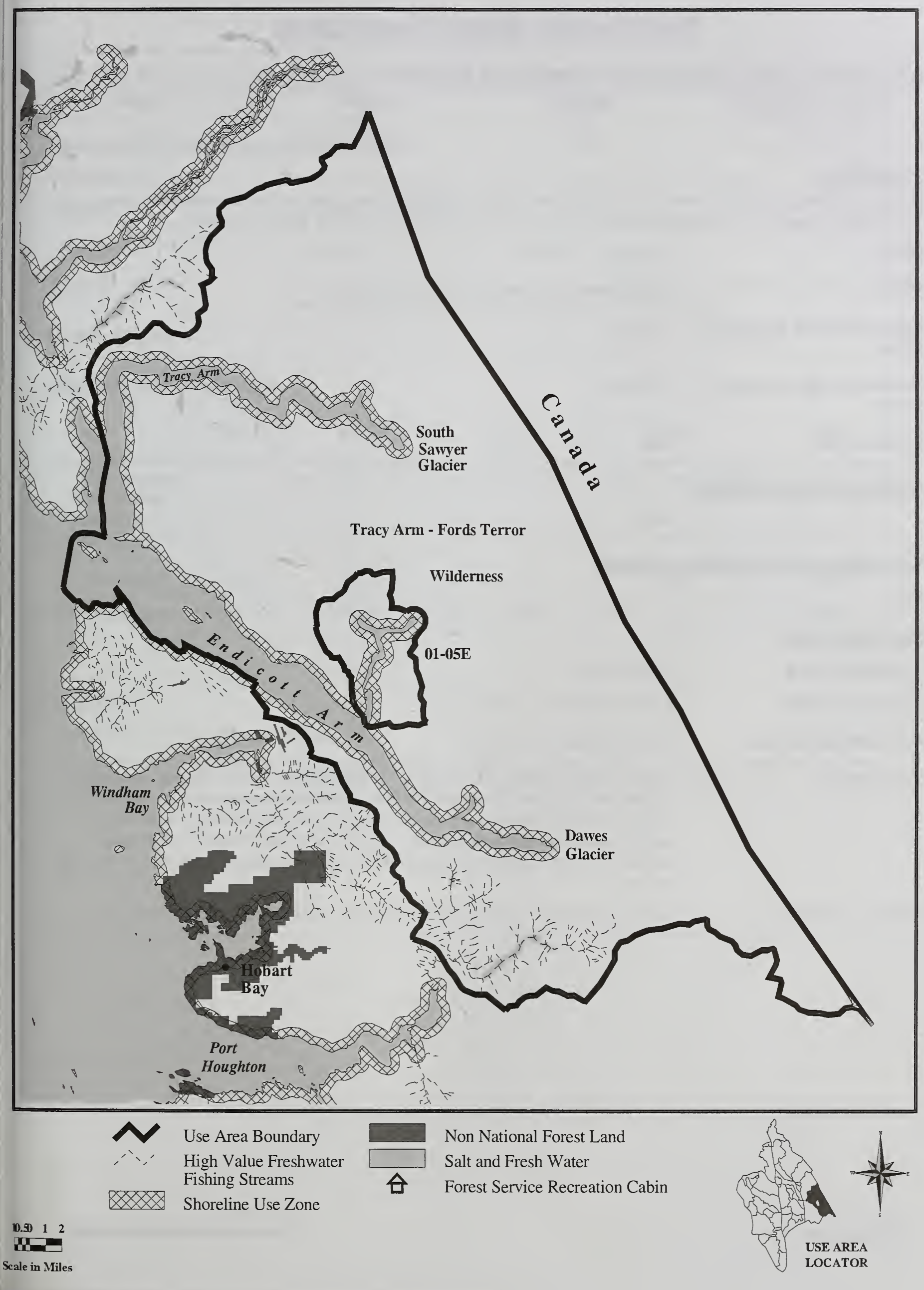




\section{Use Area 01-05E}

\section{Fords Terror - Juneau Ranger District}

\section{Recreation Carrying Capacity (total capacity for all users)}

\begin{tabular}{|c|c|c|c|}
\hline Groups at one time & Spring & Summer & Fall \\
\hline 3 & 126 & 318 & 141 \\
\hline
\end{tabular}

\section{Description}

This area encompasses Fords Terror, a wilderness area with unique characteristics that warrant a separate unit designation. Fords Terror is small fiord of Endicott Arm and has steep rock walls that can amplify and echo sounds.
LUDs
Wilderness
ROS
Primitive and Semi-Primitive Non-Motorized

National Forest Shoreline 22 miles
Miles

\section{National Forest Shoreline $\quad 6,652$ acres \\ Acres}

Communities

None

Forest Service Facilities

None

\section{Non-National Forest System Lands}

None

\section{Recreation Use}

Area Attractions

Scenic views

Commercial Use

Kayak camping tours and day use

Non-commercial Use

Kayaking and kayak camping

Use Patterns

There are six identified campsites in the area managed in a 'rest-rotation' schedule to minimize site impacts. Campsite ' $\mathrm{T}$ ' is one of the two most heavily used sites in Fords Terror. The other occurs on the west shore just before the narrows, a potentially dangerous passage of swirling water at high and low tides, hence the area's name. Because of narrow access and unpredictable currents at running tides, this is not a high use area.

Primary Use Areas

Six campsites within this use area, with the site at the ' $T$ ' receiving the most use 


\section{Use Area 01-05E}

\section{Fords Terror - Juneau Ranger District}

\section{Potential Areas for Large Group Use}

None identified

\section{Management/Resource Considerations}

Subsistence

Wildlife

Fisheries

Botany

Cultural/Heritage
There are no anticipated restrictions on subsistence resource users.

No issues or concerns

No high value fishing streams identified.

There are no known sensitive plants. This area has not received intensive surveys. Beach meadows and camping spots may be sensitive to recreation use.

There are no known sites. This area has not been intensively surveyed.

\section{Alternative Comparisons}

\begin{tabular}{|c|c|c|c|c|c|c|c|c|c|c|c|c|c|}
\hline & Alt. 1 & \multicolumn{3}{|c|}{ Alt. 2} & \multicolumn{3}{|c|}{ Alt. 3} & \multicolumn{3}{|c|}{ Alt. 4} & \multicolumn{3}{|c|}{ Alt. 5} \\
\hline \multirow{2}{*}{$\begin{array}{l}\text { Commercial } \\
\text { Allocation } \\
\text { (groups by } \\
\text { season) }\end{array}$} & \multirow{2}{*}{ N/A } & Spr & Sum & Fall & Spr & Sum & Fall & Spr & Sum & Fall & Spr & Sum & Fall \\
\hline & & 13 & 127 & 14 & 63 & 159 & 71 & 15 & 33 & 15 & 13 & 60 & 35 \\
\hline Enclaves & N/A & \multicolumn{3}{|c|}{ None } & \multicolumn{3}{|c|}{ None } & \multicolumn{3}{|c|}{ None } & \multicolumn{3}{|c|}{ None } \\
\hline $15 \%$ Areas & N/A & \multicolumn{3}{|c|}{ None } & \multicolumn{3}{|c|}{ None } & \multicolumn{3}{|c|}{ None } & \multicolumn{3}{|c|}{ None } \\
\hline
\end{tabular}

\section{Mitigation}

See Appendix $C$ for mitigation measures.

In Fords Terror, guided use will be limited to using a single site for no more than two consecutive nights. Only two camping sites, "Middle T" and "North Narrows", will be available for group sizes larger than six people. 


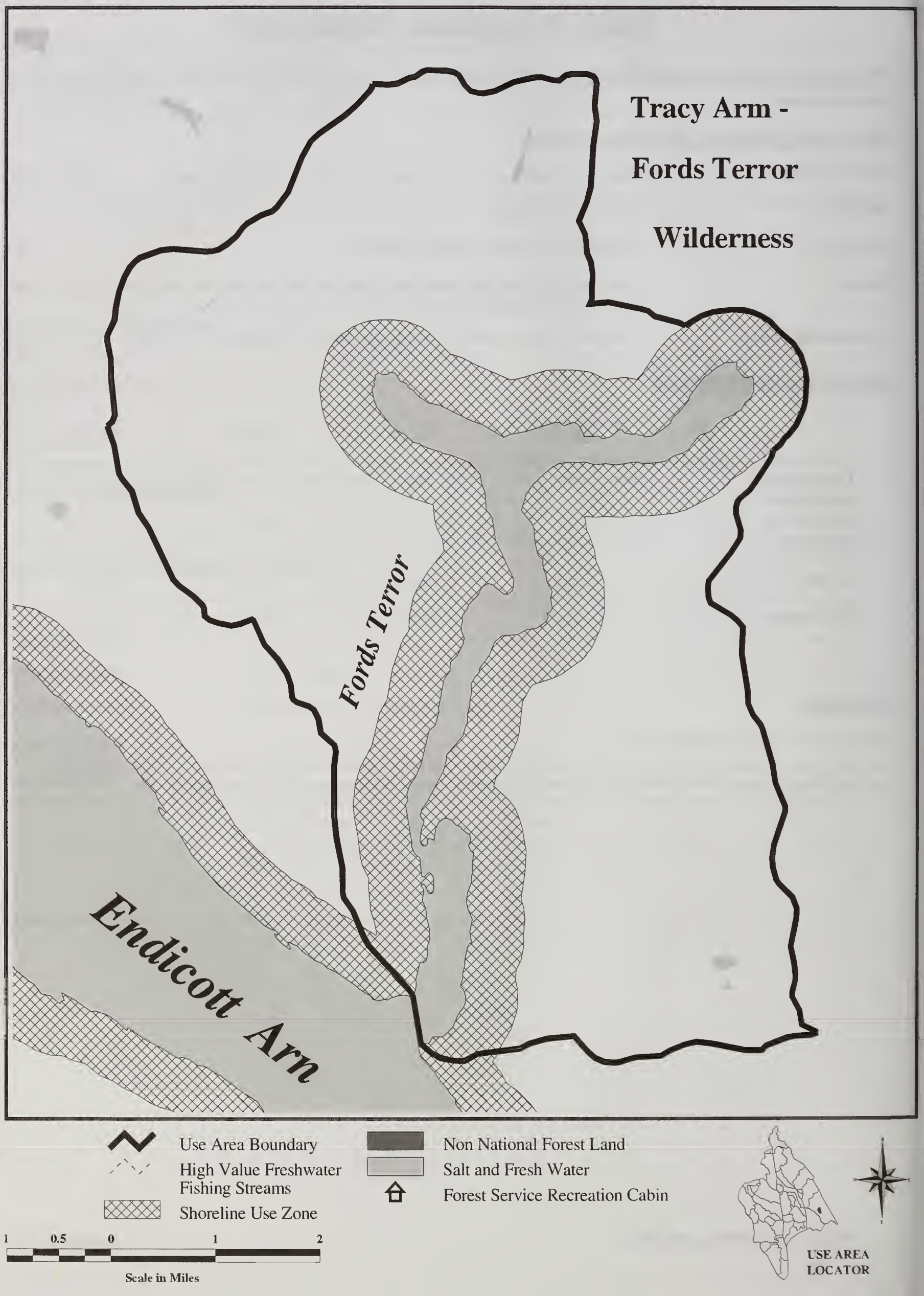


Gut Bay (Southeast Baranof) - Sitka Ranger District

\section{Recreation Carrying Capacity (total capacity for all users)}

\begin{tabular}{|c|c|c|c|}
\hline Groups at one time & Spring & Summer & Fall \\
\hline 8 & 336 & 848 & 376 \\
\hline
\end{tabular}

\section{Description}

This use area, on southeastern Baranof Island, extends from south of Warm Springs Bay to the mouth of Patterson Bay including the eastern portion of the South Baranof Wilderness. This use area is characterized by stretches of inaccessible coastline adjacent to Chatham Strait with numerous small bays and coves. Four large bays (Red Bluff, Hoggatt, Gut, and Patterson) provide reliable anchorages and good access to the uplands.

LUDs

Wilderness and Remote Recreation

ROS

Primitive and Semi-Primitive Motorized

National Forest Shoreline 123 miles

Miles

National Forest Shoreline $\quad 29,818$ acres

Acres

Communities

None

Alaska Coastal

Management Act

Sitka District Coastal Management Program

Forest Service Facilities

None

\section{Non-National Forest System Lands}

None

\section{Recreation Use}

Area Attractions

Brown bear hunting, freshwater fishing, hiking, sightseeing

Commercial Use

Brown bear hunting, freshwater fishing, hiking, sightseeing

Non-commercial Use

Most non-commercial use is transient boaters, especially on the uplands adjacent to the area's protected bays.

Use Patterns

Commercial trollers and crabbers; boat based commercial outfitter/guides and recreational boaters.

Primary Use Areas

Red Bluff Bay is a popular anchorage for boats transiting Chatham Strait and is a convenient anchorage for people accessing Falls Lake. Patterson and Gut Bays are also used. 


\section{Use Area 04-01A}

\section{Gut Bay (Southeast Baranof) - Sitka Ranger District}

\section{Management/Resource Considerations}

\section{Subsistence}

Wildlife

Fisheries

Botany

Cultural/Heritage
Gut Bay and Falls Lake support subsistence sockeye fisheries for the community of Kake. There are no anticipated restrictions on subsistence resource uses as a result of this project.

One NFMS identificd Stcller sea lion haul-out is located in this use area. Although not mapped, bald eagle nests are presumed to exist in similar numbers found in surveyed areas to the north of this GUA. Harbor seal haul outs.

Fifty-nine Class I streams have been mapped in this area. Three streams were identified with high fishing potential. Two of these, Gut Bay and Falls Lake, are subsistence sockeye systems. Gut Bay and Falls Lake support subsistence sockeye fisheries for the community of Kake. Due to possible declines in escapement, the Federal Subsistence Board recently closed sport fishing for sockeye in these systems, to protect the subsistence fishing priority. An important stream enters at the head of Gut Bay, which produces a large number of pink salmon and Dolly Varden char. See Appendix C. Mitigation Measures.

Two botanical surveys have been completed on one-half mile of shoreline within this GUA with no rare or sensitive plants found.

Eight surveys have been completed in this area covering 3.5 miles. Three historic sites have been identified.

\section{Alternative Comparisons}

\begin{tabular}{|c|c|c|c|c|c|c|c|c|c|c|c|c|c|}
\hline & Alt. 1 & & Alt. 2 & & & Alt. 3 & & & Alt. 4 & & & Alt. & \\
\hline \multirow{2}{*}{$\begin{array}{l}\text { Commercial } \\
\text { Allocation } \\
\text { (groups by } \\
\text { season) }\end{array}$} & \multirow{2}{*}{ N/A } & Spr & Sum & Fall & Spr & Sum & Fall & Spr & Sum & Fall & Spr & Sum & Fall \\
\hline & & 34 & 339 & 38 & 168 & 424 & 188 & 19 & 80 & 37 & 34 & 339 & 94 \\
\hline Enclaves & $\mathrm{N} / \mathrm{A}$ & & None & & & None & & & None & & & None & \\
\hline $15 \%$ Areas & $\mathrm{N} / \mathrm{A}$ & & None & & & None & & & None & & & None & \\
\hline
\end{tabular}

\section{Mitigation}

See Appendix $\mathrm{C}$ for mitigation measures.

Guided use on Cowee Creek and Sawmill Creek will not be allowed on weekends or on state or federal holidays to reduce the potential for conflicts with unguided uscrs. Guided use must not displace unguided users.

Guided fishing usc is prohibited during the subsistence sockeye fishery at Gut Bay and Falls Lake. 


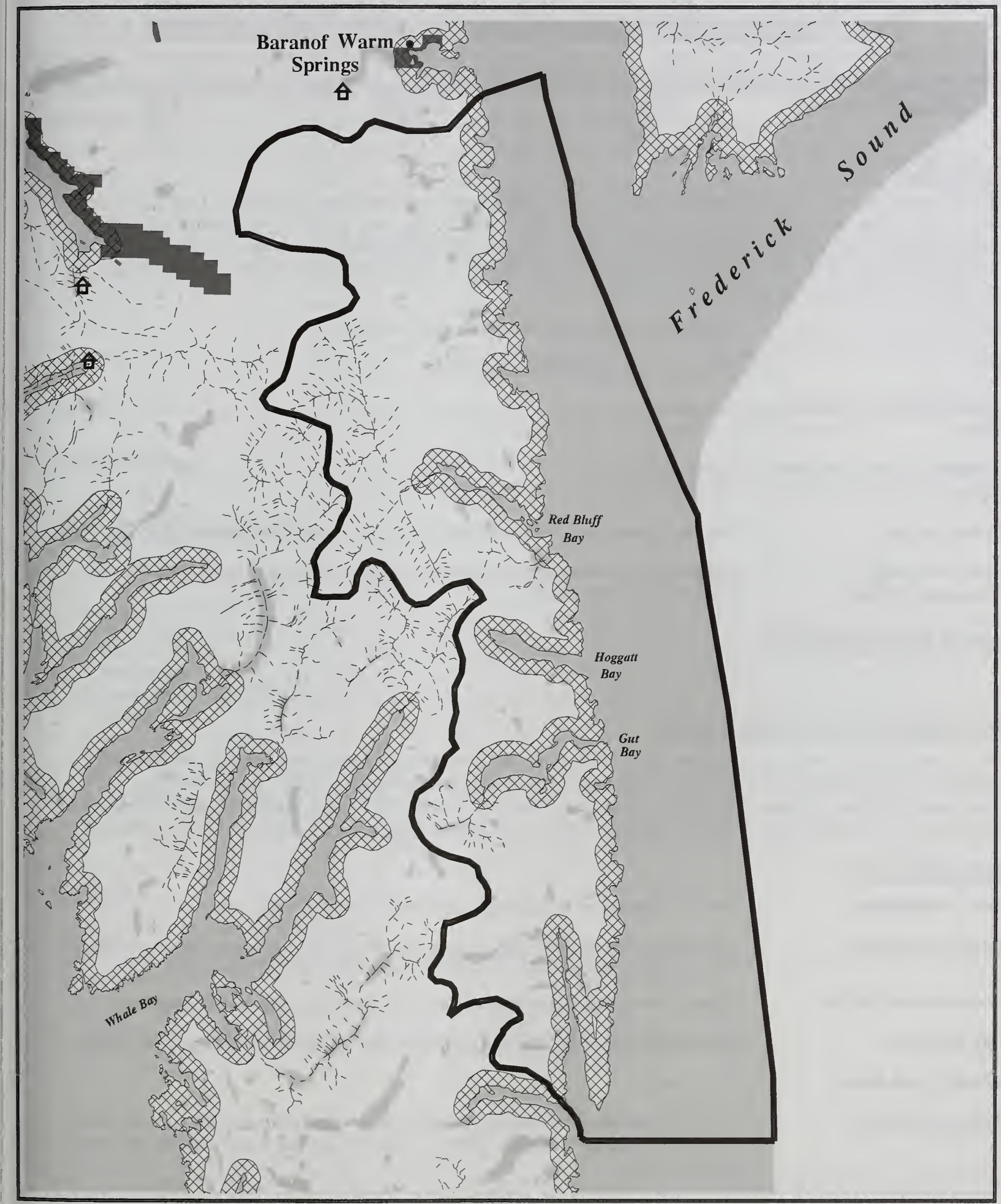

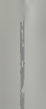

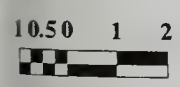

Use Area Boundary High Value Freshwater Fishing Streams $\$ 2 \times$ Shoreline Use Zone
Non National Forest Land

Salt and Fresh Water

Forest Service Recreation Cabin

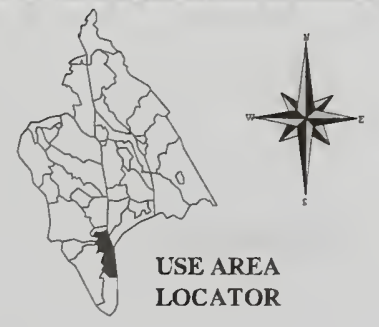




\section{Use Area 04-01B}

\section{Port Armstrong (Southeastern Baranof) - Sitka Ranger District}

\section{Recreation Carrying Capacity (total capacity for all users)}

\begin{tabular}{|c|c|c|c|}
\hline Groups at one time & Spring & Summer & Fall \\
\hline 7 & 294 & 742 & 329 \\
\hline
\end{tabular}

\section{Description}

This use area is located on southeastern Baranof Island, extending from the mouth of Patterson Bay to Cape Ommaney, then north along the west side of the island including Larch Bay. Much of the outer coastline and coastline adjacent to Chatham Strait is inaccessible. Numerous small bays and coves are accessible depending on weather conditions. A number of large bays including Deep Cove, Port Herbcrt, Port Walter, Port Lucy, Port Armstrong, John Bay, and Port Conclusion provide anchoragcs and good access to the uplands.

$\begin{array}{ll}\text { LUDs } & \text { Rcmote Recrcation and Semi-Remote Recreation } \\ \text { ROS } & \text { Primitive and Semi-Primitive Motorizcd } \\ \begin{array}{l}\text { National Forest Shoreline } \\ \text { Miles }\end{array} & 134 \text { miles } \\ \begin{array}{l}\text { National Forest Shoreline } \\ \text { Acres }\end{array} & 25,747 \text { acres }\end{array}$

Communities

Alaska Coastal Management Act
The small community of Port Alexander is located within this use area.

Excluding Port Alexander, this use arca is within the boundary of the Sitka District Coastal Managcment Program.

\section{Forest Service Facilities}

None

\section{Non-National Forest System Lands}

Privatc land is found near the communities of Port Armstrong and Port Alexander. State land surrounds the private holdings within the small community of Port Alexander. Private land with a cabin is located at the head of Port Conclusion. Northern Southeast Regional Aquaculture Association has active fisheries development projects Deer Lake and Mist Cove. A National Marine Fisheries Service hatchery and permanent housing are located at Little Port Walter.

\section{Recreation Use}

Area Attractions

Commercial Use

Non-commercial Use

Use Patterns

Primary Use Areas

Areas of Concern
Port Alexander, Port Armstrong, Little Port Walter, and Mist Cove

Brown bear hunting, freshwater fishing, and hiking, and operators of several lodges in Port Alexander are permitted for guiding on National Forest System land.

There is substantial non-commercial use from the local communities listed above.

Boat based commercial outfitter/guides, commercial fishing and recreational boating

Mist Cove

Trail to Deer Lake from Mist Cove is very scenic with falls but trail is currently closed for public use because of safety concerns. Sashin Lake trail is also currently closed for safety reasons. 


\section{Use Area 04-01B}

\section{Port Armstrong (Southeastern Baranof) - Sitka Ranger District}

\section{Management/Resource Considerations}

\section{Subsistence}

Wildlife

Fisheries

Botany

Cultural/Heritage
No anticipated restrictions on subsistence resource users.

Two NFMS identified Steller sea lion haul-outs located in this area. Although there are only 10-mapped bald eagle nests, it is assumed that nests are located along the shoreline in numbers at least equal to surveyed areas to the north.

South Baranof Island is a relatively narrow mountainous region favoring shorter steeper streams. While over 100 Class I streams have been mapped in this area, the larger fish bearing streams are absent. However, several lakes with good sport fishing opportunities are found within the project area. Betty and Jetty Lakes drain into Port Armstrong and contain good populations of rainbow trout. The Sashin Lake and Creek system empties into Little Port Walter and is an important fisheries research area for the adjacent NMFS station. Deer Lake has a coho-rearing project run by NSRAA.

Four botanical surveys have been done covering about $3 / 4$ mile of the shoreline in this use area. Mimulus lewisii was found on a beach meadow site in Deep Cove.

A total of 78 cultural surveys covering 28 miles have been completed, with 6 historical sites identified within this use area. Old cannery site in Port Walter is a concern

\section{Alternative Comparisons}

\begin{tabular}{|c|c|c|c|c|c|c|c|c|c|c|c|c|c|}
\hline & Alt. 1 & & Alt. 2 & & & Alt. 3 & & & Alt. 4 & & & Alt. 5 & \\
\hline \multirow{2}{*}{$\begin{array}{l}\text { Commercial } \\
\text { Allocation } \\
\text { (groups by } \\
\text { season) }\end{array}$} & \multirow{2}{*}{ N/A } & Spr & Sum & Fall & Spr & Sum & Fall & Spr & Sum & Fall & Spr & Sum & Fall \\
\hline & & 29 & 297 & 33 & 147 & 371 & 165 & 27 & 68 & 16 & 29 & 297 & 82 \\
\hline Enclaves & N/A & & None & & & None & & & None & & & None & \\
\hline $15 \%$ Areas & N/A & & None & & & None & & & None & & & None & \\
\hline
\end{tabular}

\section{Mitigation}

See Appendix C for mitigation measures.

Guided use of Mist Cove/Deer Lake trail and the Little Port Walter/Sashin Lake trail will not be permitted until the trails are reconstructed.

Guided hunting will not be permitted within one mile of the community of Port Alexander.

No guided use will be permitted at the Port Walter cannery site or other eligible cultural sites. 
Shoreline Outfitter/Guide EIS

Use Area - 04-01B

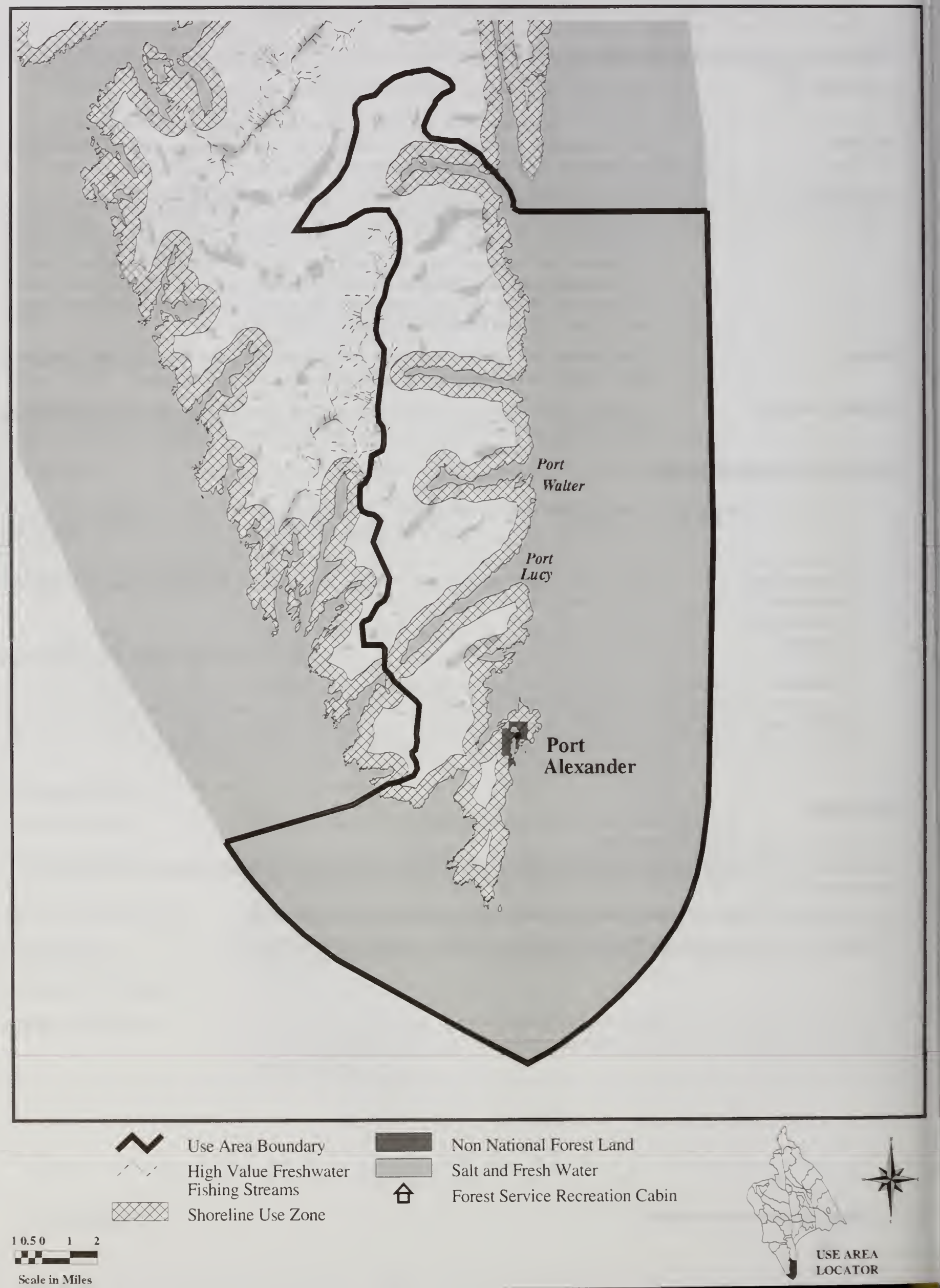




\section{Use Area 04-02A}

Redoubt Lake (Central Baranof) - Sitka Ranger District

Recreation Carrying Capacity (total capacity for all users)

\begin{tabular}{|c|c|c|c|}
\hline Groups at one time & Spring & Summer & Fall \\
\hline 20 & 840 & 2,120 & 940 \\
\hline
\end{tabular}

\section{Description}

This use area is located on the southwestern portion of Baranof Island and extending from south of Three Entrance Bay to north of President Bay including a number of smaller offshore islands. The outer coast of this use area is swept by ocean swell and largely inaccessible. However, some areas provide protected access to the uplands such as Redoubt, Kanga, Big, and Seven Fathom Bays. While boaters traveling to these areas will be exposed to ocean swell, much of the travel route is in the relatively sheltered water behind offshore islands.

LUDs

ROS

National Forest Shoreline

Miles

National Forest Shoreline

Acres

Communities

Alaska Coastal

Management Act
Modified Landscape, Old Growth, and Semi-Remote Recreation

Primitive, Roaded Modified, Semi-Primitive Motorized, Semi-Primitive Nonmotorized, and Roaded Natural

253 miles

19,081 acres

None

Sitka District Coastal Management Program

\section{Forest Service Facilities}

Public Recreation Cabins Redoubt Lake, Kanga, and Seven Fathom

Trails

Silver Bay to Redoubt Cabin

\section{Non-National Forest System Lands}

The unified City and Borough of Sitka manage several hot spring bath-houses at Goddard on city and borough property, and a trail that runs from Goddard to the west end of Redoubt Lake. Goddard is a popular destination for residents of Sitka. There are also several private parcels of land at Goddard, as well as a tract of state select land. There are two parcels of encumbered Native Allotment claims, near Kizuchia Creek, and two Regional Corporation selections at the outlet of Redoubt Lake. State select lands associated with an air navigation facility are found on Biorka Island.

\section{Recreation Use}

Area Attractions

Goddard Hot Springs (private), Forest Service recreation cabins, several sandy beaches popular for picnicking, and subsistence sockeye fishery at Redoubt Lake

Commercial Use

Brown bear hunting, camping, sightseeing, and picnicking

Non-commercial Use

Salmon fishing, hot springs, and hiking

Use Patterns

The entire area is popular with residents of Sitka for recreation, subsistence uses, and commercial fishing.

Primary Use Areas

Biorka Island, Redoubt Bay, Goddard, Big Bay, and Seven Fathom Bay 


\section{Use Area 04-02A}

\section{Redoubt Lake (Central Baranof) - Sitka Ranger District}

\section{Management/Resource Considerations}

\section{Subsistence}

Wildlife

Fisheries

Botany

Cultural/Heritage
Redoubt Lake has a subsistence sockeye fisheries used by the residents of Sitka. There are no anticipated restrictions on subsistence resource users as a result of this project.

Two NMFS identified Steller sea lion haul-outs and 30 mapped bald eagle nests are located within this use area.

In this use area, 13 Class I streams and two high value streams have been mapped. Redoubt Lake is the largest producer of sockeye salmon for subsistence uses for Sitka. Guided fishing is not allowed at Redoubt Lake during the personal use sockeye fishery.

One survey covering $1 / 4$-mile of shoreline was completed with no rare or sensitive plants found.

Nine surveys covering 2.5 miles revealed six historic and two prehistoric sites.

\section{Alternative Comparisons}

\begin{tabular}{|c|c|c|c|c|c|c|c|c|c|c|c|c|c|}
\hline \multirow{3}{*}{$\begin{array}{l}\text { Commercial } \\
\text { Allocation } \\
\text { (groups by } \\
\text { season) }\end{array}$} & \multirow{3}{*}{$\begin{array}{l}\text { Alt. } 1 \\
\text { N/A }\end{array}$} & \multicolumn{3}{|c|}{ Alt. 2} & \multicolumn{3}{|c|}{ Alt. 3} & \multicolumn{3}{|c|}{ Alt. 4} & \multicolumn{3}{|c|}{ Alt. 5} \\
\hline & & $\mathrm{Spr}$ & Sum & Fall & Spr & Sum & Fall & Spr & Sum & Fall & Spr & Sum & Fall \\
\hline & & 84 & 848 & 94 & 420 & 1,060 & 470 & 42 & 106 & 47 & 84 & 848 & 235 \\
\hline Enclaves & N/A & \multicolumn{3}{|c|}{ None } & \multicolumn{3}{|c|}{ None } & \multicolumn{3}{|c|}{ None } & \multicolumn{3}{|c|}{ None } \\
\hline $15 \%$ Areas & N/A & \multicolumn{3}{|c|}{ None } & \multicolumn{3}{|c|}{ None } & \multicolumn{3}{|c|}{ None } & \multicolumn{3}{|c|}{ None } \\
\hline $\begin{array}{l}\text { Guided } \\
\text { Fishing } \\
\text { Restrictions }\end{array}$ & N/A & \multicolumn{3}{|c|}{ Yes } & \multicolumn{3}{|c|}{ No } & \multicolumn{3}{|c|}{ Yes } & \multicolumn{3}{|c|}{ Yes } \\
\hline
\end{tabular}

\section{Mitigation}

See Appendix $\mathrm{C}$ for mitigation measures.

No more than two guided fishing groups are allowed at one time at Redoubt Lake and its outlet stream from August 21 to September 30 in Alternatives 2, 4, and 5. 


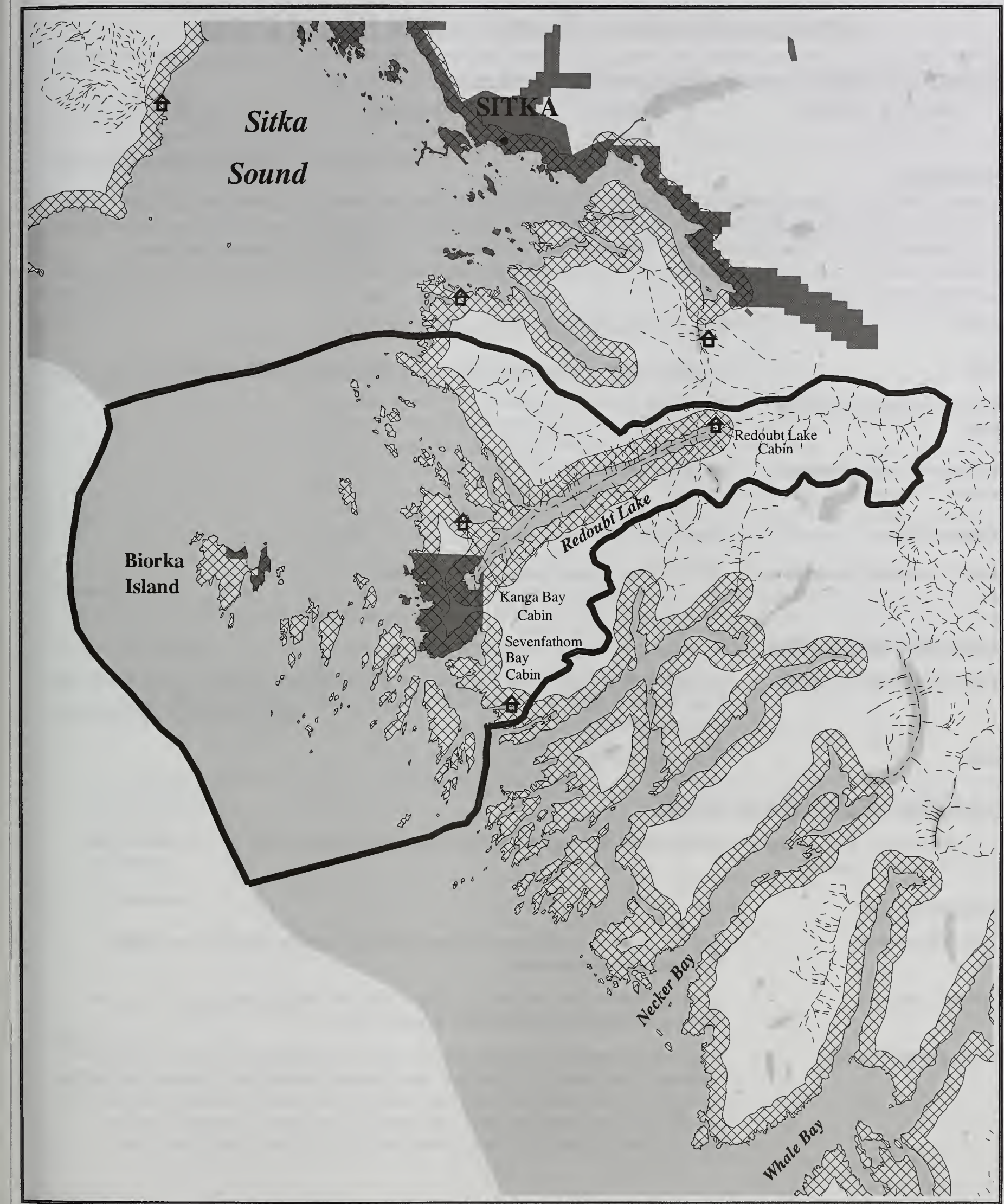
Use Area Boundary
High Value Freshwater Fishing Streams
Shoreline Use Zone

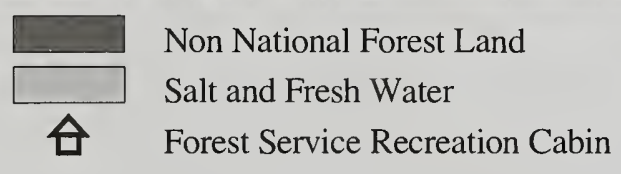
Non National Forest Land
Salt and Fresh Water
Forest Service Recreation Cabin

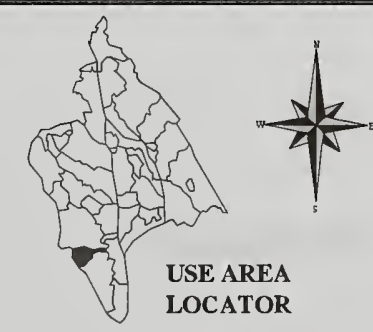




\section{Use Area 04-02B}

Whale Bay (Southwest Baranof) - Sitka Ranger District

\begin{tabular}{|c|c|c|c|}
\hline \multicolumn{2}{|c|}{ Recreation Carrying Capacity (total capacity for all users) } \\
\hline Groups at one time & Spring & Summer & Fall \\
\hline 18 & 756 & 1,908 & 846 \\
\hline
\end{tabular}

\section{Description}

Loeated on the southwestern portion of Baranof Island, this use area extends from north of President Bay, to south of Little Puffin Bay ineluding a number of offshore islands and the western portion of the South Baranof Wilderness. The analysis area is eharacterized by an inaceessible outer coast with bays providing protected aecess to the uplands including: President, Neeker, Whale, Sandy, Snipe, Byron, Red Fish, Little Braneh, Puffin and Little Puffin Bays, and both Crawfish and West Crawfish Inlets.

$\begin{array}{ll}\text { LUDs } & \text { Remote Recreation and Wilderness } \\ \text { ROS } & \text { Primitive, Semi-Primitive Motorized, and Semi-Primitive Non-motorized } \\ \begin{array}{l}\text { National Forest Shoreline } \\ \text { Miles }\end{array} & 525 \text { miles } \\ \begin{array}{l}\text { National Forest Shoreline } \\ \text { Acres }\end{array} & 82,909 \text { acres } \\ \text { Communities } & \text { None }\end{array}$

Alaska Coastal Management Sitka Distriet Coastal Management Program

Act

\section{Forest Service Facilities}

Public Recreation Cabins

One cabin each is located near the shores of Davidof Lake, Plotnikof Lake and Avoss Lake, however these cabins are eaeh loeated more than a mile inland from the saltwater shoreline.

Trails

Trail from Davidof Lake to Plotnikof Lake

\section{Non-National Forest System Lands}

All the land within this use area is National Forest System land. An outfitter/guide operates a tent camp in Rakavoi Bay during the summer months.

\section{Recreation Use}

Area Attractions

Hunting, sport and subsistenee fishing, Forest Service recreation cabins, remote

Commercial Use

Non-commercial Use

\section{recreation and seenic values}

Camping, brown bear and goat hunting, freshwater fishing, hiking, pienicking, and Rakavoi/Whale Bay outfitter/guide summer eamp

The northern reaches of this area reeeive use by residents and visitors from Sitka. Offshore islands provide a protected water route to Neeker Bay. Beyond Neeker Bay small skiff travel is determined by sea conditions and reereational use in the southern reaches of the use area is sporadie. Of particular importanee to residents are the Speeial Management Areas listed in the Sitka Coastal Zone Management Plan. 


\section{Use Area 04-02B}

\section{Whale Bay (Southwest Baranof) - Sitka Ranger District}

Use Patterns

Primary Use Areas

Due to the remote nature of this area use decreases to the south. The northern bays include West Crawfish, Crawfish, and Necker get substantial use by small skiff.

\section{Management/Resource Considerations}

Subsistence

Wildlife

Fisheries

Botany

Cultural/Heritage
There are important subsistence fisheries for the residents of Sitka. The annual average return of subsistence fishing permits is 125 for use of Necker Bay, Politofski Lake, and Redfish Lake. There are no anticipated restrictions on subsistence resource users as a result of this project.

Two NMFS identified Steller sea lion haul-outs located in this use area. Bald eagle nests are believed to exist in numbers at least equal to surveyed areas to the north of this use area.

Nine streams were identified as having high fishing values. Three of these streams are important to subsistence sockeye systems. Necker Bay contains the second largest producer of sockeye salmon (Benzeman Lake) for subsistence users from Sitka. Politofski Lake is a sockeye producer that drains into Whale Bay. Tumakof Lake drains into Redfish Bay and supports a good run of large sockeye salmon. A somewhat unique summer run of coho salmon passes through Port Banks, returning to Plotnikof Lake. This system also supports a small run of steelhead. Other important fish producing systems include the streams at the head of West Crawfish Inlet, No Name Bay (West Crawfish Inlet), and Sandy Bay.

Seventeen surveys have been completed on $3-1 / 2$ miles of shoreline, with no rare or sensitive plants found.

Twenty-two surveys covering 3.75 miles revealed seven historic and eight prehistoric sites.

\section{Alternative Comparisons}

\begin{tabular}{|c|c|c|c|c|c|c|c|c|c|c|c|c|c|}
\hline \multirow{3}{*}{$\begin{array}{l}\text { Commercial } \\
\text { Allocation } \\
\text { (groups by } \\
\text { season) }\end{array}$} & \multirow{3}{*}{$\begin{array}{l}\text { Alt. } 1 \\
\text { N/A }\end{array}$} & \multicolumn{3}{|c|}{ Alt. 2} & \multicolumn{3}{|c|}{ Alt. 3} & \multicolumn{3}{|c|}{ Alt. 4} & \multicolumn{3}{|c|}{ Alt. 5} \\
\hline & & Spr & Sum & Fall & Spr & Sum & Fall & Spr & Sum & Fall & Spr & Sum & Fall \\
\hline & & 76 & 763 & 85 & 378 & 954 & 423 & 38 & 193 & 42 & 76 & 763 & 212 \\
\hline Enclaves & N/A & \multicolumn{3}{|c|}{ None } & \multicolumn{3}{|c|}{ None } & \multicolumn{3}{|c|}{ None } & \multicolumn{3}{|c|}{ None } \\
\hline $15 \%$ Areas & N/A & \multicolumn{3}{|c|}{ None } & \multicolumn{3}{|c|}{ None } & \multicolumn{3}{|c|}{ None } & \multicolumn{3}{|c|}{ None } \\
\hline
\end{tabular}

\section{Mitigation}

See Appendix C for mitigation measures. 


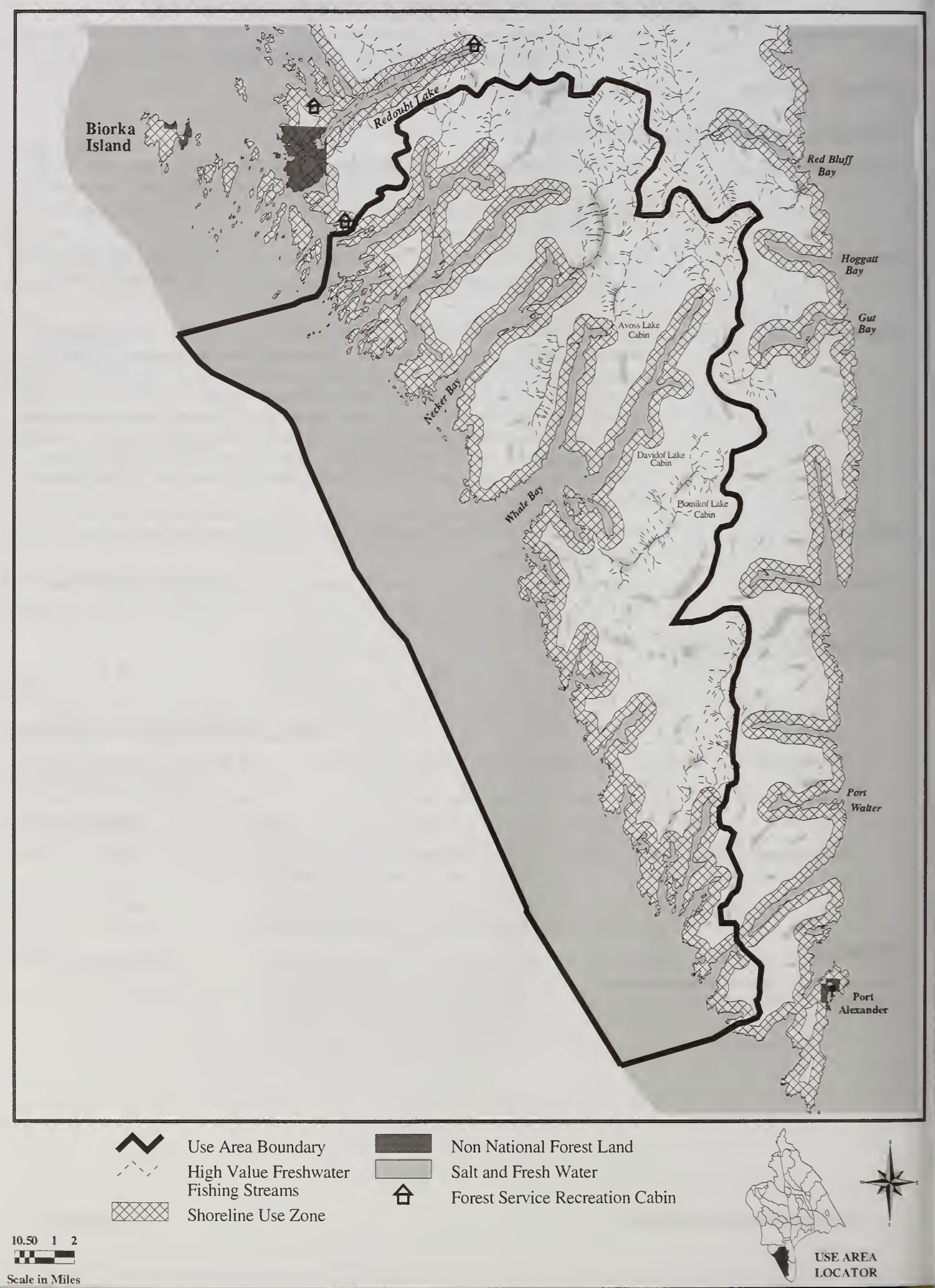


Sitka Area (West Central Baranof) - Sitka Ranger District

\begin{tabular}{|c|c|c|c|}
\hline \multicolumn{4}{|l|}{ Recreation Carrying Capacity (total capacity for all users) } \\
\hline Groups at one time & Spring & Summer & Fall \\
\hline 40 & 1,680 & 4,240 & 1,880 \\
\hline
\end{tabular}

\section{Description}

This use area includes a small portion of the West Chichagof - Yakobi Wilderness (along the north shore of Salisbury Sound) and the following islands: Kruzof, Partofshikof, Halleck, Krestof, northwest Baranof, and the Siginaka Islands from north of Fish Bay to south of Three Entrance Bay. A Special Interest Area, Mount Edgecumbe Geological Area, is also found in this use area. Much of the shoreline is protected and provides easy access to uplands in numerous bays, sounds, and straits. The outer coastline along Kruzof Island's western shore is relatively inaccessible from the water.

LUDS

ROS

National Forest Shoreline

Miles

National Forest Shoreline

Acres

Communities

Alaska Coastal

Management Act

\section{Forest Service Facilities}

Public Recreation Cabins

Special Use Cabins

Shelters

Trails
Modified Landscape, Old Growth, Remote Recreation, Special Interest, Semi-Remote Recreation, Scenic Viewshed, and Timber Production, and Wilderness

Primitive, Roaded Modified, Roaded Natural, Semi-Primitive Motorized, and SemiPrimitive Non-motorized

417 miles

76,413 acres

The community of Sitka is located within this use area.

Portions of the area are covered under the Sitka District Coastal Management Program and amendments under the City and Borough of Sitka Parks and Recreation Plan.

Cabins are located at Brent's Beach, Fred's Creek, Shelikof Bay, North Beach, Allan Point, Piper Island, Salmon Lake, Samsing, and Suloia Lake; however, the cabins at Suloia and Salmon Lakes are located more than a mile inland from the saltwater shoreline.

There are three private recreation cabins on National Forest System lands under special use permit: two in Birdsnest Bay and one in Sukoi Inlet.

Neva, Kakul and Mt. Edgecumbe

Mt. Edgecumbe Trail is a National Recreation Trail that leads to the top of Mt.

Edgecumbe. There is a trail from Silver Bay past Salmon Lake to Redoubt Lake. There are also several road systems accessible only by water that are used as hiking and ATV trails, including: Mud Bay to Shelikof Bay and North Beach, Eagle River, Nakwasina, and Saint John Baptist Bay.

\section{Non-National Forest System Lands}

There are numerous tracts of non-National Forest System lands within the area, including private and municipal lands within the City and Borough of Sitka; Native Corporation lands at Katlian Bay, Krugloi Point, and Sealion Cove; state lands at Port Krestof, Lisianski Peninsula, Kalinin Bay, Starrigavan, Silver Bay, and the Magoun Islands; and private lands at Dog Point, and on the islands of Sitka Sound. In addition, there are encumbered lands involving Native Allotment Claims at St. John Baptist Bay, Nakwasina Sound, and Sinitsin Cove. 


\section{Use Area 04-03}

\section{Sitka Area (West Central Baranof) - Sitka Ranger District}

\section{Recreation Use}

Area Attractions

Commercial Use

Non-commercial Use

Use Patterns

Primary Use Areas

Forest Service cabins, hiking trails, fishing, hunting, scenic views, and old growth forest

Brown bear hunting, camping, freshwater fishing, goat hunting, hiking, picnicking, and sightseeing

This use area is easily accessible and is popular with residents and non-guided visitors from Sitka. Of particular importance to residents, are the destinations listed as Special Management Areas in the Sitka Coastal Zone Management Plan.

Both residents and non-residents use the entire area. Residents disperse and use accessible uplands along the many miles of protected shoreline.

The most heavily used areas include all of the Sitka Accessible sites and the Kruzof road system.

\section{Management/Resource Considerations}

\section{Subsistence}

\section{Wildlife}

Fisheries

Botany

Cultural/Heritage
There are several stream systems that are important for subsistence users from Sitka. An annual average of 25 subsistence-fishing permits were returned for use at Salmon Lake, Neva Creek, and Aluetkina Bay. There are no anticipated restrictions on subsistence resource users as a result of this project.

NMFS has identified two Steller sea lion haul outs in this use area. There also are 192 mapped bald eagle nests.

This use area receives extensive use by subsistence, sport and commercial fishers. There are at least 14 major anadromous streams with high freshwater fishing values. These systems support returns of coho, chum, and pink salmon. Dolly Varden char are abundant in many systems. Some Sitka subsistence fishers have concerns about the diminished returns of coho salmon to streams near Sitka and the increase in guided and unguided sport fishing. Though guided freshwater sport fishing on Forest Service lands has not dramatically increased in recent years, saltwater use may explain some of the local crowding concerns. Most of the sport fishing effort in the Sitka area occurs on saltwater. Salmon Lake has a small run of sockeye salmon, which is protected by ADF\&G fishing restrictions.

Six surveys were conducted. Romanzoffia unalaschensis was identified adjacent to a stream.

Sixteen historic and 37 prehistoric sites were identified from 76 surveys covering 76.5 miles. 


\section{Use Area 04-03}

\section{Sitka Area (West Central Baranof) - Sitka Ranger District}

\section{Alternative Comparisons}

\begin{tabular}{|c|c|c|c|c|c|c|c|c|c|c|c|c|c|}
\hline \multirow{3}{*}{$\begin{array}{l}\text { Commercial } \\
\text { Allocation } \\
\text { (groups by } \\
\text { season) }\end{array}$} & \multirow{3}{*}{$\begin{array}{l}\text { Alt. } 1 \\
\text { N/A }\end{array}$} & \multicolumn{3}{|c|}{ Alt. 2} & \multicolumn{3}{|c|}{ Alt. 3} & \multicolumn{3}{|c|}{ Alt. 4} & \multicolumn{3}{|c|}{ Alt. 5} \\
\hline & & Spr & Sum & Fall & Spr & Sum & Fall & Spr & Sum & Fall & Spr & Sum & Fall \\
\hline & & 168 & 424 & 188 & 840 & 2,120 & 940 & 84 & 212 & 94 & 470 & 1187 & 526 \\
\hline \multirow[t]{3}{*}{ Enclaves } & N/A & \multicolumn{3}{|c|}{ None } & \multicolumn{3}{|c|}{ Eagle River Road } & \multicolumn{3}{|c|}{ None } & \multicolumn{3}{|c|}{ Eagle River Road } \\
\hline & & & & & \multicolumn{3}{|c|}{ Dry Pass } & & & & & & \\
\hline & & & & & \multicolumn{3}{|c|}{ Noxon } & & & & & & \\
\hline \multirow[t]{2}{*}{$15 \%$ Areas } & N/A & \multicolumn{3}{|c|}{ None } & \multicolumn{3}{|c|}{ Nadezhida } & \multicolumn{3}{|c|}{ None } & \multicolumn{3}{|c|}{ None } \\
\hline & & & & & \multicolumn{3}{|c|}{ Fish Bay } & & & & & & \\
\hline $\begin{array}{l}\text { Guided } \\
\text { Fishing } \\
\text { Restrictions }\end{array}$ & N/A & \multicolumn{3}{|c|}{ Yes } & \multicolumn{3}{|c|}{ No } & \multicolumn{3}{|c|}{ Yes } & \multicolumn{3}{|c|}{ Yes } \\
\hline
\end{tabular}

\section{Mitigation}

See Appendix C for mitigation measures.

On Salmon Lake, Nakwasina River, St. John the Baptist River, and Fish Bay River, guided fishing is limited to no more than two groups at one time from August 31 to September 30 in Alternatives 2, 4, and 5. 


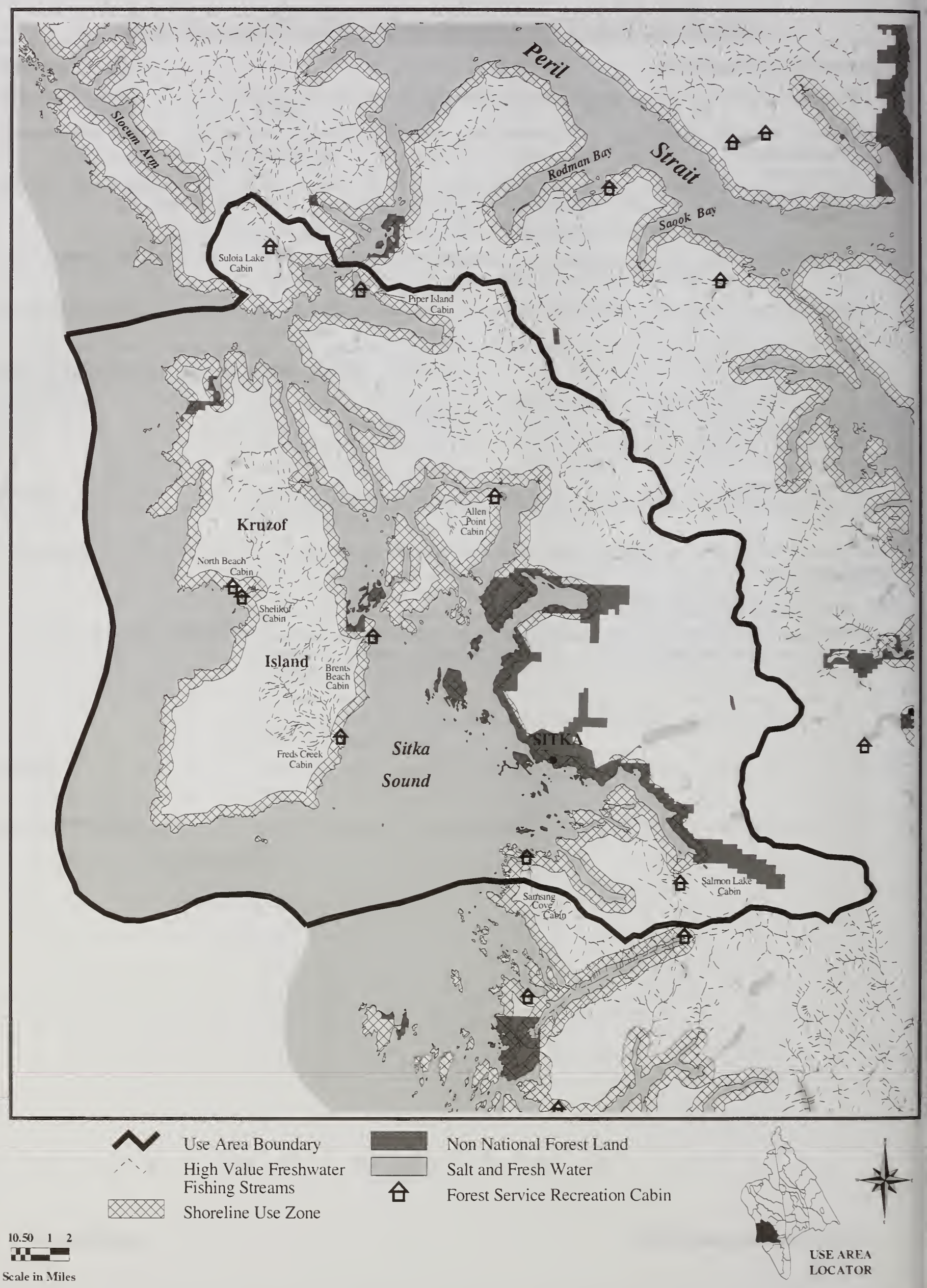


Lake Eva, Rodman Bay (North Baranof) - Sitka Ranger District

\section{Recreation Carrying Capacity (total capacity for all users)}

\begin{tabular}{|c|c|c|c|}
\hline Groups at one time & Spring & Summer & Fall \\
\hline 8 & 336 & 848 & 376 \\
\hline
\end{tabular}

\section{Description}

This use area is located on the northern end of Baranof Island extending from just west of Peschani Point, to just east of the Lake Eva trail. Shoreline access is dictated by weather conditions (north Baranof Island/Peril Strait) and by easily accessed shoreline in the areas few bays: Rodman Bay, Appleton Cove, Saook Bay, and Hanus Bay.
LUDs
Modified Landscape, Old Growth, Semi-Remote Recreation, Scenic Viewshed, and Timber Production

ROS

Roaded Modified, Semi-Primitive Motorized, and Semi-Primitive Non-Motorized

National Forest Shoreline 53 miles
Miles
National Forest Shoreline
13,457 acres
Acres

\section{Communities}

Alaska Coastal

Management Act
None

Sitka District Coastal Management Program

\section{Forest Service Facilities}

Public Recreation Cabins

Appleton Cove and Lake Eva, the Lake Eva cabin is located more than a mile inland from the saltwater shoreline.

Trail

Hanus Bay to Lake Eva

\section{Non-National Forest System Lands}

A floating lodge has been proposed in the adjacent Use Area at the False Island Bight. If the lodge becomes active and guiding activities occur, it is anticipated that the clientele would also utilize the uplands of this use area. A parcel of private land, associated with a patented mining claim, is located on the southern shore of Rodman Bay.

\section{Recreation Use}

Area Attractions

Commercial Use

Non-commercial Use

Use Patterns

Primary Use Areas

Areas of Concern
Recreation cabins, Lake Eva Trail, wildlife and salmon viewing, old growth forest and opportunities for viewing large stand of trees

Brown bear hunting, freshwater fishing, and hiking

Hunting, freshwater fishing, and sightseeing

This use area is important to the residents of Sitka. Travel to this area from Sitka is through protected waterways that can be traveled in most weather conditions. Due to its proximity to the most traveled water route to Sitka, the area receives a fair amount of unguided use by transient boaters.

Rodman Bay, Appleton Cove, Hanus Bay, and Saook Bay are use areas. The Lake Eva trail receives heavy use by sockeye subsistence fishermen and from boat-based outfitter/guides.

Lake Eva trail receives heavy use. 


\section{Lake Eva, Rodman Bay (North Baranof) - Sitka Ranger District}

\section{Management/Resource Considerations}

Subsistence

Wildlife

Fisheries

Botany

Cultural/Heritage
There are no anticipated restrictions on subsistence resource users.

In this use area, 73 bald eagle nests have been mapped.

Twenty-one Class I streams have been mapped, five of which are high value fishing streams. Large runs of pink and chum salmon, and anadromous Dolly Varden char return to these streams in addition to the resident populations of Dolly Varden char. The Lake Eva system supports sockeye, coho, and pink salmon, steelhead, cutthroat, and Dolly Varden char. Steelhead and sockeye runs are relatively small. Lake Eva sockeye are a subsistence resource for the village of Angoon and to a lesser degree for Sitka.

Four botanical surveys have been completed covering about 1.5 miles of shoreline in close proximity to the outlet stream from Lake Eva. No rare or sensitive plants were found.

One historic and seven prehistoric sites have been identified in this area from 17 surveys covering 41.5 miles.

\section{Alternative Comparisons}

\begin{tabular}{|c|c|c|c|c|c|c|c|c|c|c|c|c|c|}
\hline & Alt. 1 & & Alt. 2 & & & Alt. & & & Alt. 4 & & & Alt. & \\
\hline \multirow{2}{*}{$\begin{array}{l}\text { Commercial } \\
\text { Allocation } \\
\text { (groups by } \\
\text { season) }\end{array}$} & \multirow{2}{*}{ N/A } & Spr & Sum & Fall & Spr & Sum & Fall & Spr & Sum & Fall & Spr & Sum & Fall \\
\hline & & 34 & 339 & 38 & 168 & 424 & 188 & 33 & 175 & 19 & 34 & 339 & 94 \\
\hline \multirow[t]{4}{*}{ Enclaves } & N/A & \multicolumn{3}{|c|}{ None } & \multicolumn{3}{|c|}{ Point Elizabeth } & & & & \multicolumn{3}{|c|}{ Point Elizabeth } \\
\hline & & & & & \multicolumn{3}{|c|}{ Rodman Bay } & \multicolumn{3}{|c|}{ Rodman Bay } & \multicolumn{3}{|c|}{ Rodman Bay } \\
\hline & & & & & \multicolumn{3}{|c|}{ Saook Bay } & & & & \multicolumn{3}{|c|}{ Saook Bay } \\
\hline & & & & & \multicolumn{3}{|c|}{ Lake Eva Trail } & \multicolumn{3}{|c|}{ Lake Eva Trail } & \multicolumn{3}{|c|}{ Lake Eva Trail } \\
\hline $15 \%$ Areas & N/A & \multicolumn{3}{|c|}{ None } & \multicolumn{3}{|c|}{ Duffield } & \multicolumn{3}{|c|}{ None } & \multicolumn{3}{|c|}{ None } \\
\hline
\end{tabular}

\section{Mitigation}

See Appendix C for mitigation measures.

Outfitter Guides will not be permitted to fly clients into Lake Eva.

Lake Eva trail will need to be reconstructed before additional guided use is permitted. 
Shoreline Outfitter/Guide EIS

Use Area - 04-04A

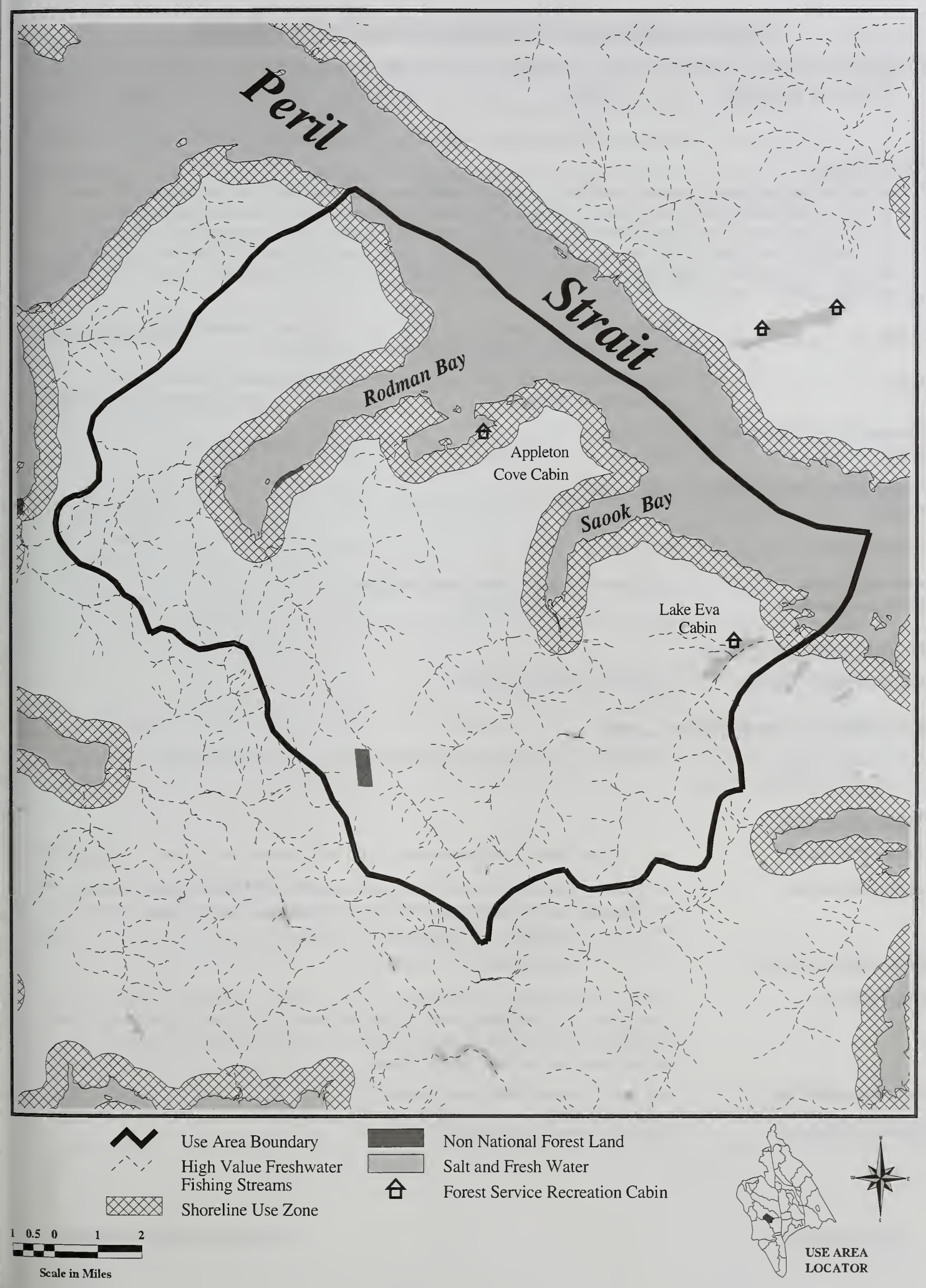




\section{Use Area 04-04B}

Kelp Bay (Northeast Baranof) - Sitka Ranger District

\begin{tabular}{|c|c|c|c|}
\hline \multicolumn{2}{|l|}{ Recreation Carrying Capacity (total capacity for all users) } \\
\hline Groups at one time & Spring & Summer & Fall \\
\hline 9 & 378 & 954 & 423 \\
\hline
\end{tabular}

\section{Description}

Located on the northern end of Baranof Island, this use area extends from east of the Lake Eva Trail, to south of Takatz Bay including Catherine Island, smaller islands in the vicinity of Catherine Island, and the islands within Kelp Bay. A Special Designation Area, Glacial River Wild River, is located within this use area. Access to shoreline is dictated by weather conditions particularly along Peril Strait and Chatham Strait. Easily accessible shoreline is located in Hanus Bay, Cosmos Cove, Kasnyku Bay, Takatz Bay, and the large bay complex of Kelp Bay. It is a scenic area. Glacier River is an eligible Wild River.

\section{LUDs}

ROS

National Forest Shoreline Miles

National Forest Shoreline Acres

Communities

Alaska Coastal Management Act
Old-growth Habitat, Semi-Remote Recreation, Remote Recreation, Scenic Viewshed, Timber Production, Modified Landscape, and Wild River

Roaded Modified, Primitive, Semi-Primitive Motorized, Semi-Primitive Nonmotorized) and Rural

157 miles

29,867 acres

None

Sitka District Coastal Management Program

\section{Forest Service Facilities}

Administrative Cabins

Catherine Island, at Hanus Bay

\section{Non-National Forest System Lands}

A year round hatchery operated by NSRAA is located at Hidden Falls. State select land is located at the head of Takatz Bay and surrounds Takatz Lake.

\section{Recreation Use}

Area Attractions

Commercial Use

Non-commercial Use

Use Patterns

\section{Primary Use Areas}

Areas of Concern

Scenic views, beach hiking, spawning salmon, and protected anchorage

An outfitter/guide operates a tent camp on National Forest System uplands adjacent to The Basin during the summer months. There is also brown bear hunting, camping, freshwater fishing, hiking, sightseeing, and kayaking.

Freshwater fishing, hiking, and hunting

This area receives some use by residents of Angoon, Sitka, and Warm Springs. Due to its proximity to major marine travel routes, a number of unguided transient boaters also use this area. There is also commercial fishing; boat and land based commercial outfitter/guide use; and recreational boaters.

Kelp Bay, Catherine Island, and Hidden Falls

Glacial River is a recommended Wild River. 


\section{Use Area 04-04B}

\section{Kelp Bay (Northeast Baranof) - Sitka Ranger District}

\section{Management/Resource Considerations}

Subsistence

Wildlife

Fisheries

Botany

Cultural/Heritage
There are no anticipated restrictions on subsistence resource users.

In this use area, 248 bald eagle nests have been mapped.

Thirty-four Class I streams have been mapped with seven streams identified as having high freshwater fishing values. Clear and Bourbon Creeks flow into Kelp Bay and are popular fish streams with commercial and non-commercial users. Both streams are good producers of Dolly Varden char and pink salmon.

Numerous invasive weed species are found near the salmon hatchery at Hidden Falls. One botanical survey was completed covering about 0.25 miles of shoreline. No rare plants were found.

Twenty-eight surveys covering 73.5 miles have been completed in this area, with one historic and 15 prehistoric sites identified.

\section{Alternative Comparisons}

\begin{tabular}{|c|c|c|c|c|c|c|c|c|c|c|c|c|c|}
\hline & Alt. 1 & & Alt. 2 & & & Alt. 3 & & & Alt. 4 & & & Alt. 5 & \\
\hline \multirow{2}{*}{$\begin{array}{l}\text { Commercial } \\
\text { Allocation } \\
\text { (groups by } \\
\text { season) }\end{array}$} & \multirow{2}{*}{ N/A } & Spr & Sum & Fall & Spr & Sum & Fall & Spr & Sum & Fall & Spr & Sum & Fall \\
\hline & & 38 & 382 & 42 & 189 & 477 & 212 & 29 & 191 & 25 & 38 & 382 & 106 \\
\hline \multirow[t]{3}{*}{ Enclaves } & N/A & \multicolumn{3}{|c|}{ None } & \multicolumn{3}{|c|}{ Hanus Bay } & & & & \multicolumn{3}{|c|}{ Hanus Bay } \\
\hline & & & & & \multicolumn{3}{|c|}{ Portage Arm } & & & & & & \\
\hline & & & & & \multicolumn{3}{|c|}{$\begin{array}{c}\text { Kelp Bay-Middle } \\
\text { Arm }\end{array}$} & \multicolumn{3}{|c|}{$\begin{array}{c}\text { Kelp Bay-Middle } \\
\text { Arm }\end{array}$} & \multicolumn{3}{|c|}{$\begin{array}{c}\text { Kelp Bay-Middle } \\
\text { Arm }\end{array}$} \\
\hline \multirow[t]{2}{*}{$15 \%$ Areas } & N/A & & None & & \multicolumn{3}{|c|}{ Bourbon Creek } & & & & & & \\
\hline & & & & & \multicolumn{3}{|c|}{ Cosmos Cove } & & & & \multicolumn{3}{|c|}{ Cosmos Cove } \\
\hline
\end{tabular}

\section{Mitigation}

See Appendix C for mitigation measures.

Guided use on Glacial River, a recommended Wild River, is limited to one group per day.

Noxious weed treatment will be included in the forest noxious weed program. 
Shoreline Outfitter/Guide EIS

Use Area - 04-04B

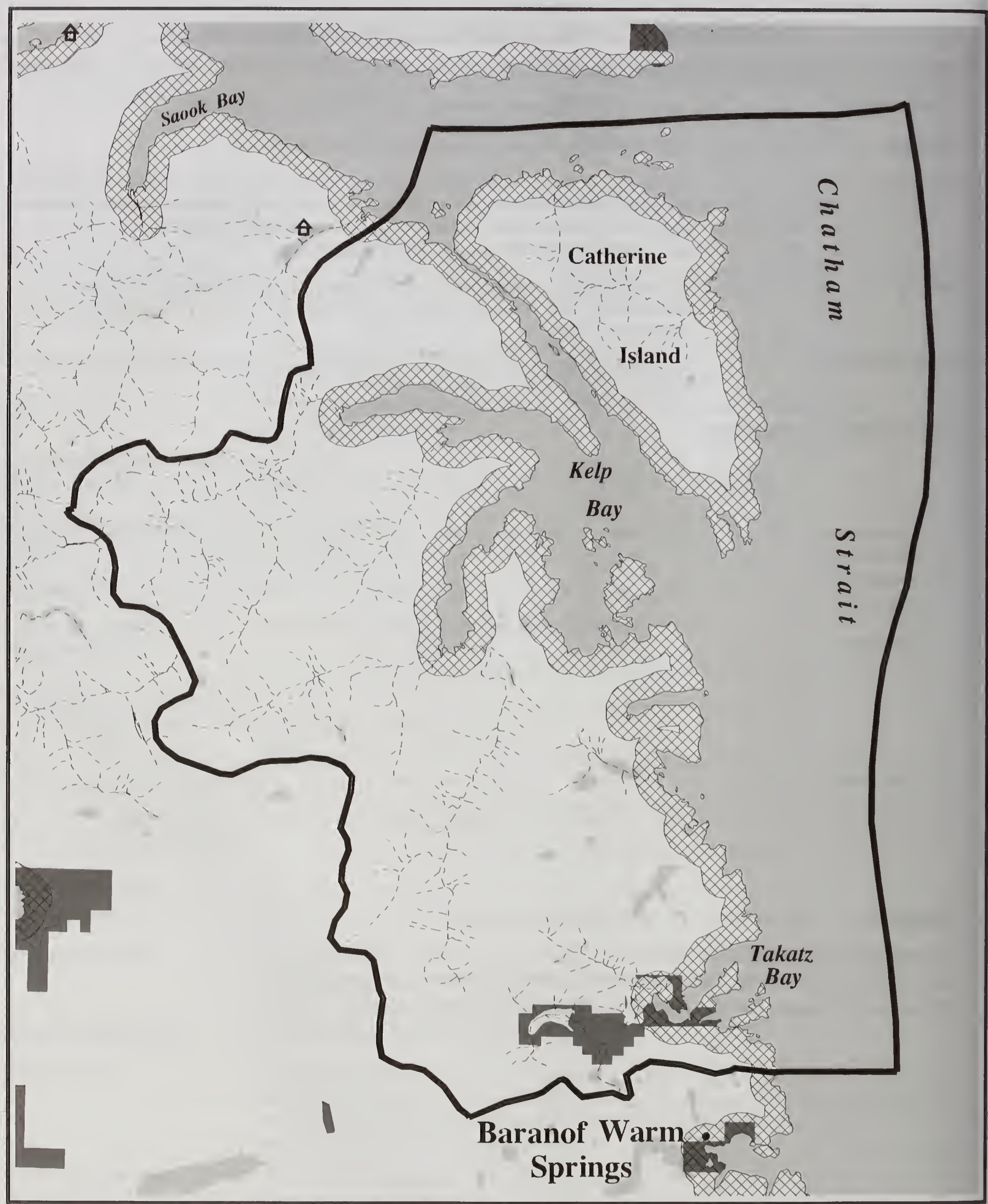

Use Area Boundary High Value Freshwater Fishing Streams

$2 \times 28$ Shoreline Use Zone
Non National Forest Land

Salt and Fresh Water

A Forest Service Recreation Cabin

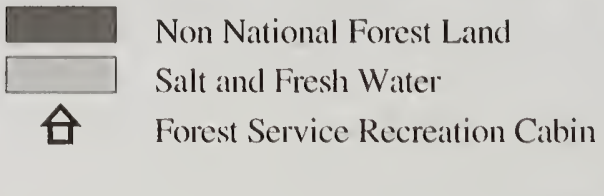




\section{Use Area 04-04C}

\section{Baranof Warm Springs (East Baranof) - Sitka Ranger District}

\section{Recreation Carrying Capacity (total capacity for all users)}

\begin{tabular}{|c|c|c|c|}
\hline Groups at one time & Spring & Summer & Fall \\
\hline 3 & 126 & 318 & 141 \\
\hline
\end{tabular}

\section{Description}

This Use Area is located on the eastside of Baranof Island extending from just south of Takatz Bay to just south of Warm Springs Bay. Access to small reaches of shoreline along Chatham Strait is dictated by weather conditions. The only protected shoreline within this use area is Warm Springs Bay.
LUDs
Remote Recreation and Semi-remote Recreation
ROS
Primitive and Semi-Primitive (motorized and non-motorized)
National Forest Shoreline
Miles
10 miles
National Forest Shoreline $\quad 2,679$ acres
Acres
Communities
The small community of Baranof lies within this use area.
Alaska Coastal
Management Act
Sitka District Coastal Management Program

\section{Forest Service Facilities}

Public Recreation Cabins

A Forest Service public recreation cabin is located on the south shore, near the west end of Baranof Lake. However, this cabin is further than a mile inland from the saltwater shoreline.

Trail

A trail that originates on state land goes to Sadie Lake. Currently, the trail receives no maintenance.

\section{Non-National Forest System Lands}

The state of Alaska owns a dock at Warm Springs Bay. A board walk trail located on municipal and state select land runs from the state dock to the shore of Baranof Lake.

\section{Recreation Use}

Area Attractions

Commercial Use

Non-commercial Use

Use Patterns

Primary Use Areas
The community of Baranof, Baranof Lake, Sadie Lake, hot springs and scenic views

Guides who transit through this area offer activities such as brown bear hunting, freshwater fishing, and hiking. The owner of a lodge located on private land on the south shore of Warm Springs Bay is permitted to take clients onto surrounding National Forest System uplands for activities such as hiking and freshwater fishing.

Warm Springs Bay is a popular anchorage for many transient boats and much of the non-guided use within the use area is by transient visitors.

Commercial fishing and land and boat based outfitter/guide use

Warm Springs Bay 


\section{Use Area 04-04C}

\section{Baranof Warm Springs (East Baranof) - Sitka Ranger District}

\section{Management/Resource Considerations}

Subsistence

Wildlife

Fisheries

Botany

Cultural/Heritage
There are no anticipated restrictions on subsistence resource users as a result of this project.

Bald eagle nests are presumed to occur in numbers at least equal to surveyed areas to the north.

Two Class I streams have been mapped in the area, but no high value streams were identified. The lake system is not anadromous, but supports populations of cutthroat trout and Dolly Varden char.

Two surveys were completed within Warm Springs Bay with no rare or sensitive plants identified.

One survey covering 0.5 miles has been completed with one site identified.

\section{Alternative Comparisons}

\begin{tabular}{|c|c|c|c|c|c|c|c|c|c|c|c|c|c|}
\hline & Alt. 1 & \multicolumn{3}{|c|}{ Alt. 2} & \multicolumn{3}{|c|}{ Alt. 3} & \multicolumn{3}{|c|}{ Alt. 4} & \multicolumn{3}{|c|}{ Alt. 5} \\
\hline \multirow{2}{*}{$\begin{array}{l}\text { Commercial } \\
\text { Allocation } \\
\text { (groups by } \\
\text { season) }\end{array}$} & \multirow{2}{*}{$\mathrm{N} / \mathrm{A}$} & Spr & Sum & Fall & Spr & Sum & Fall & Spr & Sum & Fall & Spr & Sum & Fall \\
\hline & & 13 & 127 & 14 & 63 & 159 & 71 & 15 & 30 & 15 & 13 & 127 & 35 \\
\hline Enclaves & N/A & \multicolumn{3}{|c|}{ None } & \multicolumn{3}{|c|}{ None } & \multicolumn{3}{|c|}{ None } & \multicolumn{3}{|c|}{ None } \\
\hline $15 \%$ Areas & N/A & \multicolumn{3}{|c|}{ None } & \multicolumn{3}{|c|}{ None } & \multicolumn{3}{|c|}{ None } & \multicolumn{3}{|c|}{ None } \\
\hline
\end{tabular}

\section{Mitigation}

See Appendix $C$ for mitigation measures. 
Shoreline Outfitter/Guide EIS

Use Area - 04-04C

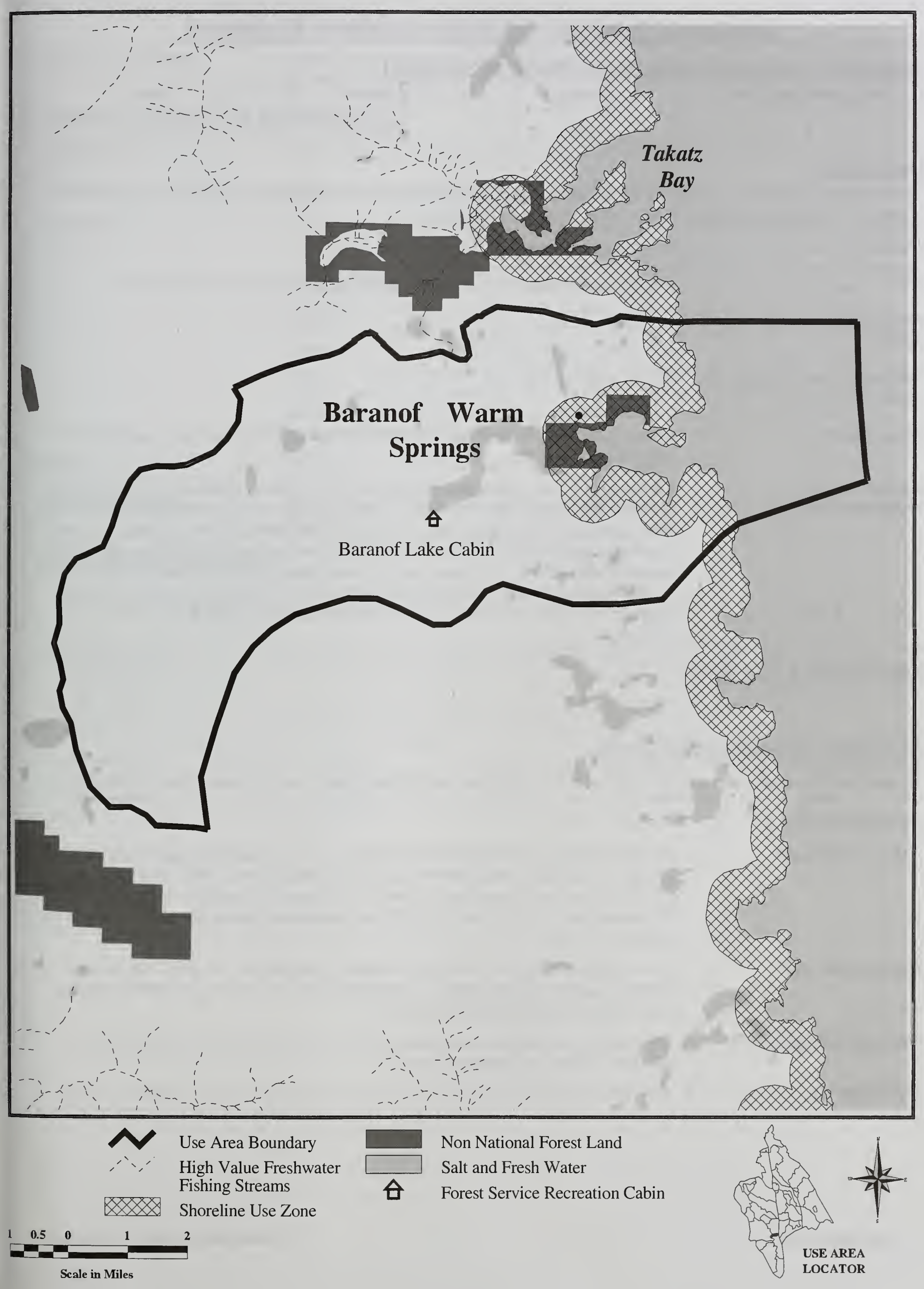




\section{Use Area 04-05}

Southwest Admiralty - Admiralty National Monument

\begin{tabular}{|c|c|c|c|}
\hline \multicolumn{2}{|l|}{ Recreation Carrying Capacity (total capacity for all users) } \\
\hline Groups at one time & Spring & Summer & Fall \\
\hline 6 & 252 & 636 & 282 \\
\hline
\end{tabular}

\section{Description}

This use area is on Admiralty National Monument and part of the Kootznoowoo Wilderness located in the southwest portion of the island extending from Hood Bay south to Pt. Gardner.

LUDs $\quad$ Wilderness Monument

ROS Primitive and Semi-Primitive Non motorized and Semi-Primitive Motorized

National Forest Shoreline 101 miles

Miles

National Forest Shoreline $\quad 24,555$ acres

Acres

Communities

The community of Angoon has a population of about 750 people and is located at to the north of the Use Area.

Alaska Coastal

Management Act
The Angoon Coastal Management Plan has Areas Meriting Special Attention (AMSAs) in Hood, Whitewater and Chaik Bays. Keys components of the Enforceable Policies for these AMSAs are (1) Maintaining or enhancing subsistence resource productivity and ensuring access to those resources; (2) Balancing recreational uses with the subsistence economy and culture; (3) Encouraging the involvement of local residents in the development of tourism related services and businesses. These bays receive use from the people of Angoon with Hood Bay receiving the most use due to its proximity to Angoon.

\section{Forest Service Facilities}

\section{None}

\section{Non-National Forest System Lands}

Private land is located on the north side of Hood Bay, Chaik Bay near Village Point, and Whitewater Bay at Neltushkin.

\section{Recreation Use}

Area Attractions

This subunit has several large bays and estuaries. Large creeks and good beaches where people can go ashore are the primary attractions. Sand Point in Whitewater Bay has a very good beach and open stand of timber. The protected "lagoons" or "salt chucks" in Whitewater and Wilson Cove offer different experiences than many other points on Admiralty Island.

Commercial Use

Freshwater fishing occurs in the major streams emptying into the bays. Brown bear hunting is another popular activity. These bays also receive use from outfitter/guides who do short beach-walking excursions.

Non-commercial Use

The residents of Angoon use this area extensively for hunting, berry picking, beach walking, fishing, and firewood cutting.

Use Patterns

Most of the commercial use is of short duration with little, if any, overnight camping. 


\section{Use Area 04-05}

\section{Southwest Admiralty - Admiralty National Monument}

Primary Use Areas

Hood and Chaik Bays receive more use due to their proximity to Angoon and the

Whaler's Cove Lodge.

\section{Management/Resource Considerations}

Subsistence

Wildlife

Fisheries

Botany

Cultural/Heritage
There are no anticipated restrictions on subsistence resource users.

In this use area, 106 bald eagle nests have been mapped.

In this use area, 41 Class I streams have been mapped, with nine streams of high fishing value. All are permitted for guided sport fishing activities for cutthroat trout, Dolly Varden char, and pink salmon. Clients typically practice catch and release. Two streams with high fishing values are located at the head of each bay. Chaik Bay, located approximately 20 miles south of the village of Angoon, received the majority of use. There is one high value fishing stream at the head of the arm of Chaik Bay. The stream passes through a very large meadow and inter-tidal grass flat and supports abundant runs of pink salmon and Dolly Varden char. One stream was identified with high fishing values; it empties into a salt chuck at the head of the bay and supports populations of pink, chum, and coho salmon and Dolly Varden char. Watershed restoration efforts were initiated in 1999 to restore the riparian areas and maintain stream productivity.

No rare or sensitive plants were identified from three surveys.

Two historic and 21 prehistoric sites have been identified from 35 surveys that covered 14 miles.

\section{Alternative Comparisons}

\begin{tabular}{|l|c|c|c|c|c|c|c|c|c|c|c|c|c|}
\hline & Alt. 1 & \multicolumn{3}{|c|}{ Alt. 2 } & \multicolumn{3}{c|}{ Alt. 3 } & \multicolumn{3}{c|}{ Alt. 4 } & \multicolumn{3}{c|}{ Alt. 5 } \\
\hline $\begin{array}{l}\text { Commercial } \\
\begin{array}{l}\text { Allocation } \\
\text { (groups by } \\
\text { season) }\end{array}\end{array}$ & N/A & Spr & Sum & Fall & Spr & Sum & Fall & Spr & Sum & Fall & Spr & Sum & Fall \\
\cline { 2 - 14 }$y$ & 25 & 191 & 28 & 126 & 318 & 141 & 38 & 111 & 71 & 25 & 127 & 71 \\
\hline Enclaves & N/A & \multicolumn{3}{|c|}{ None } & \multicolumn{3}{c|}{ None } & \multicolumn{3}{c|}{ None } & \multicolumn{3}{c|}{ None } \\
\hline 15\% Areas & N/A & \multicolumn{3}{|c|}{ None } & \multicolumn{3}{c|}{ None } & \multicolumn{3}{c|}{ None } & \multicolumn{3}{c|}{ None } \\
\hline
\end{tabular}

\section{Mitigation}

See Appendix C for mitigation measures. 
Use Area - 04-05

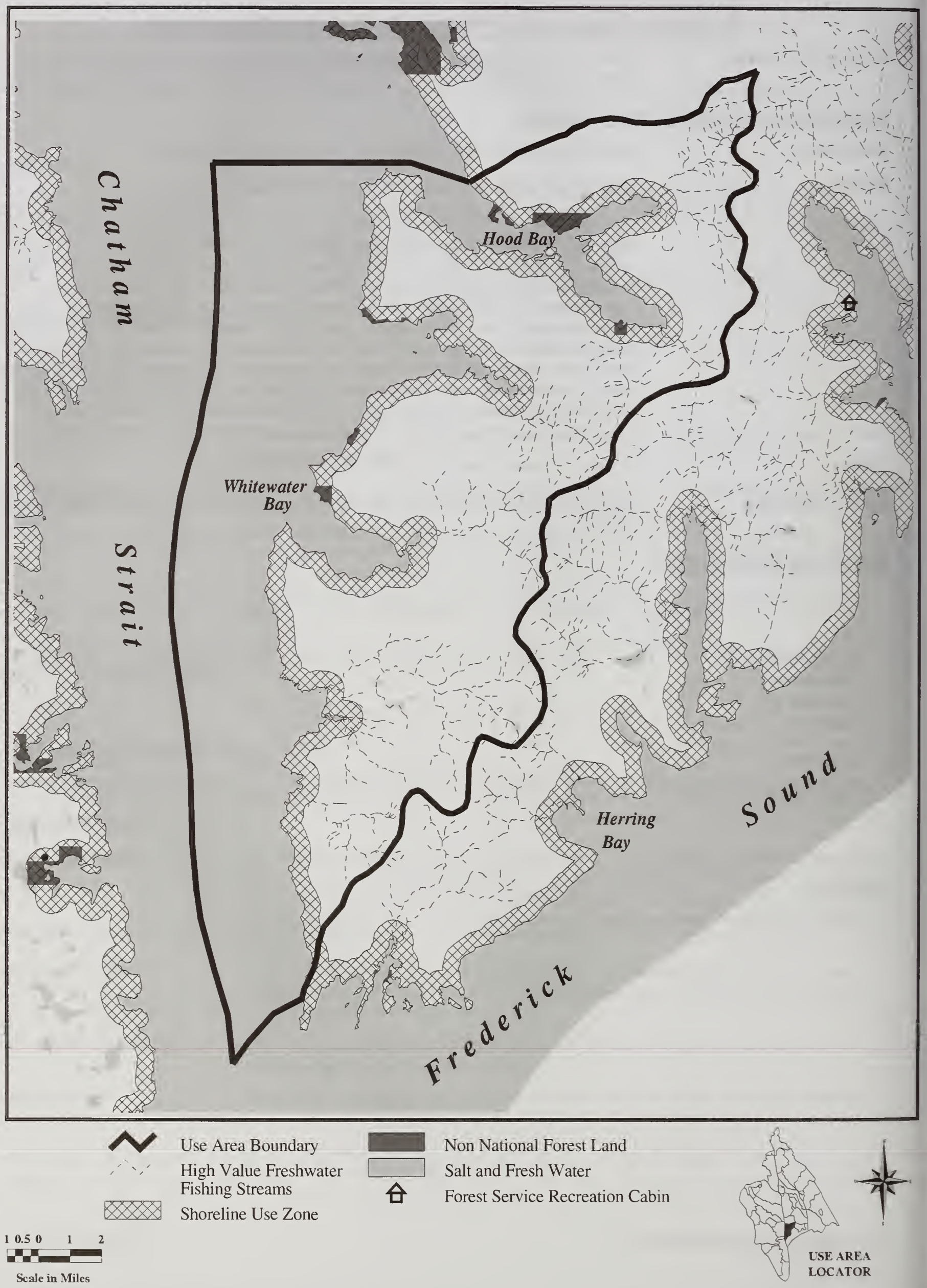




\section{Use Area 04-06A}

Pybus Bay - Admiralty National Monument

Recreation Carrying Capacity (total capacity for all users)

\begin{tabular}{|c|c|c|c|}
\hline Groups at one time & Spring & Summer & Fall \\
\hline 3 & 126 & 318 & 141 \\
\hline
\end{tabular}

\section{Description}

This Use Area is on Admiralty National Monument and part of the Kootznoowoo Wilderness located in the southeast portion of the island including Pybus Bay and the Brothers Islands.

$\begin{array}{ll}\text { LUDS } & \text { Wilderness Monument } \\ \text { ROS } & \text { Primitive }\end{array}$

National Forest Shoreline 124 miles

Miles

National Forest Shoreline $\quad 18,219$ acres

Acres

Communities None

Forest Service Facilities

Public Recreation Cabins Special Use cabin in Pybus Bay

\section{Non-National Forest System Lands}

Several private parcels of land are located in Cannery Cove within Pybus Bay.

\section{Recreation Use}

Area Attractions

Commercial Use

Non-commercial Use

Use Patterns
Pybus Bay is one of the largest bays on Admiralty Island. Its numerous coves and islands provide good protection from the weather, particularly after the long crossing of Frederick Sound. Cannery Cove is the most popular anchorage in the bay. The area has large tide flats that make it popular for bear hunting, wildlife viewing, sightseeing, and whale watching. The Brothers Islands have several nice beaches and a sea lion rookery. Boats also use the area between West Brother Island and the adjacent small island to the southwest for an anchorage.

Brown bear hunting, wildlife viewing, sightseeing, and beachcombing

The residents of Kake and Petersburg use this area for bear and deer hunting, sightseeing, beachcombing, berry picking, and wildlife viewing.

The presence of a lodge increases use on the saltwater. Much of the use of the Brothers Islands is associated with offshore sea lion viewing. The islands are receiving increased day and camping use, although camping is limited because of the lack of fresh water. 


\section{Use Area 04-06A}

\section{Pybus Bay - Admiralty National Monument}

\section{Management/Resource Considerations}

\section{Subsistence}

Wildlife

Fisheries

Botany

Cultural/Heritage
Kake is the primary subsistence community that uses this area. An average of four subsistence permits have been returned for use at False Point Pybus. There are no anticipated restrictions on subsistence resource users as a result of this project.

NMFS has identified three Steller sea lion haul-outs in this use area. In this use area, 105 bald eagle nests are mapped.

In this use area, 20 Class I streams have been mapped, of which six streams have high fishing values. The creek in Donkey Bay supports pink, chum, and coho salmon, cutthroat trout, and Dolly Varden char.

There are no known sensitive plants. This area has not received intensive surveys.

Four historic and four prehistoric sites have been identified from 14 surveys that covered 8.5 miles.

\section{Alternative Comparisons}

\begin{tabular}{|l|c|c|c|c|c|c|c|c|c|c|c|c|c|}
\hline & Alt. 1 & \multicolumn{3}{|c|}{ Alt. 2 } & \multicolumn{3}{c|}{ Alt. 3 } & \multicolumn{3}{c|}{ Alt. 4 } & \multicolumn{3}{c|}{ Alt. 5 } \\
\hline $\begin{array}{l}\text { Commercial } \\
\begin{array}{l}\text { Allocation } \\
\text { (groups by } \\
\text { season) }\end{array}\end{array}$ & N/A & Spr & Sum & Fall & Spr & Sum & Fall & Spr & Sum & Fall & Spr & Sum & Fall \\
\cline { 2 - 12 } & 13 & 127 & 14 & 63 & 159 & 71 & 19 & 111 & 15 & 13 & 127 & 35 \\
\hline Enclaves & N/A & \multicolumn{3}{|c|}{ None } & \multicolumn{3}{c|}{ None } & \multicolumn{3}{c|}{ None } & \multicolumn{3}{c|}{ None } \\
\hline 15\% Areas & N/A & \multicolumn{3}{|c|}{ None } & \multicolumn{3}{c|}{ None } & \multicolumn{3}{c|}{ None } & \multicolumn{3}{c|}{ None } \\
\hline
\end{tabular}

\section{Mitigation}

See Appendix C for mitigation measures. 

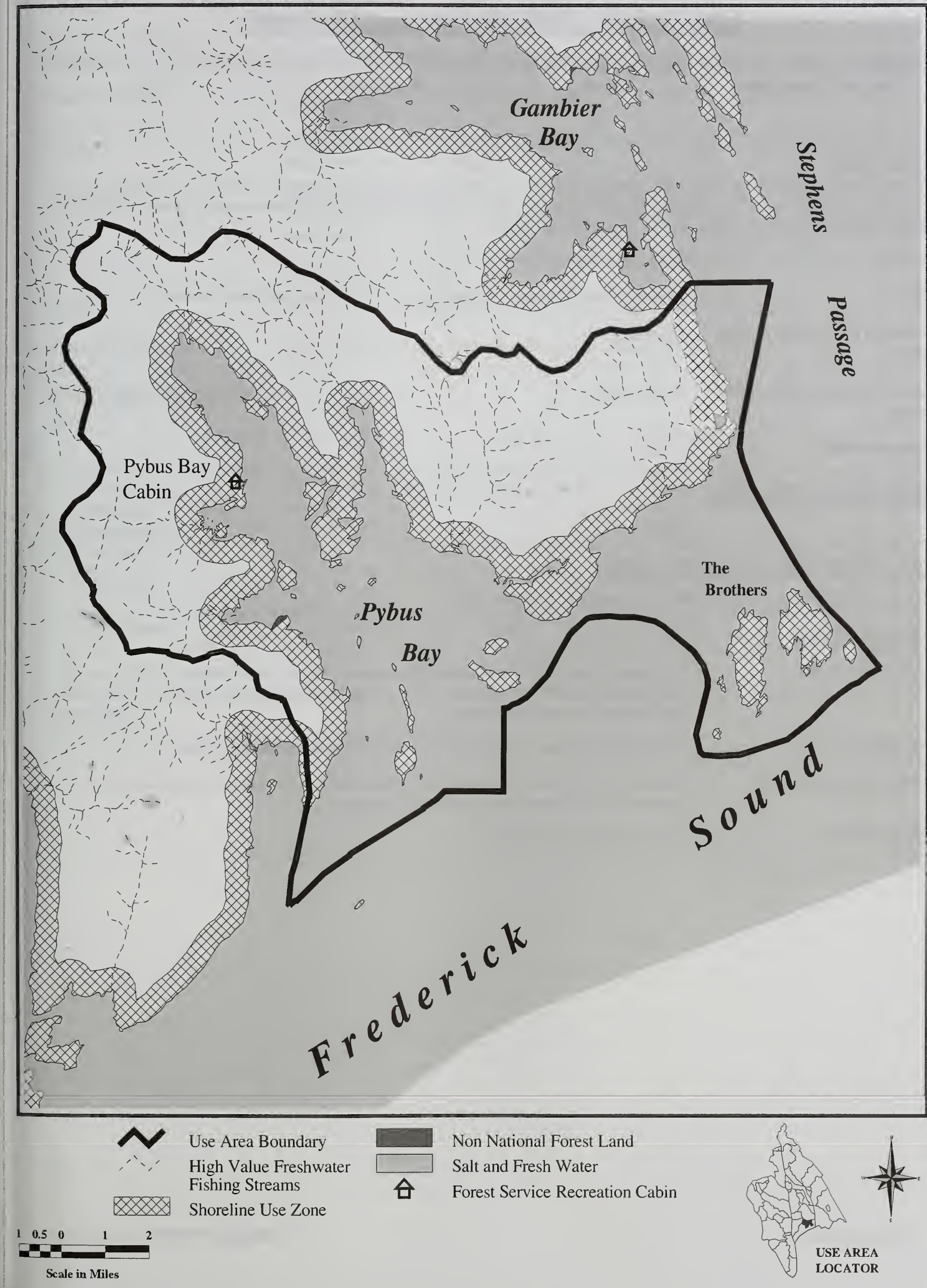


\section{Use Area 04-06B}

\section{Eliza Harbor - Admiralty National Monument}

\begin{tabular}{|c|c|c|c|}
\hline \multicolumn{2}{|l|}{ Recreation Carrying Capacity } & (total capacity for all users) \\
\hline Groups at one time & Spring & Summer & Fall \\
\hline 3 & 126 & 318 & 141 \\
\hline
\end{tabular}

\section{Description}

This use area is on Admiralty National Monument and part of the Kootznoowoo Wilderness. This area is located in the southeast portion of the island and includes one large bay, Eliza Harbor, and several small bays such as Little Pybus Bay, Chapin Bay, Herring Bay. Murder Cove, and Surprise Harbor.
LUDs
Wilderness Monument
ROS
Primitive, Semi-Primitive Motorized. and Semi-Primitive Non-Motorized
National Forest Shoreline 100 miles
Miles
National Forest Shoreline 19,693 acres
Acres
Communities None

\section{Forest Service Facilities}

None

\section{Non-National Forest System Lands}

There is one private parcel of land and an associated lodge in Tyee.

\section{Recreation Use}

Area Attractions

Deepwater Point on the east side of Woewodski Harbor has a campsite that is used on occasion and it offers an excellent view across Frederick Sound. Chapin Bay and Eliza Harbor provide good anchorages.

Commercial Use

Non-commercial Use

Use Patterns
Brown bear hunting, beachcombing, sightseeing, and wildlife viewing

Residents from Kake and Petersburg use the area for deer hunting, berry picking, sightseeing, beachcombing, and wildlife viewing.

Most of the use is boat based. 


\section{Use Area 04-06B}

\section{Eliza Harbor - Admiralty National Monument}

\section{Management/Resource Considerations}

Subsistence

Wildlife

Fisheries

Botany

Cultural/Heritage
There are no anticipated restrictions on subsistence resource users as a result of this project.

NMFS identified two Steller sea lion haul outs in this use area. In this use area, 56 bald eagle nests have been mapped.

In this use area, 36 Class I streams have been mapped, of which, 11 were identified with high fishing value. These streams support populations of pink, chum, and coho salmon, steelhead trout, and Dolly Varden char. Guided use levels are low because of the remote nature of the area from any population center and the southeast exposure of the coastline to prevailing winds and storms.

Poa laxiflora was identified from one survey that covered 0.25 miles of shoreline.

Eight prehistoric sites were identified from 17 surveys that covered 5.75 miles.

\section{Alternative Comparisons}

\begin{tabular}{|c|c|c|c|c|c|c|c|c|c|c|c|c|c|}
\hline & Alt. 1 & \multicolumn{3}{|c|}{ Alt. 2} & \multicolumn{3}{|c|}{ Alt. 3} & \multicolumn{3}{|c|}{ Alt. 4} & \multicolumn{3}{|c|}{ Alt. 5} \\
\hline \multirow{2}{*}{$\begin{array}{l}\text { Commercial } \\
\text { Allocation } \\
\text { (groups by } \\
\text { season) }\end{array}$} & \multirow{2}{*}{ N/A } & Spr & Sum & Fall & Spr & Sum & Fall & Spr & Sum & Fall & Spr & Sum & Fall \\
\hline & & 13 & 127 & 14 & 63 & 159 & 71 & 19 & 30 & 15 & 13 & 127 & 35 \\
\hline Enclaves & N/A & \multicolumn{3}{|c|}{ None } & \multicolumn{3}{|c|}{ None } & \multicolumn{3}{|c|}{ None } & \multicolumn{3}{|c|}{ None } \\
\hline $15 \%$ Areas & N/A & \multicolumn{3}{|c|}{ None } & \multicolumn{3}{|c|}{ None } & \multicolumn{3}{|c|}{ None } & \multicolumn{3}{|c|}{ None } \\
\hline
\end{tabular}

\section{Mitigation}

See Appendix $C$ for mitigation measures. 
Shoreline Outfitter/Guide EIS

Use Area - 04-06B

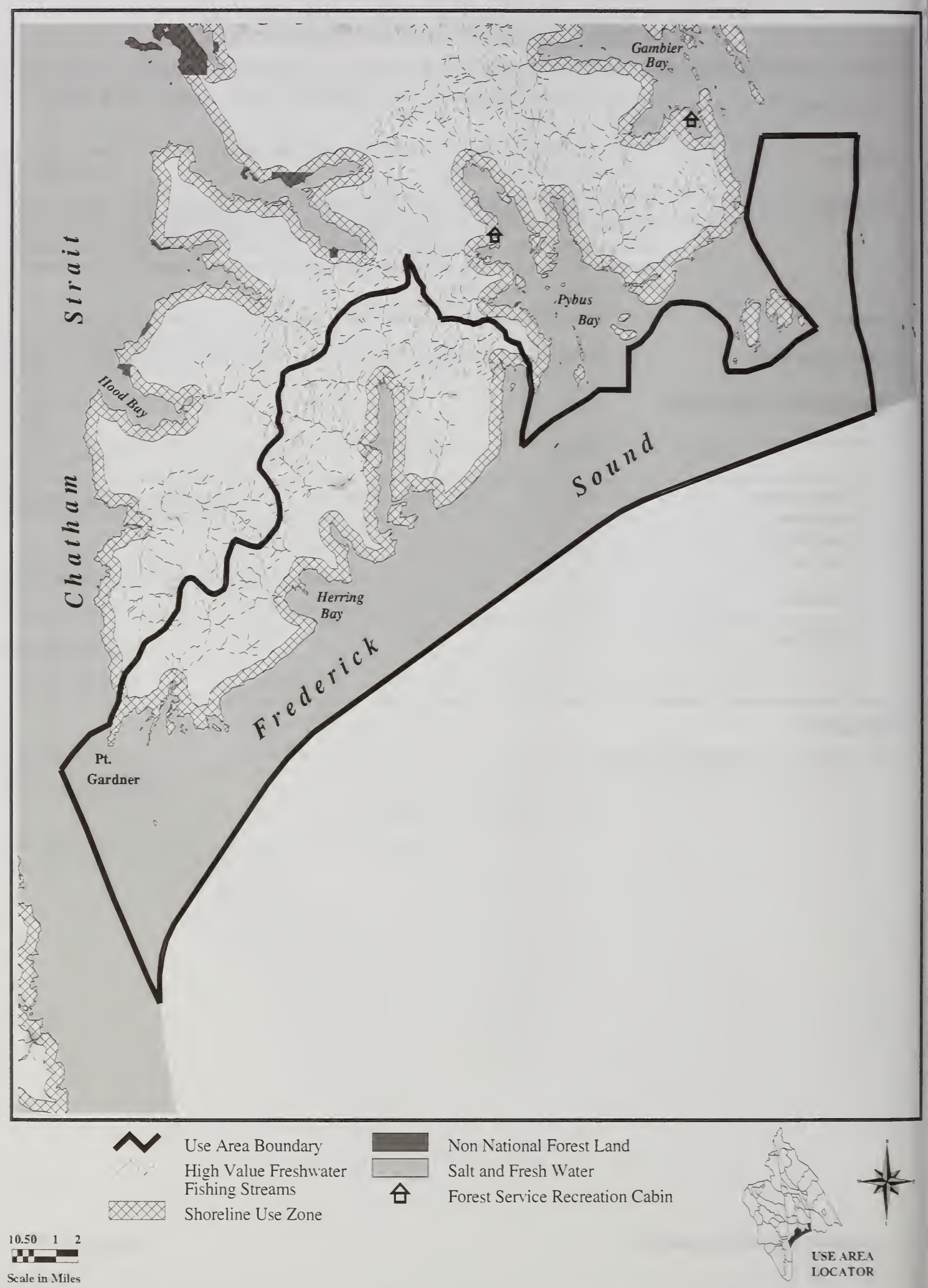




\section{Use Area 04-07}

Gambier Bay - Admiralty National Monument

\section{Recreation Carrying Capacity (total capacity for all users)}

\begin{tabular}{|c|c|c|c|}
\hline Groups at one time & Spring & Summer & Fall \\
\hline 6 & 252 & 636 & 282 \\
\hline
\end{tabular}

\section{Description}

This use area is on Admiralty National Monument and part of the Kootznoowoo Wilderness. Located in the south central portion of the island, it extends from just south of Tiedeman Island farther south to Gambier Bay. The two primary bays in this Use Area are Mole Harbor and Gambier Bay.

$\begin{array}{ll}\text { LUDs } & \begin{array}{l}\text { Special Interest, Wilderness Monument, Wilderness Monument Research Natural Area, } \\ \text { and Wilderness Monument Wild River }\end{array} \\ \begin{array}{ll}\text { ROS } & \text { Primitive and Semi-Primitive Motorized } \\ \begin{array}{l}\text { National Forest Shoreline } \\ \text { Miles }\end{array} & 133 \text { miles } \\ \begin{array}{l}\text { National Forest Shoreline } \\ \text { Acres }\end{array} & 24,858 \text { acres } \\ \text { Communities } & \text { None }\end{array}\end{array}$

Forest Service Facilities

Public Recreation Cabins

Church Bight

Shelters

Mole Harbor

Trails

A three-mile trail goes from the shelter at Mole Harbor to Lake Alexander.

Special Uses

One cabin in Gambier Bay and one tent platform in Seymour Canal

\section{Non-National Forest System Lands}

A small private parcel of land with a cabin is located in Mole Harbor and additional private land is located on the north side of Gambier Bay.

\section{Recreation Use}

Area Attractions

Gambier Bay is the largest bay in this area and provides excellent anchorages and protection from rough weather. Pleasant Bay is a very small bay that is also very protected and provides probably the best anchorage between Gambier Bay and Windfall Harbor. The trail at Mole Harbor is the only Forest Service trail on the entire southeast side of the island.

Commercial Use Bear hunting, sightseeing, wildlife viewing, fishing, and kayaking

Non-commercial Use

Residents of Petersburg use this area for bear and deer hunting, berry picking, and fishing.

Use Patterns

The use that occurs takes place primarily near the developed facilities, private land, and the special use permit cabin and tent platform. 


\section{Use Area 04-07}

\section{Gambier Bay - Admiralty National Monument}

\section{Management/Resource Considerations}

Subsistence

Wildlife

Fisheries

Botany

Cultural/Heritage
No restriction to any subsistence resource use is expected to result from this project. In this use area, 90 bald eagle nests are mapped.

In this use area, 45 Class I streams have been mapped. Within Mole Harbor, Pleasant Bay, and Gambier Bay, six streams were identified with high fishing value. The majority of use occurred in Mole River. Pleasant Bay Creek has been used by ADF\&G as a steelhead index stream.

Seven surveys covering 1.25 miles did not identify any rare or sensitive plants.

Thirty-eight surveys covering 16 miles revealed 18 sites within this use area; nine historic and nine prehistoric.

\section{Alternative Comparisons}

\begin{tabular}{|c|c|c|c|c|c|c|c|c|c|c|c|c|c|}
\hline & Alt. 1 & \multicolumn{3}{|c|}{ Alt. 2} & \multicolumn{3}{|c|}{ Alt. 3} & \multicolumn{3}{|c|}{ Alt. 4} & \multicolumn{3}{|c|}{ Alt. 5} \\
\hline \multirow{2}{*}{$\begin{array}{l}\text { Commercial } \\
\text { Allocation } \\
\text { (groups by } \\
\text { season) }\end{array}$} & \multirow[b]{2}{*}{ N/A } & Spr & Sum & Fall & Spr & Sum & Fall & Spr & Sum & Fall & Spr & Sum & Fall \\
\hline & & 25 & 254 & 28 & 126 & 318 & 141 & 38 & 76 & 15 & 25 & 127 & 71 \\
\hline Enclaves & N/A & \multicolumn{3}{|c|}{ None } & \multicolumn{3}{|c|}{ None } & \multicolumn{3}{|c|}{ None } & \multicolumn{3}{|c|}{ None } \\
\hline $15 \%$ Areas & N/A & \multicolumn{3}{|c|}{ None } & \multicolumn{3}{|c|}{ None } & \multicolumn{3}{|c|}{ None } & \multicolumn{3}{|c|}{ None } \\
\hline
\end{tabular}

\section{Mitigation}

See Appendix $C$ for mitigation measures. 
Shoreline Outfitter/Guide EIS

Use Area - 04-07

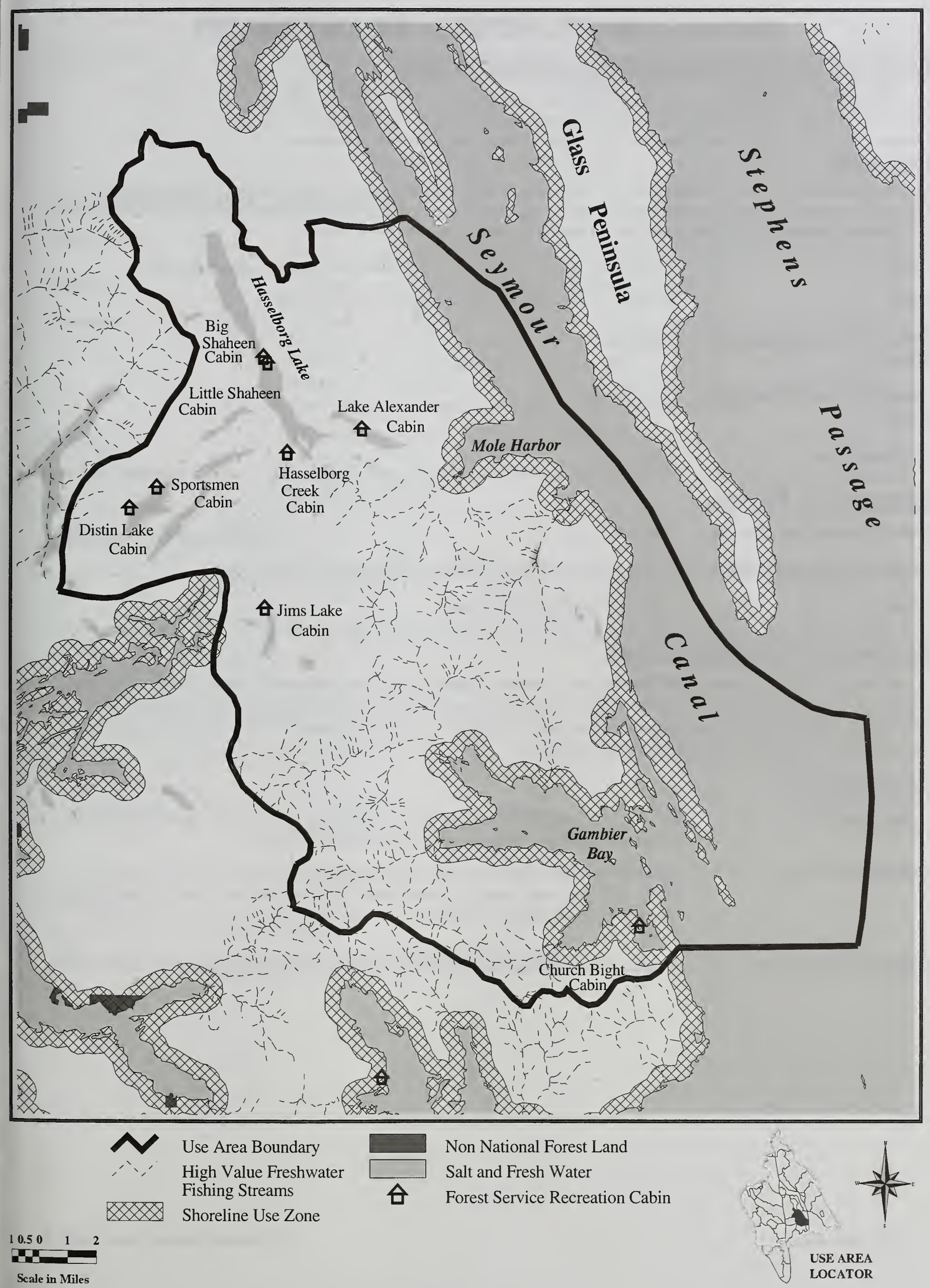




\section{Use Area 04-08}

\section{Northeast Admiralty - Admiralty National Monument}

\section{Recreation Carrying Capacity (total capacity for all users)}

\begin{tabular}{|c|c|c|c|}
\hline Groups at one time & Spring & Summer & Fall \\
\hline 28 & 1,176 & 2,968 & 1,316 \\
\hline
\end{tabular}

\section{Description}

This Use Area extends from Midway Point on Admiralty Island's eastern Glass Peninsula north to Point Retreat on the Mansfield Peninsula. Due to its proximity to Juneau, the Use Area receives considerable use. The primary bays in this Use Area are Barlow Cove, Young Bay, Oliver Inlet, and Doty Cove.

\section{LUDs}

ROS

National Forest Shoreline

Miles

National Forest Shoreline

Acres

Communities

\section{Forest Service Facilities}

\section{Public Recreation Cabins}

Special Use Permit Cabins

Trails

\section{Experimental Forest, Wilderness Monument, and Semi-Remote Recreation}

Primitive, Roaded Natural, and Semi-Primitive Motorized

135 miles

34,497 acres

None

\section{Non-National Forest System Lands}

Private land is located on a portion of the unnamed island in Admiralty Cove and just south of Bear Creek. All of Horse and Colt Islands are in private ownership. There is a dock and parking area in Young Bay used by the Greens Creek Mine. The dock is permitted via a State tidelands permit and the parking lot is on private land. Oliver Inlet State Marine Park includes a small boat tram and a public recreation cabin

\section{Recreation Use}

\section{Area Attractions}

Commercial Use

Non-commercial Use
Barlow Cove and Oliver Inlet are the best anchorages. Admiralty Cove has a large tidal meadow and stream providing wildlife viewing and fishing.

There is very little commercial use of this area, possibly because there are not many places with good anchorages for larger boats. Commercial use is not allowed within one mile of Admiralty Cove because of its proximity to the public recreation cabin there.

Hunting, berry picking, beachcombing, firewood cutting, fishing, and wildlife viewing 


\section{Use Area 04-08}

\section{Northeast Admiralty - Admiralty National Monument}

Use Patterns

This area receives much of its use from Juneau and Petersburg. Boaters and kayakers use it for day trips and overnight excursions. The high number of special use permit cabins (16) in this Use Area provides a focal point for the recreation use. There are numerous places to go ashore and areas away from the developed sites also receive use. In addition, there are many private cabins on Horse and Colt Islands and people staying in these cabins recreate in this area as well.

\section{Management/Resource Considerations}

Subsistence

Wildlife

Fisheries

Botany

Cultural/Heritage
Subsistence catches of salmon have been reported at Admiralty and Bear Creeks. There are no anticipated restrictions on subsistence resource users as a result of this project.

In this use area, 187 bald eagle nests have been mapped.

In this use area, 38 Class I streams have been mapped, three of which are identified with high fishing values. Admiralty Creek, in Young Bay, is an important Juneau sport fishery for spring steelhead, Dolly Varden char, and fall coho. The site is also popular because of the presence of a public use cabin. For these reasons, requests for guided sport fishing at Admiralty Creek historically have been denied.

There are no known sensitive plants. This area has not received intensive surveys.

In this use area, 13 surveys covering 10.5 miles have identified five sites, two historic and three prehistoric.

\section{Alternative Comparisons}

\begin{tabular}{|c|c|c|c|c|c|c|c|c|c|c|c|c|c|}
\hline & Alt. 1 & & Alt. 2 & & & Alt. 3 & & & Alt. 4 & & & Alt. 5 & \\
\hline \multirow{2}{*}{$\begin{array}{l}\text { Commercial } \\
\text { Allocation } \\
\text { (groups by } \\
\text { season) }\end{array}$} & \multirow{2}{*}{$\mathrm{N} / \mathrm{A}$} & Spr & Sum & Fall & Spr & Sum & Fall & Spr & Sum & Fall & Spr & Sum & Fall \\
\hline & & 118 & 594 & 132 & 588 & 1,484 & 658 & 59 & 148 & 66 & 118 & 296 & 329 \\
\hline \multirow[t]{2}{*}{ Enclaves } & $\mathrm{N} / \mathrm{A}$ & \multicolumn{3}{|c|}{ None } & \multicolumn{3}{|c|}{ Cordwood Creek } & \multicolumn{3}{|c|}{ None } & \multicolumn{3}{|c|}{ Cordwood Creek } \\
\hline & & & & & \multicolumn{3}{|c|}{ Fowler Creek } & & & & \multicolumn{3}{|c|}{ Fowler Creek } \\
\hline $15 \%$ Areas & N/A & \multicolumn{3}{|c|}{ None } & \multicolumn{3}{|c|}{ None } & \multicolumn{3}{|c|}{ None } & \multicolumn{3}{|c|}{ None } \\
\hline
\end{tabular}

\section{Mitigation}

See Appendix $\mathrm{C}$ for mitigation measures.

Outfitter/guide use is prohibited within one mile of Admiralty Cove cabin. 


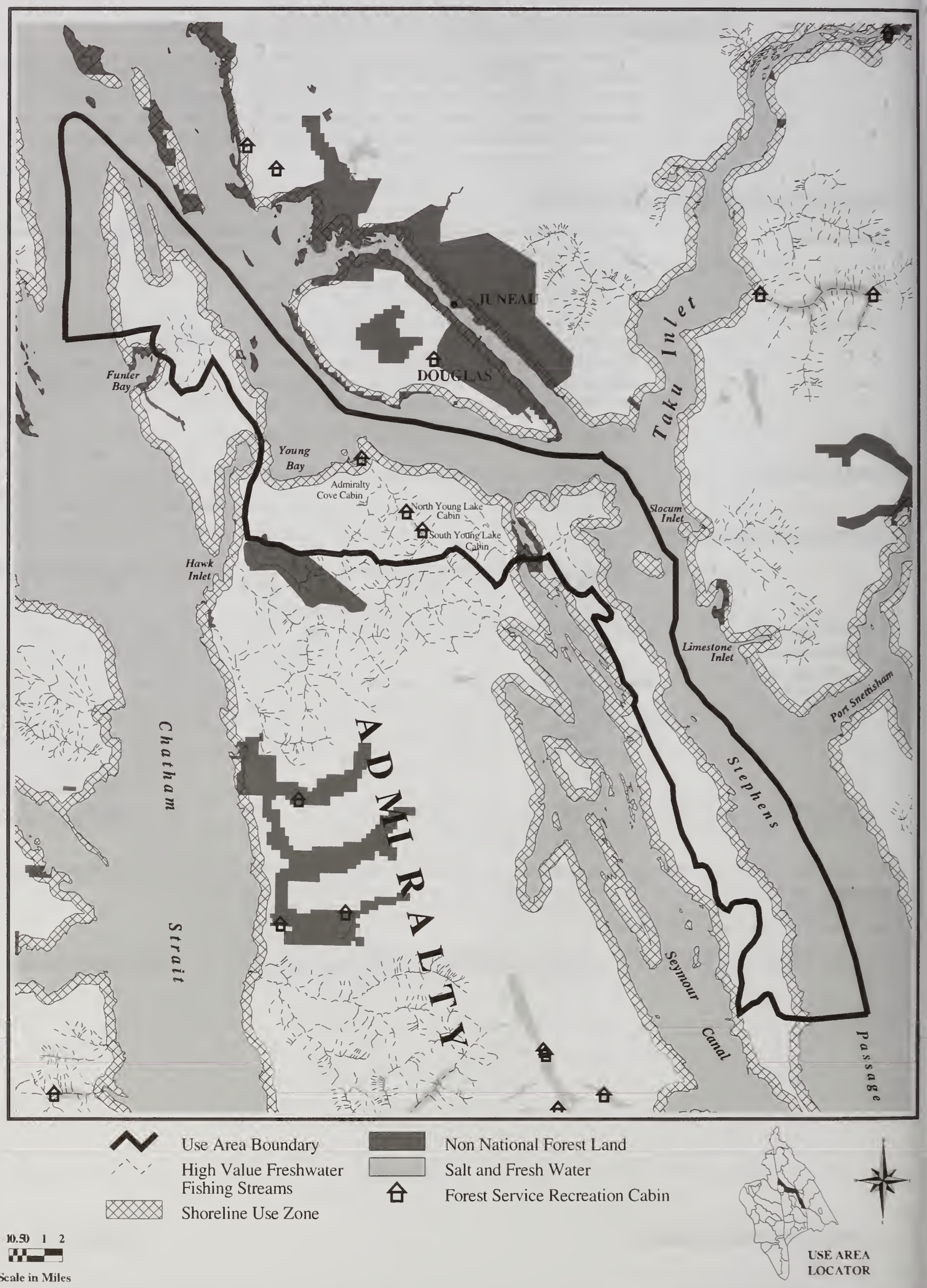




\section{Use Area 04-09}

Seymour Canal - Admiralty National Monument

\section{Recreation Carrying Capacity (total capacity for all users)}

\begin{tabular}{|c|c|c|c|}
\hline Groups at one time & Spring & Summer & Fall \\
\hline 10 & 420 & 1,060 & 470 \\
\hline
\end{tabular}

\section{Description}

This use area encompasses much of the eastern shoreline along Seymour Canal. The area is a relatively short flight from Juneau and receives local use. There are several bays but they do not have many good anchorages because of the large tidal flats and exposure.

$\begin{array}{ll}\text { LUDs } & \text { Wilderness Monument and Wild River } \\ \text { ROS } & \text { Primitive, Semi-Primitive Motorized, and Semi-Primitive Non-Motorized } \\ \begin{array}{l}\text { National Forest Shoreline } \\ \text { Miles }\end{array} & 174 \text { miles } \\ \begin{array}{l}\text { National Forest Shoreline } \\ \text { Acres }\end{array} & 33,597 \text { acres } \\ \text { Communities } & \text { None }\end{array}$

\section{Forest Service Facilities}

Special Use Permit Cabins There are 13 Forest Service special use permit cabins and one tent platform in this use area.

Shelter

Forest Service shelter at Windfall Harbor

Trail/Bear Viewing

One-mile trail leading to a bear viewing tower at Pack Creek

\section{Non-National Forest System Lands}

Oliver Inlet State Marine Park includes a small boat tram and a public recreation cabin.

\section{Recreation Use}

Area Attractions

Commercial Use

Non-commercial Use

Use Patterns

The northern portion of the area has relatively protected water, with many small islands and coves and scenery.

Bear hunting

Kayaking, hunting, berry picking, sightseeing, wildlife viewing, and firewood cutting

The area is a relatively short flight from Juneau. It receives local use from the residents of Petersburg and Juneau. Kayakers heading from Oliver Inlet to Pack Creek often stop and camp in the northern end of the Use Area. Special Use permit cabins and tent platforms are a focal point for use, particularly during the fall deer-hunting season. In the fall, hunting parties will set up multi-day camps with tents and tarps. 


\section{Use Area 04-09}

\section{Seymour Canal - Admiralty National Monument}

\section{Management/Resource Considerations}

Subsistence

Wildlife

Fisheries

Botany

Cultural/Heritage
There are no anticipated restrictions on subsistence resource users.

In this use area, 245 bald eagle nests have been mapped.

In this use area, 46 Class I streams have been mapped, two of which were identified as having high fishing values. Although the King Salmon River is a relatively productive system supporting large populations of pink and coho salmon, and Dolly Varden char, it is difficult to access because of an extensive tide flat.

No rare or sensitive plants were found during six surveys that covered 0.75 mile.

Six prehistoric sites have been identified from 16 surveys that covered 10.5 miles.

\section{Alternative Comparisons}

\begin{tabular}{|c|c|c|c|c|c|c|c|c|c|c|c|c|c|}
\hline & Alt. 1 & \multicolumn{3}{|c|}{ Alt. 2} & \multicolumn{3}{|c|}{ Alt. 3} & \multicolumn{3}{|c|}{ Alt. 4} & \multicolumn{3}{|c|}{ Alt. 5} \\
\hline \multirow{2}{*}{$\begin{array}{l}\text { Commercial } \\
\text { Allocation } \\
\text { (groups by } \\
\text { season) }\end{array}$} & \multirow{2}{*}{ N/A } & Spr & Sum & Fall & Spr & Sum & Fall & Spr & Sum & Fall & Spr & Sum & Fall \\
\hline & & 42 & 318 & 47 & 210 & 530 & 235 & 31 & 53 & 24 & 42 & 212 & 118 \\
\hline Enclaves & N/A & \multicolumn{3}{|c|}{ None } & \multicolumn{3}{|c|}{ None } & \multicolumn{3}{|c|}{ None } & \multicolumn{3}{|c|}{ None } \\
\hline $15 \%$ Areas & N/A & \multicolumn{3}{|c|}{ None } & \multicolumn{3}{|c|}{ None } & \multicolumn{3}{|c|}{ None } & \multicolumn{3}{|c|}{ None } \\
\hline
\end{tabular}

\section{Mitigation}

See Appendix C for mitigation measures.

Guided fishing is not permitted in all creeks flowing into Windfall Harbor, Pack Creek, and Swan Cove. Bear viewing is the recreation emphasis in these areas.

No guided fishing is allowed upstream of the grass flats on King Salmon River in July to protect king salmon spawning habitat.

King Salmon River, a recommended Wild River, is limited to less than five guided groups per day. 


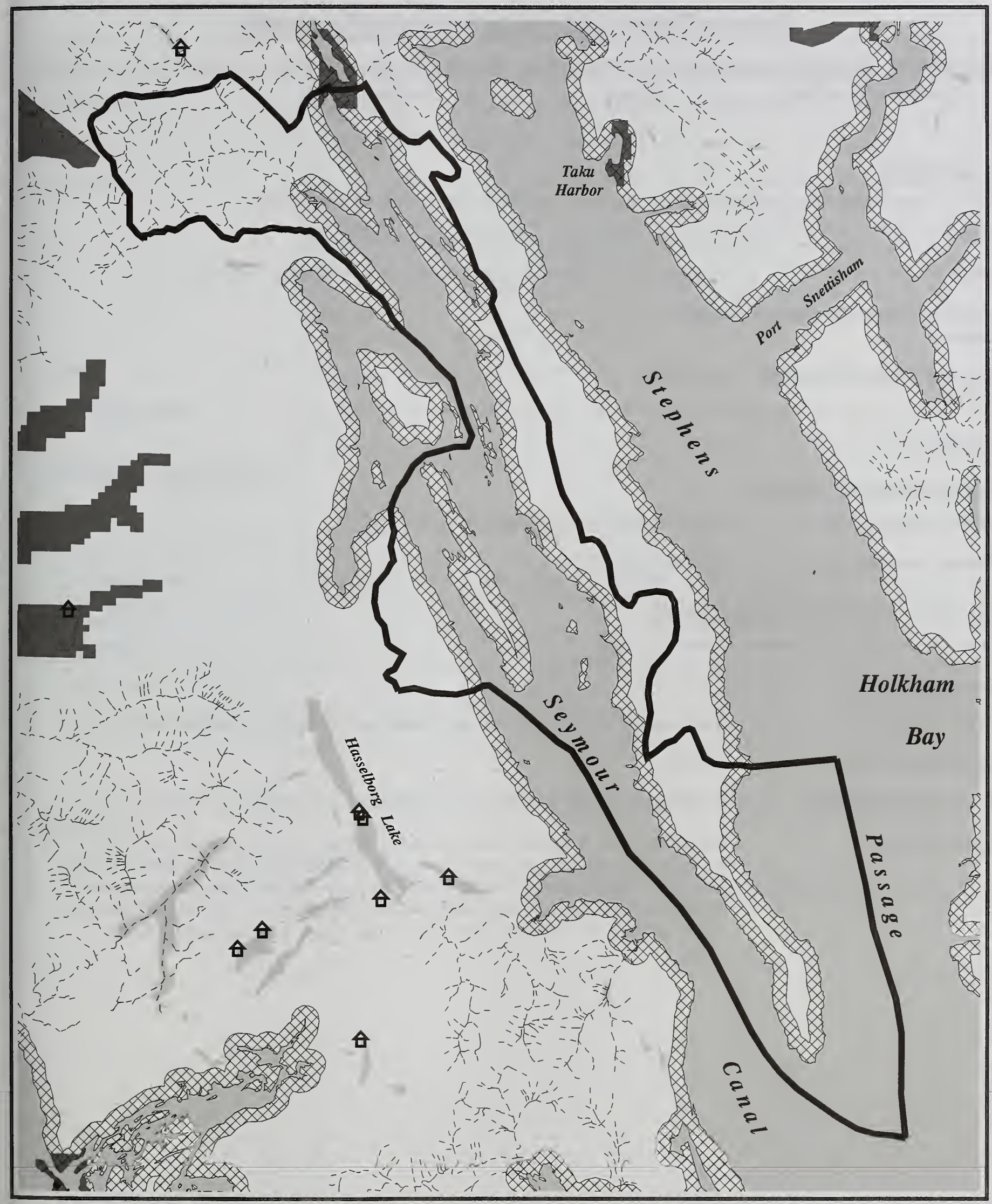

\section{Use Area Boundary} High Value Freshwater Fishing Streams

$18 \times 8$

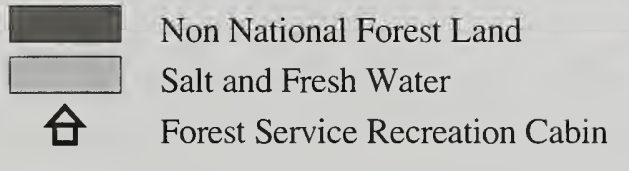

$\begin{array}{rrr}10.50 & 1 & 2 \\ 0 & & \end{array}$

Scale in Miles

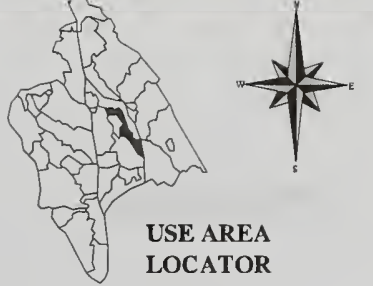




\section{Use Area 04-10A}

Greens Creek - Admiralty National Monument

\section{Recreation Carrying Capacity (total capacity for all users)}

\begin{tabular}{|c|c|c|c|}
\hline Groups at one time & Spring & Summer & Fall \\
\hline 4 & 168 & 424 & 188 \\
\hline
\end{tabular}

\section{Description}

This use area includes the shoreline from Greens Creek to Wheeler Creek along Chatham Strait.

LUDs Wilderness Monument and Non-Wilderness Monument

ROS Primitive, Semi-Primitive Non-Motorized, Semi-Primitive Motorized

National Forest Shoreline 9 miles

Miles

National Forest Shoreline $\quad 2,000$ acres

Acres

Communities None

\section{Forest Service Facilities}

Special Uses Cabins There is a Special Uses cabin at Wheeler Creek.

Communication Site Point Marsden

\section{Non-National Forest System Lands}

There are several private parcels in Wheeler Creek.

\section{Recreation Use}

Area Attractions

Commercial Use

Non-commercial Use

Use Patterns
Greens and Wheeler Creeks are large creeks that are readily accessible from Juneau.

Fishing

Brown bear and deer hunting, berry picking, firewood cutting, and wildlife viewing

The commercial component of the use is fly-in fishing of several hours duration. On some days, two groups will use the site, one in the morning and one in the afternoon. Often, this use is connected to cruise ship activity in Juneau. Private landowners at Wheeler Creek spend several days to several weeks at their cabins and participate in a variety of activities. Wheeled planes have been observed on the beach at Wheeler Creek. 


\section{Use Area 04-10A}

\section{Greens Creek - Admiralty National Monument}

\section{Management/Resource Considerations}

Subsistence

Wildlife

Fisheries

Botany

Cultural/Heritage
There are no anticipated restrictions to subsistence resource users.

In this use area, 11 mapped bald eagle nests are mapped.

In this use area, two Class I streams have been mapped and identified as high value fishing streams. Both streams are popular guided sport fishing destinations because of their high fisheries value and close proximity to Juneau. Most fish caught in both streams are Dolly Varden char and pink salmon; it has been customary for clients to practice catch and release. The Forest Plan lists Wheeler Creek king salmon as sensitive because of its island location and small population size; the Forest Plan calls for the protection and maintenance of the king salmon population. There have been no reported king salmon caught through guided sport fishing.

There are no known sensitive plants. This area has not received intensive surveys.

Two historic and two prehistoric sites were identified from two surveys that covered 3.25 miles.

\section{Alternative Comparisons}

\begin{tabular}{|c|c|c|c|c|c|c|c|c|c|c|c|c|c|}
\hline & Alt. 1 & \multicolumn{3}{|c|}{ Alt. 2} & \multicolumn{3}{|c|}{ Alt. 3} & \multicolumn{3}{|c|}{ Alt. 4} & \multicolumn{3}{|c|}{ Alt. 5} \\
\hline \multirow{2}{*}{$\begin{array}{l}\text { Commercial } \\
\text { Allocation } \\
\text { (groups by } \\
\text { season) }\end{array}$} & \multirow{2}{*}{$\mathrm{N} / \mathrm{A}$} & Spr & Sum & Fall & Spr & Sum & Fall & Spr & Sum & Fall & Spr & Sum & Fall \\
\hline & & 17 & 170 & 19 & 84 & 212 & 94 & 15 & 140 & 15 & 17 & 127 & 47 \\
\hline Enclaves & N/A & \multicolumn{3}{|c|}{ None } & \multicolumn{3}{|c|}{ None } & \multicolumn{3}{|c|}{ None } & \multicolumn{3}{|c|}{ None } \\
\hline $15 \%$ Areas & $\mathrm{N} / \mathrm{A}$ & \multicolumn{3}{|c|}{ None } & \multicolumn{3}{|c|}{ None } & \multicolumn{3}{|c|}{ None } & \multicolumn{3}{|c|}{ None } \\
\hline
\end{tabular}

\section{Mitigation}

See Appendix C for mitigation measures.

Guided fishing is not allowed in the lower reaches of Wheeler Creek in July to avoid affecting spawning king salmon. 


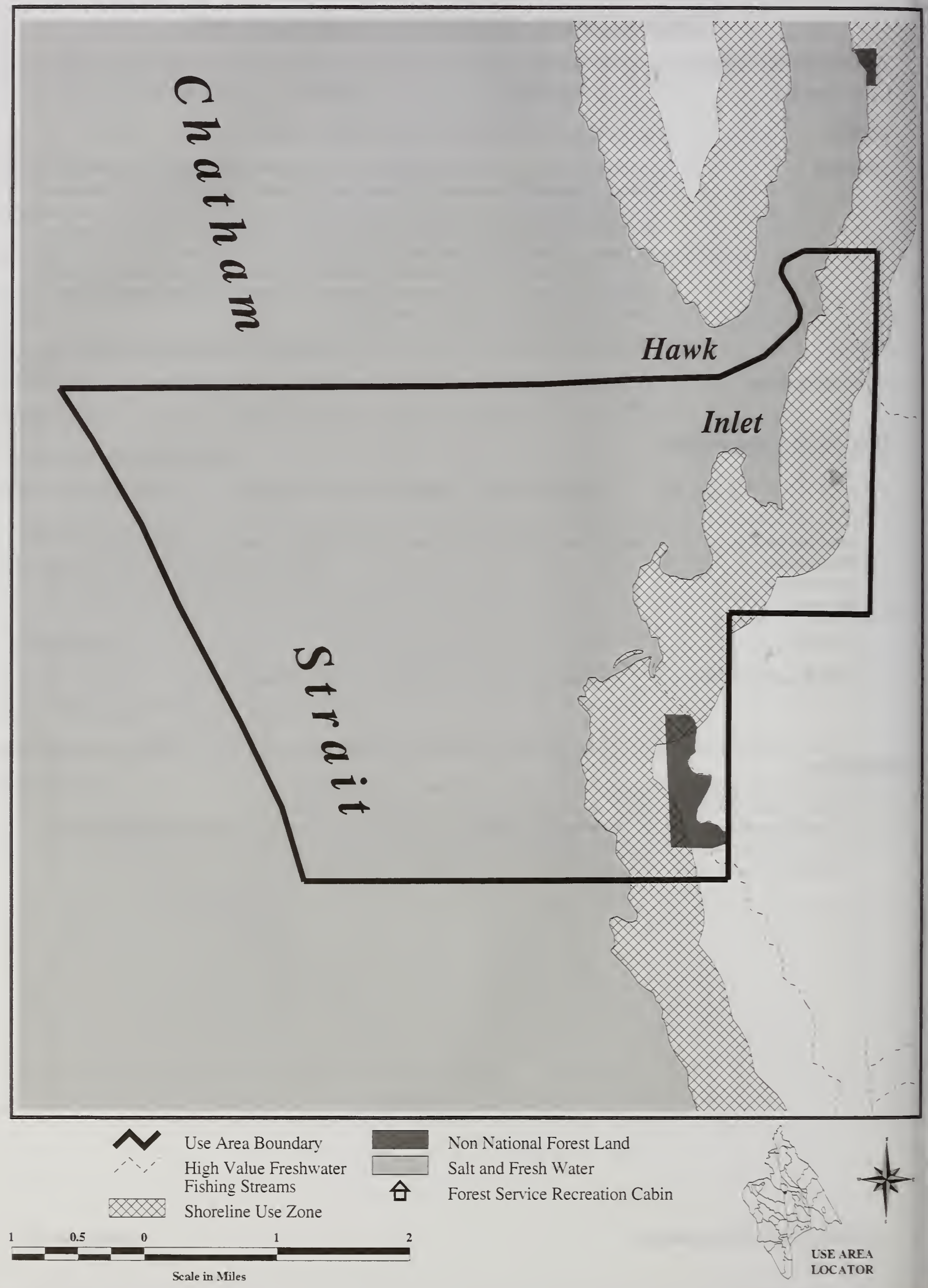




\section{Use Area 04-10B}

Northwest Admiralty - Admiralty National Monument

Recreation Carrying Capacity (total capacity for all users)

\begin{tabular}{|c|c|c|c|}
\hline Groups at one time & Spring & Summer & Fall \\
\hline 7 & 294 & 742 & 329 \\
\hline
\end{tabular}

\section{Description}

This use area is on the northwest coast of Admiralty Island and extends from Funter Bay south to Mitchell Bay.
LUDs
Semi-Remote Recreation, Wilderness National Monument, and Non-Wilderness National Monument
ROS
Primitive, Roaded Natural, Semi-Primitive Motorized and Semi-Primitive Non- Motorized

National Forest Shoreline 73 miles

Miles

National Forest Shoreline $\quad 21,055$ acres

Acres

Communities Cube Cove

\section{Forest Service Facilities}

Special Uses Cabins

Hawk Inlet

\section{Non-National Forest System Lands}

There is private land in Funter Bay, Hawk Inlet, and Cube Cove. Funter Bay has a State Marine Park on the south shore.

\section{Recreation Use}

Area Attractions

Scenic views

Commercial Use

Brown bear hunting, sightseeing, wildlife viewing, and fishing

Non-commercial Use

Brown bear and deer hunting, berry picking, firewood cutting, beachcombing, wildlife viewing, and fishing

Use Patterns

Much of the shoreline provides poor anchorages except in the major bays. Juneau primarily uses the northern portion of this use area while the community at Cube Cove primarily uses the area from Hawk Inlet south to Fishery Creek. The community of Angoon uses this area extensively. The Greens Creek Mine is located in Hawk Inlet and the mine's plan of operations does not allow workers to access the shoreline for recreation purposes. 


\section{Use Area 04-10B}

\section{Northwest Admiralty - Admiralty National Monument}

\section{Management/Resource Considerations}

Subsistence

Wildlife

Fisheries

Botany

Cultural/Heritage
There are no anticipated restrictions on subsistence resource users.

In this use area. are 137 mapped bald eagle nests.

In this use area, 16 Class I streams have been mapped. There are few sheltered streams accessible by plane or boat. Fishery and Thayer Creeks both support pink and chum salmon populations and were identified with high fishing values. Although both systems have large watersheds, these streams offer marginal fishing opportunities because of anadromous fish barriers a short distance from saltwater. These barriers greatly limit the potential fishing opportunity by reducing available salmon spawning and rearing habitat.

Poa macrocalyxI was found along a rocky bluff during one survey that covered 0.25 mile of shoreline.

Two historic sites and one prehistoric site were identified within this use area from four surveys that covered 2.5 miles.

\section{Alternative Comparisons}

\begin{tabular}{|c|c|c|c|c|c|c|c|c|c|c|c|c|c|}
\hline & Alt. 1 & \multicolumn{3}{|c|}{ Alt. 2} & \multicolumn{3}{|c|}{ Alt. 3} & \multicolumn{3}{|c|}{ Alt. 4} & \multicolumn{3}{|c|}{ Alt. 5} \\
\hline \multirow{2}{*}{$\begin{array}{l}\text { Commercial } \\
\text { Allocation } \\
\text { (groups by } \\
\text { season) }\end{array}$} & \multirow{2}{*}{ N/A } & Spr & Sum & Fall & Spr & Sum & Fall & Spr & Sum & Fall & Spr & Sum & Fall \\
\hline & & 29 & 297 & 33 & 147 & 371 & 165 & 44 & 37 & 29 & 29 & 149 & 82 \\
\hline Enclaves & N/A & \multicolumn{3}{|c|}{ None } & \multicolumn{3}{|c|}{ None } & \multicolumn{3}{|c|}{ None } & \multicolumn{3}{|c|}{ None } \\
\hline $15 \%$ Areas & N/A & \multicolumn{3}{|c|}{ None } & \multicolumn{3}{|c|}{ None } & \multicolumn{3}{|c|}{ None } & \multicolumn{3}{|c|}{ None } \\
\hline
\end{tabular}

\section{Mitigation}

See Appendix C for mitigation measures. 


\section{Use Area - 04-10B}

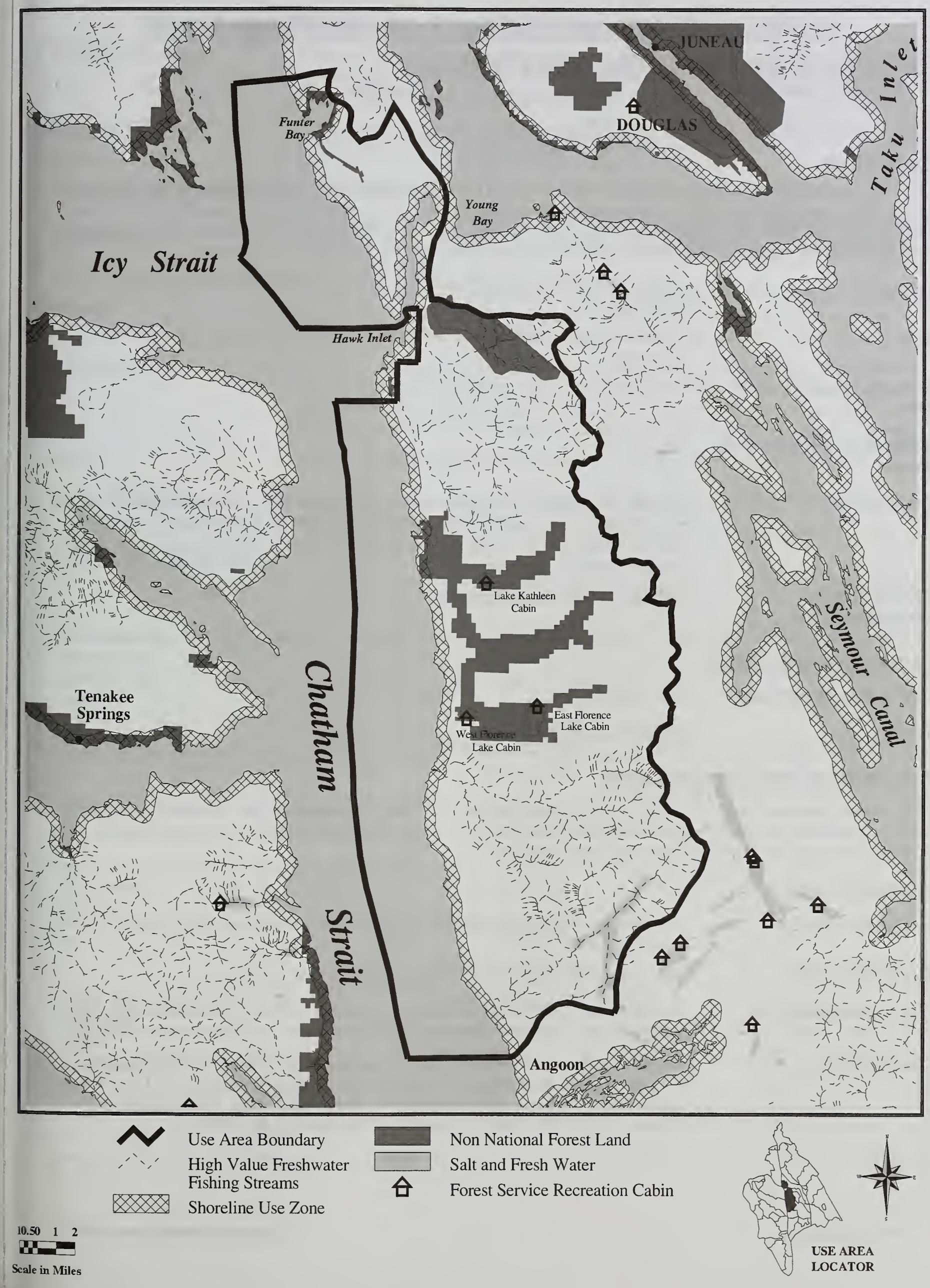




\section{Use Area 04-11}

\section{Hoonah Area (Northwest Chichagof) - Hoonah Ranger District}

\section{Recreation Carrying Capacity (total capacity for all users)}

\begin{tabular}{|c|c|c|c|}
\hline Groups at one time & Spring & Summer & Fall \\
\hline 14 & 588 & 1,484 & 658 \\
\hline
\end{tabular}

\section{Description}

This Use Area encompasses the north and northeast portion of Chichagof Island from Chicken Creek east to Freshwater Bay. Icy Strait and Chatham Strait are the surrounding waterways to the north and northeast. Principal bays within Port Frederick include: Neka Bay, Eight Fathom Bight, and Salt Lake Bay. This area also includes Pleasant Island Wilderness, which receives the majority of commercial and non-commercial use from the community of Gustavus.

\section{LUDs \\ Old Growth, Semi-Remote Recreation, Scenic Viewshed, Timber Production, and Wilderness \\ ROS \\ Primitive, Roaded Modified, Semi-Primitive Motorized, and Semi-Primitive Non- Motorized}

National Forest Shoreline 185 miles

Miles

\section{National Forest Shoreline $\quad 40,377$ acres \\ Acres}

Communities

Hoonah has a population of approximately 900 people and is centrally located in the use area. Hoonah is serviced by a boat harbor, airport, and the Alaska Marine Highway system. Tourist and recreationists visit Hoonah for access to Port Frederick, Icy Strait and the forest road system.

Alaska Coastal

Hoonah Coastal Management Plan

\section{Management Act}

\section{Forest Service Facilities}

Public Recreation Cabins

Salt Lake Bay

Trails

Wukuklook and Suntaheen

\section{Non-National Forest System Lands}

This use area includes a large area of Native Corporation lands in Port Frederick surrounding the community of Hoonah. The community of Whitestone Logging Company lies within Native Corporation lands adjacent to Hoonah. Private property is also situated along the mouth of Game Creek.

\section{Recreation Use}

Area Attractions

\section{Commercial Use}

Non-commercial Use

\section{Use Patterns}

Anadromous fish streams, wildlife viewing, scenic remote areas, and access to shoreline areas by road and boat

Brown bear hunting, freshwater fishing, camping, and sightseeing

Residents and visitors to the community of Hoonah are the primary users of this area. Port Frederick is an important recreation and subsistence area for residents of Hoonah.

Commercial fishing; recreational boating and kayaking; boat-based outfitter/guides: boat-based subsistence use; and boat-based sport fishing are popular. The Hoonah forest road system (170 miles of drivable road) receives steady traffic from residents and visitors accessing the shoreline areas of northeastern Chichagof Island. 


\section{Use Area 04-11}

\section{Hoonah Area (Northwest Chichagof) - Hoonah Ranger District}

Primary Use Areas

Areas of Concern
Chicken Creek, Pleasant Island, and Freshwater Bay are primary commercial use areas.

Other popular areas include Port Frederick, Neka Bay, Salk Lake Bay, Eight Fathom

Bight, False Bay, and Whitestone Harbor.

Float homes occupying the primary anchorages in Freshwater Bay may restrict access to the national forest and wheeled plane landing areas at Neka Bay.

\section{Management/Resource Considerations}

Subsistence

Wildlife

Fisheries

Botany

Cultural/Heritage
An average of two subsistence-fishing permits have been returned for use at Neka River and Seagull Creek. There are no anticipated restrictions on subsistence resource users due to this project.

One NMFS identified Steller sea lion haul out is located in this use area. In this use area, 420 bald eagle nests are mapped. All of this use area is within the Northeast Chichagof Controlled Use Area for state and federal management of brown bears.

The broad valleys found in the area provide for streams with abundant fish habitat and fishing opportunities. Seventy Class I streams have been mapped in the area, eight of which were identified with high fishing potential. Several streams are important fisheries for the people of Hoonah and some can be accessed through the road system. No rare of sensitive plants were identified in four surveys that covered 0.5 mile.

In this use area, 21 historic and 15 prehistoric sites were identified in 41 surveys that covered 63.5 miles.

\section{Alternative Comparisons}

\begin{tabular}{|c|c|c|c|c|c|c|c|c|c|c|c|c|c|}
\hline & Alt. 1 & \multicolumn{3}{|c|}{ Alt. 2} & \multicolumn{3}{|c|}{ Alt. 3} & \multicolumn{3}{|c|}{ Alt. 4} & \multicolumn{3}{|c|}{ Alt. 5} \\
\hline \multirow{2}{*}{$\begin{array}{l}\text { Commercial } \\
\text { Allocation } \\
\text { (groups by } \\
\text { season) }\end{array}$} & \multirow[b]{2}{*}{ N/A } & Spr & Sum & Fall & Spr & Sum & Fall & Spr & Sum & Fall & Spr & Sum & Fall \\
\hline & & 59 & 223 & 66 & 294 & 742 & 329 & 70 & 158 & 33 & 59 & 371 & 165 \\
\hline \multirow[t]{4}{*}{ Enclaves } & N/A & \multicolumn{3}{|c|}{ None } & \multicolumn{3}{|c|}{ 8-Fathom Dock Area } & \multicolumn{3}{|c|}{ None } & \multicolumn{3}{|c|}{ 8-Fathom Dock Area } \\
\hline & & & & & \multicolumn{3}{|c|}{ Salt Lake Bay Dock } & & & & \multicolumn{3}{|c|}{ Salt Lake Bay Dock } \\
\hline & & & & & \multicolumn{3}{|c|}{ Red Cliff } & & & & \multicolumn{3}{|c|}{ Red Cliff } \\
\hline & & & & & \multicolumn{3}{|c|}{ Kennel Creek } & & & & \multicolumn{3}{|c|}{ Kennel Creek } \\
\hline \multirow[t]{3}{*}{$15 \%$ Areas } & N/A & \multicolumn{3}{|c|}{ None } & \multicolumn{3}{|c|}{ Neka Bay-N. Bight } & \multicolumn{3}{|c|}{ None } & \multicolumn{3}{|c|}{ Neka Bay-N. Bight } \\
\hline & & & & & \multicolumn{3}{|c|}{ Neka Bay-S. Bight } & & & & \multicolumn{3}{|c|}{ Neka Bay-S. Bight } \\
\hline & & & & & \multicolumn{3}{|c|}{ Iyoukeen Peninsula } & & & & \multicolumn{3}{|c|}{ Iyoukeen Peninsula } \\
\hline $\begin{array}{l}\text { Neka Bay } \\
\text { Wheeled } \\
\text { Plane } \\
\text { Landings }\end{array}$ & N/A & \multicolumn{3}{|c|}{ None } & \multicolumn{3}{|c|}{$\begin{array}{l}\text { Spring: 4/week } \\
\text { Summer: } 5 / \text { week } \\
\text { Fall: 5/week }\end{array}$} & \multicolumn{3}{|c|}{$\begin{array}{l}\text { Spring: } 0 \\
\text { Summer: } 0 \\
\text { Fall: } 0\end{array}$} & \multicolumn{3}{|c|}{$\begin{array}{l}\text { Spring: } 0 \\
\text { Summer: } 3 / \text { week } \\
\text { Person's with } \\
\text { disabilities only } \\
\text { Fall: 3/week } \\
\text { Person's with } \\
\text { disabilities only }\end{array}$} \\
\hline
\end{tabular}




\section{Use Area 04-11}

\section{Hoonah Area (Northwest Chichagof) - Hoonah Ranger District}

\section{Mitigation}

See Appendix $C$ for mitigation measures.

Eight Fathom Bight and Salt Bay docks are for Forest Service administrative use. Outfitter/guides may use these docks as permitted but they may not leave boats unattended or obstruct administrative use.

Wheeled plane landings will be permitted at Neka Bay at the frequencies specified in the selected alternative. 


\section{Use Area - 04-11}

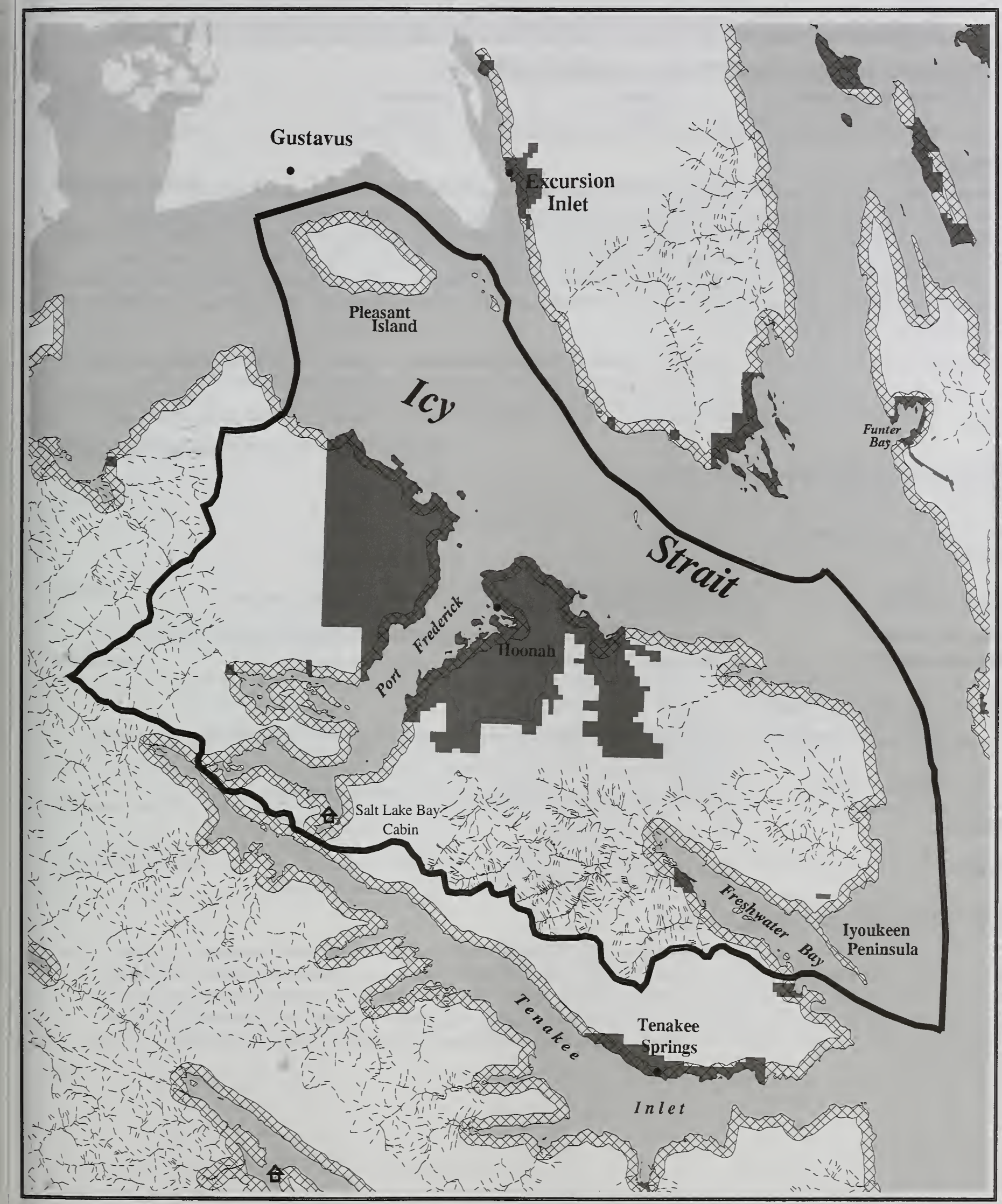

Use Area Boundary High Value Freshwater Fishing Streams 12 Shoreline Use Zone

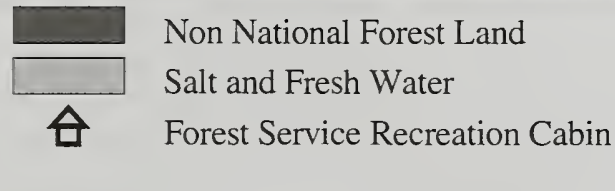

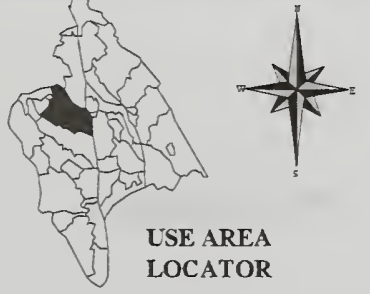




\section{Use Area 04-12}

\section{Tenakee Inlet (Southeast Chichagof) - Sitka/Hoonah Ranger Districts}

\begin{tabular}{|c|c|c|c|}
\hline \multicolumn{2}{|c|}{ Recreation Carrying Capacity (total capacity for all users) } \\
\hline Groups at one time & Spring & Summer & Fall \\
\hline 15 & 630 & 1,590 & 705 \\
\hline
\end{tabular}

\section{Description}

Encompassing central and eastern portions of Chichagof Island most of this use area is administered by the Sitka Ranger Distriet with a small portion near Freshwater Bay administered by the Hoonah Ranger Distriet. All of the uplands surrounding Tenakec Inlet from north of Pavlov Harbor to Pt Hayes are ineluded. This use area also ineludes the following Special Designation areas in their entirety: Kadashan LUD II, Trap Bay LUD II, and Kadashan LUD II Wild River. Aeeess to the shoreline areas of Chatham Strait is diffieult and is dietated by weather eonditions, however there are many miles of aeecssible shoreline in the following areas: Pavlof Harbor, Wachusetts Cove, and Basket, Long, Seal, Saltery, Crab, Kadashan, Corner, and Trap Bays.
LUDs
Remote Recreation, Semi-Remote Recreation, Old-growth Habitat, LUD II, LUD II Scenie River, Scenie Viewshed, Modified Landscape, and Timber Production
ROS
Primitive, Semi-Primitive Motorized, Semi-Primitive Non-Motorized, and Roaded Modified
National Forest Shoreline 178 miles
Miles
National Forest Shoreline $\quad 45,117$ acres
Acres
Communities
The eommunity of Tenakee Springs is located within this use area.
Alaska Coastal
Management Act
The area south of Tenakee Inlet is within the boundary of the Sitka Distriet Coastal Management Program.

\section{Forest Service Facilities}

Public Recreation Cabins

Kook Lake, however this eabin is loeated more than a mile inland from the saltwater shoreline.

\section{Administrative Cabins}

Trap Bay, Corner Bay boat dock and work center, Kadashan

\section{Shelters}

Long Bay and Saltery Bay

Trails

Little Basket Bay to Basket Lake

\section{Non-National Forest System Lands}

The Tenakee Trail is within the use area, however, only the eastern end is located on national forest lands with most of the trail located within the corporate limits of the City of Tenakec Springs. Two state of Alaska cabins are loeated in the Kadashan drainage, and a private eabin is located near the mouth of Crab Bay. Native Allotment pareels are loeated at Kadashan and The Portage. A large tract of Native Corporation land is located along much of the use area's Chatham Strait shoreline with a small pareel of Native Corporation land at the head of Basket Bay. State seleet land is located at Pavlof Harbor. 


\section{Use Area 04-12}

\section{Tenakee Inlet (Southeast Chichagof) - Sitka/Hoonah Ranger Districts}

\section{Recreation Use}

Area Attractions

Commercial Use

Non-commercial Use

Use Patterns

Primary Use Areas

Areas of Concern
Tenakee Hot Springs, Forest Service cabin and shelter, The Portage, Basket Bay, and Kadashan River

Brown bear hunting, freshwater fishing, hiking, sightseeing

Uplands surrounding Tenakee Inlet are important for their non-guided, recreational value to visitors and residents of Tenakee Springs, while the Chatham Strait shoreline has unguided recreational value to both the residents of Tenakee Springs and Angoon.

Commercial trollers and crabbers, boat and land based outfitter/guides, and recreational boaters

City of Tenakee Springs, Kadashan River, Basket Bay, Goose Flats, The Portage

Trespass on private land and Kadashan River is a recommended Scenic River.

\section{Management/Resource Considerations}

\section{Subsistence}

Wildlife

Fisheries

Botany

Cultural/Heritage
An annual average of 23 subsistence fishing permits have been returned for use at Kook Lake, Pavlof River, and Sitkoh Bay. There are no anticipated restrictions on subsistence resource users as a result of this project.

One NMFS identified Stellar sea lion haul-out is located in this use area. There are 354 mapped bald eagle nests in this use area. The north shore of the use area from The Portage to East Point lies within the Northeast Chichagof Controlled Use Area for state and federal management of brown bears.

In this use area, 97 Class I streams have been mapped and 16 high value fishing streams identified. Kook Lake supports a diminished return of sockeye salmon, and Pavlof Lake has a very small sockeye run. A cooperative sockeye stock assessment program, approved by the Federal Subsistence Board, was recently started at Kook Lake. All systems contain Dolly Varden char and coho, chum and pink salmon. The Kadashan River is the largest producer of coho salmon in this area.

No rare or sensitive plants were found during two botanical surveys conducted on 0.25 miles of shoreline.

A total of 49 surveys covering 128.75 miles have been completed in this use area, with 21 historic and 34 prehistoric sites identified. 


\section{Use Area 04-12}

\section{Tenakee Inlet (Southeast Chichagof) - Sitka/Hoonah Ranger Districts}

\section{Alternative Comparisons}

\begin{tabular}{|c|c|c|c|c|c|c|c|c|c|c|c|c|c|}
\hline & Alt. 1 & & Alt. 2 & & & Alt. & & & Alt. 4 & & & Alt. 5 & \\
\hline \multirow{2}{*}{$\begin{array}{l}\text { Commercial } \\
\text { Allocation } \\
\text { (groups by } \\
\text { season) }\end{array}$} & \multirow{2}{*}{ N/A } & Spr & Sum & Fall & Spr & Sum & Fall & Spr & Sum & Fall & Spr & Sum & Fall \\
\hline & & 63 & 557 & 71 & 315 & 795 & 353 & 37 & 80 & 35 & 63 & 557 & 176 \\
\hline \multirow[t]{3}{*}{ Enclaves } & N/A & \multicolumn{3}{|c|}{ None } & \multicolumn{3}{|c|}{ Corner Bay Road } & \multicolumn{3}{|c|}{ Corner Bay Road } & \multicolumn{3}{|c|}{ Corner Bay Road } \\
\hline & & & & & \multicolumn{3}{|c|}{ Crab Bay } & & & & & & \\
\hline & & & & & \multicolumn{3}{|c|}{ West Tenakee } & \multicolumn{3}{|c|}{ West Tenakee } & \multicolumn{3}{|c|}{ West Tenakee } \\
\hline \multirow[t]{3}{*}{$15 \%$ Areas } & N/A & \multicolumn{3}{|c|}{ None } & \multicolumn{3}{|c|}{ Saltery Bay } & \multicolumn{3}{|c|}{ None } & & & \\
\hline & & & & & \multicolumn{3}{|c|}{ Seal Bay } & & & & \multicolumn{3}{|c|}{ Seal Bay } \\
\hline & & & & & \multicolumn{3}{|c|}{ Trap Bay } & & & & & & \\
\hline
\end{tabular}

\section{Mitigation}

See Appendix C for mitigation measures.

Guided use on the Kadashan River, a recommended Scenic River, is limited to four groups per day.

Corner Bay dock is for Forest Service administrative use. Outfitter/guides may use these docks as permitted but they may not leave boats unattended or obstruct administrative use.

Use will not be authorized for access to kook Lake from Basket Bay unless outfitter/guides provide proof of permission to cross private lands.

Access to Basket Lake from Little Basket Bay will be limited to the trail corridor easement across private land. 


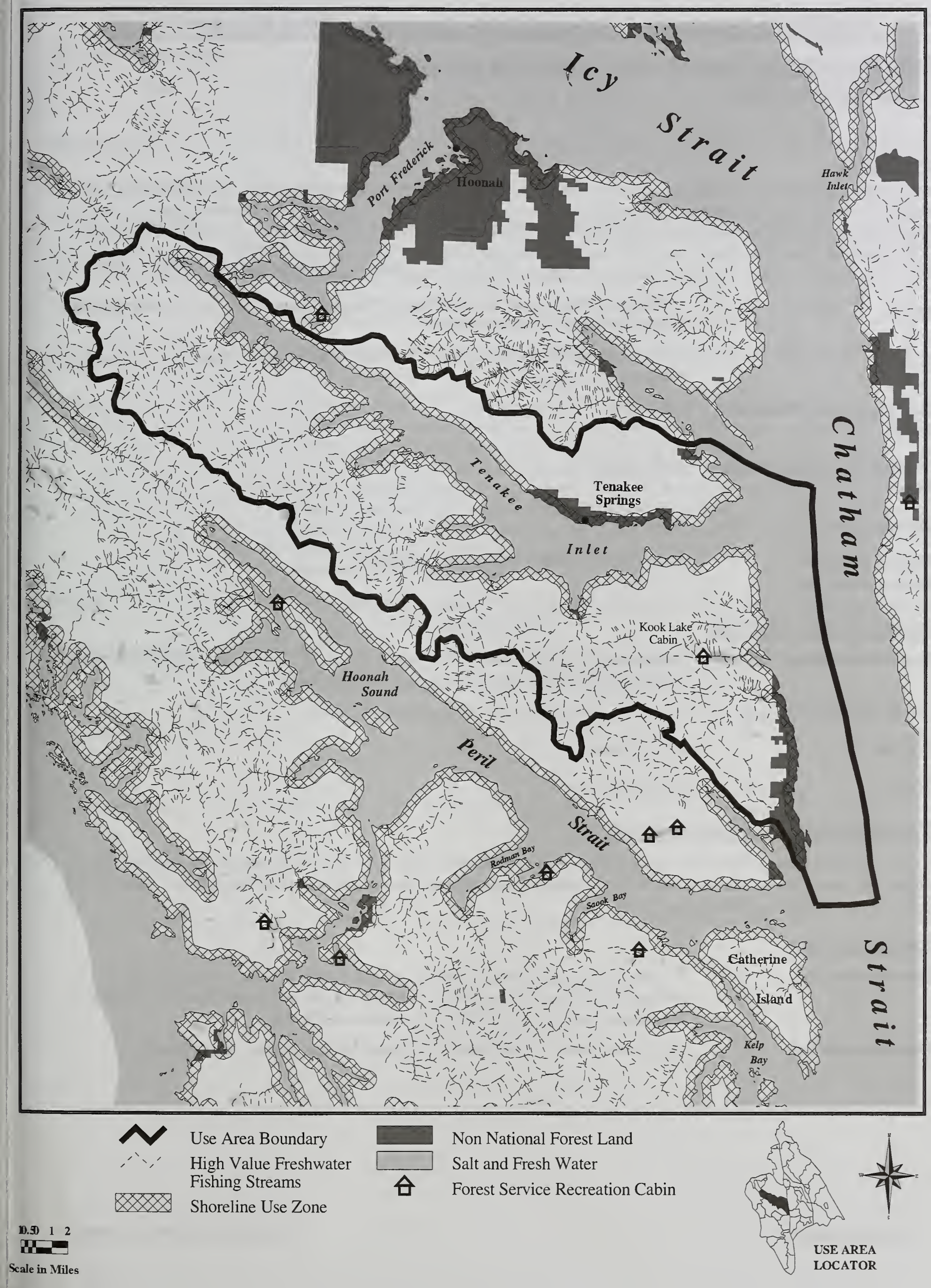




\section{Use Area 04-13}

\section{Peril Strait (Southern Chichagof, NW Baranof) - Sitka Ranger District}

\section{Recreation Carrying Capacity (total capacity for all users)}

\begin{tabular}{|c|c|c|c|}
\hline Groups at one time & Spring & Summer & Fall \\
\hline 16 & 672 & 1,696 & 752 \\
\hline
\end{tabular}

\section{Description}

Most of this use area encompasses the southern end of Chichagof Island from near Sergius Point to Pt. Hayes and includes a small portion of extreme northwest Baranof Island from south of Bear Bay to a point on the Duffield Peninsula west of Point Peschani. Access to the shoreline along Peril Strait \& Hoonah Sound is dictated by weather conditions and tidal flow. Easily accessed shoreline is found in Deep Bay, Bear and Baby Bear coves, Goose Cove, Poison Cove, Ushk Bay, Fick Cove, Patterson Bay, False Island Bight, Lindenberg Harbor, Florence Bay, and Sitkoh Bay.

\begin{tabular}{|c|c|}
\hline LUDs & $\begin{array}{l}\text { LUD II, Modified Landscape, Old Growth, Semi-Remote Recreation, Scenic Viewshed } \\
\text { Timber Production, and Wilderness }\end{array}$ \\
\hline ROS & $\begin{array}{l}\text { Primitive, Roaded Modified, Roaded Natural, Semi-Primitive Motorized. and Semi- } \\
\text { Primitive Non-Motorized }\end{array}$ \\
\hline $\begin{array}{l}\text { National Forest Shoreline } \\
\text { Miles }\end{array}$ & 200 miles \\
\hline $\begin{array}{l}\text { National Forest Shoreline } \\
\text { Acres }\end{array}$ & 50,323 acres \\
\hline Communities & None \\
\hline $\begin{array}{l}\text { Alaska Coastal } \\
\text { Management Act }\end{array}$ & Sitka District Coastal Management Program \\
\hline
\end{tabular}

\section{Forest Service Facilities}

Public Recreation Cabins Moser Island, East Sitkoh and West Sitkoh; however, the East and West Sitkoh cabins are each located more than a mile inland from saltwater.

Administrative Cabins Forest Service work center and dock at False Island

Shelters

Ostoia Island

Trails

Sitkoh Lake Trail

\section{Non-National Forest System Lands}

Native Allotment parcels are located at Deep Bay and Poison Cove, and Native Corporation parcels are located at Broad Finger and Sitkoh Creek. The former Chatham Cannery site is privately owned and located at Sitkoh Bay. A state marine park is located at Bear and Baby Bear coves.

\section{Recreation Use}

Area Attractions

Hunting, freshwater fishing, crabbing and shrimping, wildlife viewing, spawning salmon, public recreation cabins and shelters, old growth forests, historic logging area, accessible beaches, Nelson Falls, and contrasting habitats

Commercial Use Brown bear hunting, deer hunting, freshwater fishing, hiking, and sightseeing 


\title{
Use Area 04-13
}

\author{
Peril Strait (Southern Chichagof, NW Baranof) - Sitka Ranger District \\ Non-commercial Use \\ Use in this area is primarily by residents of Sitka and transient boaters along the travel \\ route to Sitka. Uplands surrounding the Hoonah Sound area are important for their \\ recreational value to the residents of Sitka. The water route from Sitka through inner \\ waterways is protected and can be traveled in most weather conditions. \\ Use Patterns \\ Commercial crabbers, boat and land based outfitter/guides, and recreational boaters \\ Primary Use Areas \\ The entire area is used. \\ Areas of Concern \\ Trespass on private land, and the trail to Nelson Falls is in poor condition.
}

\section{Management/Resource Considerations}

\section{Subsistence}

Wildlife

Fisheries

Botany

Cultural/Heritage
Sitkoh Lake supports an important subsistence fishery. There are no anticipated restrictions on subsistence resource use as a result of this project.

In this use area, there are 263 mapped bald eagle nests and one NMFS identified Steller Sea lion haul-out.

In this use area, 108 Class I streams were mapped, with 21 of these having high value. Most of these streams contain runs of pink, chum, and coho salmon as well as Dolly Varden char, cutthroat trout, and steelhead. This area also contains two large lakes, Sitkoh and Suloia. Suloia Lake contains rainbow trout. Sitkoh Lake supports sockeye, pink, chum, and coho salmon; rainbow, steelhead, and cutthroat trout; and Dolly Varden char. Sitkoh Lake is an important subsistence and recreational fishery. The steelhead return at Sitkoh Lake has attracted a very popular sport fishery. In recent years sockeye sport fishing in Sitkoh Lake drainages and Sitkoh Bay has been closed by ADF\&G because of low escapements.

One botanical survey has been completed covering about 0.25 miles of shoreline with no rare or sensitive plants identified.

Seven historic and 29 prehistoric sites have been identified from 80 surveys covering 72.5 miles. 


\section{Use Area 04-13}

Peril Strait (Southern Chichagof, NW Baranof) - Sitka Ranger District

\section{Alternative Comparisons}

\begin{tabular}{|c|c|c|c|c|c|c|c|c|c|c|c|c|c|}
\hline \multirow{3}{*}{$\begin{array}{l}\text { Commercial } \\
\text { Allocation } \\
\text { (groups by } \\
\text { season) }\end{array}$} & \multirow{3}{*}{$\begin{array}{l}\text { Alt. } 1 \\
\text { N/A }\end{array}$} & \multicolumn{3}{|c|}{ Alt. 2} & \multicolumn{3}{|c|}{ Alt. 3} & \multicolumn{3}{|c|}{ Alt. 4} & \multicolumn{3}{|c|}{ Alt. 5} \\
\hline & & Spr & Sum & Fall & Spr & Sum & Fall & Spr & Sum & Fall & Spr & Sum & Fall \\
\hline & & 67 & 509 & 75 & 336 & 848 & 376 & 101 & 92 & 74 & 67 & 678 & 188 \\
\hline \multirow[t]{3}{*}{ Enclaves } & N/A & \multicolumn{3}{|c|}{ None } & \multicolumn{3}{|c|}{ Ushk Bay } & & & & & & \\
\hline & & & & & \multicolumn{3}{|c|}{ Poison Cove } & & & & \multicolumn{3}{|c|}{ Poison Cove } \\
\hline & & & & & \multicolumn{3}{|c|}{ Sitkoh Bay Road } & \multicolumn{3}{|c|}{ Sitkoh Bay Road } & \multicolumn{3}{|c|}{ Sitkoh Bay Road } \\
\hline \multirow[t]{6}{*}{$15 \%$ Areas } & N/A & \multicolumn{3}{|c|}{ None } & \multicolumn{3}{|c|}{ Nelson Falls } & \multicolumn{3}{|c|}{ Nelson Falls } & \multicolumn{3}{|c|}{ Nelson Falls } \\
\hline & & & & & \multicolumn{3}{|c|}{$\begin{array}{c}\text { Todd Road/ } \\
\text { Lindenberg Head }\end{array}$} & & & & \multicolumn{3}{|c|}{$\begin{array}{c}\text { Todd Road/ } \\
\text { Lindenburg Head }\end{array}$} \\
\hline & & & & & \multicolumn{3}{|c|}{ Patterson Bay } & \multicolumn{3}{|c|}{ Patterson Bay } & \multicolumn{3}{|c|}{ Patterson Bay } \\
\hline & & & & & \multicolumn{3}{|c|}{$\begin{array}{l}\text { Patterson Bay- } \\
\text { North Point }\end{array}$} & & & & & & \\
\hline & & & & & \multicolumn{3}{|c|}{ Nismeni Point } & & & & \multicolumn{3}{|c|}{ Nismeni Point } \\
\hline & & & & & \multicolumn{3}{|c|}{ Moser } & & & & & & \\
\hline
\end{tabular}

\section{Mitigation}

See Appendix $\mathrm{C}$ for mitigation measures.

False Island dock is for Forest Service administrative use. Outfitter/guides may use these docks as permitted, but they may not leave boats unattended or obstruct administrative use.

Access along Sitkoh Lake trail will be limited to the trail corridor easement across private land.

Nelson Falls trail use will not be allowed for large groups until the trail is hardened.

Outfitter/guides will not be allowed to fly clients into Sitkoh Lake. 
Use Area - 04-13

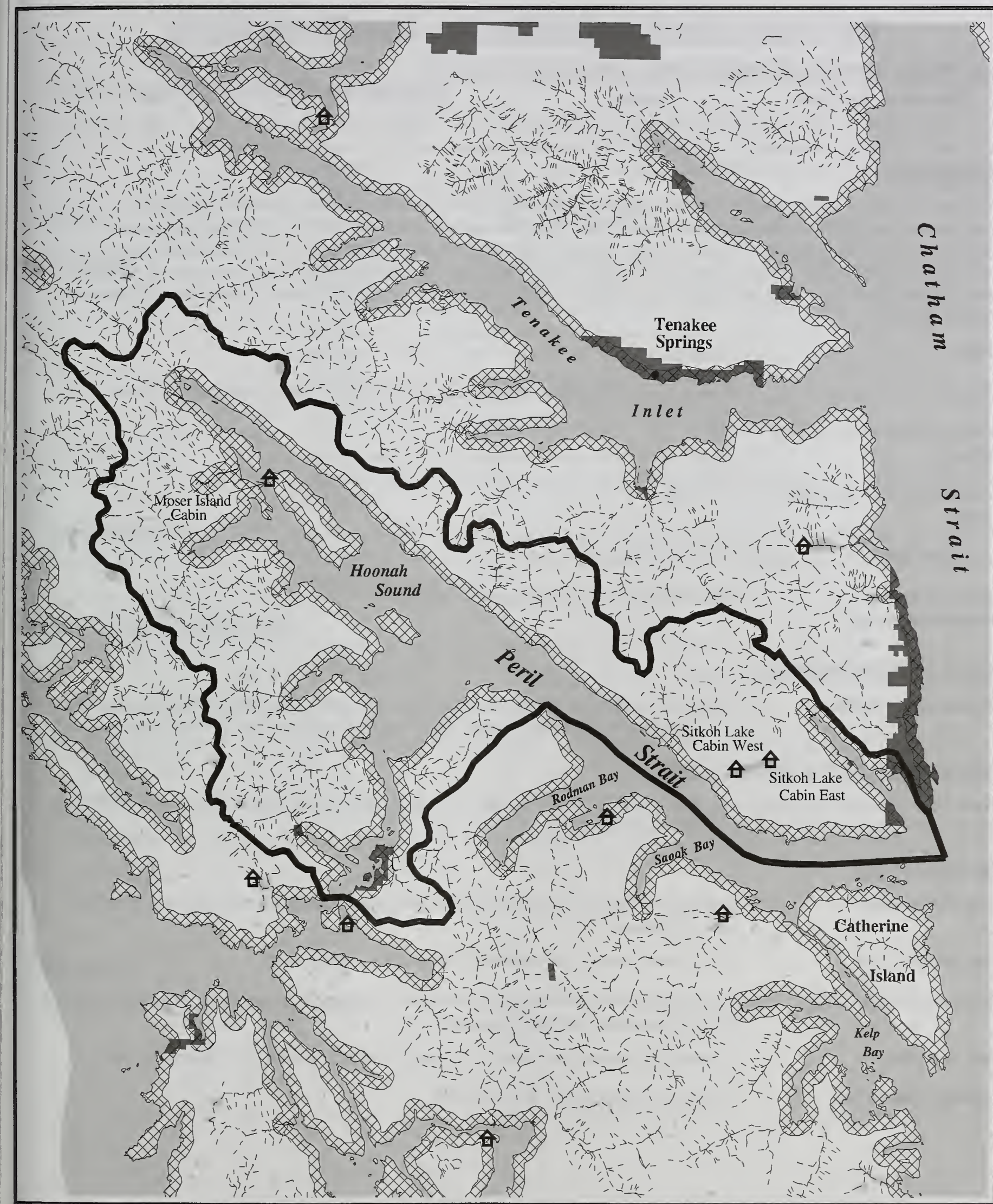




\section{Slocum Arm (Southwest Chichagof) - Sitka Ranger District}

Recreation Carrying Capacity (total capacity for all users)

\begin{tabular}{|c|c|c|c|}
\hline Groups at one time & Spring & Summer & Fall \\
\hline 8 & 336 & 848 & 376 \\
\hline
\end{tabular}

\section{Description}

Use area 04-14 is located in the southwestern region of Chichagof Island including offshore islands. This area encompasses most of the southern portion of the of the West Chichagof - Yakobi Wilderness, between the entrance to Klag Bay and Krugloi Island in Salisbury Sound. Access to uplands with exposed coastline is rarely possible because of ocean swell. Many miles of easily accessible shoreline can be found in the following areas: Leo's Anchorage, Slocum Arm, Hidden Cove, Flat Cove, Waterfall Cove, Falcon Arm, Ford Arm, Klag Bay, Lake Anna, Sister Lake, and leeward offshore islands.
LUDs
Wilderness
ROS
Primitive, Semi-Primitive Motorized, Semi-Primitive Non-Motorized, and Rural

National Forest Shoreline 245

Miles

\section{National Forest Shoreline $\quad 29,873$ acres \\ Acres}

Communities

None

Alaska Coastal Management Act

Sitka District Coastal Management Program

\section{Forest Service Facilities}

Special Uses Cabins

There are two private cabins under Special Use permit. The first cabin is at the entrance to Klag Bay and the second is where Lake Anna and Sister Lake meet.

\section{Non-National Forest System Lands}

Private land is located on Bauer Island and at several locations adjacent to Klag Bay. Small Native Corporation parcels are located at the entrance to Klag Bay and at the Potato Patch.

\section{Recreation Use}

Area Attractions

Subsistence fishery, remote wilderness and scenic values, historical mining buildings and equipment

Commercial Use

Non-commercial Use

Use Patterns

Primary Use Areas
Brown bear hunting, freshwater fishing, hiking, sightseeing

Most of the non-commercial use in this area is primarily by residents of Sitka and others seeking an isolated wilderness experience.

Commercial trollers, boat based commercial outfitter/guides, and recreational boaters Slocum Arm, Ford Arm, and Klag Bay 


\section{Use Area 04-14}

\section{Slocum Arm (Southwest Chichagof) - Sitka Ranger District}

\section{Management/Resource Considerations}

\section{Subsistence}

Wildlife

Fisheries

Botany

Cultural/Heritage
Streams in this area support important subsistence sockeye fisheries for residents of Sitka. Subsistence permits have been returned for use at Lake Anna, Klag Bay, Ford Arm, and Fortuna Straights. There are no anticipated restrictions on subsistence resource users due to guided recreation use.

In this use area, there are 29 mapped bald eagle nests.

In this use area, 33 Class I streams have been mapped and four high value fishing streams identified. Most of these streams contain runs of coho, pink, and chum salmon, Dolly Varden char, and small runs of steelhead. There are five sockeye salmon systems in the area, three of which are heavily used subsistence areas due to their relatively close proximity to Sitka. Lake Leo and Sisters Lake systems contain smaller sockeye runs. Sockeye salmon harvests have increased substantially at Klag Bay. If harvest trends continue to increase, the stock may be at risk to decline. In response to increasing harvest trends, $A D F \& G$ has restricted subsistence and sport fisheries in Klag Bay.

In this use area, 12 botanical surveys have been done covering about 1.5 miles of the shoreline. Botrychium virginianum was found at one beach meadow at one site on Khaz Peninsula.

In this use area, 26 cultural resource surveys covering 3.5 miles have been conducted. Ten sites have been identified on National Forest System lands; four are considered historic and six prehistoric.

\section{Alternative Comparisons}

\begin{tabular}{|l|c|c|c|c|c|c|c|c|c|c|c|c|c|}
\hline & Alt. 1 & \multicolumn{3}{|c|}{ Alt. 2 } & \multicolumn{3}{c|}{ Alt. 3 } & \multicolumn{3}{c|}{ Alt. 4 } & \multicolumn{3}{c|}{ Alt. 5 } \\
\hline $\begin{array}{l}\text { Commercial } \\
\begin{array}{l}\text { Allocation } \\
\text { (groups by } \\
\text { season) }\end{array}\end{array}$ & N/A & Spr & Sum & Fall & Spr & Sum & Fall & Spr & Sum & Fall & Spr & Sum & Fall \\
\cline { 2 - 13 } & & 34 & 297 & 38 & 168 & 424 & 188 & 50 & 42 & 19 & 34 & 297 & 94 \\
\hline Enclaves & N/A & \multicolumn{3}{|c|}{ None } & \multicolumn{3}{c|}{ None } & \multicolumn{3}{c|}{ None } & \multicolumn{3}{c|}{ None } \\
\hline $15 \%$ Areas & N/A & \multicolumn{3}{|c|}{ None } & \multicolumn{3}{c|}{ None } & \multicolumn{3}{c|}{ None } & \multicolumn{3}{c|}{ None } \\
\hline
\end{tabular}

\section{Mitigation}

See Appendix C for mitigation measures. 


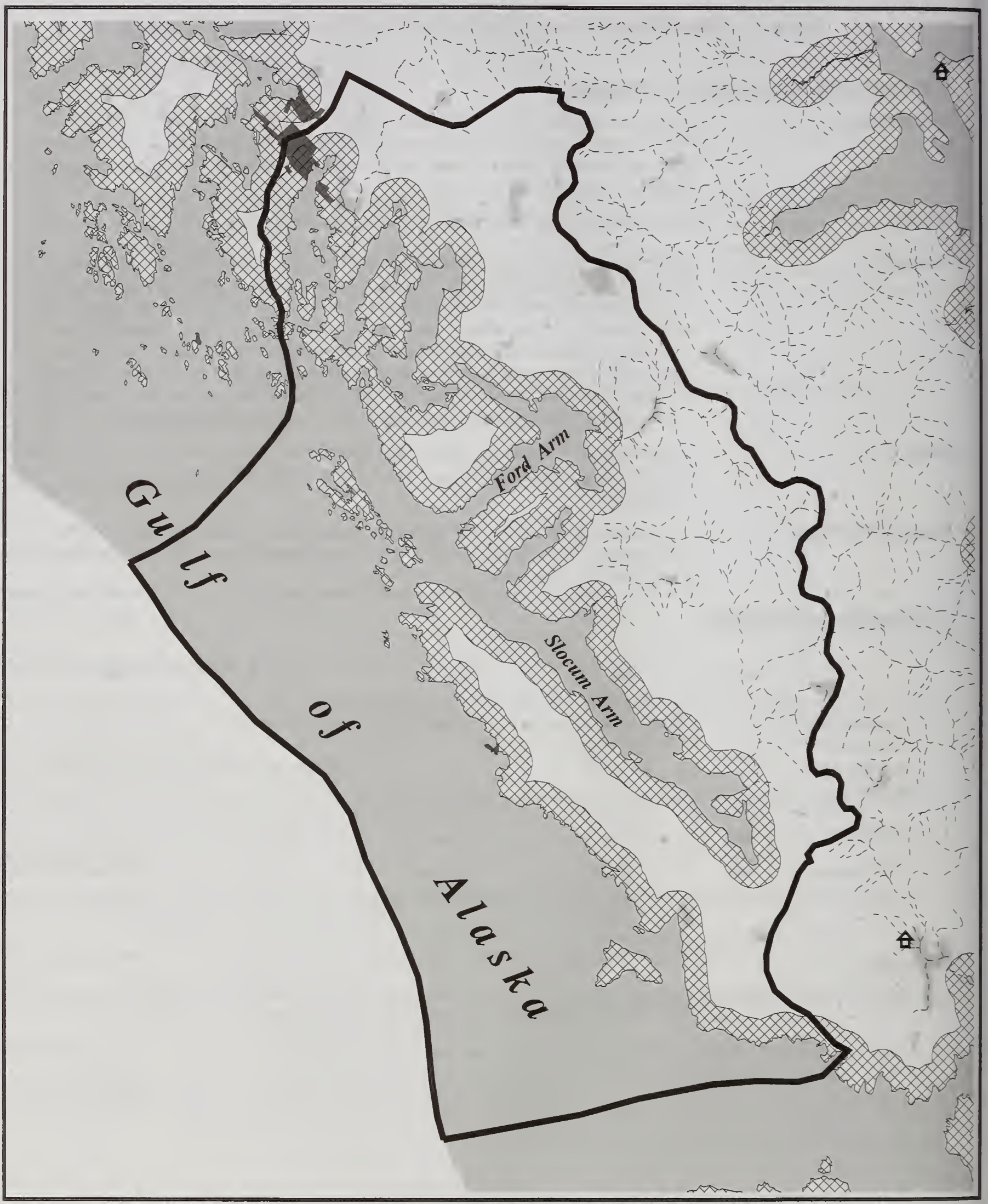

Use Area Boundary High Value Freshwater Fishing Streams

Shoreline Use Zone

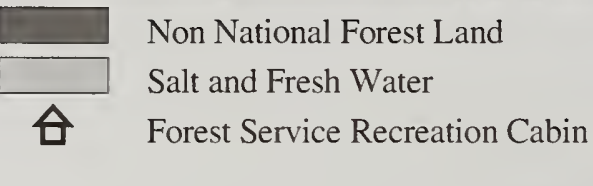




\section{Use Area 04-15}

West Chichagof - Hoonah/Sitka Ranger Districts

\begin{tabular}{|c|c|c|c|}
\hline \multicolumn{2}{l|}{ Recreation Carrying Capacity (total capacity for all users) } \\
\hline Groups at one time & Spring & Summer & Fall \\
\hline 20 & 840 & 2,120 & 940 \\
\hline
\end{tabular}

\section{Description}

This area includes northwest Chichagof Island from Three Hill Island west along the outer coast of Chichagof to Khaz Bay. It includes Yakobi Island and encompasses the northern $3 / 4$ of the West Chichagof-Yakobi Wilderness. The outer coast of west Yakobi and west Chichagof islands is characterized by an extremely rocky shoreline with intermittent coves and tiny islands. Storms coming directly from the Gulf of Alaska can make the area very treacherous for boaters. South of Point Urey are numerous coves, rocky islands, streams, and inland lakes. It also includes the inside waterways of Lisianski Inlet, Lisianski Strait, and Stag Bay.

LUDs

ROS

National Forest

Shoreline Miles

National Forest

Shoreline Acres

Communities

Alaska Coastal Management Act
LUD II, LUD II Wild River, Semi Remote Recreation, and Wilderness

Primitive, Rural, Semi-Primitive Motorized, and Semi-Primitive Non-Motorized

604 miles

66,022 acres

The community of Pelican is situated along the east shore of Lisianski Inlet. Private property adjacent to Pelican expands out across 10 miles of shoreline and includes several remote inholdings isolated from the city boundary.

This use area includes the district boundary for the City of Pelican Coastal Management Plan.

\section{Forest Service Facilities}

Public Recreation Greentop, White Sulphur Springs, and Goulding Lakes Cabins

Cabins

Trails

Greentop, Stag Bay, Stag River, Lisianski River, Takanis Lake, White Sulphur Springs, Mirror Harbor, Dry Pass, Didrickson, and Goulding Lakes

\section{Non-National Forest System Lands}

Non-National Forest System lands include: Soapstone Cove, Cape Bingham, Ewe Ledge, and Mite Cove on North Yakobi Island; the City of Pelican and adjacent private properties in Lisianski Inlet; and Kimshan Cove on west Chichagof Island.

\section{Recreation Use}

Area Attractions

Commercial Use

Anadromous fish streams, White Sulfur Hot Springs, Greentop Cabin, and remote rugged setting of the outer coast

Brown bear hunting, freshwater fishing, camping, sightseeing, commercial fishing, recreational boaters and kayakers, boat-based outfitter/guides, boat-based subsistence use, and boat-based sport fishing

Non-commercial Use

Hunting, hiking, sightseeing, and kayak camping 


\section{Use Area 04-15}

\section{West Chichagof - Hoonah/Sitka Ranger Districts}

Primary Use Areas

Areas of Concern
Three Hill Island is a popular location for mid-size cruise ships and residents of Elfin Cove. Lisianski River, Stag Bay, and various places along Lisianski Inlet and Lisianski Strait receive consistent use, along with the Chichigof Wilderness Area. West Yakobi includes the popular recreation places of Hoktaheen Cove, Deer Harbor, Squid Bay, Takanis Bay, and Greentop Harbor. Popular recreation areas include Porcupine Bay, White Sulfur Hot Springs, Sea Level Slough, Goulding Harbor, Dry Pass, Black Bay, Bertha Bay, and Portlock Harbor

Lisianski River is a recommended Wild River. Perceptions of crowding and motor craft use on Lisianski River. Use at White Sulphur Springs.

\section{Management/Resource Considerations}

\section{Subsistence}

Wildlife

Fisheries

Botany

Cultural/Heritage
An annual average of 98 subsistence fishing permits have been returned for use at Surge Bay, Hoktaheen Cove, Lisanski River, Tkanis Bay, and Klag Bay. Hoktaheen Lake and the associated outlet stream produce a significant return of sockeye salmon. Hoktaheen sockeye harvest is important for residents of small communities in the Cross Sound area including Hoonah, Pelican, and elfin Cove. Two nearby systems on west Yakobi Island, Surge Bay and Takanis Bay, have minor subsistence harvests. To ensure adequate escapement, harvest restrictions have been placed on all the above streams. There are no anticipated restrictions on subsistence resource users due to this project.

Three NMFS-identified Steller sea lion haul outs are located in this use area. In this use area, 45 bald eagle nests are mapped.

In this use area, 106 Class I streams have been mapped, of which 12 streams are identified as having high fishing values. Hoktaheen Lake and the associated outlet stream produce a significant return of sockeye salmon. Hoktaheen Lake is 126 acres in area and the outlet stream is approximately 1.5 miles long. The average reported subsistence harvest over the 1995-1999 period was approximately 1,100 fish from an average of 45 permits. Hoktaheen sockeye harvest is important for residents of small communities in the Cross Sound area including Hoonah, Pelican, and Elfin Cove. Two nearby systems on West Yakobi Island, Surge Bay and Takanis Bay, have minor subsistence harvests.

Harvests of sockeye from the Hoktaheen system have increased dramatically in recent years from an average of 406 during the 1988-1994 period to an average of 1,222 fish during 1995-1999. There has been recent concern that the system may be over harvested. If harvest trends continue to increase, the stock may be at risk to decline. In response to increasing harvest trends, ADF\&G management staff restricted subsistence and sport fisheries in 1999 and 2000 as a precautionary measure and sought funding for stock assessment programs to provide information necessary to assess the stock status and current regulations. Beginning with the 1999 season, the department reduced the season by permits allowing harvest from June 1-July 20 , ensuring that the final $20 \%$ of historic run timing would be available for escapement. Similar action was taken at Surge Bay and Takanis Bay.

Twenty-eight surveys covering four miles of shoreline revealed Poa norbergii in the rocks next to a beach and Rhododenron camtschaticum was found in a muskeg just back from a beach.

In this use area, 12 historic and 10 prehistoric sites were identified from 61 surveys that covered 19.25 miles. 


\section{Use Area 04-15}

\section{West Chichagof - Hoonah/Sitka Ranger Districts}

\section{Alternative Comparisons}

\begin{tabular}{|c|c|c|c|c|c|c|c|c|c|c|c|c|c|}
\hline & Alt. 1 & & Alt. 2 & & & Alt. 3 & & & Alt. 4 & & & Alt. 5 & \\
\hline \multirow{2}{*}{$\begin{array}{l}\text { Commercial } \\
\text { Allocation } \\
\text { (groups by } \\
\text { season) }\end{array}$} & \multirow{2}{*}{ N/A } & Spr & Sum & Fall & Spr & Sum & Fall & Spr & Sum & Fall & Spr & Sum & Fall \\
\hline & & 84 & 636 & 94 & 420 & 1,060 & 470 & 42 & 199 & 47 & 84 & 636 & 235 \\
\hline \multirow[t]{2}{*}{ Enclaves } & N/A & \multicolumn{3}{|c|}{ None } & \multicolumn{3}{|c|}{ Three Hill Island } & \multicolumn{3}{|c|}{ Three Hill Island } & \multicolumn{3}{|c|}{ Three Hill Island } \\
\hline & & & & & \multicolumn{3}{|c|}{ Bohemia Basin } & & & & \multicolumn{3}{|c|}{ Bohemia Basin } \\
\hline $15 \%$ Areas & N/A & \multicolumn{3}{|c|}{ None } & \multicolumn{3}{|c|}{ None } & \multicolumn{3}{|c|}{ None } & \multicolumn{3}{|c|}{ None } \\
\hline $\begin{array}{l}\text { Lisianski } \\
\text { River } \\
\text { Commercial } \\
\text { Group use } \\
\text { per day }\end{array}$ & N/A & & None & & \multicolumn{3}{|c|}{$\begin{array}{l}\text { Spring: 4/day } \\
\text { Summer: } 5 / \text { day } \\
\text { Fall: 4/day }\end{array}$} & \multicolumn{3}{|c|}{$\begin{array}{l}\text { Spring: 1/day } \\
\text { Summer: } 2 / \text { day } \\
\text { Fall: 1/day }\end{array}$} & \multicolumn{3}{|c|}{$\begin{array}{c}\text { Spring: } 2 / \text { day } \\
\text { Summer: } 3 / \text { day } \\
\text { Fall: } 2 / \text { day }\end{array}$} \\
\hline
\end{tabular}

\section{Mitigation}

See Appendix C for mitigation measures.

Outfitter/guide use will not displace unguided users at White Sulphur Springs Bathhouse.

Guided use on the Lisianski River, a recommended Wild River, is limited to four groups per day.

Guided motorized watercraft use on Lisianski River will be restricted if motorized watercraft are causing measurable adverse effects on fish habitat. 


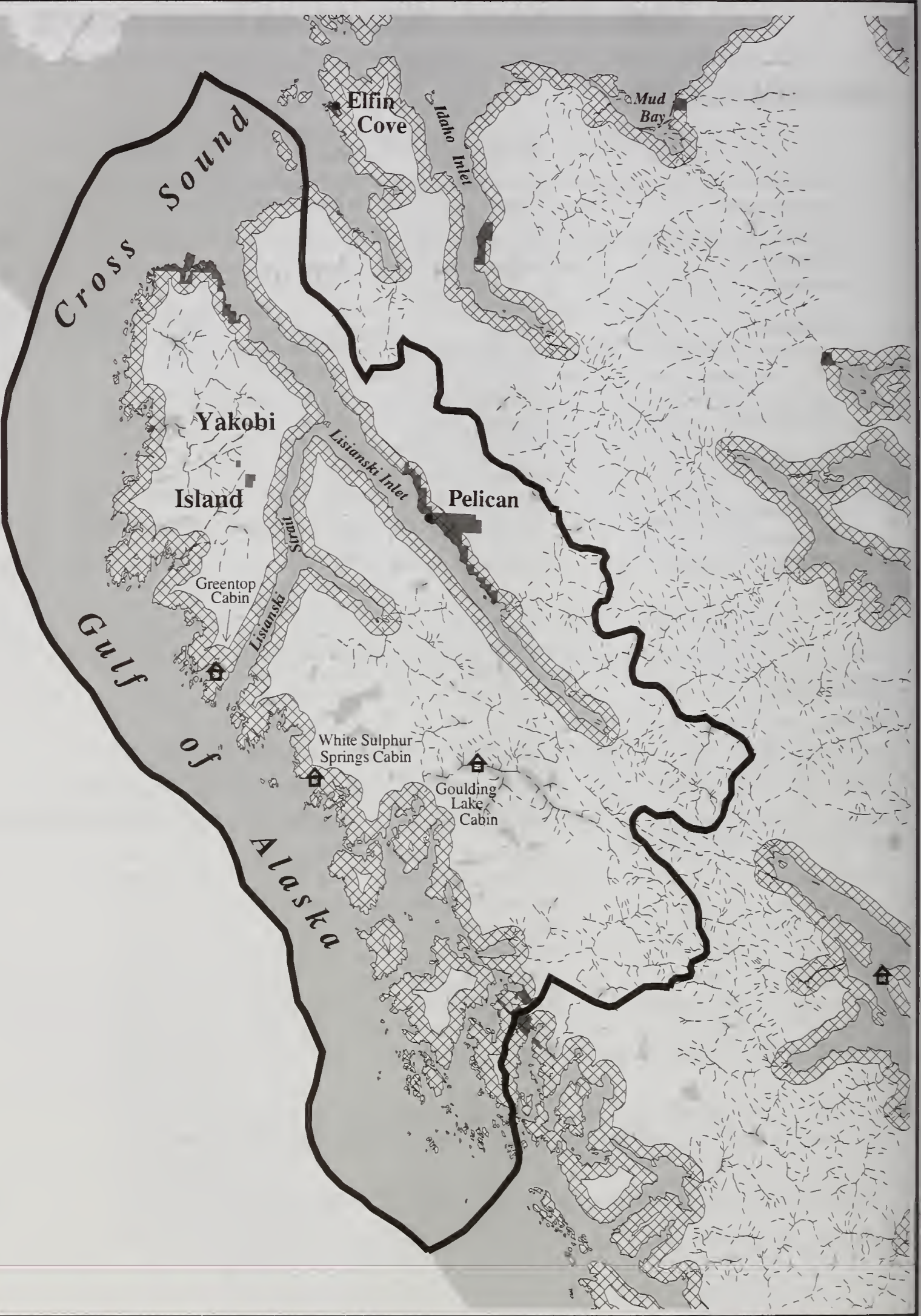

Use Area Boundary

High Value Freshwater Fishing Streams

$\infty x$

Shoreline Use Zone

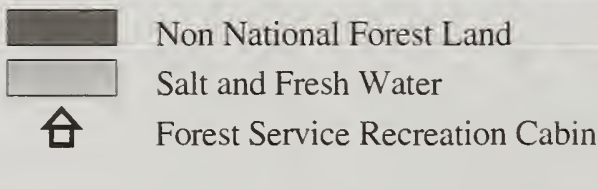




\section{Use Area 04-16A}

\section{Point Adolphus (North Chichagof) - Hoonah Ranger District}

\section{Recreation Carrying Capacity (total capacity for all users)}

\begin{tabular}{|c|c|c|c|}
\hline Groups at one time & Spring & Summer & Fall \\
\hline 6 & 252 & 636 & 282 \\
\hline
\end{tabular}

\section{Description}

This use area includes the popular areas of Point Adolphus and Pinta Cove. Point Adolphus is the northern most point on Chichagof Island bound by the waters of Icy Strait and receives some of the highest levels of remote recreational use on the Tongass. Opportunities for wildlife viewing, particularly humpback whales, attract increasing numbers of visitors each year. For this reason, this area is being managed as one of the smallest sub-units of the project area.
LUDs
LUD II and Old Growth

ROS

Semi-Primitive Motorized and Semi-Primitive Non-Motorized

National Forest Shoreline 11 miles

Miles

National Forest Shoreline $\quad 3,078$ acres

Acres

Communities

None

\section{Forest Service Facilities}

Shelters

Pinta Cove

\section{Non-National Forest System Lands}

None

Recreation Use

Area Attractions

Commercial Use

Non-commercial Use

Use Patterns

Primary Use Areas

Areas of Concern
Wildlife viewing opportunities, especially humpback whales; camping; and scenic setting

Brown bear hunting, camping, freshwater fishing, and sightseeing

This is an important recreation area for the residents of Hoonah, Gustavus, Elfin Cove, and Pelican activities include kayak tent camping and day hiking.

This area receives a variety of boat-based use from both commercial and noncommercial operators. Offshore boat traffic consists of large cruise ships; commercial fishing boats; chartered sport fishing and whale watching vessels; local and non-resident pleasure boats engaged in subsistence, fishing, wildlife viewing, or transiting between communities and other recreation areas and tour boats. Recreational access to the national forest via saltwater includes kayak transporters; commercial kayak outfitter/guides; non-commercial kayakers; tour boats dropping off groups by kayak or small skiff; local small craft sightseeing and hiking; local and non-resident pleasure boaters going ashore by small skiff; commercial outfitter guides engaged in sightseeing, hiking, and bear hunting.

Eagle Beach, Point Adolphus, Pinta Cove, and Pinta Point

Impacts from campsites 


\section{Use Area 04-16A}

\section{Point Adolphus (North Chichagof) - Hoonah Ranger District}

\section{Management/Resource Considerations}

Subsistence

Wildlife

Fisheries

Botany

Cultural/Heritage
There are no anticipated restrictions on subsistence resource users.

In this use area, 11 bald eagle nests are mapped. The entire use area is within the Northeast Chichagof Controlled Use Area for state and federal management of brown bears.

Four Class I streams are mapped; however, no streams were identified with high freshwater fishing values.

Eight surveys covering 1.5 miles of shoreline revealed Botrychium linaria and $B$. minganense within beach meadows.

Eight surveys that covered five miles revealed no sites in this area.

\section{Alternative Comparisons}

\begin{tabular}{|c|c|c|c|c|c|c|c|c|c|c|c|c|c|}
\hline & Alt. 1 & \multicolumn{3}{|c|}{ Alt. 2} & \multicolumn{3}{|c|}{ Alt. 3} & \multicolumn{3}{|c|}{ Alt. 4} & \multicolumn{3}{|c|}{ Alt. 5} \\
\hline \multirow{2}{*}{$\begin{array}{l}\text { Commercial } \\
\text { Allocation } \\
\text { (groups by } \\
\text { season) }\end{array}$} & \multirow{2}{*}{ N/A } & Spr & Sum & Fall & Spr & Sum & Fall & Spr & Sum & Fall & Spr & Sum & Fall \\
\hline & & 25 & 159 & 28 & 126 & 318 & 141 & 15 & 159 & 15 & 25 & 254 & 71 \\
\hline Enclaves & N/A & \multicolumn{3}{|c|}{ None } & \multicolumn{3}{|c|}{ None } & \multicolumn{3}{|c|}{ None } & \multicolumn{3}{|c|}{ None } \\
\hline \multirow[t]{2}{*}{$15 \%$ Areas } & N/A & \multicolumn{3}{|c|}{ None } & \multicolumn{3}{|c|}{ Pinta Cove } & \multicolumn{3}{|c|}{ Pinta Cove } & \multicolumn{3}{|c|}{ Pinta Cove } \\
\hline & & & & & \multicolumn{3}{|c|}{ Damp Marker } & \multicolumn{3}{|c|}{ Damp Marker } & \multicolumn{3}{|c|}{ Damp Marker } \\
\hline
\end{tabular}

\section{Mitigation}

See Appendix C for mitigation measures.

Outfitter/guide use will not displace unguided users at Pinta Cove shelter.

Guided campsite use will be allocated. Campsite locations will be delineated in a campsite management plan before additional guided camping use levels are permitted. 

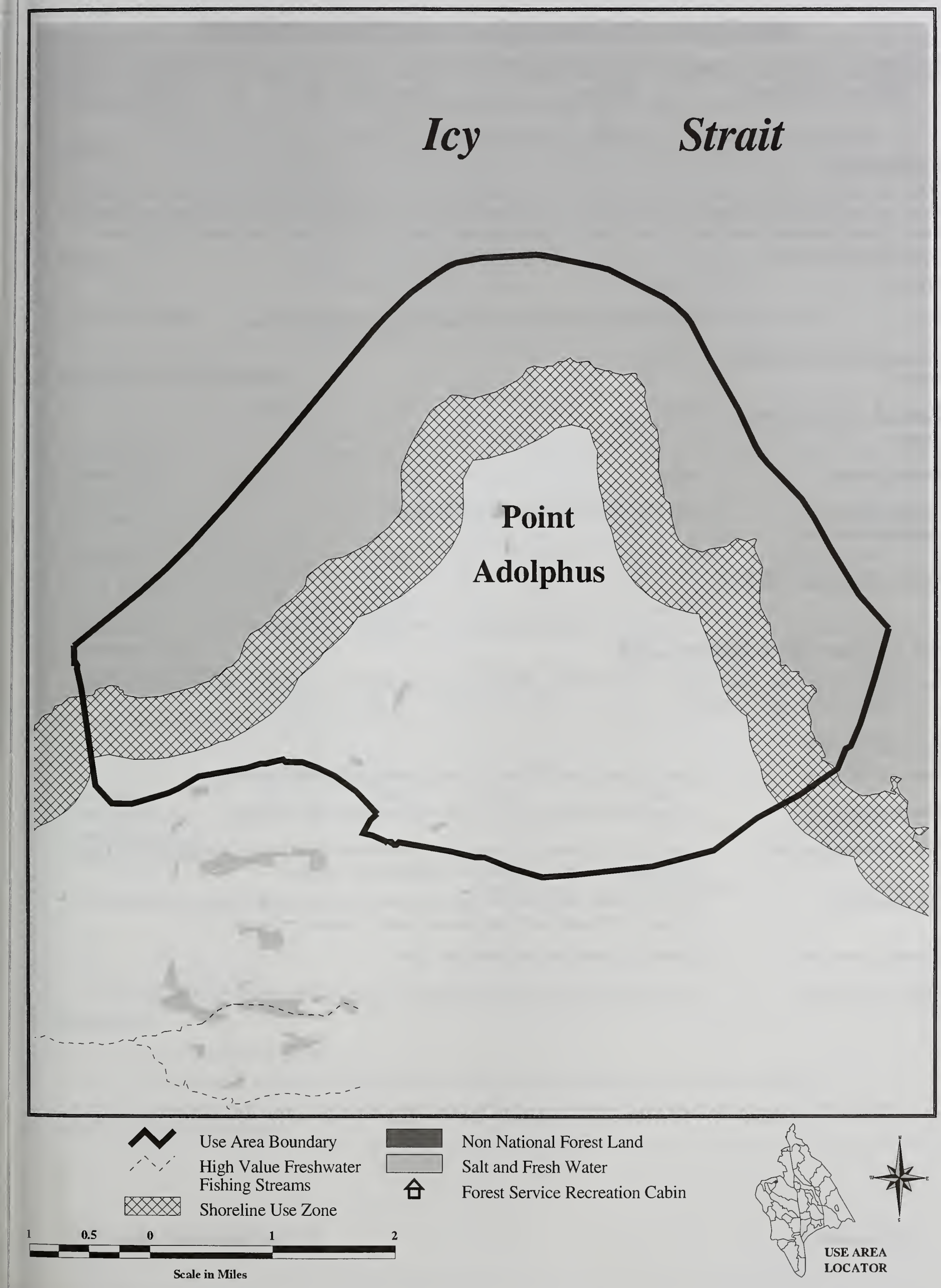


\section{Use Area 04-16B}

Mud Bay (North Chichagof) - Hoonah Ranger District

\begin{tabular}{|c|c|c|c|}
\hline \multicolumn{2}{|c|}{ Recreation Carrying Capacity (total capacity for all users) } \\
\hline Groups at one time & Spring & Summer & Fall \\
\hline 6 & 252 & 636 & 282 \\
\hline
\end{tabular}

\section{Description}

This Use Area was defined to include the relatively small management area of Mud Bay. Mud Bay is a popular recreation place and lies within 30 boat miles from Hoonah, Gustavus, and Elfin Cove. Shoreline included in this area runs from Damp Marker (between Point Adolphus and Mud Bay) and continues west to Gull Cove at the entrance to Idaho Inlet including Goose Island.

\begin{tabular}{ll} 
LUDs & LUD II \\
ROS & Semi-Primitive Motorized and Semi-Primitive Non-Motorized \\
$\begin{array}{l}\text { National Forest Shoreline } \\
\text { Miles }\end{array}$ & 34 miles \\
$\begin{array}{l}\text { National Forest Shoreline } \\
\text { Acres }\end{array}$ & 6,579 acres \\
$\begin{array}{l}\text { Communities } \\
\begin{array}{l}\text { Alaska Coastal } \\
\text { Management Act }\end{array}\end{array}$ & None \\
\hline
\end{tabular}

\section{Forest Service Facilities}

None

\section{Non-National Forest System Lands}

Private property includes areas located west of Mud Bay River, two private lodges at Gull Cove, and two hunter cabins under Special Use permit in Mud Bay.

\section{Recreation Use}

Area Attractions

Fishing, good boat anchorage, scenic setting, and wildlife viewing

Commercial Use

Non-commercial Use

Use Patterns

Primary Use Areas

Areas of Concern
Brown bear hunting, freshwater fishing, camping, and sightseeing

This is an important recreation area for the residents of Hoonah, Gustavus, Elfin Cove, and Pelican. Fishing, sightseeing, camping, and hunting

Boat based use to access Mud Bay River including: small craft, kayak, prop boats, and jet boats. Wheeled and floatplanes are used to access the area.

Gull Cove, Mud Bay, and Mud Bay River

Guided use levels on Mud Bay River and motorized boat use on the Mud Bay River 


\section{Use Area 04-16B}

\section{Mud Bay (North Chichagof) - Hoonah Ranger District}

\section{Management/Resource Considerations}

Subsistence

Wildlife

Fisheries

Botany

Cultural/Heritage
There are no anticipated restrictions on subsistence resource uses due to this project.

In this use area, 16 bald eagle nests are mapped. The entire use area is within the Northeast Chichagof Controlled Use Area for state and federal management of brown bears.

In this use area, 12 Class I streams have been mapped, of which five streams were identified with high fishing values.

Eight surveys covering 1.5 miles of shoreline revealed Botrychium lunaria and possibly one another Botrychium species.

Two historic and two prehistoric sites were identified during six surveys that covered 2.5 miles.

\section{Alternative Comparisons}

\begin{tabular}{|c|c|c|c|c|c|c|c|c|c|c|c|c|c|}
\hline \multirow{3}{*}{$\begin{array}{l}\text { Commercial } \\
\text { Allocation } \\
\text { (groups by } \\
\text { season) }\end{array}$} & \multirow{3}{*}{$\begin{array}{l}\text { Alt. } 1 \\
\text { N/A }\end{array}$} & \multicolumn{3}{|c|}{ Alt. 2} & \multicolumn{3}{|c|}{ Alt. 3} & \multicolumn{3}{|c|}{ Alt. 4} & \multicolumn{3}{|c|}{ Alt. 5} \\
\hline & & Spr & Sum & Fall & Spr & Sum & Fall & Spr & Sum & Fall & Spr & Sum & Fall \\
\hline & & 59 & 223 & 66 & 294 & 742 & 329 & 70 & 158 & 33 & 59 & 371 & 165 \\
\hline Enclaves & N/A & \multicolumn{3}{|c|}{ None } & \multicolumn{3}{|c|}{ None } & \multicolumn{3}{|c|}{ None } & \multicolumn{3}{|c|}{ None } \\
\hline $15 \%$ Areas & N/A & \multicolumn{3}{|c|}{ None } & \multicolumn{3}{|c|}{ None } & \multicolumn{3}{|c|}{ None } & \multicolumn{3}{|c|}{ None } \\
\hline $\begin{array}{l}\text { Maximum } \\
\text { Wheeled Plane } \\
\text { Landings at Mud } \\
\text { Bay }\end{array}$ & N/A & \multicolumn{3}{|c|}{ None } & \multicolumn{3}{|c|}{$\begin{array}{l}\text { Spring: 4/week } \\
\text { Summer: 4/day, } \\
5 \text { days/week } \\
\text { Fall: 4/day, } \\
5 \text { days/week }\end{array}$} & \multicolumn{3}{|c|}{$\begin{array}{l}\text { Spring: } 0 \\
\text { Summer: } 0\end{array}$} & \multicolumn{3}{|c|}{$\begin{array}{l}\text { Spring: } 2 / \text { week } \\
\text { Summer: } 2 / \text { day, } \\
5 \text { days/week }\end{array}$} \\
\hline $\begin{array}{l}\text { Maximum } \\
\text { Guided River } \\
\text { Use Per Day at } \\
\text { Mud Bay River }\end{array}$ & N/A & & None & & $\begin{array}{l}\text { Sprin } \\
6 \text { gro } \\
\text { Sumr } \\
6 \text { gro } \\
\text { Fall: } \\
6 \text { gro }\end{array}$ & $\begin{array}{l}\text { ips/day } \\
\text { ups/day } \\
\text { ups/day }\end{array}$ & & $\begin{array}{l}\text { Sprir } \\
2 \text { gro } \\
\text { Sum } \\
2 \text { gro } \\
\text { Fall: } \\
2 \text { gro }\end{array}$ & $\begin{array}{l}\text { ps/day } \\
\text { er: } \\
\text { ps/day } \\
\text { ps/day }\end{array}$ & & $\begin{array}{l}\text { Sprin } \\
4 \text { gro } \\
\text { Sumı } \\
5 \text { gro } \\
\text { Fall: } \\
5 \text { gro }\end{array}$ & $\begin{array}{l}\text { g: } \\
\text { ups/day } \\
\text { ner: } \\
\text { ups/day } \\
\text { ups/day }\end{array}$ & \\
\hline
\end{tabular}

\section{Mitigation}

See Appendix $C$ for mitigation measures.

Wheeled plane landings at Mud Bay will be permitted at the frequency provided by the selected alternative.

Guided motorized watercraft use on Mud Bay River will be restricted if motorized watercraft are causing measurable adverse impacts to fish habitat. 


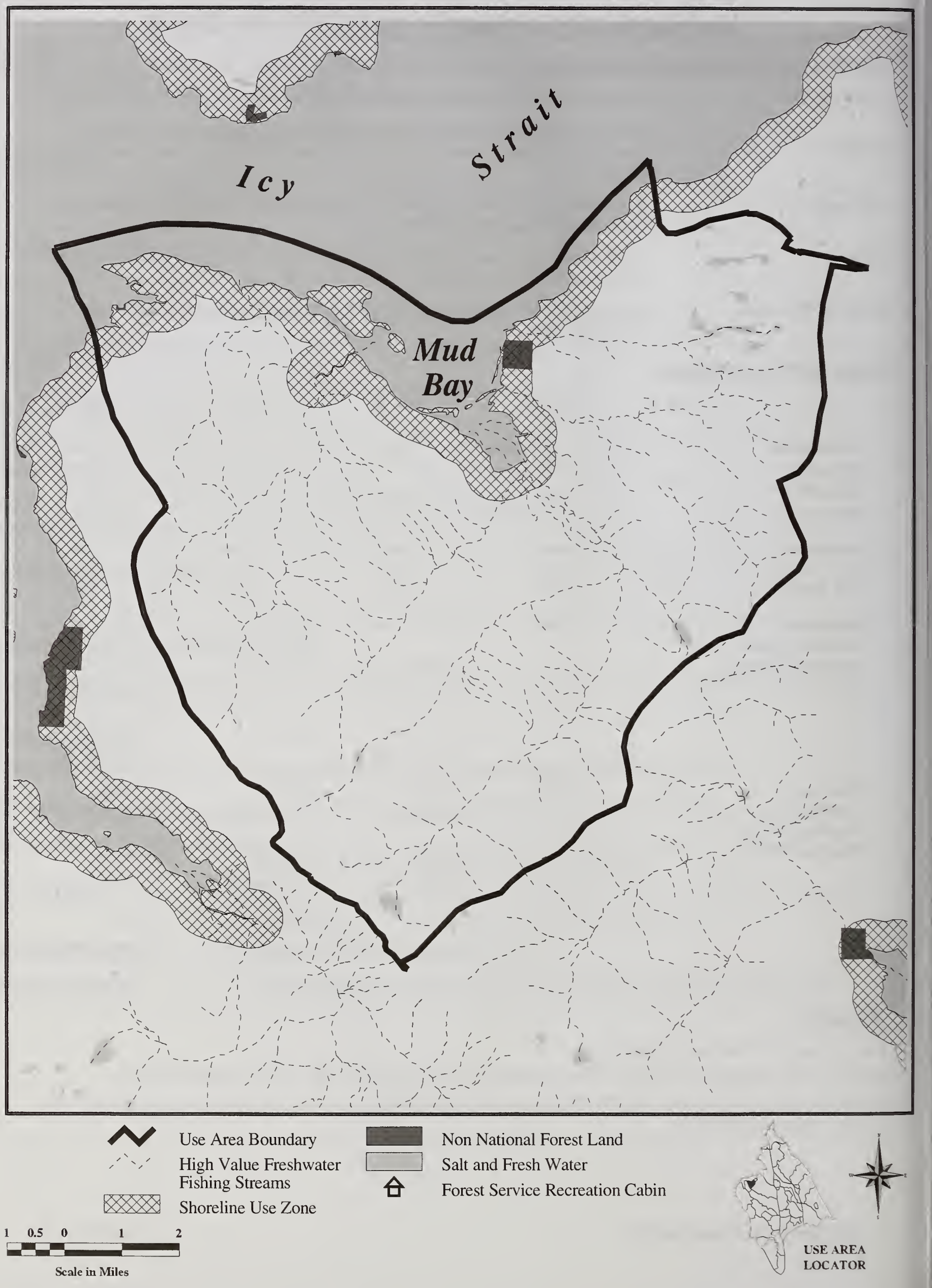




\section{Use Area 04-16C}

Idaho Inlet (Northwest Chichagof) - Hoonah Ranger District

Recreation Carrying Capacity (total capacity for all users)

\begin{tabular}{|c|c|c|c|}
\hline Groups at one time & Spring & Summer & Fall \\
\hline 6 & 252 & 636 & 282 \\
\hline
\end{tabular}

\section{Description}

This area was defined to include Idaho Inlet, the Shaw Islands, and the Trail River Estuary.

LUDs

LUD II and Semi-Remote Recreation

ROS

Primitive, Semi-Primitive Non-Motorized, Semi-Primitive Motorized, and Roaded Natural

National Forest Shoreline 36 miles

Miles

National Forest Shoreline $\quad 9,769$ acres

Acres

Communities

There is a tiny resident community of approximately 3-4 homes located on the northeast shoreline of Idaho Inlet. There are no private lodges within this use area.

\section{Forest Service Facilities}

None

\section{Non-National Forest System Lands}

One private residence at Nip-n-Tuck and one hunter cabin on the west shore of central Idaho Inlet are under special use permit. There is State selected property on east shore of Idaho Inlet.

\section{Recreation Use}

Area Attractions

Commercial Use

Non-commercial Use

Use Patterns

Primary Use Areas

Areas of Concern
Trail River is a highly productive anadromous fish stream. Wildlife viewing, scenic setting, long estuary flats, and good anchorage at the head of the bay

This area has received a steady increase in use over the last several years. In 1999, the Idaho Inlet area reported one of the highest levels of guided use within the north

Tongass Shoreline EIS project area activities include brown bear hunting, freshwater fishing, camping, and sightseeing.

Fishing, hunting, and sightseeing

Commercial and non-commercial users anchor at the head of the bay accessing Trail River by small craft for hunting, sightseeing, and fishing. Mid-size cruise ships anchor at the head of the bay where clients can hike in the estuary flats and Marble Creek or kayak in the bay.

Fox Creek, Idaho Inlet, Marble Creek, and Trail River

Motorized watercraft use on Trail River 


\section{Use Area 04-16C}

\section{Idaho Inlet (Northwest Chichagof) - Hoonah Ranger District}

\section{Management/Resource Considerations}

Subsistence

Wildlife

Fisheries

Botany

Cultural/Heritage
There are no anticipated restrictions on subsistence resource uses due to this project.

In this use area, 34 bald eagle nests are mapped.

In this use area, 25 Class 1 streams have been mapped with only one stream, Trail River, identified with high fishing values. Trail River was identified as having potential habitat concerns due to motorized watercraft. See Appendix C for mitigation measures.

Eight surveys covering 1.5 miles of shoreline. No rare or sensitive plants were found.

Two historic sites and one prehistoric site were identified during eight surveys that covered 2.25 miles.

\section{Alternative Comparisons}

\begin{tabular}{|c|c|c|c|c|c|c|c|c|c|c|c|c|c|}
\hline & Alt. 1 & \multicolumn{3}{|c|}{ Alt. 2} & \multicolumn{3}{|c|}{ Alt. 3} & \multicolumn{3}{|c|}{ Alt. 4} & \multicolumn{3}{|c|}{ Alt. 5} \\
\hline \multirow{2}{*}{$\begin{array}{l}\text { Commercial } \\
\text { Allocation } \\
\text { (groups by } \\
\text { season) }\end{array}$} & \multirow[b]{2}{*}{ N/A } & Spr & Sum & Fall & Spr & Sum & Fall & Spr & Sum & Fall & Spr & Sum & Fall \\
\hline & & 25 & 159 & 28 & 126 & 318 & 141 & 16 & 159 & 21 & 25 & 159 & 71 \\
\hline Enclaves & N/A & \multicolumn{3}{|c|}{ None } & \multicolumn{3}{|c|}{ None } & \multicolumn{3}{|c|}{ None } & \multicolumn{3}{|c|}{ None } \\
\hline \multirow[t]{2}{*}{$15 \%$ Areas } & N/A & \multicolumn{3}{|c|}{ None } & \multicolumn{3}{|c|}{ Big Shaw Island } & & \\
\hline & & & & & \multicolumn{3}{|c|}{ Fox Creek } & \multicolumn{3}{|c|}{ Fox Creek } & \multicolumn{3}{|c|}{ Fox Creek } \\
\hline
\end{tabular}

\section{Mitigation}

See Appendix C for mitigation measures.

Guided motorized watercraft use on Trail River will be restricted if motorized watercraft are causing measurable adverse effects to fish habitat. 
Shoreline Outfitter/Guide EIS

Use Area - 04-16C

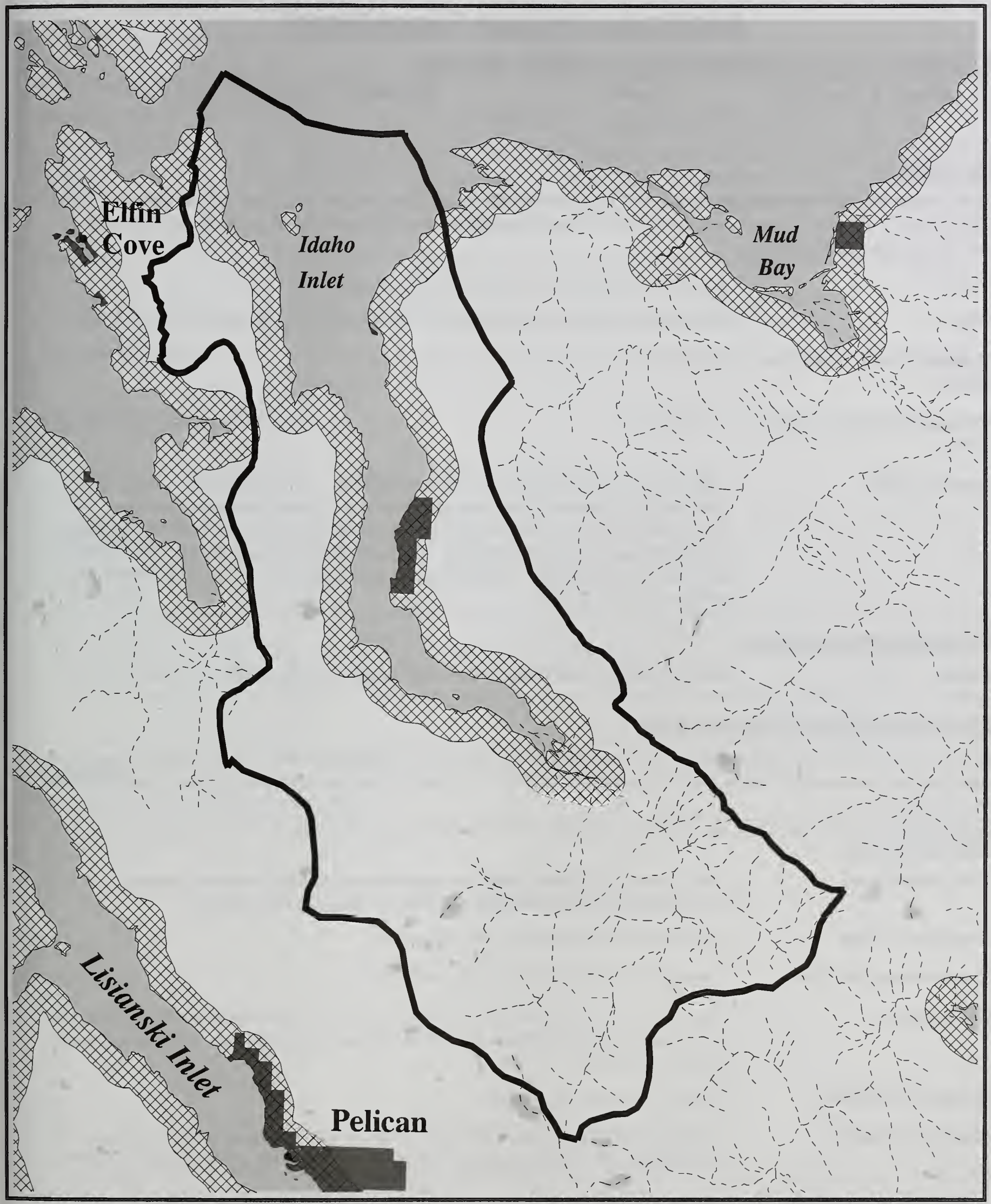

Use Area Boundary

High Value Freshwater Fishing Streams

$X X X$

Shoreline Use Zone \begin{tabular}{|l|l}
\hline & Non National Forest Land \\
\hline & Salt and Fresh Water \\
4 $\quad$ Forest Service Recreation Cabin
\end{tabular}

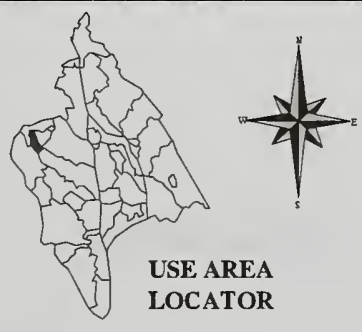




\section{Use Area 04-16D}

\section{Port Althorp - Hoonah Ranger District}

\section{Recreation Carrying Capacity (total capacity for all users)}

\begin{tabular}{|c|c|c|c|}
\hline Groups at one time & Spring & Summer & Fall \\
\hline 6 & 252 & 636 & 282 \\
\hline
\end{tabular}

\section{Description}

This use area was defined to manage the area around the community of Elfin Cove, Port Althorp, and the Lemesurier and Inian Islands Wilderness Areas. It also includes the George Islands. It has a high recreational value for both commercial and non-commercial operations.

\section{LUDs}

ROS

\section{National Forest Shoreline Miles}

National Forest Shoreline Acres

Communities

\section{LUD II, Semi-Remote Recreation, and Wilderness}

Rural, Roaded Natural, Semi-Primitive Motorized, and Semi-Primitive Non-Motorized

90 miles

\section{5,853 acres}

This use area includes the community of Elfin Cove. This tiny fishing village has a fluctuating population of approximately 125 people during the summer season, composed primarily of seasonal private lodges that provide ocean sport fishing charters, stream fishing, and sightseeing tours. The population decreases during winter to about 25 year round residents. This isolated village is accessible by floatplane or boat only and has no ferry service.

\section{Forest Service Facilities}

Trails

George Islands WWII Cannon Trail and Lemesurier Island Trail

\section{Non-National Forest System Lands}

This use area includes the community of Elfin Cove, one private inholding at Margaret Creek in Port Althorp; two private inholdings on Lemesurier Island at Jacks Cove and Willoughby Cove; and two private inholdings at Inian Island at Hobbit Hole and Inian Cove.

\section{Recreation Use}

Area Attractions

Commercial Use

Non-commercial Use

Use Patterns

Primary Use Areas

Areas of Concern
Scenic setting, Icy Strait, Elfin Cove, marine and terrestrial mammal viewing opportunities, sea bird watching, and safe anchorage in Port Althorp

Freshwater fishing, camping, and sightseeing

Oyster farm in Port Althorp, fishing, and hunting

This area is a travel corridor for commercial vessels, recreationists, and local residents of the communities of Pelican, Elfin Cove, Gustavus, and Hoonah. Tour boats frequent the George Islands.

Granite Cove and Port Althorp

George Island WWII Cannon Trail is in poor condition. Site hardening is necessary if use increases or continues at current levels. Port Althorp use levels are also a concern. 


\section{Use Area 04-16D}

\section{Port Althorp - Hoonah Ranger District}

\section{Management/Resource Considerations}

Subsistence

Wildlife

Fisheries

Botany

Cultural/Heritage
There are no anticipated restrictions on subsistence resource use due to this project.

NMFS identified one Steller sea lion haul-out in this use area. Although not mapped it is assumed that bald eagle nests are located along the shoreline in numbers at least equal to surveyed areas to the east of this use area. The Port Althorp state and federal closed area is closed to taking brown bears.

Six Class I streams were mapped, two of which have high freshwater fishing values.

Five surveys covering one mile of shoreline revealed Botrychium lunaria, $B$. virginianum, and $B$. minganense have been found in beach meadows.

One historic and one prehistoric site were identified during eight surveys that covered three miles.

\section{Alternative Comparisons}

\begin{tabular}{|c|c|c|c|c|c|c|c|c|c|c|c|c|c|}
\hline & Alt. 1 & \multicolumn{3}{|c|}{ Alt. 2} & \multicolumn{3}{|c|}{ Alt. 3} & \multicolumn{3}{|c|}{ Alt. 4} & \multicolumn{3}{|c|}{ Alt. 5} \\
\hline \multirow{2}{*}{$\begin{array}{l}\text { Commercial } \\
\text { Allocation } \\
\text { (groups by } \\
\text { season) }\end{array}$} & \multirow{2}{*}{ N/A } & Spr & Sum & Fall & Spr & Sum & Fall & Spr & Sum & Fall & Spr & Sum & Fall \\
\hline & & 25 & 159 & 28 & 126 & 318 & 141 & 15 & 156 & 15 & 25 & 159 & 71 \\
\hline Enclaves & N/A & \multicolumn{3}{|c|}{ None } & \multicolumn{3}{|c|}{ George Island } & \multicolumn{3}{|c|}{ George Island } & \multicolumn{3}{|c|}{ George Island } \\
\hline $15 \%$ Areas & N/A & \multicolumn{3}{|c|}{ None } & \multicolumn{3}{|c|}{ None } & \multicolumn{3}{|c|}{ None } & \multicolumn{3}{|c|}{ None } \\
\hline
\end{tabular}

\section{Mitigation}

See Appendix $\mathrm{C}$ for mitigation measures.

Additional outfitter/guide use levels on the George Island WWII Cannon trail will not be permitted until the trail has been reconstructed.

The Port Althorp area is closed to guided brown bear hunting. 


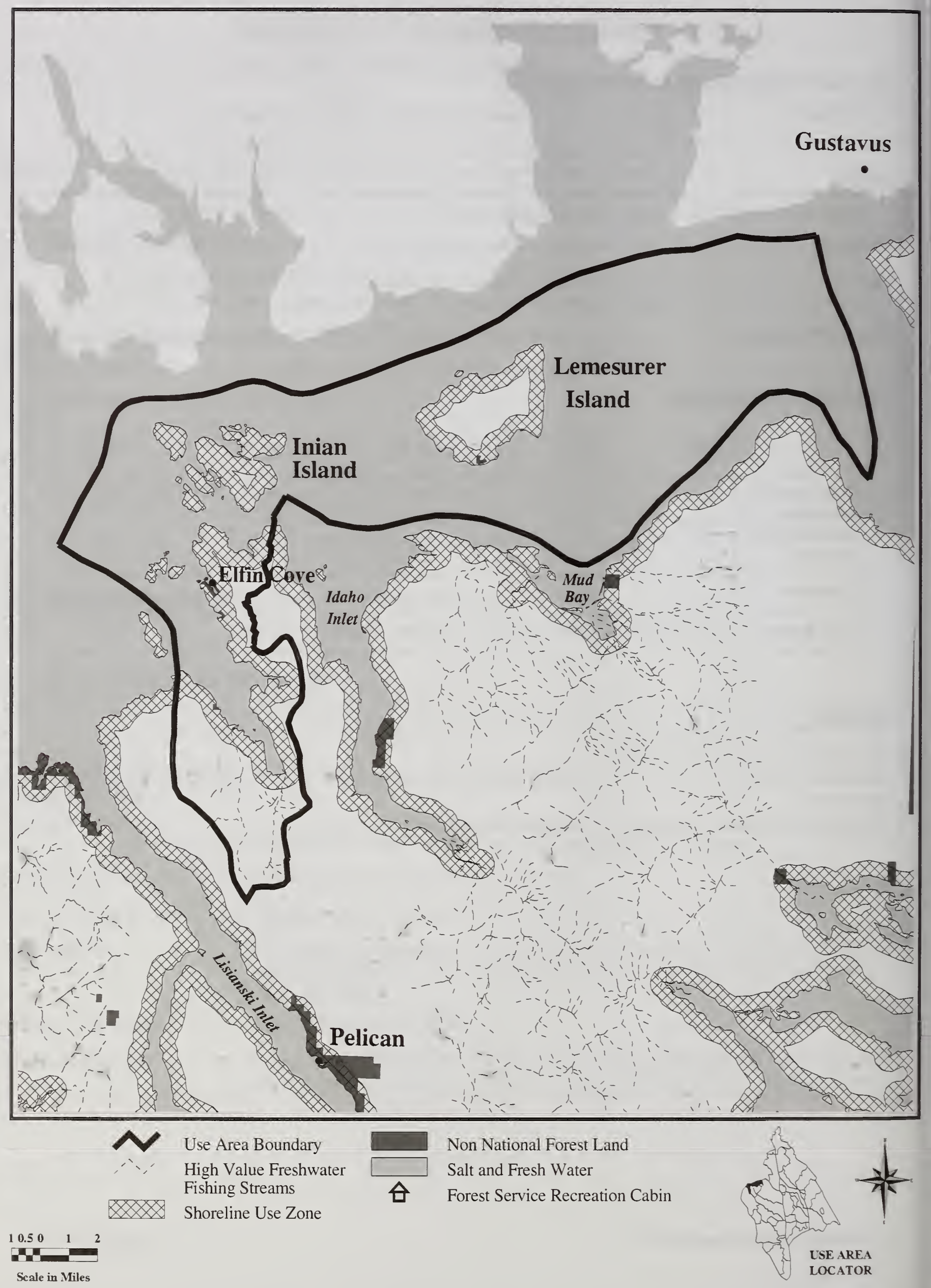




\section{Appendix B Large Group Area Cards}




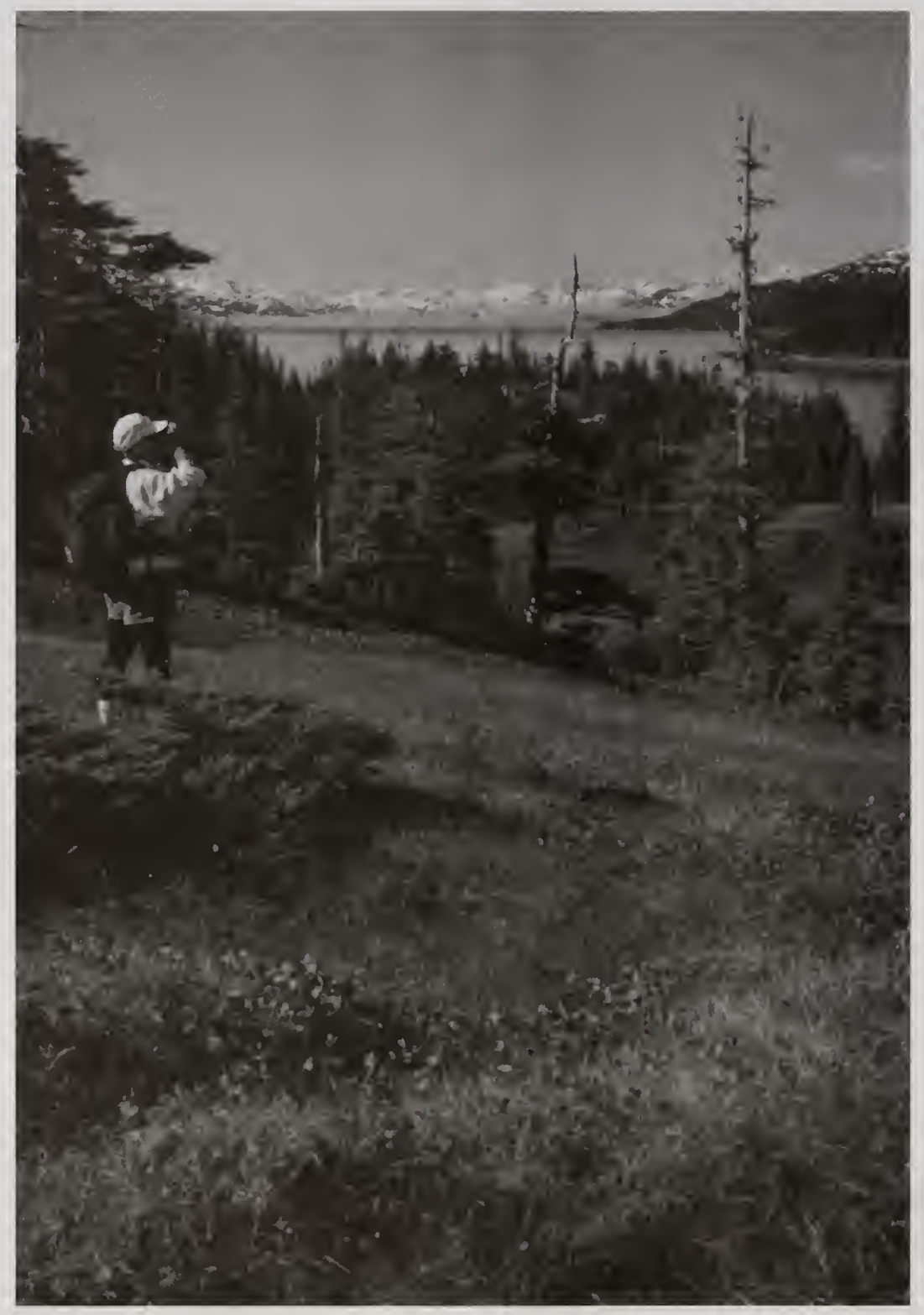




\section{Appendix B}

\section{Large Group Area Cards}

In this EIS, Large Group Areas are specific areas where larger groups of 21-75 people may be allowed. Smaller size groups are also allowed. The two types of large group areas are Enclaves and Fifteen-Percent areas. Enclaves are areas where large groups can occur on a regular basis throughout the season. Fifteen-Percent areas are places where large groups can occur only on an occasional basis, for less than 15 percent of the primary use season.

The following Large Group Area cards provide site-specific information and resource considerations relating to commercial recreation management for these areas. They support the information provided in Chapters 2 and 3. The seasonal allocations and specific measures for each alternative are displayed. Resource concerns specific to a Large Group Area are also referenced on the area card. Most resource concerns are mitigated through measures listed in Appendix $\mathrm{C}$, which apply to guided recreation use across the analysis area and are not repeated in this section.

Figure B-1 displays the location of the large group areas. No guided large groups will be allowed to camp in these large group areas. No guided recreation activities involving the consumption of resources such as fishing, hunting, or plant gathering will be allowed by large groups in these areas.

The information on these cards will be used to prepare and administer outfitter/guide permits. The mitigation measures will be incorporated into the document as permit stipulations where applicable. The permit conditions will be enforced through permit administration.

Table B-1. List of Large Group Areas

\begin{tabular}{|c|c|c|c|}
\hline \multicolumn{4}{|c|}{ ENCLAVES } \\
\hline Use Area & Name of Large Group Area & Use Area & Name of Large Group Area \\
\hline $01-01$ & Katzehin Falls & 04-04A & Rodman Bay \\
\hline $01-02$ & Sullivan Mountain & 04-04A & Saook Bay \\
\hline $01-03$ & Cant Cove & 04-04B & Hanus Bay \\
\hline $01-03$ & Homeshore & 04-04B & Kelp Bay Middle Arm \\
\hline $01-03$ & Howard Bay & 04-04B & Portage Arm \\
\hline 01-04B & Shelter Island & $04-08$ & Cordwood Creek \\
\hline $01-04 C$ & Sunny Cove & 04-08 & Fowler Creek \\
\hline $01-05 B$ & Mallard Cove & 04-11 & Eight Fathom Dock \\
\hline $01-05 B$ & No Name Cove & 04-11 & Kennel Creek \\
\hline 01-05B & Point Anmer & 04-11 & Red Cliff Islands \\
\hline $01-05 B$ & West Gilbert Bay & 04-11 & Salt Lake Bay Dock \\
\hline $01-05 C$ & Fanshaw & $04-12$ & Corner Bay Road \\
\hline $01-05 C$ & North Windham Bay & $04-12$ & Crab Bay \\
\hline $01-05 C$ & Port Houghton & $04-12$ & West Tenakee (Goose Flats) \\
\hline $01-05 C$ & Sand Bay & $04-13$ & Poison Cove \\
\hline $04-03$ & Dry Pass & $04-13$ & Sitkoh Bay Road \\
\hline $04-03$ & Eagle River Road & $04-13$ & Ushk Bay \\
\hline $04-03$ & Noxon & $04-15$ & Bohemia Basin \\
\hline 04-04A & Lake Eva Trail & $04-15$ & Three Hill Island \\
\hline $04-04 A$ & Point Elizabeth & $04-16 D$ & George Island \\
\hline
\end{tabular}




\section{Appendix B, Large Group Areas}

\section{FIFTEEN-PERCENT AREAS}

\begin{tabular}{c|l|cl} 
Use Area & Name of Large Group Area & Use Area & Name of Large Group Area \\
\hline 01-04B & Douglas Island & $04-12$ & Trap Bay \\
01-05B & Point Coke & $04-13$ & Moser \\
04-03 & Fish Bay & $04-13$ & Nelson Falls \\
04-03 & Nadezhida Islands & $04-13$ & Nismeni Point \\
04-04A & Duffield & $04-13$ & Patterson Bay \\
04-04B & Bourbon Creek Road & $04-13$ & Patterson Bay North Point \\
04-04B & Cosmos Cove & $04-13$ & Todd Road/Lindenberg Head \\
04-11 & lyoukeen Peninsula & $04-16 \mathrm{~A}$ & Damp Marker \\
04-11 & Neka Bay North Bight & $04-16 \mathrm{~A}$ & Pinta Cove \\
04-11 & Neka Bay South Bight & $04-16 \mathrm{C}$ & Big Shaw Island \\
04-12 & Saltery Bay & $04-16 \mathrm{C}$ & Fox Creek \\
04-12 & Seal Bay & & \\
\hline
\end{tabular}




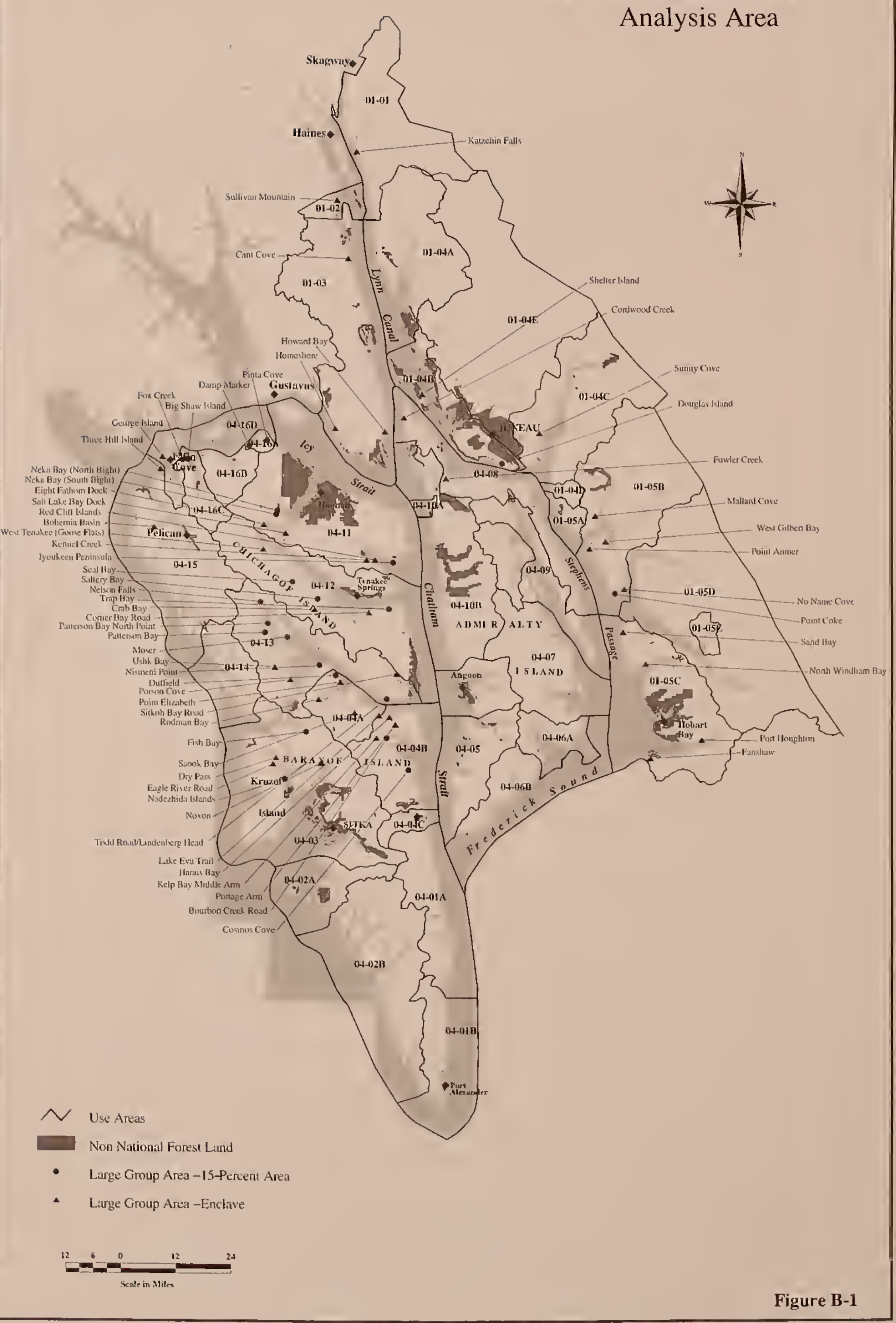





\section{Large Group Areas, Appendix B}

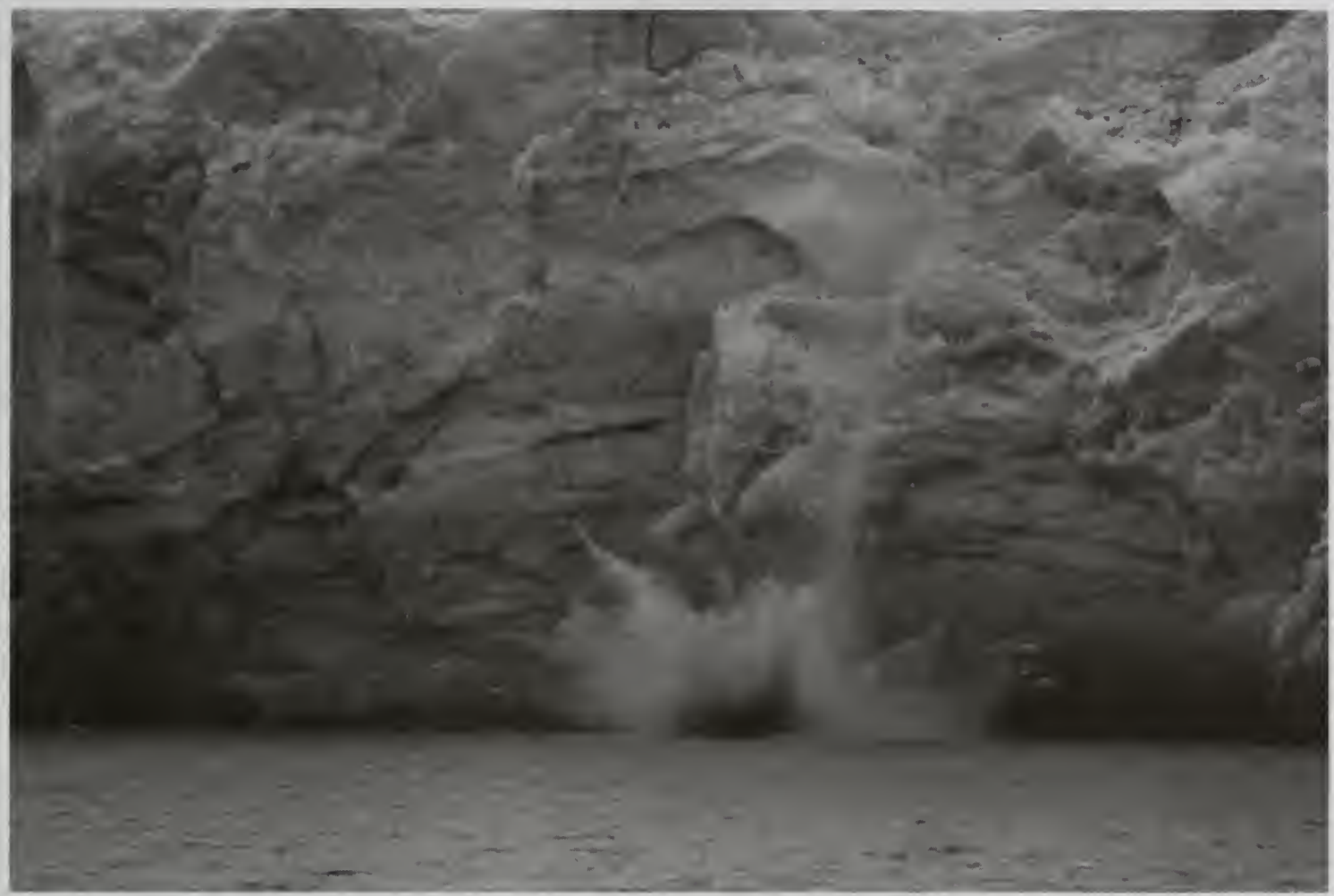




\section{Appendix B, Large Group Areas}

\begin{tabular}{|c|c|}
\hline & $\begin{array}{l}\text { Large Group Area } \\
\text { Katzehin Falls } \\
\text { Alternatives 3,5 }\end{array}$ \\
\hline $\begin{array}{l}\text { Type } \\
\text { Use Area } \\
\text { LUD } \\
\text { ROS } \\
\text { Acres }\end{array}$ & $\begin{array}{l}\text { Enclave } \\
01-01 \\
\text { Semi-Remote Recreation } \\
\text { Roaded Natural } \\
7\end{array}$ \\
\hline $\begin{array}{l}\text { General } \\
\text { Characteristics }\end{array}$ & $\begin{array}{l}\text { This site is located south of the Katzehin River on the east side of } \\
\text { Lynn Canal. Topography in this area is generally steep, rocky, and } \\
\text { forested. A large waterfall empties into a narrow tidal area near the } \\
\text { site. South of the falls and inside the tree line the understory is open. }\end{array}$ \\
\hline Historical Use & There was no reported commercial use of this site in 1999. \\
\hline Access & $\begin{array}{l}\text { There is little protection at this site except on relatively calm days. Silt } \\
\text { outwash from the Katzehin River and creek has created a shallow } \\
\text { approach. Steep terrain confines use to the narrow beach and just } \\
\text { inside the tree line. The creek has a strong flow and crossing on foot } \\
\text { is not recommended. }\end{array}$ \\
\hline Facilities & None \\
\hline $\begin{array}{l}\text { Concerns and/or } \\
\text { Opportunities }\end{array}$ & $\begin{array}{l}\text { Bear sign was noted along the creek. Due to site size and natural } \\
\text { features, there are no opportunities to avoid animals when they are } \\
\text { present. }\end{array}$ \\
\hline Attractions & $\begin{array}{l}\text { This area features a large waterfall, sandy beaches, and an excellent } \\
\text { view across Lynn Canal towards the Chilkat Mountains and a hanging } \\
\text { glacier. A large stump was found below the high tide mark, a remnant } \\
\text { of a period of glacial retreat. This area provides an opportunity for } \\
\text { viewing shorebirds. }\end{array}$ \\
\hline Mitigation & $\begin{array}{l}\text { - See Appendix } C \text { for mitigation measures. } \\
\text { - Brown bear viewing } \\
\text { - Vegetation } \\
\text { - Riparian }\end{array}$ \\
\hline
\end{tabular}




\section{Shoreline Outfitter/Guide EIS Large Group Area Use Area 01-01 KATZEHIN FALLS}

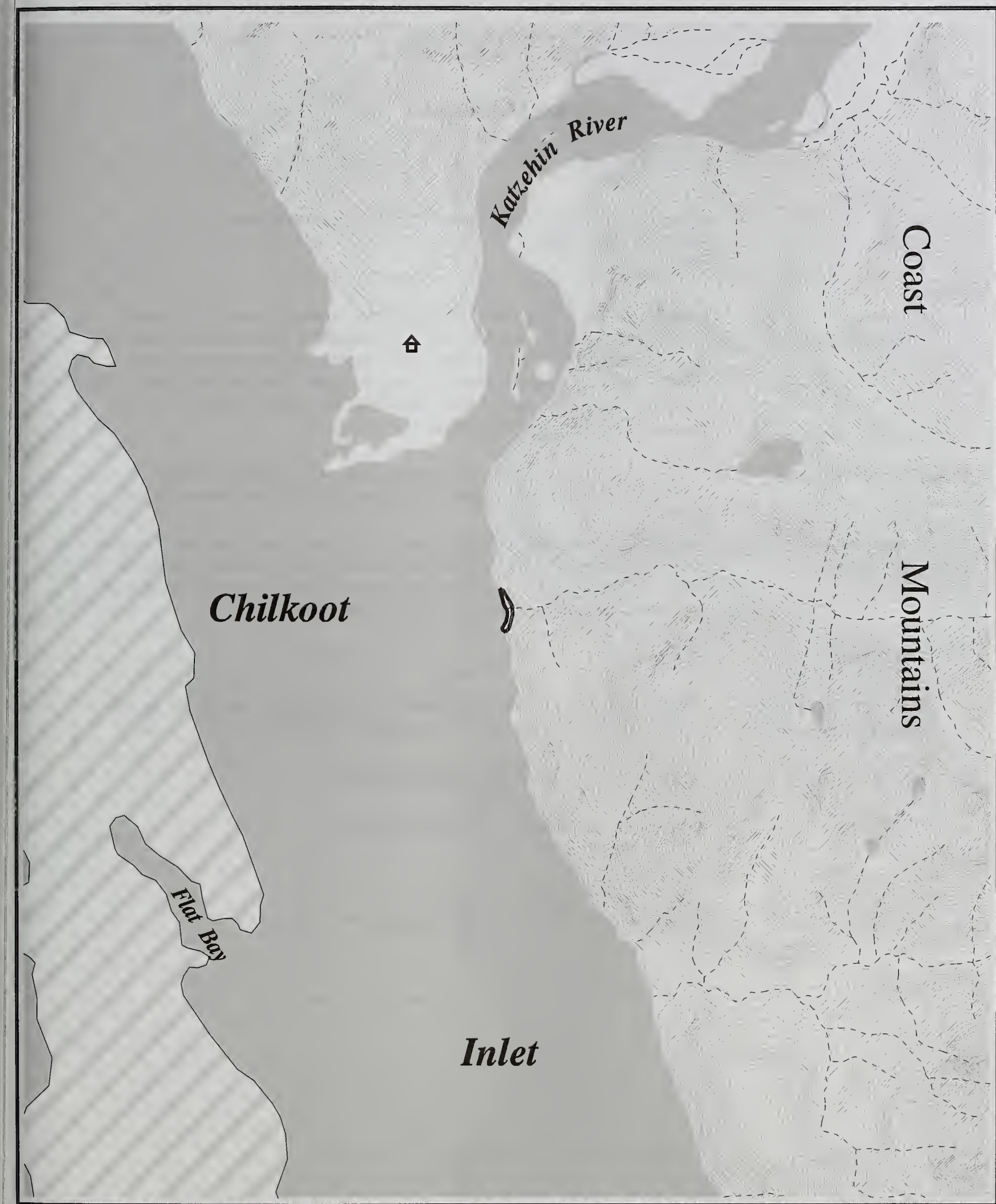

Large Group Area Boundary Streams

Existing Road
Non National Forest Land

Outside of Project Area Wilderness

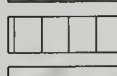

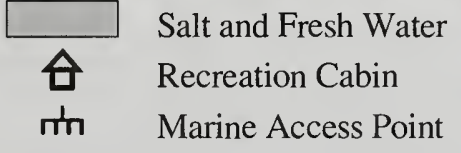

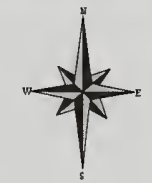




\section{Appendix B, Large Group Areas}

\begin{tabular}{|c|c|}
\hline & $\begin{array}{l}\text { Large Group Areas } \\
\text { Sullivan Mountain } \\
\text { Alternative } 3,5\end{array}$ \\
\hline $\begin{array}{l}\text { Type } \\
\text { Use Area } \\
\text { ROS } \\
\text { LUD } \\
\text { Acres } \\
\end{array}$ & $\begin{array}{l}\text { Enclave } \\
01-02 \\
\text { Semi-Primitive Motorized, Semi-Primitive Non-motorized } \\
\text { Modified Landscape } \\
235\end{array}$ \\
\hline $\begin{array}{l}\text { General } \\
\text { Characteristics }\end{array}$ & $\begin{array}{l}\text { Located at the mouth of a braided glacial outwash creek, this site is } \\
\text { characterized by an outwash plain comprised of glacial silt, cobble, and } \\
\text { boulder substrate. Alder, willow, cottonwood, and spruce mark the } \\
\text { upland flats south of the creek. Along the face of the alluvial plain to the } \\
\text { south is a long and rocky beach bordered by a beach rye grass } \\
\text { meadow extending to the tree line. }\end{array}$ \\
\hline Historical Use & $\begin{array}{l}\text { Commercial use was not reported in 1999. In the 1960's, timber } \\
\text { harvest occurred on the south side of the alluvial plain within the flats. }\end{array}$ \\
\hline Access & $\begin{array}{l}\text { Access may be primarily by floatplane or boat. The cove may provide } \\
\text { some protection for anchoring from winds to the south but may be more } \\
\text { exposed from the north. Water depths are shallow in front of the creek } \\
\text { but the beach is deeper to the south of the creek. }\end{array}$ \\
\hline Facilities & None \\
\hline $\begin{array}{l}\text { Concerns and/or } \\
\text { Opportunities }\end{array}$ & $\begin{array}{l}\text { Potential facilities could be shielded from shoreline view by the gentle } \\
\text { terrain. There area private land parcels in the area. }\end{array}$ \\
\hline Attractions & The flora and fauna of the Chilkat Mountains \\
\hline Mitigation & $\begin{array}{l}\text { - See Appendix } C \text { for mitigation measures. } \\
\text { - Bald eagle } \\
\text { - Riparian } \\
\text { - Gegetation } \\
\text { Guided activities must not trespass on private land }\end{array}$ \\
\hline
\end{tabular}




\section{Appendix B, Large Group Areas}

\begin{tabular}{|c|c|}
\hline & $\begin{array}{l}\text { Large Group Area } \\
\text { Cant Cove } \\
\text { Alternative } 3\end{array}$ \\
\hline $\begin{array}{l}\text { Type } \\
\text { Use Area } \\
\text { LUD } \\
\text { ROS } \\
\text { Acres }\end{array}$ & $\begin{array}{l}\text { Enclave } \\
01-03 \\
\text { Semi-Remote Recreation } \\
\text { Semi-Primitive Motorized } \\
38\end{array}$ \\
\hline $\begin{array}{l}\text { General } \\
\text { Characteristics }\end{array}$ & $\begin{array}{l}\text { This site on the west side of Lynn Canal is in the proposed State road } \\
\text { corridor for the road from Juneau to Haines. A large fish-bearing stream } \\
\text { bisects the area. This area is lined with large Sitka spruce and } \\
\text { hardwoods with low brush and an open understory. There is an } \\
\text { estuarine meadow behind a raised sand spit at the mouth of the creek. } \\
\text { The southern side of the creek has a smaller meadow, and a beach with } \\
\text { several rock formations, including a small, water-carved grotto. Though } \\
\text { access along the stream bank is not easy due to slope and vegetation, a } \\
\text { large waterfall is visible several hundred yards up the stream. }\end{array}$ \\
\hline Historical Use & There was no documented commercial use at this site in 1999. \\
\hline Access & $\begin{array}{l}\text { The small cove provides little protection from north and south winds on } \\
\text { Lynn Canal. Boats or floatplanes can land on the beach. The creek can } \\
\text { be forded in hip waders. The main channel is deeper in the creek mouth } \\
\text { allowing access to the shore behind the sand spit. }\end{array}$ \\
\hline Facilities & None \\
\hline $\begin{array}{l}\text { Concerns and/or } \\
\text { Opportunities }\end{array}$ & $\begin{array}{l}\text { Because vegetation and topography limit sight distances, there is some } \\
\text { potential for human/bear conflict. There may be karst located in the area. } \\
\text { There is a rock grotto. }\end{array}$ \\
\hline Attractions & Narrow $1 / 2$ mile long beach, large waterfall, rock formations \\
\hline Mitigation & $\begin{array}{l}\text { - See Appendix } C \text { for mitigation measures. } \\
\text { - Rald eagles } \\
\text { - Riparian } \\
\text { - } \text { Begetation } \\
\text { - Karst and caves }\end{array}$ \\
\hline
\end{tabular}


Shoreline Outfitter/Guide EIS

Large Group Area

Use Area 01-03 CANT COVE

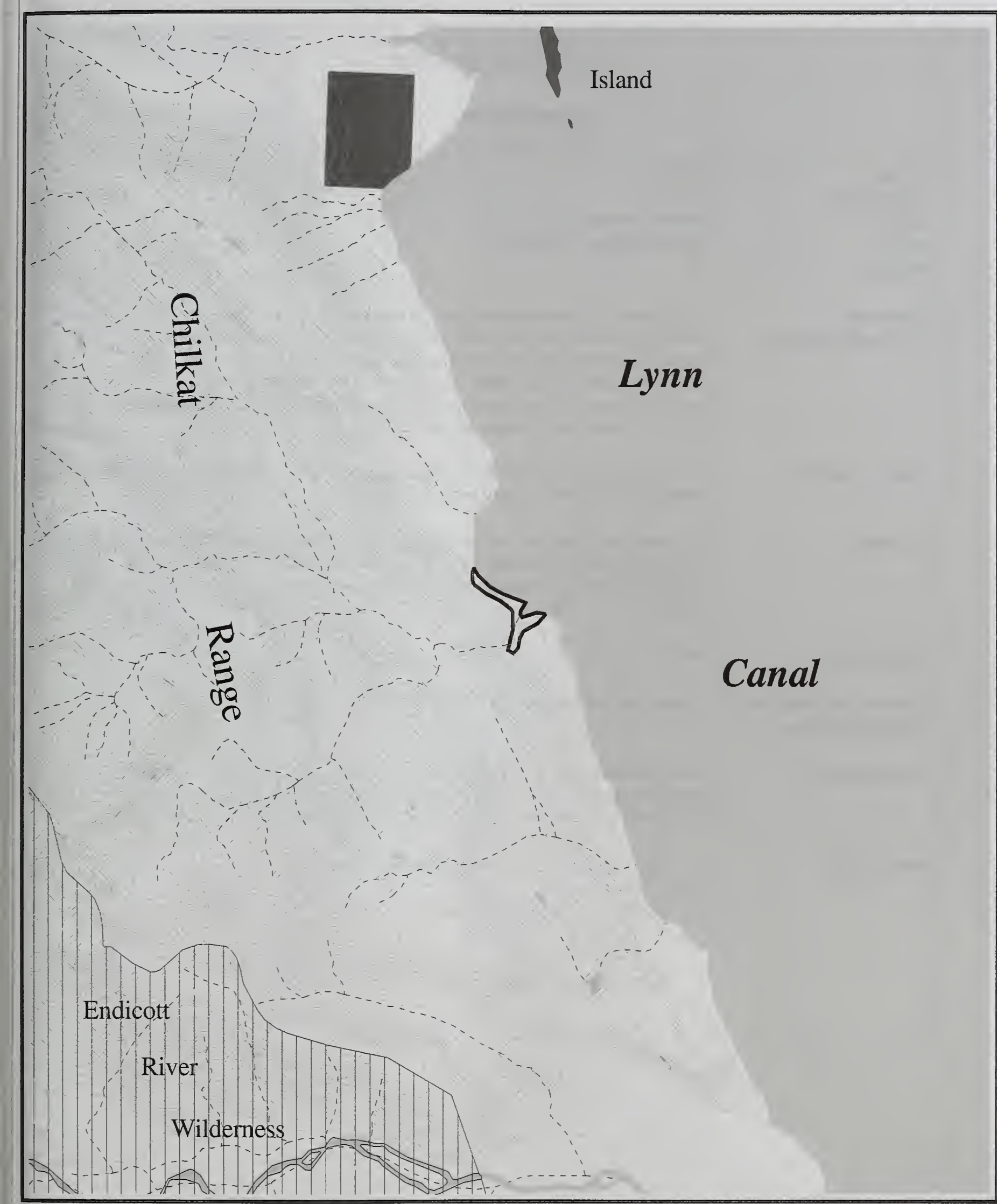

$\checkmark$ Large Group Area Boundary

Streams

Existing Road
Non National Forest Land

Wilderness

Outside of Project Area

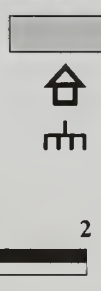

吕

Recreation Cabin

Marine Access Point
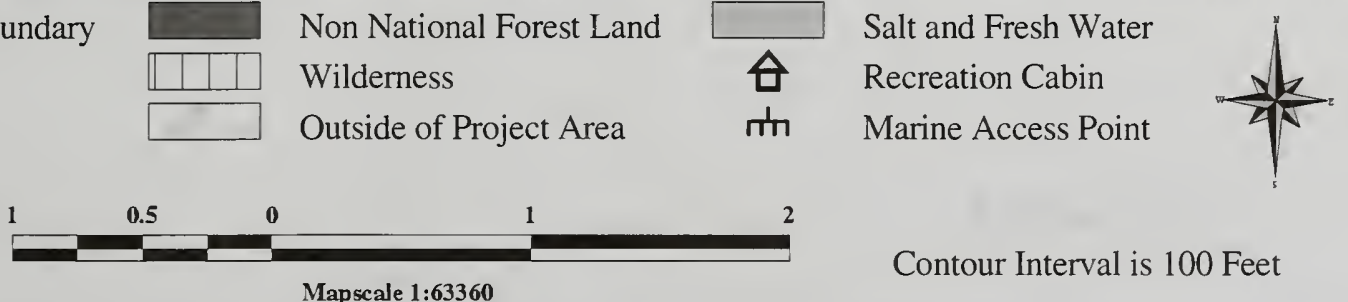

Contour Interval is 100 Feet 


\section{Appendix B, Large Group Areas}

\begin{tabular}{|c|c|}
\hline & $\begin{array}{l}\text { Large Group Area } \\
\text { Homeshore } \\
\text { Alternatives 3, 4, } 5\end{array}$ \\
\hline $\begin{array}{l}\text { Type } \\
\text { Use Area } \\
\text { LUD } \\
\text { ROS } \\
\text { Acres }\end{array}$ & $\begin{array}{l}\text { Enclave } \\
01-03 \\
\text { Scenic Viewshed } \\
\text { Semi-Primitive Motorized } \\
39\end{array}$ \\
\hline $\begin{array}{l}\text { General } \\
\text { Characteristics }\end{array}$ & $\begin{array}{l}\text { This site is on the mainland, facing west toward Icy Strait. Terrain in this } \\
\text { area is generally flat with stands of mature spruce trees. The main } \\
\text { creek is narrow but has a strong flow and deep pools. On the south } \\
\text { side of the creek is an area of well-drained soils and a very large grass } \\
\text { and forb meadow. An elevated sand and gravel spit on the southern } \\
\text { end of the site provides a vantage point. }\end{array}$ \\
\hline Historical Use & $\begin{array}{l}\text { There was no record of commercial use in } 1999 \text {. The north side of the } \\
\text { creek has numerous signs of human use. }\end{array}$ \\
\hline Access & $\begin{array}{l}\text { The area has a large tide flat and would probably be best accessed at } \\
\text { mid-to-high tide. Because of its exposure, this site does not have a } \\
\text { good anchorage. There are also shallow sandbars near the creek } \\
\text { mouth. }\end{array}$ \\
\hline Facilities & None \\
\hline $\begin{array}{l}\text { Concerns and/or } \\
\text { Opportunities }\end{array}$ & There is a small parcel of private land north of the area. \\
\hline Attractions & $\begin{array}{l}\text { The meadow is very large and has interesting contours due to sand and } \\
\text { gravel deposition, with a creek meandering through it. There are } \\
\text { wildflower and wildlife viewing areas with vistas across Icy Straight. }\end{array}$ \\
\hline Mitigation & $\begin{array}{l}\text { See Appendix } C \text { for mitigation measures. } \\
\text { - Bald eagles } \\
\text { - Rarine mammals } \\
\text { - Guipan } \\
\text { - Guided groups must not trespass on private land. }\end{array}$ \\
\hline
\end{tabular}


Shoreline Outfitter/Guide EIS

Large Group Area

Use Area 01-03 HOMESHORE

\section{Porpoise}

\section{Islands}
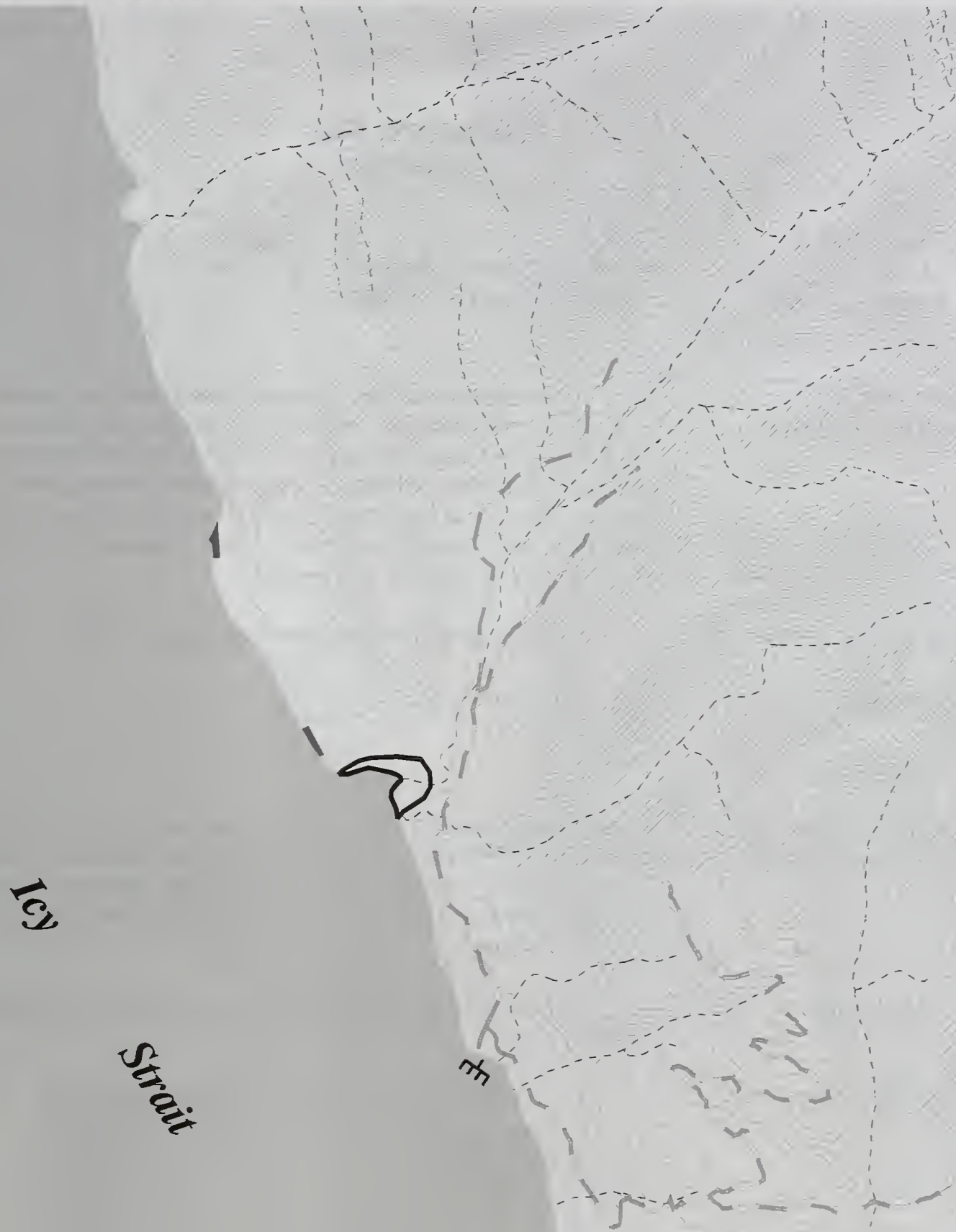

2.

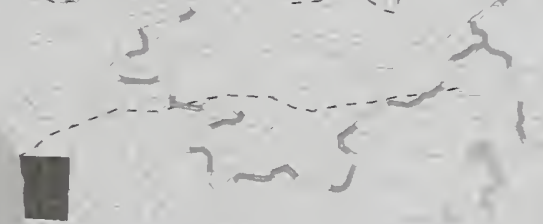

Large Group Area Boundary Streams

Existing Road
Non National Forest Land Wilderness

Outside of Project Area

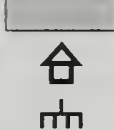

Salt and Fresh Water Recreation Cabin Marine Access Point

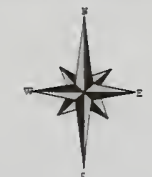

Contour Interval is 100 Feet 


\section{Appendix B, Large Group Areas}

\begin{tabular}{|c|c|}
\hline & $\begin{array}{l}\text { Large Group Area } \\
\text { Howard Bay } \\
\text { Alternative } 3\end{array}$ \\
\hline $\begin{array}{l}\text { Type } \\
\text { Use Area } \\
\text { LUD } \\
\text { ROS } \\
\text { Acres }\end{array}$ & $\begin{array}{l}\text { Enclave } \\
01-03 \\
\text { Semi-Remote Recreation } \\
\text { Semi-Primitive Motorized } \\
45\end{array}$ \\
\hline $\begin{array}{l}\text { General } \\
\text { Characteristics }\end{array}$ & $\begin{array}{l}\text { This area has a small "boot-shaped" peninsula that bisects two coves } \\
\text { looking out on a shallow, sandy bay. Some rocks occur offshore and } \\
\text { can present a hazard to boats and float planes at lower tides. Beyond } \\
\text { the tide line a stand of spruce trees extends several hundred yards } \\
\text { before opening up into a large meadow and a valley. The northeastern } \\
\text { shore has rock bluffs that provide visual interest, but opportunities to } \\
\text { walk inside the tree line are limited. }\end{array}$ \\
\hline Historical Use & Commercial outfitter/guides used this area in 1999. \\
\hline Access & Floatplane and boat \\
\hline Facilities & None \\
\hline $\begin{array}{l}\text { Concerns and/or } \\
\text { Opportunities }\end{array}$ & $\begin{array}{l}\text { Groups can disperse away from shoreline and out of sight and sound of } \\
\text { one another. This area appears to have outstanding opportunities for } \\
\text { wildlife viewing from the tree edge into the meadows without disturbing } \\
\text { animals. Wildflowers are in abundance and there are scenic vistas both } \\
\text { on and offshore. }\end{array}$ \\
\hline Attractions & $\begin{array}{l}\text { A large, open bay is protected from the north. It is a relatively short flight } \\
\text { from Juneau. }\end{array}$ \\
\hline Mitigation & $\begin{array}{l}\text { - See Appendix } C \text { for mitigation measures. } \\
\text { - Bald eagles } \\
\text { - Regetation } \\
\text { Riparian }\end{array}$ \\
\hline
\end{tabular}


Shoreline Outfitter/Guide EIS

Large Group Area

Use Area 01-03 HOWARD BAY

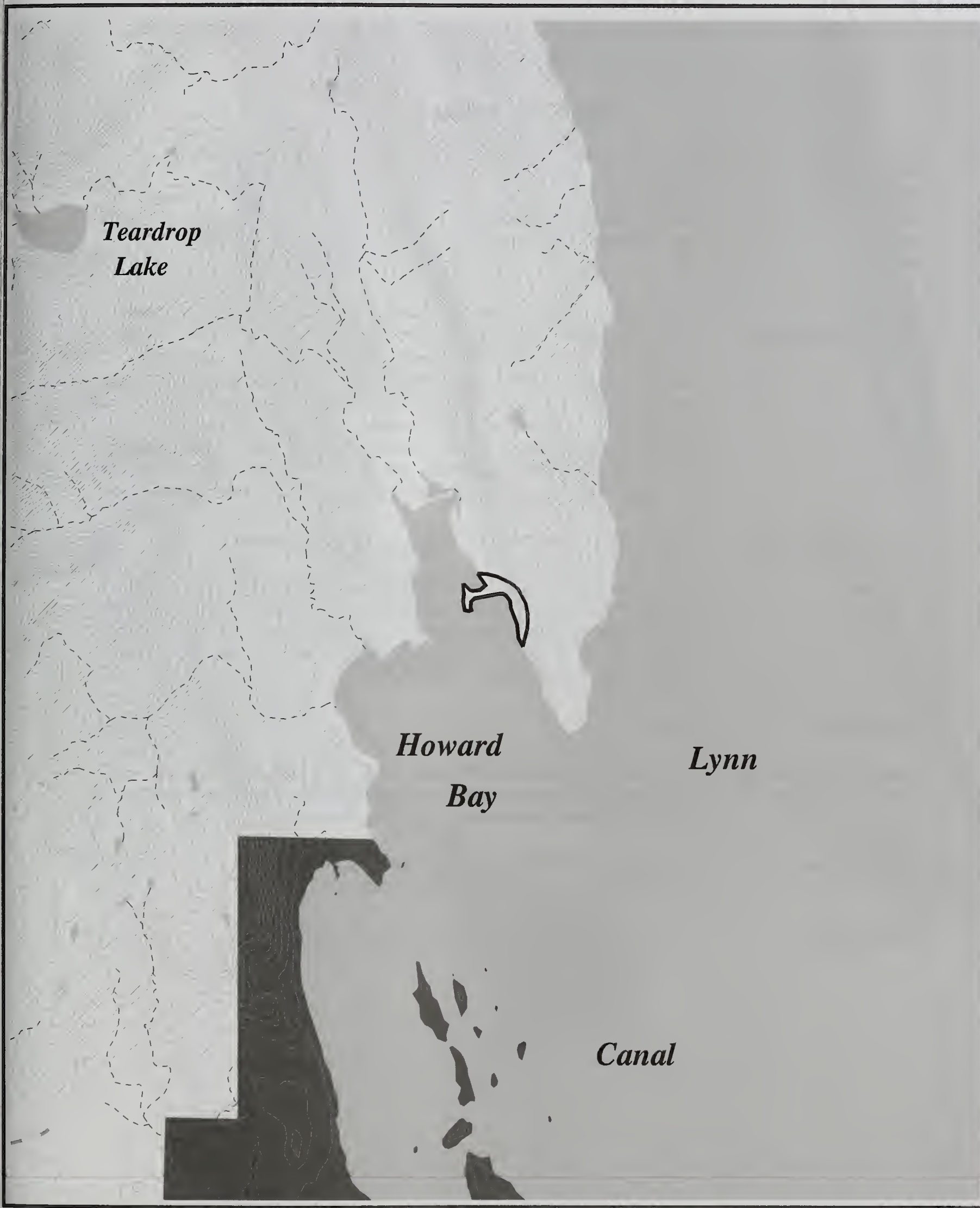

$\sim$ Large Group Area Boundary

Streams

Existing Road

Non National Forest Land

Wilderness

Outside of Project Area

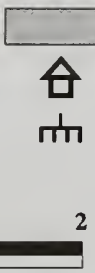

䓃

marine Access Point
Salt and Fresh Water

Recreation Cabin

Mans

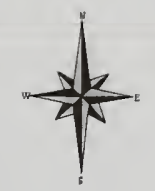

1 


\section{Appendix B, Large Group Areas}

\begin{tabular}{|c|c|}
\hline & $\begin{array}{l}\text { Large Group Area } \\
\text { Shelter Island } \\
\text { Alternatives } 3,5\end{array}$ \\
\hline $\begin{array}{l}\text { Type } \\
\text { Use Area } \\
\text { LUD } \\
\text { ROS } \\
\text { Acres }\end{array}$ & $\begin{array}{l}\text { Enclave } \\
01-04 \mathrm{~B} \\
\text { Semi-Remote Recreation } \\
\text { Semi-Primitive Motorized } \\
62\end{array}$ \\
\hline $\begin{array}{l}\text { General } \\
\text { Characteristics }\end{array}$ & $\begin{array}{l}\text { This site is located on the east side of Shelter Island approximately } 1 / 2 \\
\text { mile south of Aaron Island and one mile south of the Shelter Island State } \\
\text { Marine Park boundary. This section of Shelter Island has a long, } \\
\text { straight coastline with a rocky beach and virtually no vegetation between } \\
\text { the tide and tree lines. Upon entering the trees there is a } 30 \text { yard-wide } \\
\text { flat area with good visibility and mature trees. Further inland a steep, } \\
\text { raised terrace provides a nice bench for walking. The forest understory } \\
\text { is very open and sight distances are good. Several small creeks bisect } \\
\text { this bench but their flow disappears into the ground near the tree line. }\end{array}$ \\
\hline Historical Use & There was no reported commercial use of this area in 1999. \\
\hline Access & $\begin{array}{l}\text { This area is easily accessible from Juneau by plane or boat. There is } \\
\text { limited protection from north or south winds because of the linear nature } \\
\text { of the coastline. The rocky beach is not wide, and could be a problem } \\
\text { for planes and boats. Anchorages are poor at this location. Footing } \\
\text { along the beach is good. }\end{array}$ \\
\hline Facilities & None \\
\hline $\begin{array}{l}\text { Concerns and/or } \\
\text { Opportunities }\end{array}$ & $\begin{array}{l}\text { Local residents frequent this area for deer hunting; commercial } \\
\text { recreation use would need to be timed to avoid conflict with this activity. } \\
\text { Views of Juneau can be seen from the shoreline. }\end{array}$ \\
\hline Attractions & $\begin{array}{l}\text { The area is protected inside the tree line from the wind. A raised beach } \\
\text { bench offers an opportunity for a nature walk. }\end{array}$ \\
\hline Mitigation & $\begin{array}{l}\text { - See Appendix } C \text { for mitigation measures } \\
\text { - Bald eagles } \\
\text { - Marine mammals } \\
\text { - Regetation } \\
\text { Riparian }\end{array}$ \\
\hline
\end{tabular}



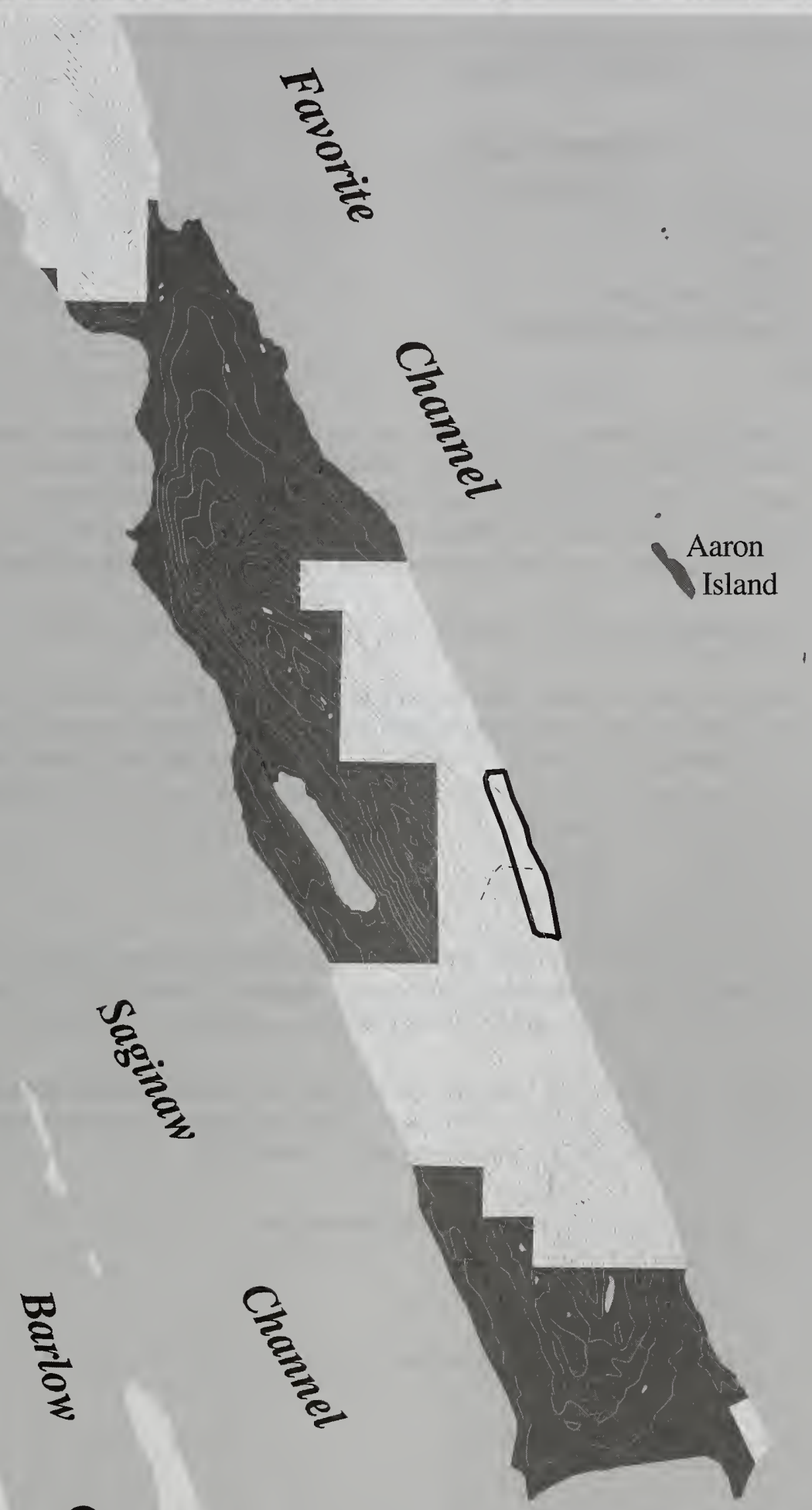

Tee

ह

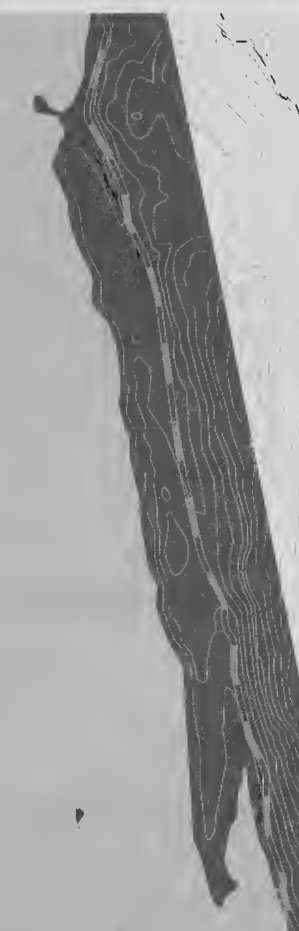

Harbor

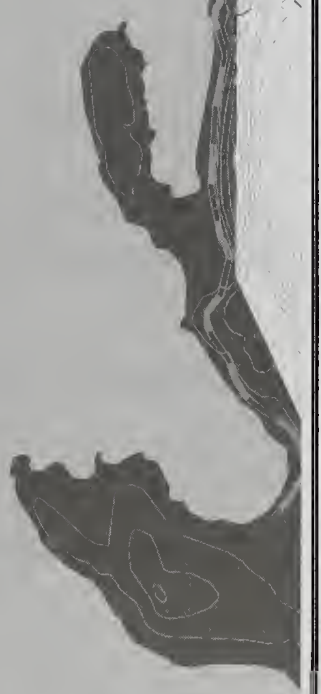

\begin{tabular}{|c|c|c|c|c|c|}
\hline & $\begin{array}{l}\text { Large Group Area Boundary } \\
\text { Streams }\end{array}$ & \begin{tabular}{ll|}
$\square \square$ \\
$\square$
\end{tabular} & $\begin{array}{l}\text { Non National Forest Land } \\
\text { Wilderness }\end{array}$ & 合 & $\begin{array}{l}\text { Salt and Fresh Water } \\
\text { Recreation Cabin }\end{array}$ \\
\hline & Existing Road & L & Outside of Project Area & 而 & Marine Access Point \\
\hline
\end{tabular}

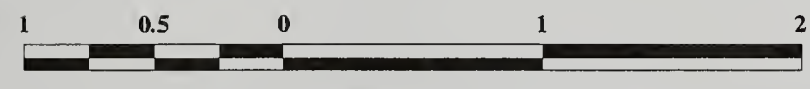

Mapscale 1:63360 


\section{Appendix B, Large Group Areas}

\begin{tabular}{|c|c|}
\hline & $\begin{array}{l}\text { Large Group Area } \\
\text { Sunny Cove } \\
\text { Alternatives } 3,4,5\end{array}$ \\
\hline $\begin{array}{l}\text { Type } \\
\text { Use Area } \\
\text { ROS } \\
\text { LUD } \\
\text { Acres }\end{array}$ & $\begin{array}{l}\text { Enclave } \\
01-04 \mathrm{C} \\
\text { Roaded Natural } \\
\text { Semi-Remote Recreation } \\
66\end{array}$ \\
\hline $\begin{array}{l}\text { General } \\
\text { Characteristics }\end{array}$ & $\begin{array}{l}\text { This site is located on the north side of Taku Inlet on Carlson Creek, } \\
\text { which empties into Sunny Cove. Carlson Creek is a wide, shallow, fast } \\
\text { moving stream with numerous pools, a rocky bottom, and large } \\
\text { boulders. A power line passes the north side of the cove but is not too } \\
\text { obtrusive. Relatively flat banks above the creek make for easy walking. }\end{array}$ \\
\hline Historical Use & There was no reported commercial use of Sunny Cove in 1999. \\
\hline Access & $\begin{array}{l}\text { The cove has a muddy tide flat at low tide and is rockier up the beach. } \\
\text { The forest on the north side is poor for walking and the private parcel } \\
\text { would have to be skirted. The timber is better on the south side and it } \\
\text { would be easier to access more of the site. The creek is not fordable } \\
\text { except with hip waders. }\end{array}$ \\
\hline Facilities & A power line runs through the area. \\
\hline $\begin{array}{l}\text { Concerns and/or } \\
\text { Opportunities }\end{array}$ & $\begin{array}{l}\text { This area provides wildlife and wildflower viewing, fishing, hiking, and } \\
\text { bird watching opportunities. Access to National Forest lands is along } \\
\text { the tide flat. There are two small privately owned parcels in the cove. }\end{array}$ \\
\hline Attractions & $\begin{array}{l}\text { Carlson Creek is a very large scenic creek. There are excellent views } \\
\text { of the mountains across Taku Inlet. This area offers easy walking } \\
\text { through bear paths, beach grass, and some rocks. }\end{array}$ \\
\hline Mitigation & $\begin{array}{l}\text { - See Appendix C for mitigation measures. } \\
\text { - Bald eagles } \\
\text { - Regetation } \\
\text { - Riparian } \\
\text { - Guided use must not trespass on private land. }\end{array}$ \\
\hline
\end{tabular}


Shoreline Outfitter/Guide EIS

Large Group Area

Use Area 01-04C SUNNY COVE
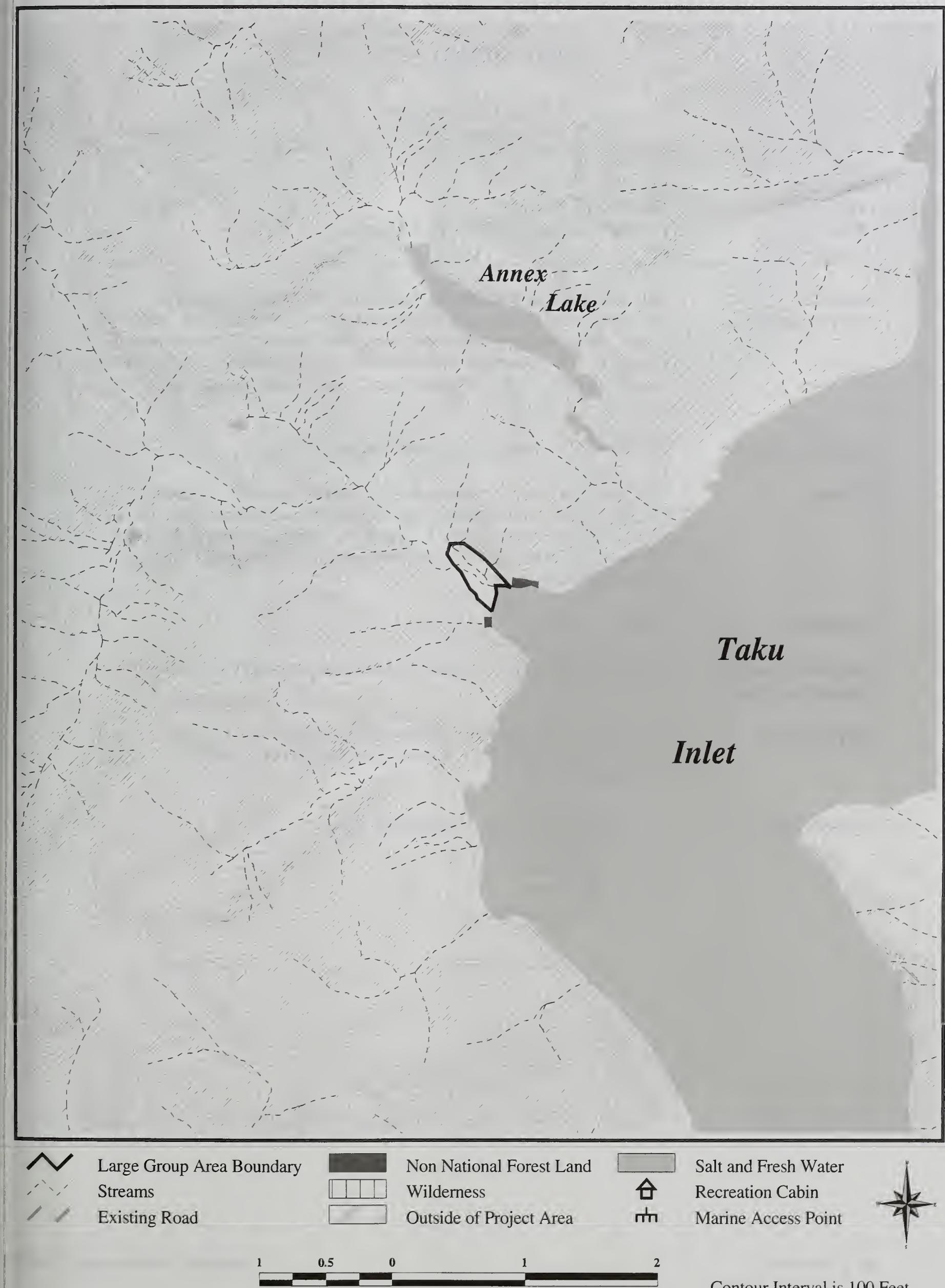


\section{Appendix B, Large Group Areas}

\begin{tabular}{|c|c|}
\hline & $\begin{array}{l}\text { Large Group Area } \\
\text { Mallard Cove } \\
\text { Alternatives } 3,4,5\end{array}$ \\
\hline $\begin{array}{l}\text { Type } \\
\text { Use Area } \\
\text { LUD } \\
\text { ROS } \\
\text { Acres }\end{array}$ & $\begin{array}{l}\text { Enclave } \\
01-05 B \\
\text { Modified Landscape } \\
\text { Roaded Natural/ Semi-Primitive Motorized } \\
96\end{array}$ \\
\hline $\begin{array}{l}\text { General } \\
\text { Characteristics }\end{array}$ & $\begin{array}{l}\text { This site is a long tidal slough that turns into marshy grassland. } \\
\text { Prospect Creek forks in several places in this grassland with beaver } \\
\text { ponds approximately one mile inland. The Snettisham power line } \\
\text { passes by the opening of Mallard Cove and the related timber harvest is } \\
\text { visible with the overhead power lines. There is an excellent view up } \\
\text { Prospect Creek into the valley. }\end{array}$ \\
\hline Historical Use & Commercial outfitter/guides used this area in 1999. \\
\hline Access & $\begin{array}{l}\text { The area just outside the tree line is probably the best for walking, } \\
\text { though there are animal trails that can be followed under the tree } \\
\text { canopy. Portions of the tide flat are soft, making walking somewhat } \\
\text { difficult. The creek is wide and deep enough to land small boats at a } \\
\text { variety of tidal phases. }\end{array}$ \\
\hline Facilities & None \\
\hline $\begin{array}{l}\text { Concerns and/or } \\
\text { Opportunities }\end{array}$ & $\begin{array}{l}\text { A seal haul-out exists on the rocks northwest and to the south of Fannie } \\
\text { Island. }\end{array}$ \\
\hline Attractions & $\begin{array}{l}\text { This area has an interesting tidal slough and a chance to walk in the } \\
\text { large meadow, in addition to wildlife and wildflower viewing } \\
\text { opportunities. }\end{array}$ \\
\hline Mitigation & $\begin{array}{l}\text { - See Appendix } C \text { for mitigation measures. } \\
\text { - Marine mammals } \\
\text { - Regetation } \\
\text { - Riparian } \\
\text { Cultural resources }\end{array}$ \\
\hline
\end{tabular}




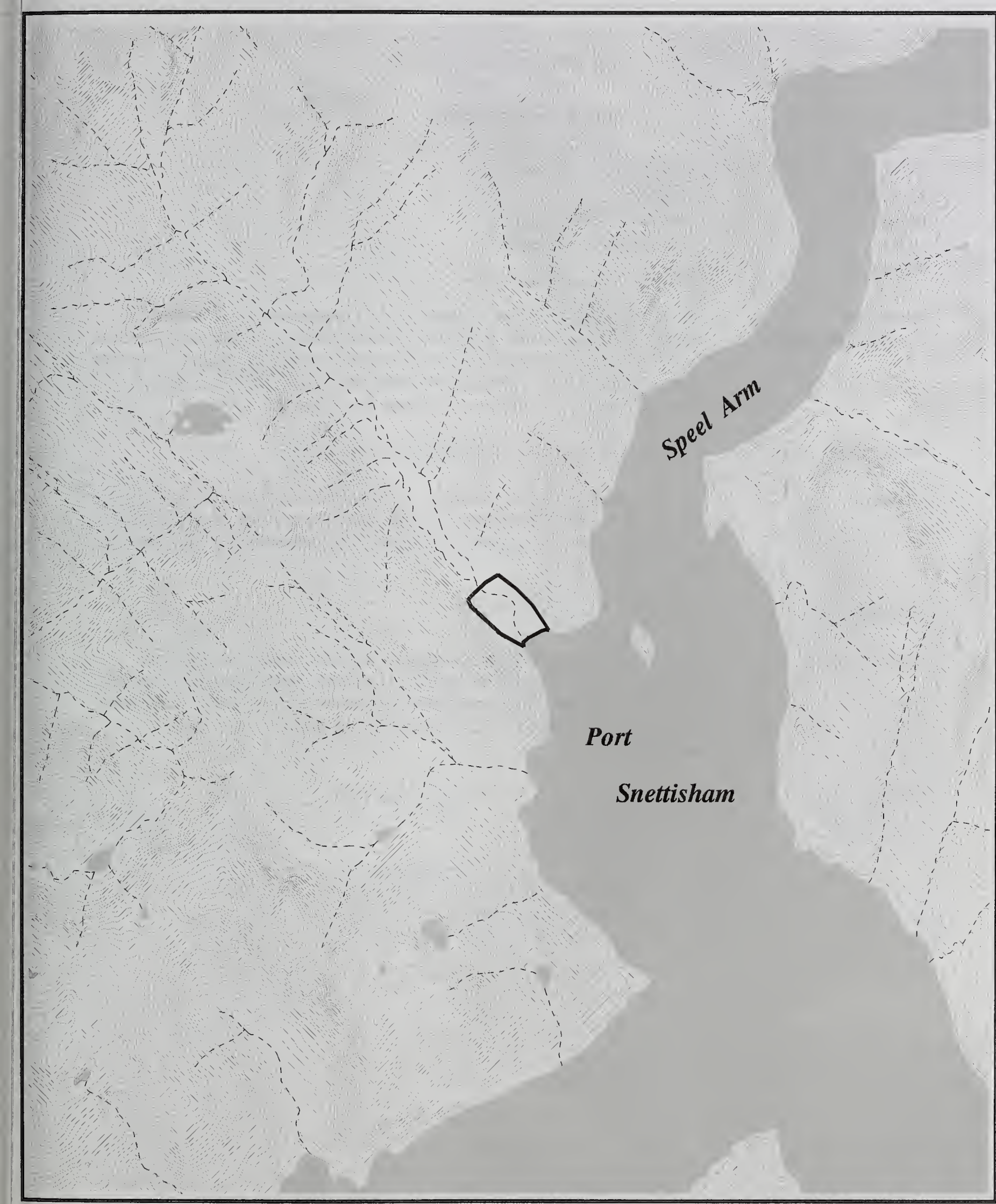

Large Group Area Boundary Streams

Existing Road
Non National Forest Land

Wilderness

Outside of Project Area \begin{tabular}{cl}
\hline & Salt and Fresh Water \\
ㅁ & Recreation Cabin \\
皿 & Marine Access Point
\end{tabular}

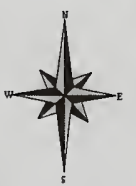

Contour Interval is 100 Feet 


\section{Appendix B, Large Group Areas}

\begin{tabular}{|c|c|}
\hline & $\begin{array}{l}\text { Large Group Area } \\
\text { No Name Cove } \\
\text { Alternatives } 3,4,5\end{array}$ \\
\hline $\begin{array}{l}\text { Type } \\
\text { Use Area } \\
\text { ROS } \\
\text { LUD } \\
\text { Acres }\end{array}$ & $\begin{array}{l}\text { Enclave } \\
01-05 B \\
\text { Semi-Remote Recreation } \\
\text { Semi-Primitive Motorized } \\
52\end{array}$ \\
\hline $\begin{array}{l}\text { General } \\
\text { Characteristics }\end{array}$ & $\begin{array}{l}\text { No Name Cove is on the northern side of the entrance to Tracy Arm } \\
\text { between Williams Cove and Point Coke. A meadow provides vistas into } \\
\text { Tracy Arm fiord. Most of the cove has flat ground and mature trees that } \\
\text { provide shelter from the weather and views of the iceberg outflow from } \\
\text { the fiord. A large, shallow rocky creek flows into the cove. }\end{array}$ \\
\hline Historical Use & Commercial outfitter/guides used this area in 1999. \\
\hline Access & $\begin{array}{l}\text { The best anchorage and beach is in the vicinity of the isthmus. This } \\
\text { area is an anchorage for many boats using Tracy Arm. Much of the } \\
\text { cove, particularly the central part, has a long, shallow tide flat with rocks } \\
\text { and gravel. }\end{array}$ \\
\hline Facilities & None \\
\hline Attractions & $\begin{array}{l}\text { This area offers a good anchorage, wildlife and wildflower viewing. } \\
\text { Icebergs coming out of Tracy Arm run aground here, providing visitors } \\
\text { with a close view. The proximity to Tracy Arm/Fords Terror Wilderness } \\
\text { Area allows for a boat trip up the fiord and a shore excursion on the } \\
\text { same day. }\end{array}$ \\
\hline Mitigation & $\begin{array}{l}\text { - See Appendix C for mitigation measures. } \\
\text { - Bald eagles } \\
\text { - Regetation } \\
\text { - Riparian } \\
\text { - Noltural resources } \\
\text { - No consumptive uses by large groups. }\end{array}$ \\
\hline
\end{tabular}


Shoreline Outfitter/Guide EIS

Large Group Area

Use Area 01-05B NO NAME COVE

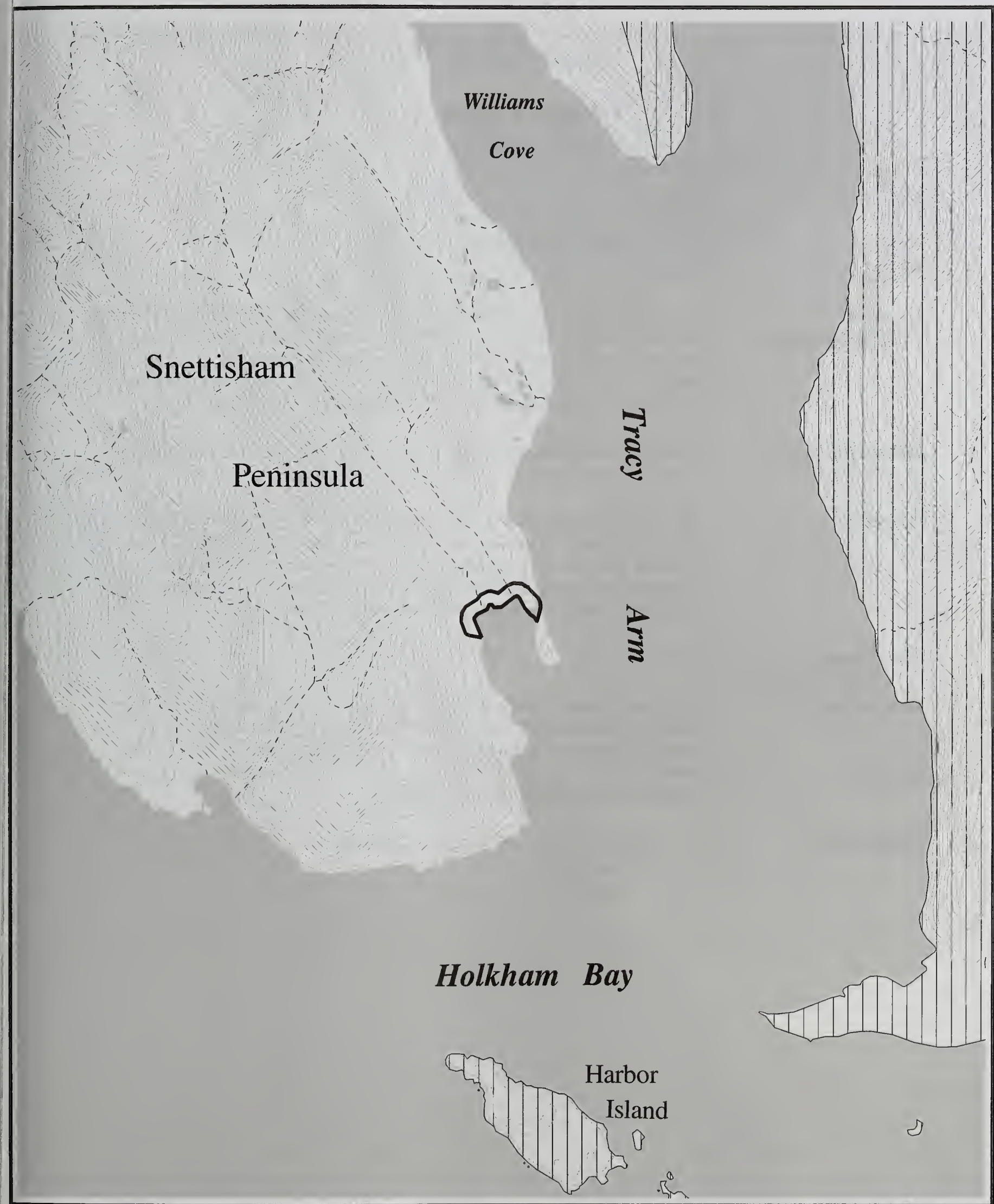

$\checkmark$ Large Group Area Boundary

Streams

Existing Road
Non National Forest Land Wilderness

Outside of Project Area

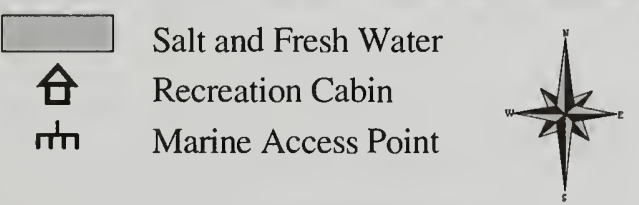

Contour Interval is 100 Feet

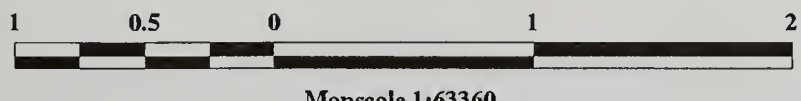




\section{Appendix B, Large Group Areas}

\begin{tabular}{|c|c|}
\hline & $\begin{array}{l}\text { Large Group Area } \\
\text { Point Anmer } \\
\text { Alternatives 3, } 5\end{array}$ \\
\hline $\begin{array}{l}\text { Type } \\
\text { Use Area } \\
\text { LUD } \\
\text { ROS } \\
\text { Acres }\end{array}$ & $\begin{array}{l}\text { Enclave } \\
01-05 B \\
\text { Scenic Viewshed } \\
\text { Semi-Primitive Motorized } \\
37\end{array}$ \\
\hline $\begin{array}{l}\text { General } \\
\text { Characteristics }\end{array}$ & $\begin{array}{l}\text { This northwest-facing cove is about } 1 / 4 \text { mile wide and about } 1 / 2 \text { mile north } \\
\text { of Point Anmer. Dense shrub patches characterize shoreline in this } \\
\text { area with large spruce trees just off the beach fringe. At the outermost } \\
\text { edge of the thicket is a forested point of land with large spruce and } \\
\text { exposed roots that follow a rocky outcrop towards the beach. }\end{array}$ \\
\hline Historical Use & $\begin{array}{l}\text { There was no reported commercial use in } 1999 . \text { The area receives } \\
\text { some unguided use. }\end{array}$ \\
\hline Access & $\begin{array}{l}\text { Low tide exposes a sandy bottom on the south end and a rocky beach } \\
\text { at the north end. The southern beach is flatter but has thick vegetation. } \\
\text { A small, steeper sand beach just to the south of the rock outcrop } \\
\text { provides good access, although this beach is more exposed to the } \\
\text { southeast winds. The beach receives high storm waves. }\end{array}$ \\
\hline Facilities & None \\
\hline Attractions & $\begin{array}{l}\text { The upper beach area provides wildflower viewing and vistas of the } \\
\text { ocean. Opportunity to view vegetation successional stages from shrubs } \\
\text { to old growth spruce forest. Rock outcroppings also provide visual } \\
\text { diversity. Tide pools support many shorebirds. A large waterfall is } \\
\text { visible offshore south of Point Anmer. }\end{array}$ \\
\hline Mitigation & $\begin{array}{l}\text { See Appendix } C \text { for mitigation measures. } \\
\text { - Bald eagles } \\
\text { - Vegetation }\end{array}$ \\
\hline
\end{tabular}


Shoreline Outfitter/Guide EIS

Large Group Area

Use Area 01-05B POINT ANMER

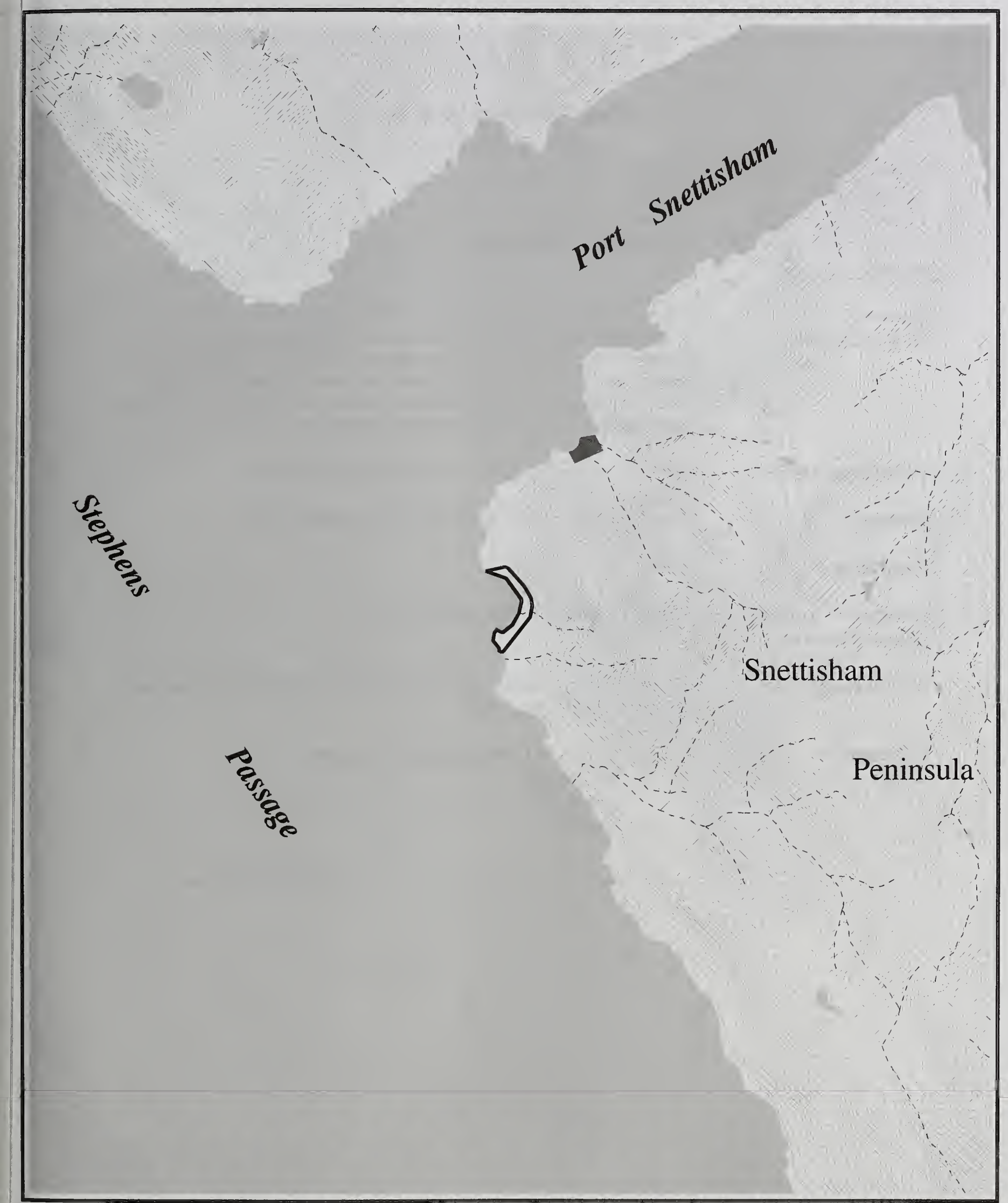

Large Group Area Boundary

Streams

Existing Road
Non National Forest Land Wilderness

Outside of Project Area
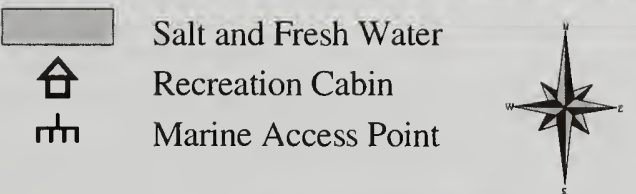

Contour Interval is 100 Feet 


\section{Appendix B, Large Group Areas}

\begin{tabular}{|c|c|}
\hline & $\begin{array}{l}\text { Large Group Area } \\
\text { West Gilbert Bay } \\
\text { Alternatives 3, } 5\end{array}$ \\
\hline $\begin{array}{l}\text { Type } \\
\text { Use Area } \\
\text { LUD } \\
\text { ROS } \\
\text { Acres }\end{array}$ & $\begin{array}{l}\text { Enclave } \\
01-05 B \\
\text { Timber Production } \\
\text { Semi-Primitive Motorized } \\
12\end{array}$ \\
\hline $\begin{array}{l}\text { General } \\
\text { Characteristics }\end{array}$ & $\begin{array}{l}\text { Located directly across from the Whiting River in Gilbert Bay. The } \\
\text { creek has river cobble and small pools, and is fordable at many } \\
\text { locations. It is possible to follow the creek along its bank during low } \\
\text { water conditions, providing a view of a forested stream for an } \\
\text { extended distance. On the northern side of the creek there are large } \\
\text { trees with an open understory and relatively flat ground. }\end{array}$ \\
\hline Historical Use & Commercial groups used this general area in 1999 . \\
\hline Access & The relatively shallow beach has large cobble rocks. \\
\hline Facilities & None \\
\hline $\begin{array}{l}\text { Concerns and/or } \\
\text { Opportunities }\end{array}$ & The site is adjacent to a salmon stream. \\
\hline Attractions & $\begin{array}{l}\text { Wildlife viewing, walking through the forest or along the creek side } \\
\text { channels during low flows }\end{array}$ \\
\hline Mitigation & $\begin{array}{l}\text { - See Appendix } C \text { for mitigation measures. } \\
\text { - Bald eagles } \\
\text { - Vegetation } \\
\text { Riparian }\end{array}$ \\
\hline
\end{tabular}




\section{Shoreline Outfitter/Guide EIS \\ Large Group Area \\ Use Area 01-05B WEST GILBERT BAY}
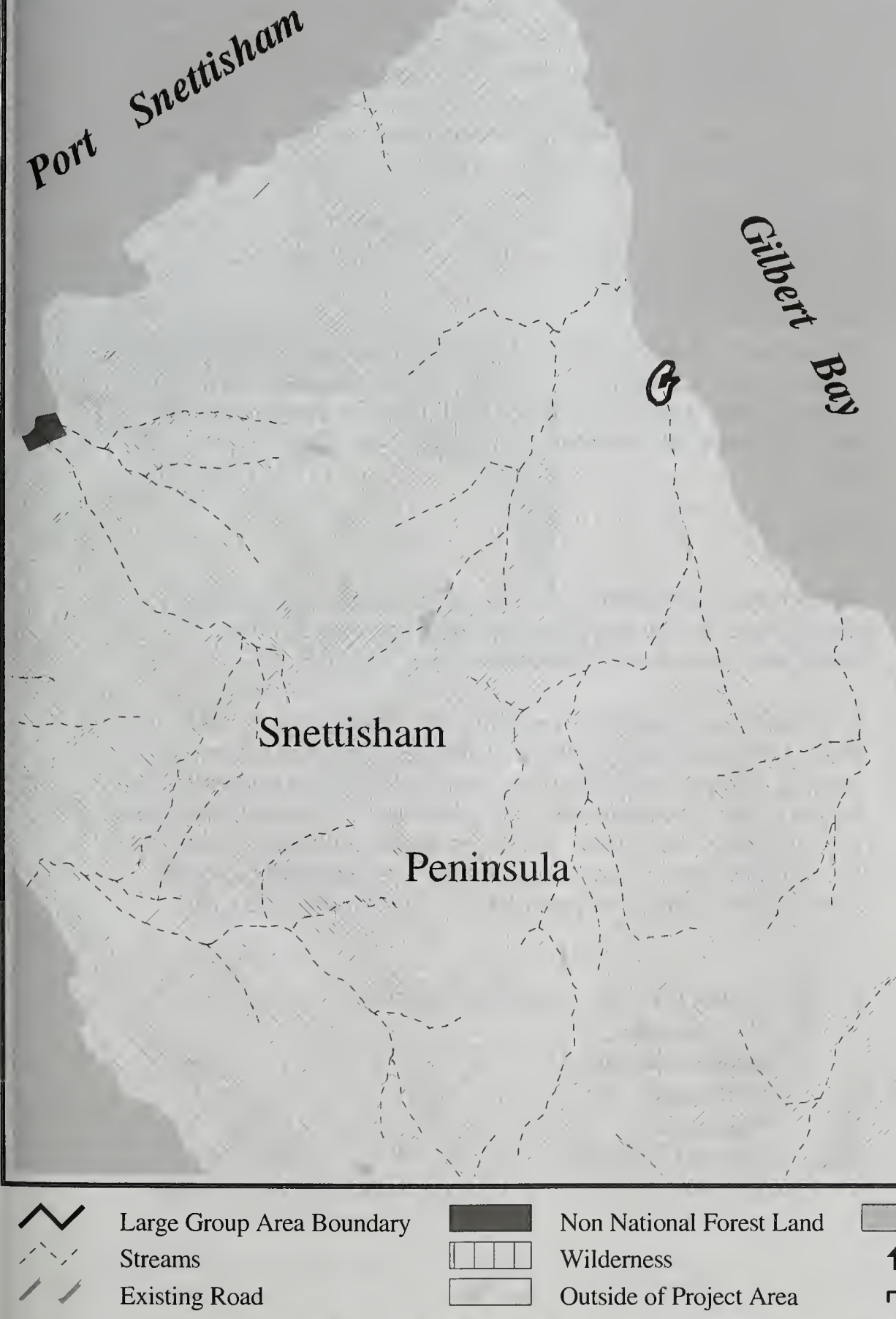

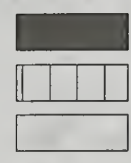

Non National Forest Land

Wilderness

Outside of Project Area
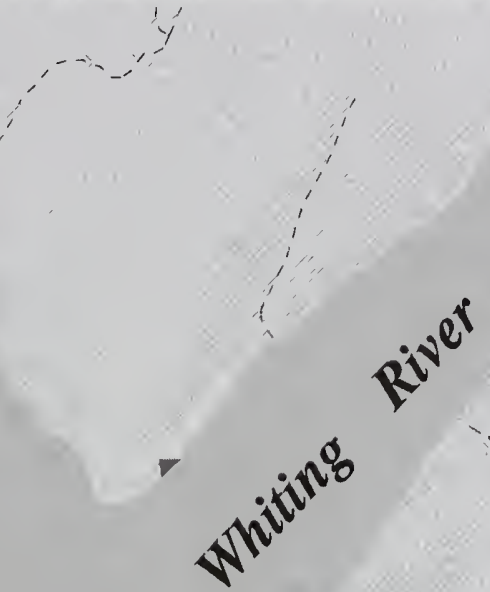


\section{Appendix B, Large Group Areas}

\begin{tabular}{|c|c|}
\hline & $\begin{array}{l}\text { Large Group Area } \\
\text { Fanshaw } \\
\text { Alternatives 3, } 5\end{array}$ \\
\hline $\begin{array}{l}\text { Type } \\
\text { Use Area } \\
\text { LUD } \\
\text { ROS } \\
\text { Acres }\end{array}$ & $\begin{array}{l}\text { Enclave } \\
01-05 C \\
\text { Scenic Viewshed } \\
\text { Semi-Primitive Motorized } \\
48\end{array}$ \\
\hline $\begin{array}{l}\text { General } \\
\text { Characteristics }\end{array}$ & $\begin{array}{l}\text { This cove is over a mile wide. A tree-covered peninsula allows } \\
\text { for views to the north with another smaller cove providing wildlife } \\
\text { viewing opportunities. Topography in the area is flat to benched, } \\
\text { with gently rolling terrain. Primarily a forested area with an open } \\
\text { understory, there are occasional patches of more dense trees, } \\
\text { brush and small meadows. The southeast corner of the cove has } \\
\text { a small creek with flatter ground and good visibility. }\end{array}$ \\
\hline Historical Use & $\begin{array}{l}\text { Commercial use did not occur here in } 1999 \text {. There has been } \\
\text { some timber harvest. Remnants of an old dock and pilings are } \\
\text { adjacent to the area. }\end{array}$ \\
\hline Access & $\begin{array}{l}\text { Shoreline on the south side of the cove is rocky and very slippery. } \\
\text { To the north, the shoreline is sandy at low tide, providing better } \\
\text { walking opportunities, but more difficulty in access by boat or } \\
\text { plane. Where the shoreline is not rocky, the beach is relatively } \\
\text { flat. }\end{array}$ \\
\hline Facilities & None \\
\hline $\begin{array}{l}\text { Concerns and/or } \\
\text { Opportunities }\end{array}$ & $\begin{array}{l}\text { Opportunities for wildlife viewing, fishing, and beach walking } \\
\text { exist. There is high plant diversity with beach rye grass, } \\
\text { wildflowers, and forest. State lands are adjacent. }\end{array}$ \\
\hline Attractions & $\begin{array}{l}\text { The beach is conducive to walking with ample opportunities to } \\
\text { walk in the woods along the tree line. Evidence of historic beach } \\
\text { logging is found throughout the cove but is most prevalent in the } \\
\text { center. From the peninsula, it is possible to get elevated views of } \\
\text { the adjoining small cove. A salmon stream abuts the north side } \\
\text { of the peninsula. From this location it is possible to get good } \\
\text { views of the small cove's tide flat, Point Walpole, and Crow } \\
\text { Island. }\end{array}$ \\
\hline Mitigation & $\begin{array}{l}\text { - See Appendix } C \text { for mitigation measures. } \\
\text { - Bald eagles } \\
\text { - Marine mammals } \\
\text { - Riparian } \\
\text { - Gultural resources } \\
\text { - Guided use on state land must be authorized by the state. }\end{array}$ \\
\hline
\end{tabular}



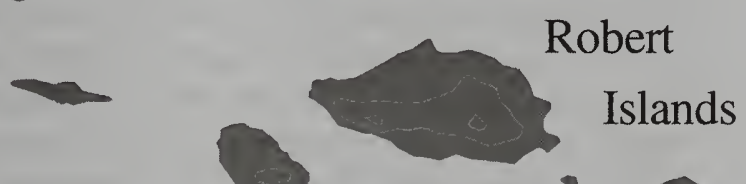

L arge Group Area Boundary Streams

Existing Road
Non National Forest Land

Outside of Project Area
Wilderness

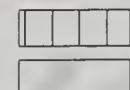

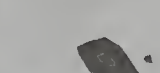

Russian

Cove

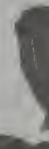




\section{Appendix B, Large Group Areas}

\begin{tabular}{|c|c|}
\hline & $\begin{array}{l}\text { Large Group Area } \\
\text { North Windham Bay } \\
\text { Alternatives } 3,5\end{array}$ \\
\hline $\begin{array}{l}\text { Type } \\
\text { Use Area } \\
\text { LUD } \\
\text { ROS } \\
\text { Acres }\end{array}$ & $\begin{array}{l}\text { Enclave } \\
01-05 C \\
\text { Scenic Viewshed } \\
\text { Semi-Primitive Motorized } \\
12\end{array}$ \\
\hline $\begin{array}{l}\text { General } \\
\text { Characteristics }\end{array}$ & $\begin{array}{l}\text { Located on the east side of Stephens Passage and directly east of } \\
\text { the entrance Seymour Canal. A large salmon-bearing creek flows into } \\
\text { the site from the north. The beach is sandy and grassy with a berry } \\
\text { thicket and wildflowers above tide line. Beyond the tide line a flat } \\
\text { valley contains young trees and man-made openings. This site is } \\
\text { within } 1 / 2 \text { mile of the Chuck River Wilderness boundary. }\end{array}$ \\
\hline Historical Use & Commercial outfitter/guides used Windham Bay in 1999. \\
\hline Access & $\begin{array}{l}\text { Access by plane or boat is possible, though this would probably not } \\
\text { be a good location for an anchorage due to exposure. }\end{array}$ \\
\hline Facilities & None \\
\hline $\begin{array}{l}\text { Concerns and/or } \\
\text { Opportunities }\end{array}$ & $\begin{array}{l}\text { The west side of the area has a fox farm cabin and related remains. } \\
\text { This site has a Not Eligible determination for the National Register of } \\
\text { Historic Places. It offers interpretive opportunities. There are other } \\
\text { cultural sites are in the area as well. There are some places where } \\
\text { wet soils would not stand up well to heavy foot traffic. }\end{array}$ \\
\hline Attractions & $\begin{array}{l}\text { This is an excellent south facing location with a good beach. The } \\
\text { creek may provide salmon viewing and fishing opportunities, coupled } \\
\text { with views across the bay and rock grottos on the east side of the } \\
\text { site. Wildlife viewing, beach combing, and limited hiking are possible } \\
\text { here. A bear trail was noted from the beach into the woods. }\end{array}$ \\
\hline Mitigation & $\begin{array}{l}\text { - See Appendix } C \text { for mitigation measures. } \\
\text { - Rald eagles } \\
\text { - Riparian } \\
\text { - Cultural resources } \\
\text { The fox farm site will have a management plan covering } \\
\text { protection, interpretation, and monitoring in place before guided } \\
\text { use is permitted at the site. } \\
\text { - Other cultural sites are excluded from guided use. }\end{array}$ \\
\hline
\end{tabular}


Shoreline Outfitter/Guide EIS

Large Group Area

Use Area 01-05C NORTH WINDHAM BAY

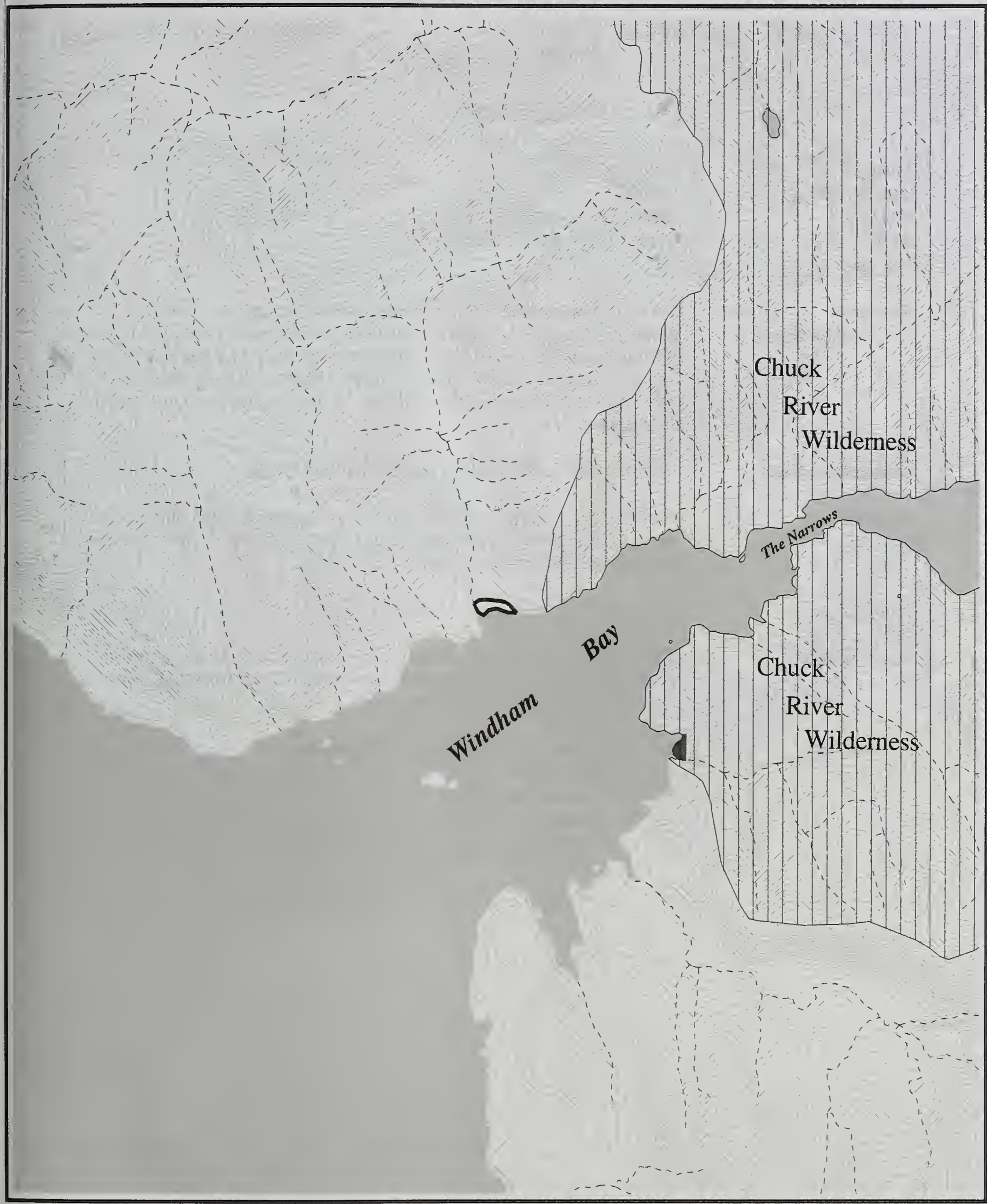

$\checkmark$ Large Group Area Boundary Streams

Existing Road
Non National Forest Land

Wilderness

Outside of Project Area
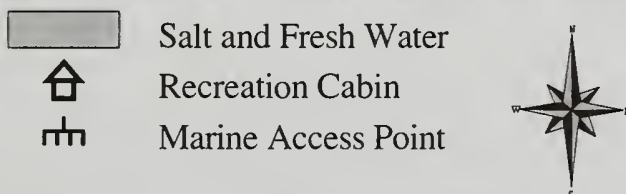


\section{Appendix B, Large Group Areas}

\begin{tabular}{|c|c|}
\hline & $\begin{array}{l}\text { Large Group Area } \\
\text { Port Houghton } \\
\text { Alternatives } 3,4,5\end{array}$ \\
\hline $\begin{array}{l}\text { Type } \\
\text { Use Area } \\
\text { LUD } \\
\text { ROS } \\
\text { Acres }\end{array}$ & $\begin{array}{l}\text { Enclave } \\
01-05 C \\
\text { Scenic Viewshed } \\
\text { Semi-Primitive Motorized } \\
10\end{array}$ \\
\hline $\begin{array}{l}\text { General } \\
\text { Characteristics }\end{array}$ & $\begin{array}{l}\text { This site is located on the north side of Port Houghton. This is a } \\
\text { small, distinct location due to the steep terrain surrounding the area. } \\
\text { A large creek is present and there are small openings inside the tree } \\
\text { line on both sides of the creek. The area contains an old slide that } \\
\text { has been colonized by alder and open canopy, creating an attractive } \\
\text { light understory. }\end{array}$ \\
\hline Historical Use & Commercial outfitter/guides used this area in 1999. \\
\hline Access & $\begin{array}{l}\text { A steep rocky beach provides access to the site. Access along both } \\
\text { sides of the creek beyond initial entry into the woods is difficult due to } \\
\text { thick brush and downed trees. }\end{array}$ \\
\hline Facilities & None \\
\hline Attractions & $\begin{array}{l}\text { This area has a scenic a stream with plunge pools. The site offers } \\
\text { nice views across Port Houghton as well as a large waterfall dropping } \\
\text { over a cliff just to the east of the creek. }\end{array}$ \\
\hline Mitigation & $\begin{array}{l}\text { - See Appendix } C \text { for mitigation measures. } \\
\text { - Bald eagles } \\
\text { - Marine mammals } \\
\text { - Regarian } \\
\text { - Vegetation }\end{array}$ \\
\hline
\end{tabular}


Shoreline Outfitter/Guide EIS

Large Group Area

Use Area 01-05C PORT HOUGHTON

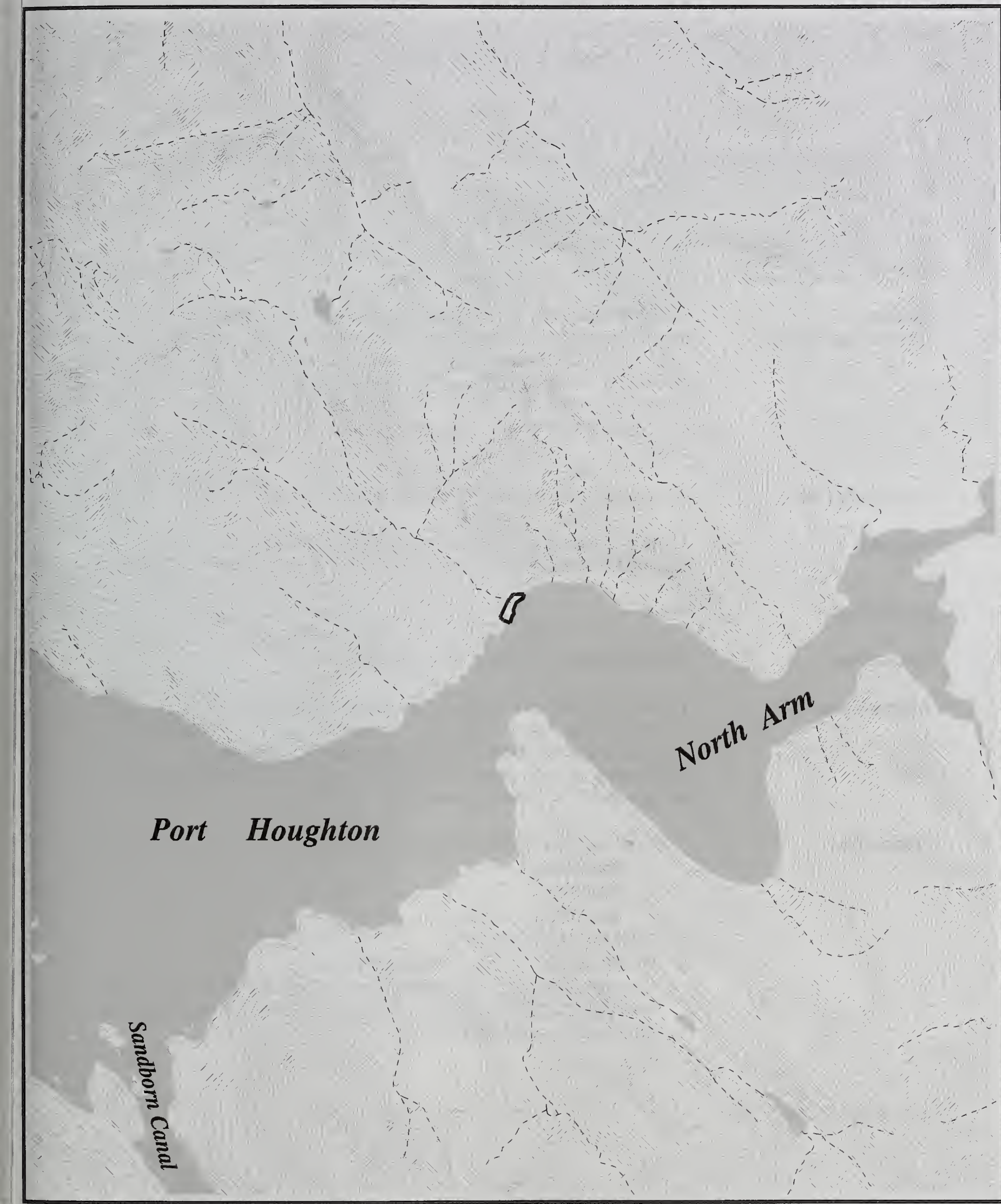

Large Group Area Boundary

Streams

Existing Road
Non National Forest Land

Wilderness

Outside of Project Area \begin{tabular}{cl}
\hline & Salt and Fresh Water \\
4 & Recreation Cabin \\
皿 & Marine Access Point
\end{tabular}

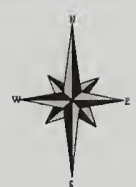




\begin{tabular}{|c|c|}
\hline & $\begin{array}{l}\text { Large Group Area } \\
\text { Sand Bay } \\
\text { Alternative } 3,4,5\end{array}$ \\
\hline $\begin{array}{l}\text { Type } \\
\text { Use Area } \\
\text { ROS } \\
\text { LUD } \\
\text { Acres }\end{array}$ & $\begin{array}{l}\text { Enclave } \\
01-05 C \\
\text { Semi-Primitive Motorized } \\
\text { Scenic Viewshed } \\
59\end{array}$ \\
\hline $\begin{array}{l}\text { General } \\
\text { Characteristics }\end{array}$ & $\begin{array}{l}\text { This site is located in a "u-shaped" cove with the enclave located on } \\
\text { the north peninsula extending south down the cove approximately } 1 / 4 \\
\text { mile. A fine sand beach and a relatively flat area above the river } \\
\text { mouth provide easy walking along the shoreline. It is possible to } \\
\text { cross the peninsula and view the adjacent cove to the north. There } \\
\text { are large mature trees inland, and visibility under the tree canopy is } \\
\text { good. }\end{array}$ \\
\hline Historical Use & Commercial outfitter/guides used the site in 1999. \\
\hline Access & $\begin{array}{l}\text { There is a rolling sandy beach with some cobble. The area is } \\
\text { exposed to weather from Stephens Passage and Frederick Sound. }\end{array}$ \\
\hline Facilities & None \\
\hline Concerns & There are three cultural sites in the area. \\
\hline Attractions & $\begin{array}{l}\text { There is a good view across Stephens Passage. The area is } \\
\text { relatively close to the Tracy Arm - Fords Terror Wilderness allowing } \\
\text { for a day trip in the fiord and a shore excursion outside the } \\
\text { wilderness. In good weather the scenic setting and varied shoreline } \\
\text { would provide a suitable location for kayaking. }\end{array}$ \\
\hline Mitigation & $\begin{array}{l}\text { - See Appendix } C \text { for mitigation measures. } \\
\text { - Rald eagles } \\
\text { - Riparian } \\
\text { - No large group camping. } \\
\text { - No consumptive uses by large groups. } \\
\text { - Cultural sites will be excluded from guided use. These sites will } \\
\text { be monitored. If impacts are detected, additional restrictions will } \\
\text { be placed guided use. }\end{array}$ \\
\hline
\end{tabular}


Shoreline Outfitter/Guide EIS

\section{Large Group Area \\ Use Area 01-05C SAND BAY}

\section{Stephens}

\section{Passage}

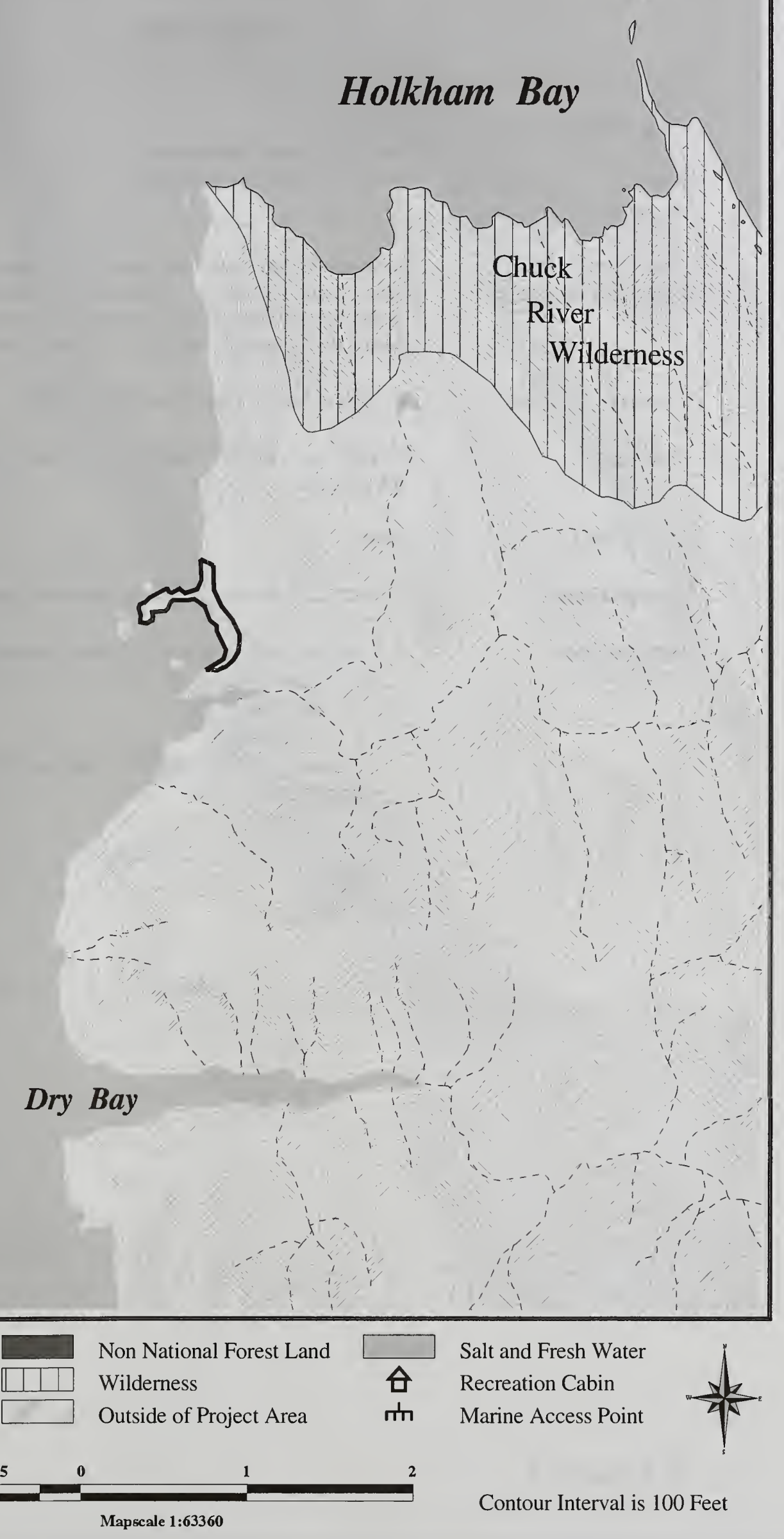




\section{Appendix B, Large Group Areas}

\begin{tabular}{|c|c|}
\hline & $\begin{array}{l}\text { Large Group Area } \\
\text { Dry Pass } \\
\text { Alternative } 3\end{array}$ \\
\hline $\begin{array}{l}\text { Type } \\
\text { Use Area } \\
\text { LUD } \\
\text { ROS } \\
\text { Acres } \\
\end{array}$ & $\begin{array}{l}\text { Enclave } \\
04-03 \\
\text { Semi-Remote Recreation } \\
\text { Semi-Primitive Motorized } \\
476\end{array}$ \\
\hline $\begin{array}{l}\text { General } \\
\text { Characteristics }\end{array}$ & $\begin{array}{l}\text { Most of the surrounding area is forested. There is a small meadow at } \\
\text { end of inlet with actual passage at high tide through to the south. It is } \\
\text { possible to walk inland for short distance at the end of the inlet but not } \\
\text { along the passage because of steep cliffs. }\end{array}$ \\
\hline Historical Use & Outfitter/guides used the area in 1999. \\
\hline Access & $\begin{array}{l}\text { There is a protected anchorage. Skiff landings are dependent on the } \\
\text { tide stage. }\end{array}$ \\
\hline Facilities & None \\
\hline Attractions & Forest and narrow passage between islands \\
\hline Mitigation & $\begin{array}{l}\text { - See Appendix } C \text { for mitigation measures. } \\
\text { - Bald eagles } \\
\text { - Riparian } \\
\text { - Vegetation } \\
\text { Guided activities will not interfere with other forest management } \\
\text { activities. }\end{array}$ \\
\hline
\end{tabular}


Shoreline Outfitter/Guide EIS

Large Group Area

Use Area 04-03 DRY PASS

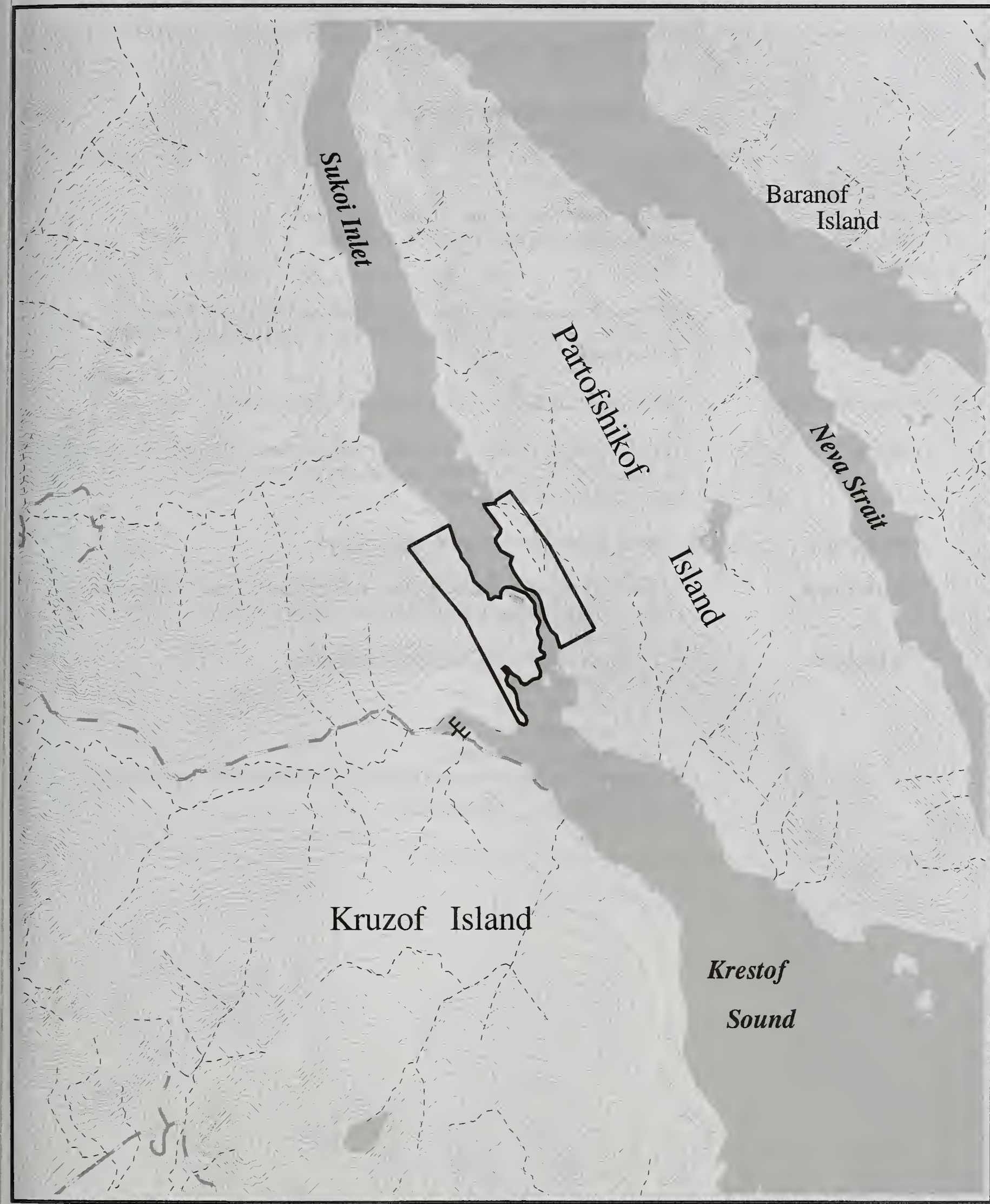

Large Group Area Boundary Streams

Existing Road

Non National Forest Land Wilderness

Outside of Project Area

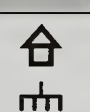

Salt and Fresh Water Recreation Cabin

Marine Access Point

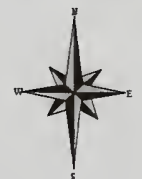

Contour Interval is 100 Feet 


\section{Appendix B, Large Group Areas}

\begin{tabular}{|c|c|}
\hline & $\begin{array}{l}\text { Large Group Area } \\
\text { Eagle River Road } \\
\text { Alternatives 3, } 5\end{array}$ \\
\hline $\begin{array}{l}\text { Type } \\
\text { Use Area } \\
\text { LUD } \\
\text { ROS } \\
\text { Acres }\end{array}$ & $\begin{array}{l}\text { Enclave } \\
04-03 \\
\text { Semi-Remote Recreation, Timber Production } \\
\text { Roaded Modified, Semi-primitive Motorized } \\
251\end{array}$ \\
\hline $\begin{array}{l}\text { General } \\
\text { Characteristics }\end{array}$ & $\begin{array}{l}\text { The area is roaded through old growth forest with recent timber } \\
\text { harvest in the vicinity. Along the road are a large meadow, muskeg, } \\
\text { and a stream. }\end{array}$ \\
\hline Historical Use & Commercial outfitting/guiding occurred here in 1999. \\
\hline Access & $\begin{array}{l}\text { The anchorage is protected during most weather conditions. There is } \\
\text { an easy landing at the marine access point or along the beach } \\
\text { depending on the tidal stage. }\end{array}$ \\
\hline Facilities & There is a road and a marine access point. \\
\hline Attractions & $\begin{array}{l}\text { Opportunity to view wildlife and fish. A large riparian area and estuary } \\
\text { offers excellent bird and waterfowl watching opportunities. }\end{array}$ \\
\hline Mitigation & $\begin{array}{l}\text { - See Appendix } C \text { for mitigation measures. } \\
\text { - Rald eagles } \\
\text { - Riparian } \\
\text { - } \text { Browetation } \\
\text { - Guided activities must not interfere with other forest management } \\
\text { activities. }\end{array}$ \\
\hline
\end{tabular}




\section{Shoreline Outfitter/Guide EIS Large Group Area Use Area 04-03 EAGLE RIVER ROAD}

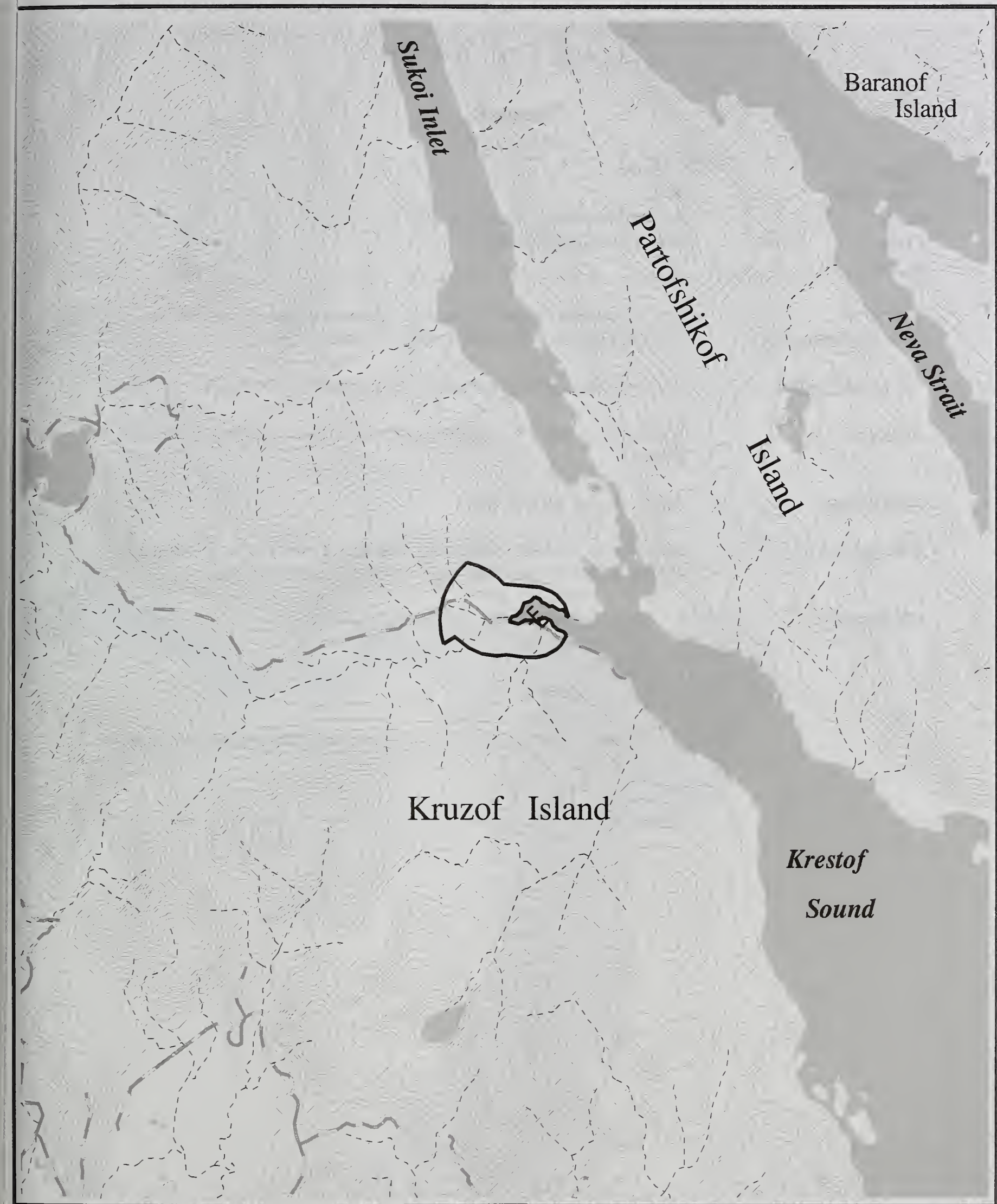

Large Group Area Boundary Streams

Existing Road
Non National Forest Land Wilderness

Outside of Project Area
Salt and Fresh Water Recreation Cabin Marine Access Point

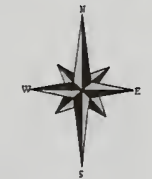

Contour Interval is 100 Feet 


\section{Appendix B, Large Group Areas}

\begin{tabular}{|c|c|}
\hline & $\begin{array}{l}\text { Large Group Area } \\
\text { Noxon } \\
\text { Alternative } 3\end{array}$ \\
\hline $\begin{array}{l}\text { Type } \\
\text { Use Area } \\
\text { ROS } \\
\text { LUD } \\
\text { Acres }\end{array}$ & $\begin{array}{l}\text { Enclave } \\
04-03 \\
\text { Roaded Modified / Scenic Viewshed } \\
\text { Semi-Remote Recreation } \\
203\end{array}$ \\
\hline $\begin{array}{l}\text { General } \\
\text { Characteristics }\end{array}$ & $\begin{array}{l}\text { The valley was logged in the } 1960 \text { 's and thinned in the 1990's. A } \\
\text { large tide flat exists at the mouth of Noxon Creek. }\end{array}$ \\
\hline Historical Use & Commercial outfitting/guiding did not occur here in 1999. \\
\hline Access & $\begin{array}{l}\text { There is a protected anchorage with access to beach at most tidal } \\
\text { stages. }\end{array}$ \\
\hline Facilities & Road, marine access point \\
\hline Attractions & $\begin{array}{l}\text { Opportunity to view wildlife and hike along the road or shoreline. } \\
\text { Opportunities to interpret forest management practices. }\end{array}$ \\
\hline Mitigation & $\begin{array}{l}\text { - See Appendix } C \text { for mitigation measures. } \\
\text { - Bald eagles } \\
\text { - Riparian } \\
\text { - Begetation } \\
\text { - Guided activities must not interfere with other forest management } \\
\text { activities. }\end{array}$ \\
\hline
\end{tabular}


Shoreline Outfitter/Guide EIS

Large Group Area

Use Area 04-03 NOXON

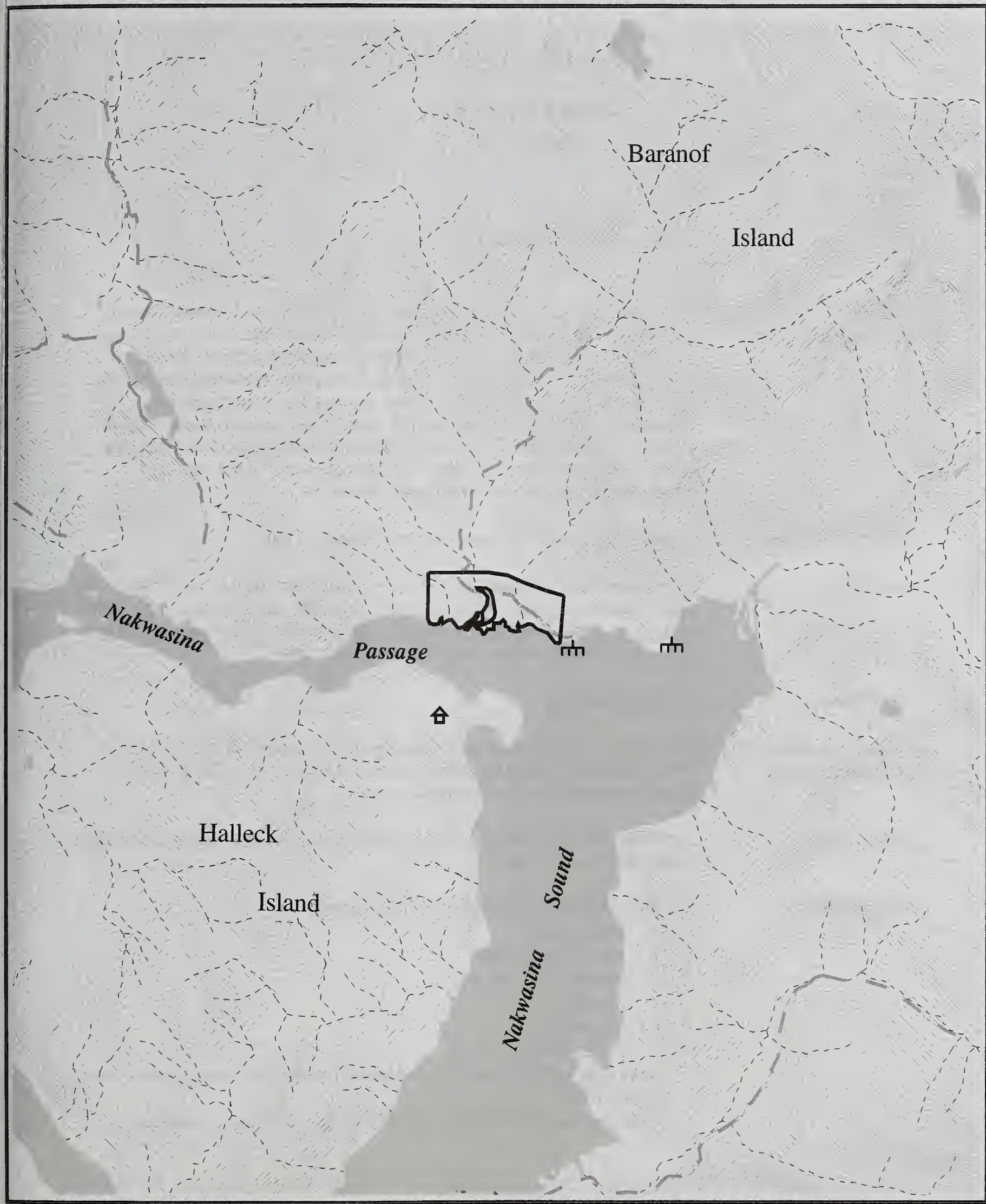

Large Group Area Boundary Streams

Existing Road
Non National Forest Land

Wilderness

Outside of Project Area $\begin{array}{ll}\text { A } & \text { Salt and Fresh Water } \\ \text { ㄴ. Recreation Cabin } \\ \text { 宑 }\end{array}$

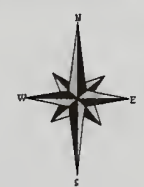

Contour Interval is 100 Feet 


\section{Appendix B, Large Group Areas}

\begin{tabular}{|c|c|}
\hline & $\begin{array}{l}\text { Large Group Area } \\
\text { Lake Eva Trail } \\
\text { Alternatives 3, 4, } 5\end{array}$ \\
\hline $\begin{array}{l}\text { Type } \\
\text { Use Area } \\
\text { LUD } \\
\text { ROS } \\
\text { Acres }\end{array}$ & $\begin{array}{l}\text { Enclave } \\
04-04 A \\
\text { Semi-Remote Recreation } \\
\text { Semi-Primitive Motorized } \\
132\end{array}$ \\
\hline $\begin{array}{l}\text { General } \\
\text { Characteristics }\end{array}$ & $\begin{array}{l}\text { This area is a good example of streamside old growth forest. Some } \\
\text { very large trees make it an area of particular interest. The trail to Lake } \\
\text { Eva makes this a good area for walking and accessing the interior } \\
\text { forest as well as the shoreline. Migrating salmon are visible during the } \\
\text { mid- and late summer as they move up the stream and over the } \\
\text { waterfalls. Brown bears frequent the area feeding on salmon. Forest } \\
\text { birds are usually seen and heard in the spring as well as some water } \\
\text { birds in the small estuary. Many flowers grow in the meadow and } \\
\text { beach fringe vegetation in the early summer. }\end{array}$ \\
\hline Historical Use & Commercial outfitter/guides used this area in 1999. \\
\hline Access & $\begin{array}{l}\text { The anchorage is protected from most directions except easterlies. It is } \\
\text { possible to land a skiff at the trailhead on small sandy beach, and skiffs } \\
\text { can get to shore in most tide stages. At high tide skiffs can get into the } \\
\text { estuary and land a short distance below the falls. }\end{array}$ \\
\hline Facilities & Trail to Lake Eva \\
\hline $\begin{array}{l}\text { Concerns and/or } \\
\text { Opportunities }\end{array}$ & $\begin{array}{l}\text { The trail is in poor shape and very muddy in places. A grove of large } \\
\text { trees exists and could be easily accessed by the trail. There is an } \\
\text { important subsistence sockeye stream. }\end{array}$ \\
\hline Attractions & $\begin{array}{l}\text { A trail leads inland along a salmon stream and through some old growth } \\
\text { forest with large trees. }\end{array}$ \\
\hline Mitigation & $\begin{array}{l}\text { - See Appendix } C \text { for mitigation measures. } \\
\text { - Bald eagles } \\
\text { - Marine mammals } \\
\text { - Riparian } \\
\text { - Vegetation } \\
\text { - Labsistence } \\
\text { is permitted. } \\
\text { - Outfitter/guides will not be allowed to fly clients into Lake Eva. }\end{array}$ \\
\hline
\end{tabular}




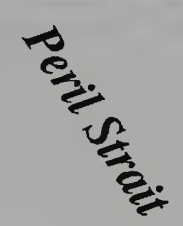

\section{Peril Strait}

\section{Baranof \\ Island}

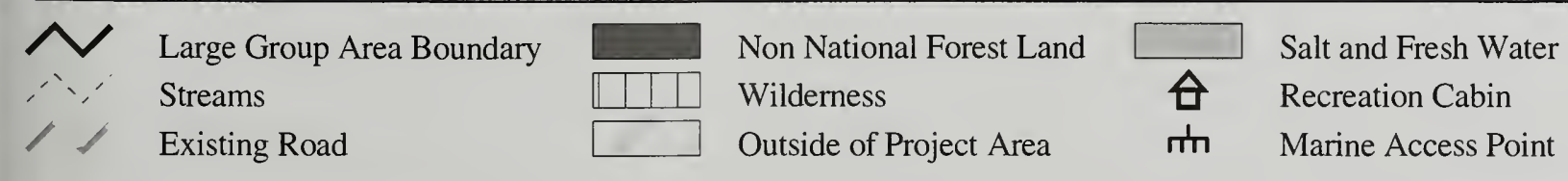

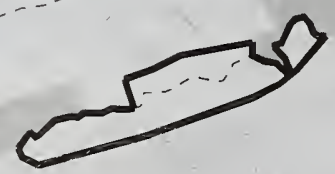

Hanus 카 Bay<smiles>[Tl]</smiles> 


\section{Appendix B, Large Group Areas}

\begin{tabular}{|c|c|}
\hline & $\begin{array}{l}\text { Large Group Area } \\
\text { Point Elizabeth } \\
\text { Alternatives 3, } 5\end{array}$ \\
\hline $\begin{array}{l}\text { Type } \\
\text { Use Area } \\
\text { LUD } \\
\text { ROS } \\
\text { Acres }\end{array}$ & $\begin{array}{l}\text { Enclave } \\
\text { 04-04A } \\
\text { Timber Production } \\
\text { Roaded Modified } \\
72\end{array}$ \\
\hline $\begin{array}{l}\text { General } \\
\text { Characteristics }\end{array}$ & $\begin{array}{l}\text { The immediate area is forested. A small bight of land to the west } \\
\text { provides some protection for anchoring. Timber harvest is evident in } \\
\text { the vicinity. Walking along the forest edge and inside the beach } \\
\text { fringe is possible along wildlife trails. Beach fringes have large Sitka } \\
\text { Spruce and small root mass ponds with interesting vegetation and } \\
\text { successional stages. Intertidal life along the pebble shoreline can be } \\
\text { viewed at low tide. }\end{array}$ \\
\hline Historical Use & Commercial outfitting and guiding did not occur here in 1999. \\
\hline Access & $\begin{array}{l}\text { The anchorage is exposed on Peril Straits but is suitable in good } \\
\text { weather. Skiffs can land along the pebble beach; the exact location } \\
\text { depends on the tide stage. }\end{array}$ \\
\hline Facilities & None \\
\hline Attractions & $\begin{array}{l}\text { A nice small beach can be walked at low tide. There is a large beach } \\
\text { fringe forest. }\end{array}$ \\
\hline Mitigation & $\begin{array}{l}\text { - See Appendix } C \text { for mitigation measures. } \\
\text { - Bald eagles } \\
\text { - Regetation } \\
\text { - Riparian } \\
\text { Brown bear viewing }\end{array}$ \\
\hline
\end{tabular}




\section{Island}

\section{Baranof}

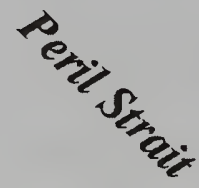

Island
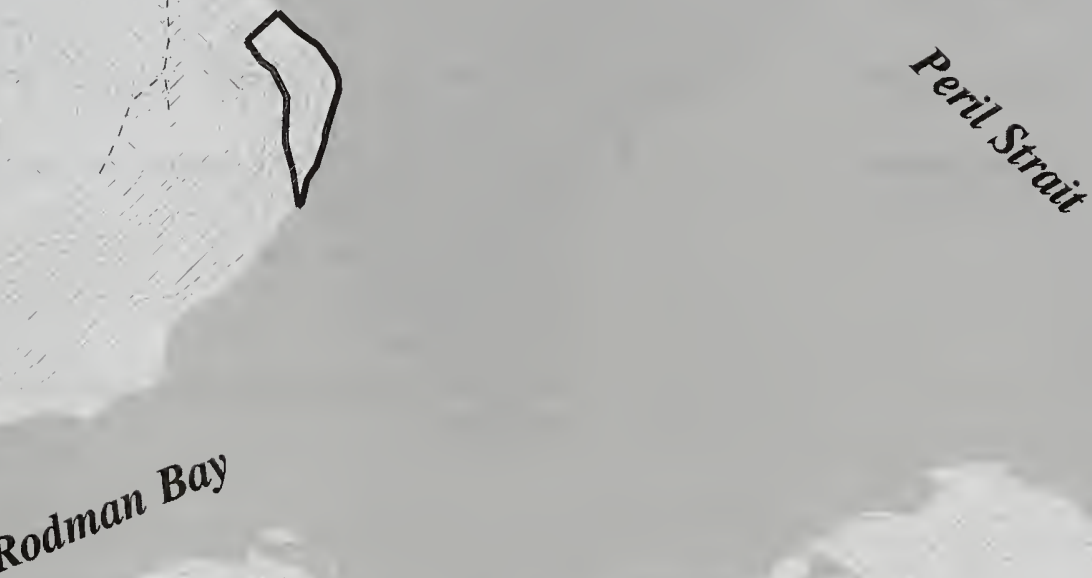

\section{$\checkmark$ Large Group Area Boundary Streams \\ Existing Road}

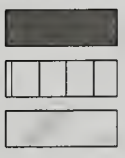

Non National Forest Land

Wilderness

Outside of Project Area
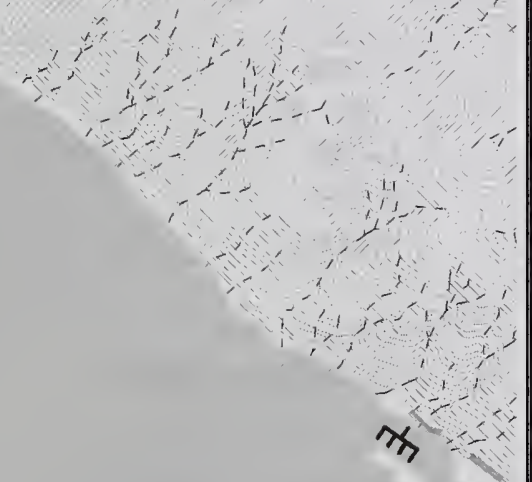


\section{Appendix B, Large Group Areas}

\begin{tabular}{|c|c|}
\hline & $\begin{array}{l}\text { Large Group Area } \\
\text { Rodman Bay } \\
\text { Alternatives 3, 4, } 5\end{array}$ \\
\hline $\begin{array}{l}\text { Type } \\
\text { Use Area } \\
\text { LUD } \\
\text { ROS } \\
\text { Acres } \\
\end{array}$ & $\begin{array}{l}\text { Enclave } \\
\text { 04-04A } \\
\text { Timber Production } \\
\text { Roaded Modified } \\
252 \\
\end{array}$ \\
\hline $\begin{array}{l}\text { General } \\
\text { Characteristics }\end{array}$ & $\begin{array}{l}\text { The area was harvested in the } 1960 \text { 's. The harvested areas are } \\
\text { regenerating with spruce and hemlock and the road is overgrown with } \\
\text { alder. }\end{array}$ \\
\hline Historical Use & $\begin{array}{l}\text { Logging took place in the } 1960 \text { 's. Commercial outfitter/guides used } \\
\text { this area in } 1999 .\end{array}$ \\
\hline Access & $\begin{array}{l}\text { The anchorage is protected during most weather conditions. Skiffs } \\
\text { can land on the beach at most tidal stages. }\end{array}$ \\
\hline Facilities & Road, marine access point \\
\hline Attractions & Wildlife viewing, hiking on the beach and road \\
\hline Mitigation & $\begin{array}{l}\text { - See Appendix C for mitigation measures. } \\
\text { - Bald eagles } \\
\text { - Brown bear viewing } \\
\text { - Regetation } \\
\text { - Guiparian } \\
\text { activities. }\end{array}$ \\
\hline
\end{tabular}




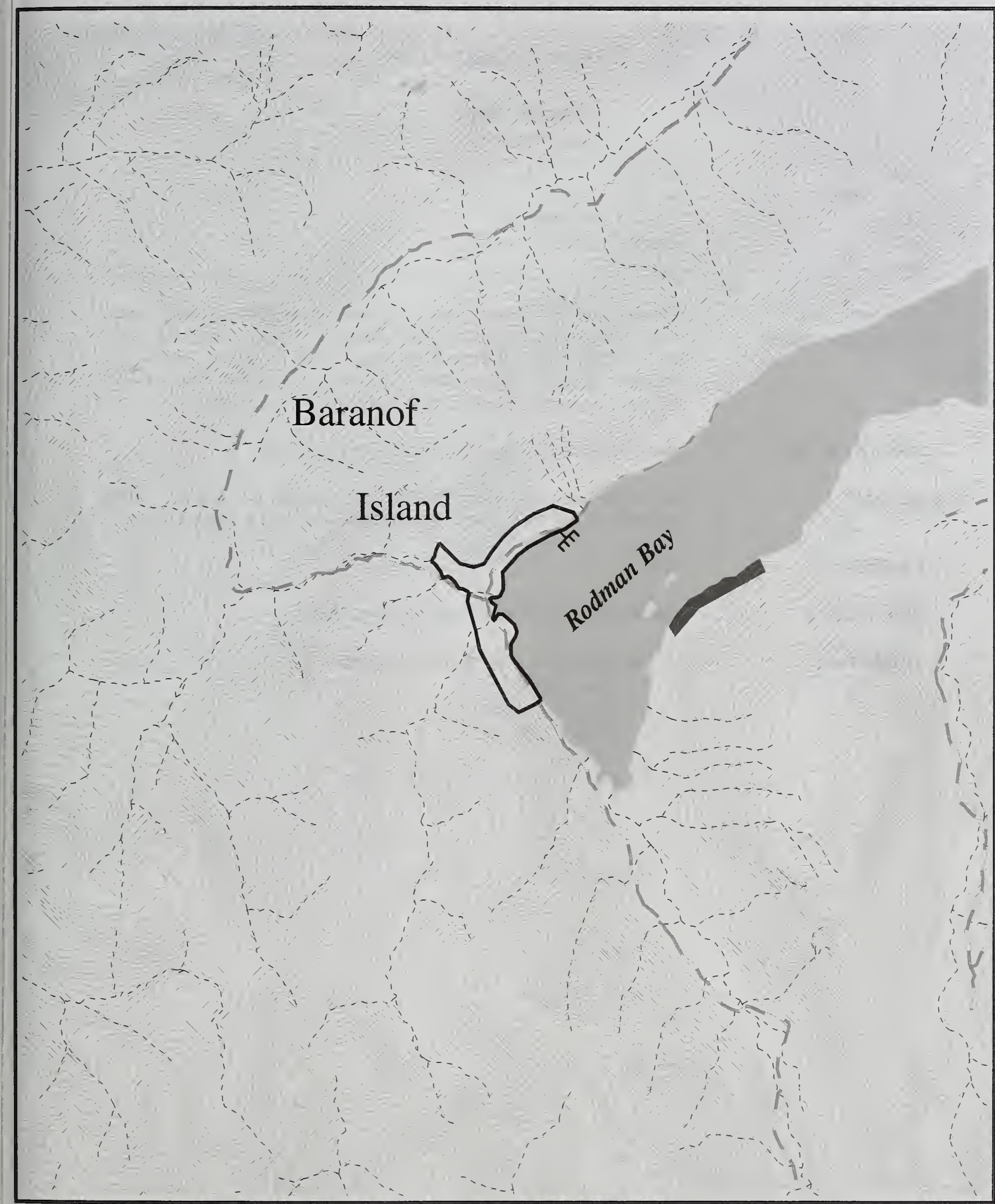

Large Group Area Boundary Streams

Existing Road
Non National Forest Land

Wilderness

Outside of Project Area

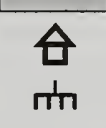

Salt and Fresh Water

Recreation Cabin

Marine Access Point

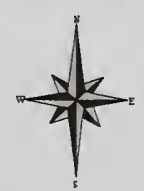

0.5

1 


\section{Appendix B, Large Group Areas}

\begin{tabular}{|c|c|}
\hline & $\begin{array}{l}\text { Large Group Area } \\
\text { Saook Bay } \\
\text { Alternatives 3, } 5\end{array}$ \\
\hline $\begin{array}{l}\text { Type } \\
\text { Use Area } \\
\text { LUD } \\
\text { ROS } \\
\text { Acres }\end{array}$ & $\begin{array}{l}\text { Enclave } \\
\text { 04-04A } \\
\text { Timber Production } \\
\text { Roaded Modified } \\
300 \\
\end{array}$ \\
\hline $\begin{array}{l}\text { General } \\
\text { Characteristics }\end{array}$ & $\begin{array}{l}\text { Broad meadows at end of fjord provide easy walking. Flowers and } \\
\text { vegetation are plentiful in the early summer. There is a wildlife trail } \\
\text { through large stand of trees at the head of the meadow, and bear } \\
\text { trails with obvious footprint paths. Salmon are present in a stream in } \\
\text { the late summer. There is timber harvest in the vicinity. }\end{array}$ \\
\hline Historical Use & Commercial outfitter/guides used this area in 1999. \\
\hline Access & $\begin{array}{l}\text { The anchorage is protected during most weather conditions. Skiffs } \\
\text { can land on the west side of the meadows next to a small stream. }\end{array}$ \\
\hline Facilities & None \\
\hline Attractions & Meadows at end of fjord, stand of large trees \\
\hline Mitigation & $\begin{array}{l}\text { - See Appendix } C \text { for mitigation measures. } \\
\text { - Bald eagles } \\
\text { - } \text { Marine mammals } \\
\text { - Riparian } \\
\text { - Brown bear viewing }\end{array}$ \\
\hline
\end{tabular}


Shoreline Outfitter/Guide EIS

Large Group Area

Use Area 04-04A SAOOK BAY

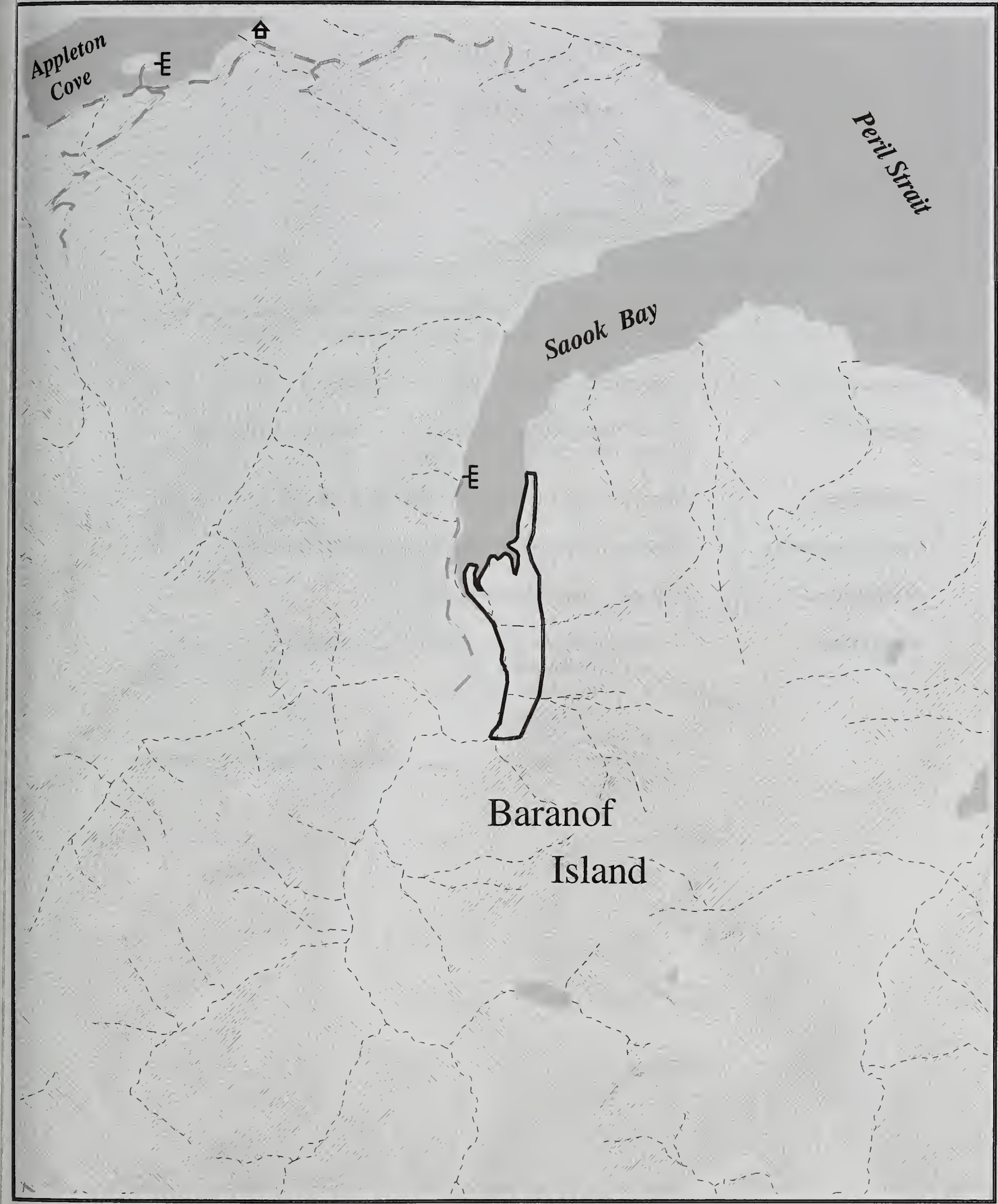

$\checkmark$ Large Group Area Boundary

Streams

Existing Road
Non National Forest Land

Wilderness

Outside of Project Area
Salt and Fresh Water

Recreation Cabin

Marine Access Point

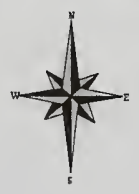

Contour Interval is 100 Feet

1

m 


\section{Appendix B, Large Group Areas}

\begin{tabular}{|c|c|}
\hline & $\begin{array}{l}\text { Large Group Area } \\
\text { Hanus Bay } \\
\text { Alternative } 3,5\end{array}$ \\
\hline $\begin{array}{l}\text { Type } \\
\text { Use Area } \\
\text { LUD } \\
\text { ROS } \\
\text { Acres }\end{array}$ & $\begin{array}{l}\text { Enclave } \\
04-04 \mathrm{~B} \\
\text { Scenic Viewshed } \\
\text { Roaded Modified } \\
278\end{array}$ \\
\hline $\begin{array}{l}\text { General } \\
\text { Characteristics }\end{array}$ & $\begin{array}{l}\text { There has been timber harvest in the area. A meadow at the back of } \\
\text { the bay reaches through to Portage Arm of Kelp Bay. }\end{array}$ \\
\hline Historical Use & Commercial outfitter/guides used this area in 1999. \\
\hline Access & $\begin{array}{l}\text { There is a protected anchorage. Skiff landings on the beach are } \\
\text { possible at most tides. }\end{array}$ \\
\hline Facilities & Road, marine access point, Forest Science Lab research cabin \\
\hline Opportunities & Interpretive opportunities for forest succession. \\
\hline Attractions & Hiking on road, wildlife viewing \\
\hline Mitigation & $\begin{array}{l}\text { - See Appendix } C \text { for mitigation measures. } \\
\text { - Bald eagles } \\
\text { - Vewn bear viewing } \\
\text { - Riparian } \\
\text { Guided activities must not interfere with other forest management } \\
\text { activities. }\end{array}$ \\
\hline
\end{tabular}


Shoreline Outfitter/Guide EIS

Large Group Area

Use Area 04-04B HANUS BAY

寻

\section{Peril Strait}

\section{Baranof \\ Island}

\section{Catherine is}

\section{Island}

\section{Middle Arm}

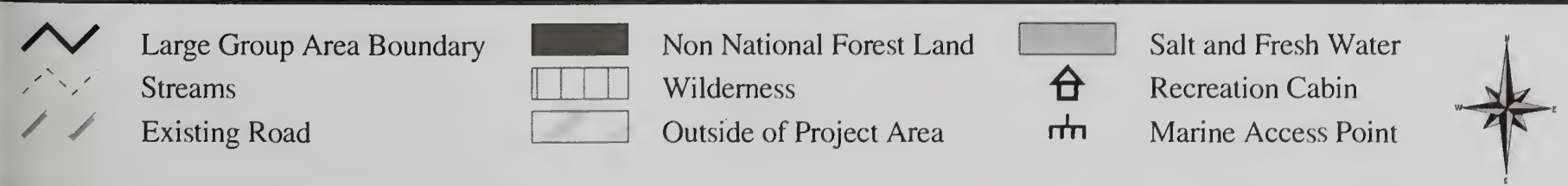

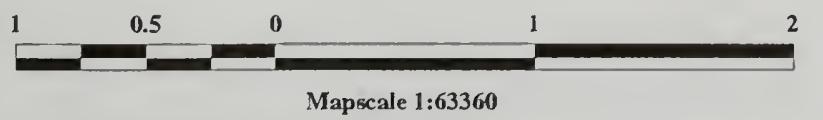




\section{Appendix B, Large Group Areas}

\begin{tabular}{|c|c|}
\hline & $\begin{array}{l}\text { Large Group Area } \\
\text { Kelp Bay - Middle Arm } \\
\text { Alternatives 3, 4, } 5\end{array}$ \\
\hline $\begin{array}{l}\text { Type } \\
\text { Use Area } \\
\text { LUD } \\
\text { ROS } \\
\text { Acres } \\
\end{array}$ & $\begin{array}{l}\text { Enclave } \\
04-04 B \\
\text { Semi-Remote Recreation } \\
\text { Primitive } \\
468\end{array}$ \\
\hline $\begin{array}{l}\text { General } \\
\text { Characteristics }\end{array}$ & $\begin{array}{l}\text { Timber has been harvested at Bourbon Creek but the back of the bay } \\
\text { is unaltered forest and logging is not visible. }\end{array}$ \\
\hline Historical Use & Commercial outfitter/guides used this area in 1999. \\
\hline Access & $\begin{array}{l}\text { A protected anchorage offers access to the beach during most tidal } \\
\text { stages. During high tide or high stream flow, skiffs are able to travel } \\
\text { up a stream to land. }\end{array}$ \\
\hline Facilities & None \\
\hline Attractions & $\begin{array}{l}\text { There is an opportunity to view wildlife and walk along a stream or } \\
\text { beach fringe forest. }\end{array}$ \\
\hline Mitigation & $\begin{array}{l}\text { - See Appendix } C \text { for mitigation measures. } \\
\text { - Marine mammals } \\
\text { - Bawn bear viewing } \\
\text { - Riparian } \\
\text { - Vegetation } \\
\text { activities. }\end{array}$ \\
\hline
\end{tabular}


Shoreline Outfitter/Guide EIS

Large Group Area

Use Area 04-04B KELP BAY MIDDLE ARM

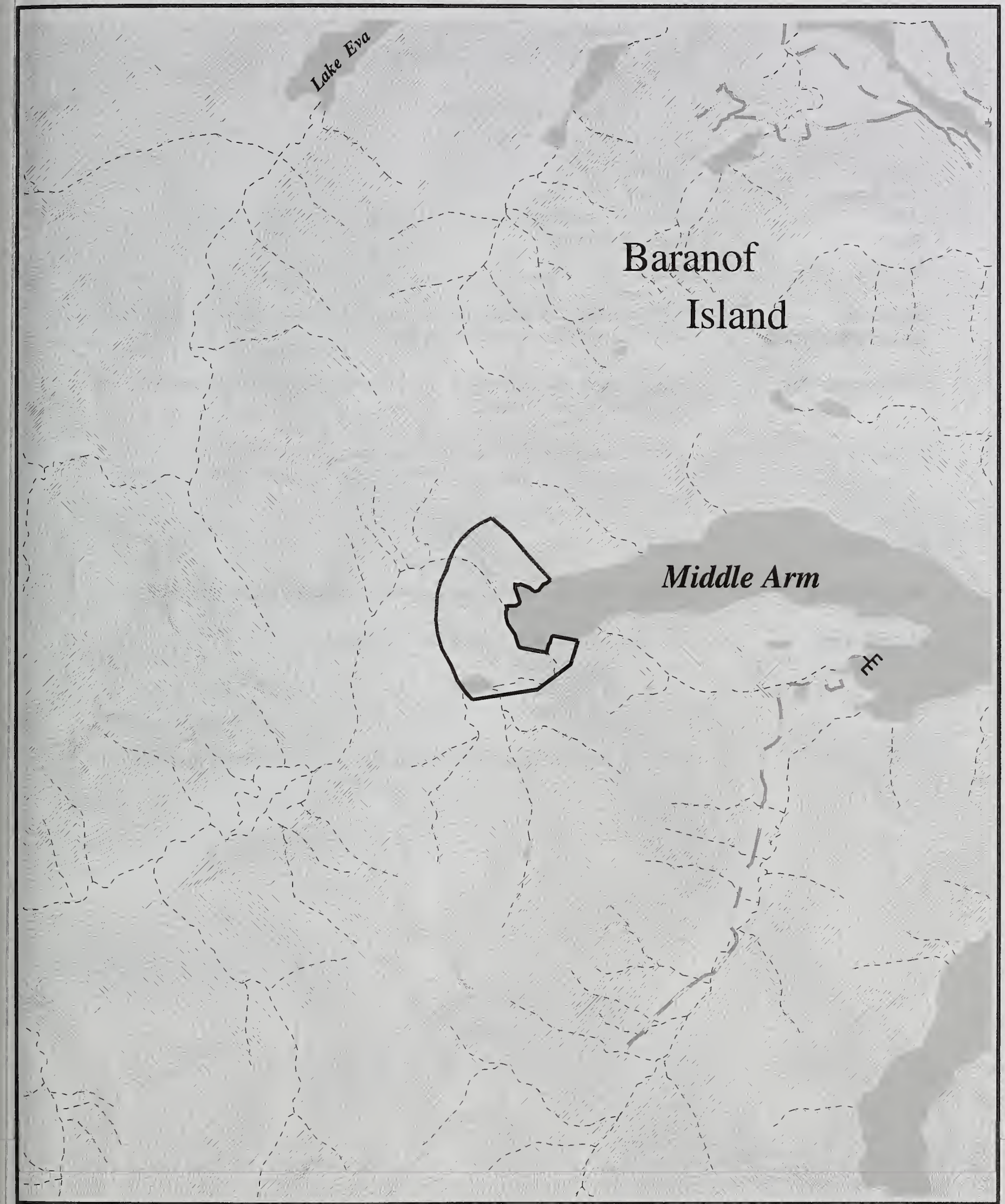

Large Group Area Boundary Streams

Existing Road
Non National Forest Land

Wilderness

Outside of Project Area
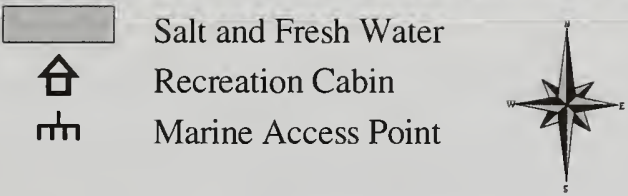

Contour Interval is 100 Feet 


\section{Appendix B, Large Group Areas}

\begin{tabular}{|c|c|}
\hline & $\begin{array}{l}\text { Large Group Area } \\
\text { Portage Arm } \\
\text { Alternative } 3\end{array}$ \\
\hline $\begin{array}{l}\text { Type } \\
\text { Use Area } \\
\text { LUD } \\
\text { ROS } \\
\text { Acres }\end{array}$ & $\begin{array}{l}\text { Enclave } \\
\text { 04-04B } \\
\text { Modified Landscape, Scenic Viewshed, Timber Production } \\
\text { Roaded Modified } \\
424\end{array}$ \\
\hline $\begin{array}{l}\text { General } \\
\text { Characteristics }\end{array}$ & $\begin{array}{l}\text { Timber harvest is in the vicinity. The meadow at the back of Portage } \\
\text { Arm reaches through to Hanus Bay. }\end{array}$ \\
\hline Historical Use & $\begin{array}{l}\text { Logging took place in this area. Commercial outfitting/guiding did not } \\
\text { occur in this area in } 1999 .\end{array}$ \\
\hline Access & $\begin{array}{l}\text { Strong westerly winds blow through the portage creating a poor } \\
\text { anchorage. The location for landing a skiff is dependent on the tidal } \\
\text { stage. }\end{array}$ \\
\hline Facilities & Roads \\
\hline Attractions & Wildlife viewing, hiking in meadows or along beach fringe forest \\
\hline Mitigation & $\begin{array}{l}\text { - See Appendix } C \text { for mitigation measures. } \\
\text { - Bald eagles } \\
\text { - Brown bear viewing } \\
\text { - Riparian } \\
\text { Guided activities must not interfere with other forest management } \\
\text { activities. }\end{array}$ \\
\hline
\end{tabular}




\section{Peril Strait}

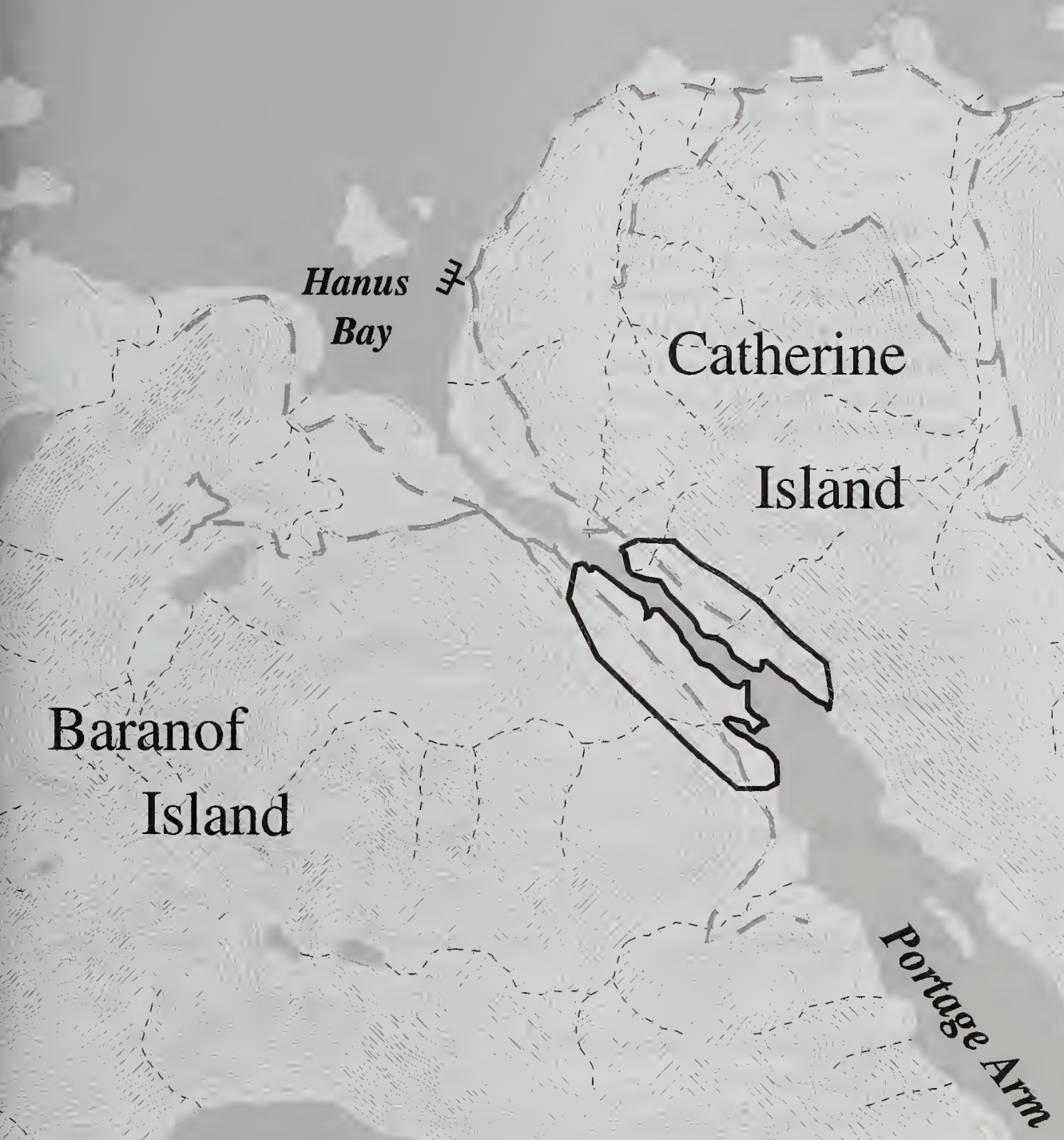

\section{Middle Arm}

Non National Forest Land

Wilderness

Outside of Project Area
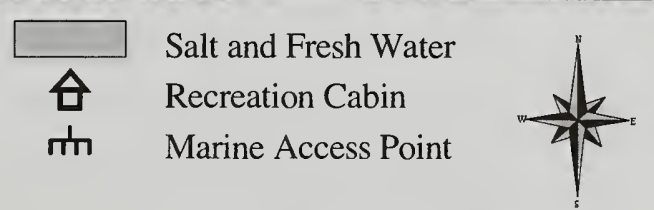

Contour Interval is 100 Feet 


\section{Appendix B, Large Group Areas}

\begin{tabular}{|c|c|}
\hline & $\begin{array}{l}\text { Large Group Area } \\
\text { Cordwood Creek } \\
\text { Alternatives 3, } 5\end{array}$ \\
\hline $\begin{array}{l}\text { Type } \\
\text { Use Area } \\
\text { LUD } \\
\text { ROS } \\
\text { Acres }\end{array}$ & $\begin{array}{l}\text { Enclave } \\
04-08 \\
\text { Semi-Remote Recreation } \\
\text { Semi-Primitive Motorized } \\
48 \\
\end{array}$ \\
\hline $\begin{array}{l}\text { General } \\
\text { Characteristics }\end{array}$ & $\begin{array}{l}\text { Cordwood Creek is a small, tannic creek that drains an inland } \\
\text { muskeg lake on the west side of the Mansfield Peninsula on } \\
\text { Admiralty Island. The site generally has a } 40 \text {-yard-wide flat portion } \\
\text { inside the trees that rises steeply to an uplifted beach. Shoreline near } \\
\text { the outflow is rocky but becomes flatter with large trees along the } \\
\text { shoreline. There is a very narrow fringe of beach grass and forbs } \\
\text { between the gravel and tree line for the whole site. }\end{array}$ \\
\hline Historical Use & $\begin{array}{l}\text { There was no reported commercial use in } 1999 \text {. Unguided } \\
\text { recreationists use this area. Logging has previously occurred in the } \\
\text { area. }\end{array}$ \\
\hline Access & $\begin{array}{l}\text { Although the cove faces southwest on the east side of Lynn Canal it } \\
\text { is large enough to provide some protection. The beach has large } \\
\text { cobble and gravel in the central part of the cove. }\end{array}$ \\
\hline Facilities & None \\
\hline $\begin{array}{l}\text { Concerns and/or } \\
\text { Opportunities }\end{array}$ & Cordwood Creek is exposed to certain winds. \\
\hline Attractions & $\begin{array}{l}\text { Opportunities for a beach walk on northern Admiralty Island and } \\
\text { fishing. }\end{array}$ \\
\hline Mitigation & $\begin{array}{l}\text { - See Appendix } C \text { for mitigation measures. } \\
\text { - Riparian } \\
\text { - Begetation } \\
\text { - Bald eagles } \\
\text { Cultural sites will be avoided }\end{array}$ \\
\hline
\end{tabular}




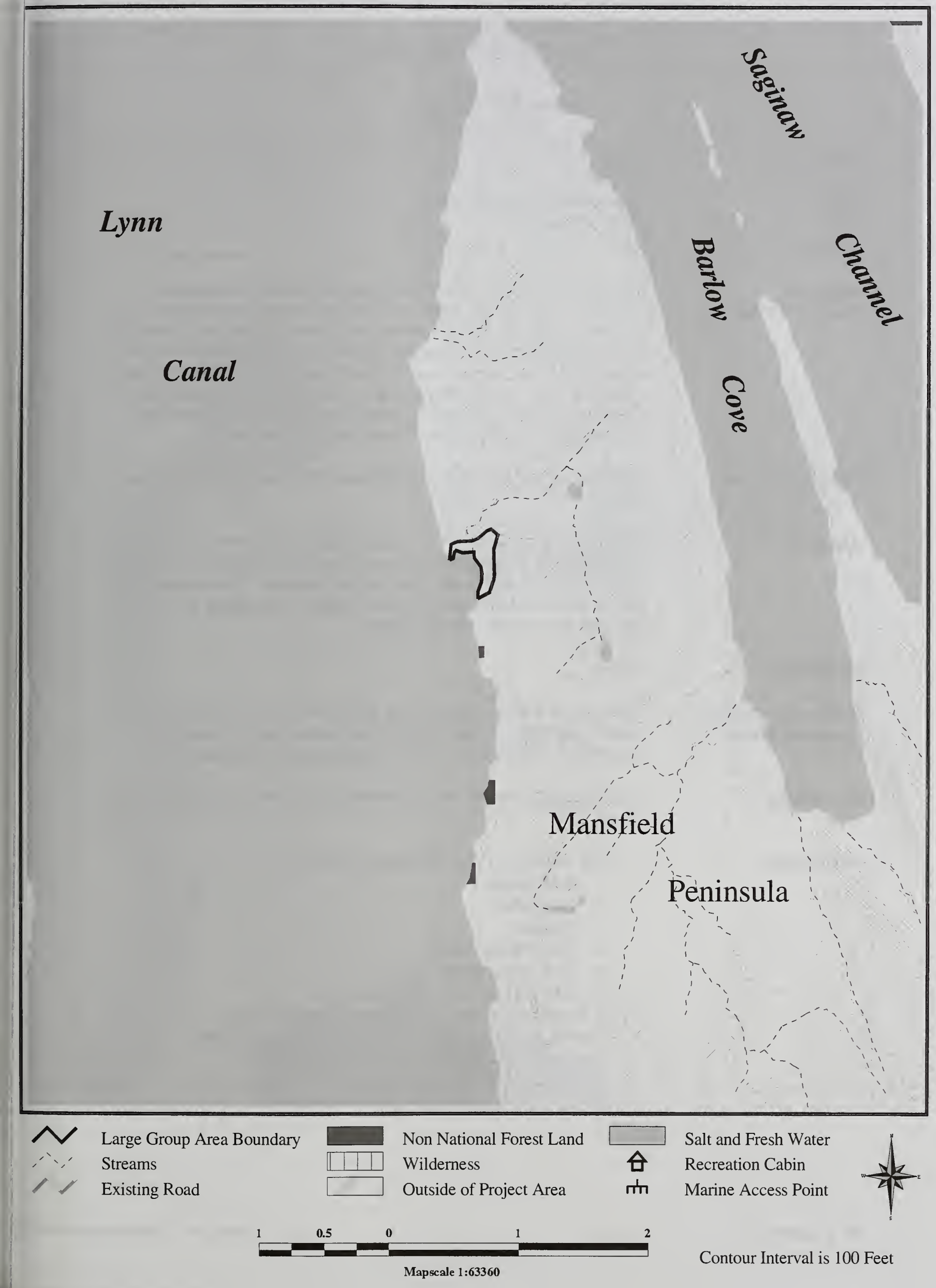




\section{Appendix B, Large Group Areas}

\section{Large Group Area}

\section{Fowler Creek}

Alternative 3, 5

\begin{tabular}{ll} 
Type & Enclave \\
Use Area & $04-08$ \\
LUD & Semi-Remote Recreation \\
ROS & Roaded Natural \\
Acres & 42 \\
\hline
\end{tabular}

\section{General Characteristics}

Historical Use

Access

Facilities

Concerns and/or Opportunities

\section{Attractions}

Mitigation
This site is located at the base of the Mansfield Peninsula on Admiralty Island. The area has a fairly large tide flat comprised of cobble and gravel. Within the tree line there is a flat area, about 20 yards wide, with large trees that slopes to an uplifted beach area. A raised gravel bar at the mouth of the creek occurs on the north side. The south side of the creek has a raised spit slightly further inland that offers a good view up the creek, and a large meadow area marked by fingers of spruce that extend into the meadow.

There is no reported commercial use in 1999 and no sign of other use.

Visitation will be weather-dependent due to wind exposure. Because of the tide flat, the best access would be at the northern or southern ends of the site where the beach is the steepest. Once ashore, the terrain is flat and provides for good walking. The creek is not deep and can be crossed without waders.

None

This area is a local hunting area. Because of limited visibility into the main creek stem, some caution is warranted due to potential bear/human interactions. There is a private parcel nearby.

Good opportunities for wildlife viewing, particularly shorebirds and bears.

- See Appendix $\mathrm{C}$ for mitigation measures

- Bald eagles

- Vegetation

- Riparian

- Brown bear viewing

- No large group camping.

- No consumptive uses by large groups.

- Outfitter/guides will not trespass on private land.

- Guided activities must not interfere with other forest management activities. 


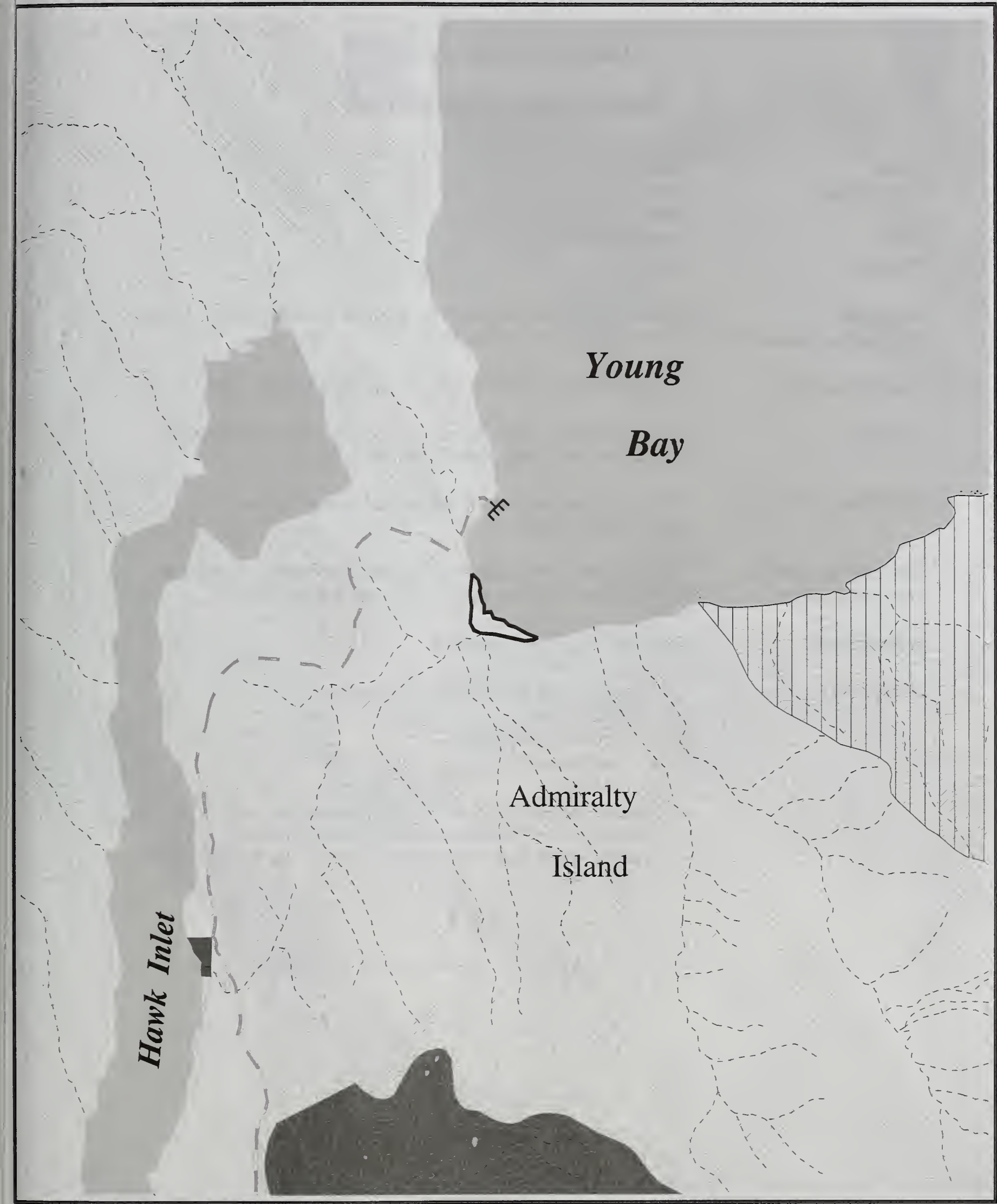

Non National Forest Land Wilderness

Outside of Project Area
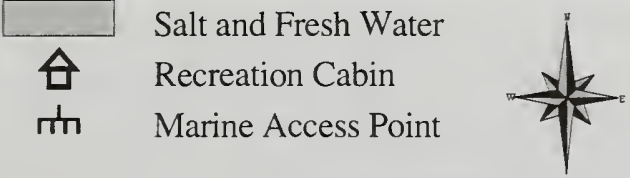


\section{Appendix B, Large Group Areas}

\begin{tabular}{|c|c|}
\hline & $\begin{array}{c}\text { Large Group Areas } \\
\text { Eight-Fathom Dock Area } \\
\text { Alternatives } 3,5\end{array}$ \\
\hline $\begin{array}{l}\text { Type } \\
\text { Use Area } \\
\text { LUD } \\
\text { ROS } \\
\text { Acres }\end{array}$ & $\begin{array}{l}\text { Enclave } \\
04-11 \\
\text { Scenic Viewshed } \\
\text { Roaded Modified } \\
110\end{array}$ \\
\hline $\begin{array}{l}\text { General } \\
\text { Characteristics }\end{array}$ & $\begin{array}{l}\text { The site was previously used as a timber transfer facility. It has a } \\
\text { scenic setting in 8-Fathom Bay. }\end{array}$ \\
\hline Historical Use & No commercial outfitter/guide use occurred here in 1999. \\
\hline Access & $\begin{array}{l}\text { It is sixteen miles from Hoonah. The dock accommodates } \\
\text { floatplanes and boats up to } 35 \text { feet in length. }\end{array}$ \\
\hline Facilities & $\begin{array}{l}\text { There is a road, a Forest Service bunkhouse, and an } \\
\text { administrative dock }\end{array}$ \\
\hline $\begin{array}{l}\text { Concerns and/or } \\
\text { Opportunities }\end{array}$ & $\begin{array}{l}\text { The hardened site will sustain repeated foot traffic. There are } \\
\text { opportunities for interpretation on forest management. }\end{array}$ \\
\hline Attractions & Scenic setting, wildlife viewing \\
\hline Mitigation & $\begin{array}{l}\text { - See Appendix C for mitigation measures. } \\
\text { - Bald eagles } \\
\text { - Vegn bear viewing } \\
\text { - Riparian } \\
\text { - Guided recreationists will not block use of the dock or } \\
\text { interfe with other forest management activities. } \\
\text { Outfitter/guide boats will not tie directly to the dock or be left } \\
\text { unattended. }\end{array}$ \\
\hline
\end{tabular}




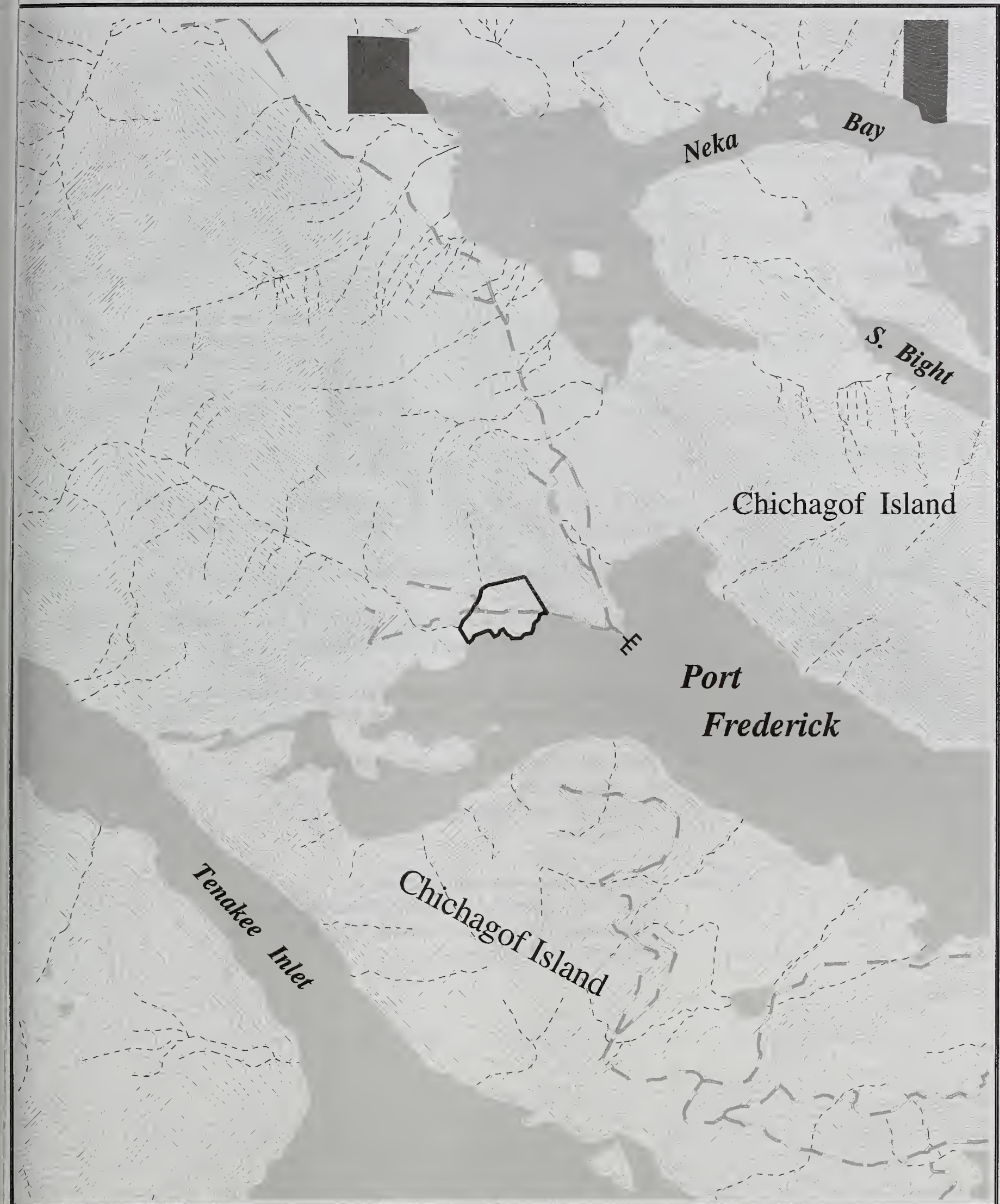

$\checkmark$ Large Group Area Boundary Streams

Existing Road
Non National Forest Land

Wilderness

Outside of Project Area

\begin{tabular}{cl}
\hline & Salt and Fresh Water \\
ㅁ & Recreation Cabin \\
皿 & Marine Access Point
\end{tabular}

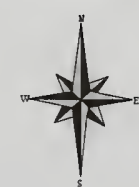




\begin{tabular}{|c|c|}
\hline & $\begin{array}{l}\text { Large Group Areas } \\
\text { Kennel Creek } \\
\text { Alternative } 3,5\end{array}$ \\
\hline $\begin{array}{l}\text { Type } \\
\text { Use Area } \\
\text { LUD } \\
\text { ROS } \\
\text { Acres }\end{array}$ & $\begin{array}{l}\text { Enclave } \\
04-11 \\
\text { Scenic Viewshed } \\
\text { Roaded Modified } \\
73\end{array}$ \\
\hline $\begin{array}{l}\text { General } \\
\text { Characteristics }\end{array}$ & $\begin{array}{l}\text { This area is centrally located in Freshwater Bay. The site was } \\
\text { previously used as a logging camp and a timber transfer facility. } \\
\text { This site regenerating naturally. The area offers excellent views } \\
\text { of Freshwater Bay, Chatham Strait, Admiralty Island, and the } \\
\text { mountain peaks above Juneau. It is adjacent to Kennel Creek. }\end{array}$ \\
\hline Historical Use & No commercial outfitter/guide use occurred here in 1999. \\
\hline Access & $\begin{array}{l}\text { The area may be accessed from Forest Road } 8508 \text {. The dock } \\
\text { accommodates floatplanes and boats up to } 35 \text { feet in length. }\end{array}$ \\
\hline Facilities & Road, marine access point, Forest Service bunkhouse, dock \\
\hline $\begin{array}{l}\text { Concerns and/or } \\
\text { Opportunities }\end{array}$ & $\begin{array}{l}\text { The hardened site will sustain repeated foot traffic. There are } \\
\text { opportunities to interpret forest management activities. }\end{array}$ \\
\hline Attractions & $\begin{array}{l}\text { It has a scenic setting, with opportunities for wildlife viewing } \\
\text { (especially brown bear), and anadromous fisheries. }\end{array}$ \\
\hline Mitigation & $\begin{array}{l}\text { - See Appendix C for mitigation measures. } \\
\text { - Bald eagles } \\
\text { - Rrown bear viewing } \\
\text { - Vegetation } \\
\text { - Users will not block use of the dock. } \\
\text { - Gutfitter/guide boats will not tie directly to the dock. } \\
\text { management activities. }\end{array}$ \\
\hline
\end{tabular}


Shoreline Outfitter/Guide EIS

Large Group Area

Use Area 04-11 KENNEL CREEK

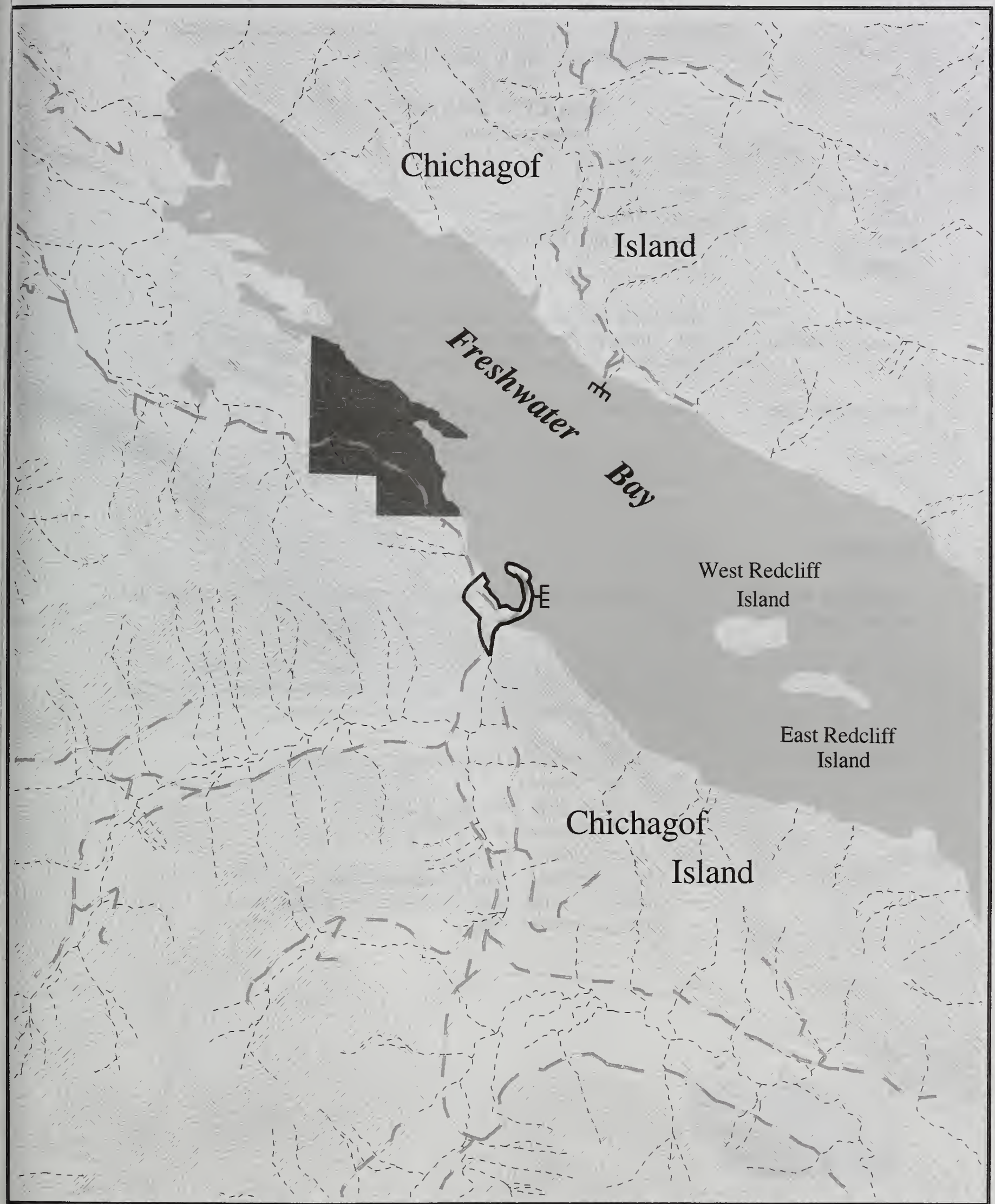

$\checkmark$ Large Group Area Boundary Streams

Existing Road
Non National Forest Land

Wilderness

Outside of Project Area $\begin{array}{cl} & \text { Salt and Fresh Water } \\ \text { ㅁ } & \text { Recreation Cabin } \\ \text { mn } & \text { Marine Access Point }\end{array}$

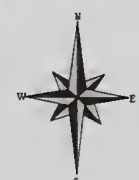




\section{Appendix B, Large Group Areas}

\begin{tabular}{|c|c|}
\hline & $\begin{array}{l}\text { Large Group Areas } \\
\text { Red Cliff Islands } \\
\text { Alternatives } 3,5\end{array}$ \\
\hline $\begin{array}{l}\text { Type } \\
\text { Use Area } \\
\text { LUD } \\
\text { ROS } \\
\text { Acres } \\
\end{array}$ & $\begin{array}{l}\text { Enclave } \\
04-11 \\
\text { Semi-Remote Recreation } \\
\text { Semi-Primitive Motorized } \\
119\end{array}$ \\
\hline $\begin{array}{l}\text { General } \\
\text { Characteristics }\end{array}$ & $\begin{array}{l}\text { This area features two isolated islands, East \& West Red Cliff, in } \\
\text { the middle of Freshwater Bay. There is an elevation rise of } 240 \\
\text { feet with scenic red cliffs. It does not receive much unguided use. }\end{array}$ \\
\hline Historical Use & No commercial outfitter/guide use occurred here in 1999. \\
\hline Access & $\begin{array}{l}\text { It is six miles from entrance of Freshwater Bay with good protected } \\
\text { anchorage, and two miles from Kennel Creek float dock and } \\
\text { Hoonah road system. }\end{array}$ \\
\hline Facilities & None \\
\hline $\begin{array}{l}\text { Concerns and/or } \\
\text { Opportunities }\end{array}$ & $\begin{array}{l}\text { Private float house at this site. Seal and/or sea lion haul outs in the } \\
\text { vicinity. }\end{array}$ \\
\hline Attractions & $\begin{array}{l}\text { This area has a scenic setting, with excellent views across } \\
\text { Chatham Strait of Admiralty Island and mainland mountains behind } \\
\text { Juneau. There are wildlife viewing opportunities. }\end{array}$ \\
\hline Mitigation & $\begin{array}{l}\text { - See Appendix } C \text { for mitigation measures. } \\
\text { - Bald eagles } \\
\text { - Mrown bear viewing } \\
\text { - No large group camping. } \\
\text { - } \quad \text { Go consumptive uses by large groups. } \\
\text { management activities. }\end{array}$ \\
\hline
\end{tabular}




\section{Chichagof}
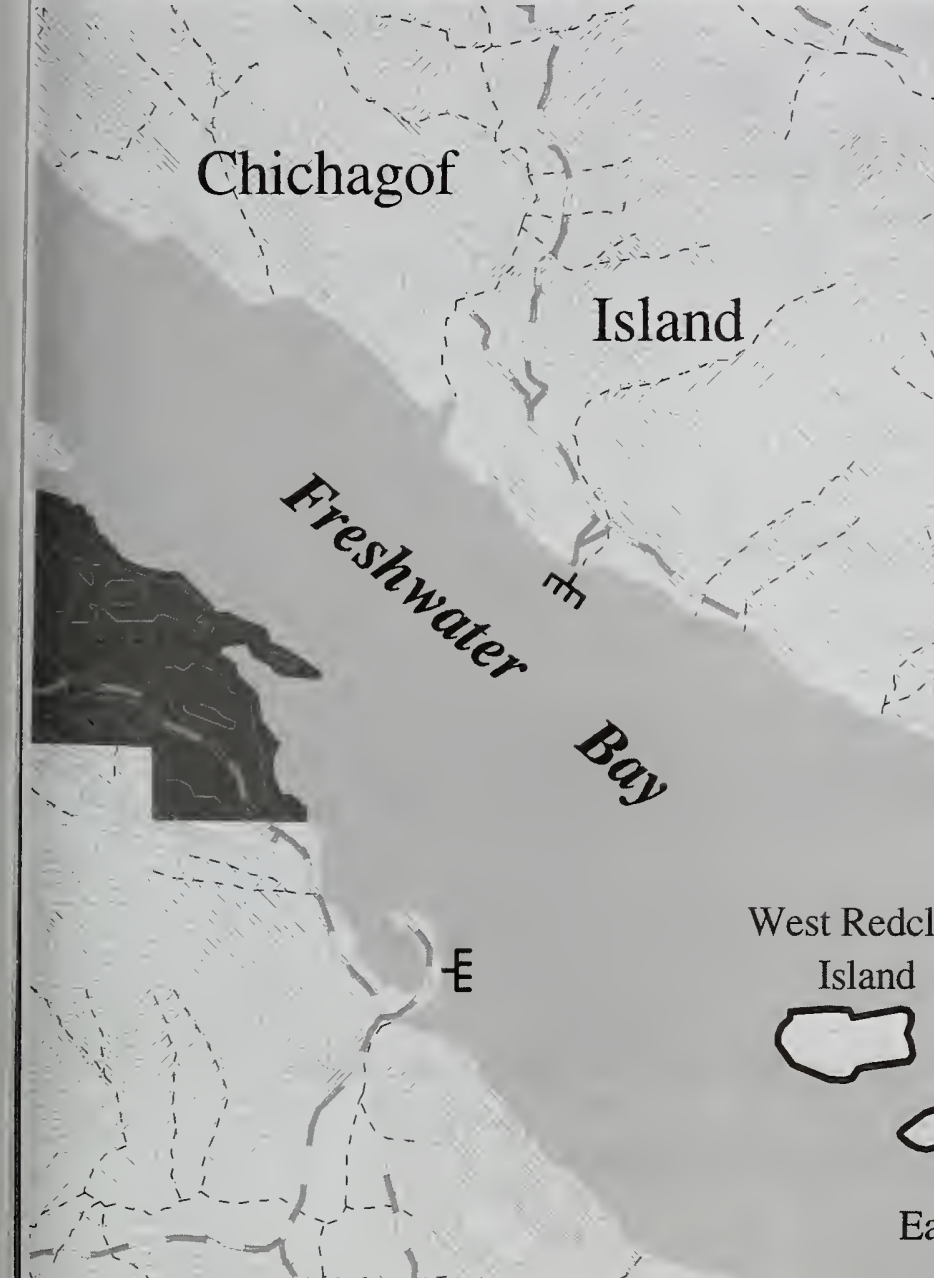

West Redcliff

Island

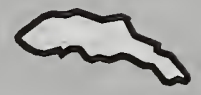

East Redcliff

Island

\section{Chichagof}

Island

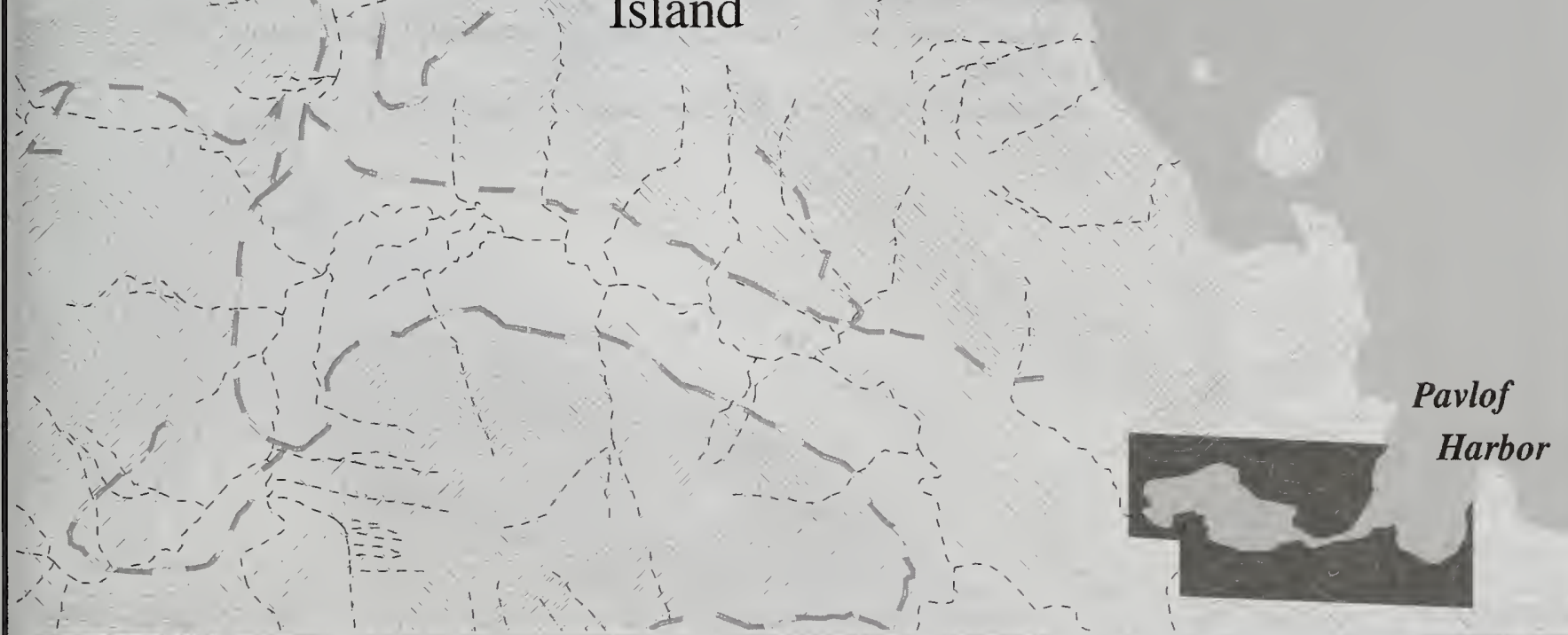

$\checkmark$ Large Group Area Boundary Streams

Existing Road
Non National Forest Land Wilderness

Outside of Project Area

$\begin{array}{ll} & \text { Salt and Fresh Water } \\ \text { ㅁ } & \text { Recreation Cabin } \\ \text { in } & \text { Marine Access Point }\end{array}$

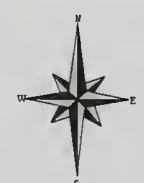

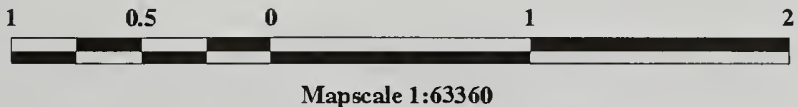




\section{Appendix B, Large Group Areas}

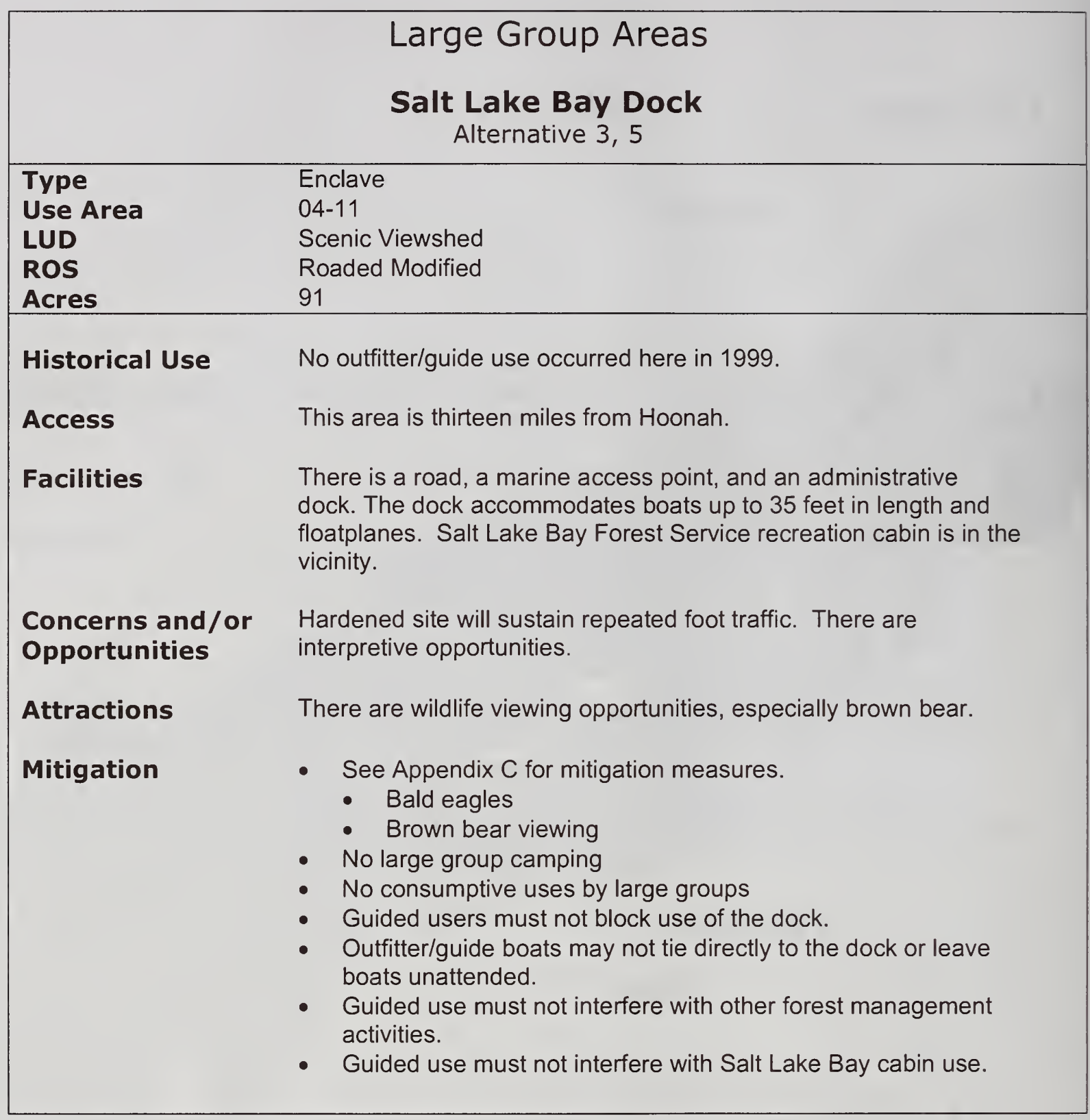


Shoreline Outfitter/Guide EIS

Large Group Area

Use Area 04-11 SALT LAKE BAY DOCK
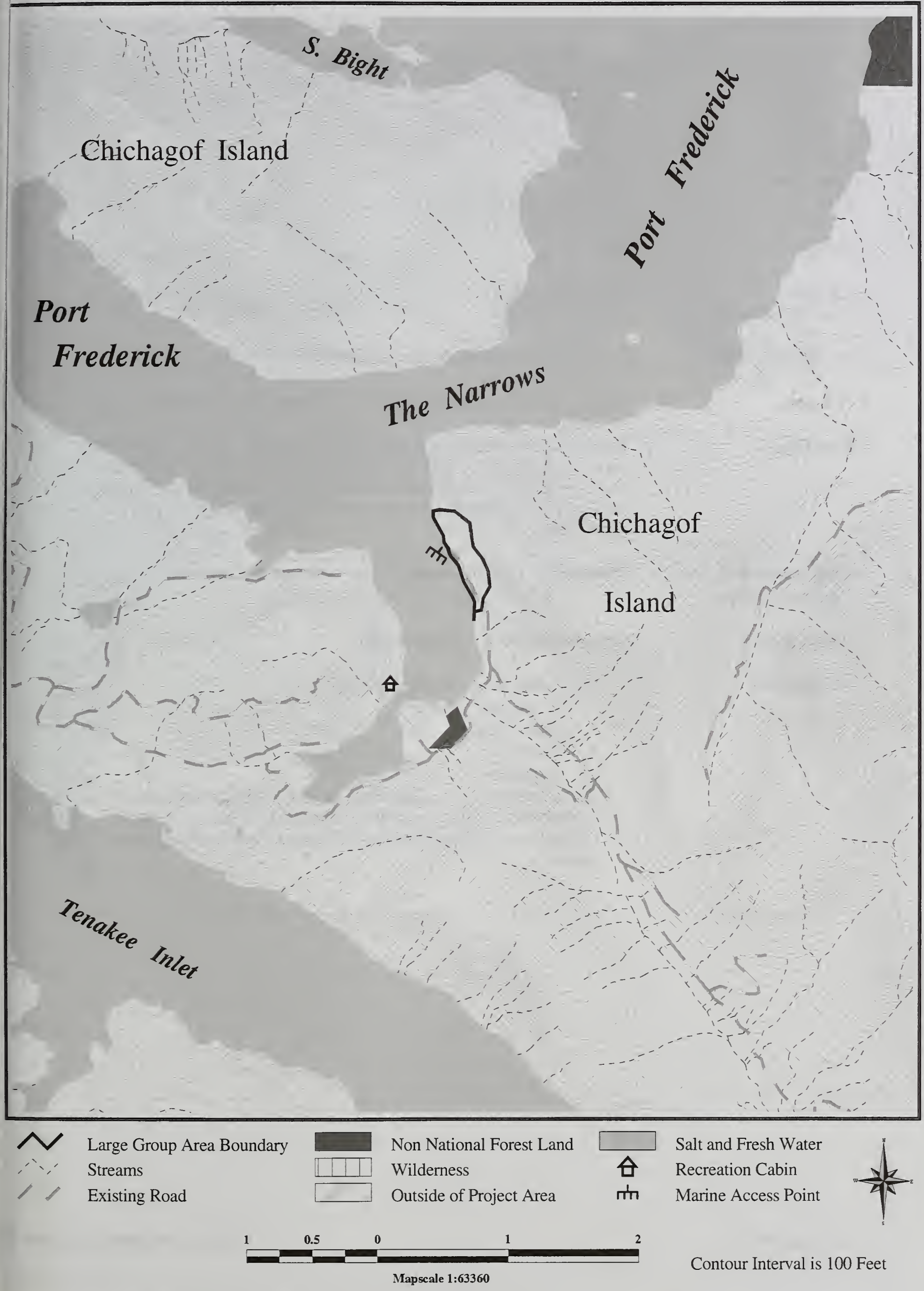


\section{Appendix B, Large Group Areas}

\begin{tabular}{|c|c|}
\hline & $\begin{array}{l}\text { Large Group Area } \\
\text { Corner Bay Road } \\
\text { Alternatives } 3,4,5\end{array}$ \\
\hline $\begin{array}{l}\text { Type } \\
\text { Use Area } \\
\text { LUD } \\
\text { ROS } \\
\text { Acres }\end{array}$ & $\begin{array}{l}\text { Enclave } \\
04-12 \\
\text { Scenic Viewshed, Timber Production } \\
\text { Roaded Modified } \\
398\end{array}$ \\
\hline $\begin{array}{l}\text { General } \\
\text { Characteristics }\end{array}$ & $\begin{array}{l}\text { Timber has been harvested from this area. There are managed } \\
\text { stands of timber with a variety of silvicultural treatments. }\end{array}$ \\
\hline Historical Use & Commercially guided groups used this area in 1999. \\
\hline Access & Many miles of road are suitable for high clearance vehicles. \\
\hline Facilities & $\begin{array}{l}\text { This area has a road and a marine access point. The Forest Service } \\
\text { maintains a dock at Corner Bay where boats and floatplanes may tie } \\
\text { up. Corner Bay is the site of a Forest Service administrative site that } \\
\text { consists of a bunkhouse, garage, water system, and electrical } \\
\text { generator. }\end{array}$ \\
\hline $\begin{array}{l}\text { Concerns and/or } \\
\text { Opportunities }\end{array}$ & There are interpretive opportunities for forest management. \\
\hline Attractions & Hiking, sightseeing, wildlife viewing \\
\hline Mitigation & $\begin{array}{l}\text { - See Appendix C for mitigation measures. } \\
\text { - Brown bear viewing } \\
\text { - Rald eagles } \\
\text { - } \text { Regrian } \\
\text { - Guided use of Corner Bay dock is permitted but guides must not } \\
\text { leave boats unattended or interfere with administrative use. } \\
\text { Guided use must not interfere with other forest management } \\
\text { activities. }\end{array}$ \\
\hline
\end{tabular}




\section{Appendix B, Large Group Areas}

\begin{tabular}{|c|c|}
\hline & $\begin{array}{l}\text { Large Group Areas } \\
\text { Crab Bay } \\
\text { Alternative } 3\end{array}$ \\
\hline $\begin{array}{l}\text { Type } \\
\text { Use Area } \\
\text { LUD } \\
\text { ROS } \\
\text { Acres } \\
\end{array}$ & $\begin{array}{l}\text { Enclave } \\
04-12 \\
\text { Timber Production } \\
\text { Semi-Primitive Motorized / Roaded Modified } \\
769\end{array}$ \\
\hline $\begin{array}{l}\text { General } \\
\text { Characteristics }\end{array}$ & $\begin{array}{l}\text { Large tide and grass flats characterize this area. Timber was } \\
\text { harvested in the general vicinity. }\end{array}$ \\
\hline Historical Use & $\begin{array}{l}\text { This area was used for logging. Outfitter/guides used this area in } \\
1999 .\end{array}$ \\
\hline Access & $\begin{array}{l}\text { There is a protected anchorage with several possible landing areas } \\
\text { for coming ashore, depending on the tide. }\end{array}$ \\
\hline Facilities & None \\
\hline Attractions & Opportunity to view wildlife and previous logging areas, hiking. \\
\hline Mitigation & $\begin{array}{l}\text { - See Appendix } C \text { for mitigation measures. } \\
\text { - Brown bear viewing } \\
\text { - Rald eagles } \\
\text { - Riparian } \\
\text { - Vegetation }\end{array}$ \\
\hline
\end{tabular}




\section{Saltery Bay}

\section{Crab Bay}

\section{Chichagof Island}

Large Group Area Boundary Streams

Existing Road
Non National Forest Land

Wilderness

Outside of Project Area
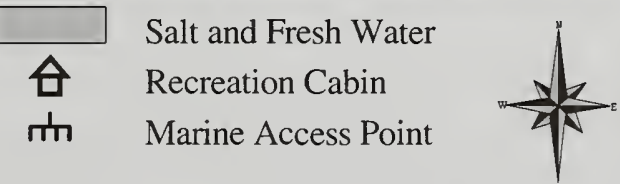

Contour Interval is 100 Feet 


\section{Appendix B, Large Group Areas}

\begin{tabular}{|c|c|}
\hline & $\begin{array}{c}\text { Large Group Area } \\
\text { West Tenakee - Goose Flats } \\
\text { Alternatives 3, 4, } 5\end{array}$ \\
\hline $\begin{array}{l}\text { Type } \\
\text { Use Area } \\
\text { LUD } \\
\text { ROS } \\
\text { Acres } \\
\end{array}$ & $\begin{array}{l}\text { Enclave } \\
04-12 \\
\text { Modified Landscape } \\
\text { Semi-Primitive Motorized } \\
300\end{array}$ \\
\hline $\begin{array}{l}\text { General } \\
\text { Characteristics }\end{array}$ & $\begin{array}{l}\text { Large tide and grass flat with old growth forest surrounding the area. } \\
\text { Behind the beach fringe timber is a large series of muskegs. }\end{array}$ \\
\hline Historical Use & Outfitter/guides used this area in 1999. \\
\hline Access & $\begin{array}{l}\text { Protected anchorage with several possible landing sites along shore } \\
\text { depending on tidal stage. Once on shore, there is easy walking } \\
\text { access to large tide and grass flat. }\end{array}$ \\
\hline Facilities & None \\
\hline Attractions & Large tide and grass flats, hiking, sightseeing \\
\hline Mitigation & $\begin{array}{l}\text { - See Appendix } C \text { for mitigation measures. } \\
\text { - Marine mammals } \\
\text { - Rald eagles } \\
\text { - Riparian } \\
\text { - Vegnetation }\end{array}$ \\
\hline
\end{tabular}




\section{Shoreline Outfitter/Guide EIS Large Group Area \\ Use Area 04-12 WEST TENAKEE (GOOSE FLATS)}
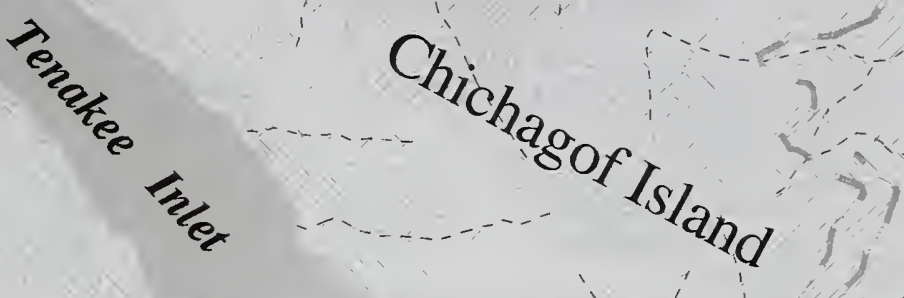

\section{Chichagof}

Island
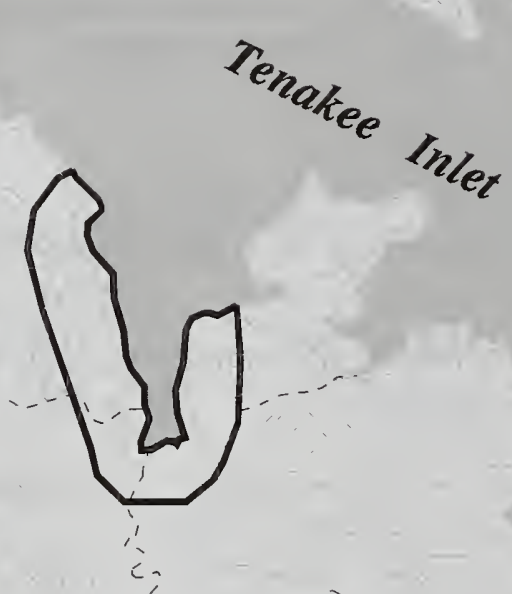

Large Group Area Boundary Streams

Existing Road
Non National Forest Land

Wilderness

Outside of Project Area
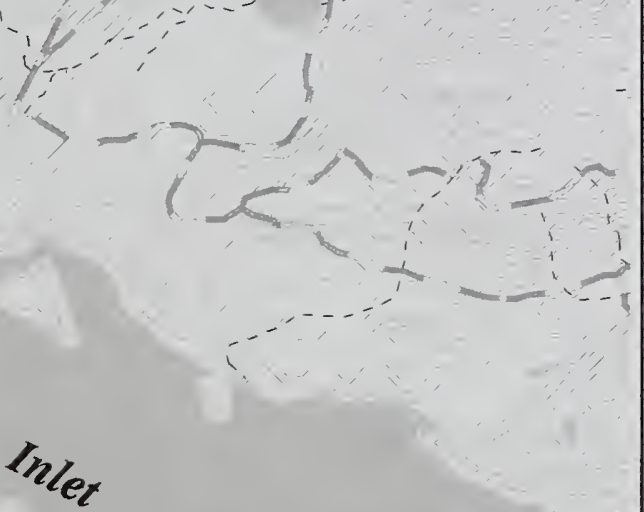

Salt and Fresh Water

Recreation Cabin

Marine Access Point

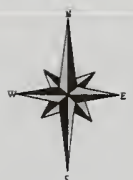




\section{Appendix B, Large Group Areas}

\begin{tabular}{|c|c|}
\hline & $\begin{array}{l}\text { Large Group Area } \\
\text { Poison Cove } \\
\text { Alternative } 3,5\end{array}$ \\
\hline $\begin{array}{l}\text { Type } \\
\text { Use Area } \\
\text { LUD } \\
\text { ROS } \\
\text { Acres } \\
\end{array}$ & $\begin{array}{l}\text { Enclave } \\
04-13 \\
\text { Scenic Viewshed } \\
\text { Roaded Modified } \\
172 \\
\end{array}$ \\
\hline $\begin{array}{l}\text { General } \\
\text { Characteristics }\end{array}$ & $\begin{array}{l}\text { An old growth forest surrounds the cove. A large tide and grass flat is } \\
\text { located at the back of the cove. }\end{array}$ \\
\hline Historical Use & Commercial outfitter/guides used this area in 1999. \\
\hline Access & $\begin{array}{l}\text { There is a protected anchorage but landing could be difficult during } \\
\text { some weather conditions. }\end{array}$ \\
\hline Facilities & None \\
\hline $\begin{array}{l}\text { Concerns and/or } \\
\text { Opportunities }\end{array}$ & A private land native allotment is across the cove. \\
\hline Attractions & $\begin{array}{l}\text { Wildlife viewing, hiking, old growth forest, a large estuary at the head } \\
\text { of the bay }\end{array}$ \\
\hline Mitigation & $\begin{array}{l}\text { - See Appendix C for mitigation measures. } \\
\text { - Bald eagles } \\
\text { - Riparian } \\
\text { - Vegetation } \\
\text { The enclave is located on opposite side of cove from private } \\
\text { interfere with access to the property. }\end{array}$ \\
\hline
\end{tabular}




\section{Use Area 04-13 POISON COVE}

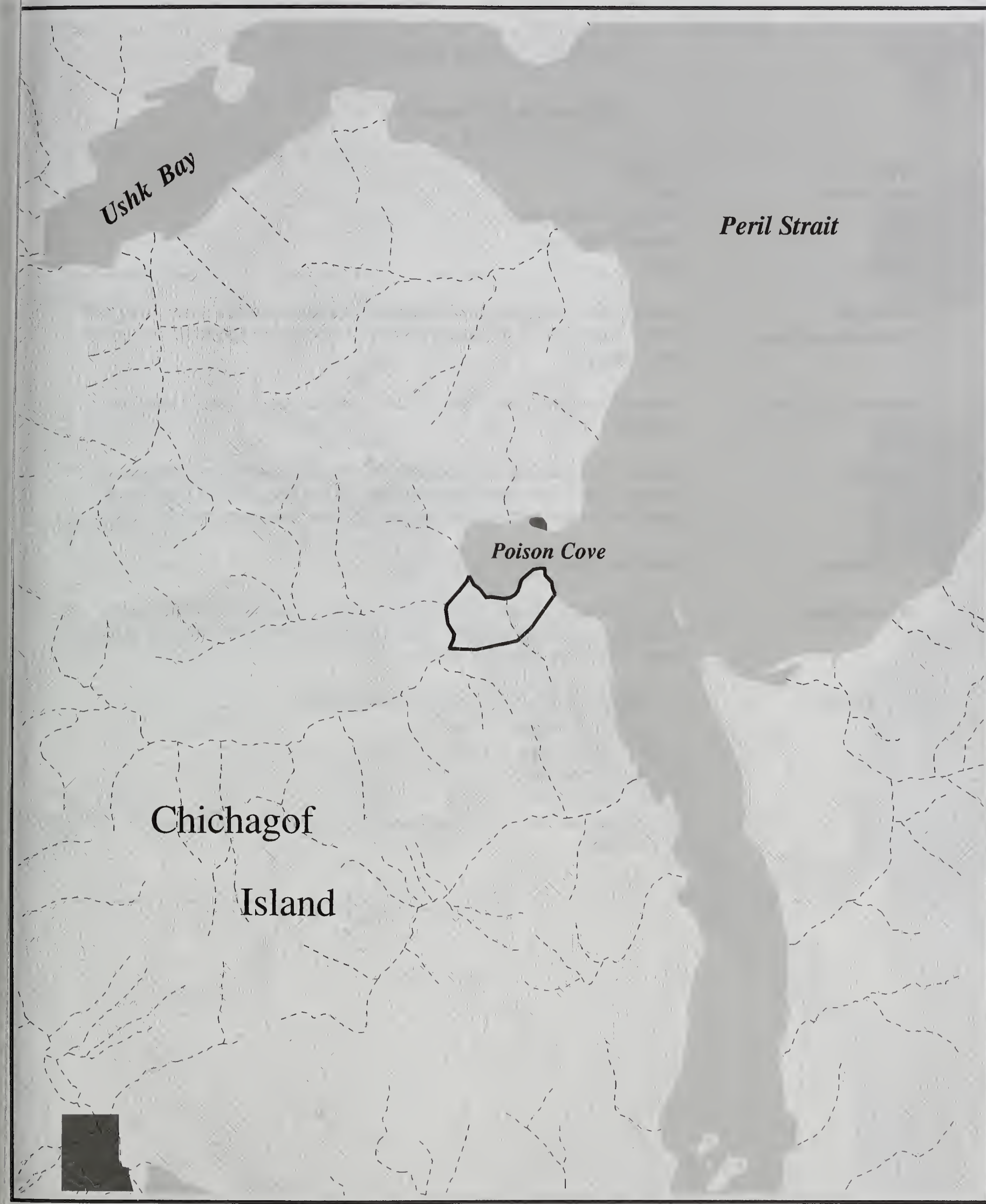

Large Group Area Boundary Streams

Existing Road
Non National Forest Land Wilderness

Outside of Project Area

\section{․ Recreation Cabin \\ inn Marine Access Point}

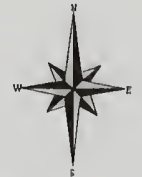

Contour Interval is 100 Feet 


\section{Appendix B, Large Group Areas}

\begin{tabular}{|c|c|}
\hline & $\begin{array}{l}\text { Large Group Area } \\
\text { Sitkoh Bay Road } \\
\text { Alternatives } 3,4,5\end{array}$ \\
\hline $\begin{array}{l}\text { Type } \\
\text { Use Area } \\
\text { LUD } \\
\text { ROS } \\
\text { Acres } \\
\end{array}$ & $\begin{array}{l}\text { Enclave } \\
04-13 \\
\text { Modified Landscape } \\
\text { Roaded Modified } \\
454 \\
\end{array}$ \\
\hline $\begin{array}{l}\text { General } \\
\text { Characteristics }\end{array}$ & $\begin{array}{l}\text { A scenic bay and past timber harvest are visible in the area. The road } \\
\text { on the north side of the bay passes just above the shoreline providing } \\
\text { easy access. }\end{array}$ \\
\hline Historical Use & $\begin{array}{l}\text { This area was logged in the } 1970 \text { s. Commercial outfitter/guides used } \\
\text { the area in } 1999 .\end{array}$ \\
\hline Access & $\begin{array}{l}\text { There is a protected anchorage within the bay. Skiffs can land along } \\
\text { the shore but the exact spot depends on the tide. During high tide it is } \\
\text { possible to land at the north end of the meadow at the end of the bay. }\end{array}$ \\
\hline Facilities & Road and marine access point. \\
\hline Attractions & $\begin{array}{l}\text { Easy access to an old roadbed for walking. Opportunities for forest } \\
\text { management interpretation. Opportunity to hike to the estuary at the } \\
\text { head of the bay and view wildlife. }\end{array}$ \\
\hline Mitigation & $\begin{array}{l}\text { - See Appendix } C \text { for mitigation measures. } \\
\text { - Bald eagles } \\
\text { - Rrown bear viewing } \\
\text { - Vegrian } \\
\text { Guided use must not interfere with other forest management } \\
\text { activities. }\end{array}$ \\
\hline
\end{tabular}




\section{Shoreline Outfitter/Guide EIS Large Group Area \\ Use Area 04-13 SITKOH BAY ROAD}

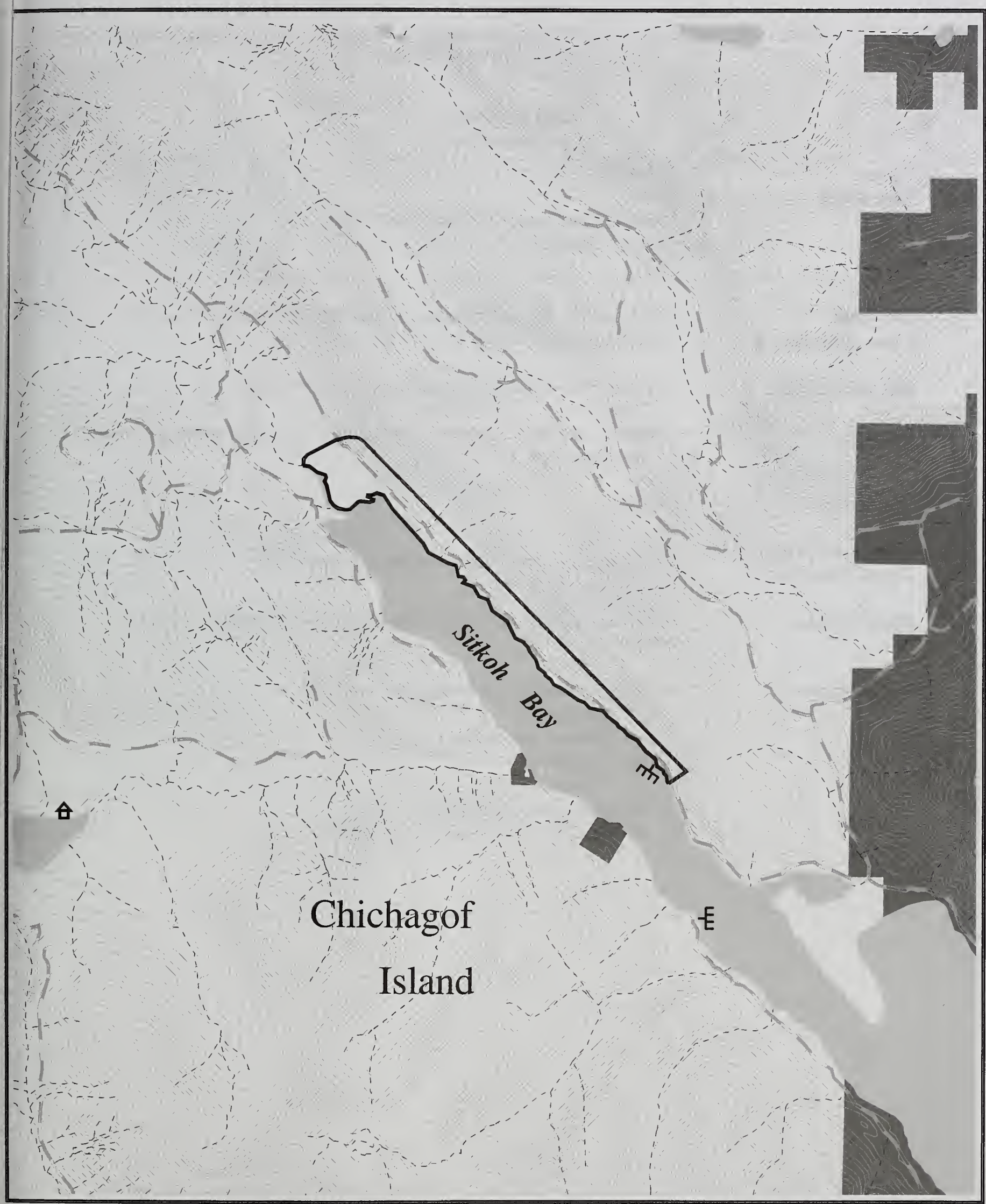

$\begin{array}{llllll}\text { Large Group Area Boundary } & & \text { Non National Forest Land } & & & \text { Salt and Fresh Water } \\ \text { Existing Road } & \square & \text { Wilderness } & \text { Recreation Cabin } \\ & & \text { Outside of Project Area } & \text { Marine Access Point }\end{array}$

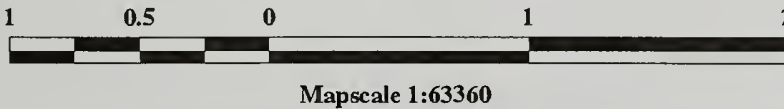




\section{Appendix B, Large Group Areas}

\begin{tabular}{|c|c|}
\hline & $\begin{array}{l}\text { Large Group Area } \\
\text { Ushk Bay } \\
\text { Alternative } 3\end{array}$ \\
\hline $\begin{array}{l}\text { Type } \\
\text { Use Area } \\
\text { LUD } \\
\text { ROS } \\
\text { Acres } \\
\end{array}$ & $\begin{array}{l}\text { Enclave } \\
04-13 \\
\text { Modified Landscape / Timber Production } \\
\text { Roaded Modified } \\
106 \\
\end{array}$ \\
\hline $\begin{array}{l}\text { General } \\
\text { Characteristics }\end{array}$ & $\begin{array}{l}\text { This area has harvested areas and old growth forest. A tide and } \\
\text { grass flat is found at the head of the bay. }\end{array}$ \\
\hline Historical Use & Commercial outfitter/guides used this area in 1999. \\
\hline Access & $\begin{array}{l}\text { There is a protected anchorage within the bay. Skiff landings depend } \\
\text { on the tidal stage. }\end{array}$ \\
\hline Facilities & Road \\
\hline $\begin{array}{l}\text { Concerns and/or } \\
\text { Opportunities }\end{array}$ & Interpretive opportunities on forest management. \\
\hline Attractions & $\begin{array}{l}\text { Hiking on tide and grass flats and on road. Opportunity to view } \\
\text { wildlife. }\end{array}$ \\
\hline Mitigation & $\begin{array}{l}\text { - See Appendix C for mitigation measures. } \\
\text { - Bald eagle } \\
\text { - Brown bear viewing } \\
\text { - Riparian } \\
\text { - No large group camping. } \\
\text { - No consumptive uses by large groups. }\end{array}$ \\
\hline
\end{tabular}




\section{Chichagof}

\section{Island}




\section{Appendix B, Large Group Areas}

\begin{tabular}{|c|c|}
\hline & $\begin{array}{l}\text { Large Group Area } \\
\text { Bohemia Basin } \\
\text { Alternatives } 3,5\end{array}$ \\
\hline $\begin{array}{l}\text { Type } \\
\text { Use Area } \\
\text { LUD } \\
\text { ROS } \\
\text { Acres }\end{array}$ & $\begin{array}{l}\text { Enclave } \\
04-15 \\
\text { Semi-Remote Recreation. } \\
\text { Semi-Primitive Motorized } \\
1,043\end{array}$ \\
\hline $\begin{array}{l}\text { General } \\
\text { Characteristics }\end{array}$ & $\begin{array}{l}\text { This area has an isolated setting adjacent to West Chichagof } \\
\text { Yakobi Wilderness. There is an old mining claim in Bohemia Basin } \\
\text { with scenic cliffs and numerous waterfalls along Lisianski Strait } \\
\text { and Lisianski Inlet. It is approximately eight miles from Pelican and } \\
\text { ten miles from the outer coast of Yakobi Island and west } \\
\text { Chichagof. }\end{array}$ \\
\hline Historical Use & No commercial Outfitter-Guide use occurred here in 1999. \\
\hline Access & $\begin{array}{l}\text { There is a dock at this location that will accommodate boats up to } \\
50 \text { feet in length. This dock is under the jurisdiction of the City of } \\
\text { Pelican. It is in poor condition. }\end{array}$ \\
\hline Facilities & $\begin{array}{l}\text { This site was the staging area for a mining operation in Bohemia } \\
\text { Basin valley. The operation was abandoned in the early } 1980 \text { s } \\
\text { and the site has been reclaimed. There is a primitive four-mile } \\
\text { hiking trail to Takanis Lake. }\end{array}$ \\
\hline $\begin{array}{l}\text { Concerns and/or } \\
\text { Opportunities }\end{array}$ & $\begin{array}{l}\text { The dock is in poor condition. The mining road serves as a good } \\
\text { hardened trail. Cultural sites are present. }\end{array}$ \\
\hline Attractions & $\begin{array}{l}\text { Boat dock, scenic setting adjacent to Wilderness, Takanis Lake } \\
\text { trail, wildlife viewing opportunities }\end{array}$ \\
\hline Mitigation & $\begin{array}{l}\text { - See Appendix } C \text { for mitigation measures. } \\
\text { - Brown bear viewing } \\
\text { - Rald eagles } \\
\text { - Vuparian } \\
\text { - Oultural sites will be excluded from guided use. } \\
\text { - Outfitter/guides must obtain permission to use the dock. }\end{array}$ \\
\hline
\end{tabular}


Shoreline Outfitter/Guide EIS Large Group Area

Use Area 04-15 BOHEMIA BASIN

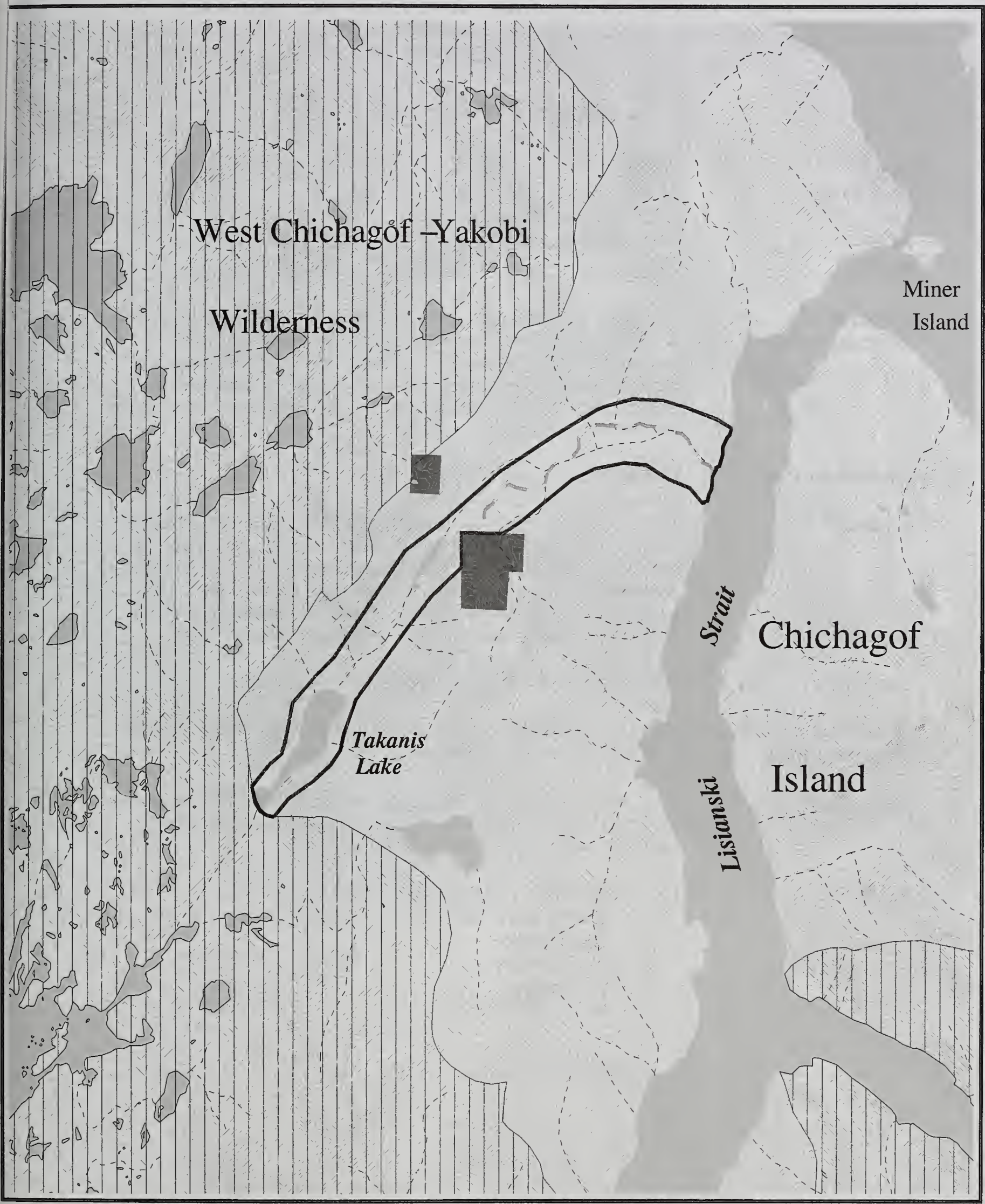

$\checkmark$ Large Group Area Boundary

Streams

Existing Road
Non National Forest Land

Wilderness

Outside of Project Area
Salt and Fresh Water

4 Recreation Cabin

向 Marine Access Point

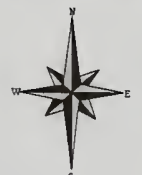

Contour Interval is 100 Feet 


\section{Appendix B, Large Group Areas}

\begin{tabular}{|c|c|}
\hline & $\begin{array}{l}\text { Large Group Areas } \\
\text { Three Hill Island } \\
\text { Alternatives 3, 4, } 5\end{array}$ \\
\hline $\begin{array}{l}\text { Type } \\
\text { Use Area } \\
\text { LUD } \\
\text { ROS } \\
\text { Acres }\end{array}$ & $\begin{array}{l}\text { Enclave } \\
04-15 \\
\text { Semi-Remote Recreation } \\
\text { Semi-Primitive Motorized } \\
362\end{array}$ \\
\hline $\begin{array}{l}\text { General } \\
\text { Characteristics }\end{array}$ & $\begin{array}{l}\text { This area is located near the entrance to Port Althorp. It is a } \\
\text { small island with secluded sandy coves, sea bird rookeries, and } \\
\text { terrestrial and marine mammal viewing opportunities. This island } \\
\text { offers a variety of recreation and wildlife viewing opportunities } \\
\text { including hiking, sightseeing, camping, and beach combing. It has } \\
\text { a difficult anchorage. }\end{array}$ \\
\hline Historical Use & Outfitter/guides used this area in 1999. \\
\hline Access & $\begin{array}{l}\text { Three Hill Island is within five miles of Elfin Cove and receives } \\
\text { unguided use from residents and visitors for hiking, sightseeing, } \\
\text { beach combing, and camping. Large boats normally anchor on } \\
\text { the east side of the island and skiff ashore. Smaller skiffs and } \\
\text { kayaks also approach from the east side, as the west shore is } \\
\text { very rocky and exposed to large swells from Cross Sound. }\end{array}$ \\
\hline Facilities & There are no Forest Service facilities at this location. \\
\hline $\begin{array}{l}\text { Concerns and/or } \\
\text { Opportunities }\end{array}$ & $\begin{array}{l}\text { Elfin Cove residents use this area. There are seal and/or sea lion } \\
\text { haul outs and seabird rookeries. }\end{array}$ \\
\hline Attractions & $\begin{array}{l}\text { This area has a scenic setting with views across Cross Sound of } \\
\text { Glacier Bay National Park. There are opportunities for wildlife } \\
\text { viewing; particularly sea bird rookeries. }\end{array}$ \\
\hline Mitigation & $\begin{array}{l}\text { - See Appendix } C \text { for mitigation measures. } \\
\text { - Marine mammals } \\
\text { - Sald eagles } \\
\text { - Veabird rookeries } \\
\text { - Riparian }\end{array}$ \\
\hline
\end{tabular}




\section{Shoreline Outfitter/Guide EIS \\ Large Group Area \\ Use Area 04-15 THREE HILL ISLAND}
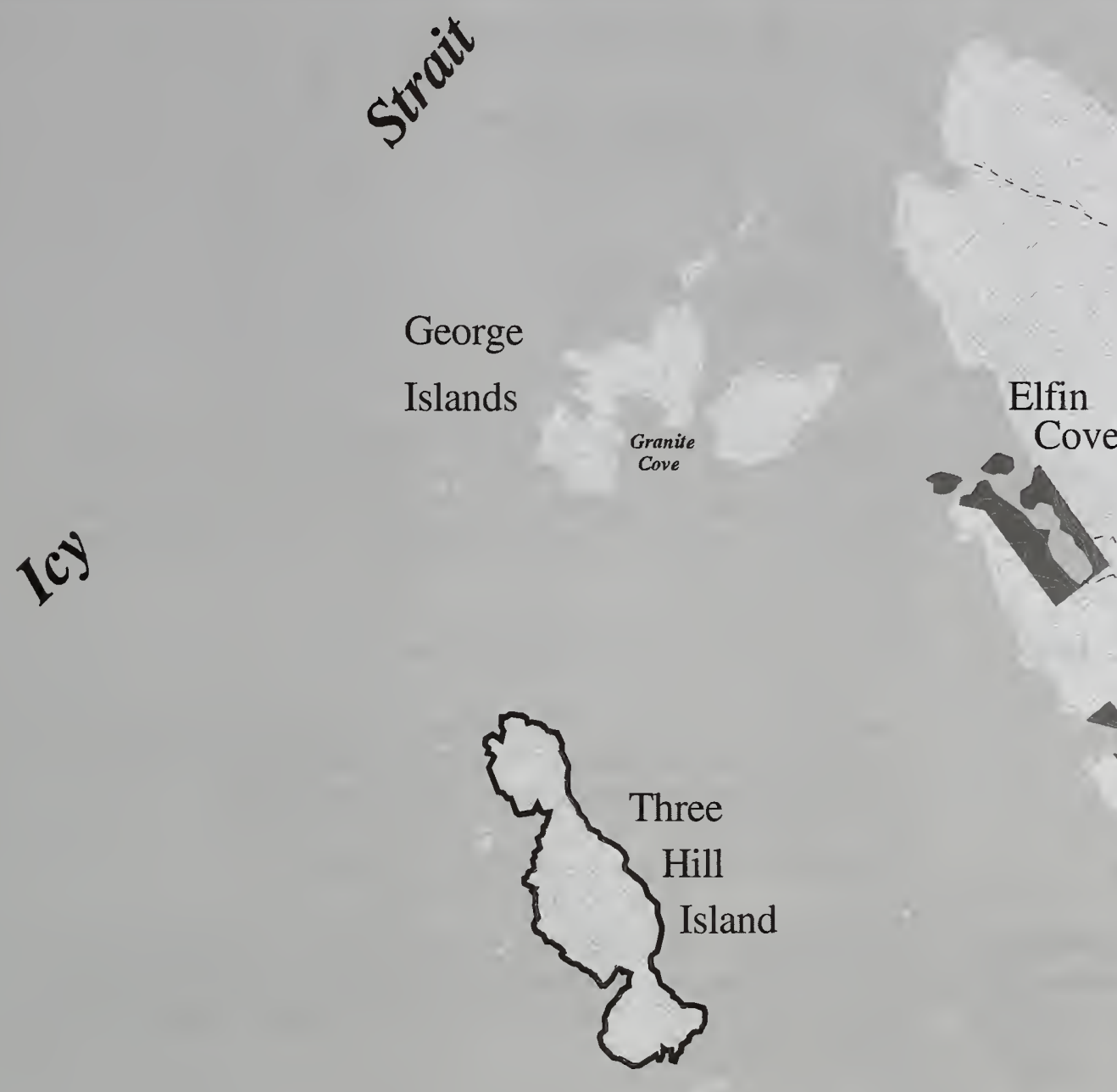

George

Islands

\section{Elfin}

Cove

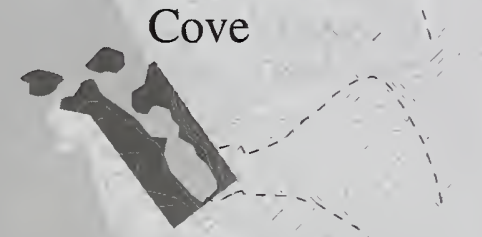

Port
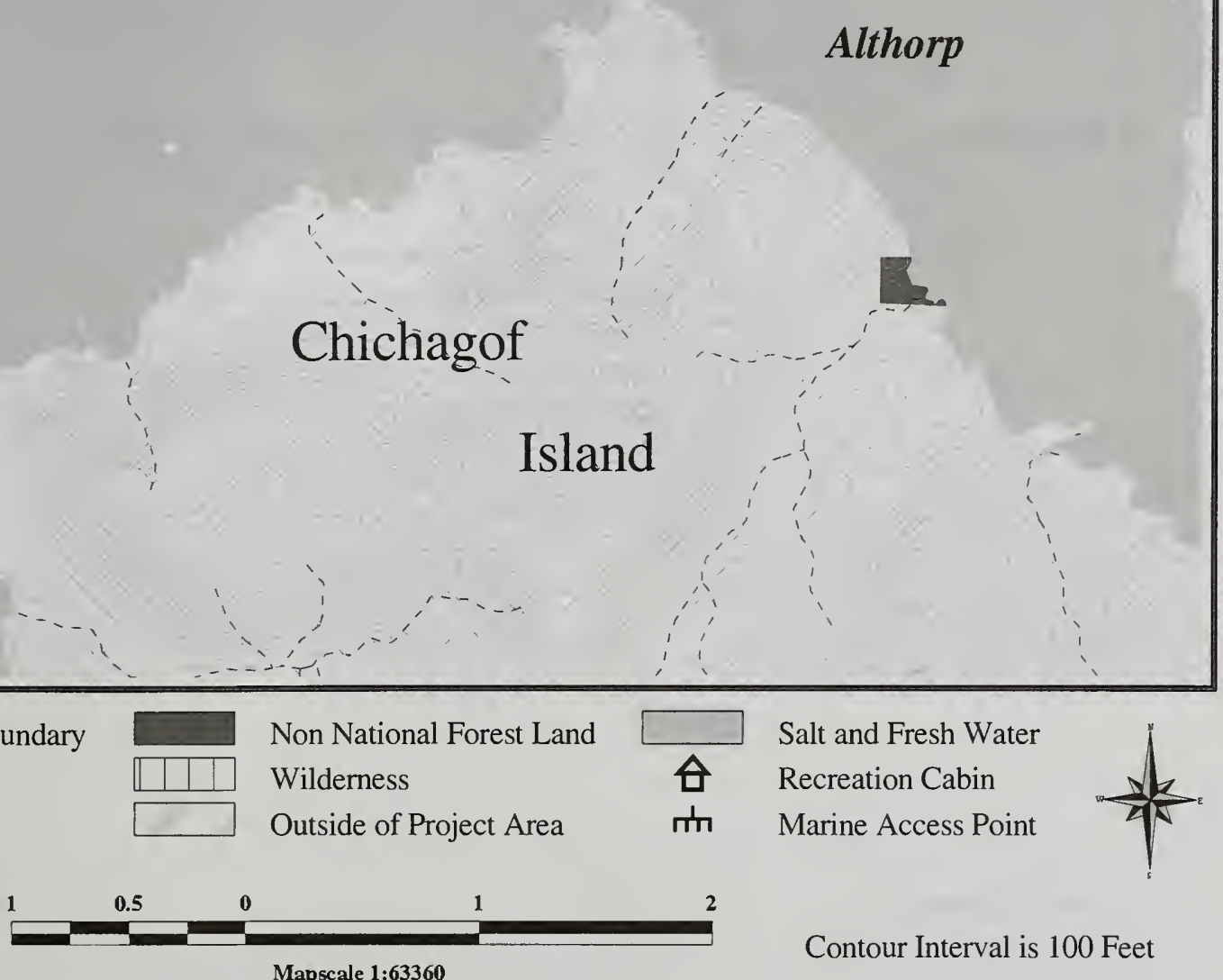

Contour Interval is 100 Feet 


\section{Appendix B, Large Group Areas}

\begin{tabular}{|c|c|}
\hline & $\begin{array}{l}\text { Large Group Areas } \\
\text { George Island } \\
\text { Alternatives 3, 4, } 5\end{array}$ \\
\hline $\begin{array}{l}\text { Type } \\
\text { Use Area } \\
\text { LUD } \\
\text { ROS } \\
\text { Acres }\end{array}$ & $\begin{array}{l}\text { Enclave } \\
04-16 D \\
\text { Semi-Remote Recreation } \\
\text { Semi-Primitive Motorized } \\
188\end{array}$ \\
\hline $\begin{array}{l}\text { General } \\
\text { Characteristics }\end{array}$ & $\begin{array}{l}\text { Granite Cove is approximately two miles from the community of } \\
\text { Elfin Cove. The area is very scenic with isolated coves, open } \\
\text { forest, and excellent views across Cross Sound. This site offers an } \\
\text { excellent opportunity to interpret the historic use of the island as a } \\
\text { WWII military site. }\end{array}$ \\
\hline Historical Use & It is a popular location for guided use. \\
\hline Access & $\begin{array}{l}\text { The site is two miles from Elfin Cove. There is an excellent beach } \\
\text { for launching small boats and kayaks at Granite Cove. It has a } \\
\text { good protected anchorage for mid-size cruise ships. }\end{array}$ \\
\hline Facilities & A primitive $1 / 4$ mile trail leads to a WWII cannon. \\
\hline $\begin{array}{l}\text { Concerns and/or } \\
\text { Opportunities }\end{array}$ & $\begin{array}{l}\text { The trail has been receiving an increasingly high amount of use } \\
\text { over the previous few years and needs to be improved to sustain } \\
\text { the increased use. There are interpretive opportunities at the } \\
\text { WWII cannon site. }\end{array}$ \\
\hline Attractions & $\begin{array}{l}\text { There are scenic views of Cross Sound, Cape Spencer, Glacier } \\
\text { Bay National Park, and Brady Glacier. This area has opportunities } \\
\text { for wildlife viewing and hiking on the WWII Cannon Trail. It is close } \\
\text { to Elfin Cove. }\end{array}$ \\
\hline Mitigation & $\begin{array}{l}\text { - See Appendix C for mitigation measures. } \\
\text { - Bald eagles } \\
\text { - Nogetation } \\
\text { - No consumptive uses by large groups } \\
\text { - Cultural resource mitigation } \\
\text { Additional levels of guided use on the WWII Cannon trail will } \\
\text { not be permitted until the trail is reconstructed. }\end{array}$ \\
\hline
\end{tabular}



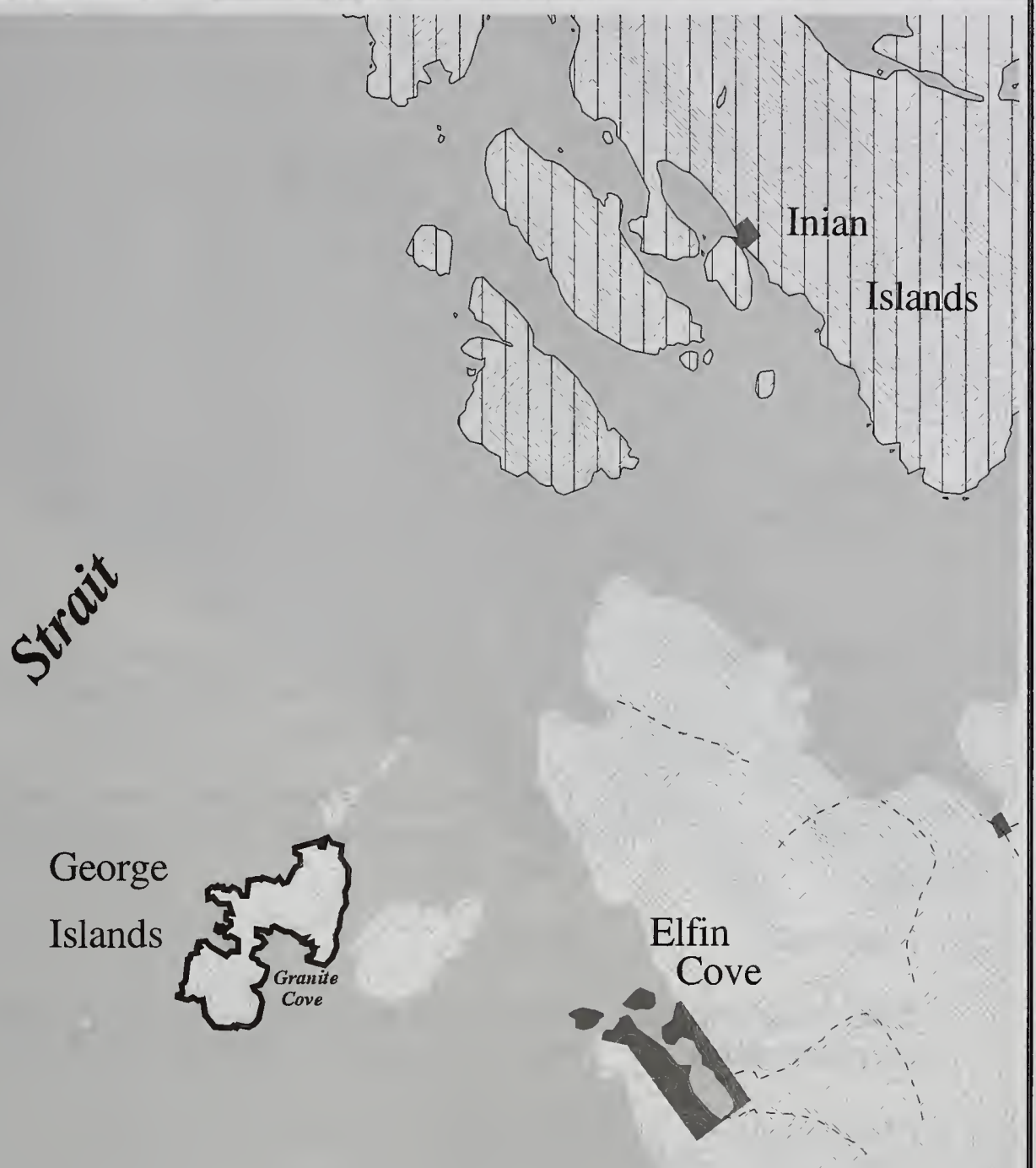

$e^{*}$

Three

Hill

Island

\section{Port}

\section{Althorp}

\section{Large Group Area Boundary}

‘ ,' Streams

Existing Road
Non National Forest Land

Wilderness

Outside of Project Area

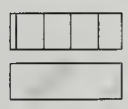

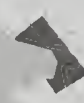
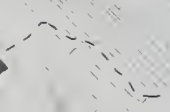


\section{Appendix B, Large Group Areas}

\begin{tabular}{|c|c|}
\hline & $\begin{array}{c}\text { Large Group Area } \\
\text { Douglas Island } \\
\text { Alternative } 3,5\end{array}$ \\
\hline $\begin{array}{l}\text { Type } \\
\text { Use Area } \\
\text { LUD } \\
\text { ROS } \\
\text { Acres }\end{array}$ & $\begin{array}{l}\text { Fifteen-Percent } \\
\text { 01-04B } \\
\text { Scenic Viewshed } \\
\text { Roaded Natural } \\
8\end{array}$ \\
\hline $\begin{array}{l}\text { General } \\
\text { Characteristics }\end{array}$ & $\begin{array}{l}\text { Located on the back of Douglas Island, this site includes a small cove with } \\
\text { a creek and nice beach. Some flat ground occurs just inside the tree line. } \\
\text { A very steep rock face rises just inside the trees on the northern side of } \\
\text { the cove. }\end{array}$ \\
\hline Historical Use & $\begin{array}{l}\text { No commercial use was reported in } 1999 \text {. Deer hunters have used this } \\
\text { site for access to alpine terrain. Kayak campers and day boaters also } \\
\text { typically use this area. }\end{array}$ \\
\hline Access & $\begin{array}{l}\text { Boats and planes can access the site depending on weather conditions. It } \\
\text { has a poor anchorage. The cove has some rocks, but generally has a } \\
\text { sandy bottom. }\end{array}$ \\
\hline Facilities & None \\
\hline $\begin{array}{l}\text { Concerns and/or } \\
\text { Opportunities }\end{array}$ & $\begin{array}{l}\text { At mid-cove, the slope rises gradually, providing a potential location for a } \\
\text { walk. A culturally modified tree was found. }\end{array}$ \\
\hline Attractions & Beachcombing, wildlife, and scenery \\
\hline Mitigation & $\begin{array}{l}\text { - See Appendix } C \text { for mitigation measures. } \\
\text { - Bald eagles } \\
\text { - Cultural resources } \\
\text { - Ro large group camping. } \\
\text { - No consumptive uses by large groups. }\end{array}$ \\
\hline
\end{tabular}




\section{Shoreline Outfitter/Guide EIS \\ Large Group Area \\ Use Area 01-04B DOUGLAS ISLAND}

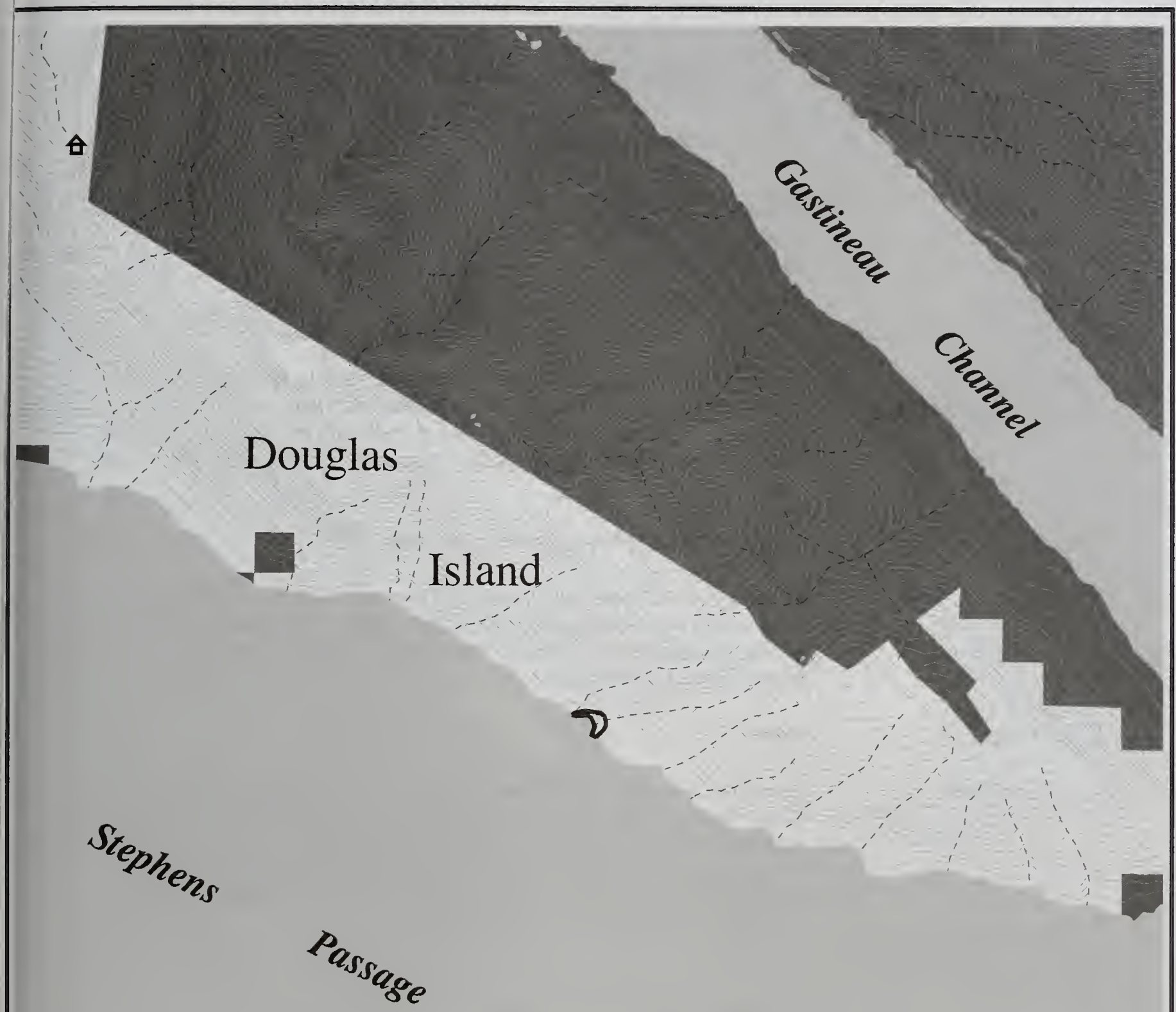

Admirailty

Island
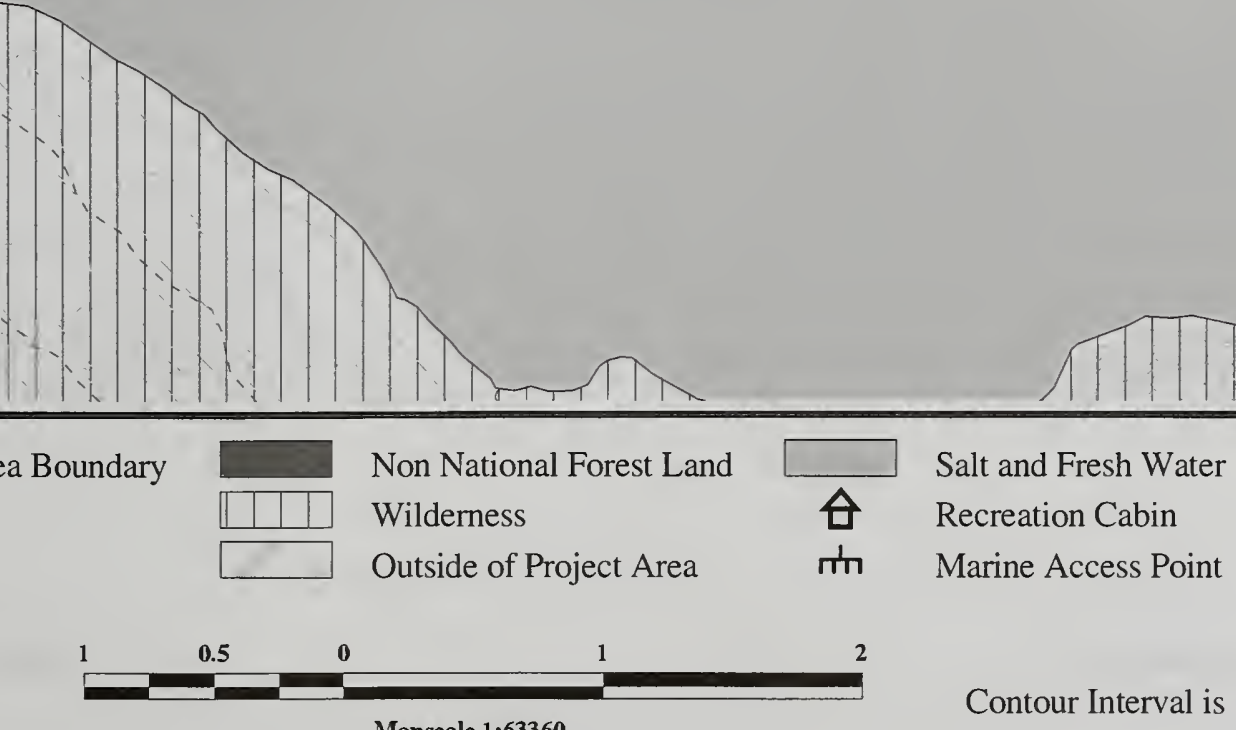


\section{Appendix B, Large Group Areas}

\begin{tabular}{|c|c|}
\hline & $\begin{array}{l}\text { Large Group Area } \\
\text { Point Coke } \\
\text { Alternatives } 3,5\end{array}$ \\
\hline $\begin{array}{l}\text { Type } \\
\text { Use Area } \\
\text { LUD } \\
\text { ROS } \\
\text { Acres }\end{array}$ & $\begin{array}{l}\text { Fifteen-Percent Area } \\
01-05 B \\
\text { Old Growth } \\
\text { Semi-Primitive Motorized } \\
22 \\
\end{array}$ \\
\hline $\begin{array}{l}\text { General } \\
\text { Characteristics }\end{array}$ & $\begin{array}{l}\text { This south-facing site is located at the entrance to Holkham Bay. The } \\
\text { cove is approximately } 1 / 4 \text { mile across. Surrounding the cove is a large } \\
\text { rock wall with small grottoes and large boulders on the east side and } \\
\text { a large meadow on the west side. A second scenic creek bisects the } \\
\text { site. }\end{array}$ \\
\hline $\begin{array}{l}\text { Historical Use } \\
\text { Access }\end{array}$ & $\begin{array}{l}\text { There was no reported commercial use in } 1999 \text {. } \\
\text { A small pebble beach allows for skiff landings at most tide stages. } \\
\text { Anchorage and access could be difficult under some weather } \\
\text { conditions due to exposure to Stephens Passage. Icebergs may } \\
\text { occasionally be in the area. }\end{array}$ \\
\hline $\begin{array}{l}\text { Facilities } \\
\text { Attractions }\end{array}$ & $\begin{array}{l}\text { None } \\
\text { Proximity to Tracy Arm Wilderness allows for a shore excursion and } \\
\text { view of upper Tracy Arm on the same day. This area offers scenic } \\
\text { views of Frederick Sound. A variety of wildflowers were noted in the } \\
\text { area. It has two creeks and provides some geologic diversity. The } \\
\text { large rock outcrop at the southwest side provides excellent views of } \\
\text { Stephens Passage and Holkham Bay. }\end{array}$ \\
\hline Mitigation & $\begin{array}{l}\text { - See Appendix } C \text { for mitigation measures. } \\
\text { - Riparian. } \\
\text { - Vegetation } \\
\text { - No large group camping. } \\
\text { - No consumptive uses by large groups. }\end{array}$ \\
\hline
\end{tabular}


Shoreline Outfitter/Guide EIS

Large Group Area

Use Area 01-05B POINT COKE
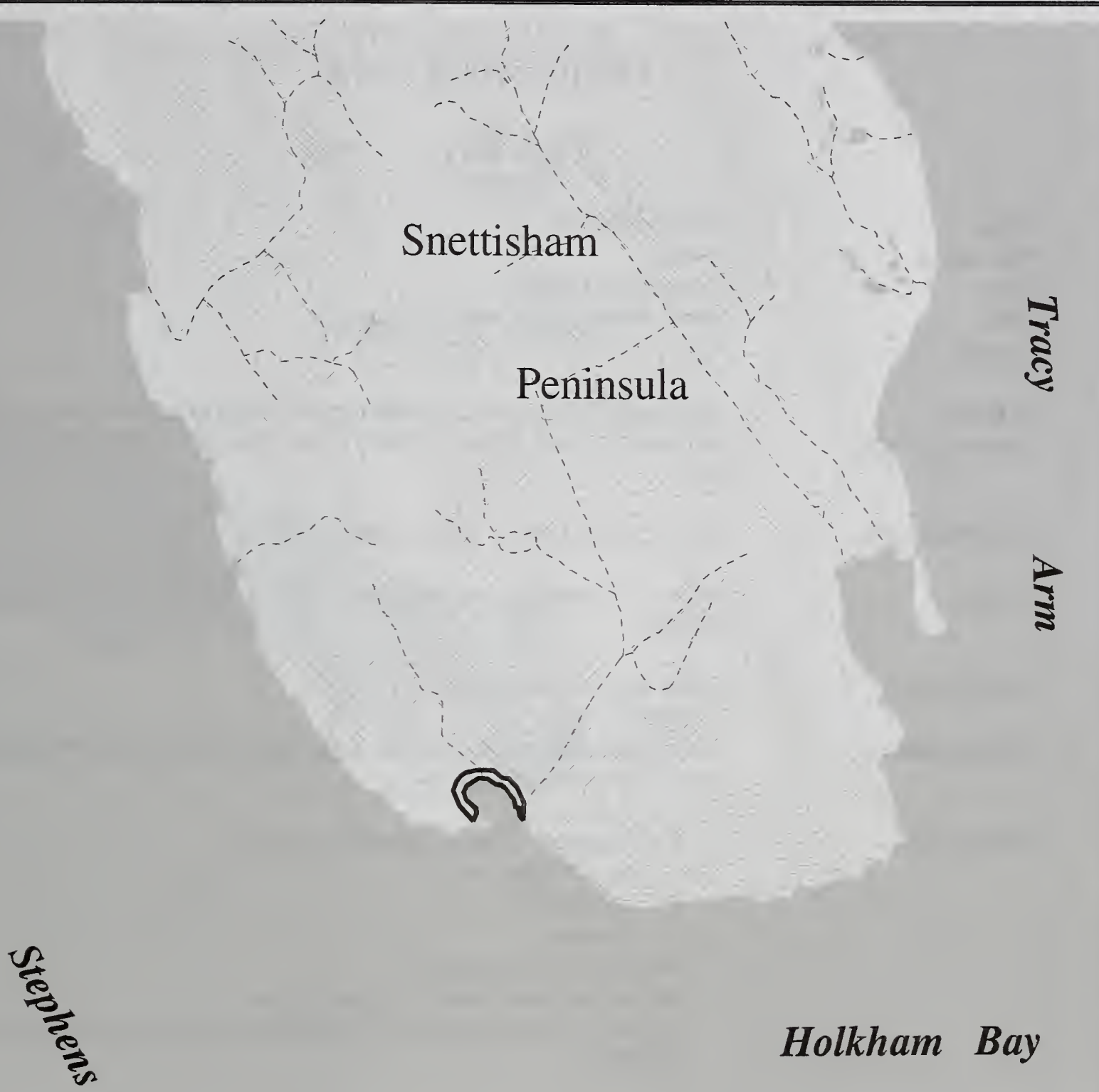

\section{Holkham Bay}
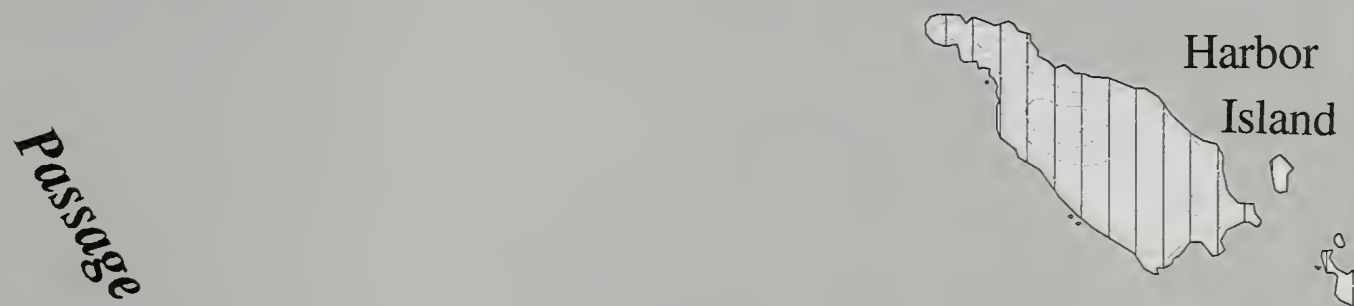

Large Group Area Boundary Streams

Existing Road
Non National Forest Land Wilderness

Outside of Project Area

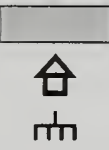

Salt and Fresh Water

Recreation Cabin

Marine Access Point

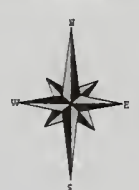

Contour Interval is 100 Feet

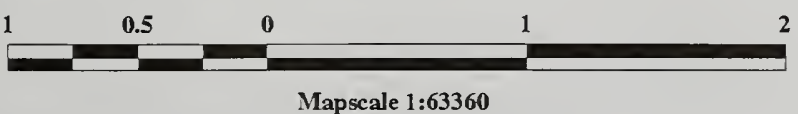




\section{Appendix B, Large Group Areas}

\begin{tabular}{|c|c|}
\hline & $\begin{array}{c}\text { Large Group Area } \\
\text { Fish Bay } \\
\text { Alternative } 3\end{array}$ \\
\hline $\begin{array}{l}\text { Type } \\
\text { Use Area } \\
\text { LUD } \\
\text { ROS } \\
\text { Acres } \\
\end{array}$ & $\begin{array}{l}\text { Fifteen-Percent } \\
04-03 \\
\text { Old Growth Forest } \\
\text { Semi-Primitive Motorized } \\
701\end{array}$ \\
\hline $\begin{array}{l}\text { General } \\
\text { Characteristics }\end{array}$ & $\begin{array}{l}\text { The immediate area is unaltered forest but logging is evident in the } \\
\text { surrounding area. There are very large grass flats at the head of the } \\
\text { bay. }\end{array}$ \\
\hline Historical Use & Commercially guided groups used this area in 1999. \\
\hline Access & $\begin{array}{l}\text { There is a protected anchorage with skiff access possible at all tidal } \\
\text { stages. }\end{array}$ \\
\hline Facilities & There is an old logging road. \\
\hline Attractions & $\begin{array}{l}\text { There is an opportunity to view wildlife and to hike along the beach } \\
\text { fringe forest and grass flats. }\end{array}$ \\
\hline Mitigation & $\begin{array}{l}\text { - See Appendix C for mitigation measures. } \\
\text { - Bald eagles } \\
\text { - Regetation } \\
\text { - No large group camping. } \\
\text { - } \quad \text { Go consumptive uses by large groups. } \\
\text { activities. }\end{array}$ \\
\hline
\end{tabular}


Shoreline Outfitter/Guide EIS

Large Group Area

Use Area 04-03 FISH BAY

\section{Băranof Island}

\section{Fish Bay}
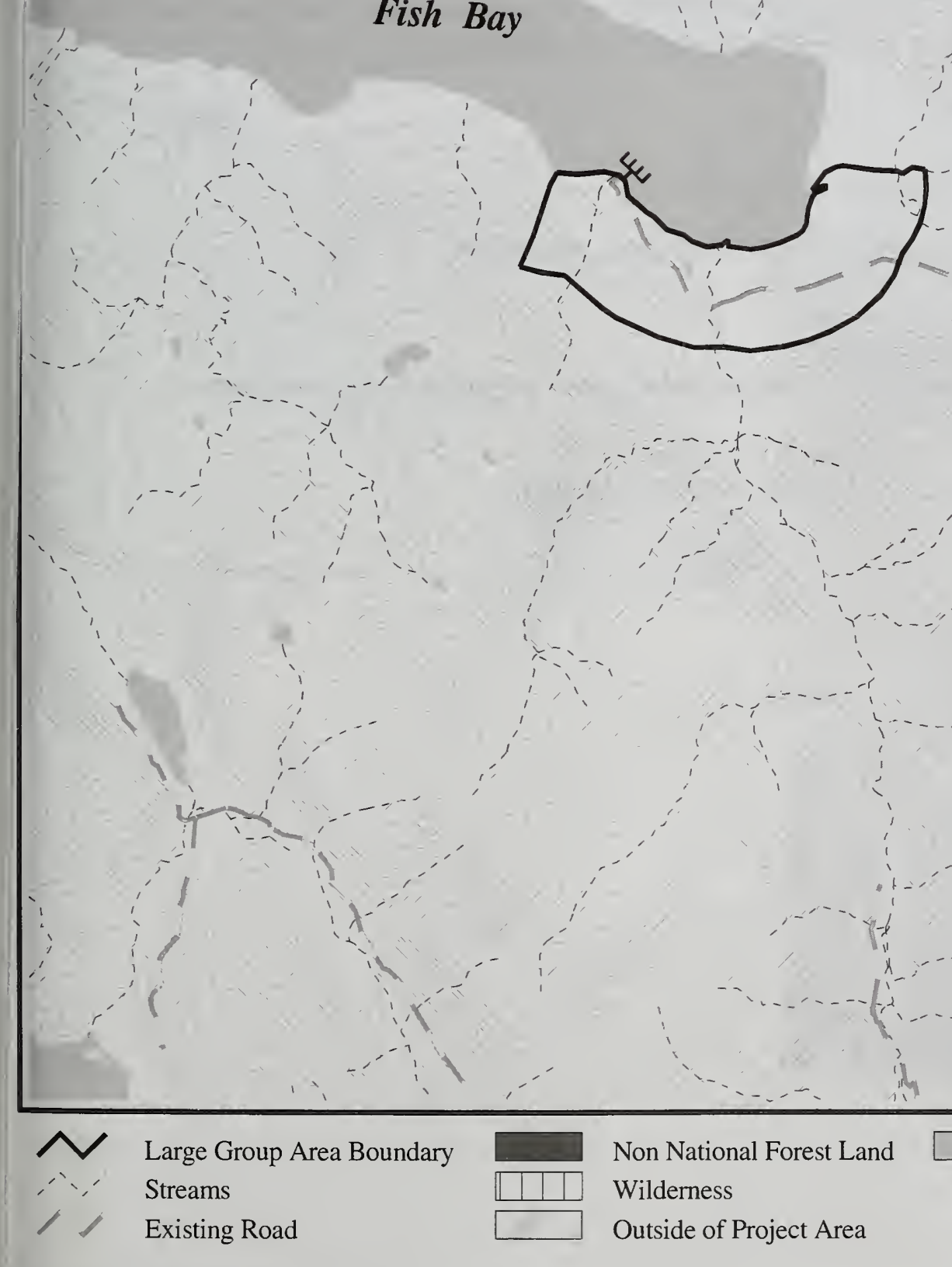

Non National Forest Land

Wilderness

Outside of Project Area

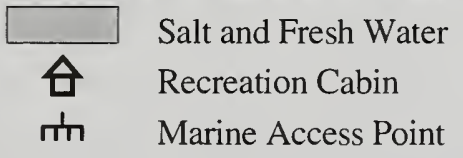

in Marine Access Point 


\section{Appendix B, Large Group Areas}

\begin{tabular}{|c|c|}
\hline & $\begin{array}{c}\text { Large Group Area } \\
\text { Nadezhida Islands } \\
\text { Alternative } 3\end{array}$ \\
\hline $\begin{array}{l}\text { Type } \\
\text { Use Area } \\
\text { LUD } \\
\text { ROS } \\
\text { Acres }\end{array}$ & $\begin{array}{l}\text { Fifteen-Percent } \\
04-03 \\
\text { Semi-Remote Recreation } \\
\text { Semi-Primitive Motorized } \\
222\end{array}$ \\
\hline $\begin{array}{l}\text { General } \\
\text { Characteristics }\end{array}$ & The area is forested with timber harvest in the vicinity. \\
\hline Historical Use & Outfitter/guides used this area in 1999. \\
\hline Access & $\begin{array}{l}\text { There is a protected anchorage during most weather conditions. Skiff } \\
\text { landings are possible on each of the islands. }\end{array}$ \\
\hline Facilities & None \\
\hline Attractions & Hiking in old-growth forest. \\
\hline Mitigation & $\begin{array}{l}\text { - See Appendix } C \text { for mitigation measures. } \\
\text { - Bald eagles } \\
\text { - Regetation } \\
\text { - Ruided activities will not interfere with other forest management } \\
\text { activities. } \\
\text { - No large group camping. } \\
\text { - No consumptive uses by large groups. }\end{array}$ \\
\hline
\end{tabular}




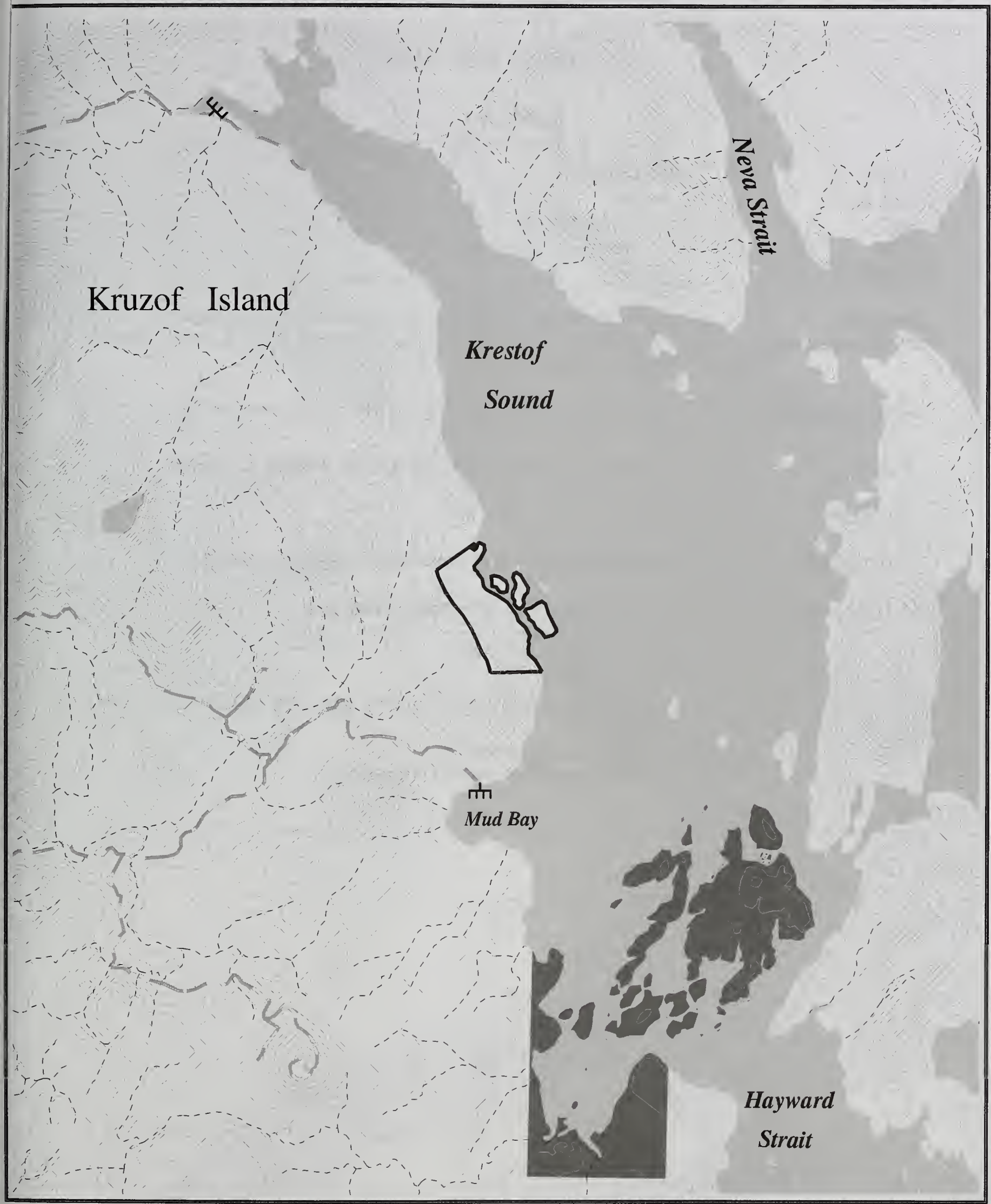

$\checkmark$ Large Group Area Boundary Streams

Existing Road
Non National Forest Land

Wilderness

Outside of Project Area
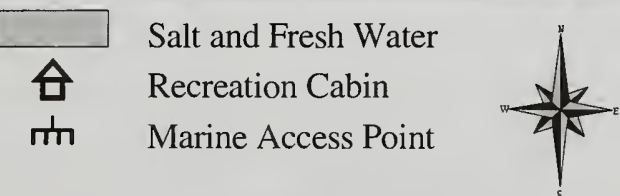

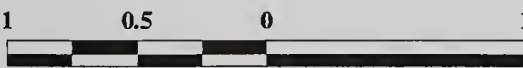

1 


\section{Appendix B, Large Group Areas}

\begin{tabular}{|c|c|}
\hline & $\begin{array}{l}\text { Large Group Area } \\
\text { Duffield } \\
\text { Alternative } 3\end{array}$ \\
\hline $\begin{array}{l}\text { Type } \\
\text { Use Area } \\
\text { LUD } \\
\text { ROS } \\
\text { Acres }\end{array}$ & $\begin{array}{l}\text { Fifteen-Percent } \\
\text { 04-04A } \\
\text { Old Growth Habitat } \\
\text { Semi-Primitive Motorized } \\
223\end{array}$ \\
\hline $\begin{array}{l}\text { General } \\
\text { Characteristics }\end{array}$ & $\begin{array}{l}\text { Immediate area is unaltered forest but with logging evident in } \\
\text { surroundings. Walking along the forest edge and inside the beach } \\
\text { fringe is possible. }\end{array}$ \\
\hline Historical Use & Commercial outfitting and guiding did not occur here in 1999. \\
\hline Access & Skiff access depends on tidal stage and weather conditions. \\
\hline Facilities & None \\
\hline Attractions & Hiking along beach and beach fringe forest and grass flats \\
\hline Mitigation & $\begin{array}{l}\text { - See Appendix C for mitigation measures. } \\
\text { - Vald eagles } \\
\text { - Regetation } \\
\text { - Ruided activities will not interfere with other forest management } \\
\text { activities. } \\
\text { - No large group camping. } \\
\text { - No consumptive uses by large groups. }\end{array}$ \\
\hline
\end{tabular}


Peril Strait

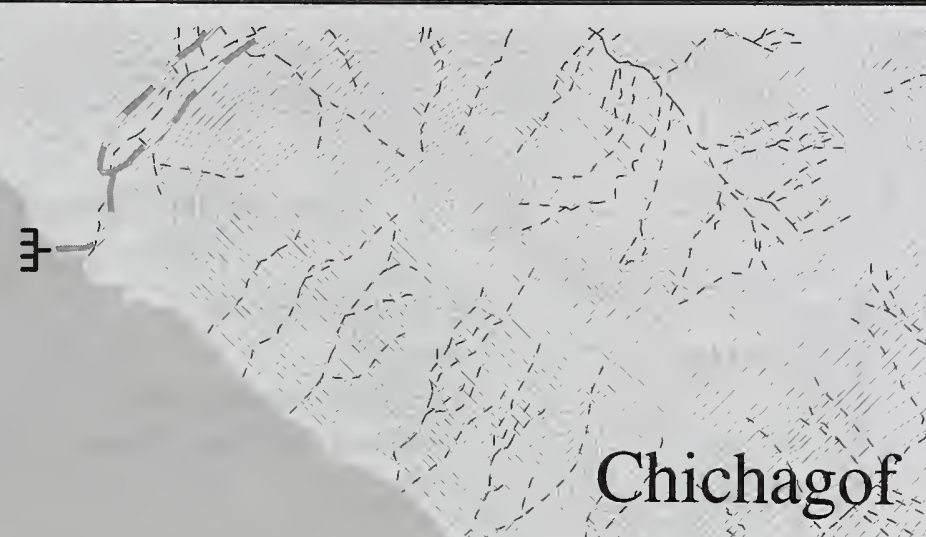

Island

\section{Barañof}

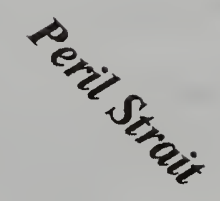

… Island

$$
\text { Rodman } B \text { ay }
$$

Large Group Area Boundary Streams

Existing Road

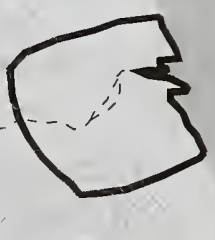

Appleton cove

Non National Forest Land

Wilderness

Outside of Project Area
Salt and Fresh Water

Recreation Cabin

Marine Access Point

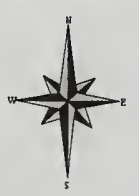

Contour Interval is 100 Feet 


\section{Appendix B, Large Group Areas}

\begin{tabular}{|c|c|}
\hline & $\begin{array}{c}\text { Large Group Areas } \\
\text { Bourbon Creek Road } \\
\text { Alternative } 3\end{array}$ \\
\hline $\begin{array}{l}\text { Type } \\
\text { Use Area } \\
\text { LUD } \\
\text { ROS } \\
\text { Acres }\end{array}$ & $\begin{array}{l}\text { Fifteen-Percent } \\
\text { 04-04B } \\
\text { Modified Landscape } \\
\text { Roaded Modified, Semi-Primitive Non-Motorized } \\
346\end{array}$ \\
\hline $\begin{array}{l}\text { General } \\
\text { Characteristics }\end{array}$ & $\begin{array}{l}\text { Timber was harvested in this area during the } 1970 \text { 's, but much of the } \\
\text { old growth forest remains. There is a small tide and grass flat near the } \\
\text { mouth of Bourbon Creek. }\end{array}$ \\
\hline Historical Use & This area was logged in the 1970 s. There is no current guided use. \\
\hline Access & $\begin{array}{l}\text { There is a protected anchorage and it is possible to use a skiff to } \\
\text { access the beach during most tide stages. }\end{array}$ \\
\hline Facilities & Logging road and marine access point. \\
\hline $\begin{array}{l}\text { Concerns and/or } \\
\text { Opportunities }\end{array}$ & There are interpretive opportunities. \\
\hline Attractions & $\begin{array}{l}\text { There are opportunities to view wildlife, and to hike the beach fringe } \\
\text { forest or an old logging road. }\end{array}$ \\
\hline Mitigation & $\begin{array}{l}\text { - See Appendix } C \text { for mitigation measures. } \\
\text { - Brown bear viewing } \\
\text { - } \text { Bald eagles } \\
\text { - Riparian } \\
\text { - Guided activities will not interfere with other forest management } \\
\text { - No large group camping. } \\
\text { - No consumptive uses by large groups. }\end{array}$ \\
\hline
\end{tabular}


Shoreline Outfitter/Guide EIS

Large Group Area

Use Area 04-04B BOURBON CREEK ROAD

\section{Baranof \\ Island}

\section{Middle Arm}

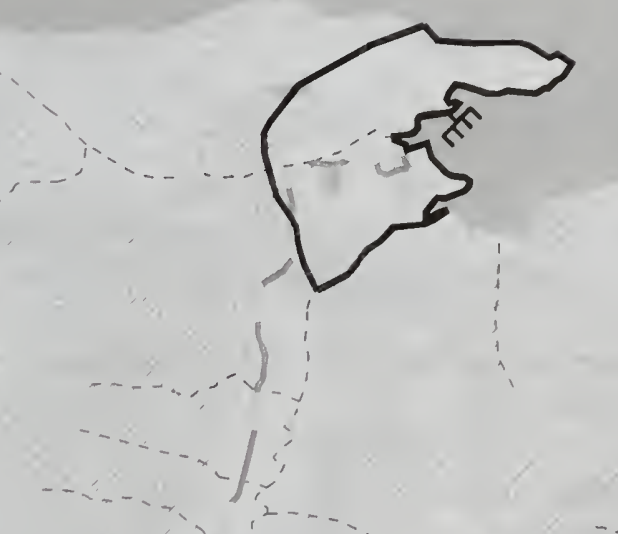

Kelp
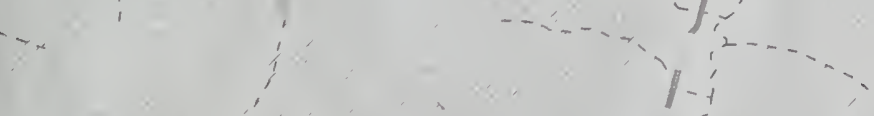

\section{Bay}
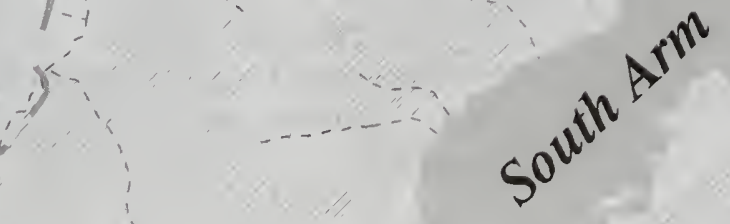

E
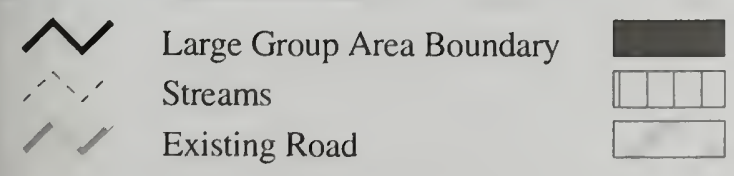

Non National Forest Land Wilderness

Outside of Project Area
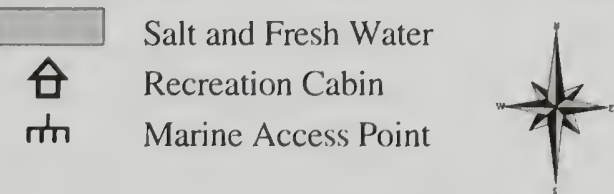


\section{Appendix B, Large Group Areas}

\begin{tabular}{|c|c|}
\hline & $\begin{array}{l}\text { Large Group Area } \\
\text { Cosmos Cove } \\
\text { Alternatives 3, } 5\end{array}$ \\
\hline $\begin{array}{l}\text { Type } \\
\text { Use Area } \\
\text { LUD } \\
\text { ROS } \\
\text { Acres }\end{array}$ & $\begin{array}{l}\text { Fifteen-Percent } \\
04-04 B \\
\text { Old Growth Habitat } \\
\text { Semi-Primitive Motorized } \\
426\end{array}$ \\
\hline $\begin{array}{l}\text { General } \\
\text { Characteristics }\end{array}$ & This is a forested area along a narrow bay. \\
\hline Historical Use & Commercially guided groups used this area in 1999. \\
\hline Access & $\begin{array}{l}\text { There is a protected anchorage during most weather conditions. } \\
\text { Beach landings with a skiff are possible but the exact location } \\
\text { depends on the tidal stage. }\end{array}$ \\
\hline Facilities & None \\
\hline $\begin{array}{l}\text { Concerns and/or } \\
\text { Opportunities }\end{array}$ & There are interpretive opportunities. \\
\hline Attractions & $\begin{array}{l}\text { There are opportunities to view wildlife and hike along the beach } \\
\text { fringe forest or muskegs at the back of the bay. }\end{array}$ \\
\hline Mitigation & $\begin{array}{l}\text { - See Appendix } C \text { for mitigation measures. } \\
\text { - Bald eagles } \\
\text { - Vrown bear viewing } \\
\text { - Riparian } \\
\text { - No large group camping. } \\
\text { - Guided activities will not interfere with other forest management } \\
\text { activities. }\end{array}$ \\
\hline
\end{tabular}




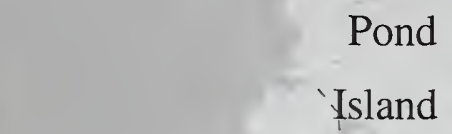

The

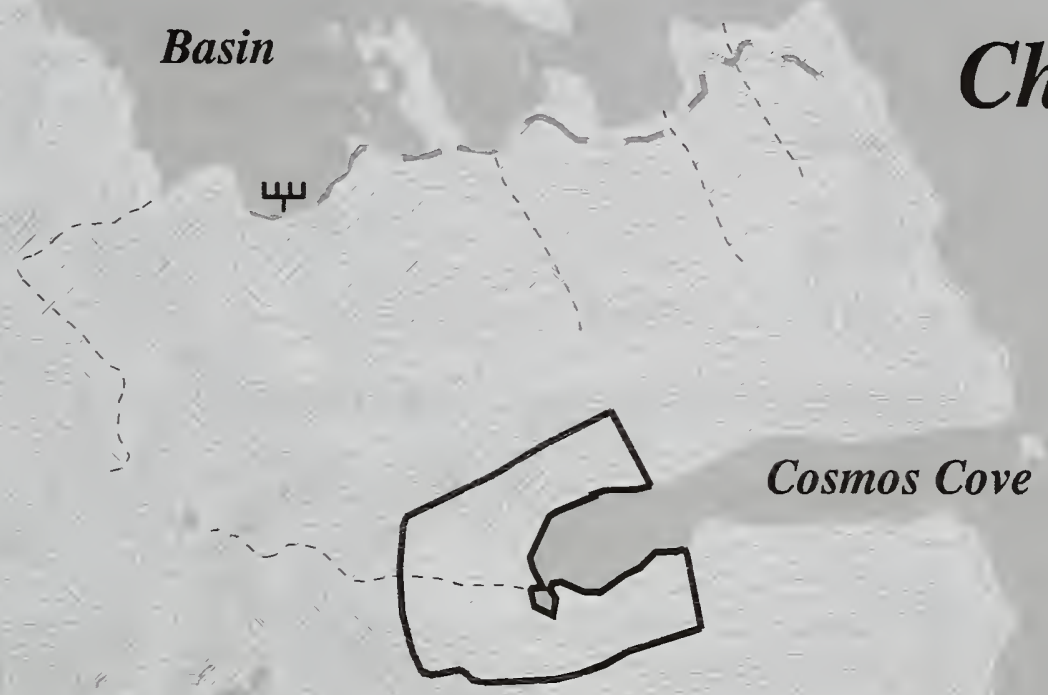

Hidden Falls

\section{Lake}

Strait

\section{Baranof}

\section{Kasnyku}

Bay

\section{Island}

$\sim$ Large Group Area Boundary Streams

Existing Road
Non National Forest Land

Wilderness

Outside of Project Area

$\begin{array}{cl}\square & \text { Salt and Fresh Water } \\ \text { 䓃 } & \text { Recreation Cabin } \\ \text { 茂 } & \text { Marine Access Point }\end{array}$

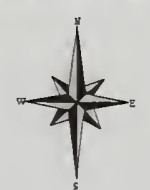




\section{Appendix B, Large Group Areas}

\begin{tabular}{|c|c|}
\hline & $\begin{array}{c}\text { Large Group Areas } \\
\text { Iyoukeen Peninsula } \\
\text { Alternatives } 3,5\end{array}$ \\
\hline $\begin{array}{l}\text { Type } \\
\text { Use Area } \\
\text { LUD } \\
\text { ROS } \\
\text { Acres }\end{array}$ & $\begin{array}{l}\text { Fifteen-Percent } \\
04-11 \\
\text { Old-Growth Habitat. } \\
\text { Semi-Primitive Motorized } \\
314\end{array}$ \\
\hline $\begin{array}{l}\text { General } \\
\text { Characteristics }\end{array}$ & $\begin{array}{l}\text { This is a narrow peninsula with excellent views across Chatham } \\
\text { Strait, Admiralty Island, and the mountain peaks behind Juneau. } \\
\text { There is a good anchorage in lyoukeen Cove on east side of the } \\
\text { peninsula. }\end{array}$ \\
\hline $\begin{array}{l}\text { Historical Use } \\
\text { Access }\end{array}$ & $\begin{array}{l}\text { No commercial outfitter/guide use occurred here in } 1999 . \\
\text { It is six miles from Kennel Creek. }\end{array}$ \\
\hline Facilities & There are no Forest Service facilities at this location. \\
\hline $\begin{array}{l}\text { Concerns and/or } \\
\text { Opportunities }\end{array}$ & There are seal and/or sea lion haul outs. \\
\hline Attractions & $\begin{array}{l}\text { It has a scenic setting with wildlife and marine mammal viewing } \\
\text { opportunities. }\end{array}$ \\
\hline Mitigation & $\begin{array}{l}\text { - See Appendix } C \text { for mitigation measures. } \\
\text { - Bald eagles } \\
\text { - Marine marnmals } \\
\text { - Vegetation } \\
\text { - Riparian } \\
\text { - No large group camping } \\
\text { No consumptive uses by large groups }\end{array}$ \\
\hline
\end{tabular}


Shoreline Outfitter/Guide EIS

Large Group Area

Use Area 04-11 IYOUKEEN PENINSULA

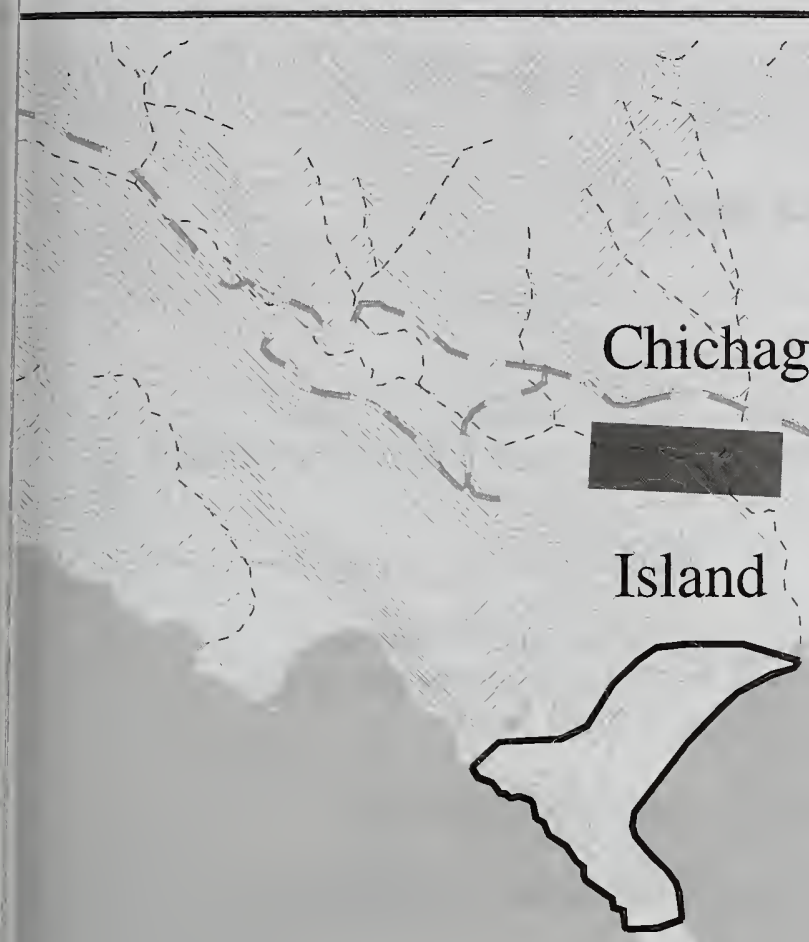

\section{Chatham}

\section{Strait}
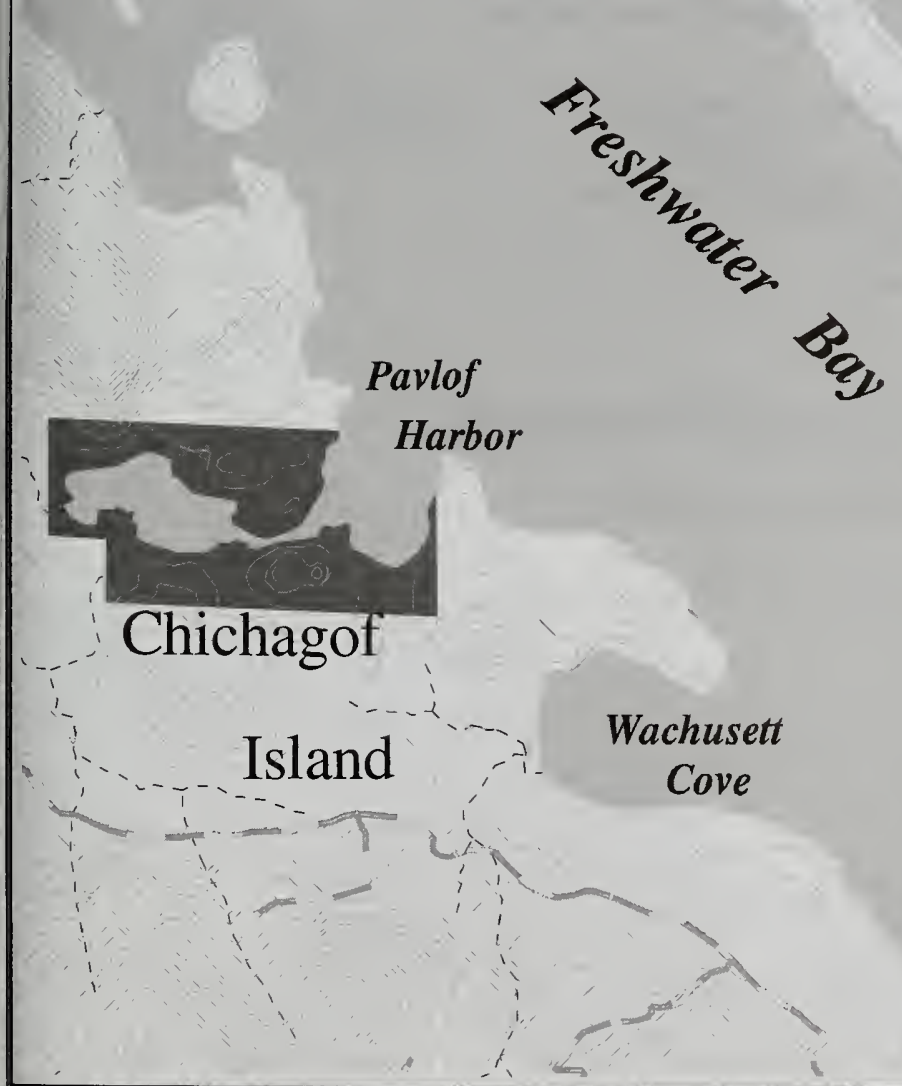

$\checkmark$ Large Group Area Boundary Streams

Existing Road

Non National Forest Land Wilderness

Outside of Project Area \begin{tabular}{cl}
\hline & Salt and Fresh Water \\
ㅁ & Recreation Cabin \\
m & Marine Access Point
\end{tabular}

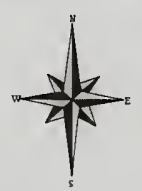

Contour Interval is 100 Feet 


\section{Appendix B, Large Group Areas}

\begin{tabular}{|c|c|}
\hline & $\begin{array}{l}\text { Large Group Areas } \\
\text { Neka Bay - North Bight } \\
\text { Alternatives } 3,5\end{array}$ \\
\hline $\begin{array}{l}\text { Type } \\
\text { Use Area } \\
\text { LUD } \\
\text { ROS } \\
\text { Acres }\end{array}$ & $\begin{array}{l}\text { Fifteen-Percent } \\
04-11 \\
\text { Old-Growth Habitat } \\
\text { Semi-Primitive Motorized, Semi-Primitive Non-Motorized, and Roaded } \\
\text { Modified } \\
347\end{array}$ \\
\hline $\begin{array}{l}\text { General } \\
\text { Characteristics }\end{array}$ & $\begin{array}{l}\text { This area has a scenic setting in a narrow secluded cove with } \\
\text { easy to access shoreline. It has a heavily forested beach fringe. } \\
\text { There is a good anchorage at the head of the bight. }\end{array}$ \\
\hline Historical Use & No commercial outfitter/guide use occurred here in 1999. \\
\hline Access & $\begin{array}{l}\text { It is ten miles from Hoonah. There is a protected anchorage, and } \\
\text { easy beach access by skiff or kayak. }\end{array}$ \\
\hline Facilities & There are no Forest Service facilities at this location. \\
\hline $\begin{array}{l}\text { Concerns and/or } \\
\text { Opportunities }\end{array}$ & $\begin{array}{l}\text { There is resource damage from repeated trampling. Possible } \\
\text { cultural sites exist. Hoonah residents use this area. }\end{array}$ \\
\hline Attractions & Scenic setting, wildlife viewing opportunities \\
\hline Mitigation & $\begin{array}{l}\text { - See Appendix } C \text { for mitigation measures. } \\
\text { - Bald eagles } \\
\text { - Vrown bear viewing } \\
\text { - Riparian } \\
\text { - } \quad \text { No large group camping. } \\
\text { - No consumptive uses by large groups. }\end{array}$ \\
\hline
\end{tabular}




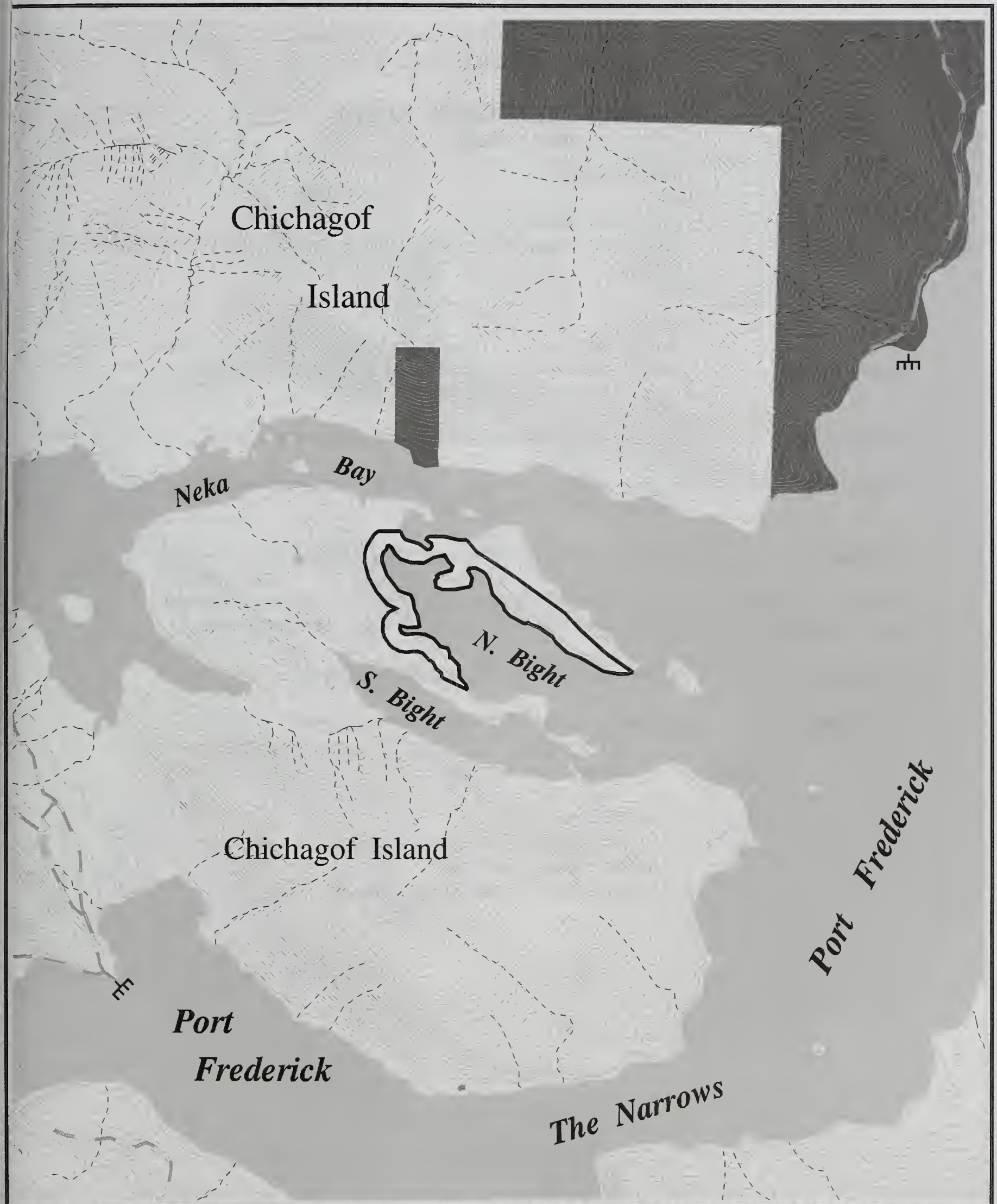

Large Group Area Boundary Streams Existing Road
Non National Forest Land

Wilderness

Outside of Project Area
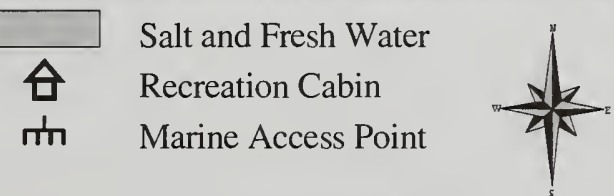

Contour Interval is 100 Feet 


\section{Appendix B, Large Group Areas}

\section{Large Group Areas \\ Neka Bay - South Bight}

Alternative 3, 5

Type
Use Area
LUD
ROS
Acres
General
Characteristics
Historical Use
Access
Facilities
Concerns and/or
Opportunities

Attractions

Mitigation

\section{Fifteen-Percent}

04-11

Old-Growth Habitat.

Semi-Primitive Motorized, Semi-Primitive Non-Motorized, and Roaded Modified 457

It has a scenic setting in a narrow secluded cove with an easily accessible shoreline. The beach fringe is heavily forested. There is a good anchorage at the head of the bight.

No commercial outfitter-guide use occurred here in 1999.

It is ten miles from Hoonah. There is a protected anchorage, and easy beach access by skiff or kayak.

There are no Forest Service facilities at this location.

There is resource damage from repeated trampling. Potential cultural sites exist. This area is used by Hoonah residents.

Scenic setting, wildlife viewing opportunities

- See Appendix C for mitigation measures.

- Bald eagles

- Brown bear viewing

- Vegetation

- Riparian

- Cultural sites will be excluded from guided use.

- No large group camping.

- No consumptive uses by large groups. 
Shoreline Outfitter/Guide EIS

Large Group Area

Use Area 04-11 NEKA BAY SOUTH BIGHT

\section{Chichagof}

Island

Neka

$B_{a y}$
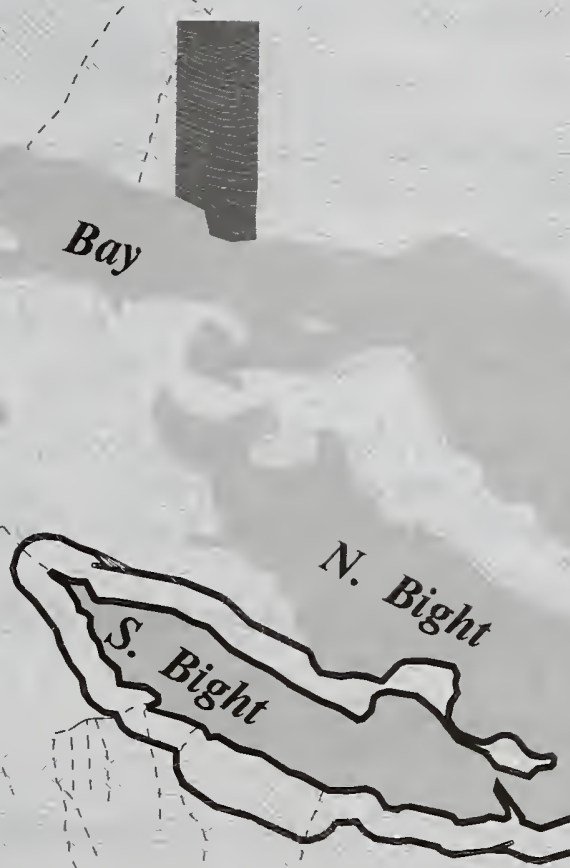

Chichagof Island

$-1$

Port

Frederick

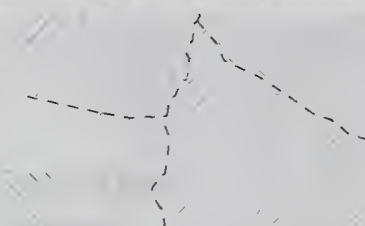

$\frac{1}{4}$

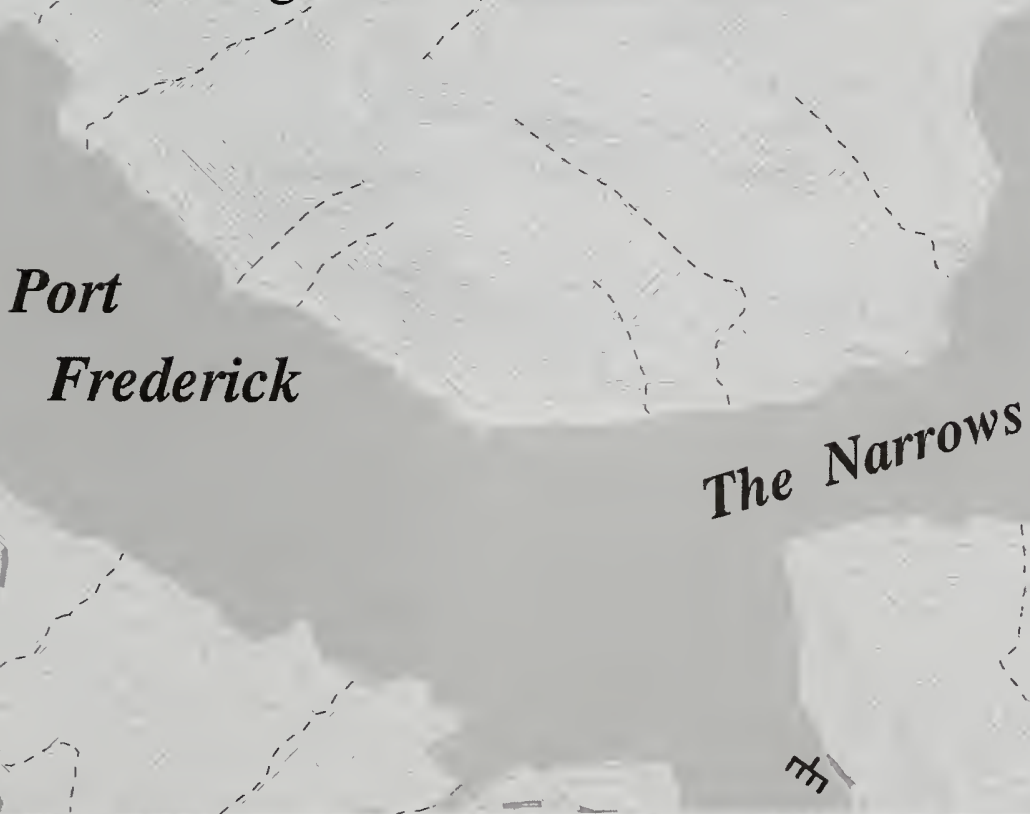

$\checkmark$ Large Group Area Boundary

Streams

Existing Road

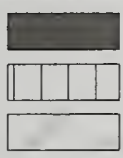

Non National Forest Land

Wilderness

Outside of Project Area

\begin{tabular}{cl}
\hline & Salt and Fresh Water \\
ㄴ & Recreation Cabin \\
瑸 & Marine Access Point
\end{tabular}

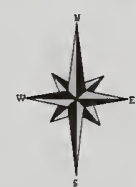

Contour Interval is 100 Feet 


\section{Appendix B, Large Group Areas}

\begin{tabular}{|c|c|}
\hline & $\begin{array}{l}\text { Large Group Area } \\
\text { Saltery Bay } \\
\text { Alternative } 3\end{array}$ \\
\hline $\begin{array}{l}\text { Type } \\
\text { Use Area } \\
\text { LUD } \\
\text { ROS } \\
\text { Acres }\end{array}$ & $\begin{array}{l}\text { Fifteen-Percent } \\
04-12 \\
\text { Old Growth Habitat, Modified Landscape } \\
\text { Semi-Primitive Motorized } \\
183\end{array}$ \\
\hline $\begin{array}{l}\text { General } \\
\text { Characteristics }\end{array}$ & $\begin{array}{l}\text { A very large tide and grass flat extends approximately one mile inland } \\
\text { from saltwater. There is an old growth forest in the bay with signs of } \\
\text { beach logging. }\end{array}$ \\
\hline Historical Use & $\begin{array}{l}\text { Beach logging took place in the } 1950 \text { s and } 1960 \text { s. Commercial } \\
\text { outfitter/guides used this area in } 1999 .\end{array}$ \\
\hline Access & $\begin{array}{l}\text { The anchorage is protected during most weather conditions. Skiff } \\
\text { landings are possible along the shore in the back of the bay. It is } \\
\text { possible to take a skiff up the creek and land on a tide or grass flat. }\end{array}$ \\
\hline Facilities & $\begin{array}{l}\text { There is a survival shelter near the mouth of the bay on the northwest } \\
\text { side. }\end{array}$ \\
\hline Attractions & Wildlife viewing, hiking \\
\hline Mitigation & $\begin{array}{l}\text { - See Appendix } C \text { for mitigation measures. } \\
\text { - Bald eagles } \\
\text { - Mrown bear viewing } \\
\text { - Vegetation } \\
\text { - Riparian } \\
\text { - No large group camping. } \\
\text { - No consumptive uses by large groups. }\end{array}$ \\
\hline
\end{tabular}


Shoreline Outfitter/Guide EIS

Large Group Area

Use Area 04-12 SALTERY BAY

\section{Chichagof}

\section{Island}

\section{Crab Bay}

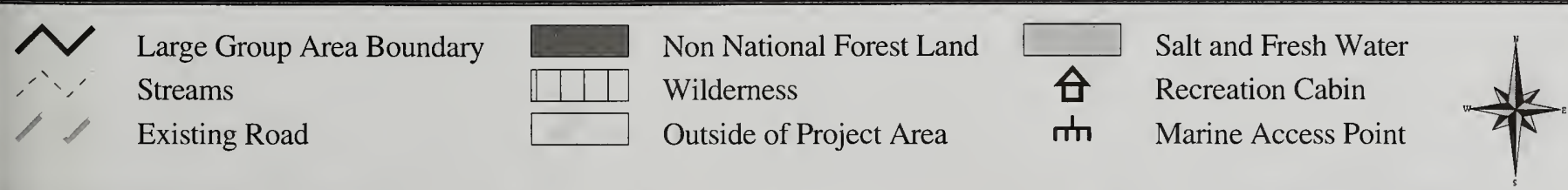

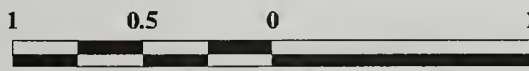




\section{Appendix B, Large Group Areas}

\begin{tabular}{|c|c|}
\hline & $\begin{array}{l}\text { Large Group Area } \\
\text { Seal Bay } \\
\text { Alternatives 3, } 5\end{array}$ \\
\hline $\begin{array}{l}\text { Type } \\
\text { Use Area } \\
\text { LUD } \\
\text { ROS } \\
\text { Acres } \\
\end{array}$ & $\begin{array}{l}\text { Fifteen-Percent } \\
04-12 \\
\text { Old Growth Habitat } \\
\text { Roaded Modified, Semi-Primitive Motorized } \\
351\end{array}$ \\
\hline $\begin{array}{l}\text { General } \\
\text { Characteristics }\end{array}$ & $\begin{array}{l}\text { A large grass and tide flat at the end of the bay with old growth forest } \\
\text { along the sides. Logging occurred in the 1970s. }\end{array}$ \\
\hline Historical Use & Commercial outfitter/guides used this area in 1999. \\
\hline Access & $\begin{array}{l}\text { The anchorage is protected during most weather conditions. Skiffs } \\
\text { can go ashore during most tide stages, but very little beach is } \\
\text { exposed for walking. It is possible to take a skiff up the stream a } \\
\text { short way and land on tide or grass flat. }\end{array}$ \\
\hline Facilities & $\begin{array}{l}\text { An old road comes down through the grass flat near the saltwater } \\
\text { edge. }\end{array}$ \\
\hline $\begin{array}{l}\text { Concerns and/or } \\
\text { Opportunities }\end{array}$ & There are interpretive opportunities. \\
\hline Attractions & $\begin{array}{l}\text { Wildlife viewing, hiking in the tide and grass flats and beach fringe, } \\
\text { hardened road }\end{array}$ \\
\hline Mitigation & $\begin{array}{l}\text { - See Appendix C for mitigation measures. } \\
\text { - Bald eagles } \\
\text { - Brown bear viewing } \\
\text { - Regetation } \\
\text { - No large group camping. } \\
\text { - No consumptive uses by large groups. }\end{array}$ \\
\hline
\end{tabular}




\section{Appendix B, Large Group Areas}

\section{Large Group Area}

\section{Trap Bay}

Alternative 3

\begin{tabular}{ll}
\hline Type & Fifteen-Percent \\
Use Area & $04-12$ \\
LUD & LUD II \\
ROS & Semi-Primitive Motorized \\
Acres & 197
\end{tabular}


Shoreline Outfitter/Guide EIS

Large Group Area

Use Area 04-12 TRAP BAY

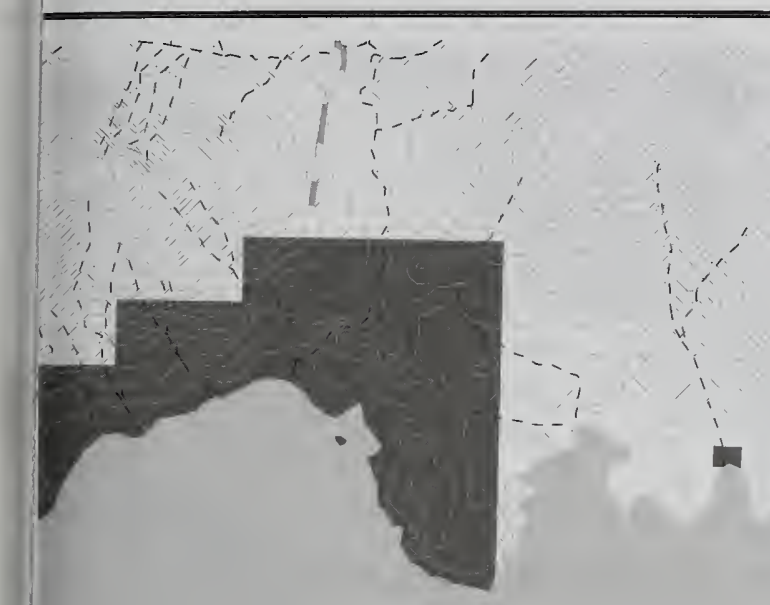

\section{Tenakee Inlet}

\section{Chichagof}

\section{Island}
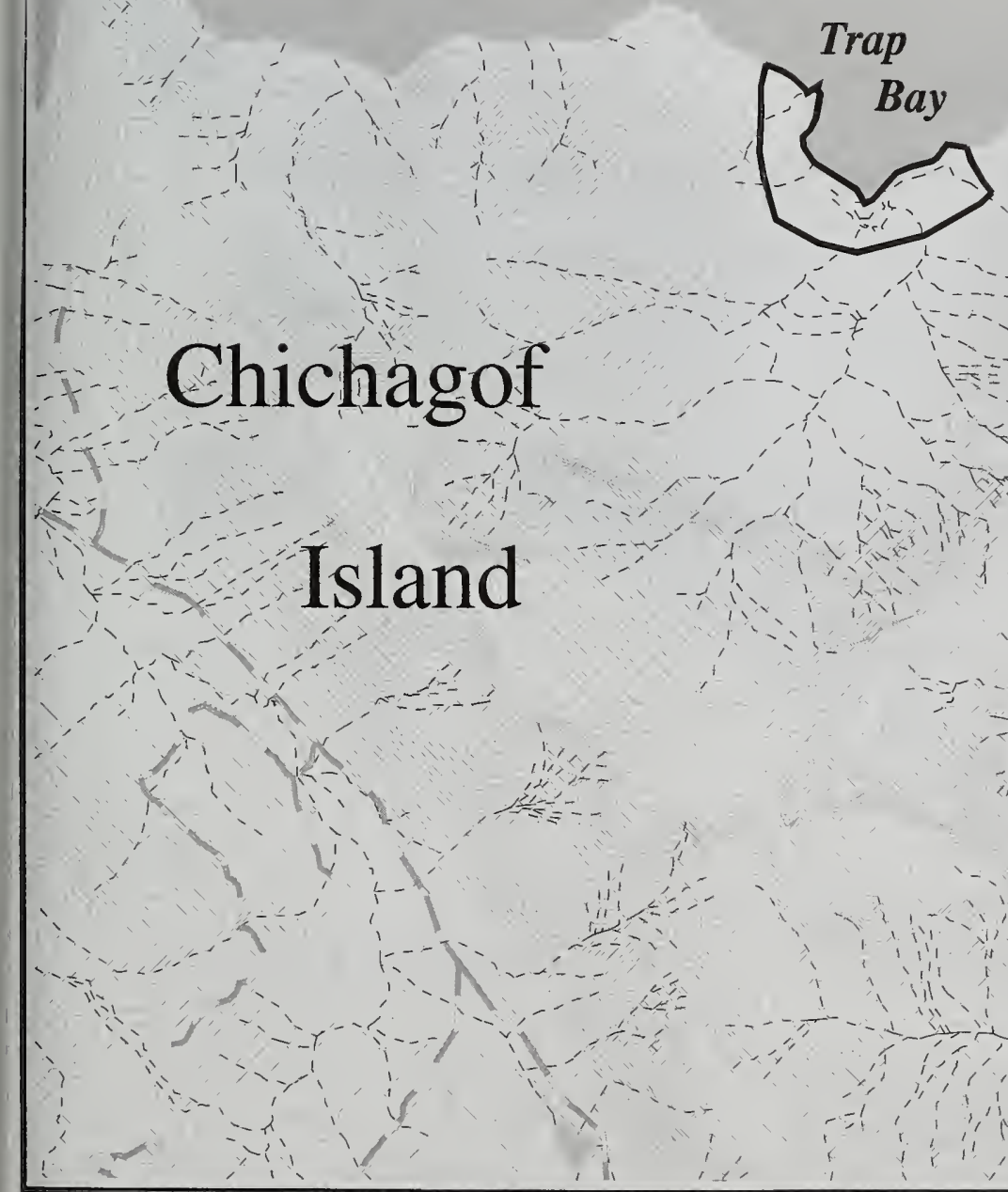

Large Group Area Boundary Streams

Existing Road
Non National Forest Land Wilderness

Outside of Project Area

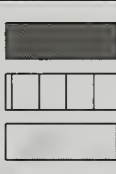




\section{Appendix B, Large Group Areas}

\begin{tabular}{|c|c|}
\hline & $\begin{array}{c}\text { Large Group Area } \\
\text { Moser } \\
\text { Alternative } 3\end{array}$ \\
\hline $\begin{array}{l}\text { Type } \\
\text { Use Area } \\
\text { LUD } \\
\text { ROS } \\
\text { Acres } \\
\end{array}$ & $\begin{array}{l}\text { Fifteen-Percent } \\
04-13 \\
\text { LUD II } \\
\text { Primitive } \\
134 \\
\end{array}$ \\
\hline $\begin{array}{l}\text { General } \\
\text { Characteristics }\end{array}$ & The area has a long sand beach and old growth spruce forest. \\
\hline Historical Use & No commercial outfitting and guiding occurred here in 1999. \\
\hline Access & $\begin{array}{l}\text { The entire beach area is good for landing a small skiff or inflatable } \\
\text { boat. }\end{array}$ \\
\hline Facilities & None \\
\hline $\begin{array}{l}\text { Concerns and/or } \\
\text { Opportunities }\end{array}$ & Cultural sites \\
\hline Attractions & Sandy beach, beach combing, wildlife viewing, old growth forest \\
\hline Mitigation & $\begin{array}{l}\text { - See Appendix } C \text { for mitigation measures. } \\
\text { - Mald eagles } \\
\text { - Marine mammals } \\
\text { - Rogetation } \\
\text { - No large group camping. } \\
\text { - Cultural sites will be excluded from guided use. }\end{array}$ \\
\hline
\end{tabular}


Shoreline Outfitter/Guide EIS

Large Group Area

Use Area 04-13 MOSER

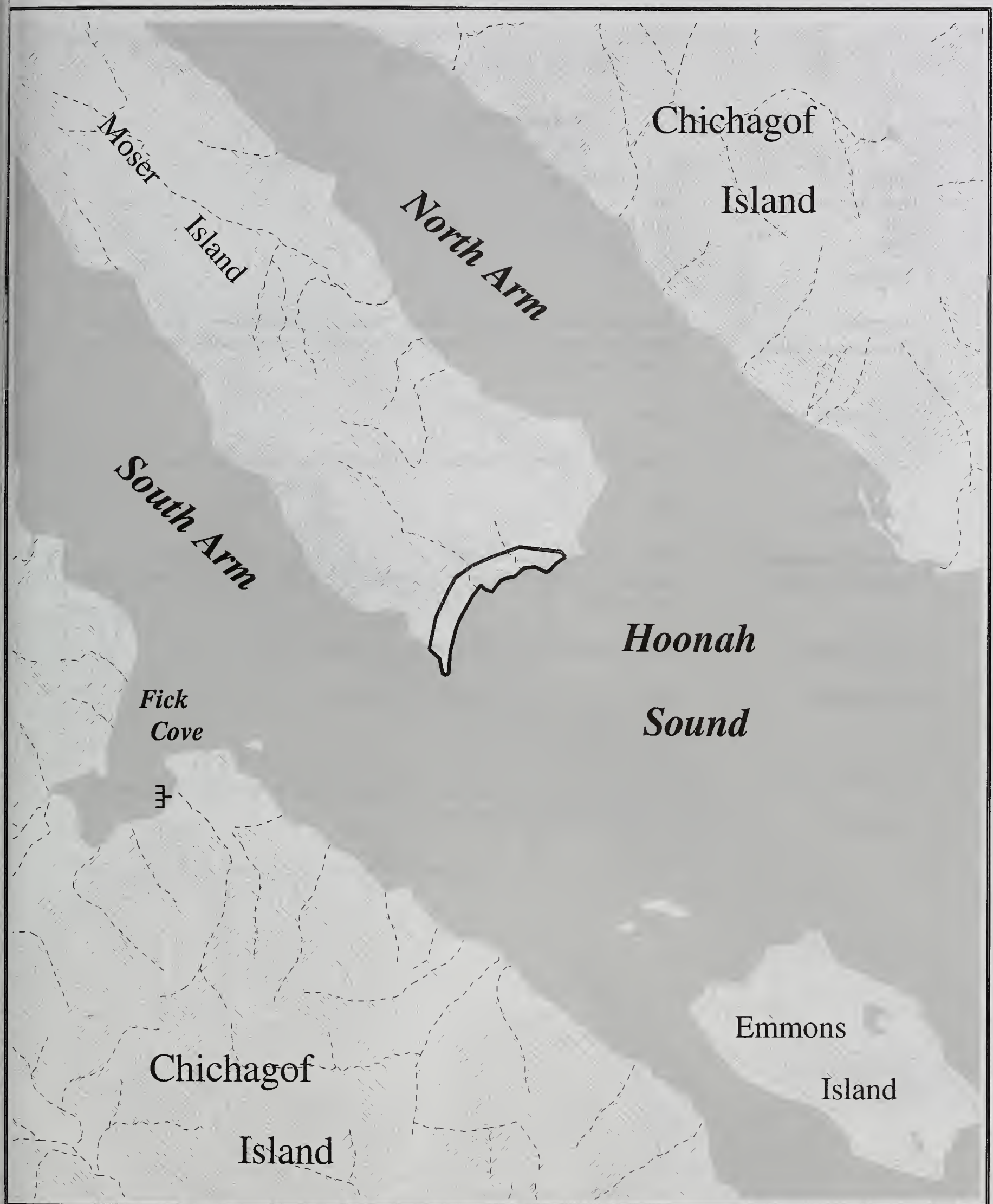

Large Group Area Boundary Streams

Existing Road
Non National Forest Land

Wilderness

Outside of Project Area

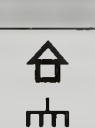

m
Salt and Fresh Water

Recreation Cabin

Marine Access Point

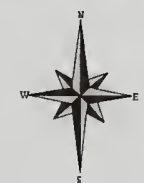

Contour Interval is 100 Feet 


\section{Appendix B, Large Group Areas}

\begin{tabular}{|c|c|}
\hline & $\begin{array}{l}\text { Large Group Area } \\
\text { Nelson Falls } \\
\text { Alternatives } 3,4,5\end{array}$ \\
\hline $\begin{array}{l}\text { Type } \\
\text { Use Area } \\
\text { LUD } \\
\text { ROS } \\
\text { Acres }\end{array}$ & $\begin{array}{l}\text { Fifteen-Percent } \\
04-13 \\
\text { LUD II } \\
\text { Primitive } \\
113\end{array}$ \\
\hline $\begin{array}{l}\text { General } \\
\text { Characteristics }\end{array}$ & $\begin{array}{l}\text { This area has an unaltered old growth forest setting with a small tide } \\
\text { flat at the mouth of the stream. Nelson Falls is approximately } 500 \text { feet } \\
\text { inland from the beach. }\end{array}$ \\
\hline Historical Use & None \\
\hline Access & There is a protected anchorage with skiff access to the beach. \\
\hline Facilities & None \\
\hline $\begin{array}{l}\text { Concerns and/or } \\
\text { Opportunities }\end{array}$ & $\begin{array}{l}\text { Heavy use of the area could result in unacceptable vegetation } \\
\text { damage. Guides will need to monitor this and assure that clients stay } \\
\text { on the trail. }\end{array}$ \\
\hline Attractions & Scenic waterfall, hiking along beach fringe forest \\
\hline Mitigation & $\begin{array}{l}\text { See Appendix } C \text { for mitigation measures. } \\
\text { - Bald Eagles } \\
\text { - Regetation } \\
\text { Large group use of Nelson Falls trail will not be permitted until } \\
\text { the trail is reconstructed. }\end{array}$ \\
\hline
\end{tabular}


Shoreline Outfitter/Guide EIS

Large Group Area

Use Area 04-13 NELSON FALLS

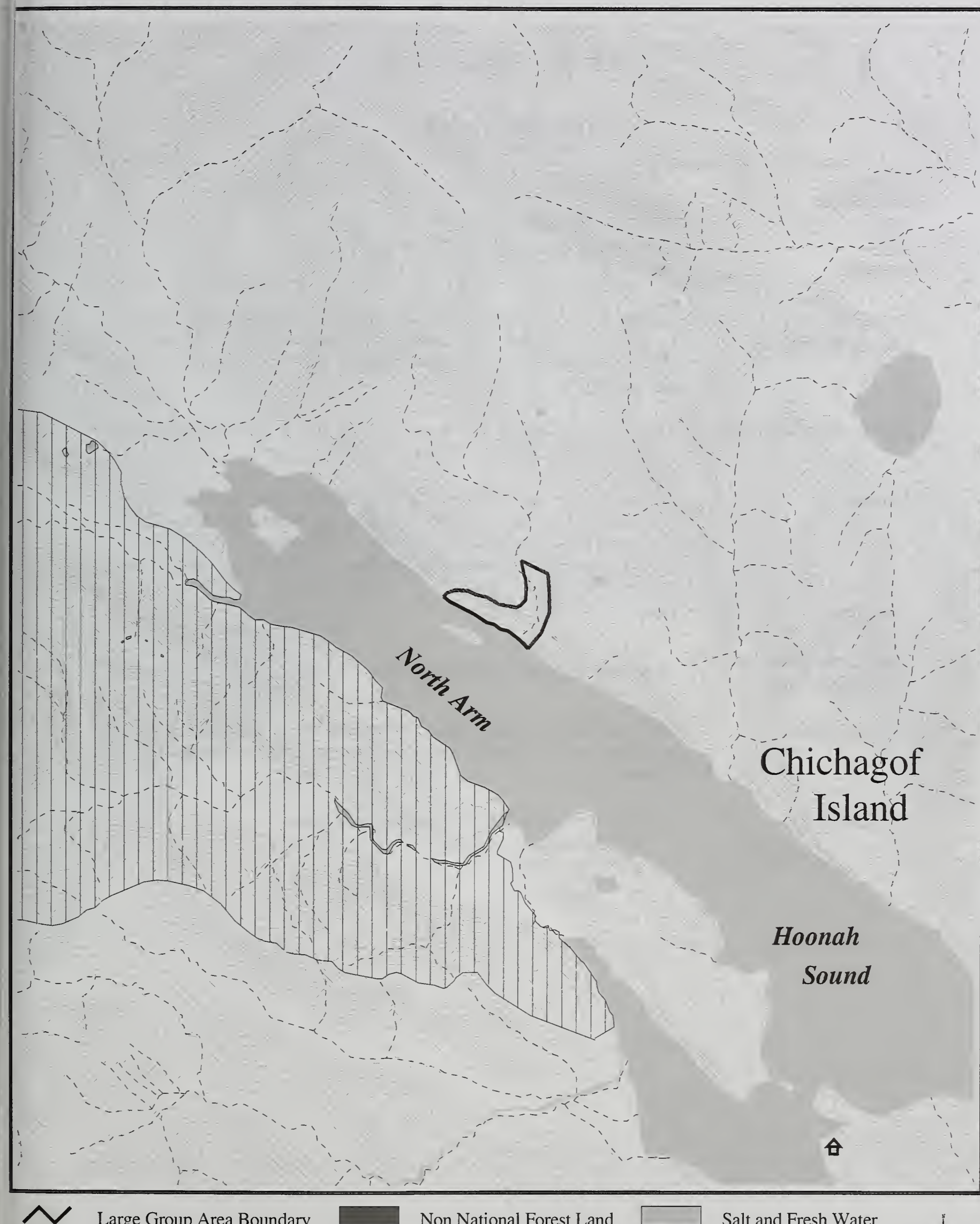

Large Group Area Boundary Streams

Existing Road
Non National Forest Land Wilderness

Outside of Project Area

\section{䓃} in
Salt and Fresh Water

Recreation Cabin

Marine Access Point

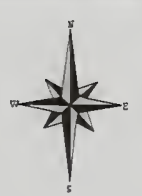




\section{Appendix B, Large Group Areas}

\section{Large Group Area}

\section{Nismeni Point}

Alternatives 3, 5

\begin{tabular}{l}
\hline Type \\
Use Area \\
LUD \\
ROS \\
Acres \\
\hline $\begin{array}{l}\text { General } \\
\text { Characteristics }\end{array}$
\end{tabular}

Fifteen-Percent

04-13

Old Growth Habitat

Semi-Primitive Motorized

144

\section{Historical Use}

Access

Facilities

Concerns and/or Opportunities

\section{Attractions}

\section{Mitigation}

This area is an example of historical second growth. Inland the area becomes open forest and patchy bogs with small ponds. There are a good variety of vegetation types. At low tide there is some intertidal life to explore.

This area was logged in the early 1960 s. No commercial outfitting and guiding occurred here in 1999.

The anchorage off Peril Strait is protected, except from the easterly direction. It is possible to land a skiff in the small bay to the east of the point; the exact location depends on the tide stage. The very head of the bay has some narrow shallow mudflats at lowest tides.

None

There are interpretive opportunities.

This is a historic logging area. There are hiking opportunities inland to open forest and bog areas. It is close to Surgius Narrows and Peril Straits.

- See Appendix C for mitigation measures.

- Brown bear viewing

- Vegetation

- Riparian 
Shoreline Outfitter/Guide EIS

Large Group Area

Use Area 04-13 NISMENI POINT

\section{Otstoia Island}

\section{Baranof}

Island

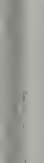

$\checkmark$ Large Group Area Boundary Streams

Existing Road

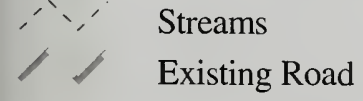

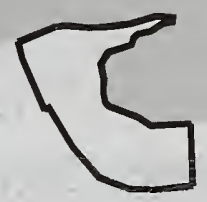
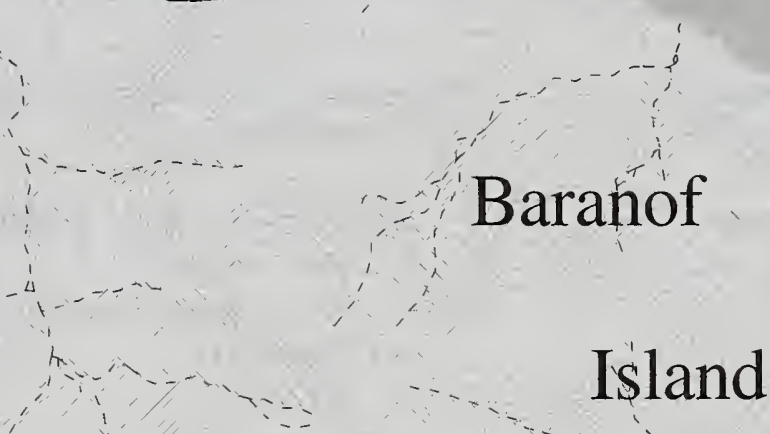

Non National Forest Land

Wilderness

Outside of Project Area \begin{tabular}{cl}
\hline & Salt and Fresh Water \\
4 & Recreation Cabin \\
in & Marine Access Point
\end{tabular}

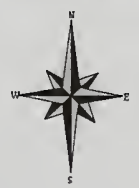

Contour Interval is 100 Feet 


\section{Appendix B, Large Group Areas}

\begin{tabular}{|c|c|}
\hline & $\begin{array}{l}\text { Large Group Area } \\
\text { Patterson Bay } \\
\text { Alternatives } 3,4,5\end{array}$ \\
\hline $\begin{array}{l}\text { Type } \\
\text { Use Area } \\
\text { LUD } \\
\text { ROS } \\
\text { Acres }\end{array}$ & $\begin{array}{l}\text { Fifteen-Percent } \\
04-13 \\
\text { LUD II } \\
\text { Primitive } \\
83\end{array}$ \\
\hline $\begin{array}{l}\text { General } \\
\text { Characteristics }\end{array}$ & $\begin{array}{l}\text { This area is a scenic location with meadows at the end of the bay. } \\
\text { There are landing areas on south side of bay on small gravel beaches } \\
\text { with easy walking along the shoreline, particularly at low tides. Some } \\
\text { usable wildlife trails are in the beach fringe forest; other trails lead } \\
\text { inland and up rather rugged slopes. Vegetation along the forest edge } \\
\text { is particularly good in early summer. }\end{array}$ \\
\hline Historical Use & Outfitter/guides used this area in 1999. \\
\hline Access & $\begin{array}{l}\text { There are protected anchorages within the bay. Skiffs can land at } \\
\text { small pebble beaches. }\end{array}$ \\
\hline Facilities & None \\
\hline $\begin{array}{l}\text { Concerns and/or } \\
\text { Opportunities }\end{array}$ & There are interpretive opportunities. \\
\hline Attractions & $\begin{array}{l}\text { Unaltered forest, beach walking, bear viewing (at the head of the bay } \\
\text { in the meadows) }\end{array}$ \\
\hline Mitigation & $\begin{array}{l}\text { - See Appendix } C \text { for mitigation measures. } \\
\text { - Bald eagles } \\
\text { - Brown bear viewing } \\
\text { - Regetation } \\
\text { Riparian }\end{array}$ \\
\hline
\end{tabular}




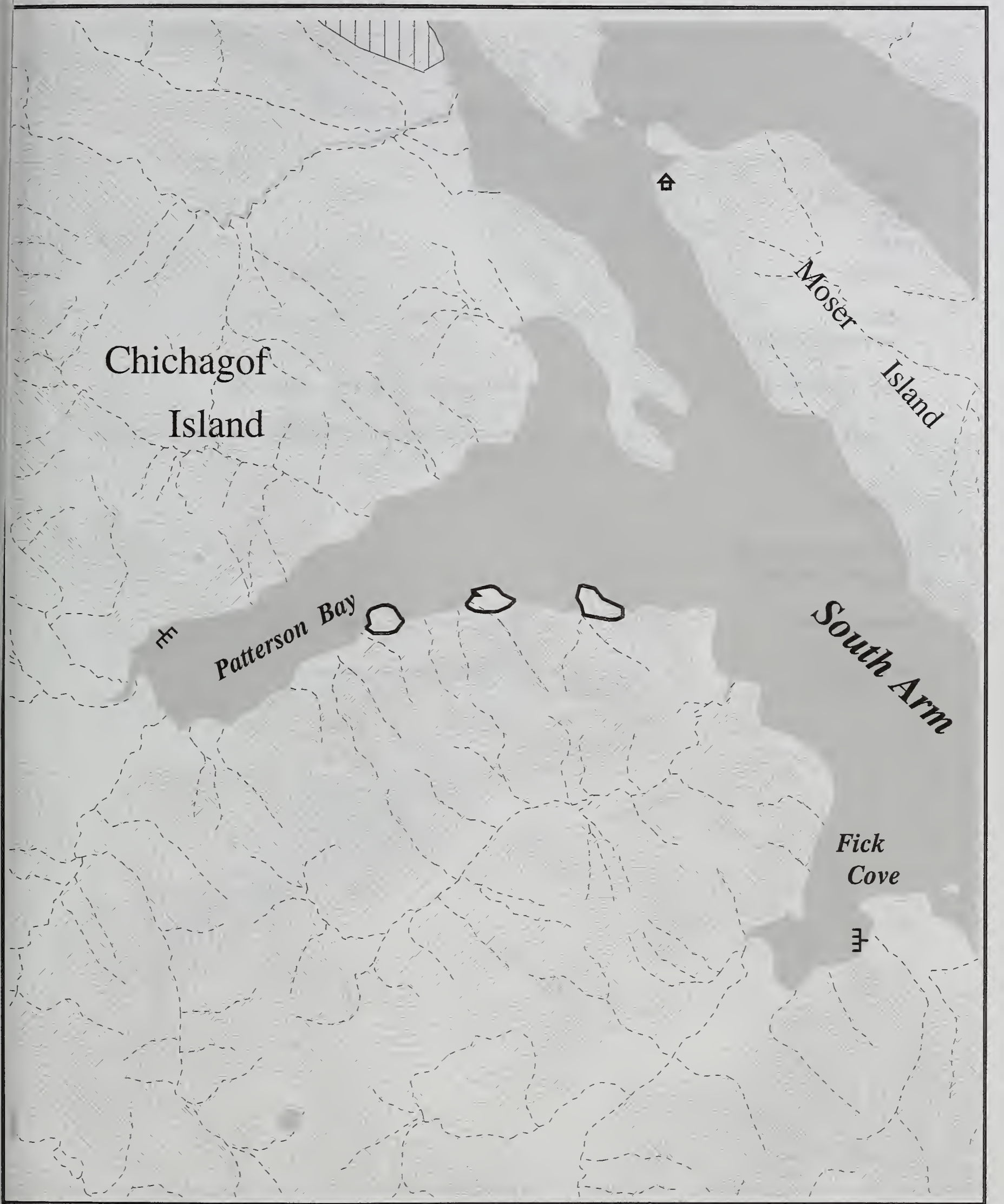




\section{Appendix B, Large Group Areas}

\begin{tabular}{|c|c|}
\hline & $\begin{array}{c}\text { Large Group Area } \\
\text { Patterson Bay - North Point } \\
\text { Alternative } 3\end{array}$ \\
\hline $\begin{array}{l}\text { Type } \\
\text { Use Area } \\
\text { LUD } \\
\text { ROS } \\
\text { Acres }\end{array}$ & $\begin{array}{l}\text { Fifteen-Percent } \\
04-13 \\
\text { LUD II } \\
\text { Primitive } \\
81\end{array}$ \\
\hline $\begin{array}{l}\text { General } \\
\text { Characteristics }\end{array}$ & Unaltered old growth forest with some large trees. \\
\hline Historical Use & No commercial outfitter/guides used this area in 1999. \\
\hline Access & $\begin{array}{l}\text { There are protected anchorages within the bay. It is possible to land } \\
\text { a skiff on the small pebble beaches. }\end{array}$ \\
\hline Facilities & None \\
\hline $\begin{array}{l}\text { Concerns and/or } \\
\text { Opportunities }\end{array}$ & None \\
\hline Attractions & Wildlife viewing, hiking on beach or beach fringe forest \\
\hline Mitigation & $\begin{array}{l}\text { - See Appendix } C \text { for mitigation measures } \\
\text { - Bald eagles } \\
\text { - Brown bear viewing } \\
\text { - Regetation } \\
\text { Riparian }\end{array}$ \\
\hline
\end{tabular}


Shoreline Outfitter/Guide EIS

Large Group Area

Use Area 04-13 PATTERSON BAY NORTH POINT
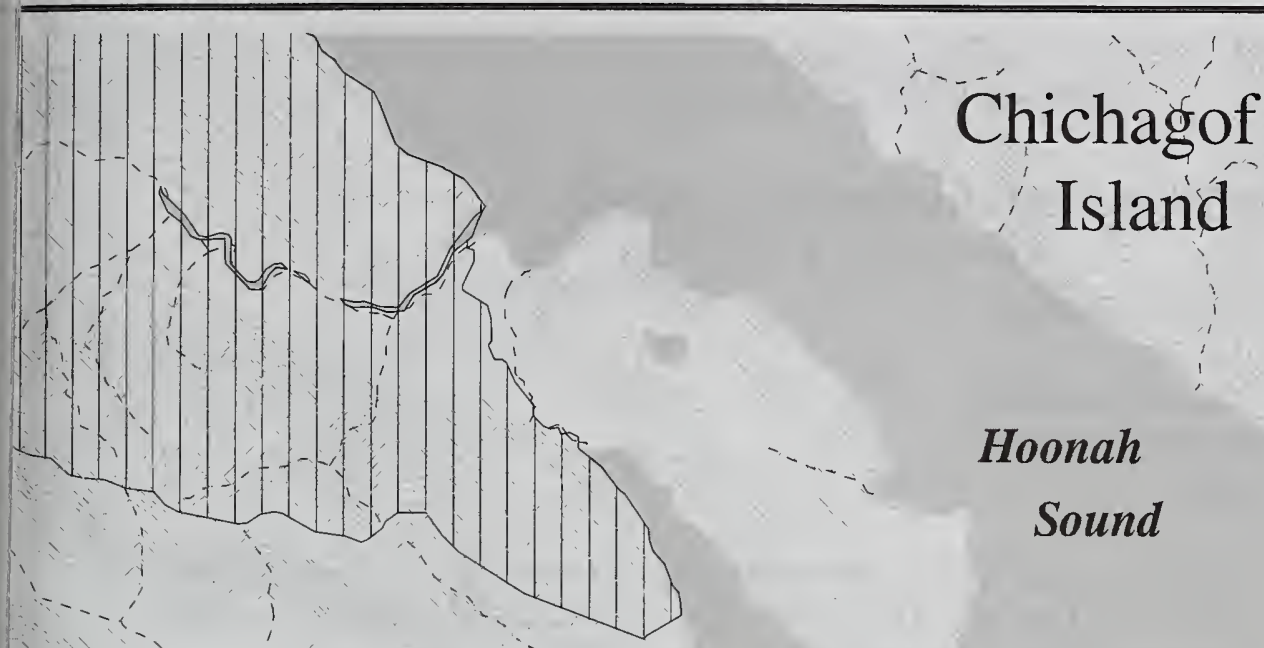

Hoonah

Sound

合

Chichagof

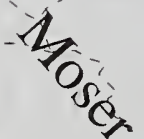

Island

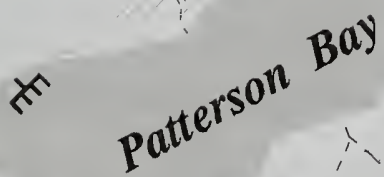

$\checkmark$ Large Group Area Boundary Streams

Existing Road
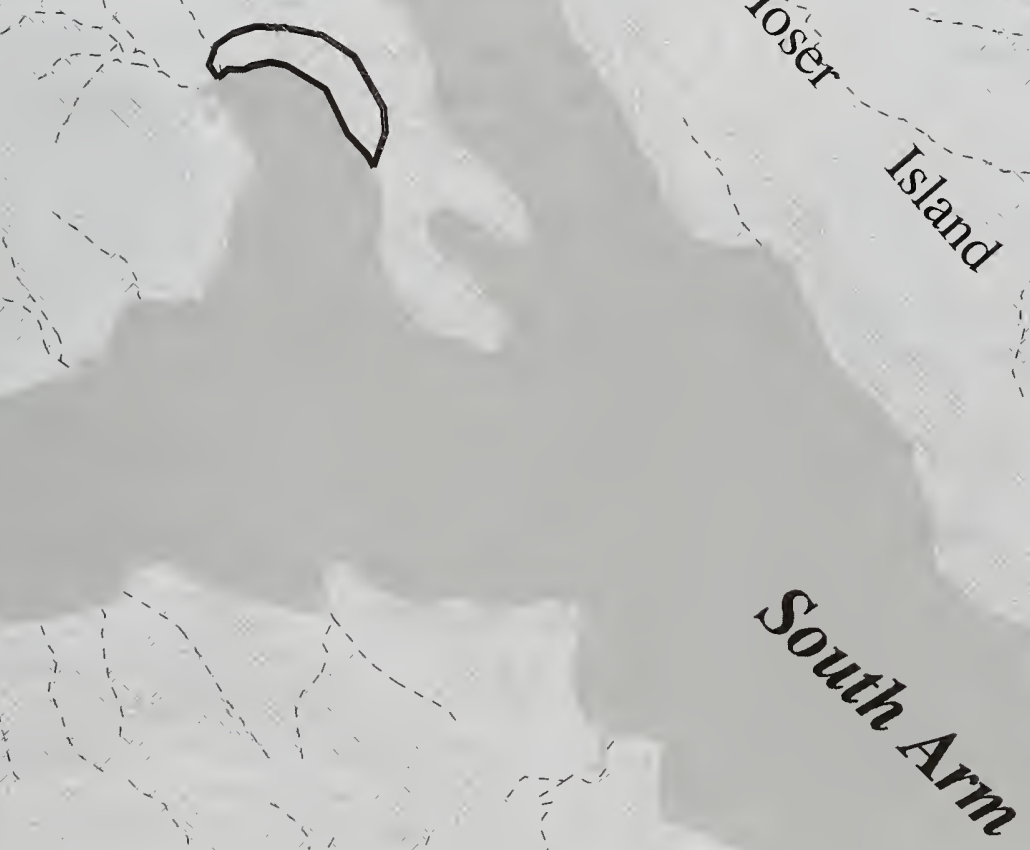

Fick

Cove 


\begin{tabular}{|c|c|}
\hline \multicolumn{2}{|r|}{$\begin{array}{l}\text { Todd Road/Lindenburg Head } \\
\text { Alternatives } 3,5\end{array}$} \\
\hline $\begin{array}{l}\text { Type } \\
\text { Use Area } \\
\text { LUD } \\
\text { ROS } \\
\text { Acres }\end{array}$ & $\begin{array}{l}\text { Fifteen-Percent } \\
04-13 \\
\text { Scenic Viewshed } \\
\text { Roaded Modified } \\
232\end{array}$ \\
\hline $\begin{array}{l}\text { General } \\
\text { Characteristics }\end{array}$ & $\begin{array}{l}\text { The surrounding area and inland slopes have been logged relatively } \\
\text { recently. The beach fringe forest is still intact and consists of large } \\
\text { trees with open understory. An old logging road comes within } \\
\text { approximately } 300 \text { feet of the shoreline and can be followed relatively } \\
\text { easily to the west for some distance. A wildlife trail along the old road } \\
\text { has kept a path open. To the east, the road starts uphill but is heavily } \\
\text { overgrown with alder. To the west, the road goes by some managed } \\
\text { stands and through old growth beach fringe. }\end{array}$ \\
\hline Historical Use & $\begin{array}{l}\text { This area was logged in the 1970s. Commercial outfitting/guiding did } \\
\text { not occur here in } 1999 .\end{array}$ \\
\hline Access & $\begin{array}{l}\text { There is an exposed anchorage to the east of Lindenburg Head. Skiff } \\
\text { landings are possible along shore, but the exact location depends on } \\
\text { the tide stage. }\end{array}$ \\
\hline Facilities & Old logging road \\
\hline $\begin{array}{l}\text { Concerns and/or } \\
\text { Opportunities }\end{array}$ & $\begin{array}{l}\text { There are opportunities to interpret historic canneries and forest } \\
\text { management practices. }\end{array}$ \\
\hline Attractions & Beach fringe forest, hardened trail, forest regeneration \\
\hline Mitigation & $\begin{array}{l}\text { See Appendix } C \text { for mitigation measures. } \\
\text { - Cultural resources } \\
\text { To avoid impacts to cultural sites, guided groups shall stay on the } \\
\text { road or uphill from the road. } \\
\text { Access from the beach to the road will be limited to a corridor at } \\
\text { the marine access point. } \\
\text { - Guided activities will not interfere with other forest management } \\
\text { activities. }\end{array}$ \\
\hline
\end{tabular}




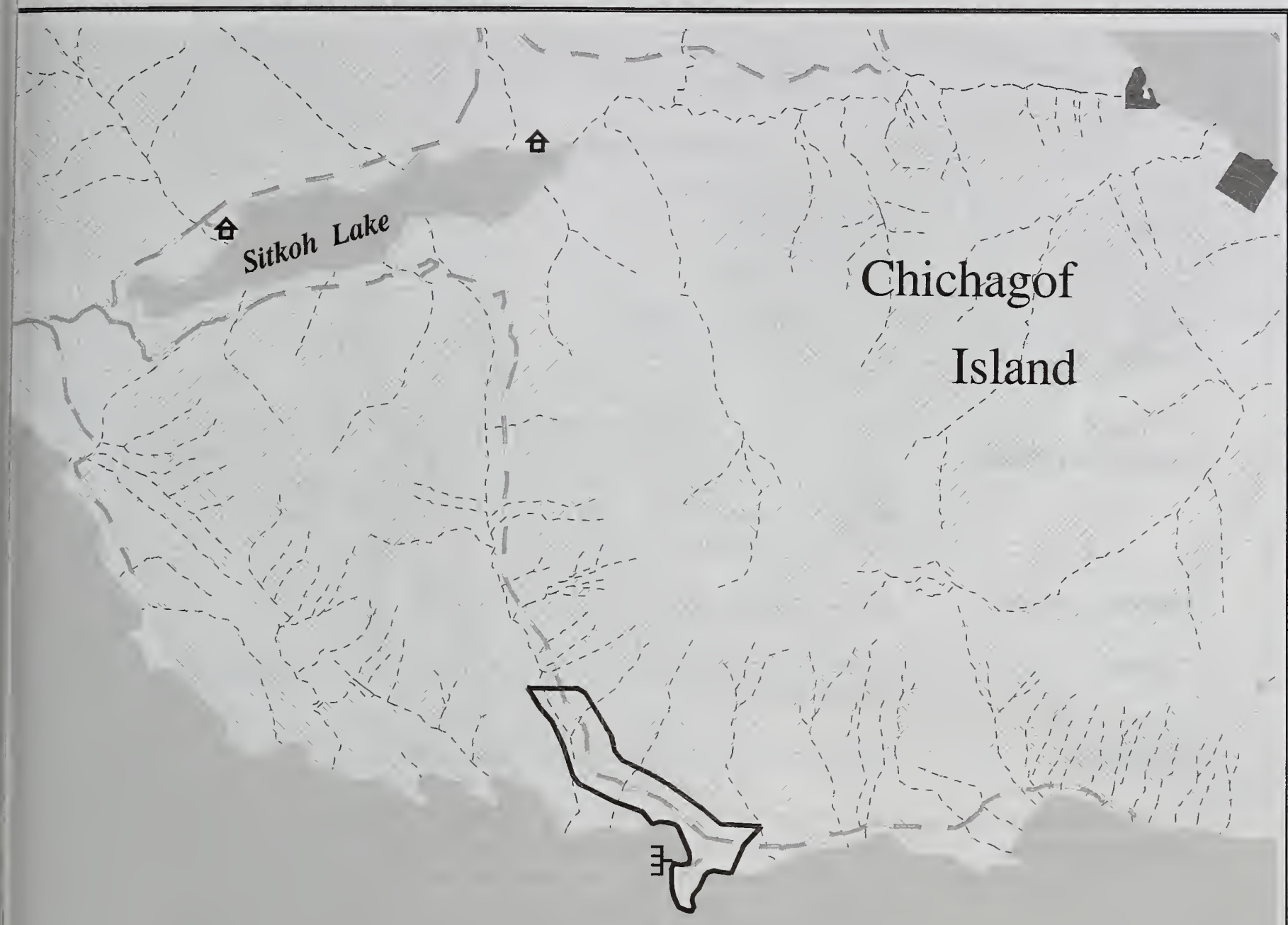

Peril Strait

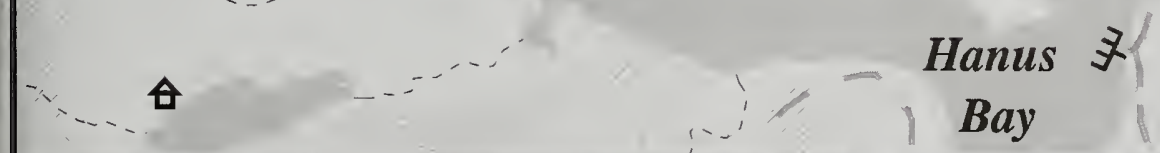




\section{Appendix B, Large Group Areas}

\section{Large Group Areas}

\section{Damp Marker}

Alternatives 3, 4, 5

\begin{tabular}{l}
\hline Type \\
Use Area \\
LUD \\
ROS \\
Acres \\
\hline General \\
Characteristics \\
\\
Historical Use \\
Access \\
Facilities \\
Concerns and/or \\
Opportunities
\end{tabular}

Fifteen-Percent
$04-16$ A
LUD II
Semi-Primitive Motorized
95

This area has a narrow uplifted beach along steep mountain slopes. It does not receive much use because the upland beach is mostly impenetrable alder and devils club. The southwestern end of this use area probably has the most potential for a hospitable large group site.

No commercial outfitter/guide use occurred here in 1999.

Good anchorage on calm days. The beach is accessible by small skiff or kayak.

There are no Forest Service facilities at this location.

This location was identified as a "Desired Area" (previously unvisited) by the participating tour boat operators during the 3/11/99 Sitka meeting - as identified on the Sitka Conservation Society map Areas Desired for Permitted Visitation by Midsize Boat Expedition Operators. This site does not receive much local recreation use. There are seal and/or sea lion haul outs.

Attractions

This area has a scenic setting with views across Icy Strait and Glacier Bay. There are wildlife viewing opportunities, especially sea lions and humpback whales.

\section{Mitigation}

- $\quad$ See Appendix $\mathrm{C}$ for mitigation measures.

- Marine mammals

- Vegetation 


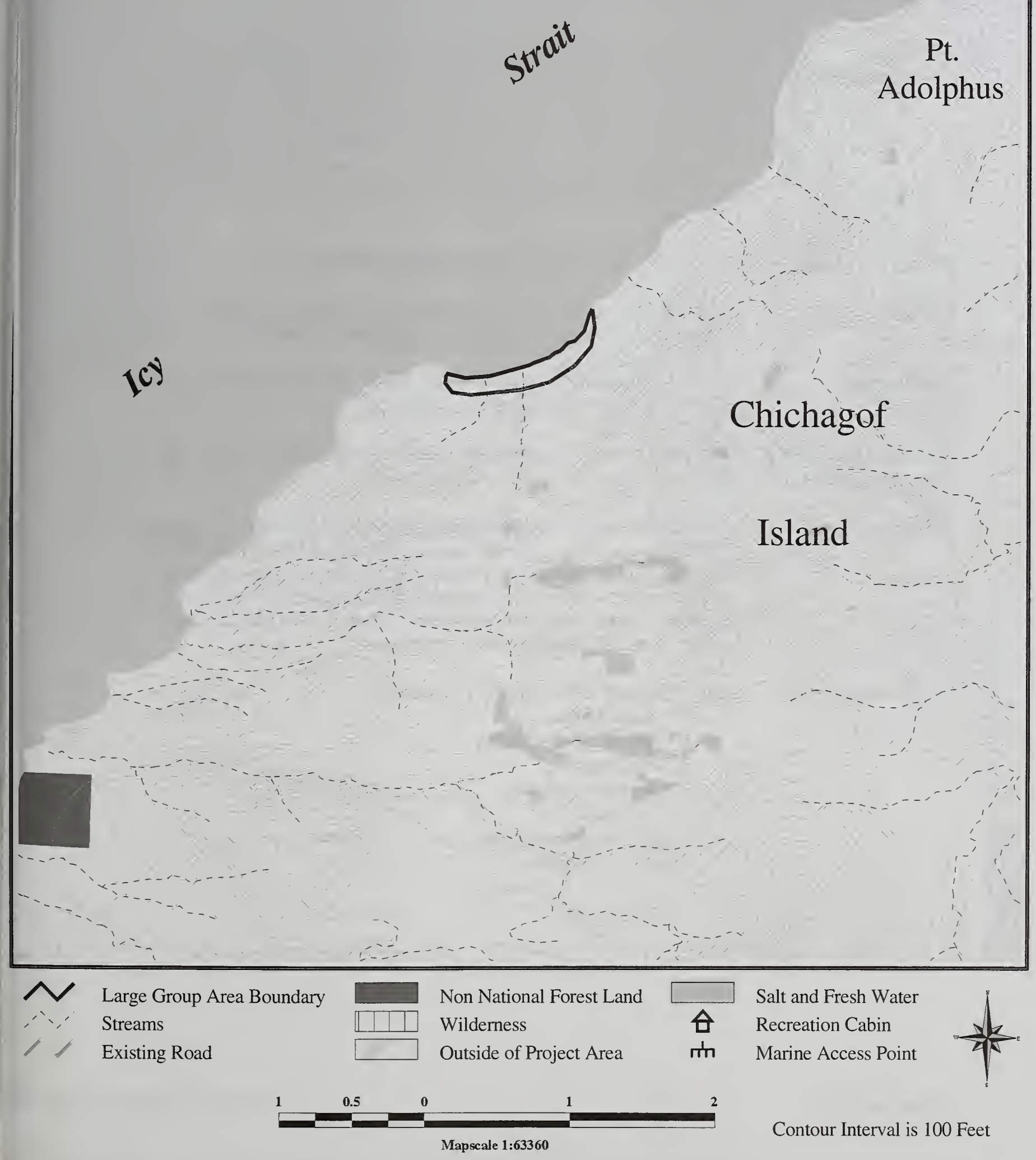




\section{Appendix B, Large Group Areas}

\begin{tabular}{|c|c|}
\hline & $\begin{array}{l}\text { Large Group Areas } \\
\text { Pinta Cove } \\
\text { Alternatives } 3,4,5\end{array}$ \\
\hline $\begin{array}{l}\text { Type } \\
\text { Use Area } \\
\text { LUD } \\
\text { ROS } \\
\text { Acres }\end{array}$ & $\begin{array}{l}\text { Fifteen-Percent } \\
04-16 \text { A } \\
\text { LUD II } \\
\text { Semi-Primitive Motorized } \\
57\end{array}$ \\
\hline $\begin{array}{l}\text { General } \\
\text { Characteristics }\end{array}$ & $\begin{array}{l}\text { This area is located on the eastern portion of use area } 04-16 \mathrm{~A} \\
\text { between Chicken Creek and Point Adolphus. It receives a high } \\
\text { amount of use. Tour boat operators use this area for kayaking and } \\
\text { hiking. Several commercial kayak/camping operators also use this } \\
\text { area throughout the summer season. Pinta Point is a primary } \\
\text { campsite that is naturally hardened. The cove also receives traffic } \\
\text { from kayak transporters, ocean fishing charters, and local } \\
\text { mariners. }\end{array}$ \\
\hline Historical Use & This site was used by outfitter/guides in 1999. \\
\hline Access & $\begin{array}{l}\text { Pinta Cove provides a fair anchorage for larger boats. The } \\
\text { shoreline is normally accessed by small skiff or kayak. }\end{array}$ \\
\hline Facilities & $\begin{array}{l}\text { A three-sided shelter that receives steady use through the summer } \\
\text { season from kayakers camping overnight. }\end{array}$ \\
\hline $\begin{array}{l}\text { Concerns and/or } \\
\text { Opportunities }\end{array}$ & $\begin{array}{l}\text { Icy Strait community residents use the area. There is heavy use by } \\
\text { both guided and unguided recreationists. }\end{array}$ \\
\hline Attractions & $\begin{array}{l}\text { This area features wildlife viewing (particularly whales), campsites, } \\
\text { overnight camping, sightseeing, day-use hiking, beach combing, } \\
\text { hunting, and an emergency shelter. It is currently receiving use } \\
\text { from mid-size cruise ship operators. It is a popular } \\
\text { commercial/non-commercial recreation place, and people are } \\
\text { accustomed to seeing others in this area. }\end{array}$ \\
\hline Mitigation & $\begin{array}{l}\text { See Appendix } C \text { for mitigation measures } \\
\text { - Bald eagles } \\
\text { - Brown bear viewing } \\
\text { - Megetation } \\
\text { - Rarine mammals } \\
\text { Large group use will not displace unguided users at the } \\
\text { Pinta Cove shelter. }\end{array}$ \\
\hline
\end{tabular}




\section{Icy}

Pt.

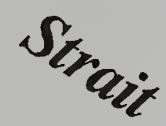

Adolphus

Chichagof

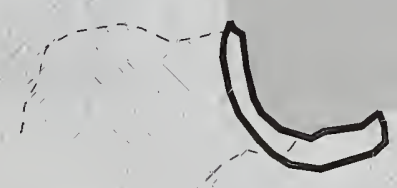

Island

Large Group Area Boundary Streams

Existing Road
Non National Forest Land
Wilderness

Outside of Project Area

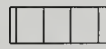

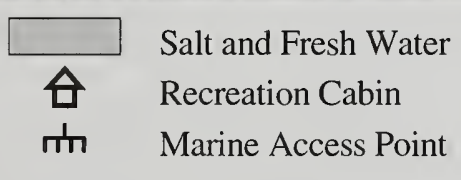

Salt and Fresh Water

Marine Access Point

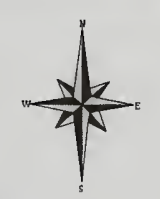

Contour Interval is 100 Feet

1

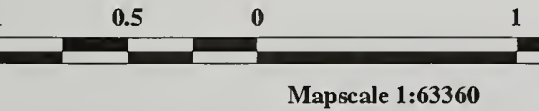

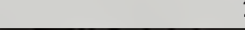




\section{Appendix B, Large Group Areas}

\begin{tabular}{|c|c|}
\hline & $\begin{array}{l}\text { Large Group Area } \\
\text { Big Shaw Island } \\
\text { Alternative } 3\end{array}$ \\
\hline $\begin{array}{l}\text { Type } \\
\text { Use Area } \\
\text { LUD } \\
\text { ROS } \\
\text { Acres } \\
\end{array}$ & $\begin{array}{l}\text { Fifteen-Percent } \\
04-16 C \\
\text { LUD II } \\
\text { Semi-Primitive Motorized. } \\
57\end{array}$ \\
\hline $\begin{array}{l}\text { General } \\
\text { Characteristics }\end{array}$ & $\begin{array}{l}\text { This area features a tiny island with rocky cliffs, tide pools, and } \\
\text { old-growth timber. Potential wildlife sightings include whales, sea } \\
\text { otter, river otter, seal, sea lions, and sea birds. }\end{array}$ \\
\hline Historical Use & No commercial outfitter/guide use occurred here in 1999. \\
\hline Access & $\begin{array}{l}\text { A gravel beach on the west side of the island is good for small } \\
\text { skiffs and kayaks. }\end{array}$ \\
\hline Facilities & There are no Forest Service facilities at this location. \\
\hline $\begin{array}{l}\text { Concerns and/or } \\
\text { Opportunities }\end{array}$ & $\begin{array}{l}\text { Icy Strait residents use this area. There is a local trolling drag } \\
\text { between Shaw Island and Fox Creek. There are seal and/or sea lion } \\
\text { haul outs. }\end{array}$ \\
\hline Attractions & $\begin{array}{l}\text { Undeveloped setting with wildlife viewing opportunities, reduced } \\
\text { chance of bear encounters }\end{array}$ \\
\hline Mitigation & $\begin{array}{l}\text { - See Appendix } C \text { for mitigation measures. } \\
\text { - Bald eagles } \\
\text { - Marine mammals } \\
\text { - Vutfitter/guide boats must anchor away from trolling drag. }\end{array}$ \\
\hline
\end{tabular}




\section{Appendix B, Large Group Areas}

\begin{tabular}{|c|c|}
\hline & $\begin{array}{l}\text { Large Group Areas } \\
\text { Fox Creek } \\
\text { Alternatives } 3,4,5\end{array}$ \\
\hline $\begin{array}{l}\text { Type } \\
\text { Use Area } \\
\text { LUD } \\
\text { ROS } \\
\text { Acres } \\
\end{array}$ & $\begin{array}{l}\text { Fifteen-Percent } \\
04-16 C \\
\text { LUD II } \\
\text { Semi-Primitive Motorized } \\
417\end{array}$ \\
\hline $\begin{array}{l}\text { General } \\
\text { Characteristics }\end{array}$ & $\begin{array}{l}\text { This area has a scenic setting with a small salmon stream } \\
\text { adjacent to a large alluvial fan. There is an open forest } \\
\text { understory and a grassy intertidal area. }\end{array}$ \\
\hline Historical Use & $\begin{array}{l}\text { Outfitter/guides used this area in } 1999 \text {. Tour boat operators use } \\
\text { this site for day use hiking and sightseeing. }\end{array}$ \\
\hline Access & $\begin{array}{l}\text { A protected anchorage between Fox Creek and Big Shaw Island } \\
\text { offers easy access by skiff or kayak to a gravel beach. }\end{array}$ \\
\hline Facilities & There are no Forest Service facilities at this location. \\
\hline $\begin{array}{l}\text { Concerns and/or } \\
\text { Opportunities }\end{array}$ & $\begin{array}{l}\text { Icy Strait residents use this area. It is a local trolling drag between } \\
\text { Shaw Island and Fox Creek. There is potential for human/bear } \\
\text { encounters. }\end{array}$ \\
\hline Attractions & $\begin{array}{l}\text { This area features a scenic setting, wildlife viewing opportunities } \\
\text { and easy beach access. It is a good area for hiking and kayaking. } \\
\text { It is out of the way and not a popular local recreation place. }\end{array}$ \\
\hline Mitigation & $\begin{array}{l}\text { - See Appendix C for mitigation measures. } \\
\text { - Bald eagles } \\
\text { - Rarine mammals } \\
\text { - } \text { Vegetation } \\
\text { - } \quad \text { Bo large group camping. } \\
\text { - No consumptive uses by large groups. } \\
\text { - Boats must anchor away from trolling drag. }\end{array}$ \\
\hline
\end{tabular}


Shoreline Outfitter/Guide EIS

Large Group Area

Use Area 04-16C FOX CREEK

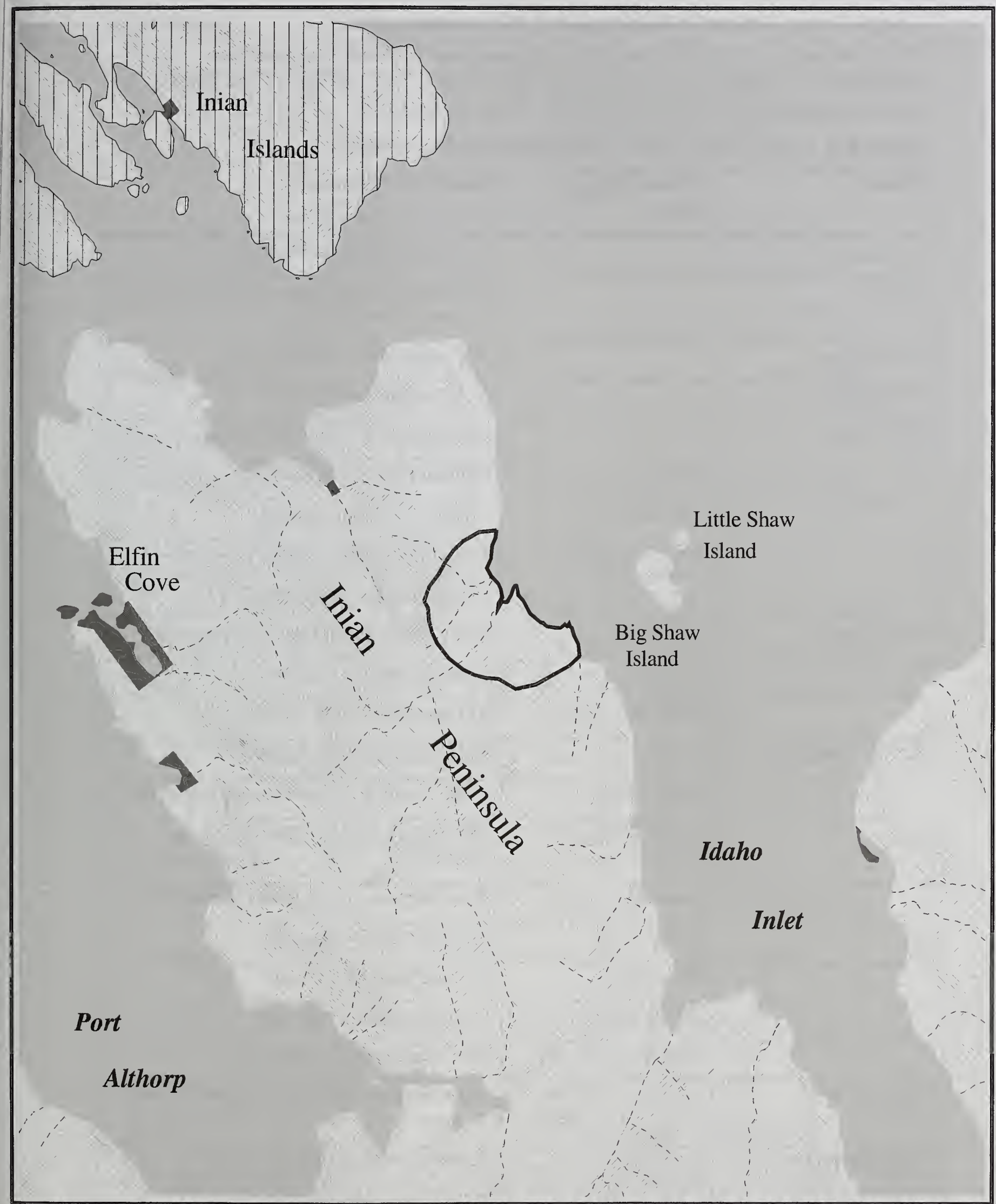

\footnotetext{
$\checkmark$ Large Group Area Boundary Streams

Existing Road
}

Non National Forest Land

Wilderness

Outside of Project Area

\begin{tabular}{cl}
\hline & Salt and Fresh Water \\
는 & Recreation Cabin \\
皿 & Marine Access Point
\end{tabular}

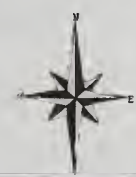




\section{Appendix B, Large Group Areas}

\section{Large Group Areas Considered but Eliminated}

The following list displays the potential large group areas that were considered and eliminated from further consideration. Other areas, such as Port Althorp and Use Areas containing communities were also eliminated from consideration.

Table B-2. Large Group Areas Considered but Eliminated

\begin{tabular}{|c|c|c|}
\hline Enclaves & $\begin{array}{l}\text { Fifteen-Percent } \\
\text { Areas }\end{array}$ & Reason for Elimination \\
\hline Deep Cove & & Not compatible with ROS/LUD \\
\hline Sashin & & $\begin{array}{l}\text { May impact NMFS research facility at the } \\
\text { entrance to Sashin Lake }\end{array}$ \\
\hline Lovers Cove & & Not compatible with ROS/LUD \\
\hline Port Herbert & & Not compatible with ROS/LUD \\
\hline \multirow[t]{5}{*}{ Cliff Lake } & & Not compatible with ROS/LUD \\
\hline & Elovoi & Cultural resource concerns \\
\hline & Shoals Point & Cultural resource concerns \\
\hline & Mud Bay Road & May conflict with historic ATV use \\
\hline & Sinitisin Cove & May impact native allotment \\
\hline \multirow[t]{3}{*}{ Lauf Island } & & Island too small for large group use \\
\hline & Thatcher & Cultural resource concerns \\
\hline & Kelp Bay-S.Arm & Not compatible with ROS/LUD \\
\hline \multirow[t]{8}{*}{ Takatz Islands } & & Not compatible with ROS/LUD \\
\hline & Sadie Lake & Most of trail is on non-national forest land \\
\hline & Kadashan Bay & $\begin{array}{l}\text { Bay heavily used by Tenakee Springs } \\
\text { residents }\end{array}$ \\
\hline & Long Bay & Better areas available in this vicinity \\
\hline & Coffee Cove & Cultural resource concerns \\
\hline & Broad Creek & Cultural resource concerns \\
\hline & Goose Cove & Cultural resource concerns \\
\hline & Deep Bay & May impact native allotment \\
\hline Barlow Cove & & $\begin{array}{l}\text { Three Special Use cabins, cultural resource } \\
\text { concerns }\end{array}$ \\
\hline Hawk Inlet (1) & & Poor access due to tide flats \\
\hline Hawk Inlet (2) & & May impact existing cabins \\
\hline Endicott River & & May impact known Sensitive plant species \\
\hline
\end{tabular}




\section{Large Group Areas, Appendix B}

\begin{tabular}{|l|l|l|}
\hline Enclaves & $\begin{array}{l}\text { Fifteen-Percent } \\
\text { Areas }\end{array}$ & Reason for Elimination \\
\hline Slate Cove & & Cultural resource concerns \\
\hline Sawmill Creek & & Cultural resource concerns \\
\hline Scow cove & $\begin{array}{l}\text { Poor access with large tide flats and shifting } \\
\text { sandbars }\end{array}$ \\
\hline Grizzly Bar & Poor access due to large tide flats \\
\hline Davidson Creek & & Poor access due to large tide flats \\
\hline Slocum Inlet & & $\begin{array}{l}\text { Poor access due to large tide flats, existing } \\
\text { power line corridor, limited attractions }\end{array}$ \\
\hline Mist Creek & $\begin{array}{l}\text { Existing power line corridor and low- } \\
\text { hanging lines directly behind the beach }\end{array}$ \\
\hline Bogert Point & Poor suitability for recreation use \\
\hline Sweetheart Creek & & $\begin{array}{l}\text { May impact unguided users- terminal } \\
\text { fishery area that is popular with Juneau } \\
\text { anglers. }\end{array}$ \\
\hline Gilbert Bay East & & Proximity to Sweetheart Creek \\
\hline Meigs Peak I, North & & Access too exposed, better sites nearby \\
\hline Meigs Peak II, South & & Access too exposed, better sites nearby \\
\hline Williams Cove & & $\begin{array}{l}\text { Proximity to Tracy Arm Wilderness, other } \\
\text { enclave sites are nearby }\end{array}$ \\
\hline Dry Bay & Poor access due to large tide flats \\
\hline Windham Bay I & $\begin{array}{l}\text { Poor access, limited anchorage, limited } \\
\text { attractions }\end{array}$ \\
\hline Windham Bay II & Cultural resource concerns \\
\hline Windham Bay South & & $\begin{array}{l}\text { Limited attractions, more suitable sites } \\
\text { nearby }\end{array}$ \\
\hline Pot Marker & $\begin{array}{l}\text { Poor access with large tide flat and rocky } \\
\text { approaches }\end{array}$ \\
\hline Sunset Island & $\begin{array}{l}\text { Exposed site, rocky shoreline, may disturb } \\
\text { sea lion haul out }\end{array}$ \\
\hline punset Cove & & Limited attractions \\
\hline Not compatible with ROS/LUDine access point \\
\hline
\end{tabular}




\section{Appendix B, Large Group Areas}

\begin{tabular}{|c|c|c|}
\hline Enclaves & $\begin{array}{l}\text { Fifteen-Percent } \\
\text { Areas }\end{array}$ & Reason for Elimination \\
\hline Unknown Lagoon & & $\begin{array}{l}\text { Limited attractions with modified viewshed, } \\
\text { Potential marine access point }\end{array}$ \\
\hline \multirow[t]{14}{*}{ Walter Island } & & Cultural resource concerns \\
\hline & Sandborn Canal & Limited attractions \\
\hline & Sandborn Canal II & $\begin{array}{l}\text { May impact a known Sensitive plant } \\
\text { species }\end{array}$ \\
\hline & Chicken Creek & $\begin{array}{l}\text { Poor anchorage and access, may impact } \\
\text { recreation and subsistence resources for } \\
\text { local and small group commercial use }\end{array}$ \\
\hline & $\begin{array}{l}\text { Neka Bay/Chimney } \\
\text { Rock }\end{array}$ & $\begin{array}{l}\text { May impact eagle nest, cultural resource } \\
\text { concerns }\end{array}$ \\
\hline & Whitestone Harbor & $\begin{array}{l}\text { May impact unguided use by Hoonah } \\
\text { residents for recreation and subsistence, } \\
\text { USFS cabin and boat ramp planned }\end{array}$ \\
\hline & False Bay & $\begin{array}{l}\text { May impact a popular unguided recreation } \\
\text { and subsistence area }\end{array}$ \\
\hline & $\begin{array}{l}\text { Freshwater Bay/East } \\
\text { Head }\end{array}$ & Unsafe access due to large tide flats \\
\hline & $\begin{array}{l}\text { Freshwater Bay/West } \\
\text { Head }\end{array}$ & Unsafe access due to deceptive tide flats \\
\hline & $\begin{array}{l}\text { Freshwater } \\
\text { Bay/Wachusett Cove }\end{array}$ & $\begin{array}{l}\text { May impact a Special Use hunter's cabin } \\
\text { and unguided use }\end{array}$ \\
\hline & $\begin{array}{l}\text { Freshwater } \\
\text { Bay/Cedar Cove }\end{array}$ & Float house in bay \\
\hline & $\begin{array}{l}\text { Freshwater } \\
\text { Bay/North Head }\end{array}$ & Unsafe access due to deceptive tide flats \\
\hline & Wukuklook Creek & Developed with trail for road access \\
\hline & Cedar Cove & Float house in bay \\
\hline \multirow[t]{2}{*}{ Porpoise Islands } & & Seal haul out \\
\hline & Lisianski Inlet Head & $\begin{array}{l}\text { Proposed Wild River, and popular } \\
\text { recreation and subsistence area for Pelican }\end{array}$ \\
\hline \multirow[t]{2}{*}{ Little Shaw Island } & & Seal haul out \\
\hline & $\begin{array}{l}\text { Idaho Inlet-Marble } \\
\text { Creek }\end{array}$ & Not compatible with Primitive ROS \\
\hline
\end{tabular}




\section{Large Group Areas, Appendix B}

\begin{tabular}{|l|l|l|}
\hline Enclaves & $\begin{array}{l}\text { Fifteen-Percent } \\
\text { Areas }\end{array}$ & Reason for Elimination \\
\hline \hline & $\begin{array}{l}\text { Idaho Inlet, Trail } \\
\text { River }\end{array}$ & Not compatible with Primitive ROS \\
\hline Idaho Inlet & & Not compatible with Primitive ROS \\
\hline & Port Althorp & Not compatible with Primitive ROS \\
\hline & Salt Chuck & Not compatible with Primitive ROS \\
\hline
\end{tabular}




\section{Appendix B, Large Group Areas}

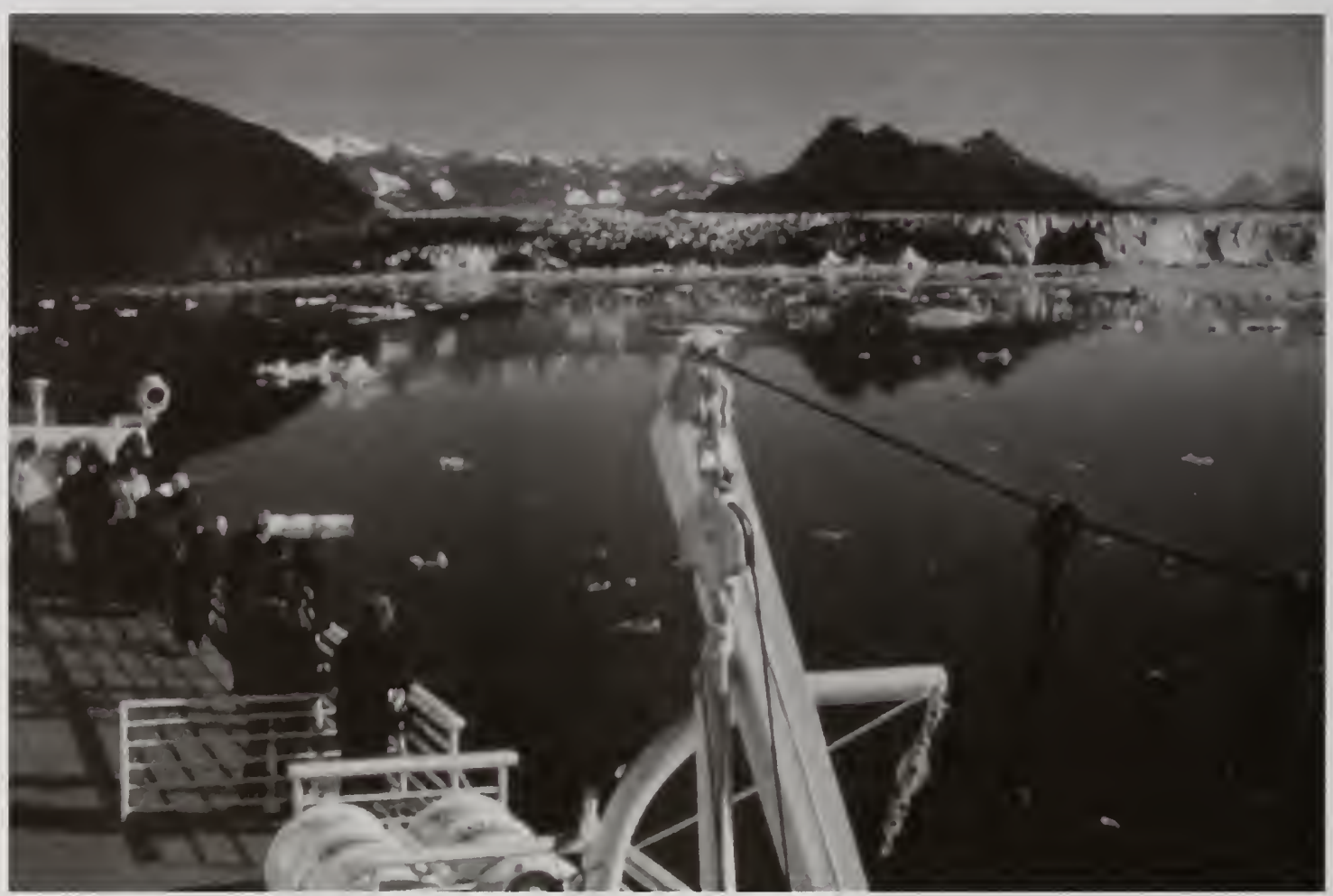


Appendix C Mitigation 


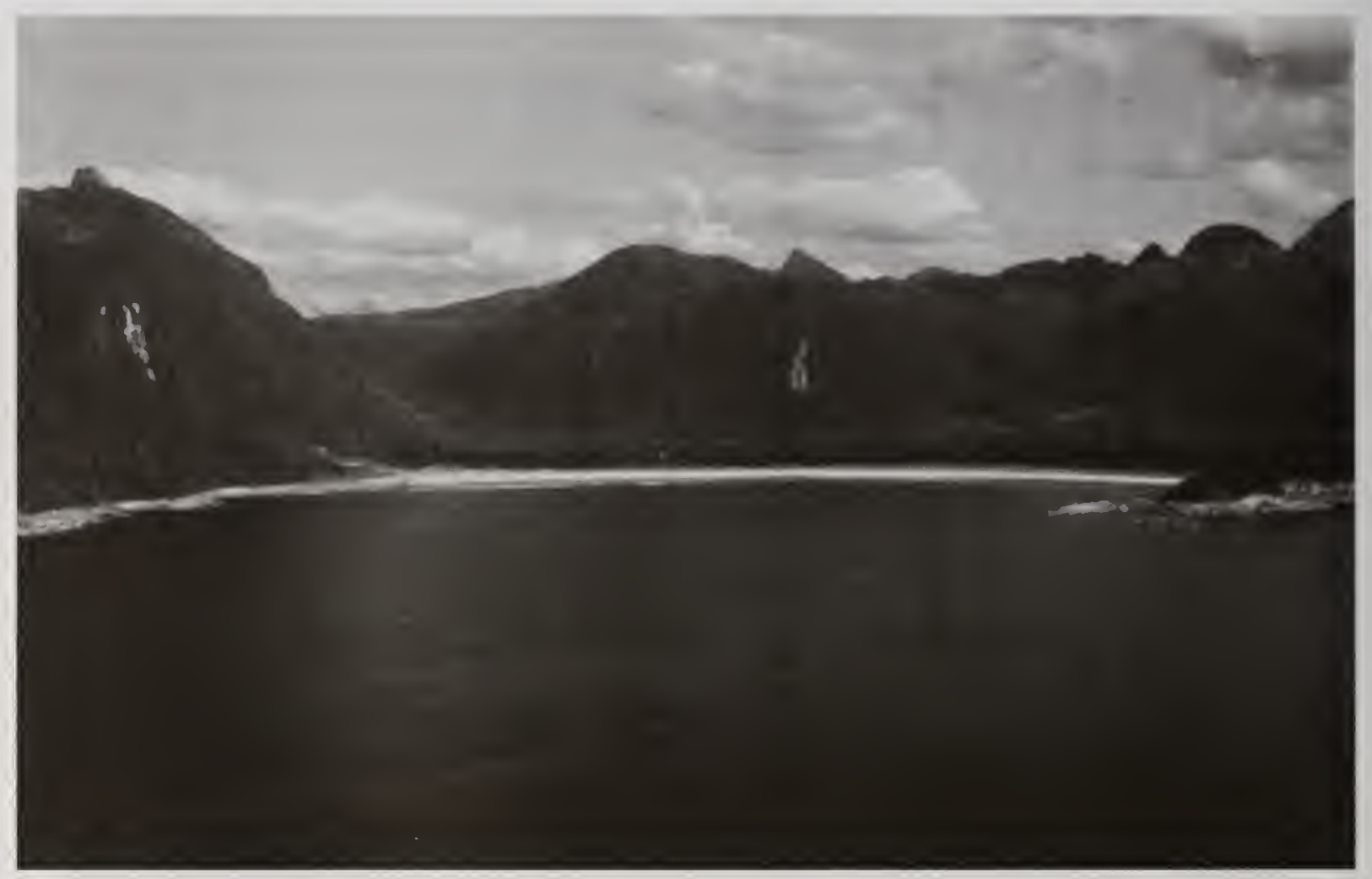




\section{Appendix C Mitigation Measures}

\section{Introduction}

The Forest Service uses many measures to mitigate or prevent negative social and environmental impacts in the planning and implementation of land management activities. These measures were developed from applicable laws and regulations, manual direction, the Forest Plan standards and guidelines, and recommendations from other sources, such as the Southeast Alaska Unit 4 Brown Bear Management Strategy and Leave No Trace strategies.

The following is a comprehensive list of mitigation measures that apply to commercial recreation activities for all of the action alternatives. In addition, some site-specific resource concerns and mitigation measures are listed on the Use Area cards in Appendix A and on the Large Group Area Cards in Appendix B. These cards provide site-specific information and guidance for commercial permit preparation and administration. These cards include a map and narrative identifying resource concerns and site-specific mitigation measures.

The mitigation measures listed here and on the cards in Appendix A and Appendix B will be used to prepare and administer outfitter/guide permits. They will be incorporated into the permits as stipulations where applicable. They will be enforced through permit administration. Mitigation measures may be further refined during the monitoring and administration of commercial use authorizations as additional information becomes available.

\section{General Measures}

Outfitter/Guide activities shall comply with all applicable federal, state, and local laws, regulations, and standards.

Use of the permit areas are not exclusive and will not preclude public use or access.

Outfitter/guide use will not take precedence over other activities allowed by the Forest Plan. Commercial recreation use may occur in areas of the national forest designated for other uses such as timber harvest or road construction, but outfitter/guide activities shall not interfere with the operations of other permitees, operators, or contractors. Recreation use of marine access points (MAPs, also known as log transfer facilities) and road systems used for timber harvest will be conducted in a manner not to conflict with other uses and to ensure the safety of all users.

Commercial outfitter/guide activities are authorized only above the line of mean high tide on National Forest System lands. Authorization for the use of the tidelands seaward from the line of mean high tide must be secured from the State of Alaska, Division of Lands. 
Outfitter/guides have an affirmative duty to protect the land, property, and interests of the United States from damage. Permit holders have a continuing responsibility to identify all hazardous conditions on the permit area that would affect forest resources, improvements, or pose a risk of injury to individuals.

Outfitter/guides shall not discriminate against any person on the basis of race, color, religion, sex, national origin, age, or disability in offering their services to the public or in their employment practices.

Outfitter/guide operations shall not encroach on state, state selected, or private property without prior written permission of the property owner.

Leave No Trace methods will be incorporated into outfitter/guide activities. See Region 10 Leave No Trace Action Plan dated March 4, 1997 for additional information.

Group size is limited to the applicable ROS standards and guidelines in the Forest Plan (See Maximum Recreation and Tourism Development Generally Allowed by LUD, Forest Plan, page 4-40). Enclave and Fifteen-Percent large group areas have a maximum group size limit of 75 people at one time. Only one large group will use these areas at a time. Large groups will not be allowed to camp or conduct consumptive recreational activities such as hunting, fishing or plant collecting.

Outfitter/guides must comply with all Federal Subsistence Board and State of Alaska game and sport fishing regulations, including method and bag limits, and restrictions for open and closed areas. Outfitter/guides must also be in compliance with state sport fishing regulations regarding fishing near any stream structure (such as fish weirs, fish traps, etc.).

Outfitter/guide activities will not interfere with subsistence resource users or disrupt subsistence resource gathering activities.

Operators conducting consumptive activities, such as fishing, hunting, or collecting, will submit harvest reports of the daily take to the Forest Service as specified in their permit.

Discharging a firearm or any other implement capable of taking human life, causing injury, or damaging property is prohibited:

- in or within 150 yards of a residence, building, developed recreation site or occupied area; or

- across or on a national forest development road or adjacent body of water, or in any manner or place where any person or property is exposed to injury or damage as a result of discharging a firearm (36 CFR Section 261.10(d)).

In addition, there may be other local restrictions on discharging firearms (such as within one mile of campgrounds, etc.) that outfitter/guides and their clients must follow. Such restrictions will be part of the authorized special use permit.

Outfitter/guide use of public use recreation cabins or their amenities (such as skiffs, firewood, and fire rings) is prohibited unless otherwise authorized. Low-use recreation cabins may be authorized for commercial use on a case-by-case basis.

All food, belongings, and gear brought on-site by guides and their clients, will be stored in such a manner as to not be an attraction to bears and other wildlife. 


\section{Mitigation, Appendix C}

Outfitter/guides will ensure that their activities in Wilderness areas are conducted in a manner that complements Wilderness management objectives and avoids degradation of wilderness values.

The services provided by outfitters and guides should facilitate the use, enjoyment, understanding, and appreciation of the national forest recreation settings.

Outfitter/guide actions shall contribute to the partnership with the Forest Service in nurturing and encouraging assistance and support for attaining the objectives of the land use designation, and to assist in increased public understanding and appreciation of the Forest Service's mission and goals.

Outfitter/guides are encouraged to provide quality services to their clients. This element will be evaluated on an annual basis as part of the performance evaluation.

Outfitter/guide Special Uses Authorizations shall be administered in accordance with the direction in Forest Service Manual 2720, Forest Service Handbook 2709.11, and Region 10 supplements. Required stipulations and clauses shall be included in the permit.

\section{Resource Protection Measures}

\section{Camping}

Air

Beach and Estuary Fringe
Outfitter/guide camps are prohibited within one mile of any Forest Service recreation cabin unless otherwise authorized.

All campfires in Wilderness areas should be built below high tide line or on firepans.

Campsites will be placed a minimum distance of 100 feet from all perennial streams, lakes, and other bodies of water. This area shall correspond to at least the recognizable area dominated by the riparian vegetation (see riparian section below).

Camping is not allowed within nesting zones (see the following raptor and bird mitigation measures).

Outfitter/guides will manage their activities to control and minimize air pollution impacts and to ensure that predicted emissions from all pollution sources do not exceed Ambient Air Quality Standards as specified under the Alaska Administrative Code, Title 18, Chapter 50.

Outfitter/guides will cooperate with regulatory authorities to prevent adverse effects of air pollutants and atmospheric deposition on forest ecosystems.

Outfitter/guides will manage their use of beach and estuary fringe areas to maintain fish and wildlife habitats. People should stay on existing paths and game trails when possible to avoid trampling or damaging habitats. In order to minimize potential impacts to sensitive plant species, outfitter/guides will not establish camps or allow their clients to camp in beach meadows. 


\section{Appendix C, Mitigation}

\section{Karst and Cave Resources}

\section{Riparian Areas}

Outfitter/guides will protect karst and cave resources as required by the Federal Cave Resources Protection Act (FCRPA).Cave use is not permitted without a Cave Protection Plan.

Riparian Management Areas are areas of special concern for fish, other aquatic resources, and wildlife values. These areas are delineated according to the process group direction in the Riparian Forest-wide Standards and Guidelines. To protect fish habitat and water quality, Forest Plan standards and guidelines for riparian areas are applied to all fish streams, and to non-fish-bearing Class III and Class IV streams within the analysis area. Best Management Practices will be used to minimize the risk of land management activities impairing water quality. Special provisions are specified to protect soil and water quality.

Campsites will be placed a minimum distance of 100 feet from all perennial streams, lakes, and other bodies of water. This area shall correspond to at least the recognizable area dominated by the riparian vegetation. This will be done in an effort to mitigate effects on riparian vegetation and water quality from human waste, grey/soapy water disposal, litter, and fuel spills.

When practical, in-stream travel shall be kept between high and low water marks (the region along a stream bank which is periodically de-watered). This will mitigate potential damaging effects on fish eggs.

Motorized boat use will be authorized only in areas where it will not cause adverse effects on fish habitat. Riparian management will emphasize stream bank protection and erosion control measures on managed trails to minimize potential sediment sources (BMP 16.4: Trail Construction and Maintenance). These protective measures will apply to all alternatives.

If motorized watercraft cause measurable adverse effects to habitat on Mud Bay River, Lisianski River, and Trail River or other rivers, site-specific motorized watercraft use will be restricted. Restrictions may include seasonal limits, water depth requirements, boat size or power restrictions, no-wake restrictions, or excluding motorized use altogether.

\section{Lower Intertidal and Subtitle Areas}

Eelgrass is assumed to be important near-shore habitat for a variety of marine species. Outfitter/guides should avoid repeated boat anchoring in vegetated areas where practicable, to minimize adverse effects on eelgrass and other marine vegetation.

During servicing or refueling of equipment, petroleum products may be spilled and potentially enter a watercourse. Locating service and refueling sites well away from wetlands and stream channels will minimize this risk.

Minor oil spills will be prevented by using good housekeeping techniques including: (1) collecting any used oil, oil filters, and grease tubes; (2) requiring equipment operators to carry absorbent pads; (3) providing containment and cleanup for portable fuel tanks (including hose and nozzle); (4) following approved disposal methods for waste products; and (5) repairing equipment leaks promptly. 


\section{Mitigation, Appendix C}

\section{Wetlands}

\section{Soil and Water}

Best management practices (BMPs) and forest-wide standards and guidelines will be used for primary mitigation for reducing the effects of recreation use on wetlands.

People should stay on existing paths and game trails to avoid excessive trampling or damaging wetlands, where practical.

If monitoring determines that wetlands have been adversely affected by outfitter/guide activities, use in these areas will be restricted and the areas revegetated or hardened to minimize effects.

Best management practices and Forest Plan standards and guidelines will be used for primary mitigation. Best management practices for soil protection associated with this project apply to all proposed commercial recreation activities and include the following:

- Wetland identification, evaluation, and protection (BMP 12.5);

- Riparian area designation and protection (BMP 12.6);

- Control of activities under special-use permit (BMP 12.10);

- Sanitary facilities (BMP 12.15);

- Control of solid waste disposal (BMP 12.16);

- Revegetation of disturbed sites (BMP 12.17);

- Road and trail erosion control plan (BMP 14.5);

- Measures to minimize surface erosion (BMP 14.8);

- Drainage control to minimize erosion and sedimentation (BMP 14.9);

- Surface erosion controls at facilities (BMP 14.25);

- Recreation facilities planning and location (BMP 16.1); and

- Trail construction and maintenance (BMP 16.4).

Outfitter/guide activities shall not result in impacts exceeding soil quality standards. In order to meet soil quality standards (SQS), the total acreage of affected soil conditions may not exceed 15 percent of the total acreage within the activity area. Activity areas are defined as the total area of ground surface affected by an activity and include the area surrounding a trail, footpath, picnic site, or other area of concentrated use. Activity areas exclude specified trails, footpaths, or developed sites. If activities and use levels result in unacceptable impacts, corrective action will occur. This may include limiting use and hardening, stabilizing, and revegetating sites.

Areas with unstable soil or hazardous conditions will be avoided.

A minimum 330-foot radius non-disturbance zone will be maintained around each identified bald eagle nest tree. Camping is not allowed within the non-disturbance zone. Other guided recreation activities should be minimized within the nondisturbance zones of active nests. Activities shall be conducted to avoid disturbing or harassing eagles. All nest trees are considered active from March 1 to May 31 . From June 1 to August 31, trees with nests containing eggs or young, as indicated by observation of eggs, young eagles, or by the presence of adult eagles in nesting activities, will be considered active. 


\section{Appendix C, Mitigation}

\author{
Great Blue Herons, \\ Hawks, and Owls
}

A minimum 600 -foot radius non-disturbance zone will be maintained around each identified great blue heron, hawk, and owl nest tree. Camping is not allowed within the non-disturbance zone of active nests. Other guided recreation activities should be minimized within the non-disturbance zones of active nests. Activities shall be conducted to avoid disturbing or harassing herons, hawks, or owls. All nest trees are considered active from March 1 to July 31. After August 1, trees with nests containing eggs or young, as indicated by observation of eggs, young birds, or by the presence of adult birds in nesting activities, will be considered active. These protection measures for great blue heron, hawk, and owl nests may be lifted if the nest(s) are inactive for two consecutive years.

A minimum 600 -foot radius non-disturbance zone will be maintained around each identified goshawk nest tree. Camping is not allowed within the non-disturbance zone of active nests. Other guided recreation activities should be minimized within the non-disturbance zones of active nests. Activities shall be conducted to avoid disturbing or harassing goshawks. All nest trees will be considered active from March 15 to August 15. After August 15, trees with nests containing eggs or young, as indicated by observation of eggs, young birds, or by the presence of adult birds in nesting activities, will be considered active. All goshawk sightings shall be reported to the Forest Service.

A minimum two-mile radius non-disturbance zone will be maintained around each identified Peale's peregrine falcon nest tree. Camping is not allowed within the non-disturbance zone of active nests. Other guided recreation activities should be minimized within the non-disturbance zones of active nests. Activities shall be conducted to avoid disturbing or harassing falcons. All nest trees will be considered active from April 15 to August 31. After August 31, trees with nests containing eggs or young, as indicated by observation of eggs, young birds, or by the presence of adult birds in nesting activities, will be considered active.

Implementing the following actions will protect the seabird rookeries and waterfowl concentration areas that provide important prey foraging habitat for the American peregrine falcon.

- For permitted outfitter/guide aircraft flights, maintain a constant flight direction and airspeed, and a minimum flight elevation of 1,500 feet for helicopters and fixed-winged aircraft when weather conditions permit. Avoid flying over seabird colonies/rookeries where possible.

- An 820-foot radius non-disturbance zone on upland habitats around seabird colonies and rookeries will be maintained. No camping is permitted within this zone. Other activities shall be conducted to avoid disturbing or harassing the birds.

- Outfitter/guides shall collect and properly dispose of their garbage to prevent gulls from feeding and collecting on it. 


\section{Mitigation, Appendix C}

Osprey

\section{Trumpeter Swan}

\section{Waterfowl and Shorebirds}

A minimum 330-foot radius non-disturbance zone will be maintained around each identified osprey nest tree. Camping is not allowed within the non-disturbance zone of active nests. Other guided recreation activities should be minimized within the non-disturbance zones of active nests. Activities shall be conducted to avoid disturbing or harassing ospreys.

No camping will be allowed within 0.5 mile of known nesting, brood-rearing, and wintering trumpeter swans. Other guided recreation activities will be conducted to minimize disturbing or harassing swans.

Guided recreation activities should be minimized within 330 feet of known waterfowl or shorebird concentration and nesting areas. Activities shall be conducted to avoid disturbing or harassing birds. Camping is not allowed within this zone.

Activities will comply with the Code of Conduct provisions in the NMFS Alaska Marine Mammal Viewing Guidelines brochure.

- Remain at least 100 yards from marine mammals.

- Time spent observing individual(s) should be limited to a $1 / 2$-hour.

- Whales should not be encircled or trapped between boats, or between boats and shore.

- If approached by a whale, put the engine in neutral and allow the whale to pass. Boat movement should be from the rear of a whale.

- In addition, operators are required to stay at least 100 yards away from humpback whales.

- 'Taking' marine mammals protected under the Marine Mammal Protection Act is prohibited; taking includes harassing, pursuing, or attempting any such activity (16 CFR Part 1532). For example, if a boat approaches a known Steller sea lion haul-out too closely and sea lions or seals leave the haul-out and escape to the sea, the boat operator may be harassing the animals.

- Outfitter/guide groups will not intentionally approach within 100 yards of, or otherwise intentionally disturb, any hauled-out marine mammal.

- Waste oil and fuels will be managed in compliance with all state and federal regulations to prevent pollution impacts to marine mammals.

- The National Marine Fisheries Service (NMFS) requires the following terrestrial, air, and aquatic zones around critical habitat for Steller sea lions (50 CFR Part 226).

- Terrestrial zones extend 3,000 feet landward from the baseline or base point of each major rookery and major haul-out in Alaska.

- Air zones extend 3,000 feet above the terrestrial zone of each major rookery and major haul-out in Alaska, measured vertically from sea level.

- Aquatic zones extend 3,000 feet seaward in state and federally managed waters from the baseline or basepoint of each major 


\section{Appendix C, Mitigation}

rookery and major haul-out in Alaska that is east of 144 degrees west longitude.

Island King Salmon

King salmon populations in King Salmon River and Wheeler Creek are distinct island genetic stocks. No other naturally occurring island runs of king salmon are known to exist in Southeast Alaska. Because of their island location and small population size, the Forest Plan lists these fish as 'sensitive', and it requires protection and maintenance of the populations to prevent listing as threatened or endangered species. The following forest-wide standards and guidelines apply to island run king salmon for this project (see Chapter 4, Forest Plan).

- There is high quality spawning habitat upstream of the grass flats where island king salmon may stay for several days in a short length of stream where they are susceptible to harm. No permits will be issued for activities upstream of the grass flats near the mouth of these streams during the month of July that would negatively affect the viability of these king salmon runs.

- The lower grass flats do not possess quality spawning habitat and king salmon are not likely to spend an extended period of time there. In addition, state sport fishing regulations prohibit the taking of king salmon in all fresh waters within the analysis area. Guided sport fishing may be allowed in King Salmon River and Wheeler Creek within the lower grass flats. Guided sport fishing in these areas would not negatively affect the viability of king salmon.

\section{Brown Bears}

Outfitter/guides shall include bear safety education elements to their safety plans. These elements will include field sanitation, basic bear biology and behavior, how to avoid confrontations with bears in the field, viewing distances, and what to do in case of a bear encounter.

Outfitter/guides will not harass or chase bears with motorized land vehicles, boats, or aircraft. Approach bears no closer than 500 feet and 1,500 feet by fixed-winged aircraft and helicopters, respectively. With regard to aircraft, implement the following best management practices (BMPs) flightseeing/wildlife viewing guidelines.

- All flight operators shall comply with FAA restrictions.

- Consistent with aircraft passenger safety, pilots shall avoid deliberate close (less than 500 feet for fixed-winged and 1,500 feet for helicopters) overflights of animals for the purpose of viewing them. However, incidental overflights on regular flight paths are allowed.

- Hovering near, herding, harassing, or driving bears or other wildlife in any way is not allowed. If an animal, or group of animals, shows signs of disturbance, the aircraft is too close.

- Outfitter/guides will use flight paths that avoid known sensitive wildlife areas, including kidding and calving areas, dens, nest sites, haul-outs, rookeries, and seabird colonies, during critical time periods.

- Consistent with aircraft and passenger safety, operators should establish flightseeing routes that will provide regular and consistent aircraft 


\section{Mitigation, Appendix C}

operations, which will encourage habituation and minimal disturbance to wildlife.

Manage food and solid waste according to the following methods.

- Outfitter/guides will segregate and store organic wastes and items, such as cans and jars that are contaminated with organic waste, in a bear-proof container for disposal in an approved disposal site. Freezing organic wastes until disposal is the preferred storage method. Alternatives are: (1) incinerate organic waste and other combustibles in a locally fabricated incinerator meeting ADEC standards for residue; or (2) use garbage grinders with disposal to a sewer system (not appropriate for septic tank systems) to remove organic wastes, while incinerating or temporarily storing (as above) contaminated combustible and non-combustible wastes.

- When storing food and organic wastes outdoors in bear habitat, use sealed bear-proof containers. Do not leave fish or game carcasses at a central site or near a campsite, or other place with high potential for bear/human conflicts.

- Burn all combustibles and pack out all non-combustibles. Do not discard organic material along or near trails.

- Baiting and feeding bears and other wild game is prohibited (except for trapping furbearers or hunting black bears consistent with state regulations regarding black bear baiting (GMU 1D in the analysis area).

The following are general guidelines for bear viewing where bears are not habituated to people.

- People should remain far enough away from the bear(s) so that human presence, if noticed, does not affect the animal's behavior.

- View bears from safe locations that do not make people vulnerable to a surprise approach by a bear.

- Do not approach bears directly.

- Avoid startling bears.

- Never allow bears access to human foods.

- If seen by a bear, avoid moving. Even minor movements will encourage wary bears to leave the area.

- Never use a motorized vehicle, aircraft, or boat to try getting close to a bear.

- Never run from an approaching bear; it may trigger a prey chase response. When moving away from a bear, do so in a slow, deliberate manner.

- Show respect and courtesy to other bear viewers. Conduct viewing in a way that does not detract from the experience. Never allow drugs or alcohol to mar the experience.

- When possible, approach from downwind of bears or areas where bears are likely to be.

- The best bear viewing is usually in the early morning or evening. Shoreline viewing is usually better during low tides on exposed beaches. 


\section{Appendix C, Mitigation}

- Small groups are less likely to disturb bears and so are more likely to have better viewing. Keep group sizes as small as possible, but keep in mind that there is safety in numbers.

The following are general guidelines for bear viewing where bears are habituated to people.

- Primary use of the area will be by bears; human use will be secondary.

- Minimize the size of the viewing site(s) to that necessary to aecommodate the group size; limit group size by the space limitations of the viewing site and by aceeptance by the bears as indieated by their behavior. Viewing sites are defined as a specific spot in an area used by people to view bears, such as a pad, platform, blind, or tower.

- Concentrate viewing to a few sites to minimize disturbanee to bears.

- Do not locate viewing site(s) in areas regularly used by bears; instead, locate viewing site(s) adjacent to these areas.

- Never allow bears aecess 10 human foods or organic waste. Remove and properly dispose of all garbage and waste.

- Access viewing sites from a single trail.

- Where possible, visually sereen the approach and departure of visitors to the viewing site(s) from the bears and make viewers at the site(s) unobtrusive.

- Minimize the number of trips to and from viewing site(s); instruet groups to plan on only one round trip to and from viewing site(s).

- Minimize the number of groups viewing bears in space and time; a larger group size is generally preferable to an increased number of groups.

- If possible, arrange for travel to and from the viewing site(s) to oecur at the same time each day.

- Keep portions of each day visitor free to allow non-habituated bears a period of use without the stress of having people present.

- Outfitter/guides will be responsible for maintaining eontrol of their elients at all times.

- Outfitter/guides will be responsible for keeping records of bear use at viewing sites. The measure of suceess will be undiminished numbers and hours of use by bears, and not neecssarily increased numbers of visitors to the site.

- Use aireraft and boats only for transportation to and from clesignated onthe-ground viewing site(s) and not for flightseeing or sightseeing in the gencral vicinity.

Human/bear high use zones, such as estuaries and other areas merit special attention. Estuaries are defined in the forest Plan as, "An eeological system at the mouth of a stream where fiesh water and salt water mix, and where salt marshes and intertidal mudflats are present. The landward extent of an estuary is the limit of salt-intolerant vegetation, and the seaward extent is a stream's delta at low tide." Estuaries and fish stream areas in human/bear high use zones will be managed on a Iwo-tier basis aceording to the following definitions, stipulations, and guidelines.

Tier 1: From the Southeast Alaska Unit 4 Brown Bear Managenem Strategy: "Areas with consistently good bear habitat with repetitive and 


\section{Mitigation, Appendix C}

frequent human use sufficient to generate immediate management concerns (amount of use may vary by location)." Includes, but not limited to, Lake Eva Estuary on Baranof Island, and Mud Bay and the head of Idaho Inlet at the Trail River Estuary on Chichagof Island.

- Required stipulations: (a) No campfires, barbeques, or picnics in Tier I locations. (b) No overnight camping in estuary areas or within 100 feet of salmon streams in Tier I locations. (c) Visitors will not be transported into estuaries by airplanes, ATVs, jet boats, or helicopters. Visitors will be transported to drop-off points outside of the estuary where they will walk in to the destination.

Tier II: From the Southeast Alaska Unit 4 Brown Bear Management Strategy: "Areas with consistently good bear habitat where human use is not immediately a problem but has the potential to be a problem and is approaching the level of Tier I areas." Includes, but not limited to, Green's Creck and Pybus Bay Streams on Admiralty Island, and Red Bluff Bay Streams on Baranof Island.

- Tier I stipulations and guidelines are voluntary in Tier II areas.

- Conditions that may change a Tier II area into a Tier I area include, but are not limited to: (a) increased use by commercial and noncommercial users; (b) change in mode of access, such as from nonmotorized to motorized; (c) conflicts with bears; (d) evidence of abuse (for example, littering or making organic material, such as human food scraps, available to bears).

\section{Plants}

Cultural Resources
In order to minimize potential impacts on Sensitive plant species, outfitter/guides will not establish camps or allow their clients to camp in beach meadows.

People should use existing paths and game trails where possible to limit trampling or damaging vegetation or sensitive plant habitats.

Sightings of sensitive plants shall be reported to the Forest Service.

Sensitive plants shall not be collected. Legitimate scientific or educational entities may collect sensitive listed plants only with a valid collection permit.

Other plants shall not be collected for commercial purposes without a permit.

Items of historical, prehistoric, or paleontological value are protected under various federal laws, including the National Historic Preservation Act; the Antiquities Act of 1906; the Archaeological Resource Protection Act of 1979; and other federal regulations.

If historical, prehistoric, or paleontological objects or sites are discovered during activities under this permit, the permit holder is responsible for assuring that those objects or sites are not disturbed during the course of the activities of the permit holder or the permit holder's clients. This includes digging and disturbing sites, and picking up and removing artifacts from sites. 


\section{Appendix C, Mitigation}

If any historical, prehistoric, or paleontological objects or sites are located, permit holders are required to immediately report their findings to the Forest Service.

\section{Site-Specific Mitigation Measures}

Wild and Scenic Rivers
Outfitter/guide use on wild and scenic rivers will follow the appropriate Forest Plan and Recreational Opportunity Spectrum (ROS) guidelines for group encounters and group size as shown in Table $\mathrm{C}-1$.

Table C-1. ROS Guidelines for Group Encounters and Group Size for Wild and Scenic Rivers

\begin{tabular}{|c|c|c|c|c|c|}
\hline $\begin{array}{l}\text { River } \\
\text { Name }\end{array}$ & $\begin{array}{c}\text { Use } \\
\text { Area }\end{array}$ & Designation & ROS* & $\begin{array}{l}\text { Commercial } \\
\text { Encounters } \\
\text { allowed within } \\
\text { Wild \& Scenic } \\
\text { Areas }\end{array}$ & $\begin{array}{l}\text { Maximum } \\
\text { Group Size }\end{array}$ \\
\hline \multirow{2}{*}{$\begin{array}{l}\text { Katzehin } \\
\text { River }\end{array}$} & \multirow{2}{*}{$01-01$} & \multirow{2}{*}{ Wild River } & $P$ & $<1.5$ group/day & 12 \\
\hline & & & SPNM & $<5$ group/day & 12 \\
\hline $\begin{array}{l}\text { Gilkey } \\
\text { River }\end{array}$ & $01-04 \mathrm{~A}$ & Wild River & $P$ & $<1.5$ group/day & 12 \\
\hline $\begin{array}{l}\text { King } \\
\text { Salmon } \\
\text { River }\end{array}$ & 04-09 & Wild River & SPM & $<5$ group/day & 12 \\
\hline \multirow{2}{*}{$\begin{array}{l}\text { Lisianski } \\
\text { River }\end{array}$} & \multirow{2}{*}{$04-15$} & \multirow[t]{2}{*}{ Wild River } & SPNM & $<5$ group/day & \multirow{2}{*}{12} \\
\hline & & & SPM & $<5$ group/day & \\
\hline $\begin{array}{c}\text { Kadashan } \\
\text { River }\end{array}$ & 04-12 & $\begin{array}{l}\text { Scenic } \\
\text { River }\end{array}$ & SPM & $<5$ group/day & 20 \\
\hline $\begin{array}{l}\text { Glacial } \\
\text { River }\end{array}$ & 04-04B & Wild River & $\mathrm{P}$ & $<1.5$ group/day & 12 \\
\hline
\end{tabular}

Source: 2001 Tongass National Forest GIS Layers, National ROS Direction, Forest Plan *P=Primitive, SPNM=Semi-Primitive Non-Motorized, SPM=Semi-Primitive Motorized 


\section{Seymour Canal Closed Area}

(Use Area 04-09)

Outfitter/guide fishing is prohibited in all creeks flowing into Windfall Harbor, Pack

Creek, and Swan Cove. The recreational emphasis in this area is bear viewing.

\section{King Salmon River, Wheeler Creek, and Greens Creek}

(Use Areas 04-09, 04-010A)

No guided fishing is allowed upstream of the grass flats on these streams during the month of July. Outfitter/guide use is prohibited unless specifically authorized. Specific areas of allowed use within these flats will be delineated on an aerial photograph and made a part of the permit.

Redoubt Lake and Outlet Stream, Salmon Lake, Nakwasina River, St. John the Baptist River, and Fish Bay River

(Use Areas 04-02A, 04-03)

Alternatives 2, 4, and 5, from August 21 through September 30, no more than two outfitter/guide groups participating in guided sport fishing activities may be present at one time.

\section{Admiralty Cove}

(Use Area 04-08)

Outfitter/guide use is prohibited within one mile of Admiralty Cove Cabin.

\section{Pinta Cove Shelter}

(Use Area 04-16A)

Outfitter/guide use will not displace unguided users at the Pinta Cove Shelter.

\section{Kennel Creek, Salt Lake Bay, Eight Fathom Bight, False Island, and Corner Bay Docks}

(Use Areas 04-11, 04-12, 04-13)

These docks are for Forest Service administrative use. Outfitter/guides may use these docks as permitted but they may not leave boats unattended or obstruct administrative use.

\section{Neka Bay and Mud Bay}

(Use Areas 04-11, 04-16B)

Wheeled fixed-wing aircraft landings in association with commercial operations on National Forest System lands within the Neka Bay and Mud Bay estuaries may be authorized under specific stipulations provided on the applicable Use Area card.

\section{Cowee Creek, Sawmill Creek, Sweetheart Lake, and Turner Creek} (Use Areas 04-01A, 01-05B, 01-04C)

These areas have high potential for conflict with local users. Outfitter/guides must not displace any unguided users. Outfitter/guides will not conduct activities in these areas on weekends or during state and federal holidays. 


\section{Appendix C, Mitigation}

\section{Sweetheart Creek (Gilbert Bay) (Use Area 01-05B)}

Guided fishing use is prohibited during the personal use sockeye fishery.

No more than two guided groups may be present during other times of the year to avoid conflicts with unguided fishing.

Outfitter/guides must know and be in compliance with state sport fishing regulations regarding fishing near any stream structure (such as fish weirs, fish traps, etc.) on Crescent and Speel Lakes and Outlets, as well as streams draining into Gilbert Bay.

Gut Bay (Use Area 04-01A)

Guided fishing use is prohibited during the subsistence sockeye fishery.

Falls Lake (Use Area 04-01A)

Guided fishing use is prohibited during the subsistence sockeye fishery. Other outfitter/guides shall conduct operations to avoid interfering with the personal use fishery.

\section{Fords Terror (Use Area 01-05E)}

Outfitter/guides cannot use a single site for more than two consecutive nights, in order to minimize resource effects. For group sizes larger than six, only two camping sites, the 'Middle T' and the 'North Narrows', will be allowed in order to prevent additional site hardening.

White Sulphur Springs (Use Area 04-15)

Outfitter/guide use will not displace unguided users at White Sulphur Springs Bathhouse.

\section{Mist Cove/Deer Lake Trail (Use Area 04-01B)}

Use of the Mist Cove/Deer Lake Trail is prohibited until the trail is reconstructed, because of unsafe trail conditions and resource damage.

\section{Little Port Walter/Sashin Lake Trail (Use Area 04-01B)}

Use of Little Port Walter/Sashin Lake Trail is prohibited until the trail is reconstructed, because of unsafe trail conditions and resource damage.

Sitkoh Lake Trail (Use Area 04-13)

Approximately the first 1/8-mile of the trail (from saltwater) traverses through private land. Use of the private land outside the trail corridor easement (including the adjacent portion of Sitkoh Creek) is not permitted.

\section{Basket Bay to Kook Lake (Use Area 04-12)}

Approximately the first 1/8-mile of the undeveloped trail (from saltwater) traverses through private land. If proposed access to Kook Lake is via Basket Bay, use of National Forest System land will not be authorized unless outfitter/guides provide proof that the landowner has allowed access across the private land. 


\section{Mitigation, Appendix C}

\section{Little Basket Bay to Basket Lake (Use Area 04-12)}

Approximately the first 1/4 -mile of the undeveloped trail (from saltwater) traverses through private land. Use of the private land outside of the trail corridor easement is not permitted.

\section{Lake Eva (Use Area 04-04A)}

Outfitter/guides will not be permitted to fly clients into this lake.

\section{Lake Eva Trail (Use Area 04-04A)}

Trail will need to be improved before additional guided use is permitted.

George Island WWII Cannon Trail (Use Area 04-16D)

Trail will need to be improved before additional guided use is permitted.

Nelson Falls Trail (Use Area 04-13)

Trail will need to be hardened before guided use is allowed for large groups.

Sitkoh Lake (Use Area 04-13)

Outfitter/guides will not be permitted to fly clients into this lake.

Port Alexander (Use Area 04-01B)

Guided hunting will not occur within one mile of the community of Port Alexander. 


\section{Appendix C, Mitigation}

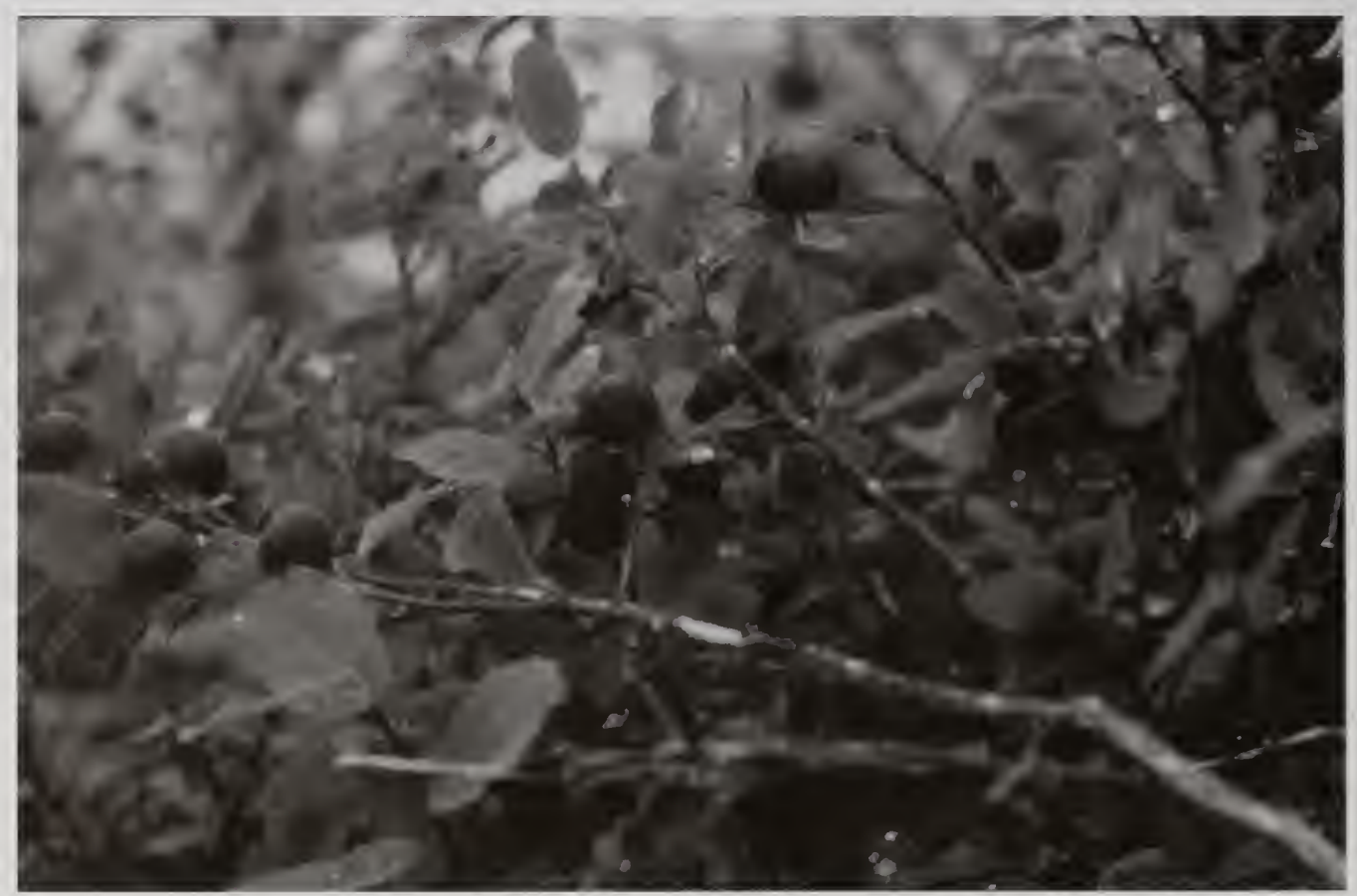




\section{Appendix D Monitoring}




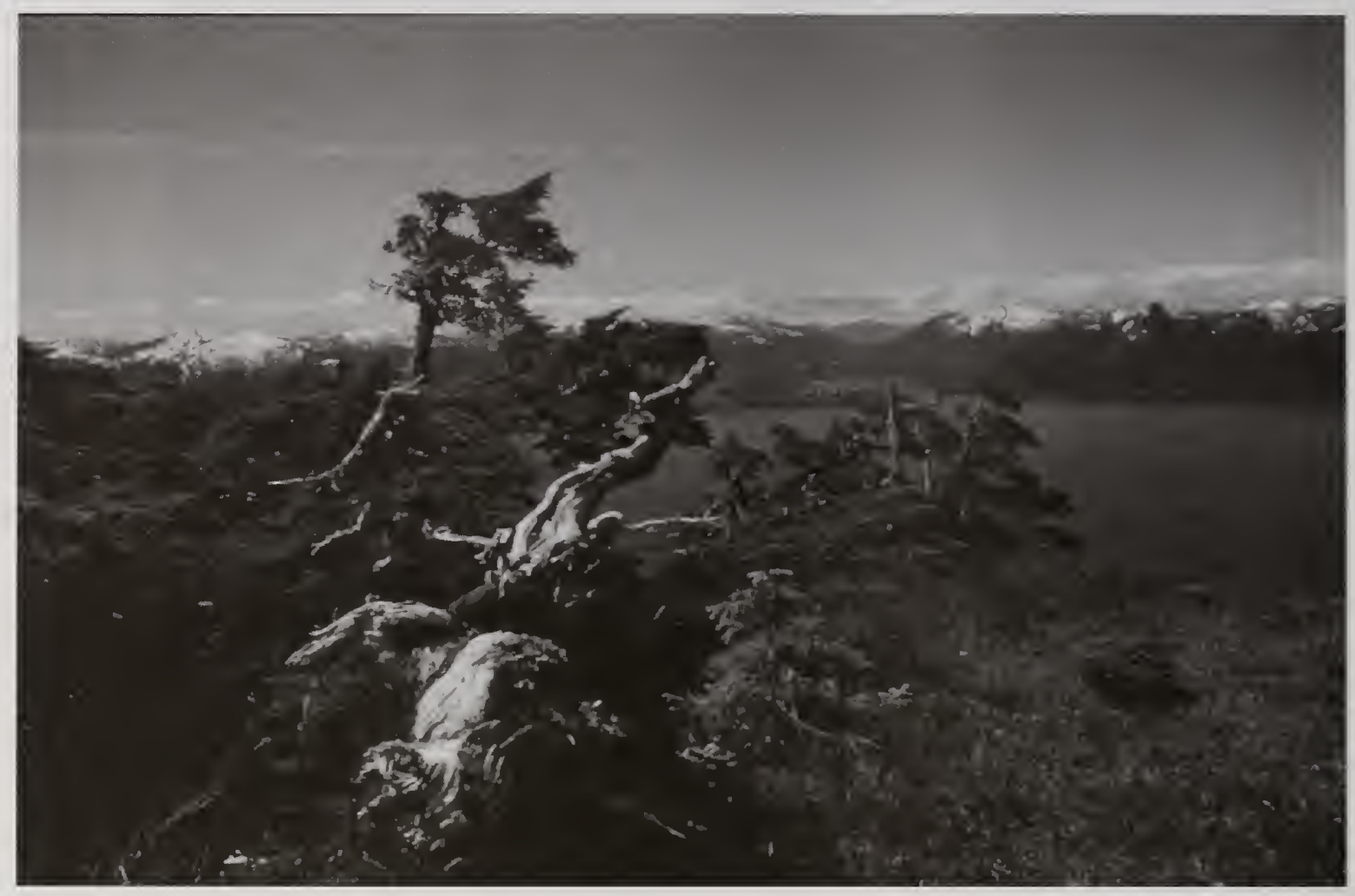




\section{Appendix D Monitoring}

\section{Introduction}

Monitoring is gathering information and observing the results of management activities to provide a basis for evaluation. Monitoring in this project is conducted to better understand the interaction of recreation use on forest resources and to ensure that we are maintaining the sustainability of those resources. It also serves as a quality control process for implementing the project. The evaluation of monitoring results for this project will provide a feedback loop to make corrective actions, as needed, to provide resource protection and the desired recreation opportunities.

This monitoring plan includes commercial use permit administration measures and specific resource monitoring requirements. The recreation activities authorized by this project may also be included as part of resource program and Forest Plan monitoring.

Monitoring will occur during Special Use permit preparation and administration, project-specific field inspections, and in annual program and plan reviews of the recreation use resulting from this project. Mitigation and resource concerns identified during monitoring will be addressed through permit administration. Monitoring will continue to ensure that the permit stipulations offer sufficient resource protection.

\section{Monitoring Through Permit Screening, Preparation, and Administration}

One aspect of monitoring assesses whether the project was implemented as proposed and whether or not outfitter/guide activities comply with policy, laws and regulations, and the Forest Plan. This monitoring is done primarily through permit preparation and administrative inspections. Use Area and Large Group Area cards (Appendices A and B) and Mitigation measures (Appendix C) provide site-specific information and guidance for commercial permit preparation and administration. These cards include a map and narrative identifying resource concerns and sitespecific mitigation measures. Other mitigation measures are listed in Appendix C. Information from the cards and Appendix $\mathrm{C}$ are used to prepare the outfitter/guide permits. The resource protection measures are implemented by incorporating them into the Special Use permits as stipulations. They are enforced through the administration of the permits. 
Outfitter/guide permit proposals are monitored in a screening process. The proposal passes two levels of screening prior to becoming a formal application. First, the proposal is checked for the following:

- Consistency with federal, state and local laws, regulations and orders;

- Consistency with the forest land and resource management plan;

- Whether the proposal falls within the bounds of the decision for the Shoreline Outfitter/Guide EIS or whether it requires additional NEPA analysis;

- Whether there would be a serious or substantial risk to public health and safety;

- Whether the use would create an exclusive or perpetual right of use or occupancy;

- Whether the use would unreasonably conflict or interfere with administrative use, other scheduled or existing authorized uses, or adjacent land owners;

- If there is outstanding debt to the Forest Service;

- To ensure that use does not involve gambling or provision of sexually oriented commercial services;

- To ensure use does not involve military or paramilitary training/exercises by private organizations or individuals; and,

- To ensure use does not involve disposal of solid waste, radioactive waste, or other hazardous substances.

If the proposal passes the initial screening, it is then checked at the following second level of screening.

- Is the use inconsistent or incompatible with purposes for which lands are managed or with other uses?

- Is the use in the public interest?

- Is the proponent qualified?

- Does the proponent have the technical and financial capability to comply with the terms and conditions of the permit?

- Is the proponent willing to accept the terms and conditions of the permit?

A proposal must pass all criteria in order to become an accepted application. Once the proposed use is determined acceptable, the authorizing officer issues a special uses permit with stipulated terms and conditions.

Throughout the duration of the permit and as a part of project implementation, the permit administrator may conduct permit and field inspections to verify that the terms and conditions are being met. If negative impacts are occurring to resources, corrective measures are taken. Permit administrators can initiate action to repair resource damage and modify or suspend operations until problems have been corrected. If permit compliance inconsistencies are found, the authorizing officer will require them to be corrected. The authorizing officer may suspend or revoke the 


\section{Monitoring, Appendix D}

permit if inconsistencies are severe or if they are not corrected in a timely manner. This process ensures that project elements and Forest Plan standards and guidelines are implemented as designed.

An annual evaluation will be done at the end of the season for each outfitter/guide permit. This evaluation reviews compliance with the terms and conditions of the permit, public service, and site cleanup. A mid-season review is conducted to notify the holder of any deficiencies that will need correction before the year-end evaluation. Renewal of a permit and assignment of priority use depends on documentation of satisfactory performance.

All outfitter/guide permit holders will be required to submit annual use and location reports that include: number of days per trip, date of trip, Use Area and a map of specific locations used, number of clients taken on the national forest, amount of time spent on the national forest, activities, and access type. If outfitter/guides are freshwater fishing on the national forest, they must also submit a freshwater fishing log that contains: total estimated fishing time, type of fish, and number caught, as well as number kept. Actual use reports will be compared to the use that was authorized in the permit.

An outfitter/guide actual use database for all outfitter/guide use in the analysis area will be used to compile and maintain the above information; the database will incorporate actual site use by guide activity. The database will provide a method to identify and assess the actual use against the capacity that has been established for each Use Area in this document. The database will also identify sites receiving higher use and serve as a valuable tool to prioritize areas for additional monitoring for resource impacts and be useful as a measure for future cumulative effects for other projects. Commercial use will be monitored for site-specific impacts as well as overall effectiveness of the mitigation measures.

\section{Project-specific Monitoring}

Recreation Use and Special Use Permit Management
Objective: To provide a quality recreation experience on the forest for both commercial and non-commercial users.

Method: Review actual use reports and database and compile and review outfitter/guide and public comments to determine if the recreation use levels and allocations are acceptable or if there are identified conflicts.

Action: Actual use data will be reviewed annually and compared to the commercial use allocation. Commercial use trends, comments, and concerns from the public and from outfitter/guides will be reviewed to identify potential problem areas. Information collected from items listed below will be reviewed. If the quality of recreation experience is not acceptable, use limits and restrictions could be imposed.

- Request input from outfitter/guides on how the recreation experience can be improved for the forest visitor and to identify concerns regarding industry conflicts by means of a voluntary comment sheet.

- District offices collect and compile public comments about recreation use and opportunities. 


\section{Appendix D, Monitoring}

- Review outfitter/guide client's experiences from the customer service comment cards.

- Review information from existing non-commercial forest use sources, such as data collected by ADF\&G, National Park Service, Alaska Division of Community and Business Development, Forest Service National Recreation Use Survey, cabin use records, and observations from agency personnel conducting field work.

- Forest Service ranger boat skippers and other field personnel will keep a record of anecdotal observations of recreation activity on the national forest.

- Identify trends and potential impacts to the industry generated from comment cards supplied to the outfitter/guides, the public, and through reports generated by SUDS and the actual use database.

- Monitor to determine if Large Group Area use restrictions are adequate to provide the expected recreation experience; if there are sufficient Large Group Areas to meet the demand for large group use; and if Large Group Areas are in the right locations.

Soil, Water, and Vegetation

Fish Habitat and Riparian Areas
Objective: Plan and permit commercial recreation use activities to avoid irreversible or serious and adverse effects on soil, vegetation, and water resources.

Method: Apply Forest Service Best Management Practices to commercial recreation use in all Large Group Areas and other areas of high use to protect the streams from non-point sources of pollution and limit soil erosion. Make soil and water field observations in areas receiving high use during permit administration.

Action: Protect water quality and sustain soil productivity from significant impacts by taking corrective action where necessary, such as restricting use or site hardening to avoid adverse impacts.

- Monitoring for resource concerns will occur by annually reviewing the actual use occurring as displayed in the actual use database for high use areas, and through special use permit administration and inspections.

- Each Large Group Area will be monitored for excessive vegetation and soil disturbance during permit administration. Monitoring intensity will be based on the amount of use identified during review of the actual use database.

- Wetlands associated with Large Group Areas and other sites with high use will be monitored for disturbance. Mitigation measures that have been implemented will be monitored to assess their effectiveness. Additional protection measures will be implemented if necessary.

Objective: Ensure sufficient essential fish habitat is protected and conserved to support sustainable fisheries and other aquatic life, and to promote old-growth and riparian-associated plant and wildlife species that contribute to a healthy ecosystem. 


\section{Monitoring, Appendix D}

Method: Visually inspect Large Group Areas and other areas receiving high use to ensure impacts to riparian areas are within acceptable levels of vegetative and soil disturbance.

Action: Conduct field reviews during permit administration to determine if appropriate protection measures are adequate for resource protection. Adjust use levels or protection measures if habitat protection is inadequate.

Method: Visually inspect streams receiving guided motorized watercraft use during permit administration.

Action: If effects to spawning habitat become measurable, restrict motorized watercraft.

Fish, Wildlife, and Subsistence Resources
Objective: Ensure that fish and wildlife management objectives are met for consumptive and non-consumptive uses.

Method: Collect guided fish and wildlife catch/harvest information. Consult with fish and game management agencies annually and share harvest and use records to assess impacts on fish and wildlife populations.

Action: The Forest Service will consult with Alaska Department of Fish and Game, the Alaska Board of Game, Federal Subsistence Board representatives, and local tribal biologists on an annual basis to review the previous year's record of consumptive use of fish and game resources, including brown bears, as they relate to outfitter/guide use. Consider adjusting seasons, bag limits, or Special Uses restrictions, such as number or location of hunts, if impacts to wildlife, fish, and subsistence resources are not acceptable.

Objective: To ensure that cultural resource sites are adequately protected.

Method: Conduct field observations during permit administration at the cultural sites in the North Windham Bay, Sand Bay, Todd Road, and George Island Large Group Areas and at other areas receiving high levels of use. Use the actual use reports data and cultural site inventories to identify additional areas for monitoring.

Action: If cultural sites are showing signs of unacceptable impacts, guided recreation use in these areas could be limited or restricted, or the site could be hardened to prevent impacts. The Forest Service will continue to consult with local Tribal governments on heritage resource issues in the analysis area as part of the regular consultation process.

\section{Program Monitoring}

Some resources are monitored on an annual basis across the national forest as part of regularly scheduled resource program activity. Wilderness, heritage, and botanical resource programs routinely conduct monitoring activities that are not necessarily tied to a specific project action. This monitoring provides a baseline of information from which assessments can be made. Commercial recreation activities authorized 


\section{Appendix D, Monitoring}

by this project may be included as part of that resource program monitoring, where applicable.

\section{Forest Plan Monitoring}

The Forest Plan (Chapter 6) contains a forest-wide monitoring and evaluation plan. Some Forest Plan monitoring items are based on the condition of the Tongass National Forest as a whole while others are contingent on forest management activities. Activities authorized under the Shoreline Outfitter/Guide decision may be included as activities considered in the Forest Plan monitoring where applicable. 


\section{Appendix E Management Direction}




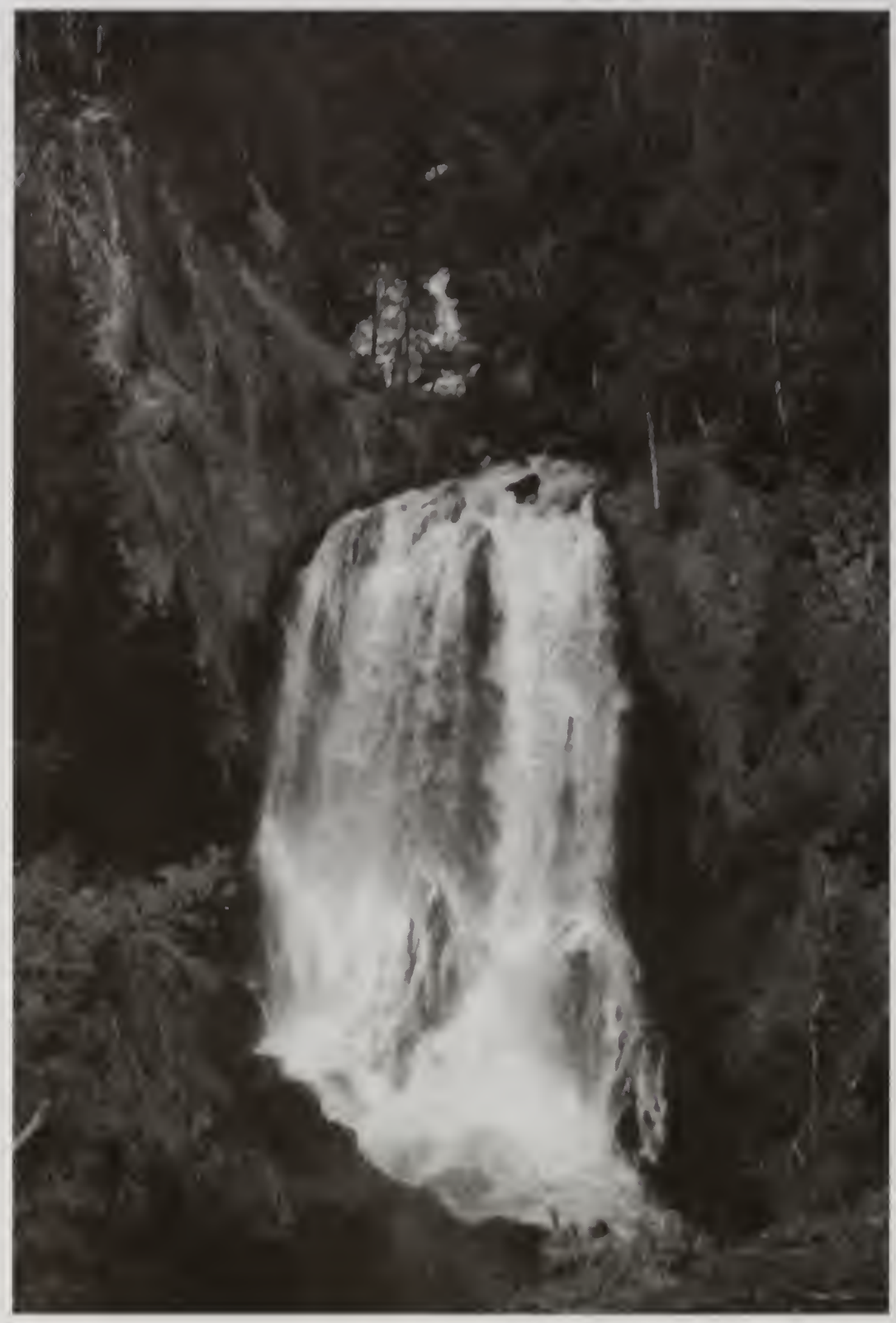




\section{Appendix E Management Direction}

Management direction governing this project comes from the national, regional, and forest levels. Direction becomes increasingly more specific from the national to the project level.

\section{National Level Direction}

\section{USDA Forest Service Strategic Plan 2000}

The USDA Forest Service Strategic Plan (2000 Revision) provides the mission statement and outlines long-term goals and objectives that set the course and provide guidance for the agency's actions. The Strategic Plan incorporates the priorities of the ageney's Natural Resouree Agenda that focuses on watershed health and restoration, sustainable forest management, the national forest road system, and recreation.

The following recreation management objectives from the Strategic Plan apply to the Shoreline Outfitter/Guide analysis.

Objective 2.a - Improve the capability of the nation's forests and grasslands to provide diverse, high-quality outdoor recreation opportunities.

- Research methods for estimating recreation capacity and demand using ecological capabilities and social factors.

- Focus recreation management, maintenance, and development activities where demand is currently exceeding or expected to exceed capacity on National Forest System lands.

- Maintain the integrity of roadless areas for dispersed recreation opportunities through implementation of a roadless area conservation policy.

- Manage recreation areas and programs on National Forest System lands to tevels compatible with ecosystem sustainability objectives by:

- Working with communities to determine recreation opportunities and priorities,

- Redirecting opportunities and use,

- Improving management of facilities and special places, and

- Increasing environmental education and interpretation.

Objective 2.b - Improve the capability of Wilderness and protected areas to sustain a desired range of benefits and values.

Objective 2.d - Increase aceessibility to a diversity of people and members of underserved and low-income populations to the full range of uses, values, products, and services.

Create and institutionalize detivery systems that are more responsive to a diversity of people and members of underserved and low-income populations. 


\section{Appendix E, Management Direction}

Enhance broader public accessibility through partnerships and contracts with federal, state, and tribal governments and other entities.

Objective 3.a - Better assist in building the capacity of tribal governments, rural communities, and private landowners to adapt to economic, environmental, and social change related to natural resources.

Objective 4.f - Provide appropriate access to National Forest System lands and ensure nondiscrimination in the delivery of all Forest Service programs.

Continue to ensure that National Forest System lands, programs, and facilities are accessible to all Americans.

\section{Forest Service National Recreation Agenda}

The Forest Service Recreation Agenda guides programs and activities to meet the recreation goals and objectives of the Strategic Plan. Recreation management on national forests is designed to meet the nation's present and future needs for outdoor recreation in a manner that protects the health, diversity, and productivity of the land.

The Forest Service recognizes the unique nature-based values national forests offer to an increasingly urban society. We also recognize the growing importance of the resource-based travel and tourism industry to provide the means for certain segments of an increasingly urban society to enjoy and appreciate the natural world. The Forest Service encourages travel and tourism opportunities that represent the diversity of existing and potential visitors in collaboration with tourism professionals and state tourism offices.

Recreation planning includes recreation opportunities within the bounds of ecological sustainability. We strive to achieve correct limits of use and balance between competing uses and values through management activities. Recreation programs are managed with an understanding of ecosystem diversity, complexity, and the natural rate of change that is vital to sustaining the amenities and experiences that society desires. The full spectrum of recreation opportunities will be considered. We will provide access to recreation opportunities. The Forest Service will work closely with other government agencies and landowners to provide for future uses and access.

Recreation planning and implementation must ensure services for all people. It will incorporate the needs of all people, including people with disabilities and underserved groups.

The Forest Service will work closely with other agencies, the private sector, and non-profit groups to enhance and improve visitor services. Planning must be conducted across jurisdictional boundaries.

The Forest Service recognizes the importance of community connections and relationships. Strengthening community connections is vital to provide relevant services and plan for economic development. The Forest Service supports community objectives for building recreational programs, facilities, and services that contribute to local and regional economies and quality of life. The economic health of local communities relies increasingly on the tourism industry. The Forest Service will join with commercial business, non-governmental organizations, trade associations, other government agencies, and educational institutions in forming viable and sustainable nature-based tourism industries. 


\section{Management Direction, Appendix E}

\section{Regulations}

\section{Manual Direction}

The Forest Service will need to develop strong business partnerships and relationships with our recreation partners and cooperators to deliver a quality, safe, and responsive recreation program. We will improve business relationships with permit holders by streamlining our processes and providing a more predictable business environment.

We will continue our close relationships with federal, tribal, state, and local governments to be more efficient and to plan for mutually beneficial recreation activities.

Federal regulations governing the Forest Service fall primarily under the Code of Federal Regulations, Parks, Forest, and Public Property 36 CFR Chapter 2.

Commercial recreation falls under the Special Uses Program regulated under 36 CFR Part 251 - Land Uses.

Agency direction for administration of the recreation program is provided in the Recreation, Wilderness, and Related Resource Manual (FSM 2300) and the Publicly Managed Recreation Handbook (FSH 2309.23), the Recreation Facilities Handbook (2309.24), and the Trails Management Handbook (2309.18).

Direction for administration of the Special Uses program is provided in the Special Uses Management Manual (FSM 2700) and the Special Uses Handbook (FSH 2709.11).

The ROS Users Guide Handbook provides guidance in using the Recreational Opportunity Spectrum (ROS) for recreation management in land management planning.

\section{Alaska Regional Direction}

\section{Alaska Region Strategic Priorities}

The Alaska Region Strategic Priorities provide emphasis and guidance in the key program areas of recreation and tourism, communities, Alaska Natives, and organization and employee effectiveness. The Regional Forester's strategic objective for recreation and tourism is to create a future where ecologically sustainable recreation and tourism have become a steady, reliable component of the economies of national forest dependent communities and other communities in Alaska.

The Alaska Region Recreation and Tourism Strategic Plan is the Action Plan to implement the Alaska Region Strategic Priorities. The Shoreline Outfitter/Guide analysis is a key task in implementing the Recreation and Tourism Strategic Plan.

The Tongass Land and Resource Management Plan (1997) sets forth the direction for managing the land and resources of the Tongass National Forest. It is the result of extensive analysis documented in the Tongass Land and Resource Management Plan, Final Environmental Impact Statement (FEIS), and 1997 Record of Decision. The Tongass Land and Resource Management Plan, as amended, is referred to as the
Forest Plan
Direction 


\section{Appendix E, Management Direction}

\section{Goals and Objectives}

Forest Plan in this document. The Shoreline Outfitter/Guide analysis is designed to achieve Forest Plan goals and objectives and move the analysis area toward the desired conditions. The Forest Plan includes forest-wide goals and objectives, and area-specific land use designation (LUD) goals, objectives, and desired future conditions.

Forest-wide goals and objectives applicable to recreation management (see Forest Plan, pp.2-3 through 2-5) include:

- Provide diverse opportunities for resource uses that contribute to the local and regional economies of Southeast Alaska;

- Support a wide range of natural/resource employment opportunities within Southeast Alaska's communities;

- Provide a range of recreation opportunities consistent with public demand, emphasizing locally popular recreation places and those important to the tourism industry;

- Manage the Forest's recreation settings in accordance with the Recreation Opportunity Spectrum (ROS) standards and guidelines for each land use designation (LUD);

- Provide for the continuation of subsistence uses by all rural Alaskan residents;

- Evaluate and consider the needs of subsistence users in making project land management decisions; and

- Manage designated Wilderness areas to maintain an enduring wilderness resource while providing for public access and uses consistent with the Wilderness Act of 1964 and the Alaska National Interest Lands Conservation Act of 1980 (ANILCA).

\section{Land Use Designations}

The Forest Plan uses land use designations (LUDs) to guide management of the Tongass National Forest. Each LUD provides for a unique combination of activities, practices, and uses. The Shoreline Outfitter/Guide analysis area includes 16 LUDs (Figure 1-2). Table E-1 displays the area and Table E-2 displays the miles of shoreline in each LUD. Goals, objectives, and desired future conditions of each LUD that apply to recreation and tourism are provided below and are described in detail in the Forest Plan.

\section{Wilderness LUD}

Goals:

- Manage all designated Wilderness to maintain an enduring wilderness resource while providing for public access and uses consistent with the Wilderness Act of 1964 and ANILCA.

- Protect and perpetuate natural biophysical and ecological conditions and processes.

- Provide a high degree of remoteness from the sight and sound of humans, and opportunities for solitude and primitive recreation activities consistent with wilderness preservation. 


\section{Management Direction, Appendix E}

Objectives:

- Manage recreation activities to meet the appropriate levels of social encounters, on-site developments, methods of access and visitor impacts indicated for the adopted or existing Recreation Opportunity Spectrum (ROS), as appropriate.

- Provide for public use of the Wilderness in accordance with ANILCA provisions for motorized and non-motorized access and travel, including reasonable traditional subsistence use by rural residents.

- Provide trails and primitive facilities that are in harmony with the natural environment and that promote primitive and semi-primitive recreation experiences.

\section{Desired Future Condition}

The desired future condition of the Wilderness LUD emphasizes ecological processes and natural conditions that are not measurably affected by past or current human uses or activities. Wilderness users have the opportunity to experience independence, closeness to nature, solitude, and remoteness, and they may pursue activities requiring self-reliance, challenge, and risk. Motorized and mechanized use is limited to the minimum needed for the administration of the Wilderness, access to state and private lands, subsistence uses, and for public access and other uses specifically allowed by ANILCA.

\section{Wilderness National Monument LUD (Admiralty Island)}

This LUD applies to portions of Admiralty Island National Monument. Presidential Proclamations of 1978 designated this unit as a National Monument. Designation was due to the superlative combination of significant scientific and historical features.

\section{Goals:}

- The goals are the same as the Wilderness LUD but also include the protection and study of Tlingit cultural resources and other historical resources, the protection and study of brown bear and bald eagle populations, and the preservation of the intact, unique coastal island ecosystem.

Objectives:

- Inventory, research, protect, and interpret National Monument resources as directed by Monument designation consistent with wilderness management practices.

- Provide for public use of the wilderness in accordance with ANILCA provisions for motorized and non-motorized access and travel, including reasonable traditional subsistence use by rural residents.

- Manage recreation activities to meet appropriate levels of social encounters, on-site developments, methods of access, and visitor impacts indicated for the adopted or existing ROS, as appropriate.

Desired Future Condition

The desired future condition of the Wilderness National Monument LUD is the same as the desired condition for Wilderness. The desired condition within the Admiralty Island Wilderness National Monument also includes appropriate research within constraints of Wilderness designation, and contributes to both the purposes of the 


\section{Appendix E, Management Direction}

Wilderness National Monument and improved management of other National Forest System lands.

\section{Non-Wilderness National Monument LUD}

This LUD applies to portions of Admiralty Island National Monument.

Goals:

- The goals of non-wilderness National Monument LUD are similar to Wilderness National Monument LUD except that limited mining is allowed. Manage Admiralty Island National Monument for public access and uses consistent with the Wilderness Act of 1964, ANILCA, and the Presidential Proclamation of 1978, which designated the unit as a National Monument because of the superlative combination of significant scientific and historical features.

- Facilitate the development of significant mineral resources located within portions of Admiralty Island, as specified by ANILCA.

- Protect objects of ecological, cultural, geological, historical, prehistorical, and scientific interest, as specified by ANILCA.

Objectives:

- Inventory, research, protect, and interpret National Monument resources as directed by National Monument designations.

- Locate and manage trails to direct the public away from mining operations.

\section{Desired Future Condition}

Protecting and learning more about the special resources they contain fulfills the Non-Wilderness Monument LUD desired future condition. Appropriate research is encouraged and supported and contributes to both the purposes of the Wilderness National Monuments and improved management of other forest lands. The NonWilderness National Monument provides the same natural settings and recreation experiences as the adjacent Wilderness National Monument areas.

\section{Research Natural Area LUD}

Goals:

- Preserve areas of ecological importance in their natural condition for the purposes of research, monitoring, education, and/or to maintain natural diversity.

- Allow natural physical and biological processes to prevail without human intervention.

Objectives:

- Provide opportunities for baseline monitoring of ecological processes and non-manipulative research and observation.

- Maintain the natural, undisturbed character of each area by permitting no permanent facilities and no roads or trails, except for research purposes or as otherwise provided by law; and limiting recreation uses to those that do not affect or alter natural biological processes. 


\section{Management Direction, Appendix E}

\section{Desired Future Condition}

Essentially unmodified environments in which natural ecological processes prevail characterize the desired future condition of the Research Natural Area LUD. They remain undisturbed by human uses or activities, and proved quality opportunities for non-manipulative scientific research, observation, and study.

\section{Special Interest Area LUD}

Goal:

- Provide for the inventory, maintenance, interpretation, and protection of the existing characteristics and attributes of areas with unique cultural, geological, botanical, zoological, recreational, scenic, or other special features.

Objectives:

- Provide opportunities for public study, use, and enjoyment of unique natural areas that are suitable to, and do not compromise, the characteristics of each area.

- Allow only facilities and recreation developments that contribute to the interpretation of natural features or provide for compatible uses, and that blend with the natural setting.

- Provide for existing ROS opportunities and activities unless public use is specially restricted for the protection of other resources.

\section{Desired Future Condition}

Generally unmodified environments in which unique natural features are preserved characterize the desired future condition of the Special Interest Area LUD. They remain largely undisturbed by human uses or activities, except for localized interpretive purposes and, in some cases, recreation developments, and provide quality opportunities for public study, use and enjoyment.

\section{Remote Recreation LUD}

Goals:

- Provide extensive, unmodified natural settings for primitive types of recreation and tourism.

- Provide opportunities for independence, closeness to nature, and selfreliance in environments offering a high degree of challenge and risk.

- Minimize the effects of human uses, including subsistence use, so that there is no permanent or long-lasting evidence.

\section{Objectives:}

- Manage recreation and tourism use and activities to meet the levels of social encounters, on-site developments, methods of access, and visitor impacts indicated for the Primitive ROS class.

- Provide trails and primitive facilities that are in harmony with the natural environment and that promote primitive recreation experiences.

Desired Future Condition

For the Remote Recreation LUD extensive, unmodified natural environments characterize the desired future condition. Users have the opportunity to experience 


\section{Appendix E, Management Direction}

independence, closeness to nature, solitude, and remoteness, and may pursue activities requiring self-reliance in an environment that offers a high degree of challenge and risk. Interactions between users are infrequent. Motorized access is limited to traditional means: boats, aircraft, and snowmobiles. Facilities and structures are minimal and rustic in appearance.

\section{Old-Growth Habitat LUD}

Goals:

- Maintain areas of old-growth forests and their associated natural ecological processes to provide habitat for old-growth associated resources.

Objectives:

- To the extent feasible, limit roads, facilities, and permitted uses to those compatible with old-growth forest habitat management objectives.

\section{Desired Future Condition}

For the Old-growth Habitat Land Use Designation, the desired future condition is for all forested areas to attain old-growth forest characteristics and provide a diversity of old-growth habitat types, associated species, and ecological processes.

\section{Semi-Remote Recreation LUD}

Goals:

- Provide predominantly natural or natural-appearing settings for semiprimitive types of recreation and tourism and for occasional enclaves of concentrated recreation and tourism facilities.

- Provide opportunities for a moderate degree of independence, closeness to nature, and self-reliance in environments requiring challenging motorized or non-motorized forms of transportation.

\section{Objectives:}

- Manage recreation and tourism use and activities to meet the levels of social encounters, on-site developments, methods of access, and visitor impacts indicated for the Semi-primitive ROS classes. Enclaves of concentrated recreation and tourism developments within the LUD or management activities in an adjacent LUD may cause the ROS setting to become Rural.

- Permit small-scale, rustic recreation and tourism facilities, and occasional enclaves of concentrated recreation and tourism facilities.

\section{Desired Future Condition}

Generally an unmodified natural environment characterizes the desired future condition of the Semi-Remote Recreation LUD. Users have the opportunity to experience a moderate degree of independence, closeness to nature, solitude and remoteness, with some areas offering motorized opportunities and others nonmotorized opportunities (except for the traditional uses of boats, aircraft, and snow machines). Interactions between users are infrequent. Motorized access is limited to traditional means: boats, aircraft, and snow machines. Facilities and structures may be minimal or occasionally may be larger in scale, but will be rustic in appearance, or in harmony with the natural setting. 


\section{Management Direction, Appendix E}

\section{Land Use Designation II (LUD II) \\ Goals:}

- Manage these areas in a roadless state to retain their wildland character. Objectives:

- Manage recreation and tourism use and activities to meet the levels of social encounters, on-site developments, methods of access, and visitor impacts indicated by the Primitive and Semi-primitive ROS classes. Apply the LUD II direction from the Forest Plan which is summarized as follows:

1. Permit boats, aircraft, and snow machines, unless such uses become excessive,

2. Permit primitive recreational facilities, and

3. Major concentrated recreation facilities will generally be excluded.

\section{Desired Future Condition}

The desired future condition of the LUD II Land Use Designation is characterized by extensive, generally unmodified natural environments, and retaining their wildland character. Users have the opportunity to experience a high-to-moderate degree of independence, closeness to nature, solitude, and remoteness, and may pursue activities requiring self-reliance, challenge, and risk. Interactions between users are infrequent. Recreation facilities and structures are primitive.

\section{Wild River LUD}

Goals:

- Maintain, enhance, and protect the free-flowing character and outstandingly remarkable values of rivers and river segments designated as Wild Rivers and included in the National Wild and Scenic Rivers System.

- Maintain Wild Rivers in a natural, free flowing, unmodified condition, and provide recreation and tourism opportunities affording a high degree of independence, closeness to nature, and self-reliance.

\section{Objectives:}

- Manage recreation and tourism use and activities to meet the levels of social encounters on-site developments, methods of access, and visitor impacts indicated for the Primitive or Semi-primitive ROS classes.

\section{Desired Future Condition}

Wild Rivers and river segments are in a natural, free flowing, and undisturbed condition. Recreation users have the opportunity for primitive and semi-primitive experiences, solitude, and remoteness in a natural setting. Interactions between users are infrequent and evidence of human activities is minimal. Facilities and structures are rustic in appearance and promote primitive recreation and tourism experiences.

\section{Scenic River LUD}

Goals:

- Maintain, enhance and protect the free-flowing character and outstandingly remarkable values of rivers and river segments designated 


\section{Appendix E, Management Direction}

as Scenic Rivers and included in the National Wild and Scenic Rivers System.

- Maintain Scenic Rivers in a natural or naturally-appearing, free flowing, condition, and provide recreation and tourism opportunities meeting these expectations.

Objectives:

- Manage recreation and tourism use and activities to meet the levels of social encounters on-site developments, methods of access, and visitor impacts indicated for the desired Recreation Opportunity Spectrum class. generally Semi-primitive.

\section{Desired Future Condition}

Scenic Rivers and river segments are in a generally unmodified, free-flowing condition. Ecological processes and changes may be somewhat affected by human uses. The outstandingly remarkable values for which the river was designated remain outstanding and remarkable. Recreation and tourism users have the opportunity for experiences ranging from Primitive to Roaded Natural in a naturalappearing setting. Resource activities within the river corridor are not visually evident to the casual observer. Interactions between users are moderate. Facilities and structures are rustic in appearance and promote semi-primitive recreation experiences and/or public safety.

\section{Experimental Forest LUD}

Goal:

- Provide for long-term opportunities for forest research and demonstration essential to managing forest resources.

Objectives:

- Roads and trails will generally complement research and interpretation. Allow facilities necessary for ongoing research, as specified in the experimental forest's development plan.

\section{Desired Future Condition}

The desired future condition of the Experimental Forest LUD is ongoing research to provide useful information for forest management. Non-research types of activities and uses may be compatible, and do not interfere with research or demonstration objectives.

\section{Scenic Viewshed LUD}

Goals:

- Provide a sustained yield of timber and a mix of resource activities while minimizing the visibility of developments as seen from visual priority travel routes and use areas.

- Recognize the scenic values of suitable timber lands viewed from selected popular roads, trails, water travel routes, recreation sites, bays and anchorages, and to modify timber harvest practices accordingly. 


\section{Management Direction, Appendix E}

\section{Objectives:}

- Provide a spectrum of recreation and tourism opportunities consistent with the capabilities of this LUD. Semi-primitive to roaded experiences may be offered.

- Design roads and trails to be compatible with the characteristic landscape.

\section{Desired Future Condition}

The desired future condition of the Scenic Viewshed LUD is characterized by a natural-appearing landscape as viewed by users of visual priority travel routes and use areas. Recreation and tourism opportunities in a range of settings are available. A variety of successional stages providing wildlife habitat occur, although late successional stages predominate.

\section{Modified Landscape LUD}

Goals:

- Provide a sustained yield of timber and a mix of resource activities while minimizing the visibility of developments in the foreground distance zone. Recognize the scenic values of suitable timber lands viewed from identified popular roads, trails, marine travel routes, recreation sites, bays, and anchorages, and modify timber harvest practices accordingly.

Objectives:

- Provide a spectrum of recreation and tourism opportunities consistent with the capabilities of this LUD. Semi-primitive to roaded experiences may be offered. Avoid changes to semi-primitive non-motorized settings when feasible.

\section{Desired Future Condition}

The desired future condition of the Modified Landscape LUD is characterized by a somewhat modified landscape, but emphasizes scenic quality in foreground distance zones. Recreation opportunities associated with natural-appearing to modified settings are available. A variety of successional stages provide a range of wildlife habitat conditions.

\section{Timber Production LUD}

Goals:

- The emphasis of this LUD is timber production and there are no goals specifically pertaining to the management of recreation.

Objectives:

- Provide a spectrum of recreation and tourism opportunities consistent with the capabilities of this LUD.

- Manage recreation and tourism use to be compatible with timber production objectives.

- Manage changed recreation settings in accordance with the appropriate ROS class.

Desired Future Condition

The desired future condition of the Timber Production LUD is characterized by a sustained yield of timber, healthy tree stands in a balanced mix of age classes from 


\section{Appendix E, Management Direction}

young stands to trees of harvestable age, and a road system providing access for timber management as well as recreation, hunting and fishing, and other public uses. Recreation opportunities associated with roaded settings from semi-primitive to roaded modified, are available. Wildlife habitats are predominantly in the early and middle successional stages.

\section{Minerals LUD}

Goals:

Mineral exploration and development is the focus of this LUD and there are no goals specific to recreation management.

Objectives:

- Authorize special uses that will not substantially conflict with present or anticipated mineral-related activities.

- Manage recreation settings and opportunities to be as compatible as possible with the LUD.

\section{Desired Future Condition}

During mining operations, mining activities are limited to the area necessary for their efficient, economic, and orderly development. Mining is carried out so that any effects on other resources are minimized to the extent feasible, and all minimum legal resource protection requirements are met. Other resource uses and activities in the area do not conflict with mining operations. After the completion of mining, affected

areas are rehabilitated and, in most cases, the area once again provides the settings and opportunities of the original Land Use Designation.

Forest Plan

Standards and Guidelines
Standards and guidelines for the management of the recreation resource are specified to achieve the objectives and goals of the LUD (Forest Plan, 1997; Chapter 3). There are also standards and guidelines that apply across the Forest and all LUDs (Forest Plan, 1997; Chapter 4). The standards and guidelines that apply to the Shoreline Outfitter/Guide Analysis are summarized in Chapter 2 of this document under Items Common To All Action Alternatives. 


\section{Management Direction, Appendix E}

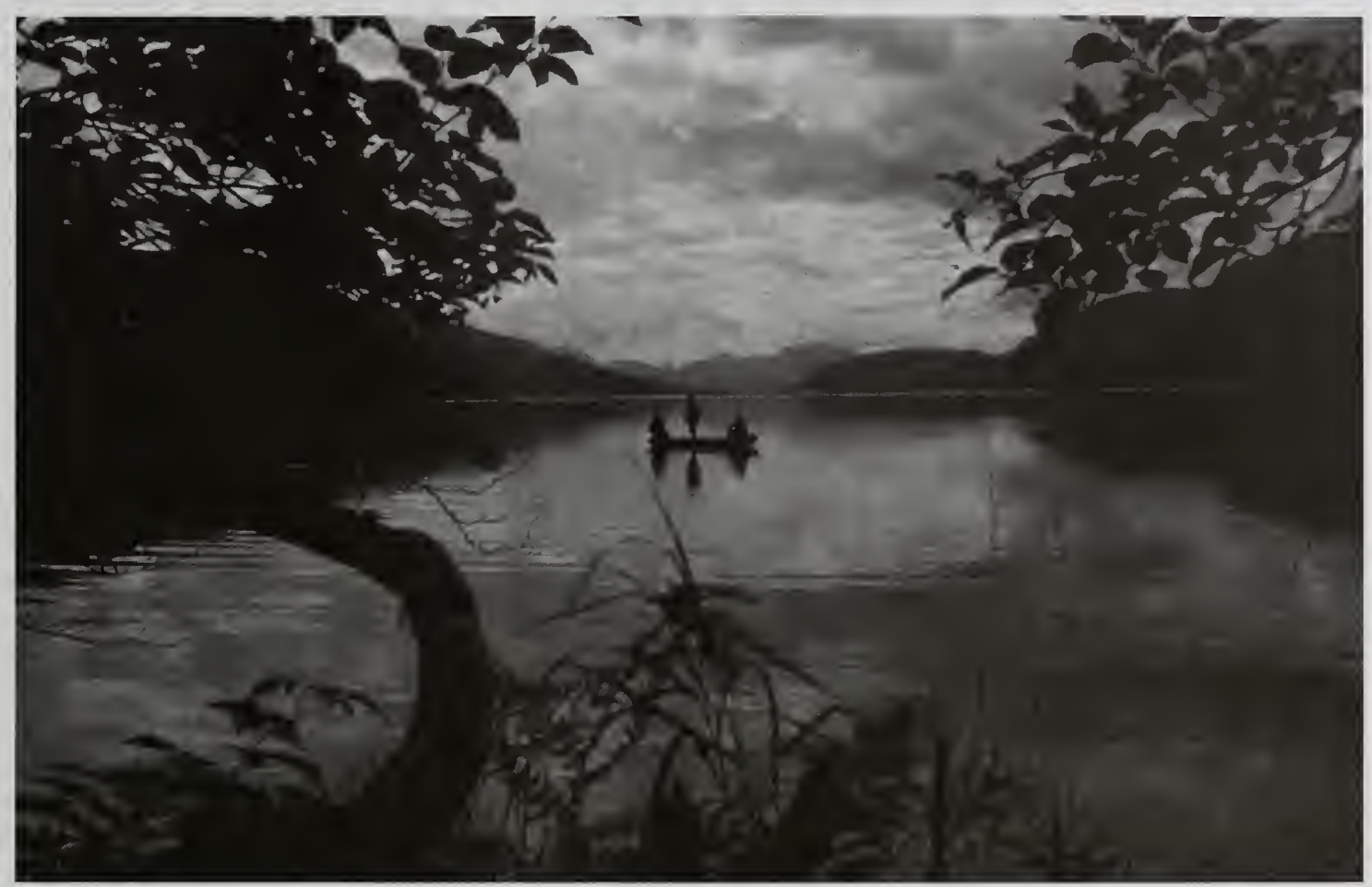




\section{Appendix E, Management Direction}

Table E-1: Area (Acres) of Shoreline Zone by Land Use Designation in the Shoreline Outfitter/Guide Analysis Area

\begin{tabular}{|c|c|c|c|c|c|c|c|c|c|}
\hline 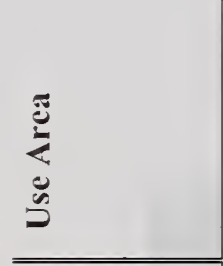 & 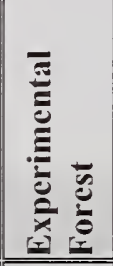 & $\underline{1}$ & 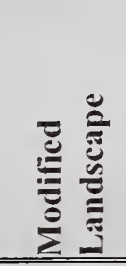 & 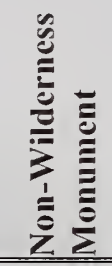 & 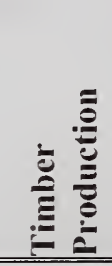 & $\begin{array}{l}5 \\
\overline{0} \\
\overline{0} \\
\overline{0} \\
0\end{array}$ & 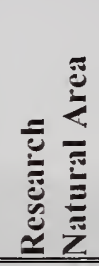 & 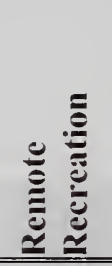 & 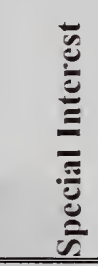 \\
\hline $01-01$ & 0 & 0 & 563 & 0 & 0 & 0 & 0 & 1,977 & 0 \\
\hline $01-02$ & 0 & 0 & 2,322 & 0 & 0 & 0 & 0 & 0 & -0 \\
\hline $01-03$ & 0 & 0 & 2,075 & 0 & 0 & 3,768 & 0 & 0 & 0 \\
\hline $01-04 \mathrm{~A}$ & 0 & 10,919 & 5,347 & 0 & 0 & 2,813 & 0 & 10,628 & 0 \\
\hline $01-04 \mathrm{~B}$ & 0 & 0 & 0 & 0 & 0 & 310 & 0 & 0 & $\therefore$ \\
\hline $01-04 \mathrm{C}$ & 0 & 0 & 0 & 0 & 0 & 962 & 0 & 73 & 0 \\
\hline 01-04D & 0 & 0 & 0 & 0 & 148 & 56 & 0 & 0 & 0 \\
\hline $01-05 \mathrm{~A}$ & 0 & 0 & 0 & 0 & 0 & 2,952 & 920 & 0 & -0 \\
\hline $01-05 \mathrm{~B}$ & 0 & 0 & 1,633 & 0 & 2,244 & 4,062 & 0 & 3,782 & 0 \\
\hline $01-05 \mathrm{C}$ & 0 & 0 & 0 & 0 & 1,925 & 13,484 & 0 & 0 & 0 \\
\hline $01-05 \mathrm{D}$ & 0 & 0 & 0 & 0 & 0 & 0 & 0 & 0 & 0 \\
\hline $01-05 E$ & 0 & 0 & 0 & 0 & 0 & 0 & 0 & 0 & 0 \\
\hline $04-01 \mathrm{~A}$ & 0 & 0 & 0 & 0 & 0 & 0 & 0 & 6,051 & - \\
\hline $04-01 B$ & 0 & 0 & 0 & 0 & 0 & 0 & 0 & 11,931 & 0 \\
\hline $04-02 \mathrm{~A}$ & 0 & 0 & 728 & 0 & 0 & 9,808 & 0 & 0 & 0 \\
\hline $04-02 B$ & 0 & 0 & 0 & 0 & 0 & 0 & 0 & 18,110 & 0 \\
\hline $04-03$ & 0 & 0 & 4,145 & 0 & 5,128 & 12,823 & 0 & 206 & 10,905 \\
\hline $04-04 \mathrm{~A}$ & 0 & 0 & 20 & 0 & 9,719 & 2,878 & 0 & 0 & 0 \\
\hline $04-04 \mathrm{~B}$ & 0 & 0 & 3,496 & 0 & 4,095 & 9,337 & 0 & 5,812 & $\therefore$ \\
\hline $04-04 \mathrm{C}$ & 0 & 0 & 0 & 0 & 0 & 0 & 0 & 922 & 0 \\
\hline $04-05$ & 0 & 0 & 0 & 0 & 0 & 0 & 0 & 0 & 0 \\
\hline $04-06 \mathrm{~A}$ & 0 & 0 & 0 & 0 & 0 & 0 & 0 & 0 & 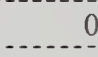 \\
\hline $04-06 \mathrm{~B}$ & 0 & 0 & 0 & 0 & 19 & 0 & 0 & 0 & 0 \\
\hline $04-07$ & 0 & 0 & 0 & 0 & 0 & 0 & 0 & 0 & 28 \\
\hline $04-08$ & 420 & 0 & 0 & $\begin{array}{c}0 \\
-\end{array}$ & 0 & 0 & 0 & 0 & 0 \\
\hline $04-09$ & 0 & 0 & 0 & 0 & 0 & 0 & 0 & 0 & 0 \\
\hline $04-10 \mathrm{~A}$ & 0 & 0 & 0 & 308 & 0 & 0 & 0 & 0 & - \\
\hline $04-10 \mathrm{~B}$ & 0 & 0 & 0 & 278 & 0 & 0 & 0 & 0 & 0 \\
\hline $04-11$ & 0 & 0 & 0 & 0 & 1,572 & 29,288 & 0 & 0 & 0 \\
\hline $04-12$ & 0 & 3,951 & 5,810 & 0 & 10,453 & 21,756 & 0 & 0 & 0 \\
\hline $04-13$ & 0 & 21,756 & 2,851 & 0 & 4,691 & 9,183 & 0 & 0 & 0 \\
\hline $04-14$ & 0 & 0 & 0 & 0 & 0 & 0 & 0 & 0 & -0 \\
\hline $04-15$ & 0 & 6,290 & 0 & 0 & 0 & 0 & 0 & 0 & 0 \\
\hline $04-16 \mathrm{~A}$ & 0 & 2,822 & 0 & 0 & 0 & 256 & 0 & 0 & 0 \\
\hline $04-16 \mathrm{~B}$ & 0 & 6,579 & 0 & 0 & 0 & 0 & 0 & 0 & 0 \\
\hline $04-16 \mathrm{C}$ & 0 & 9,761 & 0 & 0 & 0 & 0 & 0 & 0 & 0 \\
\hline $04-16 \mathrm{D}$ & 0 & 4,454 & 0 & 0 & 0 & 0 & 0 & 0 & 0 \\
\hline Total Acres & 420 & 66,532 & 28,990 & 586 & 39,994 & 123,736 & 920 & 59,492 & 10,933 \\
\hline Total Area (\%) & 0.04 & 6.02 & 2.63 & 0.05 & 3.62 & 11.20 & 0.08 & 5.39 & 1.00 \\
\hline
\end{tabular}


Table E-1 (cont.): Area (acres) of Shoreline Zone by Land Use Designation in the Shoreline Outfitter/Guide Analysis Area

\begin{tabular}{|c|c|c|c|c|c|c|c|c|c|}
\hline 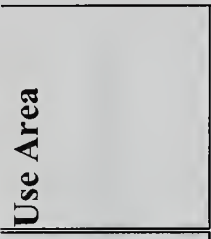 & 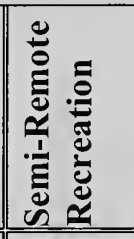 & 苞苞 & 峁 & 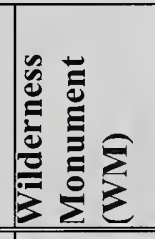 & 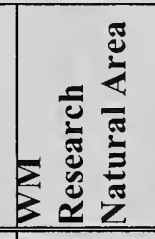 & 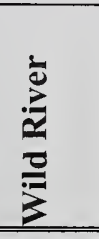 & 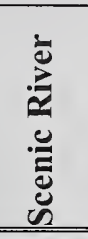 & 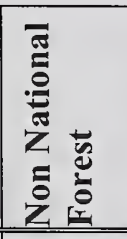 & 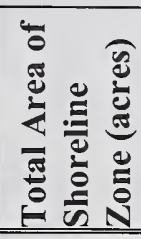 \\
\hline $01-01$ & 11,859 & 0 & 0 & 0 & 0 & 5,184 & 0 & 0 & 19.583 \\
\hline $01-02$ & 50 & 0 & 0 & 0 & 0 & 0 & 0 & 515 & 2,887 \\
\hline $01-03$ & 12,389 & 11,092 & 0 & 0 & 0 & 0 & 0 & 10,521 & 39,845 \\
\hline $01-04 \mathrm{~A}$ & 996 & 454 & 0 & 0 & 0 & 4,131 & 0 & 4,681 & 39,969 \\
\hline $01-04 \mathrm{~B}$ & 9,629 & 1,246 & 0 & 0 & 0 & 0 & 0 & 21,390 & 32,575 \\
\hline $01-04 \mathrm{C}$ & 27,079 & 7,263 & 0 & 0 & 0 & 0 & 0 & 2,505 & 37,882 \\
\hline $01-04 \mathrm{D}$ & 0 & 1,255 & 0 & 0 & 0 & 0 & 0 & 0 & 1,459 \\
\hline $01-05 \mathrm{~A}$ & 0 & 1,468 & 0 & 0 & 0 & 0 & 0 & 741 & 6,081 \\
\hline 01-05B & 32,328 & 3,703 & 0 & 0 & 0 & 0 & 0 & 710 & 48,462 \\
\hline $01-05 \mathrm{C}$ & 188 & 9,748 & 9,754 & 92 & 0 & 0 & 0 & 12,425 & 47,616 \\
\hline $01-05 \mathrm{D}$ & 7 & 0 & 40,439 & 0 & 0 & 0 & 0 & 0 & 40,446 \\
\hline $01-05 \mathrm{E}$ & 0 & 0 & 6,652 & 0 & 0 & 0 & 0 & 0 & 6,652 \\
\hline $04-01 \mathrm{~A}$ & 0 & 0 & 23,767 & 0 & 0 & 0 & 0 & 0 & 29,818 \\
\hline $04-01 B$ & 13,816 & 0 & 0 & 0 & 0 & 0 & 0 & 512 & 26,259 \\
\hline $04-02 \mathrm{~A}$ & 8,545 & 0 & 0 & 0 & 0 & 0 & 0 & 3,360 & 22,441 \\
\hline $04-02 \mathrm{~B}$ & 0 & 0 & 64,799 & 0 & 0 & 0 & 0 & 0 & 82,909 \\
\hline $04-03$ & 38,794 & 979 & 3,433 & 0 & 0 & 0 & 0 & 15,154 & 91,567 \\
\hline $04-04 \mathrm{~A}$ & 602 & 238 & 0 & 0 & 0 & 0 & 0 & 52 & 13,509 \\
\hline $04-04 \mathrm{~B}$ & 4,182 & 2,706 & 0 & 0 & 0 & 239 & 0 & 559 & 30,426 \\
\hline $04-04 \mathrm{C}$ & 1,757 & 0 & 0 & 0 & 0 & 0 & 0 & 554 & 3,233 \\
\hline $04-05$ & 0 & 0 & 0 & 24,555 & 0 & 0 & 0 & 1,040 & 25,595 \\
\hline $04-06 \mathrm{~A}$ & 0 & 0 & 0 & 18,219 & 0 & 0 & 0 & 29 & 18,248 \\
\hline $04-06 \mathrm{~B}$ & 0 & 0 & 0 & 19,674 & 0 & 0 & 0 & 37 & 19,730 \\
\hline $04-07$ & 0 & 0 & 0 & 22,720 & 2,110 & 0 & 0 & 24 & 24,882 \\
\hline $04-08$ & 11,849 & 0 & 0 & 22,228 & 0 & 0 & 0 & 1,693 & 36,190 \\
\hline $04-09$ & 0 & 0 & 0 & 33,405 & 0 & 192 & 0 & 447 & 34,044 \\
\hline $04-10 \mathrm{~A}$ & 0 & $\begin{array}{c}0 \\
-\end{array}$ & 0 & 1,692 & 0 & 0 & 0 & 48 & 2,048 \\
\hline $04-10 \mathrm{~B}$ & 9,198 & 0 & 0 & 11,579 & 0 & 0 & 0 & 1,851 & 22,906 \\
\hline $04-11$ & 330 & 3,945 & 5,242 & 0 & 0 & 0 & 0 & 16,013 & 56,390 \\
\hline $04-12$ & 225 & 2,757 & 0 & 0 & 0 & 0 & 165 & 8,065 & 53,182 \\
\hline $04-13$ & 124 & 10,079 & 1,639 & 0 & 0 & 0 & 0 & 2,178 & 52,501 \\
\hline $04-14$ & 0 & $\begin{array}{l}0 \\
0\end{array}$ & 29,873 & 0 & 0 & 0 & 0 & 302 & 30,175 \\
\hline $04-15$ & 12,771 & 0 & 46,728 & 0 & 0 & 233 & 0 & 2,932 & 68,954 \\
\hline $04-16 \mathrm{~A}$ & 0 & 0 & 0 & 0 & 0 & 0 & 0 & 0 & 3,078 \\
\hline $04-16 \mathrm{~B}$ & 0 & 0 & 0 & 0 & 0 & 0 & 0 & 167 & 6,746 \\
\hline $04-16 \mathrm{C}$ & 8 & 0 & 0 & 0 & 0 & 0 & 0 & 476 & 10,245 \\
\hline $04-16 \mathrm{D}$ & 3,152 & 0 & 8,247 & 0 & 0 & 0 & 0 & 214 & 16,067 \\
\hline Total Acres & 199,878 & 56,933 & 240,573 & 154,164 & 2,110 & 9,979 & 165 & 109,195 & $1,104,600$ \\
\hline Total Area (\%) & 18.10 & 5.16 & 21.78 & 13.94 & 0.19 & 0.90 & 0.01 & 9.89 & 100 \\
\hline
\end{tabular}




\section{Appendix E, Management Direction}

Table E-2: Length (Miles) of Shoreline Zone by Land Use Designation in the Shoreline Outfitter/Guide Analysis Area

\begin{tabular}{|c|c|c|c|c|c|c|c|c|c|}
\hline 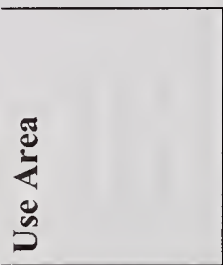 & 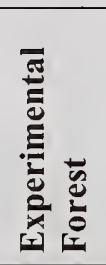 & 音 & 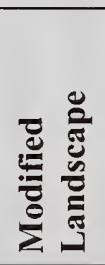 & 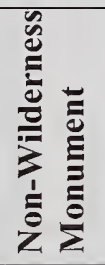 & & $\begin{array}{l}5 \\
0 \\
0 \\
0 \\
0 \\
0\end{array}$ & 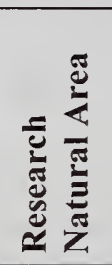 & 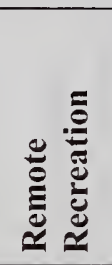 & 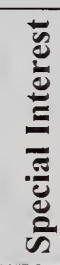 \\
\hline $01-01$ & 0 & 0 & 2 & 0 & 0 & 0 & 0 & 2 & 0 \\
\hline $01-02$ & 0 & 0 & 8 & 0 & 0 & 0 & 0 & 0 & 0 \\
\hline $01-03$ & 0 & 0 & 8 & 0 & 0 & 12 & 0 & 0 & 0 \\
\hline $01-04 \mathrm{~A}$ & 0 & 84 & 20 & 0 & 0 & 11 & 0 & 92 & 0 \\
\hline $01-04 \mathrm{~B}$ & 0 & 0 & 0 & 0 & 0 & 1 & 0 & 0 & 0 \\
\hline $01-04 \mathrm{C}$ & 0 & 0 & 0 & 0 & 0 & 3 & 0 & 0 & 0 \\
\hline $01-04 \mathrm{D}$ & 0 & 0 & 0. & 0 & 0 & 0 & 0 & 0 & 0 \\
\hline $01-05 \mathrm{~A}$ & 0 & 0 & 0 & 0 & 0 & 13 & 2 & 0 & 0 \\
\hline $01.05 \mathrm{~B}$ & 0 & 0 & 4 & 0 & 8 & 15 & 0 & 15 & 0 \\
\hline $01-05 C$ & 0 & $\because 0$ & 0 & 0 & 1 & 50 & 0 & 0 & 0 \\
\hline $01-05 \mathrm{D}$ & 0 & 0 & 0 & 0 & 0 & 0 & 0 & 0 & 0 \\
\hline $01-05 \mathrm{E}$ & 0 & 0 & 0 & 0 & 0 & 0 & 0 & 0 & 0 \\
\hline $0401 \mathrm{~A}$ & 0 & 0 & 0 & 0 & 0 & 0 & 0 & 27 & 0 \\
\hline $0401 \mathrm{~B}$ & 0 & 0 & 0 & 0 & 0 & 0 & 0 & 43 & 0 \\
\hline $04-02 \mathrm{~A}$ & 0 & 0 & 0 & 0 & 0 & 51 & 0 & 0 & 0 \\
\hline $04-02 \mathrm{~B}$ & 0 & 0 & 0 & 0 & 0 & 0 & 0 & 125 & 0 \\
\hline $04-03$ & 0 & 0 & 15 & 0 & 19 & 46 & 0 & 0 & 49 \\
\hline $04-04 \mathrm{~A}$ & 0 & 0 & 0 & 0 & 34 & 13 & 0 & 0 & 0 \\
\hline $0404 \mathrm{~B}$ & 0 & 0 & 25 & 0 & 2 & 42 & 0 & 36 & 0 \\
\hline $04-04 \mathrm{C}$ & 0 & 0 & 0 & 0 & 0 & 0 & 0 & 3 & 0 \\
\hline $04-05$ & 0 & 0 & 0 & 0 & 0 & 0 & 0 & 0 & 0 \\
\hline $0406 \mathrm{~A}$ & 0 & 0 & 0 & 0 & 0 & 0 & 0 & 0 & 0 \\
\hline $0406 \mathrm{~B}$ & 0 & 0 & 0 & 0 & 0 & 0 & 0 & 0 & 0 \\
\hline $04-07$ & 0 & 0 & 0 & 0 & 0 & 0 & 0 & 0 & 0 \\
\hline $04-08$ & 1 & 0 & 0 & 0 & 0 & 0 & 0 & 0 & 0. \\
\hline $04-09$ & 0 & 0 & 0 & 0 & 0 & 0 & 0 & 0 & 0 \\
\hline $04-10 \mathrm{~A}$ & 0 & 0 & 0 & 1 & 0 & 0 & 0 & 0 & 0 \\
\hline $04-10 \mathrm{~B}$ & 0 & 0 & 0 & 0 & 0 & 0 & 0 & 0 & 0 \\
\hline $04-11$ & 0 & 0 & 0 & 0 & 0 & 128 & 0 & 0 & 0 \\
\hline $04-12$ & 0 & 14 & 39 & 0 & 12 & 90 & 0 & 0 & 0 \\
\hline $04-13$ & 0 & 88 & 17 & 0 & 1 & 36 & 0 & 0 & 0 \\
\hline $04-14$ & 0 & 0 & 0 & 0 & 0 & 0 & 0 & 0 & 0 \\
\hline $04-15$ & 0 & 21 & 0 & 0 & 0 & 0 & 0 & 0 & 0 \\
\hline $04-16 \mathrm{~A}$ & 0 & 10 & 0 & 0 & 0 & 1 & 0 & 0 & 0 \\
\hline $04-16 \mathrm{~B}$ & 0. & 33 & 0 & 0 & 0 & 0 & 0 & 0 & 0 \\
\hline $04-16 \mathrm{C}$ & 0 & 35 & 0 & 0 & 0 & 0 & 0 & 0 & 0 \\
\hline $04-16 \mathrm{D}$ & 0 & 17 & 0 & 0 & 0 & 0 & 0 & 0 & 0 \\
\hline Total Miles & 1 & 302 & 138 & 11 & 77 & 512 & 2 & 343 & 49 \\
\hline Total Miles (\%) & $<1$ & 5 & 2 & $<1$ & 1 & 8 & $<1$ & 6 & 1 \\
\hline
\end{tabular}


Management Direction, Appendix E

Table E-2 (cont.). Length (miles) of Shoreline Zone by Land Use Designation in the Shoreline Outfitter/Guide Analysis Area

\begin{tabular}{|c|c|c|c|c|c|c|c|c|c|c|}
\hline 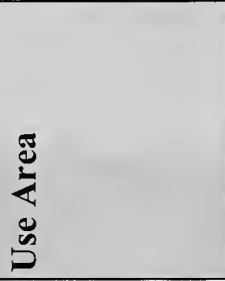 & 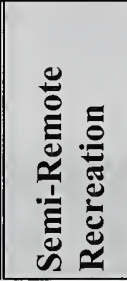 & 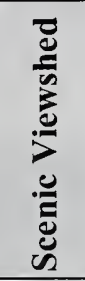 & 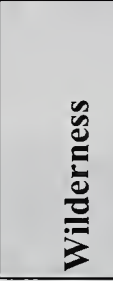 & 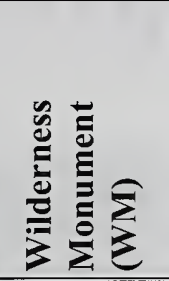 & 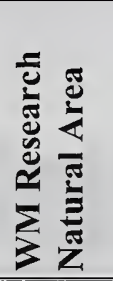 & $\frac{\substack{\delta \\
\frac{2}{2}}}{\frac{\pi}{8}}$ & $\frac{\dot{0}}{2}$ & 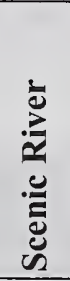 & 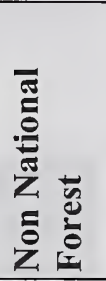 & 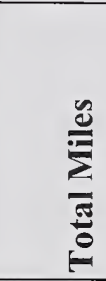 \\
\hline $01-01$ & 43 & 0 & 0 & 0 & 0 & 0 & 36 & 0 & 0 & 83 \\
\hline $01-02$ & 2 & 0 & 0 & 0 & 0 & 0 & 0 & 0 & 10 & 20 \\
\hline $01-03$ & 46 & 36 & 0 & 0 & 0 & 0 & 0 & 0 & 93 & 195 \\
\hline $01-04 \mathrm{~A}$ & 5 & 0 & 0 & 0 & 0 & 0 & 48 & 0 & 24 & 284 \\
\hline $01-04 \mathrm{~B}$ & 25 & 3 & 0 & 0 & 0 & 0 & 0 & 0 & 132 & 161 \\
\hline $01-04 \mathrm{C}$ & 134 & 26 & 0 & 0 & 0 & 0 & 0 & 0 & 18 & 181 \\
\hline $01-04 \mathrm{D}$ & 0 & 5 & 0 & 0 & 0 & 0 & 0 & 0 & 0 & 5 \\
\hline $01-05 \mathrm{~A}$ & 0 & 5 & 0 & 0 & 0 & 0 & 0 & 0 & 4 & 24 \\
\hline $01-05 \mathrm{~B}$ & 169 & 15 & 0 & 0 & 0 & 0 & 0 & 0 & 2 & 228 \\
\hline $01-05 \mathrm{C}$ & 8 & 47 & 28 & 7 & 0 & 0 & 0 & 0 & 74 & 215 \\
\hline $01-05 \mathrm{D}$ & 1 & 0 & 156 & 0 & 0 & 0 & 0 & 0 & 0 & 157 \\
\hline $01-05 \mathrm{E}$ & 0 & 0 & 22 & 0 & 0 & 0 & 0 & 0 & 0 & 22 \\
\hline $04-01 \mathrm{~A}$ & 0 & 0 & 96 & 0 & 0 & 0 & 0 & 0 & 0 & 123 \\
\hline $04-01 B$ & 92 & 0 & 0 & 0 & 0 & 0 & 0 & 0 & 6 & 141 \\
\hline $04-02 \mathrm{~A}$ & 202 & 0 & 0 & 0 & 0 & 0 & 0 & 0 & 26 & 279 \\
\hline $04-02 \mathrm{~B}$ & 0 & 0 & 400 & 0 & 0 & 0 & 0 & 0 & 0 & 525 \\
\hline $04-03$ & 260 & 8 & 20 & 0 & 0 & 0 & 0 & 0 & 170 & 587 \\
\hline $04-04 \mathrm{~A}$ & 5 & 1 & 0 & 0 & 0 & 0 & 0 & 0 & 1 & 54 \\
\hline $04-04 \mathrm{~B}$ & 33 & 18 & 0 & 0 & 0 & 0 & 1 & 0 & 5 & 162 \\
\hline $04-04 \mathrm{C}$ & 7 & 0 & 0 & 0 & 0 & 0 & 0 & 0 & 4 & 14 \\
\hline $04-05$ & 0 & 0 & 0 & 101 & 0 & 0 & 0 & 0 & 10 & 111 \\
\hline $04-06 \mathrm{~A}$ & 0 & 0 & 0 & 124 & 0 & 0 & 0 & 0 & 1 & 125 \\
\hline $04-06 \mathrm{~B}$ & 0 & 0 & 0 & 100 & 0 & 0 & 0 & 0 & 1 & 101 \\
\hline $04-07$ & 0 & 0 & 0 & 118 & 15 & 0 & 0 & 0 & 1 & 134 \\
\hline $04-08$ & 45 & 0 & 0 & 89 & 0 & 0 & 0 & 0 & 14 & 149 \\
\hline $04-09$ & 0 & 0 & 0 & 172 & 0 & 1 & 1 & 0 & 2 & 176 \\
\hline $04-10 \mathrm{~A}$ & 0 & 0 & 0 & 8 & 0 & 0 & 0 & 0 & 0 & 9 \\
\hline $04-10 \mathrm{~B}$ & 30 & 0 & 0 & 43 & 0 & 0 & 0 & 0 & 11 & 84 \\
\hline $04-11$ & 11 & 22 & 24 & 0 & 0 & 0 & 0 & 0 & 82 & 267 \\
\hline $04-12$ & 5 & 17 & 0 & 0 & 0 & 0 & 0 & 1 & 35 & 213 \\
\hline $04-13$ & 7 & 46 & 5 & 0 & 0 & 0 & 0 & 0 & 17 & 217 \\
\hline $04-14$ & 0 & 0 & 245 & 0 & 0 & 0 & 0 & 0 & 2 & 247 \\
\hline $04-15$ & 52 & 0 & 530 & 0 & 0 & 0 & 1 & 0 & 28 & 632 \\
\hline $04-16 \mathrm{~A}$ & 0 & 0 & 0 & 0 & 0 & 0 & 0 & 0 & 0 & 11 \\
\hline $04-16 \mathrm{~B}$ & 1 & 0 & 0 & 0 & 0 & 0 & 0 & 0 & 1 & 35 \\
\hline $04-16 \mathrm{C}$ & 1 & 0 & 0 & 0 & 0 & 0 & 0 & 0 & 3 & 39 \\
\hline $04-16 \mathrm{D}$ & 20 & 0 & 53 & 0 & 0 & 0 & 0 & 0 & 4 & 94 \\
\hline Total Miles & 1,204 & 249 & 1,579 & 762 & 15 & 11 & 87 & 1 & 781 & 6,104 \\
\hline Total Miles (\%) & 20 & 4 & 26 & 13 & $<1$ & $<1$ & 1 & $<1$ & 13 & 100 \\
\hline
\end{tabular}




\section{Appendix E, Management Direction}

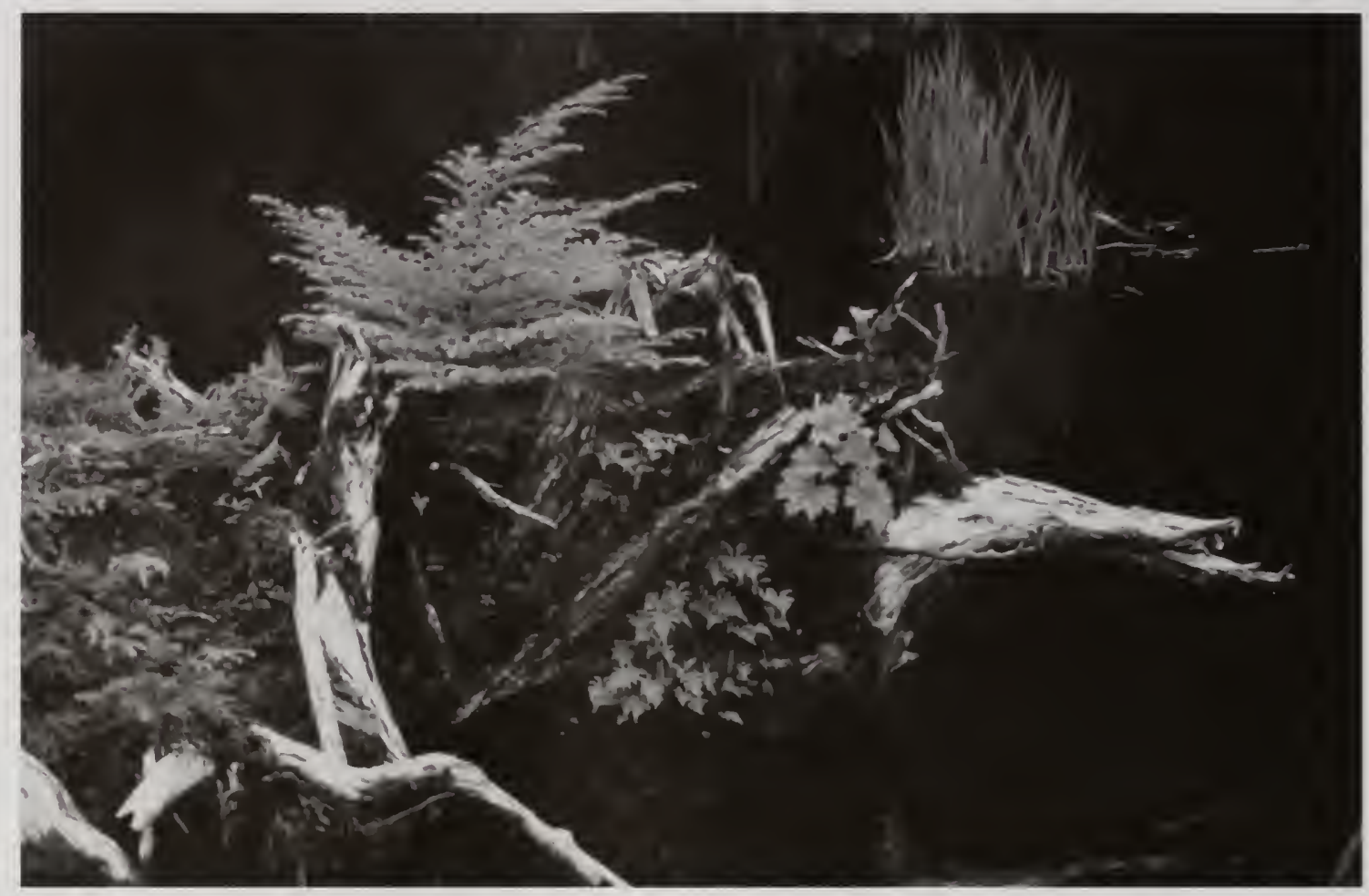




\section{Appendix F Recreation Management Concepts}




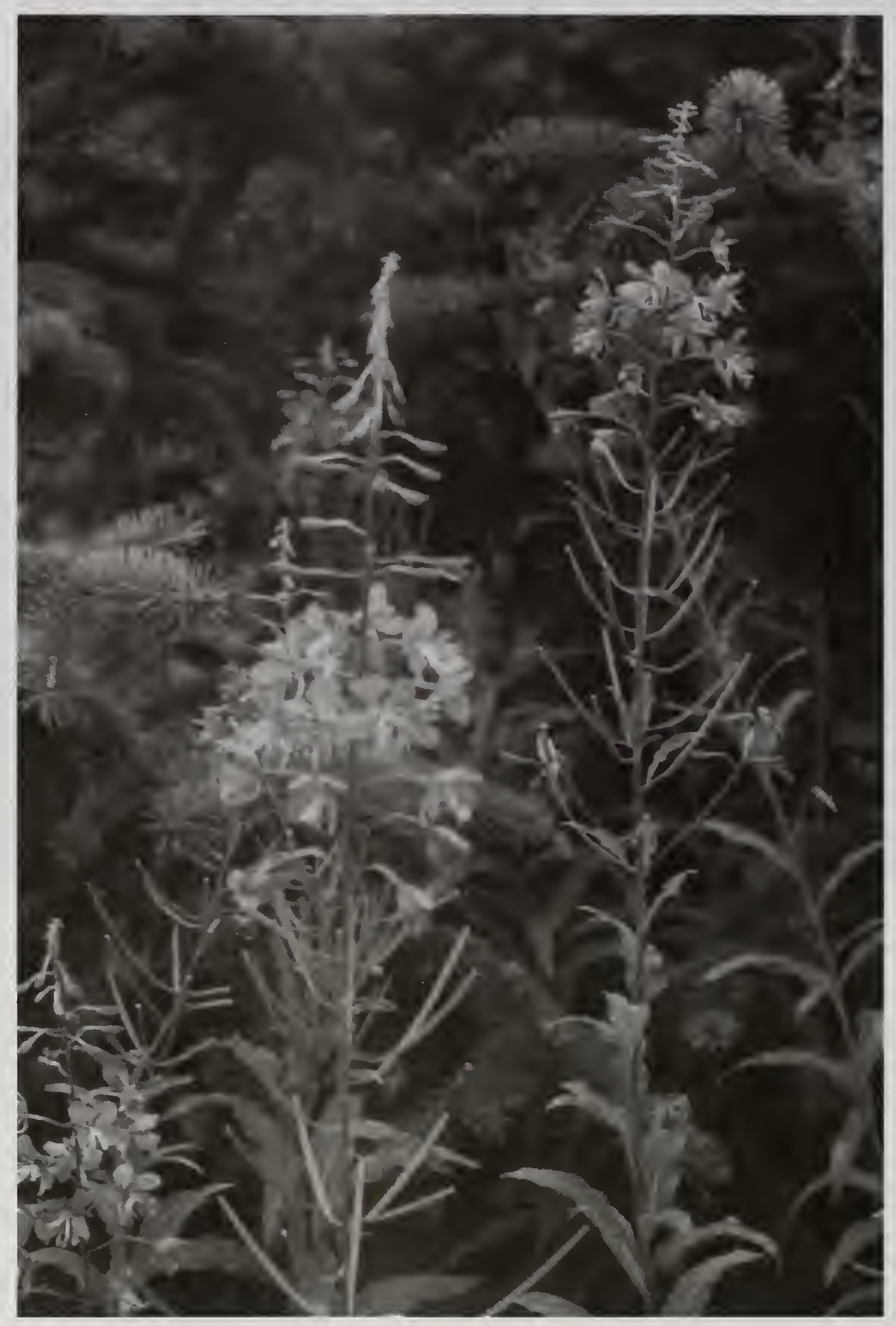




\section{Appendix F Recreation Management Concepts}

\section{Introduction}

The analysis area is managed for multiple uses including recreation and wilderness resources. The Forest Service plays an important role in the changing and diverse economic environment of Southeast Alaska.

Some forest management activities result in a product that is relatively easy to measure. For example, a timber sale will produce a specific amount of timber; the construction of a fish pass will allow fish to access a measurable area of new habitat. It is more difficult to quantify the products of this project, which seeks to manage or enhance a wild land recreation experience. People have a wide range of expectations and values and they have many different definitions of a satisfying recreational experience.

The challenge for the Forest Service is to respond to the public's desires for various kinds of settings and access. The Forest Service manages its lands to provide the public with a variety of recreation opportunities. We can influence the recreation experience by (a) providing different settings for recreation, ranging from wilderness to fully accessible trails and campgrounds; and (b) providing different facilities, such as cabins, boat moorings or roads, that make an area more accessible. Through this analysis, we are working to manage the recreation setting by regulating the number of commercially guided groups using specific shoreline-based areas.

The goal is to provide opportunities for quality recreation experiences sought by both guided and unguided users that will not adversely impact forest resources. This will be accomplished by managing the analysis area so that each Use Area conforms to the Recreation Opportunity Spectrum (ROS) class setting indicators stated in the Forest Plan.

\section{Forest Plan and the Recreation Opportunity Spectrum}

The Forest Plan provides the management framework for the recreation resource. Recreation and tourism management goals were developed through scientific review and in response to public comment. They are specified in the Forest Plan.

The primary way that the Forest Plan categorizes forest land is by dividing it into a series of areas that are each described by a Land Use Designation (LUD). Each LUD has a management prescription that includes goals, objectives, and a desired future condition. LUDs also include standards and guidelines for managing 


\section{Appendix F, Recreation Management}

recreation and other forest resources. Chapter 1 and Appendix E discuss the Land Use Designations.

The Forest Plan assesses recreation and tourism resources by assigning a range of appropriate recreation settings for each LUD using the ROS. These classes cover the full range. or spectrum, of recreation opportunities. The ROS classes, from least developed to most developed, are listed below:

- Primitive,

- Semi-Primitive Non-motorized,

- Semi-Primitive Motorized,

- Roaded Natural,

- Rural, and

- Urban.

The ROS is as an inventory tool used to describe the existing condition of recreation opportunities on the national forest. Guidelines for each ROS class describe the physical, social, and managerial setting components that affect the kind of experience forest visitors may expect. It is also used to guide management activities in order to maintain or attain the defined range of recreation opportunities within the ROS class setting. Each LUD may include more than one ROS class. ROS classifications used in the Forest Plan by LUD are displayed in Table F-1. 


\section{Recreation Management, Appendix F}

Table F-1. Forest Plan ROS Classification by Land Use Designation (LUD)

\begin{tabular}{|c|c|}
\hline Land Use Designation & ROS Classification \\
\hline Wilderness & Primitive and Semi-Primitive \\
\hline $\begin{array}{l}\text { Wilderness National } \\
\text { Monument }\end{array}$ & Primitive and Semi-Primitive \\
\hline $\begin{array}{l}\text { Non-Wilderness National } \\
\text { Monument }\end{array}$ & Existing unless scheduled activities cause a change. \\
\hline Research Natural Area & $\begin{array}{l}\text { No specific direction in the Forest Plan. Primitive is usually } \\
\text { appropriate. }\end{array}$ \\
\hline Special Interest Area & $\begin{array}{l}\text { Adopt through project planning. Before planning, manage as } \\
\text { existing. }\end{array}$ \\
\hline Remote Recreation & Primitive \\
\hline Municipal Watershed & $\begin{array}{l}\text { No specific direction in the Forest Plan. Primitive or Semi- } \\
\text { primitive are usually appropriate. }\end{array}$ \\
\hline Old-growth Habitat & Semi-Primitive \\
\hline Semi-remote Recreation & Semi-Primitive generally, Enclaves up to Rural \\
\hline LUD II & Semi-Primitive \\
\hline Wild River & Primitive and Semi-Primitive \\
\hline Scenic River & Existing unless scheduled activities cause a change. \\
\hline Recreational River & Existing unless scheduled activities cause a change. \\
\hline Experimental Forest & Existing unless scheduled activities cause a change. \\
\hline Scenic Viewshed & $\begin{array}{l}\text { Existing unless scheduled activities cause a change. Change to } \\
\text { Semi-primitive Motorized, Roaded Natural, or Roaded } \\
\text { Modified is allowed. }\end{array}$ \\
\hline Modified Landscape & $\begin{array}{l}\text { Existing unless scheduled activities cause a change. Change to } \\
\text { Semi-primitive Motorized, Roaded Natural, or Roaded } \\
\text { Modified is allowed. }\end{array}$ \\
\hline Timber Production & $\begin{array}{l}\text { Existing unless scheduled activities cause a change. Change to } \\
\text { Semi-primitive Motorized, Roaded Natural, or Roaded } \\
\text { Modified is allowed. }\end{array}$ \\
\hline Minerals & $\begin{array}{l}\text { Existing unless scheduled activities cause a change. Change to } \\
\text { Semi-primitive Motorized, Roaded Natural, or Roaded } \\
\text { Modified is allowed. }\end{array}$ \\
\hline $\begin{array}{l}\text { Transportation/Utility } \\
\text { Systems }\end{array}$ & Manage changed setting with appropriate ROS guidelines. \\
\hline
\end{tabular}

For each ROS class, the Forest Plan identifies setting indicators that describe the class. The indicators are visual quality, access, remoteness, visitor management, onsite recreation development, social encounters, and visitor impacts. The standards and guidelines for ROS classes are found in Table F-2. Not all of the criteria outlined in the standards and guidelines, such as Visual Quality Objectives, Traffic Service Levels, the Recreation Development Scale and Road Maintenance Levels are fully defined in this document; see the Forest Plan for a complete discussion of all ROS standards and guideline components. 


\section{Appendix F, Recreation Management}

Table F-2. Forest Plan Standards and Guidelines for ROS Classifications

\begin{tabular}{|c|c|}
\hline \multicolumn{2}{|r|}{ Primitive ROS Class } \\
\hline $\begin{array}{l}\text { Setting } \\
\text { Indicators }\end{array}$ & Standards and Guidelines \\
\hline Visual Quality & $\begin{array}{l}\text { Not to exceed the Retention Visual Quality Objective. An Existing Visual } \\
\text { Condition of Preservation is fully compatible and encouraged. }\end{array}$ \\
\hline Access & $\begin{array}{l}\text { Cross-country travel and travel on non-motorized trails and on waterways is } \\
\text { typical. Use of airplanes, helicopters, motorboats and snowmachines for } \\
\text { traditional activities, subsistence, emergency search and rescue, and other } \\
\text { authorized resource management activities may occur but is rare. }\end{array}$ \\
\hline Remoteness & $\begin{array}{l}\text { No or infrequent sights and sounds of human activity are present. Setting is } \\
\text { located more than } 1.5 \text { hours walking or paddling distance, or } 3 \text { miles. from any } \\
\text { human developments other than infrequently-traveled marine travelways. } \\
\text { Areas are generally greater than } 5,000 \text { acres, but may be smaller if contiguous } \\
\text { with a Semi-primitive class. }\end{array}$ \\
\hline $\begin{array}{l}\text { Visitor } \\
\text { Management }\end{array}$ & $\begin{array}{l}\text { On-site regimentation and controls are very rare. Signing is limited to } \\
\text { directional information and safety. There are no on-site interpretive facilities. } \\
\text { There is great opportunity for discovery on the part of the users. }\end{array}$ \\
\hline $\begin{array}{l}\text { On-site } \\
\text { Recreation } \\
\text { Development }\end{array}$ & $\begin{array}{l}\text { Structures do not exceed Development Scale I, except for public recreation } \\
\text { cabins, and are maintained for appropriate levels of use. }\end{array}$ \\
\hline $\begin{array}{l}\text { Social } \\
\text { Encounters }\end{array}$ & $\begin{array}{l}\text { User meets less than } 3 \text { parties per day during trip. No other parties are within } \\
\text { sight or sound of dispersed campsites or cabins. Maximum party size is } \\
\text { generally } 12 \text { people. }\end{array}$ \\
\hline Visitor Impacts & $\begin{array}{l}\text { Visitor-caused impacts to resources are slight and usually not noticeable the } \\
\text { following year. Site hardening is limited to boardwalk trails and necessary boat } \\
\text { moorings or bearproof food caches and rustic public recreation cabins. }\end{array}$ \\
\hline
\end{tabular}


Table F-2. Forest Plan Standards and Guidelines for ROS Classifications (cont.)

\begin{tabular}{|c|c|}
\hline \multicolumn{2}{|r|}{ Semi-Primitive Non-Motorized ROS Class } \\
\hline $\begin{array}{c}\text { Setting } \\
\text { Indicators }\end{array}$ & Standard and Guidelines \\
\hline Visual Quality & $\begin{array}{l}\text { Not to exceed the Retention Visual Quality Objective. An Existing Visual } \\
\text { Condition of Preservation is fully compatible and encouraged. }\end{array}$ \\
\hline Access & $\begin{array}{l}\text { Cross-country travel and travel on non-motorized trails is typical. Use of } \\
\text { airplanes, helicopters, motorboats and snowmachines for traditional activities, } \\
\text { subsistence, emergency search and rescue, and other authorized resource } \\
\text { management activities may occur unless specifically restricted for safety and/or } \\
\text { resource protection purposes. }\end{array}$ \\
\hline Remoteness & $\begin{array}{l}\text { Nearby sights or sounds of human activity are rare, but distant sights or sounds } \\
\text { may occur. Setting is located more than } 1 / 2 \text { hour walk or paddle, or } \\
\text { approximately } 1 / 2 \text { mile (greater or less depending on terrain and vegetation, but } \\
\text { no less than } 1 / 4 \text { mile) from: } 1 \text { ) infrequently traveled waterways; } 2 \text { ) roads and } \\
\text { trails open to motorized recreation use, and } 3 \text { ) clearcut harvest areas. Aircraft } \\
\text { access is only occasional. Areas are generally greater than } 2,500 \text { acres but may } \\
\text { be smaller if contiguous with Primitive or Semi-primitive motorized classes. }\end{array}$ \\
\hline $\begin{array}{l}\text { Visitor } \\
\text { Management }\end{array}$ & $\begin{array}{l}\text { On-site regimentation and controls are rare. Visitor information facilities may } \\
\text { be used to interpret cultural and natural resource features, but are not elaborate } \\
\text { and harmonize with the setting. }\end{array}$ \\
\hline $\begin{array}{l}\text { On-site } \\
\text { Recreation } \\
\text { Development }\end{array}$ & $\begin{array}{l}\text { Facilities and structures generally do not exceed Development Scale II and are } \\
\text { maintained to accommodate the types and levels of use anticipated for the site. } \\
\text { Forest Service recreation cabins are fully compatible. }\end{array}$ \\
\hline Social Encounters & $\begin{array}{l}\text { User meets less than } 10 \text { parties per day ( } 6 \text { parties per day in wilderness) on } \\
\text { trails and waterways during } 80 \% \text { of the primary use season. No other parties } \\
\text { are within sight or sound of dispersed campsites during } 80 \% \text { of the primary use } \\
\text { season. Maximum party size is generally } 12-20 \text { people. Outside of wilderness, } \\
\text { larger party sizes may occur during less than } 15 \% \text { of the primary use season in } \\
\text { limited locations. }\end{array}$ \\
\hline Visitor Impacts & $\begin{array}{l}\text { Visitor-caused impacts to resources are rare and usually not long lasting. Site } \\
\text { hardening is limited to boardwalk trails, boat tramways, moorings and docks, } \\
\text { bearproof food cache facilities and rustic public recreation cabins. }\end{array}$ \\
\hline
\end{tabular}




\section{Appendix F, Recreation Management}

Table F-2. Forest Plan Standards and Guidelines for ROS

Classifications (cont.)

\begin{tabular}{|c|c|}
\hline \multicolumn{2}{|r|}{ Semi-Primitive Motorized ROS Class } \\
\hline $\begin{array}{c}\text { Setting } \\
\text { Indicators }\end{array}$ & Standards and Guidelines \\
\hline Visual Quality & $\begin{array}{l}\text { Not to exceed the Partial Retention Visual Quality Objective. Existing Visual } \\
\text { Conditions ranging from Preservation through Retention are fully compatible } \\
\text { and encouraged. }\end{array}$ \\
\hline Access & $\begin{array}{l}\text { Travel on motorized and non-motorized trails and Traffic Service Level D } \\
\text { roads, although some Traffic Service Level C roads provide access to and } \\
\text { through the area. Use by high clearance vehicles and motorized water travel is } \\
\text { common. Road density is less than one mile per square mile. Off-road } \\
\text { snowmachine travel on snow may occur. }\end{array}$ \\
\hline Remoteness & $\begin{array}{l}\text { Nearby sights or sounds of human activity are rare, but distant sights or sounds } \\
\text { may occur. Setting is located within } 1 / 2 \text { hour walk or paddle or within } 1 / 2 \text { mile } \\
\text { (greater or less depending on terrain and vegetation but no less than } 1 / 4 \text { mile) of } \\
\text { infrequently traveled waterways or small aircraft access points and } / \text { or roads } \\
\text { which are open and maintained for passage by high clearance and four-wheel } \\
\text { drive vehicles (Maintenance Level } 2 \text { ) and provide access to recreation } \\
\text { opportunities and facilities. Areas are generally greater than } 2.500 \text { acres but } \\
\text { may be smaller if contiguous with Primitive or Semi-Primitive Non-Motorized } \\
\text { classes. }\end{array}$ \\
\hline $\begin{array}{l}\text { Visitor } \\
\text { Management }\end{array}$ & $\begin{array}{l}\text { On-site regimentation and controls are few. Control facilities consist primarily } \\
\text { of informational signs and site-specific road closures. Visitor information } \\
\text { facilities may be used to interpret cultural and natural resource features. but are } \\
\text { not elaborate and harmonize with the setting. }\end{array}$ \\
\hline Social Encounters & $\begin{array}{l}\text { User meets less than } 10 \text { parties per day ( } 6 \text { parties per day in wilderness) on } \\
\text { trails, roads, and shorelines during } 80 \% \text { of the primary use season. During } \\
80 \% \text { of the primary use season no other parties are visible from campsites. } \\
\text { Maximum party size is generally } 12-20 \text { people. Outside of wilderness, larger } \\
\text { party sizes may occur during less than } 15 \% \text { of the primary use season in limited } \\
\text { locations. }\end{array}$ \\
\hline Visitor Impacts & $\begin{array}{l}\text { Visitor-caused impacts may be noticeable, but not degrading to basic resource } \\
\text { elements. Site hardening is very infrequent, but when it occurs, is in harmony } \\
\text { with, and appropriate for, the natural-appearing backcountry setting. }\end{array}$ \\
\hline
\end{tabular}




\section{Recreation Management, Appendix F}

Table F-2. Forest Plan Standards and Guidelines for ROS Classifications (cont.)

\begin{tabular}{|c|c|}
\hline \multicolumn{2}{|r|}{ Roaded Natural ROS Class } \\
\hline $\begin{array}{c}\text { Setting } \\
\text { Indicators }\end{array}$ & Standards and Guidelines \\
\hline Visual Quality & $\begin{array}{l}\text { Not to exceed the Modification Visual Quality Objective and typically is Partial } \\
\text { Retention. Existing Visual Conditions ranging from Preservation through } \\
\text { Retention are fully compatible and encouraged. }\end{array}$ \\
\hline Access & $\begin{array}{l}\text { All forms of access and travel modes may occur. Access to and through the } \\
\text { area is typically by passenger vehicle, although motorized use may be restricted } \\
\text { to provide for resource protection, user safety, or to provide a diversity of } \\
\text { recreation opportunity. }\end{array}$ \\
\hline Remoteness & $\begin{array}{l}\text { Remoteness is of little importance, but low to moderate concentrations of } \\
\text { human sights and sounds are preferred. Setting is located within } 1 / 2 \text { mile } \\
\text { (greater or less depending on terrain and vegetation but no less than } 1 / 4 \text { mile) of } \\
\text { moderate to heavily-traveled waterways and/or roads which are maintained to } \\
\text { Levels } 3,4 \text {, and } 5 \text { and open for use by the public or those areas that receive } \\
\text { heavy small aircraft travel. }\end{array}$ \\
\hline $\begin{array}{l}\text { Visitor } \\
\text { Management }\end{array}$ & $\begin{array}{l}\text { On-site regimentation and controls are obvious. Control facilities such as } \\
\text { parking areas, barriers, and signs harmonize with the natural environment. } \\
\text { Visitor information facilities are not elaborate or complex. }\end{array}$ \\
\hline $\begin{array}{l}\text { On-site } \\
\text { Recreation } \\
\text { Development }\end{array}$ & $\begin{array}{l}\text { Facilities and structures generally do not exceed Development Scale III and are } \\
\text { maintained to accommodate the types and levels of use anticipated for the site } \\
\text { and area. Typical facilities include outdoor interpretive displays and rustic } \\
\text { campgrounds and picnic areas. }\end{array}$ \\
\hline Social Encounters & $\begin{array}{l}\text { User meets less than } 20 \text { other parties per day on trails and in dispersed areas, } \\
\text { during at least } 80 \% \text { of the primary use season. User may meet numerous other } \\
\text { parties on roads and developed recreation sites. Developed sites often are at } \\
\text { full capacity but do not exceed } 80 \% \text { of the design capacity over the season of } \\
\text { operation. }\end{array}$ \\
\hline Visitor Impacts & $\begin{array}{l}\text { Visitor-caused impacts are noticeable, but not degrading to basic resource } \\
\text { elements nor do they exceed established Visual Quality Objectives. Site } \\
\text { hardening may be dominant, but is in harmony with natural-appearing } \\
\text { landscape and appropriate for the site and setting. }\end{array}$ \\
\hline
\end{tabular}




\section{Appendix F, Recreation Management}

Table F-2. Forest Plan Standards and Guidelines for ROS

Classifications (cont.)

\begin{tabular}{|c|c|}
\hline \multicolumn{2}{|r|}{ Roaded Modified ROS Class } \\
\hline $\begin{array}{c}\text { Setting } \\
\text { Indicators }\end{array}$ & Standards and Guidelines \\
\hline Visual Quality & $\begin{array}{l}\text { Not to exceed the Maximum Modification Visual Quality Objective. Apply } \\
\text { visual management techniques to soften effects of maximum modification } \\
\text { conditions in the foreground of sensitive travel routes and recreation sites. }\end{array}$ \\
\hline Access & $\begin{array}{l}\text { All forms of access and travel modes may occur, although roads are generally } \\
\text { not well suited to highway-type vehicles. Off Highway Vehicle use on } \\
\text { designated routes or areas is encouraged. Use by high clearance vehicles is } \\
\text { common. }\end{array}$ \\
\hline Remoteness & $\begin{array}{l}\text { Remoteness from urban conditions and high concentrations of other people is } \\
\text { important. Low concentrations of human sights and sounds in a backcountry } \\
\text { roaded setting are preferred. These areas are accessed by Forest roads that are } \\
\text { maintained to Levels } 2,3 \text {, and } 4 \text { and are available for public use. They } \\
\text { generally involve areas with timber management activities. }\end{array}$ \\
\hline $\begin{array}{l}\text { Visitor } \\
\text { Management }\end{array}$ & $\begin{array}{l}\text { On-site regimentation and controls are few. Control facilities are appropriate } \\
\text { for the predominating backcountry roaded setting. Visitor information facilities } \\
\text { may be used to interpret management activities, but are not elaborate and are } \\
\text { appropriate for the setting. }\end{array}$ \\
\hline $\begin{array}{l}\text { On-site } \\
\text { Recreation } \\
\text { Development }\end{array}$ & $\begin{array}{l}\text { Facilities and structures generally do not exceed Development Scale II and are } \\
\text { maintained to accommodate the types and levels of use anticipated for the site } \\
\text { and area. }\end{array}$ \\
\hline $\begin{array}{l}\text { Social } \\
\text { Encounters }\end{array}$ & $\begin{array}{l}\text { User meets less than } 20 \text { other parties per day on trails and in dispersed areas } \\
\text { during at least } 80 \% \text { of the primary use season. Numerous other parties may be } \\
\text { encountered on roads. Few parties are visible at dispersed campsites. }\end{array}$ \\
\hline Visitor Impacts & $\begin{array}{l}\text { Visitor-caused impacts are noticeable, but not degrading to basic resource } \\
\text { elements. Site hardening may dominate at campsites and parking areas. but is } \\
\text { in harmony with, and appropriate for, backcountry roaded setting. }\end{array}$ \\
\hline
\end{tabular}




\section{Recreation Management, Appendix F}

Table F-2. Forest Plan Standards and Guidelines for ROS Classifications (cont.)

\begin{tabular}{|c|c|}
\hline \multicolumn{2}{|r|}{ Rural ROS Class } \\
\hline $\begin{array}{c}\text { Setting } \\
\text { Indicators }\end{array}$ & Standards and Guidelines \\
\hline Visual Quality & $\begin{array}{l}\text { Not to exceed Modification in the Foreground and Maximum Modification in } \\
\text { middleground. }\end{array}$ \\
\hline Access & $\begin{array}{l}\text { All forms of access and travel modes may occur, although access to and through } \\
\text { the area is primarily by passenger vehicle. Road and trail surfaces are often } \\
\text { hardened. }\end{array}$ \\
\hline Remoteness & $\begin{array}{l}\text { Remoteness is of little importance, and moderate to high concentrations of } \\
\text { people and sights and sounds of human activity are acceptable when not } \\
\text { continuous. Setting is located within } 1 / 2 \text { mile of heavily traveled roads and state } \\
\text { highways or areas that receive heavy aircraft travel. }\end{array}$ \\
\hline $\begin{array}{l}\text { Visitor } \\
\text { Management }\end{array}$ & $\begin{array}{l}\text { On-site regimentation and controls are obvious. Control facilities such as } \\
\text { parking areas, medians, and barriers harmonize with natural/exotic landscaping. } \\
\text { Information and interpretive facilities may be complex and dominant on } \\
\text { developed sites. }\end{array}$ \\
\hline $\begin{array}{l}\text { On-site } \\
\text { Recreation } \\
\text { Development }\end{array}$ & $\begin{array}{l}\text { All Development Scales (I-V) are appropriate and maintained at intended } \\
\text { standards necessary to accommodate the types and levels of use anticipated for } \\
\text { the site and area. Facilities typically include visitor centers, major } \\
\text { campgrounds, and other facilities for concentrated use. }\end{array}$ \\
\hline $\begin{array}{l}\text { Social } \\
\text { Encounters }\end{array}$ & $\begin{array}{l}\text { User may meet many (more than } 20 \text { ) other parties per day on trails, in dispersed } \\
\text { areas, on roads, and in developed facilities. Developed sites often are at full } \\
\text { capacity, but do not exceed } 80 \% \text { of the design capacity over the operating } \\
\text { season. }\end{array}$ \\
\hline Visitor Impacts & $\begin{array}{l}\text { Visitor-caused impacts are noticeable, but not degrading to basic resource } \\
\text { elements nor do they exceed established Visual Quality Objectives. Site } \\
\text { hardening may be dominant, but is in harmony with natural/exotic landscape. }\end{array}$ \\
\hline
\end{tabular}


Table F-2. Forest Plan Standards and Guidelines for ROS Classifications (cont.)

\begin{tabular}{|c|c|}
\hline \multicolumn{2}{|r|}{ Urban ROS Class } \\
\hline $\begin{array}{c}\text { Setting } \\
\text { Indicators }\end{array}$ & Standards and Guidelines \\
\hline Visual Quality & $\begin{array}{l}\text { Not to exceed the Modification Visual Quality Objective in the foreground and } \\
\text { Maximum Modification in middle ground. }\end{array}$ \\
\hline Access & $\begin{array}{l}\text { Access and travel facilities are highly intense, motorized and often with mass } \\
\text { transit supplements. }\end{array}$ \\
\hline Remoteness & $\begin{array}{l}\text { Remoteness is not important. High concentrations of people, and sights and } \\
\text { sounds of human activity are acceptable. }\end{array}$ \\
\hline $\begin{array}{l}\text { Visitor } \\
\text { Management }\end{array}$ & $\begin{array}{l}\text { Intensive on-site controls are numerous and obvious. Information and } \\
\text { interpretive facilities may be complex and dominant. }\end{array}$ \\
\hline $\begin{array}{l}\text { On-site } \\
\text { Recreation } \\
\text { Development }\end{array}$ & $\begin{array}{l}\text { All Development Scales }(\mathrm{I}-\mathrm{V}) \text { are appropriate and maintained at intended } \\
\text { standards necessary to accommodate the types and levels of use anticipated for } \\
\text { the site and area. Synthetic materials are commonly used. Facility design may } \\
\text { be highly complex and refined, but in harmony or complimentary to the site. } \\
\text { Facilities typically include visitor centers, major campgrounds and other } \\
\text { facilities for concentrated use. }\end{array}$ \\
\hline $\begin{array}{l}\text { Social } \\
\text { Encounters }\end{array}$ & $\begin{array}{l}\text { Interaction between large numbers of users is high. Sites often are at full } \\
\text { capacity, but do not exceed } 80 \% \text { of the design capacity over the operating } \\
\text { season. }\end{array}$ \\
\hline Visitor Impacts & $\begin{array}{l}\text { Visitor-caused impacts are noticeable, but not degrading to basic resource } \\
\text { elements or exceed established Visual Quality Objectives. Site hardening may } \\
\text { be dominant. but is in harmony with natural/exotic landscape and appropriate } \\
\text { for the site and setting. }\end{array}$ \\
\hline
\end{tabular}

\section{Recreation Carrying Capacity Analysis}

Recreation carrying capacity is the number of recreation users that can be accommodated in a given area without loss of the quality of the natural environment and/or the visitor experience. The Shoreline Based Recreation Carning Capacity Analysis for the Admiralty Island National Monument, Hoonah, Juneau, and Sitka Ranger Districts 2001 (Shoreline RCC) (USDA Forest Service 2001) documents an analysis that determined the recreation carrying capacity of a shoreline zone extending from mean high tide one-half mile inland on the four districts. It is used as the basis for determining effects in this EIS. The Shoreline RCC compiled the applicable policy, direction, and information related to recreation management on the four districts. Use Areas were defined and described, and unique carrying capacities (groups at one time) were calculated for each individual Use Area. Carrying capacity numbers were derived by determining the number of group encounters expected in a day within each specific Use Area considering the ROS class standards for social encounters indicated in the Forest Plan. 


\section{Recreation Management, Appendix F}

\section{Types of Recreation Carrying Capacity}

The following four types of recreation carrying capacity were considered in the Shoreline $R C C$. The social carrying capacity was found to be the most limiting and was used to develop the recreation carrying capacity.

- Physical - The amount of recreational use that can physically occur in a defined space without regard to the quality of the experience.

- Facility - The amount of recreational use that can occur within the constraints of existing facilities and improvements intended for visitor needs, such as parking lots, trails, docks, restrooms, and developed campgrounds.

- Ecological - The amount of recreational use that can occur without creating unacceptable impacts on the ecosystem.

- Social - The amount of recreational use that can occur without impairing social experiences. Social carrying capacity is the level of use beyond which social impacts exceed acceptable levels specified by evaluative standards (Shelby and Haeberlein 1986).

\section{Physical Carrying Capacity}

The physical carrying capacity for the Shoreline analysis area is extraordinary with over 5,300 miles of shoreline and 995,000 acres available for recreation use. Physically the project area could accommodate many more groups than optimum and realistic use indicates. The theoretical physical capacity is so large that managing for that number would exceed Forest Plan standards and guidelines. Recreation use is not expected to ever approach the physical capability; therefore, it is not a limiting factor.

\section{Facility Carrying Capacity}

The facility carrying capacity is not a limiting factor for the Shoreline project because most recreation use in the analysis area does not rely on Forest Service facilities. Most recreational use is wild land oriented and primarily boat-based with recreationists and outfitter/guides providing their own services and facilities.

\section{Ecological Carrying Capacity}

The ecological carrying capacity was generally not found to be to be a limiting factor in the analysis area because of the low impact of the recreation activities and the relatively low levels of use throughout most of the area. However, it is an important consideration in this analysis. A limited number of sites were identified that are approaching ecological carrying capacity. These are considered in this analysis and will require monitoring. No new facilities or ground-disturbing activities are considered in this analysis.

In addition to low levels of use, most recreation activities in the analysis area are of short duration and low impact. Dispersed remote recreation activities such as sightseeing, hiking, photography, boating, hunting, and fishing are the most common uses. Access is most often by boat and an outing is usually completed within 


\section{Appendix F, Recreation Management}

daylight hours without the need for camping. To date, our monitoring has not shown significant ecological effects from recreational use.

\section{Social Carrying Capacity}

The Shoreline $R C C$ found that the social carrying capacity is the most limiting factor for recreation use in the analysis area. It determined the social carrying capacity in terms of the daily number of groups in an area limited by a specific number of group encounters. Group encounters are an important part of the ROS classification used to define the expected recreation experience.

The goal is to manage the area so that the number of group encounters per day is within Forest Plan ROS guidelines Table F-3. These guidelines identify the number of encounters one may expect to experience in a day, maximum party size, and number of parties within sight or sound of dispersed campsites.

\section{Table F-3. Forest Plan Guidelines for Numbers of Social Group Encounters Per Day, by ROS Class ROS Class \\ Number of Encounters}

\begin{tabular}{lcc} 
& Non-Wilderness & Wilderness \\
\cline { 2 - 3 } Primitive & Less than 3 & Less than 3 \\
Semi-primitive & Less than $10^{*}$ & Less than 6 \\
Roaded Natural & Less than $20^{*}$ & Not applicable \\
Roaded Modified & Less than $20^{*}$ & Not applicable \\
Rural & No guideline & Not applicable \\
Urban & No guideline & Not applicable \\
\hline
\end{tabular}

Social Recreation Carrying Capacity Components
Three components are used in this analysis to manage social recreation carrying capacity for the analysis area: Use Areas, groups-at-one-time, and seasons of use.

\section{Use Areas}

The analysis area was subdivided into 38 Use Areas, 37 of which contain a shoreline zone and are included in this analysis. See Figure 1-1 and Appendix A for the location and description of each Use Area.

\section{Groups-at-One-Time}

The Shoreline RCC defines the recreation carrying capacity in terms of group days. These are determined by establishing the number of groups-at-one-time that can be in an area.

The number of social encounters a group has while recreating is the basic social recreation component for the carrying capacity assessment. Recreation in the analysis area occurs primarily with groups of people rather than as individuals. Encounters between individuals within a group are not counted because the people within the group typically choose to be with each other. A 'group' may be one 


\section{Recreation Management, Appendix F}

person recreating alone or more than one person recreating together. 'Groups-atone-time' is the number of groups that could recreate in a specific area without exceeding the number of group encounters specified by the ROS class to achieve a specific type of recreation experience.

Each Use Area was evaluated by the existing recreation setting, Land Use Designations and ROS classifications in the Forest Plan. Maps, photos, and field observations were used to determine the physical characteristics of each Use Area. Suitability of the land for recreation use was a key consideration in developing the number of groups that could be in Use Areas without exceeding ROS class standards.

Because not every acre of land or mile of shoreline has the same suitability for recreation use, we evaluated which areas were most accessible. Much of the area in the shoreline zone is functionally less desirable to most people because of thick vegetation, wet areas, steep terrain, or the cost of reaching remote areas. Most desirable areas tend to be relatively flat, open, drier areas without thick underbrush. A majority of the coastline is rugged and rocky, so easy access by boat is limited primarily to protected bays and beaches. We assessed where boats could access the shoreline and where groups could reasonably recreate given the local topography within each Use Area.

Easy access from the surrounding marine waters, usually by motorized watercraft, provides a high degree of mobility for most recreationists in the analysis area. This was considered in the carrying capacity determination. Highly mobile boat access increases the possibility of encountering other parties but also enables users to disperse to less crowded areas if they desire.

After determining generally where most recreation use occurs and where people were most likely to be able to access suitable areas of the national forest, we applied the ROS criteria for social encounters. These criteria identify (1) the number of encounters with other groups per day and (2) the number of other parties within sight or sound of dispersed campsites. The number of social encounters was refined by looking at topographical features to evaluate the irregularity of the shoreline and type of vegetative cover present. This information was used to predict views and sound patterns from the most likely anchorages and recreation places. This gave us the groups-at-one-time in a Use Area.

Groups of people on boats traveling, sightseeing, fishing, or anchored on the saltwater were not considered to be national forest users for the purposes of this EIS and are not factored into the groups-at-one-time figure in the carrying capacity. Groups on salt water at access points to national forest were considered only in conjunction with their upland use. See the Shoreline RCC (USDA Forest Service 2001) for more information on methodology and data sources.

\section{Seasons}

To better manage for the different activities and levels of use that occur at different times of the year, we identified recreation seasons to provide a temporal measure for recreation management and use. The seasons are displayed in Table F-4.

There are differences in recreation activities and use patterns among the different seasons. Weather, temperature, length of daylight, and fishing and hunting 


\section{Appendix F, Recreation Management}

regulations govern most activities. The summer season is the busiest season of the year for both commercial and non-commercial recreation activities except hunting. Brown bear hunting is the predominant recreation activity occurring in the project area during the spring season, along with some steelhead fishing. In the fall, brown bear, deer and waterfowl hunting are popular activities. The end of the spring season and the beginning of the fall season are known as 'shoulders' to the peak summer season. Traditional summer activities, specifically freshwater fishing and sightseeing, are increasing in these shoulder seasons. Because little or no commercial recreation use occurs during the winter season, no management is proposed in this analysis for the winter season.

\begin{tabular}{rrrr}
\hline Table F-4. Dates and Number of Days of Seasonal Use & \\
\hline Season & Starting Date & Ending Date & Length in Days \\
\hline Spring & April 20 & May 31 & 42 \\
Summer & June 1 & September 14 & 106 \\
Fall & September 15 & October 31 & 47 \\
Annual & April 20 & October 31 & 195 \\
\hline
\end{tabular}

To determine the seasonal recreation carrying capacity for each use area, the groupsat-one-time for each Use Area (based on the number of social encounters allowed by the ROS class) was multiplied by the number of days in each season. All three seasonal recreation carrying capacities were added together for the total recreation capacity for the analysis area. 
The United States Department of Agriculture (USDA) prohibits discrimination in all its programs and activities on the basis of race, color, national origin, sex, religion, age, disability, political beliefs, sexual orientation, or marital or family status. (Not all prohibited bases apply to all programs.) Persons with disabilities who require alternative means for communication of program information (Braille, large print, audiotape, etc.) should contact USDA's TARGET Center-at (202) 720-2600 (voice and TDD). .

To file a complaint of discrimination, write U.S. Department of Agriculture, Director, Office of Civil Rights, Room 326-W, Whitten Building, 1400 Independence Avenue SW, Washington, DC 20250-9410, or call (202) $720-5964$ (voice and TDD). USDA is an equal opportunity provider and employer.

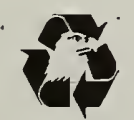

Federal Recycling Program Printed on Recýcled Paper 


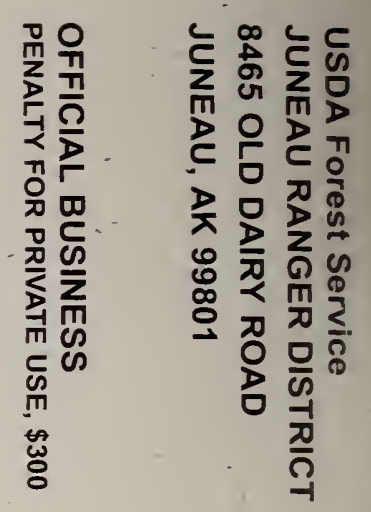

돔응

뭉

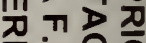

的吕

云选文爻

○统 ○而览 古兵 